
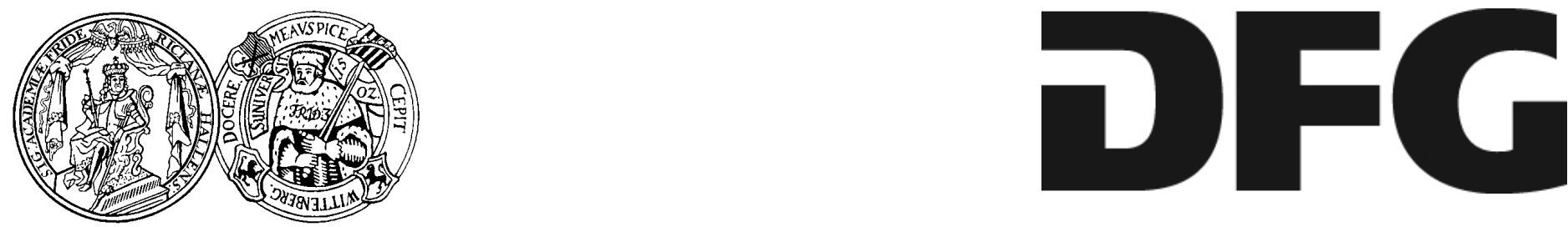

Universitäts- und Landesbibliothek Sachsen-Anhalt

Digitalisierung von Drucken des 18. Jahrhunderts

\title{
Emil oder über die Erziehung
}

Rousseau, Jean-Jacques

Braunschweig, 1792

VD18 90745825

urn:nbn:de:gbv:3:1-840321 


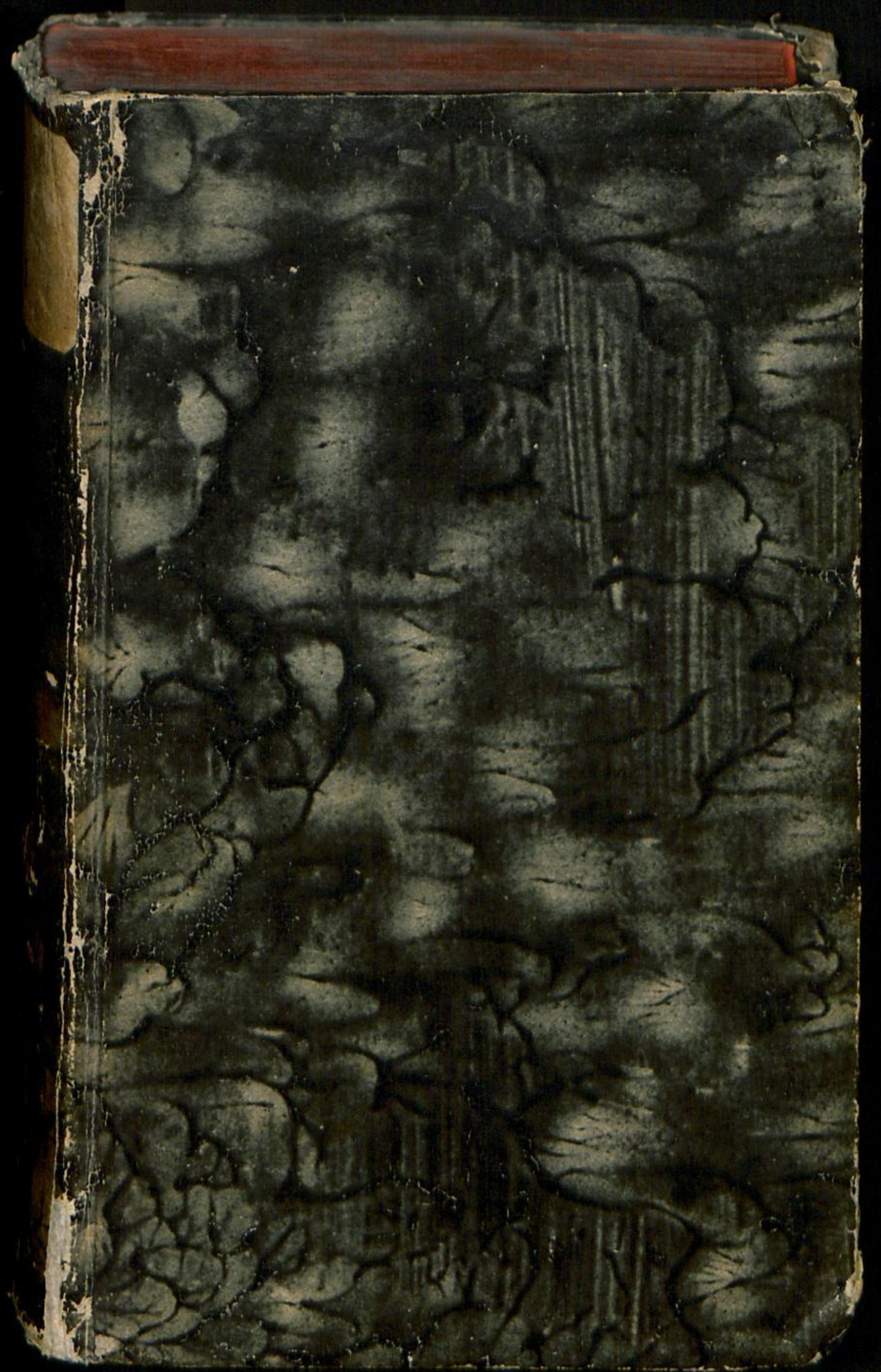




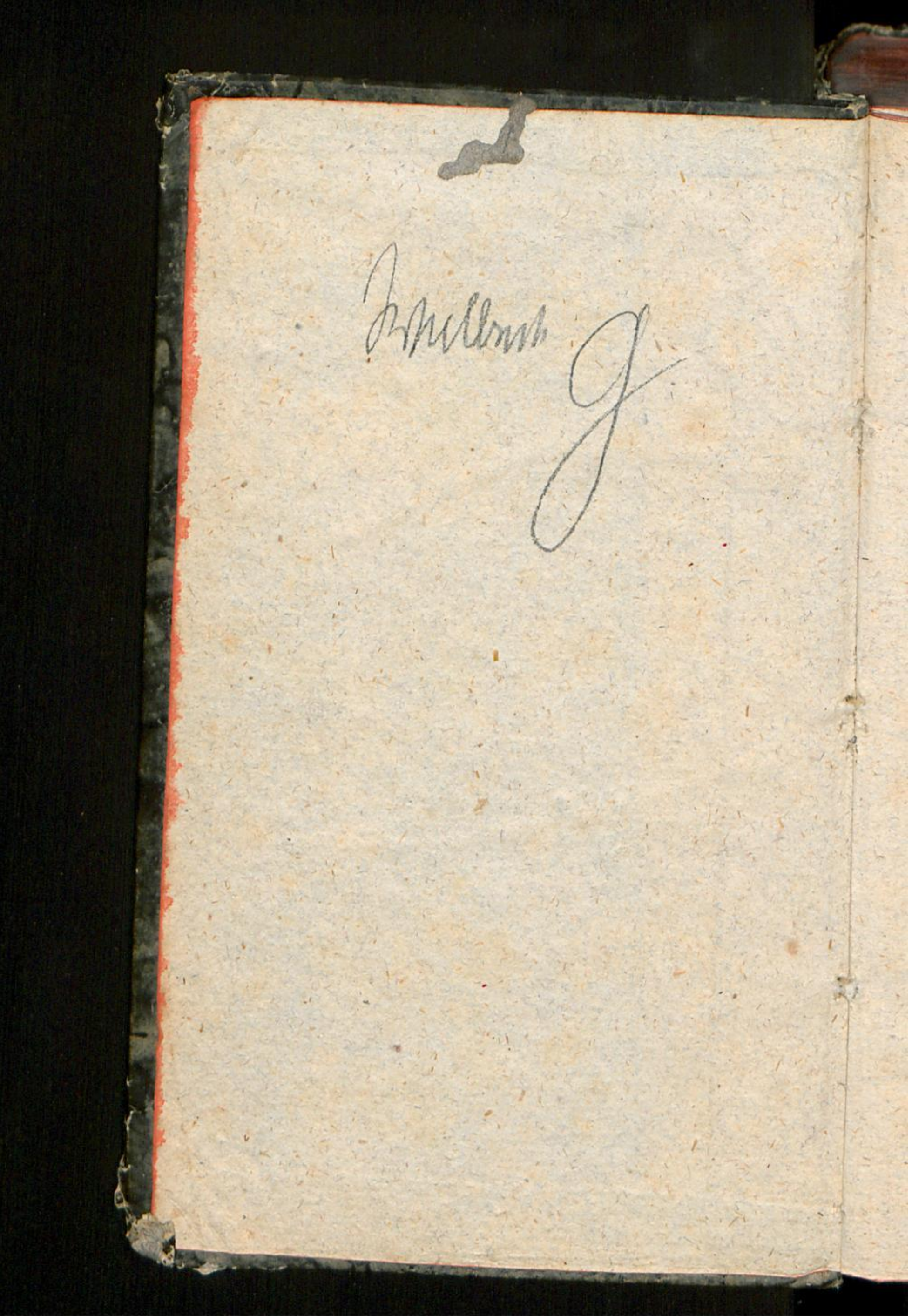




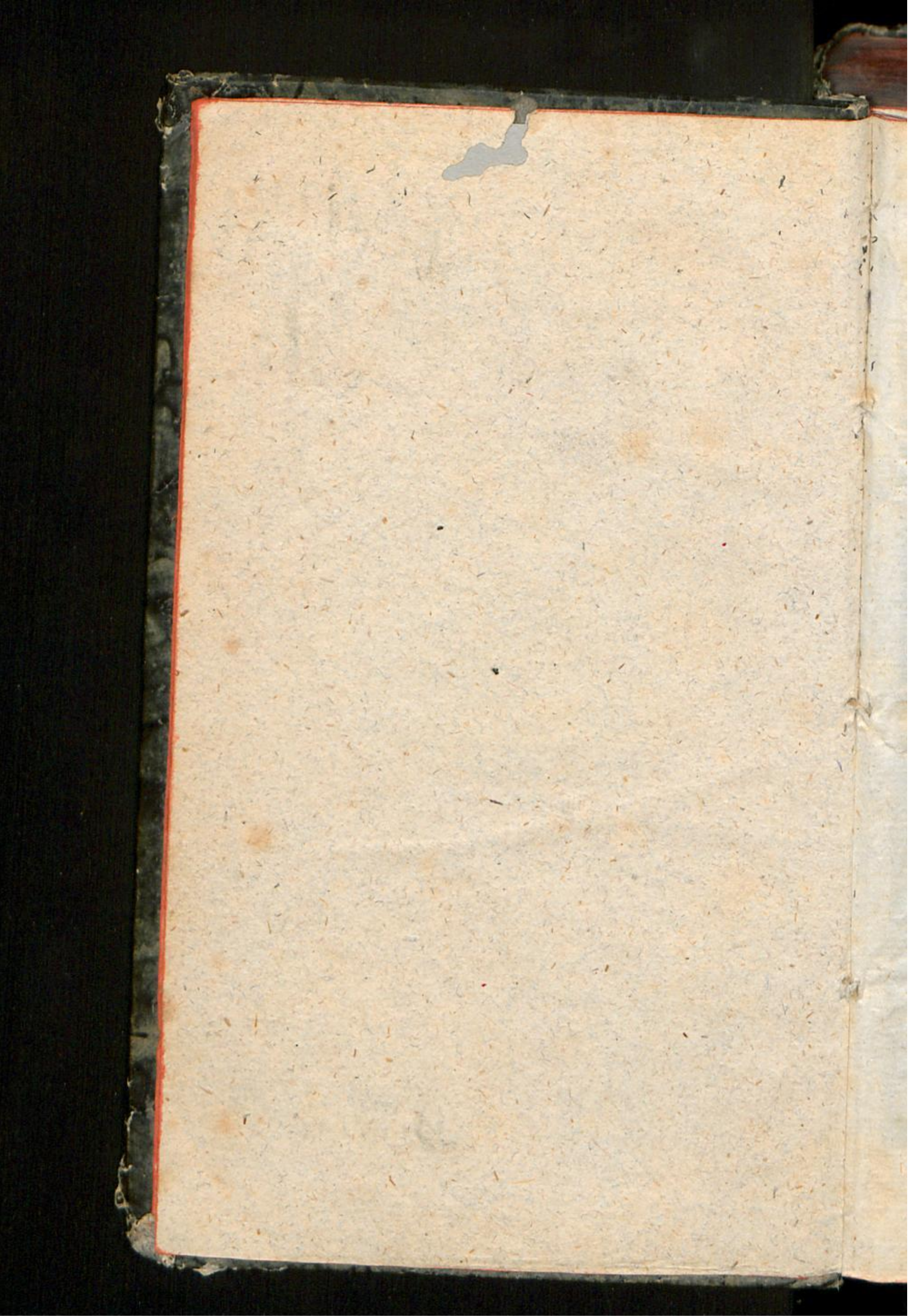




\section{(5) in $\mid$ \\ D Der

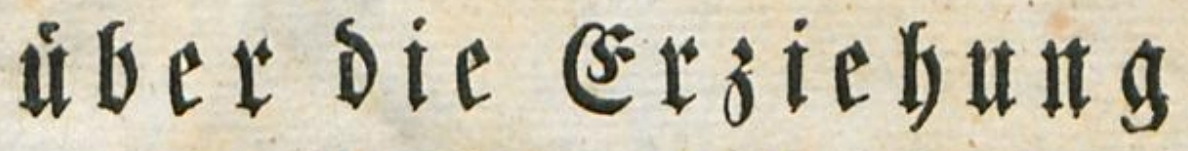

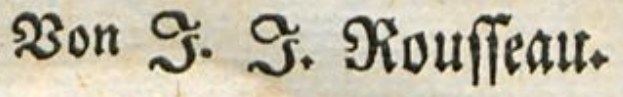

$2 B$ irger zu Genf.

Erfter 身e i

\{t

von ש. F. Cramer.

Nit

erläuternben, beftimmenben uns bericfitigenoen 2nmertungen ber (jefellf(t)aft ber Reviforen, aนв bem Sievifionswerte befonbers abge: brictit und beeraurgegeben

bon

\section{Soadsim Seintid) Eampe.}

Sanabilibus aegrotamus malis ipfaque nos in requm genitos natura, ti emendari velimus, adjuvat.

$$
\text { SENECA, do iva, L. II. c. } 13 .
$$

Sra unfd) weig, im Betlage ber Sibulfudbandlung, 1792. 


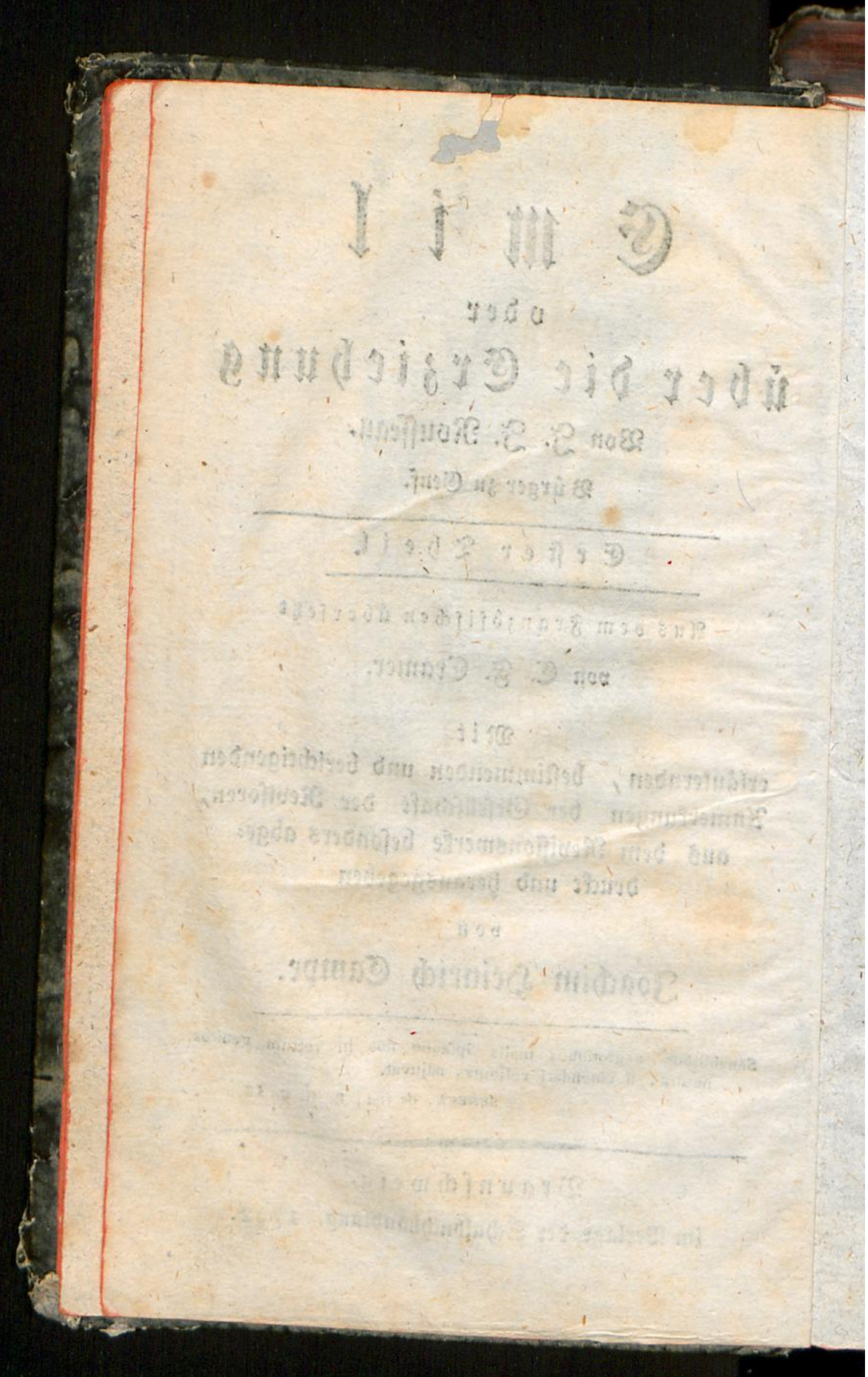




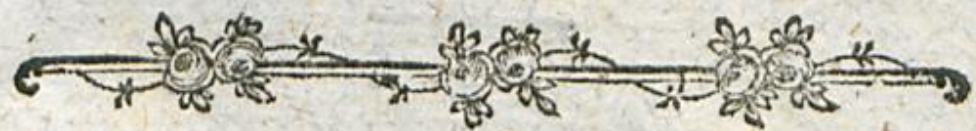

\section{Sotreb.}

(S) iefe Eammilung woit Bettachtuntgent uno Bemerfungen, of ne Sronung, und faft obne Bufammenthatig; wats

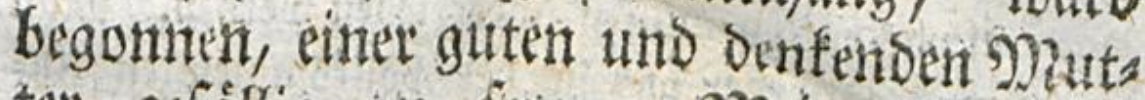
ter gefállig zu feun. Mein Entmut ging anfangs auf nichts, als pinen situf: fak von einigen Exiten: der Sigenftans aber zog midi allmáblig wiber menent 2 billen fort; und fo warb endicts ein gant zes 23 etf Dataus, bas, fur toas es ents bâlt, obne Brovifel zu grobi, flut Die Dars inn bebanbelte Naterte bingegen, su fleit iff. Sith babe lantge bei mir angeftantoent, bs befannt ơ madben; unto wábrens idf Daran arbeitete, oftmal's gefublt, eB reicte nicht zu, einige Schrifteben verfapt zu ba ben, um ein gutes Buth fibreiben zu forns sen *). ミanch oergeblicben Bemuthungett, I 2

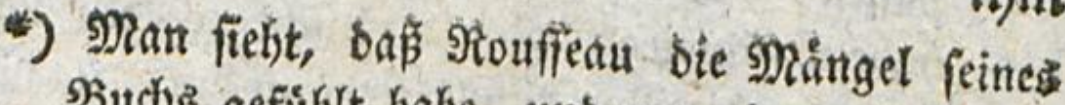
ifint Butch) gefúfilt habe, und wer, ber mit faltem Blute lieft, was er im Seuer Der segeifterung

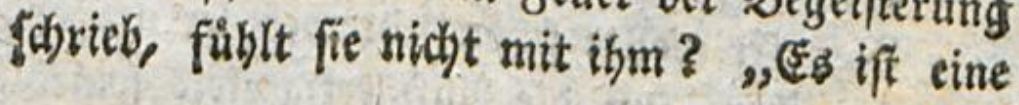

be 


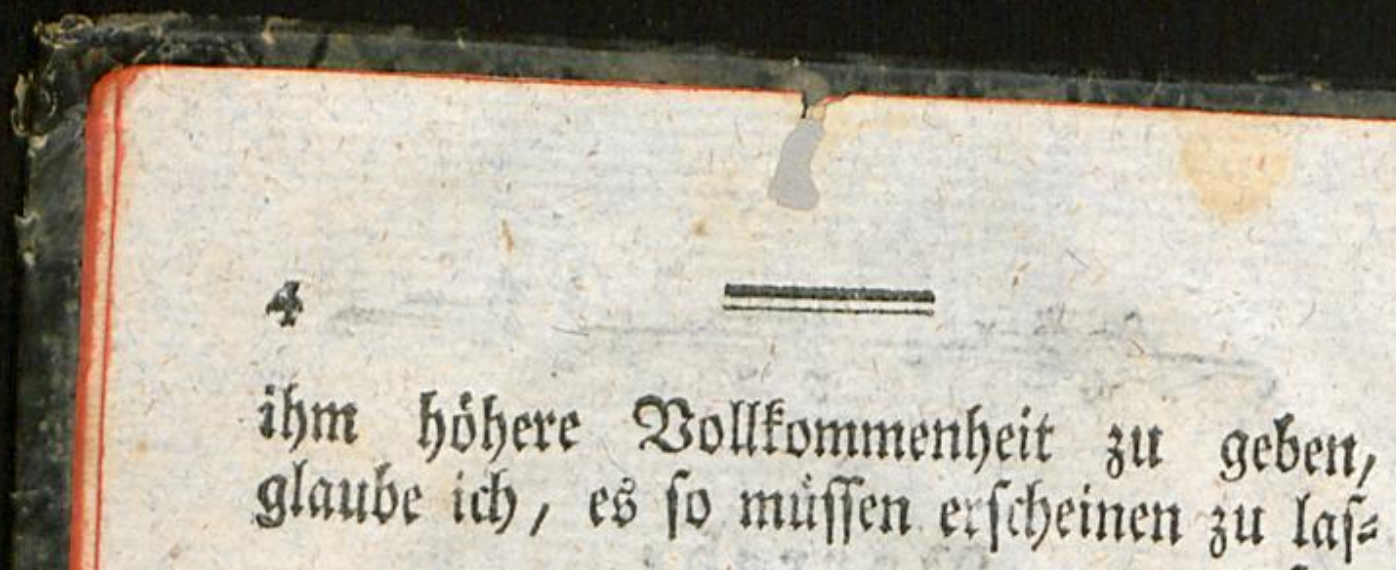
fert,

befante 21nmerfung, fagt Seerr Mrof. (Sarve in ber Sammlung einiger Zfbrandlungen,

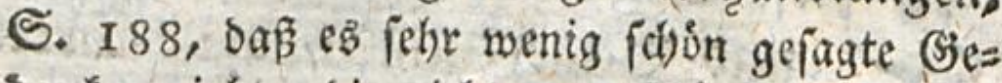
Danfen giebt, bie nicht, um fojon zu werben, etwab Gạtten múffin úbertrieben werben. Man

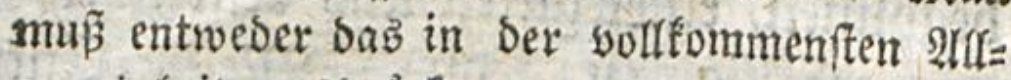
gemeinlseit auşbri̊den, was nur auf einige

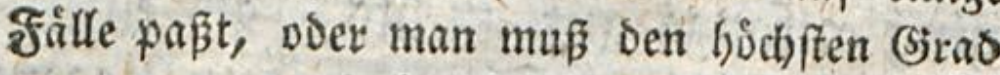
nennen, wo nut ein niebrigerer vorhanben ift. Joeen, bie nur einige \$erichiebenheiten has ben, miffen burch) bie Werbergung ihter 2lehn= lich)eiten zu einem wollfommenen (Eontrafte er= Wobst, anbert, bie fich nur in einigen Mert= malen ábnltch) find, zur volffommenen Hebers einfitimmung gebracist werben. Man unter= fuche einmal bie glänzendfen soeen aus ben

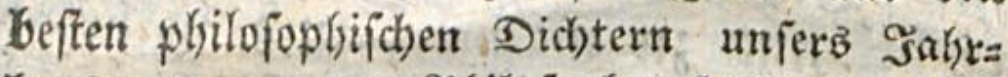
Gunbertz, aus den Mhilojophen felbft, bie aber zugleid) f(c)ón fdreiben wollen, und frage fid), vb bie Sadbe genau immer fo jey, wie fie fie sorftellen? ob es nid)t oft eben fo siel $2(u \xi=$ makmen als fällle gebe, bie unter bie Regeln pafien? ob nicht etwaz yon der 2 Bafrbeit Wabe verichwiegen ober verfâl(f)t werben múf fen, um bie sorfetlung fart unb neu zu ma= chen?" Dies ift ganz ber Fall mit unjerm

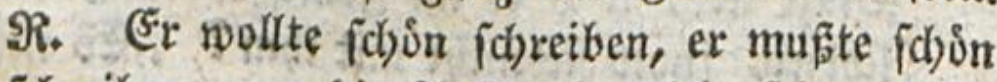

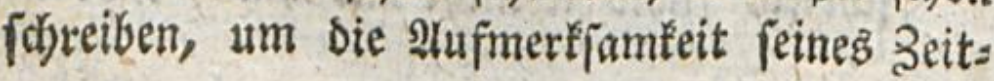
alter3, 


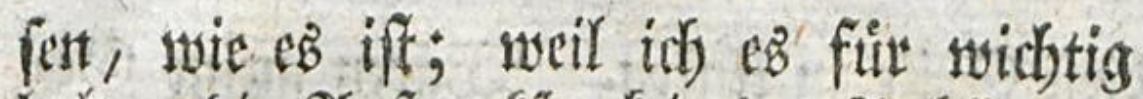
halte, Die 2ufmetffamfeit Des \$ublicums

\section{श्य 3}

nuf

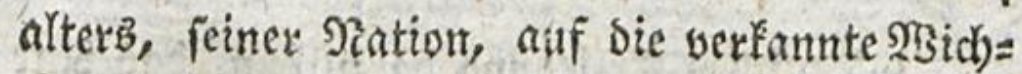
tigfeit feines Gegenfifandes rege z" mad)en; woas 2 Bunber denn, Dap ifin fo oft bas, foos

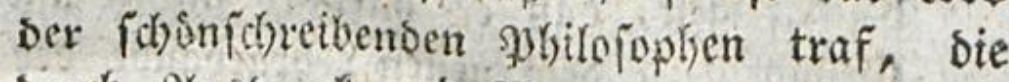
burd) 2/uabruct und sBendung mandymal zu Berráthern an ber firtengen 2sahableit befon= Ders in ben 2lugen berer, werben, Die in einer anbern Seetenfitimmung, iberhaupt unter ans

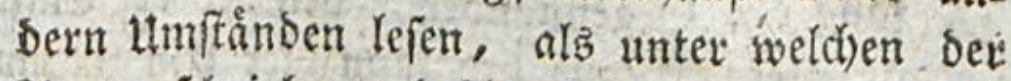
Stuctor fadrieb, und bie nid)t für iebe Şyper: bel ober anbere figuren ber fdosnen Diction gleid) $D a 3$ njothige granum falis in $\mathfrak{B}$ creito fhaft baben. Daju fonmt, Daß̧ $\Re$. weber

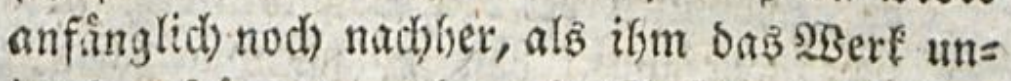

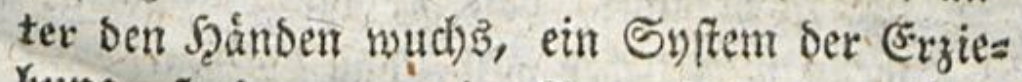
Yung, fonbern nut eine Sammlung von pába=

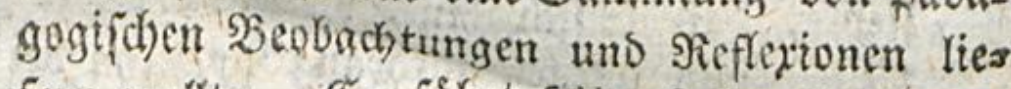

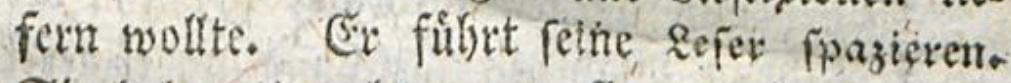
Sie haben unred)t, wenn fie auf einem Splata ziergange etwas anbers erroarten, als was aud) Der befie Ropf ba geven Yann, lebyafte

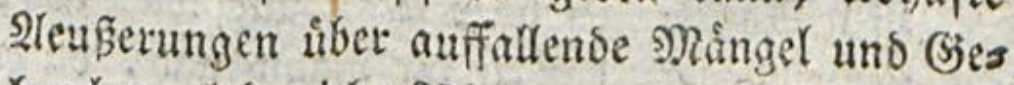

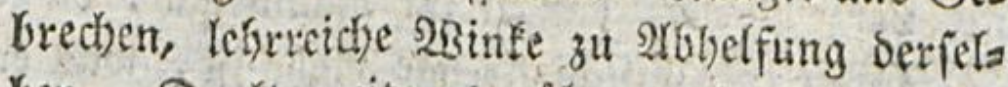
ben. Denft weiter bariber nad), fagt $\Re_{\text {. }}$, prifft und behaltet baß (3) te. Ferner fann man Yein netes Bjebsiube an bie Stelfe bes al= ten feften, bevor man ba3 alte weggeidafft hat. Die Untauglidgeeit unb Echadtidjecit ber ge= wolkn= 
6

\section{Diepe Ceite gut lenfen. 2Bärett meine (s) Danfen pogat untauglith, fo wirbe, glaube ict),}

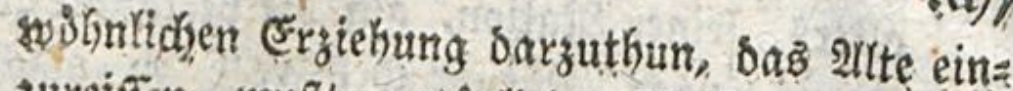

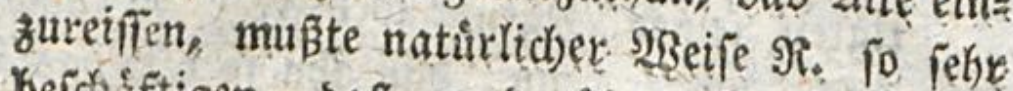
beichiftigen, Daß̧ er baruber nicbtz als ben Grunorifa zu bem neuen fehrgebáube ber bej fern Erzielyung uno auch) biefen nur unvolfs fommen geben fonnte. 3u biejen allen fommt mun noch oie Bierfeitigteit und ber grobe ltms fang bes Begenftandes, den $\Re$, im Emil.be= arbeitet. Unmóglich) fann bier Ein Mann Mls

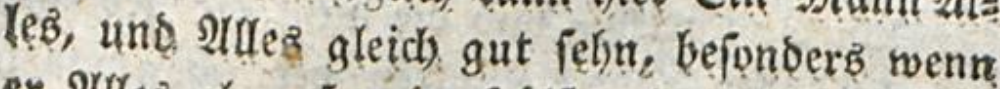
er Alleş ohne frembe Szilfe mit eigenen Alugen Peken will, wie baz bet $\Re$. Dex fall war, und eş gewollnlich) bei ben Selbjtbentern ift. Ends=

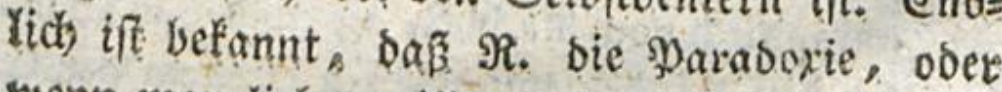
wenn man lieber will, Daß̂ die Paradotie ifn Yiebte, bafif fie fich ifhm, vielfeidht wiber feit sBiffen uno 2 Billen auforang uno ifn bei bes

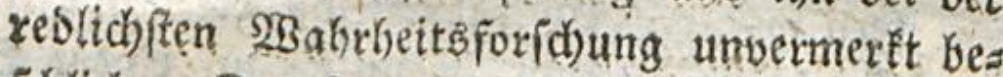

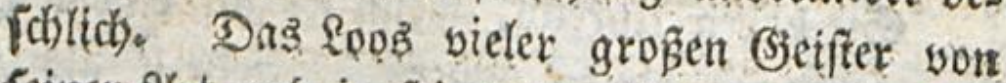
feiner Sfrt uns in feinen Utmftanden. Sei fei= nem Nachoenfen hiber Erziefung wat es befto

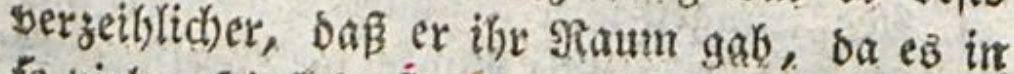
to bieler Soinfidgt ftrenge wabr ift, was ex ir= genowo im Emil fagt, baf̃ man, uṇ gut zu er= zieben, mux ber gemólyn(id)en $2 B e i f e$ fd)murge= rabe entgegen zu banbeln braudhe. $28 \mathrm{Benn}$ man aber mun gleich) nidht leugnen fann, Daß $p a=$ wooxe Giebanten pder Gebantenmendungen, fo

wie 
idf, meitte Seit boch nicht gatt sertohren fenth, went ich benirfe, baf in 2 mbern श 4 nith

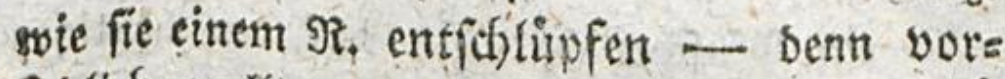
fezslicf wollte er rool nicht parabox (cyn; id fehe anbers als andere Eeute, fagt er ingenbs swo, weil $i d$ nitfot anbers fann, weil mick bie Natur in eine eigene form gổ, bie fie bann zerbrad, um fonft niemano bats cin fu giesen - zum Nadjbenfen reizen, minber befannte Seiten an einer Sadse her: sorgiehn uns ins sidjt ftellen, uno baburcb Ser Entbectung Der $\mathfrak{B}_{3}$ afyrbeit beforberlid) wers Den: fo mus auf per andern Seite bod) auds) cingeráumet werben, daß fie diejen Nukzen nur bei Denfenben Rópfen fiften. - Unb biemit babe id benn zugleid) bie Slaffe won fefern genannt, benen Rouffeau nux, parabor ober nid)t parabox, mútzlich, in fokẹm Srabe núşlid)

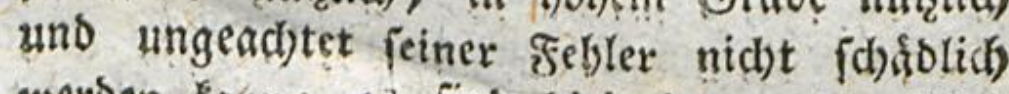
werben fann: es find biejenigen, oie felbft niber Exziefung nad)gebadth haben, ober we: rigftens felbft oaruber nad)zubenfen borzúglid) fábig find, mit einem surt bie 2loepten. , Shmen - id) borge bier zum Theil Swie= lanos 2 Borte aus feiner (Finleitung in Soras gens Epiftel an Die Pifonen - ibnen uns sur ifnen find bie Stellen, in meldben bie \$Nys= fterien ber Erzielsungbtunft eingebillt liegen, serftanolicí), gleich auf ben erften slid ver: ftånolidy, und olyne Niabraud) anwenbbar;

eins 


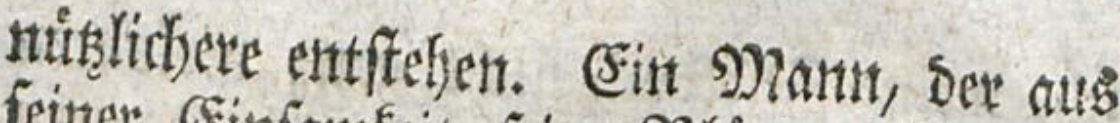
feinet Einfanteit feine Blatter obuti sob:

HeD=

ein Yfufcher bat biz ouf ben Feutigen Iag nod) nid)tż aus bem $\Re$. gelernt." Man fann Den Emil als eine 21 th won Dffentarung an= felgn, beren Sinn nirgenbz zu verferly

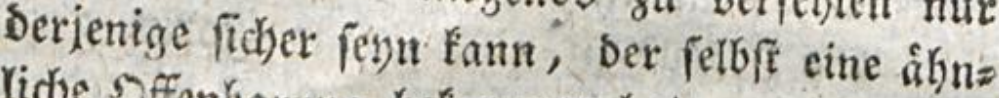
lidje Sffenbarung befommen bat.

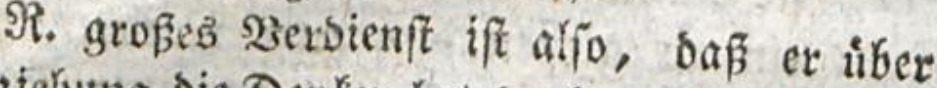
Erzielyung die Denfer hat benfen gelehrt. Die= fen liegt nun ob, feine Moefie in Drofa jut

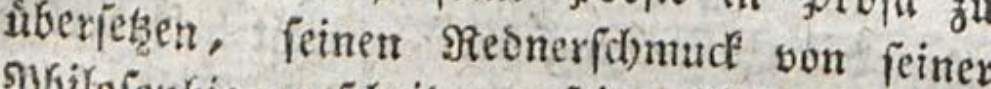

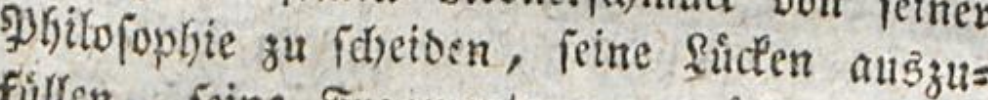
fultlen, feine fragumente zu ergánzen, feine Befaupturten auf Dem \$orobierffein Der \$er= nunft und Erfalirung zu prifen, Misbeutun= gen uno Mis̄anwenbungen feiner fefbet zu ver= Guten, bie grosen, theuren Sisabrbeiten, wo= son er solf ift, in ein foldhez sicht zu fellen, bas aud) fidwád)ere lugen nid)t bindert, fie soafrizunefimen, und fid) mit ifonen zu befieun=

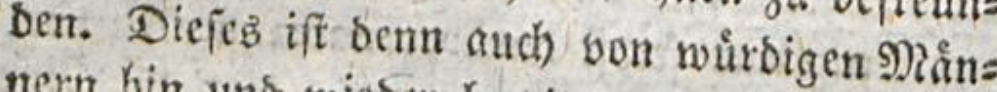
nern bin und wieder bereits geichelen, oie fich badurd) eben io viel \$erbienft um $\Re$, ertwor= Ken baben, atz গi um fie batte.

\section{Trapp. Stuve, Eampe. Neferwik. Sgeufinger.}

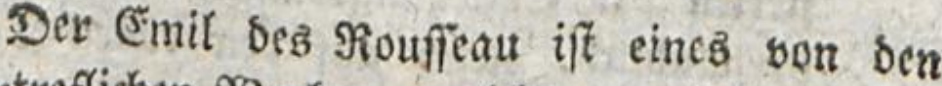

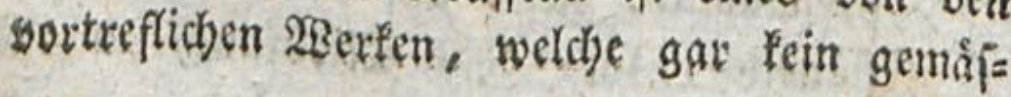
figteg 
restet, blyte eitte Syathei, Die fie wetheis Dige, obne nut cinmal zt wiffen, wab I 5 mant

figtez Urtheil erfahren. Non feinen 3erely retn ůber bie maáen erhoben, wiro es von feinen NSBiberfachern un befto tiefer herabges fest. Jenen if allez barinn 23 alyrbeit und Solfommenteit; Diefen alles parabo: und unz gereimt. Ia co haben fich Reute, fellofit wor= gebliche (Selebrten und Sd)riftifeller gefunden, welche Dem Ernft und dem Eifer Dez \$erfaf fers̈ Spitteleien entgegenfrellten. - Dodh bieje fino gefallen; uno nur berienige fenut ifse Mamen nod), der fich) um die Ritteratur Des Erziebungźfunf hemulgt. - In ber Inwens bung hat bie Stouffeaulfde Sd)xift ein âhnli= doez Sdricial erfabrem. Die mebreften hat ben fie gam diferichen und find beim allen gebleeben; andere baben beffen \$aridhlige be folgen wollen, haben Werfuche gemacht, bas ben feinen ßath misberfamben uno fobief an= gewanst, find es balb riberbriping geworbem

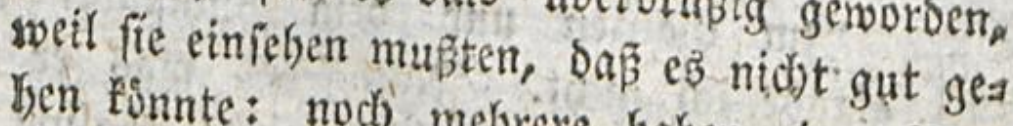
fyen fonnte: noch) melfere baben einen \$ers gleich) zwiidhen Dem bergelurad)ten Schlendrian

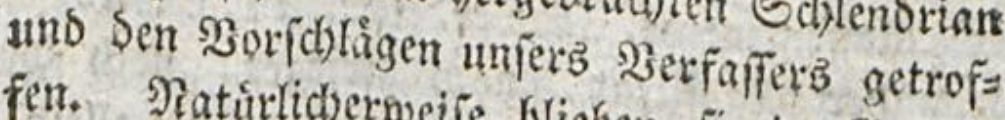
fen. Naturlidjerneife blieben fie im Grunde bei ifjer alten Methode, und was fie Reucz baran lefteten, waren mur einige in bie 9lugen falfende Einrid)tungen, bie zu bem Sianzen

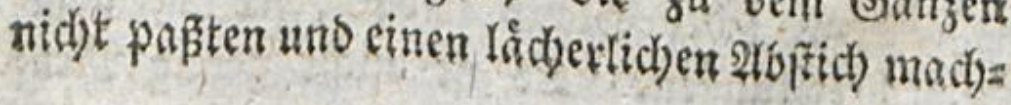


math basont Detrft, ober bason fagt, ins Şublicum wirft, Darf nicht befurdhtert,

Mtars

tert. Das bies benn Touffeauifd erziefn: ftatt ber natírlicben unbefangenkeit, entwidels

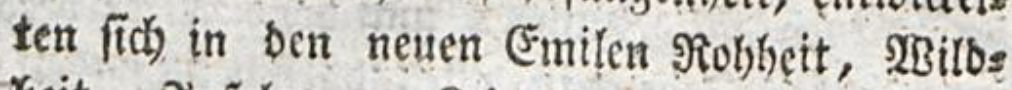
beit, snjolenz. Rein SBunber; bas innere Berberblidje ber ganzen Ffibrungamethode war geblieben; ber aubere 3wang, ber fonft bas Serberben mit einem gefürligen Firniß úberzos gen unó vor ben Ifugen berbect' hatte, was weggefallen. Arlo war baz Nerberben geblie. ben, uns fiel nummebr fred) uno etelfoft in bie Rugen.

Die Rouffeauifise Rethobe ift ein Eins. siber fie nidjt ganz anwenden will ober fann. muß feinen abgeriffenen Iheif berfelben braus c)en wollen; benn biefer wirbe immer mit bem ůbrigen unangenelim contraftiren.

Rann man benn aber bie Rouffeauijche Mee thode brauchen?

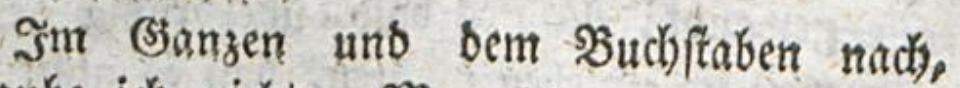
glaube id) nidbt. Man fibe, was ex felbft bason fagt: , $2 B e n n$ id) meinen 3igling ent: laffen werbe, fagt er, (ङ. 11.) wiro er wes ber Magiftrat, nod) firieger, nod) Spriefter feyn." - Nun aber muß nidbt allein jeber 5) Ren(d) etwas ienn, fonbern ex mus jich son feinen frúbern Jabren an Dazu vorbercitèn; bent jeber Stand erf̣odert bei uns lange 23ore bereitungen. (E) if nicht genug \$enid) zu

pesti? 
man werbe, wentt et fid irte, feine grts thumer obne Unterfudbung antebmen.

fern, man muf

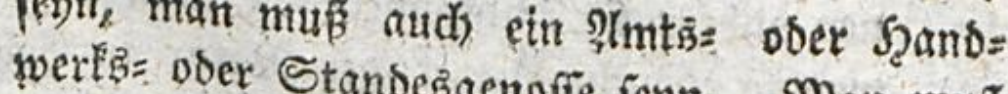
in Feine Genoffenichaft pafien. Man muß werben, fo bafi, twenn man erf bazu gebilbet

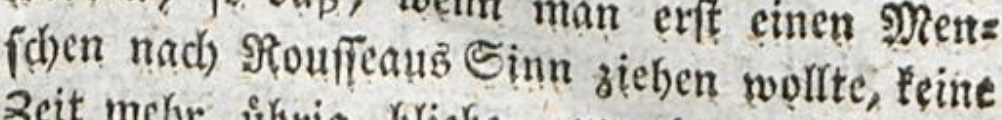
zeit melyr úbrig blicbe, um ben beftimmten

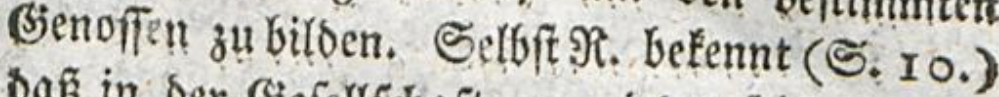

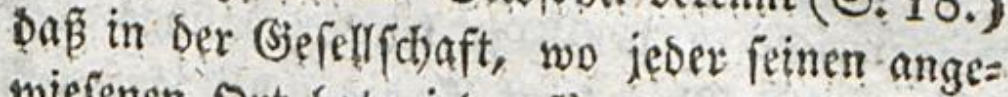
swiefenen Det hat, jeber für ben feinigen gse bilbet werden miffee. Da er aber ben blopets unbeftimmten Menjoben bilbet, fo fann er nicl)t vẹtangen, doa man feine Ergiebungỏmes thobe einfififeen foll.

28 ą̧ folf man benn aus biejer Schrift nehy men, und was nultset fic?

I) Man tann barnub ben Meníc)en, das find fennen, Das SBerk Der Natur, ifrert

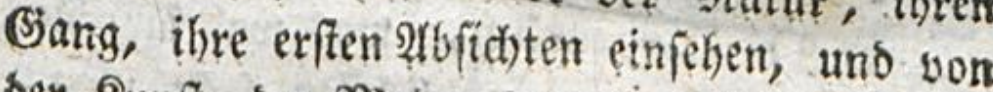
ber Sunft, ber Niode, ben eingefíktten 3ufá

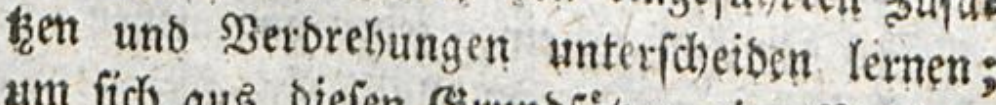
um fich) aus biefen Grundfåzzen eine Netrobe zu bilben, unb ber \$olffoumenteit ber Natur

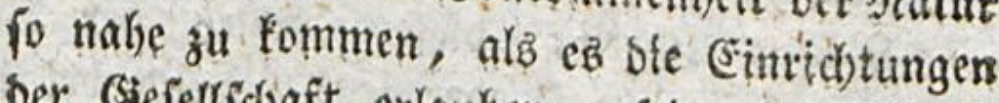
ber Gefellfchaft exlauben, Soiermit will ith biejen (Einrid)tungen gar fein ßerbammungš urtheil gejprochen haben. Die Natur muśte

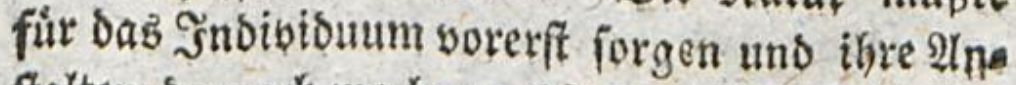
falten Darnach machen: bie (Sejellichaft Gat eis

net 


\section{Tit) Denfe wenig vont ber 2 Bidftigfeit einet guten (stzishung zu reoph; mith auth nicfit}

tren andern (S)efich)tspunct; fie mus alio noth= wenoig mand)mal mit der Natur in Eolfifion fommen.

giser aljo bieje Sdyrift muken will, muf nid)t oen Budgfaben berfelben befolgen; fon= Dern Den Geiff berfelben su finden fudhen, um itt diefon (Beifte cine Miethode su erfinnen, welche zu Dex \&age feines äuglings pasit.

2) NRan lernt ferner, bei aufmerkiamer Refung Diefer Schrift, was Der Menjich wer= den faun, welchen $23 \mathrm{eg}$ man eimidjlagen mişte, यm în zu 'bex volfétommenen Entwictelung aller fetier Sirifte zu fübren; und $\rightarrow$ was nicht minber widhtig ift.- Daß̃ bie allgemeine Solrfommentheit aller Sirafre bei bem Den= foren, in ber (Biefellford, wie fie ift, nidbt erreidist werben fann.

3) Ulno enolid), was wor fŭt die mels= xeften sefer am nuiblichften fentr mag, weil es ber Faffung eines ieben angemeffer $i$ it, fin= set man in biefem $3 u c h$ eine Penge Detail= borfd)liage, wie man biefes ober ienes mit Nutzen lefren, Diefen Fehler Der fintoes sermetoen, biefe oder jene Iugens bei ifnen exwedten fantr.

25enn ood Eittern und Erzielser von Rouf feau, ben fie bod) fo ferjur erbeben, eines nut letnen wollten, fo whirbe die Málye, die fie

bei 
nicht Yatrge bey bem Seneife auffathaltert,

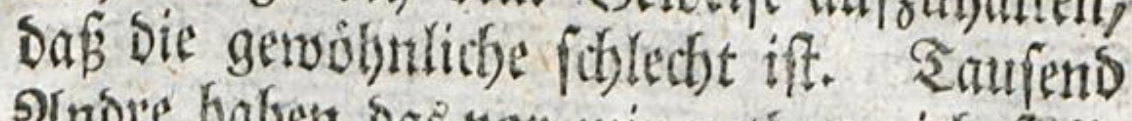
Inore haben bas yot mir getban; ith fulle nicht getn ein 3 utth mit Dingen at, Die Ses Dermant weif. gitu biez will ich bes merft baben, Das feit unoenflichent Beitent gegen bie eingefuftre ३erfabrungsart eint allgemeines Beforet ift, obne dấ ges manoficts cinfallen láñt, eine befiere vors suffhragen. Die Sitteratur und das 23 if fen uniers Sabrigunderts gebt vielmegl Darauf aus, zu zerfforen, alb zu bauen. Mant tabelt mit bem Sone eines Meiftes rers; aber un 3ofithlige at thut, mus man einen andern nelymen, in Dem ficts Die philofophiffise Erthabenthet wentiget bes bagt. Eior fo vieler Etbriften, bie, wie man fagt, nut Den offentlitben Soutsen zum

bei Refung feines subles gehabt loaben mie (Siegent gen, reichlich belohnt fesn. llno bieres Sine iff, Das die fuilise silloung ber finser, mit welcher bie Eltern uno Erzieker fo gern glân= zen, eber ein Fetler, als cine Bollfommen= menteit Dex Erzielsung ift, weldger melis ithas

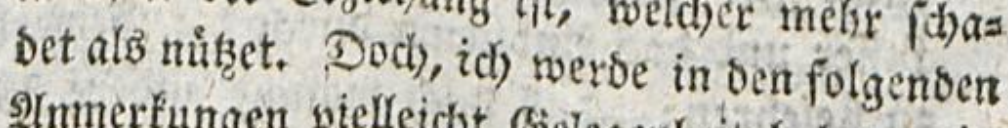
SImmerfungen wielfeidbt (G)legenbeit baben, eim Mefreres biewon zu fagen.

Biflaume. 
Cregenftande bauen, iff bas હerffte alles Nutblitben, die Giunft Menfiben zu billsen, noch unerfunden. Mein Sirgenfta D war ganz net, felbft nach Qodfens $B$ utb; ; ) uns ich) furrbte, et sverbe es auth noch nadf bem meinigen fevit.

Mlan fentut Die Rinobeit nticht ; uns Dent falfichen Begriffert zufolge, Die bott

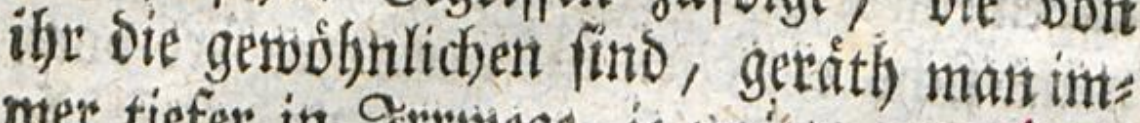
mer tiefer in Srrivege, je tweiter man forts forreitet. Dit 23erfandigiften bleibert bei Dem ftehen, was Dem Mtenfither zu wiffert nitslict, ift, und bedenfen nicbt, was Rint Der zu Yernent vermógen. Sie fucbent ims

*) Sátte Serr Sormen, Bei feitrer Evitit utiber Den (Emil, Den in vbiger erfen Itnmertung and segevenent richtigen Gefitittospunct genomment,

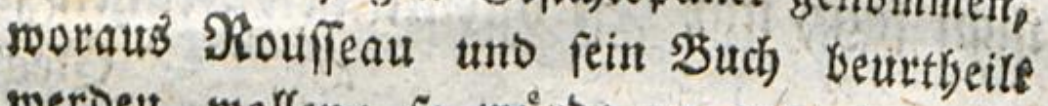
werbent wollen: fo wuirbe er entweber gat

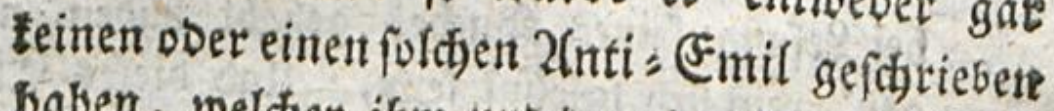
baben, weldher ifm und bent beutfihen Scharfo finn úberbaupt bei Den 2(ustándern Esyre ges madbt bátte; fo mưrbe er auch bei biejer Stelle nicht fúr nostbig erradtet baben, ben \$erfaffer und Daß \$sublicum Durd die Semertung au belefren: "Daß Doch mantie andere Tserte aber bie Eryiegung befannt und bodigeadgteg aápen!

Campe. 
met ben Mant in Sinde, wiffert aber nicht was bas Sind ift, ehe $e b$ Mann wird. Sob habe mir bier biés redbt eigentliti) zum Ctubiun gemact); Damit, wenn meine ganze Methode audb falfoh, und ein Sirm gejpinft foyst fellte, man boch immer ats

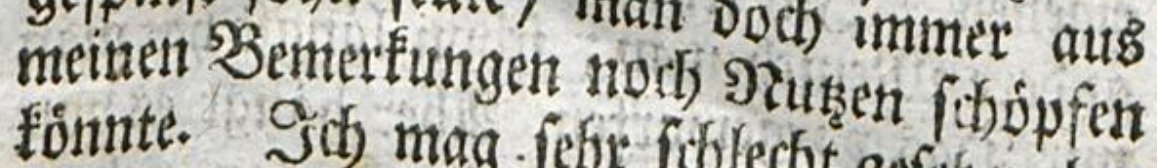
founte. Sich mag. fefte fitlecht gefeben bas bett, wab zu thun fery, aber ich glaube, Den (Begenftand, auf Den gewirft werden foll, fehr gut ins ?iluge gefaft su haben. *) Jangt alfo an, eute Bóglinge beffer zu fubires; Dent, auf mein $230 r t$, ibr fent fie nitht.

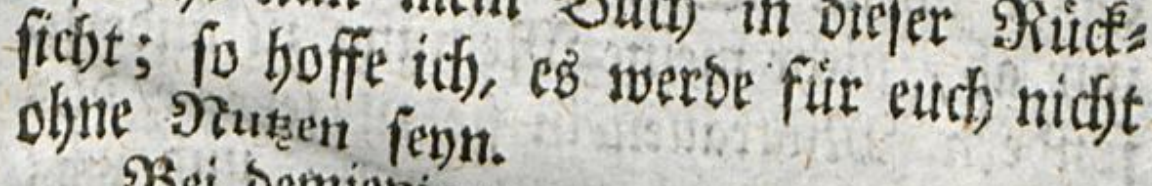

Bei bemjenigen, was man ben fuftes matifiben Theil nenten mird, Der bier nichts anders als Der (Santg Der 9atur ift, burfte man vielleicht om meifen fruten: von Diefer Srite erwarte ith obne Breifet angegriffen zu werben, uno viellectits nicbt

1) SBir bitten die fefer bez Gir mit gleid) beicheibene und wafte

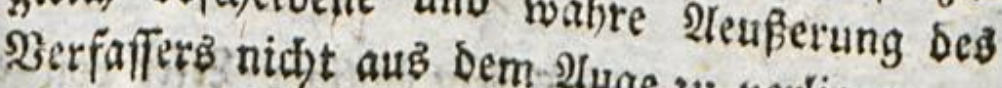

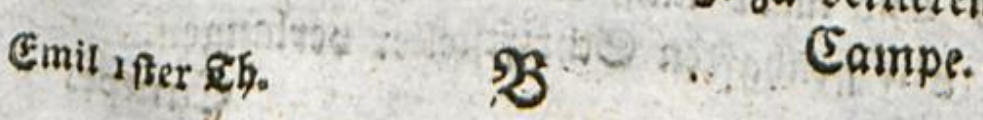




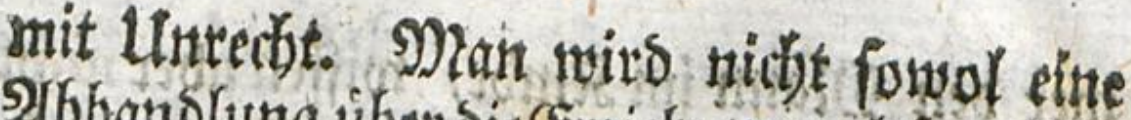

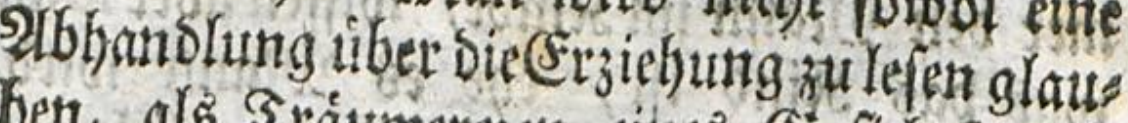
ben, als Srátumereten eines (seficthtjehers. 28as zu thun? gith forreibe nicht nach 2unorer (Sebanten; fondern nait) meinen eigenen. Sith fehe bie Sachen nidgt fo nie anbere Menfifien an; fibun längí bat man mir Das vorgeworfen. 26er bangt es vort mir $a b$, mir andre Sbedanfen zu gebeits und andere Eindrucke auf mich witfen zu

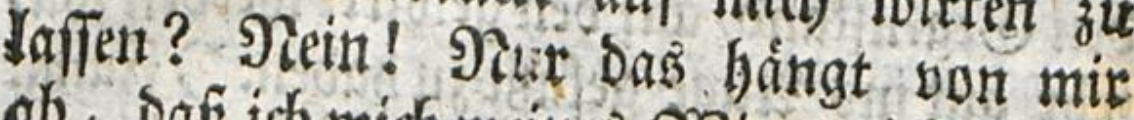

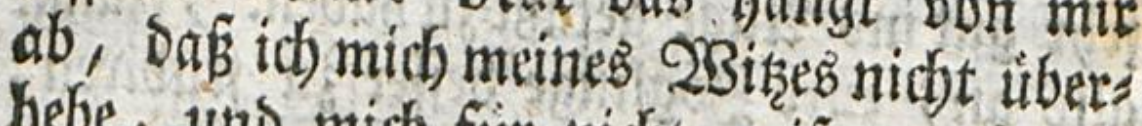
bebe, uns mich fur nitbit weifer, als bie ganze librige 23 elt balte; is baingt vout mir $a b$, nicbt meine Mteinutng zu andernt, fonderh Jistrauen in fie zu feren: bies ift 2 lles, wab ich thun fann, uno was iif) thule. *) 28 enn ich mich bisweilen bes behauptenden Eons bediene, fo gefibiehts nicht, um bes sepers Lleberzengung zu be berrfchen; fonoern um zu ibm zu reben, wie ith Denfe. $23 a r u m$ follte ich Dajjenige im Sone Des Sweifels vortragen, woran, injofern idbs einjehen fann, fein Sweifel

-) Itno mebr muß fein billtiger \&efer von iff. gewiffenbafter Schriftfeller perlangen.

Eampe. 
iff. Sch gebe nut genati wott semjentiget

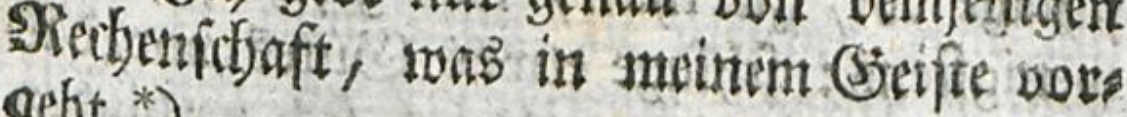
seht.*)

Setre it) alfo freimulathig meine Meis nutg auseinanoer, fo bin itf Darun fo wenig gefonnen, fie unbedingt als 20 ofditiptaufs Jitoringent, Daś itb vielmebr immer meine

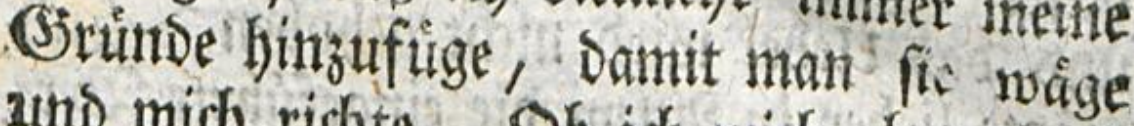
sino mich richte. $\$ D b$ ich mich aber gletith nicht bartriactig barauf fesen will, meine Soeet zu-bertheibigen, fo balte id midf Darum nodst weniger fur beredbrigt, fie burs

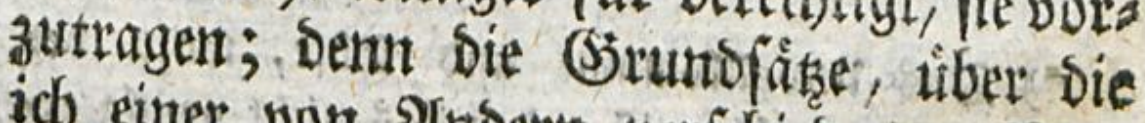
ich einer von 2 Indern verfithiedenen Meis nung bin, find nicft gleichgulltig; $\mathfrak{c}$ fint

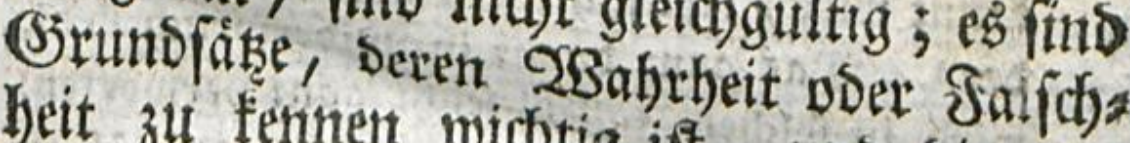
heit zu fennent wichtig ift, und bie Das

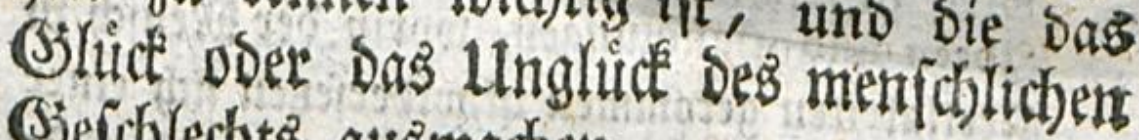

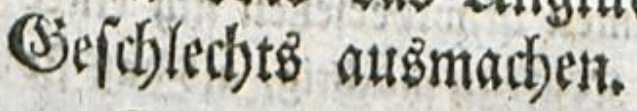

Smmerbar ruft man mir zu: Shlage nictits anders vor, als was thunlith if: Das heipt eben fo viel, als db gefagt nutrbe: ${ }_{32} 2$

7) Rudi einutal, ber gúnfige lefer wolle alle Dieje Steuperungen nicht vergeffen; unb fie wer: ben ifn vor ůbereilten uns ungerecbten Utrtheiles id ư

campe. 


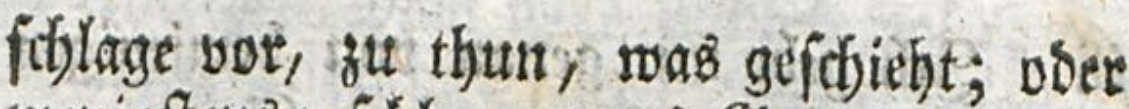
ivenigftens: fichlage etrwas (S)utes oor, bas mit Dem vorbandenen lebel fith verbinden lafie. Ein folders: Infintuen if bei ger wiffent Materien weit mehr Scirngefpinft, alb $\mathrm{CB}^{3}$ meine Sleutungen fins: Dent in Diefer Werbinoung verbirbt was gut ift; uno Des llebel wiro nidbt geboben. Gob)

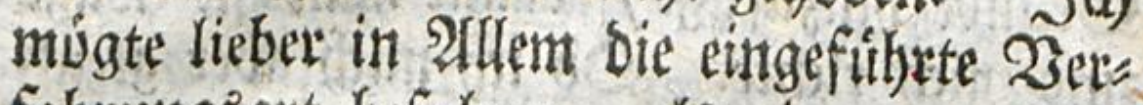
fabrungsaut befolgen, als eine gute nur 3ut Scalfte annebmen: *)

gien=

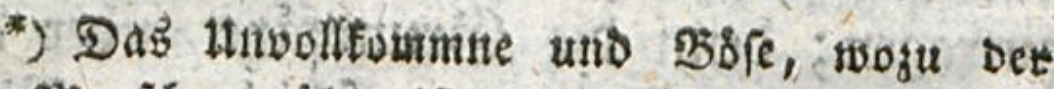

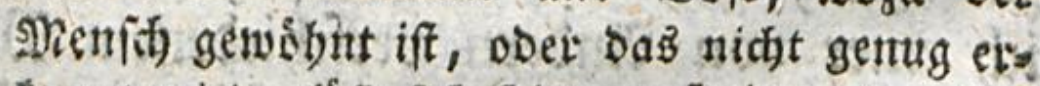
fannt mito, lás̆t fich fe!ten auf cinmtal umán

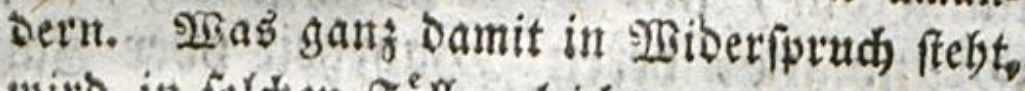
wito in foldten fällen leidjt gant verworfen. goeen unb Janblungen, norin ber Menfet iste Gertigfeiten getommen ift, noberfegen fid einer

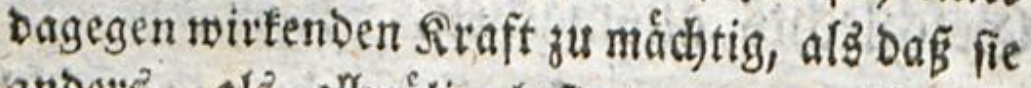
anbers, als allmálig befiegt werben fornute. Span mur fie alio anfänglich nur Da angreifen,

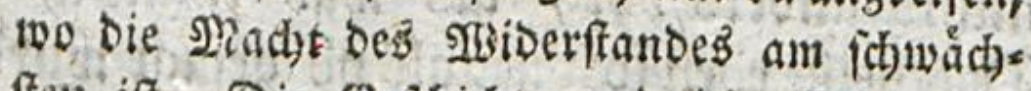
ften iff. Die Gefthithte und Die Erffabrung

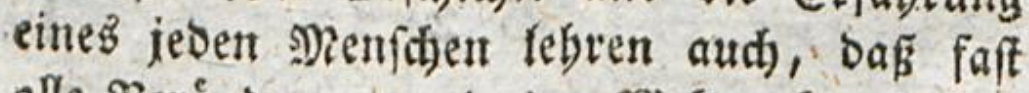
alle Betánderungen in Der Welt nadj und nab bewirtt werben. Das Begentbeil gebỏrt zu

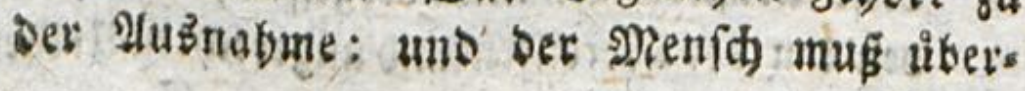
baups 


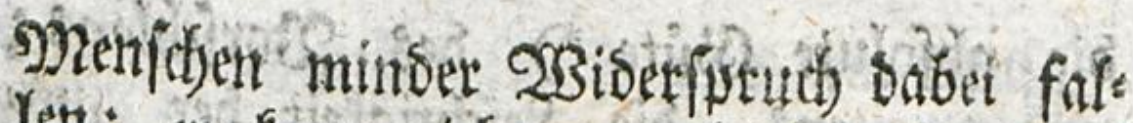
Ien; er fann nidft zat gleidjer Seit nuf Jwei fith entgegengefeste Swecte finftre: betn. *) 2 âter und Muttery oab iff thun Yich, wers ifir merbet thun mollen. Rann ich fut euren $23 i l l e n$ baften. $*$ )

Bei jeder Irt von Zorichlag mús man

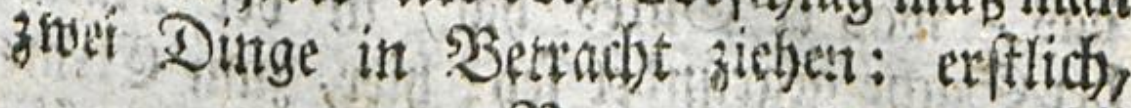
₹3 3 Dic

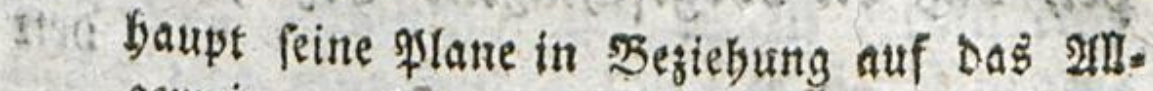
semcine madên. $2 \mathfrak{B e r}$ bả B̉ Befé auf cinmat

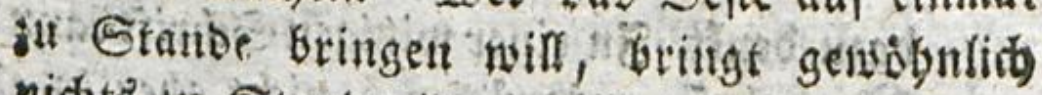
nidtes fैu Stanbe. $t$ )

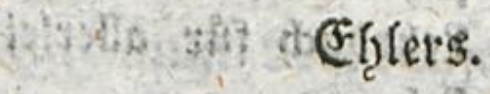

t) In-motalifher unb aufs Bante gebentert 2eranderungen if bies allgemein wabr uno Dur() Die (srfabruig beftatigt. (EB fan aud) nach bet (Beiftes Rage in oev gert nidyt ant Derí ferst:

\section{Pecentikg.}

*) Freilid nidjt. (Er wirk afer, wenth eine Sitaft. geborig auf ign wirft, eineil von ber biaberigen Ridttung wenigftens efwas abmeidjenden (3tab nefmen uns fich bem rechten tisle bei ienet fortwirfenben siaft allmálig mebr nákren.

Efferfers. Refewibs.

*) Sif nur mabr, wenn man fich Die (stutb.

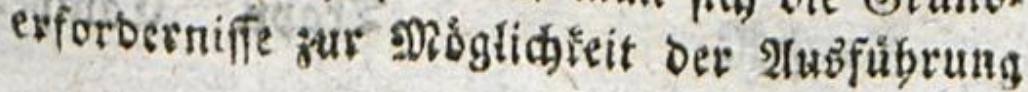

Da* 
Sie abfolute (Stite *) Ses 20otiblogs: uno zweitents, bie Seidftigleit Der $\mathscr{4}$ fuibrung.

Sn 2toficht ber erffetn if es gentig; um einen 3orfiflag zu cinem zuláficlicbent und an fich ausfithrbaren zu mastien, Dás bas, was er Siutes hat, in Der Natur Der Sache gegrütoet fen: hier, zutm Exems

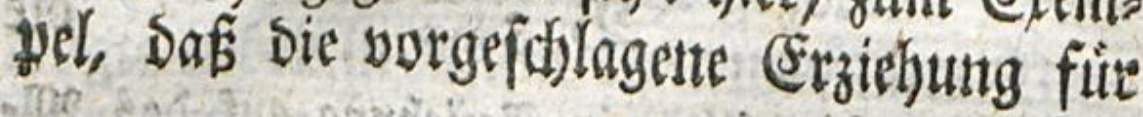
Dert

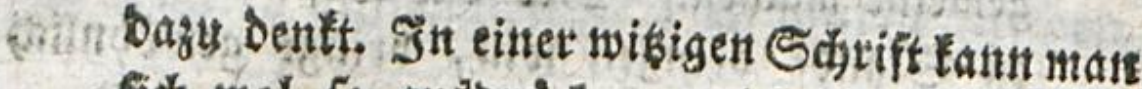
fid wol fo ausbruicten, nidgt aber in eineme Gegrbud) für allerlei Steten von Eltern uno Sebrern.

Ehlets.

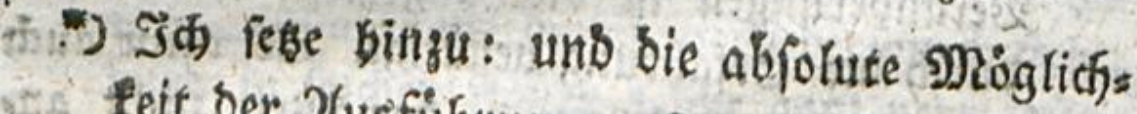

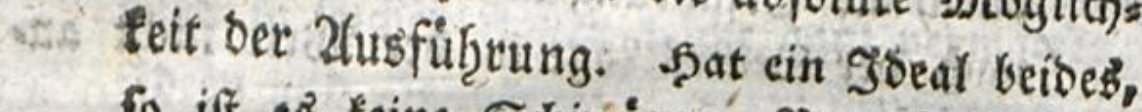

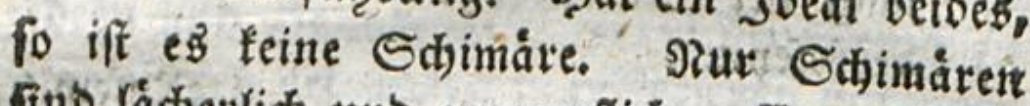

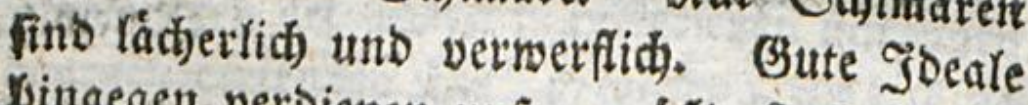

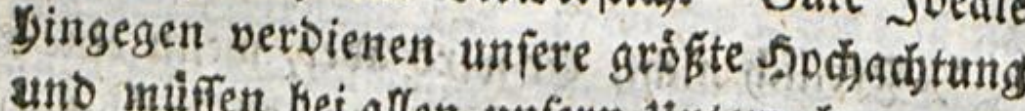
and miffen bei alfer unfern tinternebmatugen,

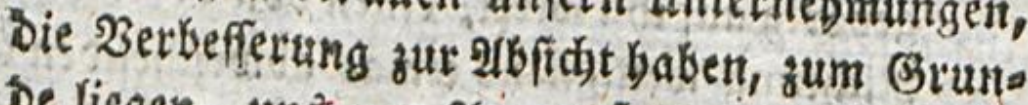
De liegen, unš vor 2ugen fenn. Sisie tóntent soir fonff wiffen, was soir tbun mulfien, wie siel wir bavon getbatt Gaben, unt waş uns anch ju thut ubvig bleikt?

Erapp. Campe. 


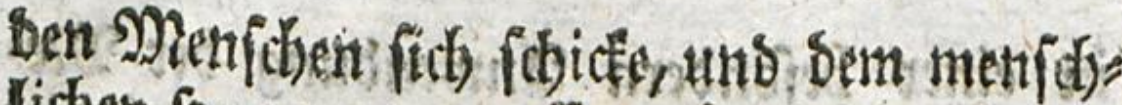
lichen Serzen ntrgeneffenctunden werde. *) Die zmeite Biteatbtung bangt voit gewiffen 2erbáltniffen in gewvifen geges benen sagen ab; pon astháltuifen dic bei Deri Sache aufallig, folglids, nicht noth: soendig find 7 und bei benen, unenolidoe Zerfithiedenbeiten ftatt finden fonnen. Dents nach ift vielleidbt eine Siziebung in bet

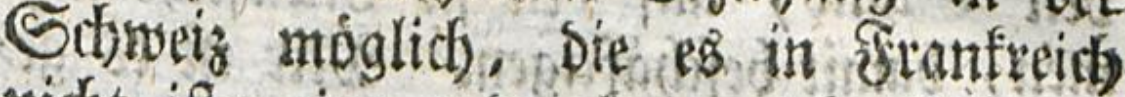
nidb if ; sine more fann es bet Singer lichen fenty uno eine anore bei sen $230 \%$

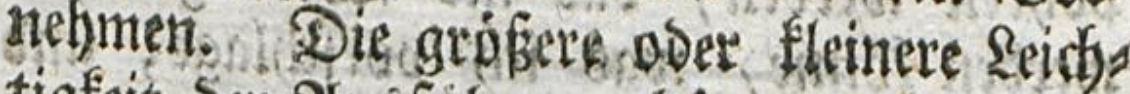
tigfeit Der alusfibung bingt von taufens Umitandest ab, bie unmóglich anoers, als - siger nid)t blof bem menjalichen semen font Dent aud Der Dermatizen YBeltverfafiung, vete Dermaligen gefellichaftliden (sintidtungen, welo ofje dbuánbetn nicht in unferm Bermógen ftebt.

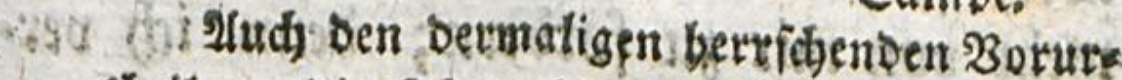
sheilen, Die fid meder burd Bemalt, nod Durd) allgemeines Raifonnement beben laffer, und oft febr bebutfam bebandelt merben múffer, senn man rthtigen ßerbefferungen Eingang berfidaffen will. Die Erfabrung bat Das febse oft uno aush of, selebrt.

Stciewifs. 
in eitter bejonbern anwenoung bet Mes thobe auf biefes oder jents fand, auf bies fen oder jenert Stans, fith beftimmen laf: pen. Da aber alle biefe befondern ?ht wentingen nidyt wefentlidh zu meinem (s)e genftande gehoren: fo gejoren fie aud nicht in meinen \$lan. 2tnoere mógen fich, went fie wollen, fur bas sand ober ben Gtant, auf Den fie Rueffitht netho men, bamit befob affigen Mit if es ge nug, bap alfentfalben, wo Sienchen ges bohren werben; dab ing 23 erf getichtet werden forme, was ifk berfiblage; und Dás matt, wern mait bas als ilgnen ges

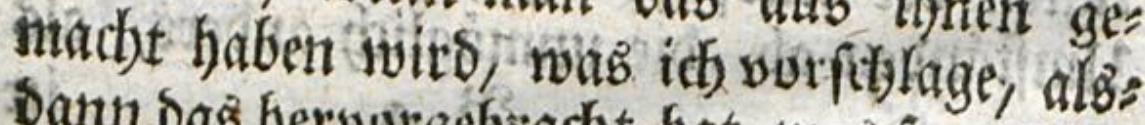
Dann das hervorgebrad)t hat, was fowol für fie felbif, als audf fir Sitdre bas 3 effe ift. Crfille its biefe 23erpflichturg nicht, fo babe ich unfreitig Untectst; erfutule ing fie aber, fo wutbe man autch lintectit thus, mebr von mir at foroern; Dent iff ver. Gredse ia tur das.

Cinil 


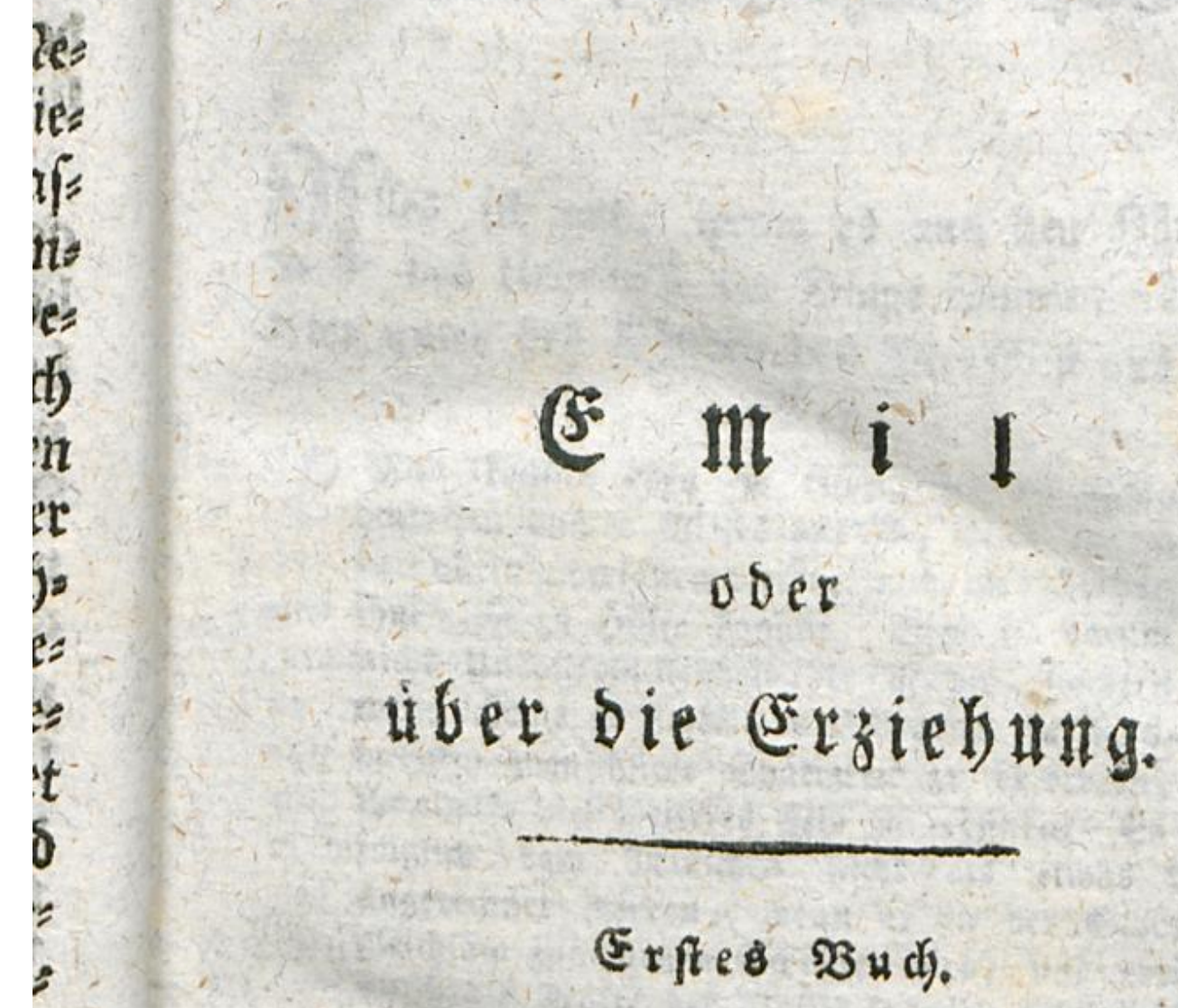

35 


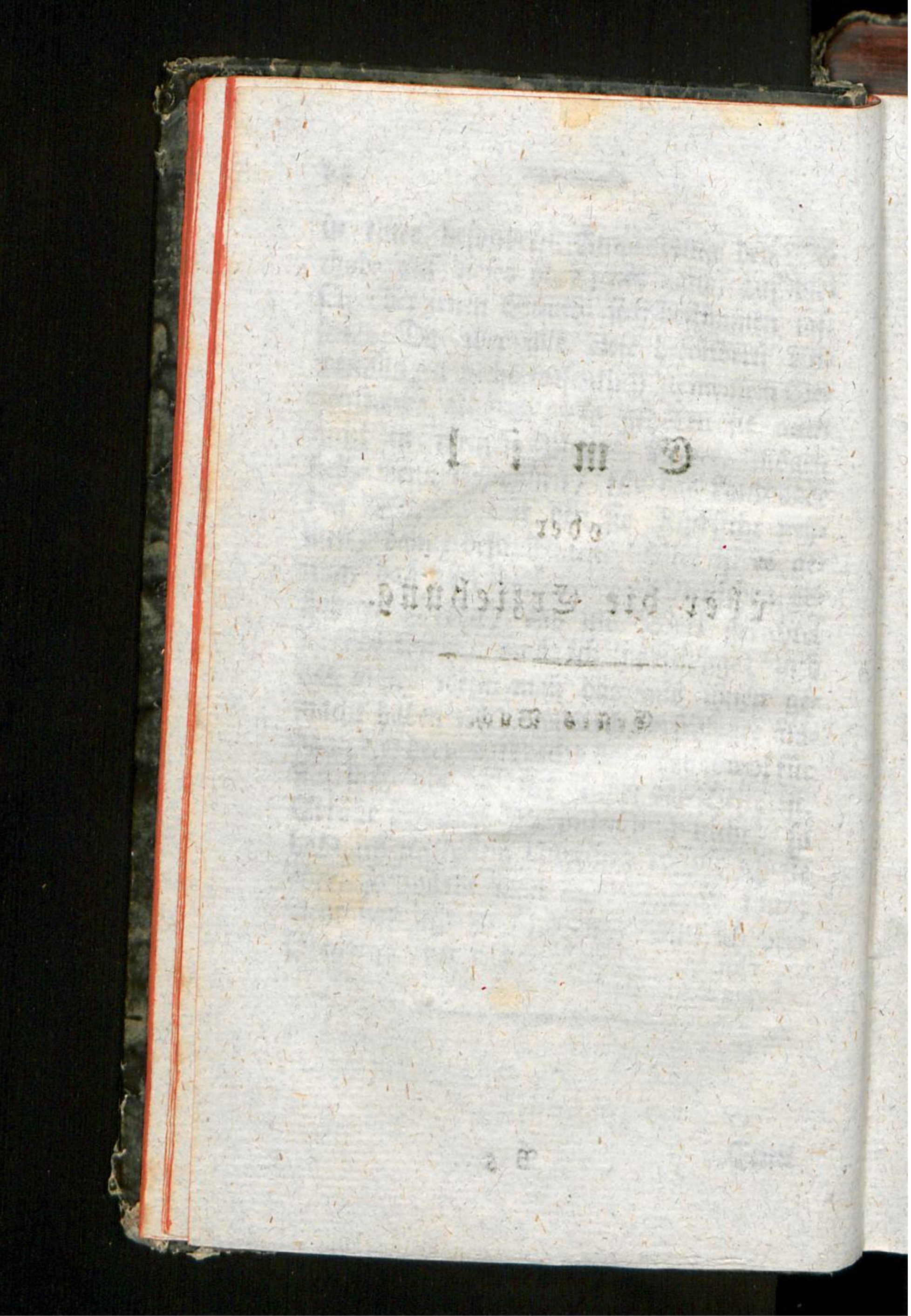




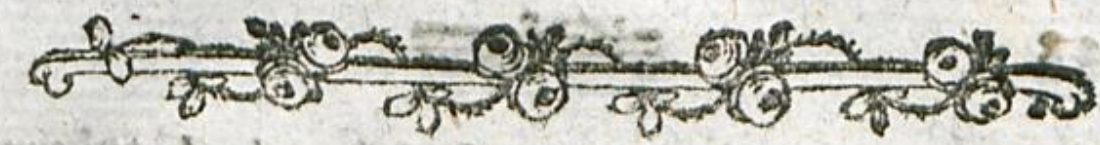

8) Clles ift sute, wenn es aแrs Den Sgsnoen bes Lurhebers ber Dinge tsmmt; 2Clles artet unter ben Şänben bes Menfichen aus. *)

$$
\text { 2I } 2
$$

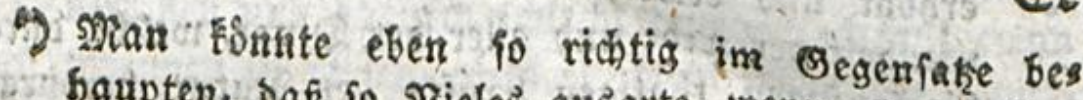

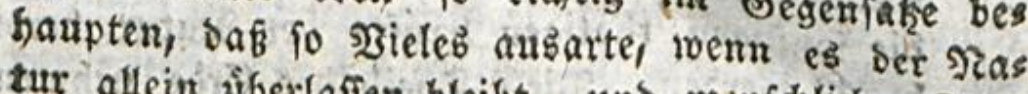
tur allein uiberlaffen bleibt, uno menfdlicher Fleiß ifh wicht ju Shulfe fommt. Dies if barum nods nicht Hnvolfommenfeit ber Ratur, fonbern viels

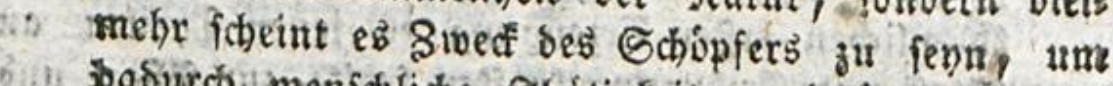

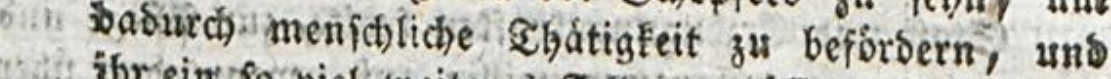

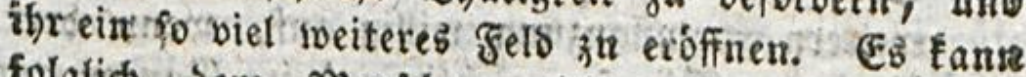
c) folgfich bem Dienichen nidht als etivas şófee angerednet werben, inenn or in ber Edjopfung gleicham zum neuten Schopfer wiro, and eben bas Burch bie Sráfte ber Natur fo viel richtiger beoto 15.6.

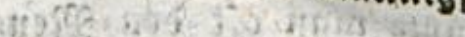

\section{Şeufinget.}

25ie ber von enblichen Dingen unzertrennbare

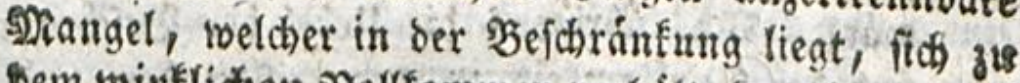

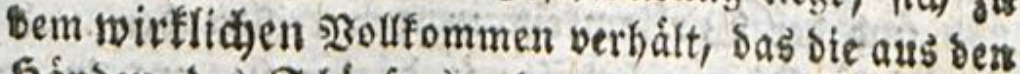
Shánden des Echópfers gehenben Dinge mitbritngen, svelchen 2iangel $\Re$. bier bods auch bátte berúbren follen: fo verbalten fich auch bie Mlánget, bie fic

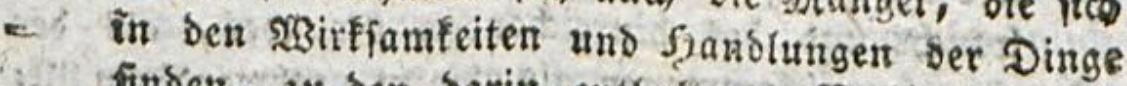

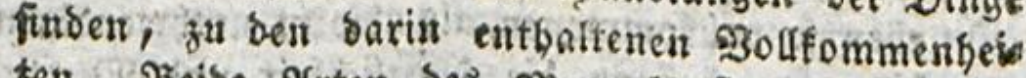
ten. Beibe dirten beb Mangels find gering, is

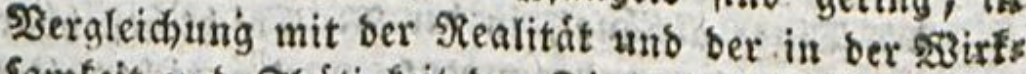

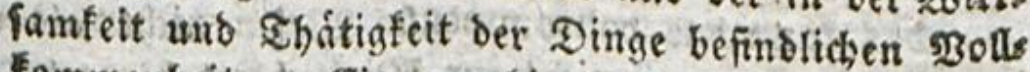
Fommenbeit. Ein gerubiger Forfder ber शatue -..79:tis mus 


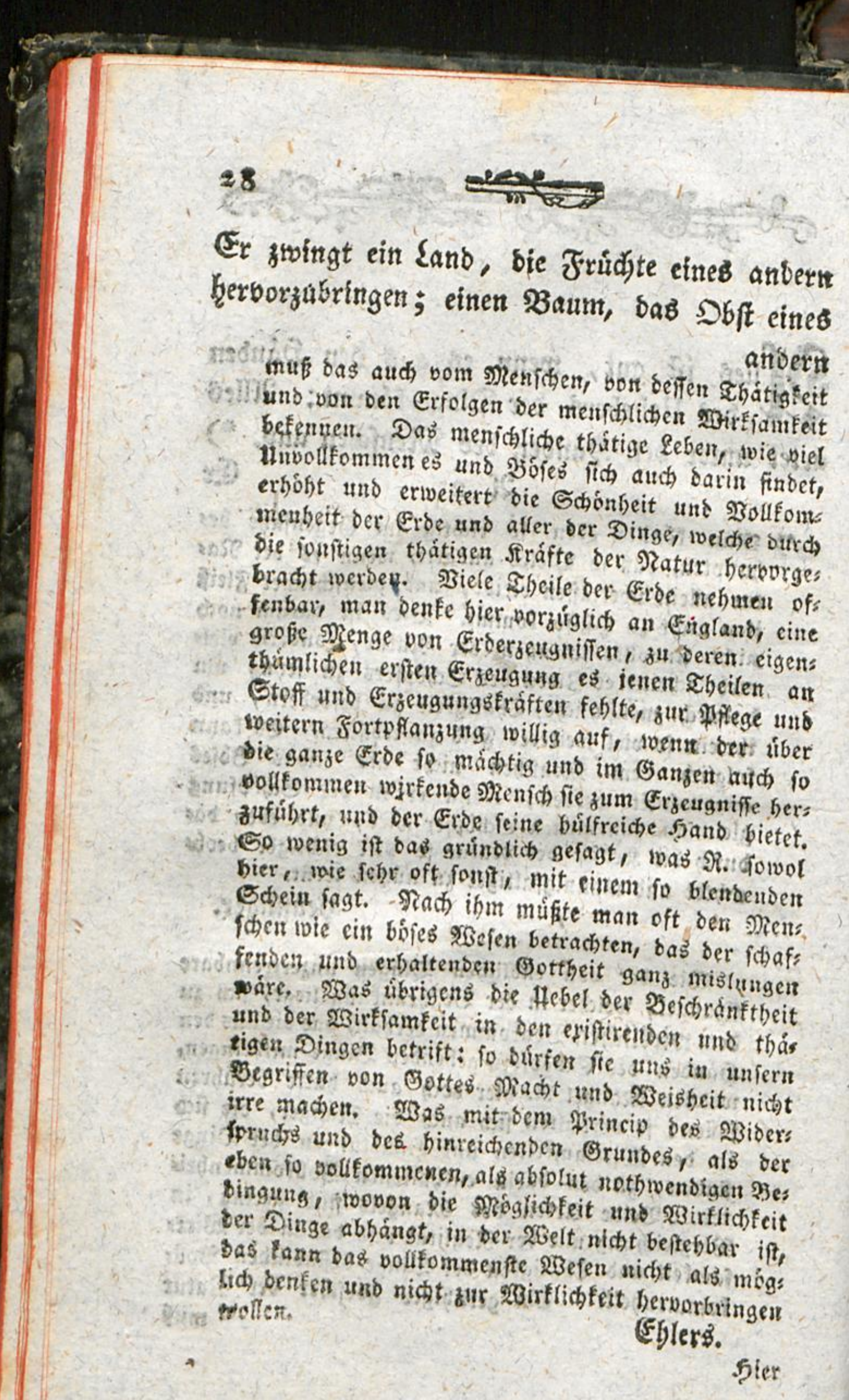




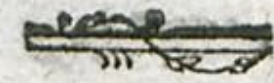

anbeth zu tragen: er vermengt bie Sitmmels: Fridge, sie Elemente, sie Saḩrzzzeiten; ex bers ftimmelt

Sier ift nut gleith ein foll, wo bie resmerifhe Edionheit bet philofophifchen Genauigfeit ber $5_{e}$ griffe Eintrag gethan bat. $\Re$. will zeigen, bá̉ bie 2Menfhen bei ber Erziebung Den 203 eg Der N2atur Derlafien und baburch fichlecht erzielnn. 4 m bierinn (3) fauben gu finben, giebt er ifnen rebnerifat, f(c)uld, Daß 2Mlleg, was bie Sratur gut gemacht habe, un ter ifren Sánben ausarte. Nan glaubt bies zoirks lich auf einen $\mathfrak{A}$ agenbliff bem Rebner, uno er hat feinen swect erreidyt.

Sirapp.

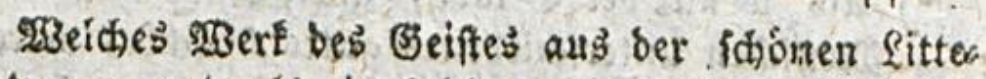
ratur - uno als ein folches, nicht als eirte cigents liche philofopbifche 2rbbiloung, mus man ben Emil betradten w wirbe beftehn, wenn man in ben Iusfprúchen ber Didhter und sebner uberall acroa matifhe Benauigfeit uno Beftimmtheit ofr Bes griffe uns bes 2 tusbrudfs verlangen wollte?

Eampe.

Pouffeau's obigersebauptung ift offenbar unridtig 5 tie phofifiche Neatur bet Dinge ift gut in igren ßráften un $\mathfrak{A n l a g e n ;}$ aber fie artet in vielen fállen aus, tvenn

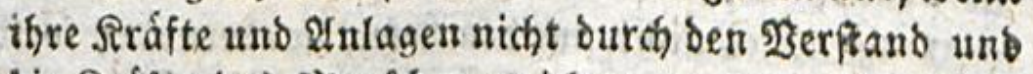
bie Sirafte bes s)ienf(chen gerichtet, angetbanot und ge: whegt werben. Die moralifiche Ratur bes Memichen ift gut, aber fid) felbft uberlaffen entividelt fie fids sicht genug, ober artet aud auts. 2Augenidheintich geht ifre Softimmung Sabiu, bap fie in ber menichs: licben (Befellichaft geftimmet, gebitbet und zu ibrer sigentlichen Solfemmenheit uno Reife gebractst toerden foll. Freilich wirs fie in biejer Befellichaft oft perfitimmt und verborben; aber bas berechtiget uns uvd nicht, bie. (Befollichaft ganz ju- verurtheis len, 


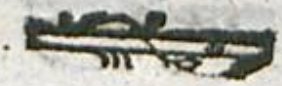

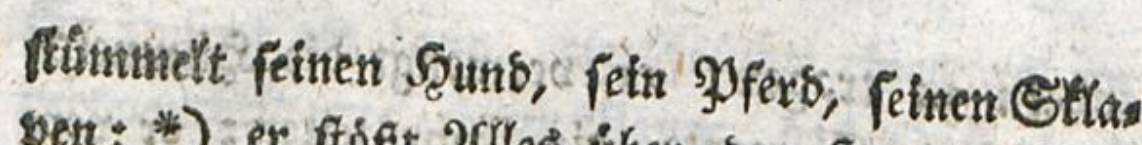
getr: *) er ftóft 20lles úber don Seaufen; ents ffats

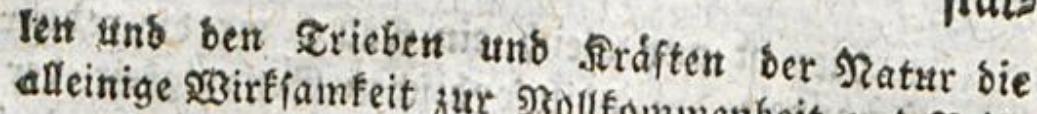

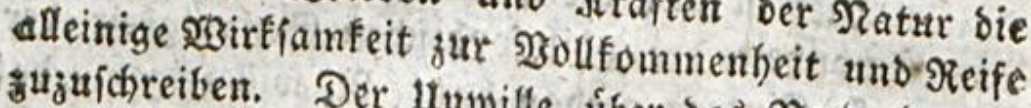

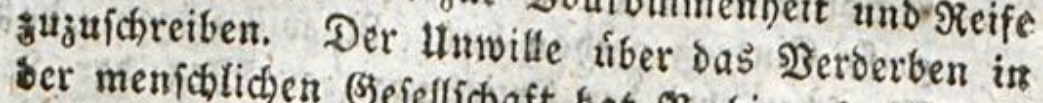
bielent anderit Drtefllichaft bat SR. bier, fo wie an

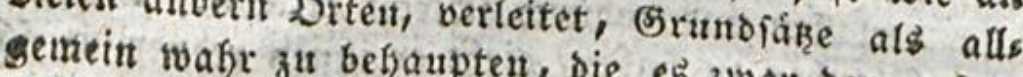
20richein nach furb, bei gente es zwar bem erftes Salb wabr unt unbeftimnt genater Prifung aber nue to gar verberblich fitimint, unb in ber 2tmoendung

-) श्ञाड

Nerifchen

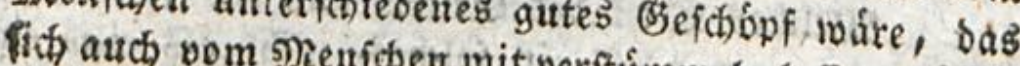
oder, als wenn túrlicken Sheich der Sflavenjutano mit zu der nas

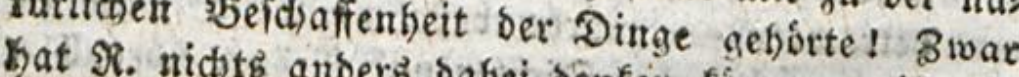
bat $\Re$. nictis anders babei benfent fonnen, als bas Wer Menici feiue Dbermacht oft fdhánblich genutg misbraudst, um eirren \$iebeumenichen jum Sflaven 3̧u machen und als SElaven zut mishandeln. Iflleit

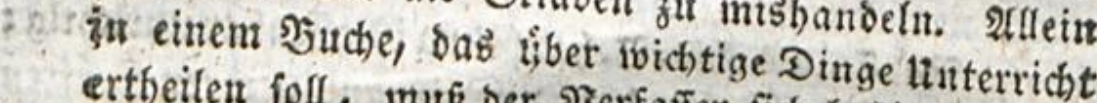
ertheilen foll, mú ber \$erfaffer fich beftimmt auts

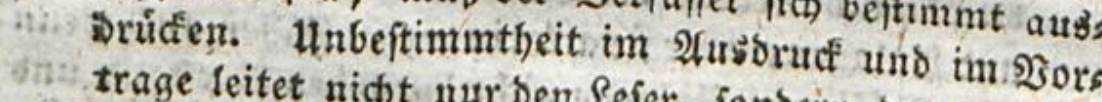

trage feitet nid)t nur ben Sefer, fondern ben fortben: Fenten Serfaffer felbit leicht in viele Jrrwege des
Denfenb bineitt.

Eblers.

Itber Nouffecu, ourfte mant vielfeidt za einis ger Entichuldigung fagen, fortieb fúr gebilbetelefer - benur andere, als foldse, founen feime Joeer nicht fâten; unb fold)en \&eiern barf ber \$erfaffer einer, sidit mit philofopbifcher Ettenge abgefaften, fons bern bloḱ liberrebenben Sdrrift bas granum falis, wos swit bergleithen gelefen (e)n will, boch wol zatrauten. Eanipe. 


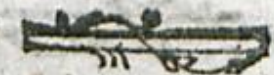

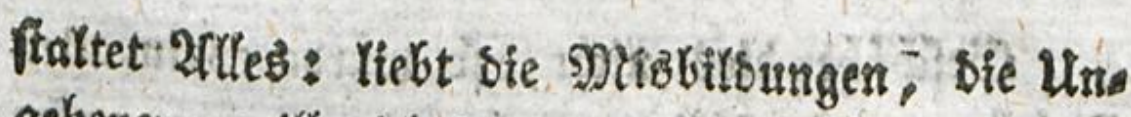
gebener; will nictitB, wie eB bie Natur gemadjt bat, nid)t cimmal ben Sienfichen; man mus ifr

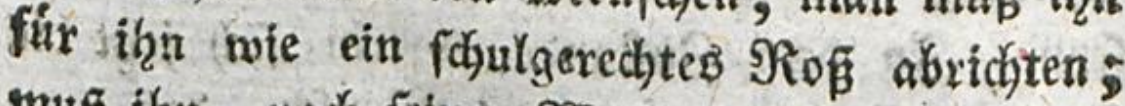

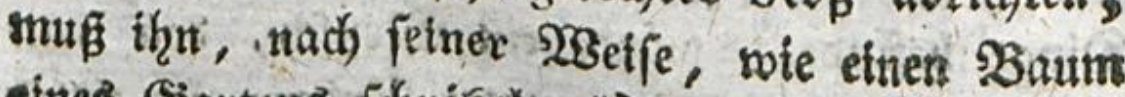

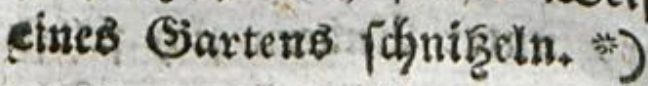

Sies

Es bleibt aber boci inmer umbafir, bask bee menich alfes burd feine fjand berberbe, und ef madt feinen wefentlichen 20 rozug aus, burch feis zen şerftand veránbern zu fónnen. Er if auch som Schopfer baju beftimmt, uno ber Disbraum bebt ben guten Bebraud nicbt auf. Diefe unber

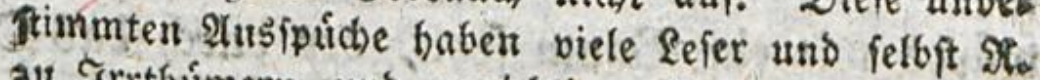

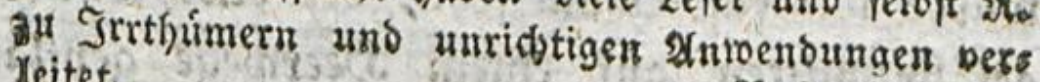
Jeitet.

Refemis.

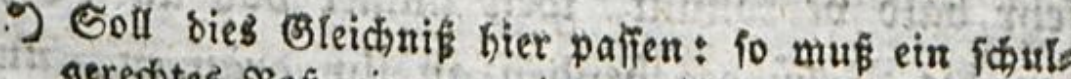

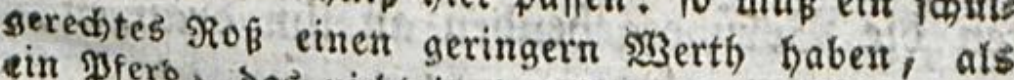

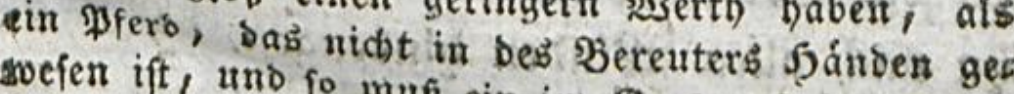
soefen ift, und fo mus ein im Barten ftebender beo \$dnittenter Daum nidst fo viel taugen, als ein wilbs

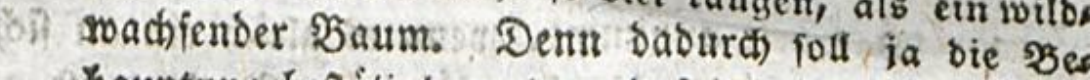
hauptung befátigt toerben, baß ber Nenif aus bem blofen Ngaturrmenífien ein ltngebeuer bilbet. uns woer fieft es nicht ein, baf bas Eine, wie bas $\mathfrak{A n}_{\mathrm{n}}$ Dere bódift falifh ift, wenn er beim Eefent nur ein soenig fill ftefht und prift! Die fchone Edrreibart Poulieau's reift inbeffien den Sefer gervófnlich fo fort, baß er nidht jum Etillfteben und zutr 9rufung fómmt. Die Eotafivirfung, bie bei gewóbntichen Refern burch

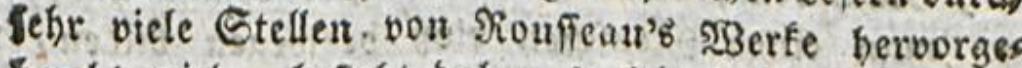
bradit iviro, beftelft bafier fo leicht in Borftelluns

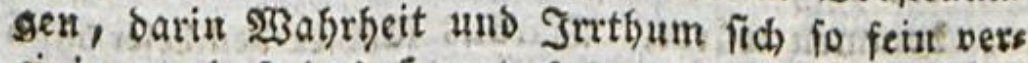
einigen, Dafi bas Sauptrefultat leidgt Den Ehein 
(Sicidadfe bles nidyt, fo wirbe sb in allen Sticten noch fothmmex Kergeben, wno unfre Sattung will nidht blof sur Sgälfte gemabelt fenn. Sin bem Buftanbe, worin fidj jest ble Dinge befinden, murbe cin Menfh, beni wan Don feiner Gieburt an, unter 2(noern fich felbf: überliefe, ber entifaltetffe von allen fegm. Die 2Borurtheile, bas herrichende 2Injeken, alle bie birgerlidjen Einridtungen, bie uns gleidjfam ưberfiswemmen, wuirben in ihm bie Siatur exe fticken, und nichts an iffre Stelle fergent Er $_{r}$ swirbe wie ein Baum feyn, ber burch ba8 Shns gefäfr mitten auf einem Szeermege gepflanzt, fehre bars berḱommt, weil immer won allen Seis ten sie Borubergehenben an įn brängen, uns 5in nady allen $\$ 28$ inden hinbeugen. *)

ber şakrheit annimmt, รั. eben fo grober, ats oft gefábrliçer Jirthum ift. onts.

(E)lerz. Nejewik.

Siouffeaut badte bier wol vornebmlich an bie

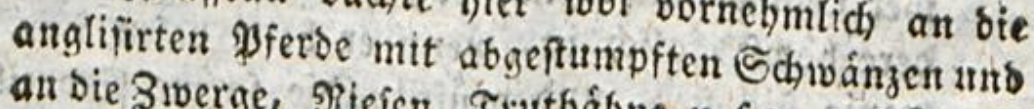

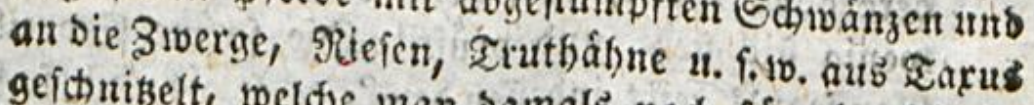
geichniţelt, toeldie man bamals nod) fír cine Bierbe

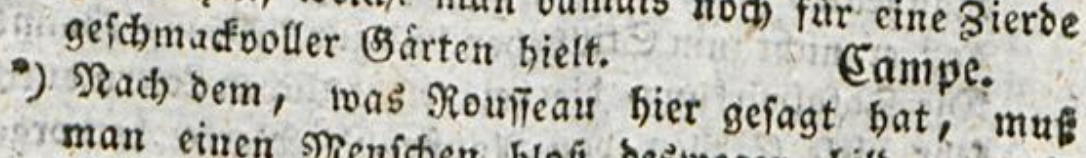
man einen Menfchen blof beswegen bilben, weil cin ufrgebildeter Mienifh unter gebilbeten tificht forts

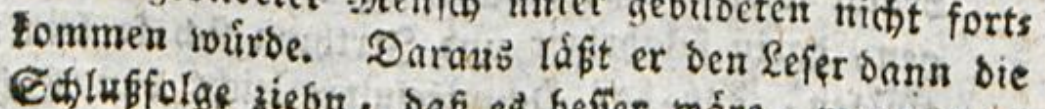
Cóluffolge ziefn, dap cs befier máre, wenn man 


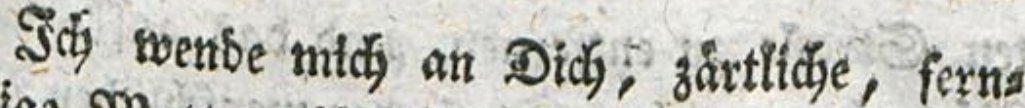 fichtige Mutter, f) sie bu bich son ber breis}

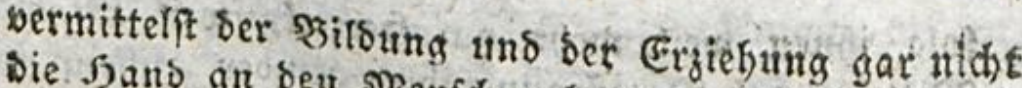
Die. Jand an ben menfonen legten. Es ift ia sub befannt, mit wie tóufchenben शुorftellungen er in Der grinoliche Denfer Edrift das befauptef hat. prifend lieft, bals dund lieht freitich, wenn er redst butch. Indere ricfteh dergleichen Эुlenbwerfe biue thátigen Seben nach) bern fich aber mut zu leicht im ziglich ein tráger fir 9 (3abrbeit angerne liegt, bun benten begietig sveifen rolt angenommen, welche bie mit einer

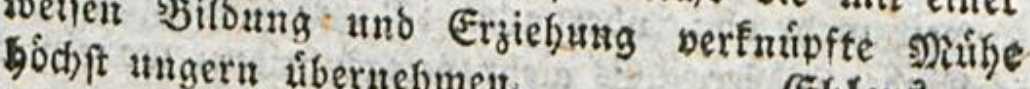

bier offenbar tur auf bas, isas ventionsmerg bes gefellifhaftlichen Nenidien (Son= baupt.

Das bátte aber

fúr jeben Lefer lebrreid. beftimmen follen, wenth et Der $5 a \hat{\beta}$ gegen bas

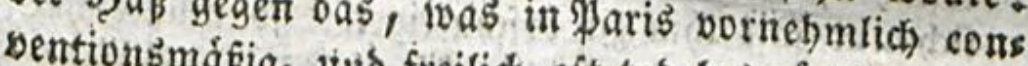
it, bat ibig, atio freilich oft tadelnswurbig gemts

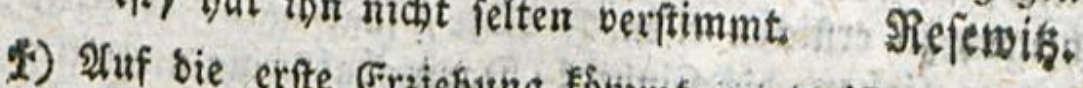

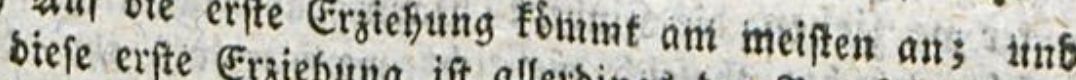

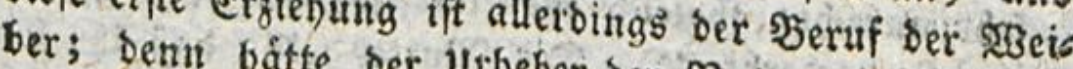
follte Der ber Dianer fltheber ber Natur gewollf, fie gegeben, die Rinber fern: fo bátte er ifnen Nild

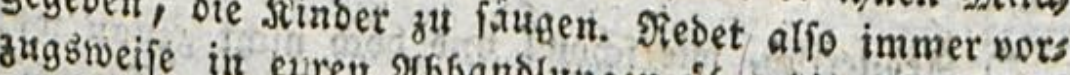
34 ben find, viel nert; benn auberbem, bas fie im Etande mebr singubere Sorge bafúr zu tragen, uns immer Emil. Ifter Th Darinn baben; fo liegt auch ber gute Ers fols 


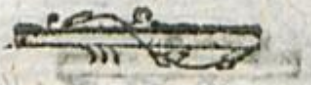

ten Straß̊e zu entfernen, uns Das auff́eimende

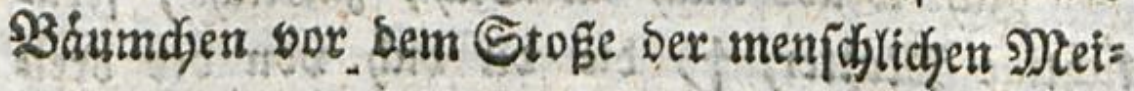

folg ifnez soeit mebr am Syergen, weil bie meiften şittiven oer Şerpllegung ifjer Sinber anheim fallen,

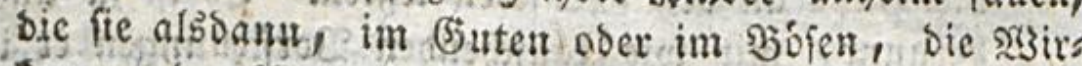

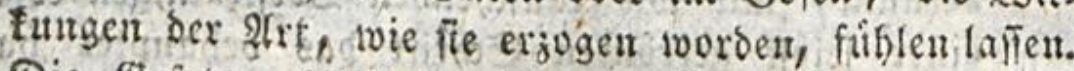
Die Bejekze, ftets fo bejorgt fúr die Gidermmg ber irrobichen shiter, uno fo wenig fúr bie bev \$erionen,

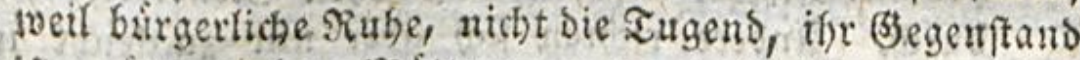
it, raumen ben muttern ju wenig 2frifben ein. Hu terbeß if ifre Şeftimmung viel aubgemachter; als bie

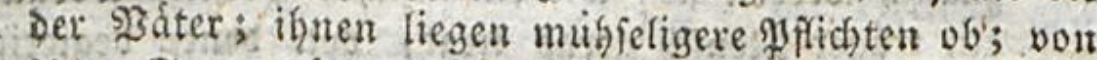
iffer Sorge hangt bie gute Dobnung in fausfande zoeit meft ob; liberbanpt ift ifre Buneigung fur bie sinder grófer. Es giebt Gelegenfeiten, two ein Gohn,

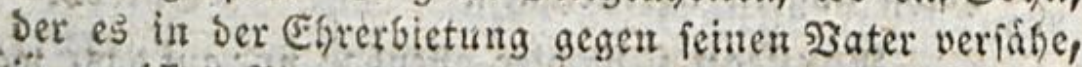
im gewifiem Setracht Entfchulbigung verbienen founte; aber wáre, bei was fúr einer solegenheit es auch wollte, cin Rino unuatứtiç genug, fie gegen feine Nintter auts bett-2Augen z!t feţen; gegen biejenige, bie ibu

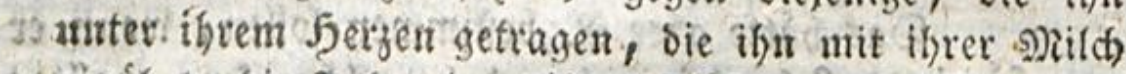
ternafber, bie gaffre laing ifrer felfft vergeffen bat, um

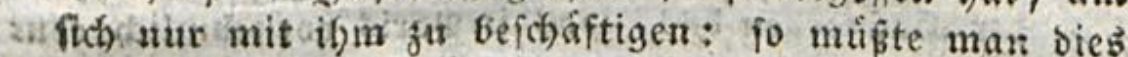

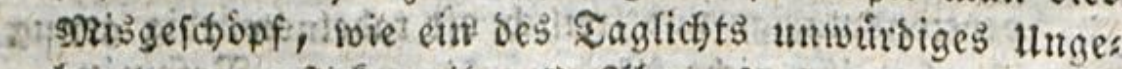

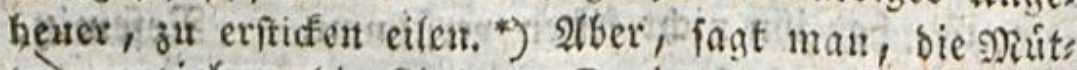
ter verziegen bie Sinder! Darin Gaben fie unftreitig

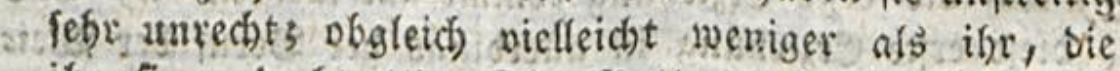
ithr fie verberbt. ${ }^{* *}$ ) Die Nutter will, bấ iht Rino

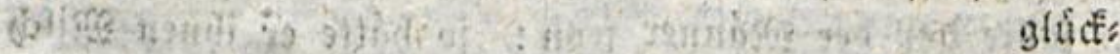

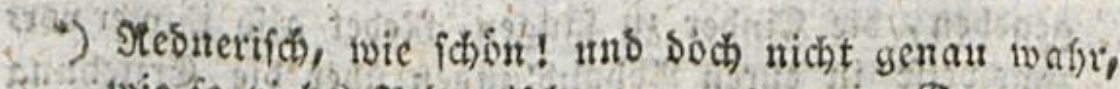
vie to bietes giebnerijche. Staps.

40) Der bier gemadite Interichied zivichen dem, was

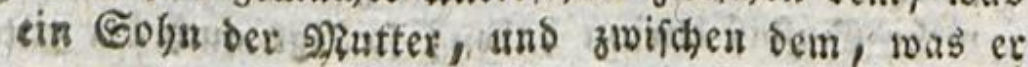

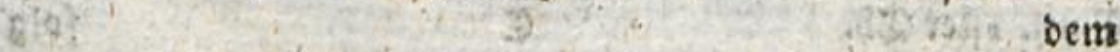




\section{nungen zu bewalgren berftanoft! Pflege, begieffe bie junge Spftanze, ehe fie roelft; ifre Fridite}

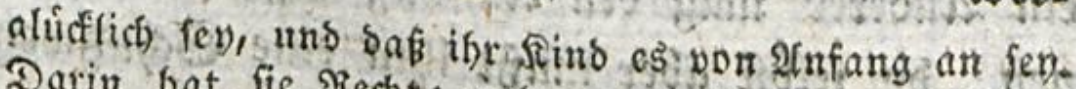

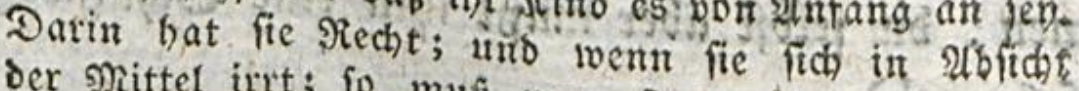
ber Mittel irtt; fo mue man fie daruber erlettóten.

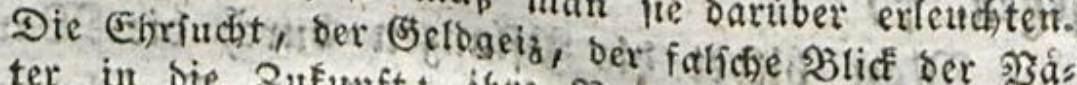

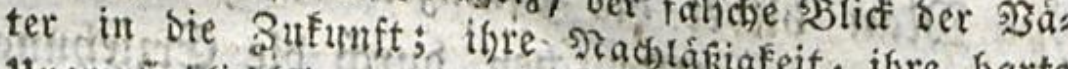
Unempfinslichecit, fins oen fim

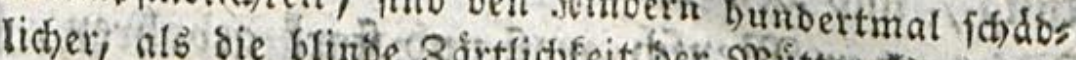

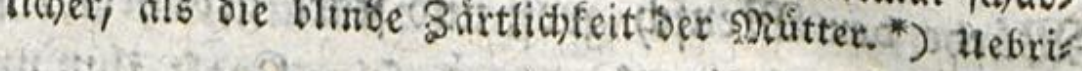

bent Sater fouldig if , hat nicht binlätglichen (3) runo. X3as ein, guten Naturtrieben folgender, uns uiber bie ifm obliegentent plichten gehbrig anfget: fläter Safer an-Sorgen, Itreiten uno Gefalsren fur Noutter und Jind in ber eriten Beit ber Ninos bett foivor, als hernach libernimmt: fommt meht als bem gleich, twas sie mutter leiftet. Es twáre mux zu wuinj(thet, Daß̉ bie burgerlichen Befek̨e allges

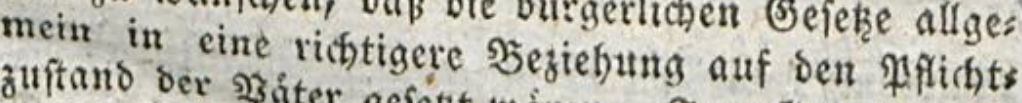

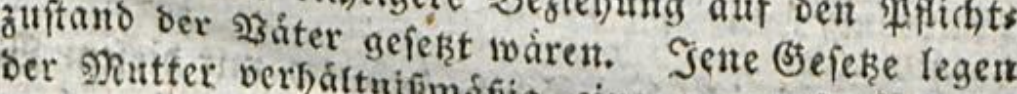

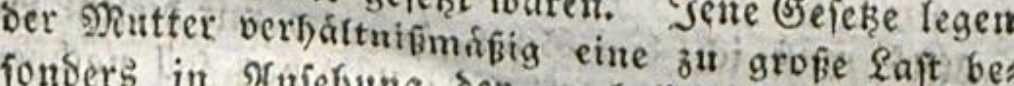

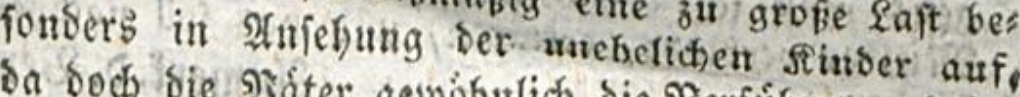
oa boch bie Nyater gewohulich bie \$erfúfret uns im Punct ber Sdbloangerung bie eigentlich thatigent Derfonen find. SBer in eirter Sache bandelt, hat

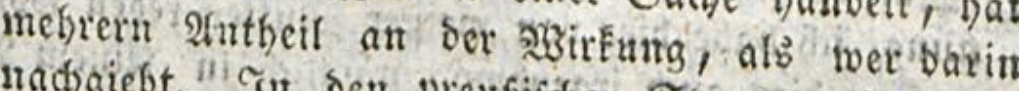
nadgiebt." In ben prentifichen Etaaten toiro auch in biefem Stuicf an bie Serbefferung ber burgerli: den Beiefre gedadit. Ebfer?.

Die Berlefung ber finblichen glfiditen gegen die sutter empórt aber bod die Cmpfintoung cines gebilbeten Renfidenganz-vorziglich. Stuve.

4*) Shan mufi bier abermal fir bie resnerifhe lleber: treibung etivali, und war nidit wenig, abrechuem.

Slapp. 
swerben sir einft Labfal fers. Utmgieb frühgeis tig bie Seele beines Rinbes mit einem Sellege: ein 2rnoerer mag ben Utmfang beffeltsen bezeidys net, bu felbft aber maft ifm eine Sdjuswebre reseren. $t$ )

Man bitbet bie Mflanzen burth die Stzara Aung, und ben Nenjchen burch sie Erzithung.

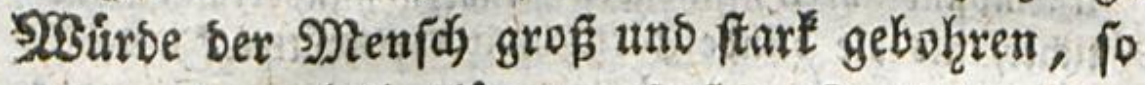

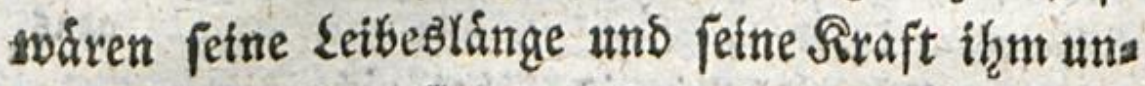

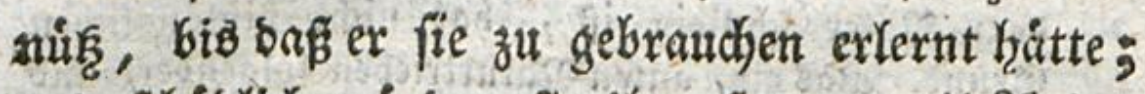

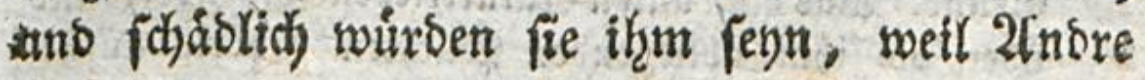
sun burch nidjto fich berwogen finden fonsten, ithm zu Seulfe zu eilen. tt) So wuirbe er, fich) felbit úberlaffen, yor Elend umtommen, bevor

er

gens mü ich ben Sinn, ben in mit biefem 930 rte M) Wuttel verbinbe, erflaren, unb bas folf nachber ges scheber.

IImert. D. Betf.

4) Man verfichert mid, f̧err Formen ftefe in ber Nieis nung, irb habe bier von meiner mutter reden wollen: er fage bies auch irgentwo, námlid in feinem 2 untis Emil. Es ift eine graufame Erotterei, entroeber tiber

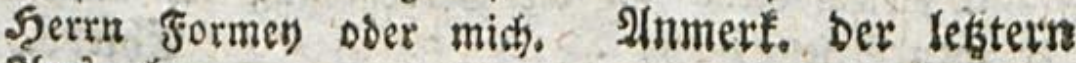
2usgate.

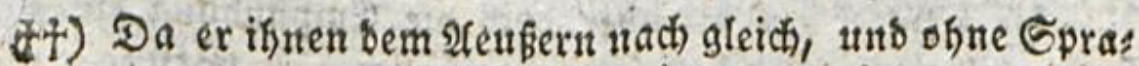
(j), fo twie obne SBegriffe, twáre; fo toúrbe or anfer Stanse fern, ifnen zu verftehen za geben, mie er th: res Beiftandes brauchte; uno nichts an ifm toutbe cs ร5) Eun Eub thus.

Inmerf. จ. 23er\%. 


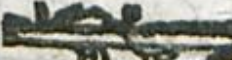

ex feine Bebinfniffe einfekzen gelernt. Nan tagt iber ben auftans ber Sindheit; und fieht

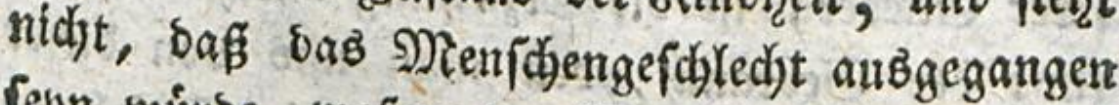

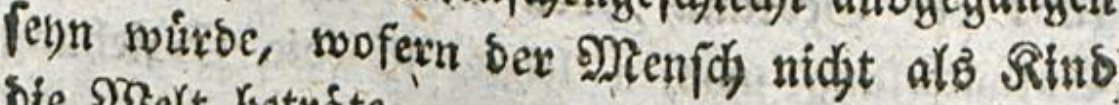
Die SIBelt betrate.

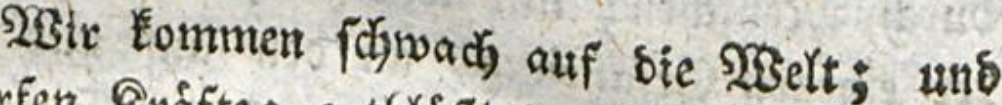
besirfen Rrafte; enţblofft son 2Cllem, und bea burfen Beiffandes: Dumm, und bebirfen Hra

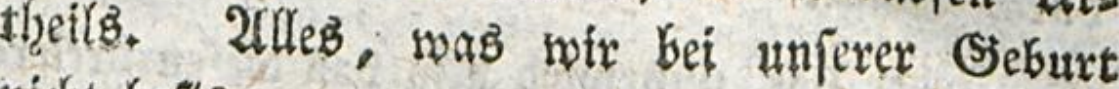
nidyt befizen, uno was nir braudjen, went wit exrachjen fins, giebt uns bie Erzziefzung.

Dieje Erzichung exharten wir burdy bie গlas tux, poer wie Nenfdhen, obex bie Dinge, *)

(5) 3

Die

-) Eryiegung ber 9iatur if ein figirlicher 2fusbruat; fo auth Ergiebung ber Dinge. Die Eintbeilung ift alfo logich feblerbaft, uno fanu nur in cinems

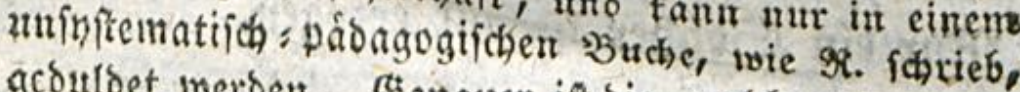
geduldet werben. Benauter ift bie, welche, went its sicht irre, Șelvetius giebt, bie Errziefung des vá trutichen Saufeb, Der Edfule uno ber \$Belt. Shier find es immer Nenfiten, welthe erjiegen, unt

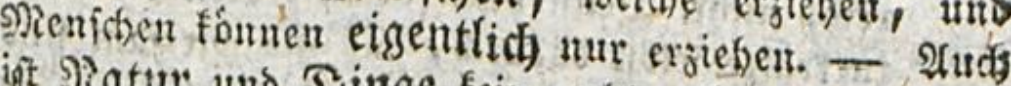
i.t. Jiatur uno Dinge fein rechter (5egenfati.

Itapp.

গู豸 tigen Ginn nimint und alles bas barunter verpefft, ivas auf ben Mienfiden uns in bem grenfden wirft, feine Sirâfte entroiffeln, ausbilbent unb modificiest

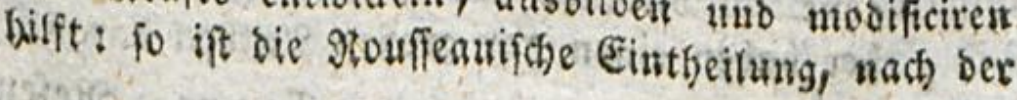


Die intre Entwickelung unfrer Rrafte un un ferex Şlteder, ift bie Erziefzung burch die Tias tux: Ser (Sebraudf, ben man unb bon biefer Entwickelung machen lehret, ift bie Erzief̧ung surch Nienchen; uns was wir, vermoge unfes rer eigenen Erfifhrung, an ben auf uns wir: Ienden Siegenftánden Yernen, ift bie Exzielsung Surch Dinge.

Şeber bon thas wirb arfo son siejen breier: rei Meiftern gebilbet. Der Sdjuller, bet bem thre serfojiebenen Llnternoetfungen fidy wiberipled)en,

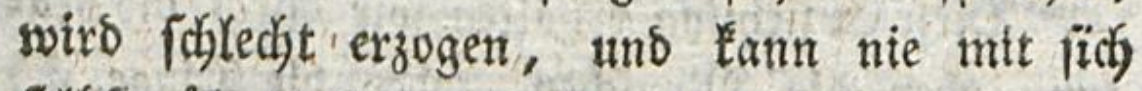
felbft úbereinftimmeno fenn: berjenige, bei bem fie alle auf einen und benfelben Punct zujans mentreffen, und nach bemfelben Biele Kinftreben, exreidit allein feinen 3wect, uno rebt conjequent. Tut ein Soldjer ift gut erzogen.

bon ifm felbft hinzugefuigten Ertllarung, Soch fo uns recht nicht. Denn offenbar beforbern bie innern s?ar turfráfte felbft baburch, baf fie wirfam find, ibre Entwicfelung; offenbar thiu bies alich alle uns ums gebenden unb auf uniere luntidsen $\mathfrak{X B e r f}_{z}$ enge irs gend cinen Eindrud madsenden Dinge; offenbar fino $e^{5}$ alfo nidbt bie Nenichen alfein, welche bas aus uns machten, twas wir find, fondern uniere cis gene mituirfende Natur unb bie Dinge um uns was bet haben eimen gar groben Antheil baran.

Campe. Refewikg. 
Untex biefen srei Exziehungent tutt, Kăngt bie surch sie शatur nicht von ung $a b ; *$ ) bie (c) 4 burch

D Es verurfactit in ber Folge wirflich einige Dunfels heit und \$̧erwirrung der Begiffe, baf গt., ofne Dem

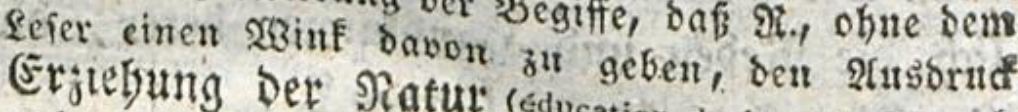
utho nadh in breierlei Ginn gation de la nature) racks wertîteft er borunter bie inn genommen bat, frier ferer sirófte, Des ging loeiter bin Diesentige Erziebung

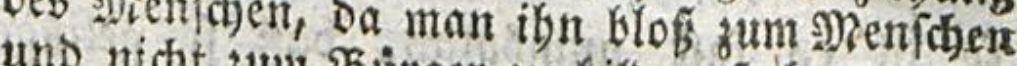
und nicht fun Sürger fu bilden fucht ober nutr auf das Jnoividum und nicht zegleich auf bie

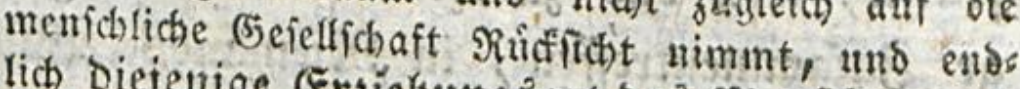

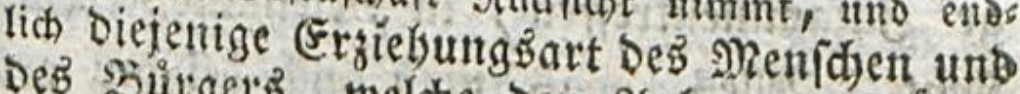
Dez Surrgets, welche Den Ifnlagen, firaften uno wefentliden srieben Der menffifichen Sta tur angemeffen ift. Diefes Shin unt STerforwans fen swichen breietlei Ginn eines und eben' befielben

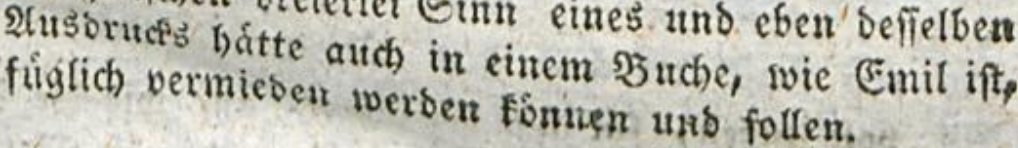

Eampe.

Dieje Bemerfung ift felyr richtig, int id filge nut noch finzu, daß bie Erzichung ber Matur, fo wie fie $\Re$. furz vorker erflät hat, allerbings fefe von unts affángt, weil weder die Siráfte des leiber nod) ber Geele bes Mienfithen einer blop̈ inuern Ento

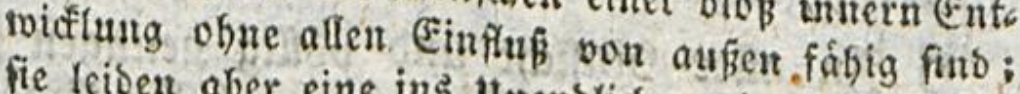
fie leiben aber eine ins Ituenbliche gehenbe \$erfchies benfeit von Nodification in ifrer \{rusbiloung.

\section{Stuve. Rejérwis.}

Da . Die Erziefung ber Matur eire intere Entriefelunts unfrer Sráfte und Bslieber genannt bat, fo nimmt er fie hier, ats ofne ben Einfus

yots 


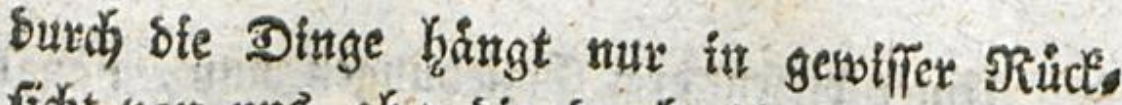

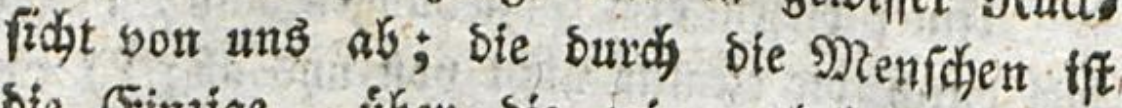
Sie cinzige, liber sie wir wafgrhaftig Sere

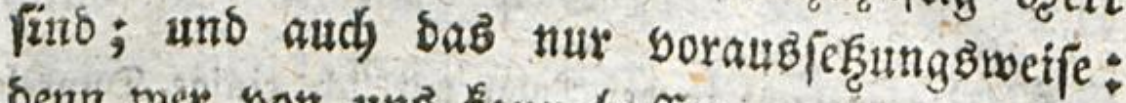
benn toer bou uns tann froffen, er werbe gánzs Yids bie Reben und Shandlungen bever, bie unt cin Rind find, renlen ssinten?

Sobals alpo die Erziebuth eine Sumft iff; fo ifí es faft unmoghlidy, Dafí fie gelingen *) folltn, weil bas a threm guten Erfolg notf̧is

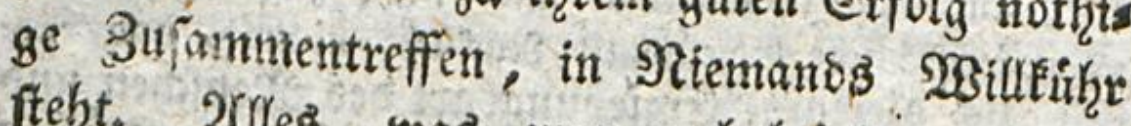
fteht, 2Ulles, was man auch bei ber grofiten Sorgíalt thun fann, ift, baß man mefyr obex

sues

bot ausen, fur fith betrachtet, an, toie die siatute bei einem in ber 23 itonif aufgewad) fenen Menfchen, fo wie bei jebem anbern, auf gleiche Art twira fen mutp. Freilich bleibt es dann nichts, als

șeufinget.

9) Int allet Sinficht uns vollig getingen follte, muste es beiper. Sis auf einen beben Grab fan boch ein einiidhts boller (Frzieher jenes Sufammentref: fert veranitalten, wie das auch aus bem, twas folgt,

Eblers. Bampe. 


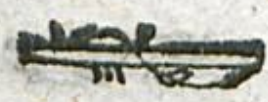

weniger bent Biele *) fich, náf̨ere; aber (s)tho: soiro bazu exfodert, eis zut erreidben.

2 seldjes ift siefes 3iel?

(c) 5

bas

-) D. i. sem nichtichimärifhen guten Joeale, das mass immer vor 2tugen haben mu. Er. Srapp.

-) Ein Biel, bas nidit getwobalid, ohne den befonderns 8ufall bes sslúcfs's erreidbt toerden fann, ift nidst ein mit geforiger Heberlegung feftgeieţtes Sie\%. Eiut weifer Ergieber bat wol Toeale ber \$olffoms menfeit vor \$ugen, madjt esaber nidjł ju bem Siel, bas er erteidgen will. (Ebler:3.

Routieau redet aber bien nidht von einem bea

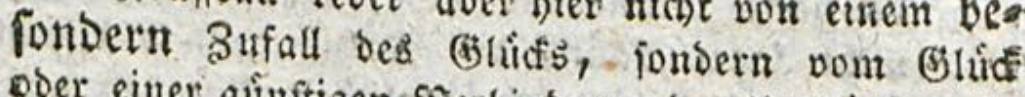
- Der einer gúnftigen şerbinbung ber Hmftánoe, in fofern folche niçst von uns ab́fángen, úberfaupt: and ba bat er benn boch allerbings Recht.

\section{Stuve.}

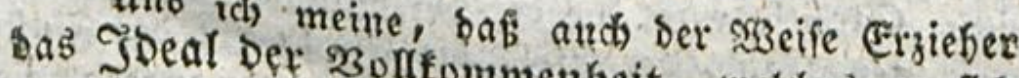
gemacht bat, allerbings menbeit, welches er fid

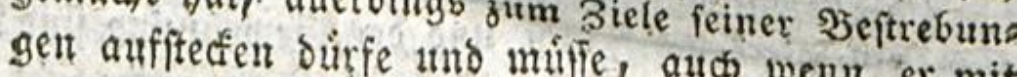

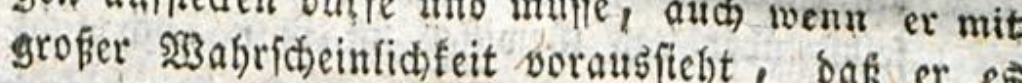
ganz ficherfich jemals erreiden werde. (5. (id) ifm zu nábern, io jebr er fam, und benft: wev nad einem guildenen sabe tingt, erbålt Doh wol eine Speidje Davon. Eampe.

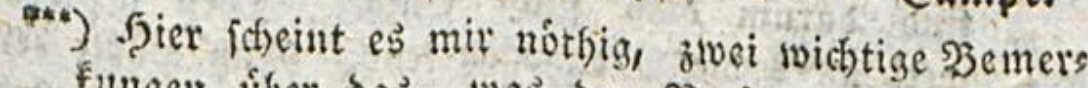
fungen liber bas, was bef $2 e r f$. von ber গatur fagt, jut macher.

1) 23 ir vermogen ưber bie Natur nid)ts, fagt er. Das if wol nicht gam cusgemadt. Sisum unite

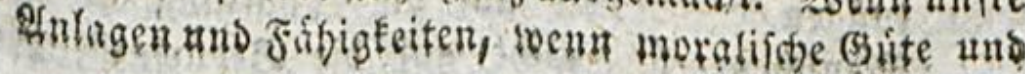

গूँญ 


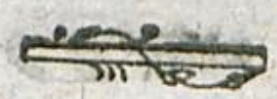

\section{bas 3iel ber গlatur; *) wie berviejen wors}

Şerberben, zum gropen Iheile bon ber গुeichaffen Geit uniers Sorper abbäingen, was mant nid)t lángs nea fann, fo ift unire Belwalt liber bie Natutur fehr grof. Die Eomfitution ber Eitern, if́r Zuftand bei ber Erjeugung, die Sefundbeit und bas Ser Galten ber Nutter wábreno ber Sdiwangerid́aft, bie 2lit bie sinber jut halten, freifeit mo Swang,

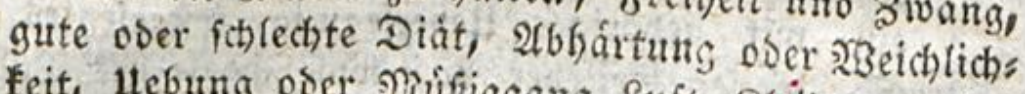
feit, Hebung ober Nitufiggang, Suft, Sileidutig, alles wirft aut bie Natur uns fimmt fie auf feine Art. Dazu fommt bie (Sewofnung, bie, wenn fie nicht bie ganze Natur ausmacht, was man in ber Shat sicht fagen fann, die s?atur boch fo ftimmt unto snbert, baß bie uriprunglichen 2Anlagen ganz uth fenntlich werdent. Der গ̧etreis bavon ift, Daß wir sricht leicht um Stande fint, zu fagen, of bies oder ienes zur Patur gefort, oder nicht. Dafer bie Streitfragen: of ber vorgugliche (3) ebraud ber rechs fen Şand, ber Efel, bie Futroht nor ber Finfternif, sie Schamfaftigfeit und anbre mefr angebohren, oder

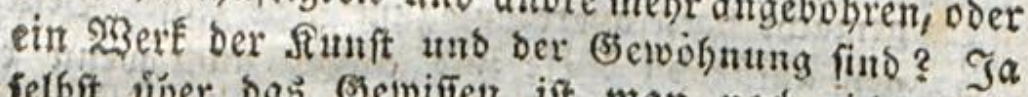
felbft ǔber bas Eetwiffen ift man nody nidht einig
geworben.

2) SBie fann man fich benn ben Bived ber

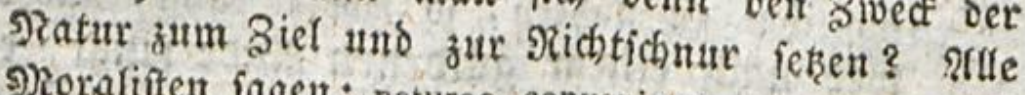
g) Torafiften fagen: naturae convenienter vivendum, uns fino barum boch nicht einig. Eben to wenig

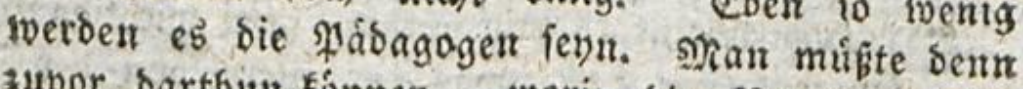

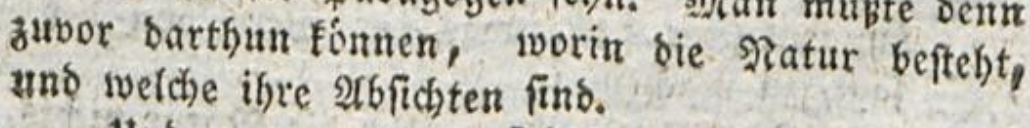

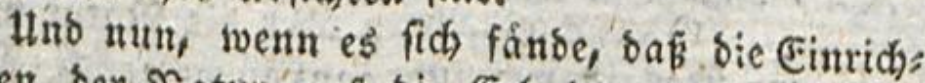
tungen ber Natur auf bie Erthaltung des lifolirter

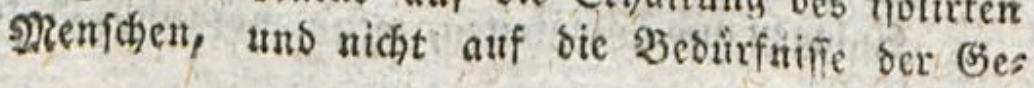

fells 
fellichaft calculirt witben, mifigte man nicht vout ber Satur abmeichen? Itno boch wirb biefes untaugbat fenn. Der Gdjopfer gab bem shenichen Sorn unt

11. 2iache, stm: fich in oem Stanbe, wo ex feine frems De feulfe erwarten Durfte, vor 2 ungrifen ju bewahs ren uno uno gegen bieferben zu vertheibigen. Tn ver (s)efellichaft ift ibm der Sorn grobitentheils uiberflus fith, unto die Rachgierde wúrbe die (se?ellichaft jers ritten. Dat habe idh-fison in ber vorhergehentear

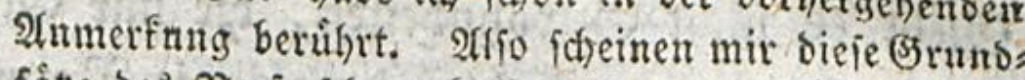

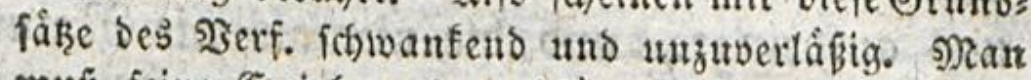
mú feine Erziehungsgrundfäze nicht aus ber Nia: tur allein, fondern aus ber Nergleichung ber Natur mit ben Erforbernitîen ber Eejellichaft hernehmen.

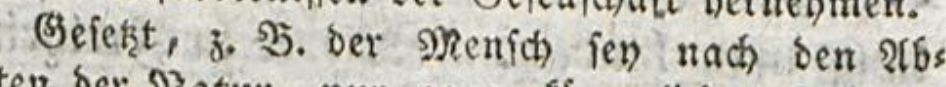
fid)ten ber Niatur, nur gegen forperlichen Gdmerg

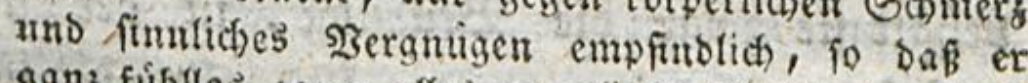
sanz fúftlos gegen afles moralifche 230 hl ober $293 e h$ bliebe; wie wird er in bie (s)efellfichaft pafien, uno Dbrigét wirs wirb biefé von ifm haben? Die Dbrigleit wits immer in ber einen 5and eir Stid Brodt und in ber andern einen Stod baben mif

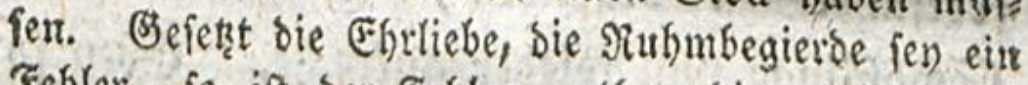
Febler, to ift ber fehler nothwendig, uno leiftet. oie vortreflichiften Dienfte. ES if uramoglich, ben Renf(t)en fúr ifn felbit gam zu ergiebn, man mus ifn fuir andre ergiefn, ifn zwifchen ifn feibfe uno andern theilen.

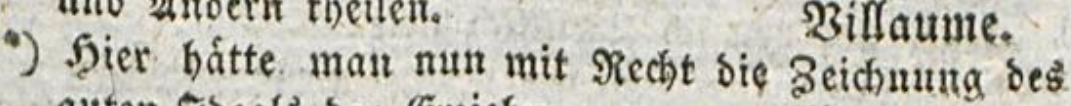
guten Soeals ber Ergiebung erwarten fomen, wenn

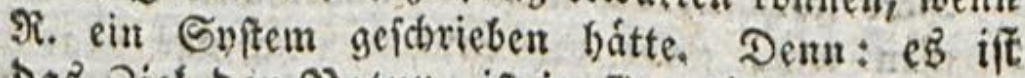

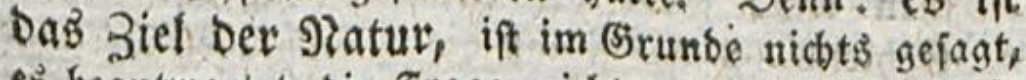
es beantwortet die Frage nicht, fonbern peranlafis nur eine neue, namlich biefe: was ift benn mux das Biel ber Matur? Trapp. Eampe. Refenibis.

$*$ *) Wo?
Eampe. Rejemíg. 


\section{4}

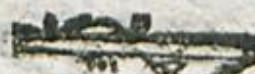

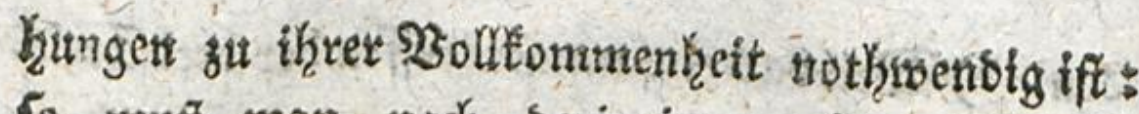
fo mü man midy bexjenigen, uber bie wir stichts sermógen, die beiben andern einridyten.

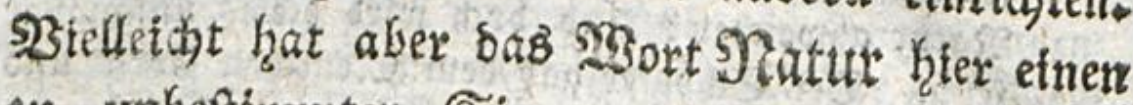
su unbeptimnten Sinn; lapt uns verfuchen, thin feftzuceren.

Die 9Ratur, fagt man, tit nidjts anders

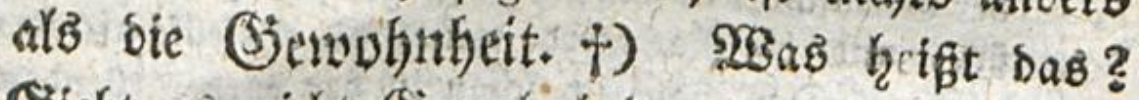
(Siebt es nicht Siemohnherten, bie nur Siemalt uns auforitigt, und bie nienials bie Natur ers

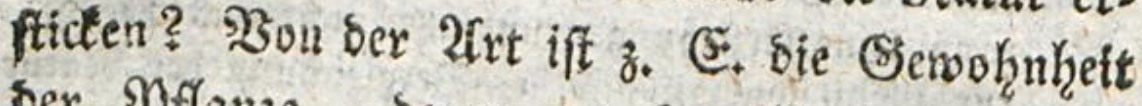
ser Pflange, beren gerabeauffitrebende Ricj, tung man binbert. S2Gieser in Freifreit geferct, behåit fie zwar bie Beugung, in ber fie zu soadjen gezmingen worden ift: aber bie innere Zriebtraft hat barum ifhre mriprimglictye sRtdys tung nicht bertoren; uns wein bie MPlanze fortfáfirt zu begetiven, nadjen bie ibrigen Sdjofglinge mun swieder aufrecl, be ben fo bers

†) Serre formen werfickert, wan foge nide hadrt beffer fdreints mir boch fefor beptimut in bem \$ererje ges fagt, auf ben ich eigentlict) ziefe:

Serr Sounature, crois moi, n'eft rion que l'habitude. thent will, ger feire Prebernmenfisen nicht ftorg mas

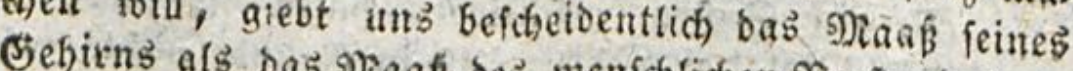

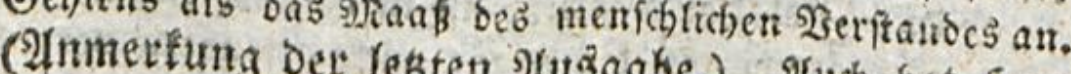

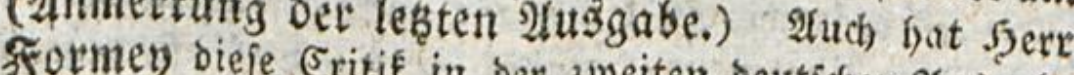
feines Inti fligitio in oer zweiten bestichen 2tuzgabe

Eampe. 
fi: vir it. lent no

Hęlt es fich unit sem Irtebe ser Menfiben: Solange mat in bempelben 3 uftande bleibt, behalt man vielleidyt siejenigen bet, bie aus Ser Giewohnheit entiprungen, uno uns minter natirlich fins; fobals aber bie läge fids ans

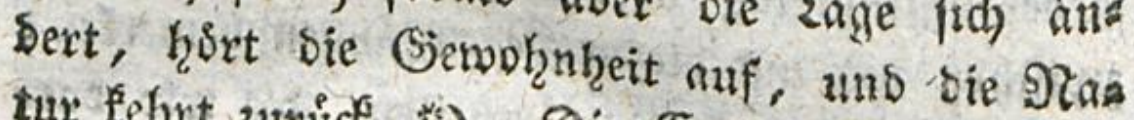
tux fefrrt zurude. *) Die (Exziefrung if gents

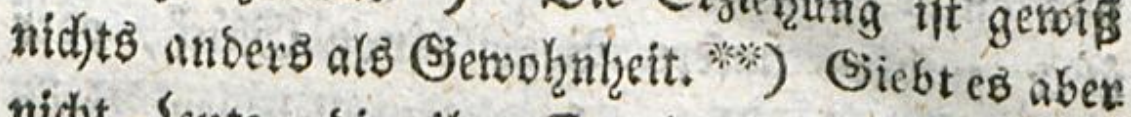
nicht Seute, sie ifgre Erriehung bergeffen uns serlieren? andere, bie fie beţalten? nno woher.

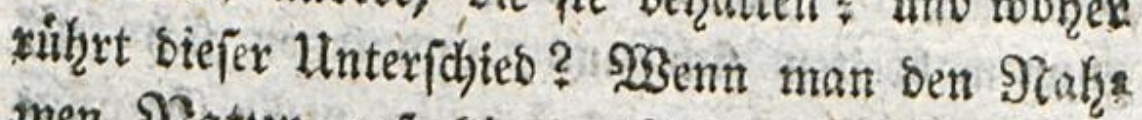
men Siatur auf bie ber शiatur gleidgformigen

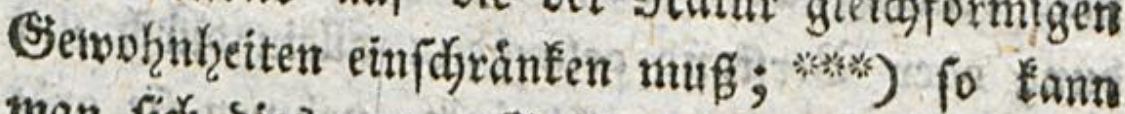
man fict) biez ganze Sallimathias exparen.

SIGix nerben alB empfindende 9 gefen gebos ren, unઠ bon unferm Entftełen an, wirfen die unB umgebenden (Gegenftånbe vexfdjiebentlid) auf unв. Sobals als wir, fo zu fagen, uno unferer Senfatios

nen

*) Naturam expellas furca, tamen vsque recurret.

* Dober viclmebr Geroóbnung nach Brunsfátzen, unt nach Seobachtungen über bie allgemeine uno indis vioutlle feibeb: and bieiftescomptitution ber 3 ut erjies benden Nienichen.

***) Es ift nicht bie Gctuts bes Syerrn Heberfeţers,

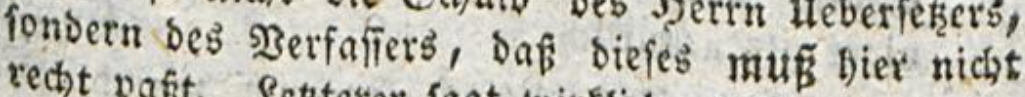
recht pafit. Qetzterer fagt lvirffich): S'il faut borner etc. Dem Sufammentarnge nad bátte er fagen folfen:

Campe. 


\section{6}

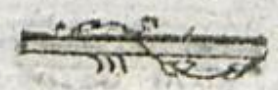

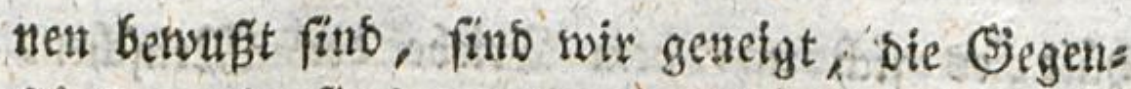
ftonde, bie fie in uns erregen, ju fudjen ober zu flieben; anfangs, je nadybem fie uns anges nehm ober mis̈fâlig fino; hernady, nad, sex Lebereinftimunng ober s)isbelligkeit, bie nix znifden uns uto diefen Segenftanden bemerken; Ints enofich, nach den lirtheilen, oie wir bars îber zufolge unfers Regrifs von Sslude, ober ber buras die şernunft uns berliebenen solls fommenbeit, follen. Diefe 3u= ober 2lbneie gumgen breiten fid aus, uns fergen fich fert; nad) Dem Mlaafe, baf wir zu nehr Smpfin sung ober Sierfand gelangen: allein ourdy utu fre Sjewohnheiten eingefdyantit, nehmen fie gros fieve obex flefreve Seránderungen, bermittelfít unierer Meinungen an. Bor biefer Berándes fung find fie, was id in uns शatuit nenne. ${ }^{*}$ )

2titf

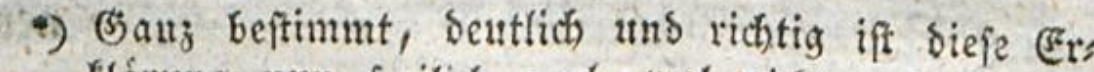
flárung mu freilich auth lool nicht. Denu ber

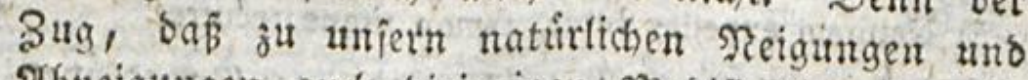
2tbreigurgen auch biejenigen Mrobificationen gebis ren, welche auts ben গ̉egriffen entipringen, die wit

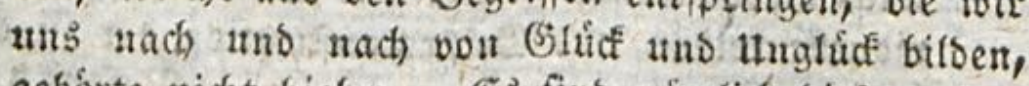
gehorte nicht biefset. Ës find námlić bieie unfere

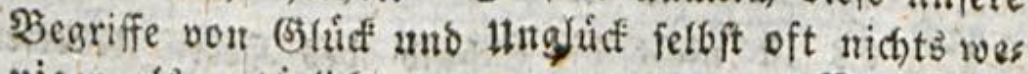
niger als naturfich. Bampe.

Die breifache \#rfach, waram wir bie (3egens fánde, bie Senfationen in uns erregen, fuchen oder 
ene

Det

ges

Dex

bit

ns

ixs

Jer

Ir

eis

if,

nd

tt

'D)

rft

les

6)

itf

Ex:

er

no

ix:

it

nt

re

les

It

er

es

2uf stefe urfpringliçe ăt uns 20bneigun. gen mighte man 2014 es suridéfiffren; und bas

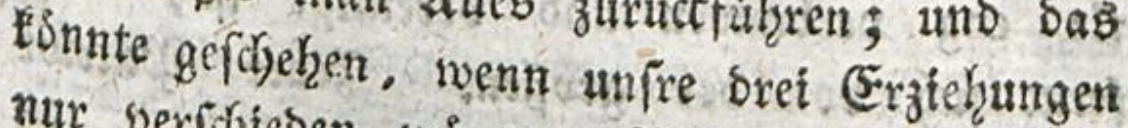
nur verfifieben twåren. SBas aber fil thum, wenn fie fich einancer gar entgegengefert fint? $23 \mathrm{enn}$, anftatt einen Mienfchen fur fich feltoft zu erziehen, mat ibn nur fur 20nore erziefjed will?

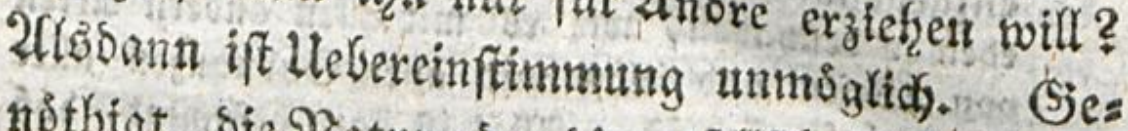
Hothigt, bie Slatuv ober bie gejellichaftlidjen Ein= richtungen zu beftreiten, mü man baznifchem wáblen, of man einen Menfdyen voer einen

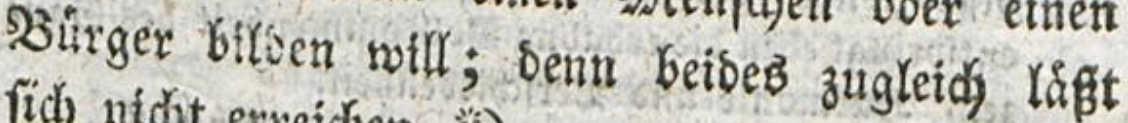
(iid) nidit exreidjen. *)

Se:

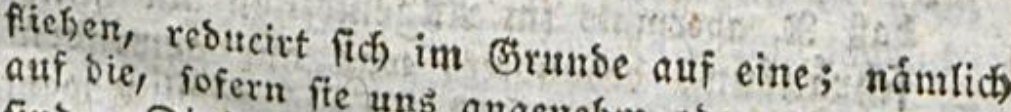
auf bie, fofern fie uns angenefy ober unangenethm fint. Dies 2tngenebme uno unangeneho bángt Des ober oft nicht von ber शatur bes Eiegentans bon ben des naturtid)en (Einsrutés deffelben, - ionbern

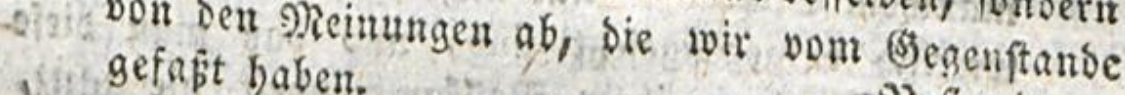
1. gefajt baben.

-) Selbit bei einter unvollf bods ben zlweifacten Endzived Erzichung bat man Nenichen felbot volffommen unb in ifum ber menichen und gluefilith fu machen ches mitalies zu liefern Diejer Endzivecf twirb an, getwifntich vor 2langen.

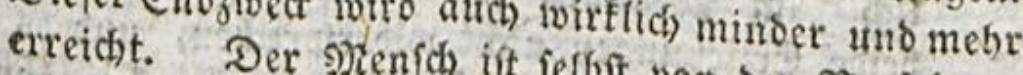
mit Intagen ans

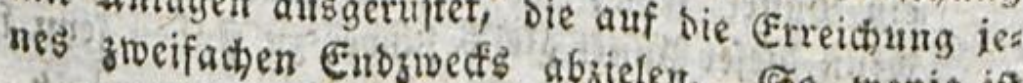
H.w. So wenig in 


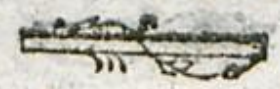

\section{Gebe partielle Gejellfojaft, wentr} fie eng berbinben und bereinigt ift, ents fernt firits won ber grufen. Şeber \$atriot

es gegrintoet, baf ber eine Enbzived bene antern entgegengefest ift. Nit bem Nenfwen ift es eben yo bef(t)affen, wie eb mit allent andetit 2frtent won ssefen und felbit mit allen Eubfanzen aller Dinge befdaffen ift. 2Alles ift bazu bejtimmt, DaE es fur fich wuirtes, dapes auf bas umber befindliche

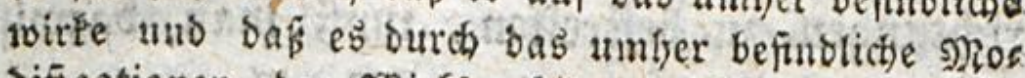
sifucationen ber S্̉irffamfeit aunehme. Darau entipringt eben bie erbabué \$ollfommenheit bes Ganb zent Sparmonie uno \$ericfiebentyeit.

(E) flet:

Der Misuerftanb liegt offenbar wieber baritt;

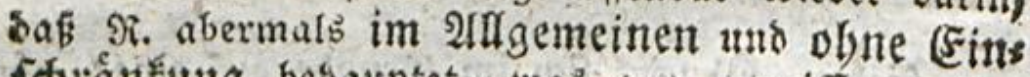
fortáfung betauptet, was nut gentiffernafen atno theillweife wahs ift. Es ift namlich twabt, baf bie Erziebung zun Nenichen und bie zum গुরirger

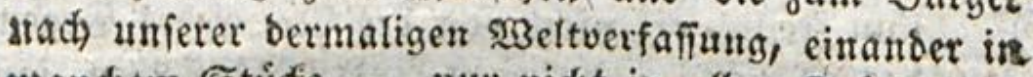
mandem Stuide - nur nidjt in alfen Studen soirtich entgegengefę̧t fino, uno dẩ man biefo

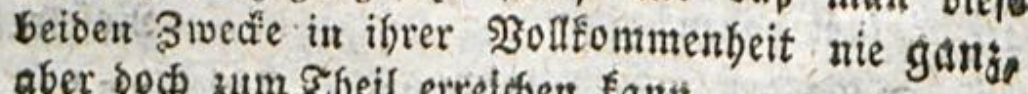
aber boch zum ₹्रheil errethen fant.

Eampe.

Da bet Nenta offenbar jut (sefellichaft bes fimint, uno ourch bie seiellichaft exft sanz eigents Yid, zum Menichen gebilbet wiro, fo fonnen fids beibe Erziefutgen nicht miderfprecten, uno es mus. cin Punce fern, two fie zufammentreffen fornen, weun biefer \$unct gleich finwer zu finden fern folltt.

siejerwib. 
intt

ints

iot

if

erts

es

tert

Hee.

Jấ

(b)

Ros

uts

ค1า6

itt;

ins

ent

af

jer

in

10

is

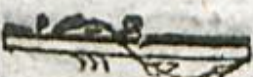

ift hart gegen bie Fremben; ${ }^{*}$ ) fie fints

-) Falf ch, ganz folpt treflither Bुurger dher Şitrger Der leines Staat3, und ein vortreflis nid)t if: fo ruibrt it jugleith fevn. Tुent er es ber Nienftheit ber. zelnen Menichen mit de bas Interefíe eines eins surch riditige fenminifem Interefie peires Stats

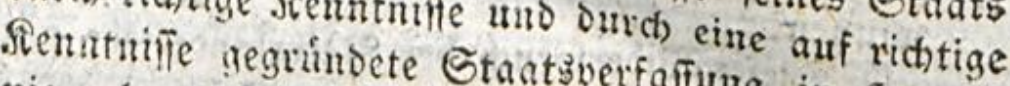
the gebradt werien foun

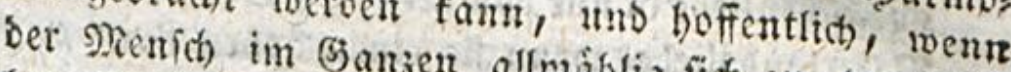

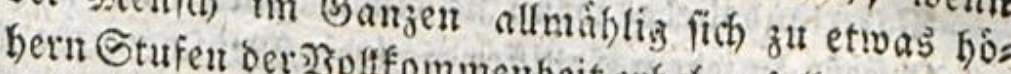
mefo in sarmonie gowenheit erheben foll, mefr uns auch sas.gntereite gebractit werben twird: fo fant anderer Gtaaten eirtes Etaafs mit bein Interefie Tisen gervific, fich fin Sormonie gebracht werben. Menfden nach ifrem so af weife haltente und andre fer bas Beoentheil saha, viel-uberiehente \$olitis breift at befiauptein glauben: fo wage ich es bod,

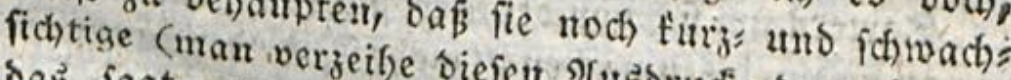

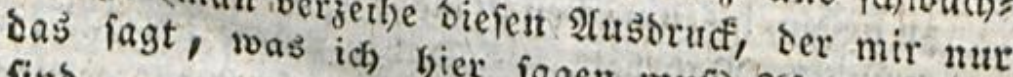
fint.

aber Rouffeau reset fier nidit Eoblers.

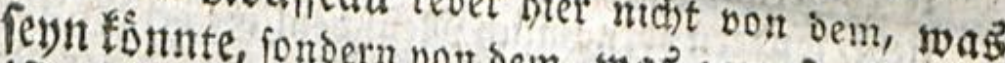
if. Ints ba ift es bod w den, was getwefen if unb

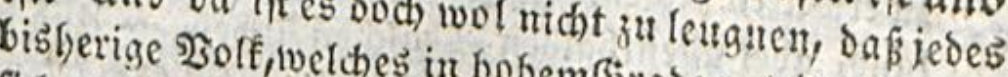

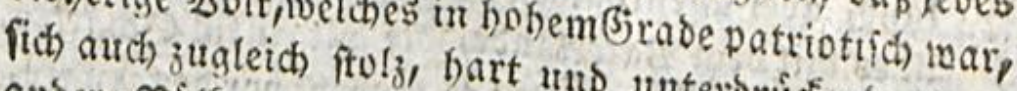
andere গSolfer gejcigt babe

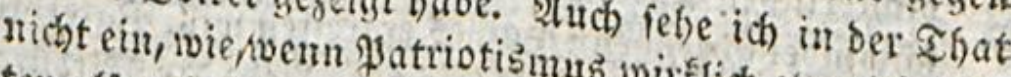

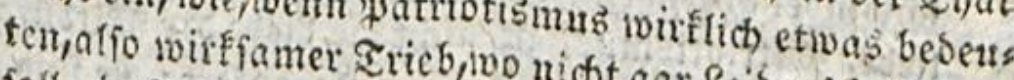

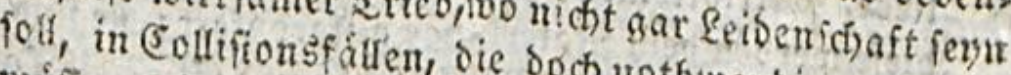

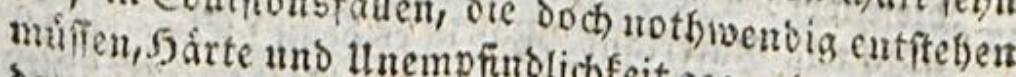

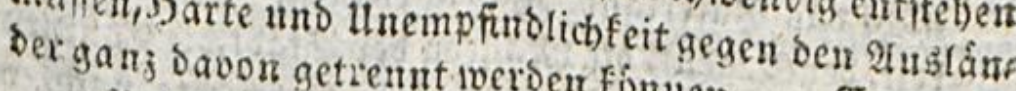
Watriotis getientut werben fómuen. Campe.

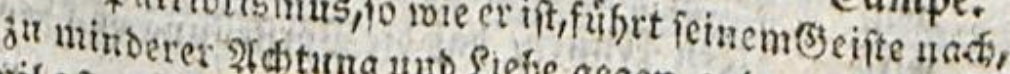

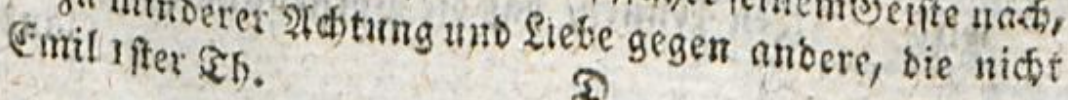
$314 m 2$ 


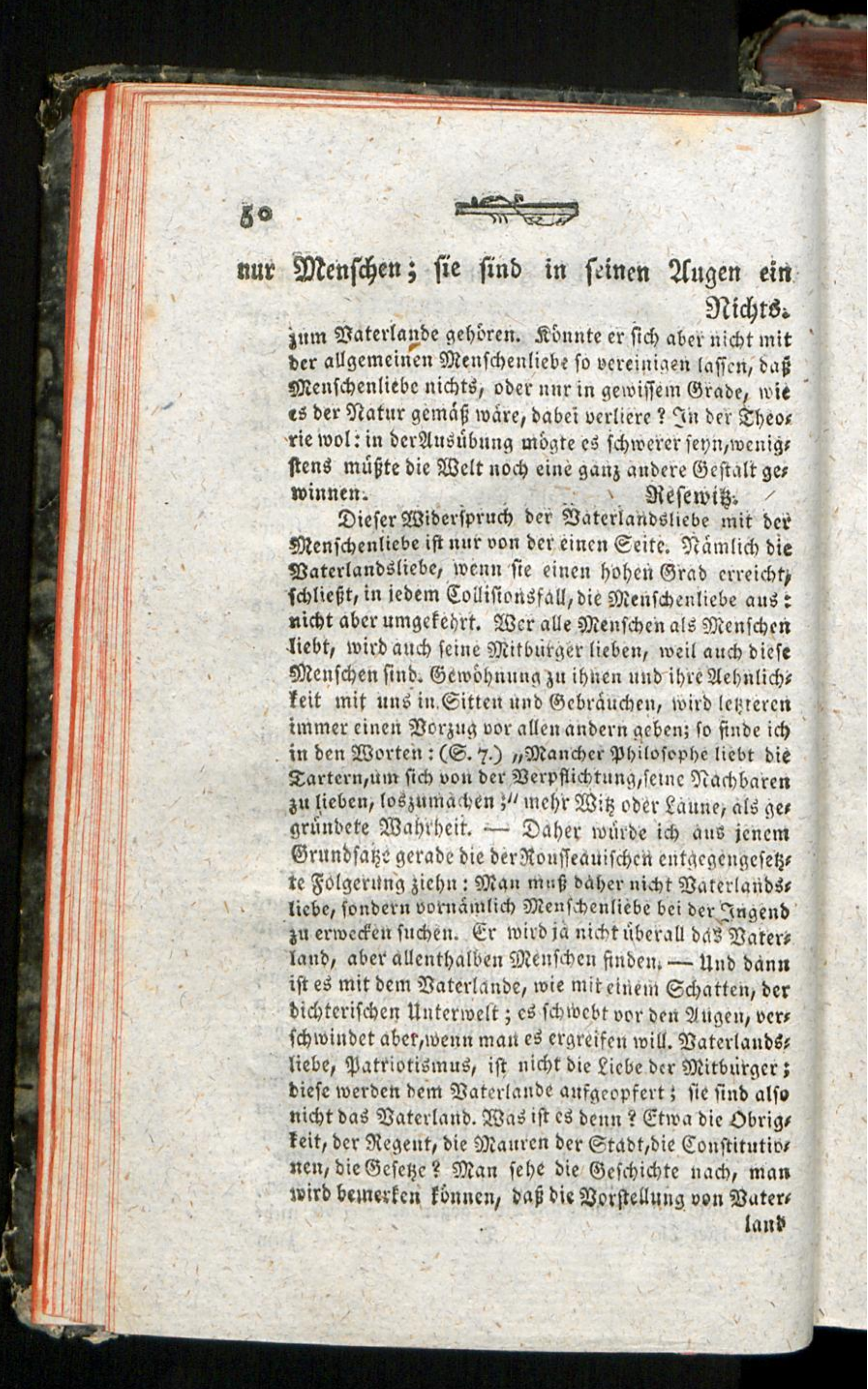




\section{Nichtb. +) Dies ift ein unbermeibliches aber} geringes Uebel. Die Satuptfache ift, gut fur

\section{2} die

land zwifhen alfen ben Gogenfánben in einem ber ftándigen Sirfel umberichloeift, und von einem sum anbern bufpt. Es ift alfo ein \$bantum, welches mats

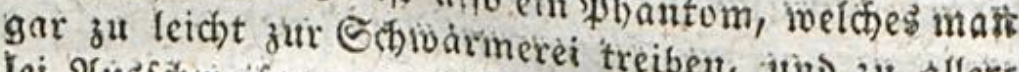

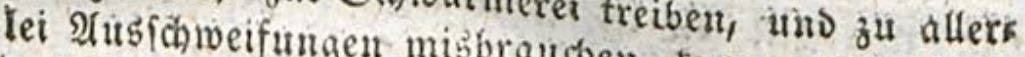
Der Mentichen aber yat inchen fann. Die liebe Bंegenftant.

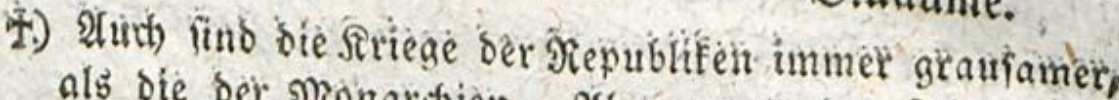
als bie ber Mronartfien. Mber went ber Strieg, bent Nonige fuffren, gemafigter ift; io ift ibr friebert forrecflich:"*) mait fábrt beffer babei, ibr feind als

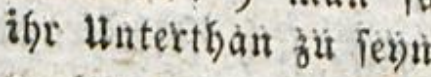

Inmert. D. Berffo lind feftándigen Biflaume.

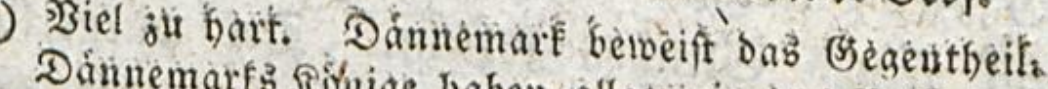

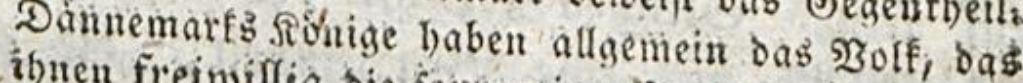
itnen freinsillig bie fouverainte Nacht gab, geliebt und burch diefe liebe fich fur bas grofite in fie ger The Staat noch nicht Den (befimitutaen ber to glúflith, als ex es nach

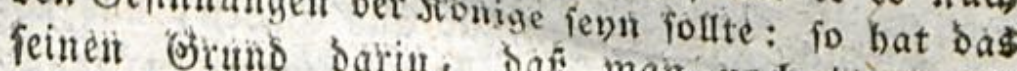

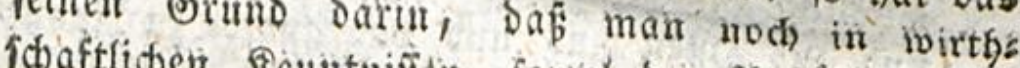

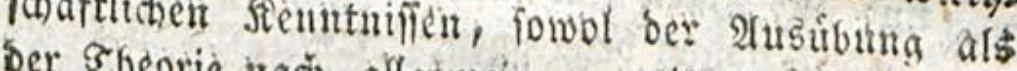

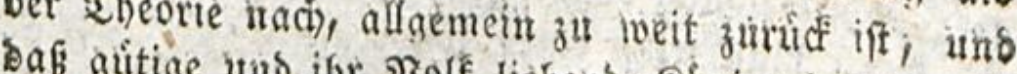

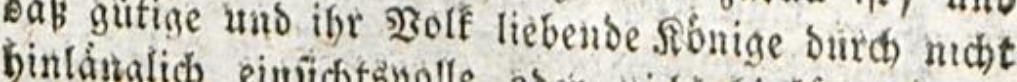

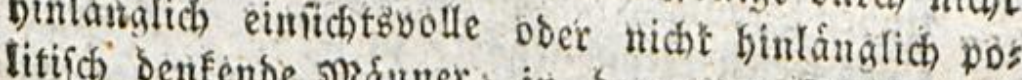
Etaats atende sianmer, in ben zum Şeften bes

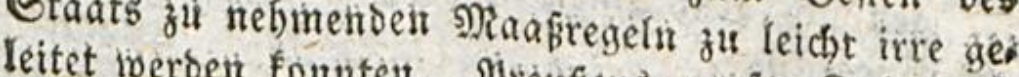
bat auch partielle Weem gleich oft etwas zu biel 5árte uno

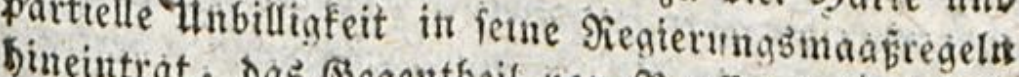
tuntrat, das ङegentheil won Rouffeatis şehaups tung immer mefr und mebr practifis beiviefen. 
Ste zu fent, mit benen man lebt. Sn 206: fidjt ber 2fustwärtigen war Der Spartaner efrre fiid)tig, geizig, ungerecht: allein Uneigenní Gigfeit, SBilligeteit, Cintracht herrfditen innerbुalb feimen Mauern. Iraut nicht Sosmopoliten, sie weithin in ifgren $B$ irdjern $\$$ ffichten fuchen, sie fie in ibrer Niahe nidjt exfillen migen. Sandiex Sphilofoph liebt bie Iartarn, 11m ber Siebe feiner Эachbaren ůberhoben zu fenn. *)

Der Naturmenich ift 2ulles fur fich felbft. (Er iff bie numertiche (sinfieit, ein abfolutes (S)anzes, welches fich nur auf fich felbft ober auf feines (S)leidjen bezieht. Der buirgerliche

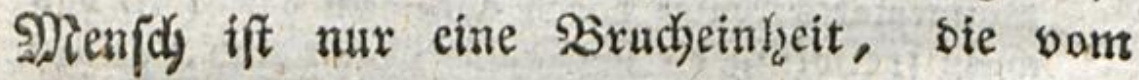

Yen:

Exempla funt odiofa; fonft Yiefse fith hier bod roirflich aus Tcorben uno aus Euben, aus Treften unb aus Dften cins unb bas antere zu rouñeau's sechtfertigung beibringen. Webrigens ift es fower, wenn man felbit einer fouverainen oder gar bespos tifchen Staatsverfoñung gewolnt ift, mit Dear $\mathfrak{A}$ ger eines freien Reputblifaners zu iebn. Die Ditnge zeis gen fich sem Einen ing ganj anderm Sichte alb bem andern.

Eampe.

2) Ein פoriourf, ber viele fogenannte Eosmopoliten trift, ber aber feimesweges aus ber sratur ber Sadhe fiest, fondern in einem unoolfommnen Elfenntnif́ zuftande feinen Girund bat.

(Eb)lers.

Destoegen fagt ia aber $\Re$. auth mur mandjer, nicit ieber \$bilojoph.

Samne. 


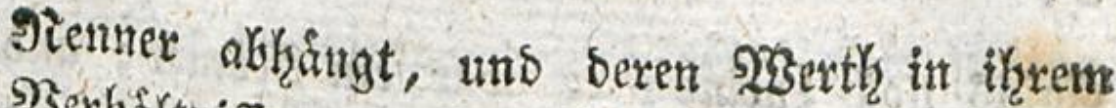
Berhąltniffe gegen bas (Jianze, ben gefellichaft Yichen Siorper beftelyt. Die guten gefellichaftlts d)en Einrichtungen fins biejenigen, bie ben

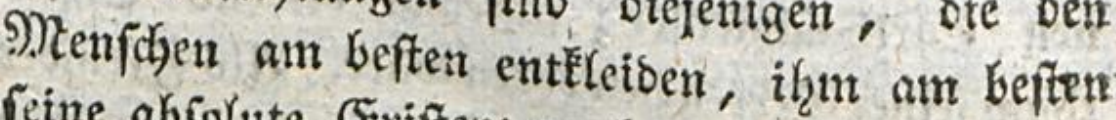
reine abfolute Exiftenz rauben, um ibm eine res rative zu geben, und fein Ioth in bie gemein: ibaftliche Sinheit hiniberzutragen; io Dafi fich

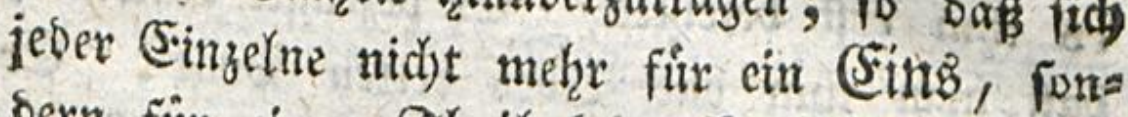
bern für einen Sheil Deir (Sinteit halte, Ser nid)t mehr anbers alz im Şanzen bemerts (id) ift. ${ }^{*}$ ) (sin rómifiber Birger nar weber

D 3

(5a

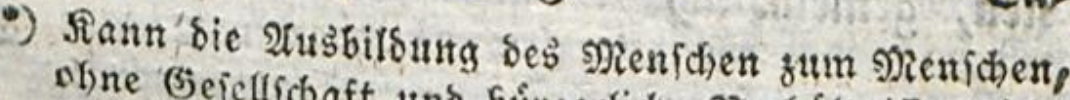

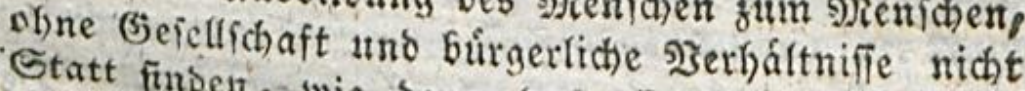
Statt finden, wie benu das offenbar ber Fall ift: fo ift Sas ganze Paifourement utmionit. *) Der aber bod, wenn ber Gefantstobrper weife or:
ganifitt ift, als \$heil bes Ganjent mefrere \$olls

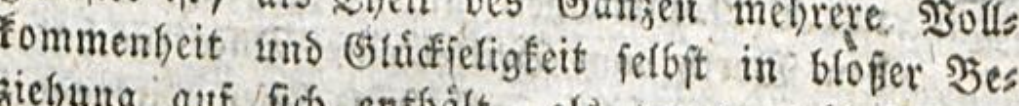
zielyung auf fich enthält, a!b weenn et blof́, als Banzes für fich betrachtet roirb. Hebrigens paß̂t

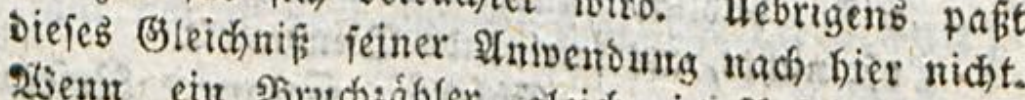

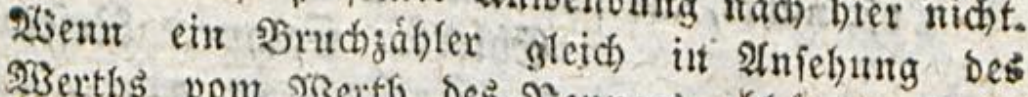

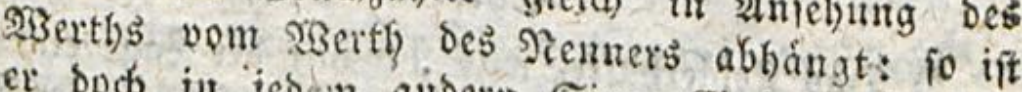
er boch in ieben aibern Simn Eintheit fir fich,

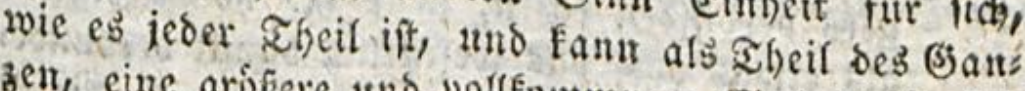
zen, eine gróbere unb vollevmmucre Einheit fúr fid Penn, als cine andre Einfeit, die nicht Theil eintes Gamzen ift. Eir ganzer Sroichen ift weit weniger werth, 


\section{4}

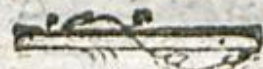

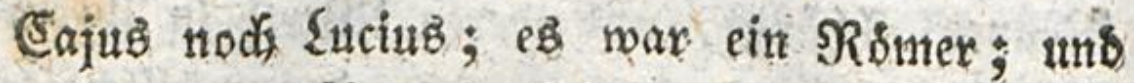
ex liebte bab Baterlano fogar mit 2usfdltefung feiner felbit. Siegulus betrathtete fich alo ets nen Eartfrainienfer; fintemal ex das Eigene thum feiner f̧ercen gemurden wåre. 2fis frember speigerte er fich, Sif und Stimme in römifdan Seiate zu nebmen; ein Earthaginfenfer muffte

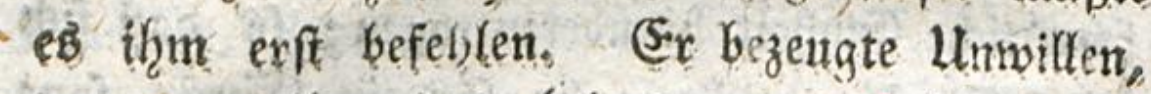
bafi man ifgm das Eeben retten wollt. Es ibernano, uno Eefrte triumphireno zuride, in ben Foltern zu fterben. Dies hat, wie midh benct), wenig mit ben Senfidyen, die wir fens nen, gemein. *)

Dex

\{erth, als ein Drittel eines Ducaten, Der eine

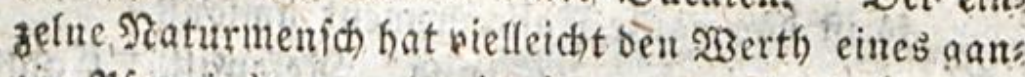
gen \$fennigs, wenn bef in eimem nur mittelmáb g gus ten Staat lebende Staaţoúrger in der Dialie feis

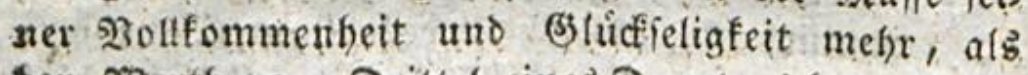
Sen $\$ 3$ erth vom Drittel eines Dutatens bat. Rouf: feaus fo mátbig auf feine Leier wirfende Ssleids:

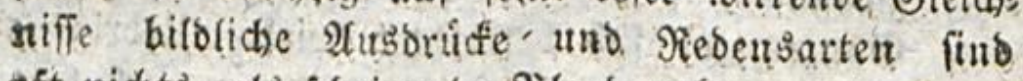
pft nichts, als fobeinende গlentwerfe.

(E) fer: Sampe. Reientib.

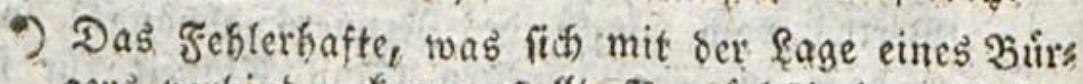
gers verbinben fann, ftellt $\Re$. bochftirriger $293 e i f e$, als ctroas nor, bas weientlich bamit verbunben fent muiffe. Soll man benn bie Mángel, bie fich oft im 3ufälligen unit dem 23 Befentlichen bereinigen, bieicm şsefentliches zut Hupollfommenbeit anrechs nen? 
t1เ

ing

ets

ene

ber

jent

Efte

en,

5is

itt

id

ents

Jex

ine

an:

345

jeis

als

uा

(d)

nto

irs

iifen

in

oft

en,

(b)"

n?

Der Eacedámonier Şádaretes giefot fich an, mit in ben Rath ber Dreifhunoert angenommen zu werben; ex wiro berworfen. (Ex geht nads Şaufe; froh, bafí fich in Sparta Dreifundert

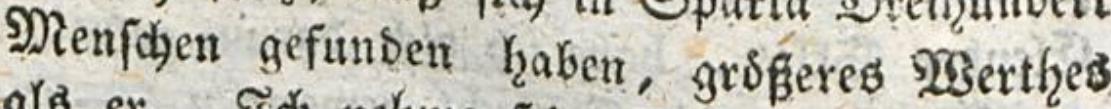

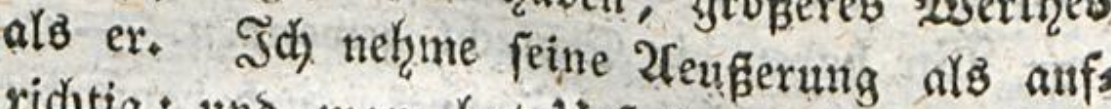

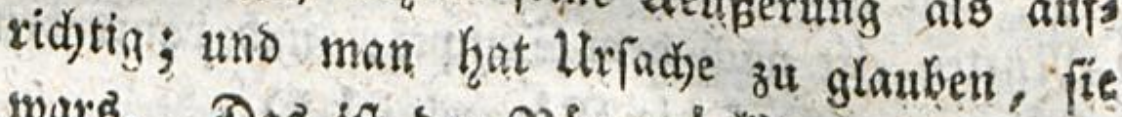

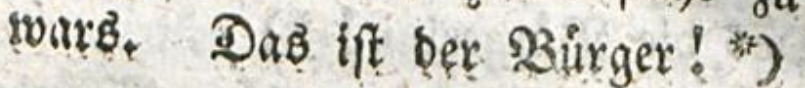

(2) 4

Eine

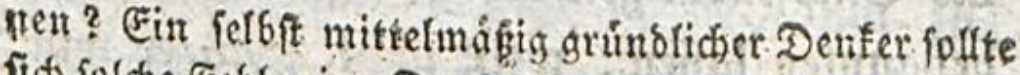
fith foldhe Sebter im Denfen nidht zu Erdutben fom men lafien. Huto ich weip aus ber Erfahrung, Daf Der Neiz ber Einfleidung nur zu leidst Sefer hus gieid, irrigen $30 r f f e f l u n g e n$ hinleite, bie, wenn fie

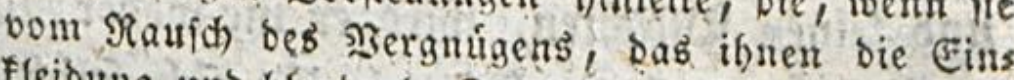
fleibung und blenbenbe Bufammenftellung ber Sipuls feariffien Speen gemacht hat, wieber nuidstern ges worben find, und jouft eine fúr $23 a b r b e i t$ ofre Ecele haben, bei náberer grufung fich mumbern, twie fie bei ibren foult richtigen Semutnifien fich fo blens ben lafien founten. S3ie gropi if aber bie Nienge

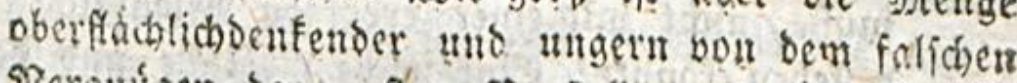

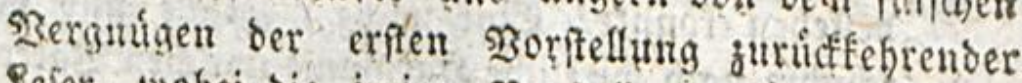
Eeier, wobei bie irrige Torîtellung bángen bleibt, mab nut fu ftarf auf bas praftiche feben wirft!

(E) TerB:

1tub biere Eindrúfe bes mánulichen uno ents

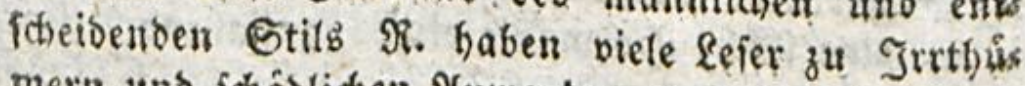
mern uno fóabliden 2anvenbungen verleitet.

গiejemits.

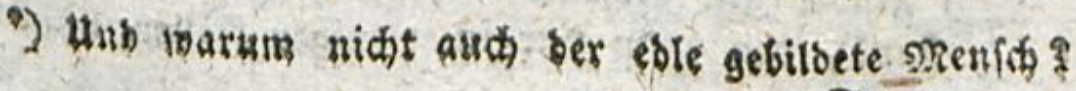
Etupe. 
56

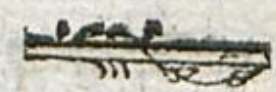

Eine Spartanexinn hatte fünf Sshnte bei Sem Szeere; tIn exwartete Naachrichten aus ber (s)jladjt. Fin Slot langt ant; sitterno befragt fie thr. Deine funf Solnte find getóstet! Elenber Sflas, habe ith sidh barum gefragt? - IBir haben die Schladjt gewonmen. - Die Mutter eilt nad) ben Iempel, uno bantet ben (Sibttern.- Das bie Birgerinn! *)

Derjenige, ber in bem buirgerlichen Stanbe Sie Empfinsungen ber Satur Sie Sberhand will behaupten lafien, weif niddt, wab ex will. Sm= mer im 23 iberfpructye mit fich felbft, ftets bins

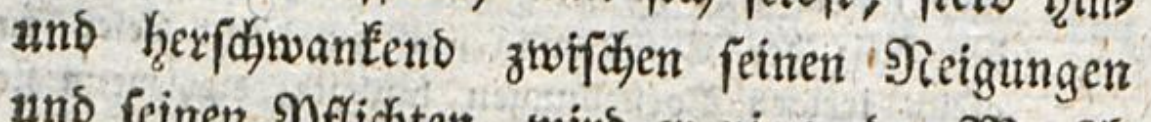

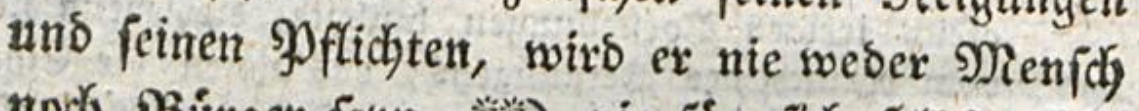

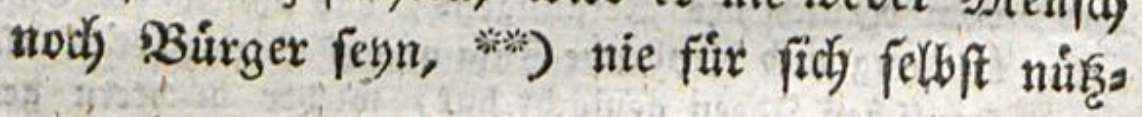
Yich,

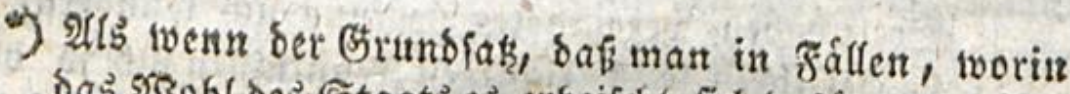
bas 5 şohl bes Etaats es crlfeifot, fich bafúr aufopfern

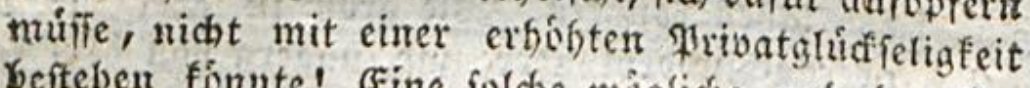
befteben fonnte! Eine folche möglithe und ber Ges fajichte nach wirfliche Sjarmonie jnifichen Saterlands: pficht uno Eclbitnflicht ift zu wabr und gewiś, als

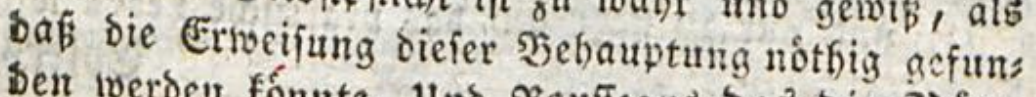

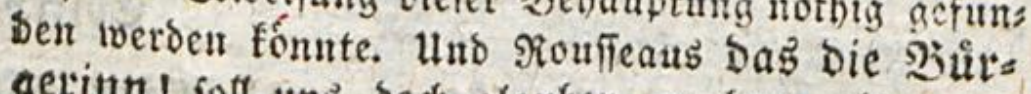
geviun! fott uns boch glauben machen, afs weut eine folde farmonie etwas auffalleno lingereimtes
lvare.

(घ)) (ers.

*) Findet nutr bei cintem mangelbaften Erfenntniģou frand, ben man nur in wentigen Játlen nidjt vers meis 


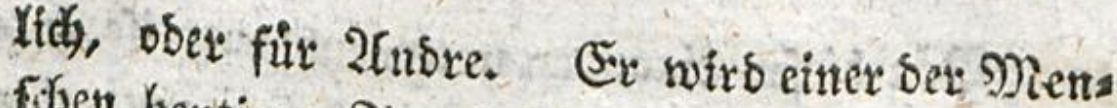
fitsen heutigen זages rent; ein Franzore, ein (5ngellanber, ein Srábler (un baurgeois) ein Sitdits !

Um etwas zu fein, nur immer Er felbft und Eitter zu fenn, mus man handeln, wie man fpridyt; ftets iber bie Parthet, bie man at ergreifen hat, beftimmt, fie laut ergreifen

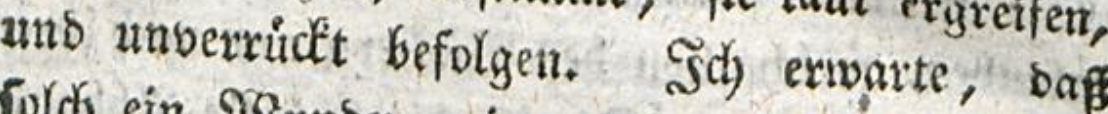
fold ein 23 unber mir gezeigt werbe, un zu

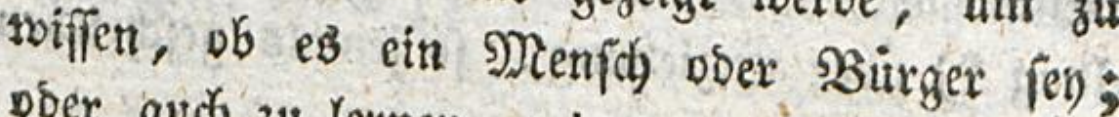
Doer auch zu lernen, wie ex es anfangt, beis bess zugleid, zu fegn, *)

meiden fann, Statt. Ein blok fuir fich forgender saturmenich fommt ia aud nur zu oft in cines folchen Buftand bes folu: unb seridbivanfens bins ein, went er nićft weí, was er unter mebrerz Dingen fúr fich wáblen ober verwerfen foll. Der ganje folgende abjats ift auch nichts weiter als eine leicht taujosende Declamation.

(E)

4) Stiver if́t es; vielleicht and felten genug bei ser Serftimmung, bie unter ben झenichen berricht, unt zum Theil burch Eonbention, jum Theil burch falfiche Staatsfunft cingefofit ift; aber bod nicht unmog lid. Humoglict foun es aud nicht Mienich ift offentar beibes jutht jenn, benn ber zum unmigliden betoes jut fern beftimmt, uno font bátte ber faun er boch nicht beftimmt fenn: bondelt.

Rejentik. 


\section{2.}

Fon stejen einander nothrwendigermeife ents gegengeferten Siegenftanden entfehen zmei eint

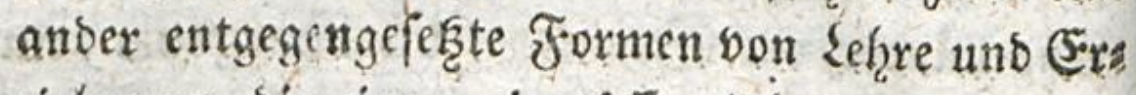
ziehung; Sie eine, eine offentliche uno gemein

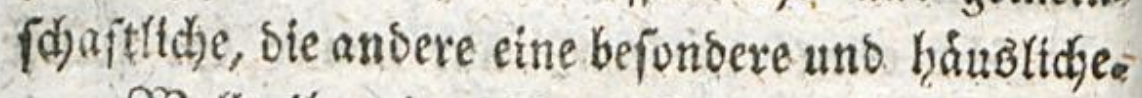

W3ollt the einen Begriff von ber offentlicyer Erriebung haben? Seret \$Ylaco's Rebublif. Sie ift Ein politifches 2 Berk; wie biejenigen g(auten, weldye von ben Baichern nux nad ifgren Iiteln urtheilen. Sie in bie fizsnfte 2G6hands lung *) ibter Erzitefung, fo jentale gefdurieben morben.

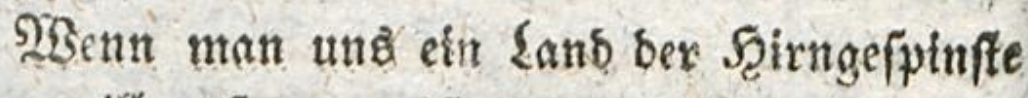
zeigen will, fo verweift man auf bie platonifche Einrid)tung Shatte Sncurg bie feinige nur furiftlid) gegeben; fo wirbe ing fie nod oiels

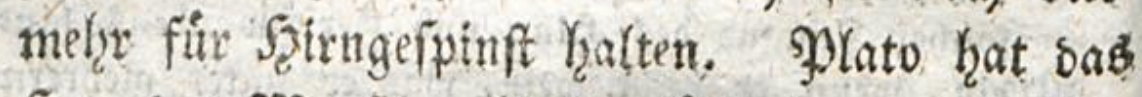

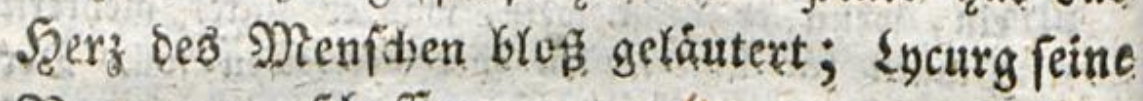
Slatur unaefónaffet.

Die Sffentliche 2initalt ift nidit mef̧r bors banoen; und fann nidgt meḩ borhanben fenn; weil

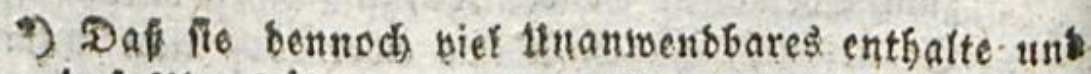
daf Plato piberbaupt oft mebr ourch reizenbe Imas ginationsbilber, als ourch grúnbfiche Erfenntnif unb burch eine fefte riotige Seurtbeilungsfraft geleitet

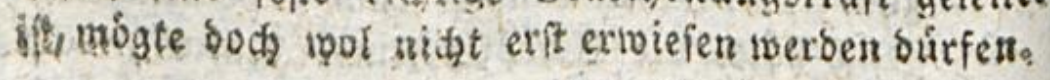

Eblers. Refemit. 
weil, wo es Eein soaterlans nebre giebt, aud) feine sürger melyr geben fann. Diere betben SBorter: 23 aterland und 3 utrer, muf

teins man aus ben nenern Spracken berbannen, ") Sch id dyer ilife. igen jrett inds ber

nfte

race

nut

siels

bas

ine

sors

bnt

peil

unt

mas

unto

eitet

ello

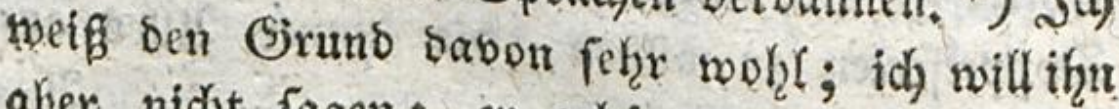
aber nidyt fagen; ex gehbet nidyt fux meinen Siganftano.

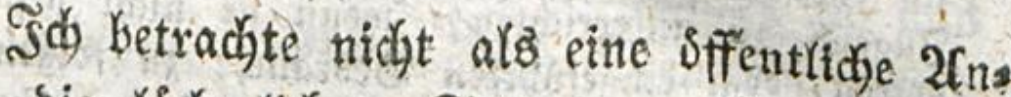
ftalt bie ládberlichen Stiftungen *) bie man

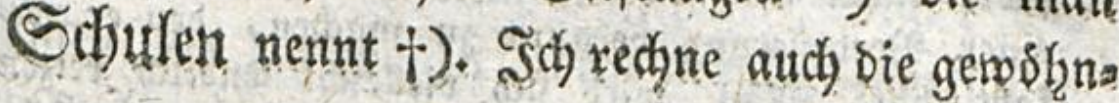

Das nun wool nicht; es twird genutg fenn, in unfern 23 orterbuchern babei anzumerfen, daßj woir beibe nicht mebr ganz in demienigen Simne baben, ben

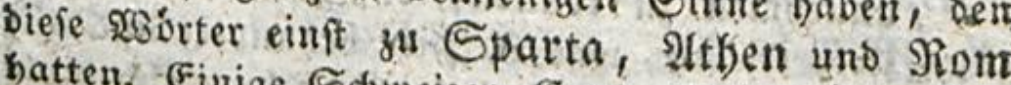
batten. Einige Sdiveijer: Eantons aber burfen biefe भrnmerfung in bem ibrigen bermalen noch austafien.

3en ber gegenve Campe.

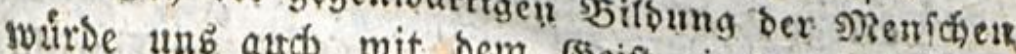

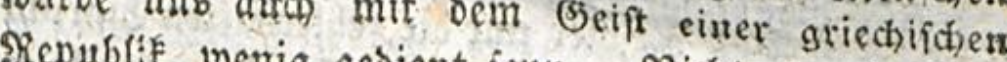
Oepublif toenig gebient ienn. Sicicht zu gedenfent,

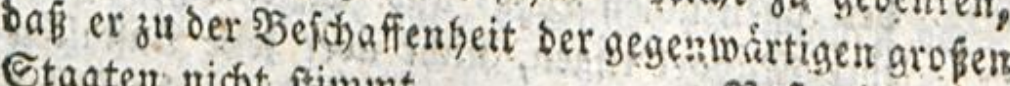
Etaaten nicbt fimmt. Refemits.

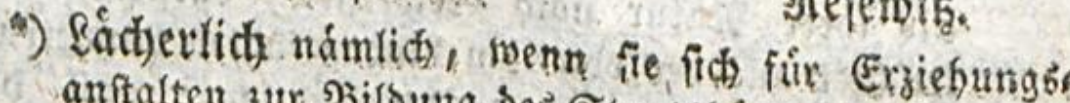
anftalten zur Siloung bes Staatsbuirgers geben wolls ten, ba fie inur Lebranffalten find; und auch als

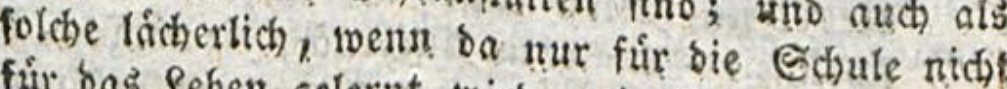
fur bas leben geternt toirb, wie bas fo bajuig bet fall ift. Id glaube, bas $R$. bie in Gebanfen get babt habe.

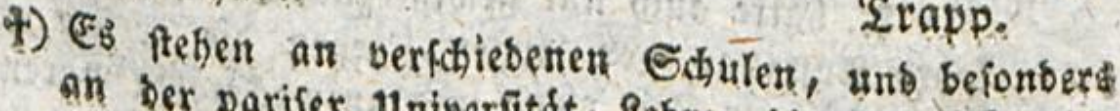
an ber parifer Hniverfitát, febrer, bies ich liebe, bie 


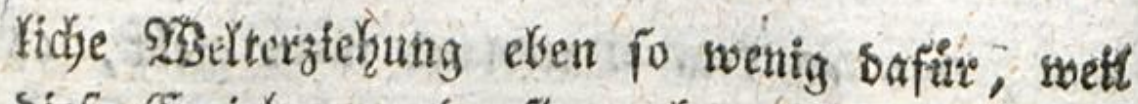
diefe Erriehung, ba fie nach zwei einanoer ents gegengefersten Beilen binftrebt, fie betoe bers fefilt. *) Sie taugt mur bazu, Menichen mit Doppelfeelen zu bitben, bie inmer 2ưes auf

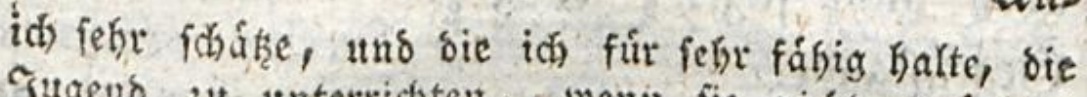
Iugeno fut unterrichten, wenit fie nicht genotbigt waten, bem eingefuffrten (bebrautche zu folgen. Idy fobre einen gevinjen unter ignen auf, ben eztronf einer Nerbelierung betannt ju madien, ben er ver; fafit bat. Nan wirb fid viefletcht entich teizent laffen, bas. Hebel zu beilen, went man inne roirb, ज्ञ

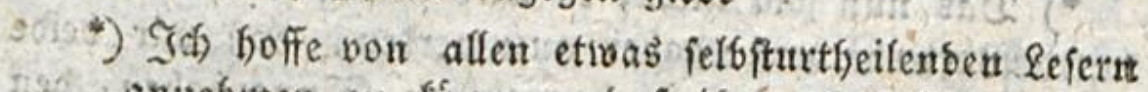

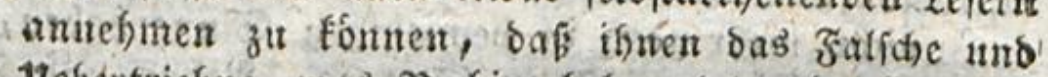
Hebertriebue, toab o. Gier bebauptet und allgemeir

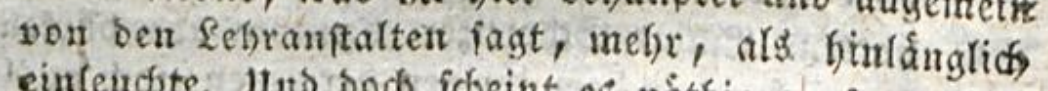
einteindje. Hub bod fdeint es nothig zu fern, baf 2lufurerffamfeit auf diefes faliche und Hebertriebene erregt whtro.

(E) let:3.

Dafis $\Re$. Fier nur bie feblerfaften (Einrid)tungen Ser offentichen Sehr: uns Erziésungsanftalten unb ibre Niángel rugen, nidbt aber iene Initalter felbit, als iffer seatur nad, vertverflich, baritellet will, reuctet alts ber bon ifm bintugefugten Immerfung Getbov, soorin er ia aubbrictlich lagt; baf́ bas Hebel fid beilen laffe. Der lejer fennt mun aber

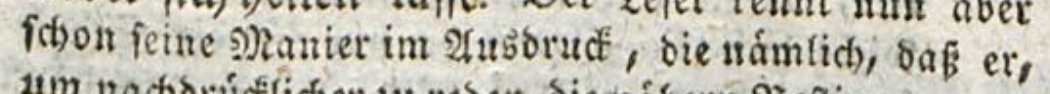
um nachbrícflidser zu reben, bie nábern Beftimmungen sveglấpt.

Eampe.

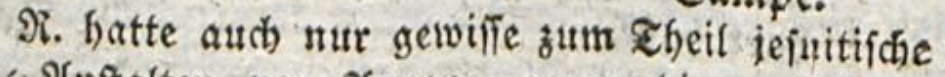
Lebr: Afuftalten bor 2fugen, gegen bie er fich et: Flâter, bie ber acit elento uno unzlvecfimápig warets, stho es Hod fitro.

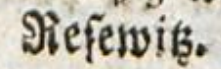


Zndere ou bezieben fobeinen, uns 2alles tur auf fich allein brzielgen. Da ein Şeber fich abix eben fo aupert; fo wirs niemano mefer baburăs hintergangen. Diefe Bezengungen fino berlobrtie Nivite! *)

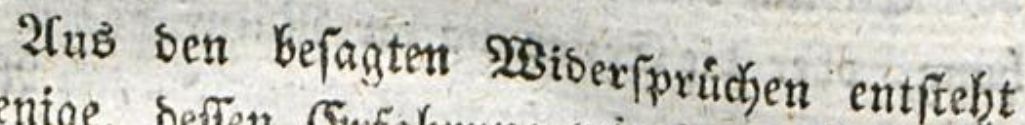
Derjenige, beffen sufahrung wir immex an uns felbit macken. Slatur uno 9)enít)en zexren uns auf einander entgegengerefste Mege; wir fiblen uns gezmungen, bem berfidebenartigften Unftoge zu folgen, uns enslid) wandeln wir fo anf einer zufammengeféften Strafe bin, ste toe: ber zu bem etnen nody za ben andern Biele uns fiffrt $* \%$ ). (So beftritten, und auf $S_{20}=$

gen unb ba noch ic jobabrbeit, wenn és auch bic

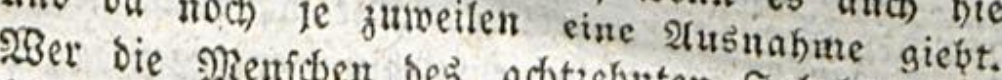

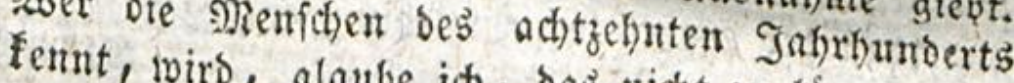
gefren.

Eampe. actige Stof babe murt gefchehert. Der verficticben:

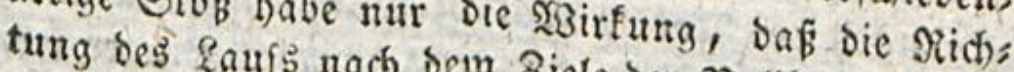
Gitugebe, unb baß fid siele ber \$ollfommenheit 10ohl aeborig vercinige Prwativols ind Gtaats: S3eltforper treils ang. Der boppelte Stop, ber bie stach bem mittelpunct ber Sireisbabn heraus, theils jene §orper eben inct der Лreisbahn biutreibt, erbált

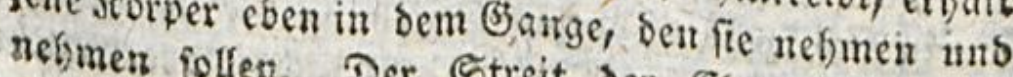
negmen follen. Der Streit Der Elemente buinat ititit 
gen unfer Sebelang bin uno ber getworfen enst. gen wir bas trrofictye Dajern, ohne jemals mit uno felbit einig, ober fur uns felbit ober anore nuglid) geworben zu fern.

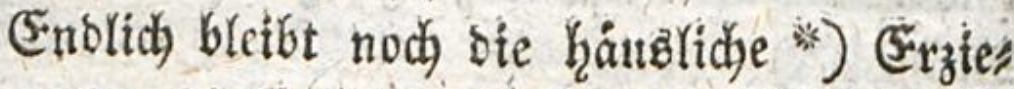
fung, ober bie (srzieloung ber פiatur ${ }^{*}$ ) itbrig. 2uber

juft bas Probuct ber Jollemmentheit heroor, bas bervorgebracht werbent foll. Es ift ein nothwendis ger $\Re a m p f$, wobei wir armen Sterblichen nut nicht bie eigentlich auf Jgarmonie binleitenben Siráfte genug wabrtebmen.

Eb)

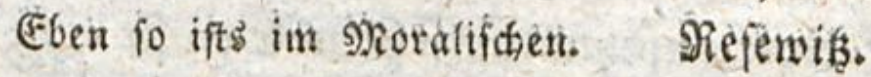

-) Sisegen bes berichiesenent Gimnes, ben $\Re$. mit beut 2Ausbriffen Ergiebung Der Siatur berbindet, ber jiebe ids mich auf eine vorbin gemadjte Sinmerfung. Spier ift zu erinnern, dấ in bem Ginn, worinn er in bieier Stelle biefe âtuboritfe braucht, iene Eraies bung tricht wobl zugleich eine bå genannt verden foune. Die bausłliche fę̧t mau fonit Der bffentlichen Erziehung extgegen.

(5) Ilers.

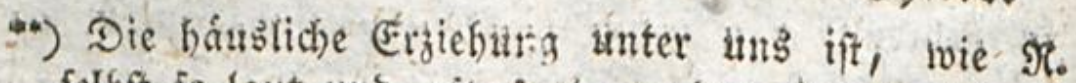
felbit fo laut uno oit lagt, weber eine Ergiehung nací) ber Siatur, nod fu ver Niatur, o. i. um einen

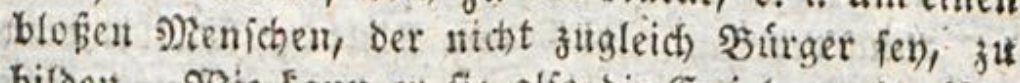
bildent. 23ite Eam er fie alfo bie Erziehnug ber Nab tur nettien? Doet bachte er fich etroa die baustis dhe Erriefung nidht wie ile ift, fondern twie fie fernt follte? Hber bamu begriffe fie immer bods auth ba\$ in fich, was et vorbin (Erziel)ung ber Menichen unt bet Dinge namnte, wáte alfo nidht blope Ergielsung ber 
Sto

nit

ore

ies

ig.

ex

105

bis

(h)t

fte

eit

jes

ig.

et

ies

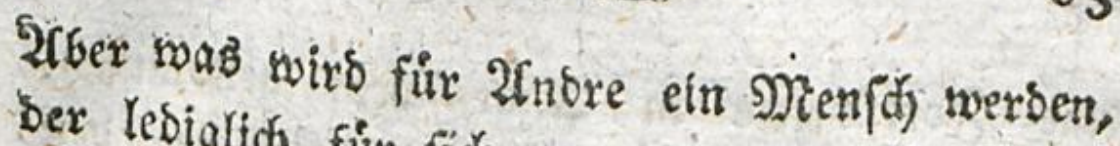
bex lebiglidy fur fich erzogen worben? Sgenin bielleidt bex doppelte (S) genftand, ben man ficts borfest, zu einem einzigen fich) vereinigen Yiefäe, To toinde man, insem man bie 28 iserfpridge

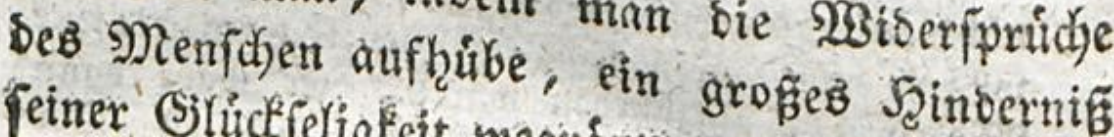
feiner SSludéfeligkeit wegraumen. Utm stes aber z̆ beurtheilen, múfte matt ifon fónon ganz ges bilbet fehen; *) feine פetgungert beobachtet,

feine

Det Tatur in bem Sint, ben er oben bem 2 Borte gab. Es fcheint, oab bier ber gute f̧omer gefohlas Trapp.

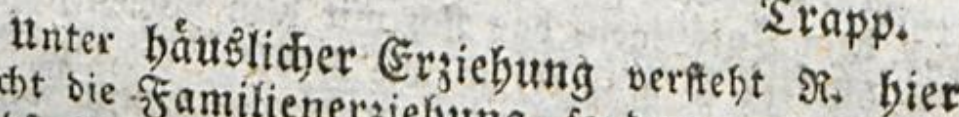
nicht bie Familienerziebung, fondern - wie er Daś Individut, Dicjenige, roobei ganz allein auf baher er fie aud but auf beu Etaat gefehen wirb; Der Niatur, im Eregen sen शtubbrud (Erziehung umichreibt. Fi hotte ats der Staatserziebung bie Segriffe siefer aber freilid beller gethan, fur jeben untergeotborter vorber feftufeezen, uns

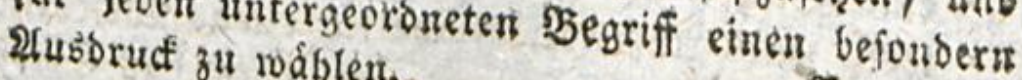
2utch mus in biefem Sinn Eampe.

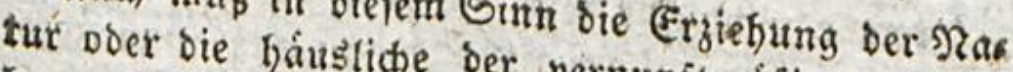
bung fúr bie şät niche vernunftmástgen Erzier Reben' antougtide nat entgegen feben, fonft ents

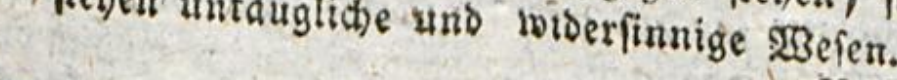

2) Menn man Refemis.s.

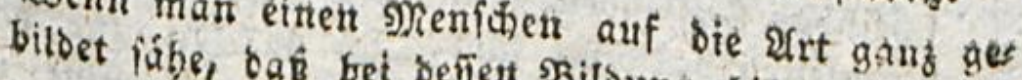
bildet läbe, bẩ bei beffen silldung bis babin gar uां) 


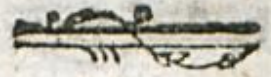

Feine Fortidyrtte in 2 ugenfodein genommen, feinen Gang verfolgt, mit einem ŞEorte, ben

ridat auf bas gefehen wate, toas er fưr \&nore fenn foll: fo wutre man nicht erfennen fonnen, toie iene

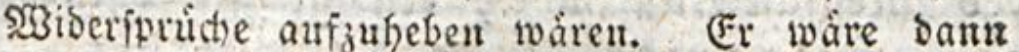
fchon bou bem sigege ber siatur abgeleitet. Der Menich ift burch weientlicbe Anlagen uno sirafte Der Niatur bazu beftimmt, Daß et nicht nur für fich, fonbern aud fur 2lndre leben foll. Ein iveifer Er: jieber muß alfo, wenn er für einen Emil gauz les ben faur, bei ber erften Entwicfelung ber S?aturs

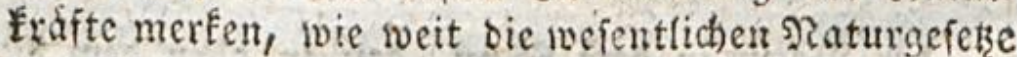
sas Jind zum sienfdeu fur (id) und zum sRenichen

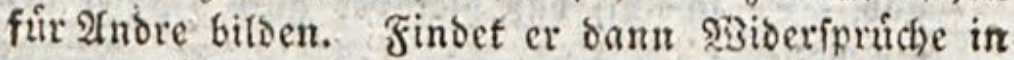
bem 3ufálligen, bas fich mit bem sgscientliţen vers

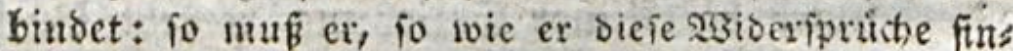
bet, fie fogieich beber. Sábe er eriftich blof auf ben Sang ber sibirfianteit, best die Ratur des Rindes in Fejiefung auf bas Sins felbft náfme: fo wurbe bas feblerbafte in sufáligen, das im 28iberiprud mit Dent freft, was es als Befellichaftss nench feisn foll, richt bemerft werben und an Ente eine Stáffe uno feftigfeit befommen, bấ mau Yeicht ienes 2uberweientliche fur etwas SBefentliches balten und glauben wourde, es wáre dab Selbftins terefle nicht mit sem Sntereffe $\mathfrak{A}$ norer in Şarmonie

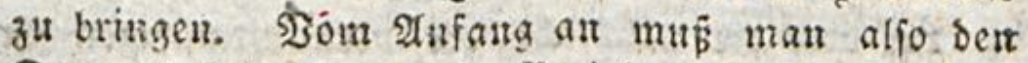
Doppelftof ber ?Ratur in Sejiefung auf bas, uas

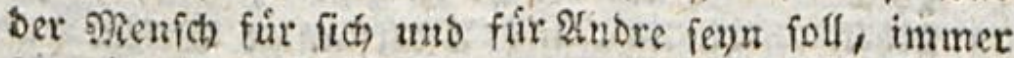

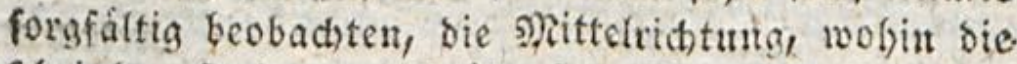
fibeinbar freitenden Sirafte ben Nenichen eigentlich binzuleiten beitimmt fins, fíc merfent uno babei

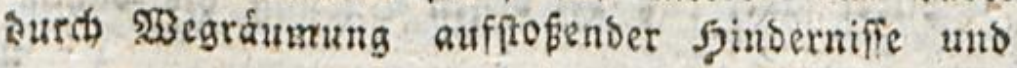




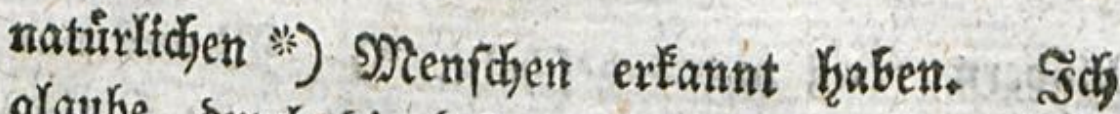

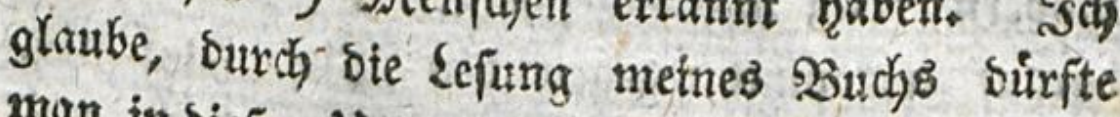
man in biejen Unteriugungen um einige Sdyritte weiter geridet ferm.

Diefen feltenen Menifjen zu bitben, was baben wir zu thun? SBie! ohnftreitig; zu bero Hins Surct) mitivirfenbe Nittel beth rechtent (sang ber Naa tur erleiditern uno befórbern. Eblerz.

T(t) unterichreibe biefe richtige 2Inmerf futs, Dods mit bem 3ufatze, daß man anfangs, o. i. in dent Sabren der Sinbbeit, mefre auf bie Ausbildung bes Dienchen, alb bes şurgers, binarbeiten múfíe.

9) 2us ber vorhergehenden Stnmerfung erhellt ez, bas Cimme Niefenits. ein 刃eench, bei befien Entwidfelung und Silbung fidh alles auf ifn bezieft, nid)t eigentlich ein natuirlither meníd ift. Diejenige beichaffenheit, bie ein mit anberk Dingen umgebentes Ding surch zroeffe

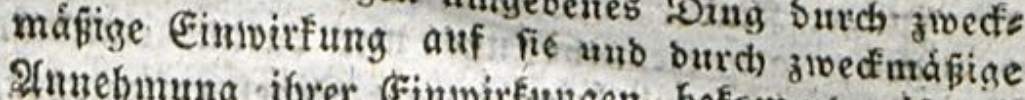
Sfmebmung iffer Einvirfungen befommt, if als

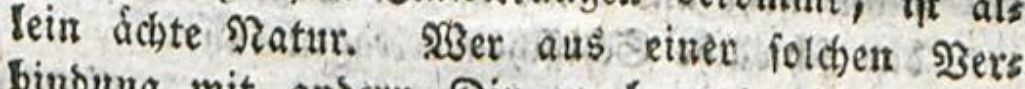
binbing mit andern Dingen herausgeriffent toirb, soirb mut halb ober nicht einmal balb natititich ges

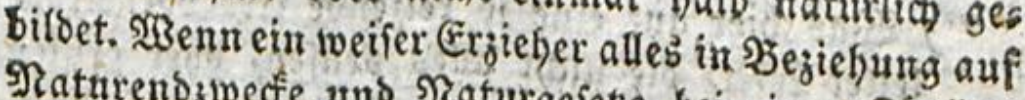

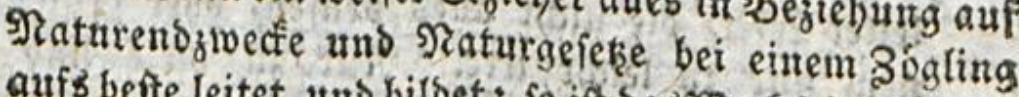

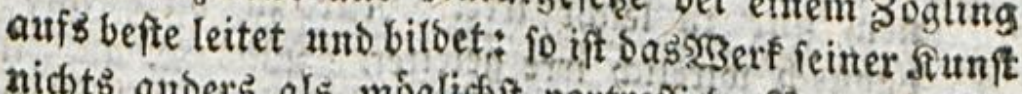
nichts autoers als móglidit vortrefliche statur. WSie Sumft uns Natur forit nie in 2 Biberipruch fommen múfien, fo muk bas vorziglich nie beim sheniden ber Sall pern.

- Emil y fter \$f。 Eblet: Nefenis. Campe. (5) 


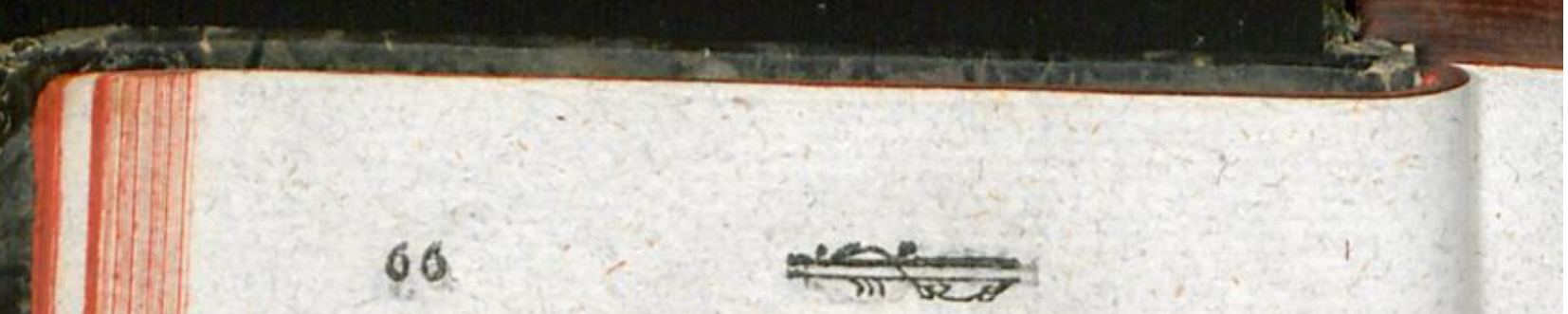

60

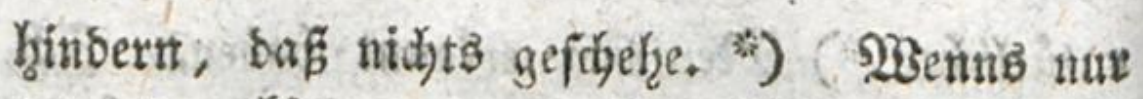

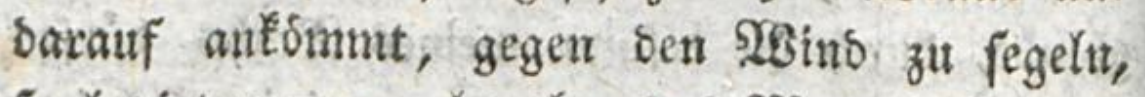

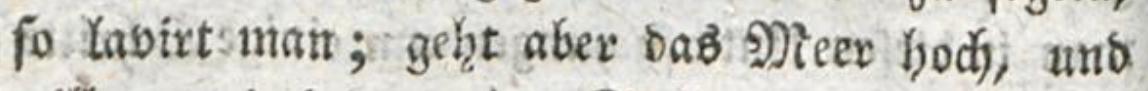
sill man babei an einer Stelfe bleiben: fo mu ber 2 nfer ausgeworfen werben. Şieb wol2ddt, junger Stetiermann, Daf Dein Eabeltau nidjet folleppe, oier bein 2Inker im Sande pflige; bas Schiff burfte treiben, ehe ou beffen ges waher wirbeft. *at)

Sก

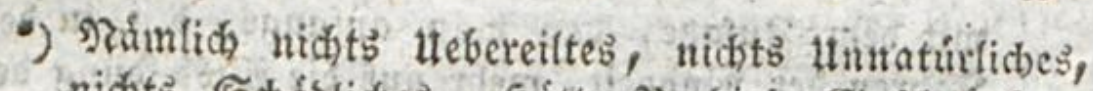

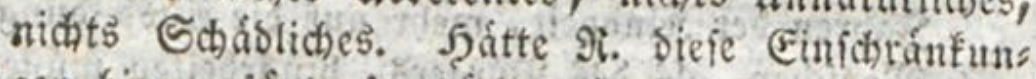
gen binzugefúgt, fo winte niemand etwas baviber cimbunenben baben fómen. Afber bann wáre feine

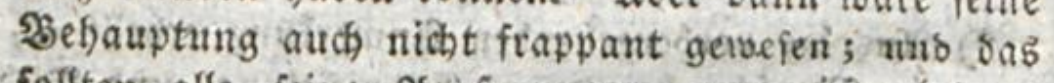

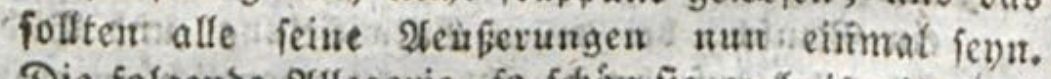

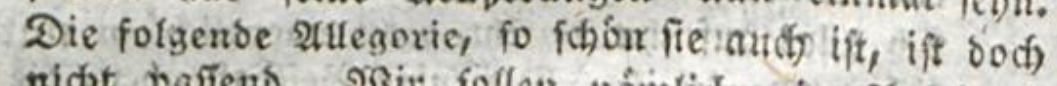

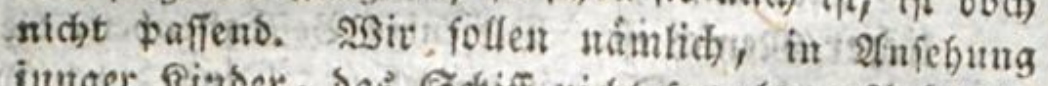
iutger Siraber, bas Gcbiff nicht fowor vor 2Infer les gen, ats viefmeth uths matr barauf cirrchtânfent,

is nidgt meho unb feine anbere Gegel aufoutesfert, als bas ichrocte Sthiffchen ertragen faint.

*0) vosas bier auf eine fo relizense ounte.

leitet Sefer, Sic nidit allze pufint vorgetragen ift, leitet Lefer, bie nicht alles pruffèr, ober prifen fons nent, nut zut leight irre. Nont ju viele fint anth

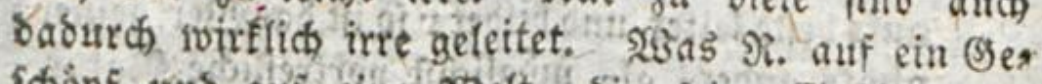
fobipf uns arf eine 29 elt, Sie feilte Einbiloungs"

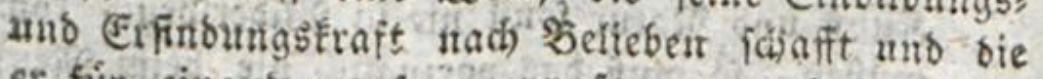
er fir einahber zufaminenpaft, antverbet thro in

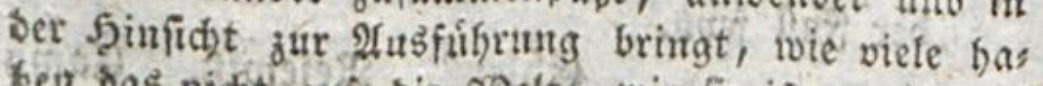
ben bas nicht alf bie 2solt, wie fie ift, uns anf 

Xen beftimmt fino, muE şeber fir die feinige exs

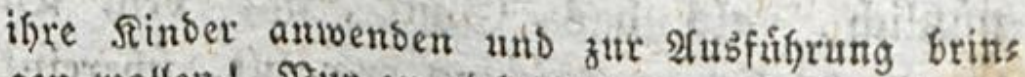
geit tooffen! Tritr zu viele baben geglaubt, Roufs feaut zuf folgen, weenn fie iffe Sinber bis an's zefnte ober zlvóffte Gahr fin von allern Unterricht uno vort

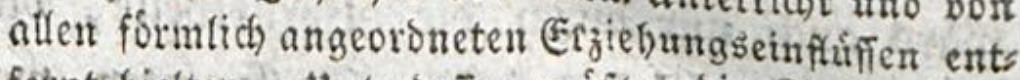
ferntibielten. Hnterbefien múftein bie Sinder ja in biefer twirflichen $\mathfrak{S B}_{\text {elt }}$ allen Einvirfungen ber Dinge unb ber Mienichen, womit fie zufálliger X̧̧eife in Serbindurt traten, und allen fict) Dajut gefelfenden (b)e? genvirfangen, wobei fith fo viel Mangelhaftes unto Ђófes finbet, libertaffen werben. Die Ђefoigung Des "Raths von Rouffeau ift mit fo fern moglich,

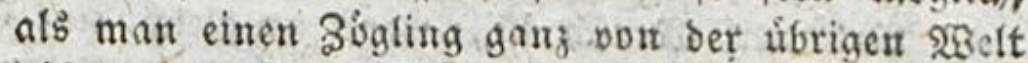
abfonbert. Daun Fant abet and ber Bogfing auf

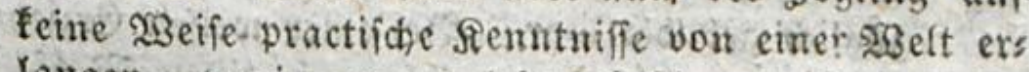
langen, woriu er fut teben beftimmt ift. Geber

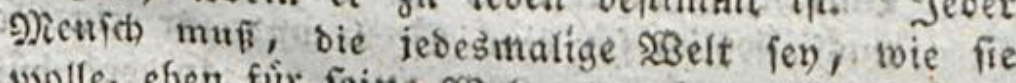

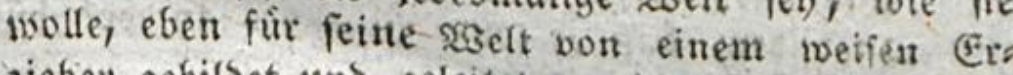
ziefier gebilbet und geleitet werben. Der Ergiefher muß bafút forgen, baß fich mit ber Exiftenz uno ber Sgirfiamfeit feines Elevent fo viele solltom

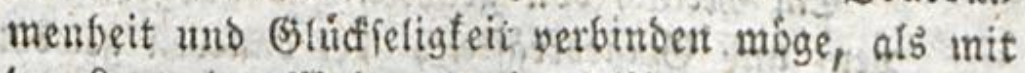
Der Sage ber 23 elt, worin jellbiger lebt, beftehert

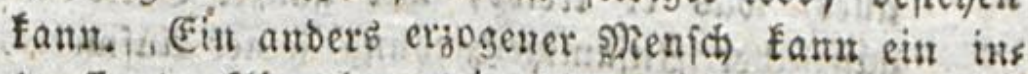
tereffanter Abentbeurer in jeinem febenswandel wer: ben, wie Sientiean felth ja cigentlich feinem feben nach nichts altbers war, aber er wotrb tweber fúr bie,

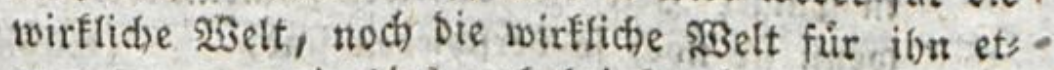
was taugett, wie bies auds bei siputheaut in hobem

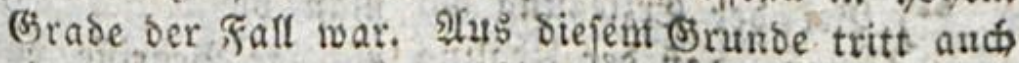
ein io hober (sras von bitterer Eabelfudit in fein

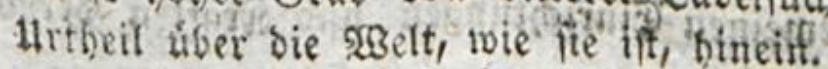

EEblerb. Rejemiș. Campe. 
zogen fernt. Serlafpt ein fur feine Stelle Stea bilbeter fie; fo if ex fur nidgts weiter melzer

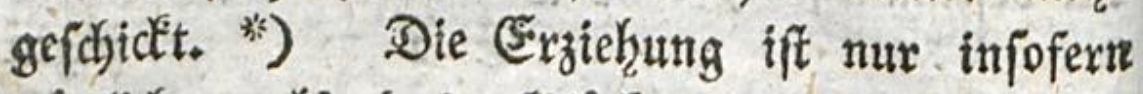

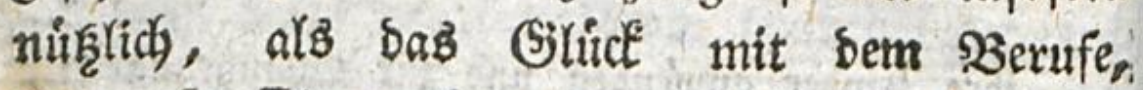
ธen unjre (5)tern fưr uns erwáb̧lt, íbereintrift: in jebem anbern Falle fohadet fie sem Zsglinge: soirs auth mur ourdy sie 2 Sorurtheile, sie fie

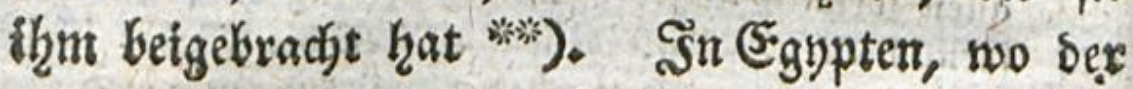

Soḩn

") Der Menich befiţt fo mannigfaltige fóbigfeiteir

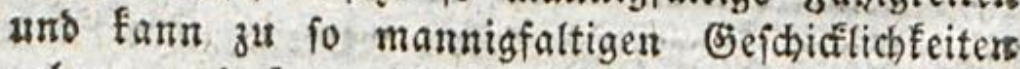
gelangen, baje er tricht cin fúr ben Staat unb fich verlorner Nenfich ift, renn er gleich eine Etelle sticht erbált ober cine Etelle verliert, zu ber er vors zuglich gebilbet war. Sei einer weifen Erjiehungss einrichtung britet man fich auch, einen Neníben io

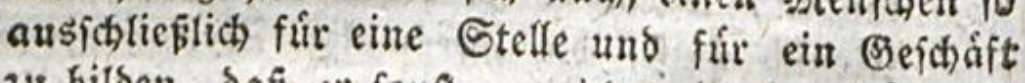
zu bitben, bap er fonft ju nichts in bet burgerlis dgen (öefellichaft tauge.

\section{(Eb) Ter:3. Refelvits.}

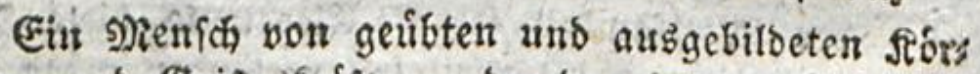
yers and Geiftesfraften, ber baneben getwobut iffg alles, toas er treibt, mit ganzer Geete uns mir gámzlicher Sufaumenzichung feiner 2Affuerf́famfeit auf fein iebesmaliges (seichaft zu treiben, papt in Gunbert fficher, ober fann fich) wenigftens leicht uno in furger: Beit in siefelben hineinarbeiten, aud toenn fie riod) fo veríchieben finb. (Sampe.

**) Эei ber (Erbiehung hat man vorzúglich bafúr zu forgetl, bak ber Bógling ridjtige כegriffe von ben allgemeinen Einrichtungen uno Siráften ser शRatux úber: 


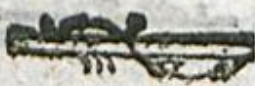

\section{Solgn betbunben wat, ben Stand fetnes SBaters ơ ergreifen, hatte bie Erzitefying zum wenigs

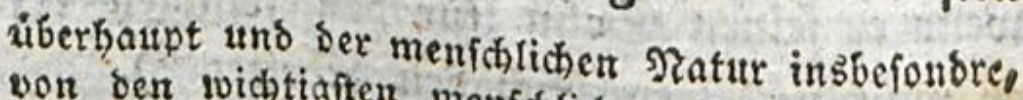
von ben widbtigften menfकlichen-şefugniffen uno

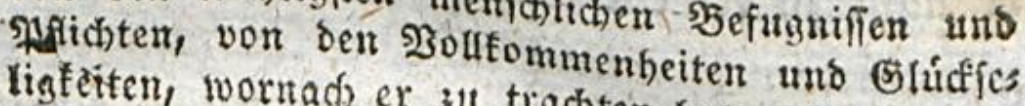
ligfeiten, wornad, ex zut trachten bat unb von ben babei anjulvendenden sittela crlange, dab ein fols

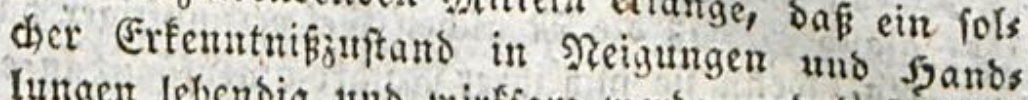
lungen lebendig and wirffam werde and baf alles bas, was er thut, in Hebungen beftebe, weldse fiof auf bas eben angefúbrte Jilbungsgeínáfte bejies ben. wer fo erjogen wirb, erbált eine ju jebem

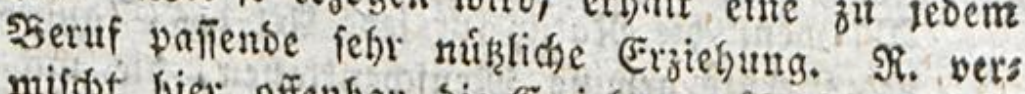
mifdet biet offenbar bie Ergiebnng liberbaupt ans bie Bemubung, einen zu ben Befcháften eincs ges

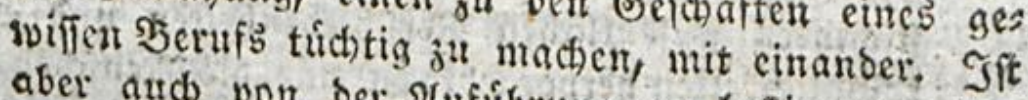
aber aud von ber flufibrung zu beftimmten જुes

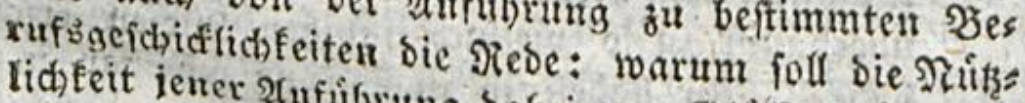

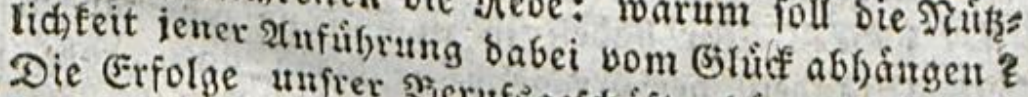
mit vou einem svir nidht vorberinger ber Dinge, ben Epradigebrauch, vom (Studt ab, das ift, rach bem Erfenntnif wann wann iener Sufamment)ang ber Dinge einen gludts Yichen Erfolg bindert. Ind was baben am Enbe Sorutbeile mit ber Anfufsung zu cinem geiviffest 3erufe jut thun? Fisuigitens find fie nid)t weients (ich) bamit verbunden. Dernunftige Eltern Iváblen auch nicht einen Sebensberuf fir ifgre sinder obne Rúfficht auf bie ₹alente uns Reigungen berfelben. $2 x_{i}$ bier bie Eadje vorgeftellt ift, pollte man ben" ten, baßs Ettern nie sarauf fófen. (Eblers.

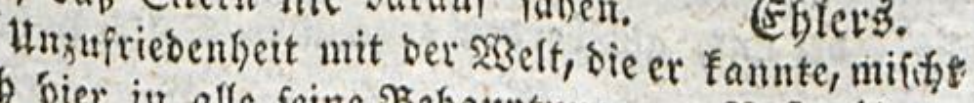
fith bier in alle feine Bebauptungen. Refentio. 
ften ein hơkgeres 3iel; unter uns aber, wo nux ber Stano etwas Bleibendes ift, bie Menftyen aber thn immer verandern, wein niemand, $\Delta \mathfrak{b}$, wenn ex feinen Sohn für den feinigen erzief̧t, ex nidjt zu feinem Shaben arbeitet *).

\section{In}

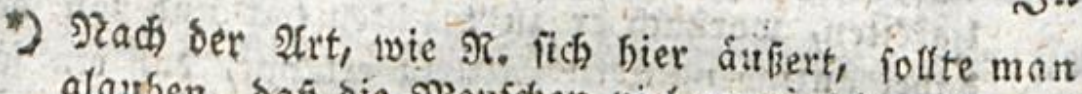
glauben, baß́ die Mienfchen viel vernuinftiger bandels ten, wenn tie mit iffer Nachfommenithaft in cinem uno eben bemfelben Stande bleiben. Die in Jus sien noch Statt findende Sertheilung in beftummte

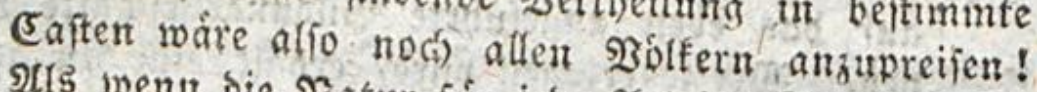

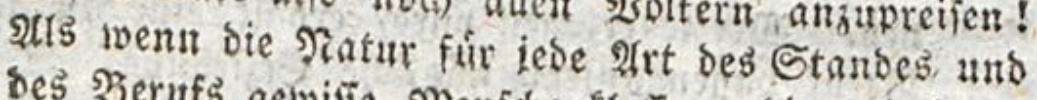

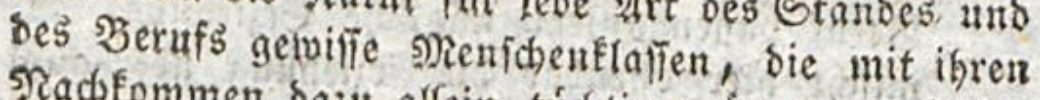
STachfommen baju alfein tíftig wáren, nach bes ftimmten weientfichen \$3erichiebentheiten und Eigens thuimlidfeciten Kerborgebracbt und sie Nienfichent nicht uxberbaupt ju to vielfach fábigen \$gcient erichaffent babe! \$Bir haben ia in Europa offenbar in allen Stánden beroorragend gejchicfte und grobe máns ner, bie aub ganz, anbern Etäben heraustratert. 20. nimmt is felbft eine foldhe \$erfdiebenbeit nicht an.

(Eb)let:s.

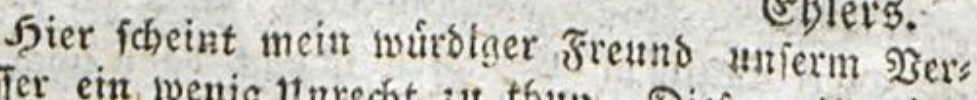
faffer ein wenig thrrecht zu thut. Diefer will nám, rich, wenn ich ifn anders recht verftefle $\mathrm{mir}$ bem (5efagtent feinesiveges befaupten, daß̉ bie chemalige egyptichte und - bie noch jekzt fortbauternbe inbifithe \$erfailiung, nach welcher ber Sohn gerabe bas nám Yiche wirb, was fein গ̧ater war, ber unitigen vorjus ziehen fen: fonbern er will baburch mar zeigen, wie viel grófere EGfwierigfeiten bie \$sereinigung ber blos menfoblichen Ergiehung mit ber buirgetlicthen bei uns, als bei ben genanten 20 blem, babe, weil mis 
Sn Der Sronung Der Statur ift, ba bfe

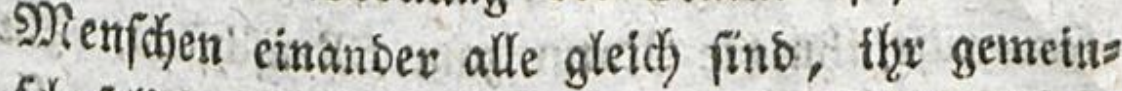

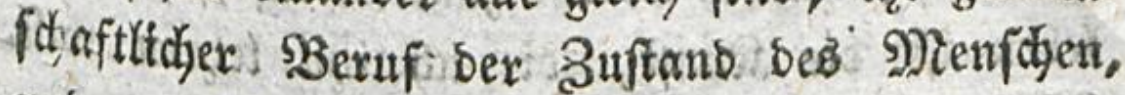

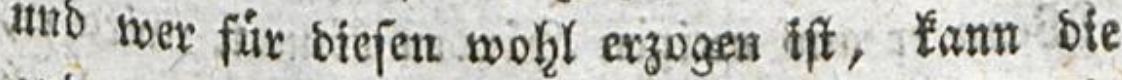

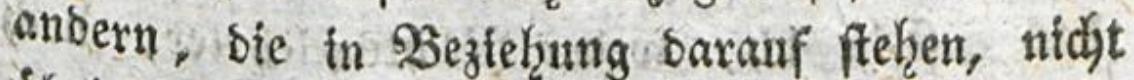
tibel exfutllen *). Mtan beftinme meinen 3 Sogs ling für ben Solbaten: firr ben geiftlichett, für Den Stans Der Geję̧⿸丆巳tener***), Daran Yiegt

(5) 4 mix

wir nicht einmal bie flinftige beftimmte Bernfsart bes Sindes mit ciniger Bsenipheit voraubleben fon nen.

Eampe.

) Freilich nicht, wenn man inn fo gebilbet bat, baß Dabei zugleich auf bas gefelent wirb, was er für bic

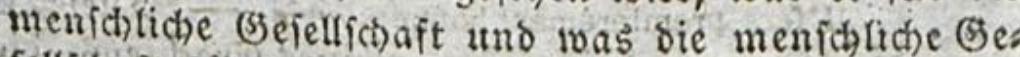
fellifiaft fúr ing fenn wiro und fenn foll. Sebt eis ner min in einer beftimmten búrgertichen błefell f(d)aft: io ift es aus eben bem srunbe auth nothig, baßi bet bet Sitbung auf bie eigentlide शुeichaffen

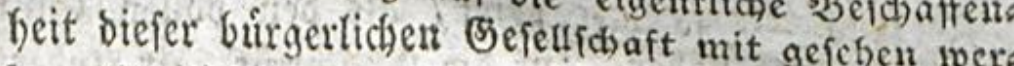
be. Freifici) fann er bann bo(h) nod) bet ciner fol chen Ergiehuting Eolbat, Eteiftlicher 4. 1. w. 10erbent.

Éblets.

*) Obent leugnete ber gute Routifieau, bafi mar शientch und Burget zugleich fern forture. Shier giebt cr zu, Daf mau Nienfol un Golbat 2c. zugleid fenn faut. Er munte, wie es fobeint, ienes nicht leugs nen, ober vies nidht zugeben. Der Solbat ift ein 2ienich des Staats fo gut wie ehemals Der \$zír: ger Rums uns Epartas. Seine Pffichten als Sols bat uno als Renfich fommen motfywendig bișweilen in Eollifito. saito bei inm Die Erzichung zum 
mix wentg. Ehé bie S.ltern thn zu etwas rus

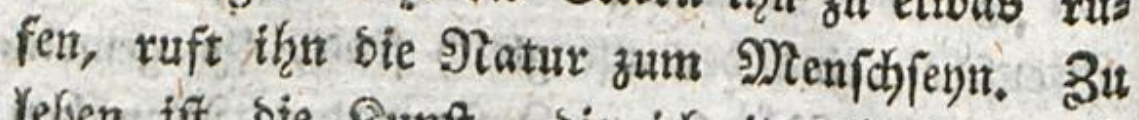
Yeben iff bie siumft, die idb ib̨n Yehren will. 93 enn ex aus meinen Şånden foumif, wiro ex, brs geftebe idh, weder Rechtogelebrter, nods Soloat, noch Srejigex fenn: fondern nur exft:

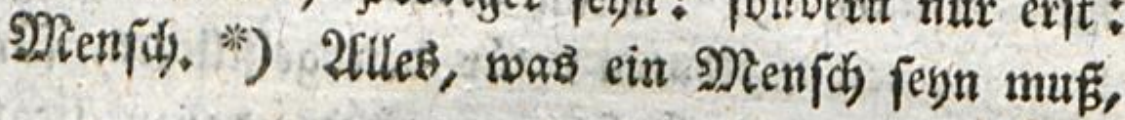

witro

Menfoben machen, baf er feime Pflichteit als Sols bat nicht libel erfuffle, warum follte bas bei bem כírger anders fenn?

2)

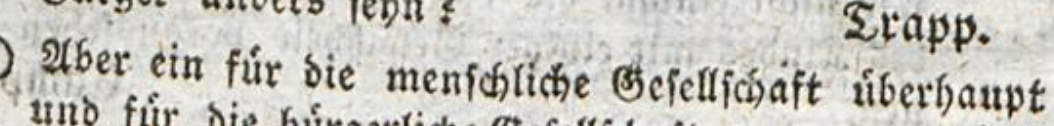
uno für bie búrgerliche (5) fellfchaft, wozu er gehort, boc) zugleich gebilbeter 2)(enich.

(E) lerb.

II fera premierementhomme, - - Diefe Stelle, bie fo glámzend ît, hălt, meires Eradjteng, die Prats fung nibt aus, sBenn - Nenich febn - mit bem - Sútger feyn - niemals in Collifion fáme; ia, bann ware es gut. \$renn aber - Nenfach fenn - fo viel heist, als ben vollen Sinn ber Freiheit, haben, auf bie (s)eichbeit mit $\mathfrak{A n b e r n} \mathfrak{A}$ m

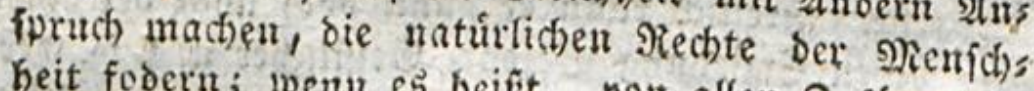
heit fodern; penn es heiṕt, bou allen Bufákzen zu Der SRatur, von allen Ṡeoúrniffen แnd Noruntbeilen Der (b)efllichaft frei fern; bann fteht bie Mienichs heit ber Brefellichaft entgegen; dann wiro berienige, rvelcher gelernit fat - ein sienid zu fenn - nicht gut in bie Beiellfichaft palien.

Mit girtem Bedachte babe id gefagt: bie গুors urtheile dex Befellichaft, obne auf eir \$aradoron sago machen ju wotlen. Saşenn bie Befellichaft blye altzugrobe Miúbe ifie swecte erreichen foll,

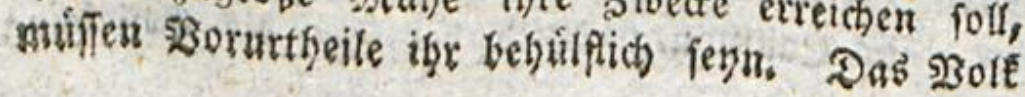
mup 


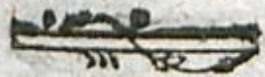

swiso ex in Siothfalle fo git zu jegn wiffer,

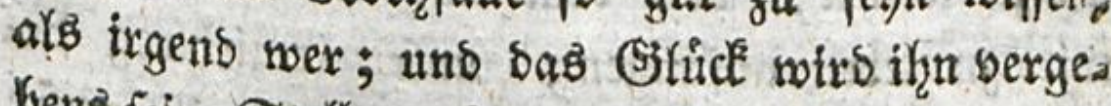
bens feine Stelle sexaindern lafien, ex wiro immer an feinem Slafe feyn. - Occupavi te, fortuna, atque cepi: omnesque aditus tuos iris terclufi, ut ad me adfpirare non poffes *).

Itnfer sabres Stubium ift bas Stubium bes șlenfchenzuftanbez. Derjenige unter uns,

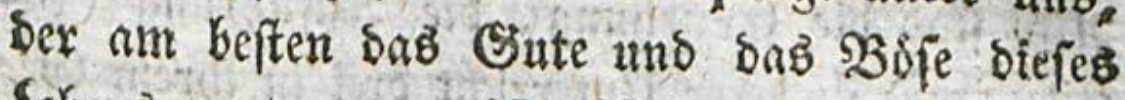
Sebens zit tragen weî́, ift, meinem Bebinken tach, aun beften erzogen; woraus benn folgt, baf bie gute Erziebung meniger in Sorichrifs ten als in Hebungen befteht **). 238 ir fargen

$$
\text { (5) } 5
$$

ait

muE ben syenfer für unebrlich Galten, uns ber (S) rofe

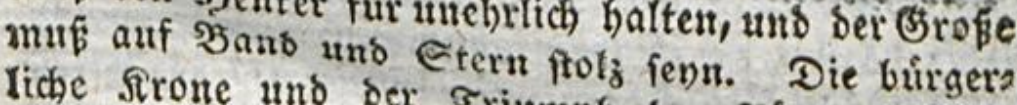
liche sirone und ber Exiumph ber Romer waren sodb nichts als Sdjummer; und wie fehr bienten fie Sem Stante nicht, Eine Sefellichaft obne Soruts theile ware ofure Eifer uno Enthufiasmus; und obne Enthufiasmus giebt es feint grobe Ehatentp Eeire Dpfer. Hno wie febr fino letzętere nótbig! Der ভchlü, ben $\Re$. auf ber folgenden Geite aus

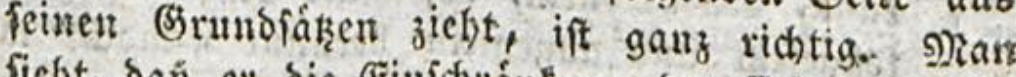

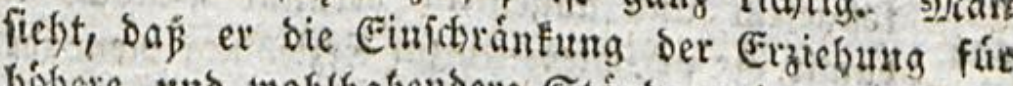

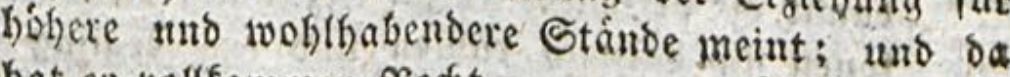
bat ef bollfommen Recht.

7) Tufoul: V.

Billaume.

*) Dies ift cine ber grópten 2 Bahtheiten, sie rours

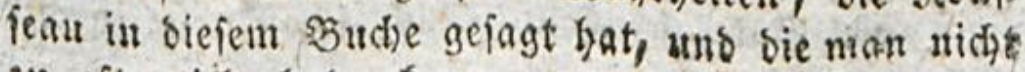
ill oft wieberfgolen fants.

Eampe. 


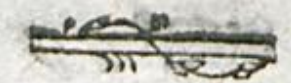

an zit lernen, bou bem 2fugenblicke att, bafs whis zu leber anfangen; unfre Erziebzung bes ginnt mit $u n$; unfre erfte Eef̧rerin ift unire 2tume, 2fuch Hatte dies 2 Sort Erziefiung bet ben 2fiten einen anscrn Sinn, ben wiv if̧m nidyt methr geben, es hicef Sirnabrung. Educit obftetrix, fast 2arro, educat nutrix, inftituit Paedagozus, docet magifter. *) Alro fins sie Erziefung, bie 2infiffrumg (Inftitution) uns ber linterrifit brei in ilgrem (Se\%

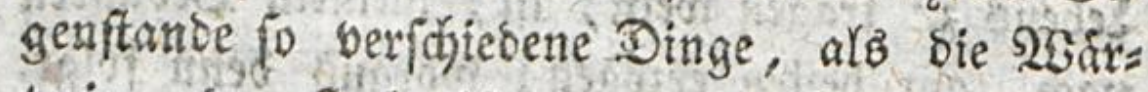
terin, Der Seofmeifter uno ser Eehrer. 2lber Diefe Interfobiebe iduffent nidjt viel Sutes; uns

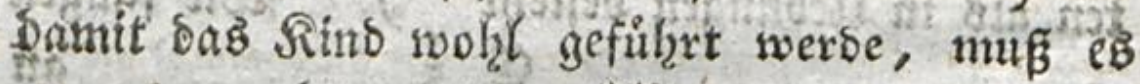
nux einem (eiter folgen ***).

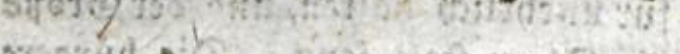

WBix

IN9 Non, Marcelf.

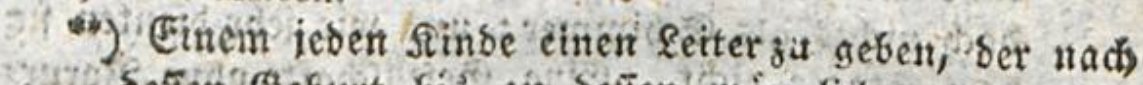
befien Breburt bis zit beflen mátulithem alter bia affes thut, was die $23 a$ arterin oder $\mathfrak{A}$ mme, was ber \$abagog uno mas ber lefrer fonft thun, das ift fd)ledterbings unausfubrbar. 2ules, was gefdeben

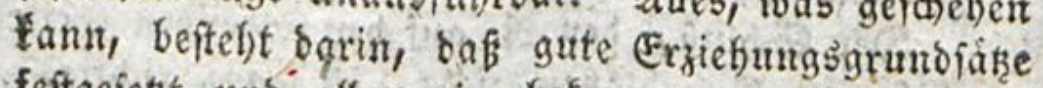
feftgeient und allgentein befannt gemacht werden, bamit Die verifhiebenen zur Erziebung . Dienenden ¥ers fonen fich barnad) richten uno ben Bogling einans ser geborig jubereitest fonnent. Die bier getabeltet verichiebenen \$erionen, welche allgemein mach bent Buftande ber $2 B e l t$ befteben founen, fonmen baum viel Butes fchaffer. Shch fobaffen fie in bet That minber 
15. 28 ir miffen semnad) unfren 2fusfiçtem mekzx 201gemeinheit geben, uno in unjrem Boblinge nux ben \$enidyen in abftracto, *) ben alley 3ufállen des - ynenfidichen Lebens unterworfeneq Mlenichen betradjten. IBurben wir gebohycen, beftinunt, an unferm vaterlichen $\mathfrak{B o b e n}$ anges Jieftet zu Gleiben, bauterte bieferbe Jahrozzeit bas ganze Saffr fintourch; ware Sebem fein :Schict? fal fo unabwenbsar zugemeffen, baß̧ nie etroas

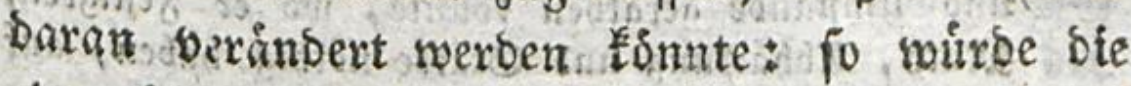

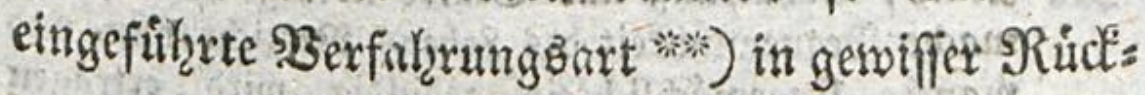

minoer und mefr viel of utes, wenn gleich, wie bie Sachen bis itzt fino, lie noch viel mebr (Gutes ichafs" fen fömten. Eglers. Sampe. Nejewis.

*) Das beist bod einen Menichen, bei bem mar ichon fich sie Szeftimmungen benft, bie ihn zH einem Nitgliebe ber menfeblichen (Befellichaft und zu einem 23urger ber Erbe tûditig madben. Einen foldten \$ien: feten follte man nidf mebr einen Rienf(t)en in abftracto nennen.

(5b)

Der 2usbrud iff freilich nicht recht walieno, aber bas, was $\Re$. bamit ingen will, ift bod ganz

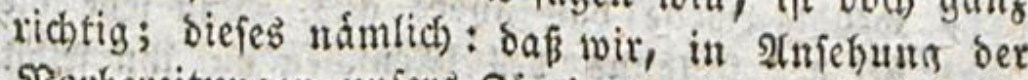
Sorbereitungen uniers Böglings auf die 3ufálfe bes menfididien Lebens, nicht auf eine beftimmte lage, auf cin beftimmtes ortuif, fonsern vielmefrr auf alles

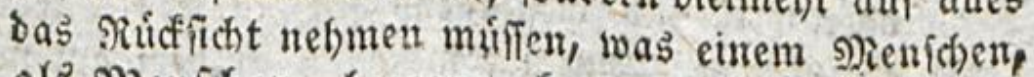
als Dienfiúten, begegnen fam. Eampe.

*) Da man z. E. ben Soln bes গeichen burch cirte iveichliche Erziegung fo folwad), furchtfan, und weis 
fidit gut, uns bas fur feinen Stand ") ets

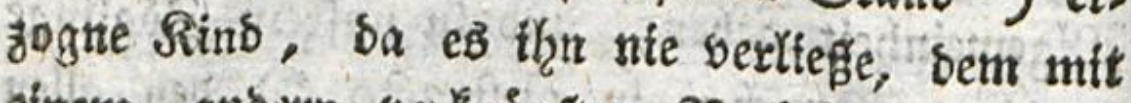
eitrent anbern bertuipften STadjtheiligen nidjt

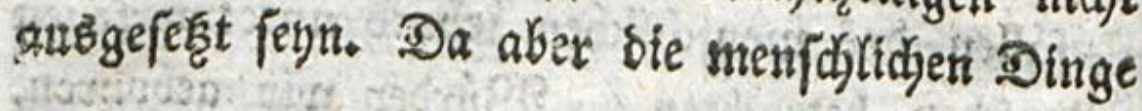

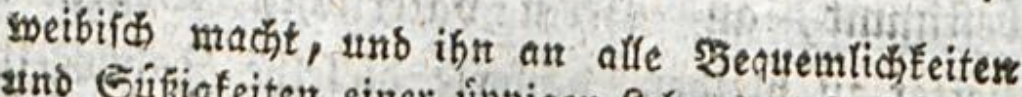
and Eifingfeiten einer lippigen \&ebensart po fefre ge: soobnt, als wenn maumit volliger Sewisheit wúfite, baf et immer in Heberfute leben atto nie in fagen uns umitánbe gerathen fonnte, wo er Jeftigfeit,

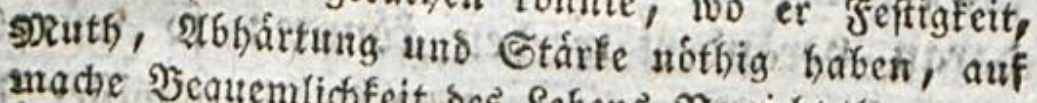
madbe গुequemfichteit bes Lebens Bergidst thut, und manche Intgemádblidffeit gebulbig wiro ertrageu muiften.

Bampe. Niefenth.

Aber $\Re$ fontht bier mit einemmal auf bie gangbaren febler Der Ergieburn, als wáre fie ber

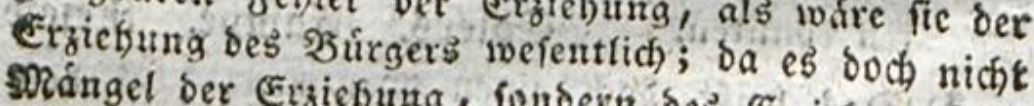

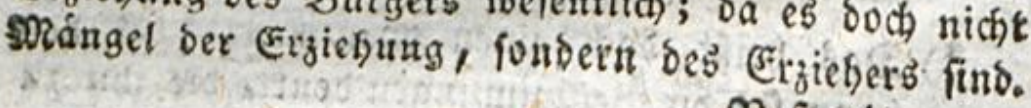

Sieferviks.

7 Ej if noch lange nicht vom Stanbe, von einer ges wifilen Rebensart bie Rebe, twem Der Menfoh audis nicht zu einem Sirger Der gamjen $23 e l t$, fonder rut zu einem tauglichen Şurger fúr den Staat gebilbet wirb. Das eine idslieft nber ia nie noths soendigeriveife bas andre auts. Man fehe vielmehr bei ber sitbing bes Nenthen auf ifn felbjt, auf

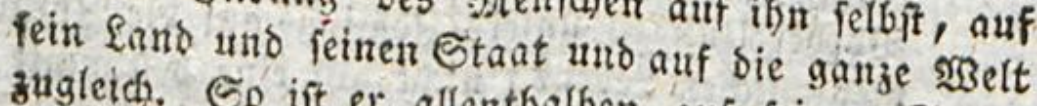
zugleich. So ift er allentbalben auf feiner Etelle, boer weís fich wenigftens bals in jebe Stelle bins ei:zuffigen. SRur ribe man ibn in bem am meiftent, soorin ev wabrfcheinlidjer şeife feine Rolle fpielen,

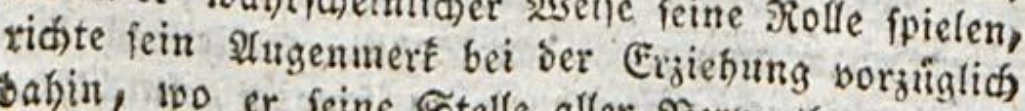
bahin, two er feine Stelle aller syermuthung nach Finder ivirt. Eghlers. Sieferwiş. Eampe. 
fo anbeftansig fins, sa sex Grift siefes Şahres bunberts fo unrubig uns 20lles aufrubrens if,

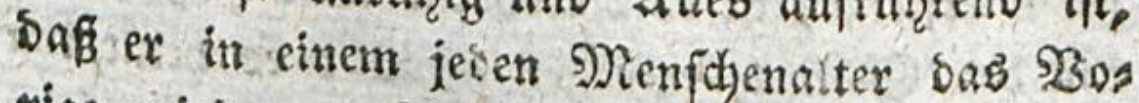

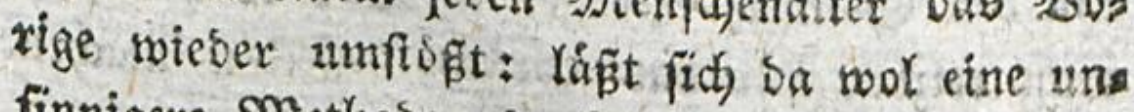
finnigere Metlqobe exbenfen, als sie, ein Sins fo zu exziefzen, alb of es nie ans feinem Jim mer wirbe zu gefien baber, als ob eb immex bon feinen Eeuten umgeben bleiben fónte? *) Sos balo ber Ungliditicke einen einzigen Schritt auf Der

-) S\$Bie qubertrieben! SGenn man ein Sins in Llebers eimptimmung mit ber jebesmaligen form des sec bens in befien lanse erzieft: erzieht man es bann 10, als ob es nie aus dem Simmer fomme, immer mit einerlei leuter ungeben feru wird? So wenig bángt alles geforig zufammen, was $\Re$. fagt. Rllein ftellung liber alles woirft, berbirgt auch bie auffallents ften In uriditigfeiten bem Saufen ber. Lefer, bie mit ibren 2 ugen bei bem fojomen Gewande verweiten uno nidit forgfáltig auf $D a b$, was barunter enthals ten ift, binfchauten.

(E)blers.

Fouffeau rebet bier nicht mebr vou ber Era ziehung für bas buirgerliche Reben úberbaupt, fondern er ift unmerflich ju ber Rige des in grofen Sjáufern herridhenden Er ziebungsfeblers tibergegangen, ba man bie Sinder fo weichlich er jieft, fo belicat unb fchwáchs lid) an leib unb Seefe macht, als ob fie bazu bes ftimmt wáren, immer bas 3inamer ơ huten, uno bei iebeut Bebrirfnifie immer von fremben Soánben bebient zu werden. Diefe goritellung if Sod io úbertrieben eben nich! Eamps. Sieferwibis. 


\section{8}

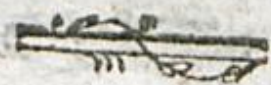

ber Erse thitt, fobals ex eine eithige Stufe herunterfteigt, ift ex verlohren. Das heifit nidbt,

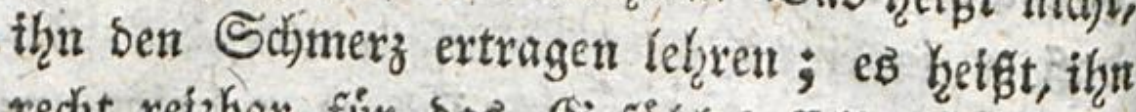
redjt reizbar fir bas Siefügl beffelben madyet.

Man ift nut Saralif bebacht, fein Rind zu erhalten; baran aber gefchieht nod nidjt genutg: man mug es autch lebgren ficts felbit zu exbalten; wenn eb Mann geworben fenn wirb; bie Scalis ge bes Sdjidefalö zu extragen; bem lleberflufie unb Der Dirftigfeit zu troten; went es fent

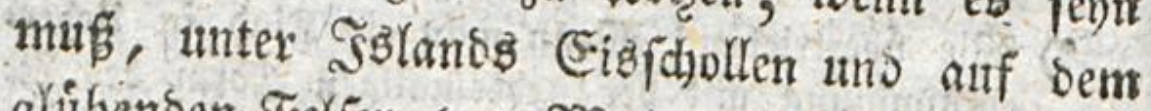
glíbenben Feljen son Malta Yeben zu Honnen. Siod) fo fehr tmigt ifyr Sorfichten amwenben, zu berk̨iten, baf́ eB ferbe; es wirb bod) fterben

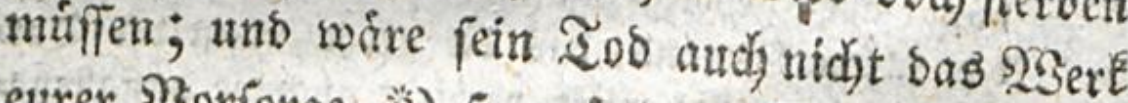
eurer Borjorge, *) fo wirben es bennod) ufbel serftandene Sorforgen fern. Man muß́ nidgt fo fehry berhiten wollen, daf es fterbe, alo biel: meht

-) Afts twáre Ser Tos getwógntich, oder fogar allgemein

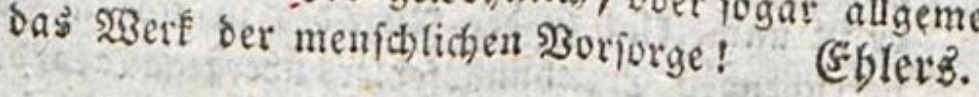

Das will nut $\Re$. auth lool nicht fagell; or meint nut, bas manthe Eftern ourch) \$erzartelung

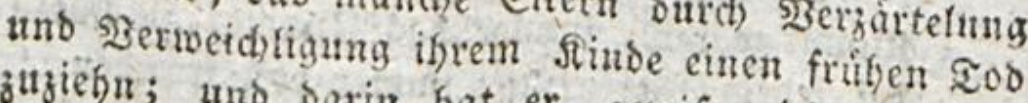
zuziéfn; und barin hat er geviiß nicht untecht.

Campe. 
mehre fijaffen, bafs es zu leben wiffe. *) $\Omega_{e}$

infe ben betât aber nicht blog atf̧men, es heifit bुanbeln; ев beifgu Gebrauch von unjern Gitieba maaßen, un ern Sinnin, unferm Geifteß̈ber: mogen, fturg allen Iheilen unjerer felbit madjen, Die uns das : Bewufterenn unjers Dajerns ers

*.) Niesner uns

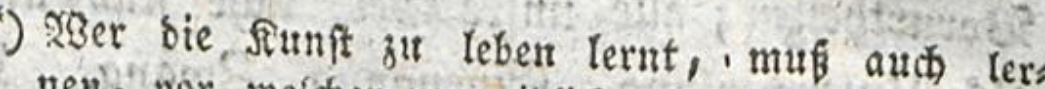
nen, wor weicthen vermeiblicten Hracten bes ₹o, bès ex fich zu huten babe.

(5) Ier?.

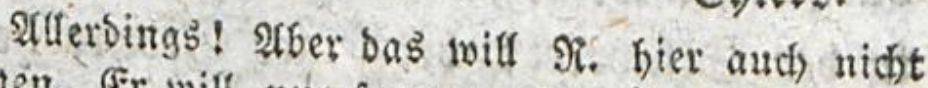
letgonen. Er will mur fagen: noch liber bie Eorge fúr bie Erthaltung des phyfiichen Rebens muß uns

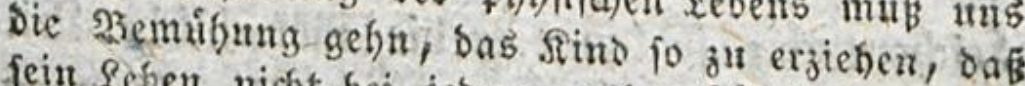
feir Seben nicht bei jebem rauken Suftchen, woodu oas Sind angelveht wirb, in (jefabr gerathe; es

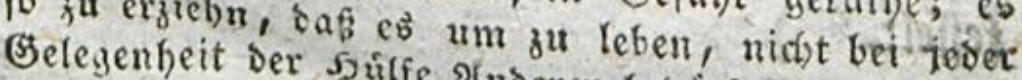
\{elbit ju erhalten wifie 2 nderer bebsirfe, fondern fich 3u erziefen, daij os

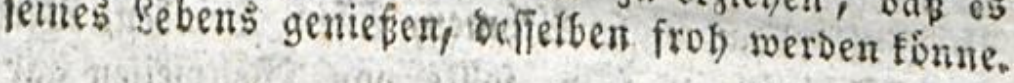

3iegriff mit dem flet tontent lool eitren jolden \$3uch bes wiffenithoftlid le ben verbinbent. Tn einem Feinen noturlichen Ginu b interrichts mú leben

Eglers.

Der in biefer Ifrmertung entfaltene Dabel Soceint mir ungegrintet, ba man aud in pbilojo:

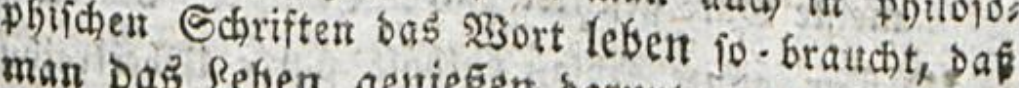

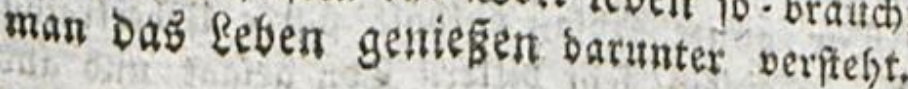

Stuve. 


\section{0}

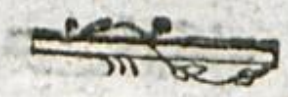

Yebt Kat, ift nidjt berjenige, ber sie meiften Sahre gezahlt, fondern bes an meiften bas $\mathfrak{s e s}$ ben gefúfilt hat. *) Mancher ift in fyunderten Safhre begraben worden, ber fdyon son feiner

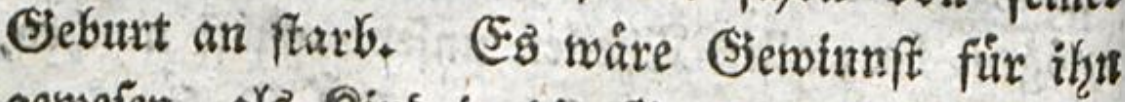
gewejen, alb Rins in bfe Giruft zu finten, wents ex banit rut biefe Rinoheit fiber gelebt ḩatte. Unire ganze 23 eisheit befieht in tuedjtifochen Borutrtheilen; alle unfre Siebraudbe fins nichts ałв Unterwerfung, Einengung, 3twang. Dex burgerliche Menjch wirs gebohren, lebt uns ftirbt in ber Selaberei: bei feiner Seburt Keftet man ifh in eine 2 indel; nach feinem Tobe in ein Seidjentuch; fo lange er bie menjidjlidye Bitoung trakgt, ift or ourd unfere Einridytungen ges feffelt. **)

פ⿹⿻弋𠃋⿻上丨

Das blopie Stthmen, Effert, Erinfelt, Szeroautet,

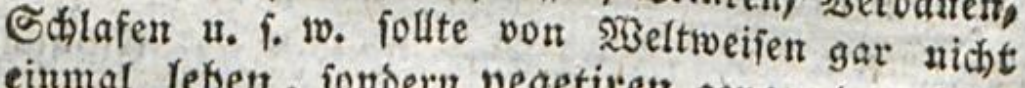
einmal leben, fortoern vegetiren genanut wersent,

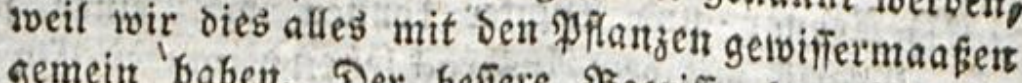
gemein babent. Der beffere Şegriff, ben bier $\Re_{0}$ vom Seben giebt, fcheint mir ein ebent fo philofos whilch richtiger als tourbiger zu Yeyn. Campe.

") Und ser mit feiren Iráftent uno fábigfeiten das meifte Gutte geftiftet bat. Eampe. Rejerwib.

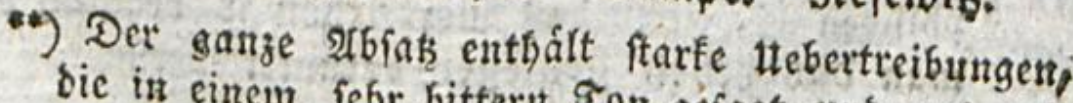
bic in cinem fefr bittert Ton gefagt und aus gals fichten mijantropifden

Durd 
thett

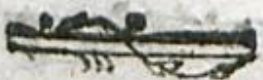

Man fagt, gewiffer stebaminen bef̧aipteten.

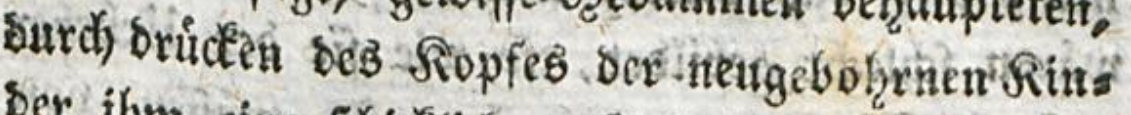

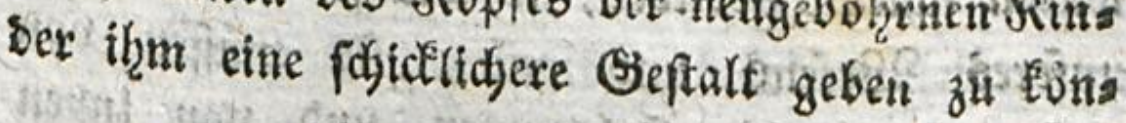

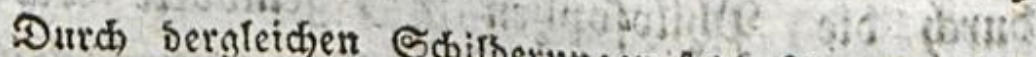
ben Renichen nidht in sen Lebent mit senth entgegenzand, allen 11 ebeln bes

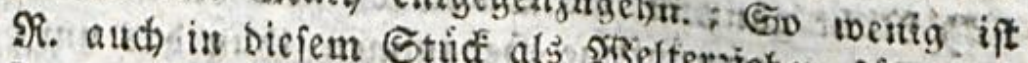

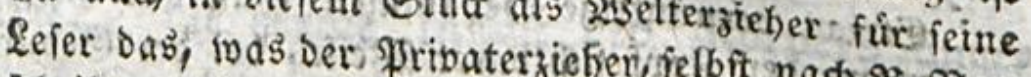
fbriften fur ben

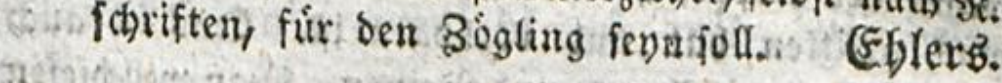

Sherr formen orufft fich, in feutem 2lutis Emil bei biefer Stelle mit einer sjitterfeit aus, oif ids bann, nidht wurde billigen fonmen, wenn in bies fex, freilich ubertrieberien siounfeanifon 2lenfes rung auch wentiger 23 abres toare, als bods, wirflich babei jum (Srunoe liegt, Niemals, fagt er, bat man eine iammertichere Eshulrede, als bieie,geielsu."

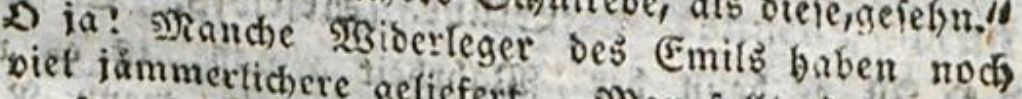
mafen, baf entweser bie s. "Mian polfte fait muths 27. gebolt, ifm bei feinem" Eintritt welche ser Sherru Sopf auf eine bobftieltfante art zus oie babe, ober safs die siseltwetsheit

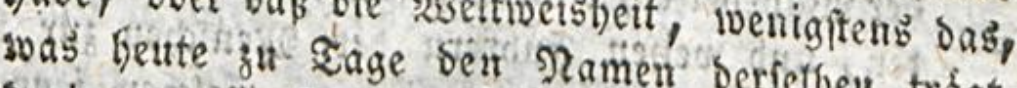
Sarin ganj" aufierorbentlicbe weruffacit baben." Das beist ar it

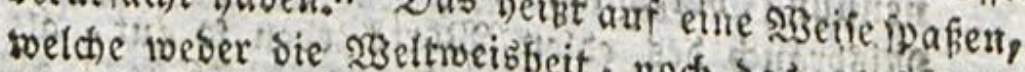
Ju Sage ben ramen serfet noch bas, wasbeute Fann.

\section{(5impe.}

thebertrieben uno ebent fo unriditig und unpas

sith fens if soch die ganze Declamation, uns Defto tachs theilige:, weil eben dieje tibertriebenen goeen von $\Re$.

4i. uns aubern falfót angetoandt merben. Nefensib. Emil zper $\mathfrak{x}$ 


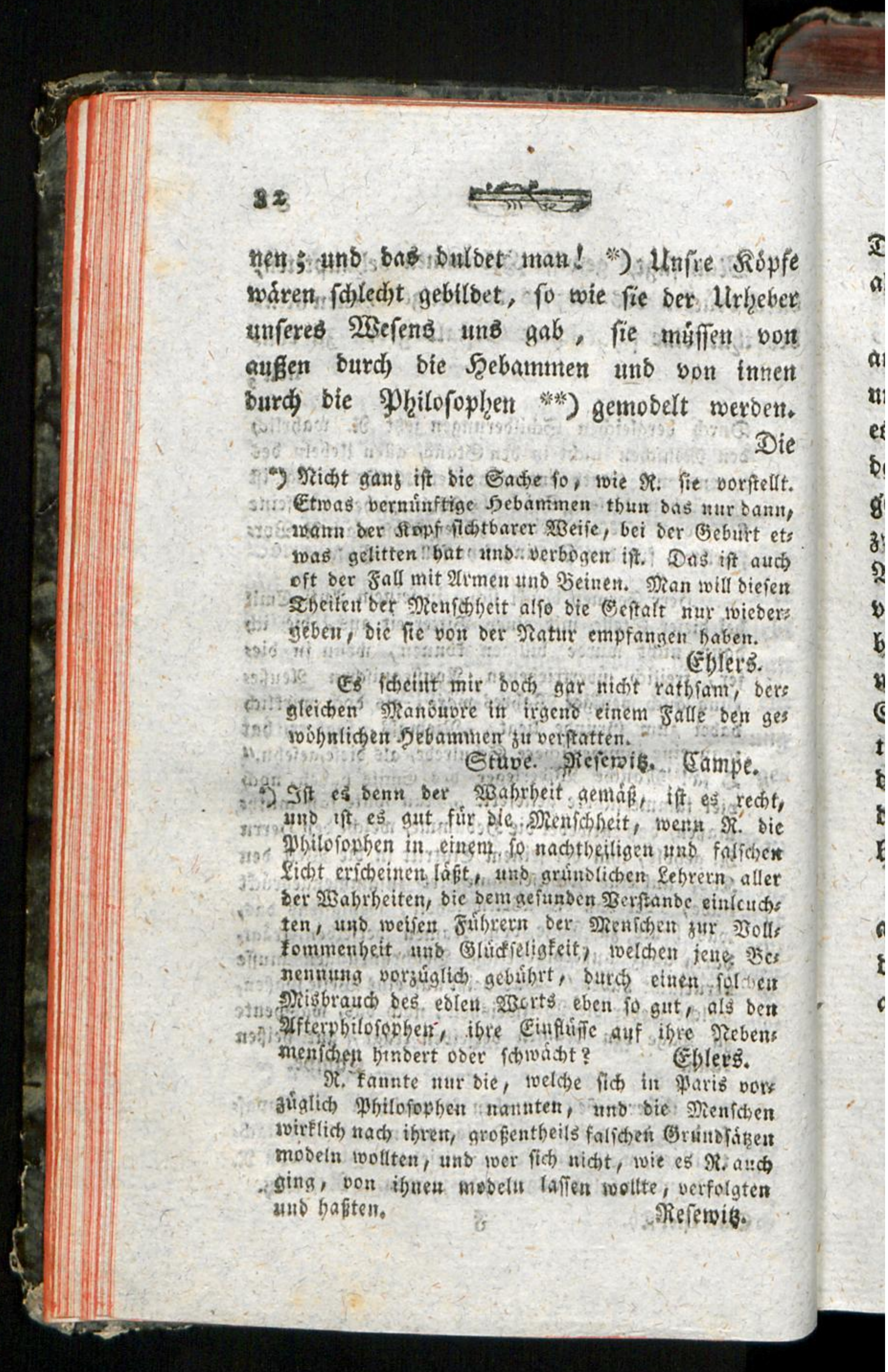


Die carafben find um bie Scarfte glictilifjer. als wir. *)

„SRaum tft sua Rins aus Mutterleibe bere aus, uns sentefst ber Freifzeit fid zut bewegen and fetne Silieber auszuderznen, fo feffelt mat es son neutent. Man toictelt es ein, man bins bet ifm ben fiopf unberbeglth, sie Beine ausె geftreclit, bie 2trme längft bes Siorpers anges zodingt; und unglebt es mit $23 i n d e l n$ uns

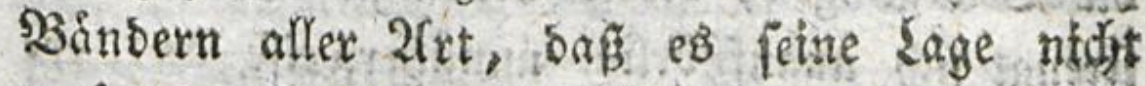
berknbern Eann; not) glictidis, wenn eB nidgt bis zum Erfticten feftgefchnurt mirs, uns man

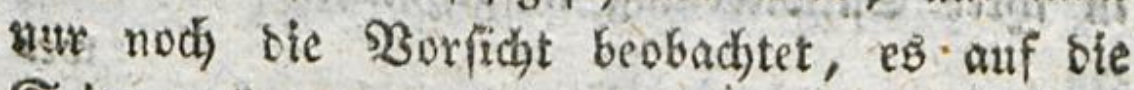
Seite zu legett, bẩ thm bie abgebenben Fench. tigkeiten vom Minne laufen ksnnen; bent bazu, Viegt es nidst fref genug, Sen Rovf auf Die Seite zu wenben, bamit es felber ben 2tblauf beforteren ${ }^{2}+$ )

*52 Dab natugebohne Sins tump feine Stlieber aublebren uns betwegen fortien, inm he aub bev E. ftartuna zu bringen, in Der fie, fo range als es, ein Situmpen, in S) nutterlétbe Tag, fich

$$
\text { F } 2 \text { sac sial bea }
$$

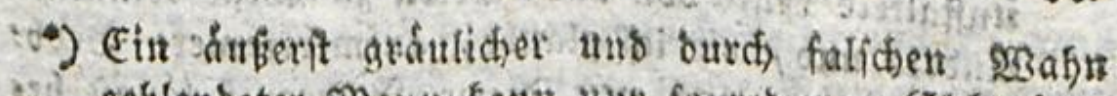
geblenbeter Dian fartu mar forteben. (E)lev3.

Ein beclamatoristher Edfilffieller and, ubna oben bas eine ober Das andere jit Pentr. Camise.

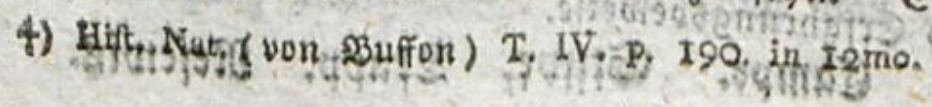




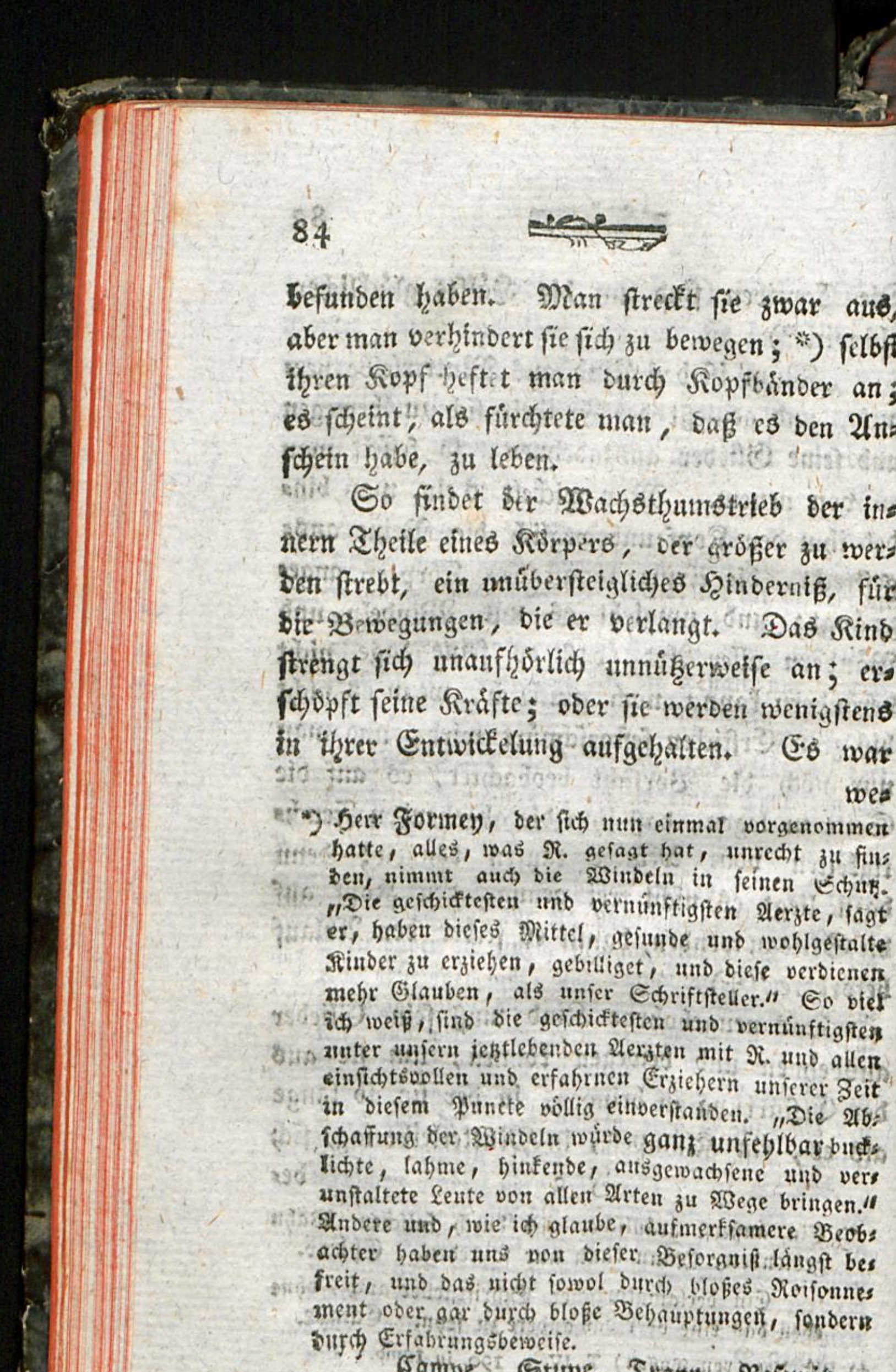

Campe Stupe Spapp. Netewito 


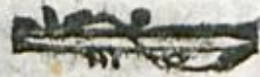

weniger beengt, weniger eingerwängt, weniger gefeffelt im 2 Imnios $\%$ ), ats es in feinen 2 Bins betn ift: idy fible nicht, was es babei gewons then hat, gebohren zut werben.

Die Lintḩ̧igkeit, ber 3roang, in bent matt

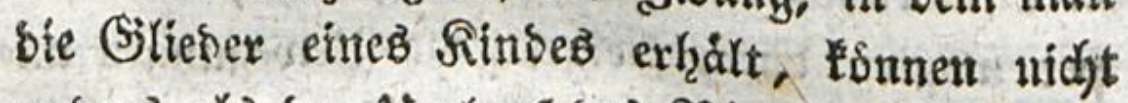

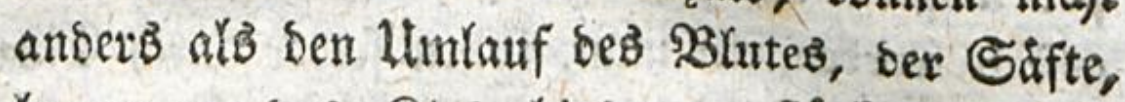
hemmen; Das Rins bindern, ftárfer zu roers

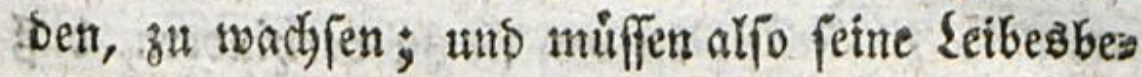

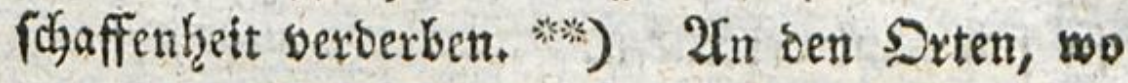
nan biefe audfoweifenden 30 forgen nidjt

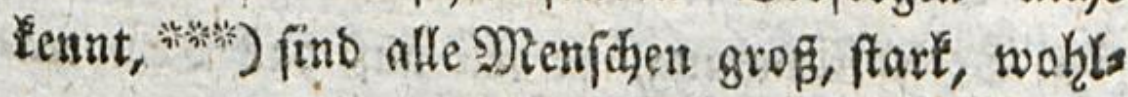
F 3

ges

") Das Sáuttcin, toorin ber Embrio int Nutterteibe eirgervidfelt ift.

*) IIIIle Golbaten ser groperr preufifichen Fataillons, fagt 5er. Formet, fins gelvidelt norben, und bies fes bat boch nicht in ifonen ben Erteb ber innerlis

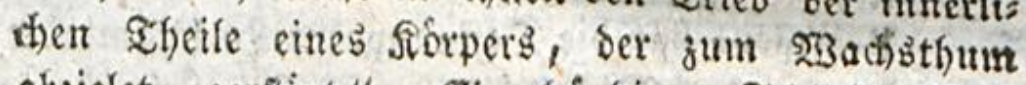

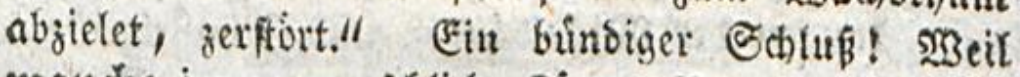
mandise junge mentalidse Sorper s?aturfraft genttg batten, ben Gobaben bes ibuen angethanen unnas tirrliden swauges ju berwinden, fo fonmen alle junge menfoblidie sebrper ein Gleidges thun?

\section{Eamise.}

-**) Ia, fagt man bagegen, bas betweifet nidbts; bent bie G(h)wadhfichen fterben; unfre Derivaf)rungsmit: tel erbalten fie; barmu fieht man f(two achliche s) ren: then bei uns, bor' aber nicht. - Dicier Einwans ît ganj ungegrúnoet. Dab faut mast wol juges

bey 


\section{6}

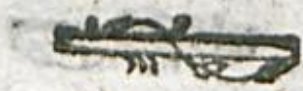

gebaut: i) Die Lanber, in benen man bit

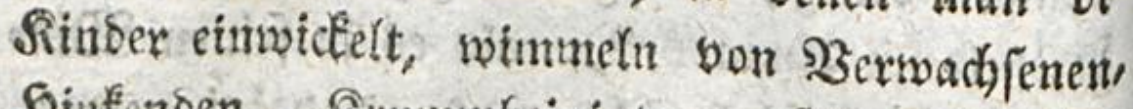
Seiufenden, firumubeinigten; SSlieberíd) wám me, englijg) Airanťlgeiten, Mriägeftalten aller 2rt finder man barin. 2fus Furd)t, bie Rion per mógten butrch freigelaffene Bemegungen uns geftalt werben, eirt man, ifnen filker surdy (Ein preffen biefen Dienft zu Keiften, Siern ${ }^{3}$ ) madjte man fie zu Firippeln, un fie zu verbitndern, baf fie fiid) iddt verrenten.

Sollte eit fo graufuner 3mang nidjt auf Sie Seelenftimunng, fo wie auf bas Zemperas

Ben, bas bei einer rohen und unvermunftigen $\mathrm{Ex}_{\mathrm{r}}$ ziebung mande sinber umfommen mbinen, die fonft sool gelebt bátten. Ess fagt aber niemano, bap man roh, unoerninftig und forglos erzichen foll. Ëhroáche Yichfeit uno Bifliebergebrecten find nicht einerlei.

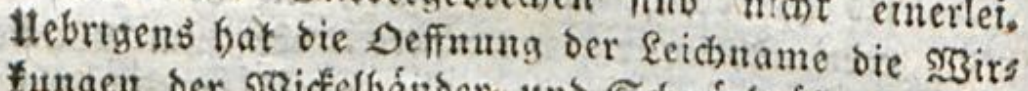

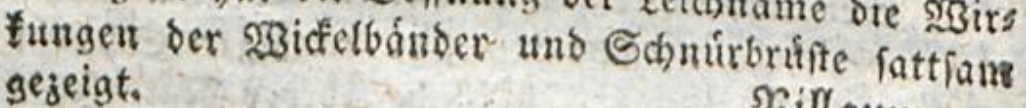

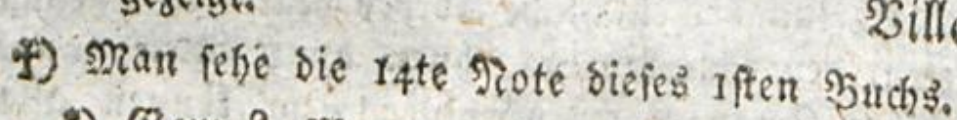

-) Bern? Şarum foll ber Nenfch mefr mit fich im23iberipruch exicheinen, als er es ift? Erittich ift ein folfficr Zabel an fid ungerecht. Sweitens reigt cine fo bittre firt bes ₹abelns nur ju mandhen शjes sounderer Roufieaus, fich auf eine gleidh bittre $\mathfrak{A r t}$

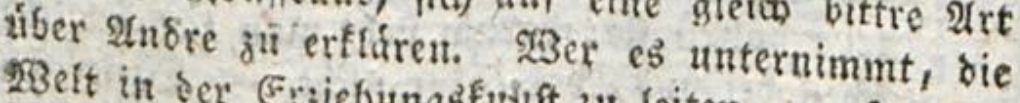

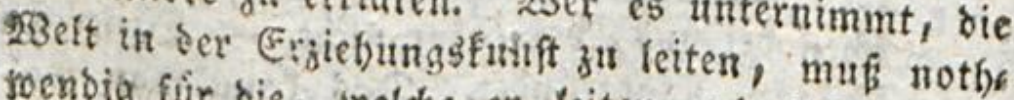
soenbig flir bie, weldje or leiten uno bilben will, sin 2 ) $u$ îter kenn.

Eblers, 


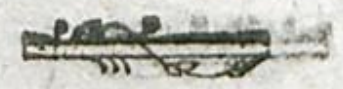

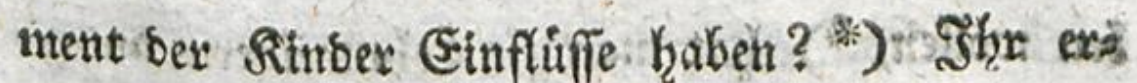
ftes Gefufhl ift ein Gefifhl bon Sdimerg and

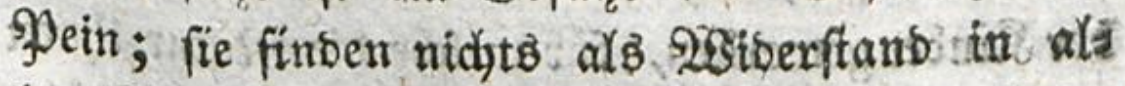
len Bewegungen, bie für fie Sevirfinifí fint;

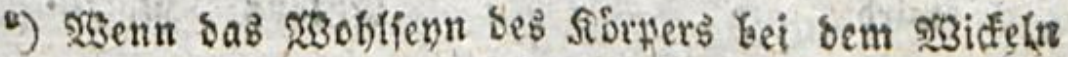
auc) gar nicht in Setrachtuting fáme: fo ware bies fer cinzige.(Bruno - oer unfáugbare Ed)aben, Den Die iunge Eeele bes Sindes bavon baben muß ishon allein enticteibent.

Sampe.

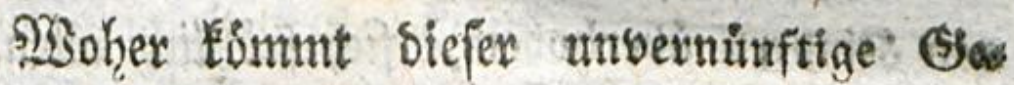
braudi? 2us cinem anbern unnatirlidisen Sebrats d)e. Seitbem bie Mitter, bie exfte ihrer Wflidyten veradjteno, nidgt methr thre Sinder baben ftils $F_{4} \quad$ Ten ftrengen fie fich vergeblic) an, exgrimmen, fchreien. Shre exfter Laut iff, fagt ihzr, nen. Das glaube idy wot; the thut thnen won ihrer Geburt an wehe; bie erffen Gejdente, bie fie oun ench empfangen, find Feffetn; bie erften Begegnungen, die fie erfahren, Martern. Da thnen nid)tz freigelaffen if́, alob bie Stimme, soaxum follten fie fict) ihrer nidft bestenen, fid zu beflagen? Sie fdjreien íber bas $\{e i b$, sas ifir thenen anthut: fo zufammengerabelt wirbet. flye nody lauter fdreten, ałb fie. 


\section{8}

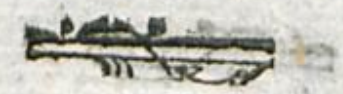

len wolleth, ") kat man fie Eohntoibern ansers

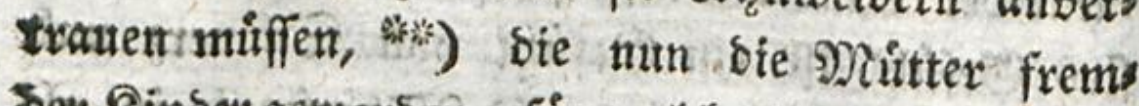
ber Rinver getworben, fir weldbe die Natur thrnent nidyts fagte, ans die nur gejudyt ḩaben, fich Múbze zu erporen. 2luf ein in feiner Freiheit getars

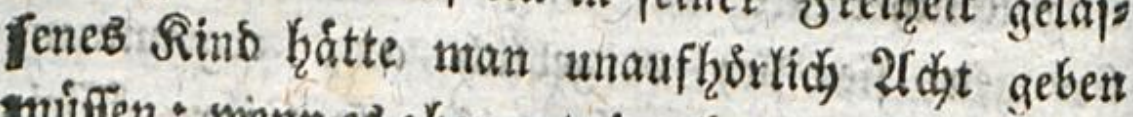
sinffien; wenn es aber gut eingebunben tf : fo mirft

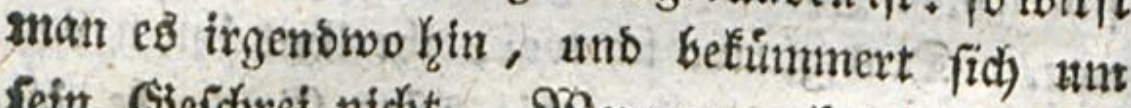
fein Sefdret nidjt. S2Benn nur teine Bemeife

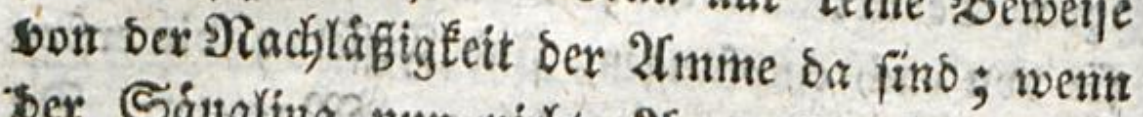
ber Saugling nut nidyt 21rm ober Bein zers bridjt, wab Yiegt benn baran, of ex umtumme, Dober feine Ribrige Sebensizeit findurdy trántlich

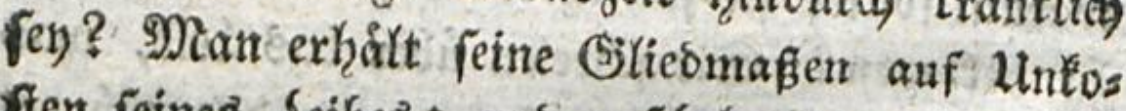
ften feines Keibes; und gefdjehe bent was oa soill, fo ift bie Afmme aufer Sdguld.

Diefe fanften פRittex, Dic, ber Laft mit irs

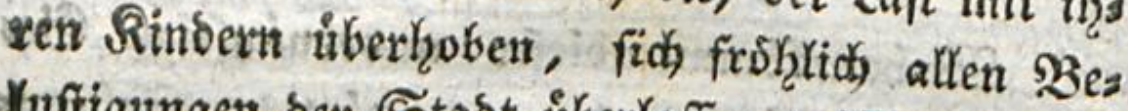
tuftigungen ber Stabt uberlaffen, wiffen fie, wie unters

Y Dak bas Einwiđeln baher entiprungen fen, bưffte fdiwerlich errwiefen werbent fonner. Diefer (Sebrantich ift auch ba Sitte, wo nicht an $\mathfrak{A}_{\text {mmen }}$ gebache soit'.

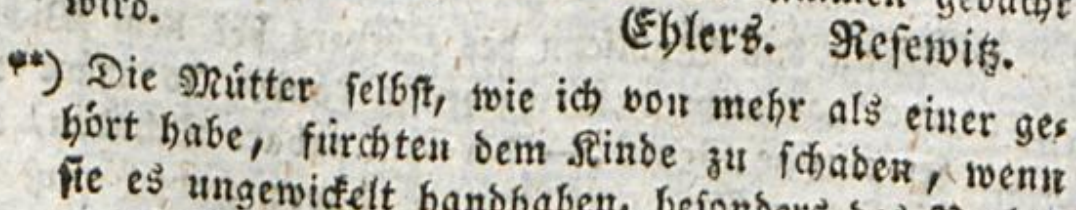
fie es ungenidelt handaben, befonber's bes Nachts ait bie Şruft legen toolltent.

Traps. 


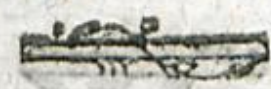

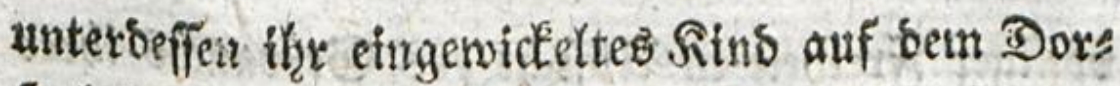
fe behandelt wito? SRuft irgend etwas die 2lmme ab, fo hadugt fie bas Rino, gleidh einem SBálíd) biuroel, an einen Pagel; uno bas arme Sies fojopf bleibt fo gefreuzigt, fo lange alo bie Znme, vhne fich zu úbereilen, ibr. Sjefchaft abs soartet, 2rlen benjenigen, bie man in oicfer Eage gefunden, toar bas (Sifid)t braum uns

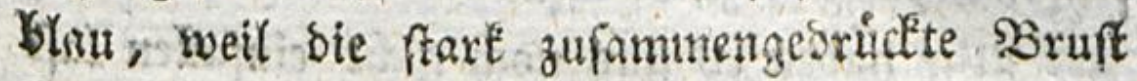

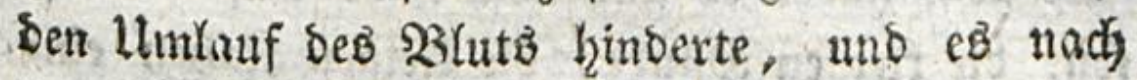
Dem fiopfe zutrteb. Şndeffen glaubte man oas

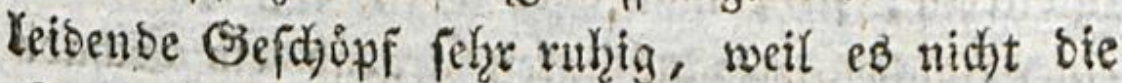
Sirnft hatte zu fdureicn. İh weif́ nid)t, wie biel Stumben ein Sino in foldhem Buptanbe bleis ben tann, ohne bas keben zu verlieren; abex (id) zweifle feha, baf es ihn lange aush ålt. Dies iff, glaube idj, einex ber grofiten Dienfte, ben sos Einmideleln leiften tann.

Mcin behaupter, bie Sinber, wenn fie itr Freiheit gelafien wuroetr, tonnten ible Lagen nelgmen, uno burch acfäbrlithe $\Omega_{\text {Bemegungen ber }}$ guten Billoung ihrer Şliesmafen fdyaben. 2Uber bies ift eine ber citeln Bernunfteleien unferer falfichen SBeizheit, bie nie burd) irgend eine (Ers fahrung ift beftatigt worben. Ilnter ber Menge bou Rinbern, bie, bei thigern STationen alb wir, mit

$$
\text { F } 5 \text { osriget. }
$$




\section{0}

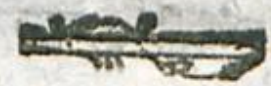

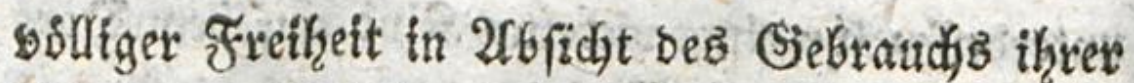
Sllteder aufwadbfen, fieht man nid)t ein einzis ges fich berwunben, ober gebredslich werben. Sie fint noch nidit in Stante, in ifre serwes gumgen bie firaft zu legen, bie fie gefähralich mas d)en fann, uno, wenn fie fity in eine getwalts fame Eage werfen, fo eximert fie ber Sibmer: fehre balo, foldie zu ärbern.

2Bir haben es uns nod) nitht einfallen lafs Fen, ste fleziren Shunbe, die fleinen Riazen eins zunoide'dn; fieht man aber wol, baß̈ thren aus einer foldyen Niadslägigteit trgeno ein Sdjabe erwådit? Die Rórper ber Rinber finb fduers falliger; wabyt! aber bagegen fino fie aud vers

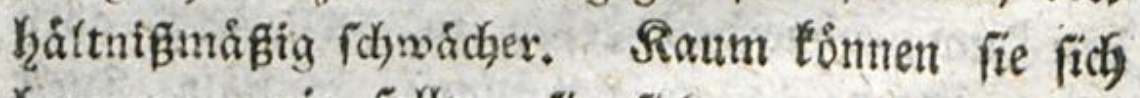
beweren, wie follten fie fich verrenken? Segte man fie auf ben Ricten, fo mirben fie in bies fer Lage, wie bie Sdyftotroten, fterben, ofne fich) irgetro umwenten zu És̆nen.

Dod) nidbt genurg, baf bie $23 e i b e r$ anfges hort haben, thre Sinter zu ftillen; fie fangen an, iberhaupt teine haben zut wollen. Die Fols ge ift fefzr natirlidy. Sobals ser Mettterftans fir eine laft geadjtet wiro, filloet man balb bas 9)ittel, fich ganglid, bavon zu befreien: man verridgtet ein gewiffes Gejobift Meler frudytlos, 


\section{m}

Itta es immer wieber bon netrem anfangen fut E⿱onnen; unb wendet bea গReiz, Der zur ßerbiels

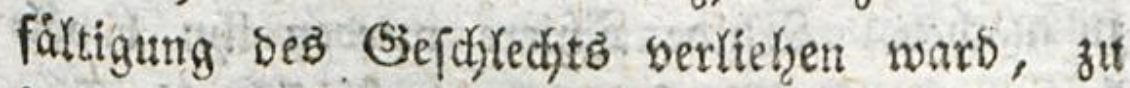
Deffen Nadbtheile an. Diefe Siewohntheit, in 23erbinsung mit ben übrigen Hrfadjen ber Ents bsrkerung, bertúnoigt uns, was fúr eit nahes

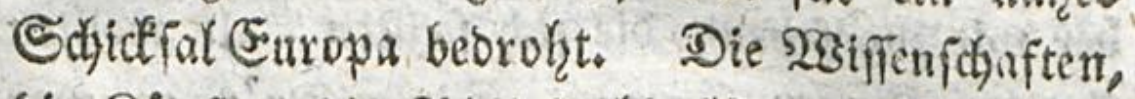
bie Siunfte, die Shlitofophite*), uns sie Sits

- Ein fefr ungerectiter 2fuzfall auf die sisifientichafs ten. 2fber freilich follten bie herumfdivármenben Shivinder im Denfen, bie fo biel ttebels antiditent, ben wifbegierigen Denfern zur 23 arnung bienen

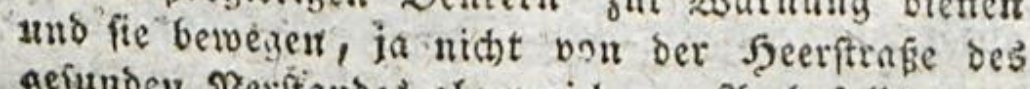
gefunden Berfitandes abjubeidjen. 2fich follte man Das moberúchtige şefen, Das menifden in fo vielen Dingen beherricht, nicht in bie willenifhaftliden $\mathfrak{A}$ :s

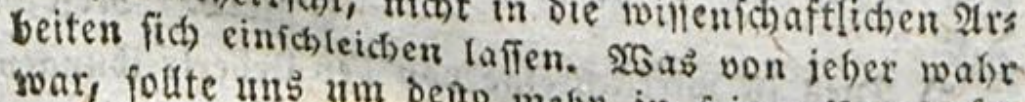
war, follte uns um bento melfr in feiner lluerínsits terliáfeit gefallen. Webe alfo freitich ben Nenf ichen, wenn bie ssabrheit in ihrer sefitalt ibinen zut altmobich wirb, und ween fie bem Jittbum blö Ser netten. Form wegen nadtaufent und ithm bers Namen der şabrheit andictten! Gollen aber bie 2 Bifienichaften uno bie $\$$ bilofophie für bas búpent,

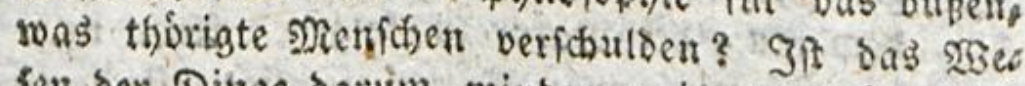
fen ber Ditrge sarum minber ewig unberánberlid

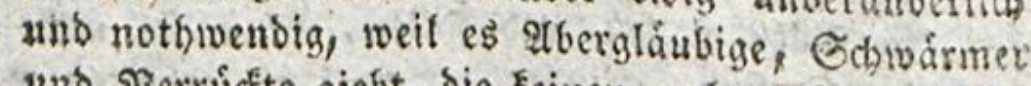

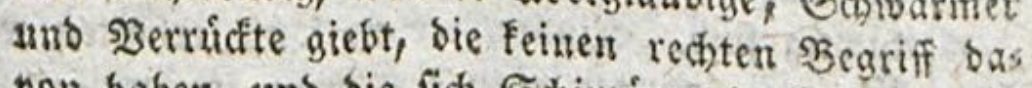
von babent, umb bie fid Edimáren benfen, worit alles unter einanber und mit ben Befekent ber Mígas

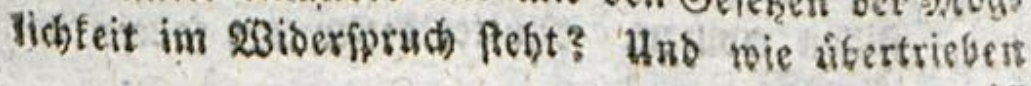




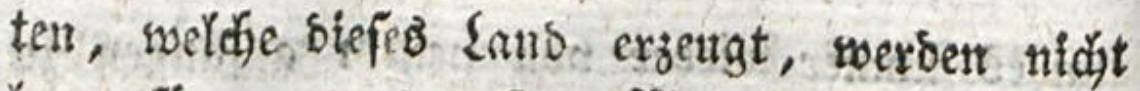
Yange făumen, aแz unferm 2 Belttheile eine 283 ifte su madyen. SBitoe Thiere werben if̧n bevơts

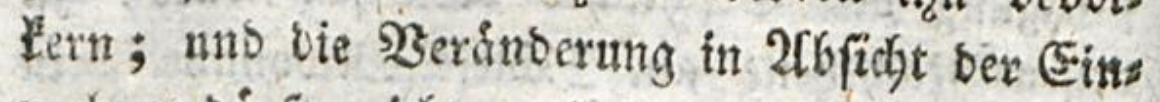
wohner birfte nidgt groff fenn. *).

(e. Sh) habe bisweifen ber Biererei jutnger 23 ei. ber mit zugerehen, bie-fich ftellten, als mollten fie ibre Rinser fäugen. Sie wiffen's zu mas d)en, Daf man ifuen anliegt, biefer Sirille zu

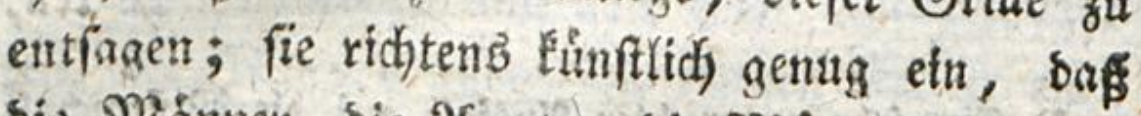
bie Mianner, bie 2(erzte, bie Mrutter injonbers beit bazwifhenfommen. **) (Ein Siatte, ber's

wagte;

it zugleich bas, was er Gernach als eine folge ber nicht geborig genikgten $23 i f i e n f(h) a f t e n$ anaiebt:

Eglerz. Refenvis.

y) Dies ift wirflith eine von ben tlebertreibungen, wels die mit ber Pregierbe ichón und frappant ju fobreis ben nidit entichulbiget werben fann.

Campe. Rerenis.

") Fei nutr zu vielen Frautert verhált fich bie Gadie genau fo, wie fie fier vorgefitellt ift. Scit cinis ger Seit fheinen iesod bie \$rútter im osanzent mefr

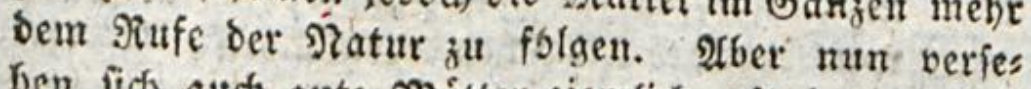
ben fich auth gute Mhitter siemficts oft barin, baś fie pitllen wollen und fitfen, went fie nicht baju tíchtig fint. Sinder, weidhe fonft exhalten werben fónnten, fommen eben besivegent um, weil gu fidivas dhe uno zu twernig gejunde Mritter burd)aus fie felbft fillen wollten, maitter biefer att follten bods bex 


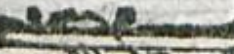

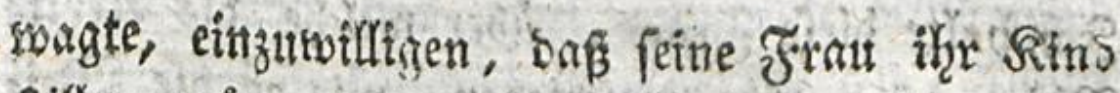
fifllte, wire eti bexlohrner Miann. Ex múroe

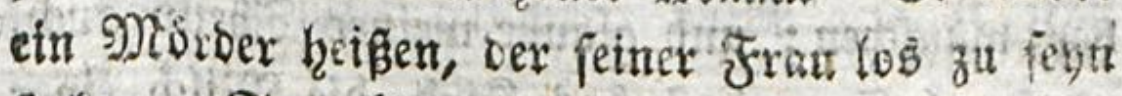
fuchte. Seno flug, Jreunde! Spfert eure \$o terliebe ben Şaus frieben auf; es ift euer Slúct, Daf fith auf bem lanoe enthatt famere sgeiber, als bie eurigen, finden! Fod) mehre habt ifgr bon Shlick zu fagen, wenn bie З3eit, woldje Stefe geminnen, niddt anbern alb elid beftimm wirs!

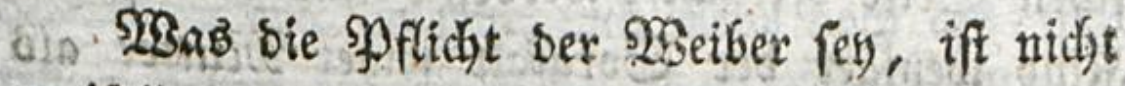
zweifelthaft: aber die Streitfrage ift nur, ba fie fie einmal hintanfegen, ob es für bie Sins bex gleidysiel ift, surch bie Mattermild ober bie Mild einer Fremben exnáţrt zu werben?

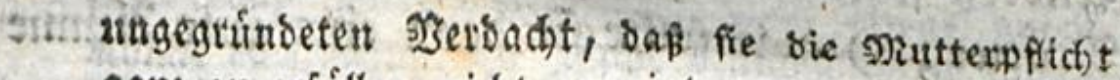
Whis ganz. zu erfullen nicht geneigt genug fenn, licber ertragen, dls ifre sinder nach tunt nach Hinfoinmen

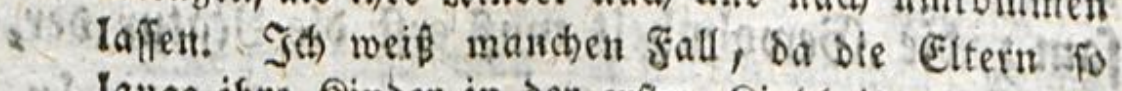

aiti. lange ifre Sinder in ber erften Sindbeit verlobren, als bie 2utter felbit fillte, und bernach fie bebiels ten, on ben ßindern $\mathfrak{A m m e n}$ gegeben untron. Bine mobifche Sittle war's, wenn man aus gefunder Pers fonen groern gefundes şlut in Perionen yon verbors benen glute fiubiberleiten wollte. Hber sie llebers tragung einet gefunben Nilch in ein Sinb if un

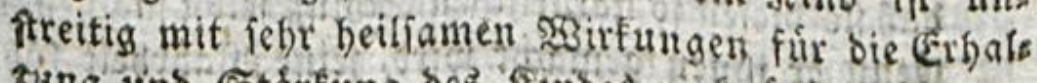
ziang und Etántung bes Situbes verfnkipit.

(5) Ter's. Nejentis. 


\section{4}

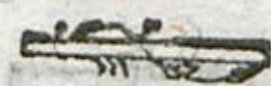

Sals balte blefe Frage, itber weldye sie Terzte Ridjter fint, fir entfdieben, wie es oie SBeis ber winfthen; uno glaube meines Iheirs aud, eB fey beffer, baf dab Ritno bie Malld einex gefunden 2 mme, als einer Nutter son bers borbener Seibesbefdaffenheit trinke; wenn es anbers yon bem Sebrite, aus bem es entiprof: fen ift, noch ein neues Llebel zu befúrchten kaa ben tonnte.

Soll aber bie Frage blof son ber phyfis f(c)ent Seite betrachtet wersen? unb bebarf bas Rino wentger ber Sorgfult fetner Mintter als three 3ruft? 2tnbere Fratten, shere logat, isment thm bie Match geben, bie fie thm bers fagt; aber bie mutter(idje emfige 3ártlict) lit ers refst nidjts. Diejenige, bie tas fitro einer 2libern fratt bes thrigen faugt, ift cine follechte S) (utter; *) wie folte fie benn eine gute 2Cmme fern? Sie wirs es twerben ísnnen, abér fangs

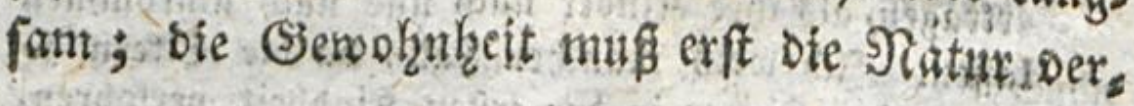

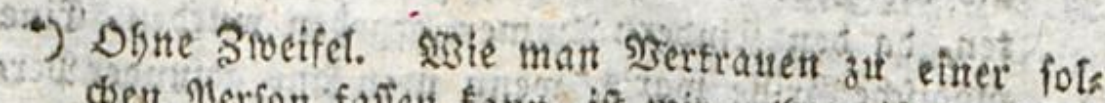
chen Perfon faffert fath, if mit utibegreific. Stber

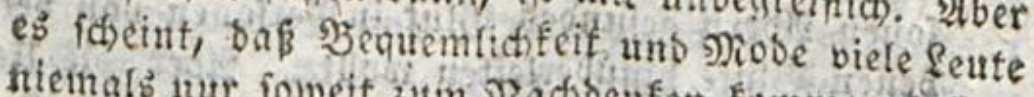

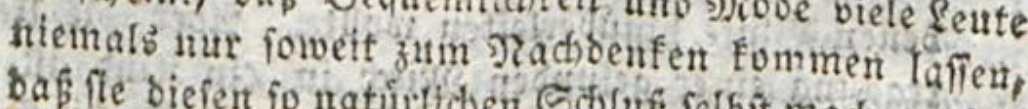

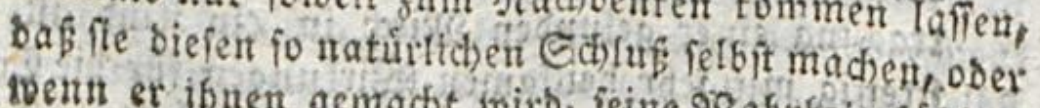

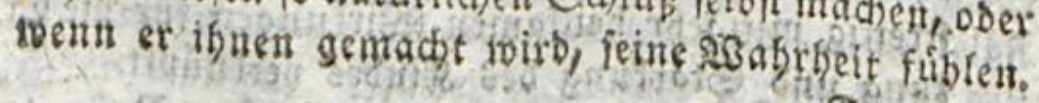
Stapp. 
anbern; Ins sas jubel gewartete Sind wiro hundertmal améommen fonnen, ehe feine 2 fmme gu einer Mutterzártlidjleit bafür getangt fern swito. ")

2lub bieferm Sortheile felbft entipringt ein Sraditheil, ber allein foun jeber Mutter won

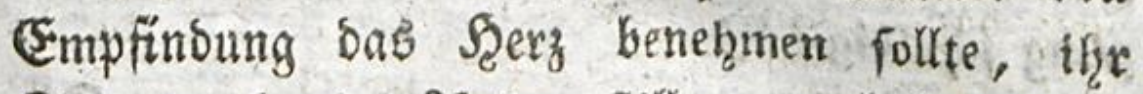
Sino burdi) eine 2Inbre fitllen zu laffen; ber

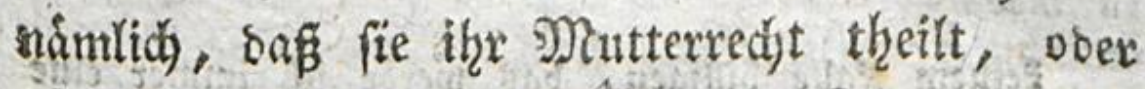
bielmehr veráufert, Dafí fie ifgr Sino eime at: Dere Frau eben fo fehre uno melgr nod) alह fich fetber lieben fefzen roiro; bafi fie es fükllen sotro,

2) Das bier (s) elagte ift nicht genug ber Erfahrung ges máp. Eine 2umme geivinnt oft fehr balb, twahre Mentterliebe fuir bas Jinb, bas fie ftillt. In ben erfien Tagen, Da fith nod) nicht eine foldhe \&iebe ges niug regt, wirft bagegen bei einer etwas guter 2rmine das (Sefúbl ber Pfficht binlanglich fo lange, bis bub Eefuifl jener art ber liebe eintritt.

Sthor wie fann man bei folcten Ammen, welche the eigenes Sind guruffekten und endern iberfaffen, um iich einem fremben Sinbe zu roibmen, Pflichts gefuibl voransiekent? 2uth ith bin ber Neimung, baß eb Falle giebt, wo eine Nutter beffer thut, ifr

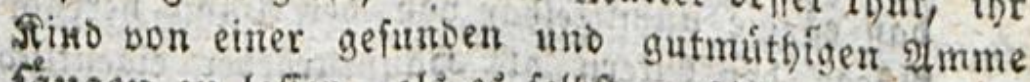
faugen ju laffen, als es feloft zu ftitlen; aber bas

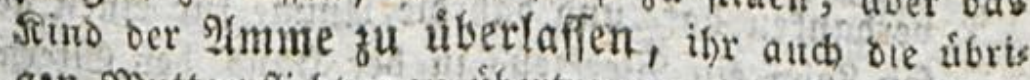
ven Distterpfichten zu ubertragen, bas fanm id) in 3). feinem 


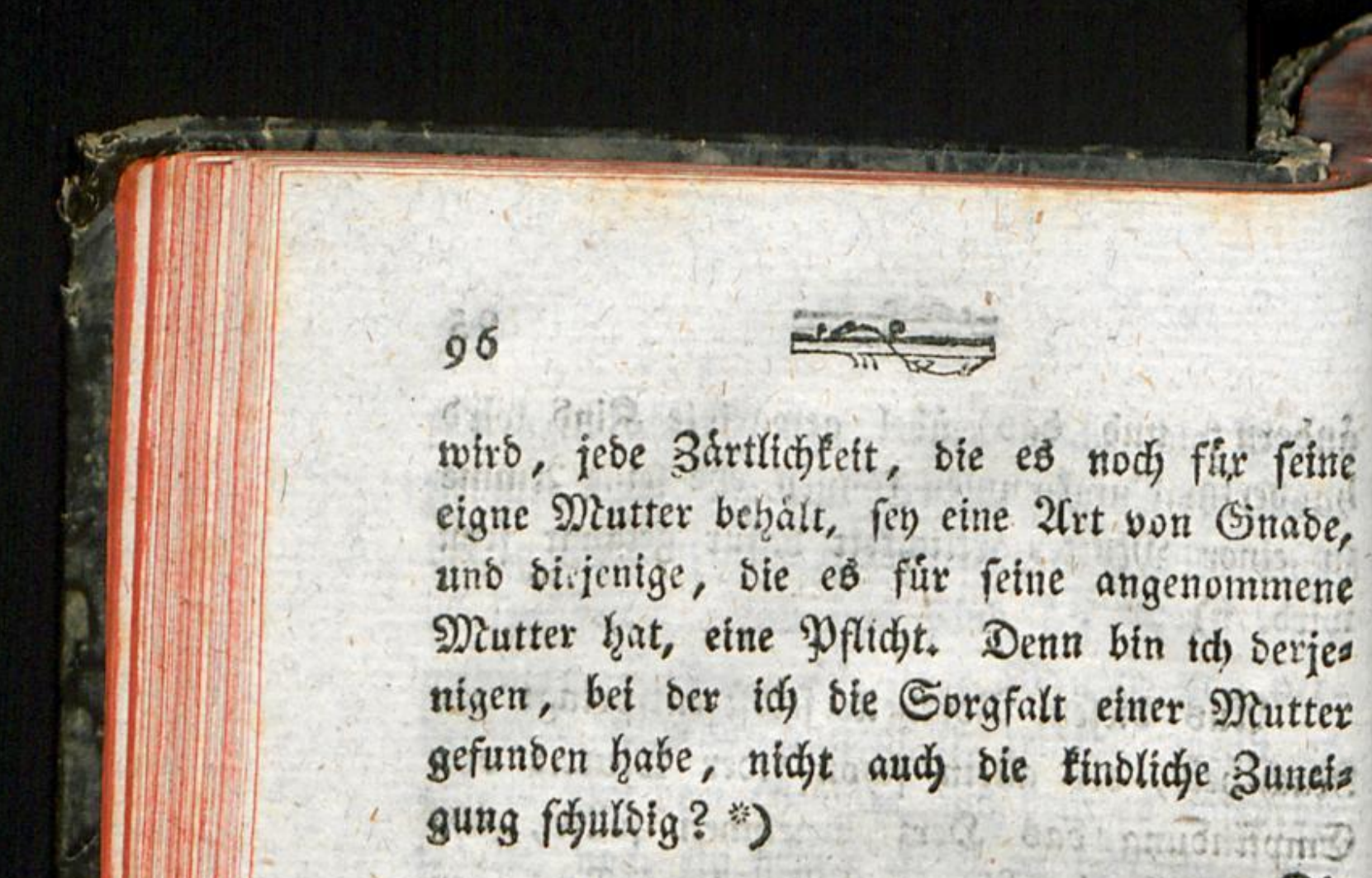

Die

Eeirem falle billigen, bas focroe ith immer eine fdwere Derfundigung an Der Nenid)heit nenten.

Campe. Refenvib.s.

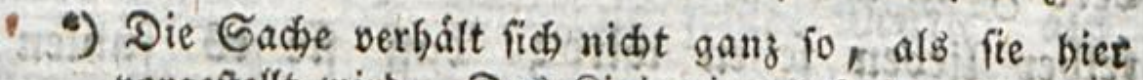
borgeftellt wirs. Das find nimmt batb wabr, oa bie Amme in \{bhängigfeit von ber sutter ftebt, bấ die Gorge uno झflege, welche sie $1 \mathrm{mme}$ ibm unmittelbar belweift, bod burch die gituter und ben S3ater veranfaltet werden, und Sab es ben Elterm feine Erhaltung und plfege alio bod zu verbanfent bat. S(t) habe Soeen ber 2 rt und bazu gébirige Empfindumgen fichtbar bei manchen von Sinmer gefáugten findern wahrgenommen. Dab eines fols

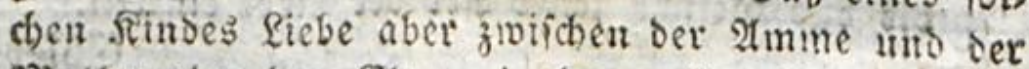
s)iutter ober ben Eltern in der erften Beit getheilt werbe, if naturfich und billig. In diefer J̧inficht ift bie $21 \mathrm{mme}$ jedo(h allgemeiner Evfabrung und bee Natur ber (Saç)e nad it eimer nadtheifigern Sage,

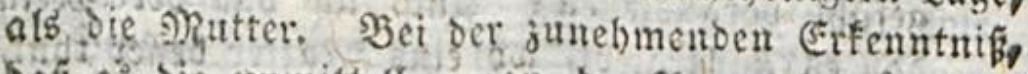
báb es die unmittelbar von ber 2 mme berribrende Dflege Den Eltern als faupturbeber eigentlich zu verbanfen bat, uns baf bie slmme fúr einent gewis? fen Sobn ein sigerfzeug in ser Sano ber Eltern ift, sreigt fich bellen Siebe genobntich lelbft oft mebr, als 


\section{돈 \\ $9 ?$ \\ Die 2rt unterbefien, wie man siefem গladja theile vorbengt, ift sie, Dafi man ben Rinbert \\ IBer}

ats es billig titi, alfináhlig zul ben eltern gant bitt soenn biefe fouft fich geforig gegen iffr Rino betras

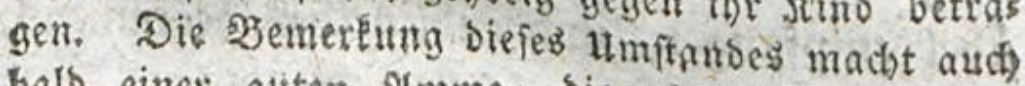
balb einer ghten Hmme, bie etwas lange beim sinse bletbt, einen eben fo bittern als gevechten Stummer, wernt fie es fufflt, bafi fie nicht fowol firt ben $\mathrm{Lohm}$, als aus einer ber Meutterliebe nabe foms menden ober ielbit gleithen fiebe ibten Saugling Derpflegte. 2uf bat Nergmigen, bas ber Nitter

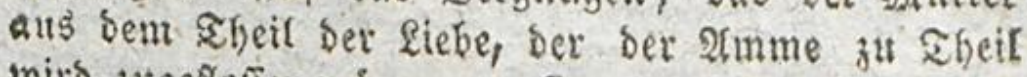
woirs, zugeflorfen wåre, twem fie es felbft geftillt batte muf abet eine verninftige Nutter, bie ifo fitno nicht anders als zu biefes Sindes siachtjeil batte

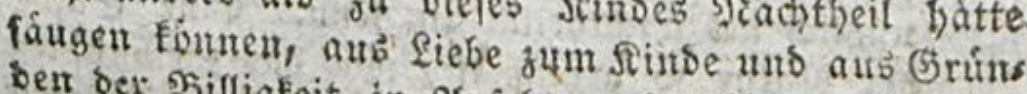

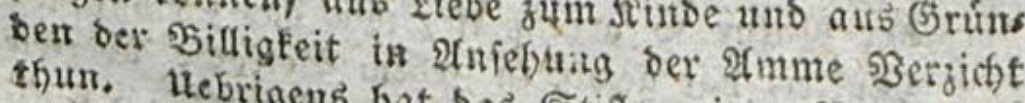
Eeiten bes

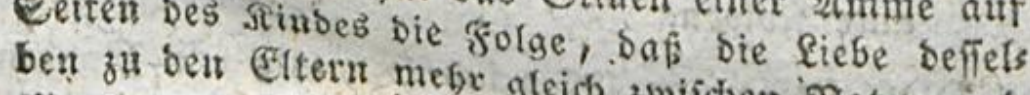

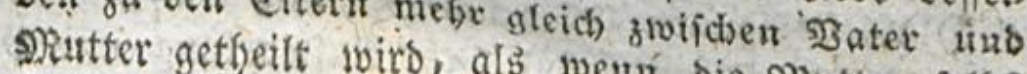
eb faugt, und auf Geiten ber mituter sutter felbft Diefe der \$erjartelungsneigung weniger unterwots fen ift.

J4) glaube nicht, baf biefe beiben Jolgen aus bem Stiflen ber 2 (mmen io naturlich entfeberr. Die

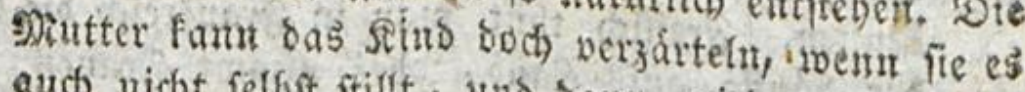
auch nicht felfit fillt, uno Danu wito es von bet Simme, Deren Serzartelungsart if m getwebritich nachs theiftger iff, uno Der Niutter zugleich verzarteit, turb wem auds bas Sinb in ben frifinefen Saibren eine grobere \$tnbátrgligfelt an bie Nutter als an Emil. Ifter 2 f. $\quad$ (3 it 2iutter als ou 


\section{8}

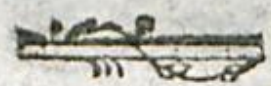

Beradjung gegen ifgre 2fmmen einflifgt; ins bem man biefen wie wirtlichen Mágoen begegs net. *) ${ }^{2} B e n n$ thr Dienft and ift, fo nimmt man baz Rino weg, ober berabjhifiedet die $2[\mathrm{~m}=$ nte; befucht fie bas Sgaub wieber, fo wirb fie ibel empfangen, uno endlich bez fiommens, um

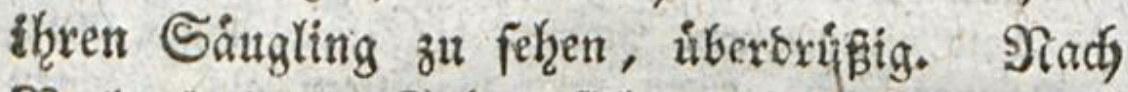
Bertauf einiger Saf̧re fieht ex fie nicht melgr, fennt fie nidht mehr. Die Mutter, bie ifrre Stelle einzunthmen, uno Die eigne Nacklafigs feit

Den Bater bat: to fabcinet mir foldhes eber gut ins niblich als nachtheifig zu fenn. Eine Eache, bie Der Niatur fo gemápi ift, roie bas Gelbitpillen der Nutter, hat gewiß in iebem betracht liberiviegend sute Folgen.

Stuve. Eampe.

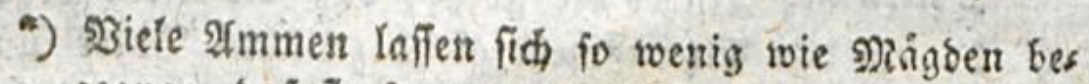
gegnen, bafi ïe fogar mehr 2fufwartung und \$fiege verlangen, als bie frau von fyaufe felfft. Sie find troķig, unverichámt, gefrápig, und wenn ifnen nidit in allem gewillfafot twirb, io gerathen fie in Sorn unt 33 th. Das mifien benn bie armen Jins

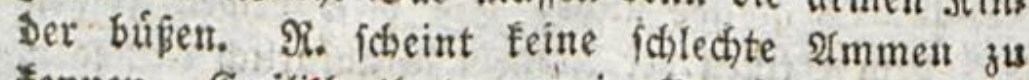
fenuen. Freilich thut man in Franfreich bie Rim Ser haufig aufs Sant, ober trimmt frauen bom Sanbe zu 2 mmen ins 5̧aus; bas giebt benu burd) sehends beffere 2 mmen, als wenn fo viele bavou Şuren iuno. Diefe leķtern baben geróbulich alfe doie obgenannten Febler und Daun oft noch benerif fhe frantheit und Sott weif was fonft obenein. Srapp. Refewis. Campe. 


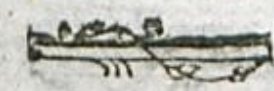

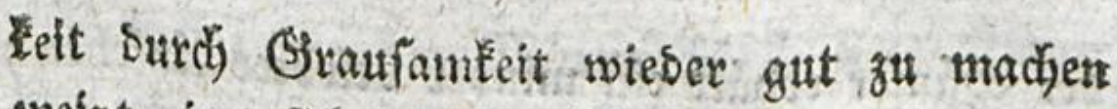
smeint, irrt fich inbeff. 2Cnftatt aub einem uma matiotidyen Sisuglinge eimen zårtlichen Sohn zu

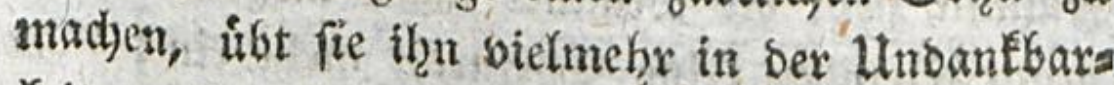
Feit, fie Yehrt tha einft bie serachten, bie thym bas Leben gab, fo wie bie, bie ifhn mit ihs ver Milch sefätrget hat *).

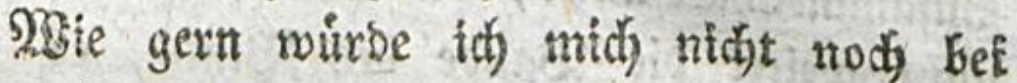
stefem Suncte bermeilen, wie Sringens babei werven, wenn es ein minber nieberfálagendes (Siefchaft waire, bergebenb foldhe nirslidhe Bes tradjtungen wieberholt anzuftellen! 2lllein bies Kzángt mit mehreen Dingen zufammen, als man benlet. $230 l l t$ if̧r Seben wieder zu feinen exfen Spflititen zuriclebringen? Fangt bet Den Nita tern an, thr nerbet iber bie Sexanderungen, sie bies berwirten miro, exftaunen. 2Cles ftams met alfmihlig aus biefer erften 3 Berberbnif her: sie ganze moraltifje Sronung wird bertefgrt; bie Natur extifdyt in alfer Serzen; Das Sinnere

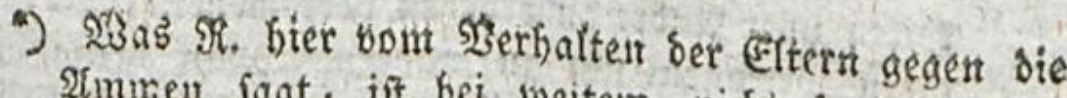
2lmmen lagt, ift bei reeitem niffit fo allgemeir 1waht, als man es nach Der $\mathfrak{2}$ rt, twie er bavon res Det, glarben follte. Es indet geivíg in der aróserri

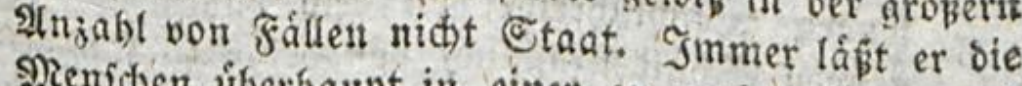
Mienfichen riberbaupt in einer zu nachtheiligent un bojen Eoptalt ericheinen.

Giblers? 


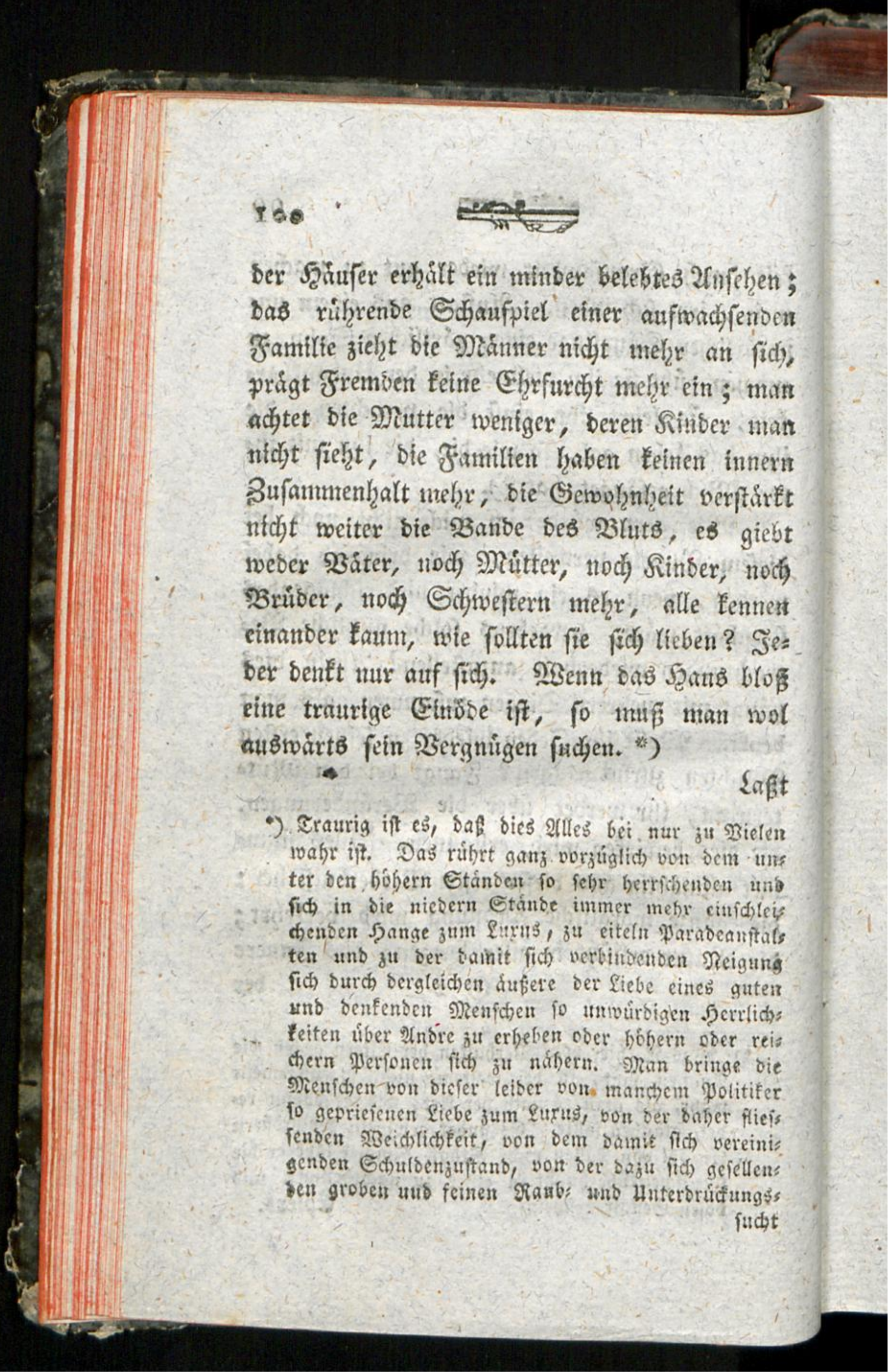




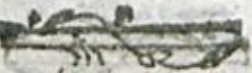

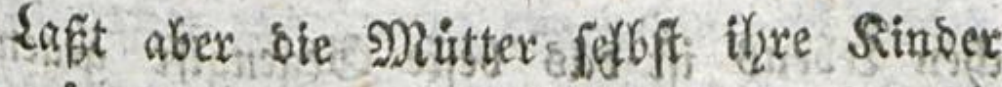
nutr wirroigen, fie zu fillene fo werben Die Sitten fid won fids felbft fidon werbeffern, bie Empfindungen Der Natur in aller Syerzen aufs soadjen, oer: Stant fich wiebertin bebsleern; biefer erfte Yunct, Diejer einzige Pounct, miro alles vereinigen. Dả 2 Inzietzense bes hăublis

$$
\text { (5) } 3 \text { क्या }
$$

fudt uns bon ber grofen Edaak anberer Hebel, bie Folgen savon fint, zuruis, uns, man forge sermits telit eirer guten Enjiehingseincicbtung und einer cintachen den Datureiniehtungen gemâfen- Sebents

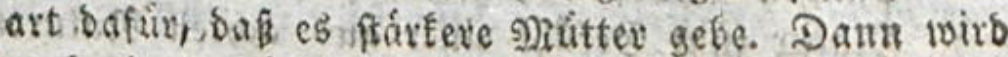
aud ein fo bosh ft anftopiger háusticher suftand, als Gier gefchilbert ift, minoer uno minder unter ben

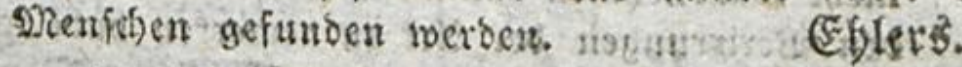

So viel mir befannt ift, findet in Deuthchlans ein foldher 3 ufano nur in oen gréften Etábten uno auch ba mix bei einigén toénigene teht vovitefmen

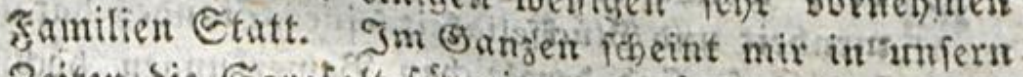
Beitent bie Gorgfalt fît eime perminftige Ergitefung

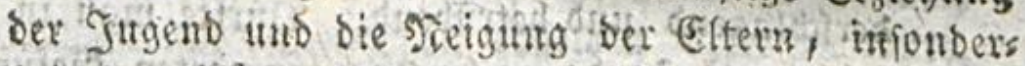
Geit bet stutter, fich felboft mit iffen sinberti zu bes fchaftigen, in ben gefitteten oset bofferir Gtánben bei weitem mefor zu als abigenommen zu babetr.

\section{Stuve.}

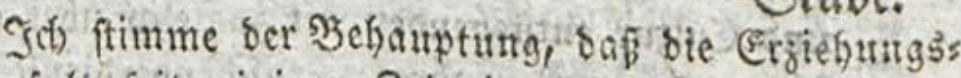
forgfalt feit ciniger Beit in ben hobern Stánden fithtbar zugenommen bat, aus Heberzeugung bei; aber es finb mir bemobngeaditef, midst nur in grofs pen Stábten, fondern auch ait fleinesi Orten, now viele Familien befant, auf welche die obige rours featrithe Schiberimg mir gar jut gut past.

Sampe. Siefenis. 


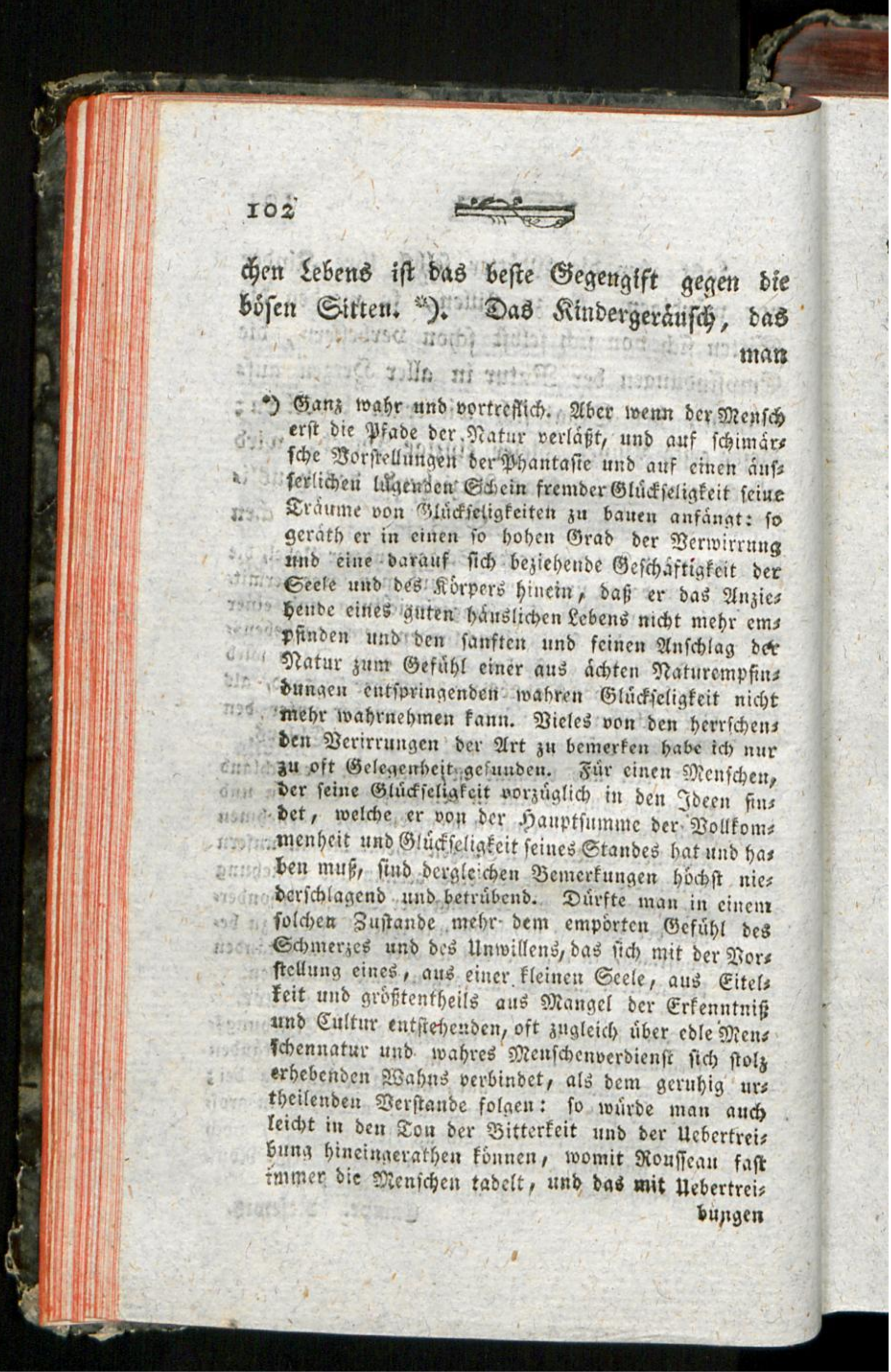




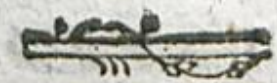

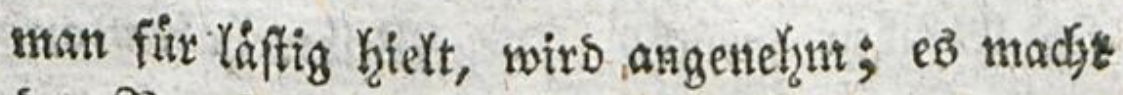
ben Sater und bie Nutter eineB Dem andert notínenbiger; es zieḩt unter ihnen bas eḩelis dhe Bans fefter zufammen. 2 Senn bie Famis Yie lebt uno rebt, fo maḑen bie ḩăublidjen Sors gen bie geliebtefte Siefchaftigung fir Die Fran aus, utto find ber angentehimfte 3eitvertretb fur Den Mann. So wirbe bie 20fockaffung bie.

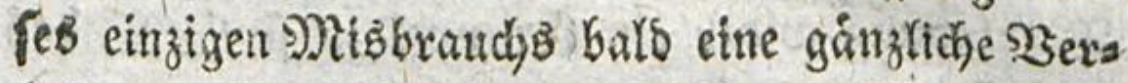
befierung bemixtéen, und bie গatur fdnell gor

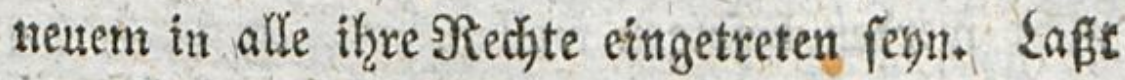
bie 5 seiber nut cinmal wieber Mnitter werben, fo werben bie Mianner aud feht bals wieber Bater uno (Satten fern. *)

Eitle Reben! Gelbft ber lleberbunf an

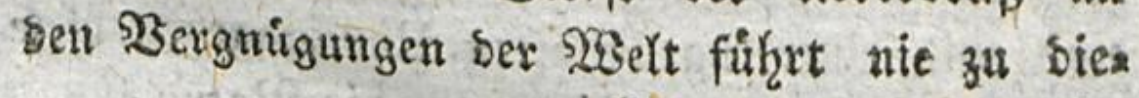

$$
\text { (G) } 4
$$

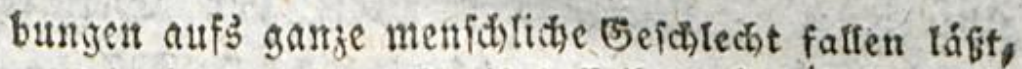
was bod) un einen Wheil beffelben betreffen follte. (E) fer:

*) Freiliक. 2tber oft muifte man auth umgefefrt fas

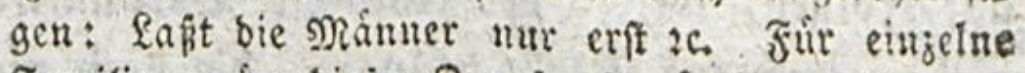
Familien wáre biejer 3 uruf oft nóthiger als jener, weil bier bie Schutb an bem \$ranu liegt; ob anth fúr ciure Etabt wie \$arib? 2Ber vermag bas zu ents itheiben?

Trapp.

Dicje ganze fthóne und wabre. Stelle mup roof

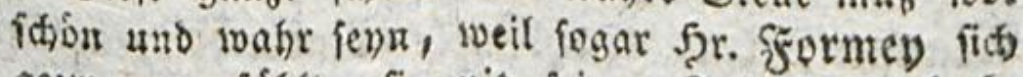
geztoungen fúflt, fie mit feinem \$Beifalle zu beełs xen.

Sampe. 


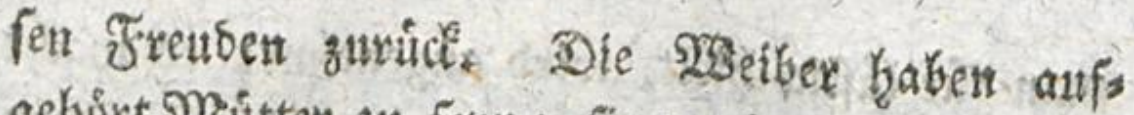
geţơrt פ्रlutter zu fegn; fie tortoen es nidjt mies ber werben; fie wollen es nidgt mefr finn. $22 \mathrm{~B}_{0}$ llten fie es fogar, fo wúroen fie es laum isnnen; Keutzutage, ba ber entgegengeferste (Sies brouch eingefubnt ift, warbe jede ben 23 tbers ftans aller, bie um fie fins, zu beforgen has ben, uno genothigt fenn, gegen eine allgemeine Sुerbinsung wiber ein Exempel zuf ftreiten, bas sie Finen nicht gegeben faben und bie 2 ndern nicht merben befolgen wollen.

(E. finsen fidy unterbefien bod nod) bismeis len junge gutgearte fratienzintmer, die es was

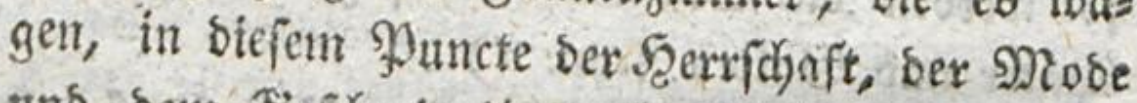

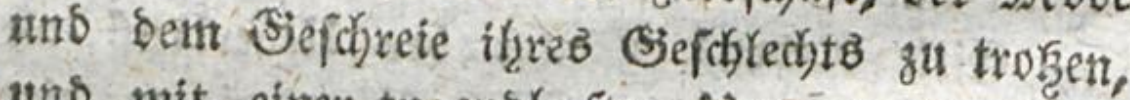
uns mit eirer tugenolgaften Utnsergagtheit biefe

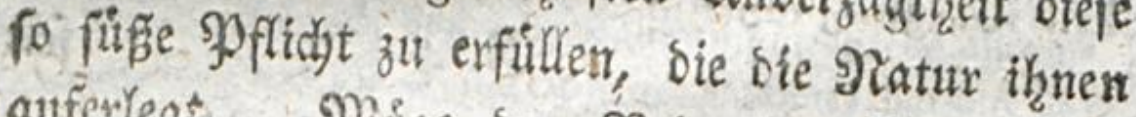

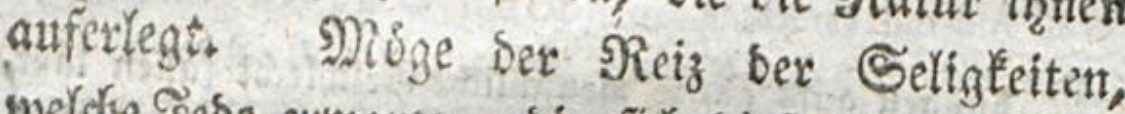
suetdje Sebe exwarten, bie fich biefer 30 fidjt iber:

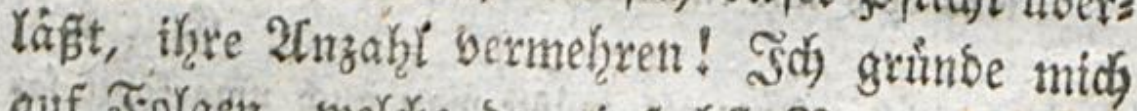
auf Folgen, weldhe ber cinfadifte 2 ermuftichluf giebt, uno auf Beobadytungen, Die nod nie ein witoriger Srrfolg súgen geftraft bat, uno getraue mit Daraus biefen wivbigen Mlüttern; eine fefte uno ftanshafte Buneigung oon Seiten ifrex

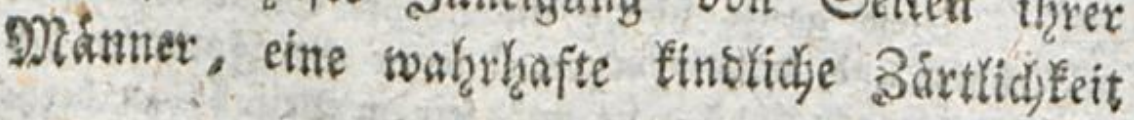




\section{$\frac{\operatorname{los}}{\operatorname{mit}=8} \quad 105$}

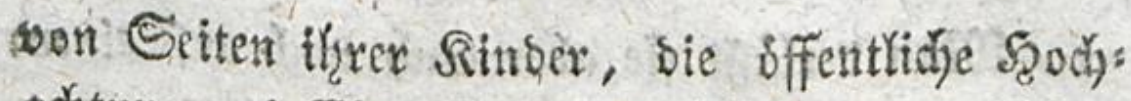

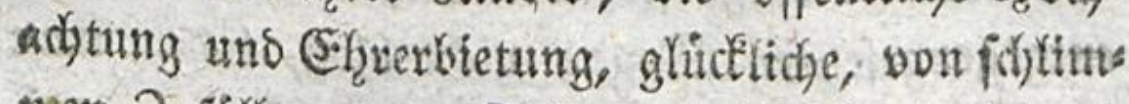
men Bufallen uns Folgen freie 5 gochenbetten, etne fefte uno sauerhafte Eefmobeit; tnto eno:

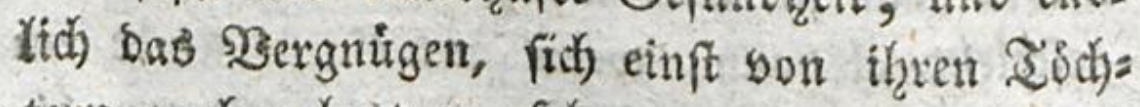
tern nadjgeahmt zu fefgen, uns als ein Şeis fpiel fir bie Iodjtex Anberen angefifint zit wer. Den, zu berheifen. *)

15 Reine Sutter, Eein Sind! Die Yyftiditen untex ihnen find gegenfeitig; und werben fie oon ber einen Seite foblecht exfillt, fo werben fie son ber andern bernadylafigiget. Dons Rino muf feine Mntter lieben, ebุe eB noch die Şers binslidgteit bazu tennt. $28 \mathrm{enn}$ bie Stimme bes Shuts nidgt Durds bie Serwohnheit uns Dienftleifrungen geftartet worben ift, fo extif(j) fie in sen exften Jabren; uns sas Seerz firbt, fo zu fagen, efce es gebolgren nirb. T2Biv fins alpo som exfen Sdyrtt an aus ber פintur heraus.

\section{(5) 5 92)}

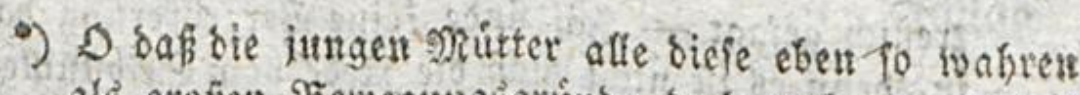
als gropien Şelvegurgsgrimbe Doch, recht ju Serjer nefimen mógten!

4*) Das hier. Befagte if fo widhtig, bap feime Rutten ofue Noth ifr. Sinb einer 2 mme zum Săugen un

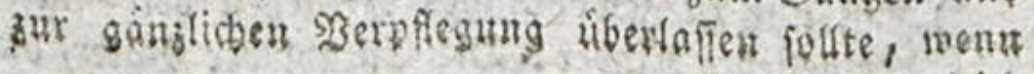
gleich 
S) entgegengefesten Wege; nicht blog, insem mars oie Mitterborforge vernad)lafiget, fondern auth indem man fie ubermåfig weit treibt. Dies

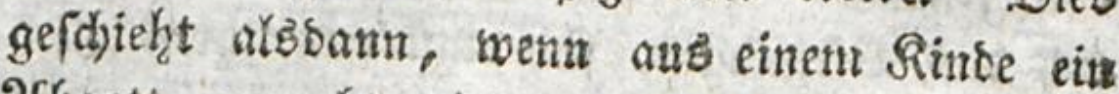
20gott gentadyt wirb; went eine Mutter bie Sid) waidie deffelben bermeb̧rt uns ernaffrt, un

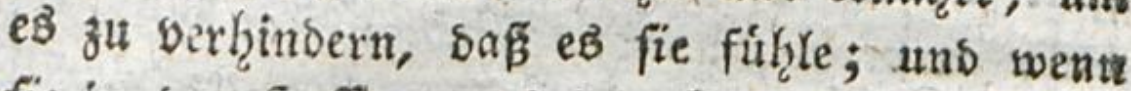

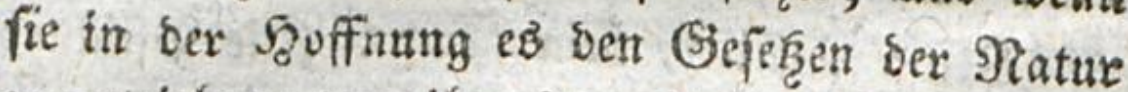

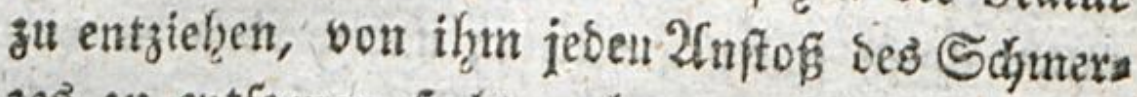
zes zu entfernen fucht, ohne zu bebenten, wie felgr fie, weil fie auf einen 2 uggenblidi lang ets nige Ulnbequemlichteiten von ifgn abwenben will, itt ber frerne fojlimme 3ufolle uno (S)efahrets ibnt bereitet. 5s ift eine barbarifice 90 orfidjt, bie Sdyruadje set Sinskgeit fo zu verlängern, saf fie fich nody zu bem gefelle, was gebilbete

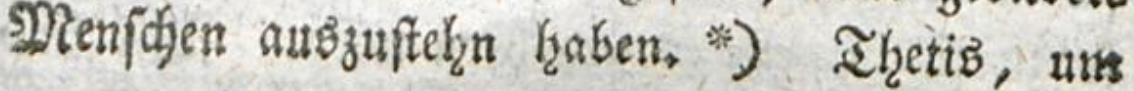
iffrent

gleid bie nachtheiligen folgen bes (3) egentheils auth bier vergrópert Mwáren.

Esbler:

Ia wor wichtig - unb burdiaus wabr uno vors

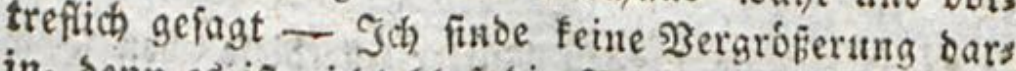
in, benn es ift nicht blofí bie Rede vom Selbptitllen, fonbern bon bem ganzen ltmfange der zu exfillenden Nutterpflicht gegen bie fleinen Finder.

Stuve. Eampe. Sieferviţ.

a) Eit nut au getvófnliches \$ergehen ber Mlitter wia Der getiebte sinber! Die Amjabl ber \áter, bie auf

bie 
iffuen Soķn unberwunobar zu madjen, taudjte than, wie bie Fabel fagt, in bie Senvajpet bes

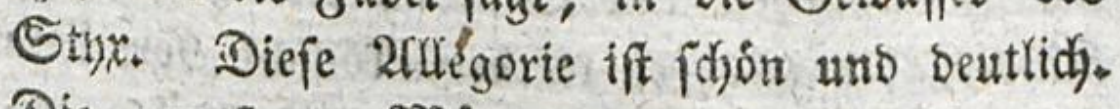
Die graufamen Miuttex, bon benen tí) rebe, thun bas Siegentheil ; fie taudjen ifgre Rinber in sie SRBeidylidsfeit, uno bereiten ihnen baburds Eeiben; iffnen fir fie bas Ihor zu Uebetn jeber 2 rtt; beren Seute fie, exwachjen, gemí̈ fenn werben. *)

Beobudjtet bie Natur; uns serfolgt Dets भyfas, ben fie end sorzetdnet. Sie ibt die Rinber beftándig; fie härtet ihre Keibesberdjafe fenheit surch mannigfaltige \$rúfungen ab; Tie Yehrt fie fruilzzeitig, was \$lein, was Schmerz ift. Das 3ahnen bringt ihnen Fieber zuweģe; fiharfes. Baudhgrimmen mad)t ihnen 3uctungen; anbaltender Şuften fideint fie exfticten zu nols Yen; bie $\mathfrak{B u r m e r}$ quâlen fie; Bollblitigkeit entzinbet ifrr (Seblit; veridjiedenartige Gali:

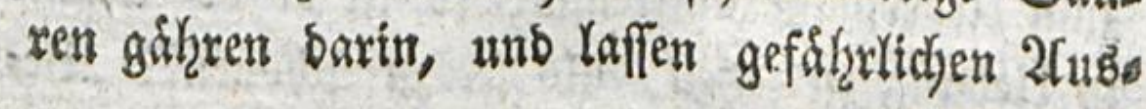

fd)lag

sie Ert felbff fehlen, ober bie Sache ben Nittern

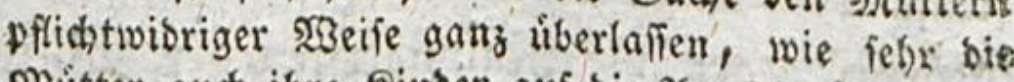

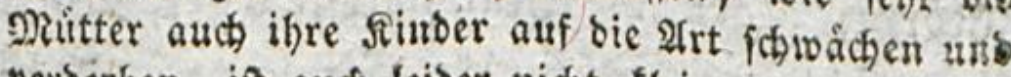
verberben, ift auds leiber nicht flein.

(Eb)

9) 23abr und vortreflich gefogt: हamp? 
fotlág herborbredsen, Faft bas ganze erfte 20ls tor if Rrantheit uns (Siefahx; bie Sedifte Der Rinber, bie gefohren merben, formut bor bem adjten Saf̧re unt, Sins aber biefe જुorifungen uberfanton, fo if bas Sind su Sitaften ges rangt; unb fobuld es feines Lebens gebraiticten ann, fo wiro ber Sirumbftoff beffelben gefis d)erter.

Daछ ift bie Regel ber 9atur: 2 garum banbelt man thr zumiber? Sieht ntan nidht, bag, trbeut man fie zu berbeffern gebente, man iffr תgert zerfort, uno sie 23 intungen, sie fie

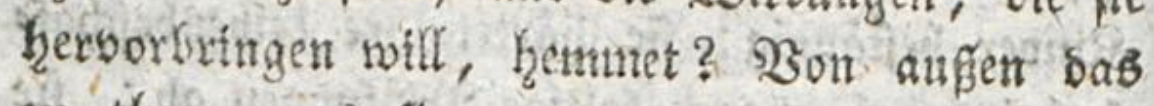
zu thm, was fie bon inuen thut, heift, wie gement wirs, bie Sefahr bersoppeln; no bills mehre lentit man fie basurch ab; man vermins bert fie. Die Erfobrung rehrt uns, Saf nod mehrs zatutlid ergogene sinber, als attove, fters

- ben. gुßufern nan nur nidit if̧re Rráfte bis

- sum lieformage anfrengt; fo iff $\mathrm{eB}$ beffer, fie in llebang an feren, als fie za fdyutren. Ses reitet fie bemnad) auf die 2 uffoffe oor, bie fie einft merben zu eroutoen haben. Sgartet ihre Rorper gegen ste SRaubigleiten ber 528 itterung, ber. Simmelsfridje, ber CHemente, Des̉. Soum geroె, Des Durfts, ber Ermíbung ab; taucht 


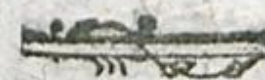

2015

Der

$\mathrm{cm}$

gett

ges

jent

efis

m

Gt,

an

fie

as

die

ils

ins

(1)

rs

โชี

fie

ies

iie

re

g,

17\%

Gt

ie

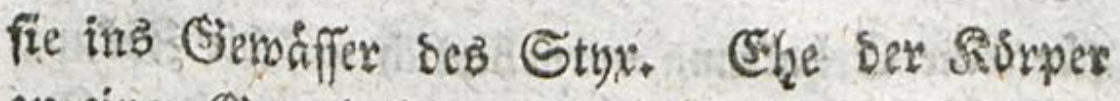
zu ciner (S)enohnhbeit gefommen if , giebt mat ifhin jede, sie man will, whye Gefabr; abes wenn er einmal feine Eonfiffenz exreidit hat; wirb jebes Ungewol̨nte ifhm nadytheilfg. Eit

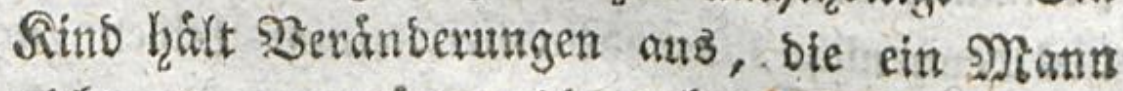
nidyt extragen wurbe: bie noch weichen uns beugs famen Gibern bes exftern Yegen fich okne Mảhe in bie Falten, bie man thnen giebt; allein sie abgethårtetern bes \$anne werben ans ber ein mal exfgaltenen nidgt ofge Eeswaltfanteit hers allegebracht. Nian Eam folglid ein Sind fart inachen, ofgne fein Eeben uno feine Siefundfyeit, ou gefafhrben; wenn aber auch etwas babet fus wagen waive, fo mifipte man bods nidjt bei fich anftehzen. Da es einmal Sefahren giebt, bie som imenfidficjen Eeben unzertrentbar fint; fant man benn mol beffer thym, als wenn mat fie auf bie 3eit feiner Dauer Kinberlegt,, wo fie ant wenigften nad)theilly fins?

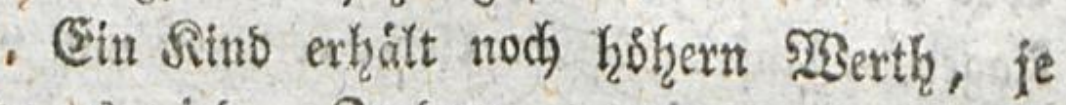
altex eB wirb. 3 u bem, was es an utto fü fich gilt, gefellet fich ber Preis der Sorgfalt, bie es̉ getoftet hat; in ihm ferber gejellt jït zu bemsiserlufte des Lebens sfe Empfintoung bes

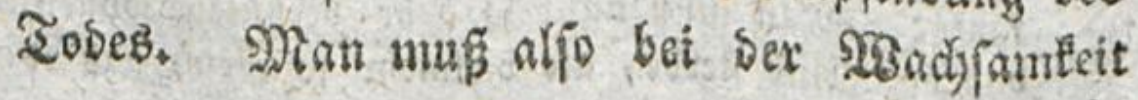
fưr 


\section{IIO}

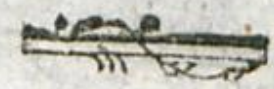

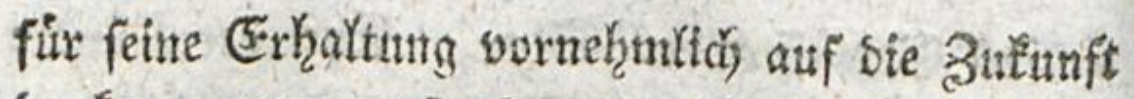
Denfen, man mu命 $C B$ gegen bie Llebel ber Sus gent bewafnen, elge cB bazu getangt ift: bent wenn ber $933 e r t h$ Deß \{ebens bis zu ben 2liter.

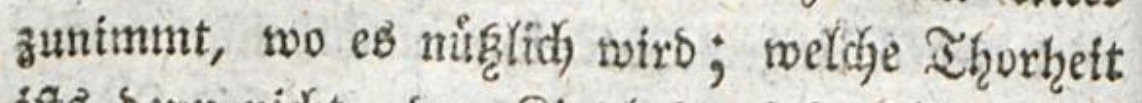
ifts benn nidyt, ber Sinoheit einige Seiben ju exfparen, und fie auf bas 20tter ber fhim aufzufammlen? Sino dab bie Eehren bes Mieifters? *)

ङ5 ift Das Loos bes Mtenfiden, an allen 3eiten zu leiben. Selbft bie Sorge für feine

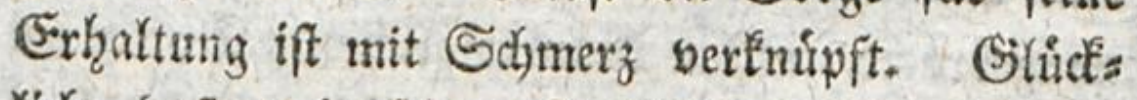

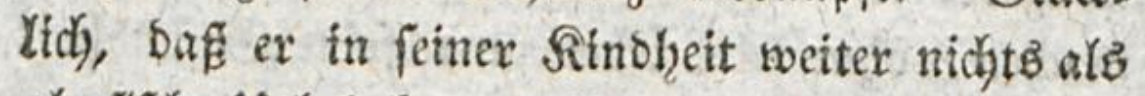
phyfificte Llebel Eennt; Hebel yon weit minder graufanter, flomerzbafter 21rt, ald bie anbern; und bie uns feltenet urferm. Leben entfagen mas d)en. Mian tóstet fich nicht um Des Bippers Yeins willen; felten bringen anore als Seelens Yeiben Serzmeifung hersor, MBir bef́lagen bas Soos ber findheit, und miers follten wir bes Ilagent. Ulnfre gróften Hebel fommen uns won uns felbft.

Fin

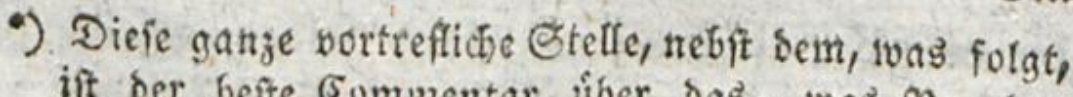
ift ber befte Commentar, liber das, was $\Re$. obert

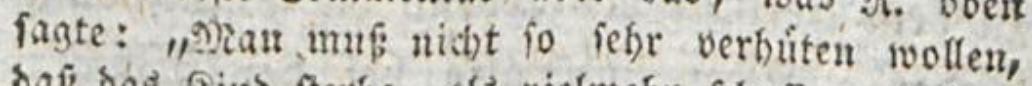

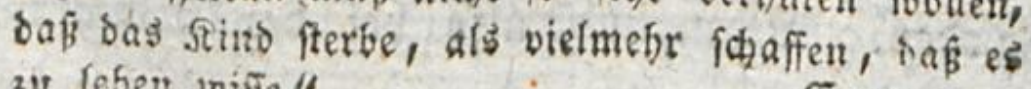
gt Teben wifife."

Eampe. 


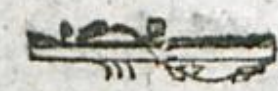

nft sus

int

ter

ett

fit

aft

es

ent

ne

$t=$

ไรี

eE

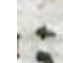

Ein Sins fojreit wenn eb gebohren miro; feine exfte Rinoheit vergeht mit 2 Beinen. Bals fasmenet man eb, liebloft ihm, un eB zu fitlen; bald bebroht min es und giebt ifm Schligge, es zum Sdyweigen zu bringen. Entweber wir thun, was bas Rind haben roll; oder wir bers langen son ifhm, was wir wolfen; wir waters serfen uns feinen Grillen, ober wir unterwer: fen es Den unfrigen; fein Dittelweg! ев тuß Befehle geben, ober weldhe annehmen. So

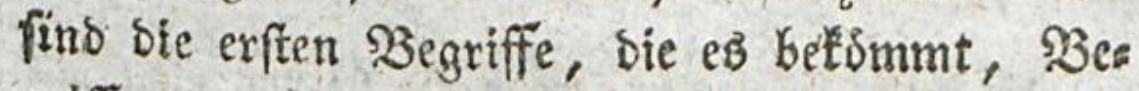
griffe son Şerridjaft uns Sinechtichaft. (E.he es

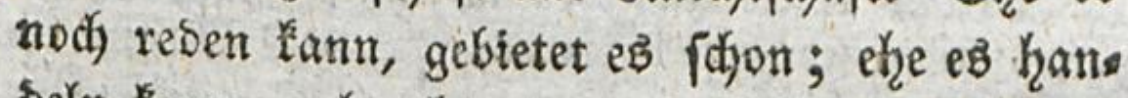

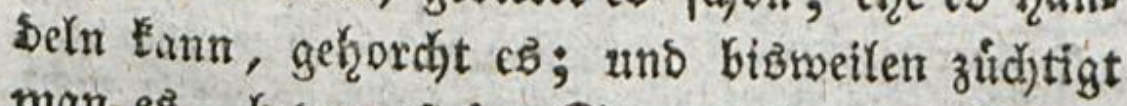
man es, bebor es im Stande ift, feine Feḩlex zu exfennen *) obex sielmebre meldje zu begeţer.

So

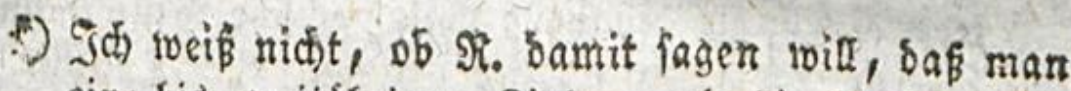

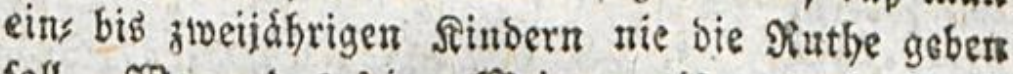
foll. MBenn Das feine \$einang ift, fo famm i申 sifm nicht beiftimment. Siurber áufern in biefer erf ften Periobe ibres Eebents bisweilen figon thrarten, Wie man nut zut inrem fúnftigen Sthaben inges ahnbet bingehen lafien Fónnte. 2afber fie Dafúr zis beftrafen, ober wenn man lieber will, fie bariber 3u belehren, mú man, fo wiel id feken fann, bišs

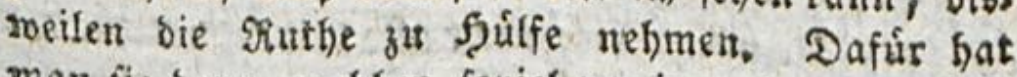
man fie benn nadher foviel weniger ober gar niwt

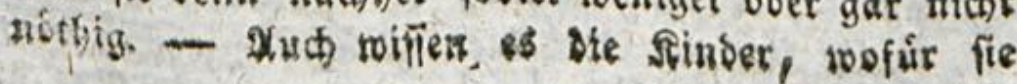




\section{12}

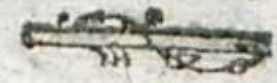

So flofen fid fetrem Eleinen Şerzen fruifzeitig

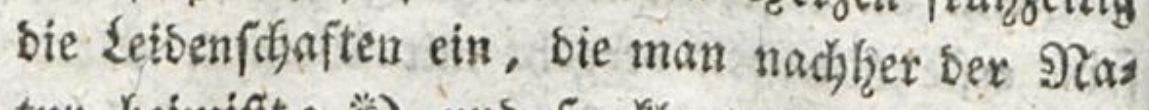
tur beimigt; *) uno fu flagt man, nadjoens man fich Mithe gegeben, es boskgaft zu machen, sariber, ธaศే man eb fo finbet.

Ein Rind bringt fects oder fieben Sabre

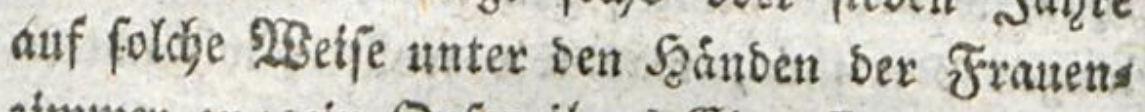
zimmer zu; ein Spfer ihres Eigenfinns uno bes feinigen: uns nacboem man eв bies und jenes f̧at

lers

Die Pinthe befommen, ivent fie fie nur nidht mit unrecht befommen, obgleich iffr $23 i f f e n$ von bene tufrigen febr verfidiesen iff.

Trapp.

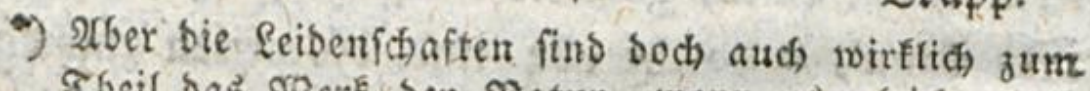

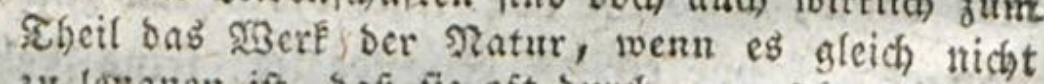

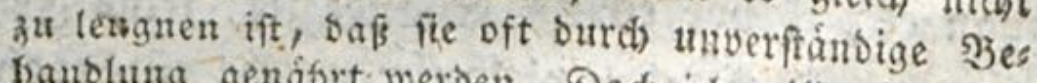
Fanblurg genafgrt werben. Dod id will mid felbft an meine aflgemeine Afnmerfung fu ber \$orrebe eriunetn und von Rouffeau, bem Reoner, nicht an. feber Etelle bie genauefte philofopgifde Sefimmung foberti,

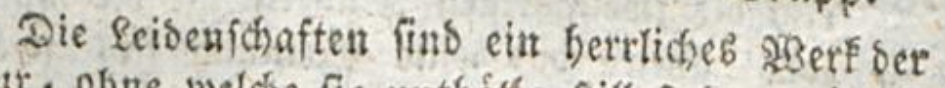
Trapp.
siserf Der
en woiree;

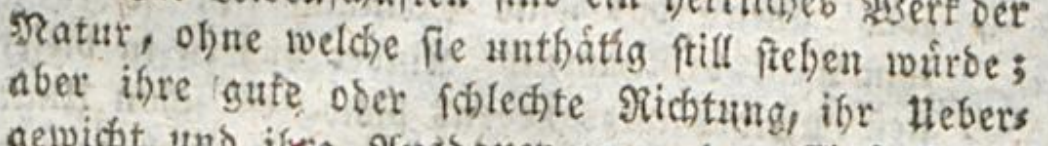
gelvidht und ifre Rasbauter gegen bent Einfuti bet S3ermunft ît bas 2Berf. ber Sernad!áfigung, Des bópen Beifipieles und ber falfchen Neinutngen ber sienidien.

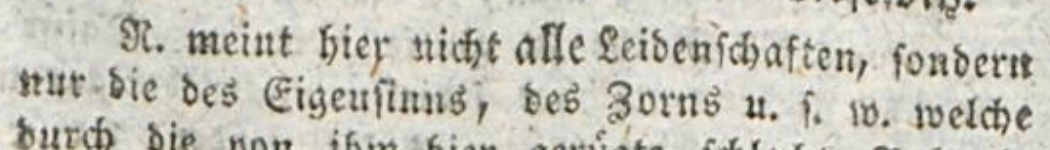
burdh bie von ifin wier getrigte jofledte Tefanbs

16 latighart eingepobt werben. Eampe. 


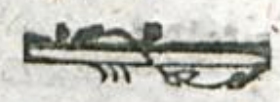

tig

as

m*

it?

re

ns

3

at

rs

it

ne

$\pi$

it

is

fit

e

it

Xernen lafien; Sas heifft, nacbsem man fein (5) bádjtnifi, entweber mit 2 Borten, die es nidjt berftehen kam, voer mit Dingen, bie ihm zu nichts Gelfen, belaben; nacboem man feine nas tiurlichen 2fulagen burch Seidenfchaften, bie man barin auffommen laffen, exfictét hat: fo subers giebt man bies gemadfte şefen ben Scanden eines Sefarmeifters, ber vollenos sie tumftichen Sieime, bie ex fojon ganz gebildet borfinset, entroidzeln bilft, uno es alles ref̧rt, nux nicht fich felbft extennen; felbftfåndigzu fenn; uno die Sumpt zu leben und fich gluctelid zu madjen zu wiffen. Enslich menn diejes Rinb, beibes Stlab und Iirani, bollgepfropft bon 2 Biffenjodaft uns Yeev an Simn, gletd) fdomady an Eeib und Seele, fich in bie $23 \mathrm{elt}$ gewourfen fieht $;$ \%) fo zetgt es

ganz

-) Seer Frormey macht zu biejer Stelle folgende pas thetifche uno gelebrte anmerfing: "Sollte fich fyerr i. wol unterftefa zu befaupten, daí diefes die Frucht alfer Eryieloungen waire, bie von ber Ere ziefung eines Emils unterichieben fint? Sollte er fict) wool beifommen laffen, in diefe \$ुerweijung einen Jetyon von surgund mit zuberwicfelt, fo tois er war, als er aus den 5 antent bes গ̧erfallers bes Telemachs fam; ober einen Dagueffeau, fo tvie feine verifbiebenen lobidriften ifn uns abbilben? it. f. 10. " 2tber fyerr formen bátte, wenn bieie Emilgegengeiek̨ten Эeifpiele betweijend fenn follten, erft beis 


\section{IIf}

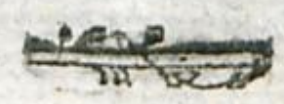

gang feine Ulntauglidhteit, feinen Stolz, feine

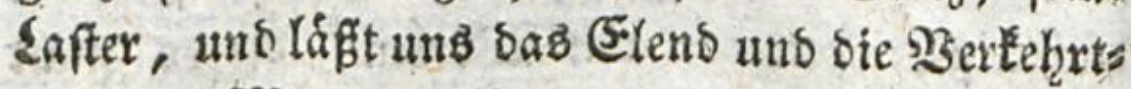
Keit ber Men[donen beweinen. Man irrt fid);

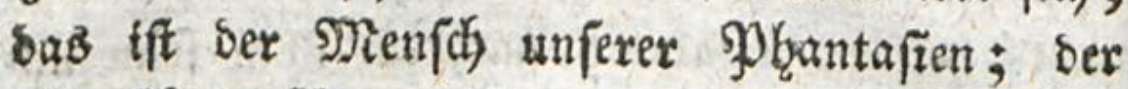
Menids ber Tatur ift ganz anbers gemadjt. *)

Wollt iffr alfo, ex folle feine urfpringlicige Form behalten: fo extbaltet fie gleid) yon bem Zugenblicte an, ba ex auf bie 2 Belt Sobals ex gebohren wirs, bemaditigt euch feiner, smo sertafit thn nidjt cher, als bis ex Maanu geworben; ohne bies wirb es eud) nie gelingen. 23 ie sie wahre 2 mme nur bie Wlitter ift; fo ift ber wahre (efyer aud') nur ber 3 ater. Ste

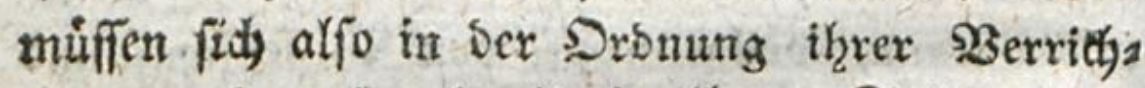
tungen eben fowol alo in ifrem Syfteme mit

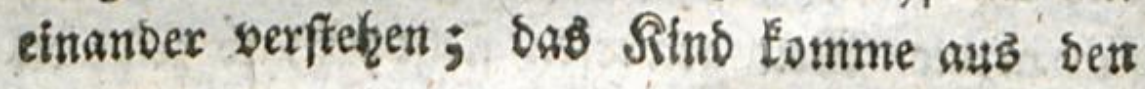

Şân

seigen miffen, baf́ man bei ber Ergiehung bes Syerzogs von Şurguno und Des Dagueffeau wirflic alle bie Fefler, weldie $\Re$. hier rigt, begangen bas be; und wern er bies aud wirflich batte jeigen fonnen, wie id ond bezmeifle, fo bátte er boch noć) bedenfén múñen, Dẩ, wie man im Sprúchs wort fagt, Etine Shwalbe noh nidt Den Soms mer madot.

Eampe.

-) Dá nur zu báafig auf bie 2Art, alङ $\Re$. es bier bee fchreibt, in ber erften Erziehung bei fleinen Sindern gefehlt wird, ift freilich wafgr; allein fo allgemein unb in fo bohem Srabe, geichieht es nicht, als ot at bem Lejer will glauben machen. Eblers. 
Sanden ber (5inen in sie Sarnbe des 2Tnbern. (E) wirs beffer burch eimen verftandigen $\mathfrak{B a}$ ter *), wenn gleith bou eingerdoralteren Rennt niffen, als burds ben gefdickteften Lebumeifter Don ber 13 elt erzogen werben; benn ber Cifer

") Schabe, etwig Schabe, baß nicht alle \$áter ver ftándig find, und dấ bie verftandigen fo jelten Darúber fern mogen, auds freilich oft gefindert werder, fich mit ber Erziefung iffrer Jinder zu befaffen! Ifun fie es einmal allgemein, to ift bie goldure Beit fúr bie Nenichbeit ba, eithe befiere golbne Seit, als bie ber Dichter, wo bie şbiffe ber Rámmer Freunde find; eine golbire Beit, auf bie fhoner Eraum!

4*) Eitern follten freilich aus bein of Trapp. (8) runde fid vorgiglich mit ber von $\Re$. angefúforter Der befchaftigen. Die widht Erziefung ibrer Jins fáke follten IBer formlich auth allen Eitern befannt fevu. ten er fich foult, mit welcheu SBifienfohafs gogif vorzuglich befchaftigte, múfite die Mádas zu mebre, als geivoffulich treiben, und wer fonft baupt erhebt, oer muifte ben Senntniffen fich úbers auf bie Erziehungsfunit riduters fein Augenmert bas, was cin, fich bem ten. Alleit barum bleibt frembe Sinder wiomender Erziefungsgefcháft fưr mit Finficht uns Enfer lid boch sgerth. Siele) leiftet, eine Sache von febr gropein werth. Dex gropte Theil der Eltern leiftet an Enbe 
2Cfer bie Siejchafte, Die Sekridytungen, bie

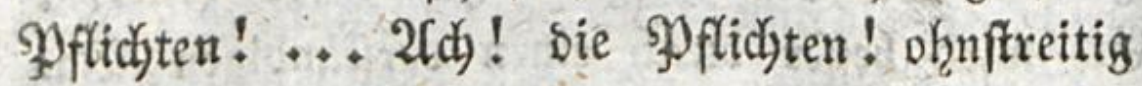

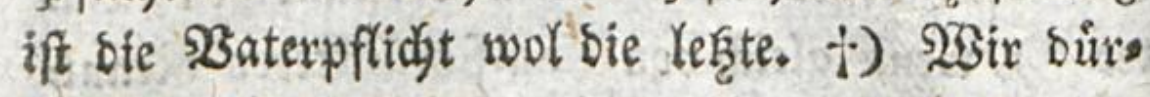

sod viel tweniger, weil theils bas, was fie in ber f̧iuritht thut, weder mit finlánglicher fiennts nif́, noch mit wahter s?eigung thun, fondern gegent ifgre Sinter to hanbeln, als es iffen iebesmaligen Saunen uno dem icbesmatigen (3)

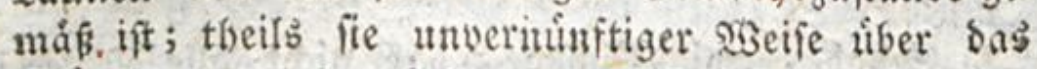
sttigeln, ras ber Seffer ober Erzieber thut, ober theils ibre Šerufgeichafte es ibnen nicht erlauben fich mit ber Erziefung ber Sinder genug zu beichaf:

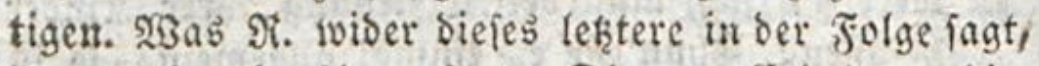
ift zu fef) obenfin geiagt. Die zur Erbaltung bies

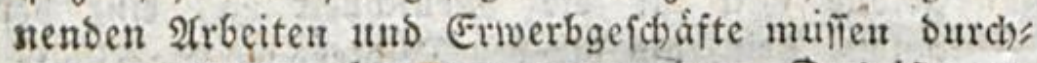
auts von (E)tern úbernommen werben. Das ift aud mit ben (ङeçcháten ber Fall, bie ber Stant cinem nibertrágt, uno die man theils aus Plicht fúr ben Staaf, theils beswegen, weil man basurd jum Şefits sist Der Erffaltungsmittel gelangt, Lfbernefmen mns. $x_{\text {. }}$

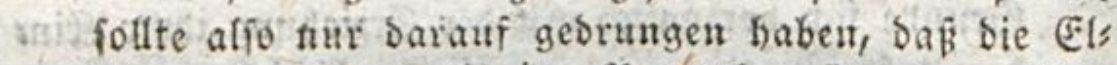
3.tritern allgemein mehr im Punct ber Ergiefung thun sollten, als fie wirffich thum. Ein fuir cinen Bogling ganj lebender Er ziefer faut faum f̧urtentobnen zu 2u Sheil merben. Der Nientich findet einen folchen A Ergicher faft nie in Jremben und farn ifon nicht

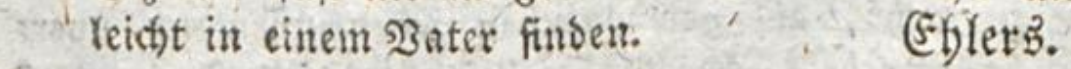

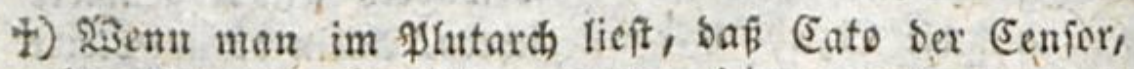
ber Rom fo rúfmlid regierte, feiren Sohn von ber ribiege an felfit aufergog; unb bas mit einer foldent

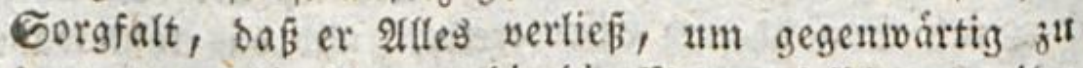

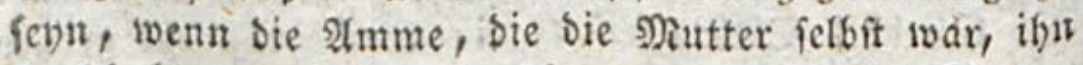
5anthabte, uno ifn wain; wenn man im Sveton lieft 


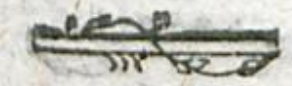

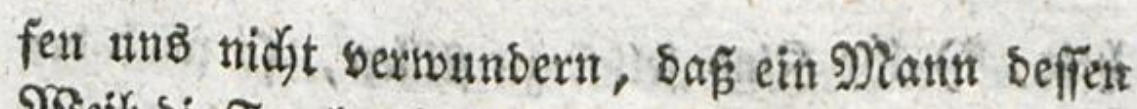
bie tig ive ent

lieit, bas Sugutt, ber Scerr ber $23 e l t$, bie er erobert batte, uno felbft regierte, feine Enfel felber bab Sdhrei-

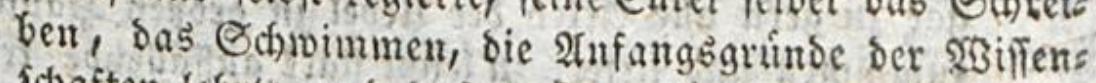

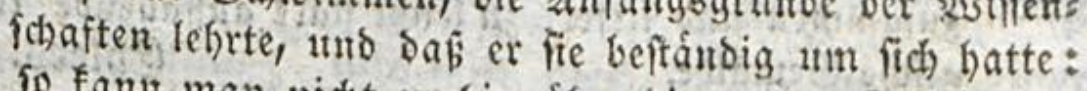
fo fant man nicht unfin fiber bie armen Seutchen jes ner 3eit zu lachen, bie fich mit folden $\mathfrak{T}$ dnteleien $a b s$ gaben, und obne sucifel zu eingefidsinft waren, ben

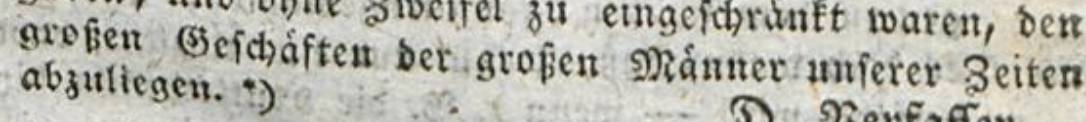

4) Ob fid Auguft aus פ̧aterifich D. Serfaffer. bejhaftigt babe, batan ift net mit feinen Enfeln

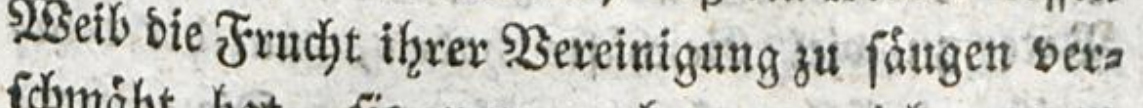
fdymabt bat, fie nun suds zir exzichen sero fdmatht. *) (5) giebt fein liebreizenderes (S) mâhlbe, als eine Framilie; wirb aber nut eft Bug verfehlt : fo find alle librigen serunfalts

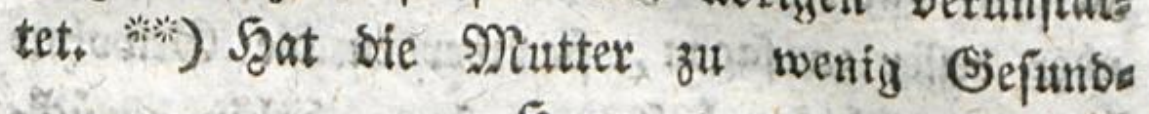
Fु 3 heit, Ge daftigt babe, baran ift noch zu zroeifetn.

\section{Niefewiz.}

**) Ein fefor wafrer (5ebanfe! W3etri id mir sen Fall

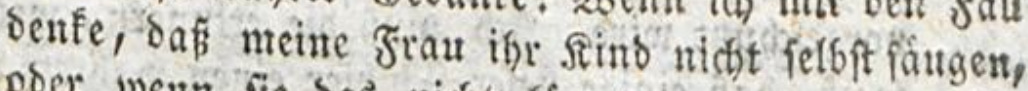
oder went fie bas nicht formte, locrigftens felbft fuittern mogte: fo wofrtbe mir, denfe ich, bie \&uit

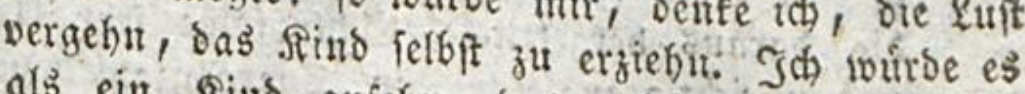
als ein seins anfeln, bas midh nidits anginge. Singegen wirbe bas Theilnebmen "Der stutter an oem sinde meine Theilnefmung, meine liebe vere soppeln.

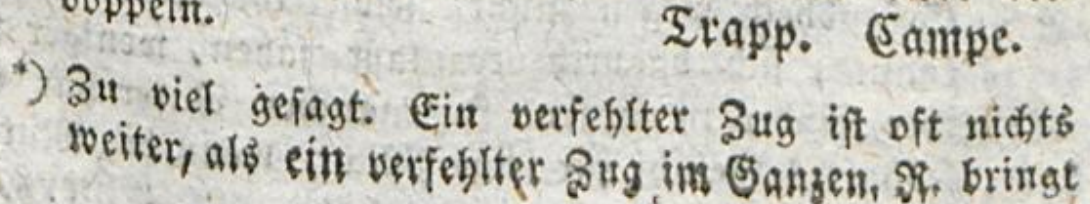
gar 


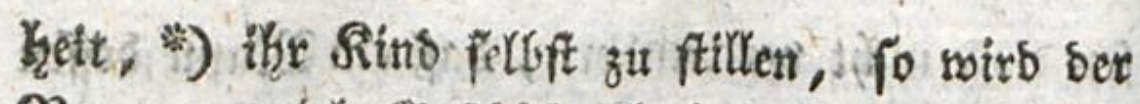
23ater zu biel Sefforifte haben, um ber Selgrs meifter seffelben feun zu fonnen. Die entferns ten, zerftrenten, in bie Roft, fir bie Slofter, anf. Sdyulen gefofictiten Rinder, merben die Siebe su bem baterlichen Sganfe anberšmohin bringen; ober beffer au fagen, fie werben bie Sietwolgns heit aut nidhto gebefte zu fenn, babjin zuxudets

britts

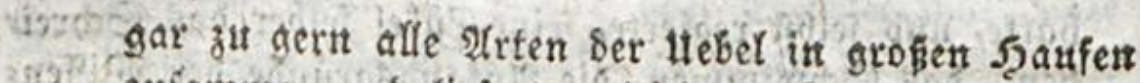
zufammen und licfert out leicht parf auffallende tras siffie Bentátbe.

Eblets.

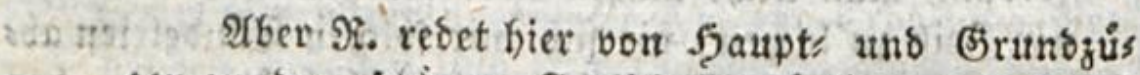

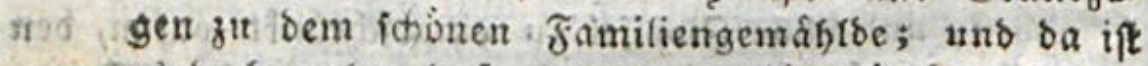

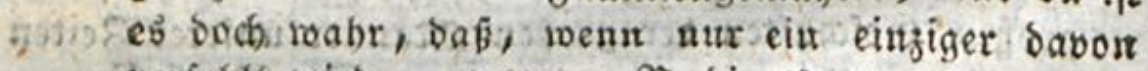

.7. verfeblt wiro - wenn $\dot{z}$. S. Die Niutterpflicht bints

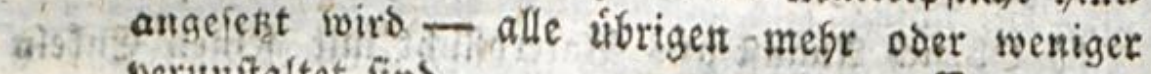
verumitaltet fins.

Eampe.

*) भi. rebet hier bon NRittern, von benen ber Mangel ber. Béundbeit fálichlicher WBeife our. Entidulbigung vorgeidsubt wiro. Ith mus die erimern, tweil id socin, oab einige fejer fid bier einen wabren Naus get ber Sifundeit benfen. In biejem Jall wúrbe bie barauts bergeleitete Echluffolge fehr bobartig und umrichtig zugleich fenn. Die 2mzabl bou \$ुá tern ift, wie unvollfommen aud ber Nenich iff, boch gewoip febr flein, bie, wenn cine Niutter ifjer (Sefundbeit-wegen nidht felbjt ifre fins fángen fonnte, fich Saburch veranlafit fáben, weniger fúr ifre rinber zu forgen. Ia mandjer $23 a t e r$ hat eill

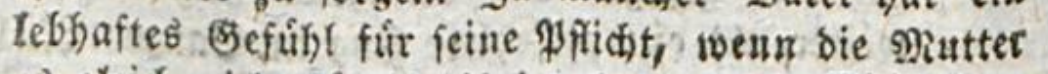
es gleid's nidat fúr sie ifrige bat.

Eglext. 


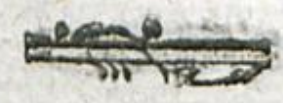

jer

axs

ens

exr,

ibe

in:

ins

di:

ins

fett

ras

zưs

ift

ont

nts

ser

gel

ng

id

Its

to

tig

उấ

ift,

er

ex

úr

itt

er

bringen. Die SBruber uns, ble Sdimeftert werben (ii) taum einanber tennen, 28 em alle bei Eeremoniengelegentzeiten verfammelt fern soerben. to meroen fie fehre kifflid unter fid feyn Esnuen, aber fith als Frembe begegnen, Sobals fetre

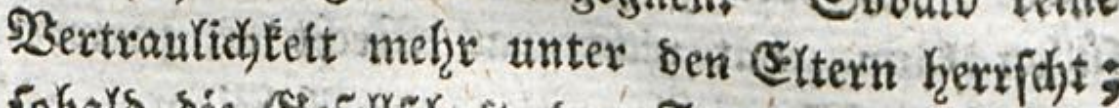
pobals bie Sejellidyaft ber Familie nidit mehre

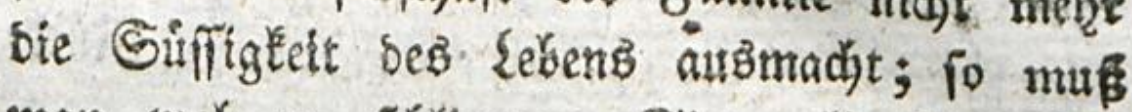

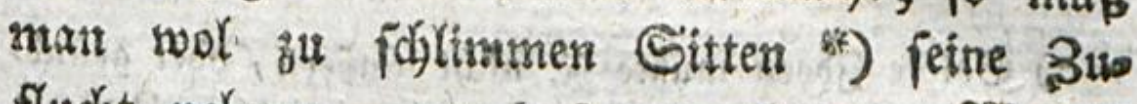
fludjt nefguren, um bas z̧u expersen. $2 g_{0}$ tit ber Nenifh, ber cingefobrant genug wate, bas ex nicht fähe, wie fohr bies zClles gleid einer Siette aneinander fiangt? *\%)

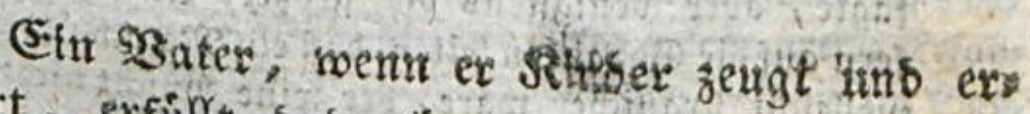
nákzrt, exfílt baburd nur eir Drittel feiner SWliegenlyeit. Ex ift feiner Sattung Nenf́den, ex ift ber Siefellidjaft gefillfwaftliche Menifhen,

$$
\text { Sg } 4 \text { : bem }
$$

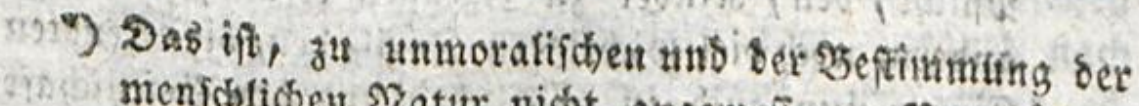

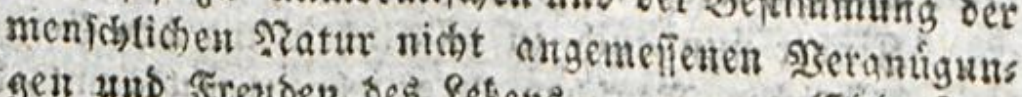

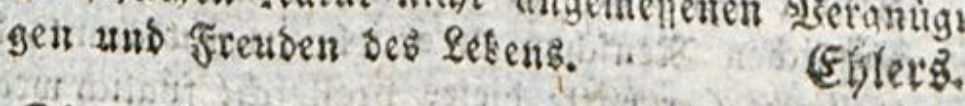

3i") Diefe Shige fint tool grofentheits won ben Marifer

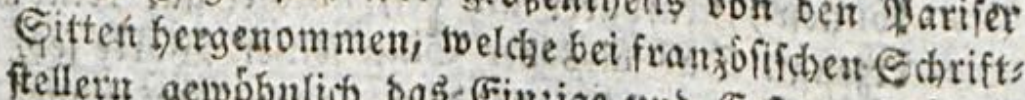

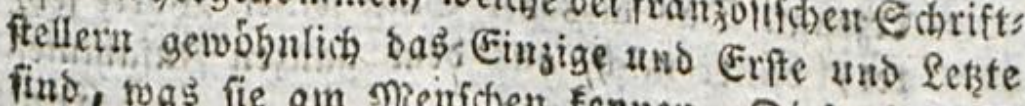
fint, was fie ain Dienffyen fennen. Diefe hat $\Re$. auch inmer im 2uge, utnd gegen biefe ftureibe er

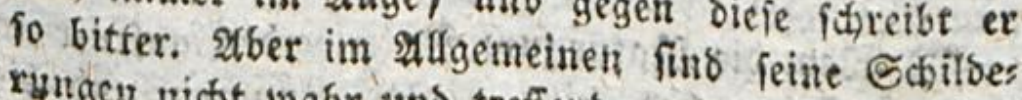
ryngetr nicht wabre und treffetto, und tooft unt, ba.j

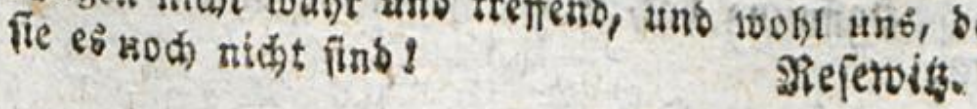


Sem Staate Burger fduuloig. Seber Mrenifh, ber oiefe oretfache Sifuld bezahlen tann, uno es nicht thut, beroient Strafe; und grofere Strafe bielleicht, *) went ex es̉ nur zur Şålfte

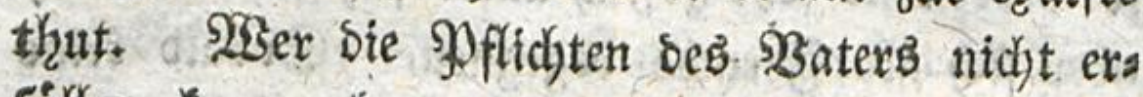

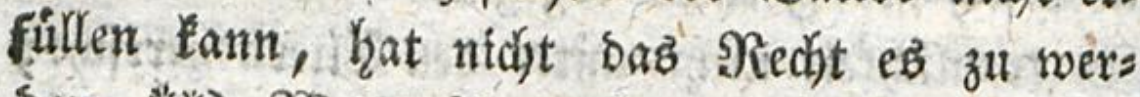
sen. *\%) SBeber 2(rmuth, nod) 2(xbeiten, nod

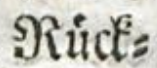

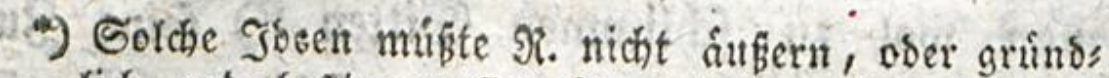
fich uns beftimmt fich úber einen forchen auftano einer bobern Stráflidffeit jugleidh etfláren. Ein folcher auftano fintet gewiji jefo jelten Statt, uno gefort jut ben feltnet 2 tusnabment von der Fiegel. Go wie es on geichrieben febt, miro bas hier Ges fagte; aber wentightens bie grófere $\mathfrak{A n}_{3}$ ahl vou $\mathcal{L}_{\text {es }}$ fern auf bie Sebaufen Yeiten, baj ein Dieních liberhaupt wielleidit frodflicer wáre, ber feine fiflicht nicht ganz erfúll, als einer ber nichts bavost erfifllt. ?fus einem folchen Sirtfum bringt bie lefer aud bas zunádjit Jolgende nid theraus.

(E) ler:

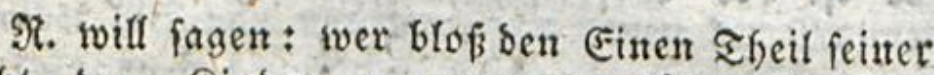
Pllicht, ben, Sinder zu erzeugen erfulllt, aber ben anbern, noch viel, swichtigern Theil, ocn, bie ergengten Simber mu auch su glitélichen unb ber Befellichaft

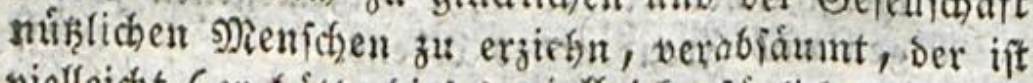
vielleicht (er bátte biejes vielleidar friglich weglafient Fonter) ftrnfbarer als bet, weld)er gar feite Jimber erzangt. Das bics der Ginn feiner 230 orte fen, lenchs tet, binft midy, aus beur ganzen Sufammentange beutlid) genug herwor.

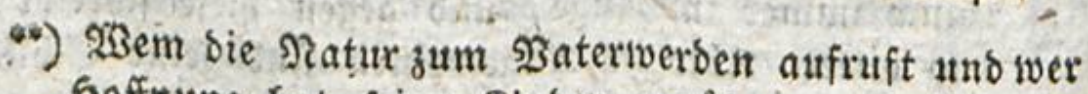
foffutung hat, feine sinder ermábren und Jis zut, 
(4),

no

sre

fte

ers

ins

)乩

dis

$20 \%$

no

iit

ins

el.

ses

Zes.

$p t$

iz

$m$

jit

er

in

211

$\mathrm{ft}$

ift

itt

er

b)

je

ir

tes t)

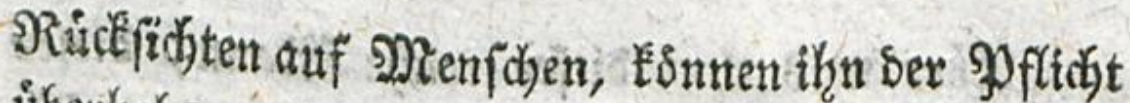
ưberheben, feine Sinber zu ernábren, und fie

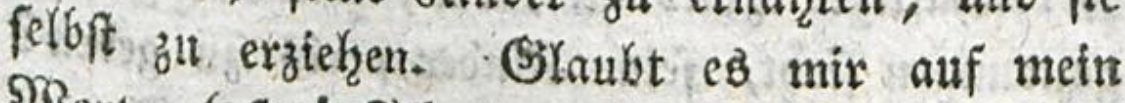

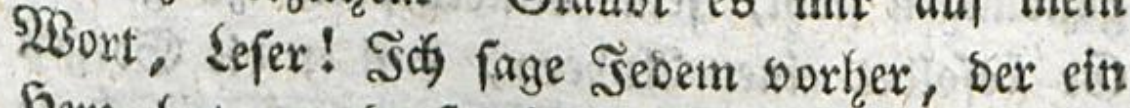
Şerz hat, und fo heilige Pflidsten vernadys

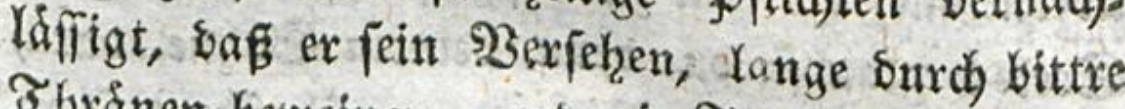

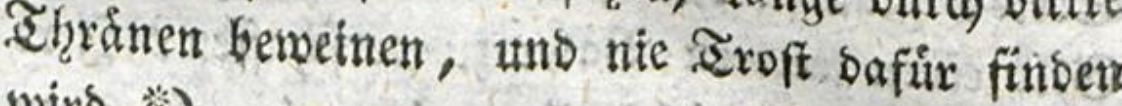
wirb. $\%$

$$
\text { S5 } 5 \text { arta: }
$$

Seit, da es ifnen móglich wirb, felsft fü die eriłen Nothwendigfeiten bes Lebens zu forgen, erbalten ju fonnen, Der bat fison bas Recht Sater zu werben.

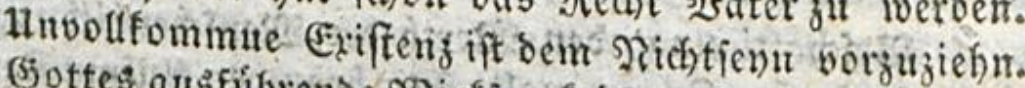

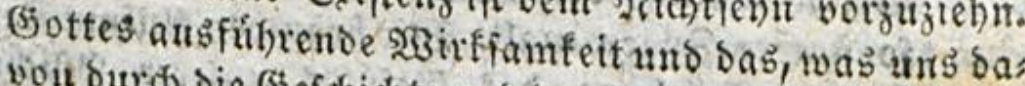

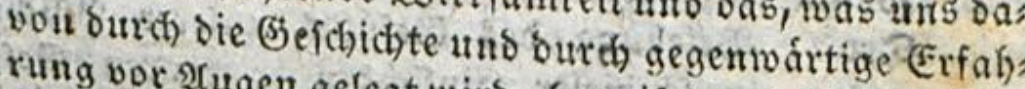
rung vor 2ugen gelegt wiro, belveifet auth biejem Sak, Die 28 ahribeit biefes Sakes minbert aber bie \$3erbind lichfeit ber (Ettern nicht mad) Sein ganzen unfang ibres Sermógens ifre finber burch Exzichuta mótickit vollfommen unto glifflich zu madien. Ebfevis.

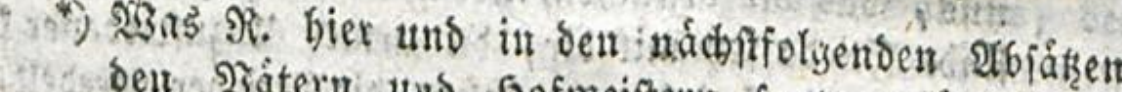
ben Şatern und 5ofmeiftern fagt, gråmzt, unch meinem (s)efüfl, au bas Erbabene. En fortieb es,

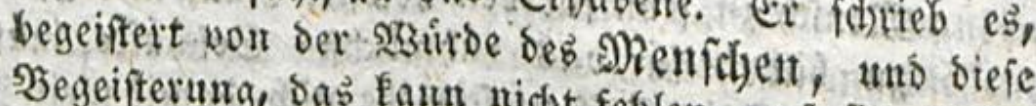
פegeifterung, das Eaun nicht feflen, mú fich vielen feiner lefer mittheilen, und viel butes wirfen, 2 uth ber befte von, unz, ber als sater ober Stellvers

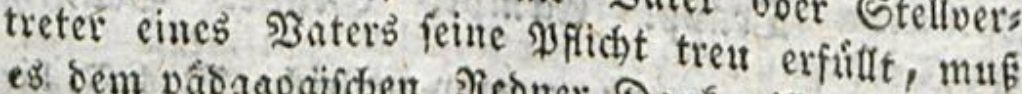

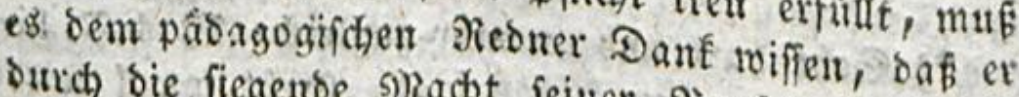
butch bie fiegende s)acht feiner Sjerebfamfeit uns gleidbfam ciber uns felbft erbóbt, baf er uns unfern soertly friblen lápt, inbem er beil sgerth unferer

SBes 


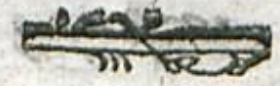

206er soab thut biejer reidje s)tant, stefer fo beidhaftigte Seanjbater, ber, wie er fingt, fich gezmungen fiefzt, feine Sinber preis zu geben? Er bejolbet einen 2Tndern, baß̧ er bie Sorgen übernefme, bie ifhm zu befowertich fino. Feile Seele! glanbit bu benn beinem Sokne burds

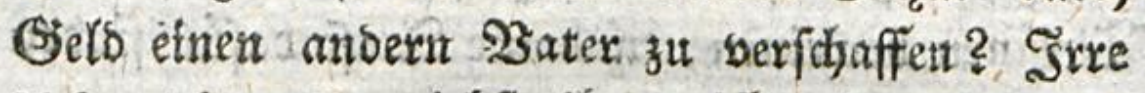
sidi) nidgt; bu giebft ifgm nidyt einmal einen Dietfter, tur einen Rnedjt. Diejer wiro baro einen zweiten barans bitben. *)

Mars

S3ef baftigung, ben 23 erth ber Meufdenbildoung, mit fo ftarken 3 ígen malt. Ss3ir brauchen 2 fufmunterung,

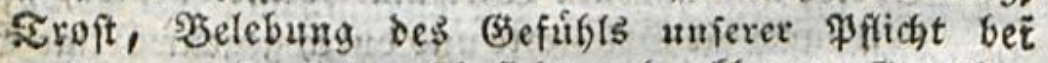
anferm in fo vieler Sinficht andanfbaren (Sefdóft, bei ber Berachtung ober do (b) Eleichgúftigfert, wo: mit man auf Erjiebung uno Ergicher berabzufehere Pflegt, bei ben unzábligen Sinderniffen, womit wir in uns uns auper uns jut támpfen baben. $\Re$. gibt Ins, was wir brauden, intom ex uns jetgt, was twie finbo Friebe fen suit bir, bu armet. Inzufriebetier! Dut baft bie Ergiefung gefobes, bie Erzieber beredelt,

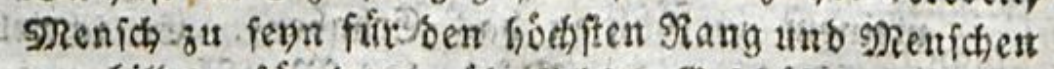

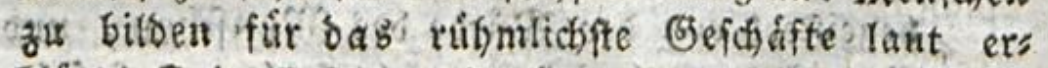
ftairt! Dein (oeif umfdwebe mich, bamit mein Muth the finetr r meitte: Geele nhie lä werben móge!

\section{Srapt Erimpe. Stuve. 5eufinger.}

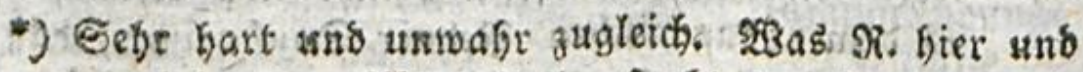
un folgenten 2fbfar fagt, firebt forol wieber bie Erfalycung, alb tviber bie innere \$efchaffenteit bee

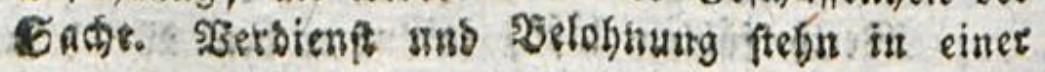




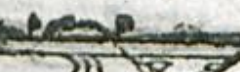

Mat raifonirt biel itber sie (Sigenfobafter einesิ guten Sofnreiftexb. Die exfte, Die id́

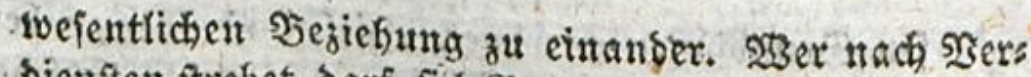
bienften ftrebet, barf fich গ̧elohnumgen wounfcen un soer Sclobnungen anbietet, barf auch פerbienfte ex" warten. Ein etwas guter Sofmeifter uno \&ehrer mú feiner Erteuntniß uno feirrem হriebe nach itets

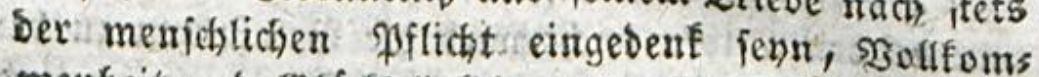
mentyeit uns ssflicffeligfeit aus allen Jiáften zu bes

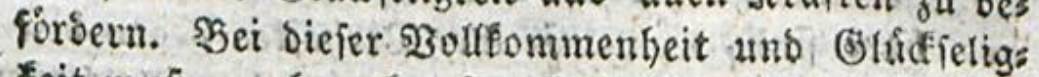
feit mus ex aber eben folvol auffict), als aup sindre \{efn, und fo weit er fann, fein zwiefach 28 efreben fúr 2Andve unb fich úber ben Pinct in Şarmonie zu bringen huthen. Sieft ev ahfieine Eleven uno beren Eltern: fo muf er von:şegierbe biemuen jene aufb beftè zu erzichen und biefe toie iend y burch eine reife shiloung ber Sinber gladiflich hind frobs za mas đen. Er mup ein fo ebles \$robuct devigollfoms

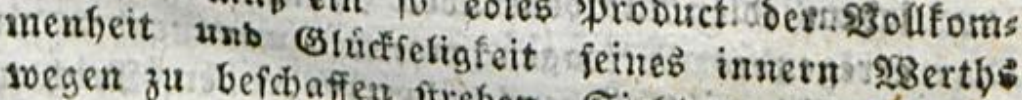
soegen zu befchaffen ptreben. Sieft or auf fich: fo Darf er zuerit fidh bet einem fold)en Sुeftreben fid Den edlen uns geligen Geelenzuftand wünfche, bee mit bem Zuftanbe eirer nerichlichen souffornmens

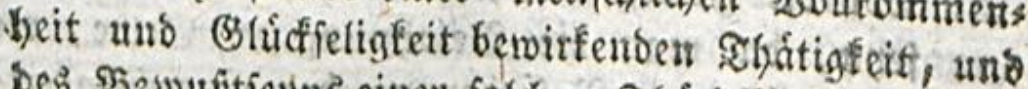

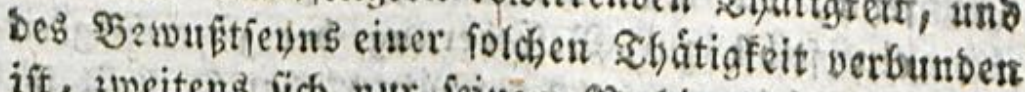
ift, jweitens fich nur feiuèm şerbient angemeriente

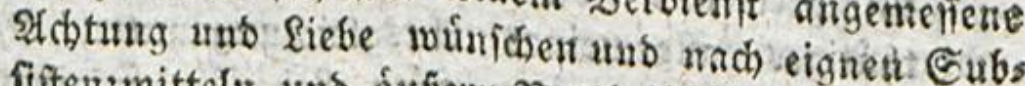

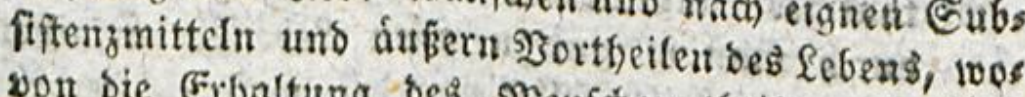
won bie Erbaltung bes Nenf(hen theils wefentlid, theil' naturlidjer SBeife nach ber Dronung Der. Dinge abhångt, uno alfo nath átufern Belohnungen voss Seiten ber Eltern feiter Eleven ein \$evlangen babet!. Şei fé́r vielen Syofmeiftern und lebrern fins auds

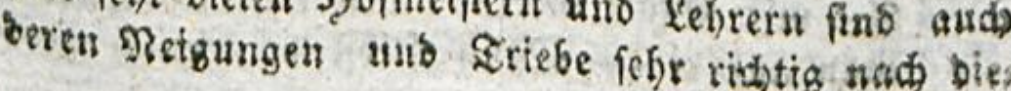




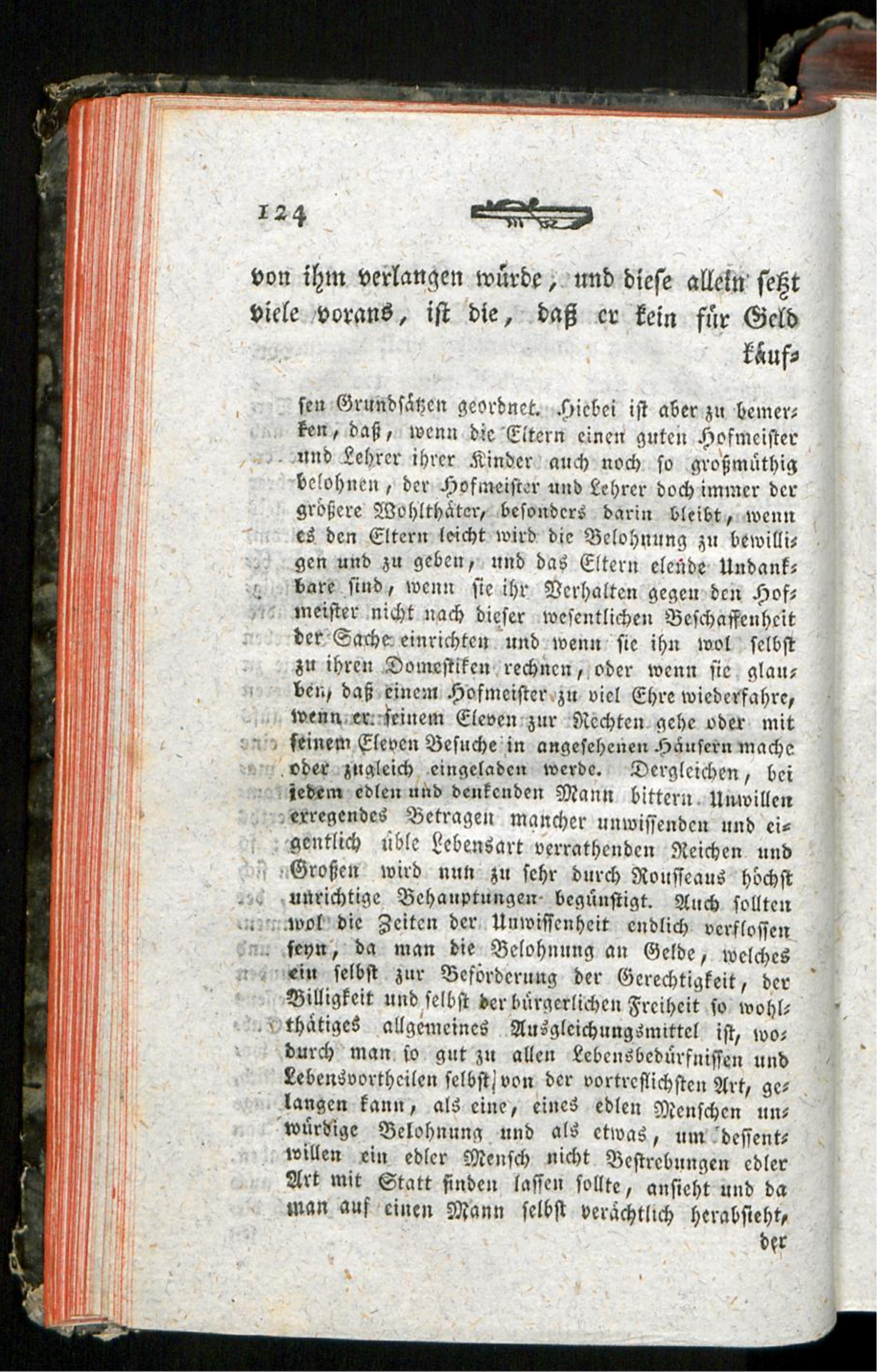




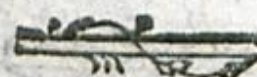

I 25

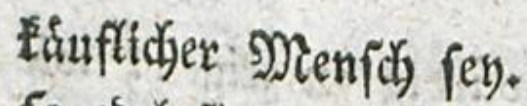 fo edel fins, baf man fie nicht fín (Sielo thun fann, \\ (5B gibt Šefchåfte, sie}

Ser bei feinen 2rbeiten uns bei Sुeftrebungen ebler 2rt mit sach (Jelbbelohmungen trachtet. Afles; loas ber gute Mienfich babei zut beobachten hat, beiteht bloṕ darin, baf́ er die sieigung zu eimer (5)elbbes

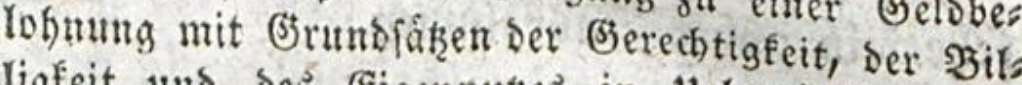
ligfeit und bes Eigennußes in Hebereinftimmung bringen mú ind bab man eimen eifrigen nno wobls thatigen Seforberer alles (S) tuten, aud went man

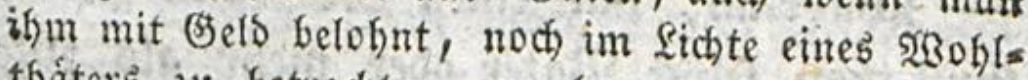
thaters zu betrachten, zu efren und audb, wem man felbft ber biegenftand feiner Şeftrebung gevefen ift, benfbar ou lieben fyat. Hebrigens mub ich bier noch bie snmerkung machen, baß́ befonderb unite

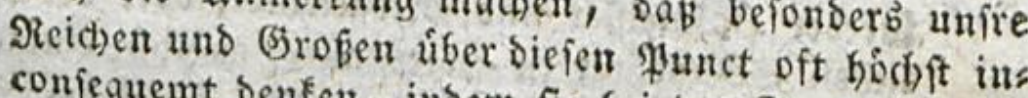
confeauemt benfer, inbem fie bei ben Gtaatsámtern eiue refoldung von vielen Zaufenden, fur ibre wabre ibrer gar nicht ulof angeblictse Dienfte, als ettwas hoher Sjefoldungen wegen annefmen un offenbar

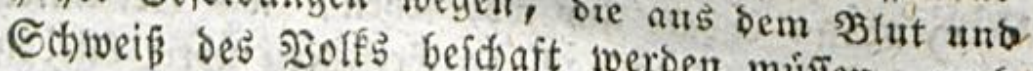
boben und anfebufínen bem fie jugleids es

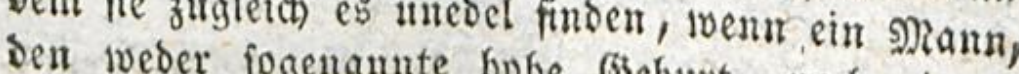
Sermogen logenamte bobe beburt, noch eignes Sermogen zu amentgeltlichen Dienftleiftungen vorzugs (ich) auffordern, oder fálstg machen, bei bem fo widhs: tigen Dienft, dent erifren Sindern leiftet, mit anf Belbbelohnumgen fieht, unb Selbfaufopferungen, bie eigentlid, pflidstwibrig find, ausiveidht und babei

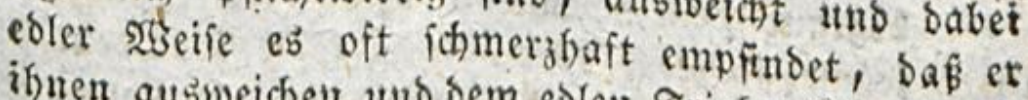
ihnen ausweichen mo bem edlen Triebe, Eitern und Sindern zu bienen, entiagen mut. Miogten bod alle btejenigen, in berenţánben bas duperliden Sobits 
tann, oftne fich ibrer untwirbig zu zeigent wie zum Seifpiele bas (Sjerdjaft des Rriegers, bas Sefdyaft bes Unterweifers. *) SBger foll alfo mein Rins erzicken? Şh habe bies ficon gejagt: Du felbft. Şh tann es nicht. Du tannft es̉

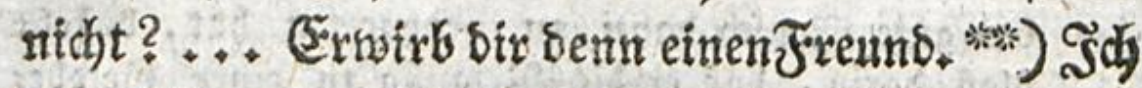
fefe tein ander 2 tublommen.

(Fin Sofineifter! o melcte extzabene Seele! - SGahrlich, unt einen Mienídien zu bilben,

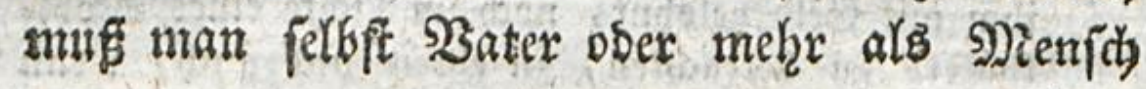
fent.

Sal ber Sofmeifter uns Priwattefrer, ober ser sffents Iichen Sdjulfefyrer ift, bies alles endich einmal in jebem Staat beherzigen uno einem Theil ber graus famiten Hngereditigfeit uno Iyramei ein Enbe machen!

Eีblerళ.

D) Danur mógte íh trol fehen, soie viel unter taus feno Nienfichen noch zu Ergiebern uibrig bliebent.

\section{Rẹerviş.}

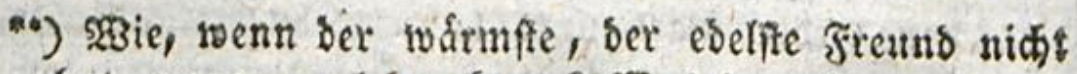
hat, wovon er reben fann? $\mathfrak{B a s}$ bann?

(E) flevi.

SMadje Dit einett freund, Fann anth heifen: begegne Dem, bem bu' beine Naterpflichten úbers

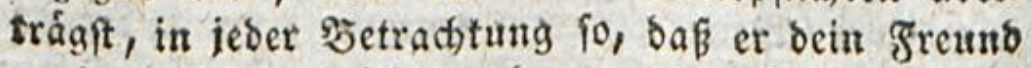
serbe, bafi er nidjt mefr um bes Qofns willen, ben er empfángt, fontern aus waffer liebe fúr Dich und bein Szaus, Dab $2306 \mathrm{l}$ Deines Rindes ber forge.

Enmpe. 


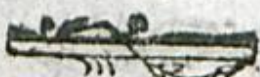

fent. Das iff sie \$erribtung, sfe ihr rubgh Eshnlingen anbertraut.

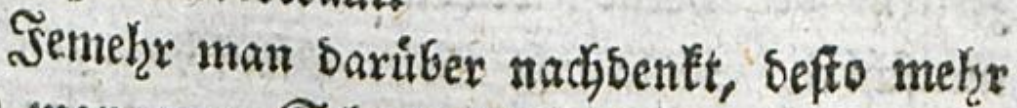
wiro man neue Sdywiertgleiten gewahr. Beis nake thate es noth, baf ber Septmeifter furt feinen 3\$gling wáre erzogen worben; baf bie Bebienten fir ifhen Serren wairen exzogen wor Den; baß alle biejenigen, bie fid thm naken, Die Einorudie befommen hatten, bie fie ihne mittheilen múffen; baß man fo son Errziefung zu Exziełzung, id̆ meiff́ felbft nicht swie roeit,

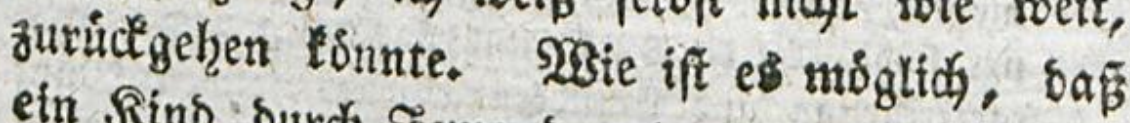
ein Sind burd, Jemand gut erzogen werbe, ber felbit nicht gut erzogen worben? *)

(ápit pich biefer feltene Mann nidjt aufo

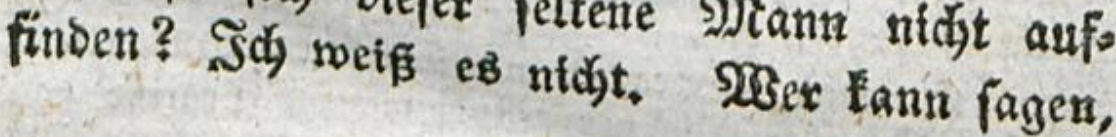

bis

art

(क)

9) Sherr Gormey meint, bafi, ment man biefe Etelle gelefen habe, man nicht weiter fortfabren forne, Dies Berwegungs̊grunte Der \$etugierde und Der $\mathfrak{B}_{\mathrm{e}}$

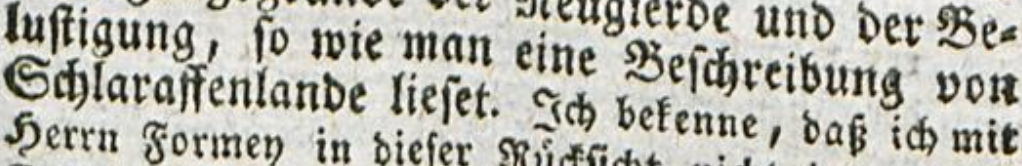

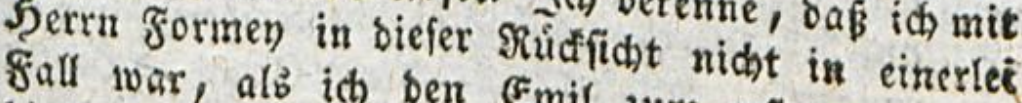
Fall war, alb ith ben Emil zum erftermate faus Dirte, Dafi id vietmehr bamals aud aub bem fols genden fehr viel Gutes lernte, unb baf id fogar noch heute bie nochmalige Durchlefung biefes ganjen geiftreidgen geneḩme Đeiftesbefódftigung balte. Eampe. 


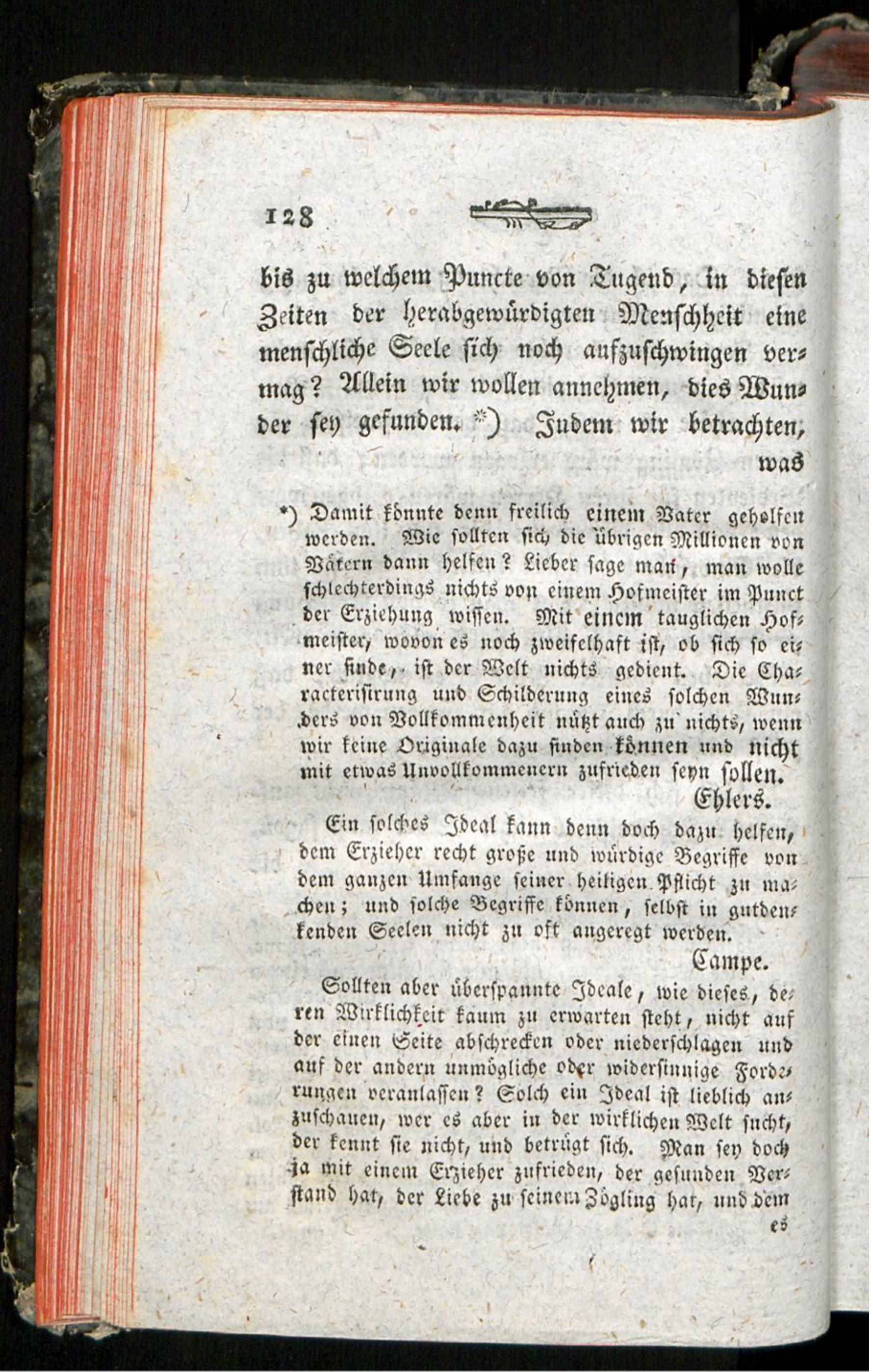




\section{गi}

?fen

ine

jexs

uns

ent

วas

Ifelt

yon

olle

urct

jofs

eis

bas

แII"

ent

(b)t

I.

its

$101 t$

ata

elts

bes

uif

no

325

ins

it,

(h)

xh

m

eb

was unfer Sofmeifter thun muहf, swerben wit

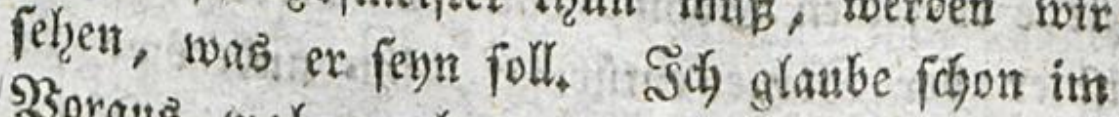

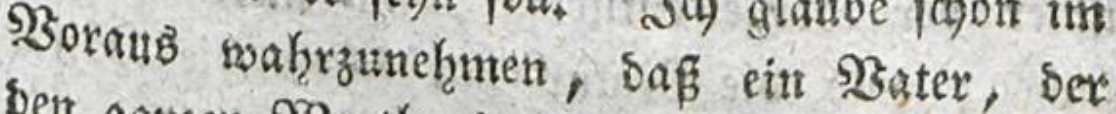

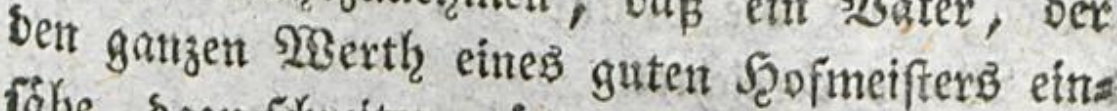
Tâhe, bazu folveiten wiribe, feiner zut entbelgen;

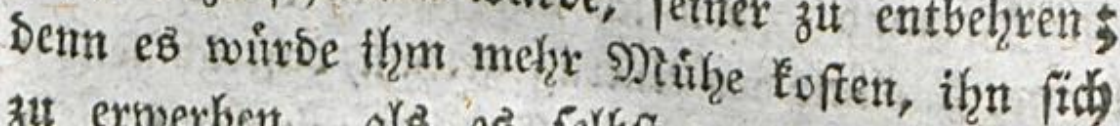
3ut erwerben, alb eB felbft zu werbet. er fiti alfo einen Framb *) bitsen? Sp exs ziekge

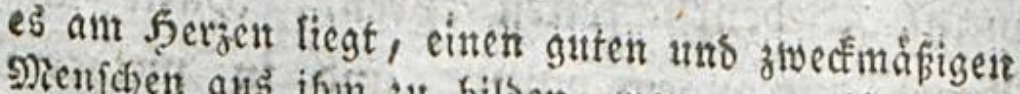
Mienficen aus ifin zu bilben, wenn man ifrt anch noch fo fefy efren und belofuen wifl, als man beis bes wenig zu thun gewobnt ift. Refewis.

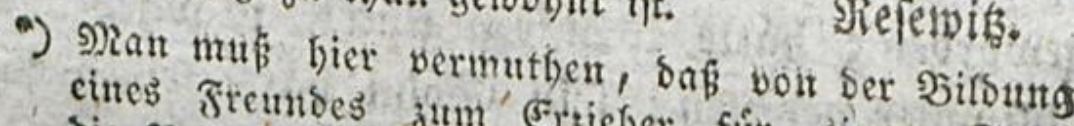

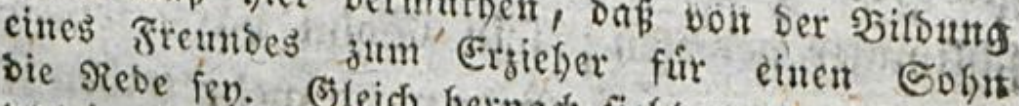
won ber Erron. Steich hernach fieft man, bas nut Stelle bie Rebe fen eines freuntes fúr fich in biefer

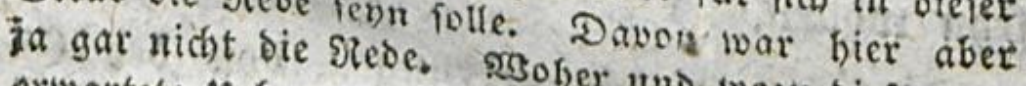
erwartete llebergang zu einer fremo twozu biefer uns

(5)blets. Sreuns und unfere ganjen, ber ganz an unfere Stelle treten man eben fo viel, ia nod erfúllen fonne, mufie als man baben wurbe, feinch orife anwendent, ben. Shan fonne alio jene fohn felbot zu erjies nut biefer zu untergiefien.

Eampe. einen 28 ent tur beibes jebem 3ater móglid wáte

Gimil Ifter

भieferwib. 
ziefre er feinen Sohn, Dafi ers merbe. Dant ift or ber Sorge entubrigt, if̧n anberşwo ju fucken; uns bie Natut bat fitjon bie Seálfte

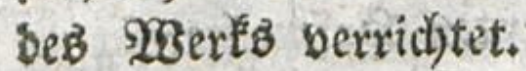

Semans, ben idj nut feinem SRange nads Fenne, hat mir ben 2lntrag gethan, baf idy feinen Solin exziehen mógte. Er hat mir ohnftreitig siel (Shre ertwefen; anftatt aber fich lber meine abfalabige 2tntwort zu befdyweren, follte ex meine Sebentlichteiten ebren. Sgatte ich feir 2rnerbieten angenommen, uno in meiner Mes thobe geirrt, fo wars eine berfehlte Exziehung

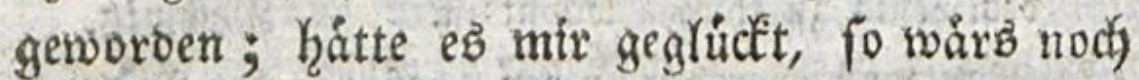
fiflimmer gewefen; fein Sohn bătte feinen ßi: tel berlengnet; ex muirbe nidyt meḩr b̧aben Fiurft fenn wollen, *)

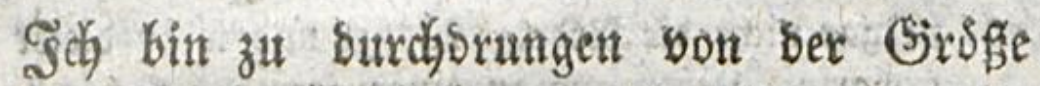
ser soflidyten eines Sehrers, ids, fithle zu fehre meine Unfähigheit, jemals ein foldhes (Siefchift

*) Da wáre er freilich fefor tibel ergogent. Foufiear jagte boch ia worker felbit: "Der S3afer ift feimer (5attung o)enichen, er if ber Gefellichaft gefells

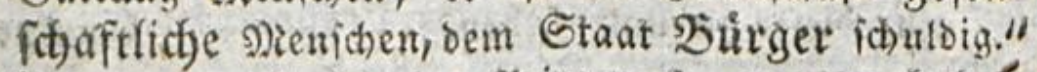
Und nun nollte $\Re$, dent \$rim jen io erzogen haber, Dẩ er nicht ber Sjúrger dés Gtaats báttè werben wollen, woju er beftimmt war.

Ebler:

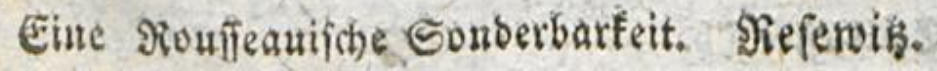




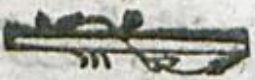

ơ uibernebmet, won woher es mix auch anges tragen werbe; und felbft bas Sintereffe bex Freunof(y)aft sourbe fir mich nur ein netter $\mathfrak{B e s}$

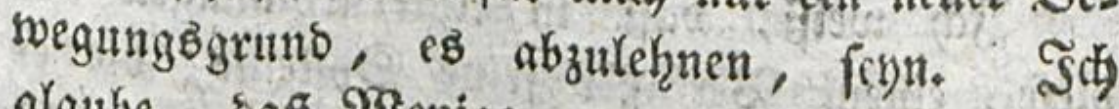
glaube, safs 23 enige, wann fie siefes 3 ud gelefen, nod) berfucht fertn werden, mix biefes 2Cnerbieten zu thun; und ich bitte siejenigen, bie $P$ sే bemohngeadjtet nodh Esnnten, niemals

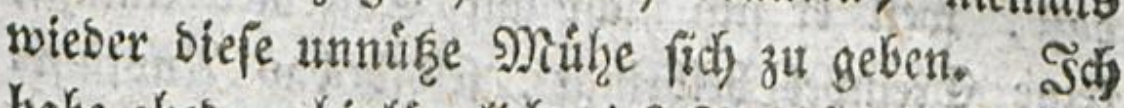

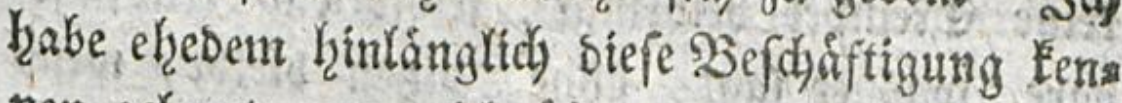
nen gelernt, um mich uberzengt zu fuhblen, oaß idf nidyt fur fie gefdjidet bin; uns mein 3 sts fand wirbe nidy binsern, mich sarauf einzus raffen, wenn idf fotbft sie exforberlidben Salente befápe. İds babe geglaubt, biefe offentliche Exteläung benénjenigen fobulbig ză fegn, bie. mix nidjt Şodjachtung genug suzugeftehen fodjets nen, un midg in meiner Entichliefung fur aufa richtig zu halten, und gu glauben, Sabis ich das bet meine Sirunde b̧abe.

Yufier Stans aber, Sas nüblichere Sies fdift zu úbernehtmen, will $i$ h wenigftens bas leidjtere berfudjen; nadj bem Beifpiele fo wies

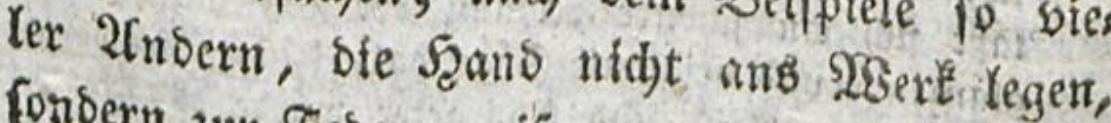
fondern zur Feber greifen; uns, anftatt, mas

$$
\text { \$ } 2
$$




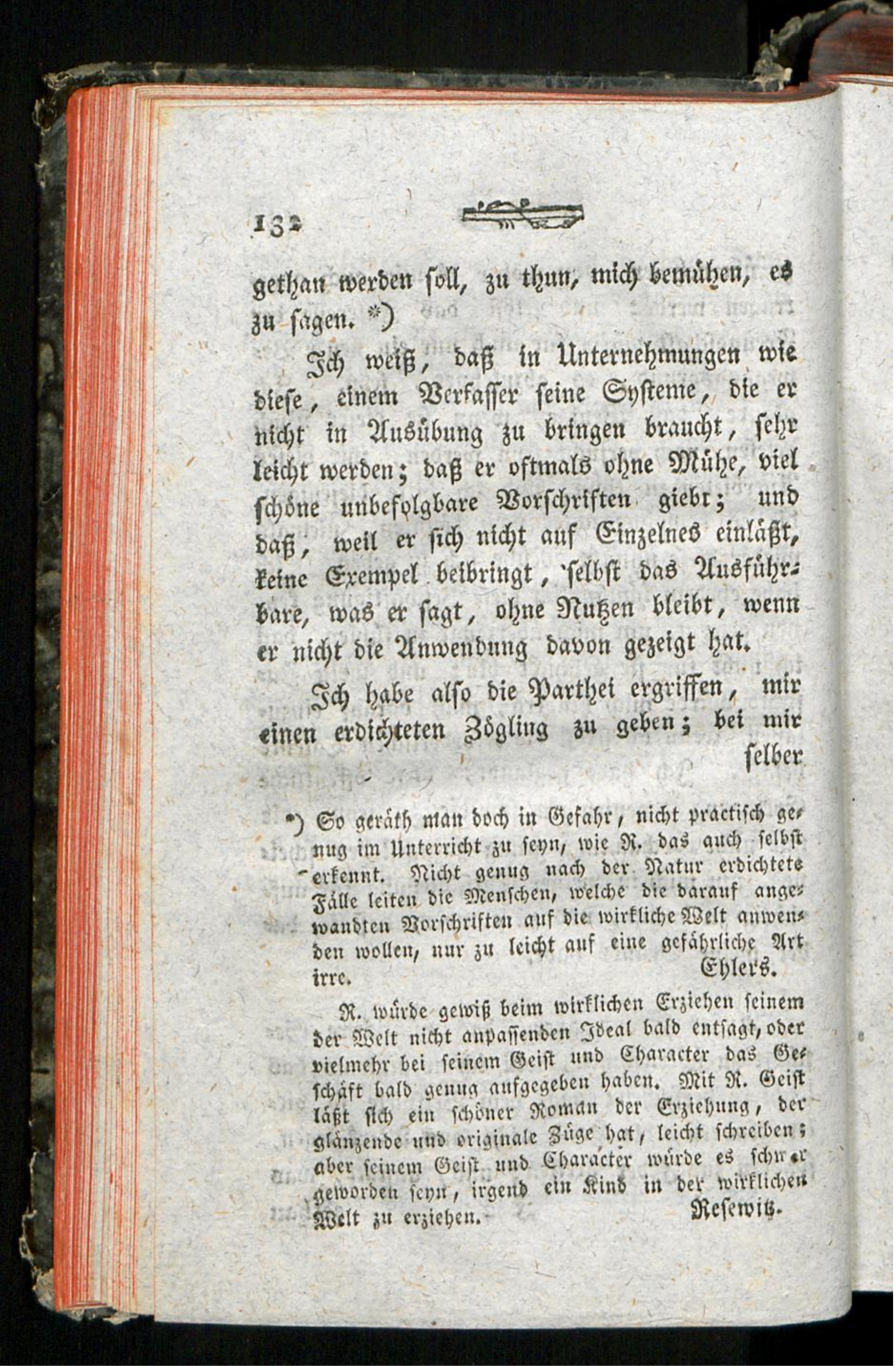




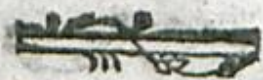

Felber bas 2ltter, sie Sefundheit, bie Fientsts Mifle, bie ralente borauszuferen, sie erforbers lich fitts, an feinex Erziefzung zu arbeiten, wels aje (da) gon bent 2 ungenblicte feiner Seburt an, bis zu bent 3eitpuncte zu fiffren gedente, wo er ein gefildeter Mann geworden, feinez, weis tern Seitery alo Seiner fellaft bedixfen wirb. (Sine Mithode, bie mir bequem fcheint, einen 3erfaffer, wenn ex in fids felleft Distranen

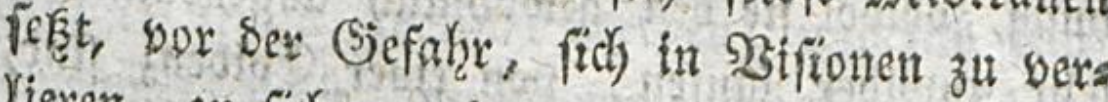
Xieven, zu ficjemi benn er barf alobann, for

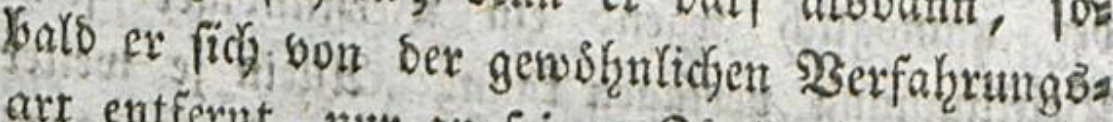
art entfernt, nutr an feinem 3 ojglinge bie reinige serfudjen; tuls wiro fdyell, ober ber Eefer wirs

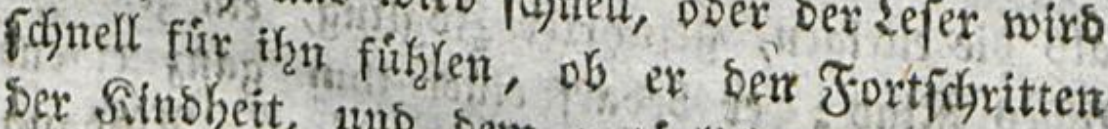
Sor Sinsheit, uno bem natiurticten Gange bes menidjichen serzens gehorig gefolgt iff.

Das habe idy bet allen Edjwoterigteiten, bie

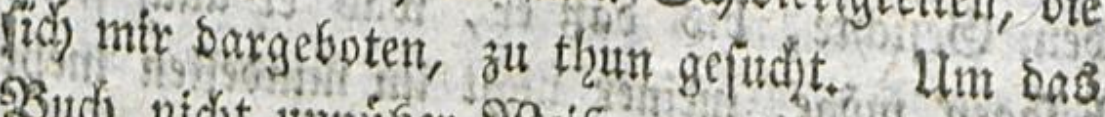

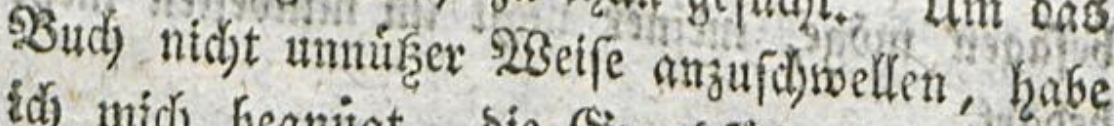
id) midy begnigt, bie Grunsfaręe feftzuftellen,

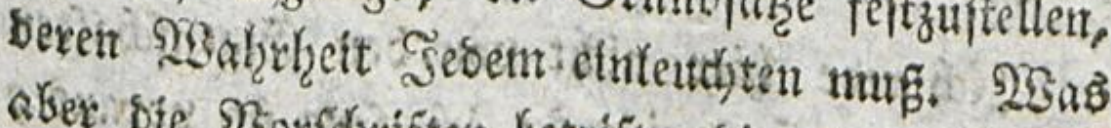
aber bie Borfdyiften betrift, oie eines Berveis fes bebinfen tornten, fo habe idy fie alle meis then Guif oser aubern Beifpielen angemeffen;

$$
\text { ฐ } 3
$$

4nס 


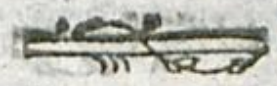

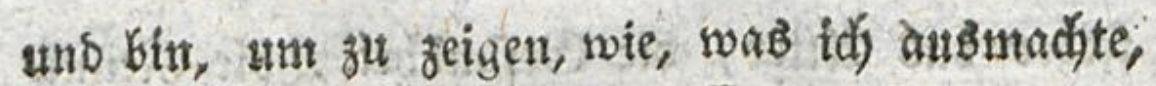
anmenobar fer) felzy inb Einzclne gegangell. Dies ift wenigftens ber Mlam, ben ids mír zu befolgeu borgejef̧t baber Der Lefer moge ure theilen, of es mix bamit geglictit ift.

Sieratro ift bas sfe Folge geweren, daf id) anfanglid, wentig bon meinem Emil gerebet babe, weil meine erften Srundfáke bon Errzies hang, obwol fie ben gewoihnlted angenommenen fehr zuniber laufen, von einer Ebibenz fins, Der unmoglity frgens ein Sierftandiger feine SBeiftimumng berfagen famn. 20llein je weiter idi) fortricle, befto weniger if ntein, anoers ałB bie eurigen, gefuifrter 3 bgling, ein gerwohns liches Sind; et bebarf einer them ganz cigens thimlid, angetmefienen $B$ chanolung. 2frobann tritt er ḩå̆ ten berliere id') ifhn nid)t eimen 2(ugenblice aus sem (Sefichte, bis bas er, was er auch felbft befagen moge, meiner nidjt im minbeften mehr bebarf.

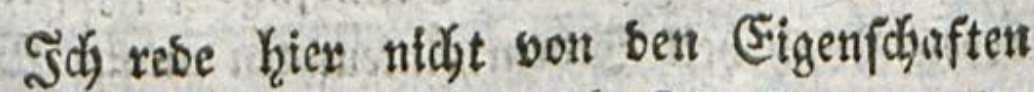

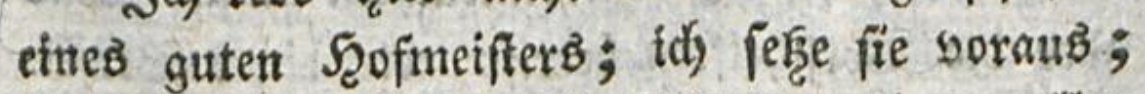
uno nehme an, baß̈ idh felbft mit thnen allen begabt bin. Gnsem man biefeò $203 e x t$ lieft; wirs 


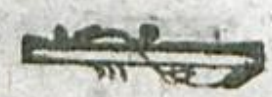

swirs man fefgett, soie freigebig ify gegen mich getwejen.

STur will idh, gegen bie gewshnlidje Mets

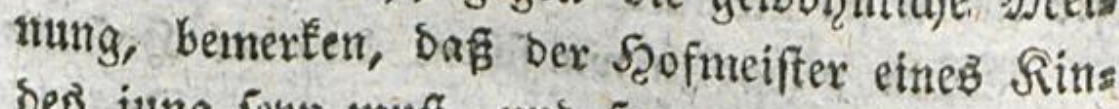

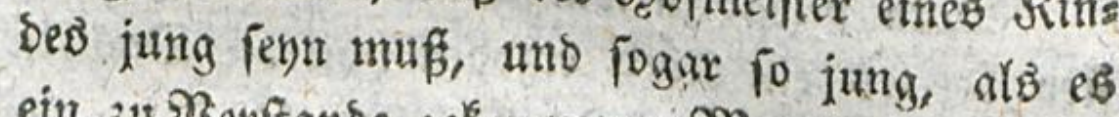
ein zu Berfitande getommener Sann nux je feyn iann. *) $\mathfrak{S}^{2}$, idi mollte, ex mógte, falls es migs lich waire, felbft nody Sind fent, bamit ex ser Siefpiele feines 3ెoglings merben, uno fich fein.

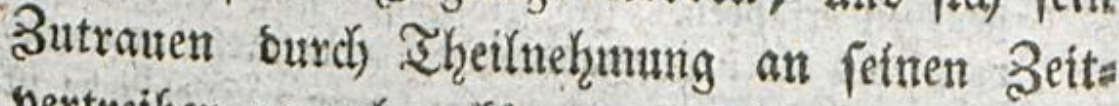
bertreiben erwerben fonnte. Die Rinobeit hat mit bem reifen after nicht Sachen genug gea

$$
\text { ऽ } 4
$$

meitt,

") $230 \mathrm{enn}$ ein Sofmeifter, ber nicht fefr jung ift, fich bei feirrem Sógling liebe zu eriverben weif, fo ver Ebrerbietigf́cit uns liebe leicht ein (Sefúbl ber nem Sofmeifter befonder bohern 233eisheit, bas eis פerfúbrung uns unb oning und serfuchung grope Dienfte leiftet, fer for ein junger auth noch fo geidfidfter und weis fer Spofmeifter nicht leich)t zu erregen im Stande ift.

(5b) lev's.

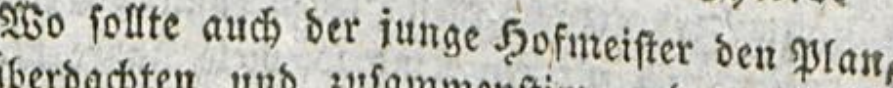
Sie liberbachten und zufammenftimmenden Grund fátze, bie Attsoauer, bas Seelenitudium und Beobe actiten ber menichlichen Entwidefungen, bie Jilug. beit, furz alles das, was $\mathfrak{R}$. won ifm forbert, ber: nehmen, weur er noch fo jung ift, baßi er an ben Beitvertreiben feines bóglings eigenen antheil neb. men fann?

Referwik. 


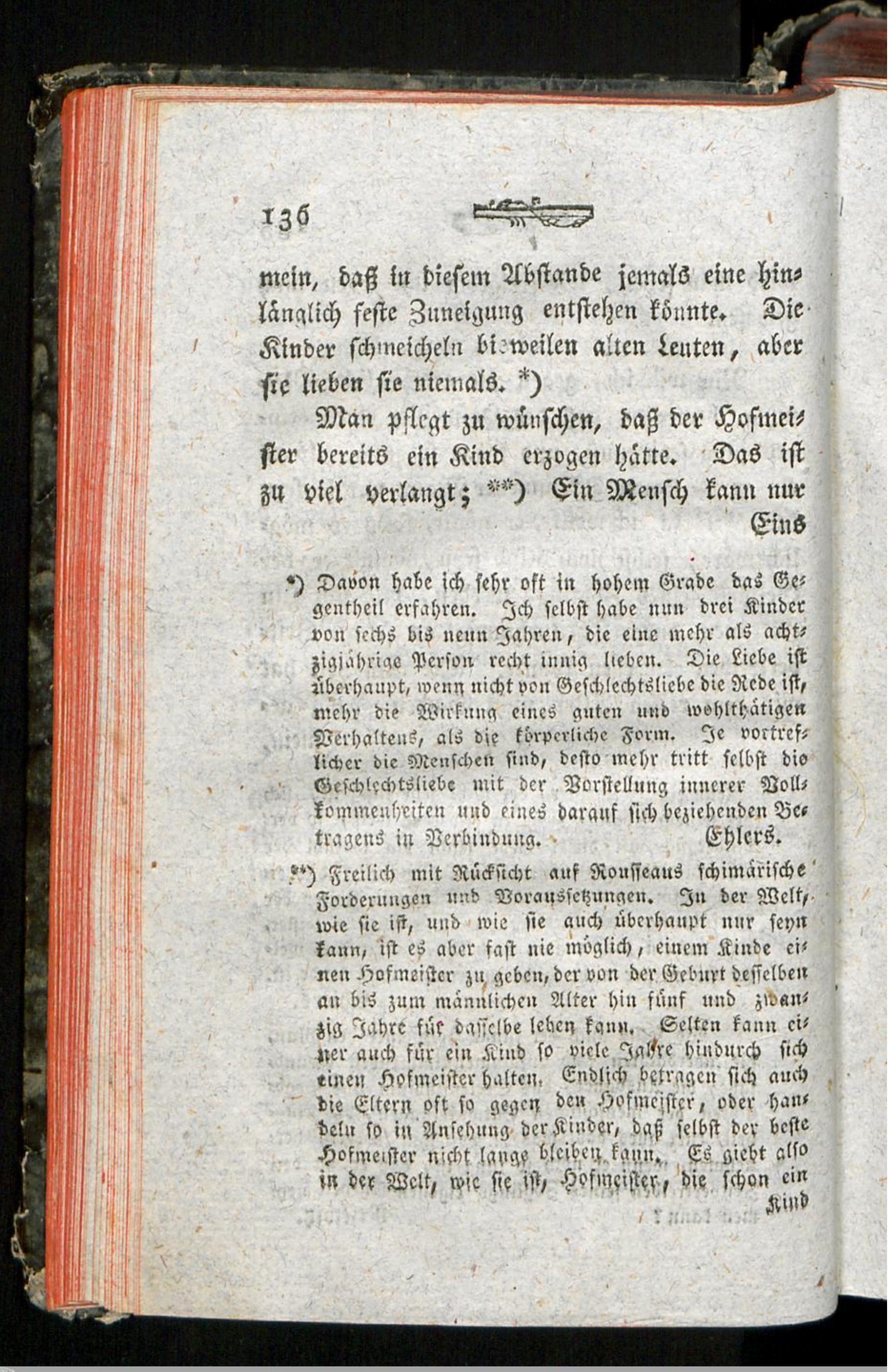




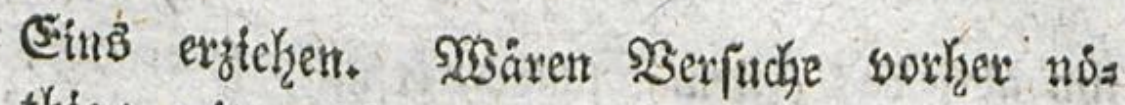
thitg; mit weldyem Rechte wirbe man bie exfte Erzichung unternehrmen?

Mit mehr Erfahrung wirse man freilici) es' beffer machen tónnen; aber man wirbe es

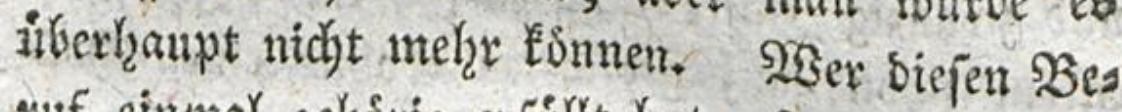
wuf einmal gehorig exfillt hat, fo bafa ev alle Mlibfeligkeiten beffelben ertéant, bex berfucjt es nicht mehr fich barauf einzulafien; *) bzat ex

$$
\text { ร } 5 \text { ifhn }
$$

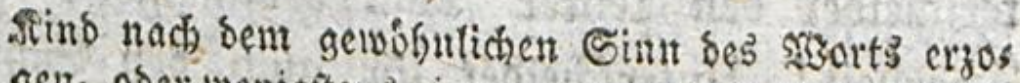
gen, ober wenigitens eine getaume Seit bintom ch fich im Erziehungsgefchaft genibt baben. Sjaben dieie un fonft die ivefentlichen Eigenichaften eines guter Jofmeifters: 10 baben fie surd bie Erfafrung uns Hebung, sie fie gehabt haben, unftreitig viel gewone einen foldhen fofmeifter fute Эुerlaugen ber Elteru, ift alfo feinesiveges zu tabelure sinder zu lonben, minftig und papt gan zu biefer sBelt.

\section{(E) Jers. Refenits.} in Dab mannlidse siter offithes Sintes an bis gerveien wáre: fo wirde flelben binein Sofmeifter viele Sirafte mus spirnterfeit nicht leicht noch fo tm noch ein joldheb sficr हl baben, als or braudit,

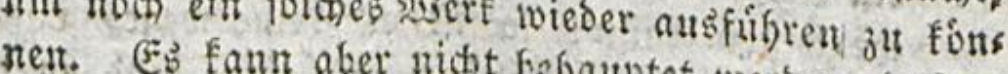
ifm, wenn ifm feine erite whterntef werben, vafis es wáre, an muth unto Neigung febleng gelungen

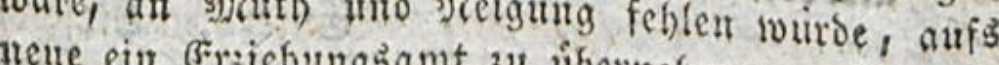
Hetre eut erjicbungsamt an úberncbmen. Gin pors

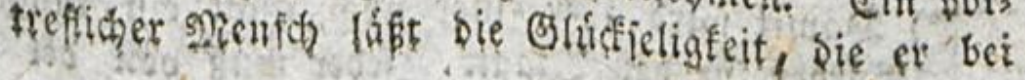
sitter 


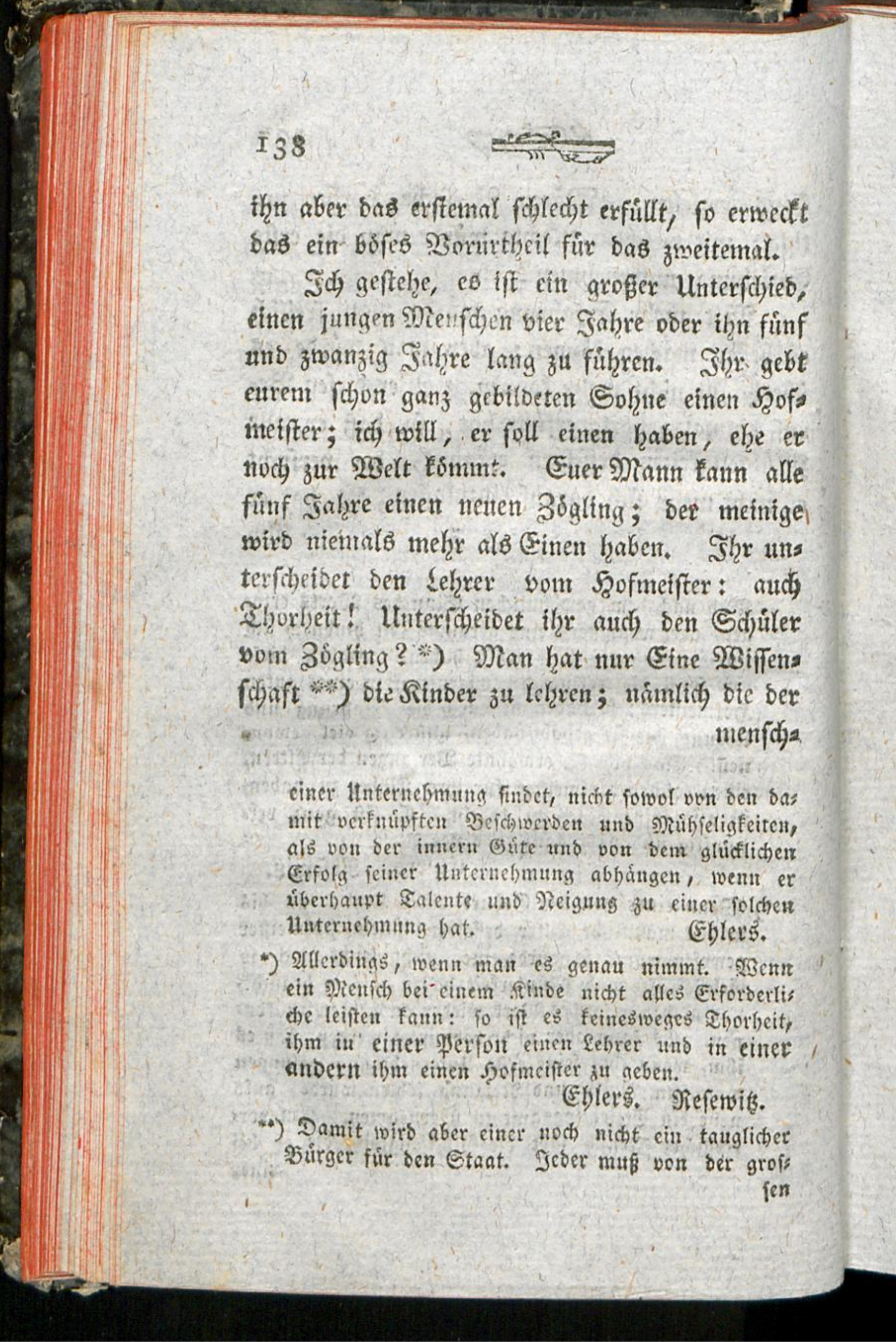




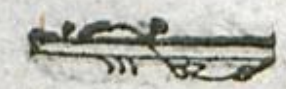

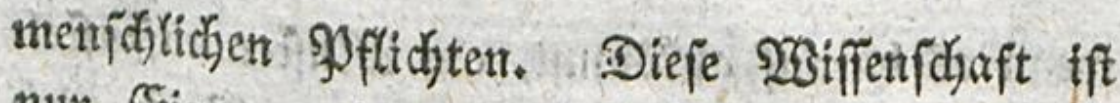
nur Eitu, uns was audy Xenophon son ber Erziehung ber MJerfer gefagt hat: fie theilt fidy nidbt. Llebrigens nenne id) Den, Der in

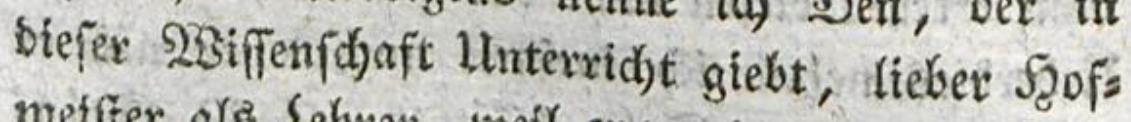
metfer als Sehrer, weil er weniger zin unterrich)= ten alB zul leiten hat. (5.r foll 3 bridyriften nidyt. geben, fondern fie aubifindig machen laffen.

S2Eenn man mit fo siel Sorgfalt ben Sgufo itreffer wahken mus, fo ift es thm aud wol ers laubt feinen 3ogling zu wákllen, *) bejonders

wenn

Fen fantsivirthichaftlidsen Maichine einen Theil

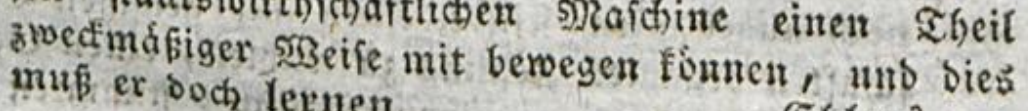
mu er boch levnen.
Ëblerz.

-) Jit ber wirfliden rgelt finbet ein foldes gegeniei

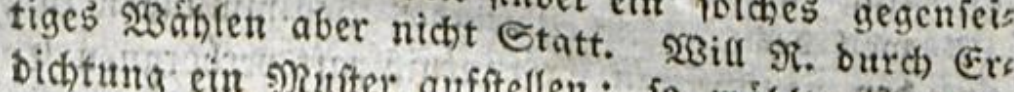

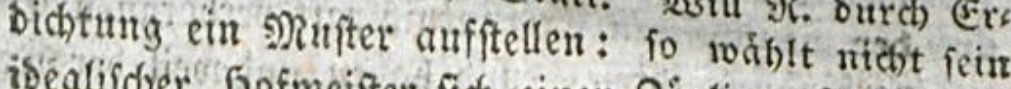
ibealifdrer Syofmeifter fich einen Bogling, forbern $\Re$. selbit bifbet fich zu feinem Soeal bes Jjofmeitters eir soeal eines Söglings. Nin bat ex fich lelbet zu cis nein folchen Soeal beftimmt, und ben Şegriff ber 2Birftichfeit mit bem bुegriff eines erbichteten Joeals vereint. "Sollte dab Eine zu bem Sfndern paffen: to mifte, weldses fier nidht ber fall ift, einte foldhe

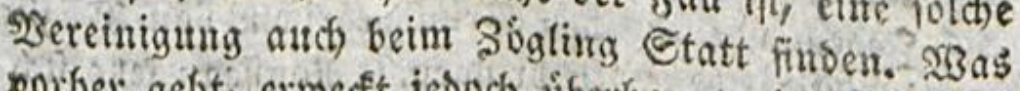
worber gebt, erwecft ieboch riberlhaupt nicht bie Joee bon folchen 23 ejen ber Erbichtung, foubern bie 20 ors

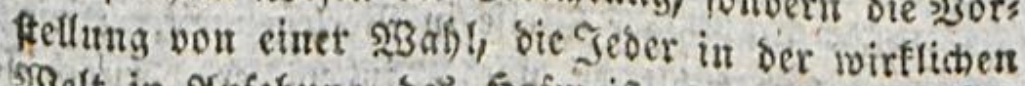
solt in 2rifehung bes shofmeifters anjelfen follte มี 


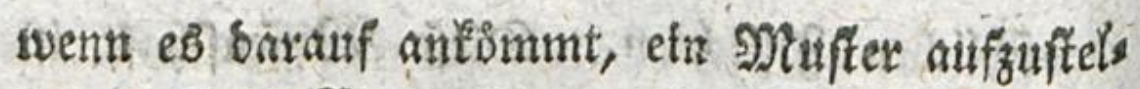
Ken. Diefe $23 a b y$ tann weber ben Sieift nod Sharacter bei sem Sinde zum Šegenftande baben; man exfennt biejen nicht bor sollenbetem $223 e r f e$. Ueberbies nef̧me id incinen nod) efger als et gebohrentwiro, an Sohnes Stntt auf. *) Stins

Inb fonnte. Eo geht $\Re$. oft vermittelit cimer faum bemertbaren şending auf cinmal won einer soee 3t ciner, bamit nicht jufammengángenden fremben Soee uber.

3) 2150 ift es auth nicht moglth, fich eiment toealifich bes ftimmten Sogling zut wáblen? SR, modht hier offens bar itriger sigeife bon bein Hnvermogen in einem stod mactornen simbe einen mit getviffet eigens (d) aften begabten Bogling żt wáblett, eluten Gobluf

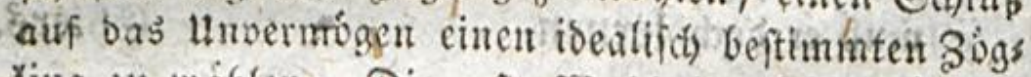
fizhg zu waiblen. Die erite 233 ahl ift nidgt mogtich) 35) soeil des nirélidsen Jindes sjeptimmungen in einer, so ber menfoglichent Erfenntniffraft verborguen Caufals

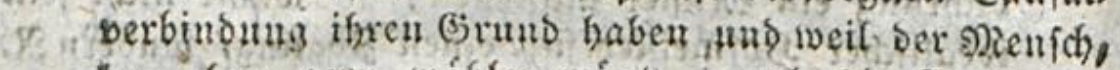
mis ser eben gen wáblen migte, auch bie Eanfalvers

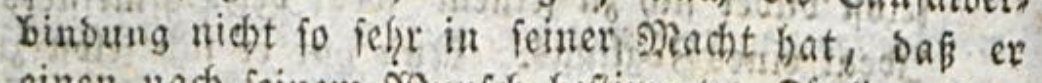
einen uach feiucm siunfd beftimmten Boglitg bars

21. aus berletten fam. Einen ibealifchen 3ogfung fant

21 man aber beftimmen, wie man will, wemp man fich

St nur futet, bie gewáblten ßeftimmutrgen mit ben

in Sebcm vorliegenden (Srunblegrifien pon Nobglid)feit in sibiberipruch zu bringer. Flomfent jert fich alio in Arrehung ber freien şahl feines ibealifhou $30 \mathrm{gg}$

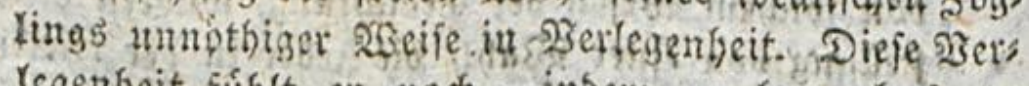

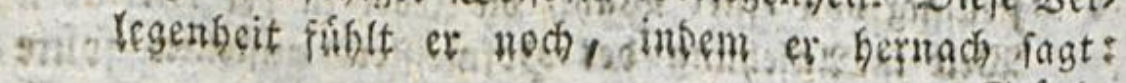
"Stúnte 


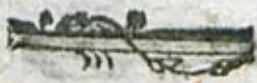

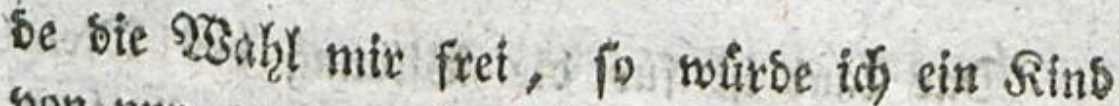

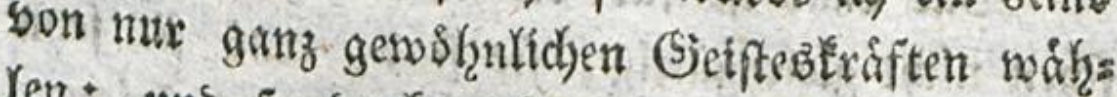
Yen; uns fo benfe id) mir meinen Lutergebes

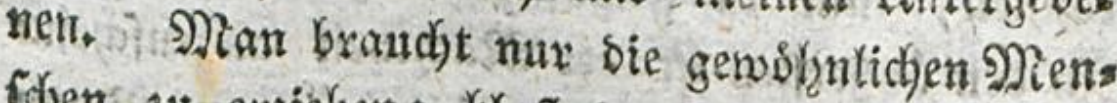
foren zu erziegen; Glops seren Erziefung mus Der Erziehung thres ŞYeidyen zum Beifpicle siea netr. Die andern erziehen fidy son ferbft; *) trof uns.

(3)

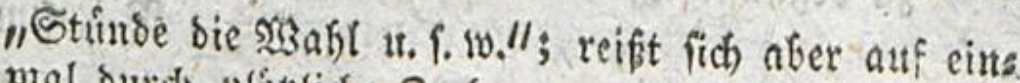

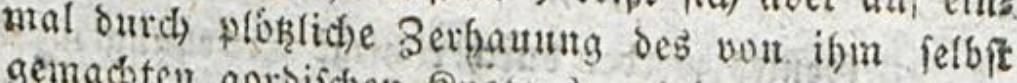
gemachten gorbichen Snotents auts ber serlenentheit beraus, inbem er gleid barauf fagt: „utho jo Denfe ic mir meinen lintergebentu" "Eglers.

-) MYas foll man, nach biefer fo tuafren ßjeobacistung,

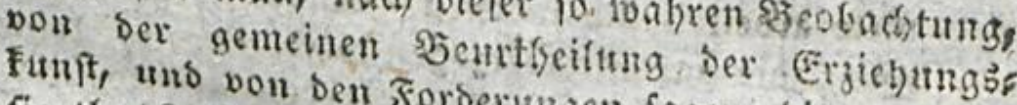
Funlt, uno von ben forberungen fagen, sie man an fie thut? Mian frágat, weldie grofie Diánner fie ges

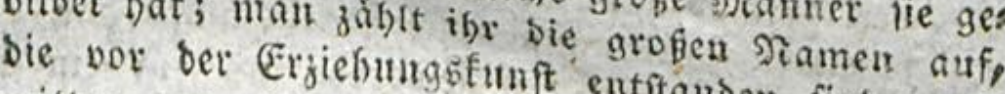
mitten unter ben

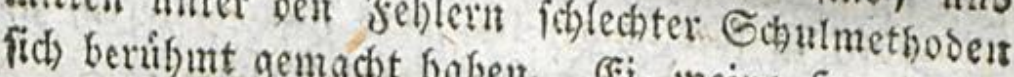

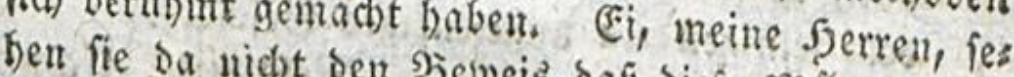

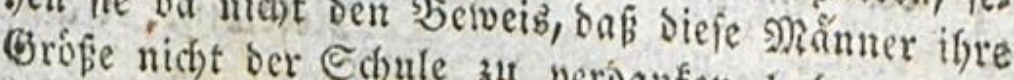
find trob ber Gente but veroanfent baben. Sie

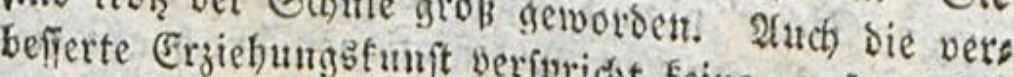

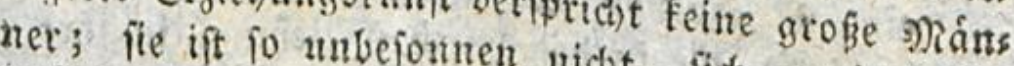
fichaft th wagen, utto

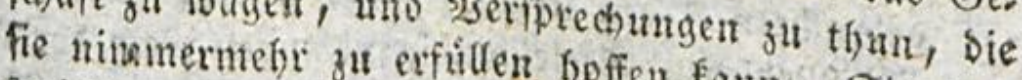

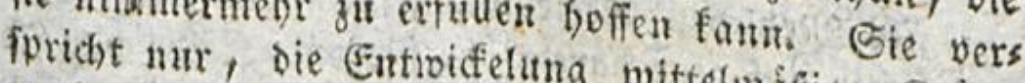
3u begúnitigent, who sarats

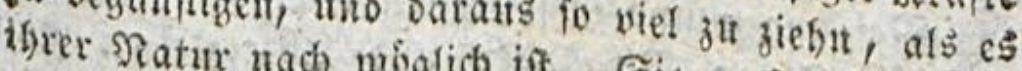

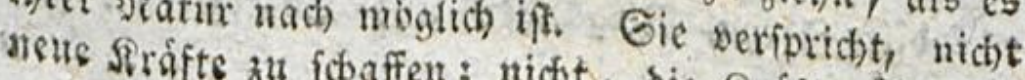

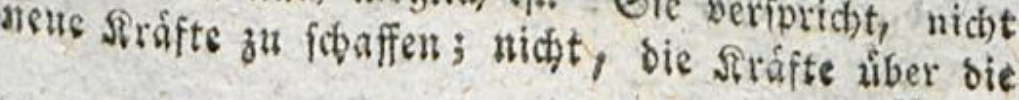

श्रiatus: 


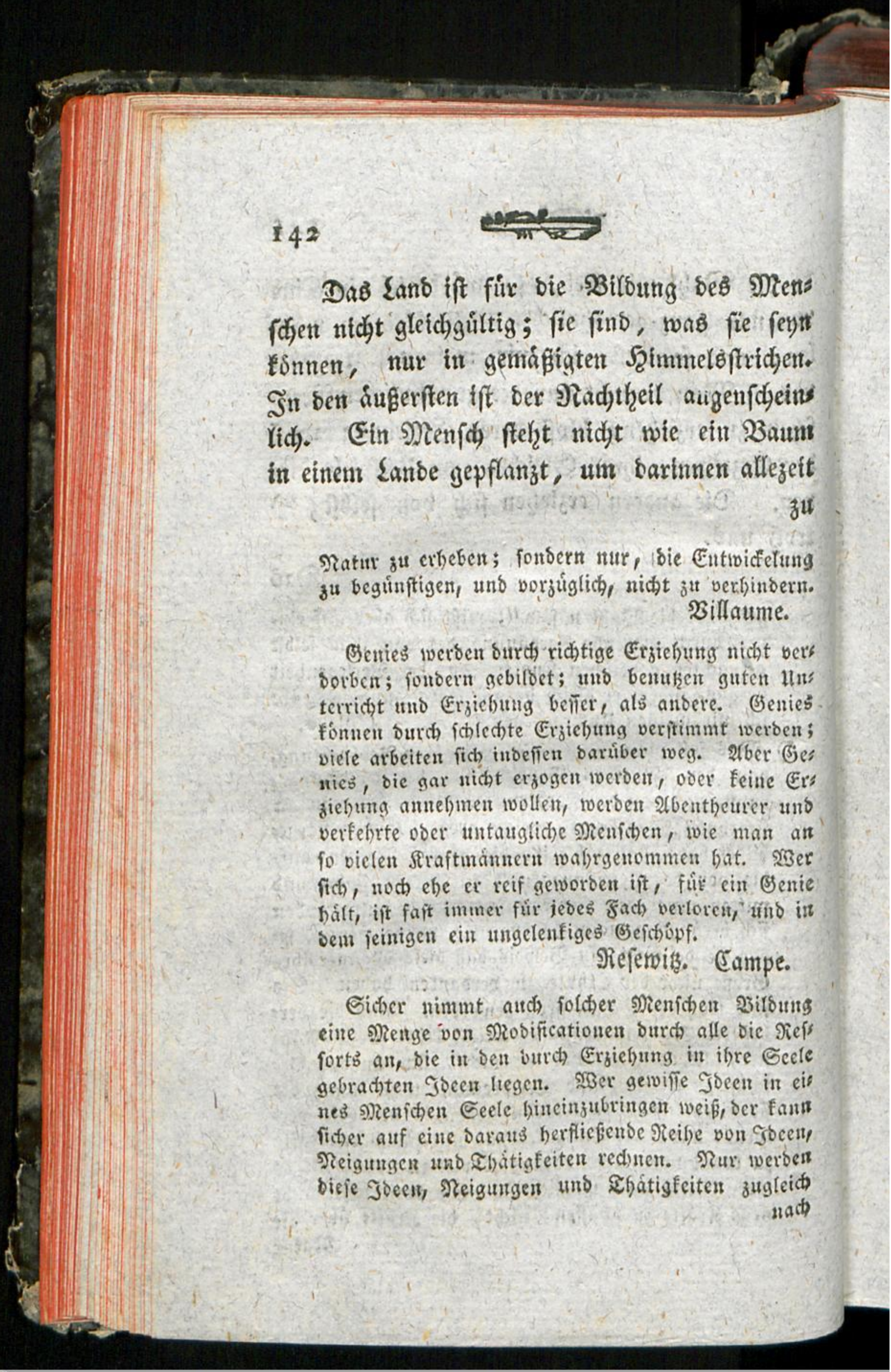


Ju bletken; und berjenige, Ser son einem ber Extremen auß̈geht, zum anbern fu tommen, bat ben boppeit groffern 3 seg zu madjen, wenn ex zu Demielben B̧iele gelaugen will, ałs wer bon ber פnitte an ausgeht. *)

Bereift ber Bewof̧ner eines gemáfigigten Sanbes reifherm bie beiben Extremen; fo ift feit Sortbeil nod immex angenficheinlidy. Denn ob ex gleich eben fo ftart mobificirt ift, alB serjes rifge, ber von bem einen áuferften snde bisz an sas andere geht, fo entfernt ex fid sod) gleid)=

toot

uach bem Naaf mit Syautmodificationen verbum: ben fenu, die cine SBbirtung eines bein Sinde eignen ober cinter untriebes find, als die Stârfe des sentes

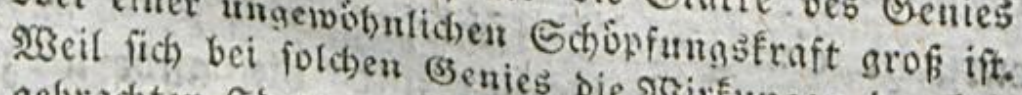

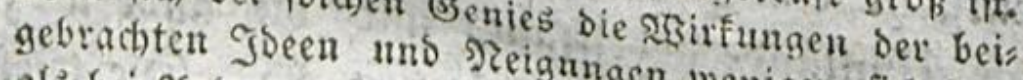
als bei Sfndern jeigen uns in wen weriger fichtbar, Das eigenthúmliche berborbringente Sirifungen, die: gleichian fich verichmelan Sbeobachter unb Denfer ben Benies nichts. So cintelsung vermoge bei fer if mun freilich গ⿰冫欠 nicht.

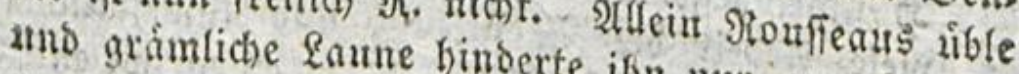
nen Scharfblid auf iede Spite cin mu ju oft, feis ten. Hno Das ift bod $34 \mathrm{~m}$ einer Sache ju richs fiben Denfen burthaus erforderliofichen infematts

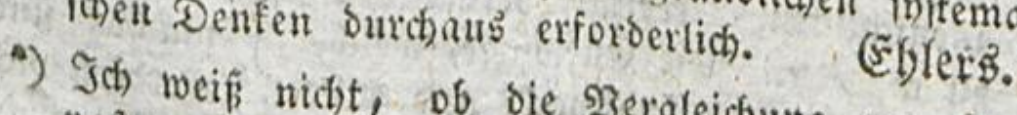
मaहt. SBenigitens ob die Dergleichung zur Sache

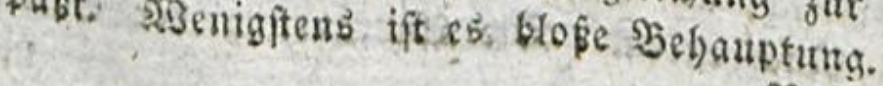

Rejervis. 


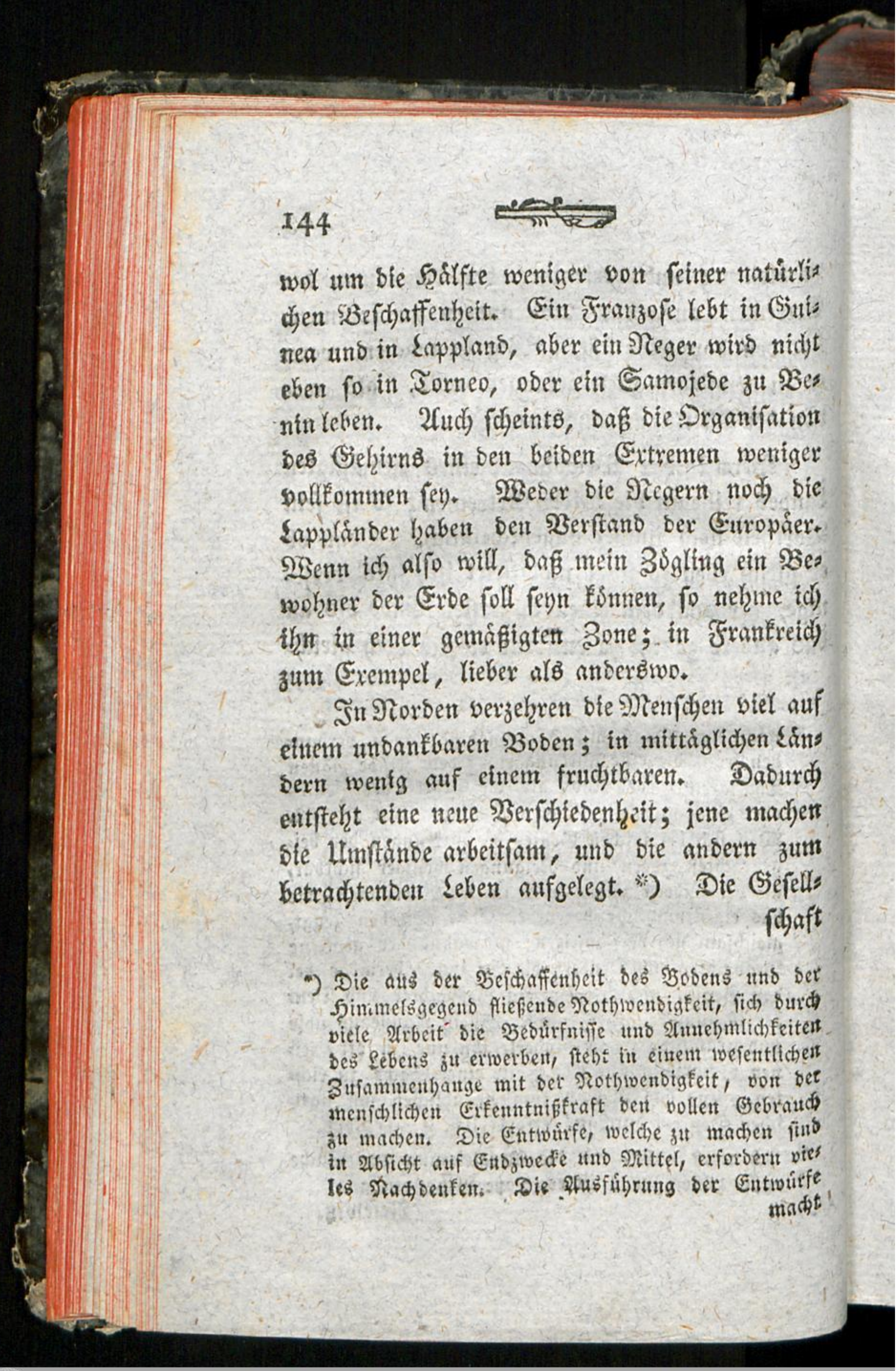




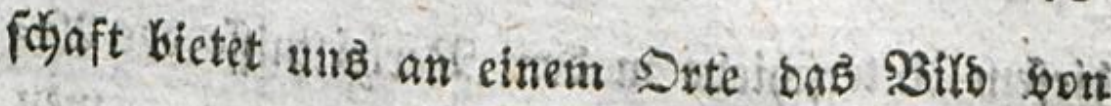

matht, fernach fein theoretifdyes Denfivelf practifh,

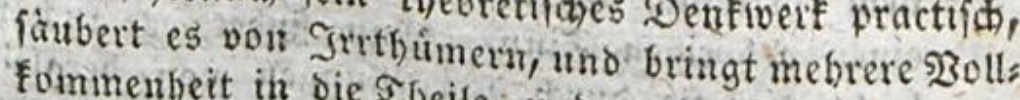

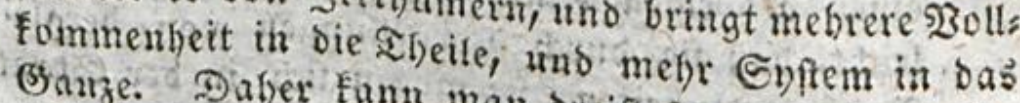

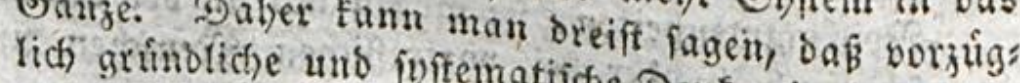
Siorben fin liegenven Esndern gefufer in ben nach Fir bie शeatur ber Erfins ing fefunden werben, woor: fraft ber Menfothen fin

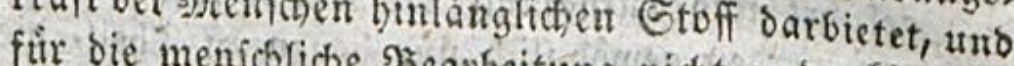
fn ben fistichliche গ̧earbeitung nicht undanfbar ift, In den fúblichen (3egenden, wo Die SRatur von Felbft bie

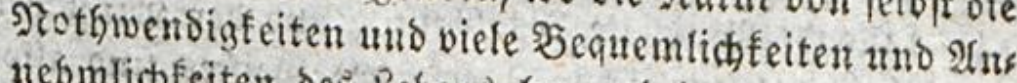
nebmlichfeiten bes Lebens bervorbringt, und two ber Nenich nut alles aub ben anbietenden Jánden ber Nar tur aunebmen barf, find die DenEwerte bes Mienichen grofitentfeils fruichte bes blofen sriebes bei ertfennt nif̧́fraft, wobei bie oft peinigende langeweile mit eine Pregetin abgiebt. Da giebt eb bann einzelue bucte bes menfinon in bie \$hantafie fallende Pros enthalten aber felten Denfens uno Ginnens. Diefe terte SুSafurbeit und Pintánglids reine und geláu ben aber bie verichiebentidseit. Taft nie wer:

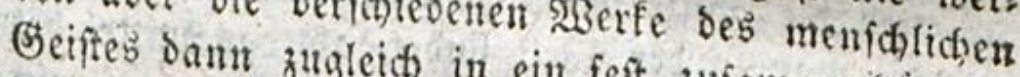
bes Sriftem gebract). (s. ein feft zujammenhännen

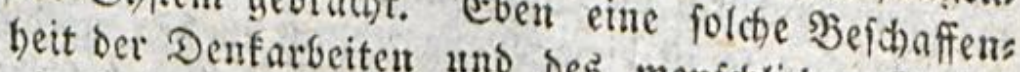
glaube ich auch allgemein in bes menistlichen (5)enics ben bei Denjenigen Röpfen ben norblichen Gegens ben, bie im Heberfus oce Thatgenommen zu ba: Anuebmlichfeiten, bie ber Notbwenbigkeiten und fie bervorbringen, leben arbeitenden \$ुriber fúr grundlichen und fojtematifhe baben felten fur bie bie erborne njtematifchen Denfarbeiten unb fúr

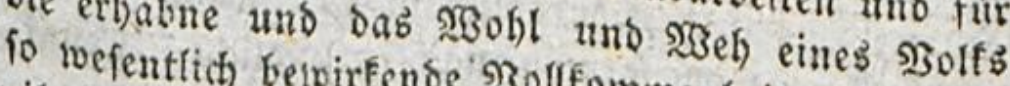
Emil Ifer $\mathfrak{s}$. nein 


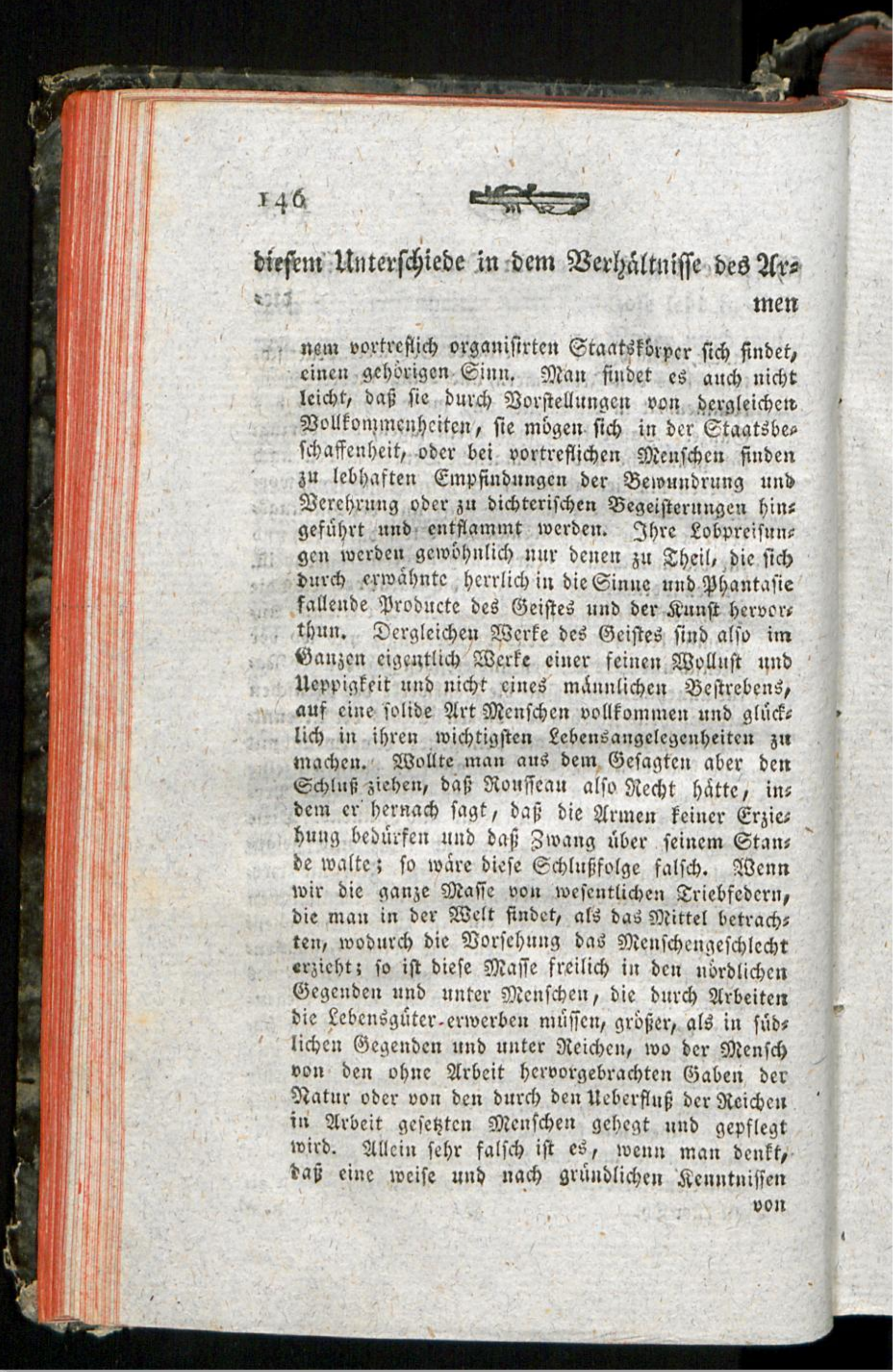




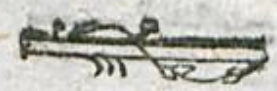

\section{men zum SReidjen Sar, Die exfern berwohnen \& 2

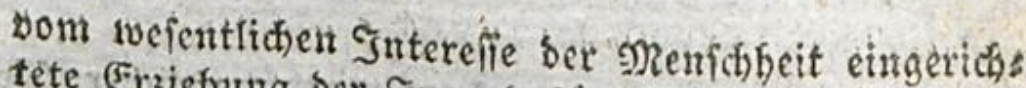
tête Erziefung ber Jugend fur bieienigen, bie ourch Rine, nicht felbft alles auts ifrem Schoofi bergebente famfeit hingeleitet nerden burch 2 rmuth fur Nrbeits

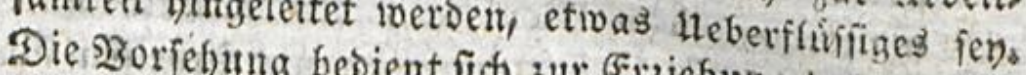
lichen (sefchlechts nidht nun jur Erziehung des menichs Der menfols nibt nur ber gangen Diganifation Hinftichen Natur, nicht mur oer Dinge, bek fchen winfent ber Şeburfutifie, die anf ben Nens (t)en wirfen und auf welchen er wirft, nid)t nur ber

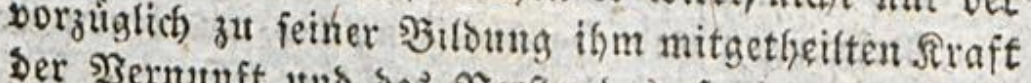

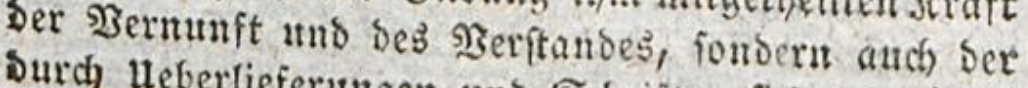
surd, $\mathfrak{H e b e r l i e f e r u n g e n ~ u n o ~ E d ) r i f t e n ~ f i c h ~ a l f m a ́ b l i g ~}$ anbáufenden Maffe der alle Hrten von menichficher פolffommenfeit und Gltidfeligfeit betreffenben alls

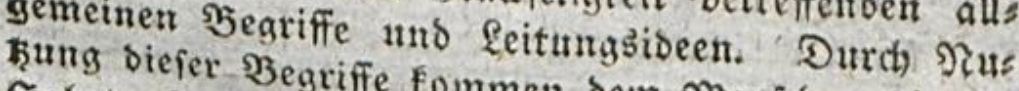
Jahrtaufenden nad) fommen bem Menfichen bie in rungen und Sentntuiffe ber nach gefammelten Erfahs gehoren in ber That Jabrtaufente ju ftatten. EB Renfich fo weit fommt, de Sollfommentbeit, baf er alles, was perfontis גiberbaupt, uno buit, gefellf(h) aftliche \$̧ollfommentheit

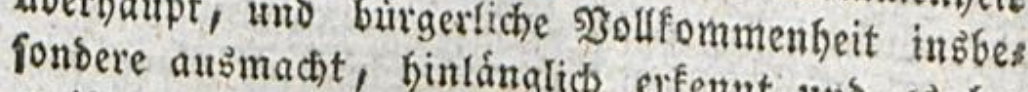
greift, wie diefe verfchiedench erfennt und es bes menbeit unb Bithiffeligfeit in Strten ber Sollfoms unb bie bazu geforigen Syftem zu verarbeiten fern. breipt jagen, bas man noch in feinem oarf es ja wor wiffen uno beutlicben Senntnifien Gtaat zu ges zu einer vollfommenen ftatsilfen liber alles, was aifation eines Stants exforscrlid if 


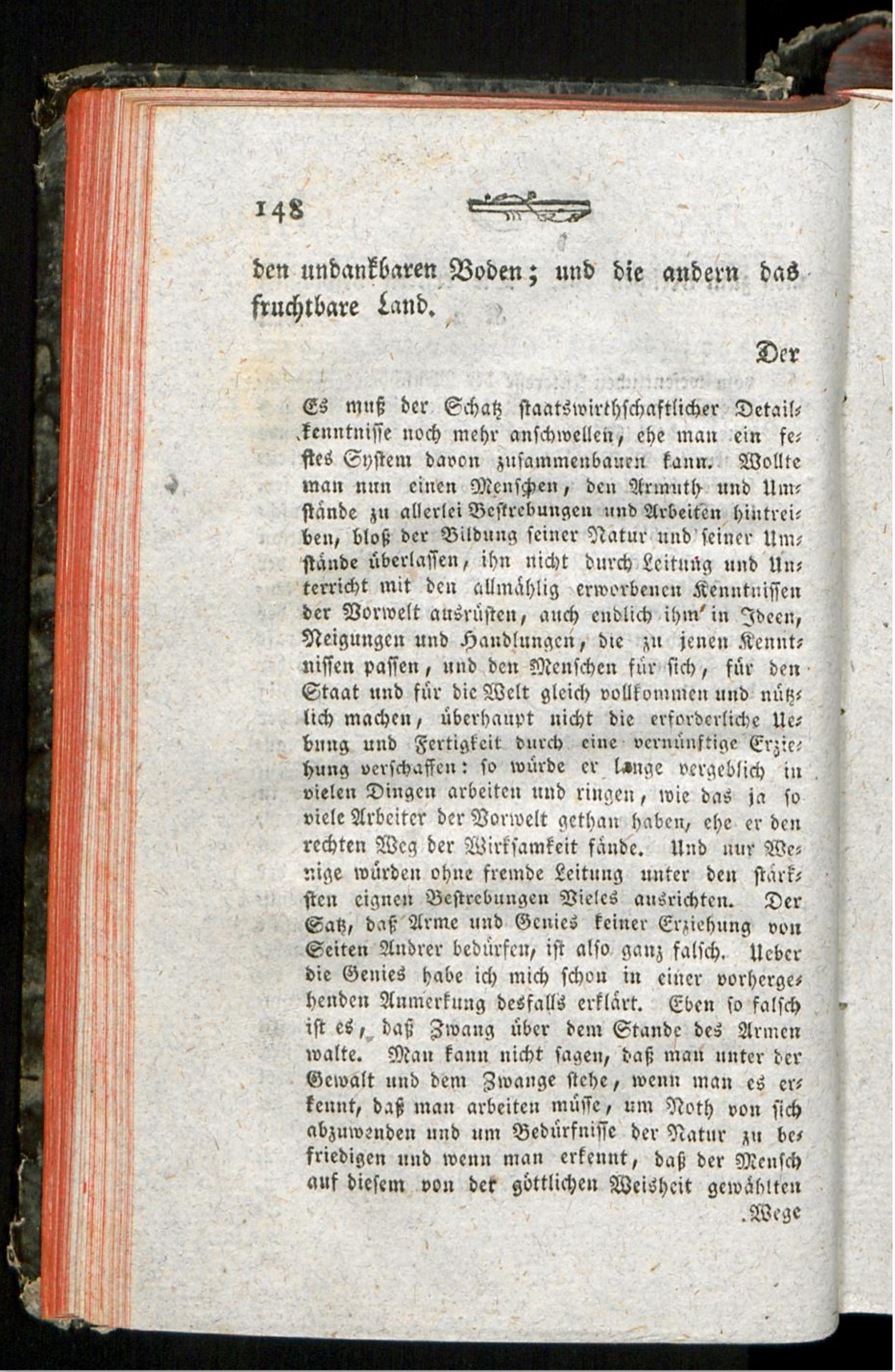




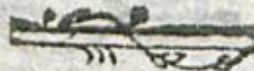 \\ Der 2rume bebarf keiner (Erziefung; *) 3wang waltet iber feinem Stande; ex hat bie, 爪 3

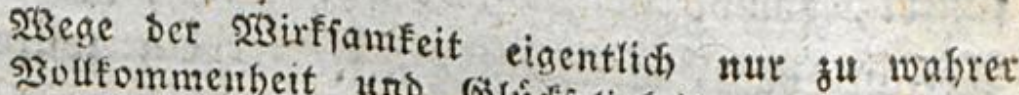

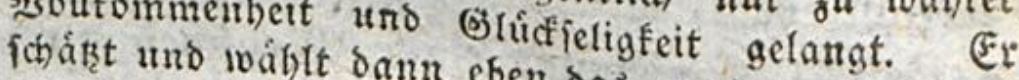
erforbern, wilffithrlich und bas, was bie ttmftánbe

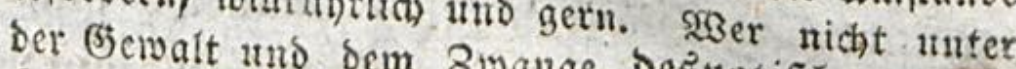

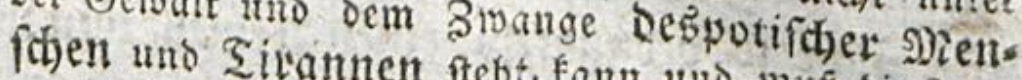
worin ifn bie Niatur uns beren und min bie lage,

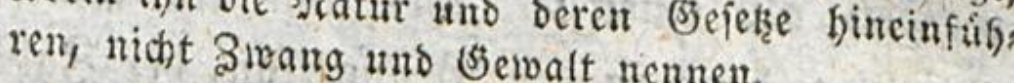

(5) leţ. Siejenis.

*) ए: witro ieber unbefangene uno verftánoige fefer

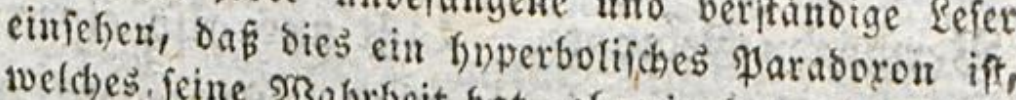
welches. feine $\mathfrak{Z}_{3}$ abrbeit bat, aber in ber ganzen 2 tt gemeinheit bes 2 usfpruchs nicht behauptet werben faun. Allerbings bebarf ber Arme (5rziehung, nidht

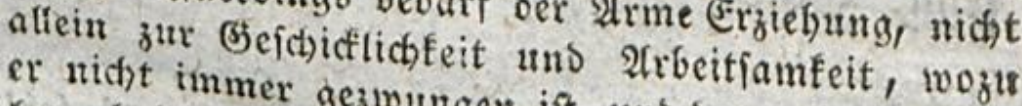
brauch ber wor gezivungen ift, uno ber er burch geis: entgehen faum; (ondern genichenliebe nur allzu oft Reniclentiebe, zur 3ufriesenbet, sur 3 ermunf, zur Den bitgerlichen Tugenden wahr, baf feine sergenden. - Das ift aber auch ter, als bie des

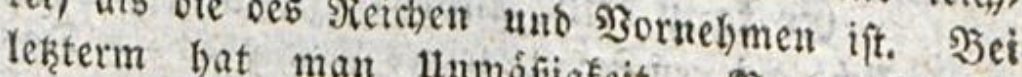
Stols, Evedfeit uno alfe

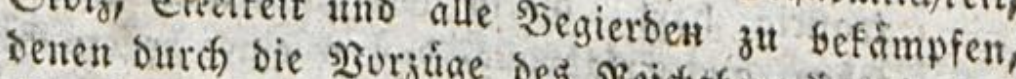
Standes ein freies fels des Feichthum sto und bes beiten uno Zafter bes Reichen un 10irb. Die ₹for= gefáfrlicher, weil fie mefrren unt গ̧ornebmen fino baben, uno in einem grifere $28 e^{2} f_{z}$ etrge uns. Stráfte nus folat aber gar nicht bap Steife wirfen. Dax

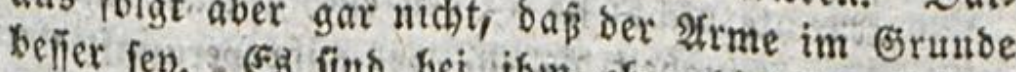
bener fen. - (5g. fint bei than eben biefelben gebler

Efor 


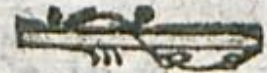

Die ex haben fant. Ejegentheils entufängt bet Reiche eine foldhe Erzichung, bermoge feines Standes, wie fie fid) am wenigften für ihn fojict, fowol in 2lbjidyt feiner felbrt, alö in 2rofidje dex Eefellfijaft. 2lufervem follte sie natirlidje (5rzichung einen Menichen zu allen

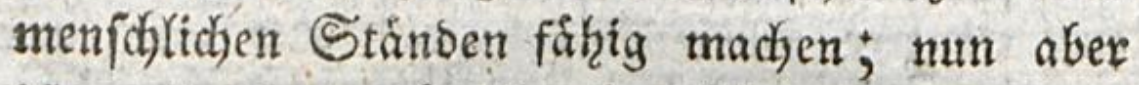
ifts nidjt fo beuninftig, einen 2Crmen zum গReidy= sorben als einen Reidyen zum 2 Srmtverben zu

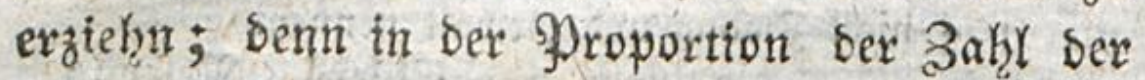
beiben Gtánde giebt es mefre Berarmte als zum SEermógen Sielangte. Laft uns alfo einen গeis d)en wáhlen; wir werben wenigftens gewis

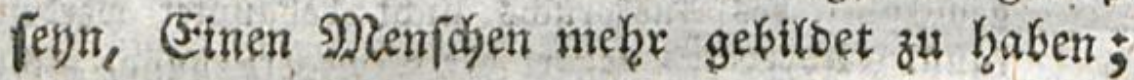

ba

beiten, Fegierben unb \&eibenf(h)aften; es fehilet its sen sutr an s) zitteln, fich fo ftarf zu entwiffeln uns fo nachbrúdflich yt wirken. Der giger im Siafig iff sticht milber als ber in bem şalbe; er raubt nicht, allein mar, weil or nicht rauben faum.

Er fann feine andre (Eviebung babent nams lid, als ben alwang feines auftandes - Das wáre traurig, hart. (E) it aber auch nidgt wahr, sूBir - Tehen, atts Eviabrung, Daś er eincr beffern Bitbung, einer fobbern Berebling fábia ift. Sho Szerzen ber Nenichen, laffet eudi) Paraboge nicht blenten! Sicin Buftand beraube den Nenichen feiner soúrbe uns feiter Riechte. Derfindert die Bereshung eurer fited)te nicht; fie werben euch eifriget und mit mels reree silugheit bienen, wenn insoverninftig und bifs lig fend.

3iflaume. 


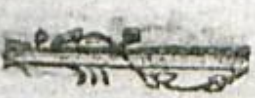

$\$ 5 x$

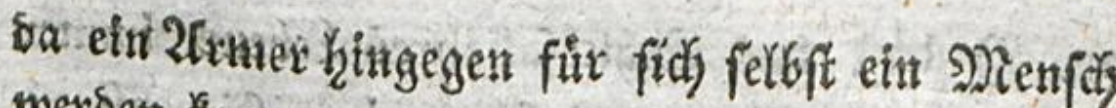
werben fant.

2us bemfelten Strunbe follt's mir nidgt leis Fern, svenn mein Emil son Eeburt ware. (5E if imner ein Sdylachtopfer mefye sem Sorut theil entriffen!

Emil if efne 2 Salfe. Er braudst weder SBater nod) Mitter zu' haber. Da idh alle

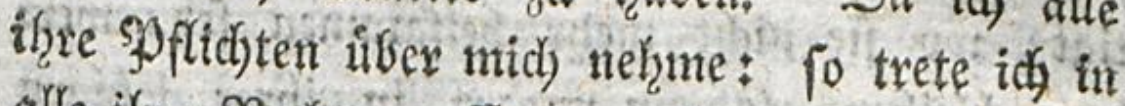

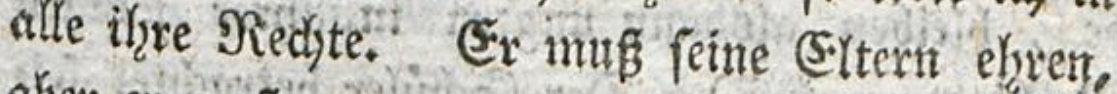
aber er mis nur mir getrorchen. Dies ift metne erfte, oder vielmehr meine einzige Bebins gung. *)

Sch mur nods biefe binzufifigen, bie nur eine Folge saraus ift, bą́ man uns ntemalż Eins gon Dem 2fnbern, rufier mit nuferm gute: sigillen, twenne. Dieß ift eine wefentlidge Efauta fel, uno id wollte fogar, ber asgling uno ser Szofmeifer fôken ficy fo fehte als unzertrennbar

$$
\text { R } 4
$$

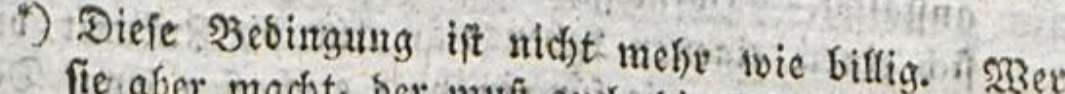

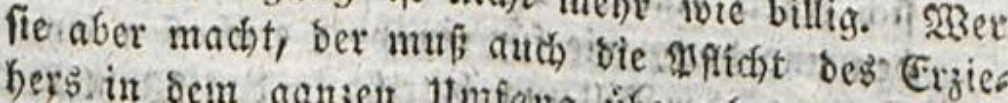
bers. in bem genjent thimfing tibernetimen, ben $\Re$ ihr : giebt, Es giebt, feitbent $\Re$. Gbles gefortiebent

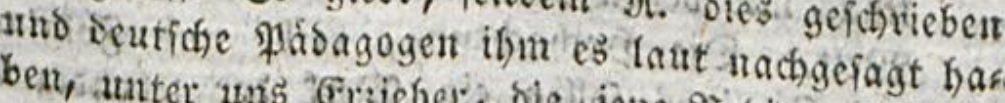

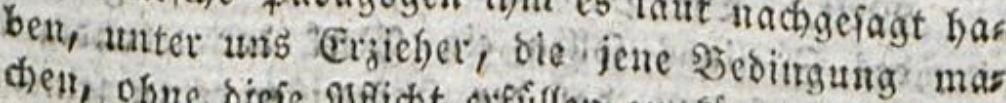

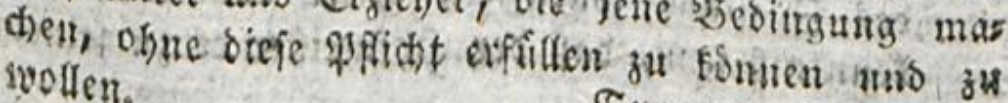
wollen.

Stapp. Emmpe. 


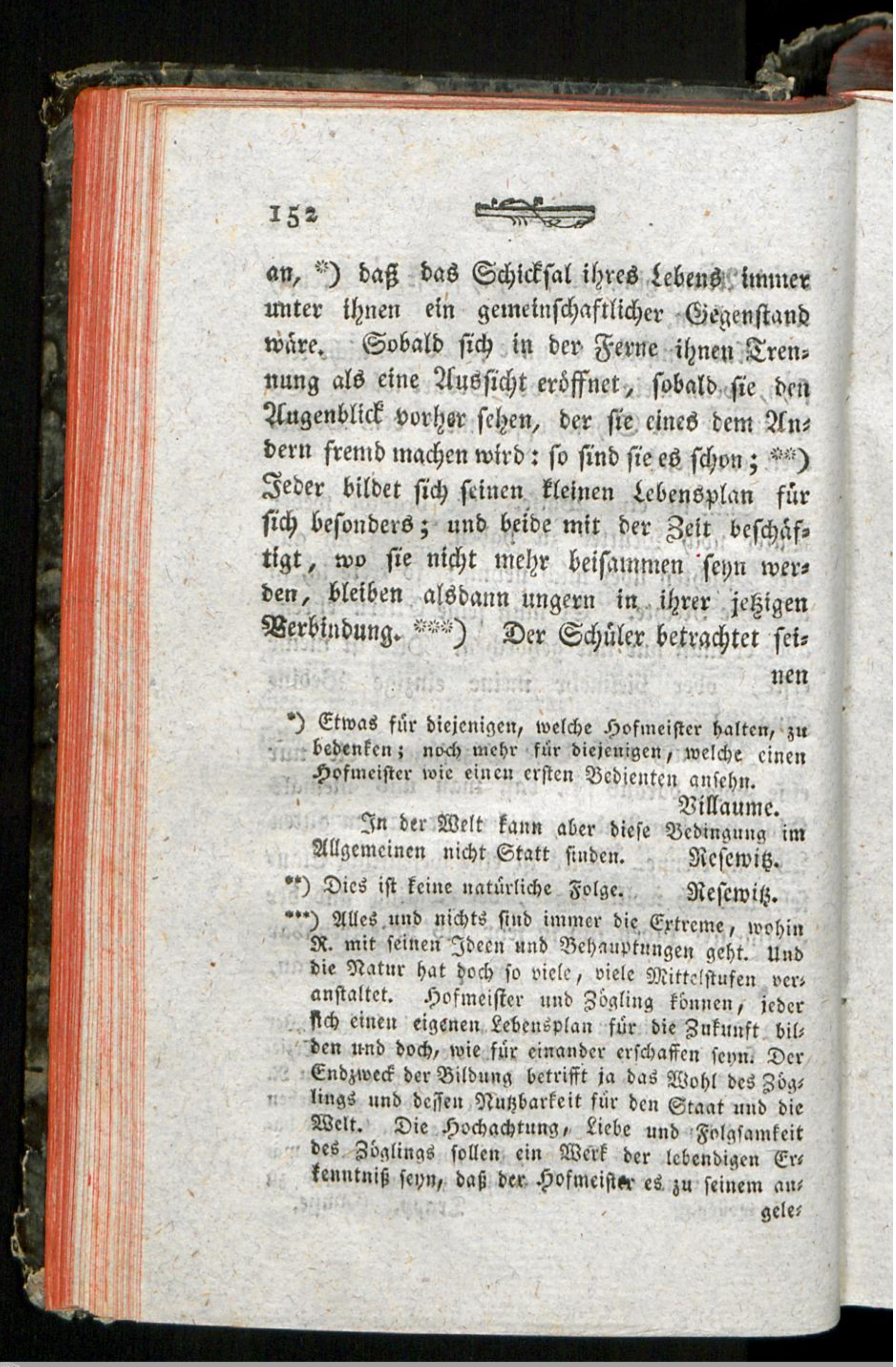




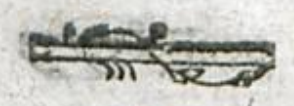

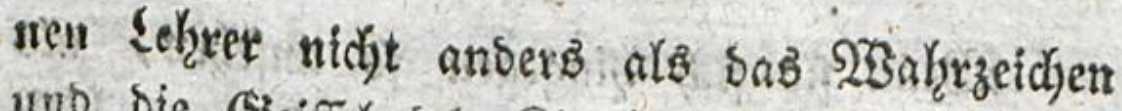
Imb Die Seiffer bér Sinsheit; ber Sebuer ben

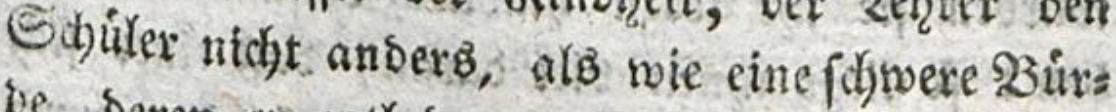
be, beren ex entlaben zu werben brentit; beloe fibner fich nach bem Fugentrlicte, wo jeo s som andern befreit fenn wirs; $)$ uno ba folglich unter ifgnen nie eine wahke 3uneigung Statt fin Det: fo mino ber Sofmeifter naturlichex SEeife wewig Sgachjamteit uns ser Schúlex wenig Forg: fainteit baben. $*$ )

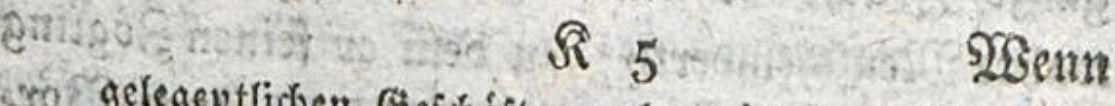

wo gefegentlichen Geicháfte mache, ienen Enozived zH erreichen uno baf er in allem weife fandle. Toeen einer fortbauternden Berentigung] werben fúr જुeibe wol etwas Reizentes baben und wol sarauf fich bes

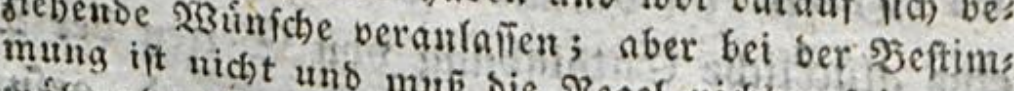

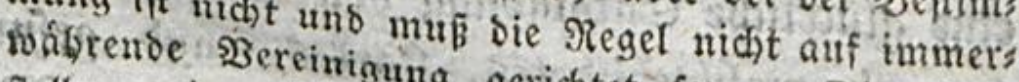
fleflung ciner finftigen gerichtet fenn. Die SYov aus nicht bie Soirfung, Drenmung hat aud durchs bindung unangenchm und begenwártige গুer: gentebme Empfinoung, welche werde. Die unans Soritellung ber fing, welche juweilen burch bie bervegt vielme hr funftigen Irenning-veranla bit wiro, lieber, fich ber gefmeiter tund Bógling, bie fich mehr zu frestl.

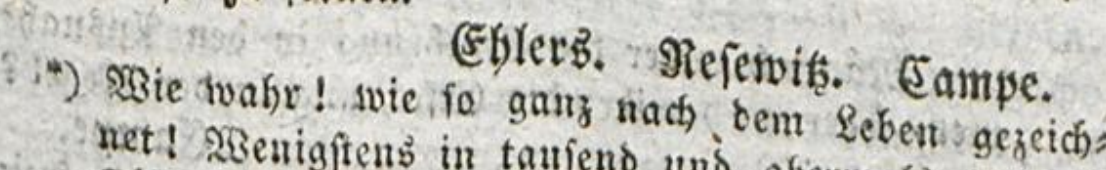
net! NBenigftens in taufeno und abermals tauieno zófllen.

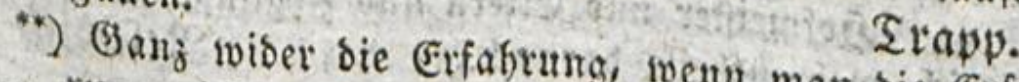

Sim: xumg nicht vou fhlecten fornt man bie Erfabs - Gernimint.

Eुblers.

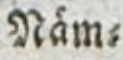




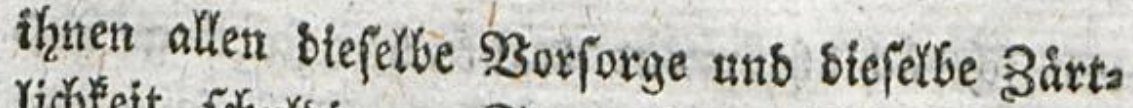

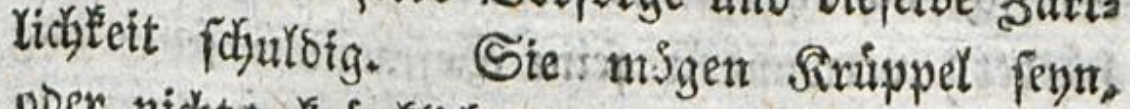

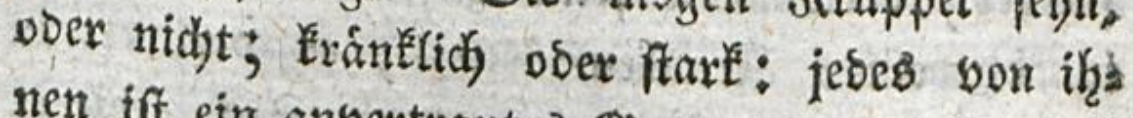
nen ifit ein anbertrautez Giut, bon bent er ber

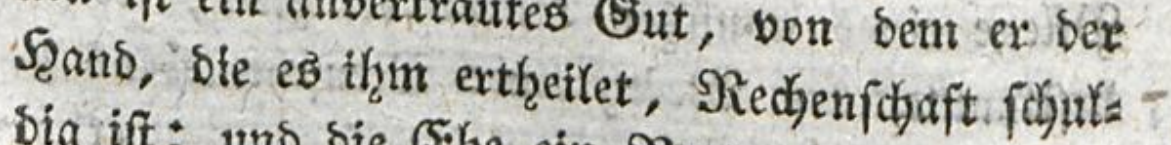
sig iff; uno bie Eifge ein Sertrag, der mit bee Siatur fo gut als unter sen \$3erkunbenen eint gegangen morben,

ZCllein Seber, Ser fíd eine Wflidjt aufers Yegt, welche sie Statur ihgm nidjt auferlegt Kat, múf fid zubor ser Mittel serficteen, fie zu erfítlen; fouif unterwirft er. fict felber in $2 C_{6}$ s

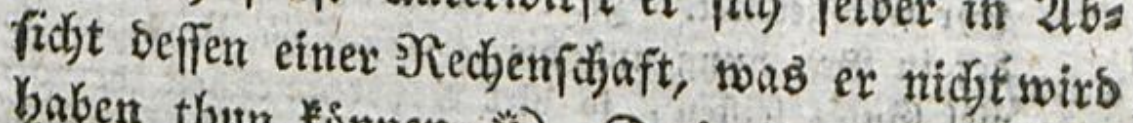

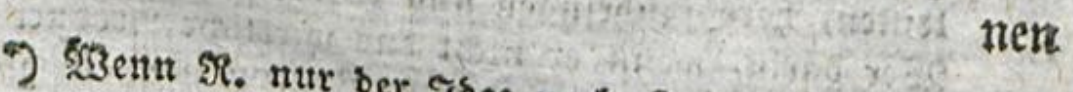
fo fteft es ifm aud frei, fich sofmeifter fenn will: fen llmitanbe zu benfen, wie er will Emil uno befs bei weiter nichts zn beobachten, als bos all hat $\mathrm{Das}$ er annimmt, wabrfcheinlich fen bas alles; to as

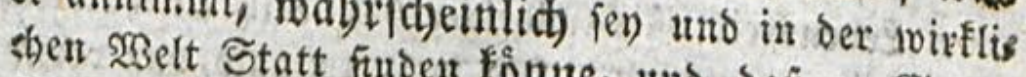

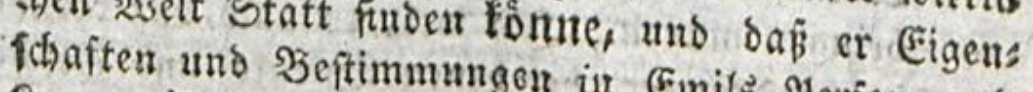
Zage wáfle, wovon or bie meiten uns Petion uns Inlaffe berleiten Eann, iebr lehren naturlichften şas er fo thut, braucht er fehrreich Ju werben. Setrachtungen, als or in feinesweger auf folde

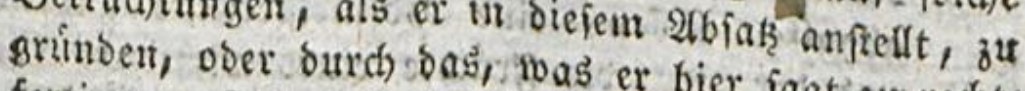
fertigen. Der ganje fuffas or bier fagt, nem 3 ufammenthange in beftht ourchans in feis

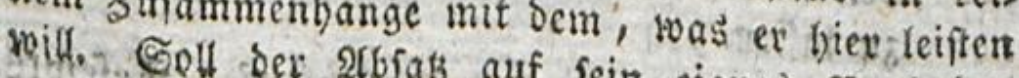
toin. Solt det Afbats auf fein eignes \$orbaben 


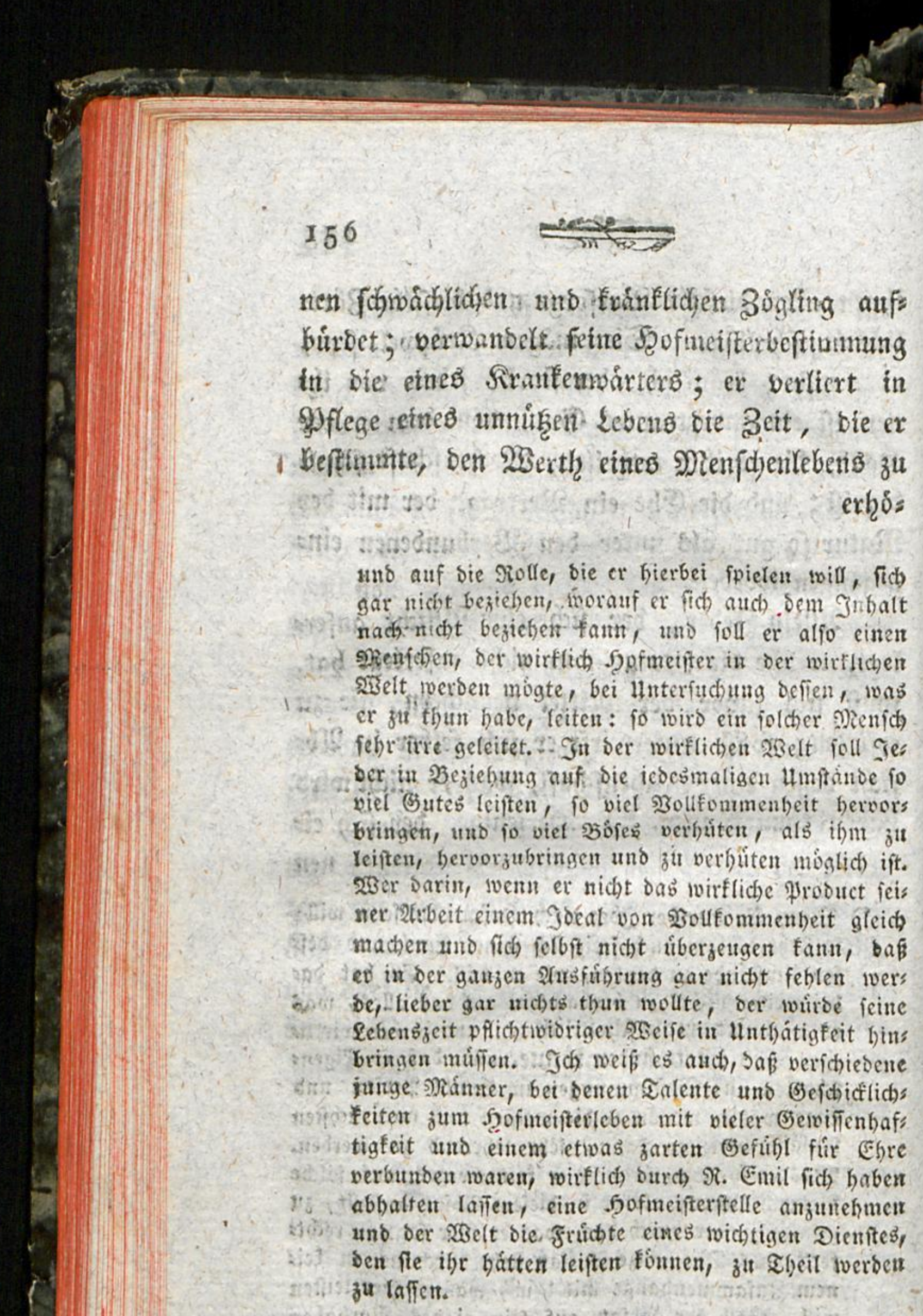

Eblet:s. Nieferwik. 


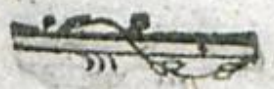

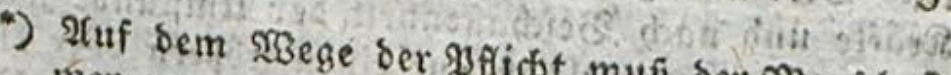

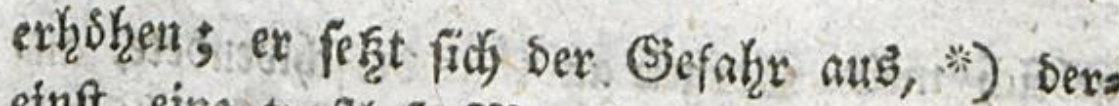
einft eine troftloje Mutter zu fehen, bie ifm ben Iob eimes Sohnes bowwirft, ben ex lange wirb exhalten baben.

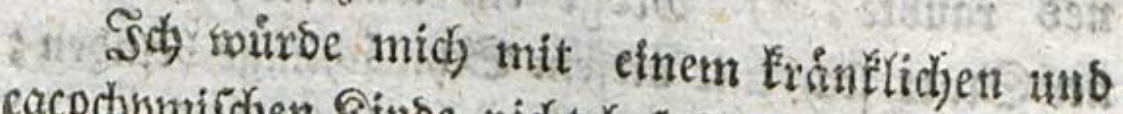
cacoctyntifgen Rinoe nidht befafien; **) forte es

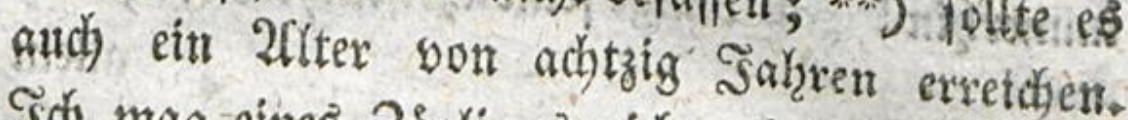

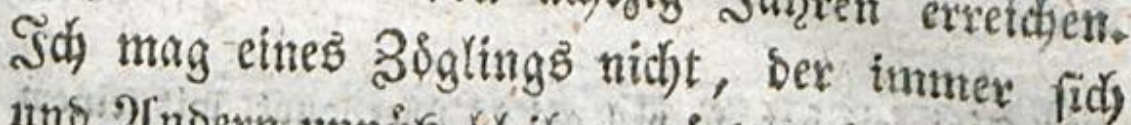
uno 2Tnoern unnis bleiben wirse; ber fidf ein= zig uno allein mit feiner Erbaltung berchaftighte,

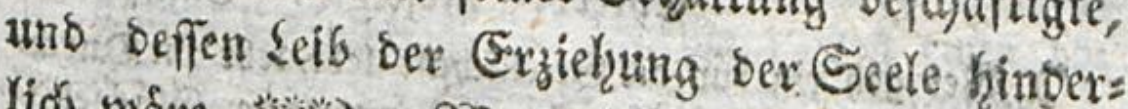

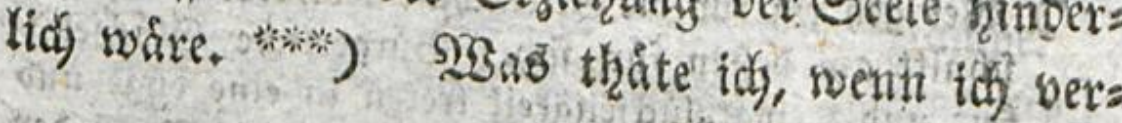

mer inancherlei of Hnbanfbarfeit, ungeren unb auch ber (B) faht ber lei Nisbeutungen ausfer Szorwurfe und manchers

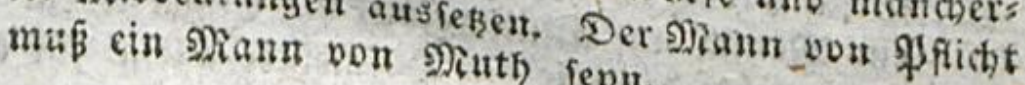

(E) lets. Rejerbib.

*) Dab wuirbe ein Anbrer, feinen faunen gemán $l_{e}$

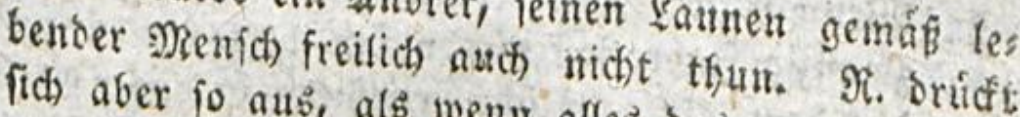
(iid) aber jo aus, als went alles bas, was fur fols de leute gilt, fur Jeben gelten fonnte uns dirfte.

***) Itno boch láft bie গুor

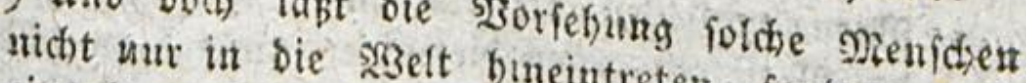
eine lange febenszcit fintmeintreten, fondern auth

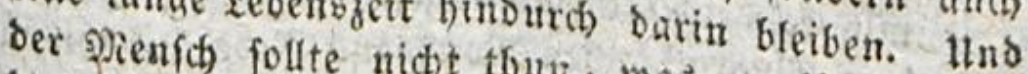
bas Dafenn folcher theter, was er fornte, um

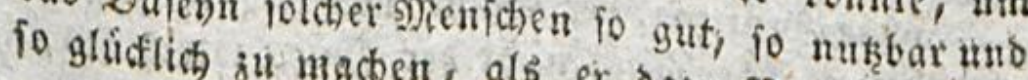

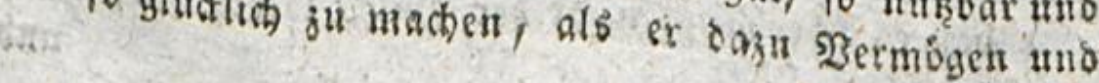
Fóbigns. 


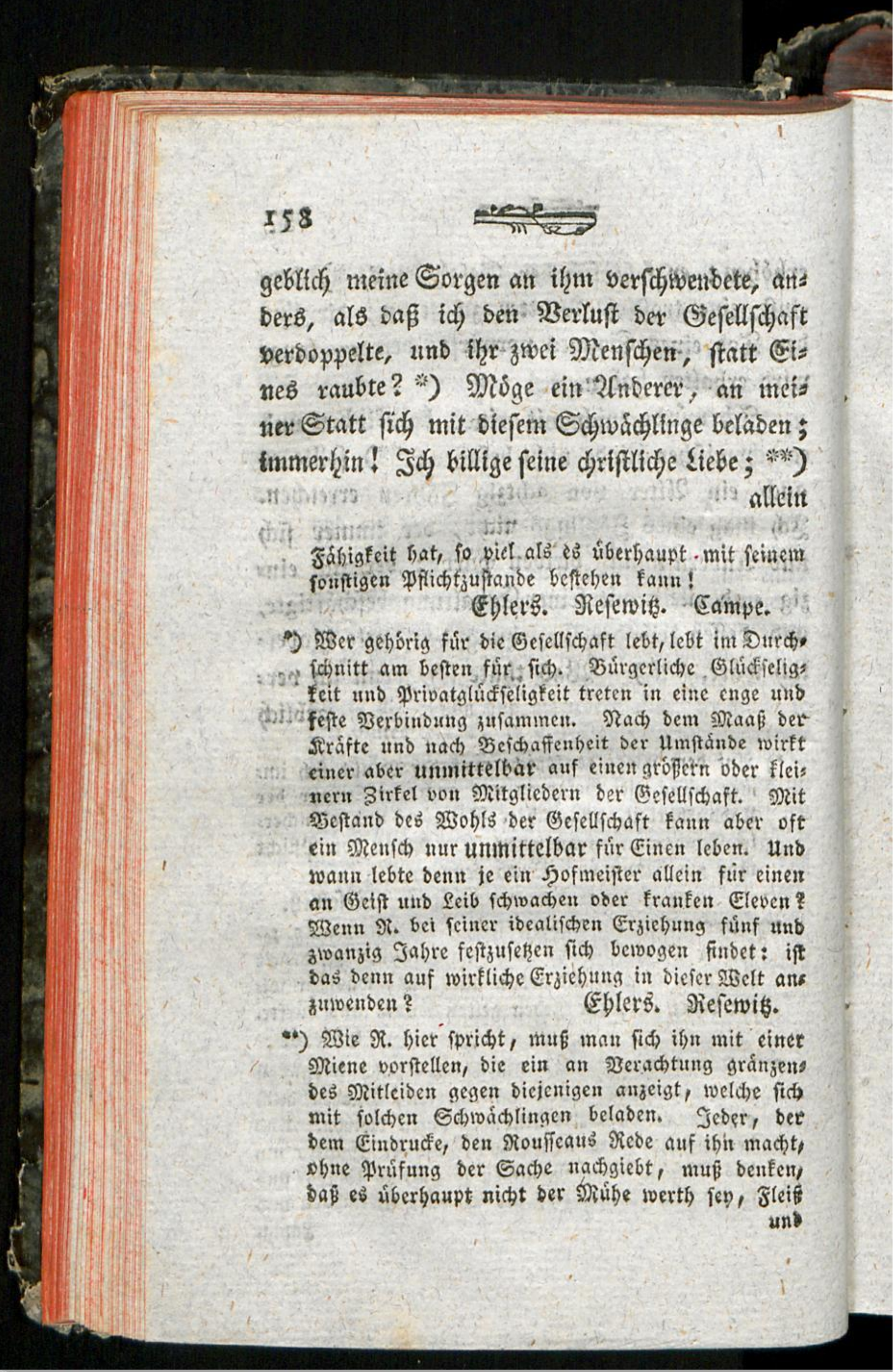




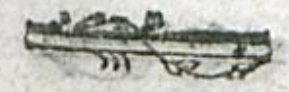

allein meine Gabe if bas nun nidjt; idy ser

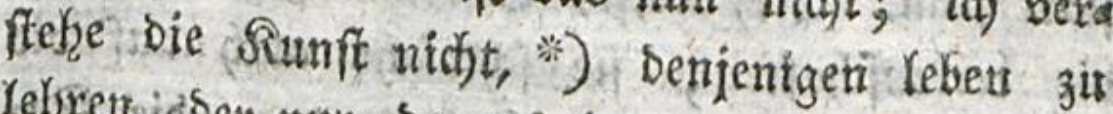

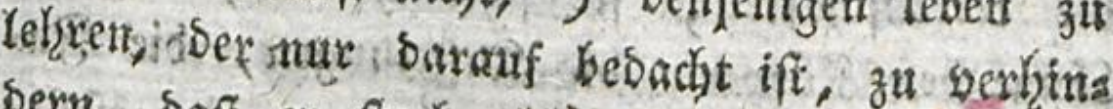
sern, bafiper fterbe. **;

Der Riorper mufi Riraft haben, mit ber Seele zu gehorcyen; ein guter Diener num का

fart

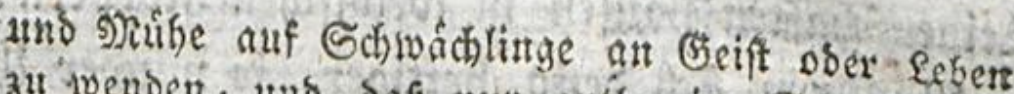

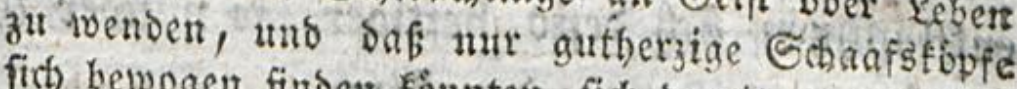
fich bewogen findor fornteit, fich, bamit zut befaffert.

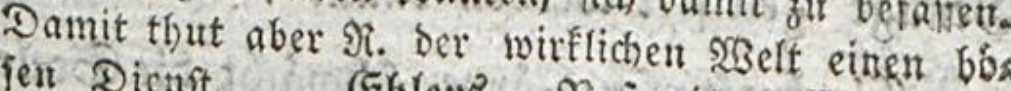
Fen Dicut. Eblers. Rejewis. Eampe.

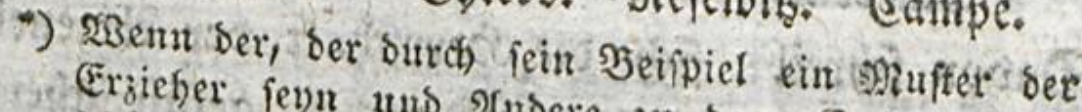
Eroiefer fevn und 2trdere

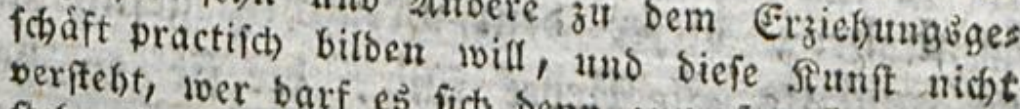
verffebt, wer-barf-es fich benn anmafen fie zil vers

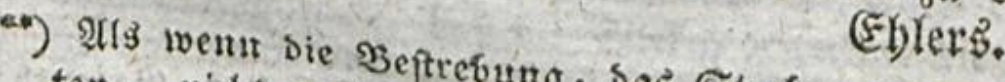
ten, nidht wejentlich of bas Gterben zu verfais

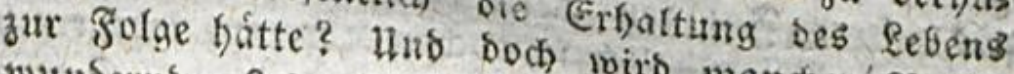
wutbertwer feier fo ridt toiro mandier' $\Re$. bes

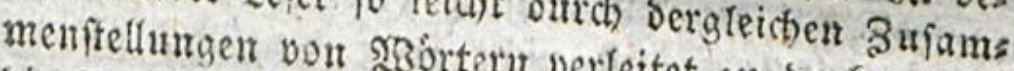

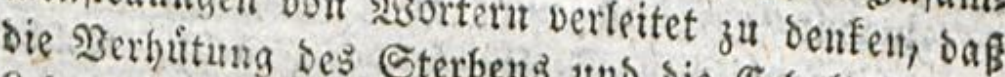
Rebens 100 etwes Sterbens und bie Cirbaltung bes

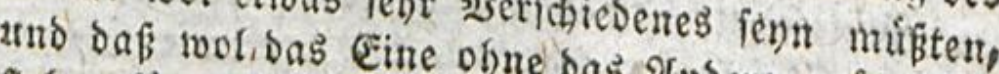
ftefen föntert.

Diefer Tabel trifft nicht

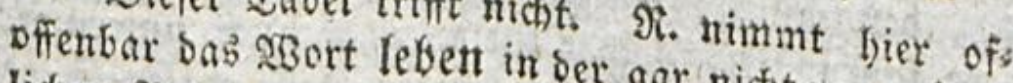

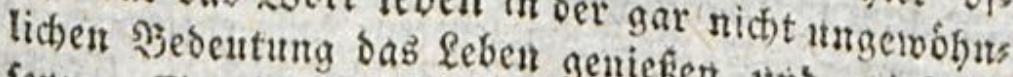

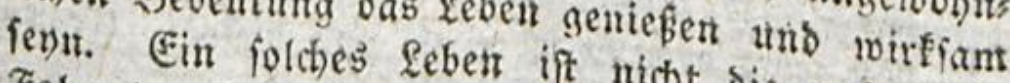
Folge der ß̧eftrebung, Das Ster Davon if mur bas গुegetiren obeen z" verbuten Folge.

Stuve. 


\section{0}

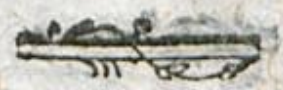

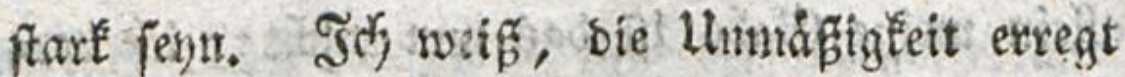
bie Eeibenfiduaften; fie fortodest and auf bie Sange ben Siriper; Die Raftetungen y sobie $g a$

- ften bringen oftmals burd) eine entgegengejeste Lirfadye diefelben S3irfungen herbor. Je fonwa d)er ber soib if , Deftomehr gebtetet, je ftarter cr ift, Sefto beffer gehordyt ex. 2role finnlidyen Seibenfichaften baufen in weibifidyen Roxpern; fie entflanmen fich befro beftiger, je minber thmen Sienuge geleiftet werden famn.

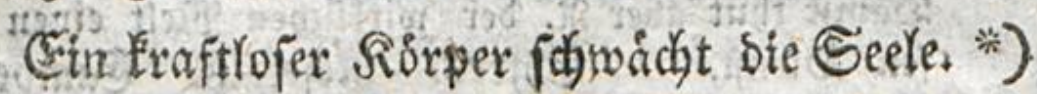
Dason foreist fich Die Serrfdyaft ber 2 rzzeneis

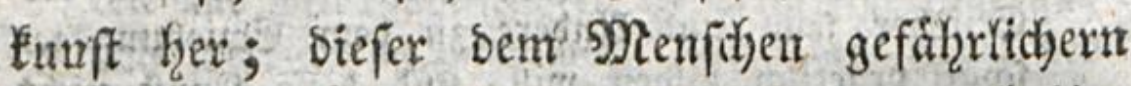
Sinnf, als alfe lleber finb, die fie zu beilen

bors

*) Sherr foumey belpauptet arabc bas Begentheil. "In-uriprunglich forwaden fiorperu, fagt er, haben altemal bie am meiften whiloiophifchen Seelen ges woobut." Es ift nicht recht beutlich, ob er unter philofopfifiden Geelen foldhe verfteht, welche von

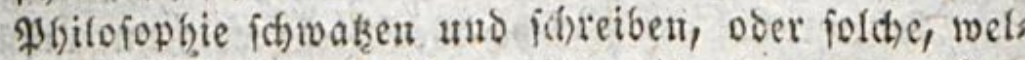
(h) Whilofopfic ausutben, alfo mit exfeuthteten (Ein fidten eine hervorragende Etatife ber Seele verbin: bell. Im exiten falle batte er, facint eb, bie Ers fabrung auf leiner Seite, aber aud) unfern 2 . gar nicht wiber fich; im leţtern Falle entfernte er fich von iener eben fo fehr, als von biefem. Eampe.

Inbeß ift biejer Sak des $\Re$. nidft allgemein

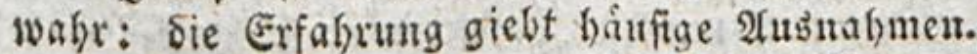

S?eferviş. Eampe. 


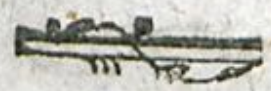

\section{I $6 \mathrm{I}$}

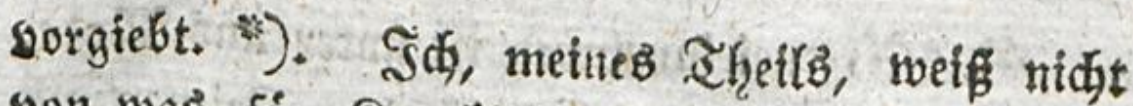
won was fúr Girantheiten unb bie 2ferzzte hets

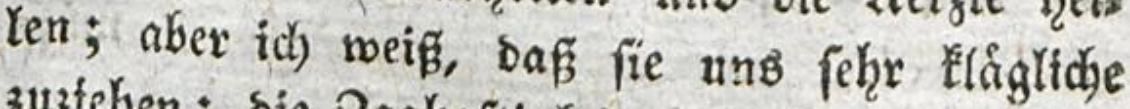
zuztehen: Die 3aghaftigkteit, sen Fileinmanth, bie Eeidytgláuligkeit, bas Sdyrecten bor bem Tobe; wenn fie ben Rörpex heilen, fo murben fie ben

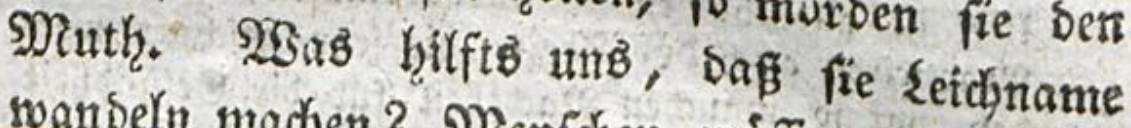
wandeln macten? Menfduen miffen wir haben, und bie fiefht man aus thren Sợnben nidjt ḩer. vorgefgn。

*) So fehr bie গુortuírfe, welche $\Re$, bor bier an bets

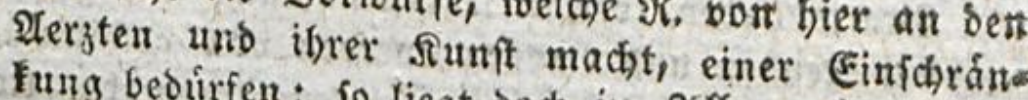
fung bedirfen: fo liegt boch in Sillgemeinen viel fér zu wabeit babei zum Grumbe; uno es váre recbt

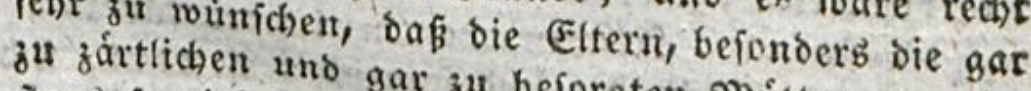
itens fo viel baraus zu beforgten @utter, wenigs es in neut zállen oon zefn find ber scatur at den immer befer fen, bas Fer zut libergeben. Sint zroat in vielen te lestern werden bas franfe ben meiften wurbe fien heilen fonnen; aber its fung der ber Natur bat bor getfan faben; und die Nur

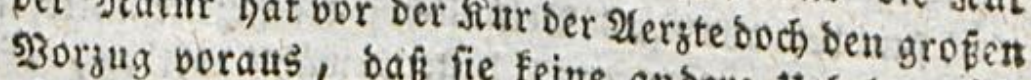
lábt, die oft folimmer, ols andere llebel zurúcts fitito.

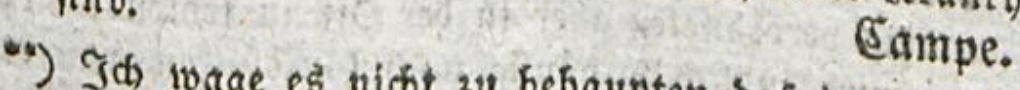

periobe ober felcht in behaupten, on $\beta$ in jeder Beit: ten oder felbft in ber jerigen bie Maffe bes (Sur

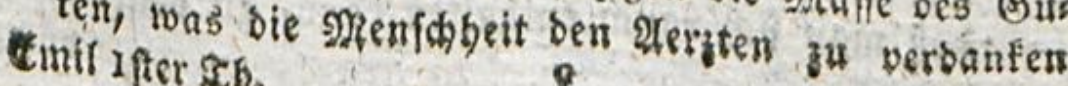
bat, 


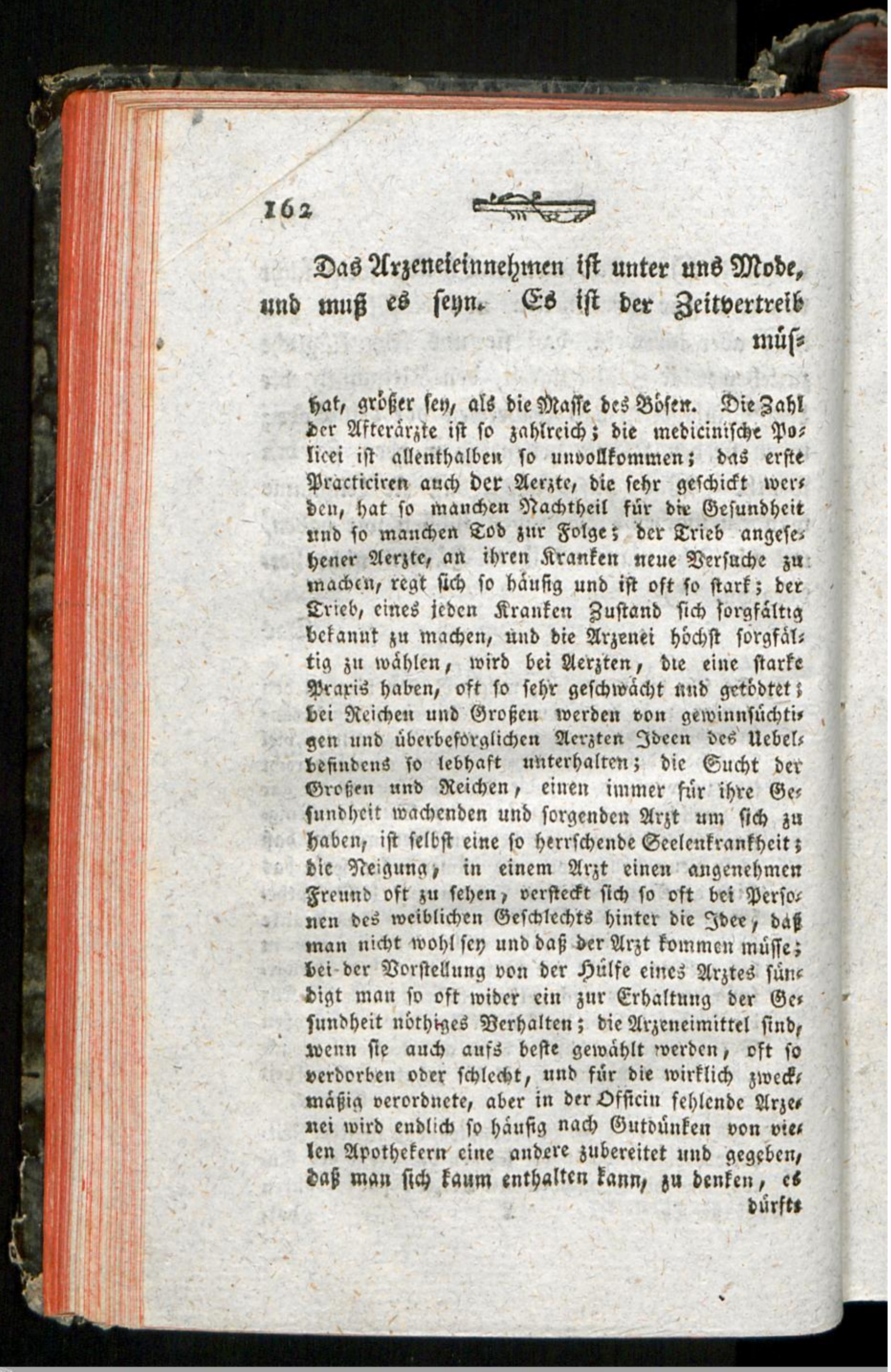




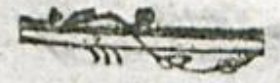

Eniffiger, nidjtisthuender Seute; Sie, swefl fie nidjt wiffen, wie fie ithre 3eit anlegen follen, fie samit binbringen, fich zu ertralten. Saatten fie bas llnglice gehabt, unfterblich gebohren zat soet: ben, fo wirben fie bie elendeften (G) fobopfe fenth. (5in keben, bas fie nie zu wexlieren furditeten,

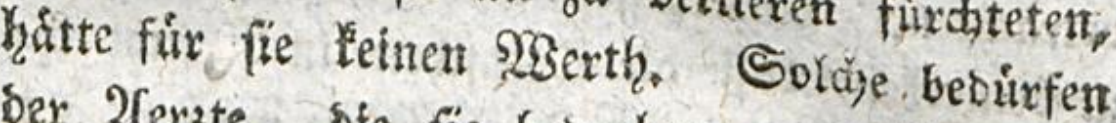
ber 2ferzte, bie fie bebroben, um ibnen zu fidmeitheln, uns bie ihnen alle Iage bas einzige \& 2

Rex:

Surfte itt matnden Seiten bie Malfe ber thebel, bie (fid) mit bem (sebrauch ber Aergte und ber bon ihs nen vetorbuten Mittel verbinben, wol merflich fiárs

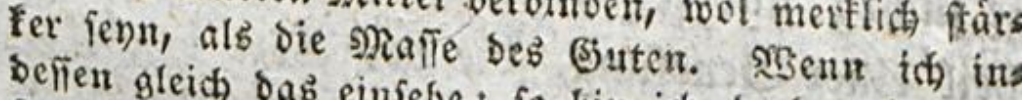
Defien gleidh dab einfelfe: fo bin ich bod) loeit ent=

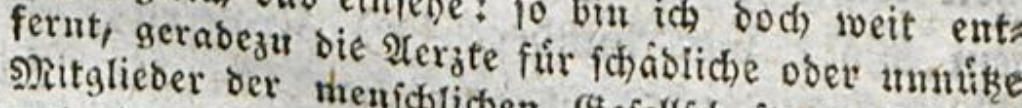
Mitglieber ber menfकtichen Befellich aft -zu halten, und Den $\mathscr{2}$ rzeneimittelu alle beilfame ssirfungen abzuiprechen. Soi gemiffen sirantheiten unb Epis bemien if ber Dienfi, Den gute Ierzte den Men: fohen leiften, fo fictitbar und auffallento, bafin ifn feir

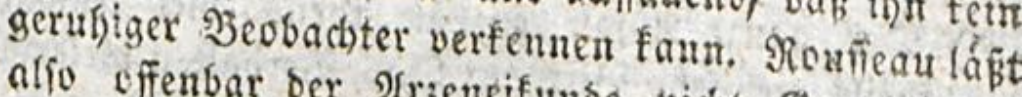
alfo effenbar ber Ifraeneifunbe nicht Bereditigfeit swiberfabren. Ssenn Niotiere bas nicht that: fo toar bas bem Schaufpiefer bis mif einen gewifien

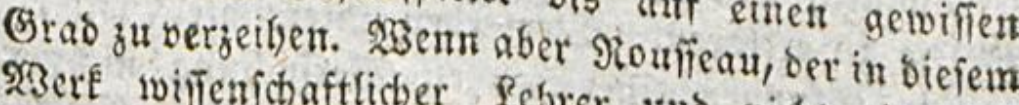

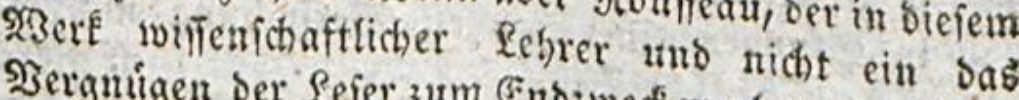

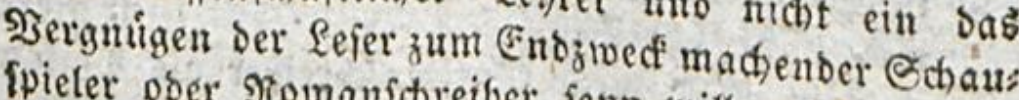
fpieter ober Fomanficteiber fenn will und ienn foll,

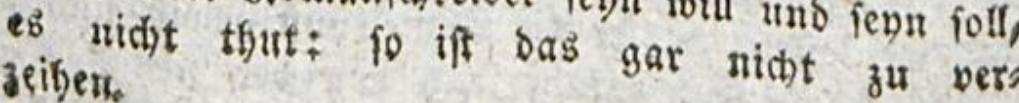

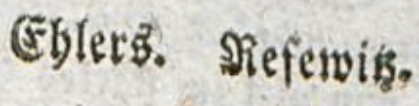


Bergnugen berfdaffin, beffen fie fähig find, bas నexgnigen nidjt tobt zแ feyn. *)

S(d) bin nidyt 2 sillenb, mid) bier uber bie

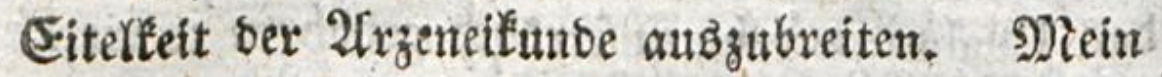
3weck byeift midh nur fie bon ber fittlichen Seite betradjten. Ulnterbeffen tann id) nidyt umbin,

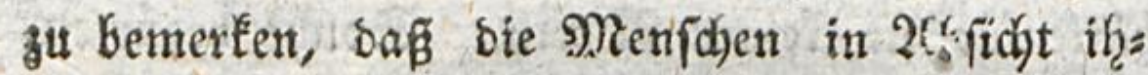
res Ssebraudjs eben bie Zrugfolyfiffe madjen, aไs

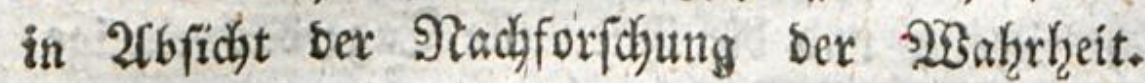
Sie fergen fmmer voraus, man heile einen Rran= ren, went man ifgm eingiebt uno if̧n wartet; fo wie, man finde eine $23 a$ hrbheit, wenn man

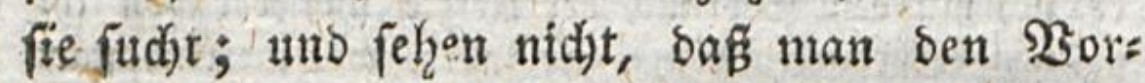
theil einer Sienefung, Die ber 2 rzzt beniret, mit bem Zode bor hunbert ***) Siranten, bie er anf ben Sirdhhof gebracht hat, in die SEaage

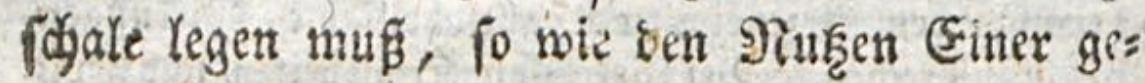

fur:

- Der ganje ofbjats enthált theils viel Hnwabres,

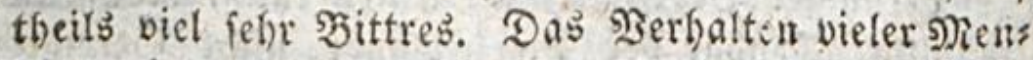

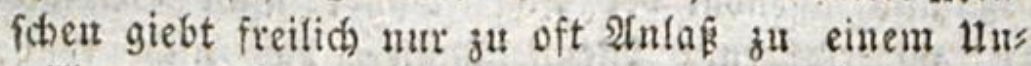
willen, wobei, man leicht verfutbt werben fann, fich fo zu erllaren. $253 e r$ aber unterrichten will, muß in Stumben einer folchen Beriuthung nicht reben uno nidbt idbreiben.

Ebler.

Sier ift $\Re$. mefr Satirenfchreiber als Pbilojoph:

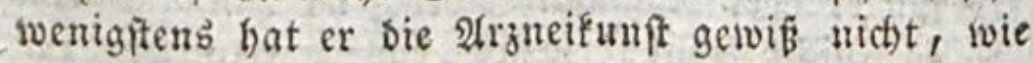
ex boch.gleich barauf fagt, won ber fittlitinen Seite betrachtet.

*) Ein viel zu ftarfes gribuerbáltniß̄. Eblers. 


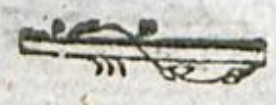

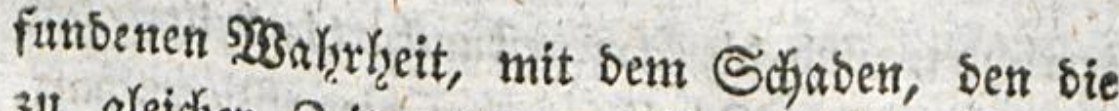

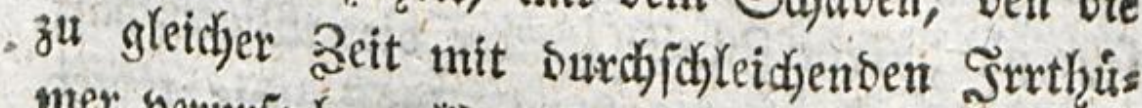
mer berurfadben. *) Die Sgiffenfdaft, bie un,

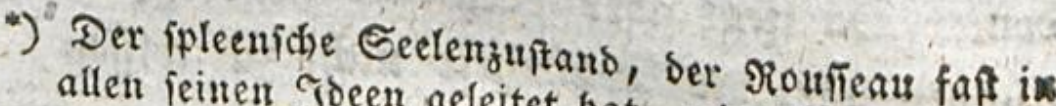
allen feinen Joeen geleitet bat, jeigt îth vorzuglich in ber 2frt, wie er bier uber ben Erfenntnif̧zuftand bes Nenichen urtheilt. TSie mangelhaft aud sie menichlichen Nenntnifie find, unb roie biel Jrriges (iic) in biefelben bineinf(d)leicht: fo ift Do(h) getvis in ben Goeen, die das gemeine \&eben betreffen, die Nenge ber Srrthumer in Nergleichung mit Der

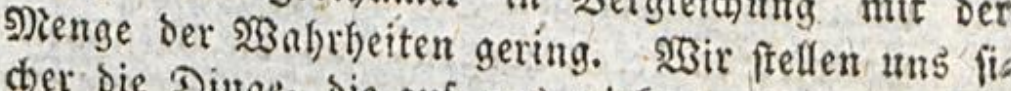
cher bie Diuge, bie auf uns wirfent und auf welche twir wirken follen, theils nad) ifhem weientlichese

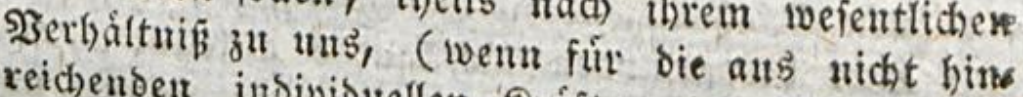
reichenden inbividuellen Sexiften bet Natur ents fpringenden Misgefcjopfe an Seele und Leib eine 2(usnahme gemad)t wirb) allgemein auf eine gleidie, theils jeber nad) ifrem auperordentlichen mit bem weientlichen Serbáltuí beftehbaren und bamit bars monirenden गुerháltniffe auf eine in ber befundern Jildung des insiviouellen wabruefmenten Drgans unb Beiftes und in ber inbivibutlen গ̧eidhaffentheit ber Dots unb Seitbeziefung gegruntete abiveichenbe Ifrt, bas ift: wit ftellen uns bie Dinge theils stach inrer weientlichen, theils mads iffer relativen (wie bie Sdule fith ausbrufft) sisabrbeit vor. Eine all gemeinte oder gewófnliche 3 erfeflung bes rechten

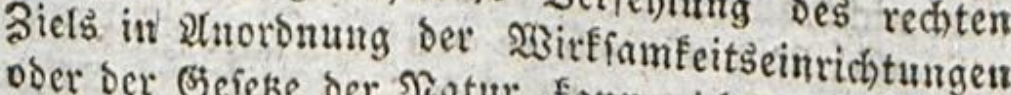
ober ber Gejek̨e der Niatur fann nidht mit গ̧egrifs fen von gottlicher soisheit uns Nacht beftehen. Auch ift es utr franfen ober idjwadjen fpeculiren Sen Ropfen, nie aber burd viele Erfabrungen un

3eobs 
terridatet, uns sie 2frzeneilumit, sie beilt, fins fehre gut; Hein atweifer! aber bie MBiffenfdyaft, sie tåufd, und die 2rrzeneifunt, sie tiotet, fins vou 2 sffen. Sehrt uns alfo fie unterifbeis ben. Da liegt aber eben bex Rnoter. Sexa ftunbert wir, bie 2 sabrezeit nidht zu wiffen, fo souits

Deobadsungen cutivirten menfoben bọt gefuntem Szerfande eingefalfen, bie 3 orfetgung eines to grof

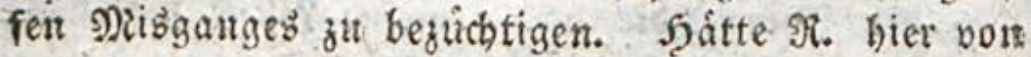
manchem angeblichen Gyitem ber Sieligion ober ber Pbiloiophie reben wollen, bas bie Renichen nidjt mit gemenish aftlichen fánoen nad bem aus allgemeis sten Erfafrungen unt beobadtungen entiprungenes Sidht beš gefunben शerfandes aufbauten, fenbers Das ifnen von herrfofichtigen, unbefaunte who ges beimnisvolle Dinge voripiegelnben F̧etrigern ober Echwármern aufgebungen une zum \$heil unterm Sciftande einet bespotifden Madht getwaltfam burds Sorfolgurgen aufgeztoungen lourbe: fo wáre nichts

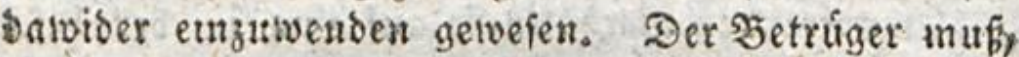
suenn er feinen Enbjuccf erreictien will, auf bein

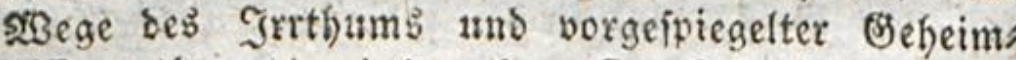

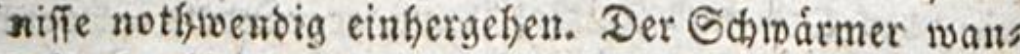
Delt obnehin in ber finfternifip ober in einem fo blems benden Qieht, bafi er in beiben fitllen nidstb als feine ßifionen wabrnimmt. Aflein bas ift boch auch

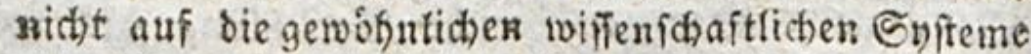
aller Afrt, wie wir ife von afriftotefes zeiten her gos babt haben, anzuwenden.

(E) lev's.

 93abrbeit forfchen: Denn Strthtumer, mefr oder wes siger, fdeleiden immer mit ourch.

Rejerwits. 


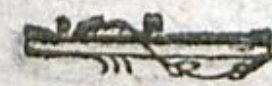

soirsen wir niemals bon ber Sage bas Sidjt fübren laffen; *) barftunden wir, ber Natur zum Irofge nicht genefen zu wollen, fo sourben wix nie durch die Sgand bes 2 rutes fters ben. $\left.\left.*^{*}\right)^{*}\right)$ Sebe biefer 2irten son Enthaltjams

$$
\{4 \text { eit }
$$

4) Şie toabr! wer soch baran zlweifelt, ber fefe Rant? Iritif ber reinen $\$ 3$ ermunft.

Irapp.

eln

ofs

ot:

rec

(b) $t$

eis

ent

tris

ges

vet

in

(d)

ts

(ifi)

ine

me

IIs

its

II 3

(c)

ne

Iof

(4)

ses

4a) Die Gier porgetragenen Ģebanten haben mehr blenbenden Echein, als Wahtheit. Der Nenich hanbelt nur infofern tweife, wenn or bie S3abxs beit niđat wiffen will, als eine $23 a b$ rbeit auber bem menfdliden Erfenntuiffeteife liegt uno ber barnach fuchende Menif in Jrrthum hineingerathen mu. Thei einer folchen toeifen. Enthaltiamfeit im zors foumgștriebe, die pielen 203 aghálien im Epeculiten fehr zu empfehlen ift, faun man aber boch in 2 fries bung ber bon ber menichlichen פerftandsfraft ela reid) baren 28 afyrbeiten leidht irre gehen, wenn maur sicht befutiam benft und foricht. Noch irriger ware Roufreaus Ëebanfe, wenn ev úberbaupt bas Nidjt: forfthen nach $23 a$ abrbeit, als ein ficheres 3)ittel ges gen ben Srrtfum anpreifen wollte. Da iraend eirt Eifenntnifjuftand bei șafurnef)mung der Dinge wes fentlich beim Nienichen Statt finbet: fo wurde, went man fich nicht um bas finden ber Ngabrheit befums merte, maut zufáltiger sieife eben fo wol zu iretgear als watyen Soritellungen unb Gebanfen gelanaen. (sben fo ift eb mit bem fotgenden Gak beichaffen. Ein vermuluftiger Renich wiro ber Niatur in bem Fall bie Genefung nicht abtrokzen looflen, ia bie (5entefun nicht mit ben firáften der Natur befteben faut. Er wirs alsbann auch feinen 2 rgat fuchen 


\section{I.68}

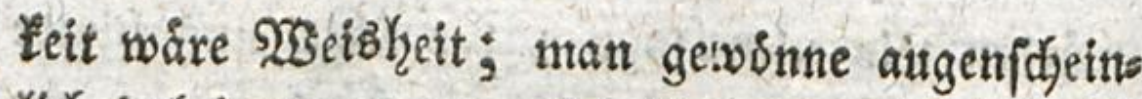

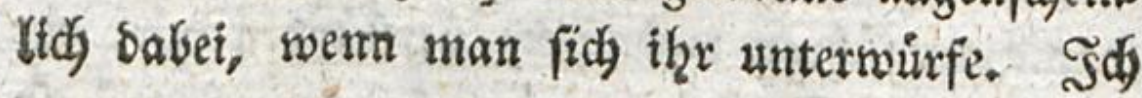

und alio nioht burch die Syand bes 2 frztes ferben. Dafe er burch sie frand bes arztes in dem Fall, ba er bennoch einen $2 r_{j} t$ brautcht, fterbe, ift jedoch aud

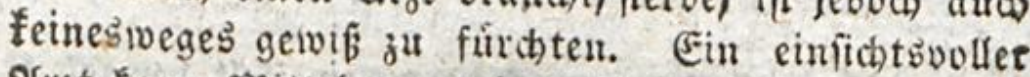
Irgt fann Mittel anvenden, bie bas Enbe beb fes bens baun un feine Ninute beichleunigen, und fo ftirft er feinesweges dutch die 5yand - bes Argtes. Sit bie Jiranfbeit aber jo beichaffen, baf ber Mans

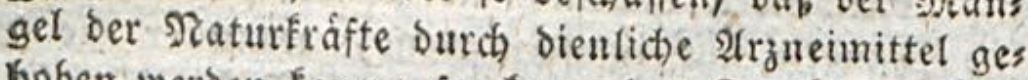
hoben werden fann: fo fann ber firaufe vernúnfs

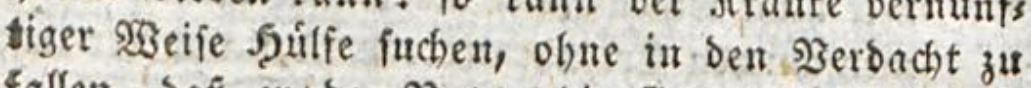
fallen, bấ er der Nhatur bie Seneiung abtrok̨en soolle. Er Eann Dann boch burch die Jjand bes,

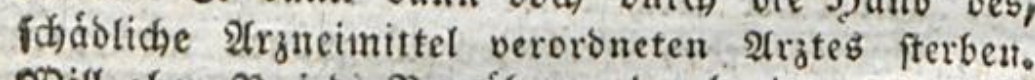

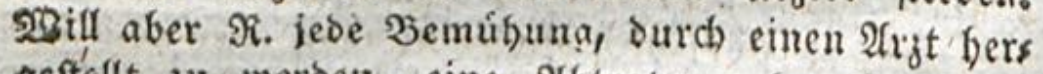
geftellt zu verbes, eine Abtrok̨ung ber B̧enefung son ber Natur nemen und dies, als ein ficheres Nittel wider bie (Sefabr, ourch bie Syand bes $\mathfrak{A r z}^{3}$ tes zut fterben, empfeblen: fo ift bas sittel freilid febr ficher; fo verivirft er aber auch jeden (3ebrauch

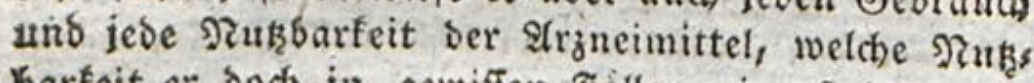
barfeit ex bod in gewiffen Fallen eingeftebt. গ̧ei

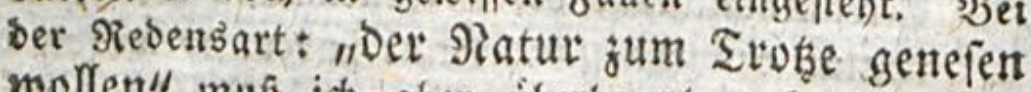
mollen" mus ich aber uberbaupt nob anmerfen, baßi bieje menfshliche Ihorbeit nicht leicht Statt futs bet uno dá̉ man felten einen mit Recht einer fors d)en Thorbeit idutbig nennen fant. Der Nenich fann faum jemals in einem gewifiten 3uftande ber

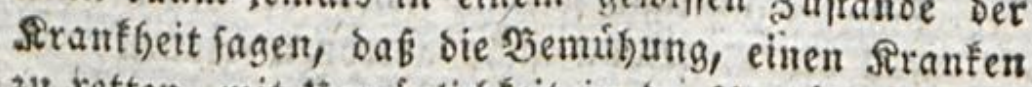

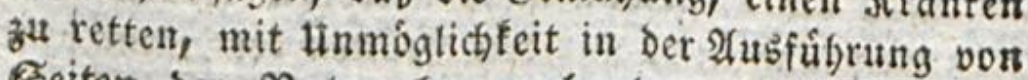
Beiter der Natur her verbunden fey. Der eins

fichtos 


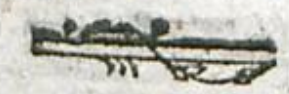

ftreite aljo nicht saivider, safs sie 2trzeneifunde

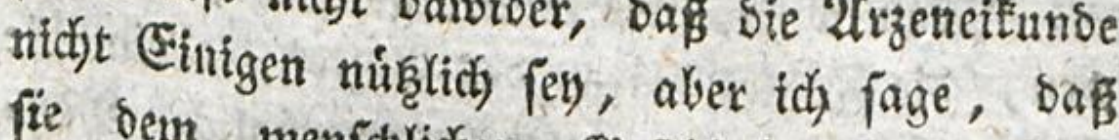
fie bem menjolidyen Sefdjledgte verberblich
ift. *)

fidtsuollite Argt glaubt oft ganz irriger ş3eife eine

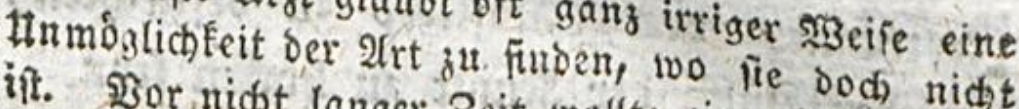
iff. Sor nicht langer 3eit wollte einer ber grósten शlergte aus bem Grunbe nichts weiter fur einer firanfen thun, gab bem ß̧itten eines fid ángligens ben $\mathfrak{S B}_{\text {eibes an }}$ Ende aber nach und verfucite ife 3u Befallen, ofue alle eigne fofnung noch etivas und rettete durch das gevóblte Mrittel einen Miann, ben wan fchon als tost anfaf und ber ficjon in ben Beitungen beskvegen fogleich) als geftorben angefuks bigt wurbe.

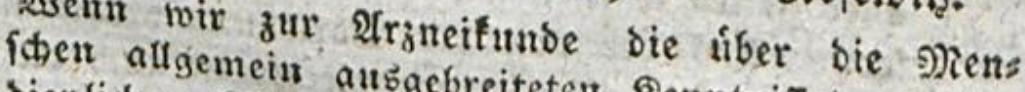
bienlichen Ritter ausgebreiteten Renntniffo gewifier wendung im (5amzen benfen an biefer Mrittel 2 tus fichert, baj ber शathen iener fo balte ich mich vers gend gegen beren श्achtheif Arzneifunde úberwies ber Simficht fichere Netheil ift. Die Natur hat itr núk̨er গু马eife gemacht.

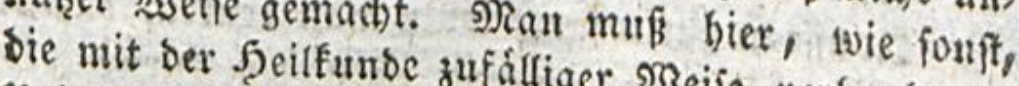

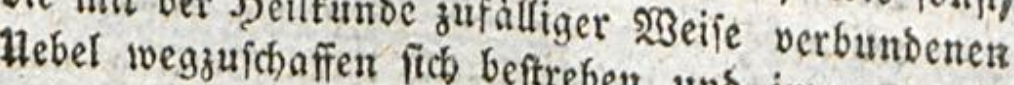
und mehr nad den bavon un und immer mebr len trachten. $28 \mathrm{enn}$ ich

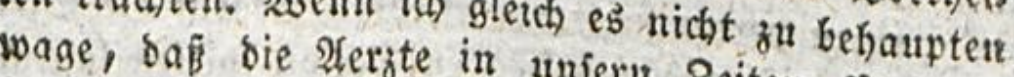
belfen, als fhaben, Mefrere vom seiten Niebrern tobten, fo glaube ich boch om Tobe erretten, als zu Énnen, dasi bie Folgen felfict tid) behaupten

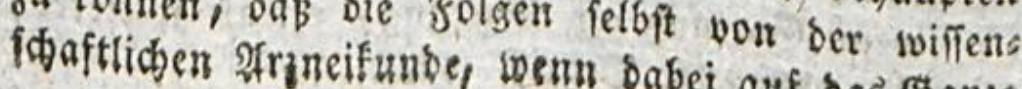
aller. 


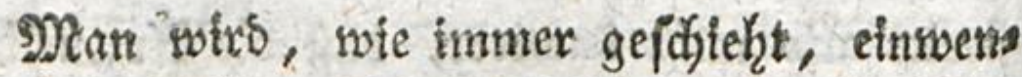
Den, biq Fehler waren bes 2 rztes, allein bie 2rzencifunft an-fich felbft fen untriglid). Neis netwegen! fo fomme fie benn nux ohne bets 2rzt: benn fo lange als beibe zufammen tom men werben, wiro hunbertmal meḩr opn ben Surthinter bes Rinftlers zu befurdjten, als sou ber Soilfe bex Runft zu ḩoffen fenn.

Diere lugnerif́che Siunft, bie mebr für bie Uebet bes Seiftes, alsె für bie llebel bes. Leis bes gemadgt iff, hilft fir jene nidjt mebre, als firc oiefe: fie beilt uns weniger von unjern Sirants

afler 3eiten gefehent wirs, weit mehr gut, âs bófe fer. 2fus ber von ber Erziehung bes Nenf(hengejhlechts ift auth bie şifs fenichaft ber $\mathfrak{A}$ rgneifunde mit entiprungen. Itno Tie \$̧orfefung madite feine Plane, beren Sfusfúhg ruing im Durchichitt der şirfungen mistinger. Dies if auth mit bei Durchlefung bes folgenten $\mathfrak{A}$ bs fakzes in Erwágung. zu ziehen. Srach bem, was Trouffean barin fagt, follte man benfen, baf bie sís reifunde in abfracto bie Nentichan furiren fómte. So geht $\mathrm{es}$ unfern durch iffen Sortrag uno şits

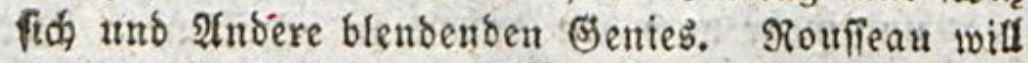
einen perionificirt vorgeitellten Begriff bie Stelle eis ner exiftirenden belfenoen Perion fpielen laffen. $2(n s$ bere twollen, bak Bott wol fuir Battungen, aber nicht fuir einzelne Nenichen forge. Berabe als weun Eattung als Sattung, ctwas weitereb, als ein abftracter gegriff toáre.

Egletż. Siefemis. 
ins

bie

eis

ets

ms

en

เรื

bie

eis

IS

$\mathrm{rn}$

its

ófe

ets

iifs

nช

ifg

tr.

bs

25

in

te.

its

iii

is

ns

er

IS

(5)

Sirantifeftem, als fie unb Sdjrecten bavor eins flópt. Sie entfernt nicjt fowol ben Tob, als

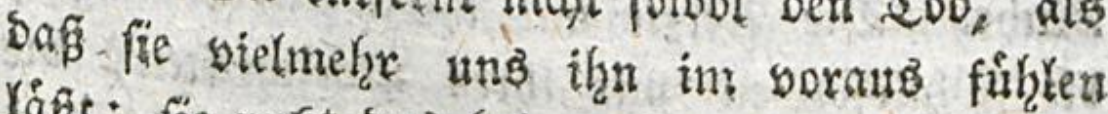
Xagt; fie nurbt bas \{eben ab, anfratt es zn Ders Xángern; uno, geferst fie serlángerte $e B$ aud); fo wirbe es immer zum Nachtheile ber Sats tung fern; meil fie uns burch die Sorgfalt, bie fie unb auflegt, ser Sefelffdiaft uns unfern Sffliditen, vermoge dor Sdyredten, bie fie uns mittbeilt, entziefzt. Die Renntniß̈ ber Sses fahe madjt, baf wir fie firchten; wer fich fir unberwunbbar bielte, soirse vor nichts in 2 (ngft ftebyen *). Sor Didjter benimmt bem

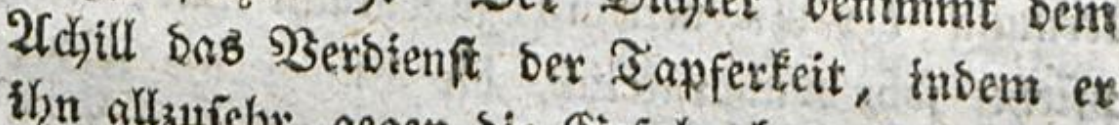
ifhn allzufehr gegen bie Gefahr bewafnet; jeber 2rnore an beb Szelsen Stelle mirroe auf bie \$Bea bingung auds ein 2 dditl gewejen feyn.

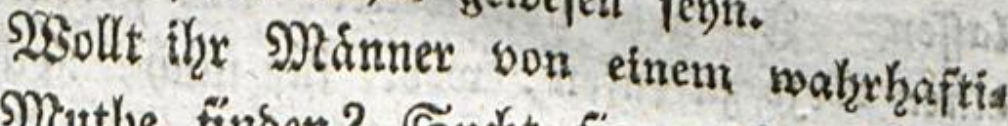
gen Suthe finden? Sudyt fie an ben Srten, no eb leine 2 erzte giebt; wo man bie Folgen Ser Rrantfyeiten nidjt fennt; uno wo man nidj;

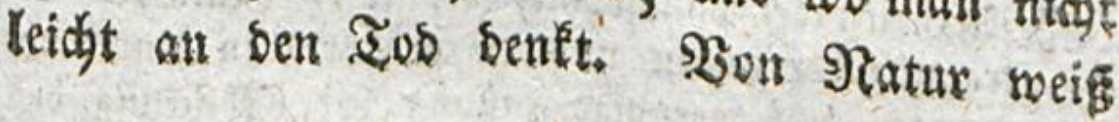

Ser

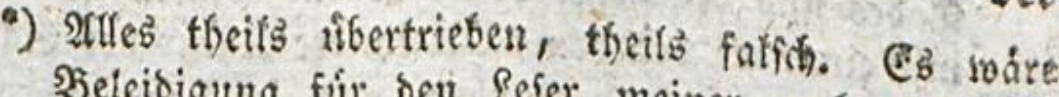
Эुeleibigung fúr ben lefer meiner vorbergetgentes Ifrmerfungen, wenn id bas Hebertriebene und zas fibe bier náber inb lidft fetllet wollte.

Ebletr. Referwis. 
Dev Menfes ftanshaft zu Yeiben uns ftirbt in Surbe. Die 2lerzte mit ihren Seruronungen, bie Whilofopher mit ihren Borfdyriften, die SOrfefter mit ifren Errmahnungen fins's, bie bas Seerz erniebrigen, und uns bas Sterben vers (ernen madjen, $)$

Man gebe mir bemnach einen 3igling, bet aller biejer Seute nicht bebarf; ober id berbitte

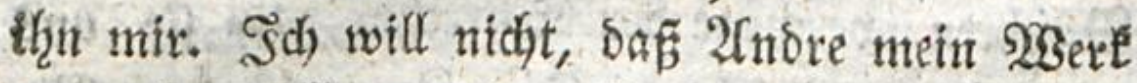
serberben follen; idy mill ifn allein erziefzen, ober nidjts bamit zu thun ḩaben. Der weife Sodte, ber einen Zheil feines Lebens mit Er: Yernung ber 2frzeneifunft zugebracht hat, ems priehlt fehr nadjoridelid), bie Rinoer nie weber fur Sidberung bor funftigen Rrantheiten, nods Iin Yeidgter Befdjwerben willen einnef̧men zu rafien. Sid) gebe nod) weiter; und gebente nie einen 2frjt zu rufen, weber für midy, nod) fur meinen (5mil; es̉ miffte benn in einer augen cheins

Yichen

T. Arjueifuttbe, Philofophie, Religion, Nuth zur Er: tragitug ber Leiden und zu gefábrlichen Interneb; mungen und geruhige foffing bei Erblictung bes Zobes und ber thebel biefes febens fónnen febr gut mit einander beftebert. Die inmere Sratur ber Sache zlvingt uns bas zu glauben, unb id habe bas aus meiner eignen, toie aus mancher andern Erfahrung selernt.

(ङ)ler'.

Diefe shittel recht gebraudjt, lernt man fterber. Reienis. 


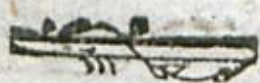

Itden Siefaby *) fegn; bent alsoann Eann thm budy nidhts Sdylimmers wibexfahren, als:baß er untomme.

Sch) weif́ wol, baf bex 2 ragt nidjt unterlajs fen wirb, aus biejem 2fuffchube Bortheil zuzies hen. Stirbt bas Sind, fo wirb man ihn zu fpat gerufen haben; fommt es babon, fo hat ers gerettet. (E) fer: Der 2 rzt triumphire; abcr bor allen Dingen werbe ex nicht anders als in ber aufierften 9loth gerufen.

26 eil bas Rino nidjt zu genefen wein, fo mifle es trant zu fenn; diefe Rumfi exfert bie 2nore; und fdright oft beffer ant fie if bie Siunft Der SRatur. ***) $23 e n n$ Das Shier frant

2) 2fllein bei vielen STranf und ibren (5)ang nicht fennt merft einer, ber fie eher, als wenn tem foraten grobe Gefabr nicht soerden fann. Rach STouñeaus uor mebr gebolfen

terungen burfte. es baun auch th

tutr jum Trob aencion zu reich fern, ben Tod ber bishe

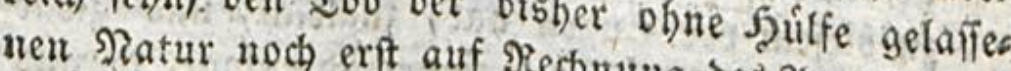
men lafien zu wolletr.

**) Die Sumf zu genefen if

Numit ber Natur, alb die fo gut und mebr eitte

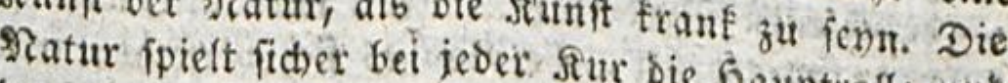
Ser Srat bie Sebenrolle Sur bie Sauptroffe unb Sentus 


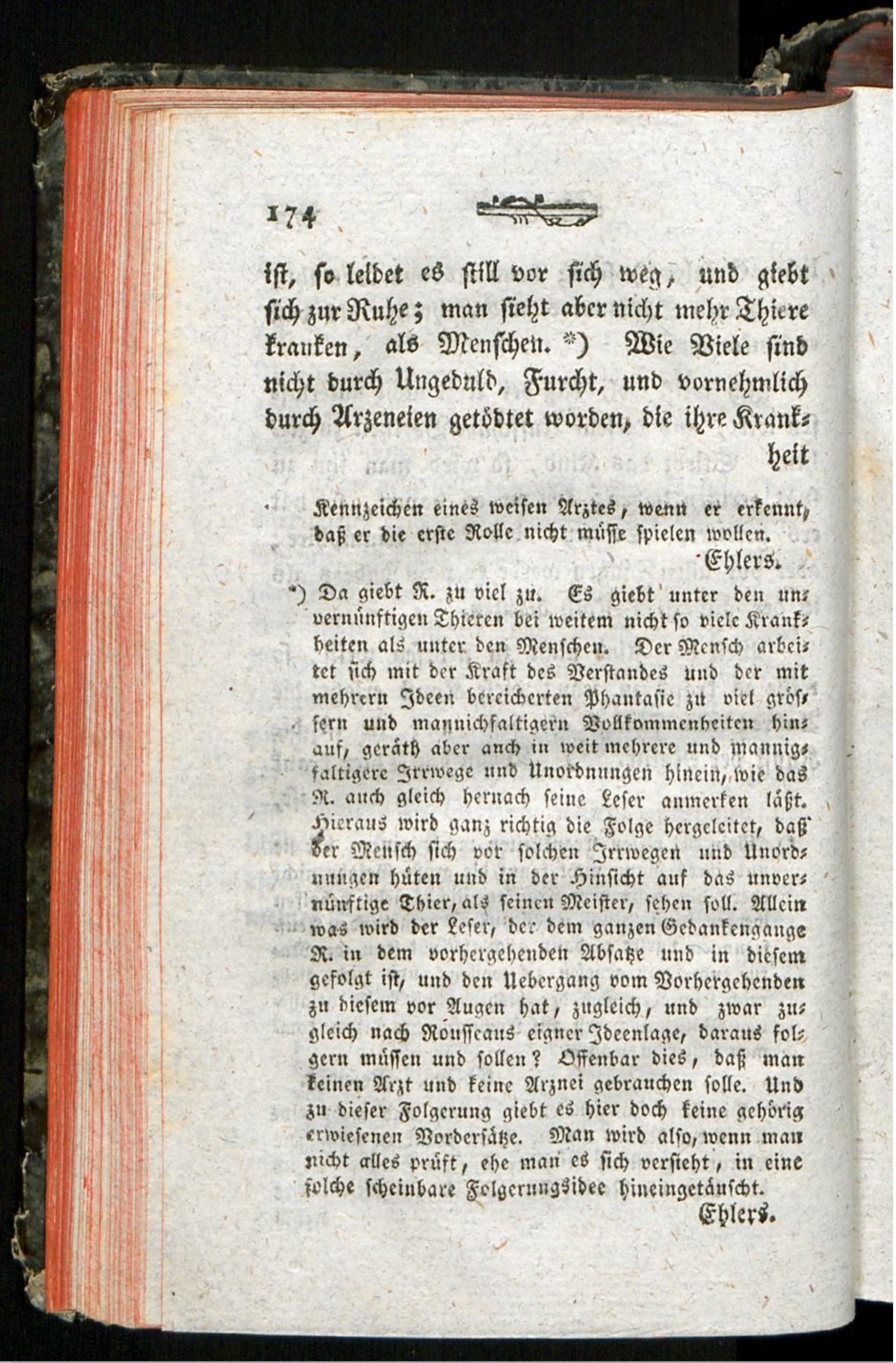


Keit berfidyont, uno bie 3eit allein gefheilt Katte? Man wiro mir einmenden, baf bie Thtere ber Slatit gemaffer Yebten, uns folglfá) weniger tórs perlid)en Uebeln, als wir unterworfen fegn múj fen. Nitu wofil! gerabe bieje 2 rrt zu. leben will

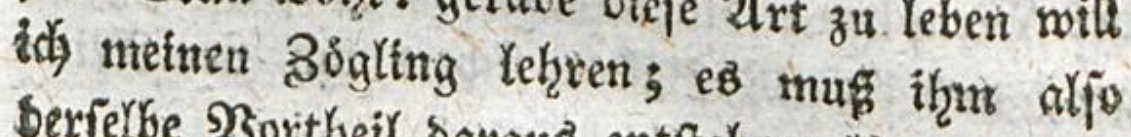
berferbe \$ortheir Daraus entịtehen. *)

\section{Der}

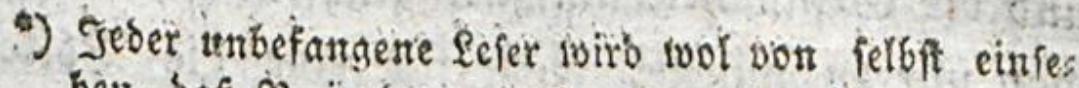

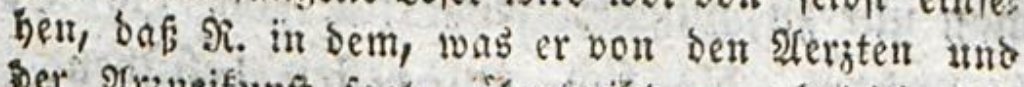

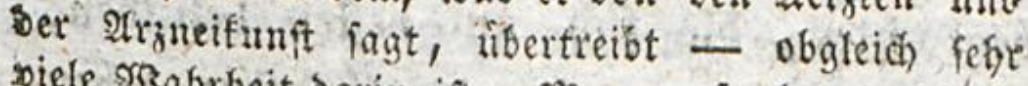

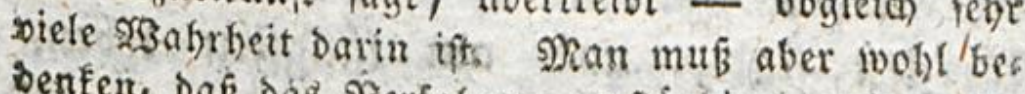

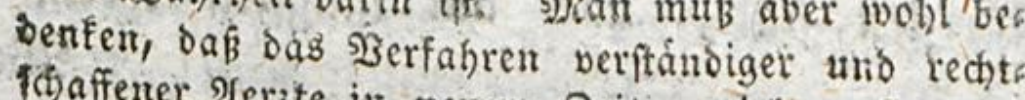
F(i) affener 2ferzte in neuern Beiten viel vorfichtiger unb weifer ift als vor sem - felbit wie nod) zut ber

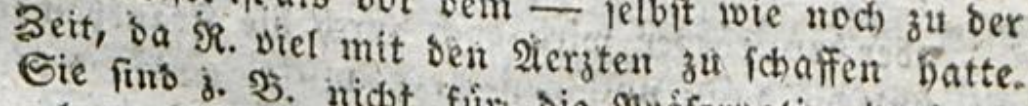

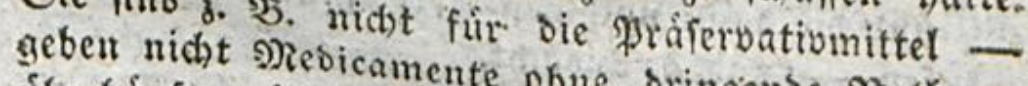

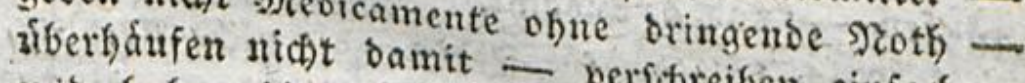
mito Gaben bie náchjtent Itrfachen ber Srantheiten befier fenten geternt. Snifonberbeit aber geben fie Sindern nicht leidst \$rizenelen, fortoern wiberrathen folches viefmefre ermiftlich, weent es Hidit bie Noth - offenbar erforbert. Der Grunblak̨ des œ. nur bann feine 3 ufludt zu ben sterzten zu nebmen, wann bie

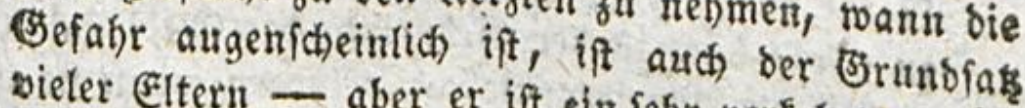

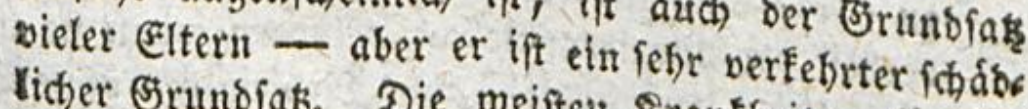
Vicher Srundias. Die meiften Siranfleiten fóntren

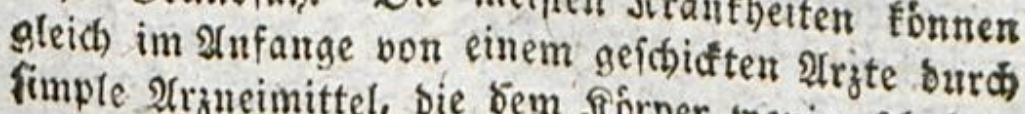
fimple 2 razueimittel, bie bem Jórper twenig forabest, gehoben werben - aber ift bie befahr erft nugens idheinlid, baun fommt ber gute Rath bínfig zu fpát, poer 


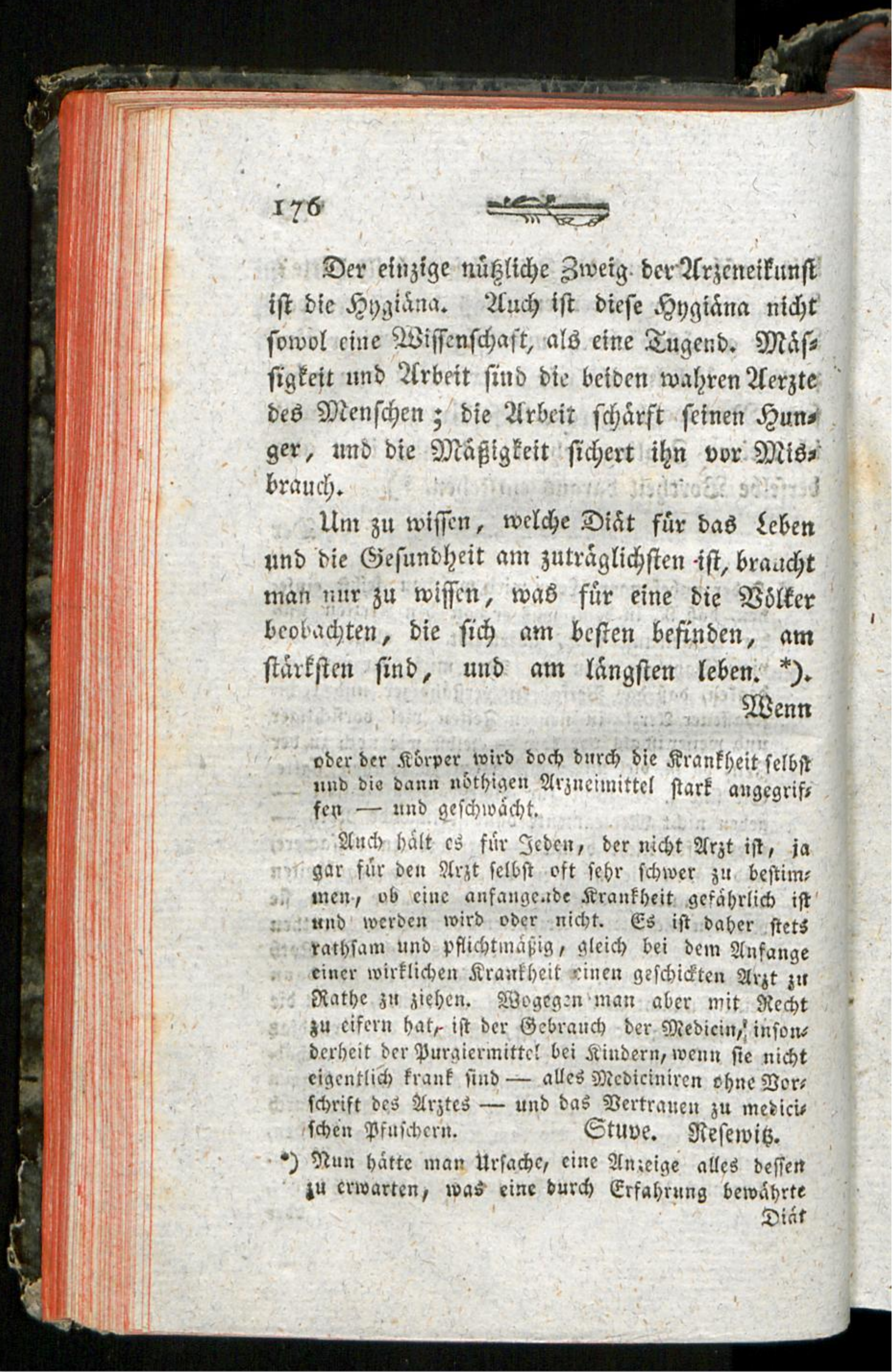




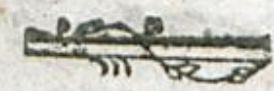

ift

yt

ifs

ite

ms

$83 i^{3}$

ett

Get

er

m

).

iti

int

ifs

ia

$n=$

ift

t5

ye

ti

it

w

it

es

is

tt

'e

it

IBenn man Durch bie allgemeinen Sisobaditum gen nidjt findet, baf́ ber (Siebrauth ber 2 rzzes nei zu einer fíntern Sefundkeit ober einem lans

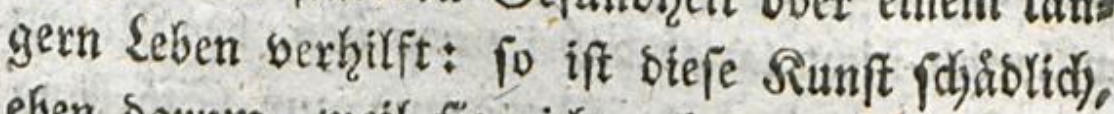
eben barum, weil fie nicht nisklich ift; weil fie 3eit hinbringt, unb bie Menidyen unb Dinge

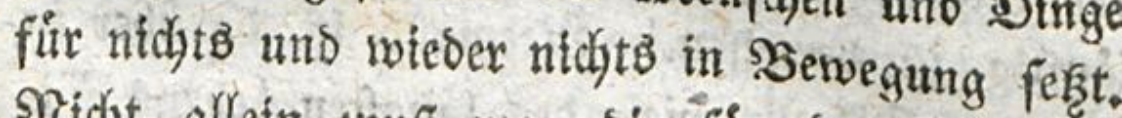
Nidyt alletn unup man bie fir ben (Sebraud) berlorne Seit son ber Summe bez menjalididen Lebens abziefzen; fonbern fie ift, wenn fie ans gementet worben, uns zu quâlen, nod, fojlims mex alo gax nicht gelebt zu betracjen; fie ift

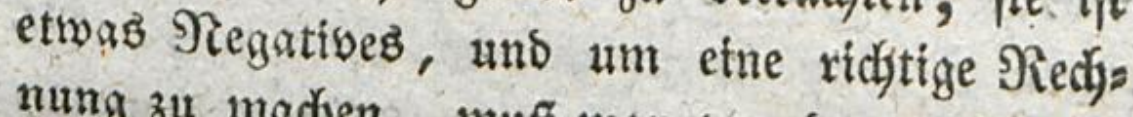
nung zu madjen, muß man von ber, bie uns bleibt, nod eben ein folds Duantum argiefrn. Sin Mann, Der zehn Jahre ohine 2lerzte lebt, lebt mehre fur fid felbft uns 2 nove, als berje= nige, oer breifitg Sakfr, ifgr SpFer, fosmadjtet. Da idf vas Eine uno bas 2fnbere berfitibt habe, fo glaube ich berechtigter zu fern als Semano, ben Schlü Sarauz zu zieḩen.

Diát erfe-sert SIlein er

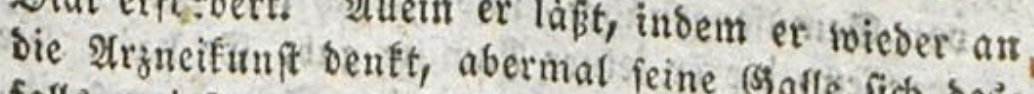
falls ergiefen, unt greift ben feine (Safle fich bess mit aller crp̈nntichen 3 itterfeit auffs neuter Runft bas, was et ragt, gebstig zu beftinzmentho obne weifen.

atemil Ifter gh.

श2

EElet:B, Refenvis. 


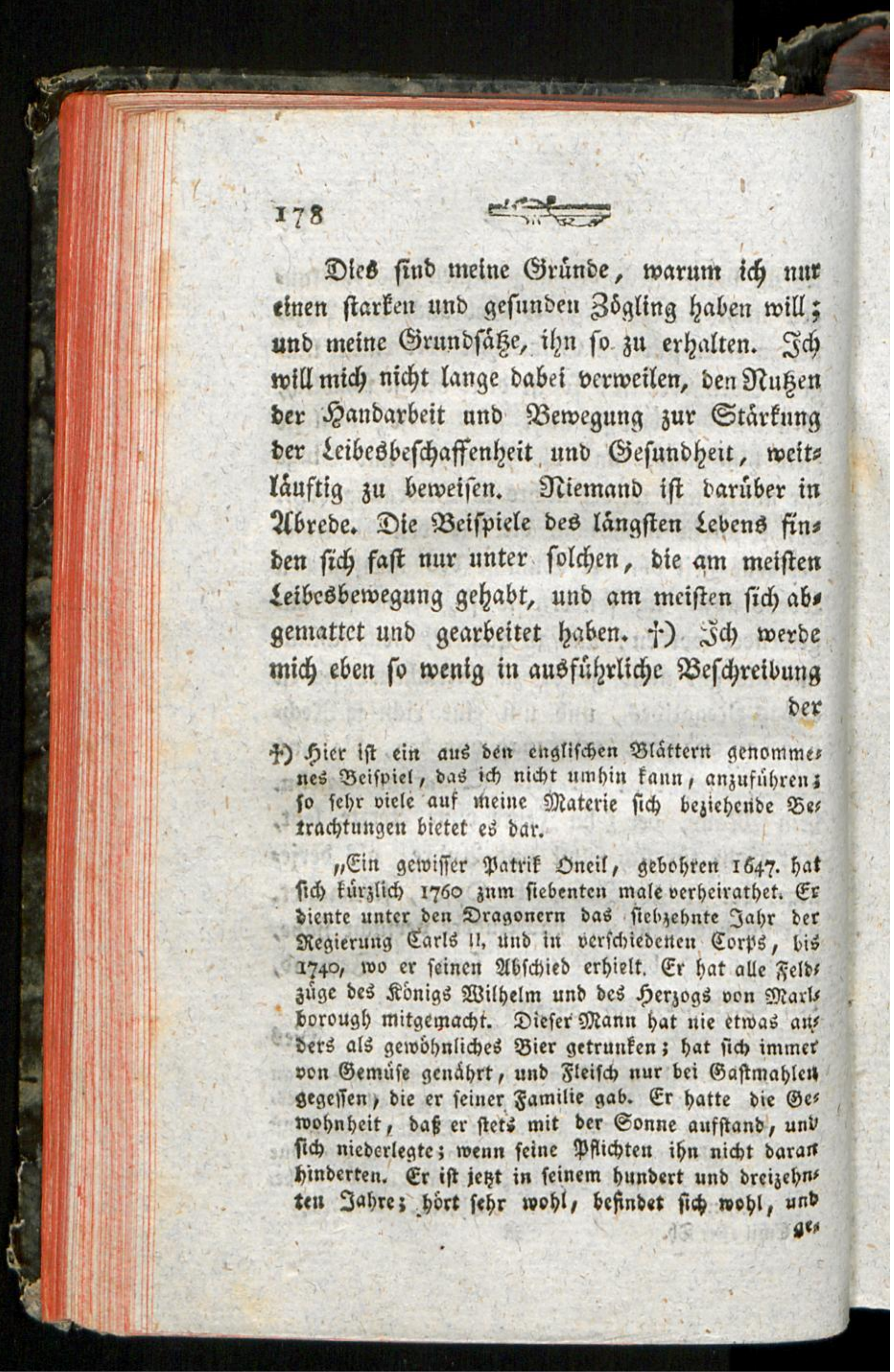




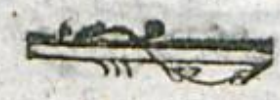

IItt

II:

s(d)

ien

$\mathfrak{n g}$

its

in

ins

tert

ibs

doe

$\mathfrak{n g}_{\mathfrak{g}}$

ber

nes

in:

5es

hat

Er

Der

bis

elos

aris

ants

ner

lets

5ुes

เกi

art

bns

int

ges

Dex Sorgfalt einlaffen; bie tib siefes einstgen Gegenfandes halber anwenden twerbe. Mar wiro fehen, oag fie fo nothwendig nit zu bem, soas id, mir auszuaben sorfeke, geboren, daf man nux ben Sieift babon zu faffen braudit, um Eeiner weitern Errlárung babei zu bebuirfen.

Mit Dem Leben beginnen bie Bebirfniffe. Das neugebohrne Sind brautht eine 2 mme, IBila ligt sie Mutter ein, ibre goflidit zu exfüllen;

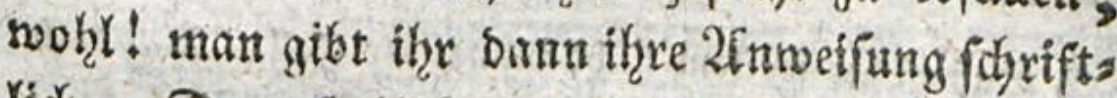
lick. Denn freillidf wiegt Diefem 30 ortheite auf Der anbern Seite aud) etwas entgegen, uns ber Soufmeifter wiro baburch etwas mebr in (Ents fermung von fetnem 33glinge gefest. 2ulleines rafit fich glauben, bafí sas Befte des Rinbes, uns bie Soodsacbtung fur setijentgen, sem fie ein fo theures Unterpfans anbertrauen will, sie 9) Mtter aufmertfam auf bas (E)utaditen bes \{eb? rers machen wirb; uns babon tann man ges

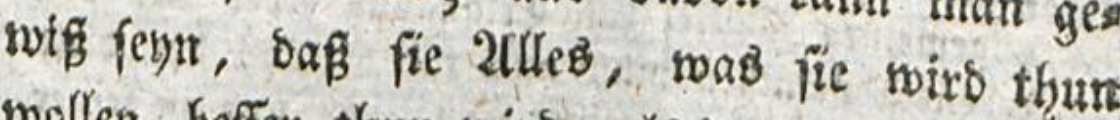
wollen, beffer thun wiro, als irgend eine 2 trore. Bebirfen wir aber efrer fremben 2tmme; fo sollen wir fie zuerfit recht ausjuchen.

פ्) 2

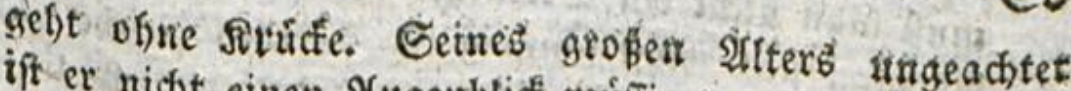
iff er nicht einen 2 tugetrblict minfig; und wandert now alle Sonntage nach der Rird)e, von feinen Rinbern,
Enfeln, und Hrenfeln begleitet,"

D. Berfaffer: 


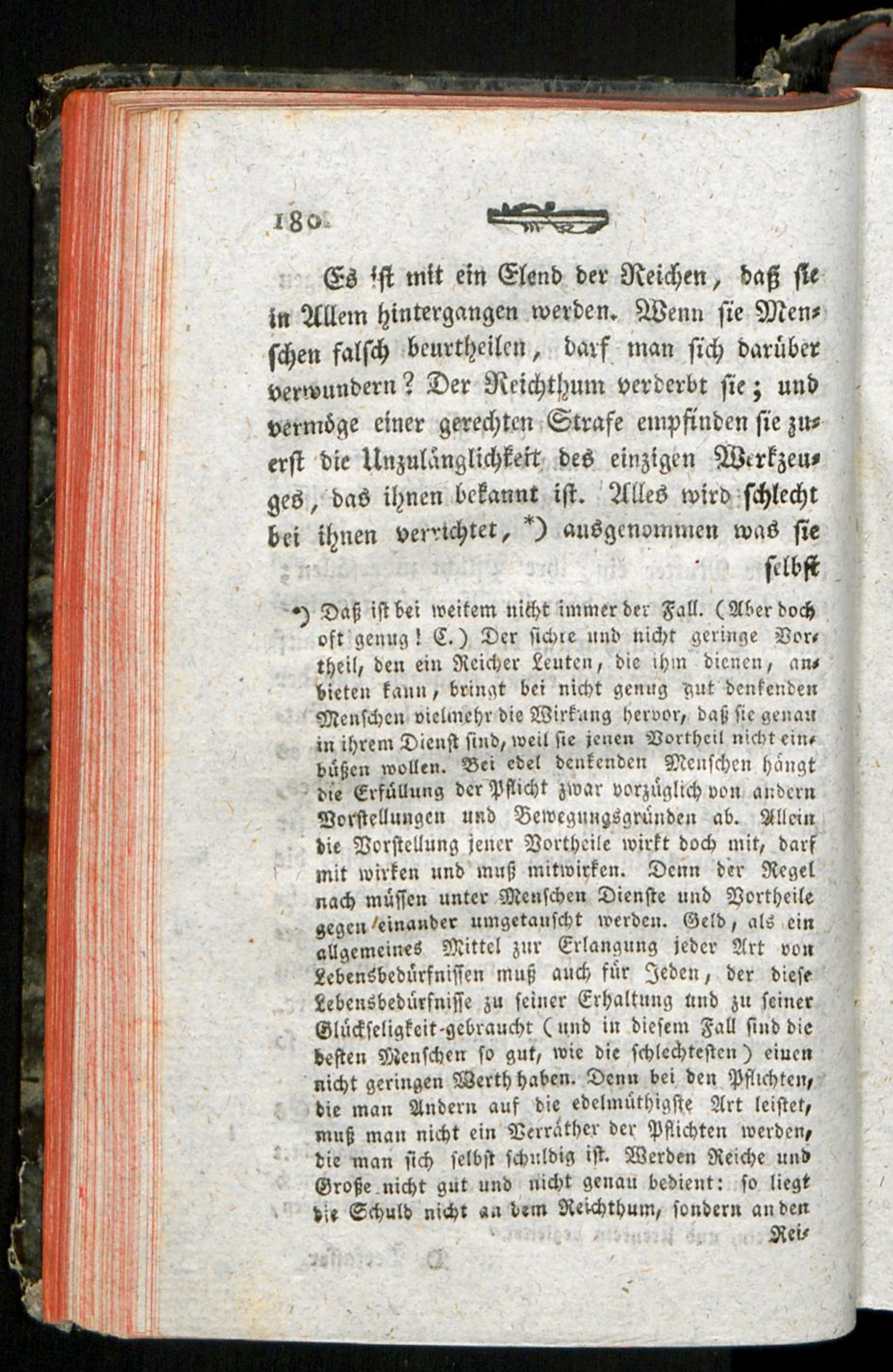




\section{$18 I$}

ferbfi thun; uns fie thun faft niemals etwas. Soll eine 2imme ausigefud)t werben; fo lafít man

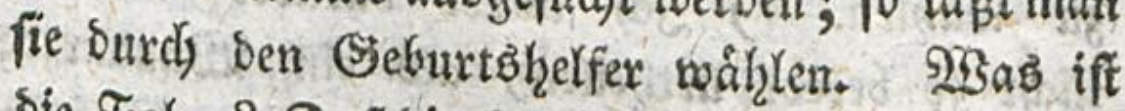
Die Folge? Daff die befte 2 tnme inmer biejenige ift, bie thm an beften bezahlt. Sith mexbe aljo teinen Sieburtşb̨elfer wegen (5milb 24mme asts?

9) 3

Rath

Reiden unb ben Erofent felbft. Şaben einige biefersteis den und (sroben aud gleiđ Urtapi von ber Joee bes Reidstfums hergenommen um felbit nicht genus thatig uno loadfam zu fenn: io faun man bod

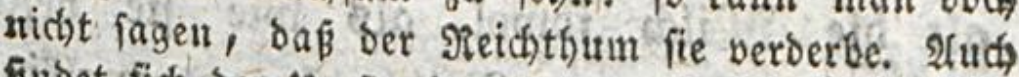
firbet fich ber Umitano, baf reide ichlecht bebient werben und nidht auf Benautigfeit uno Dienft ten, ntcht fo háūig, als man denten follte. Şei reichen uno grofien Saufleuten finbet man úberhauyt Benanigfeiten ber 2 rt. Şei bent reichen J̧ollánbern ijt eine folche (5enauigfeit felbft berrichende Sitte

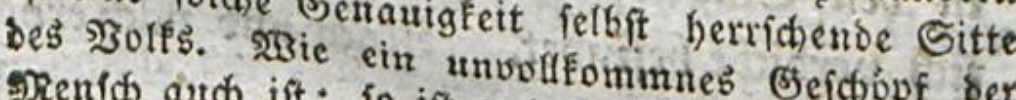

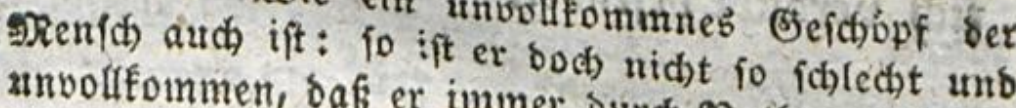

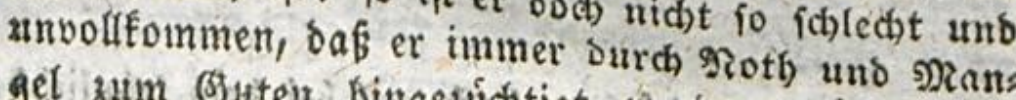

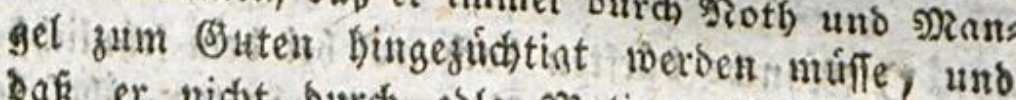
Dá er nidjt burd edle siotive geleitet werben Foure. Alno wiro er ourds ede 2)rotide geleitet: fo befalten bie von Noth und Jebuifnitfe herges nommenen Motive zugleid fir ifn ifben $\mathrm{N}_{3}$ erth. 2Eabre 230 ffommenheit und 23 eisheit fuiht auf bie Mittelitrafie bin, ba man alles nadi feinem vers

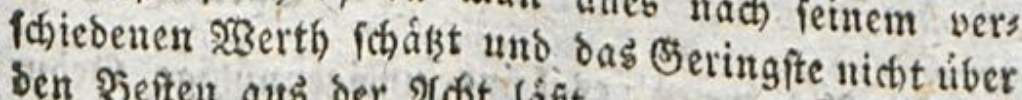

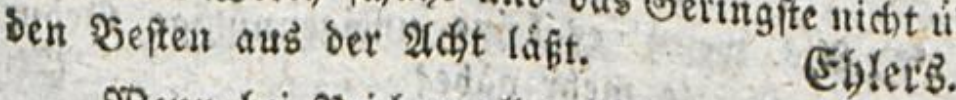

शु-un bei Reichen alles idhlecht verridytet wirb, fo liegt bie Sduld nioht am Reichthum, fonberu an Der Yerfon, die iga befint. Das ift wahr.

Nieferwis. 
Sath ziehen; idy werbe Sorge tragen, fie felbft

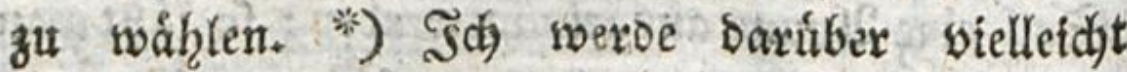
nicht fo berest intheilen, als ein 9 gunbargt; aber ficherlich aufridutiger fegn; uno mein (sifer soird mid, baruber minder tảufhen, alo fein (Seiz, *⿻一𠃋十)

Diefe S2Bakgl exforbert leine tiefen Rennts riffe; bie Regeln berjelben fino betsunt; id sweifs aber nidst, of man nidjt ein wenig $2 \mathfrak{u f s}$ merffamteit mehr barauf berwenden follte, nie alt ble Milde jowol, als wie fie befhaffen (eb. W Die neue Mild if ganz molfigt; fie muß̈ faft ein Deffnungsimittel fern; um Den lles

berreft ses meconium abzthonbern, das nod in Den Eingendeiden bes neugebohrnen Rinbes

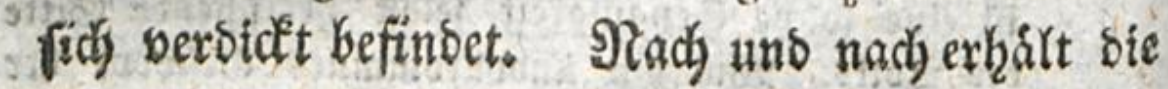
Mild,

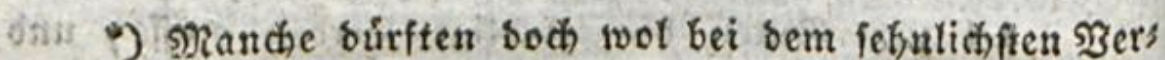

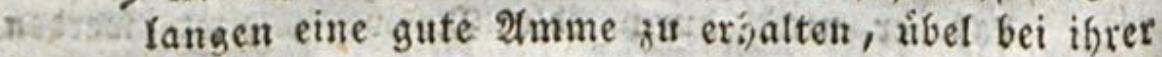

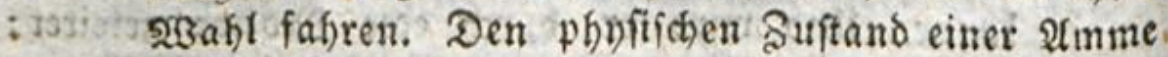
zu beurtbetlen mo zu unterfucben ift nicht Geber fâbig. 2 Bas bazu erfoberlich fev, ift nicht fo allges

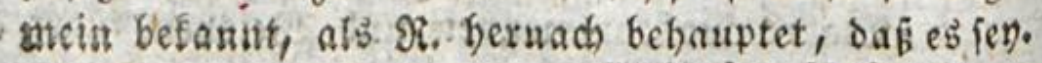

(5)blev. giefenis.

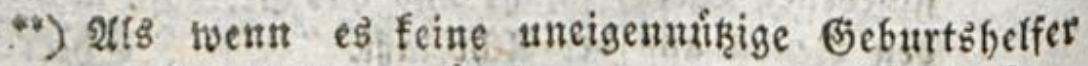
and Qerzte mebr sábe?

(5) levs.

**) WBie fie bejchaffen fenn muifie, bas ift eben ber $\$$ unct/ seorriber fo weaige Eitern urtheilen fonnen.

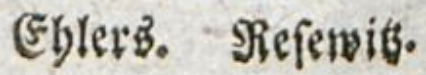




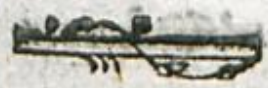

16 fit

idat

zt;

ifex

ein

ints

nie

fen

fie

lles

10d)

Des

bic

illa)

Bers

Grer

nme

eber

llges

fer.

3.

elfer

3.

nct,

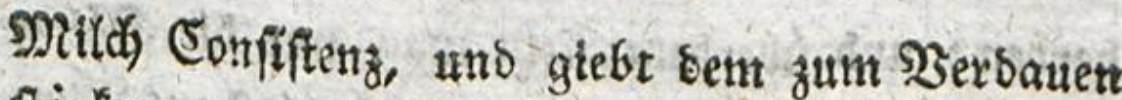

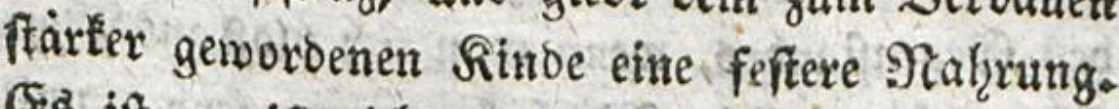

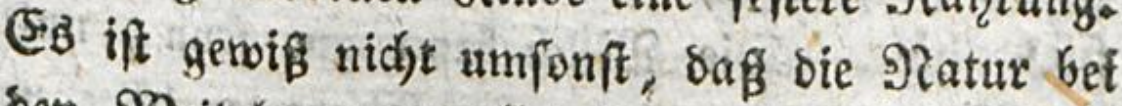
ben $23 e i b d) e n$ oon aflen 2lrten bie Dice ber

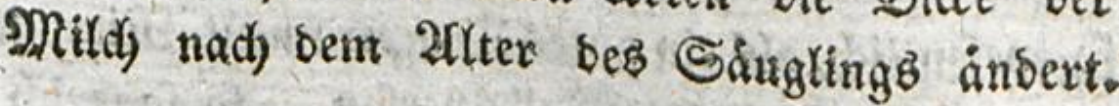

Es geḩirte alfo fir ein neugebohrnes Rino auch eine fiunzlich niebergetommene 2 (nume. ") Dies hat feine Schwierigteiten, oas weiß id, aber fobalo man bie Sromung ber Natur berlingt, hat $2 \mathfrak{k}$ es feime Shjwierigkéten, senn man es gut inachen will. Der einzige bequeme 2(uşweg ift, baß man es fdjledjt madje; uno ben fdjlagt mats audi) ein.

Man mifste eine 2 mme haben, bie an Seete eben fo gefunb, ałz am Leib wáre: bie linren gelmáfigteit bex Leibenfahaften tann eben fowor alb bie Unorbunng ber Siffte ihre Mildid vers M 4 Dera

-) Ituch biefer hóchitwahre Saks bat bas Itnglifé, bem fyerrn Formey zu misfallen. "Die Schladbtopfer, fagt er, vervielfáltigen fid,. Sgir haben ben Sofs

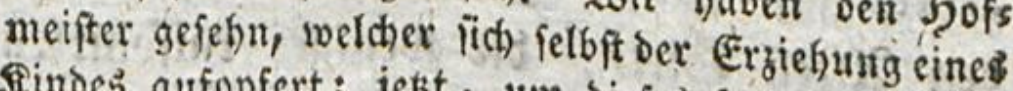
Sindes aufopfert; jetht, um biefes fo eben erft ges bobrne Sind zu fầgen, muf man cin anderes von ben Bruiften feiner Mintter reiffen, unter bem Bornante, bafi bie' silch befto gefunber fenn soerbe, ut. f. w."l Die 2 utwort auf bieien Borwurf siebt R. felbft in ben unmittelbar folgenben Seilen.

Eampe. 
Derben; uno îberbem fieht man ntu bie Salfite

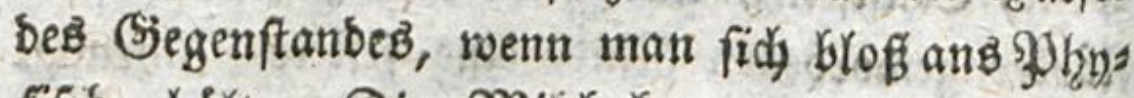
fifce, ḩålt. Die Mild tann gut fenn; uno bie 2fmme bsje; ein guter Sharacter ift ebent

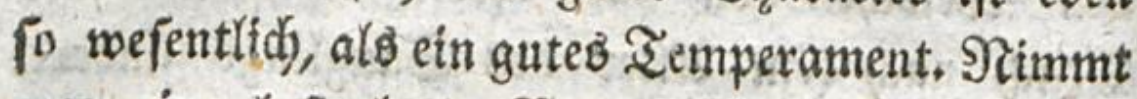

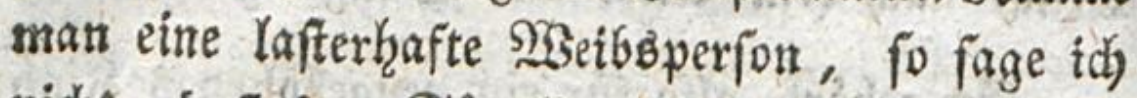
nictit, baß ber Siugling eben thre Lafter eins faugen wirs; aber id fage, er wirs bavon lefoen. Sift lie thm nicht, neben ifrer Silkt), Sorgs falt, bie Eifer berlangt, Sesuld, Sanftmuth,

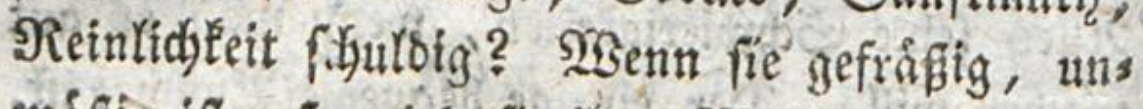
mafig ift, fo wirs fie ibre Mcildy bals verdere ben; ift fie nadjlaffig ober jadjzornig, wie wirs

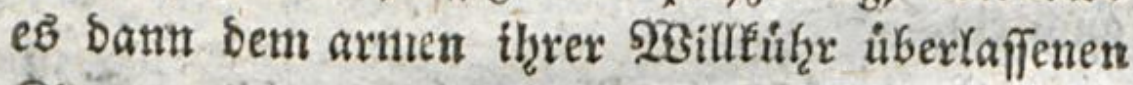
Rinbe gefien, bas fid nidjt bertheioigen nod betlagen Eann? STientals fino die Bisjen zu ets

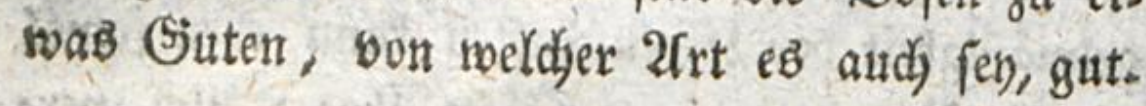

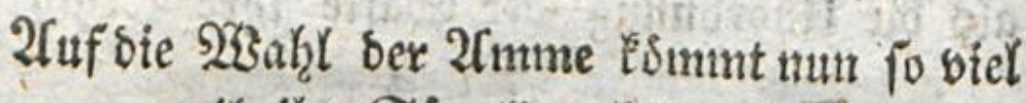
meknr an, weit ihr Saugling feine Solmeifterin weiter als fie haben foll, fo wie feinen anbern Sebrex als feinen Sofmeifter. Dies war bei ben 2Uten Sitte, die meniger ritioniten uno

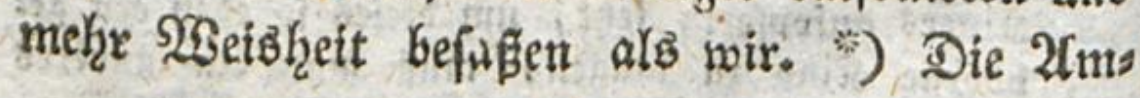

mett

7) Dicie शुebauptung mógte tool mit Ërund toibers legt werben fonnen, fofern bei ber 238 ib̆bit auf ben 
8

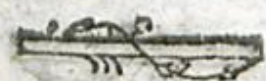

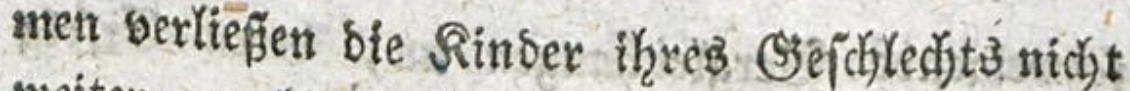
weiter, nadjoem fie fie grofi gefaugt Dabex find in thren Sichaupieten bie meiften Bertraus ten 2(mmen, (5o if numoglid), bafs ein Rino; meldyes allmáfilich burdy fo vill berfabiebene Sgande geht, je gut follte erzogen werben fons nen. *) SBei jeder Serankerung ftellt $\mathrm{BB}$. fitills M 5

f(j) weis

(E) letr.

2lber aud in fofern man auf bie Sftwenbung ber erivorbénen Einfichten fieft? (Sempe. flyeiben frage toird, buntt midh, folwer zu ents

) Ein betaunter Oak; man Fejemis. Beweis nur bie serichiedenteit plegt aber zu befien zufúhren. Die Serfhiebenheit ber Methoden ans Den ift allerbinas fháslich, ber Erzichungsmetgos zut eiuer gemifien sógling baburch gebirber getwiffen Inbeftandigfeit bes Etharacters gebildet ivird. Die 刃erf́hiebenheit der Lehrmethoden aber if minder ficháblich a!z vortbeillhaft; benn io fefje baran gelegen ift, baf bas Jerz Seftimmte beit uno geftigfeit befommt, to febr wichtig ifts bingegen, baf ber 3erftand sticht einfeitig gebilbet

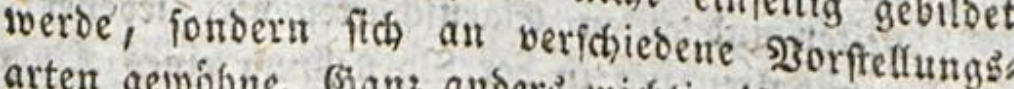
arten gelvohne. Sanz anders wichtig ift ber stund,

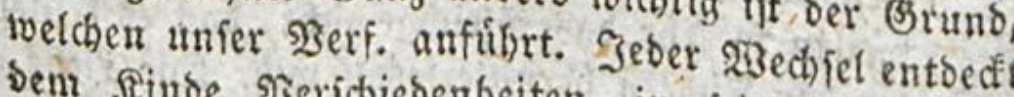
vem Sinbe sisericbiebenheiten in leinen fúfrern

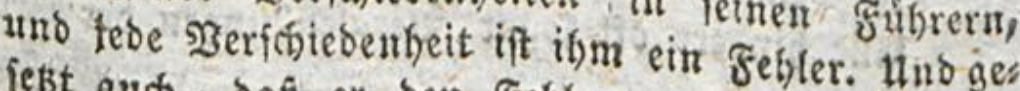
iefzt aud, bak et ber febler mur in bem verabs

fohic 


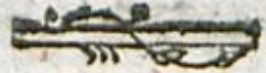

Fijweigenbe SEergleidungen an, berent Erfolg tmmer ift, bafí fich bet thm oie 2 d)tung gegen bie, die es regieren, bermindert; *) uno folgs (iod auch biefer Ânfeben über baffelbe, Siommt

fólebeten Erzieber fánbe, fo wúrbe boch biejer leţs tere in feiner 2 ugen verlieren, und mit ihm die ganze Erzieherzutt, unb folgtich aud ber neuere,

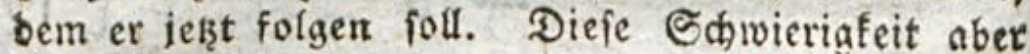
if unbermeiolid, benn fie wiro aud zwifden ter und Nutter fiatt finden. $\mathscr{S B}_{a b}$ foll man thus? Die Schwierigfeiten fo fefre als mógtich vermeiben; soenig wechieln; gut wáblent um nicht wectjieln zu

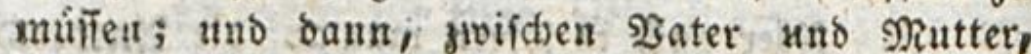
zlwifchen Ëttern uno Erziehern, fo Garmonifth; fo planmáfig handeln, als móglids ift, ind Einfälle und Qaumen zu vermeiben fuchen.

Billaume.

Die Sache hat ifre Sdyierigkeit, aber foll bas Sinb, wenn man fehlerbaft gewáblt hat, wie oft ber fall fenn mus, nicht aus follechtern it befiere Scande fornmen? Siefenvits.

*) Segen 2 tlle, bie es regieren ? Der Erfolg fann fenti, baß́ es rale hod) achtet und liebet, die es regieren: umb Dieier Erfolg finvet wirflich oft Statt. Nur iff es maturlich, bafi es Einen gervifunlid mehr hodad" tet und liebt, als einen $\mathfrak{A}$ ndern. Hno bies feibet

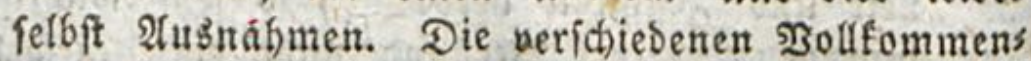
beiten uno guten Eigenichaften werichiedener \$erios uen balten fich in ber Sorftellung, eines Sinbes zus sveilen fo fehr das (sleidhgetvid)t, baßi es feinen uns ter ben 2indern herunteriek̨en will. Die Siebe gegent Qffle bindert oft fogar פ̦ergleidungen ber Art.

Eb) Jers. 


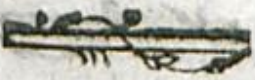

eB cintmal auf ben S5ebanten, eB gebe (Erroach,

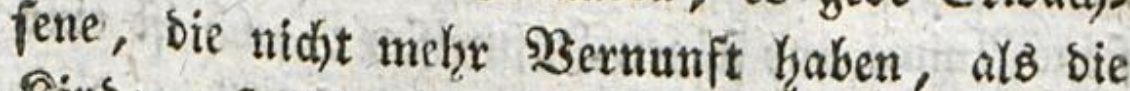
Rinber; fo ift alles 2ufeben, was 2olter giebt, berlohren; uns die (Exziehumin verfefylt. *) (Fin Sino muf teine anbern Sbern tennen, als

Die Erfakrung lént, bás cinige finder zwis fiten \$erionen, bie von ifnen geliebt werben, nicht leidjt 2Sergleidjungen anftellen, und einer ober ber

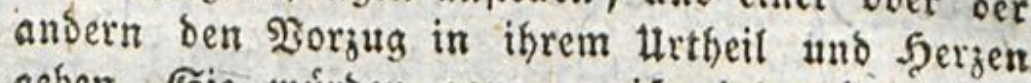
geber. Sie wurben ganz getviép viel fpater, auf biefes an und fúr fict felbft fo feblethafte und vers

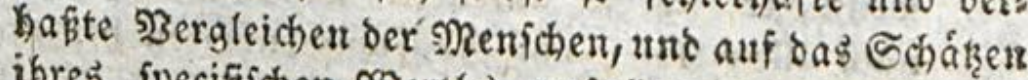
ibres fpecifichen 2 erths verfallen, twent man fie nicht Durch allerlei bumme frragen baju verteitete 3. 3. wen haft bu lieber, Dater oder \$itter, wee ift beffer u. f. wo,

Stuve.

-) B̧ei ciner weifen Exziehung muß vorjúglids bafúr

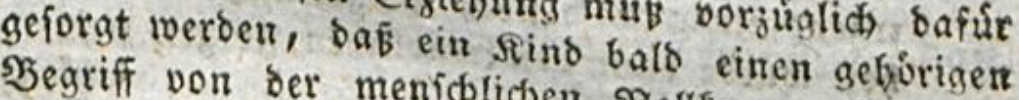
Şegriff von ber menichlichen গ3olfommenheit und Invollfommentheit befomme. Dam wirb es nicht surch Ningel, bie es bei Sllten entbeft, gefindert soerben, fie boch zu fcháben, zu lieben uno felb ş fu verebren, weun es mebrere menfobliche sollfom, menbeiten findet, als Nenichen mach bem iffm er: theilten Hnterridt uns nad ben fich fammefnoen Erfahrungen gewoontid) habert. Eine foldhe (Frgiehung muk nothwendig auf eine ridjtige Erfenntnif. ber 2Belt und ber Nenfichen gebaut werben. Damit wirb ein Lehrer boer Sofmeifter feinesiveges yon ber SBer: binblidbeit losgefprochen, alte feine fráfte anz̧ senden, um felbft ein Nupter ber গুollemmenteit fur feinen 3ogling zu fenn. Dies if nothmentig, 
SEater un5 Mutter ober, falls es bie nidjt hat, feine 2rumse uno feinen Sofmetfter: aud ift eins

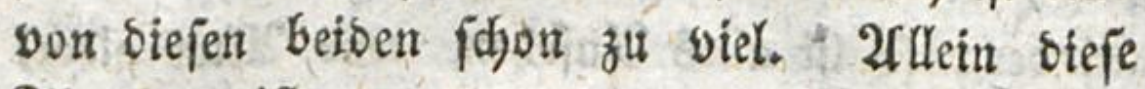

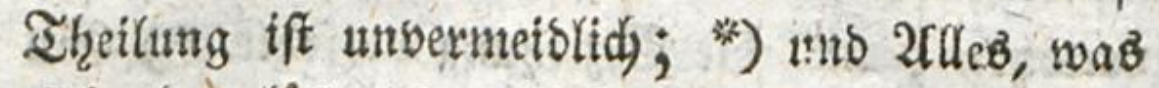
fich thun lafit, Dem Hebel babet abzubelfen, ift,

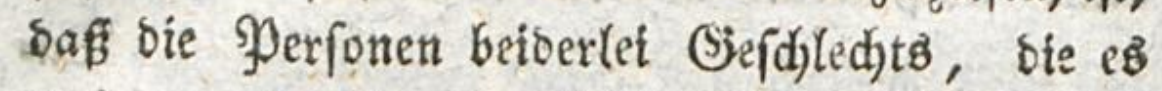
regieren, fo fefor in 20ficht feiner ibereinftims

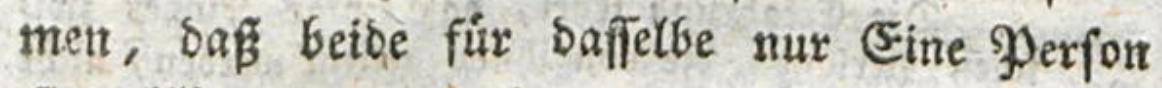
fino. *ै:

Die

went et felbige anfeutern bill, mit Sgelbenmutb nach, alfen Irten bon 3 olffommentheiten binzuringen und feine Btúctefligfeit nach ber Stufe zu berednen, bie bei jenen ßुeftrebungen erftiegen finb. Snbem ber Sofmeifter aber felbft Mitter fír ein sino zit fenn fich lebbaft beftrebt: fo muf er fich bod hutiten, fich bem §inde zum פiufter vorzuftellen. Gebe Entbecfung irgeno einer auth noch io geringen Unoollfommens beit wurbe dann von faldablidhen folgen fenn.

(ะ็) ไeเชี.

* Dieiren \$3ater uno Mutter einer 5̧errichaft, wie bas fowol bei vornebmen, als geringen Eltern ber Fall ift: io if es eben fo unvermeiolich mefrere Dbern fennen zu fernen. Eine gute Ergiefung ex: forbert es, daf eit Rinb bie es zunádit umgebende

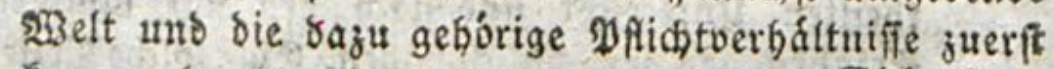
fennen lerne. Eblers.

") Eine 90 vollfomme Hebereinftimmung findet fid in ber wirflidien 23 elt uicht. Es f́ant felbft bei bent beften Nieniben nut vom gemeinichaftlichen જुeftrer ben, in Şinvirfen nath einem und bemielben ziel

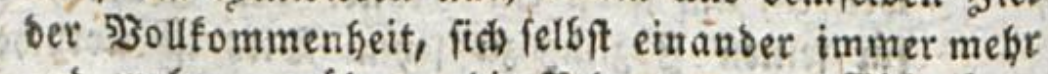
und megr ju nábern, bie sebe fens. Ejlerb. 


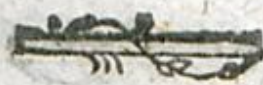

Die 2 mme múp einigermanffen bequem les ben, fie muf einer etwas nathrenden fioft gea niefsen, aber nicht ganz thre vorherige gewohnte Sebenbart anbern; fonn eine pris Flidìe unb gånz

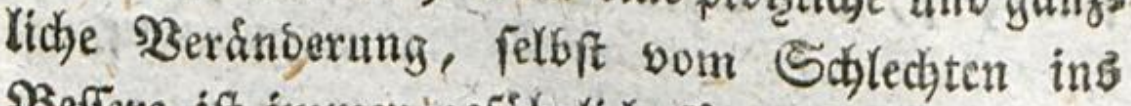
Beffere, ift immer gefährltids fix die Sefundbeit; uno ba thre getwobhnliche $2 \mathfrak{d r t}$ im Effen uno Irins ken lie gefund und wohl bei Leibe gemadjt ober gelaffen hat, wozu follte $e B$ bern gut jern, baf man fie ferbige Derinbern liefe?

Die Båterinnen effen weniger Fleifa und mehr Rrüuterfpeifen, als die Stadterinnen; und bies vegetabiltfthe Eeben fotheint ihnen und tben

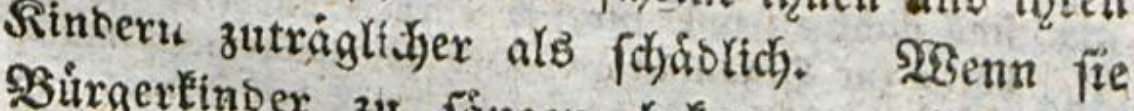
Burgertinder zu färgen befommen, fo giebt man ifgnen Siochtopfe; in ber Sleinung, bafí Fleifhiuppen uno Brithen innen einen beffern Nahrungsfaft und mehr Millch geben. Sid bin ganz uno gar nicht biefer Meinung; uno byabe Die Erfahrung für mich, bie uns beleḩrt, baf Sie fo ernábzrten Rinber Dem Bandjgrimmen uno ben ISBirmern meht unterwor fen fins, als andere.

Dieb ift auch gar nidjt zu berwunbern, weil bie animalifitye Subftanz, wenn fie in Faulnif übergeht, bon

Der 


\section{0}

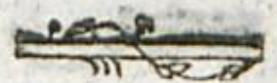

ber segetabiltiden nidjt alfo tif. ") Die Matld aber, ob fie gleid) in bem Leibe bes §hiereỏ bereitet wirb, ift ood, eine begetabilifdje, Subs

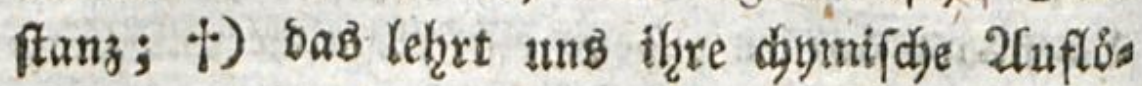

fung.

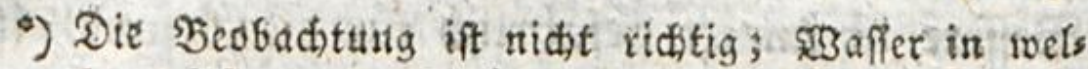
chem Pflauzen aufgelöt werben, ja felbit lauteres faulentes 23affer, ift ganz voll fleiner Ibiere: ber Efig felbft, retun et verbirbt, hat feitie bes

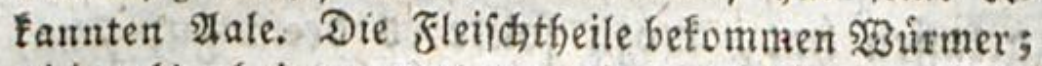
sicht als of iene geneigter wáren, foldi)e zu erjens geti ; fondern; weil biefe voit Sefuiten binein gelegt sorben. Das ift befannt. Rouffeau irt fich gewiß, went er glaubt, bafi Sinder, bie fein frieifd zu eॉlet

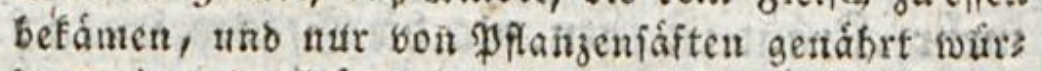
ben, niemals siburmer baben migten. Die sebrirme: fino tiidat dn und fair fich eine Siranfheit; fie ges boren zur Drganifation. Fiur ifir Hebermaapi macht fie fódolich, fo lvie bas Hebermaapi des જslutes uns ber beften Sáfte. 2ulle ฐbiere, felbft foldhe, die nut

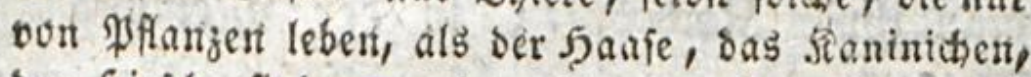
ber firich, fino - unb wobil zu merfen, obne frant ober mager zu fenn, - voll 93úrmer. Sierin ift unter ben fleifdfrefienden und grafenden Shieren alles vollfig gleich. Fiiche unto 30 gel fint nidjt attss genommen. Zu ber Beit aber, als Siouñeau ichrieb, saren bieje Naturericheinungen noch niöt befannt. Sillaume.

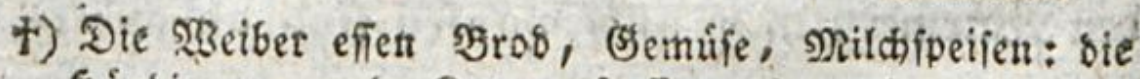
Suindinnen und Rakzen freffen eb aud); felbft bite Sglolfinnen weiden (S)ras $a b$. Dab fino sié pflanzens artigen (áfte fúr ifre Mild); nur múfien nun nod bere jenigen Ifierarten ibre unteriucht werben, bie fid burd)s aus un bou gletich uabren, wern es beren giebt; woran ic aber zrocifle.

D. 3erfaffer. 


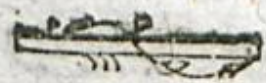

fung. Sie wirs leidjt zur Sáure; und anftatt, oafi fie bie geringfte Spur von einem fluddtigen 2rrealt geben follte, wie die animalifdaen Snbs ftamzen thun; fo giebt fie, wie bie Pflanzen, ein seientlicjes Mitteljalz.

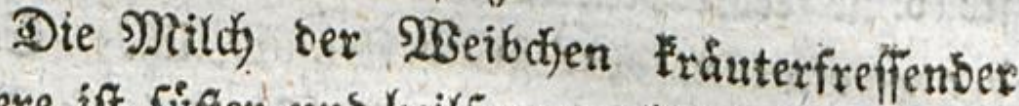

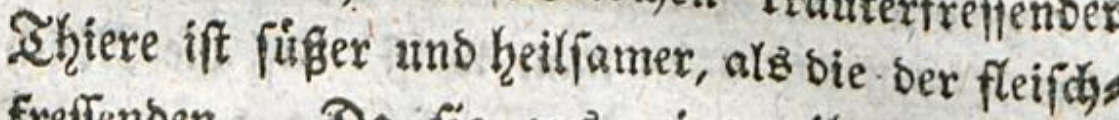
freffenden. Da fie aus einer ihretn Sagejen gleidjartigen Gubftanz entifteht, fo erb̧ất fie thre Siatur beffer, uno iff ber Föulnif nicht fo febre unterworfen. SBill man auf bie Nenge fehen,

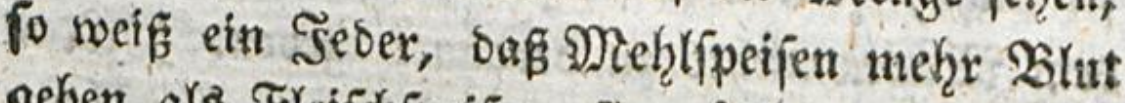
geben als Fleifdypeifen, fie múffen auds folglidé) mehr Mild madjen. Sd) fann nidjt glauben, Daßz ein Rins, welches man nidyt za bald ents mof̧nte, uber bas man nur mit Rrånteripeifen entwishnte, und befien 2 mme gletdffalls nux bon Rirateripeifen lebte, je von MBurmern Slage leiden Hónnte.

Bielleidjt geben Speifen von Rrautern eine fojleuniger fauterwerbende Mildy. 2(ber id bin

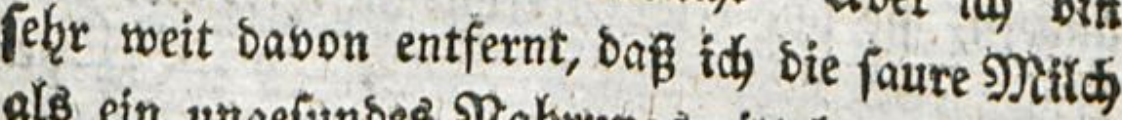
als ein utgefundes গlabrungàmittel anjetzen folls te. Sianze SBolfer, sie tein anders baben, bes finden fich febr robl babei; und alle sie 2lno ffalten mit 26 forbentien fogeinen mir nidbts als sine 
cine Martifjureierei zu fent. (5s gfebt Leibes: bejdyaffenfzetten, wald)e gar teine Mildy bers tragen Esnnen, und alsbann madjt fein 26fors bens fie ithen bertraglich; bie 2noern vertragen fie of?ne 2fojorbentien. SMan furchtet fich oor ber geronnenen ober geläberten פ্রildy. (5) ift

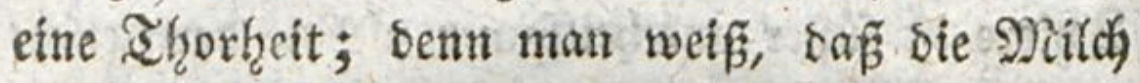
immer im Magen gerinnt. E. Ben Daburd; wirs fie zu einem binilänglidg feften Nathrungsmittel fur bie Sinver und Sungen ber Ihtere; geróne fie nidjt, fo wirbe fie fonell burd)geben, ins Dem Magen nichts zu berbautr geben. *) Nan

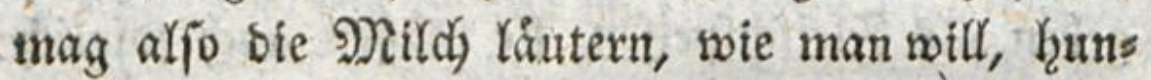
bert 2 b forbentia anwenden; wer Milld ifft, vers

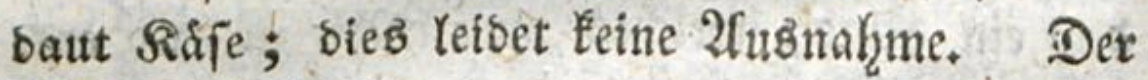
Dagen ift fo fefur bazu eingeriebtet, bie Matd gerinnen zu laffen, bafi man gerabe mit Ràls bermagen saab madist.

Scl) glaube alfo, eb fey genug, ben 2 mo men, anfatt ifre gemsfynlidyen Speifen zit ver: ánbern, fie nur reid)lidjer uno in ifrer 2 rt aus,

2) Dbgleiç bie Sáfte, bie uns ernáfren, fliefiens find, fo múfien fie boch aus feften शabrungsmitteln aus's gebrift iern. Ein Arbeitsmant, ber nur von fleif(h) brúbe leben wollte, wurbe febr bald verfommen. Nit Mil(t) wúrbe er fich weit beffer erbalten, weil biefe gérumut.

3. 3erfaffer. 


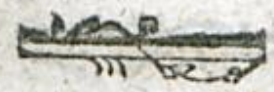

(B)

ex

ive

eII

lor

ift

(d)

to

tel

ne

no

in

ns

ix

lex

di)

Is

ito

$r=$

B.

es

is

181

(3)

tis

it

fe

gefuchter zu geben. Das Faftenefien erthist niç. Surdy die Natur ber Speifen; nur bie 233 irze baran madyt es ungefund. 2(enbert enre Rocha recepte, habt weber Sieriftetes noch Gebeates nez; Kagt weder 23 utter, nod) Sal, nody Nitldy ans Fetter fommen; lafit eure in 23 affer geo

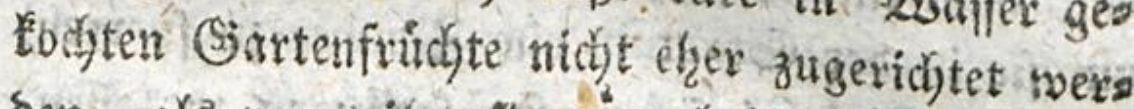

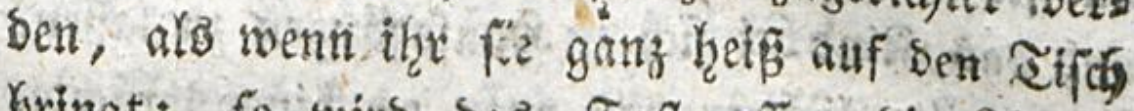

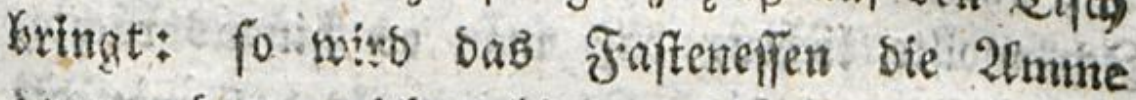

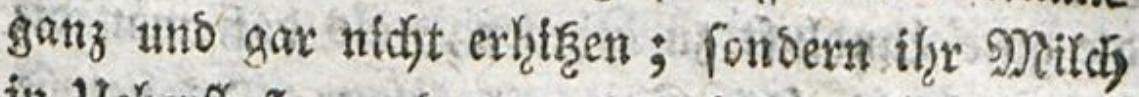
it Heberflus, uno bon ber bepten, Befdjoffens heit *) machen. Sollte es mogtich feyn, Dr,

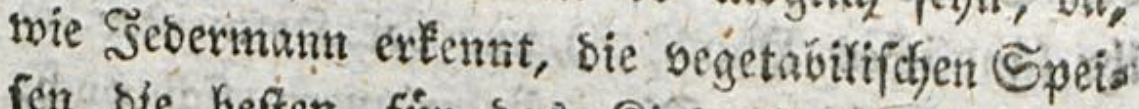
fen bie beften fir bas Rino finb, daf bas Freifdeffen bie befte Mialarung fir sie 2fmme

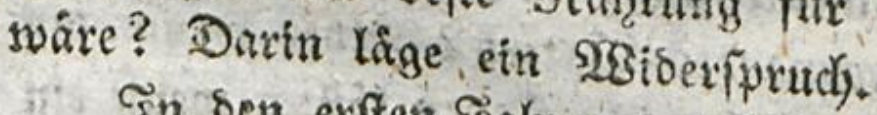

In ben exften Sahren bes Eebens vornefms (id) wirte bie luft auf sie seibesber(t)afengeit Der

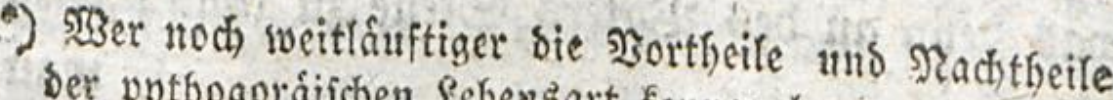
ber pythogoráichen \&ebensart fennen lernen will, barf

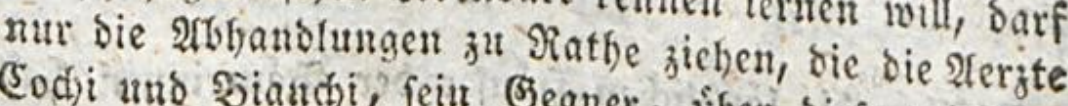

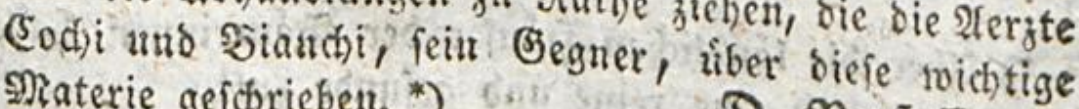
Materie geichrieben. *) D. Berfaffer.

-) Heber biefe Naterie hat man thrade vorzúglich die fiebente 2fbhandlung wou Itnzer und die achte von IIben im britten Eheil des Revifionsiverfs uno

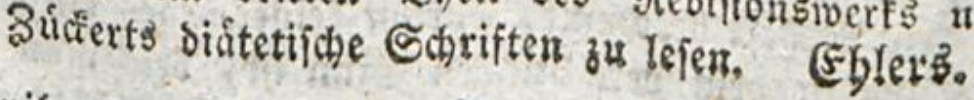
Emil, Ifter \$f,

श 


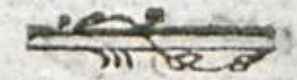

ber Sinber. Sie oringt ourdy alle Sdyweials: deer in cine zurte uns rofdje Şaut; fie greift biefe werbenben Ropwer gewartig an; uno läpt Einoride an ifnen zurude, die nie vertilgt wers sen. Sh wurbe alfo nidjt ber Metnung fern, baf́ man cime Băurin aus if̧rem Dorfe nâhme, um fie in ber Stabt in ein Bimmer zu pperren, uno Das. Rino bet fich zu Scaufe faugen zu Yaifen.

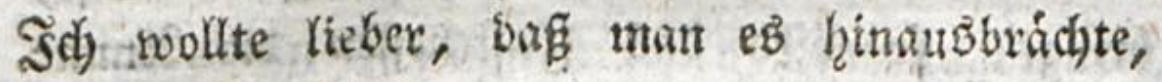
bie gute \{anoluft zu athmen, als safo man bie 2lmme in die ible Stabluft führte. Es nehme ben Stans feiner nenen Nutter an, berobne

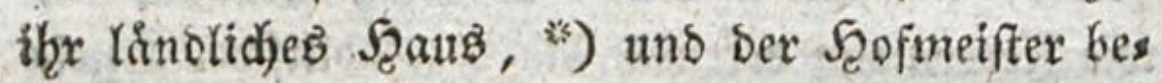
gleite es bahin. Die Lefer exinnern fich bods,

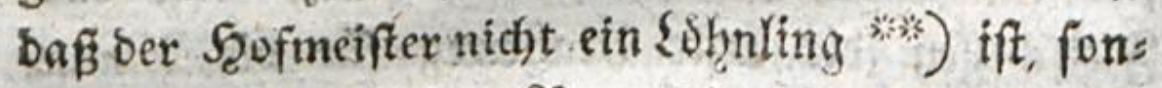

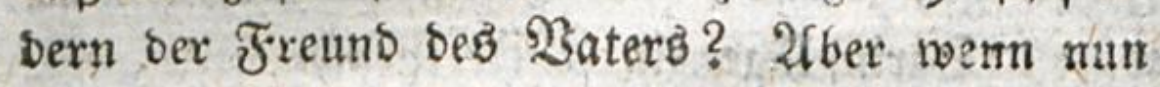
siejer Freund fict) nidjt finben lafst; wenn ein foldger (5nthufiasmus nicht leidgt getroffen wiro; wenn nid) ts yon bem21ngerathenen ausfübrbar ift: was benn an Des Baterb Stelle zu thun? wirs

matt

*) Alber bie lándliçen f̧áufer ber Báuerinnen baben mur felten eine reine und gefunde luft.

Fefemitz.

*) Es ift vorfin fiton gejeigt, ठấ ein f̧ofmeifter, ber

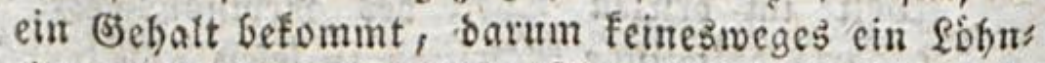
ling in bem verád)titchen Sinn ift, ben man mit biefem $\mathfrak{x}_{30 \mathrm{t}}$ perbinbet.

(E)blers. 


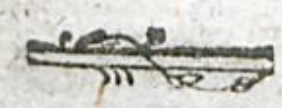

I95

S:

ift

fit

'rs

in,

le,

$n$,

$\mathfrak{n}$.

te,

je

ne

ne

ies

t),

ns

III

in

;)

$t$ :

ro.

in

en

ber

ins

ait

mats mich fragen.... S. Sh brabe es ench fochon gefagt; ras ihr thut! Dazu bebarf es Keines Rat'zes niónt.

Die Menichen fino nicht gemadit, wh in 2-meifenlzmfen ůber einanver gethirmt zu werben, fondern fich auf Der (5roe zu jerfirenen, die fie bauen follen: Semetgr fie fid fammeln, befto grofigeres నerberb für jüe! Eeibesgebredien, fo wie Seelenlafter, fino die unfehrbare $23 i r$ fung $^{2}$ Diejer allzuzahtreidsen 3ufammengebringtheit. Der Menfd if unter allen Thteren basjenige, bas am wenigften in Sceerben leben Éann. Unter einanber wie Sdjafe gebáufte Stenidjen wúrben fántlidy in Euzzer Beit vertommen. Der Soem

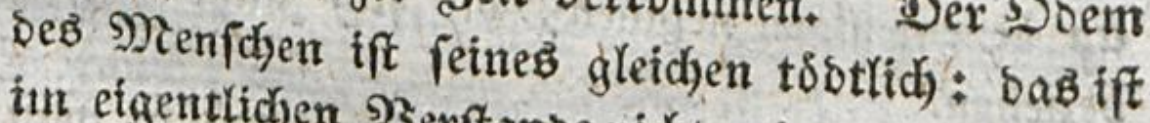

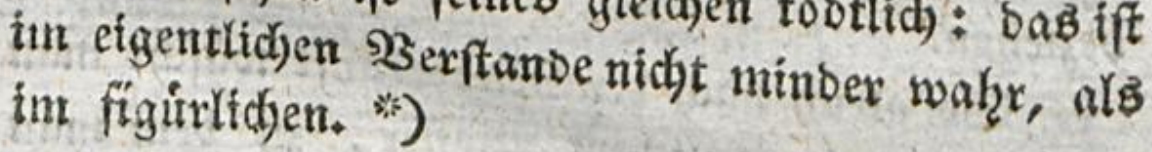

Die Stabte find ein 2\$gruno, ber bas

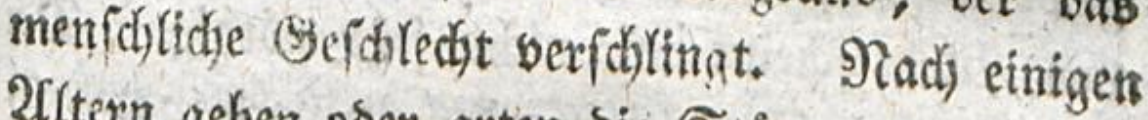
2fltern gehen ober arten bie Stimme alts ; man

- mufi fie erneuern; uno immer gefdoteht biefe 구 2

(Ers

2) Dies nenth Serr Formey cine beleibigende \$er

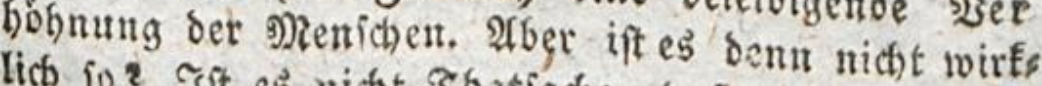
lich fo? Fit es nicht Thatjache, bas in grofen uns volfereichen Stábten bie Sterbfichécit unb bie llus fittlidfect arofier fey, als an Elsinen Orten unb auf Dem fande?

Eampe. 


\section{$x 96$}

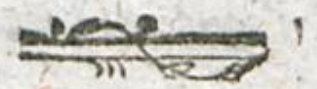

Entrenewng von Eanbe ker. Berfenbet alfo eure Sinoer, baj fie. fo zu fagen, fid felbft ernettern; unb bort die Siraft wiebergewinnen, sie man in ber ingefunden suft allzubeboiferter Sote berliert. Die Státeximmen, wemn fie auf bem Lanbe forwanger werben, eilen, nun niebers zulommen, in bie Stabt zuride; fie follten bas

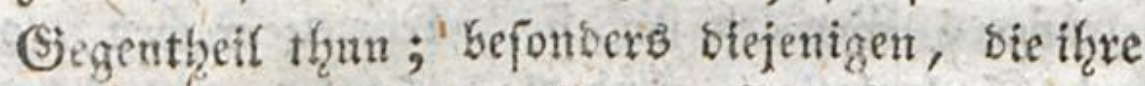
Sinber relsft fitlen wollen. Sie birrften wents ger oabet verlieren, als fie wol beifen; uno in einem für bie Sattung natirlicherem 2fufenthalte wirden bie mit ben Mflidjten ber Niatur bera bunbenen Frettoen, ihnen balo ben Gerdymact an benenjenigen nelgmen, bie fid) nidjt barauf beziehen.

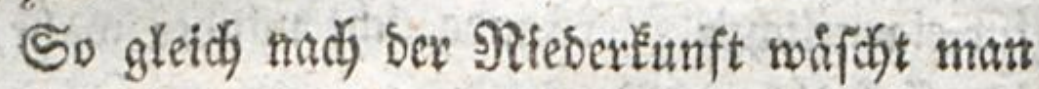

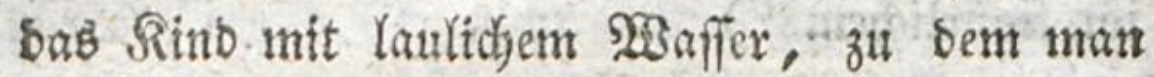
gemolsnigltex) etwas 2 Bein gieft. Diejex 3uja

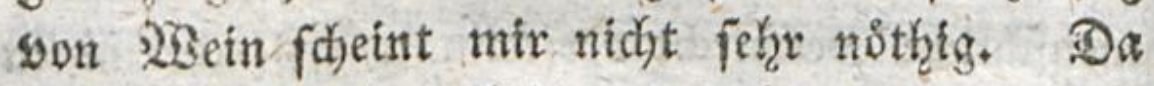
Sie Siatur nicyts Saihrendes herburbingt, fo ift nidjt zu glauben, bin ber Gebrand einer Surt) Runft bereiteten Frinfigfteit zu Dem Leben ihrer Siefdjopfe etwas thute *)

$2 \mathfrak{A B}$

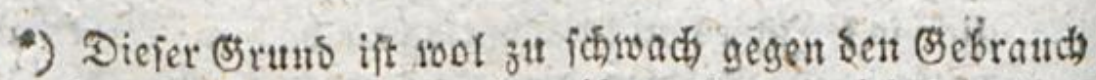
bes 23 eins etwas ju beweifen. Skgenn niddts ju bem Seben ber Befchopfe etroub tháte, als mas bie sias 


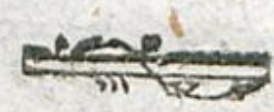

$r r_{0}$

$6 f^{2}$

m,

ter

ux

er:

as

ine

nits

in

Yte

cra

$x c^{2}$

iIf

ati

an

a

Da

10

ter

en

แลื

(1)

ent

ins

tutr

Zub sempelben Srunbe ift auch ble SBors

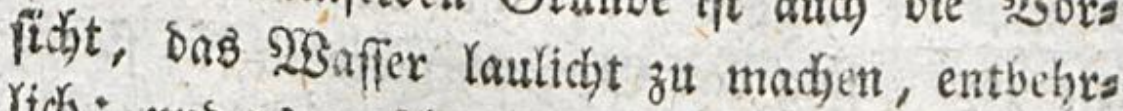

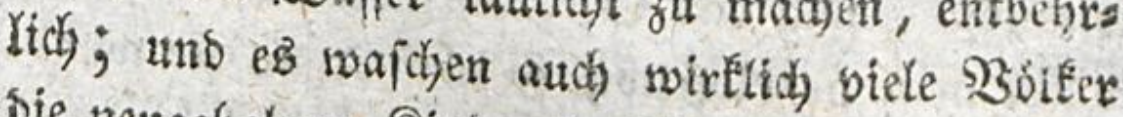
bie neugebohren finder in Ftuffen, oder in Der See, *) ofnne weitere Utmftínde: allein ste un

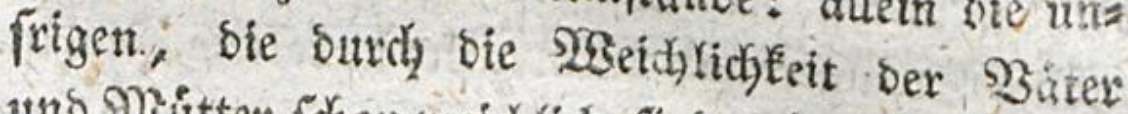
uns Mritter fichon weichlid find, ehe fie gebohren merben, bringen eine bereits veroerbte feibess berd)affenkeit mit auf oie sigelt; welche man nicht gleidy anfanģ allent Sprifungen auझferen nurg, bie biefe \{eibes̈befdyaffenheit wieser heva ftellen follen. Stur ftufonmeife fann man fie roieber zu ifgrex urfpringlidyen Eebenstraft 3us riclébingen. Sháltet eucis aljo anfangs an ben (Gebrauch; ; uns entfernt ench nur ofluáblid bavon. शr

fur unmittelbar kernotro s23apdist Das Sefen ber (stitiptent, fo mípte, Mieles fúr

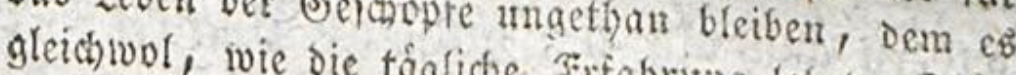

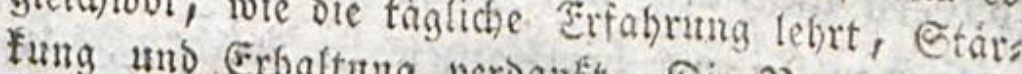
fein sinnen fertur verdant. Die slatur bruat

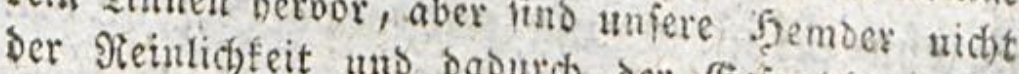

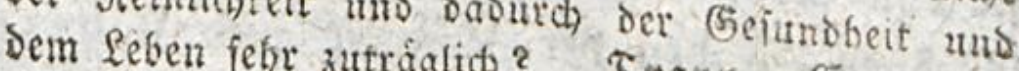
bem Leben fefr zutráglith? Trapp. Eampe.

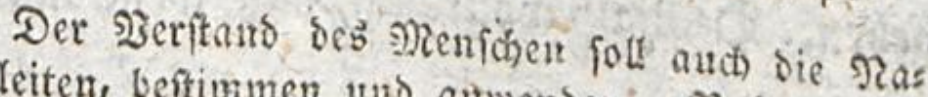
tutr Yeiten, beftumen und antwenden. Viejerwis.

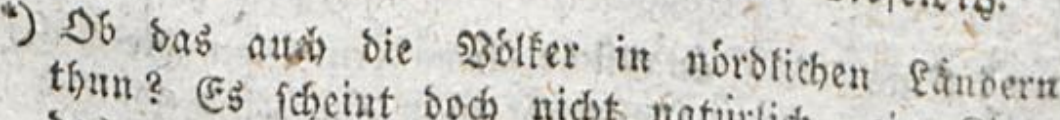

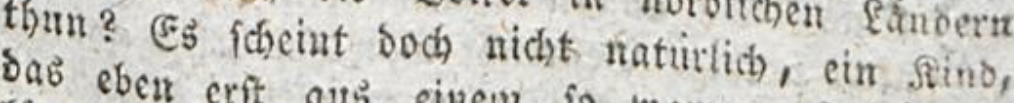
bab eben erft ats einem fo warmen Bebaltritis

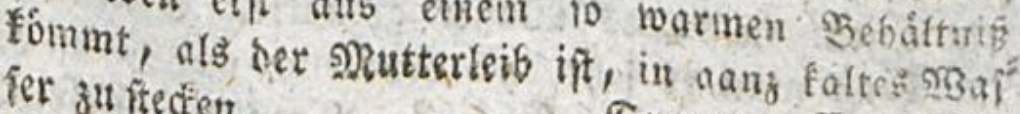
fer zuftecter. Stapp. Emme. 
IBafdyt bie Rinder oft; ifye Unjauberfeit zeigt soie nothmendig bas Ssemafdjentwerben für fie ift; soifot mun fie blofa ab; fo madht man fie wund. 2 ber fo wie fie ftarter werben; berminbre mant

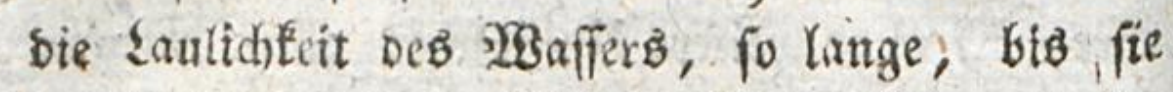
enolich Sommer uns $\mathfrak{B i n t e r}_{\text {fich }}$ in Faltem, ja tin Eiomatfer wafden laffen. SBgetl biel baran ges Yegen iff, bafi biefe ßerminberung langfam, nad) uno nath, und unvermerft gefdjelye, bamit man fie nidyt in (Sefable ferge, fo tamm man fidy bes Thers mumeters sabei zur 2(bmeffung bedienen. ${ }^{*}$ )

$23 \mathrm{em}$ biefér (S3ebraudy teB 2 abenz einmal eingefưhlnt ift, fo muß̊ ex nidst wieber unters brochen werben; uno es if widytig, baf man thrn benn bas ganje \{eben hinourd betbehalte. Id) betradjte ihn nidjt allein bon Seiten oer Reinlidłeit, uno oer gegentwartigen Siefunoheit, ponbern aud als eine beilfame 20 oridit bae (jes webe ber Fibern benglamer zu machen, fo oas fie ohne 2 nuftrengung und ohne Sefabr ben vers fChiesnen Giraben ber SBarme uno Rålte nachy geben. Deshalb wollte id̄), Dafa, wenn na: gröfaer wirts

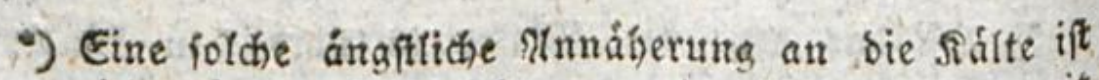
nidgt nóthig. Đeffreiđt man ein Sino fogleich mit cirem in faltes 253 afier getunften Eqfiwamm: io fann man es ferbr balb orbentlich mit falten 28 anifer roajoren. Eglers. Eampe. Rejerwis. 
eigt ift; into. natt fie 1 itt ges Iadi) $i$ fie gers

mal iters natt ilte. ber jett, Sies Dag bers ach sfer virs te ift mit $:$ io ariet 6.

witroe, man fič nach uns nach arigenosknte, fich fll weilen in warmen $2 \xi a f f e r$ bon allen nur ers tråglichen Sirnoen, uno zuweilen in Ealtem, gleidyfalls bon ailen miglidjen Siraben zu baben. So wirbe man, wenn man fo weit getommen

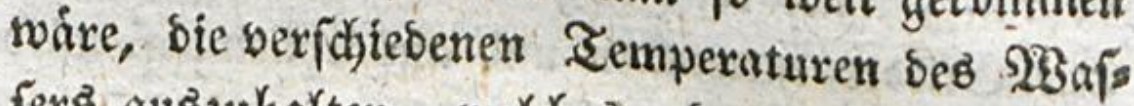

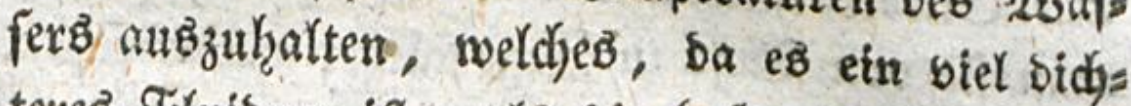
teres Flutbum ift, als bie Suft, uns an viels mehr Suncten beribbrt uno viel ftárter angreift, faft unempfinslidy gegen alle 2inftspe bon suft werben. *)

Seibet nicht, $\delta a \beta$ in bem 2ugenblicte, wo bas Sinb zu atf̧men anföngt, feinen Şúllen heraus ift, man ihm ansre gebe, bie es beinatze nod) enger eingeid)lofien balten. Reine Ropfbinden, feine IBindelfannire, feine

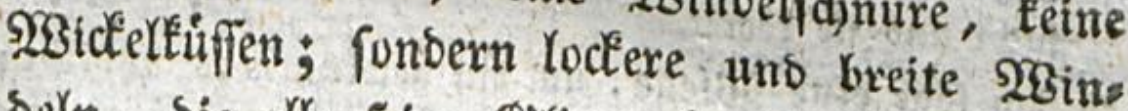
beln, bie alle feine Gliteber in Freiheit laffen, Imb bie weber allzu fdyer fins; ong fie feine Berwegungen in 3mange balten, noch fo warm, daf́ fie es Kinbern, Die Einorude der Suft zu ? 4

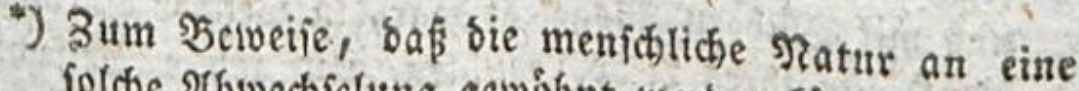
fold)e $\mathfrak{A f}$ wechfelung gewobnt werben fonne, und fid Daun wohl babei befinde, dient ber Fufie, ber aub Der heipen \$abitube in cinen mit Eis belegten FIn ipringt.

sampe. 


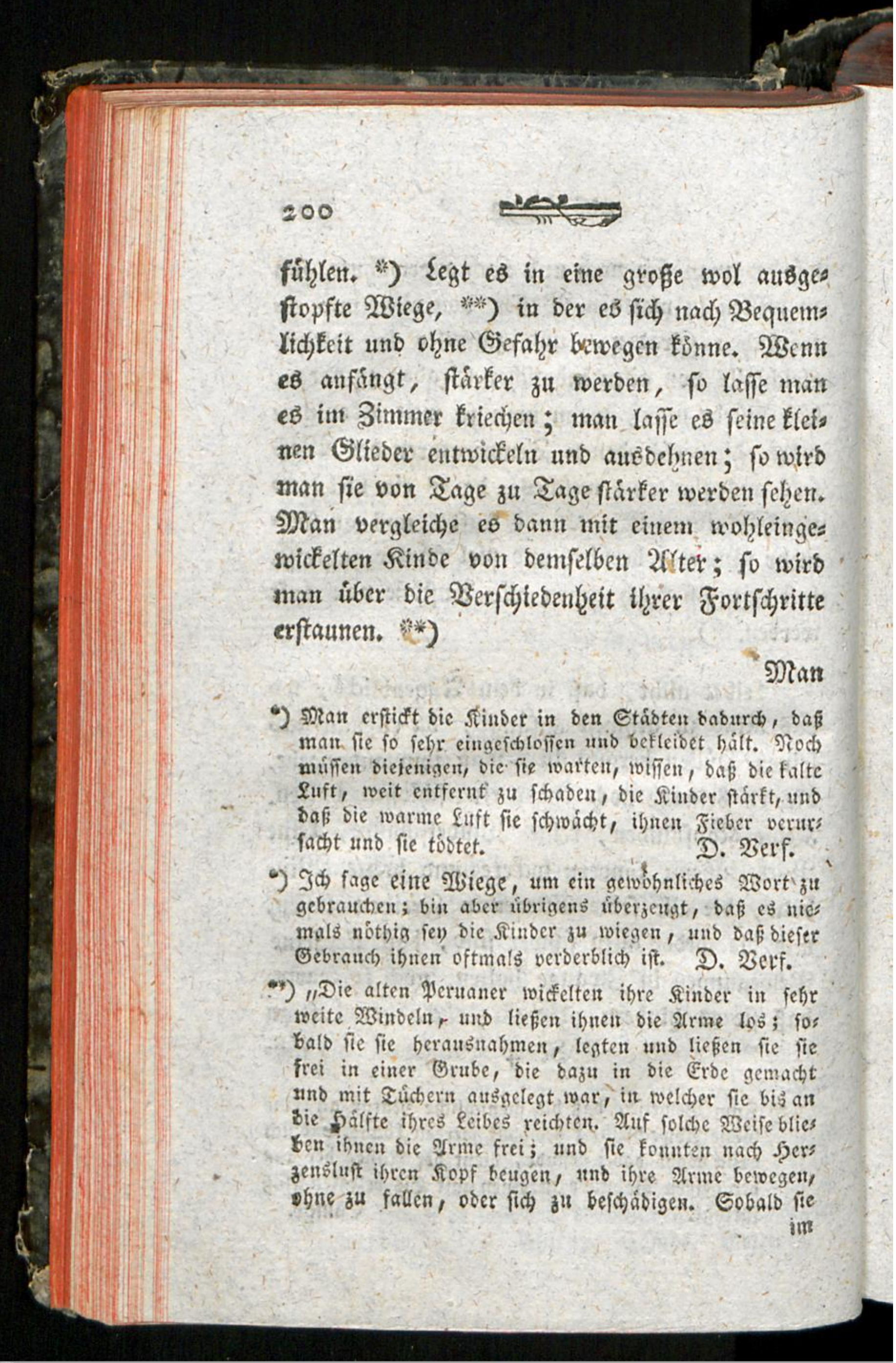




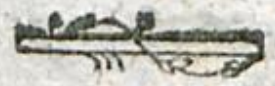

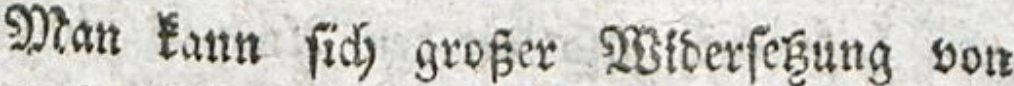
Seiten Der 2fmmen getwirtigen, Denen ein wofrl

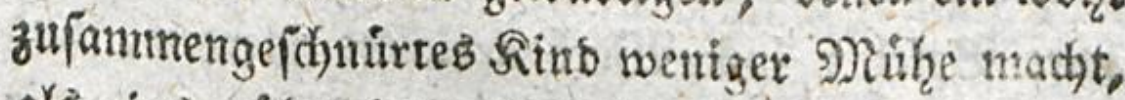

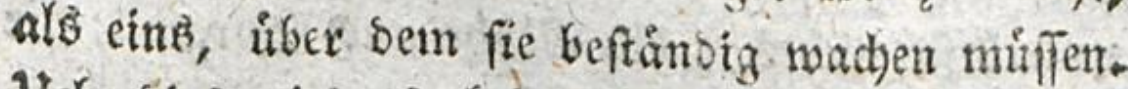
Uteberbies wirb es bei offenent Riteibern mertlta dyer, wenn ein Sind unreinlidily gêhalten witro; man mus es alfo sifter fáubern. Enolid, ift

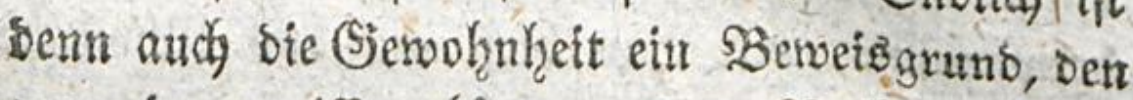

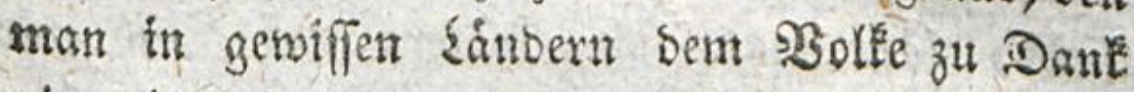
nienuts wiro wibertegen tósnen.

$$
\text { श } 5
$$

im Stanbe roaren, einen Schritt $z$ th thun, reidite man ihnen bie গुruft etwas von weiten, um lie baburch jum

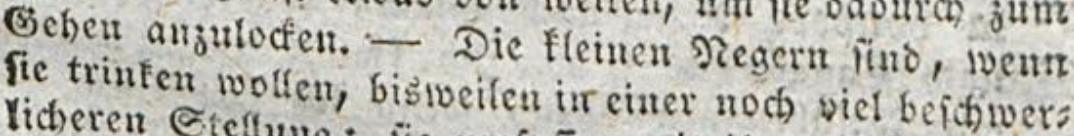
licheren Eteflung; iie umforien mit ifgren frifien un

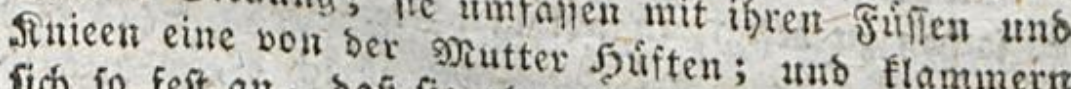
fich fo feft an, bấ fte obue Şeibúlfe ber flammern s)utter bangen bleiben; alsoem faffen fier wime ber Sinben die Şruft, unb faugen beftindig mit ibren ofue fic irren ju thfien ober ju falleng baran fort, bie bie wafrenoer seit ifre 2robeit wie gewobnlio forts thut, mag. fich bervegen, wie ïe tvifl: Dieje Jinber faugen, wenn fie zwei szonat alt find, ichou an zus geken, oder vielmebr, fich auf ben. 5 anden nno fuffers zu follepwen; eme Hebung, bie ibnen in ber folge die Jertigfeit giebt, faft eben fo idsnell auf alfen Sieven

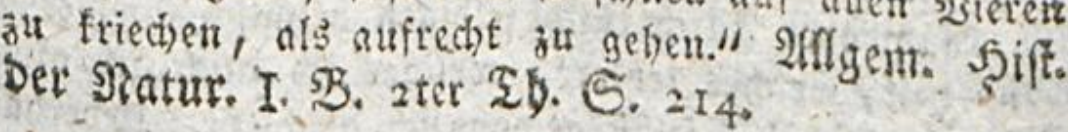

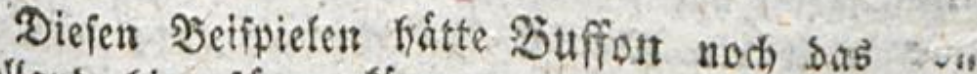
Engelland Ginzufígen fonnen; too bie thórigte uno bare 
Lafit eud alyo mit ben 2(mment nidht aufo (5)rinbeanführen eir. Srbnet an; feftr $z u$, Dä eitre 2 Befehrle ins 2 gert gerichtet werben, uno unterlağt nidhts, bie Máke und Sorgfalt, bie vorgefdrieben sorben iff, in ber $\mathcal{U}_{\text {usubung }}$ Yetdjt zu madjen. *) $2 \mathfrak{G a r u m}$ molltet ihr nicbt Daran ŢGeil netgmen? Bei ber gemóhnlidben Sin bermartung, no man flofi auf oas \$olyfifdye

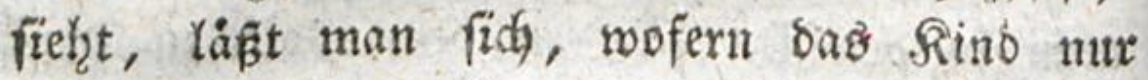
Yebt, uno nidjt berfómmt, bas Llebrige nidjt jebre

batbarijhe Betwobuheit, bie Sinder zu widétn, von Tage du Tage mefr abfommt. Naut felse auch beb la Soubere Nieife nad) Giam; bes le Sheau Reife nach Eanaba, ur. f. 10. Sch fonnte zivanzia Seitert

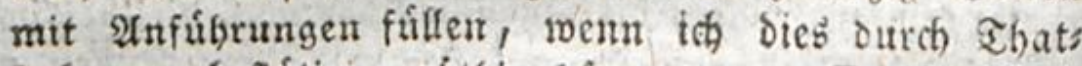
\{açen zu beftátigen nỏthiz hátte.

D. Berf.

-) 2(us eignen Erfabrungen weif́ ich es, dak es bers nutuftige Smmen giebt, bie, wenn man ifnen (3rübe anfuifrt, biefe begreifen uno fich willix badurd leiten

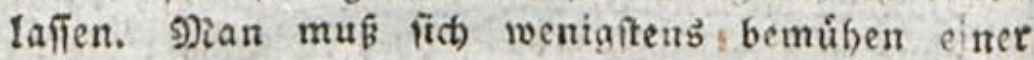
Amme Soeen mit bem, was fie thun foll, in Ules bereinftimmung zut bringen ober boch fo viel zu bes tvirten, bẩ fie den Eltern oder einem Sofmeipter mebr Einfioft, als fich, zuzutrauen fich belvogen findet. Sie handelt fonit wenigitens ben Soridhrifs ten nidist genug gemás̄, wenn fie aud aus (S)ehor" fam ooer Furdit nidit jelbigen heimlich zHviber hans belt, weldses lestere, welches ich auds zu oft bes merft babe, felfit gevobntlich gejhieht. Heberhaupt thut ein Nenich bas niemals gat, was et blof anf SBefebl uno wiber feinen Erfenntnifzuftand thut.

Eglers. Rejenik. 


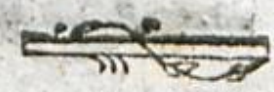

เที

Daßg

ino

bie

ing

idft

iins

fde

mutx

éfre

ans

von

bes

cife

itert

ats

sers

ube

tent

ner

Ue:

bes

pter

gert

rifs

jor"

ans

bes

upt

lob

uts.

angelegen fenn; in unjerm Falle aber, wo bie Erziehung mit bem Seken beginnt, mü̈ man bas Sind fhon von ser Sjeburt an alsె \{efrr Itng, nicht zwax bes Scofmeifiers, aber ber Natur betradjten. *) Dir Soufmeifter thut meiter nichts, als baß er unter biefer exfen Sehrmeis fterin ftubirt, uns berhindert; baf threer Sorgg falt nidjt jumiber gefgandelt werbe. (Ex mad)t ifber ben Saugltng; beobad)tet ifgn; folgt ihm; ex ipåkget aufinertfan nati) bem erften Sdjimmer ber fdyadyanbredjenben Bernunft; fo wie, wenn Daß exfte Biertel aufgeţt, die Mlufetminnex

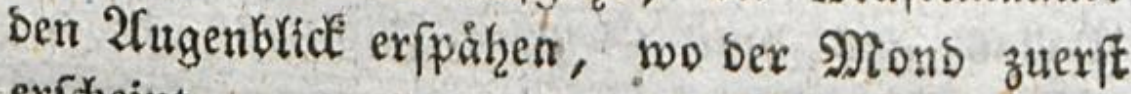
exf́theint.

IJir

*) Eberr fo gut bes 5ofmeifters, als ber Natur. In

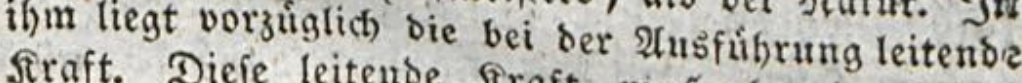
Jiraft. Diefe leitende Straft mús aber burd) bie

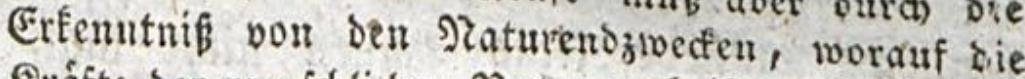
Sirafte ber menichlichen Natur nach iffren $23 i r f u n g$, s. gefetzen wefentlich) abjielen, von ben wefentlichen SBirfungseiuridfungen felbit und von ben gegen

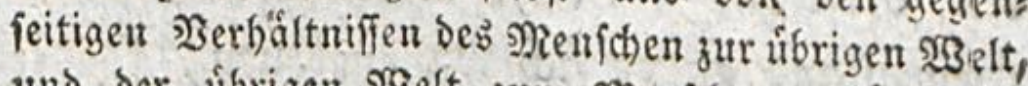
uno ber librigen $\mathfrak{B e l t}_{\text {zum }}$ Menichen geborig ges bilbet unt in ฐGátigfeit geferzt werden, wie $\Re$. aud biejes felbft etfennt. So balo ein Sind anfóngt Soeen anjunebmen: fo fchaft ber 5ofmeifter aud nicbt blof mehr Sjinderniffe auts bem Sूgege, fondern

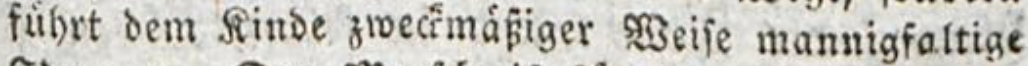
Joeen zu. Der mienfó iff fur ben Nenichen ber wirffampte und im Bangen aud ber befte abeil bet bilbender und teitenben श̧atur.

(E) bers. 
23ix werben nit Faḩgheit zun Eernett ges bohren; wiffen aber nidjto, entren nidjtb. Die Seele, noch gefefleit in unbollétomment und halbgebildeten 2 Bertzeugen, ḩat nidyt eins mal sie Empfindung iffres eigenen Dafenns. Die Sewegungen, Das Sdyreien bes neugebolyrs nen Rinbes, find etroas blof Med anifiches, wobei tweder Bewutfienn nods 9 Bille ift.

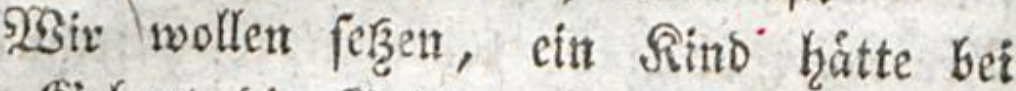
feiner Sieburt die Grófe uns Stårfe eines er: soad) fenen Nienfdjen; eв fprange, fo zu fagen, ganz. bewafnet aus feiner Mntter Leibe, wie Syallas aus bem Şeb̧irne Supiters heroor:

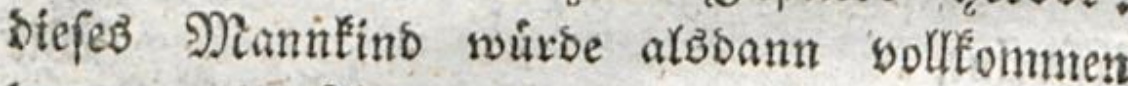
Summ, ein 2utomat, eine unberwegliche uns faft unempfindliche Statue fern. (5.B witroe

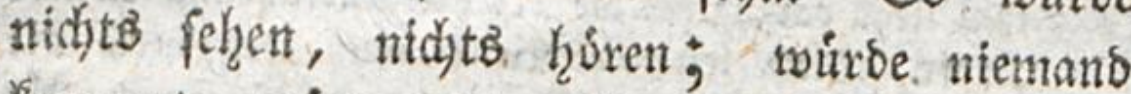
Iennen; witroe feine 2utgen nicht nach bem Șegenftande, ben еБ zu feben beburfte, zu ridjs ten berftefrn. Sriclyt alleint wirroe $\mathrm{eB}$ feinetr Segenftand suber fich wahbrnebmen, fondern es surbe nidjt einmal einen in Das Srgan bes Simnes, ber es bemielben wahruef̧men ließ̧e, auffafien; Sie Farben wirben nidjt in feinem 2uge, bie Zone nidyt in feinen Shren fern: Sie Sirper, bie es berubrten, wirben nidgt an 


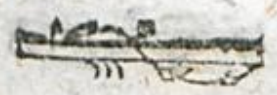

fetrent Leibe fenn; es watbe nidjt einmal mifafen, ob es einen Sirper ḩatte. Das (Sefühl

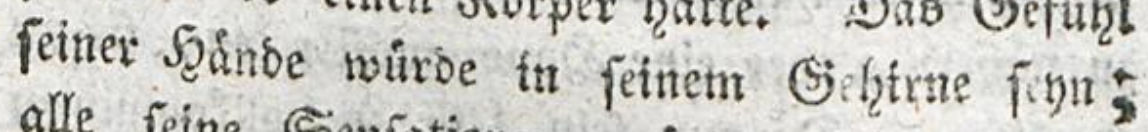
alle feine Senfationen wurben fid anf einen einzigen 9ुouct bereinigent; es wirbe nidjt ans

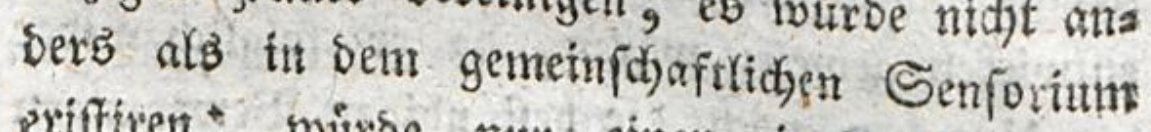
exiftiren; wirbe nur einen einzigen Begriff baben, námlidy ben Begriff bes Jibbs, auf ben es alle feine Sempationen zurictifíbrte; jei $x=$ uno biejer Begriff, oder wielntefgr diefe $\mathrm{E}_{\mathrm{m}}=$ Pinnsuing wave Denn die cinzige Sache, bie es Sor cinem gewóf̧nlidjen Rinbe boraus ḩatte. Diefer anf eimmal gebirbete Mtenid), witroe

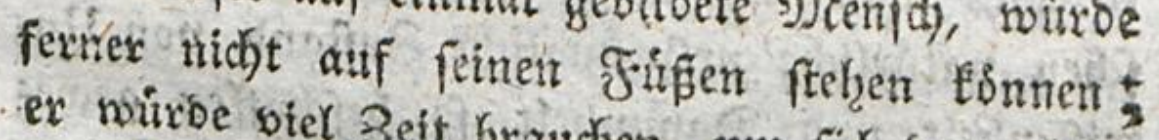
ex mirbe siel 3eit brauthen, nm fid baralif ini Sletadgewtcht ḩalten zu fernen; sielleidyt wirbe ers gat nicht einmal berfucht haben; uns man bratte biefen grofen Risrper wie einen Stent ouf ber Stelle bleiben, ober lvie eitnen jungen Soims triedjen, uno fich fortichleppeit fefin.

(iv wirbe alle Unbequemlidyfét ber $B_{e}$ Ditritiffe fihlen, vhne fie zu Eennen, uns ohne irgens eir Mittel aubjufinmen, bafír zu fors gen. (5.8 finbet fid) leine unmittelbare (Sies

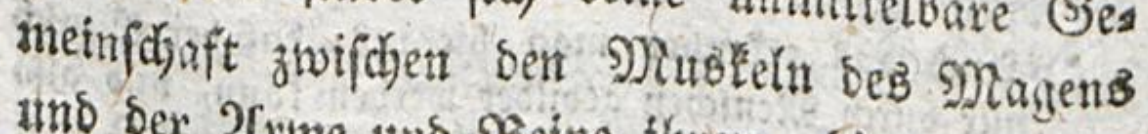
uno der 2frme uno Beine thren, Die, wenn ex

aidi 
aud) mit Speifen umringt wáre, if̧n nur eis net Sd)ritt batten thun lafien, fich Denfelben zu nåbern, ober eine Şand ausftrectien, fie zut ergreifen. Da min fein Seib zu volleommuem S3achotrum getommen, da feine Silieber ganz entwidelelt gewejen wáren, ba er folgridy weber bie Unruhen nodi). Die beftintigen Bewegutgen bex fintor gehabt hătte, fo wirbe ex Soungers tgaben ferben esmen, ehe ex fich aus ber Stelle bemegt bátte, feine Rabrung zu fuchem. Scat man nur ein wenig iber oie Sromung uno sen Fortgang nnfrer Sienntniffe nadgebadit, fo tonn man nidgt leugnen, baff ber bem Nen: fohen naturlidje uriprunglidje Buftand von Ilns soiffenbeit uns Dummbeit fo befdyaffen gewes fen feint múgte, ebe ex etwas surch hie Erfabs: rutig, ober von feines Şleidjen gelernt gehabt beatte.

Man exḱennt alfo, *) obex tann den ers ften ஒunct extennen, bon Dem ein Seber von uns auछgeht, zur gemeinjdjaftlidgen Stuje ber

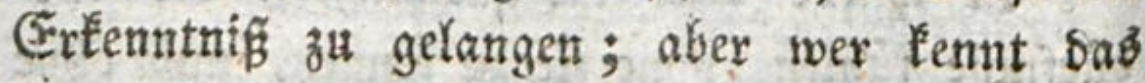
anore áuferfte 5noe wol? Şeber rictit feiner nas

-) 2(uc) bas erfentet man bieraus, baf ber Nieníb mur burch Nenichen gebilbet werden fann, uno alfo feiner SRatur nach zur (Befellfohaft beftimut ift.

Refravikg. 


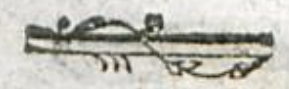

$r$ eis

riben

e 311

inem

ganz

eser

tigen

gers

Der

ben.

uno

idst,

2en:

Ilns

etues

fabs:

jabt

ers

botl

ber

$\mathrm{Das}$

iner

nas

आांक

alfo

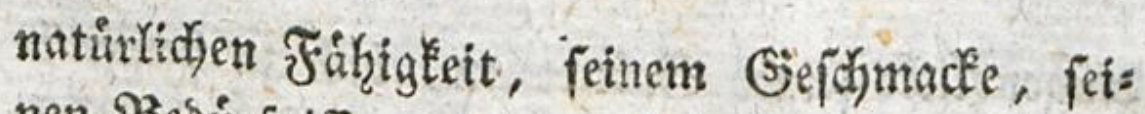
nen Besurfniffen, feinen Siaben, feinem Ěifer, unb Den Sielegenheiten nadr, bie or hat fich benfelben zu úberlaffen, weiter fort. Ş⿻上丨 whifte nichi, baß̈ irgents ein Sphilofoph nod) thifhn ge= nug bazu gewefen maike, zù fagen: Das ift bas 2leuperfte, wozu ber Menfid) getangen fann, uno bas 3iel, sab fich nidyt son thm úbers fd)reiten lofft. . SBir wiffen nid)t, waB unfre STatur uns zu fern erlaubt; feiner von uns hat ben 2lbfand gemeffen, Der zwlicjen (Sinem

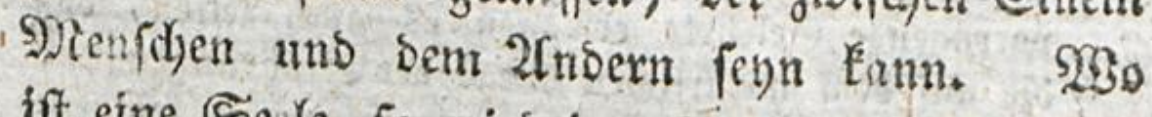
ift eime Seile fo niebrig, Dafg biefer Sebante fie nie erwarmt, uno bie nicht bisweilen in fifrem Stolze gefagt haatte : wie Bielen Kin ich fdon vorgetaufen! uno wie Siele fann idy nods erreidsen! warum follte einer meines ESTeidjen weiter fommen als id)?

Sil) mieberhole es: Die Erzielyung bes Menidjen beginnt bei feiner Seburt; eke ex fpricht, ehe ex hoirt, unterridftet ex fich fidon. Die Erfahrung eilt Den Sehren zubor; in Dem Ylugenblicte, wo ex fetne 2fmme erfennt, hat er fchon biel ermorben. Mtan wurbe über bie Renntriffe des ungefchladgteften Menichen erffaus rien, went man feine Fortfohritte bon bent 2) 


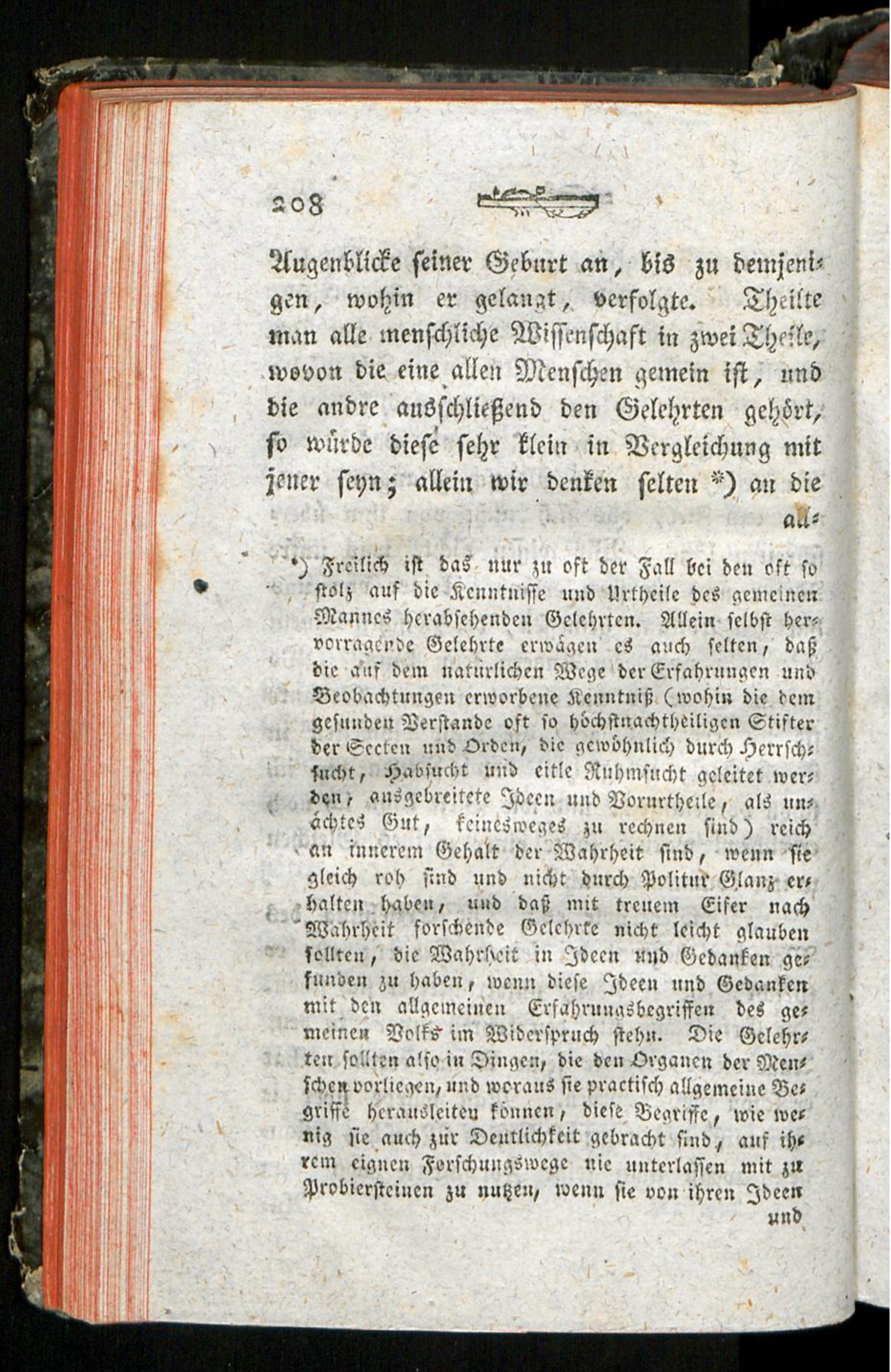




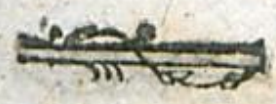

nis

ilte

Ye,

no

vt,

nit

bie

has

allgemeine (5rwerbunget, weil fie gerdyeben,

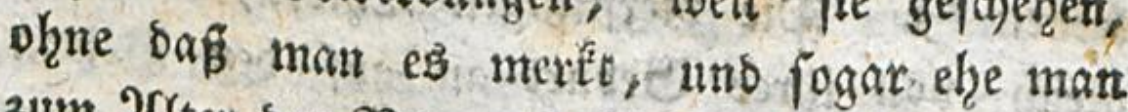

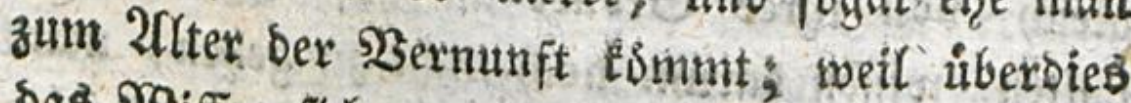
sas 2 Biffen fid) nut surdi) feine Utnterfdiede bes merf́en láft, uns, wie in ben algebraifjent

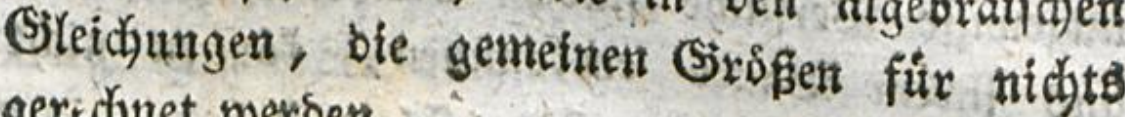
geridjnet werbet.

\section{Selbft bie Thiere erwerbet siel.} haben Sinne; fie miffen fie gebrauthen lers nen; fie haben Bebirfniffe, fie muifen fur biefe forgen, fie miffen freffen, geḩen, fliegen

lers

unb Bebanfen bes inuern lernen wollen. Misgte bas boch von ben Befeim: geift, ober fauptbetruger itgeno einem Saztptirrs Dbern in fo vielen Ger, ober bon unbefannter geheimen (5efellichaften hinteichlogen, uno anbern and ibren Sountanfich hinters licht leiten lafien bend fich zigt werben! Sallein bie groferfsengen bienen, bebers

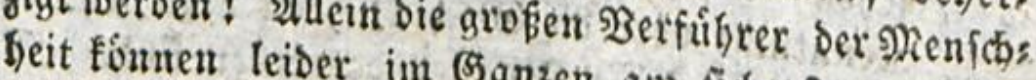
treue Subánglichfeit und am ficherten auf bie berer rechnen, sie, wenn faurente Serblentung toúrben, befennent misten lie múdternen $\gg$ Seritandes grobe 2 rt betrogen und , daß fie auf eine fefr zu viel Gitelfeit ob getaufat foáren; und bie

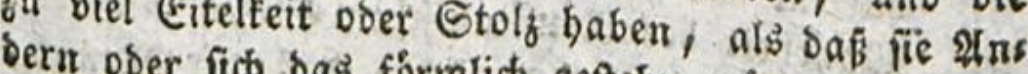
dern oder fich bas formlich geftebn múgten!

Emil rfter \&6.

Ebler子. 


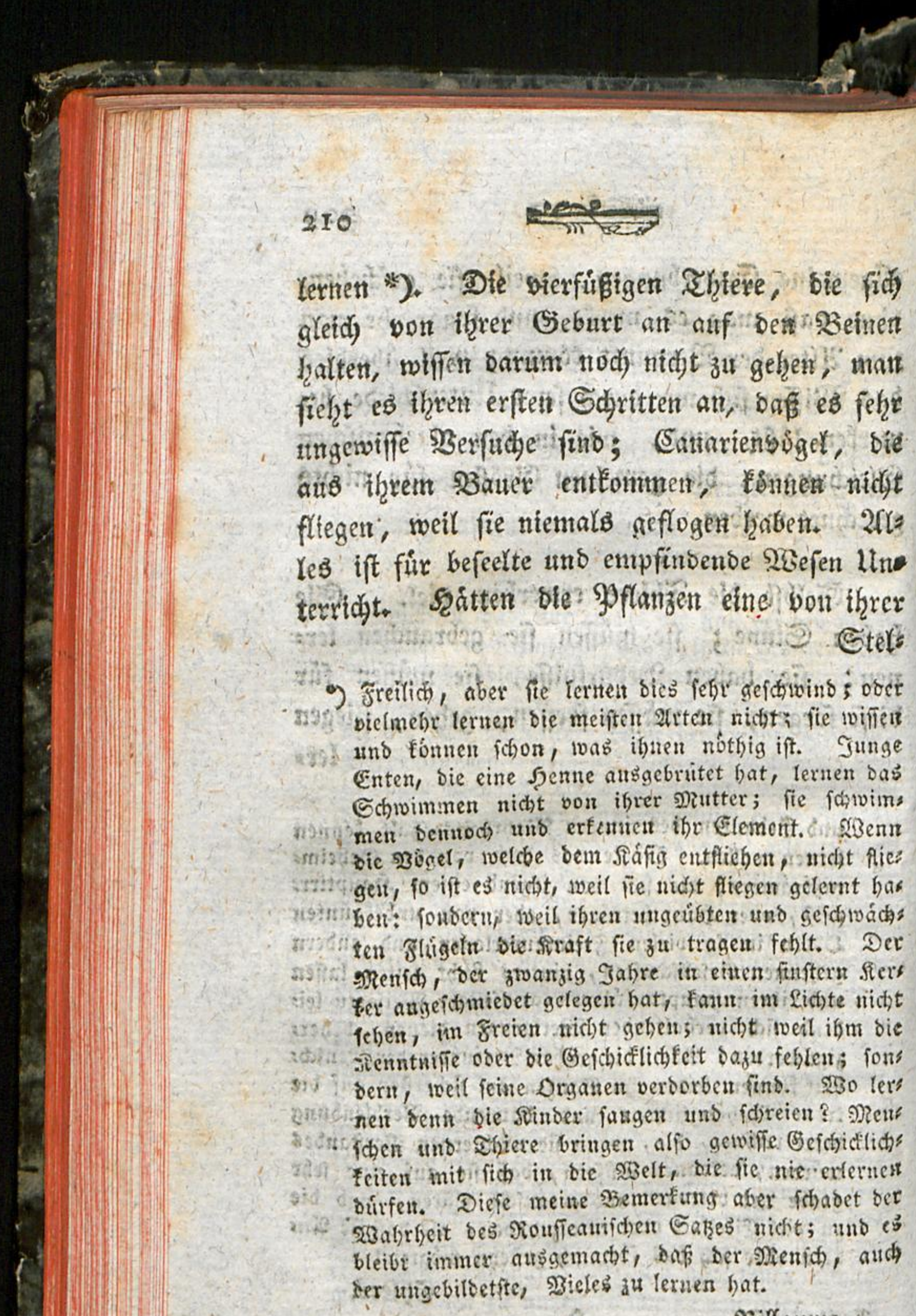

Sillaune. 
Stelle soegftrebende servegung, fo miften fie aud) Sinne haben, Ind fich Renntniffe erwers

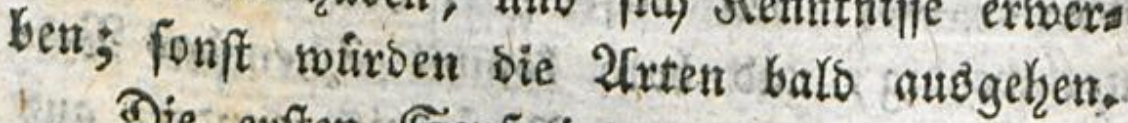
Die exten Senfationen ber Rinber fint. bloge affective; fie nehmen nichts wahy, als sergunigen oder Schnierz. Da fie weber ges hen noch etwas exfaffen fismnen, fo bebirfen fie steler Beit, nach unb nach zu ben repráfens tatioen $: 30$ ofítellungen zu getangen, bfe ihnen

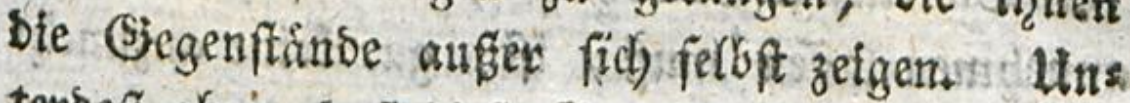

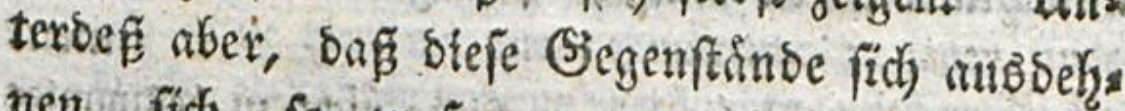
nen, fich, to zu fagen, buin ifren 2rigen enta fernen, uns fitr fie 20bmentungen uns Figuren

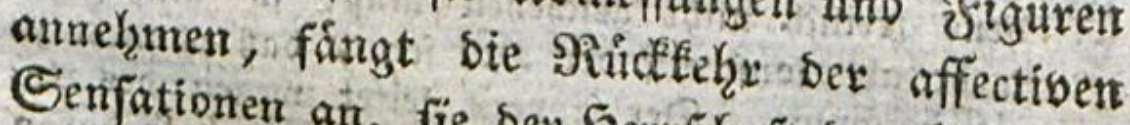
Senfationen an, fie ber Szerrifhaft ber S̈enobnt heit zu untermerfen, man fieht fie iffee 2fugen

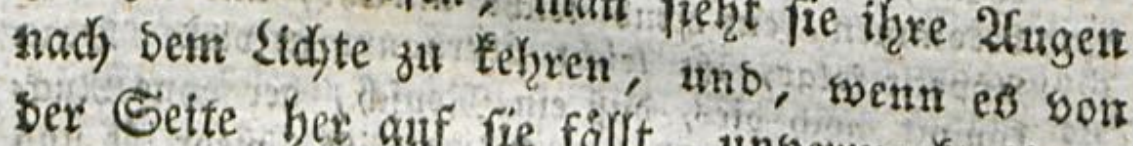
ber Seite her auf fie frill, unvermert ifnem

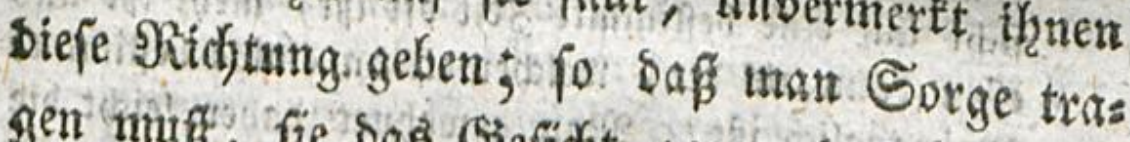
gen mige, fie bas Gefídjt gegen bas licht has ben zu Yaflen, weil fie fonft leidjt fojelend ober man fie audi an bie Finfternif̈ gerosfinen; fonft weinen uno foreien fie, fobalo fie fich im Duntetn befinóen. SBerben bie Nakrung uns ser Schlof thnen gar zul genaul auf beftimmte S 2

Stun: 


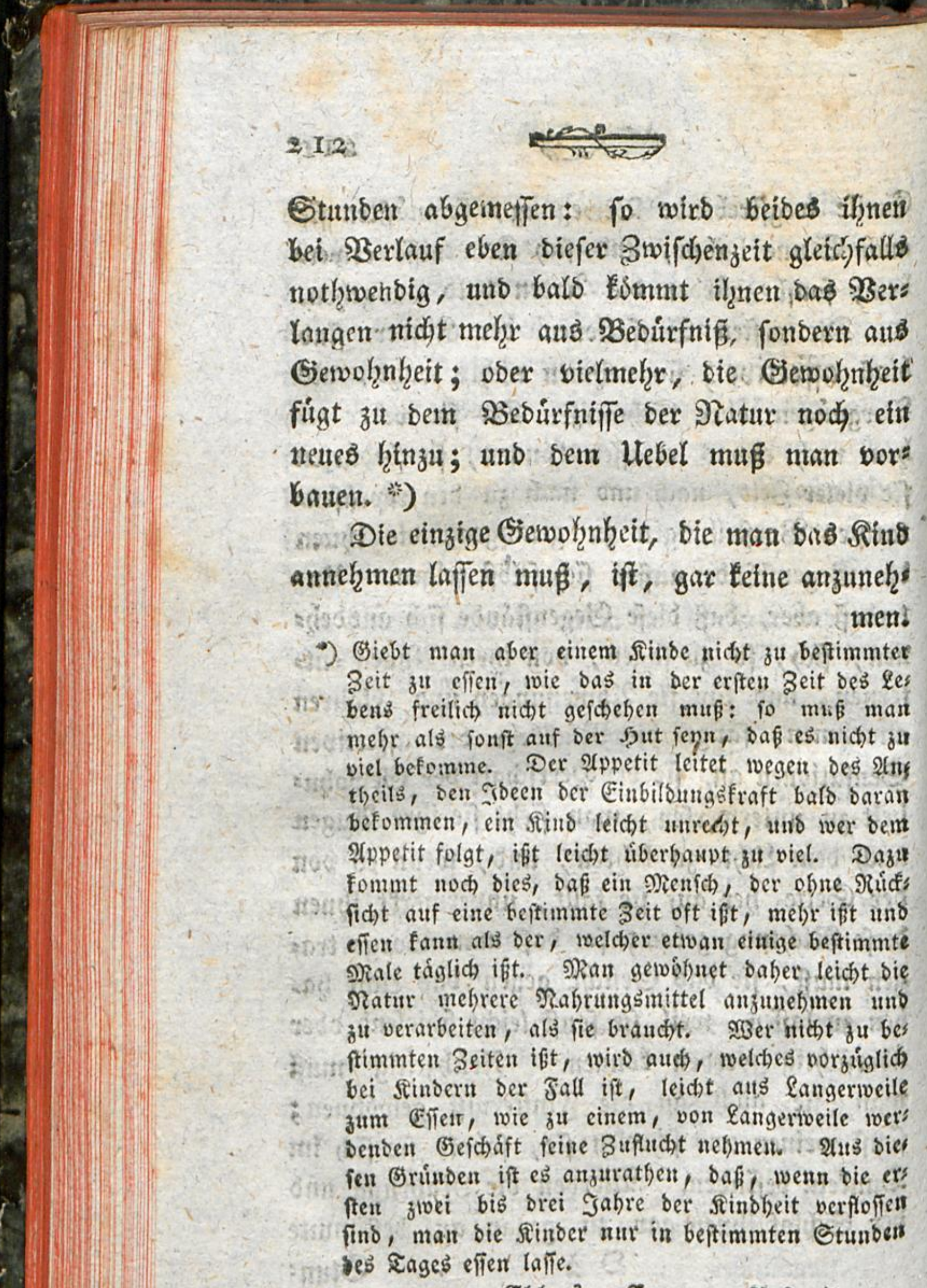

Ebler8. Campe. Refentis. 
men. *) Dan trage es bakget nidjt mefir auf einem 2trme, als auf bem andert; man bers hite, bás es nicht bie Giewohnheit annehme, eher bie eine Stano als bie andore zu geben, fich ber einen von beiben borzugbiweíe zu bebienen, za einerlet Stunde zu effen, zu falkafen, ober irgend etwas zu thun, unb weber bei Tag noch bei Nacht allein bleiben zu mollen. **it) Dian bes

3118

teh?

ten.

nter

Les

man

t. zut

Stm

Iran

bem

lazal

liciós

uns

imte

bie

uno

bes

Jich

seile

wect"

sies

ers

Ifient

ibers

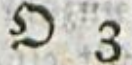

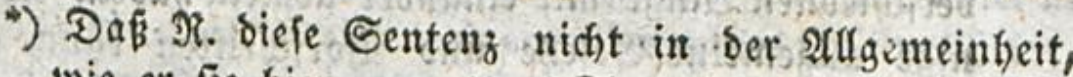
twie er fie bier, um etwas Sinureiches fat fagen, aubs oricict, veritanden habe und veritanden wifien wolle, er: bellet aus mehreren entgegengeferzten গুorichwiften, Die er jelbit giebt, 8. 23. aub ber auf ber bors ftêrenden Geite: man muś fie an Die Finfternif́ gemóbrten.

*) Es' giebt piefe heilfame Oampe. Mense von Gantiame Bervobubeiten. Th einer

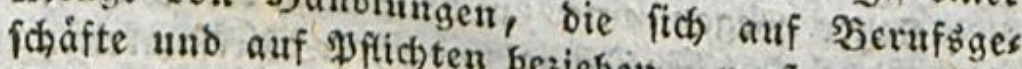
frertigfeitent tradtent.

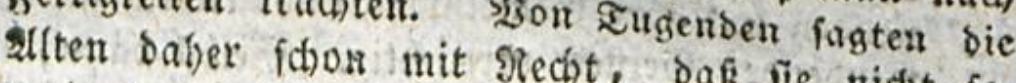
(wetben muffert. Die Est Bsemong einer gertigfeit veranlaft aber zugleich Belvohnheit verbindet in buirgertidentich mit Seit: unb Ditoronung, bie nutsung ser firfte an, tho zut vortheilhafter গ̧es

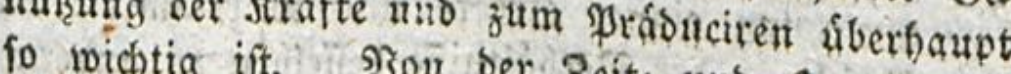
to wichtig ift. S3on ber Seit: unt Drtorbmung tho von bent sarauf fid beziehenden (Sewohnheiten

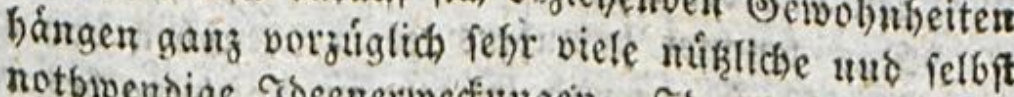
notbivendige Socenerwedtutgen, Soeenverbinbingen und bazu geforige T3illens's uno 5andfungabeftims murgen ab. gioufiean follte alfo nitht wiber iebe

2(rt 


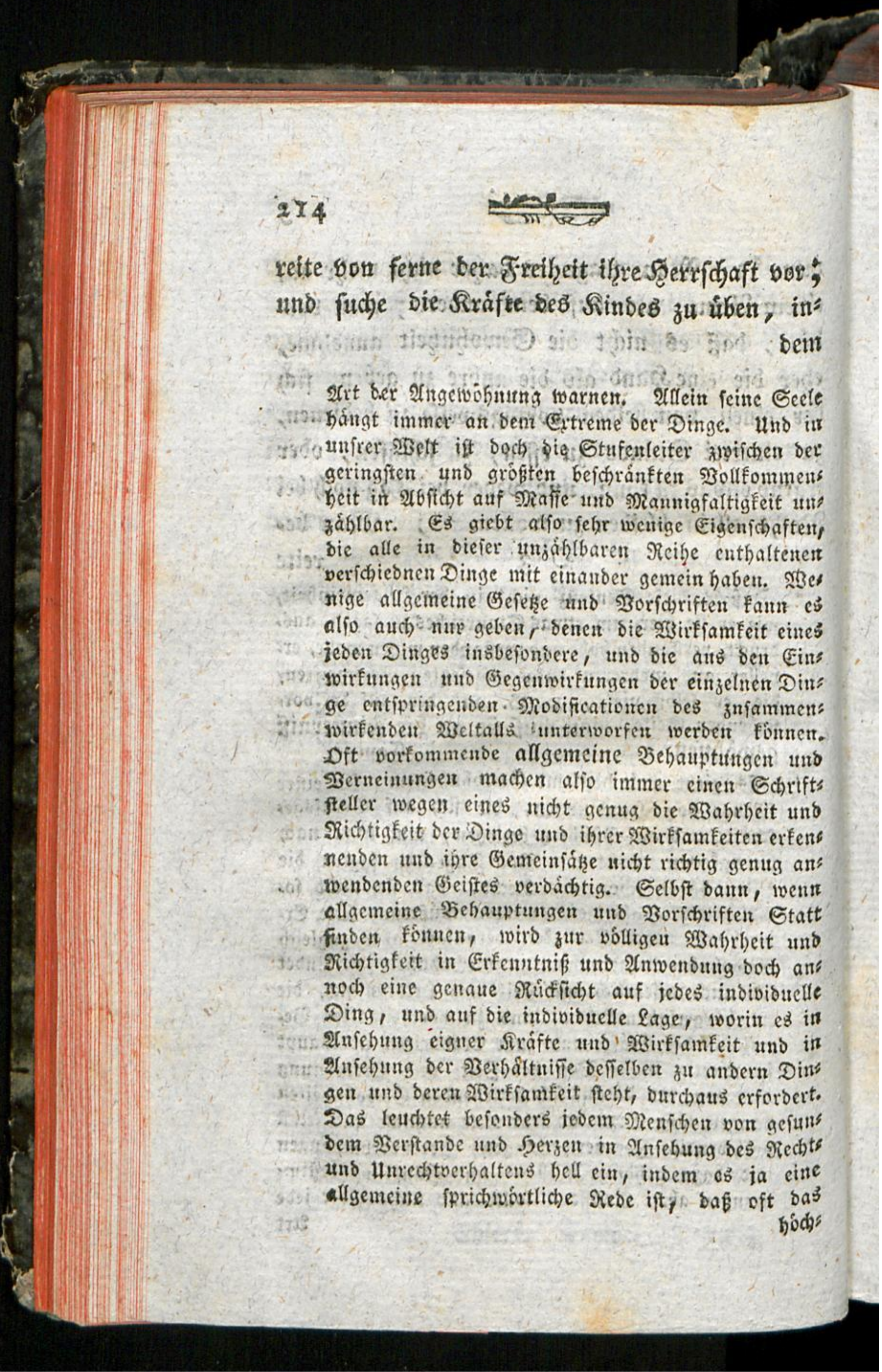




\section{Sem mon feinem Rónper ofe natúrlidje SEenohns} heit Kafpt; es in Den Stand pegrt immex Sear

D 4 iber.

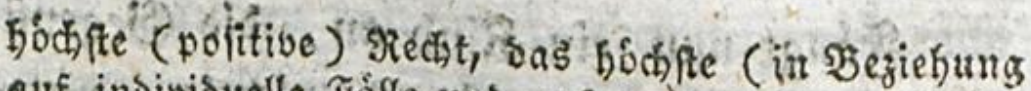

secle

o itt

bet

netts

ItI)

ftent

entert

sties

$1 . \mathrm{CS}^{3}$

simes

Fins

Dins

ment

metr.

4เก

rifts

4า

ifeen

ans

oent

5tatt

uno

ant

welle

8 in

D in

Dins

Dert.

viuns

echts

cine

bas

bods

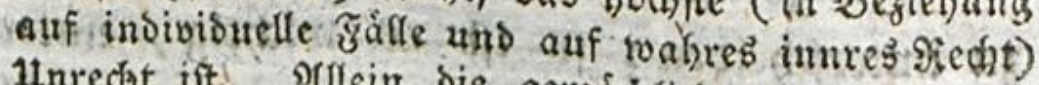
Inredat ift. Iffeim bie gemádichen ober launigs

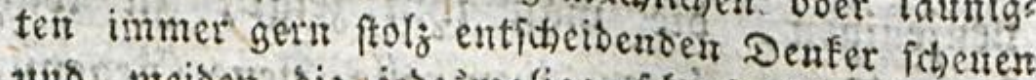
utio nteiben bie jebesmalige forarfe unterfuchutg eines jeben Dinges and 3uftandes liberkaupt eben

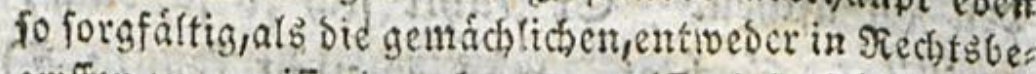
griffen zu umbifichoet, ober zu genifienlojem?ichter umb

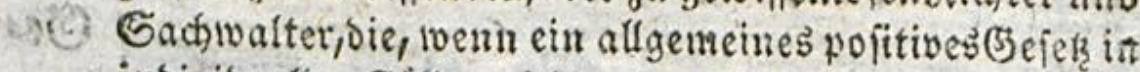
inbivibuellen Föllen nidht, ober nicht gentg antebbuar

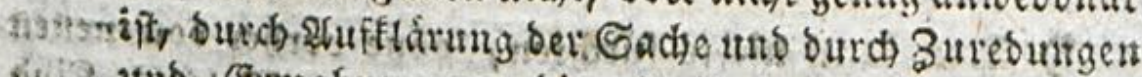

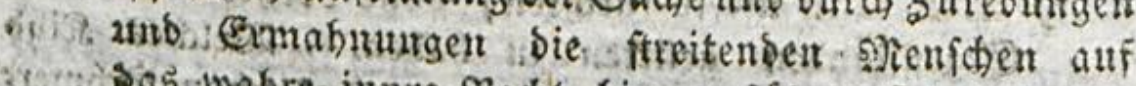

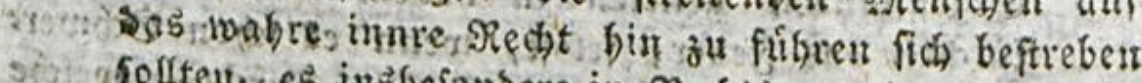
Solltent, es insbefondere in Rechtsmatevien und Pros

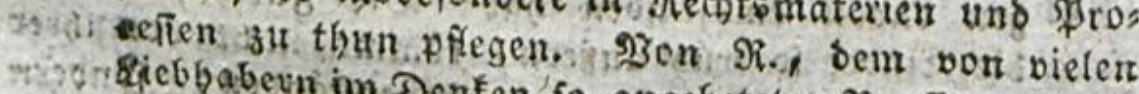

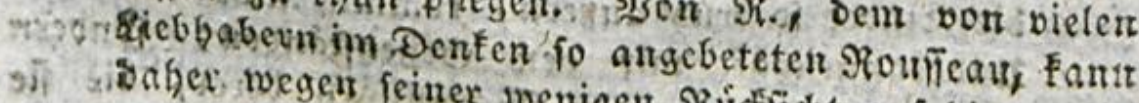
9i) Sorber wegen feiner wenigen Rlúfficht auf sie toabre

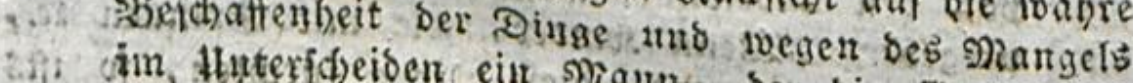

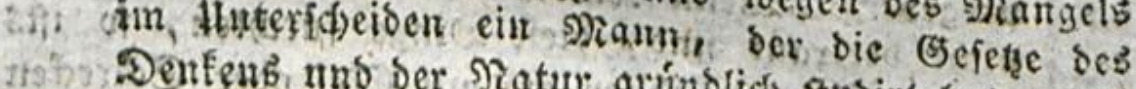
7to ho Denteub, nno ber Niatur grúnblid' ftusirt bat, nicht 2. 'sortheiffafter, urtheilon, als oft ber nach aller

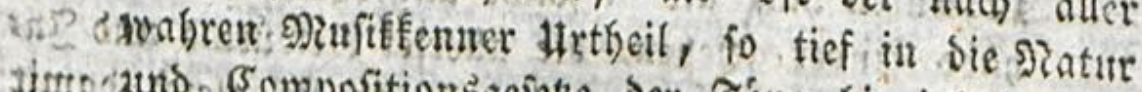
Jims anto (Compofitionsgejęe ber Tone bincinbringente

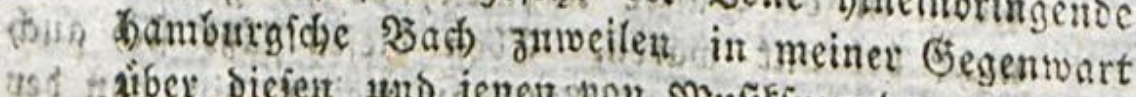
ust th abev dicfert und ienenson Miufiffreunden oft bochs gepricienen Eomponiften gu artheilen pfiegte, went s er iur beten Arbeiten viel, Senie und manche herr Wiche Stellem fant, im Sanjen aber grinsliche Jennt:

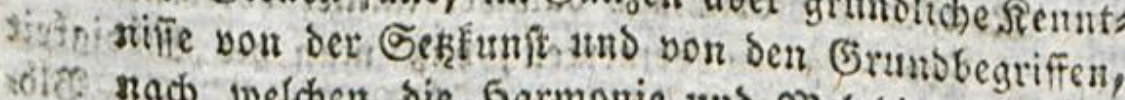
soice nach welden bie 5armonie uno 2kelobie ber Sone

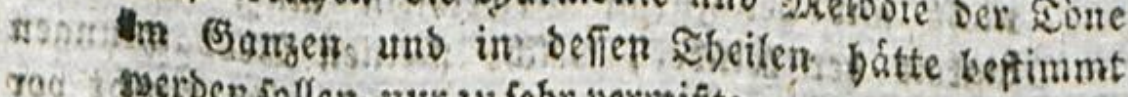

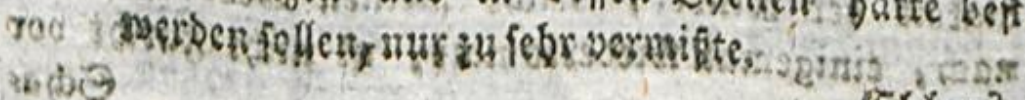
रकम०

(E) Terร. 


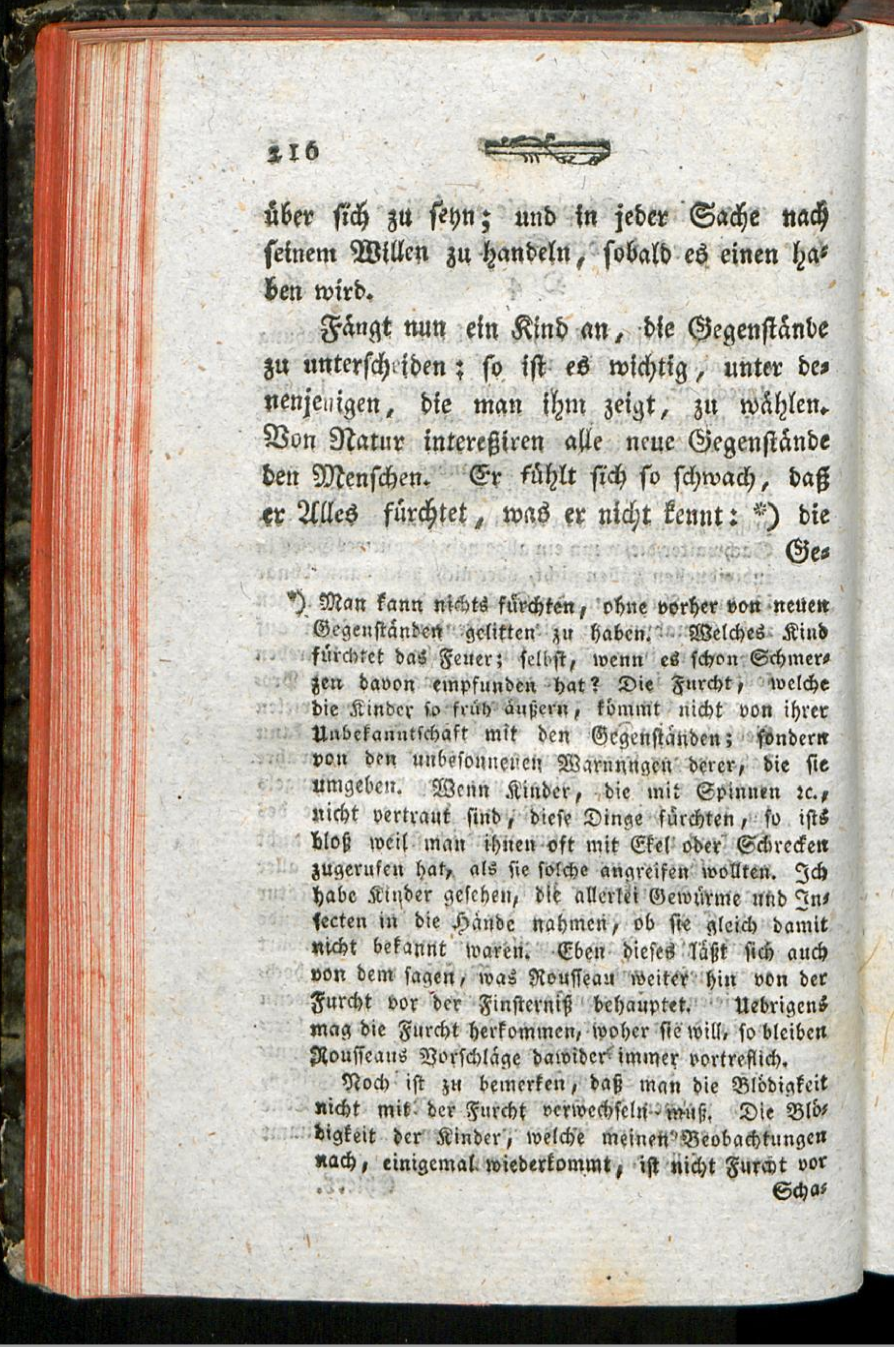


adi)

hat

noe

bes

ent.

noe

jaf

bie

Sies

tiett

ins

ners

Id)e

joet

rerit

fie

2c.,

ifts

celt

Эक

Ins

mit

เuch

ber

ents

ben

feit

5 los

gent

vor

由) as

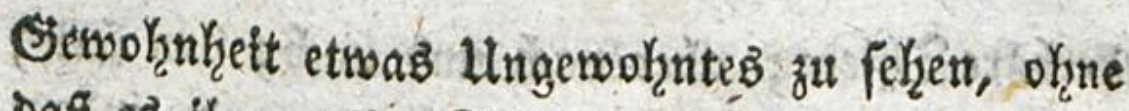
Daßs es thm weber Scymerz nod) Bergnigen bers urjacht, zerftsert bieje Furcjt. Die Rinber, bie it reinlicyen Şäujert exzogen werben, in benen matt Peine Spinnen bulbet, firctsten fich vor Spinnen; and siefe Furcht bleibt ifhen oft, wenn fie exs

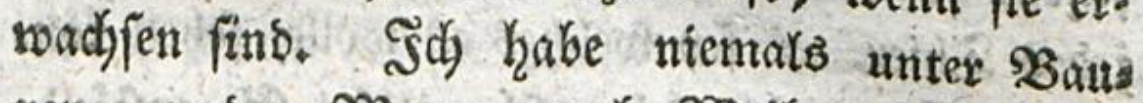
ren, weder Niann, nod SEeib, nody Rinb,

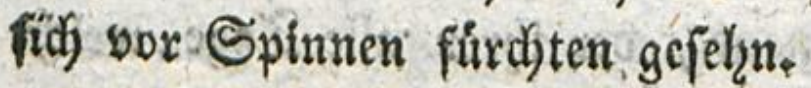

Warum follte alfo die Erzief̧ung eines Sindes nidjt anfangen, ehe ess nod) rebet uns berfteht; weil bie bloffe $283 a h l$ ber S̈egenftinde. bie man ihm vorfommen läft, fchon im Stans be ift, es furchtfam pber herzhaft zu madjetr.

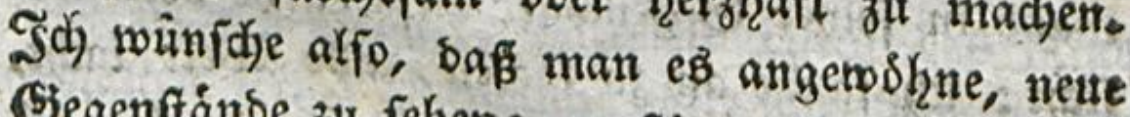
Gegenftänoe zu fehen; garftige, etelfhafte, fon

$$
5 \text { Ders }
$$

Schasen; fonbern theits Ghambaftigfeit, fich vor Unbefanten zu aukerii, theils Mangel an Soets trauen zunb Sureigung, গxBenn ich nidbt irre, bángt Siefe Shlobigkeit von gewiffen Perideen in ber Ents woideliting ber situber $a b$, bie id aber zu beftimment nicht im Stande bin. Billaume.

Daß̉ zurcht vor unbefannten Begenftanthen

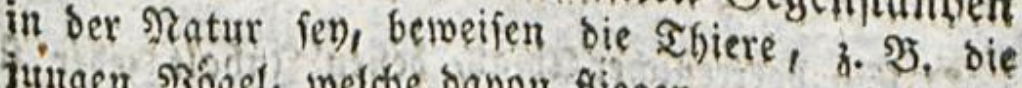
jurgen şogel, weldse bavon fliegen, wenn der erif̌e

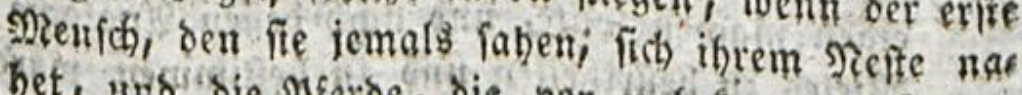
het, unb Die Pferbe, bie bor unbefannteri Begens

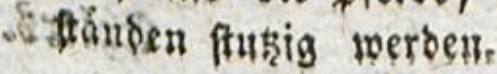

Sampe. 


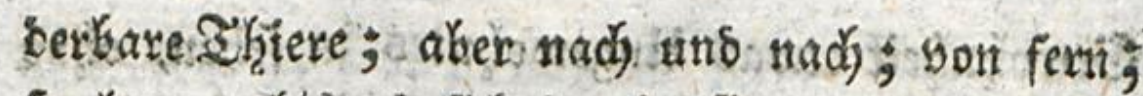
fo lange, bts es fist darein finset, nns, indent es Yunore fie oft anfoffen gefehn, fie enolid jelbft anfaffen lexnt Sgat eo in feinex Sinobzeit phue Schanber Ruiten, Salangen, Sirebresiges reken, fo wirs es audh erwadafen ohtue Srauten,

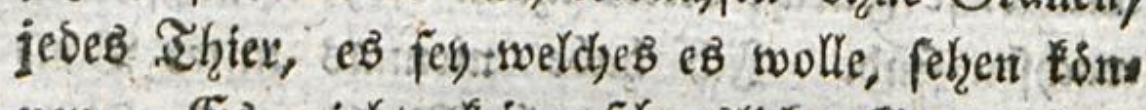
nen. (5) gieft teine fousublidse Siegenftínbe mebrr fuix Semano, ber ibrex alle Iage weldfe fiebt. *)

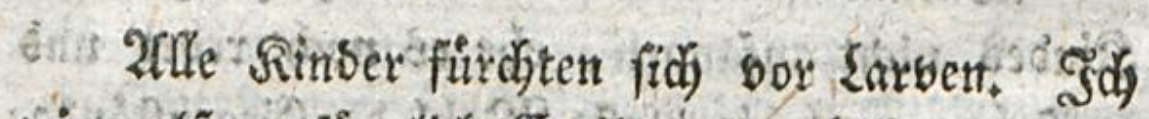
zeige alfo nufänglich Emilen eitre Larbe oon et= sier angenelfimen Sieftalt. Sgieraut nimmt S. Itand in 'feiner Segenwart Diefe Earbe bors (les richt; ta fange an zul lacken, alle $23 e l t$ lacht,

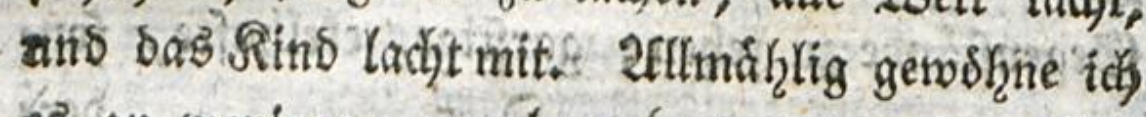
eق att weniger angenelyme Larben, uns enslich

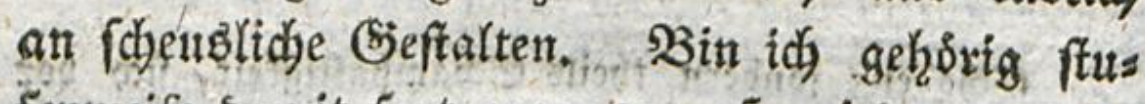
fenweife samit fortgegangen, 50 wirs $e B$, ftatt bei ber festern zu erforrecten, eben fo gut als bef ber erften laçen. Sernach beforge id gar twiantiofit

-) Eiri sortreflicher Srbfaḱ, belien Inkalt Jeber fich zu cigen machen follte, uno nach Deffen 2tualogie fonft sieles zu beurtheilen uns zu beftimmen wáve. 


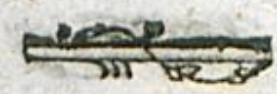

nidjt weiter, baf̈ man es mit Sarsen in Furcht Fersen werbe.

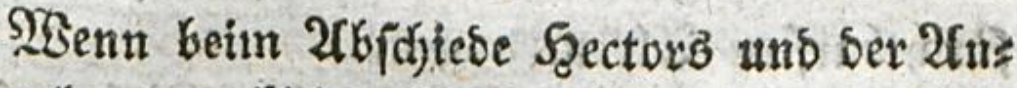
Sromadya ber fletme 2(ftyanax bor bein flats

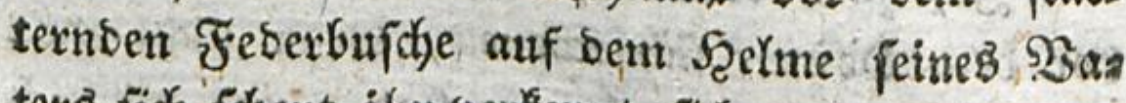
ters fid) fdeeit, ithn berfennt, fid) weinens an bie

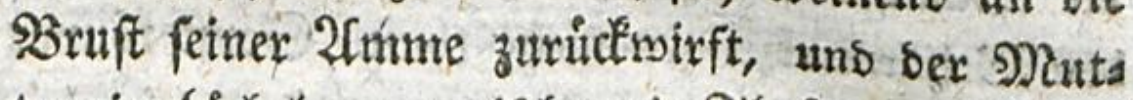

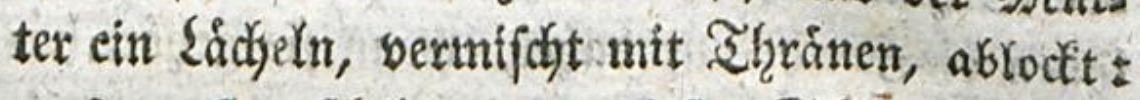
was mü̈ gefdyeţen, um biefes Shjenten zu hes ben? Sierafe bab, was Sbector thut; er fefę ben STetm auf bie Erbe, und liebfoft bab Rind. Şn efnem nidyt fo getuimmeloollen 2ugenblicke V̧atte ber Solo es babet nidjt bewenden lafien;

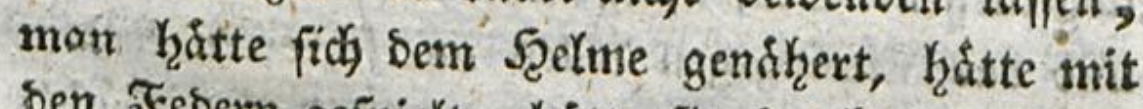
Den Febern gefipielt, haátte fie burch' Das Jino betaften lafien; enolich haatte sie 2lmme setr Sgetm genommen und fich the lächelno aufges

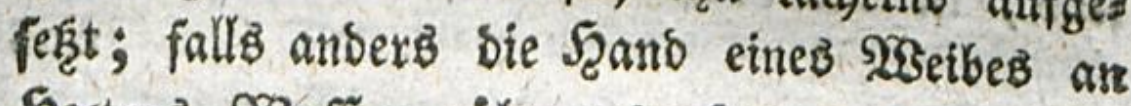

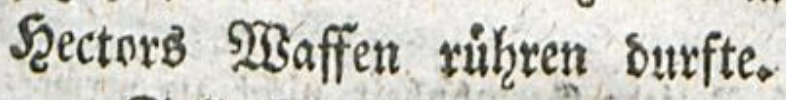

Soll Emil an sen Rnall cints Fenerges wehres gemolhnt werben? So brenne tob ans

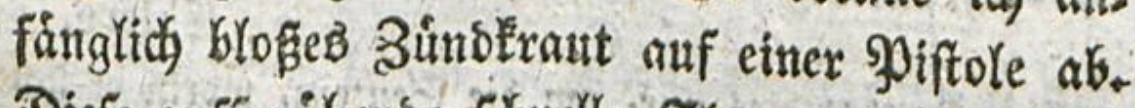

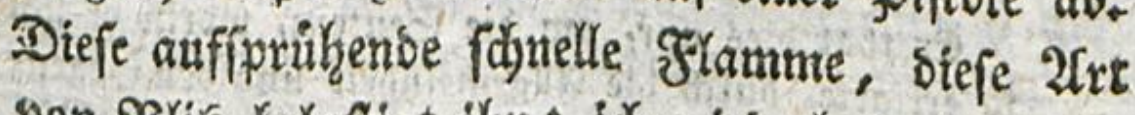
son Blich beluftigt ifn! ich wieberhole eben bas

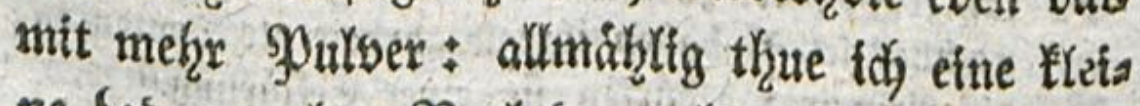
me Labung ofgne Sortabung Kinzu, brauf eine ทосй 


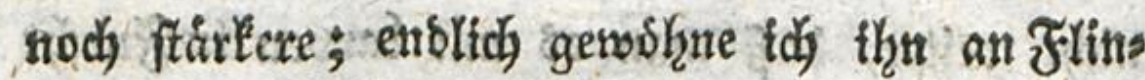

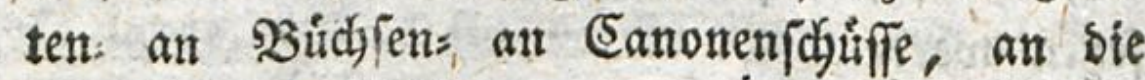
furditbarften 20ffenerungen.

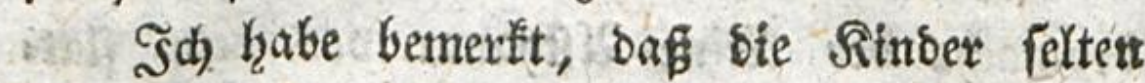
vor Sem Donner lidy. fibeuren, wenn nicht etwa bie Sdjlage gar zu heftig fino, und wirtlids ben Gebrorwextzengen wohe thun. Sonft tommt thrnen Die frurcht nux bahex, wenn fie gebort has bon, bas Eiemitter befdjábige ober toste zuweis Yen. Fängt alfo bie Bernunft an, fie zu ers fdreden, fo forgt, baff ibnen bie (Sewobnţeit *) sieber Mith gebe. Durch eine langfame unb abgemeffene Stufenfolge nadit man ben Mann uno das Sins gegen 2ules unerfodroden **).

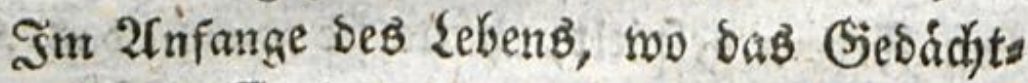
nif uno bie cinbiloungstraft nod) unwirtfant find, ift bas Rins nux auf Das oufmertfam, was

9) थllo if nad $\Re$, jebe Stelvohnheit, nidht zu verwers fen, wowiber er fith borber fo gam ofne (Fin fóliảntung ertelârt hatte.

Eblets.

Er that bies nut, um bie Eentenz, worin or fid To etflátte, burds bie Allgemeinfeit uno ben (3) egen= farz frapwanter zu machen. "Solche Gákze, pagt $\Re$. nackher felbft, haben ihre $23 a$ brheit als Gentenzen; als Principia beburfen fie einer Ertlánung."

campe.

(ए)il) Sebr victig!

Sampe. 


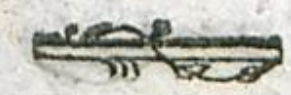

ns

ie

it

10

d)

it

x०

tร

ts

)

18

in

to

n

,

roas tmmer gegentwåtig auf feine Sinpe mirlt. Da feine Senjationen ber exfte Sioff feiner Senntniffe fins, fo Keif́t es, went man in eis

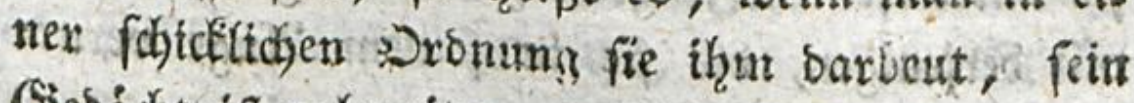

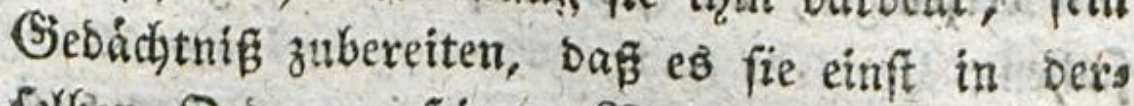
felben Sronung feinem Berftinbe barreisbe. "*) S2Beit es aber nur auf feine Senfationen aufs nextram iff, fo fann man fich anfänglid oamit begnigen, ihm mux red)t beutlid, Die $\$ 2$ erbin= bung eben oiefer Smpfindniffe mit ben Segens ftaboen, ote fie beruxfiachen,

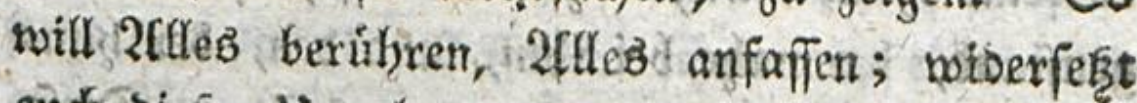

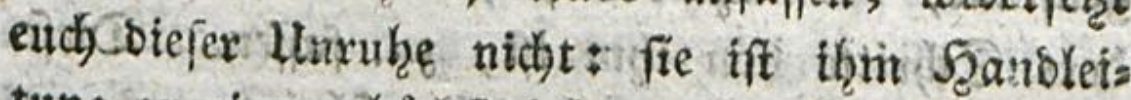

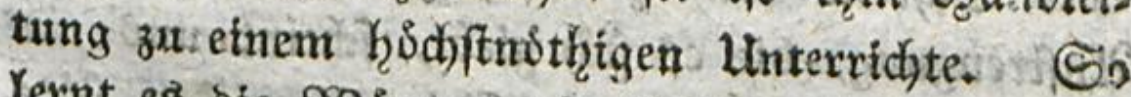

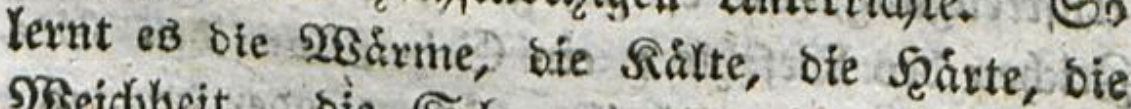
2SBeidjbeit, bie Sctwere, bie Seidytigleit ber Rorper fennen; Yernt bon ifgrer Sirske, three Figur, unb allen ibren anoern burch die Sinne bemertbaren (cigenfhbaften, bernittelft Sehen, Befiblén, t) Sgoren urtheilen, sornebmididgaber

vers

-) Şier ift in Eurzem bie mitilichite, fruchtbarffe Itet Der (sebád)tnifúbungen befdrteben. Trapp.

7) Der (Beruth) ift von allen Simnen berienige, ber fid am fwáteften bei den fintorn entwictelt. Şis fie zivei oder brei gahr alt finb, fcheint es nicht, als wo dren fie gegen gute ober foflimme Dufte empfindlich ; fic babert 


\section{2}

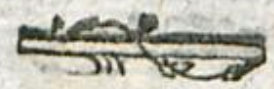

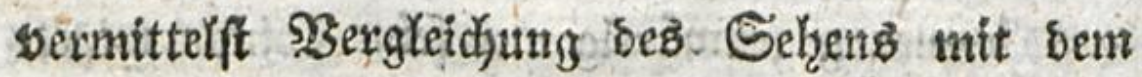
Jifhlen, uno Nefinng ber Simpfinoung, bie fie unter feinen Fingern berborbringen wirben, nit berjenigen, sie fie in fetnem 2uge berurs fachen.

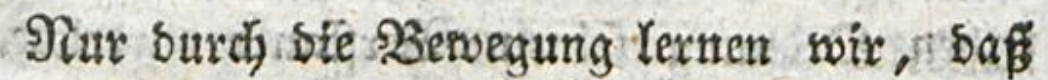
eg: Dinge giebt, ote nicht $\mathscr{2 B I r}$ find; uno nut basurch, soff wir uns felbft benegen, gelairgen wir gu Begriffen son Der 2 Beite SGen weil sas Sino biefen Begriff noch nicht bat: ftredit

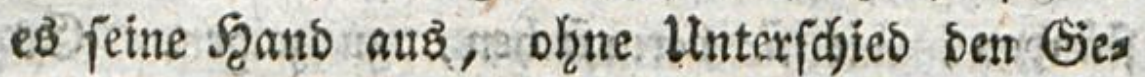
genftanb, ber nâhe bei ibm, und ben, berfiuns. bert Sdyritte bon ifgm ift, zu faffen. Dieje 2tuftrengung, bie es fick giebt, fófeint uns cin

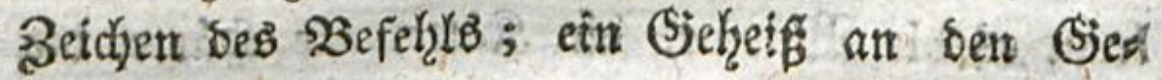

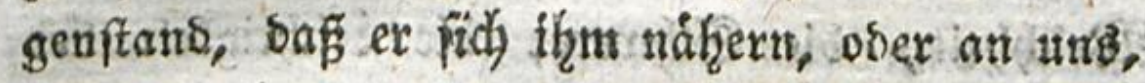
bafs wiv ifum die Sadje herbeibringen follen; teis,

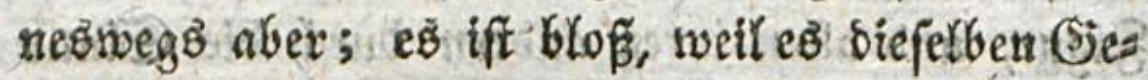
genftände, die es anfangB in feinen Sehtrue,

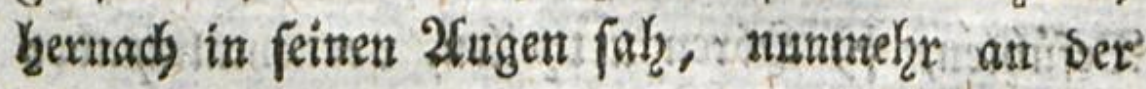

Ejpis

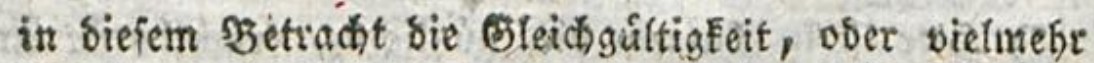

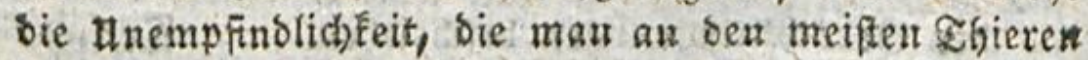
bemerfet. *) D. $\mathfrak{B e} \mathfrak{f}_{\text {. }}$

-) Ino woh! ifnen, baß siefer Gimn fich am páteffen bei ifnen entwidelt! Dent in den meiften Sinders

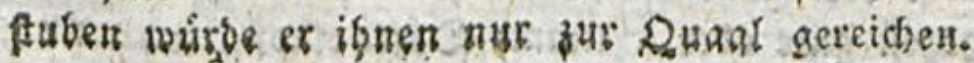

Eampe. 


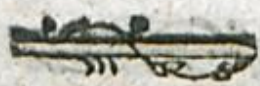

223

$m$

ite

$\mathfrak{n}$,

in

2 if

iit

ent

zil

it

es

ins:

fe

in

ed

3.

is

es

?

$x$

is

jr

n

u

is

Spice fonter 2litue fieft, und fich weiter teis

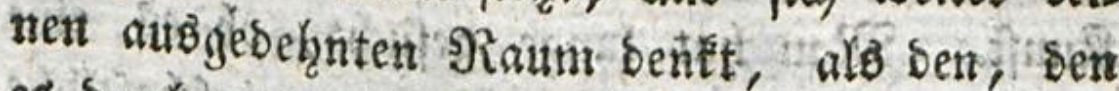
es burchguetfen tann. Sorgt aljo bafur, oaf eB oft fin unb fier gelurad, voi einer Stelle Jur andex bewegt werbe, Daff es die Serardes rung bes sits meste, unb fo von-ben Enffers

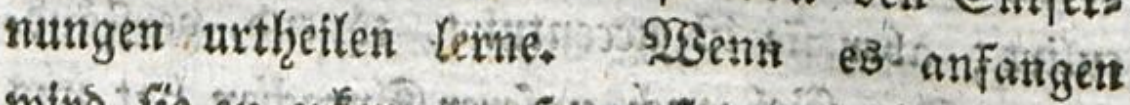

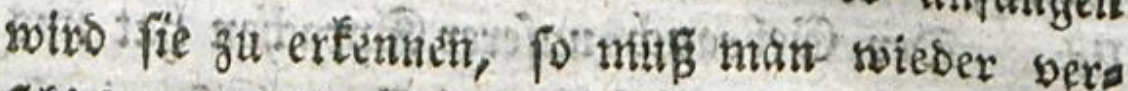

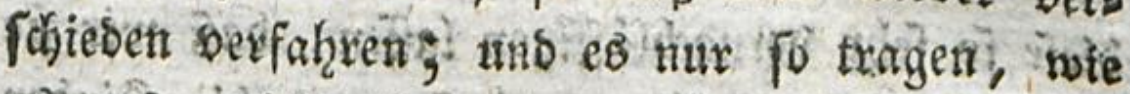
es unb, nidjt aber wo es iftu gefallt, seatu

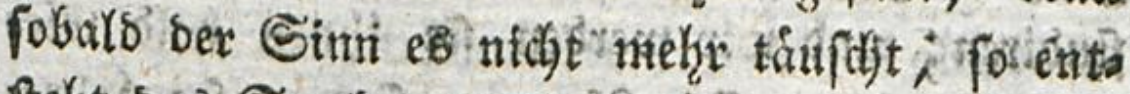
Pef̧t Das Streben befferbef jobn nus etner ats

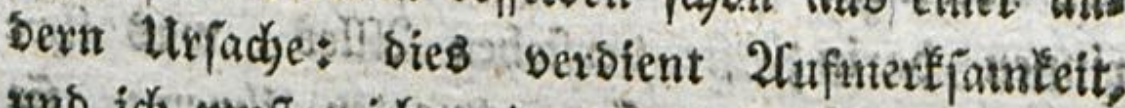

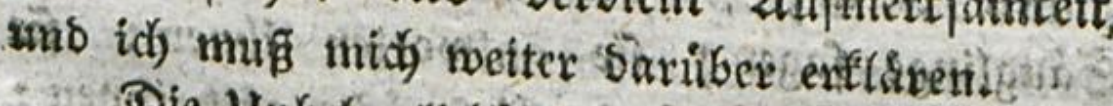

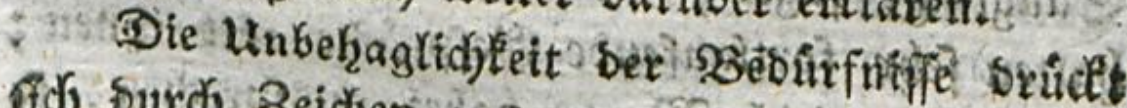

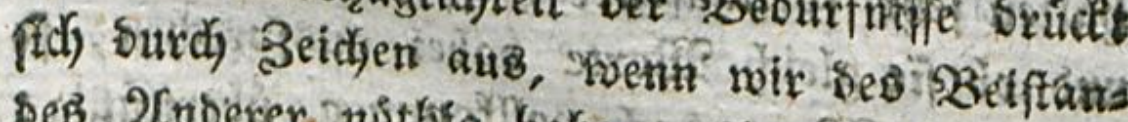

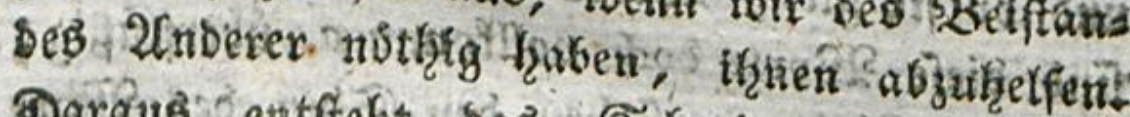
Daraub entfteht bas Schreirn ber Rinber: Sle weinen viel, unb sab mufs fo fenn, Da alle ihre Senfationen affective fins, fo gentefs fent fie bie angenebmen barunter in ber Stille; ofe ifhen laftigen hingegen bructen fie in three Spradje nus, uns Derlangen Exteidterung. So lange fie aber wachen, fonten fie faff nidjt in einem 3uftande Der (Sleidjgưltigfeit Sleiben; fie fid)(afen, ober fie werben afficirt.

2tre 


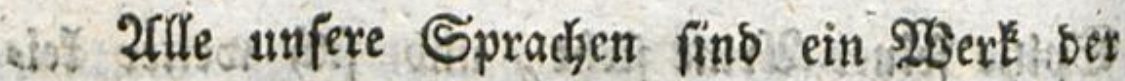
Sunft. Sian hat lange gefucht, ob ez eine

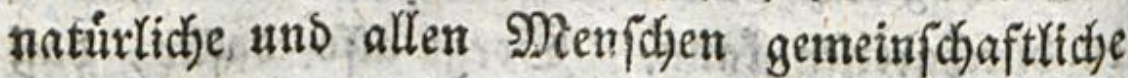
Sprache gadbe: obne Zweifel gitebt eb eine, uns eb ift ote, weldje bie Rinoer reben, ebe fie zull reben wiffen. *) Diefe Spradje ift nidht artis culint; aber fie if accentuilt, toneno, verftanos (ic). Der Siebrand umferer Spradjen fiat uno sieje fo fehr vernadjlafïgen lafien, onfo wir fie gauz vergefen haben safft uns ote Rinder fulliren; und wix werden fie ifnen bald wies Ser ablexnen. Die 2tmmten fins unire Selgres rintien barin; fie berftehen 20lles, was ifzre Sauglinge fagen; fie antworten ifhen; fie balten fehn fortloufenbe Sefpråde mit ibnen; uns ob fie gleich 1 Bonte babei ausfpredien, fo find biefe 230 orte soch bolltomment iberflusitg;

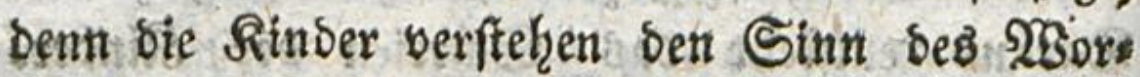
tes nidht, bas fie horen, fondern nur ben 2 cs cent, bon bem es begleitet wirb.

Mit

4) Spert frormey merft bier fút feine Lefer att, bal e

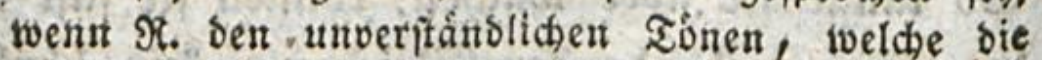
Sintor bon fich geben, bent Stamen Eprache beic legt. Ich zeige bies fút biejenigen an, oie biefer Bselehrung bebutrett.

Eampe. 


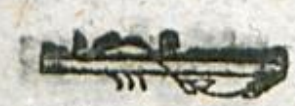

\section{5}

Det

eine

Yictue

uns

;il

Ixtis

inds

นกร

: file

iser

vies

bres

iffre

Ife

en;

10

tg:

Sore

2les

nit

bal

fevi

bie

beic

efer

Mot ber Sprache ber Stimtine serbinbet fich Sie nidjt minser bebentfame Epractse bet Ees behroe. Dieje (Sjebehrobe liegt nidjt in ben fdiwas shen Spátibchen ber sinber, fonbert in iffrem Sefid)te (5s if zun Exftannet, wie viel

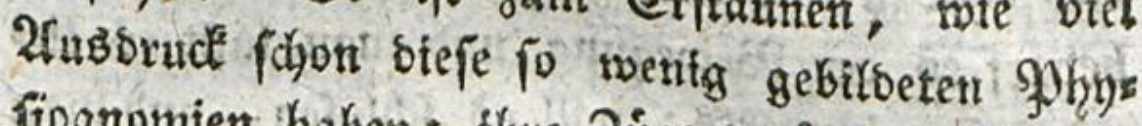
fiognomien haben: thre 3igge berchtern fich son 2uggenblict zil 2lugenblid mit einer unbegreiftis

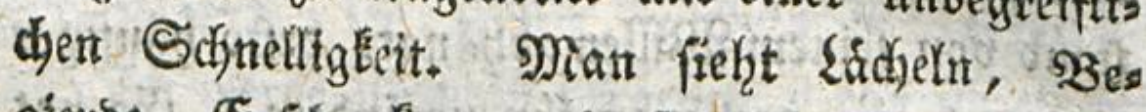
gierbe, Erfchredten, wie fo biele slike barit entfebeit uno werfdyoinden; jebesmal glautut mat ein atwereB Sieficht zu exbliden. Şzre Sefiditis mufteln fins ohnftreitig beweglicher, als bie unt frigen. Dafût abev figen ihre matten 2uget faft nichtz. *) Dex 2frt mus auch ble Battung Der 3eidjen in einem 20rter feyn, in sent mat nitr nody Estperliche Bebirfniffe hat; bev 2 uBs surct bet Eupfútoungen liegt in ben Sirmaffer,

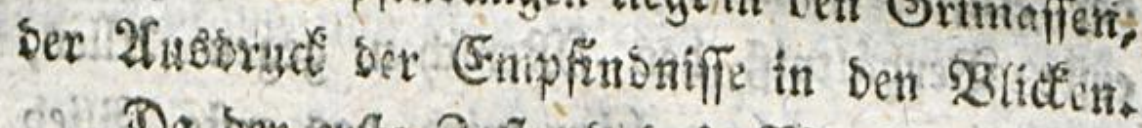

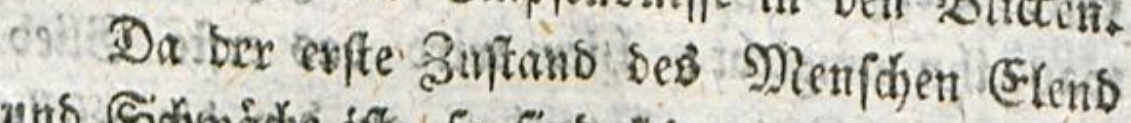

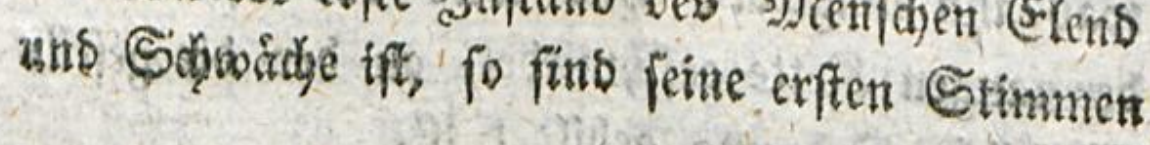

Silas

2) Treset hier offenbar non ganz iungen Sinbern,

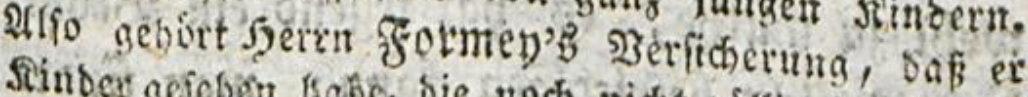

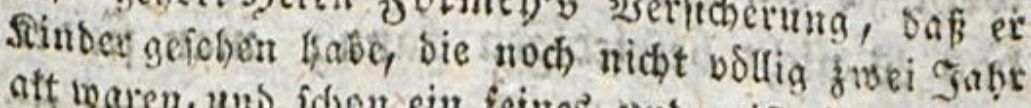

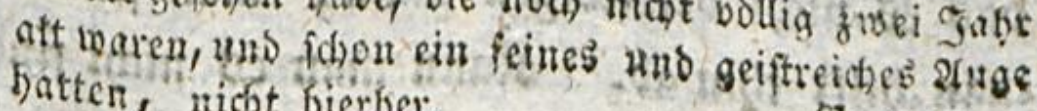
batten, wicht bierher. Eamps.

Einit tRer $\$$ b.

P 


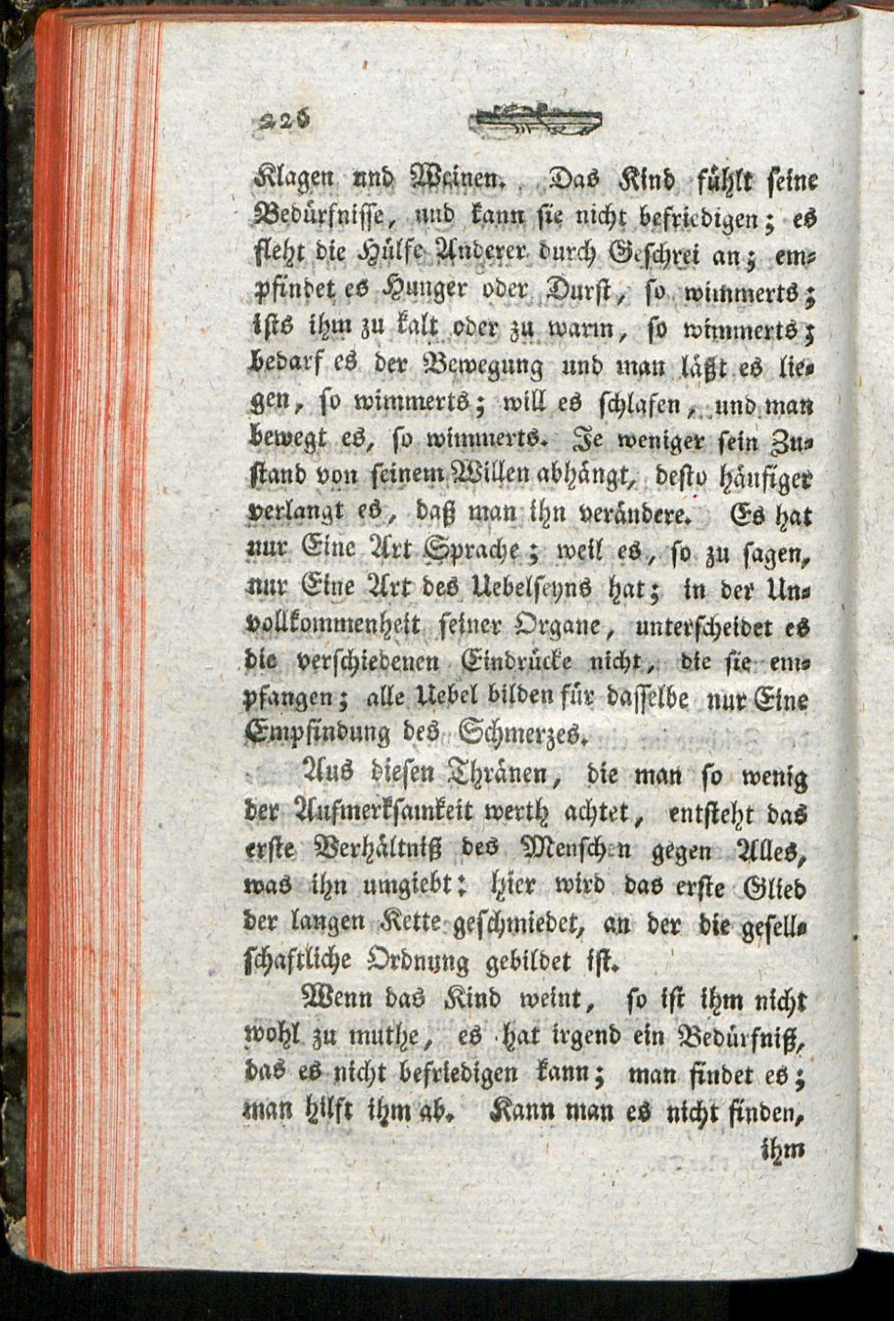


ifhin nidjt abfielfen; fo bautert sab . 2 Beinen fort; es wire uns zur Laft; wix lfebfojen bas Sino, un es zun Sdfwetgen zu bringen; wix wiegen es; wir fingen ihm vor, oaf es fdulafes. bletbt es bqartnadig, fo lägt man fich sur Llts: geould fortwetfen; aman bebrobzt es ; uno robe

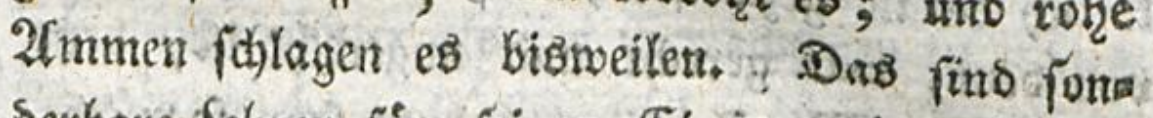
Serbare Eebren fir feinen Fingang ins Eeben?.

s.h werbe niemals vergeffen, safi id einft einen diefer unbequemen Gdyretherfe bon fetnet 2lmme fo haben follagen feben (st forwieg

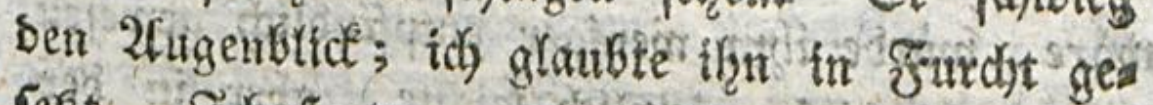
fegt. S(b fagte zu mix felber + barmis wirs einmal eine firlabifdye Seele', botn ber fich nidjts anbers als burch Schárfe wirb exfralten taftent. Sid) itrte midy; bas fleine Ding exfticlte por Sngrimm; esi hatte ben 2thetn sextof̧ren; $i d$. fah es braun und blau merben. *) (5inen 2 us

$$
\text { आ) } 2
$$

gen

") Sherr Formey lagt: "es ift eine retht litfige gyor: ftellung bon bein Siribe, weldses, nach em es zur Itnzeit geichlagen worben, burch eine Emufindung Des Siechts uno Unrechts gans braun wirb." Nir fheint in diefer luftigen sorfiellung, 8as vielleicht Hlebertriebene nbgerechnet, boch etivas zu Yiegent, was fids in ber siatur wol finder mag. Die sinber baben frúher (sefuigl von Fecht und Hitrecht, als man benfen follte.

Eampe.

(E) 


\section{8}

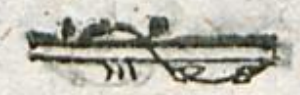

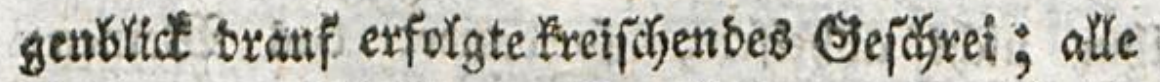
3eiden ber beleisigten Empfintung, ber 23 uth ser ßerzweiflung Diefeß 2lterz, waren infetwen.

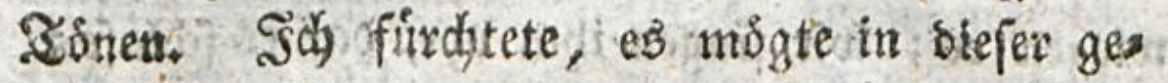
waltjamen Bewegung feiten Şeift aufgeben. Shits: te th baran gezneifitt, baf́ die Empfindurg 5on bem, wat gerectyt wio ungeredjt ift, bem Serzen bes Menificen angebolycen fen, fo mirrbe. Sies Beifpiet allein firon mich savon úberzengt

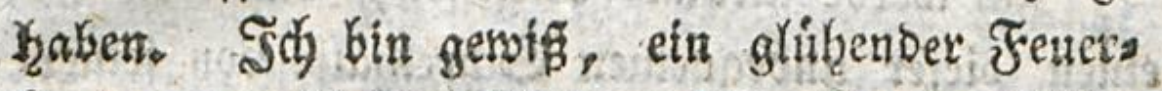
brand, Ser biefem Sinde auf bie Şand gefallert roire, minoe ifm weniger empfinditib gemeien. feyn, als biejer ziemlich leidhte, aber in ber pffenbaren 2(bfidjt es zu beleibigen, ") geges bene Sd) $(a g$.

Dies

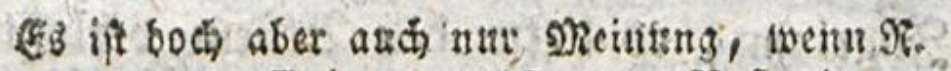
\{agt, onf es yor Srimm erficft fey. Sefenwis.

a) Die 2(bfidst zu beleibigen fans wol nicht Statt. Sie bielt sas Echlagen tool fúr eit zwecfmábiges Dittel bem Gdgreien, als einer willfibrtidten boien Şandlung frafend ein Enbe zin machent. Darit irte fie benn freition feft: Denur nach ber buthéfn

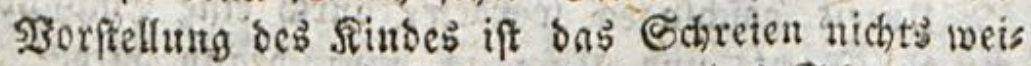
ter, als cine natürliche

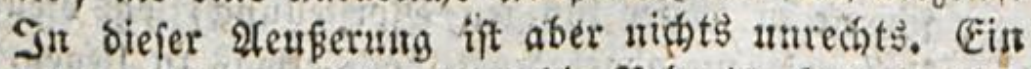
folder હchlag, wovon bier bie Rebe iff, fommt abes auth oft aus bein fia regenden thoollfoumnen ariebe, - Dhne alle Stúffictit auf bie Erreichntig'eines guten

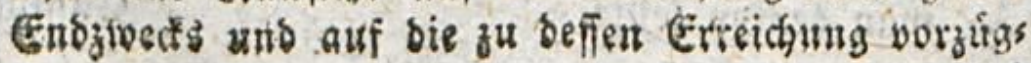




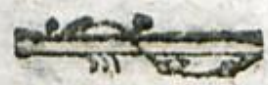

Diefe Sleigung Ser Sinser zut Entrúftung.

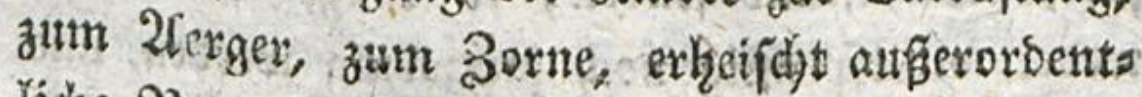
Iiche Bebutfanteiten. Boerbave ift Der Sleis

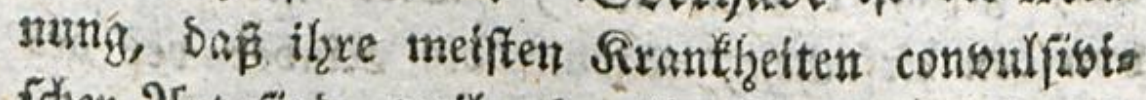

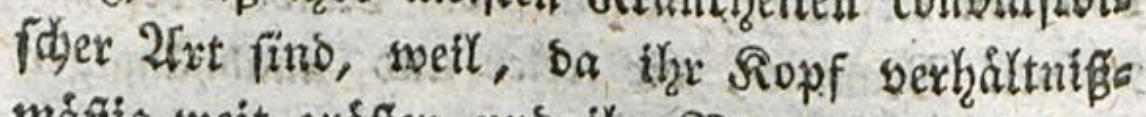

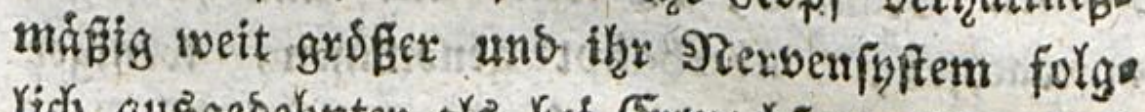
(ic) ausgesefnter als bet Erwadjenen ift, sies Sierbengerwebe audj eiter siel grofïern Empfins.

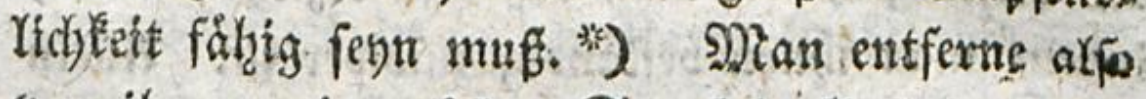
bon ifnen mit groffter Sorgfalt Giefinbe, bas Fie nedit, fie reizt, fie ungebuldig madjt; es iff thnen zefrnmal gefahrlictyer, berberblicter, als alle SRauhigkeit ber SBitterung nut immer fenn fant. So Kinge Rinber blog in ben Sadjen

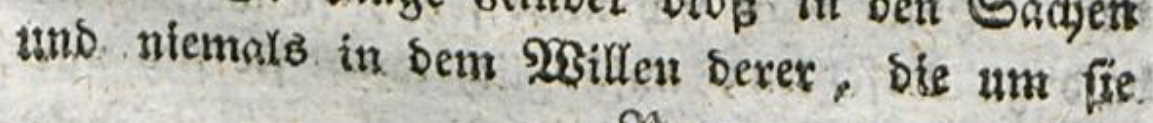

$$
\text { भ. } 3
$$

fintop

tid Sientidien Nittel, cine empfangue unangenehme Empfittoung mit eiter unangenefment Empinoung

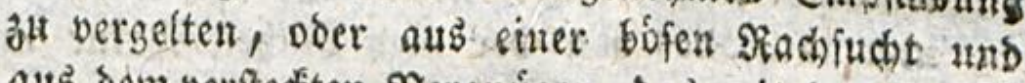
aus bem verfecten Sergnigen, das mit der Sefries bigung ber Rachfudt) bei unvolffommnen Mendsen mach ifrem Soeenzutande verfnupft ift. (Eblets.

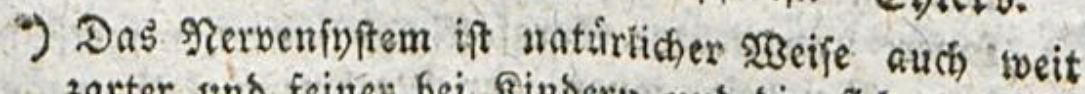
zarter smo feiner bei Sindern uns sie fich bei ben Sinbern findenben convulfivifonen Exichisterutigen und die babei zam Örunde Kiegende Reizbarfeit móns ten wol violmebr von iener 3 artheit, als por bee

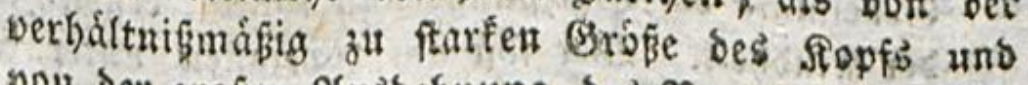

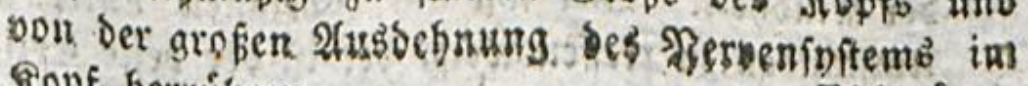
sopf berribren.

Eglert?. 


\section{0}

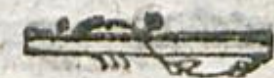

Finb, MBiberftants finden, fo lange werben fie soeber widerfpenftiy nod) jachzorntg werben, und auch gefinter Gleiben. *) Dies ift mit eine son ben Linfacten, soarun die Rinder beb ges meinen Nannes, ste freier uns unabhängiger aufroactjen, iberhaupt genonmen, weniger Fobmichlich, mentger berzärtelt, uns ftäreer fino, alb biejentgen, bie man beffer zu erziehen meint, inbem mat ifnen beftándig zuwiber ift. 2Cllein sman follte mohl bebenten, daf fid) ein grofect Ilnterichied sarzwifichen befinbet, ifun nicht zu geferchen, uno ffrnen zumioer zu fern, 范范)

Die exfen Thránen ber Rinder find 3 its ten. Shitet man fids nitht fehte, fo noerben fie

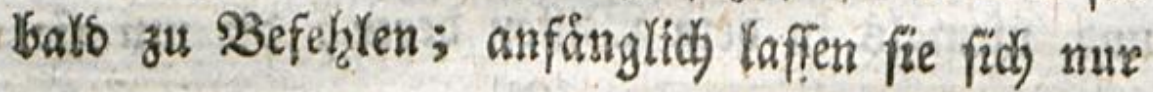
bets

5) Eine fefr richtige, ntr bes Erwágung aller Ëltern twúrbige જemerfung! Nan taffe bie fintoer sach umb nad) altes bon ber menidhlicten Natur unzers tresntide lingemach empfinben, und fie werden fich bald baran gewónnen; aber Seiben, bie wir ifnen

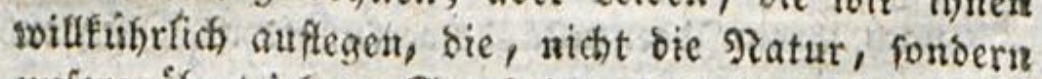
unfere kibertriebene Gorgfalt und unfere misverfans

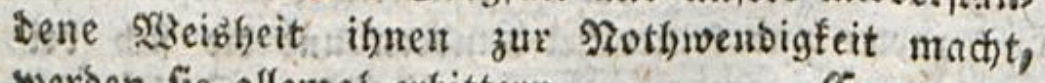

3.s. werben fie allemal erbittern.

Campe.

an) In biefem widffigen Itnterichiede liegt bas ganje

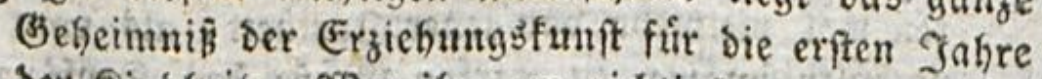
ber Sintbeit. sger ifn am ridtigfen unter allen

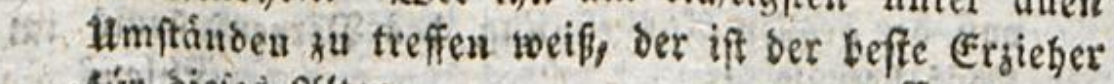
fitit diefes alter.

Eampe. 


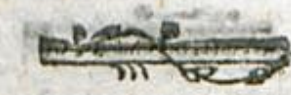

Weiffen, ऊuleşt aber bebienten. So entfteht aus

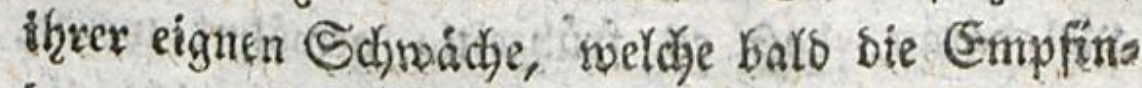

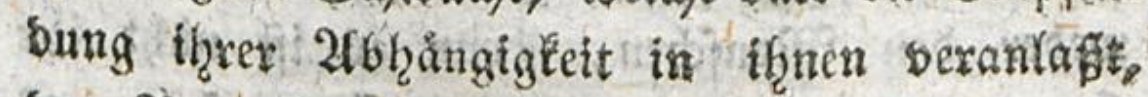
ber ßegriff bon Regieruthy utto Sgerridjaft aber ba brefer 3 egriff nid) forol burty thre

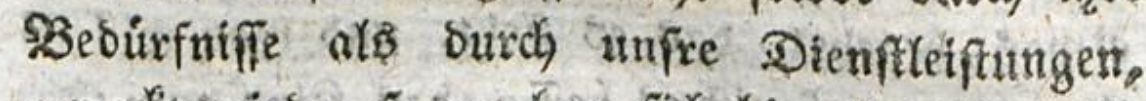
erwedt wiro: fo madjen fich bier foson bie fitt Yidjen 28 irfungen bemertlidy, beren unmitters

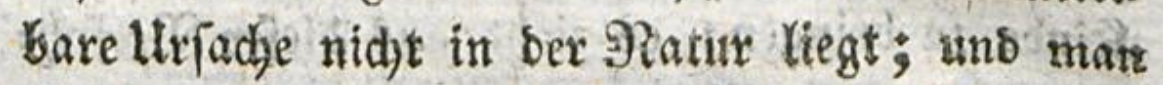
fiefre fichon, waram es von biefent exfen 2litete an bereits widytig ift, auf bie gebeime 2lbficht fa meuten, weldie die (Siebetzoe ober bas Sdjuetes amzetgt.

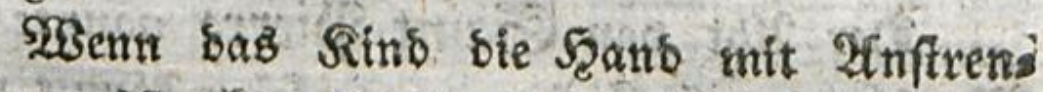
gutig aubftrect, fo gloubt es bea Segenftans ofl exreichen, weil eB die Entfermatng beffetbent nidjt abmift; es ift in Srrthim; aber wenr es fich beflagt uns fefreit, inbem es bie Saand

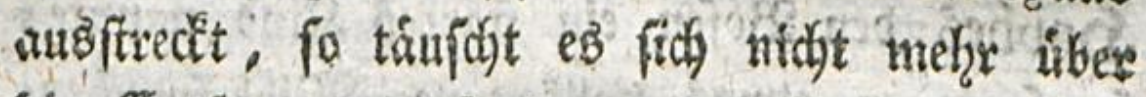
Sle Entfermung, fondern es gebietet entweber

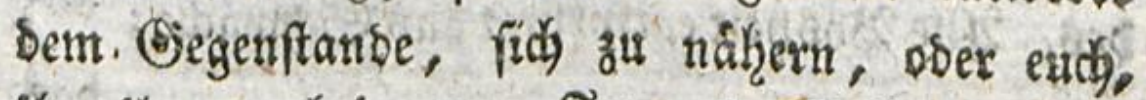
thit ihm zu bxingen. Şm exften Falle tragt es Yangram ins mit Fleinen Sdyritten nach sem Gegenftande zu: fm zweiten, thut gar nicht eirs extal alb ob the es berftimbet; *) fe firiter es

$$
\text { भ) } 4 \text { forreiet? }
$$

Y. Eitte soife Rieger! Eampe. 


\section{2}

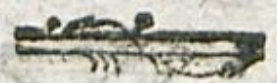

fichreiet, befto weniger foint banaufs Es riegt

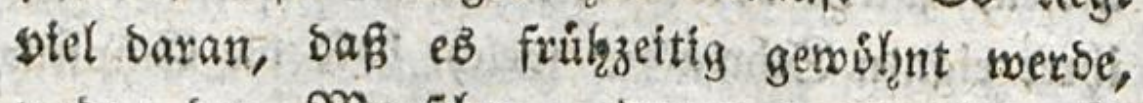
weber ben Menfiden, bent es if nicht ifre Sgerr, nodi) ben Dingen, benn fie werfteken es nicht, sut befeblen. , SBenn folglich ein sins ètwas begehrt, bas eb fieht, uno man will ez ithm geben : fo it es beffer, bas Rino zum (jes genftande binzutragen, als ben Giegenftanb bent

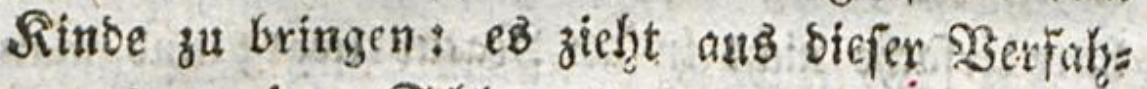

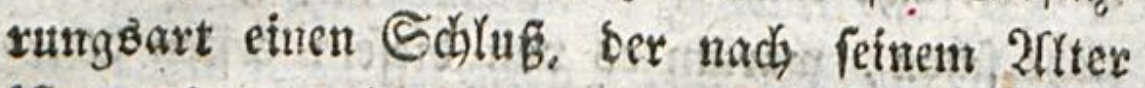
ift; utto man hat fein ander Mittel zu serats fralten, baj es thr madje *).

Dex 20bt von Saint Spietre nannte ble Senichen grof̧e Rinber; umgef́ebrt tonnte mau

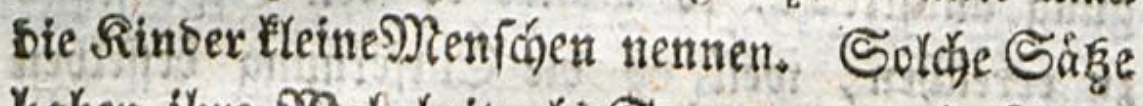
baben ihre 28 ahrheit als Sentenzen; als \$rtus cipia beourfen fie eimer Ertélarung: aber went SobbeB den Bófen ein ftarǩes Rino namute

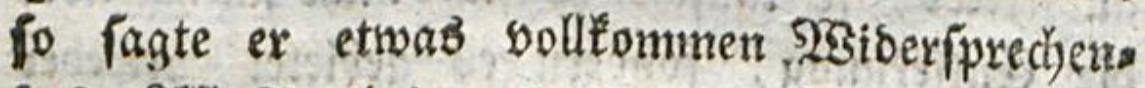
bes, 2llle Bosheit entipringt aus Sdjwadbe; *i;)

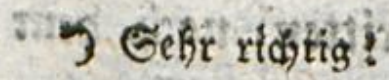

Campe.

S Der Gat font letät misvertanben fverben, twenn anders Rouffeauts sebante richtig gewefen iffe Richa sig iff aber nut ber Sab, wenn unter Edhwácie

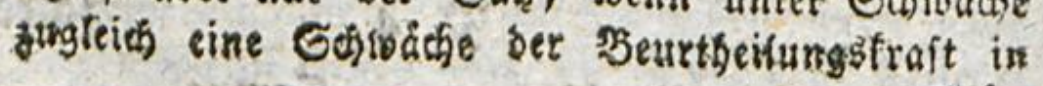




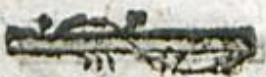

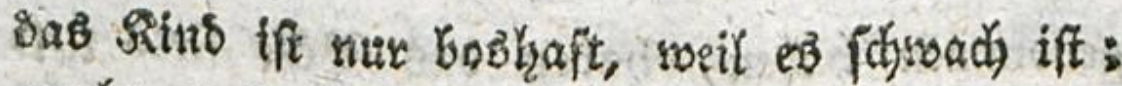
madit es ftark, yo wivo es gut fent: Derjenige. Ser 2ffes Esonte, roirbe niemats etwas $\mathfrak{B d}=$ fes thun. *) Ulnter allen (sigenichaften ber almádjtigen Esottheit, ift bie Sitte stejenige, whe bie man fie fich am wenigften benten fanu. alle Polier, werdye zwei Srrmnoprincipia ans Y 5

ges

Mirbiguth ber Dinge begriffen wib. Sonft is oft cin sienfich von viefer forpertichen betwalt stno solitif(her Nacht feht boshaft. Er fundet bann cine

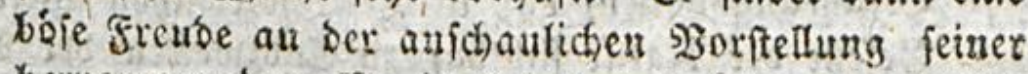
bervoriagenden Diacht bei interbrúchung und Peis zigung Plubrer uns an ber auf(h)anlichen SBivtung eincs boben Brabes von şatafúfr in Beftimmung befien, was gefdyeben foll, es mag aindern gefallen ober uicht gefallen. Nan barf aur bierbei su ben Sterzog von 2ulba benten.

2us Gctwáche tool nidte aber immer erbofit und beimt immer. Der wiro Seideníchaft entgegengefebten Sinderni ber bie jeiner

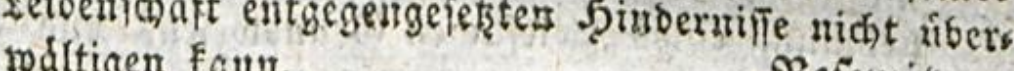
rodltigen faut.

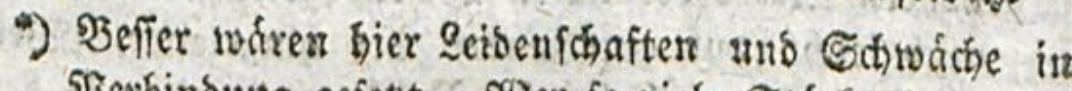

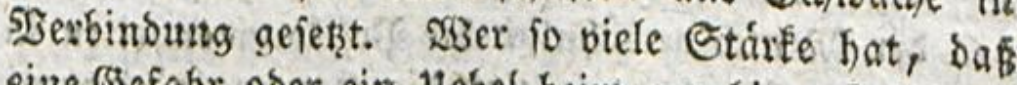
eine (3) fabt ober ein thebel beim gerufigen Bebraut) feiner getoifnlichen Sirdfte, feincr Soyfeflung nad, Leicht befiegt werben faun, bet brandit midht in Furcht uno Born zu geraffen, uno braucht feine Rrâfte nicht ungewóhnlich, als welches im leibens fobaftlichen Buftand fouft gefchieht, amzutitengen - ber bis zur lieberipanumg zu crbeben. Naach bem Nanfi, als also einer ein ftarfer feeto iff, ift of ater olye leibenichaft.

(E) 


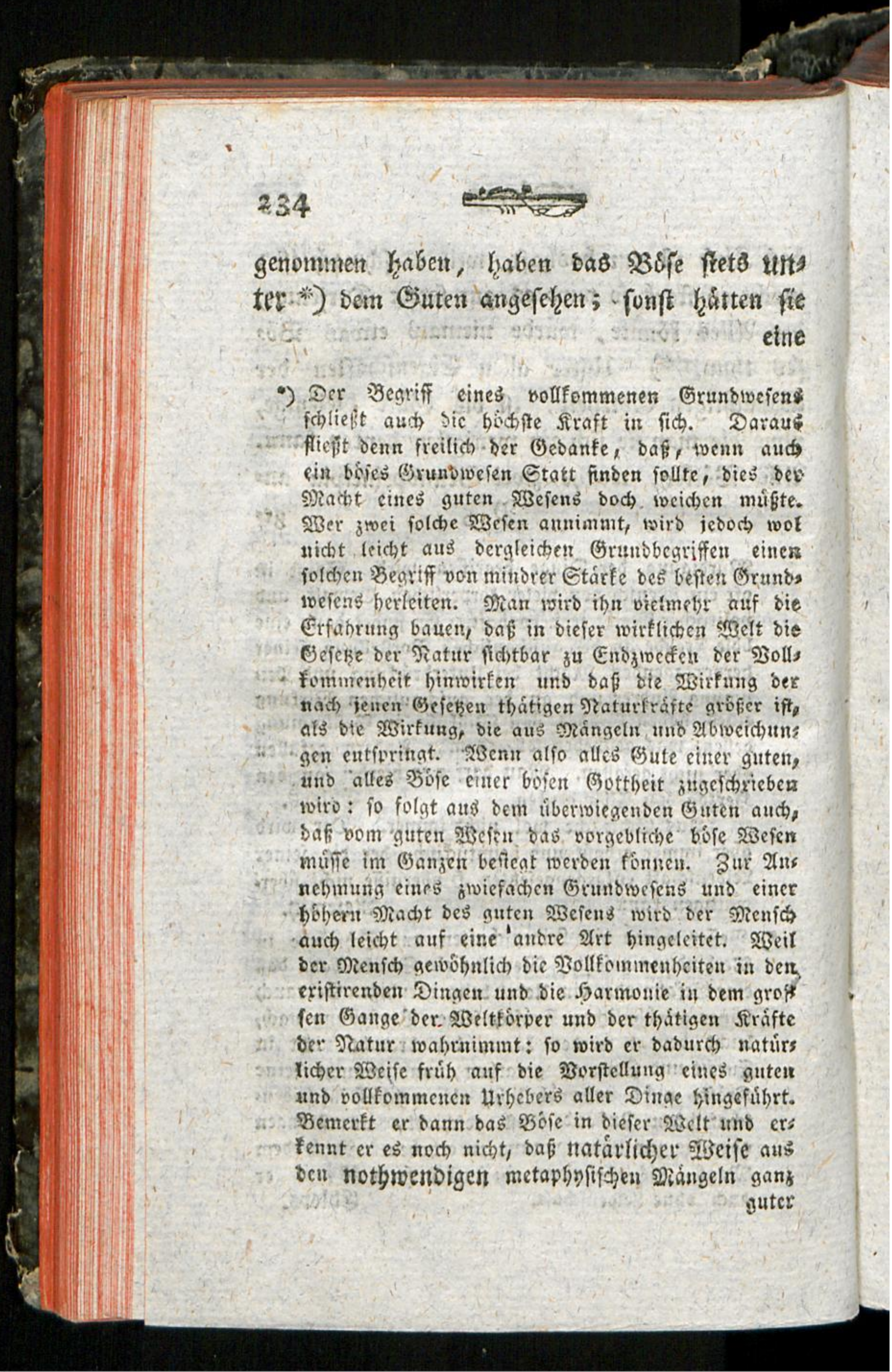




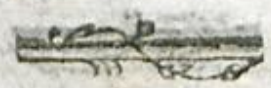

eine ungeveinte Suppofition gemudf. STan ref̧e weiter unten Das Shlaubenbbefenntniß bes fabogifdyen Bicars.

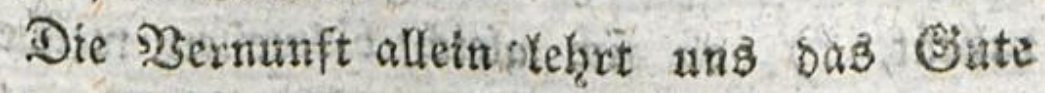

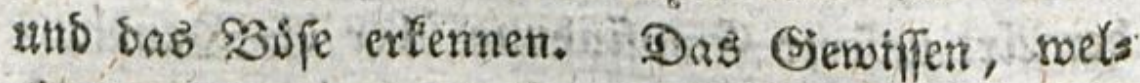
d)es uns oas eine liebert uns bas anbre haffen lafst, tant ficl) alfo, obgleich) unabhàngig yon

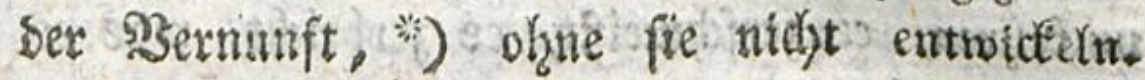

she

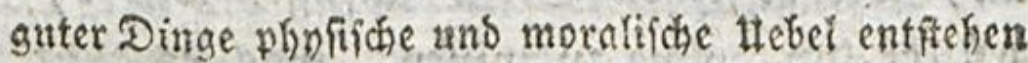
uno alfo mit ben SBirtiaméeiten beichrânéter Şsefent fich phyfifthe unt moralifhe Hebel verbinden: io wirb er zraar beim शachbenfen kiber ben Hriprung

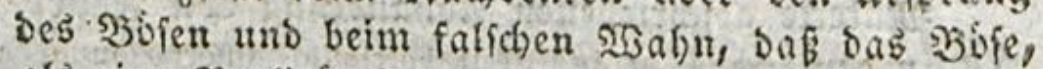
alb cine Tiealitát beroorgebracht fenn muifie, niclet aber von einem gittel Gott fervorgebrad) fenn Fonte, leidt auf bie soee fommen, daf es ein bifes Ulrwejen gebe, bas bie Hebel in bes guten Bottes siselt hineingebracht habe; allein er wirb biefes boje siseien!boch als ein Hrwefen vom ziveiter Fange anjehen, bas bem guten Sisefen nidht an siad) gleich fen uno das bie grofien Fealitáten ber 930 lls Fommenheiten uns bes (5) uten nidht zu (5iunde rid)s ten, fonderu nur etwas ß̧ojes binanfúgen fonne. Dấ ein über biefe Naterie nachbentender, nber sicht genug zu ben baju fo, nothwendigen, practis

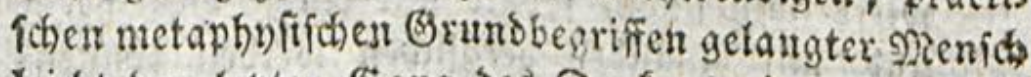
leidht ben lekten Esang bes Denfens nimmt, erbellt atts bem in Sayle enthaltenen 9atrifel uber bie Dianidáer uno \$nulicianel.

(E)blerv.

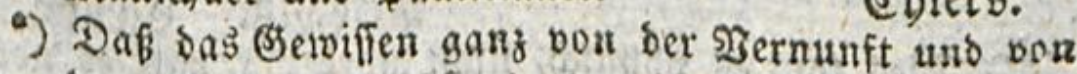
dem Ierfande abfingig fen, if in ber uber biefe 2) rates 


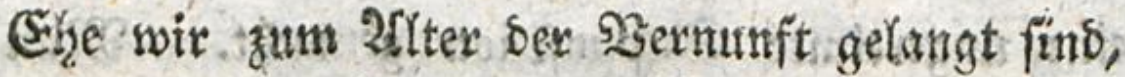

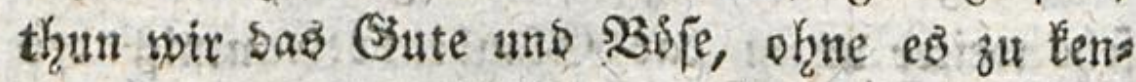
nen; und unire Scandlungen b̧aben feine Mros ralitat, *) of fich gleith bisweilen weldye in bex 2frt unferer Empfindung über ste Shandtune

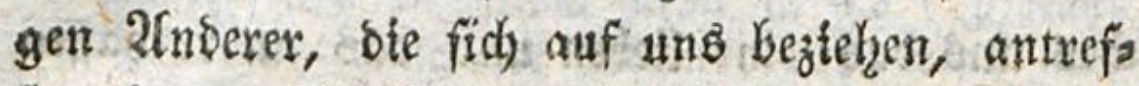

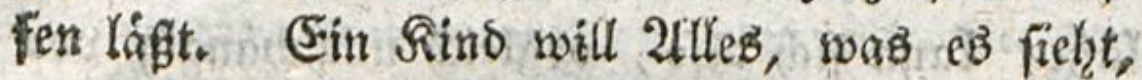

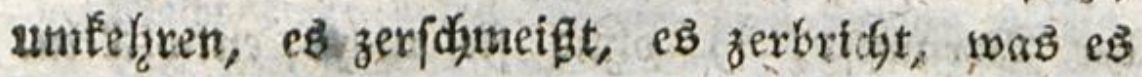
erreidyen tann; eB faffit einen Sogel eben fo an, wie es einen Stein anfaffen wirrbe, uno erfidit ifn, ohne zit wiffen, soas es thut. **a)

matum

9)aterie gefdriebenen 26bfandung oon Febet uns in bem, twas in meinem Fafeicula differtationum argumenti philofophici entbalten ift, mefr, als binlânglich ertviejen. Die Annebmung des Begentheits fant auch nicht nur nicht surch richtige (5)runofáce der 2ntfropologie beftehen, foubern ift auth furts practi

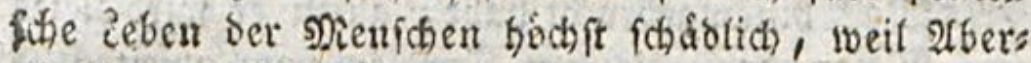
glaube uno Sd)wámetei unter bem Sduts bes Sas

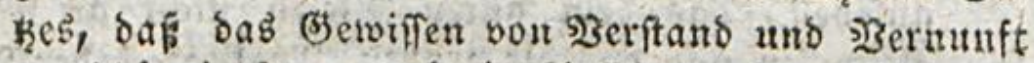
unabóngig fey, auch in virtebung bet afferunges reimtefent \$sebaùtungen nicht mit gutem erfolg fonnen angegriffen werben.

हE)

- Das ift wor fowerlid gegruntoet. Die şernunft

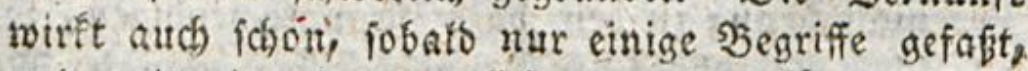
und mit einander vergficten werben fónten; $O b$;

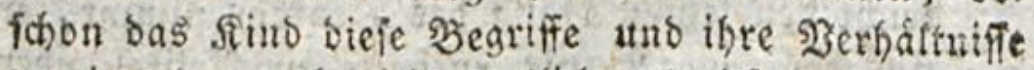
zu cirander nod nicht beutfich entivicefin faur:

Reetmis. Eampe.

94) Dies that es pinftict, nidht moralifक, weil es nod

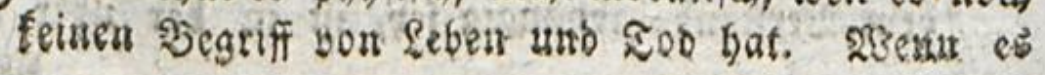
aber 


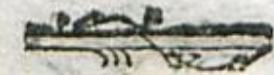

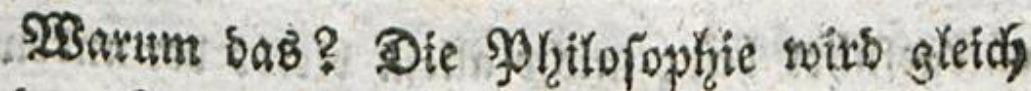
bet oer Sans feun, *) bie Utradje babon in sex naturlichen Serderbtheit zu fucken; far Stolg

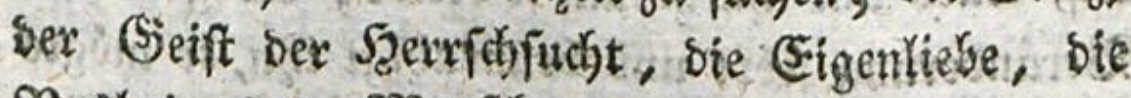
Bosheit des Menfchen, Dri SEffibl feiner

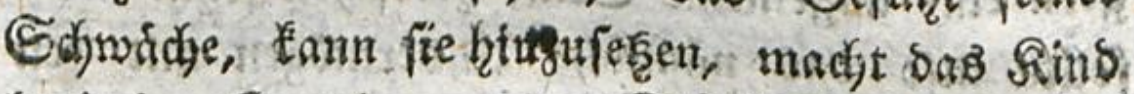
begierig, Sanshungen oon Stärie soxzunebmetr. und fidy felbft fein eigne Ba Rennigen su beweifen. Zabex nam febe jenen abgelebten und hituforligen

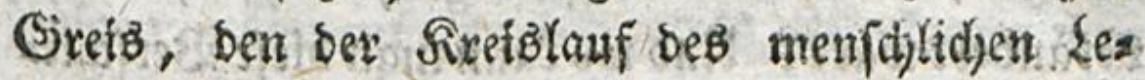
bens wieder zu Der Sdywádge oex Rinoheit zits

xuำis

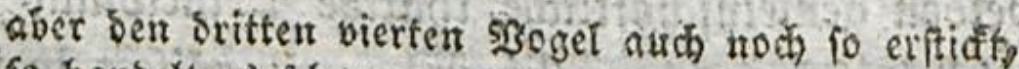
fo bandelt es fifon gegen feit erivachtes pioratifeles (3)

Siefervits.

7) Sgarmin phlectiveg sie \$ibilofoptie? Sicht gentus grundlich benfeute Şbeologen find baufig su folcher Szebauptungen in bem Sange ibres Denfens vers reitet und wenn ein \$hilofosh bie nts o a mit eits ftimme: fo war er ticht fowot sinfuifier als

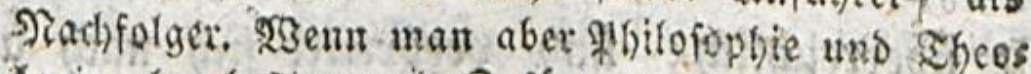

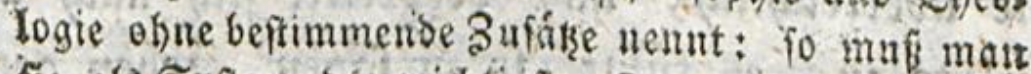
fie, als Syftene sér wichtigiten fienutnîje betraditeir

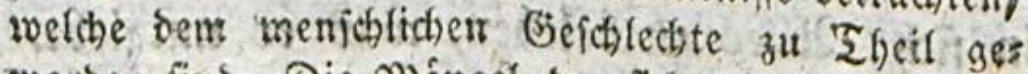
worden fuld, Die Niangel ber fich mit diefen ssifs. renichaften befendtigenden (Selefrten fimnen eben fo roenig auf bie Rethung ber sigiffenf(b)aften "gefebre werben, als bie slángel in inbividuellen Dingen uns 2Birfiamfeiten (mangelfafte s) iobeldeterminationen) boin strefen ber Dinge zut \&oift fallet fomen.

(E) lerts. 


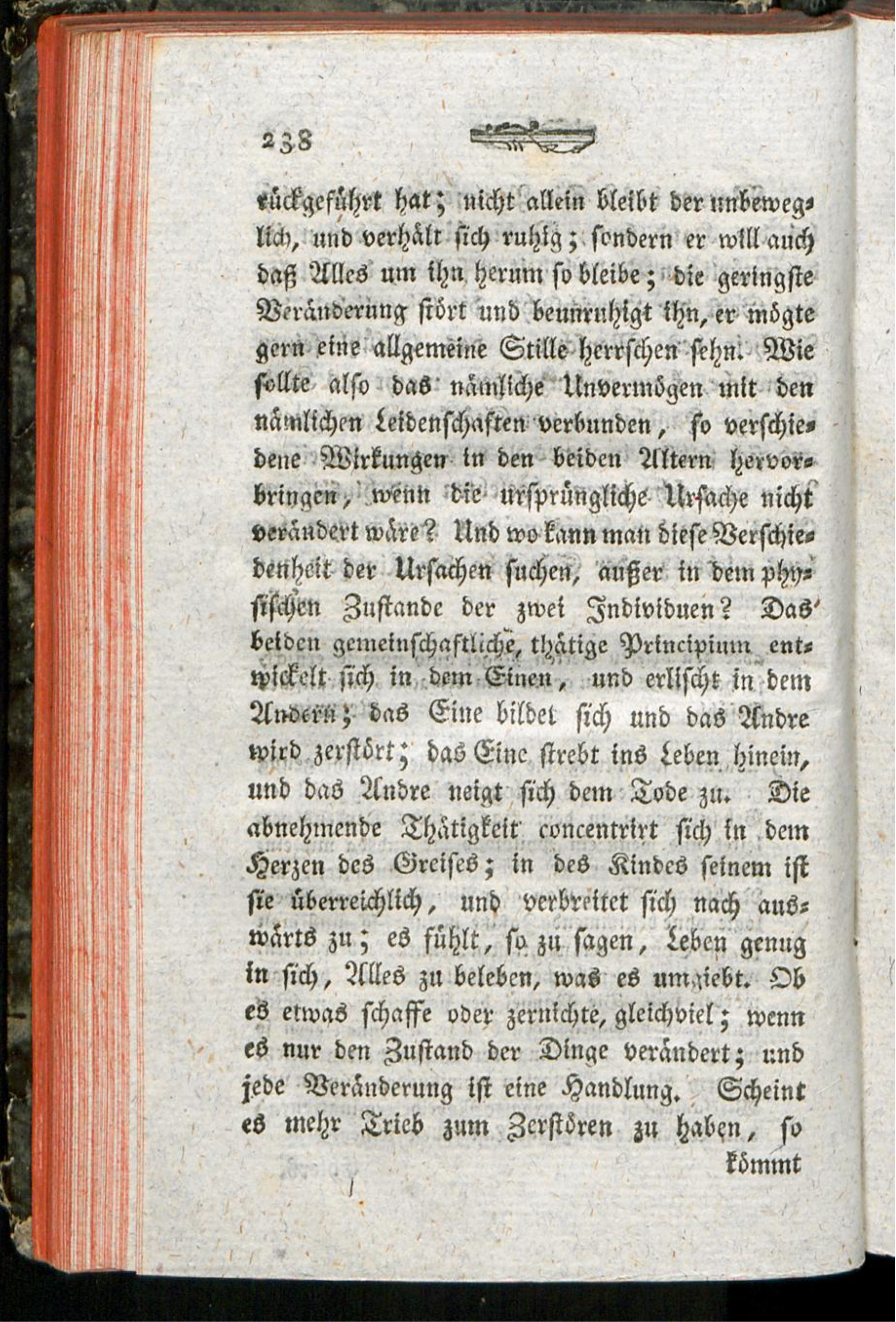




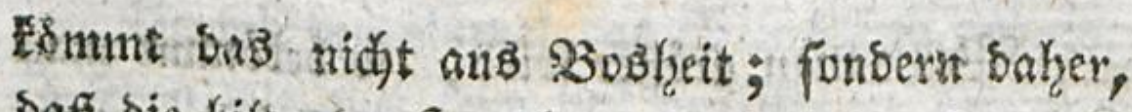
saf́ bie Gitbenbe Sgandlung inmex Kangiam ift, uno bie fdneflere bed Berftoxens fich beffer fur feine Lebhaftigheit fojictit.

Sndem ber Hrheber ber Natur ben Rindern Dies thatige Sprincipium giebt; trigt ex zugletich Sorge; baf es ifgnen nidjt felzr fojadid werbe,

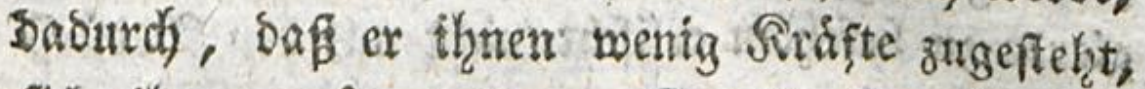
fich ifm zu itberlaffen Sobalo fie aber biea

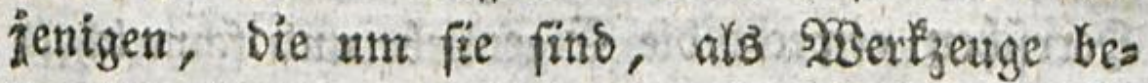

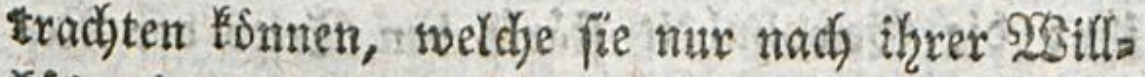

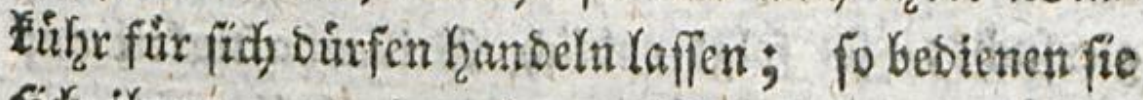
(iid) threr, um ber eignen Sletgimg zu folget, and einet Erfar ifrar Sdymadje zit findent Soldyergeftalt werben fie liberlaitig, befehlthas berifh, boshaft, nnbándig, ein \$̧erderb, ber nicht

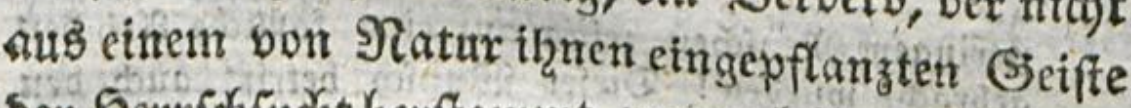
ber Seerridy fud the berfammt, woourd) ihnen aber bies fer Seift mitgetheilt wiro; benn es braudjt Feiner langen Exfahrung, zu fúflen, wie ans

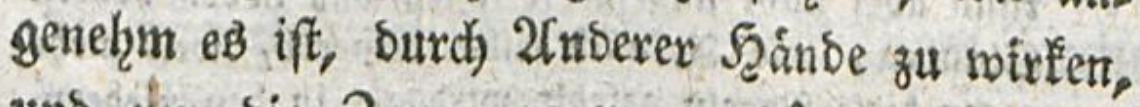
und tur bie 3unge regen on birfen, um bie

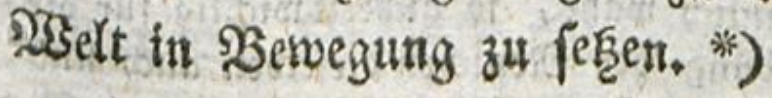

SBEกn

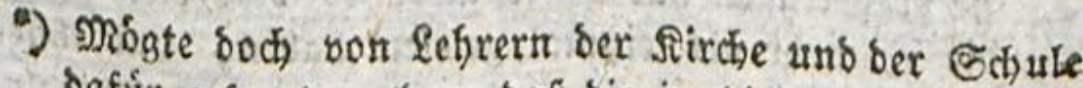
bafúr geforgt wertoen, bafi bie in biefem vorttefichen $24 b$ ab enthaltenem midytigen 230 abrbeiten auch aller 


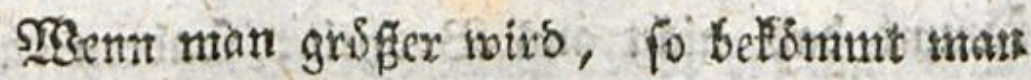
Sidffe; die Unrule, bie SRaftlofigleit nimm ab; wan serfchltefft fich ntefy in fich ferght. Die Seele und ber Rorper fefen fid), fo zul ragen, in ein (S)leidgetwicht; unb bie SRatur berlangt weitex niegtos bou unỏ, alo bie zu miferer (5rs baltung nithige Bervegung. 2alletn bie sies

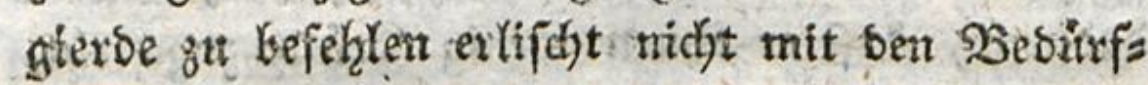
niffe, burdi bas fie erzengt morben ift; sab Serrichen erwect't ste Eigenliebe nus fonmeichelt

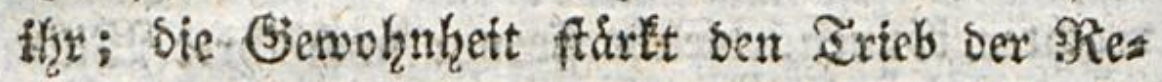
sierfucht; fo folgt enoltid Errillenhaftigkeit anf

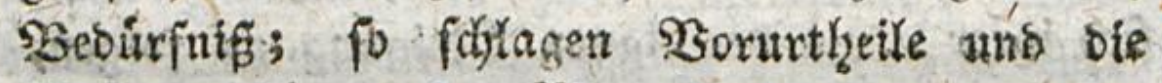
Meimung ifze exften 28 uxzern.

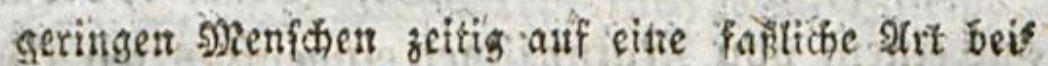
gebradht wutiden! Diefer \$3unth betrift auch ben

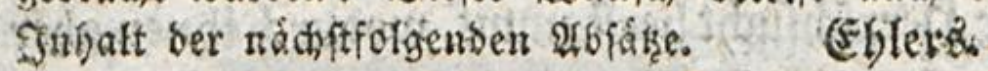

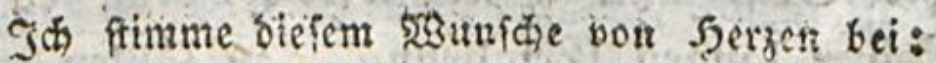
fam aber nictit nibemerft laffen, baf in bell bohern

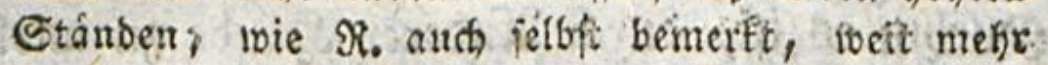
segen biefe Regeliz gefehlt wits als in ben siebern.

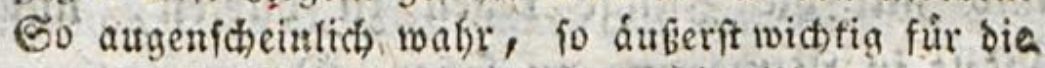
ganje Nusbiloung bes s)entiden biefelben aud finb zanb io vortréfich und unmiberiprechfich) evident $\Re$. fie vorgetiagen hat - fo giebt es both viele Reutep bie $\Re$. mehr als eitmal gelefer haben, unb ifinen gleidovol immer fonurftadfs entgeger handeln.

57tuve. Canpe. Fepewis. Trapp. Wouftnget. 


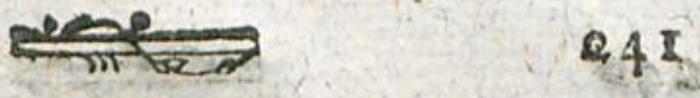

Da wir nun einnal bas \$rincipiutm Éennen,

II.

tof

te.

tit

$3^{t}$

ro

es

if

IB

its

ies

แf

ife

Ja

eis

en

i:

$\mathrm{rrs}$

bic.

'It.

jia

no

R.

tep

entis

n.

To jekgen woir aud febre bell sen. Shounct, no man Den Pfad ber Siatur zu berlaffen anfangt. $2 B i x$ sollen jest untexfucjen, mas man zu thun habe, auf biefen gofabe zu bletben.

Die Rinber, weit entfernt, nit úberfluffia gen Siráften ausgeftattet z" fern, haben ifrree nicjt etrmal binlangliche firr 2trese, was bie Natur son if̧nen verlangt: man mufi ithen alfo Den (sibrautb aller Derjenigen lafin, Die fie ibuen giebt, und Deren fie nidjt misbraudien fonten. Erfter Srumbja.

gran-muß ibnen belfen, uns exfescen, was ifnett, es- fet nun an Einfitet, doet an Siraft, in Slllem, Das zum winfl: fiben Beourfniffe gebort, abgebt. Zెweiter Grumbras.

Man mus in des Scilfe, die man ibnen giebt, fith einzig auf bas wirtlich saibliche cinfit)ranfen, obne irgend etwas ifger saume Doer ber anvernunftigent Sogierbe einzus ráumen; bern bie Eane wirb fie nicht melgr plagen, wenn man fie nichst bat auff́mmen laffen; fintemal fie nidit in ber Statur ift. Dritter Srundjar.

Emil toter ef.

2

รกกเ 


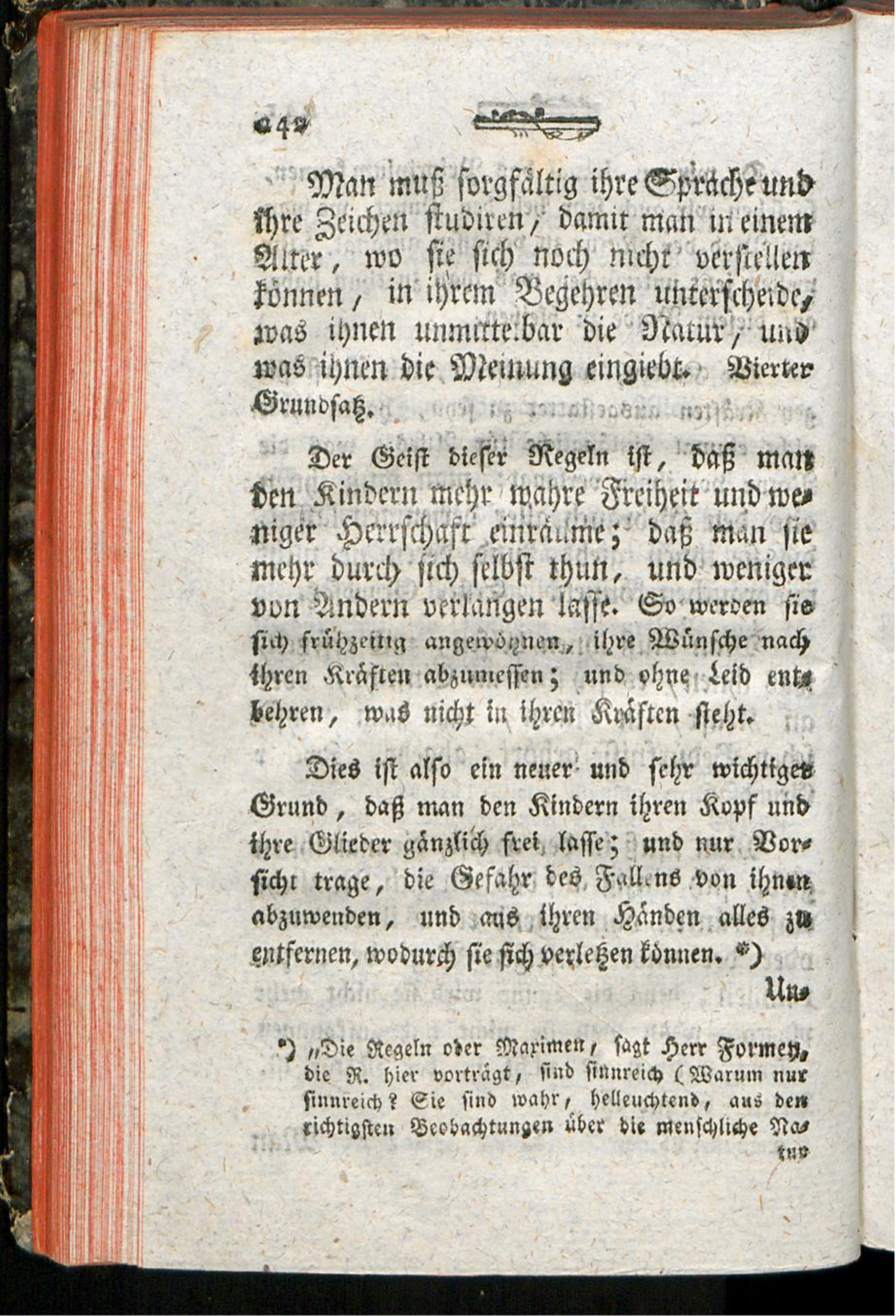




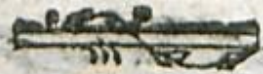

$+243$

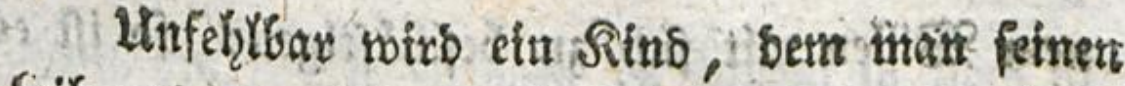
Seib uno feine Şlieber frei lást, weniger weinen,

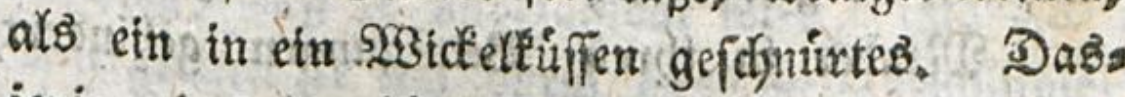

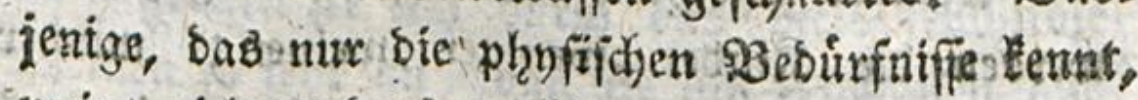
soeint nicht anders, als wenn es letbet; uts bubei gerwinnt man biel; Sent ałżann meiff man auf efn Sgar, meñ es̉ Beiftans braudht,

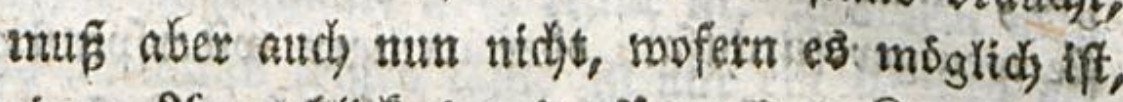

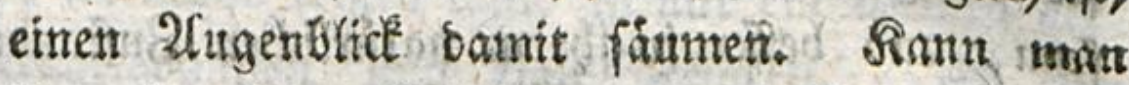

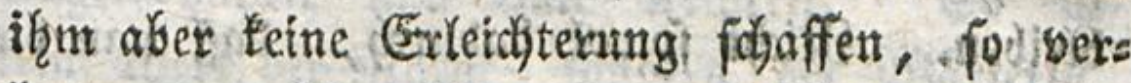

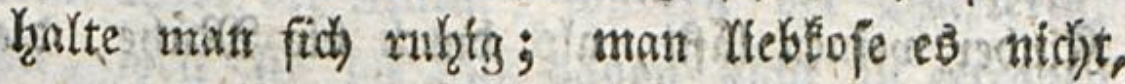

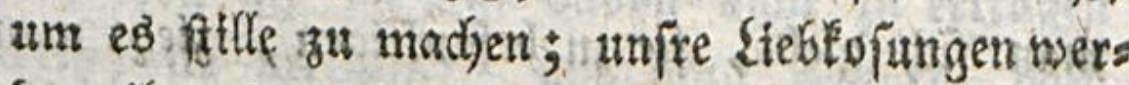

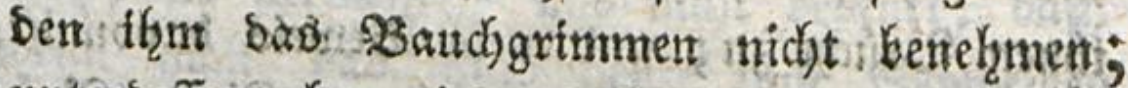
unterbefien abex wiro es fích merten, twas es at tfun hadbe, fitlle gentatht zu merben; uns kat eB̉ einmal sie Sinnft gelernt, uns nady feis

2. 2

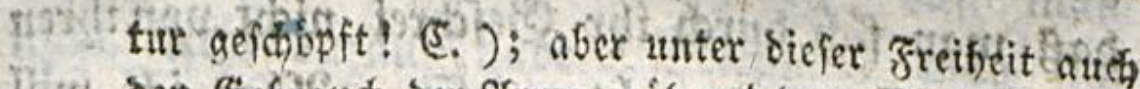

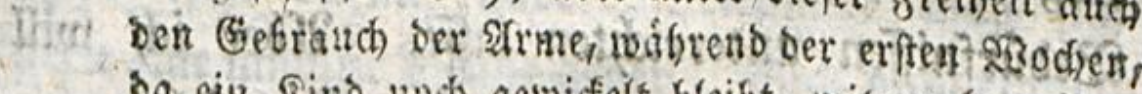
ba cin Sino wodh gervifelt beibt, mit zu begreifen,

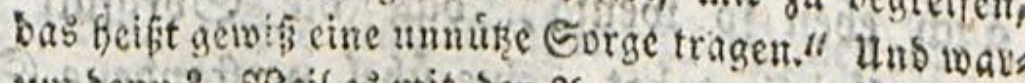

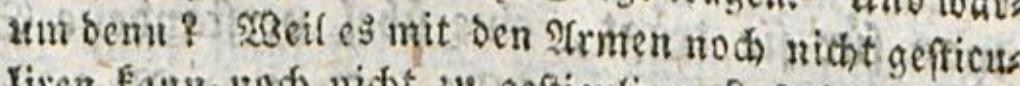

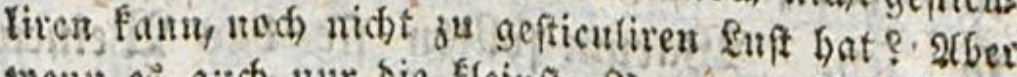
toenu es aisth unt bie fleinfte Bewegung bamit vor:

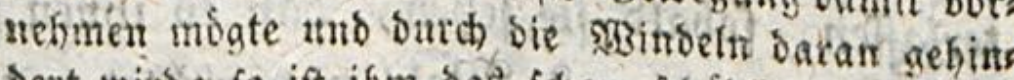

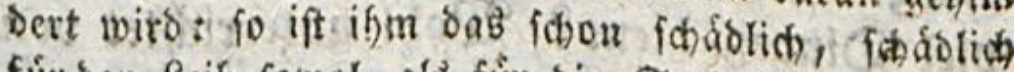
fúr ben Reíf foronl, alb für bie Geele. Ino rectuet Serr formen benn gar nichts auf bie Ectsibtidjteir Des Cinverfiens an fich, allh wemt sas Sinb nod

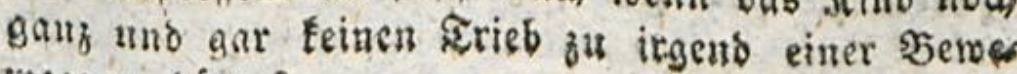
wegung bátte?

Gampe. 


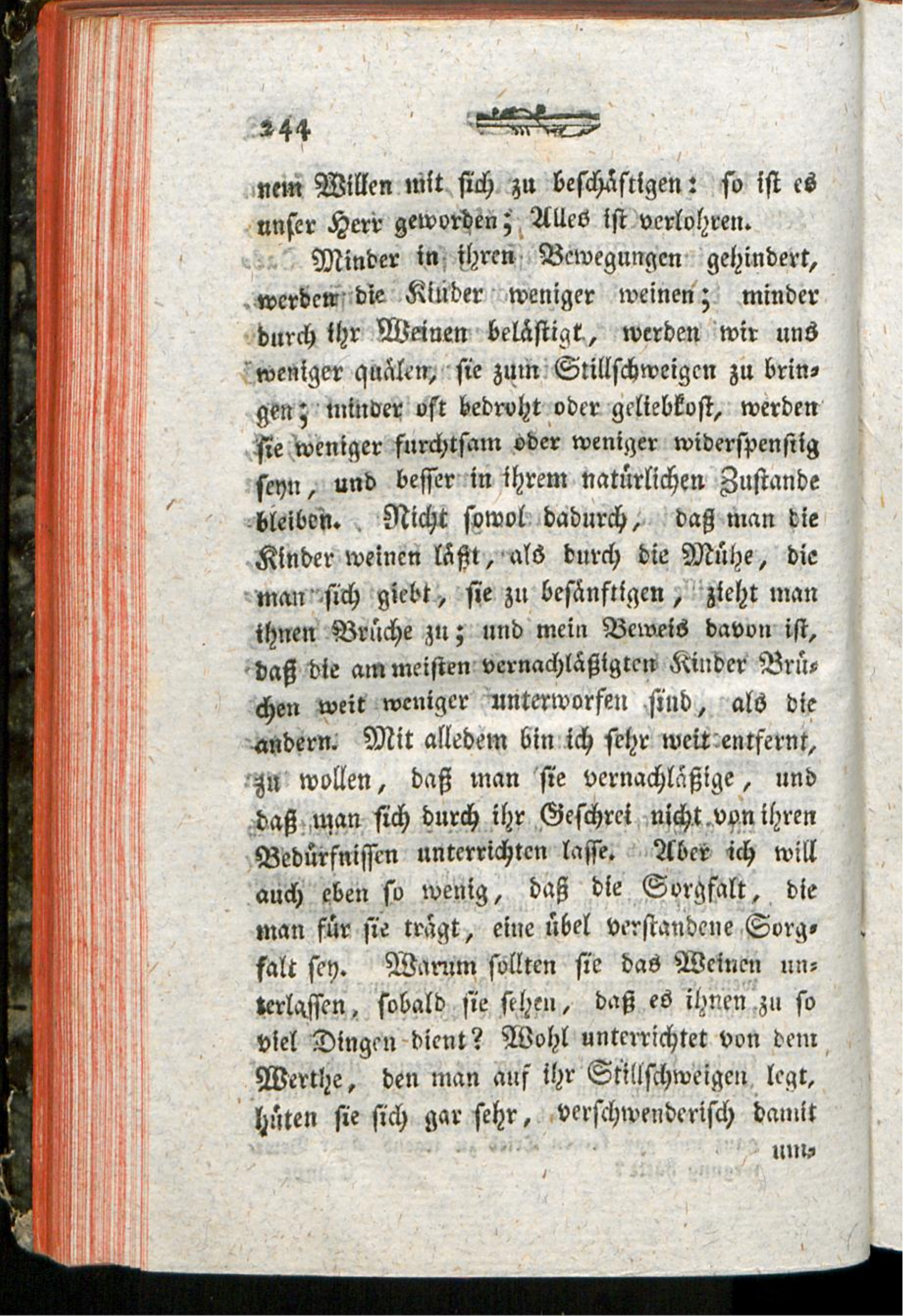




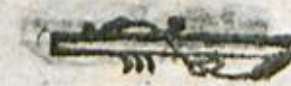

umzugetzr. Sie bringen es zuldert fo hod in

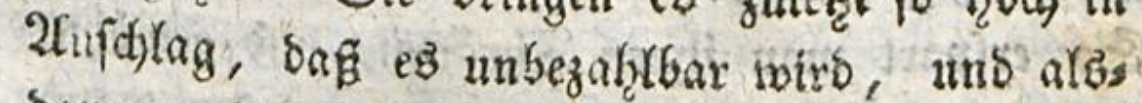
bann greifen fie fidf burdy bas biele fruchtlofe IZeinen fo fehr an, bug fie fid exichopfen, uno Den T̃Do zuzielzen.

Das lange Gethente eines Sinbes, bas weber eingefdynitt noch trant in, unb bem man $e^{B}$ atr nichts feḩlen läb̆t, ift nutr cin 2 Beinen ser

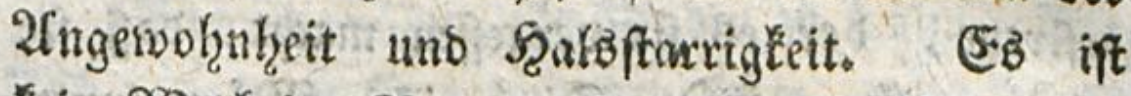

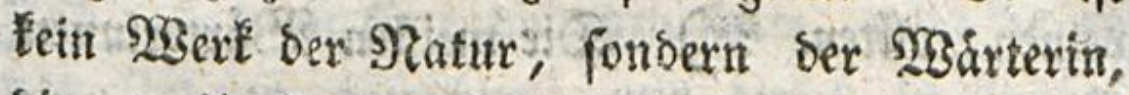
Die, weil fie sie Laft babon nidjt za ertragen weiǵ, fie sermef̧rt; uno nidjt bebente, baf, wenn man baó Rino bente zum Schmeigen bringt, man es anfpornt, norgen nur befto mehr ful weinen. *)

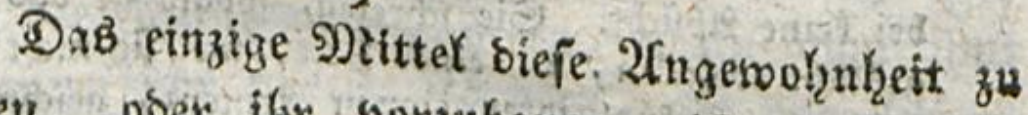
beilen, voer ihe vorzubanen, ift, baß nan nidjt 2fojt sarauf babe. Sciesmans mag fich gern eine umíre Mithe geten; ands nidht cinmal bie Simber. Ste frito in ifren 3 serfuchen bart: nadtig; aber habt ifgr nux nods melar Stanohaf: tigfeit, als fie Seartnd d'igteit; fo twerden fie's

$$
\text { D. } 3 \text { ubers }
$$

7) Xule biefe 5eobachtungent fint fo unisiberipredffich wabr unto von fetbif einfeudtend, daßj ñe weber einer Dbeftáftiguig, nod einer Empfebrung bedúrfex.

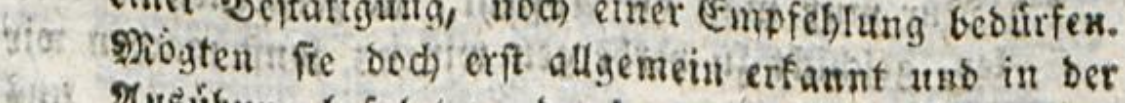
tyan 2husubung befolgt werben! Eampe. 


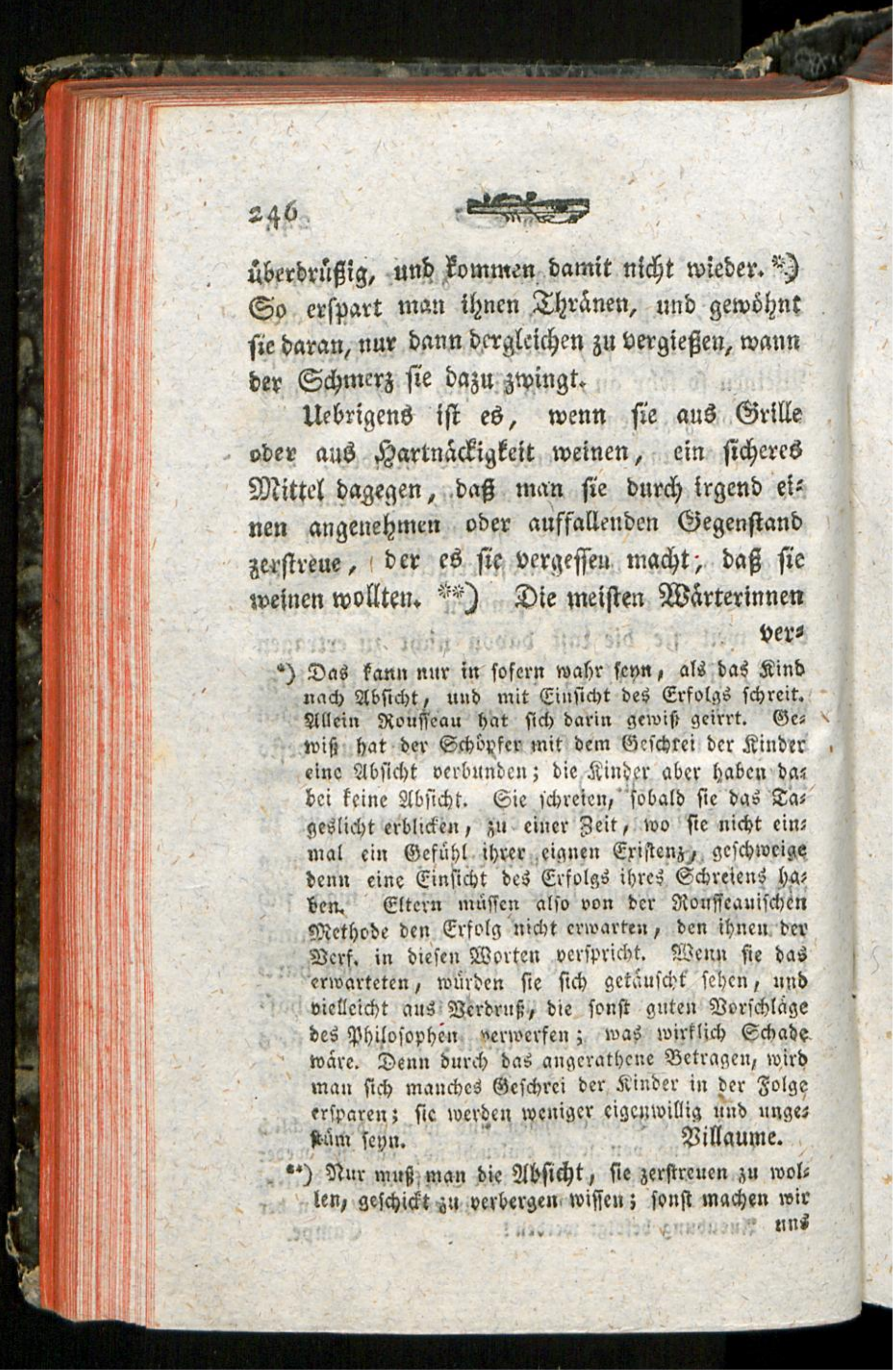


Gerfekhen biefe Sinnfi meifterlich; uns zut redj:

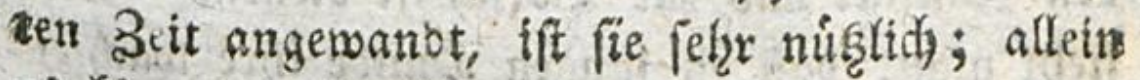
es tsmmt aud) alles barauf an, Daßs Dab Rino bie 2lbfid)t es zerfireuen zu mollen nidst merle; uno baß es fid ergoge, ohne zu wifien, baf swir babei auf feine Ergsegung beoadt fins; and babei neflmen fich Die Märtexinnen gemeis

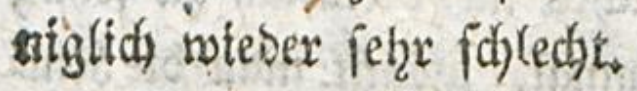

Man entwofgnt alle Sinder zu frith. Die Beit, two man fie entwoiznen follte, wiro ourdy bas 3afgnen bezeddinet; uns diejes tiz insgen meir befdswerlidy uno fdmerghaft. Durds eis nen mafdinenmåpizen Inftinct führt alBsantr bas Sino ḩáufig alles, was, es in ben Szänden Kålt, zum Mumbe. Mrau bentt diefe \$erridys tung der ఇatur zu exleidjtern, wenn man ifm Silappent von harten Rorpern, als son Elfens

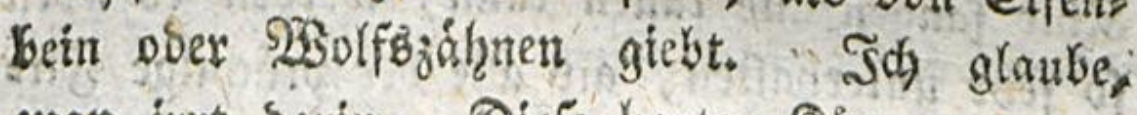
man irrt Dorit. Diefe harten Ribrper, went fie ans 3afgnfleifh gebradst meroen, machen es

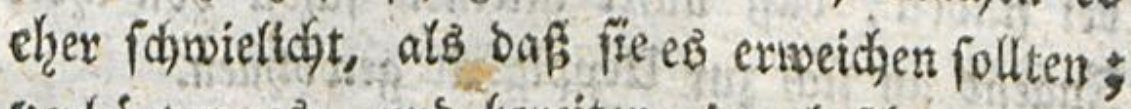
serhárten $e B$, ano bereiten eine bejdywerlichere sno fogmezhaftere Jerretfing oor. Enpt ftets

$$
24 \text { Dew }
$$

ant abermals abfángig vot ifnen und fie zit unferis

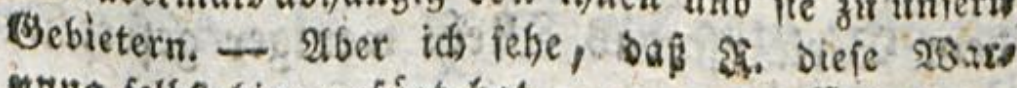
Emape. 
ben Snftinct uns zux 20 orfdrift bientet. S)at fieht nidjt, baf̈ bie jungen Şunde thre wadjfens ben 3áhne an Riejelfteinen, an Eijen, an Snos djen; fondert an Solz, an Leber, an Lumpen, furz an wethen Sadjen iben, bie nadjgeben, unb in bie ber 3ahn fidh einbrictet.

Man weif in nichts mehre einfach zu feun; audf) in oem nidyt eimmal, womit man bie Rin= ber verfieft. Sijetlen bon Silber, Solo, Rorallen, gefdyliffenen Siriftall; Slappern bou jebem Spreife und allerlei 2rrten - was fur unníger uno fádablidjer Iano! $\mathfrak{B B}_{\mathrm{B}} \mathrm{mit}$ alle bem! Reine Shellen, feine Slappern! Rleine Baumzoeige Init ifren Frúdbten uns Blattern, ein Mohntopf, in betn man ben Saamen raf feln hiort; eine Stange Süftzolz, an ber bas Rino faugen und fautn tant, werben es eben fo febre unterkalten, als alle ber práchtige Firs

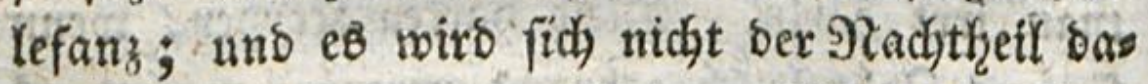
bet finben, baß̧ unfre Rlemen ficon bon ihrer Sugeno an fid zur Uleppigkeit gemolgnen.

פRan hat ertannt, baf ber Rinberbret teis ne felfr gefunde Spetfe ift. Die getodite Mitler

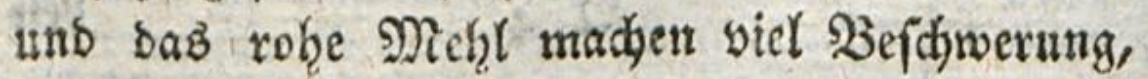

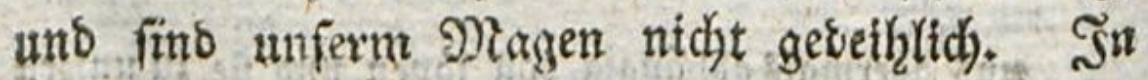
bem Srele ift sas MTeḩl meniger gefotten, alB 
in bem Brobte, und ákersies hat es leine Gakhrung geḩabt. Brootjuppen uno Reismis Ber foyeinen mir siel surgúglidyer zn fern. SBill

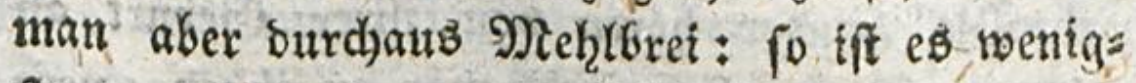

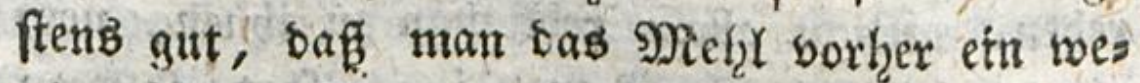

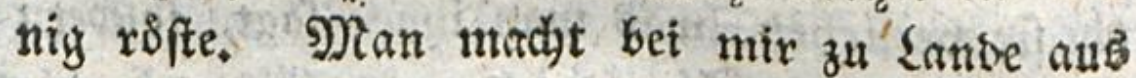

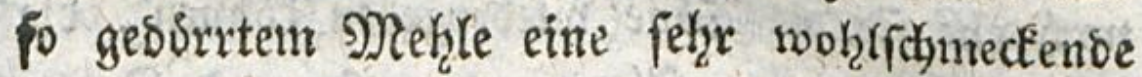
und gefunbe Suppe. Fleifty uno Rraftbrihen find gleidffallz eine nux mittelmafigige Speife, beren man fich bier fo wentg besienen muk, als moglidy. Es ift viel baran gelegen, baf fid bie Rínber gleich anfangs gerobhnen zu Eaut. Dies ift bas mahre Nittel, ben 2 (uBbruch ber

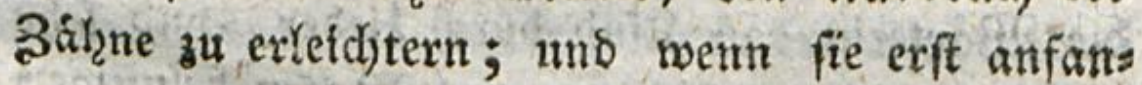
gen, etwas nieserzufáducten, fo beforbert bee mit ben Speifen bermengte Speichelfaft bie Sertautug.

Sh) mitro fie bemnad anfangs trudthe

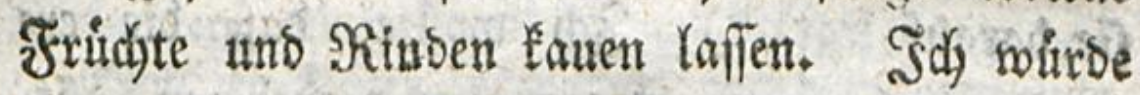
ifhen, bamit za fpiełen, Heine harte Brobtftris

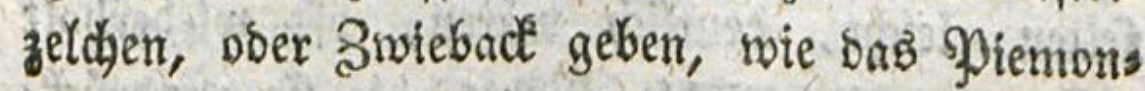
ter Srobt, baß̧ man in bem lande Sriffes nent. Snbem fie biefes allmåḩlid in Munbe erweidyten, wirben fie enblid, etwaz babon ntes bexfajlucten: ihre Båf̧ne wuirbe man herbor: tommen felzn, uno fie faft etze man fidjo wer:

$$
\text { 2. } 5
$$

[a: 


\section{0}

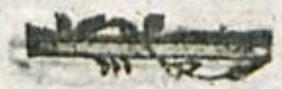

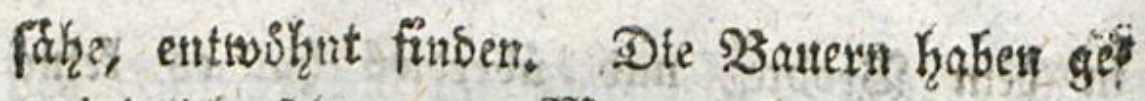
meiniglid') feltr gute Nagen, uno fie werbest anf teine anore $2 \mathrm{Crt}$, als biefe, entwohnt.

Die Sinder horren pon ifuer Geburt an seben. Situt allein rebt man zu ibnen, nod elze fie verfiehen, was mant ihnen fagt, fortoern nody ehe fie die Zune wiedergeben fonnen, bie fie vernehmen. Sfle nod erfartes Sorgats

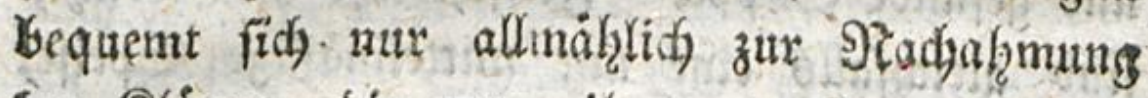
ser Rlánge, bie man ifhnen vurfagt, uno es ift nidit eimmal gemifs, ob biefe Rltange gletch anfangs fo Deutligh in thre Shren fallen, als in bie, unfrigen. Sđd) mistillige es nidjt, bas Sie 23 krterin bas Rins Durch Sieber, smb Fehe

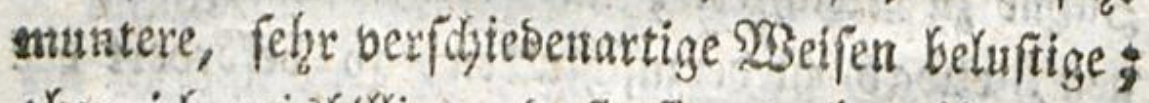
aber id misbillige, bafi fic es̉ ofzne Unterlaf Surd einen Sdymall unnirger Morte betaube,

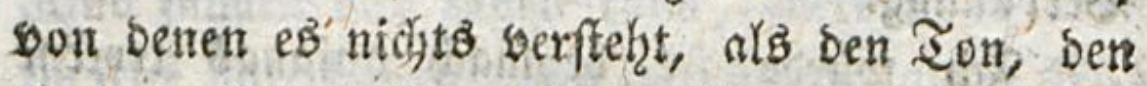
fie barauf Yegt. ") SCy roollte, baf die exd ften 2rticulationen, bie man es bernefgmen lä̧̆t, felten, leidst, beutlid wáren, oft wieberholit wuirben, uno bafie bie 33 orte, bie fie cusbricts

- tett;

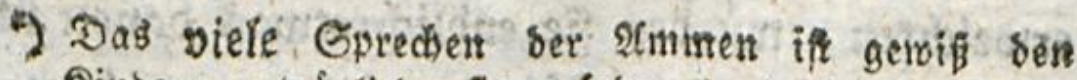
Sinbern: zutráglich, fie wúrben fouft viel langfamer

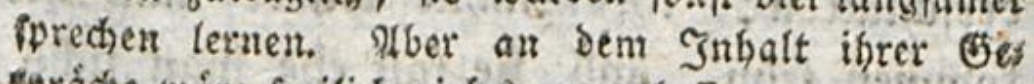

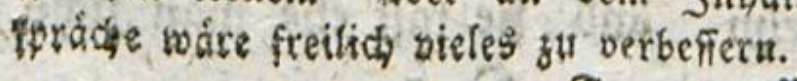

Sropp. Eampe. 


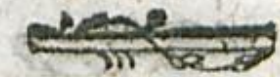

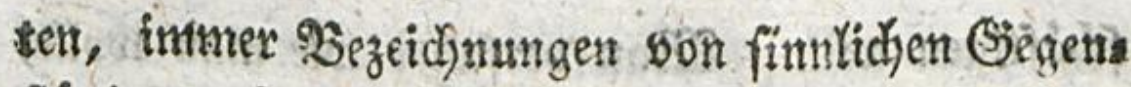
fånsen wåren, bie man fogleidy bem. Sinde sorzetgen tonnte. Ilnfre unglidéticte Éid)tigs reit, uns mit 5 Borten zu bezahlen, die mis

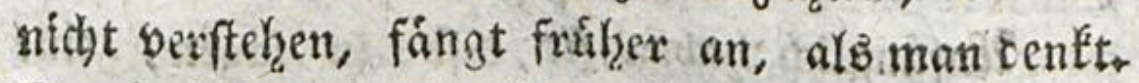
Dex Sdjuller hiort in feiner (Staffe auf ben SIorts

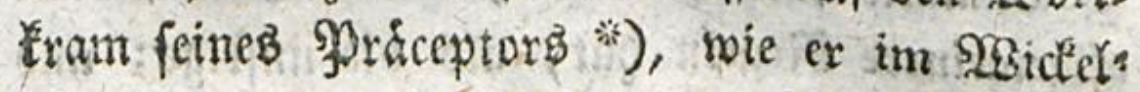
Hiffen auf bas Sejampir feiner 2 mme hordbte.

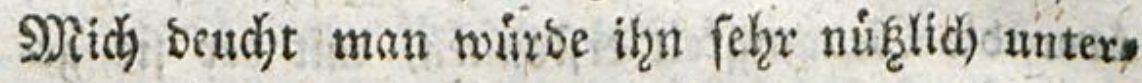
richtet baben, menn man tha baz̧ auferzogen batte, gar nidits bavon zu berfteflnt.

Die Betraç)tungen orángen fidh, fobals man fein giadibenfen liber bie siltoung bet Spracbe uno ber exften Sieben ber Rinder bes

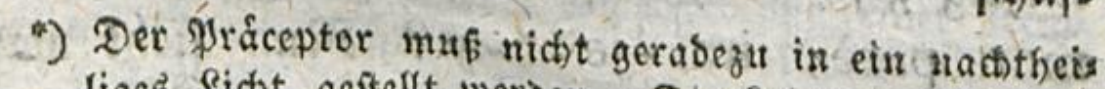

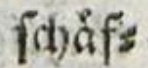
liges fidjt geffellt werben. Die Rebrer-ber Jugents getbren im Ganzen zut ben beiten Mienicten, Eie theilen gerwitgntich Bthidffeligfeiten mit, sie weik mefrern innern siserth an uno fir fich und in bea Finftigen Folgen baben, alb eine auth fogenante

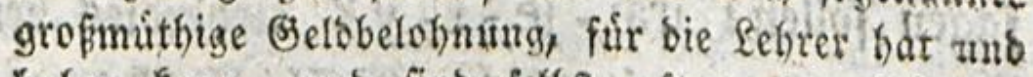
haben fann, uns find petbft oft wabte 2adatiser

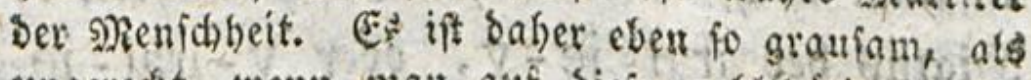
sungerecht, went man auf biefe toogrthátige Elaffe non sientichen, Sabon ein 2fntonit mit to bielen Seiden der Serefrung und Danffarfeit bei ber Surviderinnertung an bas, was or feinen febrem 3u berbanfen hat, redet, allgemeir eine polche goee

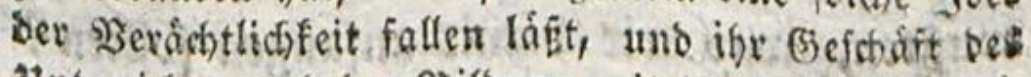

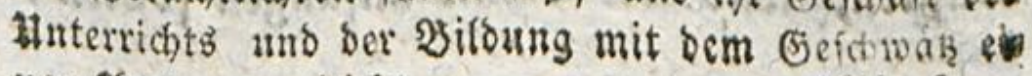
Her stmme pergleicft.

Eblerio. 


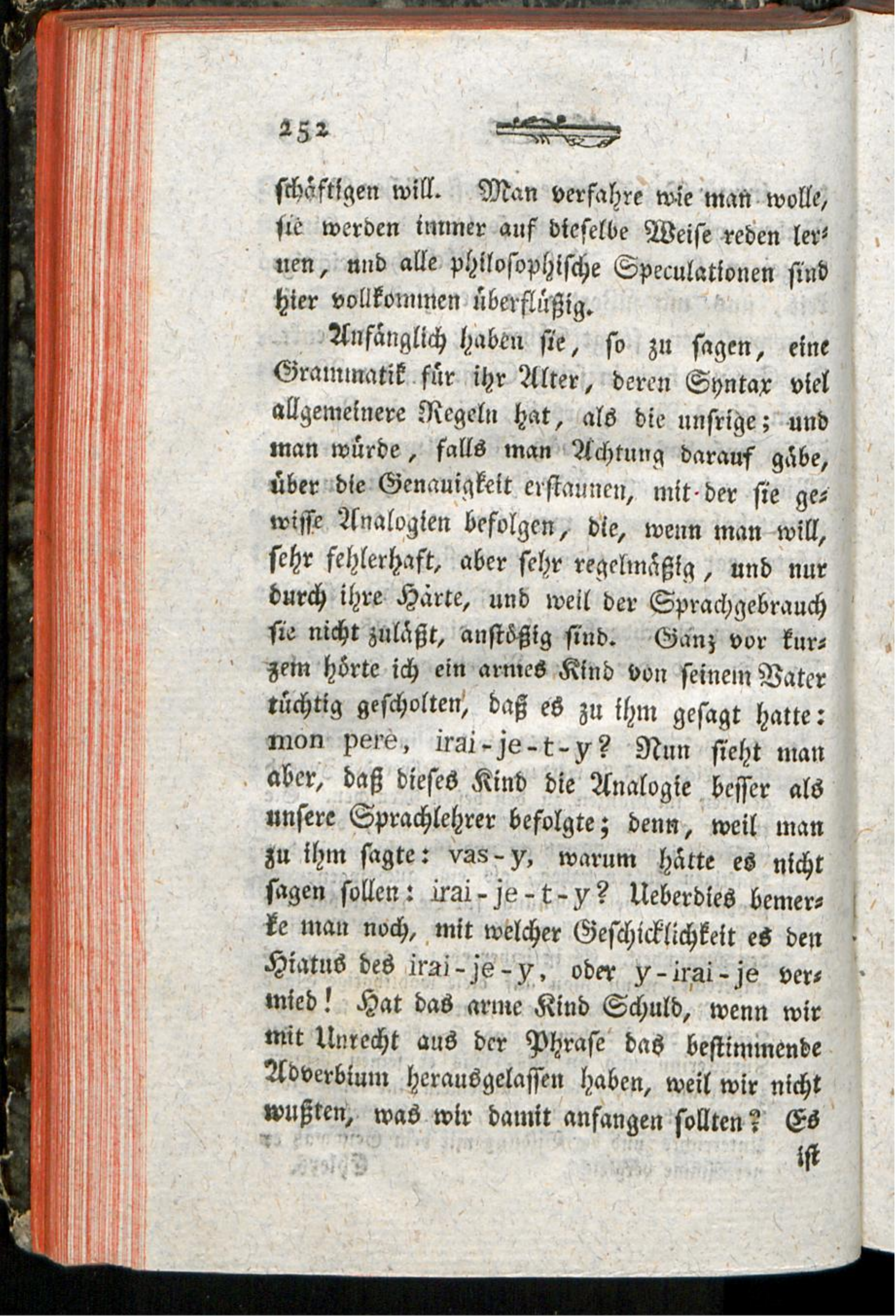


flle,

levs:

ino

ine

otel

ino

be, ge:

ill,

uit

udf)

ure

ter

te:

ant

ปtร

an

dit

ers

ient

ers

sir

ioe

(b)t

503

ift

ift eitne unetvialicke spebanterei, uns efne ber ibberflifgizften Mihken, oie wir uns geben, wenn wir uns angftlich befleigigen, an Sinbern alfe sie thinen Fehter gegen ben Sprodhgebraith

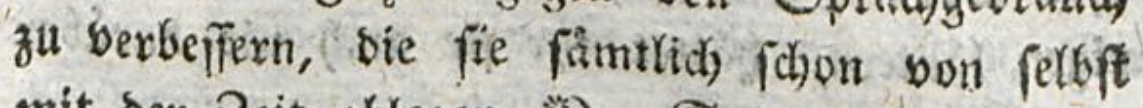
mit ber 3eit ablegen. *) Spredjt nux immer

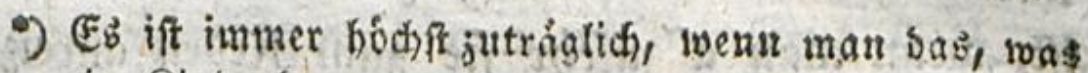
ein Sind ebent umrecht gefagt un augefprochen bat, gleich barnuf recht fagt und ausfpricht. (C) merft

th baun fogfeich bas Hnrichtige uns Sichtige, unb ges wobnt fich ful letzterm, $d a e^{b}$ fich fonft fo leicht zut elferm gewobut. Son welcher ஒebeutung eine fals

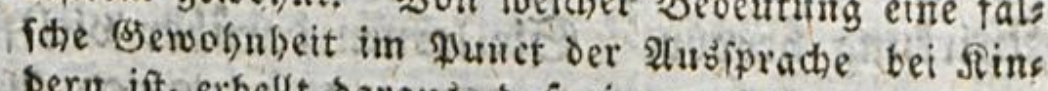

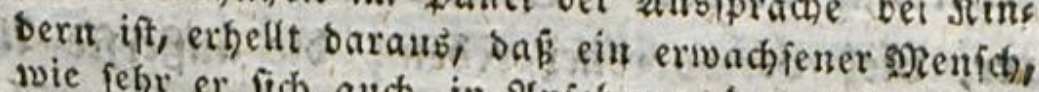

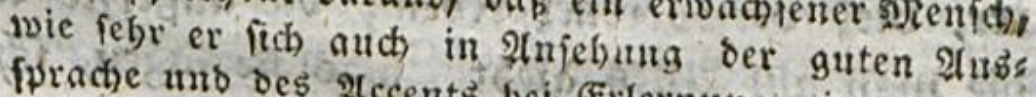
fprache amb bes 2lccents bel Erlernung einer frem ben Sprache úbt, bod fait uie es bavin bis jur \$ुous beit auf reben gelernt babent. Sprache von Sinds

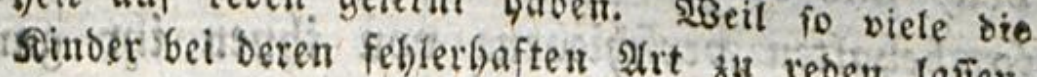
ober wol gar mit febterbaft nadipreden: fo reden baher einige faft erivadfene sainglinge uno Nábs then fo ichlecht. Sian fraucht tibrigens gar nidit angfticí) gegen bas fefletbafte Reben zu wadhen. Seur mú man es nicht unbemerft bingehen lafien. Eeichiebt bies nicht unt ipritht man mit einem liebs reichen Ssefen riditig vor oder nach, toenn ein Jinb fehlt, fo reset ein Sind bald rixhtiger. Sith habe bas-bei meinen uno aubern Sindern gnug erfabren, fo wie ich auch B̧eifpiele gung weiń, ba, wenn man bie sinder bei ibrer fabjoen 2rt at fpreden gelals

iets 
ridgtig it ifgrev (S)gennart; betragt end saf́ eg ighuen bei niemano anbers fo wohl ges

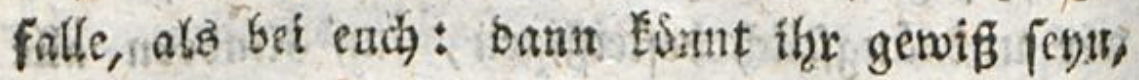
ifre Spradje toiro fich unveruertet nad oer eus sigen lautern, battet thr fie auth nie baruber geneifrent:

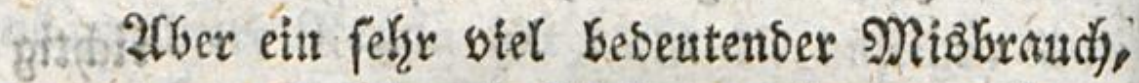
uno bem man eben fo leidyt zubortommen tann,

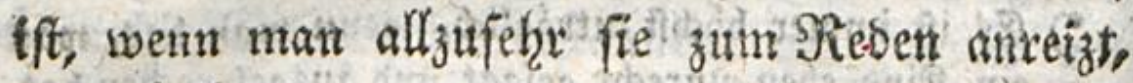
als furchtete man, fie rwirben eb oon feltift nidyt lernet. Diefe unborfid)tige (S)efdadftigfeit fringt eine bet gefuctiten flang entgegengejergte S3irtung hersor. Sie lemen bariber viel fpas ter, biet berworrener reden; Die aufferfte 2f djt, bie that auf 20 les giebt, was fie fagen, fd aft,

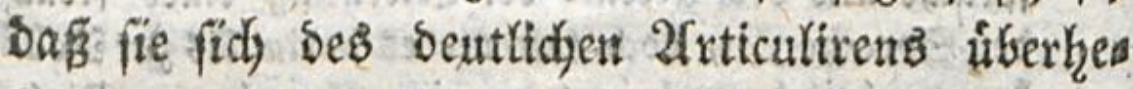
ben, und ba fie tam ben 9Mund offien mogen,

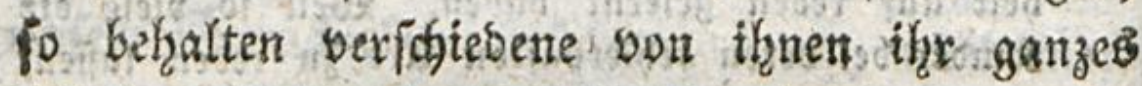

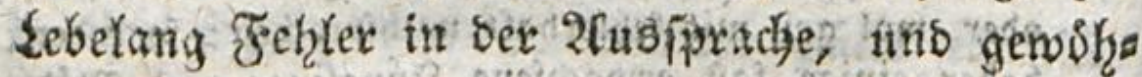
nen fic) eit Sthattern an, Das fie faft un sexftánolids macht.

fen bat, fie oft nie gut einer leidhten ung biegfamen \&uड़prache fornmen.

Erlers. Cantpe Tefervis.

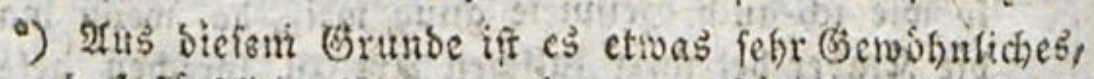

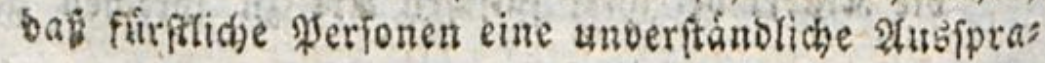




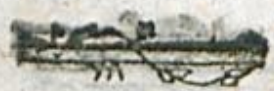

25 주

10.

ges

()15;

eits

ber

lins

(cib)

$\mathrm{nm}_{\text {, }}$

iats,

ibfi:

Eeit

grte

pis

its.

ift,

bes.

ettp

ze⿰3

$3 \mathrm{~h}=$

$m=$

รั.4.

Iet

$e^{3}$,

ras

(4)

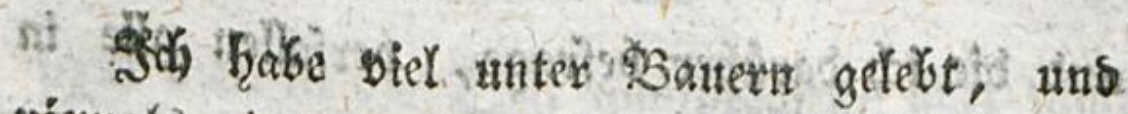

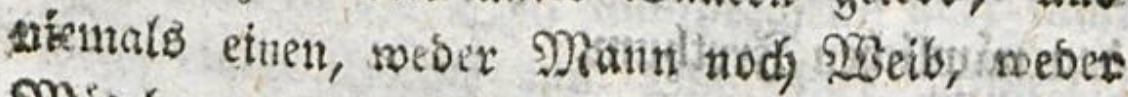

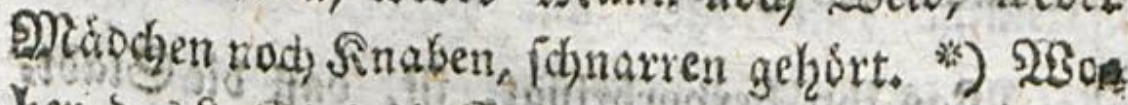
ber bas? (Eins sie Sprachmertzerge ber Sauerm anders befdaffen, als bie unfrtgen? Shein, abex fie merben anders geibt. S3or meinem fenfter. tof ein Crobiger, auf weldiem fir bie Sinoex bes Sits zum Spielen berfammler. Sb jie gleid, ziemlich weit bon mir entfernt find, fo

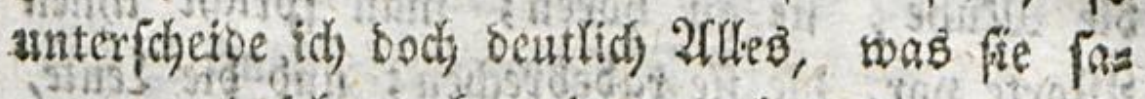
gen uno ich merte mix monches saraus fút Diefe Edrift. Zaghte taurd mein SShr mich Libex the atter. of hore finderftmmen bou sehn Sabren, Febe binans, uns erblicke Sinser,

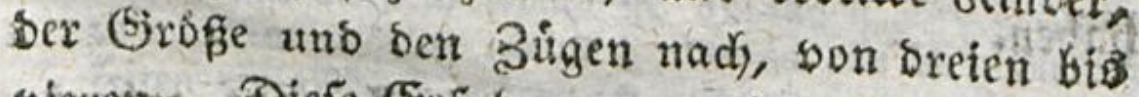
vierentm Diefe (Evfahrung madye id nicht fur unidy allein; Stawtbenohner, bie mich befucken,

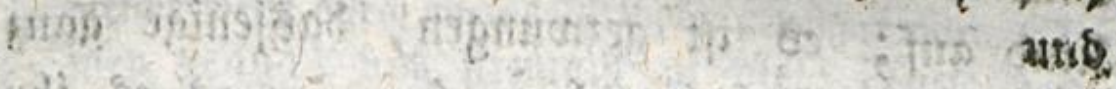

6he baben. Man foberbebt fie in ber Sinbheit uns

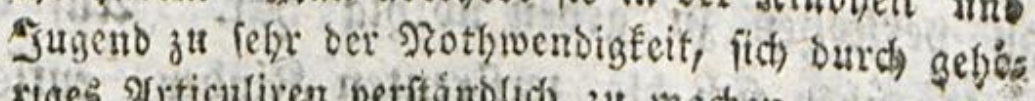
riges articuliver berftánolich ju machen.

Eampe. Refervis.

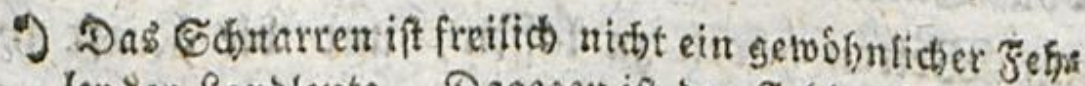
ler ber faubleute. Dagegen ift ber febler bei ifners

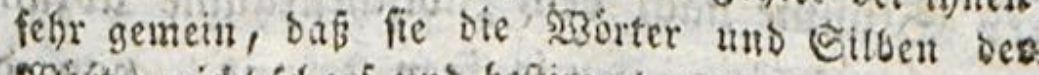

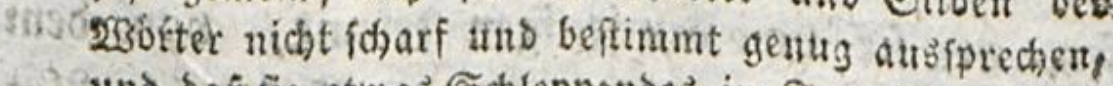
und bas fie etwas ๔ableppendeb im ฐon baben.

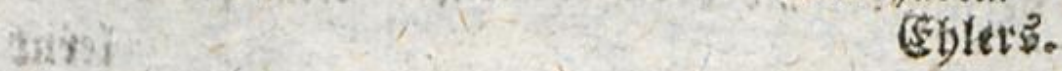




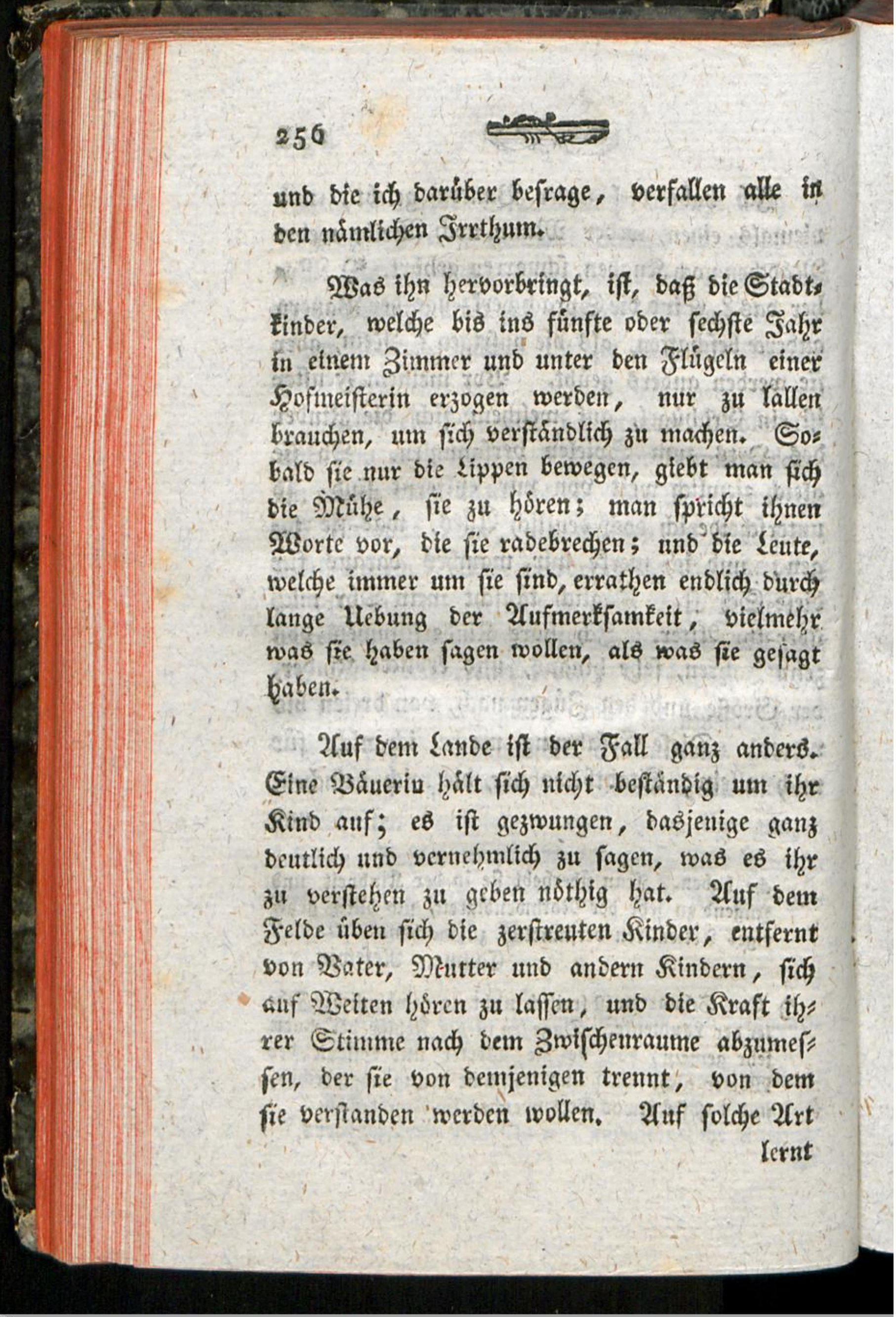




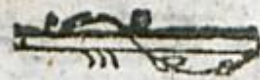

lexnt man in ber. That ausfpredjen, aber nicit,

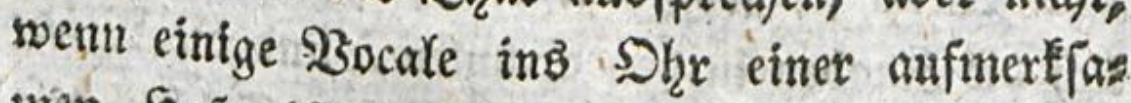
tmen Syofmeifterin geftanmelt werben. Fragt man audy ein Bauentind um etrons, fo tant vielleidjt bie Sdjuchternheit es wexhindern, zil antworten; wab̉ es aber fagt, fagt eв beutlidy; anftatt, Daß die Ma ßounne Dem Staotétnoe zur Dollmetfcherin bienen muf, wenn man etc suas bon bem ḩoren foll, was ę zwijhthen feif sen 3åfįnen hermummelt. ${ }^{*}$ *)

WBent

7) Dies ift niøt ofine StuBnahme. Sftmals betáuben eis nen bie Sinder, bie fich anfangs am wenigften hobren liefen, am meiften, fobald fie anfangen ifre Etimme fut erheben. Gollte id mich aber in alle biefe fileinigs feiten, eintaffen, to lotirbe id nicht fertig werben; icber pernuinftige Sejer muß 9)isbrautite entftanbene Hebermábige und Nangethaite, gleiderweife burch meise Methobe gebefiert wirb. Im* mel genug! uno niemals ju piel! Diefe beiden

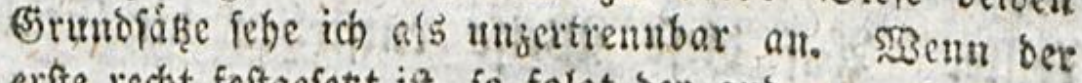
erfie recht feftgefeţt if to folgt ber andere nothiwendig Daratts.

D. Berf.

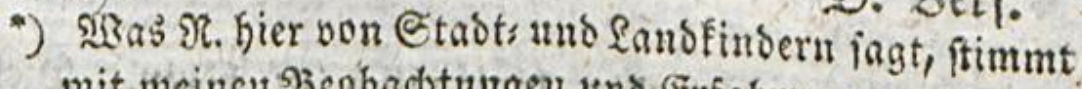
mit-meinen 3 cobadsturgen un Erfabrungen nidst ges mutg tiborein. Das Febferbafte, was bier $\Re$. StabtEfins

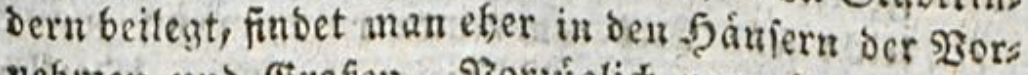

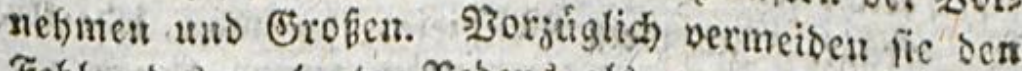
Fefler bes zu lauten Necbens als etroas llngefiemens Des, fo fefr, bafi fie viel zu leife reber und bafinan

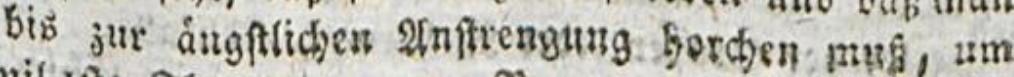

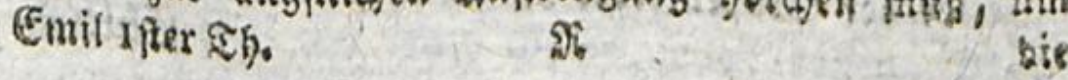




\section{8}

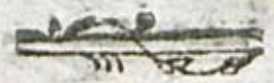

SzEenn fie groffer wersen, follten fid frets lidy sie Fnaben in ben Sitjuten, uno die Mias, dyen in ibren Rlsftern bon biefem Fohler befs ferm. 28 inteltity auth fprechen jene und biefe, úberhaupt genomnen, Dẹtlicher, als biejenigen, bie immer in bem baterlidyen Saurfe erzogen morben find, 2liser, was fie berhintoert, jes marbु zu einer fo toentlidyent 2fubfprache zu ges

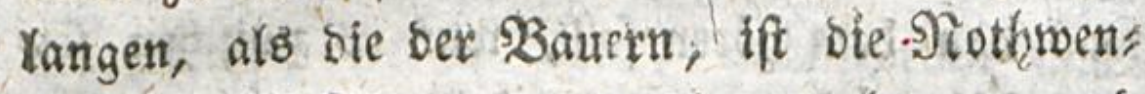
sigkeit, biel Dinge auswendig za lernen, uno bas, was fie gelernt haben, laut herzufagen. Denn bei bem Eernen gewsihnen fie fich an, bax

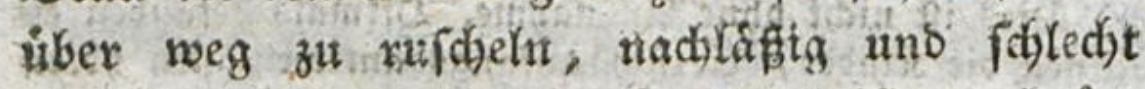

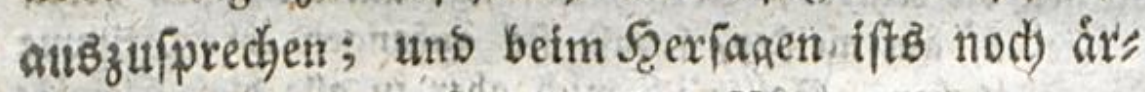

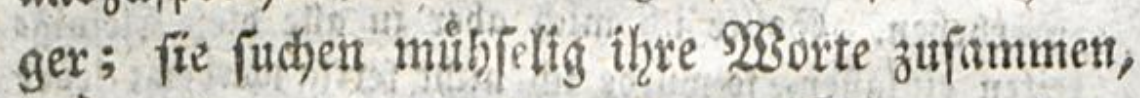
umb ziełgen uno berlángesn ihre Silben : Denn

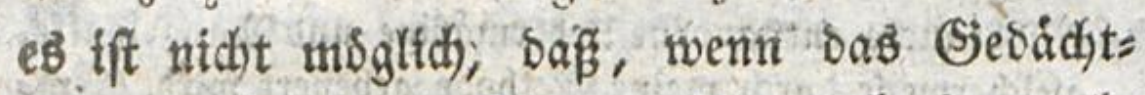
niß̧ wanket, bie sânge nidjt aud ftammeln

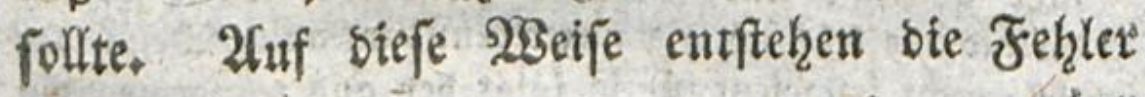

Sie sizorte min eben hinlánglich za horen. Diefer Fehler wirb befto eher febr láftig, weil es auth. leicht febe tibel genommen woiro, wenn man nads frágt. Эch weis গ̧eifpiele, oa man iebe Hnterres bung mit vornehunen ober hohen Perionen aus bem Gruthe foraffitig vermieben hat. Won biefem Jehy ler ber stopert rebet Ningernach ebenfalls.

Ëblers. 


\section{9}

ber 2 uspprache, uns werben beibehaltet. *)

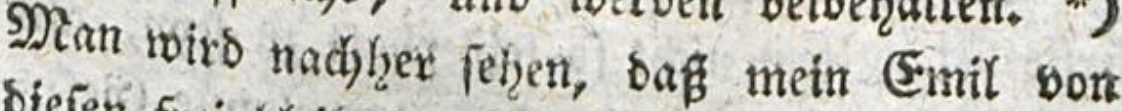
biefen frei bleiben, ober baj er fie zum wenign ften nidjt aus benfelben Urijachen angenommen baben toirs.

Sith gebe za, bas Solle uns bie Dorfbeo wof̧ner verfallen it cinen entgegengefercten Fehs ler; fie fpredyen fait immer lauter, als fie folls. ten; indem fie allzubeutlich *) ansipprechen, bुas

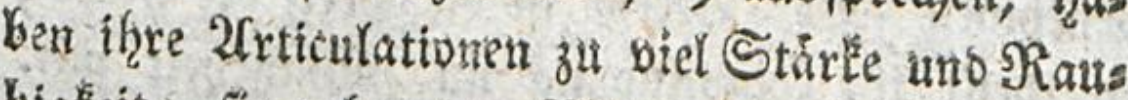
higkeit; fie geben ben 236 brtern zu biel 2fccent: fie wáblen thre 201

\section{$\Omega_{2}$}

24

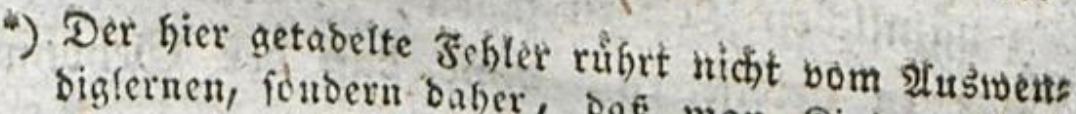
Digleinen, fonbern baher, dafi man Sinder basier nige, lwas fie auswendig lernen follen, nicht vorber gut lefen und ausfprechen lebrt. 2lus biefer urfache fagen Sinder, bie in follechten Schulen etwab auss wendig fernen; bas 2 tusivendiggelernte fo fefr foledst

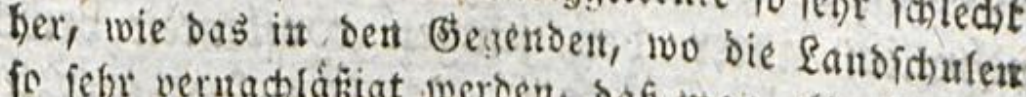
fo lefr veruablabiat werden, bas man alte snualis bet und Salndwerfer, die nod gern etiwas Schuls geto nebentyer verbienet wollen, zu Schntmeiftert macht, vorguglich háufig gefunben wiro.

-) Das \{uzubeutlichauspreden habe ich nirgends auf bein Rande gefunder. Daf fie aber oft gar zu laut reden und mit einer geivilien Niaukeit háuñg ben \$on zu rebr auf eine Sylbe falien lafien, wabe ich háufig gefunden. 


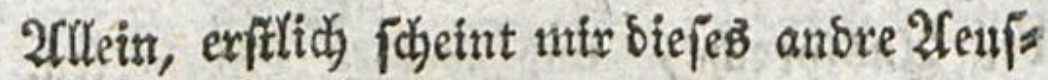
ferfte bei meitem nicht fo febjlerţaft zu fesn, alb bas exfte; fintemal, da sas vornefrmfte Siefes ber Rebe iff, fich Derftandich zu madjen, teitt grwfferer Feb̧lex geoad)t werben tann, alह zи

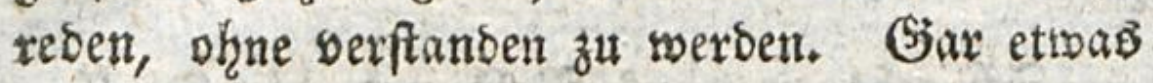
sarit fuchet, baß man Eeinen 2 acent f̧abe, Heifft etroas barin fudjen, Dafi man ben కḩeis Yen feiner SRebe ifre 2trmuth uno thre Rraft benefyrie. Der Wccent ift bie Seele ber Rebe;

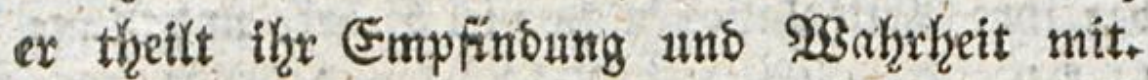
Der 2Uccent lúgt weniger, ats die Rebe; viets reich)t firrchten ebendebirwegen bie wohlerzogenen

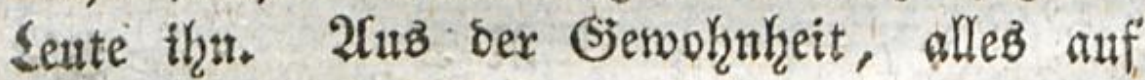
sen namlidjen Ion zu fagen, ift benn audj bie

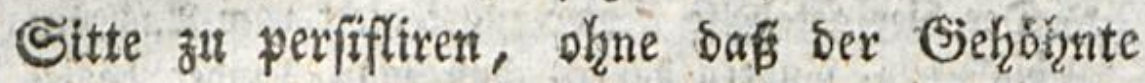
es mert, entfanden. 2 uf ben berbinnten $2{ }_{c=}$ cent folgen Yäberlidie, gezierte, und ber Mlobe unterworfene 2frten zu reben, wie man fie vors netzmlid unter ben jungen Sopfleuten bemert. Dieje Bitererei im Reben uno im 2 Betragen ift

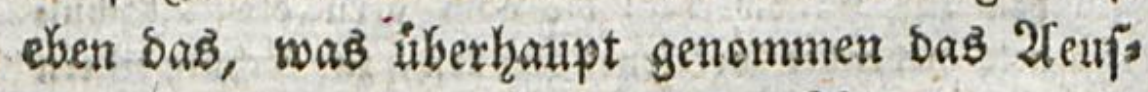
fere bes Franzofen, beim exften 2luftritte, an sern STationen fo wiberwartig uno unangenehn madjt. 2Unfatt 2lccent in feine Siede zu les gen, Yegt ex 2lir bुinein. Das iff nidjt bas 


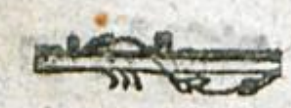

261

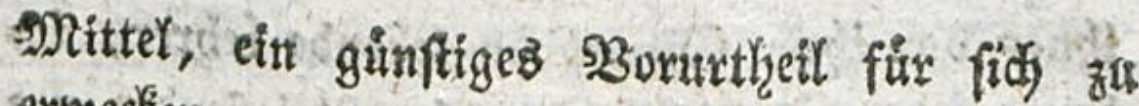
erwedten.

2llle bie fletnen Spradjfehter, von bent

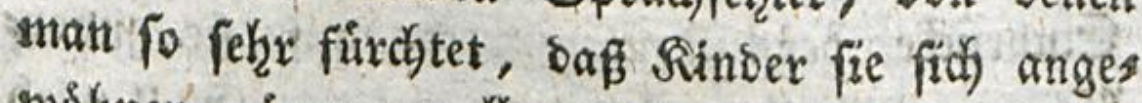
wofthen mógen, wollen nidjt biel fagen; wan Hommt ifgnen mit gróster Seidytigfeit zuvor, ober serbeffert fie: aber bon benenfenigen, an benen man felbft bei fhnen Sdjuld wiro, inbem man unablaffig thren Son meiftert, uns immex an allen if̧ren 28 orten máfe!t, son ben sumpfen,

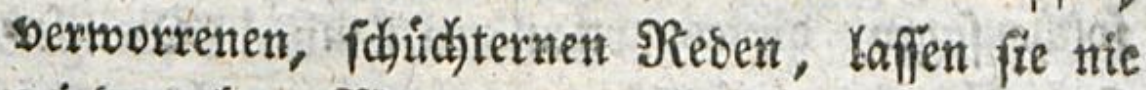
sieber ab. S2Bex nut in Sdjtafzimmern reden gelernt hat, befien Stimme wiro fid an dex Spirge eines Batafllons fod)ledyt ausnef̧ment; uno bem 30 blte bet einem 2tuflaufe tein Sttlle fámeigen gebieten. Lehrnt dic Rinder nux erff,

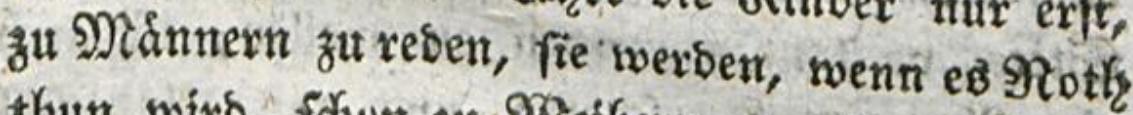
thun wirb, fodjon zu 28 eibern zu reben wiffen.

2uf bem Lande in alle bem trinslicijen Sauterleben erzogen, swerben eure Rinber eitre seit tonendere Stimme befommen; fie sotbent nidjts bon bem berworrenen Stammeln ber Stabtfinder an fidy thehimen; fie werben baruth eben auth noch. nicht bie Dorfiribensarten, beh Dorfton fich zu eigen madyen; obey ikn wentgr ftens Yeidyt mieser sexlernen, wenn ser bort mit

$\Re 3$

ifnen 


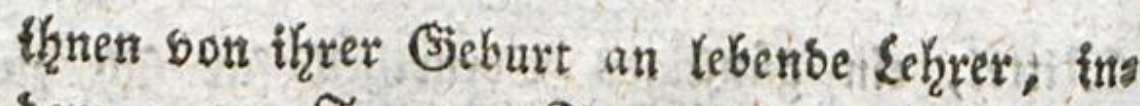
bem ex von Tage zu Jage ausflitefenter un fie ift, Durdy Die Ret igkeit feiner Spradje bem Eintrude oex Baucrnipradje alf fie zubor: ¥ommt, ober tha wieder abidsleit. Emit miro

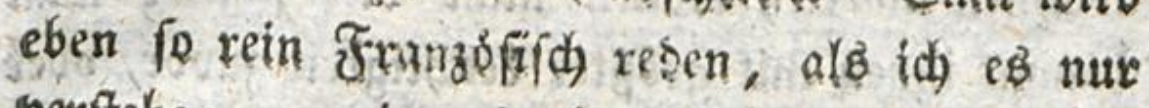
berftehe; ex nizo ea aber piet oentlicher auba fpreduen, und nod, weit beffer articutiren, ałB idf).

Das Rino, weldes reden mill, muf nur foldhe 23örter bóren, die es verftehen, uno nux foldse fagen, bie eg articuliten finn, Die 2fm ftrengung, bie cs fich bazu gicbt, madistes ges steigt, einerlei Silben zu verooppeln, gleichfam

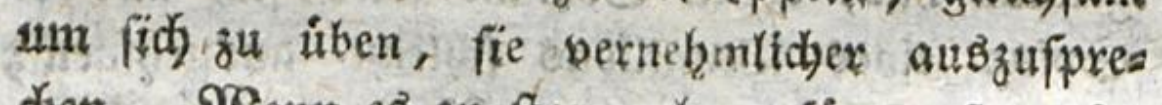

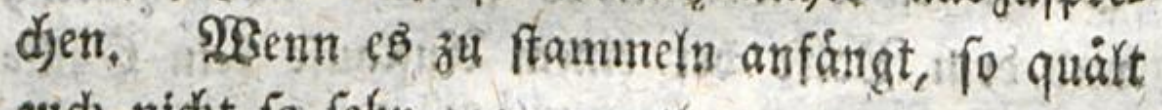
eud)-nicht fo fefre, zu erratben, was es fage. Stete perfianden weronn au wollen, if aud - eine 2frt ogn Seerrichaft; uno bas Rino foll

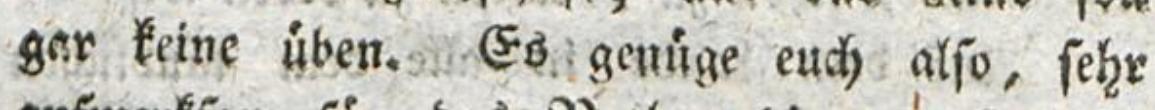
aufmertian für, oas शiothwendige zu forgen;

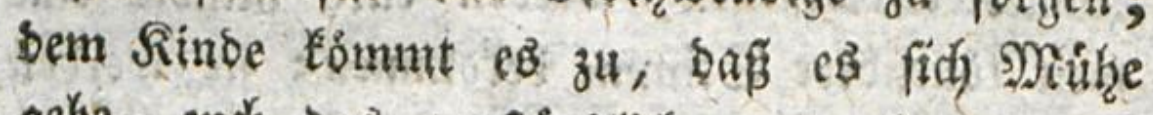
gebe, euch bas berfínblid) zu tmadjen, was

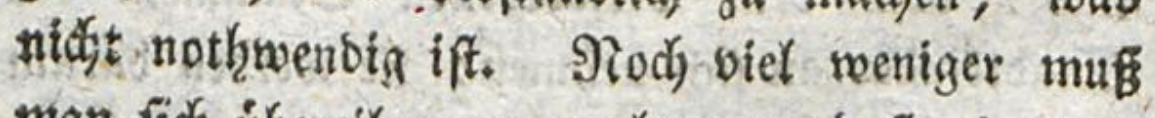
man lidd) íbereilen, zu bertangen, baf ez rebe; eb wirb fódon son felbit zu reben wifien, nad)

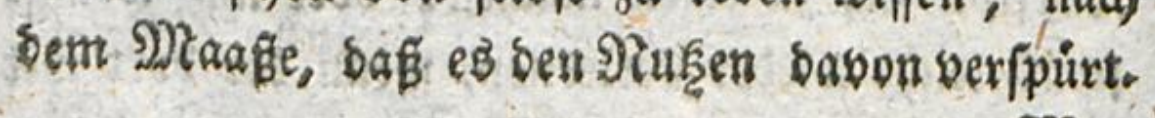

Mtan 


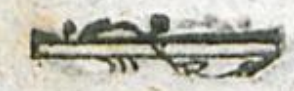

Man bementt freilid, baß biejentgen, sie felcy fpat aufaigen resen za Yernen, niemals fo beutlich reoen, als bie andern, aber nidbt, weil fie fipat gerebt haben, ift ibre Srgain unbehilfflid, fonbert vielmeḩv, weil fie mit einem unbebilftichen SDra gane gebohren worben fino, baber fie fpat ans gefangen reoen zu lernen; Denn warnin follten fie fonft pater alb andere anfongen zù reben? Şa ben fie wenther (S) legenheit bazu, uno reizt man fie nidjt fo fehr an, alb andre? Sexabe bas Siegentheil! Die Unruhe, Die bierex Şerzing azs wedt, fobals man feiner gewaht woird, madht, Dafi man fich viel mebr qualt, fie ftammeln gu laffen, als biejenigen, bie fruber articulirt bras

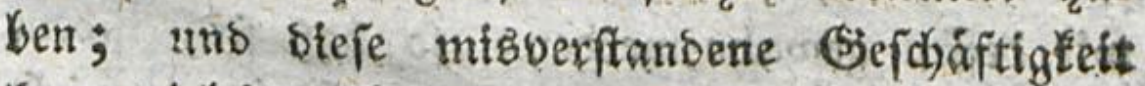
tann biel bazu beitragen, iht ßieben nod werwors rener zu madjen, bas fie, minber ibereilt, bie వెeit

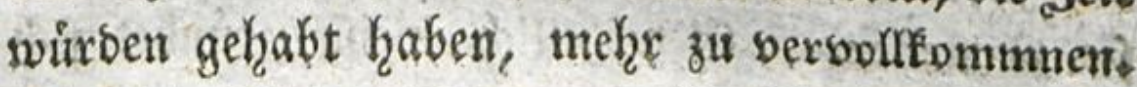

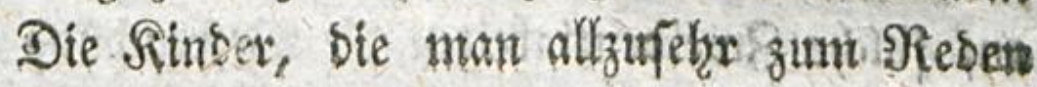
antreibt, haben teine Beit, bas, was man fie fas

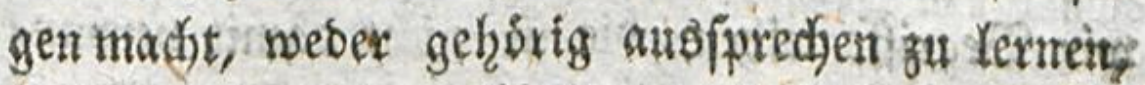
noch) gut einzujeţen, Låf̆t man fie Kingegen ibrest

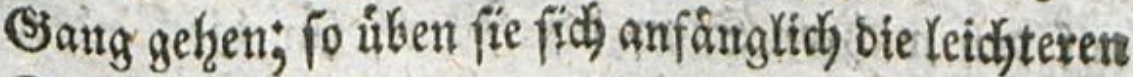
Silben ausizufprechen, uno verbinden samit irs gens eine Bebeutung, Sie man burdy if̧re (Ses

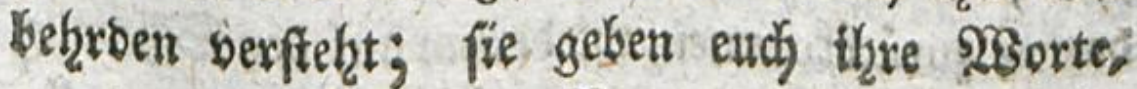
श 4

etie 


\section{4}

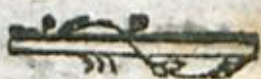

the fie bie eutigen empfanget. Die Folge babon ift, baf́f fie albbann oteje nux empfangen, nachbem fie fie woblt oerftanden haben; sa nidjt the fie gebrungen wiro, fich ihrer zu bedienen, fo fangen fie bamit an, wobli zu bemerten, was the ifgnen firt einen Sinn beilegt, uno wenn fie sason genoifi fins, mehmen fie fie an.

Das grofite, mit ber Hebereilung, wonit man bie Rinber bor bein geţorfgen 2flter zun Reben antref6t, verbunone llebel, ift nidyt, bafi die erften Siefpráche, Die man an fie richtet, uno bie erften 2 Sorte, die fie fagen, Heinen Sinn für fie haben; fonbern, baf́f fie einen antern Sinn als ben unfrigen haben, ohne baff soir beffen gewahr werden; fo bafí fie, insem fie nub ganz genau zu antworten foheinen, wirks Itch) zu uns reben, obne oaff fie uns, und wie

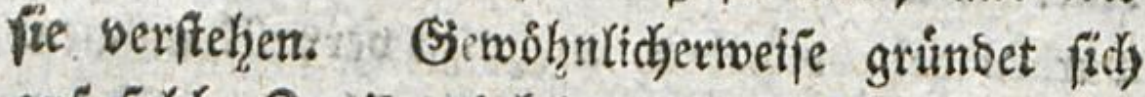
auf foldhe Brocibentiaḱeiten bie Befremoung, it be uns Gisweilen ifgre Einfálle fergen, Denen wir Beariffe leihen, bie fie nidht bamit werbuns

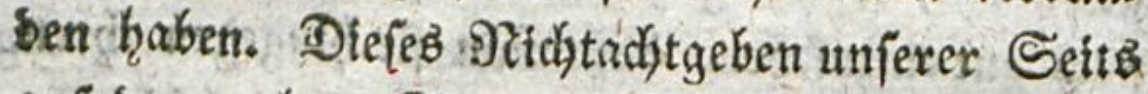
auf ben wahken Sinn ber 28 orte für bie Rinber; flyeint mir bie erfte Uriad)e ihree Srrthumer zu

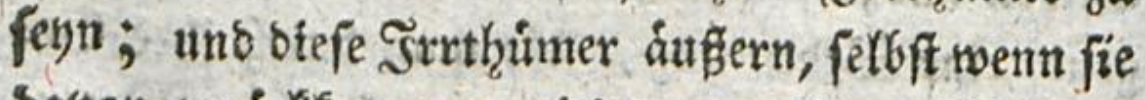
sagon zuxiditomonen, soiebexum auf ben Sijwung 


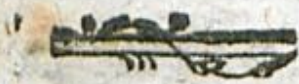

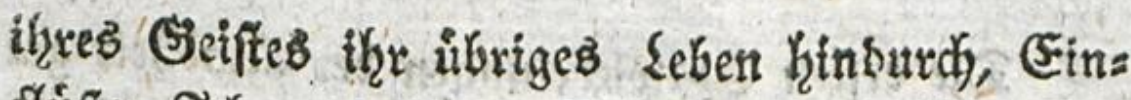

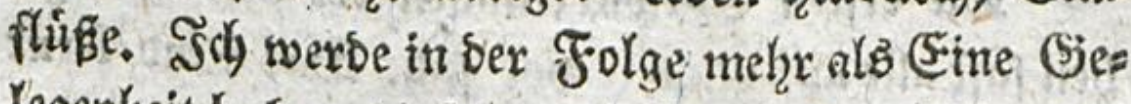

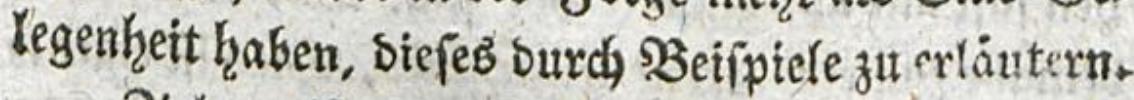
3ieht alpo bas 2 sosuterbudy des Simb of fo

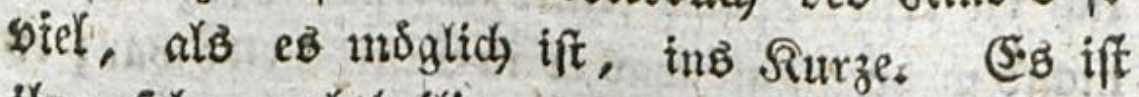

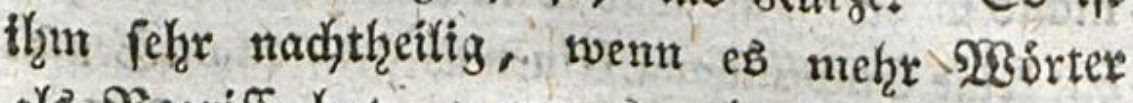
alb-Begriffe hat, wenn ç melhr Sachen fagen,

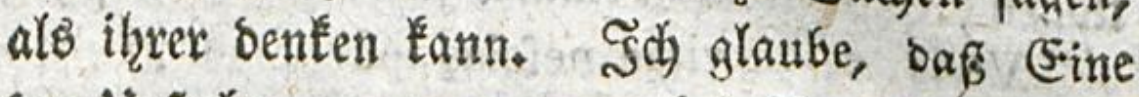
Der Lriacten, warunt man bei Bautern gemein Kin mehre Mntterwi als bei Stabtleuten findet,

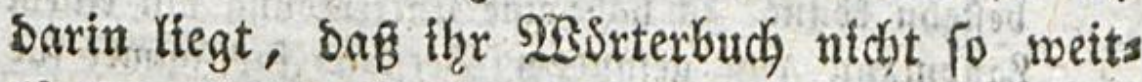
Yauftig iff. *). Sie haben wenig \$egriffe, aber fie

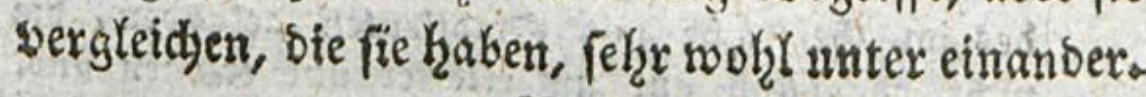

\section{$\Re 5$}

Die

2) ES ift bie פ̧emerfung von $\Re$. pehr ridhtig, Daf Eandleute, bie nicht in Sflaberei und Leibeigenfthaft reben, weit mebrern geiunden Derftand unb Nutterwits in ibren urtbeifen und Reben zeigen, als Stabtleute? wie vornebm diefe audh thun. Die Hriache liegt: aber nitht darin, baf ber Lanbleute 230 orterbuch weniger

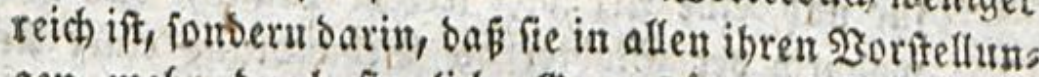
gen mefr burth finnliche Stegenftánde und finntiche Jandlungen geleitet werben, mit. SBbitern und ges Sensarten, die jene Porftellungen ausorúdfen, Den Binn berfelben richtiger verbinben und aus báufigen Erfabrungen and গुeobacbtungen richtiger abftrabiren. Die Stábter boren bagegen vor vielen Dingen reben, Davon fie nichts feben und erfabren. Shre Şorftellungen find alpo oft unbollfommen oder falich und ifore riebe ift oft ein leeres (jeflingel. So falich ift eb, wenn

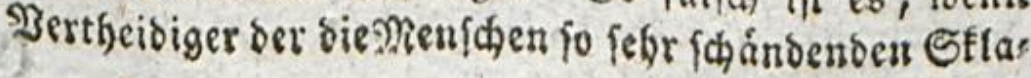




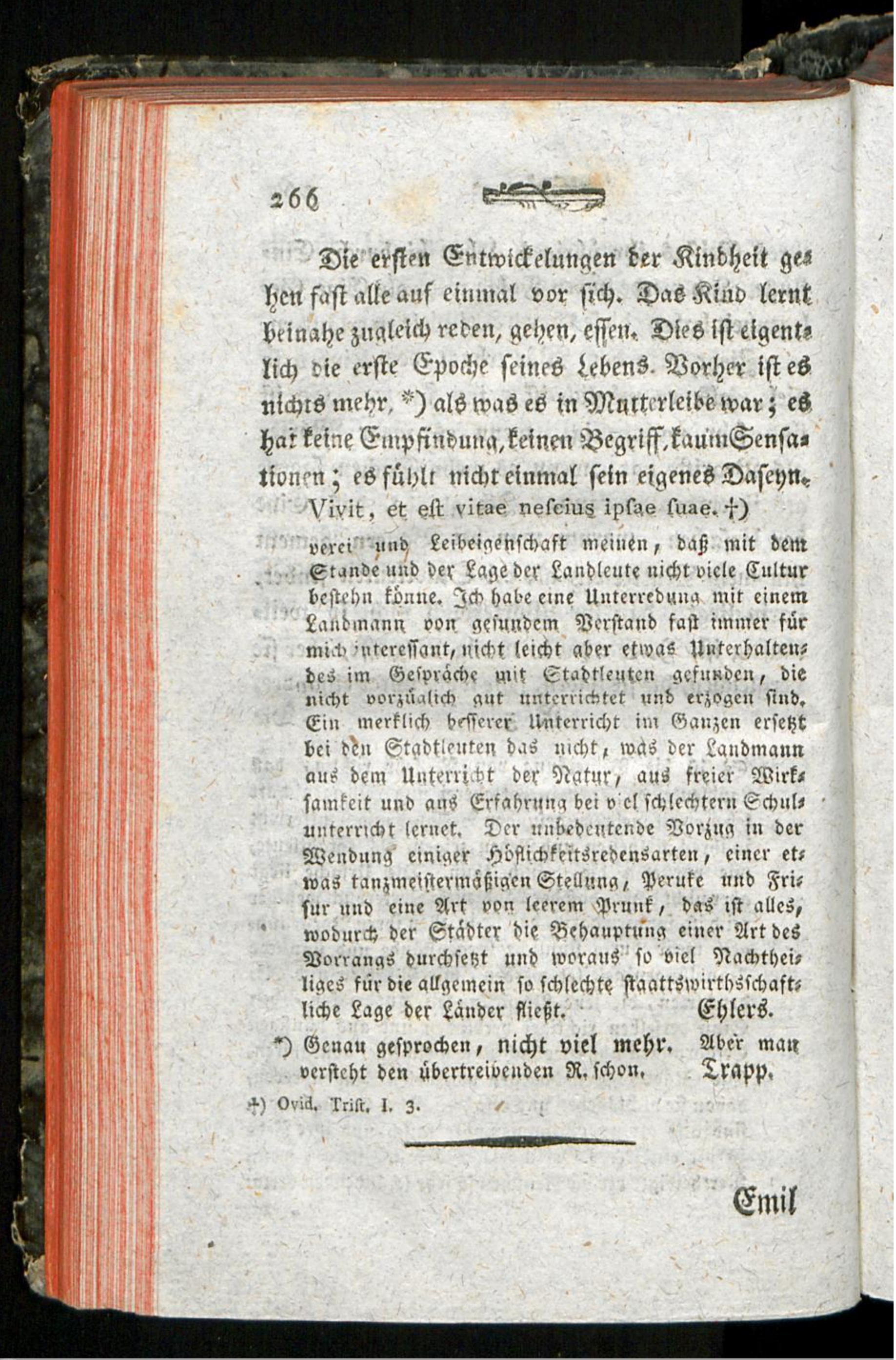




$$
\text { (5: } \operatorname{mil}_{\text {ober }} i
$$

liber bie Ergiebung.

$$
3 \text { weites } 3 u d \%
$$




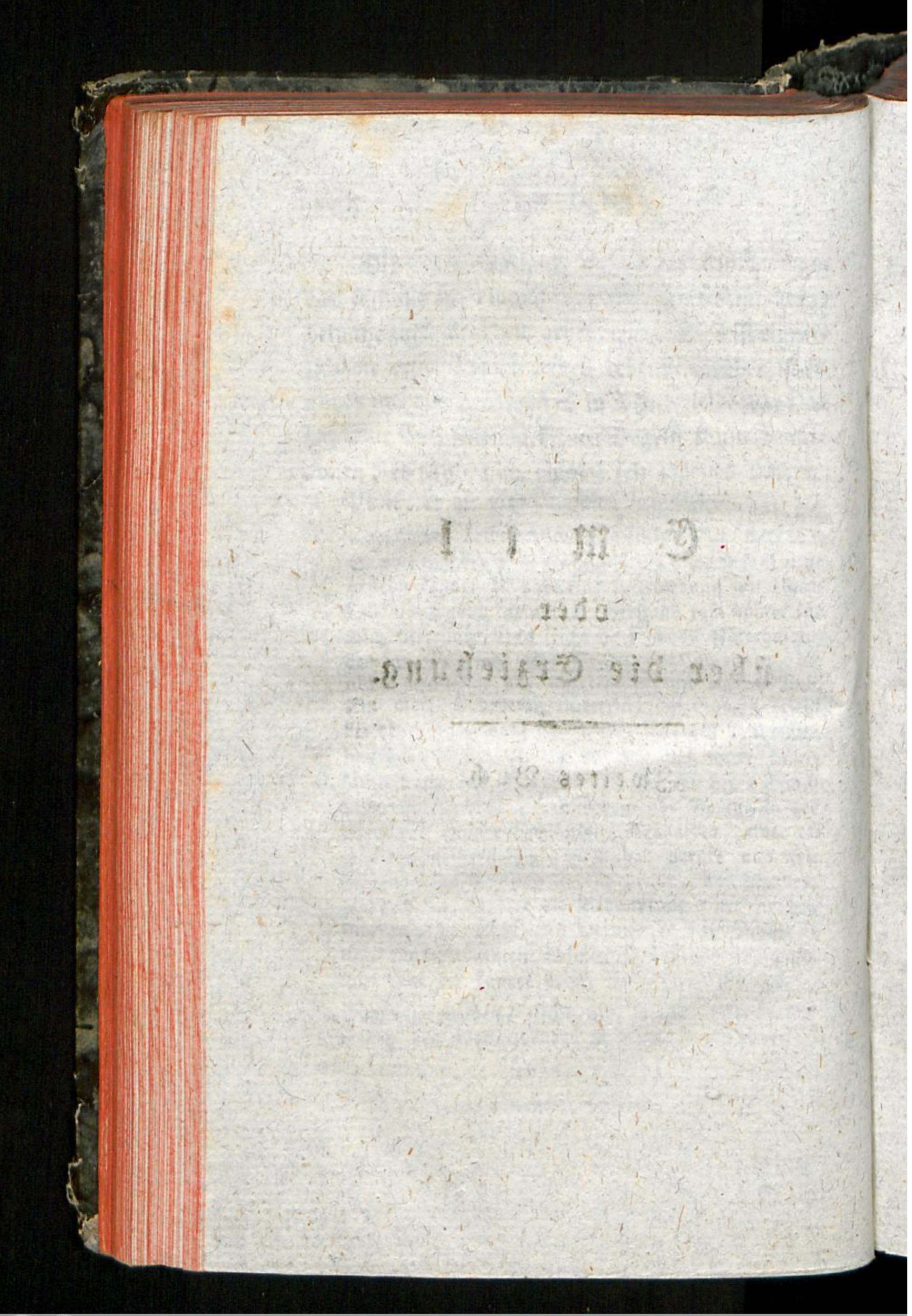




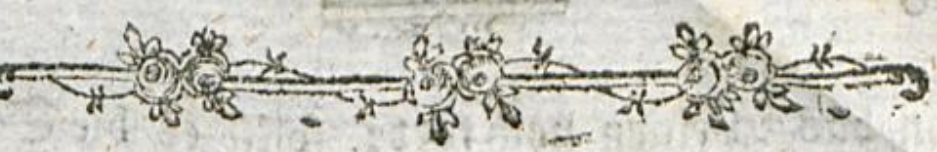

S) iv Lommen zum zweiten Şrânzpuncte bes Eebens. Sgier enbigt fich eigentlich bie Rindfyeit (enfance); benn bie 2 sisnter Infans and Puer: find nid)t gleidjbebeutent. Eifferes ift in Yersterem enthalten, und bezeidynet wer noch) nicht redent fann; baher man in Yerius Maxinus puerum infantem firset.

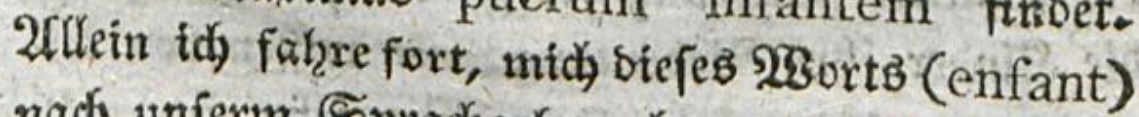
nadh unferm Spradigebraudje zu besienen, Gis zu bem 20lter, fir weldyes wir andre giamen haben.

STSenn bie Sitnber zu resen anfangen, wets seen fie weniger. Defeer Fortichritt ift natur. lidj; eine Spracte tritt an bie Stelle ber ano

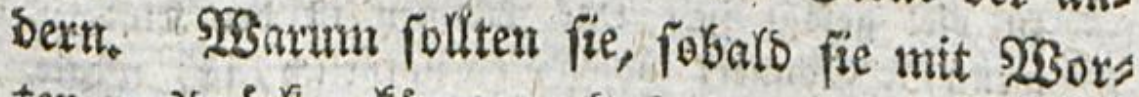

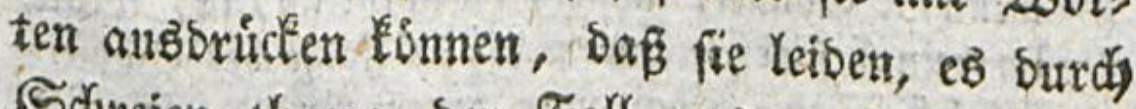
Stypeien thun; ben Fall, aus̉genominen, bafi

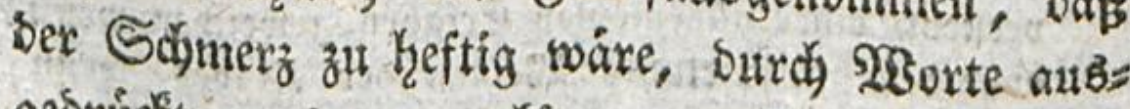

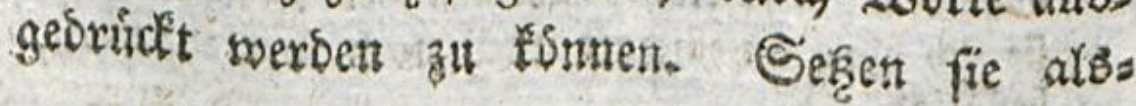
bann 


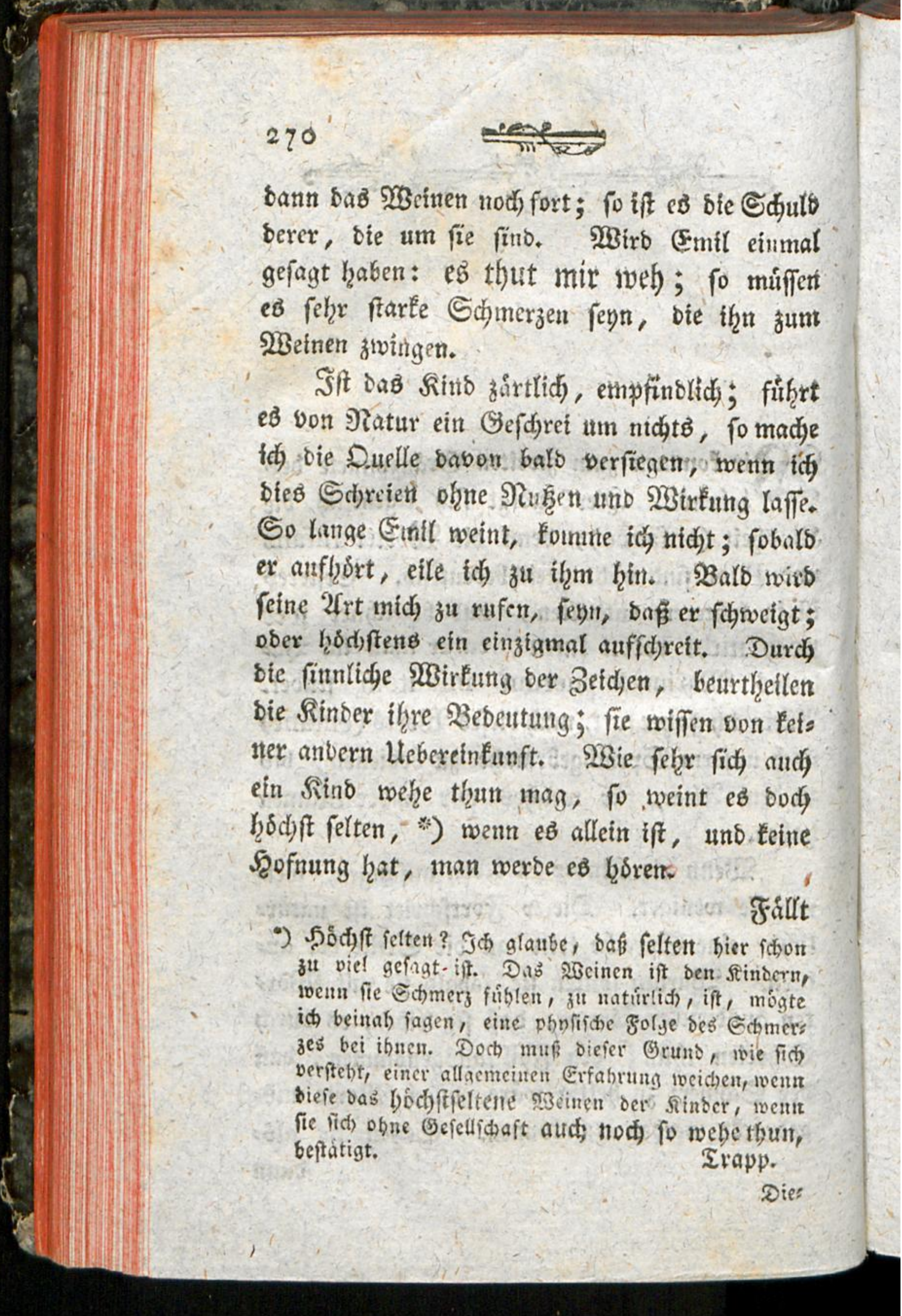




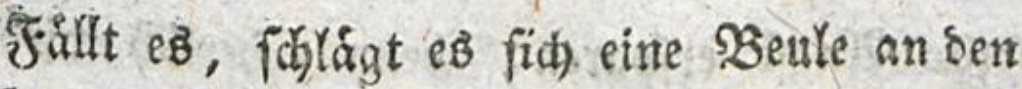
Ropf, madjt es fich sie Slafe blutig, founetoet (es) fich in ben Finger: anftatt mit cinem bes fturgten 23 ejen zu ibm zu eilen, werie ith midj, wenigftens eine $\mathfrak{t u r z e}_{2}$ geile, fillle berbalten. Das Lebel ift gefdefien; Die Nothwentigteit bringt es mit fich, oafß es ausigefzalten werbe; meine ganze Sjefoúftiaftit wurbe das Sind nur mebr enfdyredien, uno feine (Empfindlidbleit bers mebren. Sin Grunde qualt uns, menn wir

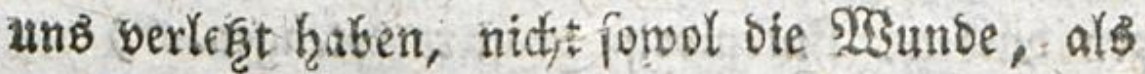

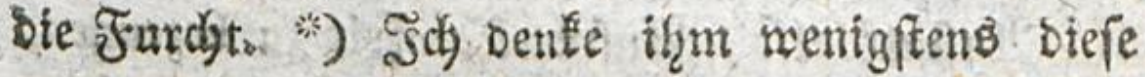

Diefe Erfabrung habe ich oft zu mactien (s): regentyeit gehabt, tubem id) fahe, dap Rinder aber freifich folctse, bie man ourch gar zu ángiftiche Bewachung vor S(haben jeber 2irt noch nicht angit: lich und futrchtiain gemacht batte - fich ourch fals

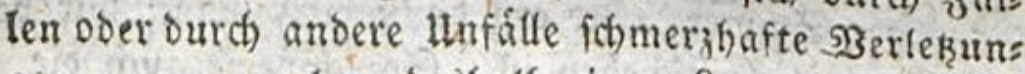
gen zirogen, obne beshalb einen laut oon fith zu

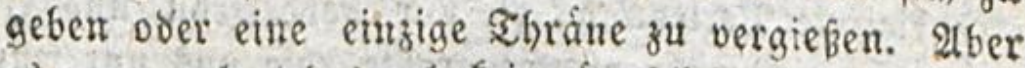
es war auth tebesimal fein ángftlich bejorgter Fr= toachfener zugeaen, welcher Daruber in Sुepturzung gerieth uno zuprang, um ifmen Şulfe ju leiften. (ES ift unglaublich, wie viel foldhe Siutper ertragen

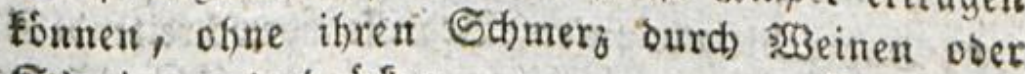
Schreien auszubrúcten

Eampe.

") Srlie febr forverliche Shmerzen ourch die Einbils Dumgsfraft verftartit werden fonuen, das erfellet uns ter anbern aus folgender Erfalorung, die mol Jes Dere 


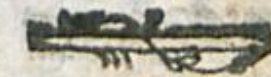

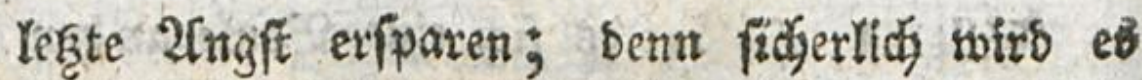
uber feinen Shaben urtheilen, wie id baruber urtbeile. Sieht es midy befturgt herzulaufen, eô troften, es betlagen; fo wiro es glauben

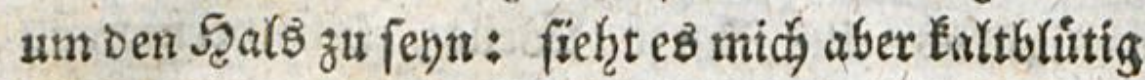
bleiben, fo miro es fich auch burlo nieber faffen, uno ben Sibaben für geheilt halten, fobalo es. ihn nidht weiter fühlt. Die exfter Eehren ber Sherzartiglett werden uns in biefem 2lter: wir rernen, inoem wix ofne Sdyrecten leidjte Sdymers zen oulben, ftufenweife grofiere extragen. *)

Inftatt alio, 2lufmertiamieit zu bezengen;

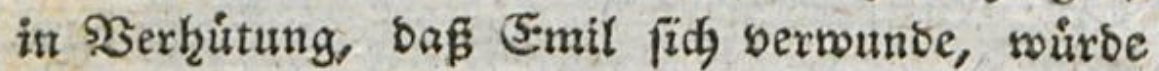

Derman an fich felbit gemacht bat. SBenn man fich unveriehens verivundet, ober von andern verivundet svirb, fo pfleat man in bem 2Augenblicfe, oa bas

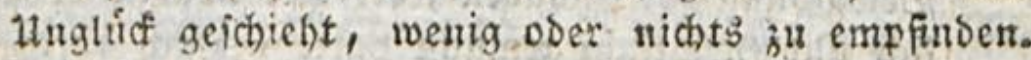
Der Schmerz tritt erft Dann ein, roam wir bemers Fen, was gefchehent iff. So fotmerzt auch bie aller: Fleinfte Serlę̧utg, bie wir vorheriehn uno erwars ten, vicl mehr als bie gróste, bie uns «thermuthet angethan wirb. Es ift alio Erfahrung, baß Stors perichmerzen ourch bie \$orftellungen ber Ceele ves: gróbert werben.

Eampe.

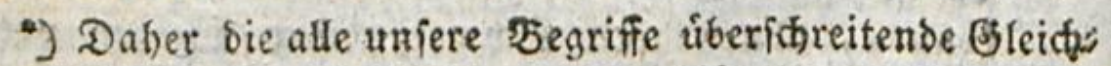
gúltigfeit, loomit bie norbamerifanifchen Snbianer, weur fie von ifren Heberwindern zu Tobe gequalt werben, bie allergraufampten Martern ertragen. Diefe Seute funo in ifrer Sintheit, wenn fie fich verleşs ten, von zátlid)en Nuittern gervis nidt fo beflad morben, toie wir.

Campe. 


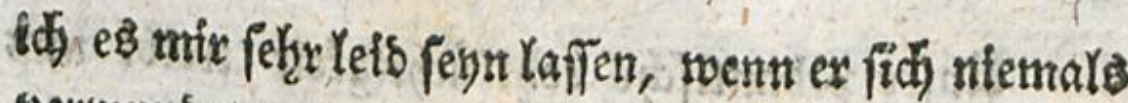
vermunbete, uno aufwiddfe, ohne Sijmetz zu erfahren. Seiben ift Das Erfte, was ex lernen

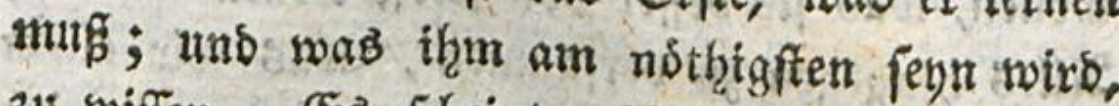
zut wiffen. Fs fojeint, bie Sinber feven nux barum flein und fdrwach, bamit fïe ohne Ges fafer bieje wichtigen \{ehwen erkalten migen. Feallt bas Rino feiner lange lang nieber, fo wiro es

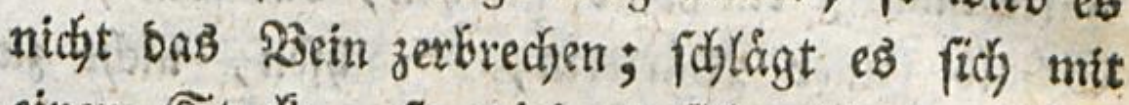
einem Stode, , fo wirb es fid nidyt ben 2 rim

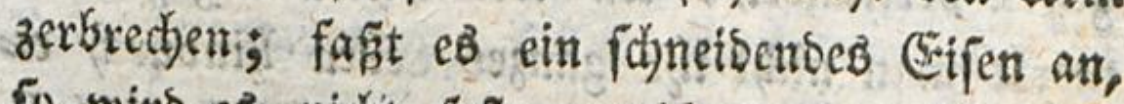
fo wiro es nidfit feit zugreifen, uno fich nicht

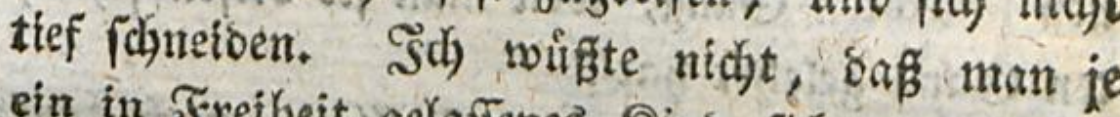
ein in Freikeit gelaffenes Rino fich wmbringen,

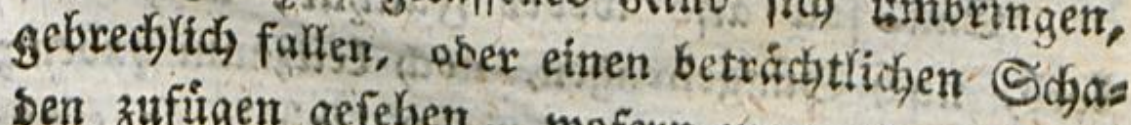
Den zufugen gefehen, wofern than es nidjt ume oorfidtiger Nisetfe an haben Sextern, ober am

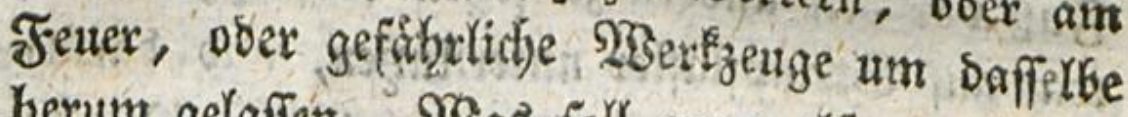
herum gelaffen. 2 gab foll man aho bon affem bem Utmwefen won 3uriftungen fagen, womit sir bie Sinder gegen ben Sctumerz bewafnen, ber fie nun, etwadjfen, ofgne Nuth uno ohne $\mathrm{F}_{n}$ fahrumg, fifts felbit liberlapen, treffen wirs, fo

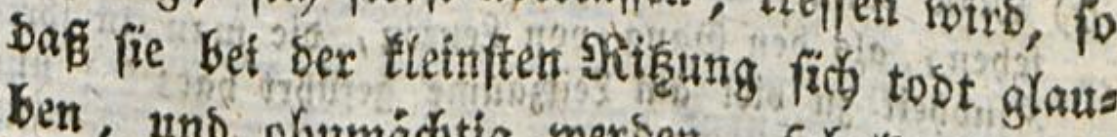
ben, uns obumáditig mexsen, fobals fie ben exften 8 Shutotrapfen fehm.

Emil. Ifer E⿱⺊.

Utue 


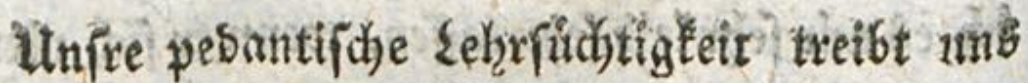
fets, ble Sinber in 2(llem *) unterridenten $z^{\text {th }}$ wollen, nas fie beffer yon felbit lemen wirbet; 2Ales ḩingegen z̆ berjăunten, was wir alletn

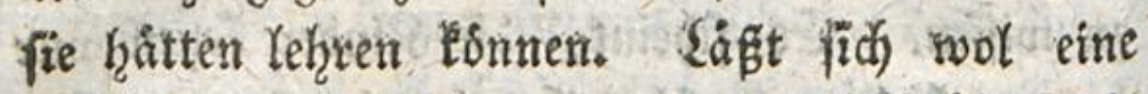
grofsere Ihorheit gebenten, wie bie Mithe, bie wir uns geben, fie geh̨en zu reḩren, gleich als Ķatte man je ein Sins gejeken, bas burch bie Sdjulo feiner $\mathfrak{3 a r t e r i n , ~ e r r o d j e r t , ~ n i d j t ~ z u ~}$ gehen berftanden? $2 \mathfrak{n}$ mie 3 Bielen bagegen bea mertet man nidyt thr ganzes (e)ben hitnourd) eis nen foblechten Gang, weil man fié biêfen fajledj: ten Şang geleḩrt hat?

119. Emit foll alfo weber Fallhut, noch Laufs

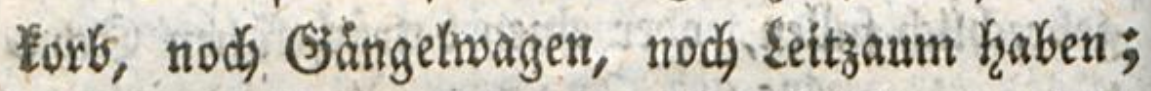
ober wenigftens wirs than thrn, fobalo ex eineti zuß por ben andern zu feren Derfteht, nur ets soan auf Steinpflafter unterftiren, uno Sarifer then fo fisnell als miglich wegbringen. \%) 2(n

fratt

*) Die meiften Lefer werben von lelbft bei silfem fid Bielem benten.

Ebler子.

4) Nean faun nichts Sacherlicheres uns 11 nbebolfneres fehen, als ben sang pon fenten, bie man in ibrer Sinbbeit zit viel am Seitzaume gefúbrt hat; **) unb

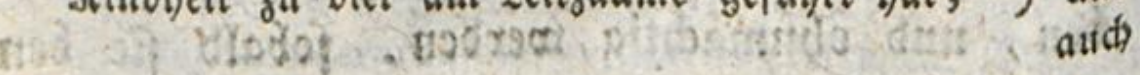

-) Şerr frormey, bem man es purr zu oft anjieft, of er tabelt, um zu tabeln, merftt bei biefer Etelle 
ftatt ifgu in ser sumpfigen Stubenluft pecten zu laffen, fúfree man then tíglidi mitten auf sine 23iere, Da laufe er, ba mache er fich luffig, ba falle er bes Zag ziber wol fimoertmal; befto beffer! er wiro bals lernen wieber aufzus ftehn. Das NBohlforn der Freiheit ift Bers

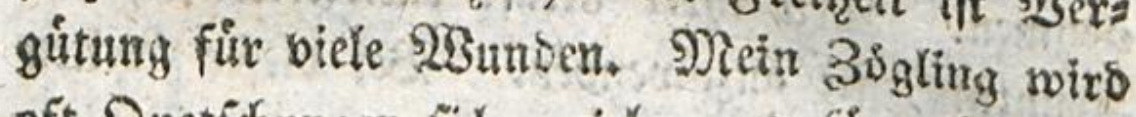
oft S.uetiofongen jich) zuziehen; oafür aber ün

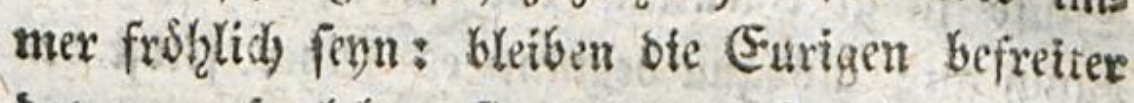
bavon, fo leben fie unter befíto, pinlicherm 3awange, find fets gefeffert, fets trauria. Sald ztweifle, bap ber Seminn auf ihrer Seite fey.

idje

\section{S 2}

2itio

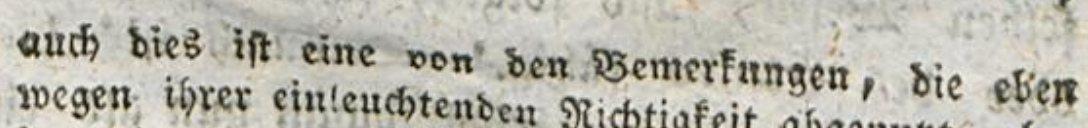

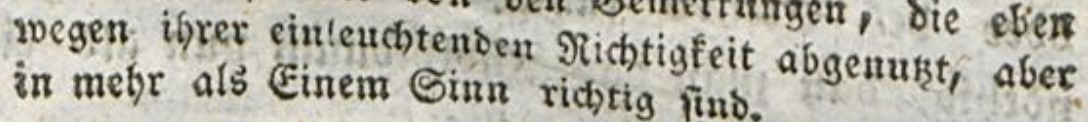

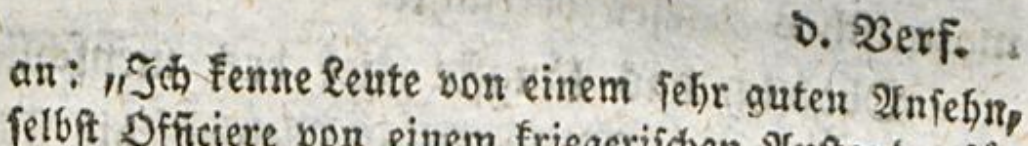
felbft Dfficiere von einem friegerifhen 2antande, fir welche man biefe ubertriebene 2rafmerffamfeit ges babt, unb benen man in ibrer Sindbeit ganz aufs ferorbentlich weichlich begegnet ift. Intwifhen vers range ich nicht, bie über biefen Gegenftant von S)rn.

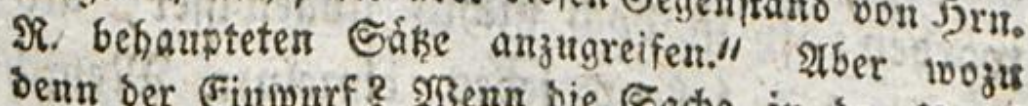

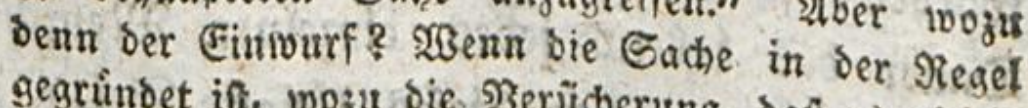

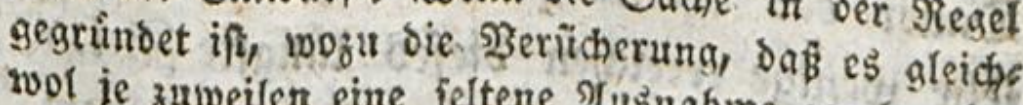
wol ie zuweilen eine feltene 2lusnabme gegeben bas ben mag? Solf ber Erzicher fich nicht nads ber sies sel, forbern nach ber feltenen 2/4smabme ricten ?

(Sampe. 
2tuth noch wegen cines anbern Fort färitteo Ift ben Rinbern hab 28 einen jeft wentiger Ses Dixfnig. Słzre Rráfte haben zugenommen, fie

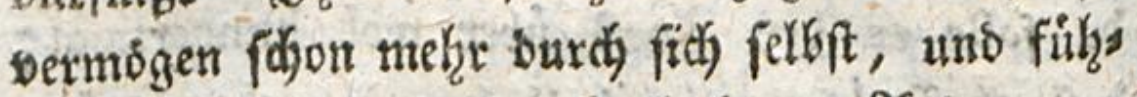
ten minser Drang ihre 3uffucht zu 2lnoern fu tref̧nen. Sit three Siraft entwictelt fich bie Renntriff, fie anzumenden. Bet biefer zmeiter

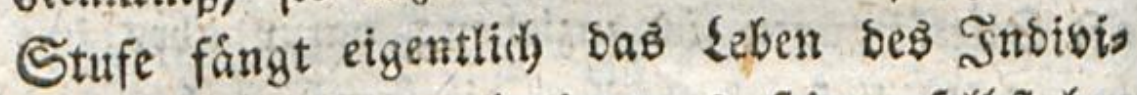
Surum an; albbann beginnt eB̉ feiner felbft bes souft zน werden. Durch das SEetadytuif behnt. es bie Empfindungen ber Soentitát ouf alle 2 tus genblicte feenes Daferyts atto; $C^{-B}$ miro wahys Jaftig zu einem Eins; fu einem unb eben bem: jelben 2 sefen, uno folglicy fojon bes Siluctes ober bes Eetenos fáfgitg. Demnach tfts biex insthig, baß man bas Snoibioutum mun als ein moralifiches 2 (Sejen betradite.

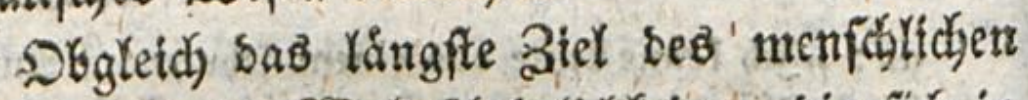
Sebens, und bie SIGahrifheinlidjéten, Die fich in jebem 2llter finben, an bies 3iel zu gelangen,

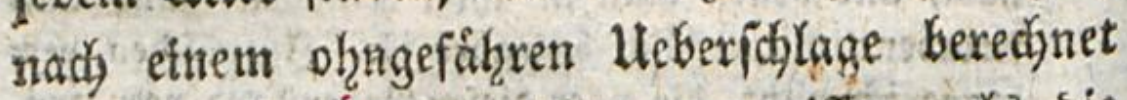
sooben: fo ift ooch nitfts ungenifier, als sie

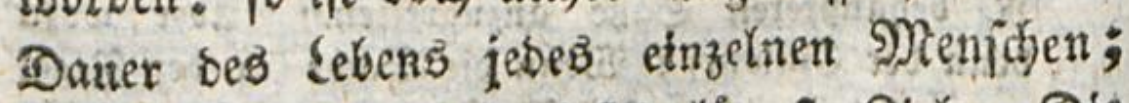
fefler wenige erreichen stefes långfte Ziel: Die meifte Siefahr rauft unfer Leben in feinem 2 w fürige. \$3on ben Rinbęn, bie gebohren wers 


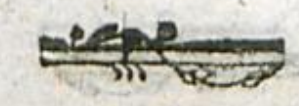

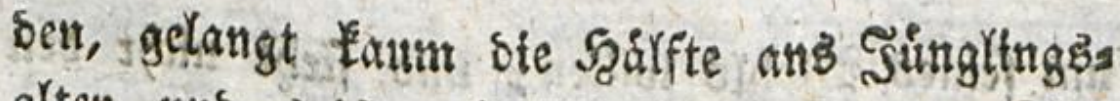

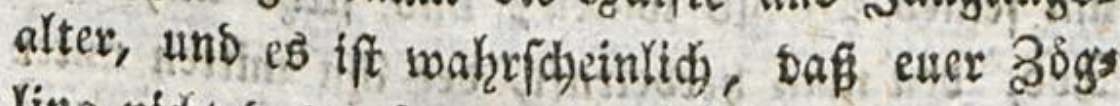
ling nitit oas mánnlidje exteidjen wiro.

um

İas foll mist alfo bon otefer barbartifien Erziebung Denten, bie bie (Stegenwart ciner uns gewiffen Bufunft aufopfert, ste cin Sind mit Feffeln allex 2 [nt belaftet, uns es borerfi, uns gluctelich madat, um in ber Ferne itsm, meif Ser Sgimueh mas fúr ein vermeintes Silucé zu bereiten, zu beffen Giezuffer soje fich parmutbert

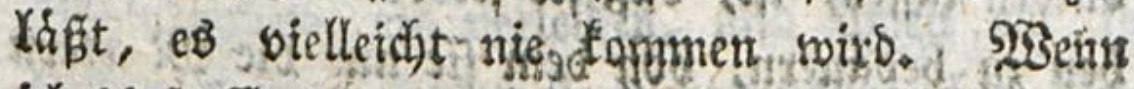

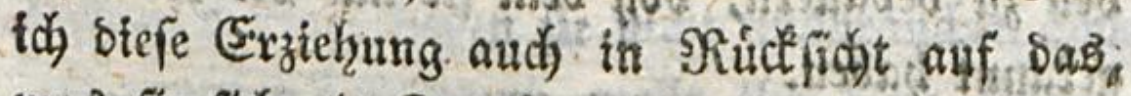

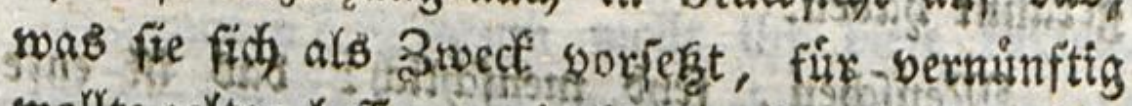
soollte gelten läfien; wie tsunte for senrohngeads: tet olgne bittern utrwillen sie armen lingluctélis dyen einetn unertráglichen Sodbe unterworfen,

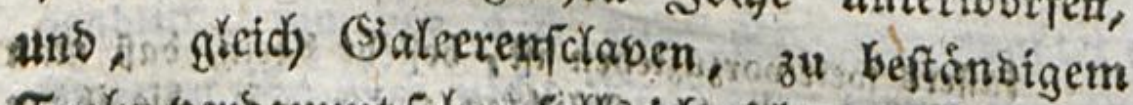

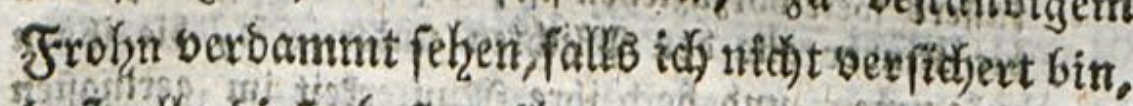

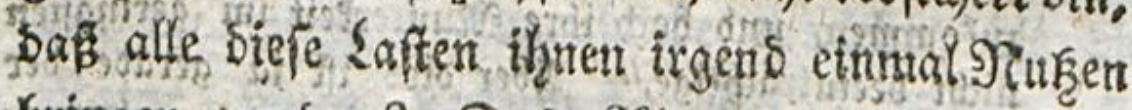
fringent wexden? Mas 2fter oer Froblichteit

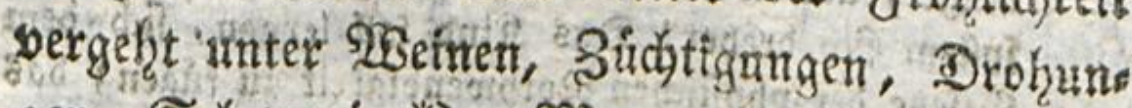
gen, Sclaberei. *) Mian quilts ben Elenden

(S) 3

7) 5r. Formey merft bierbei folgendes an: "\$R. Sat Pecht; fefr biele Ergielsungen fins swirffich tiraus nifh und nieberichlagend. Illein bab Neifterptuif

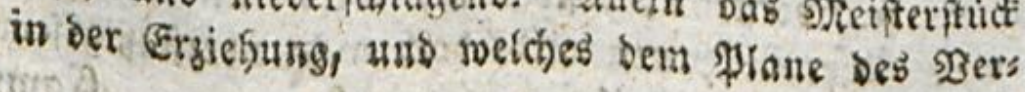




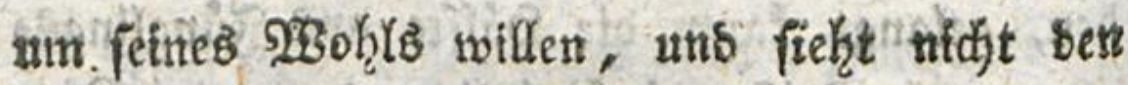
Zob, ben tman herbeiruft, ber iḩn mitten untet siefen tratrigen 3uruffungen exgreifen wirb. \$3Ser fann fagen, wie viel Rinber atz Schladjts

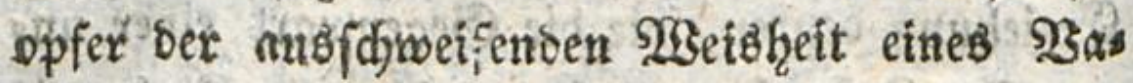
ters voer eines Séhrers fallen? Sie haben bott

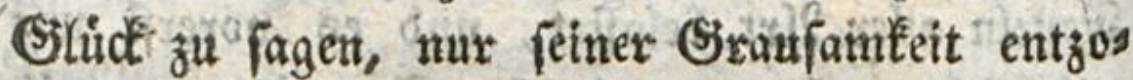
getr zu werben, und ber efnzige Sortheil, ber thrnen aus ben Eeiben extradyit, fo ex fie hat

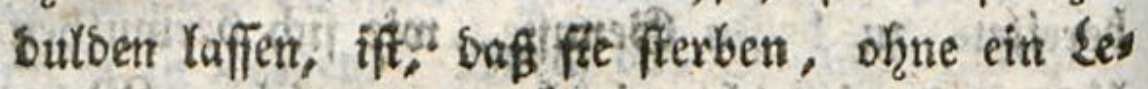
ben zu bedtuern, Gok Dein fie nue bie Narterts getiunt habent?

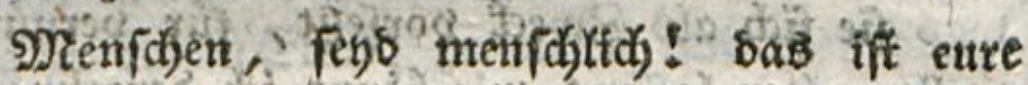
erfe splidt: Send es fur jebes atter, jeben Q.4 Thand

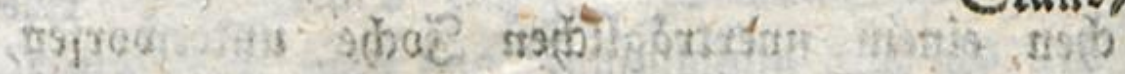

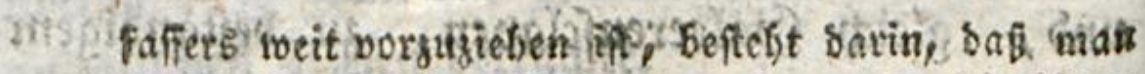

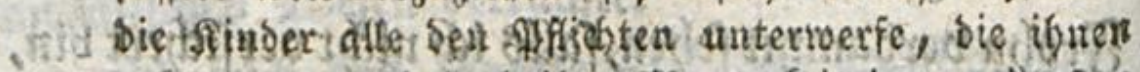
zufommen, uno boch ibre Ninterfeit im gethigferin

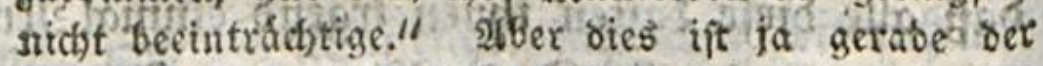

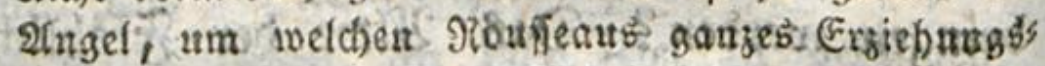
foftem fich orebet! Das Sins foll Lernen, fich bem

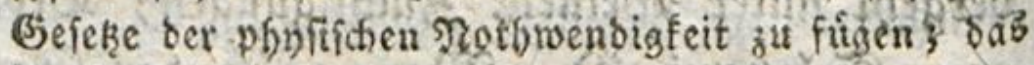

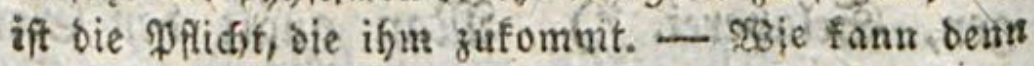

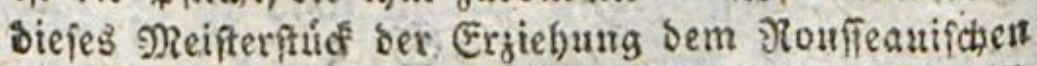

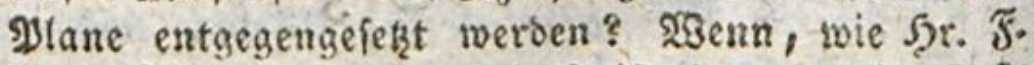
binzufúgt, bie sheifter uno Meifterinnen, Die Rổs

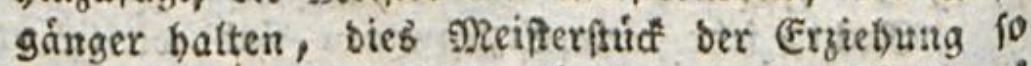
gut verferehn: befo befier fít fie und ibre Sóglinge!

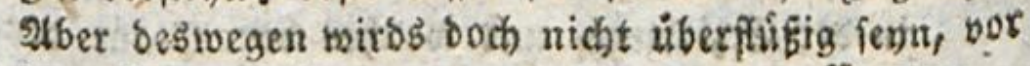
bem Begentfjeile gu warnen? , Eampe. 


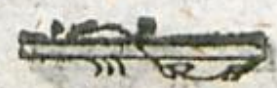

lest

tet

r.

Gts

sas

10rt

gos

ber

hat

(e)

erts

ure

Deft

no,

hats

HTex

ifter

ber

ab 5

bem

$8 a^{b}$

sem

chent?

$\therefore 5$.

Rops

3 . 10

nge!

yor

R.

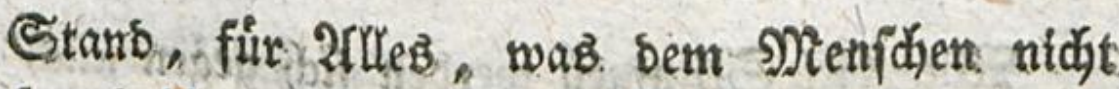

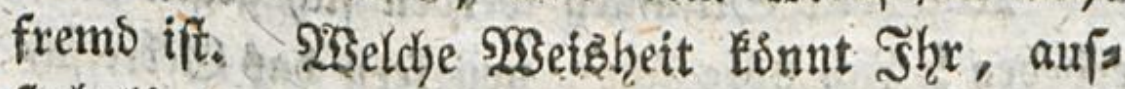
rerkalb Dem Bejirke ber. Menid)lidjeit fuchen? Siebt bte Sinsheit, ' beginftigt ihre Spiele, ihre. Bergnigungen, ihren liebenzmurbigen Suftinct.

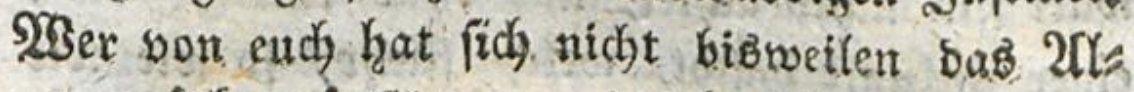
tex zuridigemuinicht, wo bas \{acheln immer alf ber Lippe ifjwebt, und ftetz Friebe in ber Seele wohnt? S2Barum wollt ifge siejen fleinen Lnidsuls Digen ben Genuf einer fo turzen, fo fanell enta fatwindenben acit verletben, uno ihnen ein fo Eoftbares Sut, beffen fie nidit misbraudyen tona nen, rutben? SBarum wollt ibr biefe turzen, fo eilenden Salze bie fúr fie elsen fo wenig als. fir eud) nitebertommen, mit Bitterfeit uns

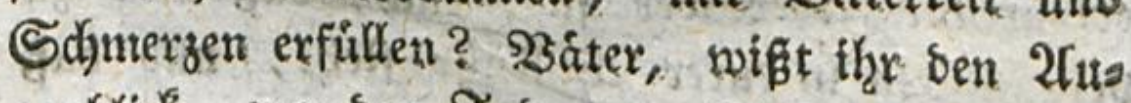
genblick, wo bex Zoo eure Rinber erwartet?

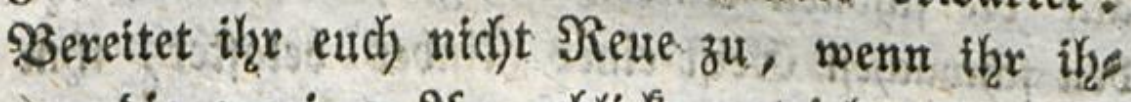
nen bie senigen 2ugenblicte entzitht, bie sie Natur ifhnen berletht? Nein! fubald fie ber Freube zut fentt geniefen tonnen, fdoft, baf fie threr geniefen, fijaft, bafis s zu weldjex Stund: Ejott fie rufe, fie nidjt fterben, ohne Das leben geidumedt a haben, *)

$$
\text { S. } 4
$$

WBie

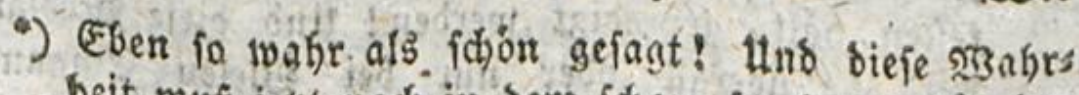
beit mup jek̨t nech in bem fobon to lange fuir hus

ยกเม่ 
S2Bie siel Stimmen werben fid gegen mid

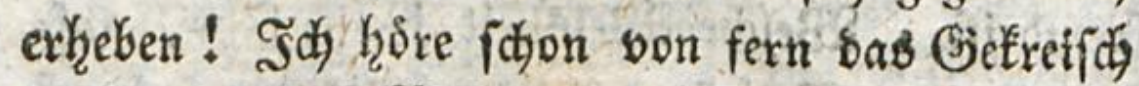

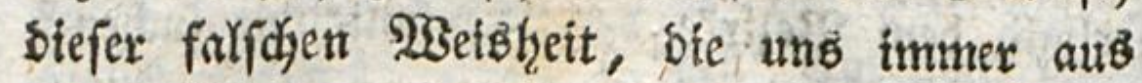
inb felbft heraustwirft; bie immer bie Siegens

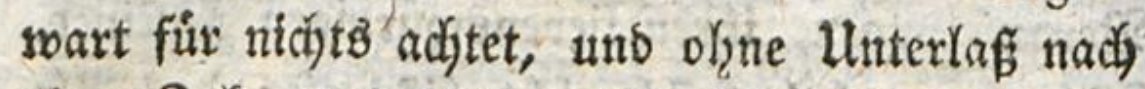
einer Butumft hafd)t, weldge flieflt, fo wie wir fortricten; uno, weil fie uns fets binbringt, soo wir nidjt find, uns hínbringt, wo wir nies mals feyn werben.

Die Rinskeit, antwortet fikr mir, if sie z̧eit, wo bie bofen Neigungen bes Mlenfdjen berbeffert werben muiffen; in sfefem 2uter, wo

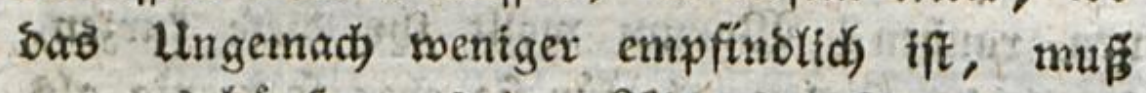

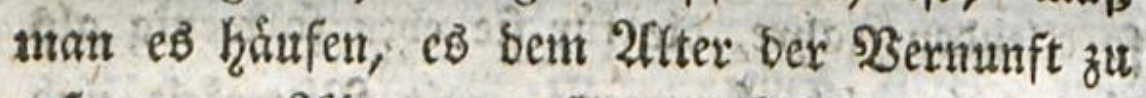

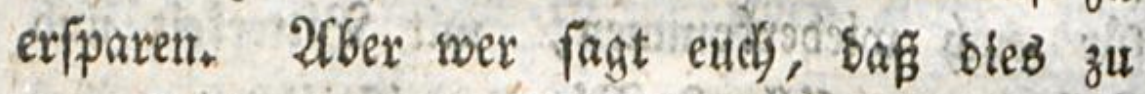

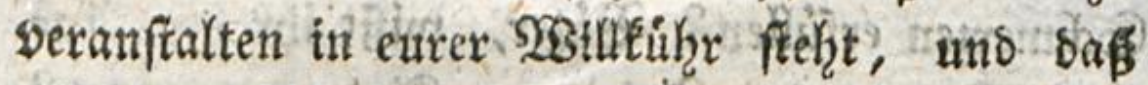
alle bie fissten linterweifingen, mit benen the

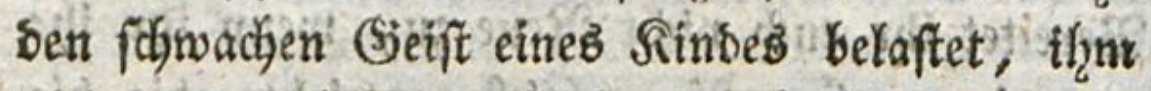

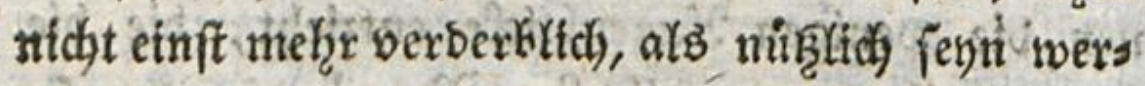

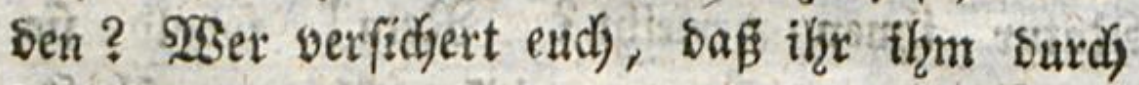

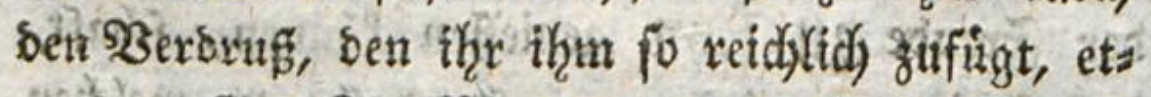
was exfpart? SISarum bexurfadjt ihr ifgm niekge

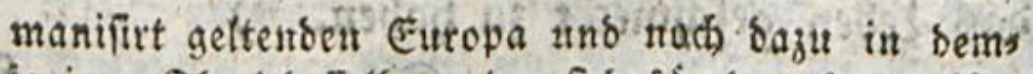

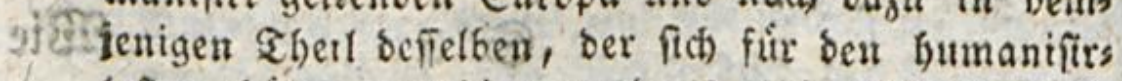
teften bál, geprebigt werben! Hnd bieje Frebigt, roiro fie libernal ober mat bet șielen Eingang Finden? Srapp. 


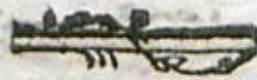

mefix Hebel, als fein 3uftand extrågt? wofern

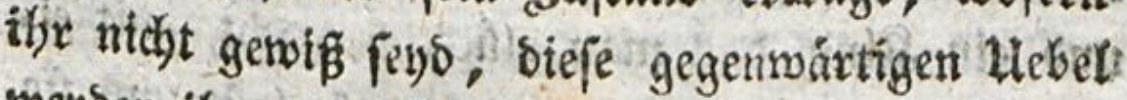
serben thim zur Exreidterung turfftiger bienen?

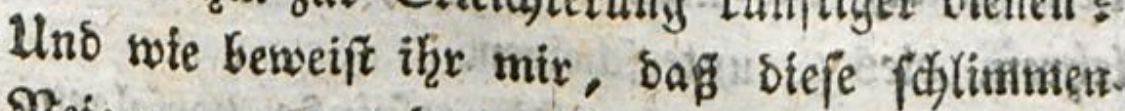
Neigungen, bont benen ihz es ḩeiten sur wollen

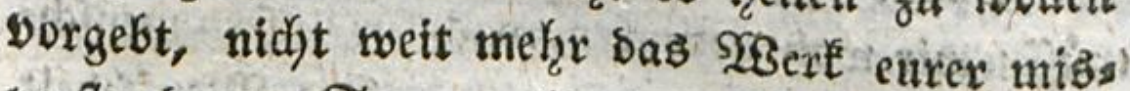

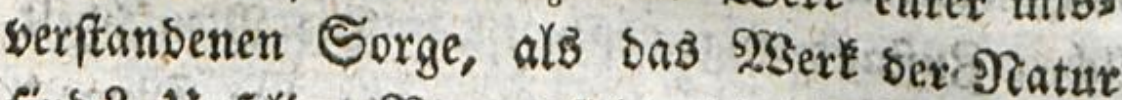

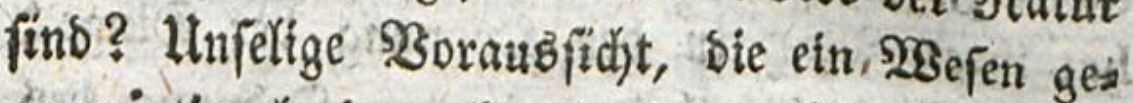
genwartig elens madjt, in ber wohtle ober übets

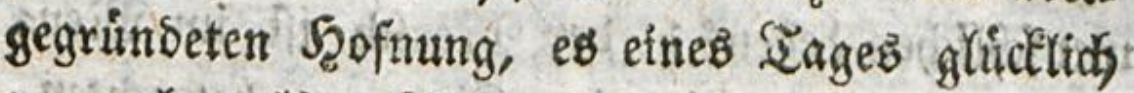
zu machen. *) Berwedjpetn aber biefe 2ultagis:

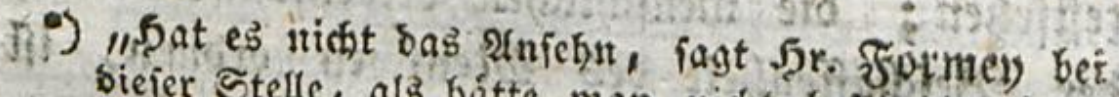
siejer Stelle, als bátte man nicht beftanbig libers

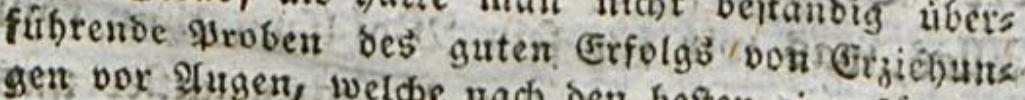
gen oox \&ugen, welche nach den beften cimgefulyten (5tebráucben und folglich in einem ganz anbern (5): fchmad, ats ber Erziehing bes Emils, vollbracht

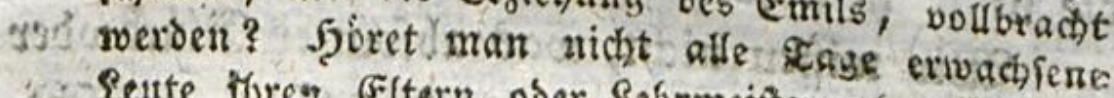
Seltte Titren Eltern ober Sebrmeiftern ber Etrenge rogen banfen? beren fie fich gegen fie bedient?

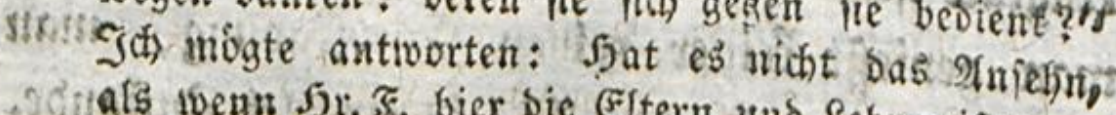

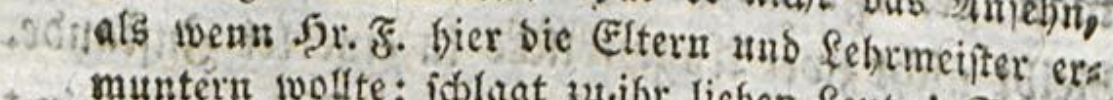
muntern wolfte: id)lagt zu,ibr lieben feute! Solont eurer arnter fiumer nicht! Ge metyr ibr îe mishandelt, Sefto berjlicher werben fie euch funftig bafur santen. Bei Sumben foll es wirflich ber fall fenn, bafi. fie senen am meiften ergeben find, von denent lie, locibs renb ber 2lbrichtingszeit, am unbarmberjigiten ges misbandert wurben: aber frunde follen auch nup abgeridjtet, senjohen bingegen effugen werben.

Eamper. 


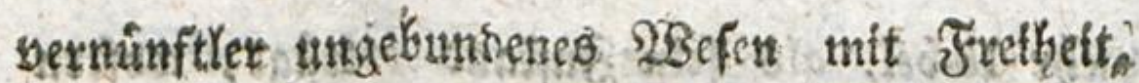
und ein Sino, bas mam iglúclich madbs, mit ei nem Rinoe, bab man vevoirot: fo laftuns fie Yehren, ofes zu unteridgeipen.

Damit min nidyt Sinngeipinfte berfolger. miffen wir wohl bebenten, wab fir unfern menjhs Kidjen Buftans angemefiem ift. Die Prenjobleth hat iferen Splace in Der Sronung ber Dinge" bie Sinsheit ben thrigen in Dex Sronung bed. ntenidj(idjen Lebens, Der s) remid) if im s)iens fhen, uno Das Rino im Rinoe zu betradyten. Sebem feinen Plare anmeifen, uno thn barit feftrferen; sie menfdylidyen Eetbenfdyaften nady.

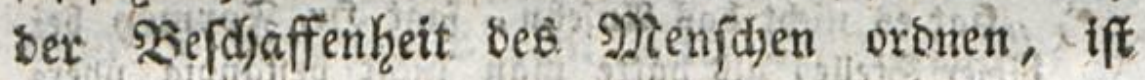

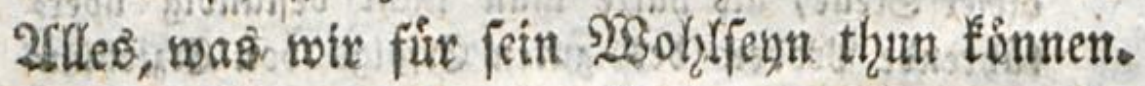
Das Ulebrige baanght bon Urfachen aufer uns ab, Sie nidht in unjerer Siewalt ftehen.

23it miffen nidjt, was abjolutes Silud ober

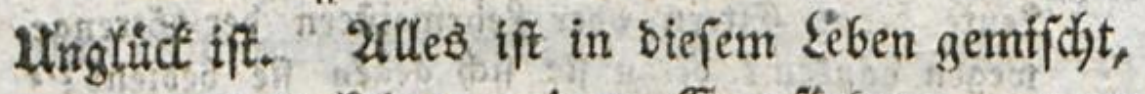
man genieft feiner reinen Empfinoung, man

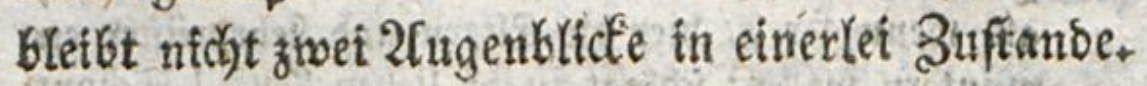

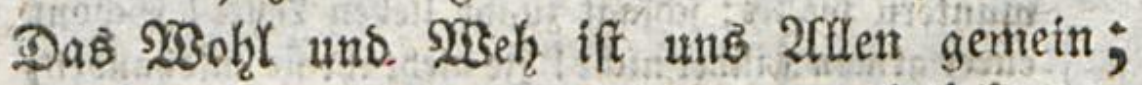

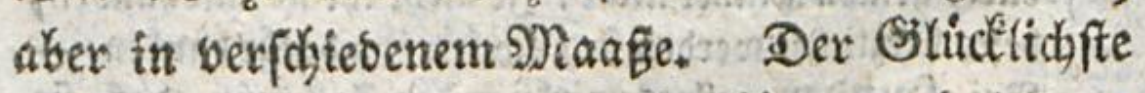
if berjentge, bet am wenigften Ungemady leibet; bet Elendefte serjenige, ber am menigften Bers gutigen empfindet. Sinmer mehr Leiben als

Ses 


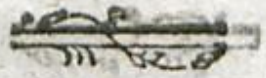

Siennff; mu sarin fommen nit weniger obet

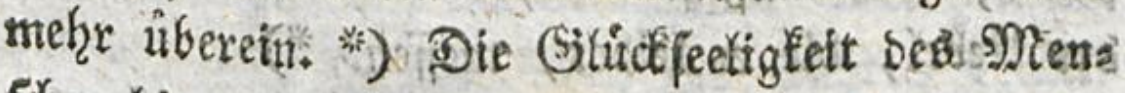

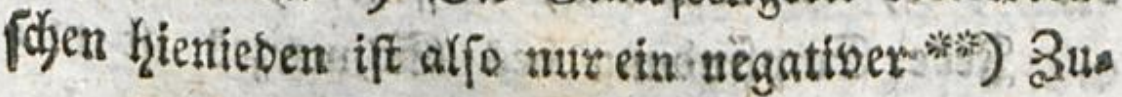

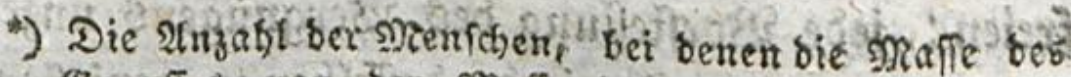
Benuffes von ser maffe bes Reidens úberivoget

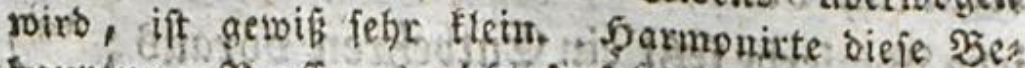
bauptung Sonffeaus nicht fo febr mit Seffen gráms

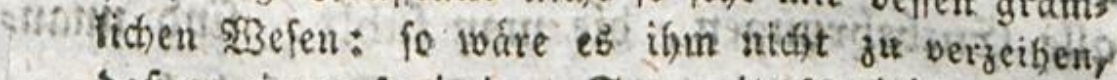
sta safil ex eineu fo irigen Sabs mit fö vielen mittels másigen oder meniger als mittelmábigen Siopfen

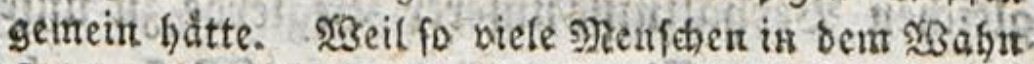

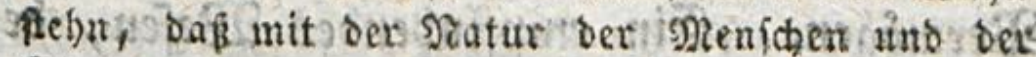
Dinge ciu ununterbrobsener (5tenuf angenebmer Empiñoungen múpte vereinbart iverben fonnen: fo

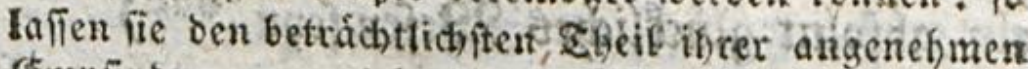
(Empfutungen aus ber $\mathscr{U}(\mathrm{h})$, rechnen aber alle uts angenebme Empfindungen iorgfáltig zufammen unb berweilcu pabei mit ibren \$3orftellungen. Daber

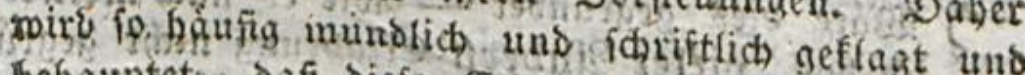
bebauptetio cafi diefe Erbe, nichts anders als

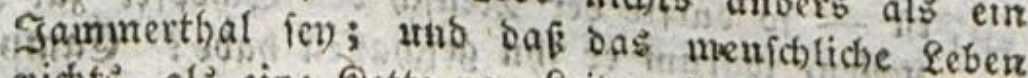
nichte, als cine fiette vou leiden lew. Solcher un:

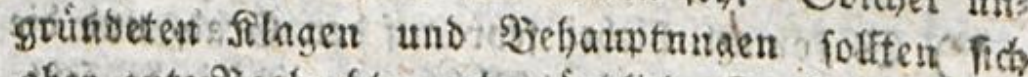

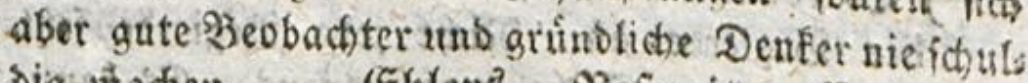

sisu oig untadien.

(Eblers. Siefentib. Samps.

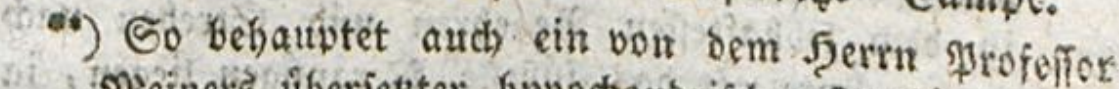
Mieners liberiekzter fypoctonorifcher Ttaliáner, Dafi bas Bergnugen ber Nenfihen im abrebmen uns भufforen bes Gdimerzes und in ber Joffnung bes Szefieriverdens blof beftebe. SBer mit gerubiger Faffung bes Beiftes alles beurtheilt, exfent es aber

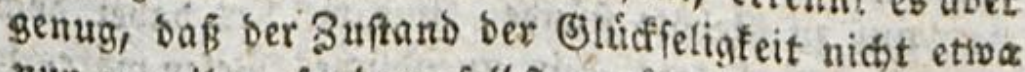
nur zubeilen, fonbern felbft gewobnlid, ein zuftand sofitivet angerebmer Einpfindungen ift.

Eblers. Rejerwis. Eamve 


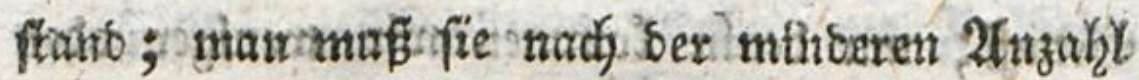
bet Lebel, sfe exsletset, ineffen. *)

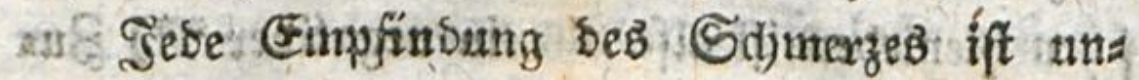
zertreñulidos von ber Segiexbe, fich Dabon za bes

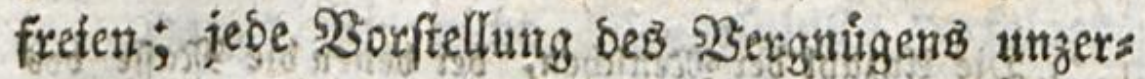
trennlid) bonsoer SBegierbe, beffelben zu gente Ben: jebe Begieró fegt ein (Entbefren boratis; **in) uns qulle (sntbeformigen, bie man fablt, fins unans genefzm; folglid befteht unfer S.lend in betr uns

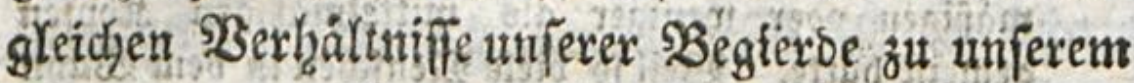

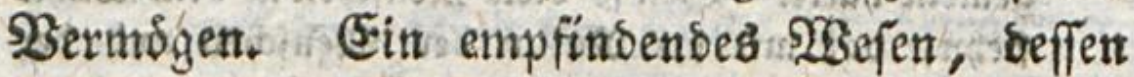

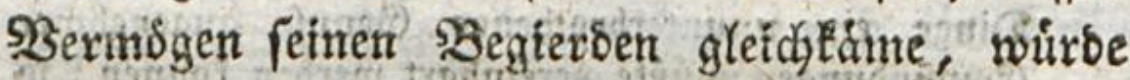

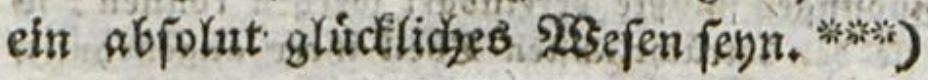

भูลือ

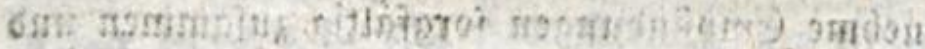

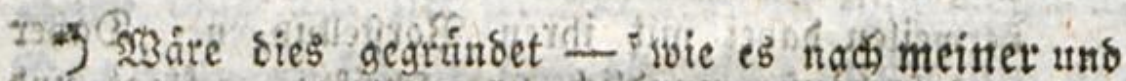

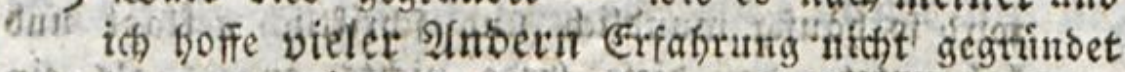

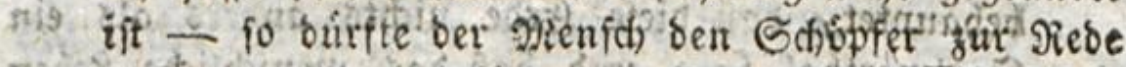

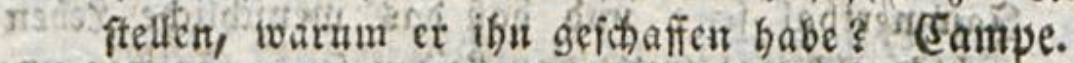

4*) (Es fommt hiebei fef) alf ben (5tabp uns bie 2frt

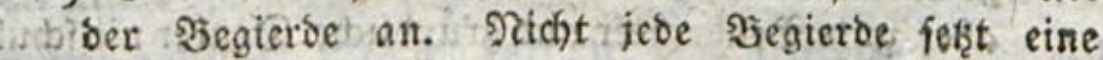
unaingenchme Entbefrung voraus. Es fant felbft in bem lebbafteften Segebren uno Streben nad cinem Brite oft oas fíbefte \$ergnúgen liegen, ia wol gar ein grốer Theil unfrer ganjen. Şlidifeligfeit.

Stuve.

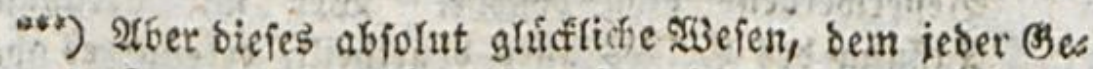
nuE zu Bebote ftuinde, uno welches babei boch ein eingefchránftes, fein unendiches 23 efen wáre, würbe in furjer acit ein febr ungludflidges feyn, toeil eb 


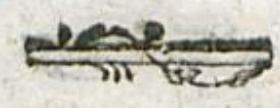

\section{5}

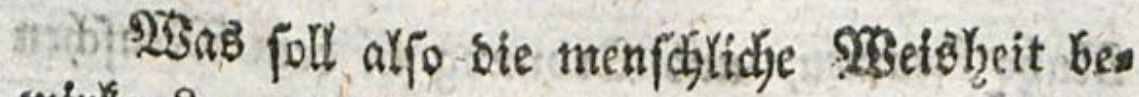
wirten? roas tif ber 2 Seg zur wahren Biticts

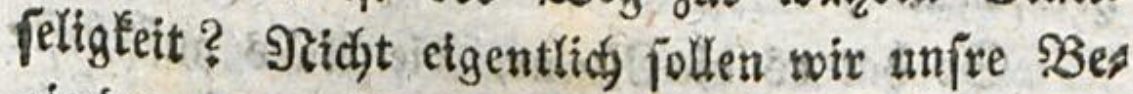
gierben berminbern; benn wann fie unter un ferm Sermógen wairen, fo wurbe ein İteil umperex Siráfte mifigig bleiben, uno wir nidjt

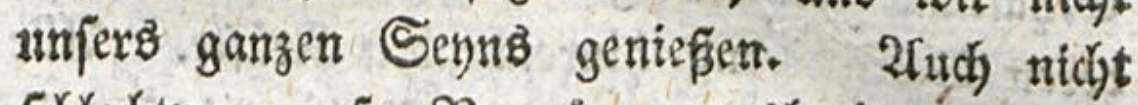
fchlectitweg unfer $\Re$ Sermogen ausbreiten; benn,

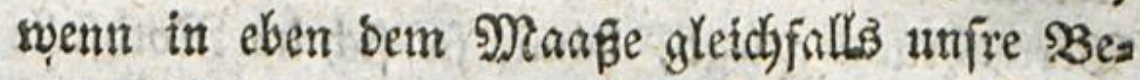
gierben fich ausbreiteten: fo wirben wix nur befto unglictlicher werden: fonbern wir follen bas lles bermaaff unjerer Begierden nad) unjerm 2 Bermó.

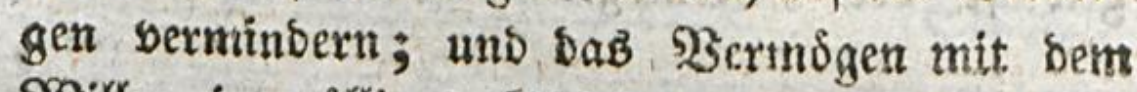

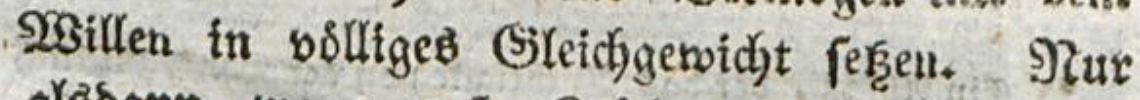
alb̈bann, mann unfre Rráfte ganz in Seanblung find, wirb bie Seeke in einen Buptans bef গith

gar feine lebrafte Segierben, alfo aud gar feine befeligende Sefriebigung berfelben mebr fentuen mirbe.

Eampe. Trapp.

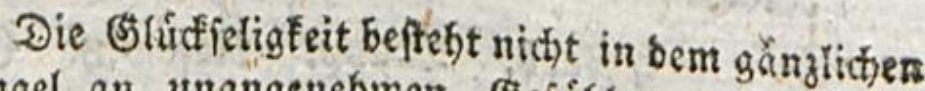
Shangel an unangenebmen Gefúblen, als ivelche

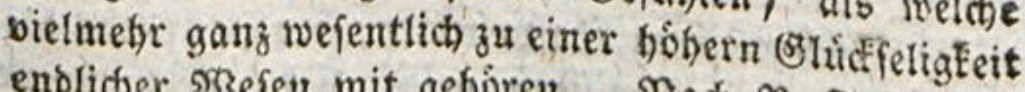
endlider ş̧efen mit geforen. Mad, $\Re$. Definition Fonnte bas auf bet allerunterfen Stufe ftehende mit Emprinoung begabte 23 eien am erfent ein abs folut glidfliches pery. Heberbaupt fins in biefem

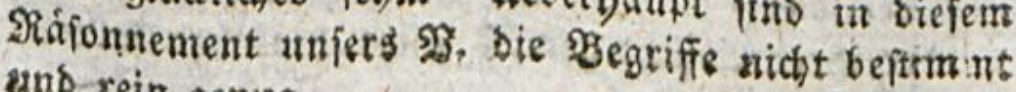
end rein genug.

Stuve. 
Ruke formen, und Sronung in bem Menfijen Herridjen. *)

So hat es bie Natur, bie 2Nles aufí befte thut, gletch anfangs eingerichtet. Sie giebt ihm unmittelbar weiter nid)t Eihgaltung nothwenbigen $\mathfrak{B e g i e r b e n , ~ u n o ~ D i e ~ z u ~}$ beren Sefriebigung hinreidjenden Rráfte. 2tile iftirigen hat fie tief in feine Seele gleid) ain in Berwahrung geregt, bamit fie fid im Nothfalle

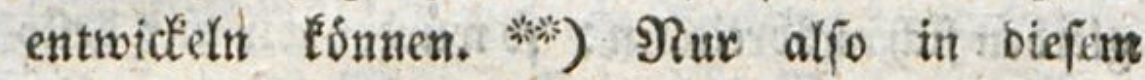
uxipringliden 3uftanbe trift man bas Sleidys gewid́l beś \$ermigens uno bet Begierbe

an

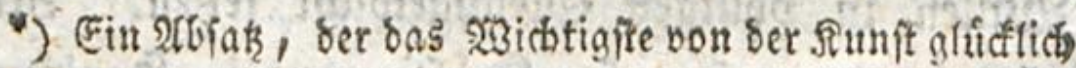

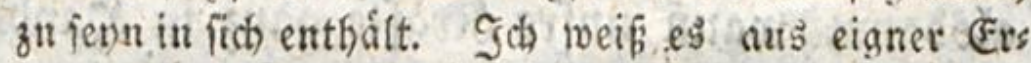
fabrung, baf auch ein Nensch, ber wiber grobe, viele und mannigfaltige Hebel unt Seiben bes menf(c)lichen febens zit fámpfen hat, surch forgs fáltige 2fmwenbung ber barin enthaltenten Bedanfer

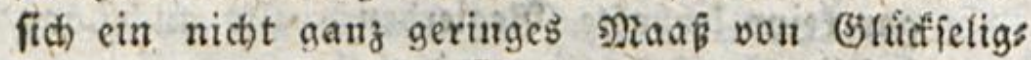
feit in verichaffen und fith in einem nidf) getingen (5rab von gerubiger Fajiung und felbft fleiterfeik bes Bseiftes zu ergalten im Stande ift.

Eblets. Trapp. Relenits. Campe.

av) Nach meinem Dafuirbalten ift alleb, twas bie Nas tur in ber Menfden gelegt hat, fur Entividelung beftimmt, und es fdjeint mir cine ber fonberbarftent

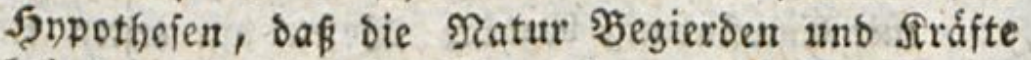
bei Den פienichen in Servafirung gelegt' habe, bie

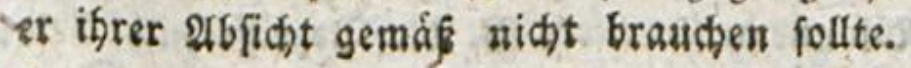

Sture. 


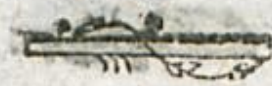

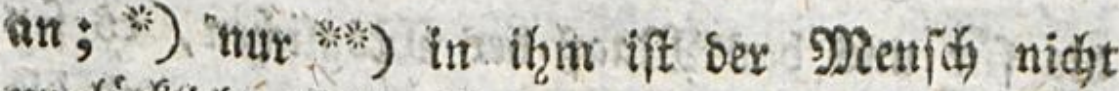

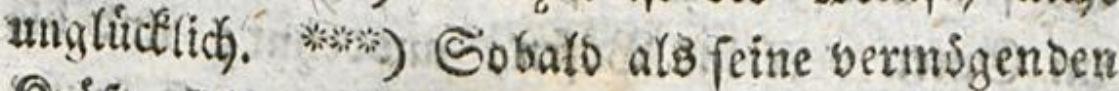

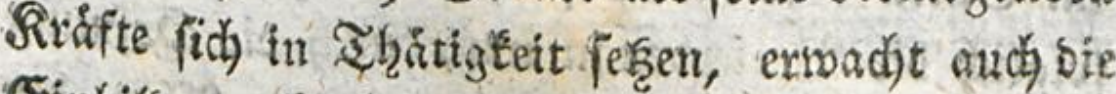
cinbildungstraft, bie thathifte von allen, unb etlt ihnen zubor. Die cinbiloungaleraft ifts,

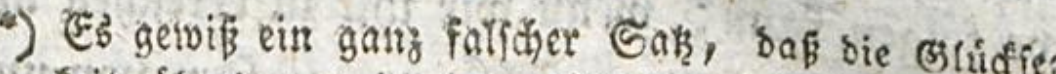
feit liberbaupt in bem - (Sleichgetvicht bes $\$ 3$ rmo

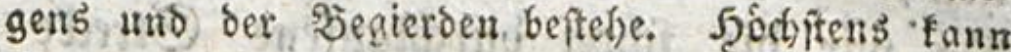
et nut relatio bou 23 efen einer 3 trt, ober wol gar nur von ben verfchicbetren auftanden eines un seffetben Inbrbibumm gelten. Hebrigens ift der Maw gel, bes (3)leidhgenidots bei sBilben toeniger merflion, twetl fie twenig Segierben babet.

Stuve.

0) Diefes nur if ungegrünbet. Es láßst fich niđat btops benfen, fondern es ift auth Erfahrung saf ber ausbebilbete wienfict) eben fo gut, als ber rohe, fich in bein glidfichen 3 uiftande bes sileich getwichts

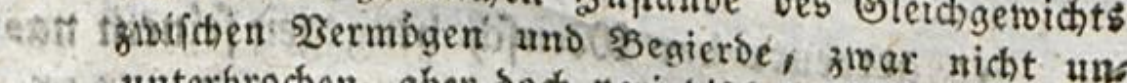
atbij) unterbrochen, aber. ooch periodich befinden fonne.

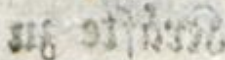

Eampe. Trapp. Refenis.

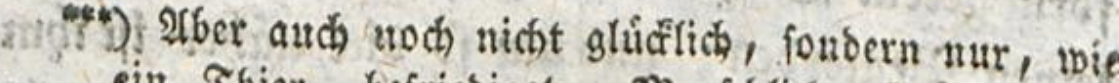
ein Thier, befriebiget. Nensthliche ETlúffeligfeit befteht mebr in bem Soeftreben nadi getwunichten

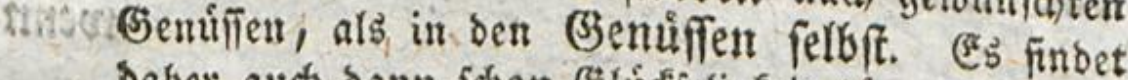
Daber auch bann fchon Ghlicfieligkeit fîr uns Statt, wam \$ermogen und Segierbe nod nicht im volli: gen Eleichgewicht find, wenn twir babei nur füblen, Daß́ wir uns Diefem (s)leich)getwichte nábern, oder mit andern SBorten, wenn wir mur fúflen, baf wir bei fortgeferztem Beftreben den (5)egenfano unferer Zegierbe wabricheinlich erreidhen toerden.

Empe. Trapp. Stuve. Referwit. 


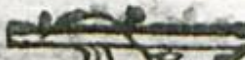

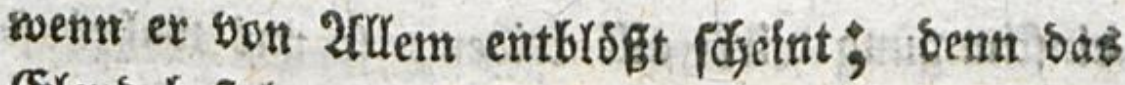
(E)eno beftefgt nidjt fibledjthimin Entbef̧ren, forto bern im Entbehren, bas ein Bedurffnis fúblgat madjt. *)

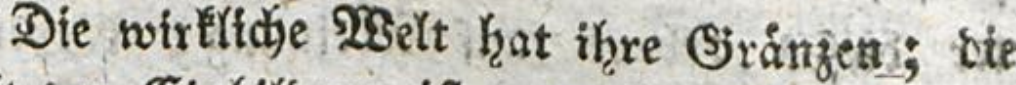
$23 \mathrm{elt}$ ber Einbiloung ift unendlich. Da wir bie

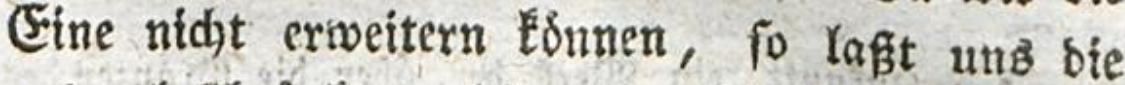

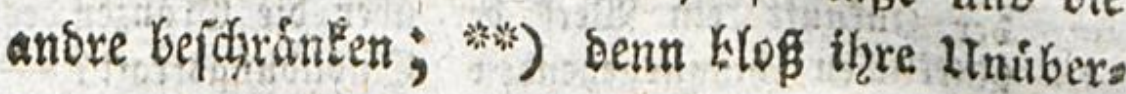
efn:

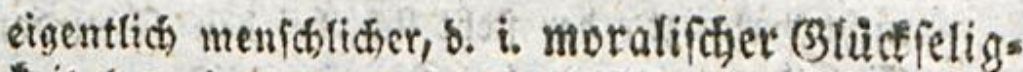
feit hat ciu folder nichts', weel er feine moraliche 刃ुedúrfnifie hat. Smipe. Trapp. Stuve.

Und genieñt alfo and nidbt eigentlich bas bes

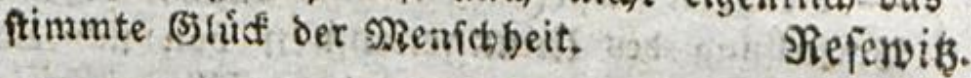

") Wsafrlich nitht iebeb Entberren, weldhes ein hes dúrfni fáblbar madt, macht elend, wnd diefe Erflärung deb Elends fann alfo nicht richtig fenu. Stuve.

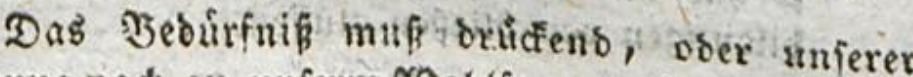

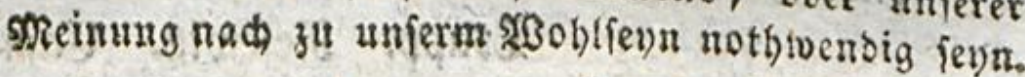
Reérnis. Campe.

*v) Dan forme fragen, of man nidit aub eben sicfem (5runbe gerade bas (segentheil thun, die treit der Einbilbung erweitern milte, utm fich fár bie Bráu zen ber wirflidien SBelt idsablob zu baltem? $x_{3} \mathrm{enn}$ man mur fither ware, in bie Fiegionen des furms mers nidht eben forvol und vielleidit gar ifter a!t in bie ber Frenbe zu gerathen jo mufite manb fiton than. Ind thun wirs nicht wirflich? Git nicht jeber

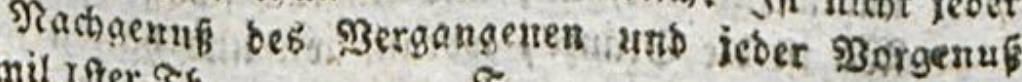
Emil rper If $\mathfrak{I}$ Der 


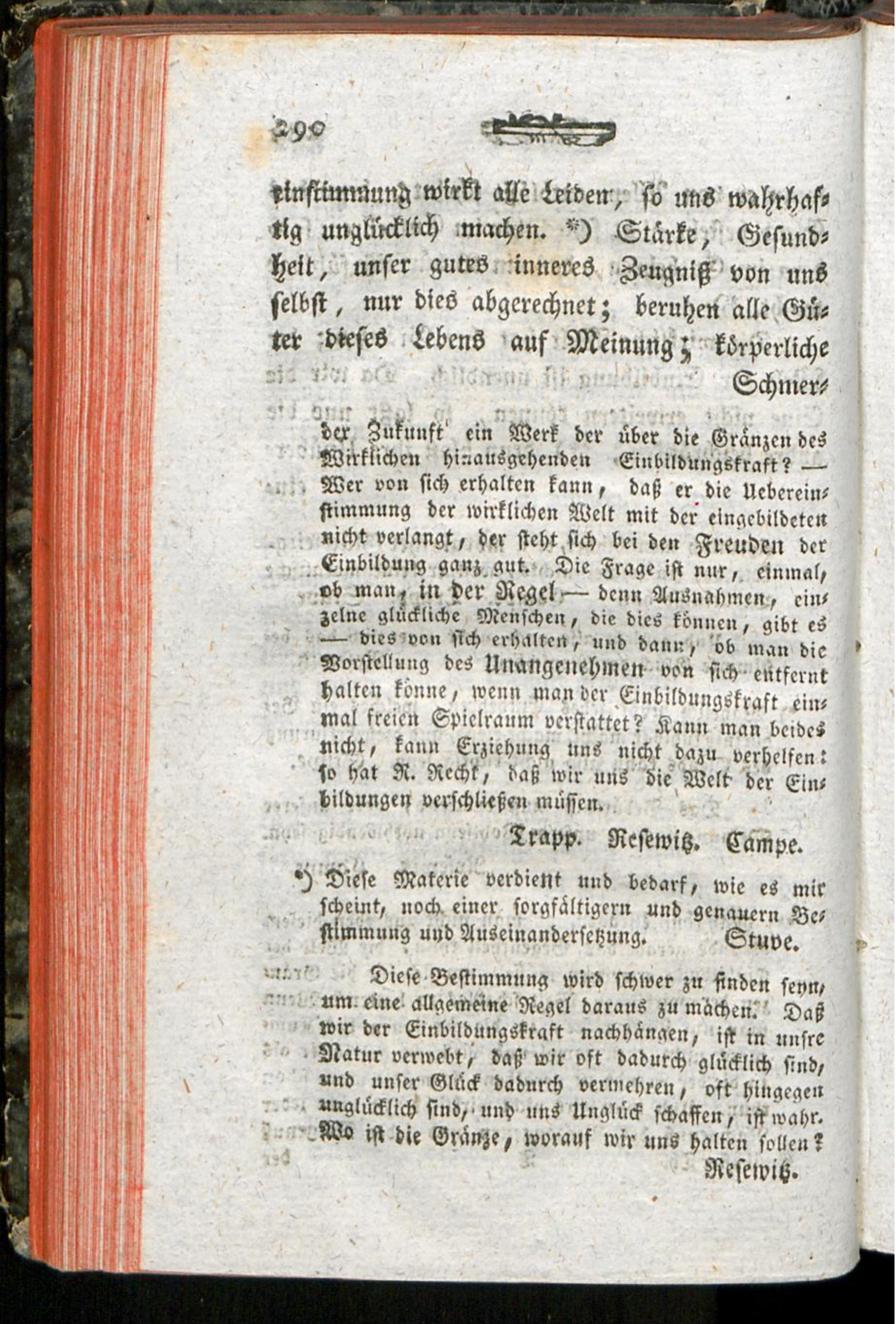




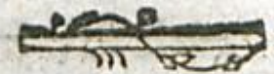

iafo

no:

เกเ

ijits

idje

lex

deg

eins

te tt

bet

zal,

eins

: ${ }^{3}$

bie

int

eiris

bes

en:

Eins

mit

Bes

t)ti

วa

ifre

no,

gett

(b) $\mathrm{r}$.

it?
Sdjmerzen uns S̈ewiffenşvormuinfe abgerechnet, fins alle, *) unfre Eeiben eingebilbete. Dies I 2 .

*) Nouffeau fibertreibt bier sie Sache wieder. But Eforperlidjen Echmerjen wiro er freilich jede unam genehme Empfindung rechnen, bie aus phnificher Eimvirfung ber Dinge auf bie menichliche Natur entipringt, ob bies gleid) nicht genng bem Sprads

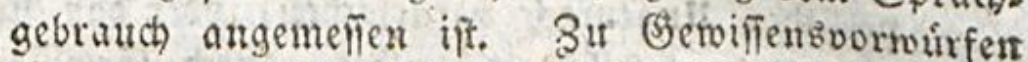
Eomen aber follechterbings nidjt alle wirfliche feident ber Seele gerechnet werben. Die vorgangige Ers fentutí eines llebels, bas in ber Jolge nach ber Natur ber Sache Dem Siorper mangentefme (Fms p pindungen titl Schmerz zuwege bringen wiro, uns die Erferntnif einer jeben Unvollfommenteit, fie

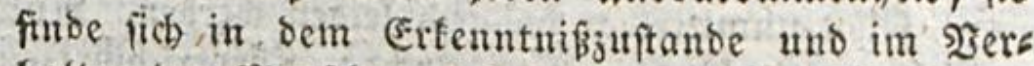
balten ber Mienf(hen, ober in Der Eistrictutung ber menfohlichen (sefellfichaft, ober enofich in bet aud nicht auf uns wirfenden whyitichen Natur, muf́ nas turlticher şeife Seiben ber Eeele zur Folge baben. Nian fann alfo feinesweges fagen, Daß̈, forpertiche Schmerzen unt Betwiffensvorwirfe abgerechnet, alle unire leiben eingebilbete \&eiden fenn. Eblers.

Nicit freuns crlaube mir, zu geftefn, baf qeine

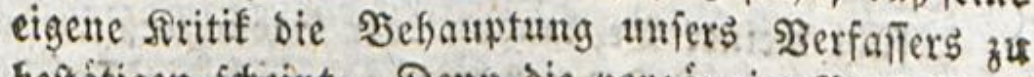
beptátigen fcheint. Denn die vorgángige Sorftellung vou einem Hebel, bas noch nicht ba ift, ift bod ohnftreitig eine SHGirfung auferer Einbildungsfraft, alfo etwas Eingebilbetes. Sben sie Sjerwanonif hat es auch mit jeber anbern Siorftellung von Hnvolls Eommenheiten, bie wir theils in Dem Erfenntnifs atitande, theils in bem Nerbalten ber Menfdent theils in ber Einrichtung Der menifhlichen (sefells fidaft, theils in ber nidht auf uns wirfenben phofic finear 


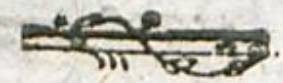

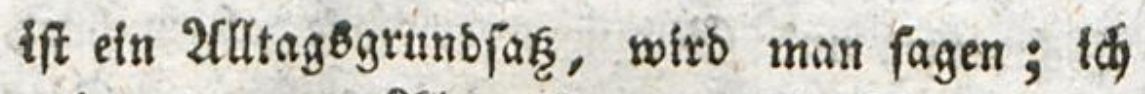
gebe es zat. 2lber bie practifde 2 nnendung bavon ift nicht alltâglich; uno hier tommts nur ouf bie $\mathfrak{Z} \mathfrak{n w e n d n g}$ an.

28as

ithen Natur bemerten. Sinb diefe Unvollommen beiten nicht von ber 2rit, baf fie uns entweber fors perliches Ungemach verutiachen, ober dấ fie uns, alb vou uns felbft verichuldet, butch (Serviffensbiffe quálen: fo fonnen fie ichlechterbings nitcht anders, als bur(h) Şutfe uaferer Einbilloungsfraft unt Ed)mero feu machen, indem biefe entweder unb an bie Etelle Desienigen verfekzt, welcher unmitielbar baburch leibet, Dber ans ben fall vergegenwártiget, ba wir einft felbit unmittelbar baburd leiben werben. Fouffeau bat alfo in ber Fhat Redjt: Rorperichmerzen uno (3) elvil̄ensbifie abgerechnet, fins alle uniere Seiden

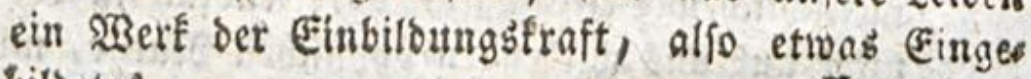
bilbctes.

Banpe.

S3ent eindebilbete Reiben folche beifen follen, bei benen bie Einbiloungsfraft mitivirfet, fo finb alle unfere Seiben eingebilbet. Sollen eingebilbete Setben aber btobe 23 irfungen ber Einbilbungstraft fenn, io if $\%$. Satz faich. $z$. 3 . ift beun bas Bes

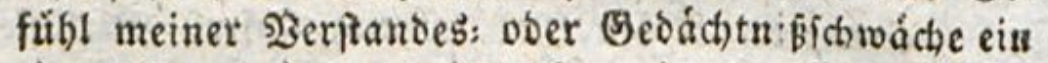
eingebildetes Seiben? Szie fann ith bie (Emp finbung bes Untechts unto ber Şeleibigungen, die man mir zufúgt, ein eingebilbetes leiben nenuen u. f. w. Eins ferner biefe fogenannten eingebilbeten leiben nidjt. gariz weientlid, in ber menichlichen Piatur gegrúnbet; wáre eś móglich uno gut obue biefelben zu fenn?

Stuve.

Ferner bie Leiben des Nitgefübts, die bod fo ebrfam fúr bas menfobliche syerz find, finb fie bens 


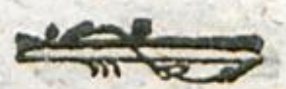

528 as will man bamit baben, nenn man (agt, baß ber Nienich fdywad ift? Dics \$ort

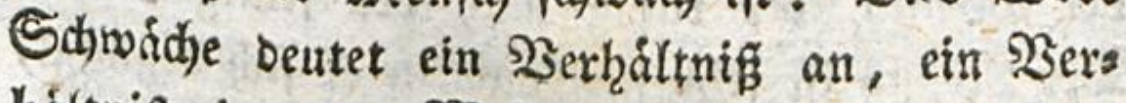
báltnis in bem 2 Befen, bon weldjem man Sdunáche bebauptet. Das 2Beien, beffen Rraft rein Beourfnif úberfteigt, márs ein Snfect, ein 23urm, ift ftart: Dasjenige, Defien Beourfniß feine Rraft úberfteigt, wârs ein Frephant, ein Some; bårs ein Erpberer, eit Seelo, wärs ein Sott *) ift fdnoud. Dex aufrubzerifdye (Enget,

$$
\text { I } 3 \text { ber }
$$

benn blop eingebilbete Eelben? ober entitehen fie

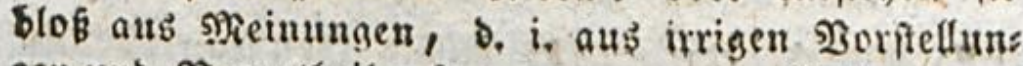
sen und รorurtheilen? शieferwits.

Der misverfans focint burd bas 230 rt eins gebilbet veranlaft zu werben. Eingebilbete feiden fint hier nidat unwabre, erbict)tete, fondern folche, welthe in Borfellungen befiehn, Die uns Dardh Die Einfildungitraft gugefubit werben. Diefe leiben fonnen febr reel felyn, obngeadtet fie hut in Sorftellungen beftebn. - Das (5) fuib! meiner Bers Fandes: ober (5edáchtnifichwaiche, und das (Befribl eines mir angetbanen lunrectits werbén beibe nur burch bie כorftellung von ben unangenefmen Fols gen, bie beibe fúr mich haben toerden, bitte:, und fino alfo, in fofern id babei teide, cine șirs Fung meiner Einbilounngfraft. Eben fo entiteft Sas Nitgefúfl, jwar nicht aus irrigen Neinungen ober Sorurtheilen, aber bod) aus 3orftellungen, bie wir ber Einbillungsfraft verbanfen. Saupe.

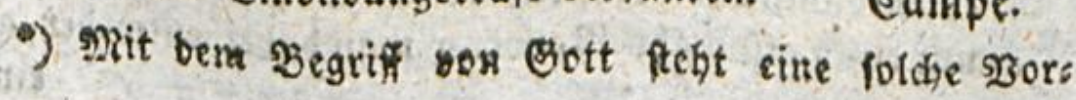
ous: 


\section{4}

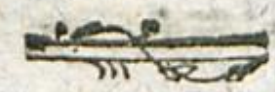

ber feine STatur bertannte, wax fojwácher alo ber Plenfch, bex ruhig nach ber feinigen lebt. Der Mienich if fefer ftart, wenn ex fich begnigt, baz za fenn, was ex ift: ex ift fehr fidwady, swenn er fidy über bie Nenidhleit erheben will. silloet endy alfo nidjt ein, ihr behntet, inderns thre euer Bermogen *) aubbreitet, audj eure Rrafte

ausfektung in geradem şiberipruch, und ie if alfo unftatthaft.

(E)

Alleroings; aber man fieft wol, bẩ $\Re$. bas sBort (3)tt hier mur brauchte, um cine fobone Steis gerung von Segriffen zu machen.

Eampe.

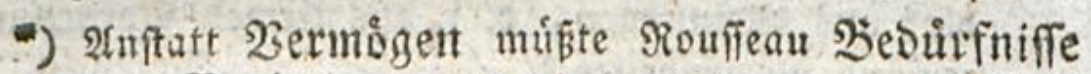
ober Segietben geiekt 'gaben, forvol in Biteficht auf bent Sufammenthang feiner eigenen Bsedanfen, alb aulf bie Natur ber Sache.

(E)let3. Trapp. Rejemiț.

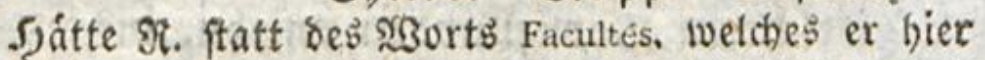
brautht, befoins gefeste, fo wurbe er freilid, auch meiner Meinung nad, wafrer gerebet baben. 2iber bấ dás erftere nicht in ben sufammentang uno sidet zu feinem Griftem paffe, fann id nicht finbert. Dicfer Gak fheint vielmefr, fo wie er ihn ausges brifift hat, vollfommen Sioulfeauifich z"l fenn. Er svill námlich, glaube ich, jagen: jemebr Der Menfín alfe feine Inlagen und Fáabisteiten entwistelt uno auşbildet, befto fowwácher wird er; uno fo ausgevrifft paft bieier Sak, fowor zum siorhers gehenben und Nactforgenben, als aud in Rourieaus eigenthúmliches Enftem recht gut, ohngeachtet or sur banz erft wabr if, wenn man babei entweber an cine 


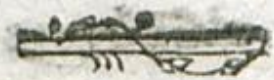

Sirifte atb; sielnehre verminsert ifgr fie, falls euev Stolz eitren hisheren Fllig als fie nimmt. Lağt unz ben Raotus unjerex Spháre meflet, Ino in sattelpuncte *) Gleiben, whe die Spins the in ber Mitte ifres Sienebes; wir werben uns bann immer fergif genug feyn, uno und ilber unjere Sdjwádje nidjt zu betlagen haben: benn wir werben fie nie fühlen.

2llle Zhiere befifgen genau bas su three

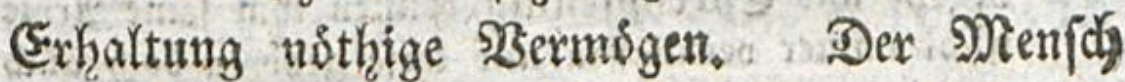
allein hat ein íberflusiges. Sit es nidft fon Derbar, Daf biejes Ueberfliffige Daß ŞSertzeng,

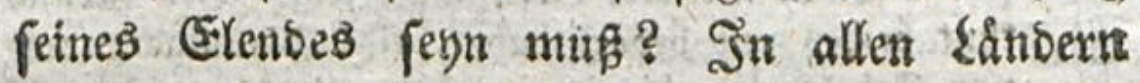

$$
\text { ก } 4
$$

brims

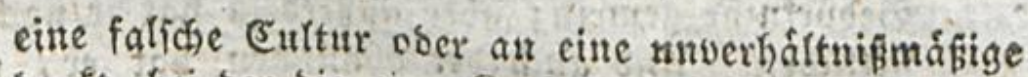
benft, bei ber bie eine firaft yor der andern ciren STorfprung gewitut.

Eampe.

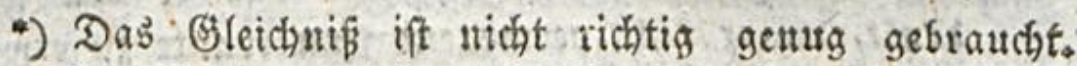
Die Spinte twirtt nicht blofi int der Dritte ibres Giencbes, fonbern bis zum åuferften rande Sejielben. So mu auth ber Nerich in allen Theis Yen bes IImfreifé wirfetr, Den bie siatur fúr feine Sirafte beftimmt hat.

(E) Ier'B.

(Eben bies hatte atif Rouffenit, fheint's, im Cint Er twill nur warten, Dap wir nicht etwa

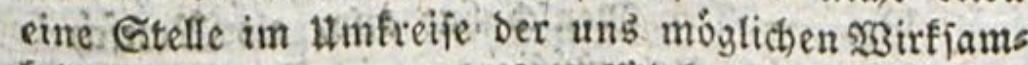
*eit gum Mittelpuncte unfere Whirfens madien mos

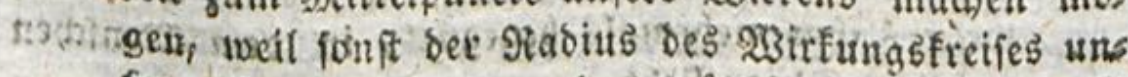

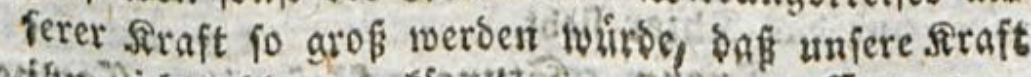

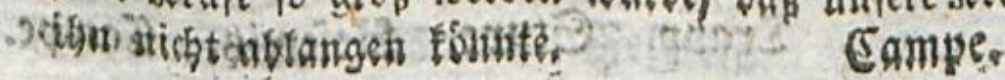


bringen bie 2rume eines Nienfoken mebre pin, alb ex oft finer (5xhaltung *) bebarf. IBare ex weife genug, biefen Ueberídü für nidjto zu adjtet, fo wurbe ex immer bas. Nothroendige has

-) Freifich fur Erbaltung feiner tbieriftsen \$a

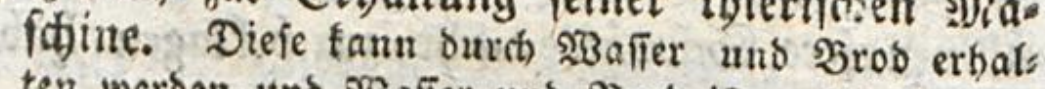
ten werben, und 23 affer und Fुros if wohlfeil. Der Gebrpfennig ift alfo fúr einen zu sedferbififen nidht verwobnten Menichen leicht zu erwerben. Aber ben S?otb) = uno Ebrenpfennig fónuen ifm feine Arme 40 nitht immer verichaffen, uno biefe geforen boch auch

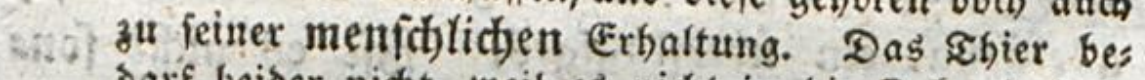
barf beiber nicht, weil es nicht in bie 3 ufunft fefht

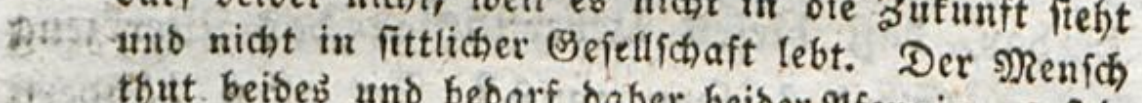
thut beibes und bebarf baber beiter Pfennige ju feis ner Erhaltung, bie von gróserm Umfang ift, als oie ber Ifiere. Er hat mit biefen bie phofifchen Beouirfniffe gemein; aber auperdem hat er noch bie fittlichen. Ind audh ber phnitiden hat er, wenn

stosis er noch fo einfach lebt, folour daburch mehr, bas er bie fúnftigen vorauşteht, und bas er ben fall denft, wo er nicht vermogeno fern fonnte zut eriver: beu, ob er gleid, bas S3eburfnif fúflen wird zu efs fen 2 c. Er batf alfo, bas fúblt er wohl, was auds

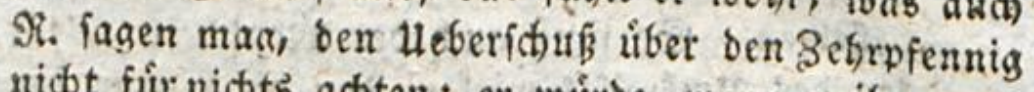
nicht fuir nichts achten: er wirbe, wenn er ifn regs touitfe, nicht immer bas Nothwellibige haben, wie ఇ. fagt. Demn gerabe um das 3iotbmendige ims mer zu haben, muf er bismeilen ju viel has ben. - Der soenids gat alio, als Menifty betrad,s tet, nichts Heberfuifiges, wie $\Re$ meint; ber hier, joeldbes ifm mebrmals begegnet, in Dem Menichen q7as mur bas Sbiev fiebt.

Irapp. Stupe Rierentio Campe. 


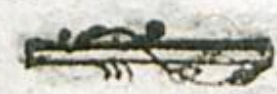

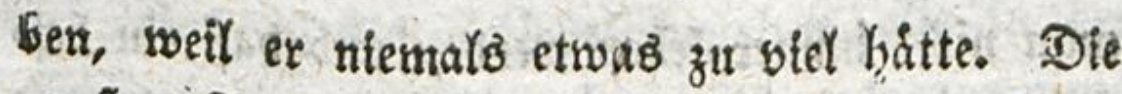
grofien Beburfniffe fagte Faborin, $t$ ) entftehen aus ben grofen Sintern; und oft ift bas befte Mittel fich bie Dinģe zu veridyaffen, bie uns abgehen, uns berex zu begeben, bie wir haben; eben baburda, baßs wir nns po abarbeiten, unfer Slick zu vermebren, berwandeln wir ez in Elent. Seber Menif), ber nidytb meiter ber=

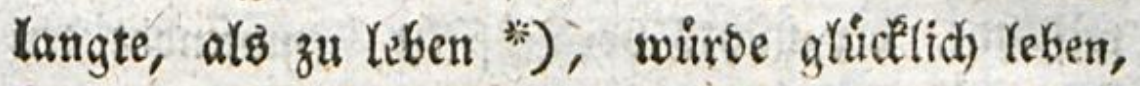

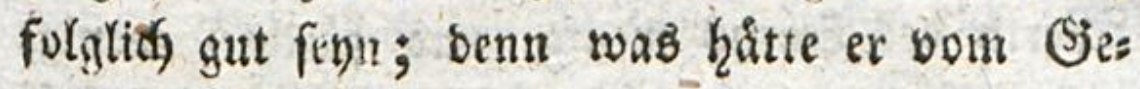
gentlyeile für 3 ortheil?

Reine elenbere 2 Sejen als wir, menn wir unfterblich wåren! Es if hart zu fterben; fein 3woifel! es ift aber angenehm, zul hoffen, baf

$$
\text { ז } 5
$$

man

†) No\&. Artic. L. IX. C. 8.

-) $233 i r$ múffent burchaus mebr verlangen, als blos thierifh fu lebeit, unfere Nienfthennatur bringt bas mothivendig mit iich. TBáre es alfo gleich wahr, bap wir ohne bieies siebrverlangen gludflid leben fonnten, fo beruft es boch auf einer 23orausjek̨ung bes Hnmiglichen; und es bilft alfo ju nichts, uns bavon vorzufagen. Stber ich zweiffe aud, ob es

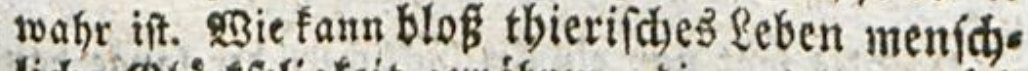
lidbe (Sltidfeligfeit gewáhren, die aus der gehoris gen Serbinbung und Wifichung von thierifiten, im teflectuellen und fittlichen angenehmen Empfindun

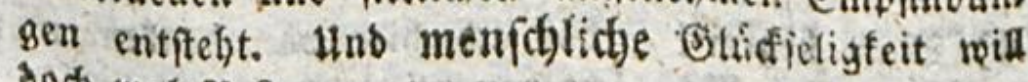
bod rol $R$.?

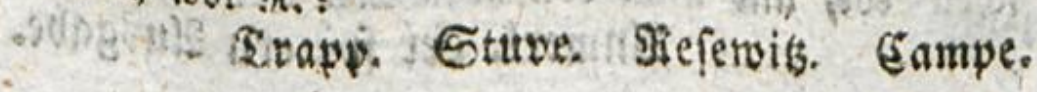




\section{8}

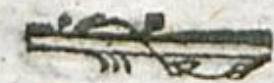

unan nidht inmer Yebent merse, uns baff eit befs reres Leben bie Keiben deả jef̧igen enbigen wirb.*) $28 e n n$ man uns Unfterblidjét auf bex Exbe anbste, wer wuirde des traurige (Sefdyent ant nefgmen wollen? $\phi$ ) SBeldae Buflatht, weldhe Sgofmung, melther Broft wurbe uns gegen bie

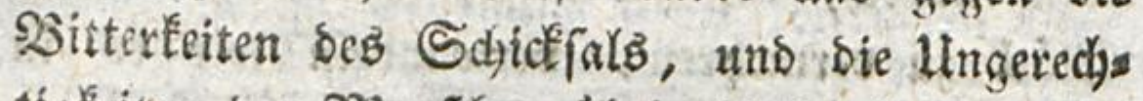
tigfeiten ber Mienfowen übrig bleiben? Der Uns wiffende, ber nichts vorausfiefyt, cmpfindet bets 22Berth bes rebens wenig, uns fuirchitet wenig,

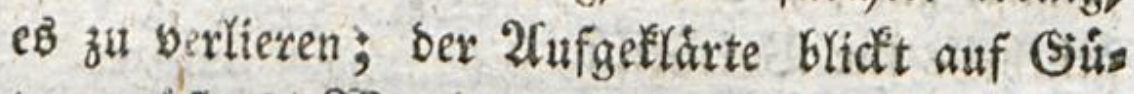

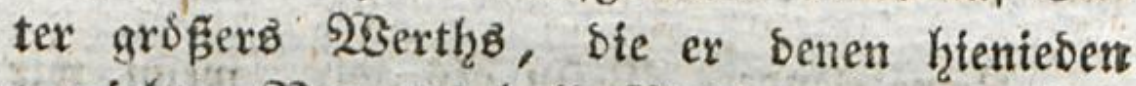
worzieht. Nur oas halbe Sुgiffen uns bie falfche SBeishrit machen, invem fie uns ble 2fusficht bis zum Iode him, uno nidjt weiter hinaus er Sfnen, bas fdlimmfte oer Llebel barans. Die शrothwendiateit zu fterben if fir ben 238 eifen sur ein Siruno, die Eeioen des Lebens za ertras gen. TZáren wir nidjt gewifí, e8 einmal zu serlieren; fo extauften wir bie Erhaltung bas son zu theuer.

\section{Unire}

-) Dies fagt nut cin Unglideficher, ber finge bauternbe

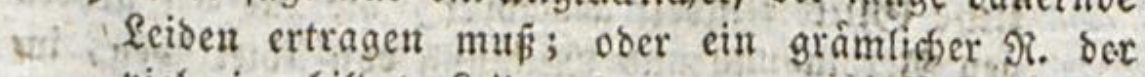
wur viel eingebildete Reiben hatte. SRelervib.

7) Man begreift, bẩ ich hier won benfenben Mens

fchen rebe, uno nicht von allen Menichen. on

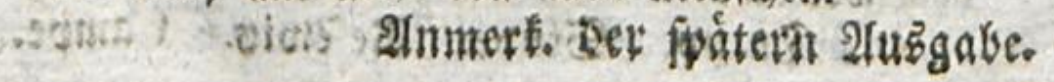




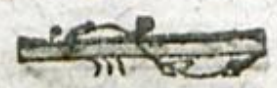

Utnfre fittlicken llebel beftehen alle in ber Einbiloung, *) ein (5inziges aubgenommen: bos lifter; uno biejes hángt bon ans ab. Unfre phyifichen llebel zerforen fich, poer zers ftoven uns. Die 3eit, ober ber Zoo, find uns fre-Sgeilungämittel: abex wir Yeisen utm po viel mehr, je wentger wix zu leiben verftehn; wno machen uns meffr Duaal, unire Rrantheit zu heben, als es uns foften murbe, fie zu extras gen. Lebe nady ber Statur, gebulbe bid, uns treibe bie 2(erzte aub: ***) sul wirft bem Zube nidjt entgehen, aber ou wirft ilgn nur Einmal finhlen, ftatt baf fie ihn jerst jeben בag in ocine beunruhigte Einbiloungztraft bringen, uno ihre ligneriīche Runft, bie beine Tage nidjt verlơns gert, bir ifren Genufs raubt. Id) werbe ime mer fragen, mas bieje Runit ben Nenjechen fir mahres Sutes gebradjt hat? Einige von senen, bie fie heilt, mirben allerbings ferben; als Xein Millionen, bie fie tsotet, wirben Yeben bleiben.

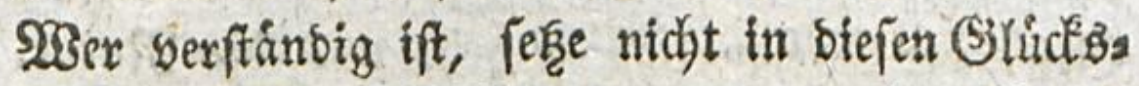
topf, wo zu viele Niteten gegen uns find. Eeibe, fitirb,

") Sch beziehe mich bier auf bie zur Seite 291 ges machte $\mathfrak{2}$ nmerfung.

Eblers.?

-) Heber biefe Materie ift bas Niotbige in bon jum ers ften soub gemadten frumerfungen gejagt.

Eblers. 
ftirb, ober gencie; aker oor allen Dingen lebe bis zu beiner leģten Stunce!

2Utes ift nur Thorheit und 23 iteripruds int

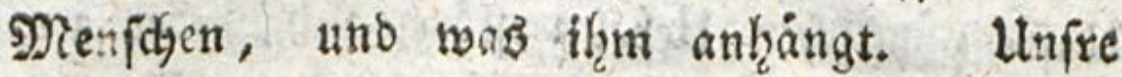
Sorge für bas Leben nimmt zu, jemeḩe es oon feitem 2 Berthe verliert. Die Sireife fehen mit

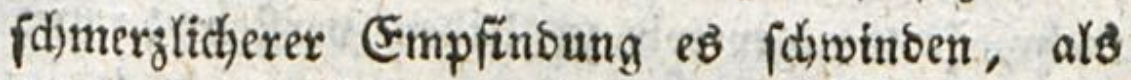
Singere; fie roollen bie 3uriftungen, bie fie gemadjt ḩaben, es̃ zu geniefen, nicht verlieren; in ben jechzigen ift es felyx hart zu fterben, ehe man angefangen hat zu leben. Man glaubt, in ben Menjhen wohne eine petge heftige $\mathfrak{B e s}$ gierbe (id) zu erhalten, unb bas ift wahrr; aber man fielzt nicht, bag biefe 2 Begierbe, fo wie wir

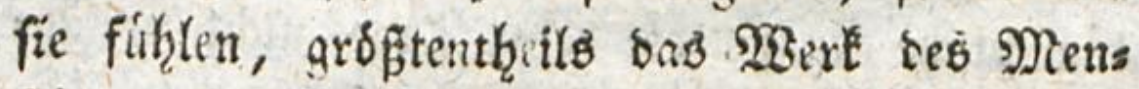
fden tft. Bon Diatur iff ber Mienfids nur in fo fern um peine Erhzaltung unruhig, alo bie Mittel bazu in feiner Senwalt find; fobalo bieje Mittel if̧m entgeben, beruhigt er fid, uno fatbot, olgne fid) unmígerweife zu quâlen. Das erfte Gefer ber Relizgnation ertheilt uns bie Natur. Die $23 i d$ en ftrouben fid, wic bie Jhiere, fehte weni, gegen ben Iob; uns erbulben thn, faft

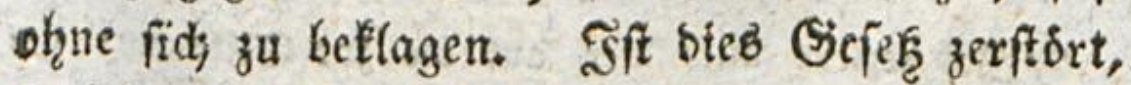
To bilcet fid ein anbercs, tas uns bie Bernunft giebt; allein $23 e n i g e$ wiffen fid bies ans the 


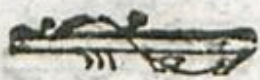

gu ziehen, und biefe gemadyte Refïgnation if niemals fo villig und ganz als bie erfte.

Die Norausficht, bie Borausficht! bie

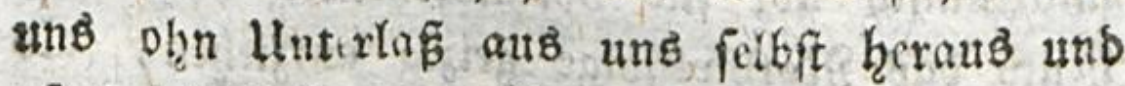
oft sabin bringt, rouhin wir niemals gelangen merden; diefe madjt bie wahre Ducle oll s uns fers Etenos ans. WBeld ein Llifinn benn für ein to bergánglidjis ftets fern in eine sufunft zu fdrauen, bie fo felten fosmmt, uno bie Gigentwart zu grnad) Jáfïgen, beren ex gewíp ift! *) Ein befto ver:

Serbs

-) Man geftebe indefi, bab biefer ttufinn, wenn es eis ner if, febr grofie uno tooblthátige fotgen fur bie פicnfobleit, im Banzen genommen, bat. 2Bo if bie uneigennúb̨ige beroijcbe Geele, die, obne diefen Inim, fưr bie Nachwelt arbeiten, ringen, téiben wolite? \$gm, und nux ifm alleiu berbanfen wir jese grofie gemeinnukige Hnternebmung, die ein Ses gen fur bie ş3elt und fúr die Rachwelt ward. Denn wer - wenn geder fo flug wáre, fich follechterdings mur auf ben (S)enuß bes Bjegenwártigen ciuzufchráns fen - wurbe fich baju bergeben wollen, etivas mit Scibe, duftrengung und Befabr zu beroirten, wos oon bie Fruid) erft in ber 3 ufunft reifen fonnen? Ran laffe unb alio bieien woblthátigen unfiun, und bemithe fich blofi inm eine richtung nach ben wórs bigiten und gemeinnikigiten Sielen zu geten.

Eampe. Trapp.

Obne diejen lnfinn, wie ibn $\Re$. nennt, wurben wir aud nidht cinmal Nenjiden fen].

serewis 


\section{2}

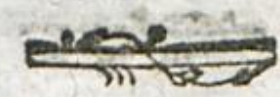

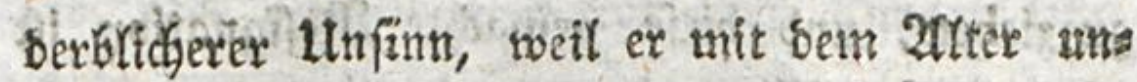
auffesrlide zunimmt, uno weil bie Greife immer misiranifa sot fid boransfęend, lieber fids hente sas Nothwendige geizig entziehen, als hundert Sahre weiter hin Mangel bran frabent roollen. *) So hängen wir bon 2lleem ab;

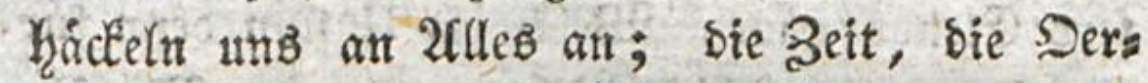
ter, sie Mtenictyen, bie Dinge, 2tfes, was tit, 2Ules was fent wirb, liegt einem Sesen bon une am Şerzen; unfer Șd tift ber Hleinfte Zheil inferer felbfi. Ein Seber berbreitet-fich, fo zu ragen îber bie ganze Erobe, unb wirb empfinds. lich auf diejer ganzen grof́gen Skerfláche. Sft ez, zu serwumbern, bafi fid́ unfre keiben in allen ses rifkrungspuncten berbielffittigen, in senen wir nux Qexwunbbar fino? NBSte mandje Jirften

bers

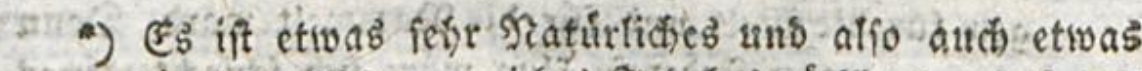

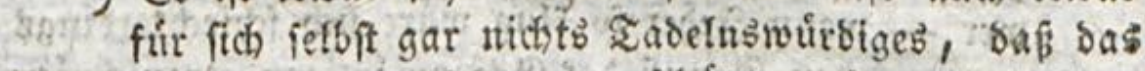

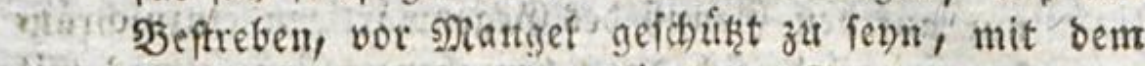
thia 2flter zunimmt. Die firafte bes Alten nefmen $a b$,

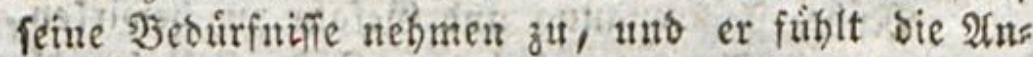
nowhertig ber Beit, ba er zu criverbenten 2 trbeit unfabtig unt gleichwol ber Şequemlichfeiten bes Les bents meht als jemars bevitiftig fern wiro: ift $\mathrm{eb}$ ifim ou verargen, pentit er etwas forgfanter uno

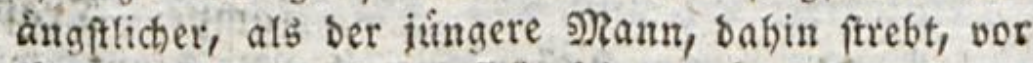
Nanget unb Ploth zur Seit feiner gánjlichen Jirufts yoligfsit gefichert of fers?

Campe. Neferpit. 


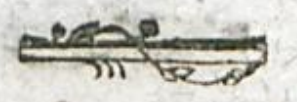

wergelfren fich nidyt in Eeib liber ben nes Landes, bas fie niemals géphen haben? $2 B i e$ siele: Raufleute barf man nur in Snbien

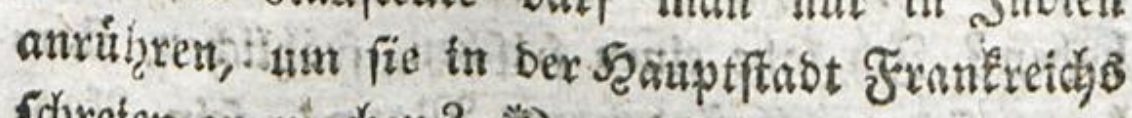
fchreten zи mathen? \%)

STft es bte Natur, weldge ben Menichent 10 weit ans fich felbft bercusmirft? *) 28 ill fies, bag Seber feim Shidefal non 2rnbern ers fathe

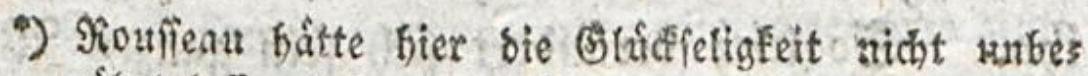
xuibrt tafien follen, bie fich wefentlich mit, 2auzbreis ting bes Nermogens zul wirfen und ber (Empfins Durgsfábigfeit verbindet. Derimentíg handelti alfo nicht weife, went er ben Irreis siefés zrwiefachen S3ermúgents nicht erweitert ober felbft verenget, fonts bern weinn er son biefem sermbgen eirren beifent

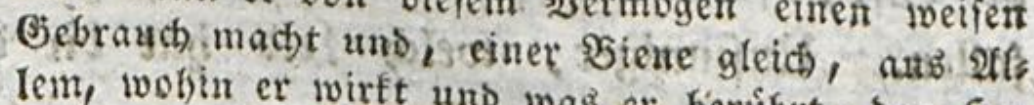
lem, wobin er wirft und was er berúbrt, ben $50 \%$ nig ber Bthicffeligfèit herautsholt, und wenn er bie Ephare, worin or wirft uno emprinbet, mit feiken

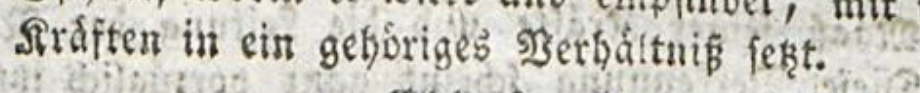

Eglers. Stapp. Seferits.

2*) Der Menich wirft fich nicht ats fid felbpt Gerauts, wein et fich einen Zhátigkeitss. Empfinoungs: uns Erfenntnifftreis bilbet, ber zu feinen fríften paft. 2tuch wirs er in jenem 5eftreben allerbings bon ber Tiatur geleitet. Die Natur verlief ibm bie firdffe Sakz, Die Niatur leitet ifn in Dem. Siteis umber, ben er fich eigen macht, utub die Natutur fetht alles in jenem Sireife Befrnoliche init ifm in Serbindung

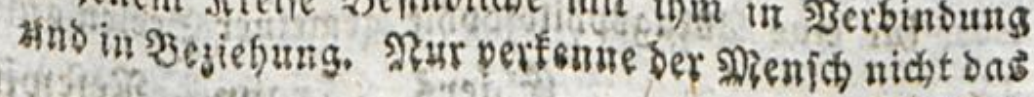
2xant 
fabre, unb autweflen ber lefgte fey, bet es ers

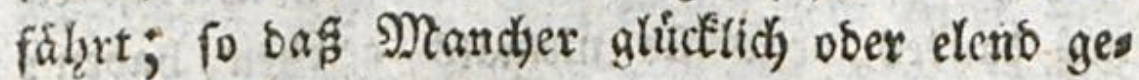
ftorben ift, ohne je etwas sason exfahren zat baben? $\Im^{d}$ falge einen frifdyen, froblidjon, fars Een, fich wohlbefinbenben Mann; fein 2tus? fohen, flisgt Frenbe ein; fetue Blicte bertuns bigen Sufriebenbeit, SBohlfeun; ex trảgt bas

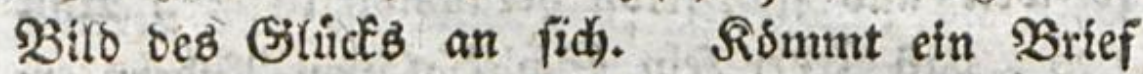

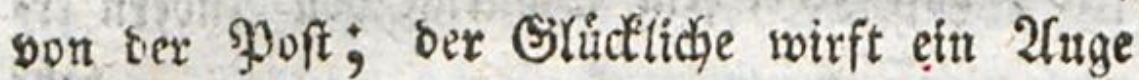
barauf; ex ift an thrn; ex sfnet thn, lieft ibtr. Sogleid) beranoert fich fein ganzes IJes fen; ex exblafit, fällt in Shnmadt. 2Bteber fu iids gefommen; weint er, tobt, feufzt, rauft fid) bie Seare aus, burdjommert mit Sefdarei sie Luft, fobeint in forredr!ctie 3udtungen vers fallen. Utminniger, weld, Seit hat bir benn bied

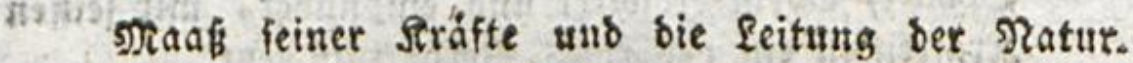
Diefe 3erfennung ícheint ganj vorzúglich ik̨t bei bielen wafren ober fich bafúr haltenben philofophis fchen Sopfen Statt ju finten, die bas, wab Eicero

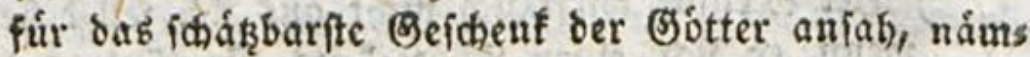
lich an Bsmeinfint ber NRenich heit und an gefunbem 2zerfande frarf́ ju ienn, wie etivab gemeines vers achten uno die cine $\mathfrak{Y}$ bifoiophie, bie aíles, was fie lef̧rt, vorgutglic für die Fiolle ambenobar macht, reldhe der sienich, un mogfichit núkliot und mogs

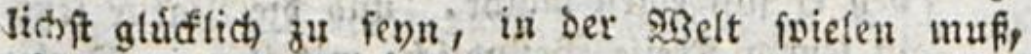

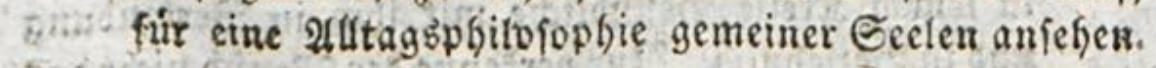

Ëblers. Trapp. গiejemil. 


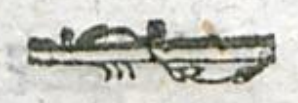

\section{Sies Papier angetban? *) was fur ein Silied} hat es bir genommen? meldy ein 2 erbrecken bat es bidj begehen gemadjt? Rurz, was bat

*) Sier mache sjerr formed folgende stumerfung: "1ein bloker rebuerifcher 24usruf! Şenn man autch wollte, fo wifirde man fich boch nicht von ben áupers fichen uno entfernten Begenftándes losmachen forns nen; aber gefeķt, mant bráchte ę fo weit, Daß́ man biefe Şanbe fchloćchte ober zertiffe: fo twirbe man Daburch an ben syergnuigungen, bie baraub bei sus Sern Selegentheiten entipringen, eben fo viel ver: lieven. Der Untergang cines Sdjiffes betrúbet heirte ben Raufman, ber fich uiber bie glícflidse 2tnfunft von funfaig anbern'gefreut hat. (I) babe eitum Sohn im Nriege; feine Şriefe liegen mir an şers zen, und haben mich oft exfreut; ietzt fommt sin verbrúphlicher; er ift gefangen: wollte ich wúnchen, biefen Goln niemals gehabt, niemals গ̧riefe von ifm empfangen zu haben? So ift bas feben be fhaffent ber sgeisheit fommt es zut ind bas befte Dfeil baraus zit ziefun; unb getvis fie fant es thun."

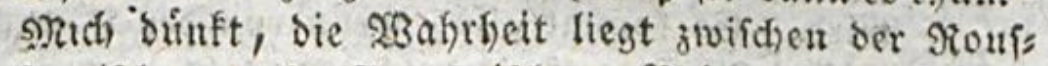
feauif(ben und formenifchen S3efauptung in ber Nitte. Niach jener mifste man fich von allen menichs lichen Serbăltniffen losmadben uno fowol fein Em: pindurgsvermogen, als auch feine IStraft ju wirken mur auf fein eigenes $\mathfrak{g}$ (b) cinf(t)ránfen; nach biefer fonnte man beiber fireipe nicht zu felsr nubsef)nen, rocil bie angehmen folgen bavon bie unangentehmen

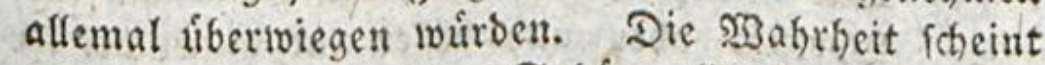
fu (enn, bas man feine Spháre allerbings erweitern faun und folf, aber wohlgemerft! immer in richtis gem \$erbáltniés mit feimen Siráften. So lange siejes 3erbáltuif beobadtet toiro, min̄en soir bei jeber Emil Ifter \&6. \#

Er 
es an sir fellff beranbert, sidy in sen 3uftans

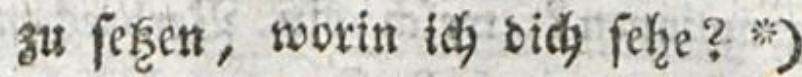

Sgitte ber Srief fich verirrt, hadtte eine Yiebreidye Sand iffn ins Fener getworfen, fo wáre bas Sdjictialotefes zugleidy gludélidien uno unglideftiden Mtannes, wie midh beutht, eine Feltfane 2Tufgabe gewerett. Sein Linglict, wers bet ther mix fitgen, war eit wirtlidyez, Sehre wohfl; aber er empfand es niddst; wo twar

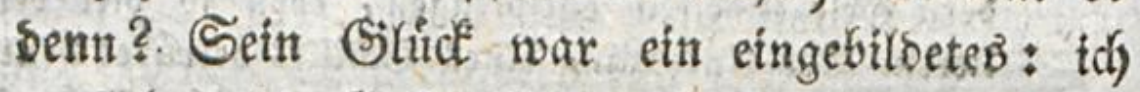

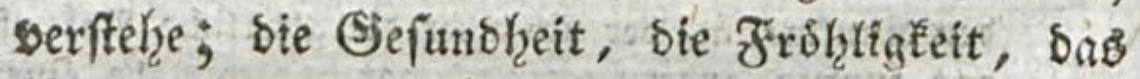
2sohlfernn, bie Seifteszufriesenḩeit, find nut Exfódeinungen. SWir find nicht mehre, no wir fino,

Erweiterung nothivenbig getwinnen; aber and ebetz fo nothwendig verlieren, fobald balielbe úberfdsritten twirb. Es fommt alfo, wenn von ber Sbeftimmung

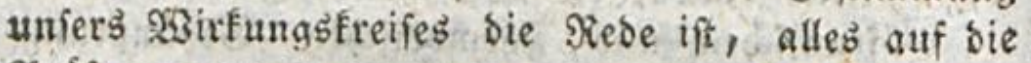
Prifung an: quid humeri valeant, quid ferre recufent.

Eampe. Tlapp.

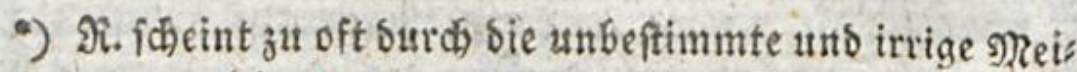
numg geleitet zu werben, bafi ber Naturmeníd vor Sem gefitteten ober burch) bie (5efellichaft gebilbeten

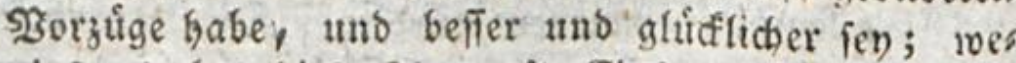
nigftens hat biefe Goee oft Cinfluf, fo wie hier, auf feine 2utsipricthe uno Urtheile, welche baburd eine falide Stimmung erbalten.

\section{Referwiss. Eampe.}


find, soir find nur, wo wir nicht find. *) Ş: eB ber Mitige werth, eine fo grofe Furcht bor sem zode zu haben, wenn anders nur bas bletbt, sorinnen wir leben?

\section{2}

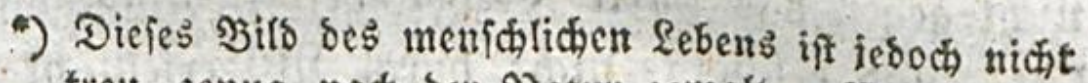

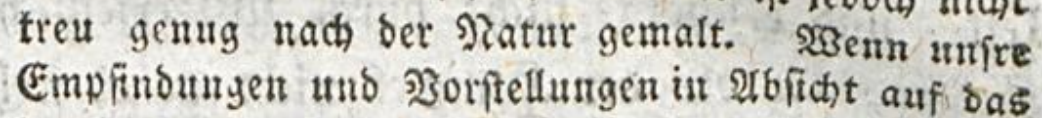
bamit verbundue Strgenebme oder Hnangenebme mit bein Einorud úbereinftimmen, ben auf ber 2)enichen wirfende áupre Dinge allgemein unb nach Der naturlithen empfinbbaren bef haffentheit ber Dinge auf ibin macten: fo ift bas nicht ein 2 SerE $^{-}$ ber Einbilbang. 2utch ift es nach bem gemeines Eprachgebrauch alfo feine blopie Erfobeinumg, went man gleich diefen 2 fußbrute in bem Sinne, worin

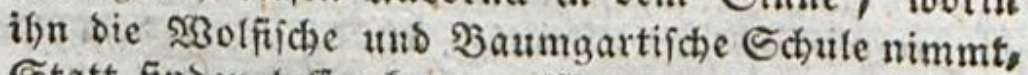
Statt finden lafien Eamu. 2 Benn nach ber fier ans gegebenen 2frt zu empfinden, wohin bie Natur alls gemein bie Nenfichen leitet, ber Nani; welder ben ¿̧rief befommt, mişvergnuigt ober traurig fenu muñ : fo ift es barum noch nicht unveife, wenn

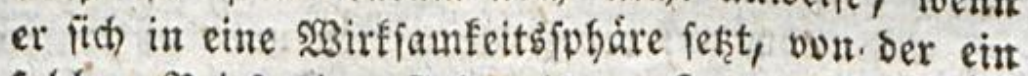
folcher SJrief eine Solge ift. Sgat er fich feine

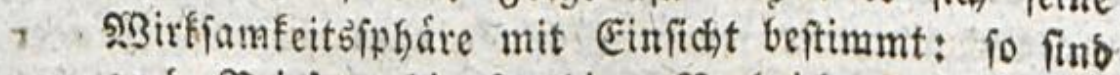
auch Sriefe, bie freubige Nachrichten enthalten, eine Folge davon. Damit, bẩ man einen foldten Nenichen einen Srief, ser boie Nachrichten enthditt, nicht in sie soánde fommen lábt, ift inm auds nod feinesweges ficher eitr Dienft geleiftet. Diejer গुrief funnte ihn vielleicht in ben Stand fekzen, ein noch gróseres Hebel ábzuwenben, das erfolgt twáre, went Dev Jirief fich verirt ober wenn man ifn ins feuter getworfen bátte, \&્flez̉, was sin weijer \$mann in

fols 


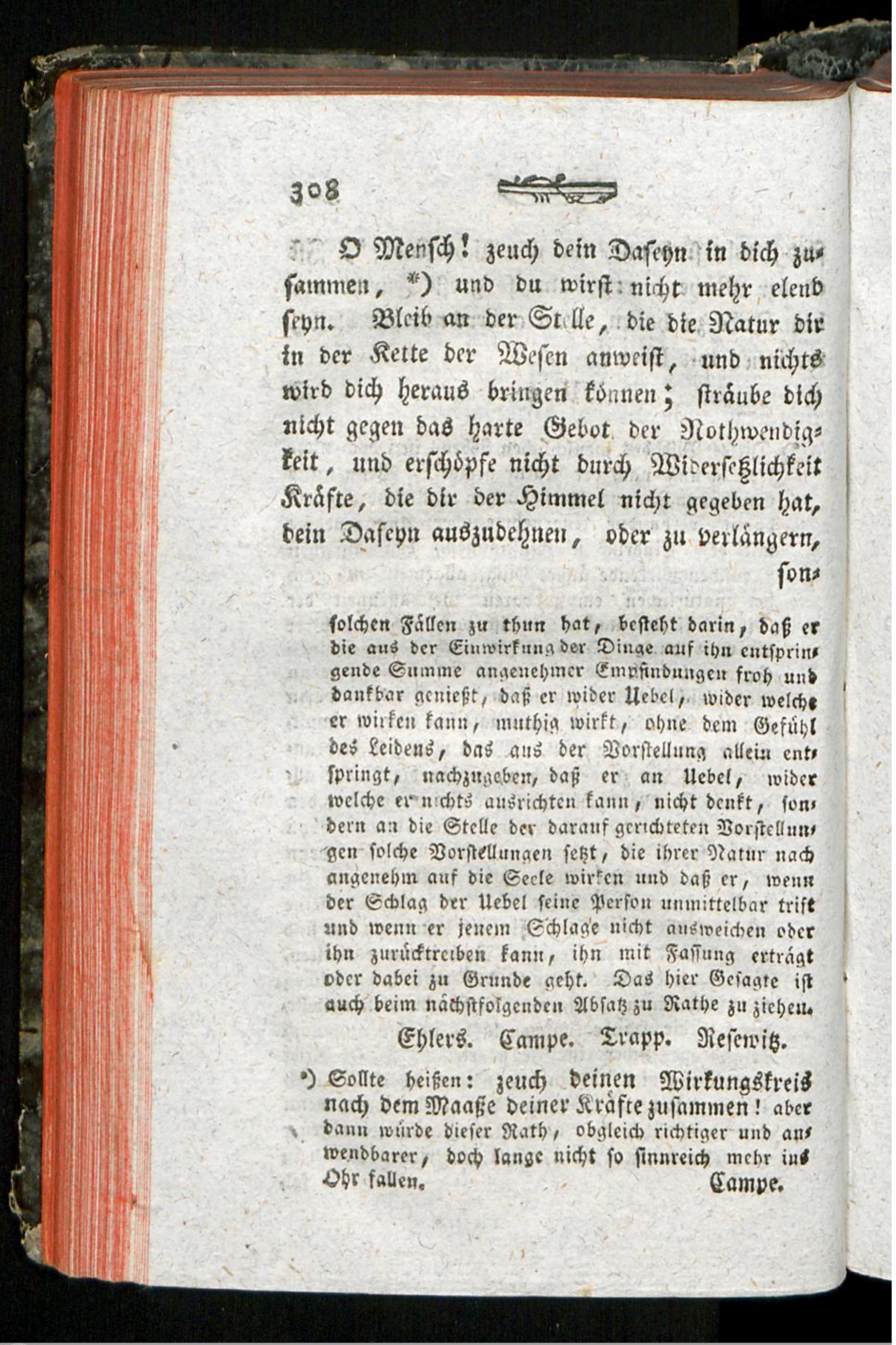




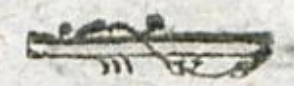

fits

no

bir

its

(d)

igs

cit

it,

$\pi$,

$n$

er

ins

no

be

ing

ats

ier

ns

III

(1)

in

ift

er

git

ift

t1.

i3

er

as

1

Fonbern mur zu erfhalten, soie es thm gefallt, tind fo lange es ifim gefâlt. Deine Jreiheit, beine Niad)t eritrecken fich nur fo tweit, al\$ Deine natúrliden Sráfte, ") uns nidyt bariber binaus; alles 2fnore if mur Sinechtidaft,

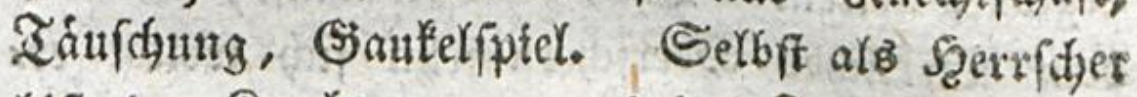
bift bu Sinedot, wenn bein Seerr fens von ber Meeinung abhångt, benn ałB̉baun ḩängft bu mit you ben $\mathfrak{B o r u r t h c i l e n ~ b e r j e n i g e n ~} a b$, bte su burd) \$orurtheile regierft. ltm fie zu Yen fen, wie es bir, must bu sidy feteft fo nefrmen, wie es ihgen beliebt. Sie birfen nur thre $2 \mathfrak{r t}$ zu benten verábern, fo wirft bu wol gezwons

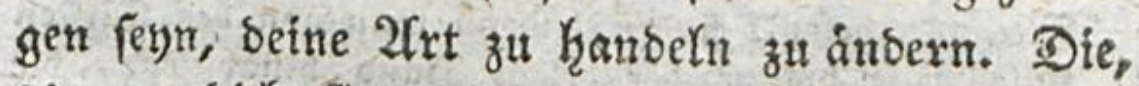
bie unt sidy finto, Graudfen nur bie Meinungen

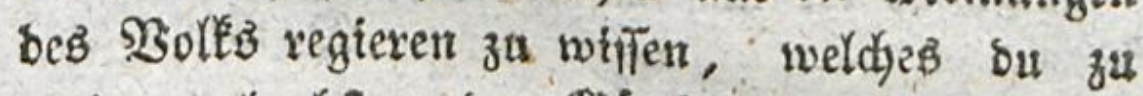
regieren gluubft, ober Shinftlinge, bie sidg) res gieren, ober bie Meinungen beiner Familie, obet beine eignen: Diefe $\mathfrak{B e z t i t e r e , ~ b i e f e ~ S o f l e n t e , ~ s i e j e ~}$

$$
\text { Ul } 3 \quad \text { gofafo }
$$

- aber auch bie geúbten, auszgebilbeten unb verịtárts ten Firáfte bes aebilbeten Nienichen verbienten noch) tratůrlidje Seráfte genanst zu werben; und mit biefen barf er and foll er einen weit grófern fireis ausfúllen, als ber rohe Naturmenf́h mit feinen ungexibten uno unentividelten Sid́ften $e \xi$ zu thun

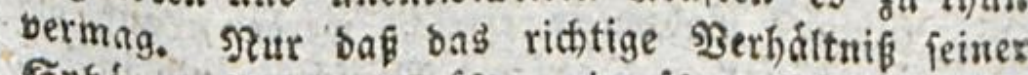
Engáre zu feinen Siraften nie úberidhritten werbe.

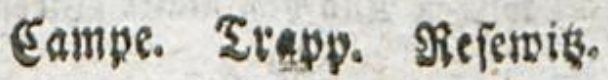




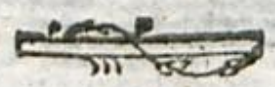

IYFaffen, bieje Solsaten, biefe Keibsiener, bieje Rammersirnen, ja Rinber, werben bidi felbft, wenn ou aud ein. Bhemiftufles an Gieifí soárft, $\dagger$ ) wie ein Sino mitten unter beinen Segionen leiten. Thu, waz bu willft, nie wirb Sein wirtlidjes Şerrfdyeranfehn fid weiter ers

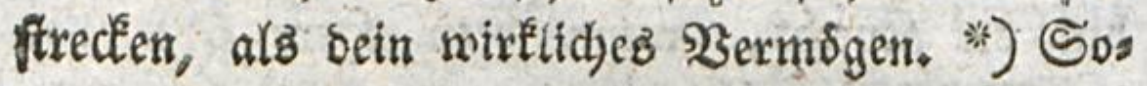

ballo

¥) Diefer fleine Sitrabe, bent ifr ba feht, fagte shes miftotles zu feinen Freunben, bat das Edhiffial Gries dentands in Sáduden: Denn Ev regiert feine Diutter; feiue Diutter regient midh; ich regiere die Itthenienfer, und bie Atthentienfer bie Briecten. O D, wie wúrbe. man fo oft bie grofften Sieiche burch bie winzigftert Menfthen gelenft finden, ween man von ben fúriten ftufentweife bis zu ber erf̂ten fjanto binabftiege, bie inśgeheim ber Mzafdine ben Sdjwung giebt!

D. Berfaffer.

") Themiftofles toúrbe feine Freunbe, Denen er bas fagte, fúr felfr cinfáltig gebalten haber, wenn fie Das, was in einem gewiliten Ginn an biefer giede

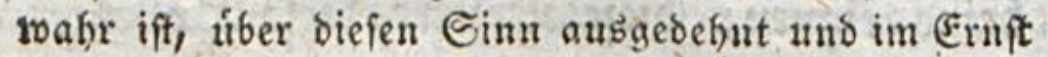

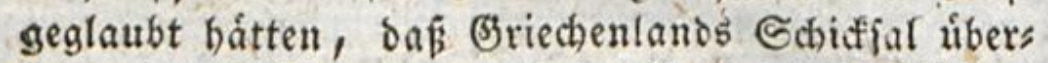
haupt vielmefr vom Snaben, als vom Themiftofles abbinge. Eblets. Nefêtwik.

-) Das wirflide \$ermógen bes Mienjchen gebt aber fo weit, als er burch Dittel bie in einem gefórigen

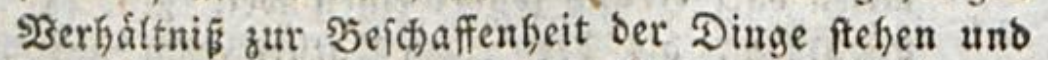

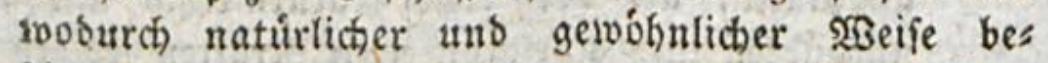
fimunte Enbzluede erreiht werber, auf bie rBelt Liberhaunt und auf bie Nenichen auch insbefondere soirten uno beftinumte Ş̧irfungen herborbringen fant.

Eלblerß̧. 


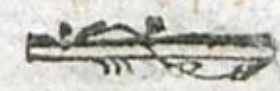

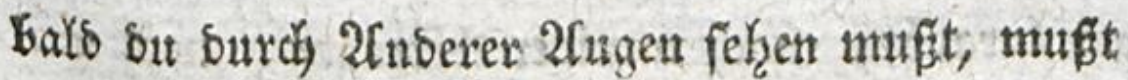

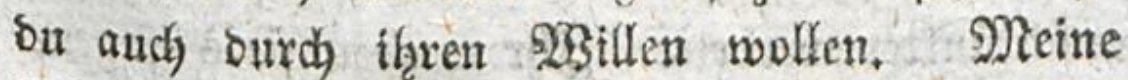
Boffer, meine Unterthanen! fanft on ftolz. (5:B fey; aber bu, wer bift ou? Der Unterthan beiner Minifter; uno was fins wieber beine ginifter? Die Unterthanen three Schretber, ifrer Buflertmen, Die Dienex ifrer Dies

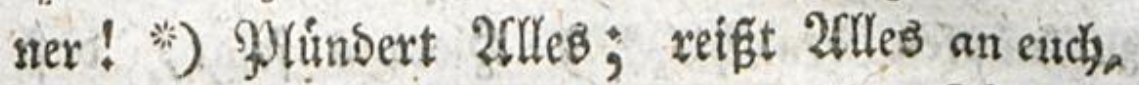
uno veraendet bann Şeld mit vollen Ş๕noen,

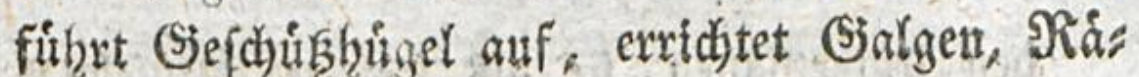
ber, gebt Serefe, Beroromungen, bermebrt bie Runofăhafter, die Solbaten, bie Senter, Sie Siefangniffe, die Sietten: arme, fdumadje

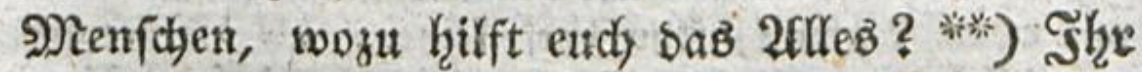
werbet barum weber beffer bebient, nod wenia il 4 gere

9) Das if freilich oft, aber feinesiveges immer ber Fall. Şem fált hier nidjt ber zulef̧t verftorbene grope Sibnig vou Prewpen ein?

Eb) Rers. Refenibs.

-) Fier madt fyerr formels eine Anmerfung, die eines \$bilofophen unwurbig ift. "Dieje arment fifwadjen \$penficit, fagt ex, verbienten ein wenig mebr 2(d)tung, nicht allein weil fie lange Arme baben, fonbern auch weil baran gelegen ift, Dafs Der Einbruct Der Ebrfurdt, bie man ibnen fit) ulsig if in Der (Sefellfhaft feine berwegenten Ingriffe leibe. Sen Ronigen fommt es ou, fid in erinnern, Das fie Denforen find, uno QetI 


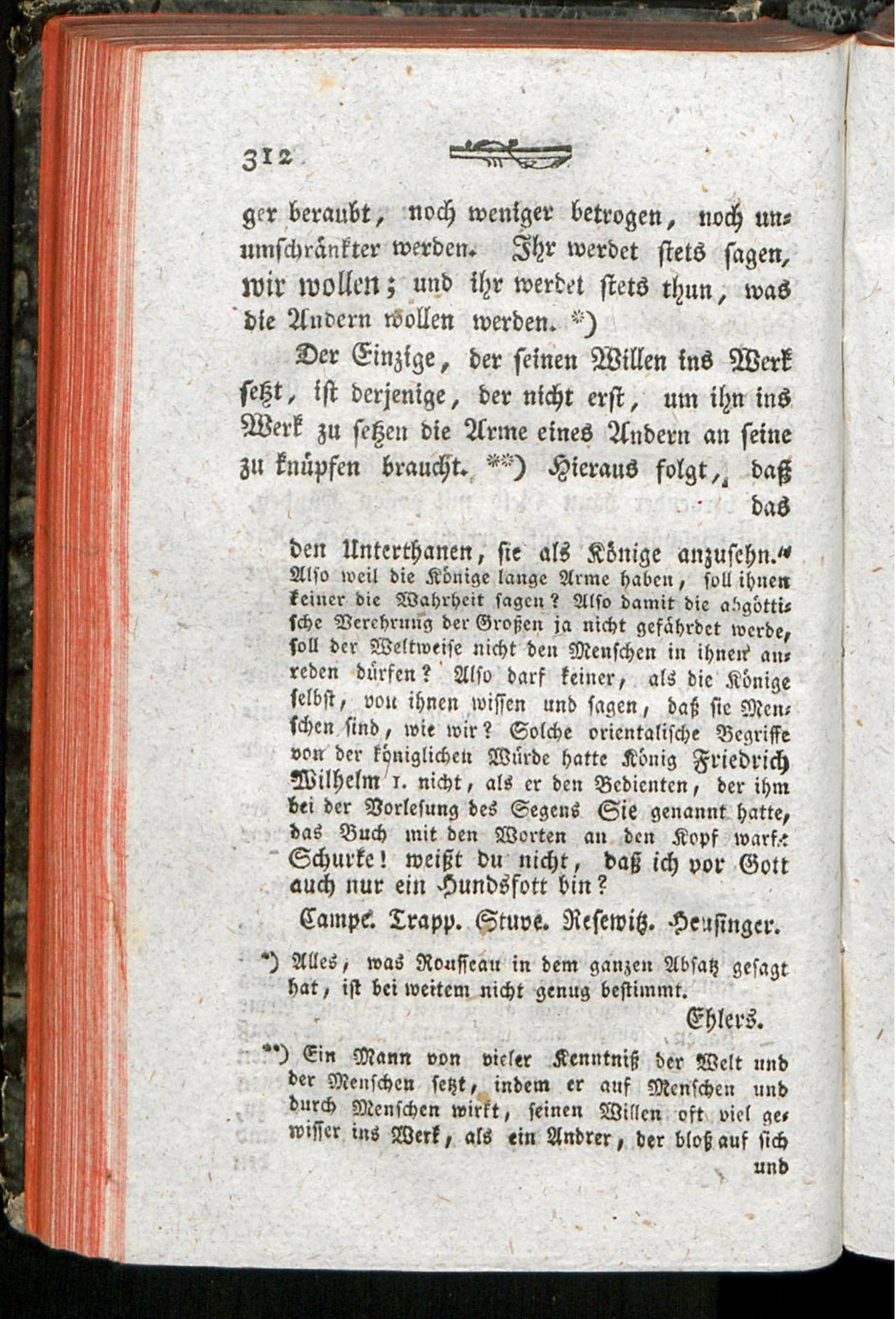


- Das exfte aller Gititer nicht Madjt unb Gerwalt, fonbern Jreiheit ift. *) Der wahrehaftig freic Mann will nux bas, was ex fann, uno thut, sats if̧m gefallt. Das ift mein SStundagunds fing. Co foumt nur barauf an, ihn anf bie Ritnder anzumenten; uno alle Regetn ber $\mathcal{E}_{x=}$ żieflung werben baraus fliefen.

\section{U 5}

Die

und burch fich unb auf bie lebloje und Duth bie leblofe Natur wirft. So roenig ift das bier Gefagte wabr uno auf eine geborige firt ins lidit geferit uno beftimmt.

(E) ler?. Referris.

") Sreikeit uno Nadht werben bier nibt alf cine ges horige 2rt unteridjieben. Ohne einen getviffen (brab bet Nacht giebt es feine Freiheit. Worzúglicher 25 seife verftebt man unter Freibeit freilich bas $23 e r$ mógen bes \$enfchen von feitren perfontichen Rraf: ten uach feinem eiguen joecrzuftande (5)brauch ju maden. Es if aber auch bem allgemeinen Spracts:

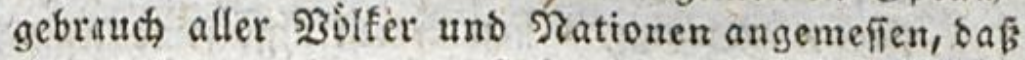
man ben ungehinderten (sebrauch aller rachtlich er norbenen (3) uter uno গुefugniffe mit zur Sreikeit rechnet. Eine folche erveiterte Freiheit fólieft offens bar cine bazu ftimmenbe eribeiterte Nacht in fich. Nan fommt alfo bei ß̧etrachtung ber Paterie, bavon Rouffeau bier rebet, am Enbe blofi zu bem seffuls tat bin, bab ein weifer Mann nicht weiter nuffe uuf bie sigelt wirfen wollen, als er nach ridhtiger Erfenutnif feiner eignen Sráfte, ober Eigenjchaften uno Sirafte anbrer Dinge uno ber weicntliden Ein ridtung, nad iveldber alle iene firáfte toirfen, veldse wefentlidbe Einrichtung wir un's unter Sas

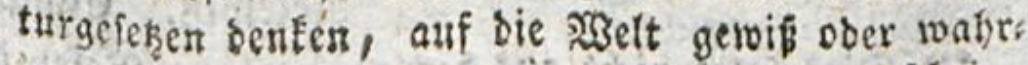

fdein" 


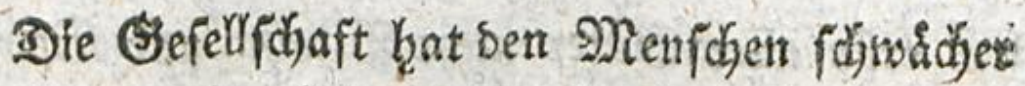
gemadyt, nid)t allein baburd), baß̧ fie ihm bas Recht benommen, weldes er über feine eigenen Sixafte hatte, fonbern vorneḩmlich Dabuxd, baßß

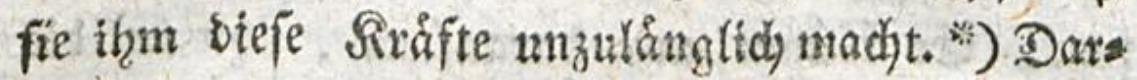
um verneţren firth feine Begieroen **; ) mit feiner Sdjwadde, und hienin liegt bie Sdhwadje ber Rindheit verglidien nit bem Mannbalter. Sît Der Mann ein ftartes 2 zefen, uno bas Rino ein fdjwactjes! So ifte nidjt, weit bei exferem methe

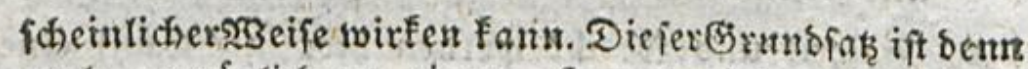

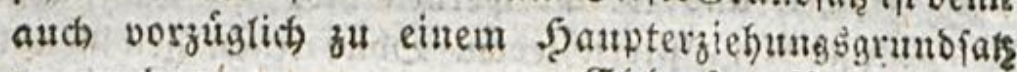
zul macten.

Eblet:s, Referwit.

*) Nan mú fich, um dicfe Eteile recht zu verftefu, an bie richtige Erflárung erinnern, bie $\Re$. oben woul Echwáche uno Stárfe gab. "Ein Ţefen, fagt er, Deffen Siraft feine ஒुeburfuiffe überfteigt, ift ftarf; Dasienige, beffen כeoburfnifie feine Straft tibers fteigan, ift foblwad)." 23 seil es mun báufig gemug ber frall ift, bap das gefellf(t)aftliche leben bem Menfchen mefr Beburifniffe giebt, als feine Niráfte befriebigen foumen: fo ift es auds, oft genug wahr,

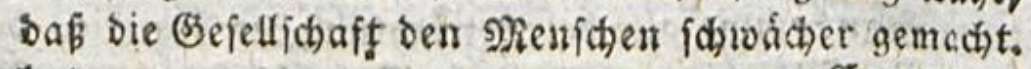
hat.

Eamipe.

atber went sie Befellichaft bem Menichat zus toeilen Siráfte nimut, ober feinen şirfung;freis einichránft, fo giebt fie ifm auch oft Sirafte burth

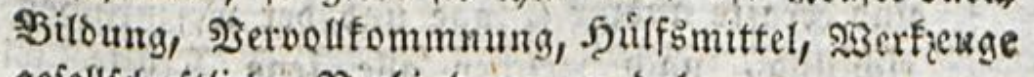
gefellictaftlictie serbinbung it. Dgl.

Rejenis. Eamte.

a*) Dieb folgt nicht aub bem vorigen. Siefews.t. 


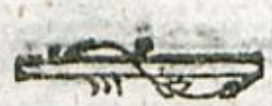

mefhr abjolute Stárfe, alz bei Yeşterem fid fine

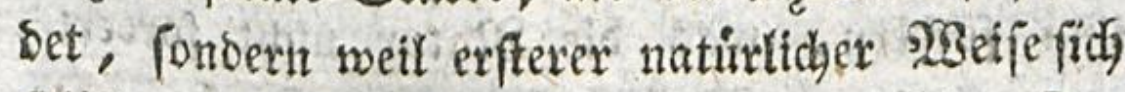
felfoft genug fén Eaun, uns Kef̧teres nidht. Der

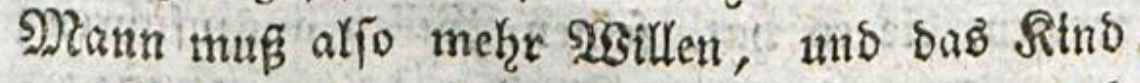

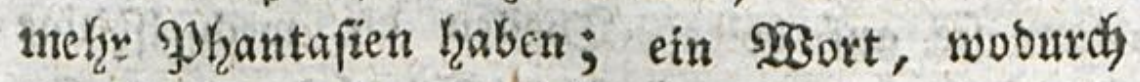
ids. alle Begierben berfteke, bie nicht wahre $\mathfrak{B} e$ Sirrfniffe fino; uno bie man nux surch den $2 B$ eis ftand eines 2 Indern bifriesigen tann.

Shis habe die Urfache diefes 3uftandes ber Sthwáche angegeben. Die Natur forgt bafir surch bie elterliche Stebe; allein bet biejer liebe

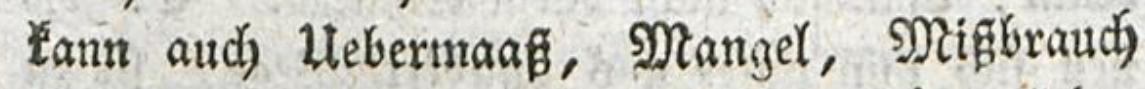
Statt finden. Ertern, bie in bem birgerlichen Stande leben, berfergen ihx Sino zu fribzeitig in biefen Stand. S̈noem fie ibn melgr Bes surfniffe geben, als es hat: fo helfen fie feis ner Sdjwadje nidjt auf, fie wermehren fie. *)

2(ud)

-) Dies if fefr ridstig. Man follte bie untivitiden

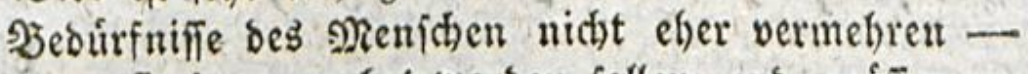
ween fie ia vermefrt werben follen und múfien als bis man anth feine natirliden Sráfte in gleis dem Serbáltuiffe vermebrt hätte. 2(ber leiber? thut man gerabe bas Begentbeil. Nan that alles,

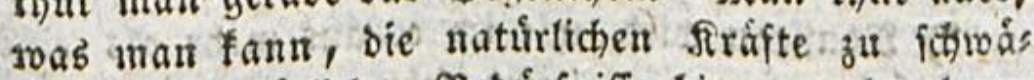
den, bie naturlideen beburiffiniffe bingegen surch uns

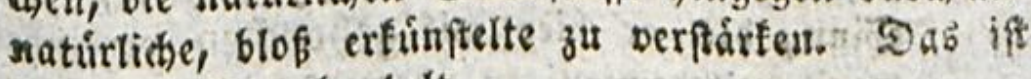
Pefre unueife gefanbelt.

Eampe. Stropp. 53 
2ud bermetcren fie fie Saburds, went fie son ifgm foroern, was bie glatur nidyt forberte, soent fie ifrrem Willen bie wenige Rraft unters werfen, bie cв hat, feinen 2 Billen aนถ่zufübren; wenn fie auf beiben Iheilen bie wedbfletige 2lbhángîftit, womit feine Schmád)e es an fie, 1 uno ibre Siebe fie an Das Sino Enupft, in Sclirs serei bermandeln.

Der weire Mant weif an fritter Stelle

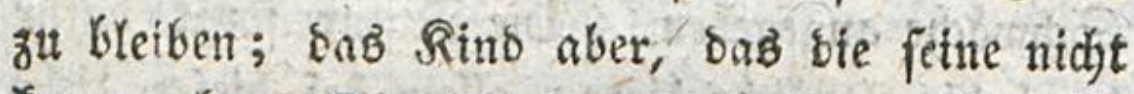
fennt, fann fich nidjt barin extgalten. (5. $\delta f=$ nen fich ihm unter uns bqunbert $\mathscr{Y}$ gege, fie zu verlaffen; Denjenigen, bie $P B$ regieren, formmt $e^{B} z$, $e B$ barin zurietzuhalten; uns $\delta a s$ ift fein Yeidjtes MBerk. (5. foll weber ein Laft= thier, noch ein Nann, fonsern ein Sind fern;

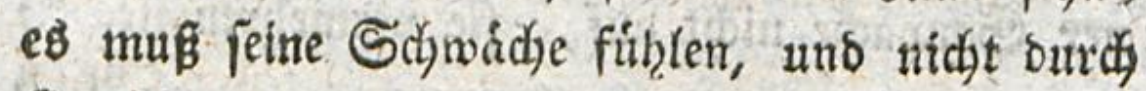
fie leiben; es muß abhången, nidjt aber ges hordjen; *) es muf verlangen, aber nidbt ges

bieten.

Es Gålt nut fdjlver, bier bas riditige Maab zu treffen.

Rễernikg.

7) भouffeau wiro, wie id es aus mehr als einer Ers fahrung tweí, leidht fehr gemifbeutet, weil ber Sinn, ben er bier mit gebordien verbindet, jut roenig mit bemienigen kibereinftimmt, ben man bies fem $\$ 30 r t$ allgemein beilegt. Er ivill námlich, ba

matk, 


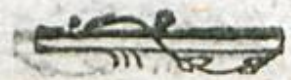

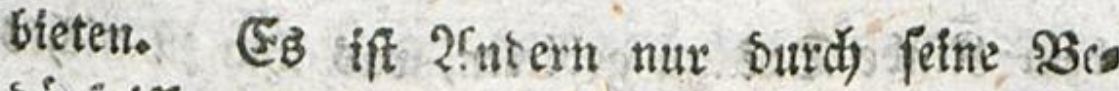
Sirrniffe unterworfen, uno weil fie beffer fehen, als $e \xi$ felbft, was iftut nitglich ift, was feiner Exhaltung zutrảglidí ober fdadolich fogn f́ann. Seiner hat bas Niedyt, nicht eimual ber Bater,

man, fo viel als es miglict) ift, ein Sins surch: befo fen eignen Joeenjuftand uns burch bie auf baffelbe toirfenden Ilmitande bilbe und leite. Sigsentu bas aber auth mit aller eritunlichen 23 eisfeit uno (jes fchicflichfeit geiduteft: fo bleiben bennodh unzalblige Sáalle librig, worin Befehle notbig find, uno worit bas Sins geforchent mus. Dazu fomint Mod, baß man cin Silio, wedches beftimmt ifi, in buirgerlicher Sefellichait zu leben, uno bie aus der gefellichaftlis (hen 2 erfolinng entipringenden 2 thoronungen und כefehle ju befolgen, jeitig getvóbnen muf, bie Steigung, auf cine vermuftige 2 rt zu gebord)en, mit einem gebörigen freiheitşinn zu verbinden. Ta es ift, bamit das ภino vor Einbirdung, súgelloritgs feit und einem ju weit gebenden Eriebe nach feirem eigenen Sinn ju handeln, bewahit werbe, febr beits fam, es von 3eit zu Seit erfabren zu laffen, baß eb, fich ganz felbft uiberlafien, fich oft uno leicht in cine bófe und ungluctitide lage feßze, und baṕ beffen fheinbar eigner socenzutand uno bie Daranf fich

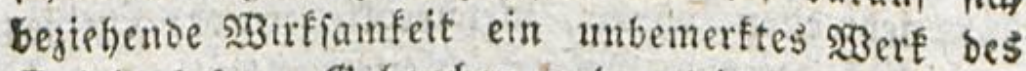
Ergiebers \{e\%. Selfordjen und geleitet werben ges Gort alfo zu bent wichtigften Erforberniffen ber תinos heit, und ein Sitno muf́ es jeitig wifien und exfaho ren, bä́ es gebordjen múfle.

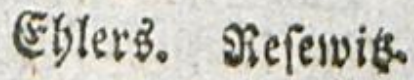




\section{8}

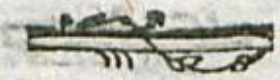

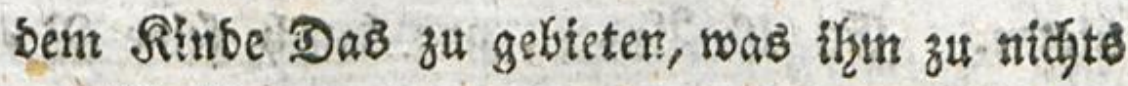
gut ift. *)

So range noch nicht bie Sorurthefle uns bie menfolidgen Eintidytungen unjere naturlis dien Sieigungen berántert banben, befteht bie Ghickifeligkeit ber Rinber, fo mie ber Errwadjfea

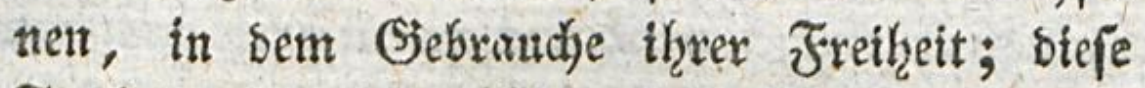
Freifgett aber teibet bet exfern Einfdurinfungen burd) ihre Sdywadheit. W3er bab thut, was ex will, ift glicelich); wenn ex fid felbft genug ift; in bem Fall Yebite ber Nenja im Stanbe Ser Natur. SEBer bas thut, waB er will, tit nicbt glidetid), wenn feine Beobirfnifle feine Rrafte itberfteigen; in bem fall lebt Das Rins in bemfelben Stande. Die Sinber geniefien fogar im Stande ber Siatur num eires unoolls Fommenen Freilgeit, bie Derjenigen gleid)t, bes ren sie Erwadjienen in bem burgerlfdjen Stande

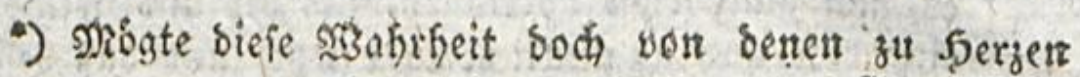
genommen werben, bie da glauben, daṕ fie nidht za fefr eilen fonnen; jarten Sinbern Jienntniīe, Fers tigfeiten uno Sefchidflichfeiten mityutbeilen, bie ihs nen, weil fie für biefes Sflter etwas Hnmatúrliches find, allemal fobaben, niemals nikzlich werben fons nen, und bie fie nach zuridigetegter. Sindsheit viel (eichter unt auf eine fúr iffe ganze 2 usbilbung mins ber fitadoliche ảbeife erwerben fonnten!

(5ampe. 


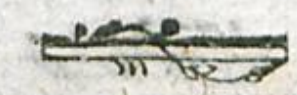

gentefent. Da Feber pon ins Ser 2rnbert nidyt mehrix entbefzren fann, fo wirb ex fin biefer 20 bo ficht wieber forwadi) uno elend. Sigir waren ges bohren, Nanner zu fern; bie Siefefe aber uno bie Siepellidaft haben uns sieber in bie Sitnos

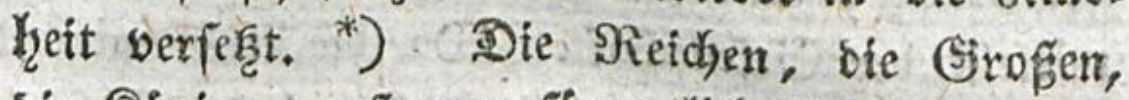
sie Rónige muß̈ man fámmtlid, als Rinner bes tradjten, bie, wenn fie fehen, bafí man fíd) bea eifert, threm Elende abzuthelfen, eben baourch Hindifis, eitel, uno ftolz auf Dienftleiftungeir werben, fo man ifnen nidht erweifen mirbe, wenn fie gemadgte Mianner waren, **)

\section{Die:}

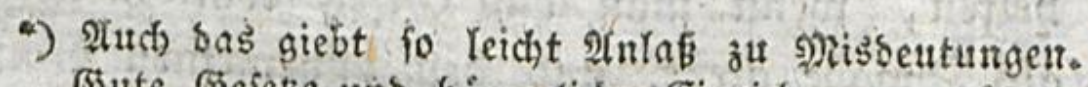
(5)te Gefę̧e uno búrgertiche Einridhtungen fúfreir uns nid)t in bie Rinbheit zutudf, fonbern veranla|s fen unz perminftig hanbelnde Nadnter zu werben. 5l3er Poufieau nid)t mit vieler eignen (Einitht lieft, sirb tiberbaupt Duth bie 2urt, toie felbiger oft fdreibt, leicht veranlabt, niber \$ieles auf eine unges Guifrliche unb unvernúnftige art juberfichtlich und enticheibend zut urtheilen und zut reben, mit bem, was in ber menichlichen șefellichaft gefdieht, ims mer misuergnigt zu ferna uno bas im Staat zas werbell, was man fid unter einem unrubigen Ropf Sent. Eglers. Srapp. Riejemibg. Eampe.

") Shr. Formen finbet hier abermals, baj man von ben' Seichen, ben Sropien, den Sionigen fo etwas,

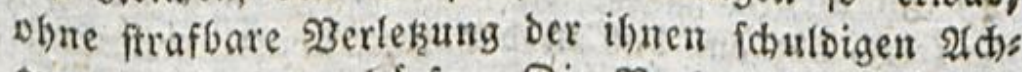

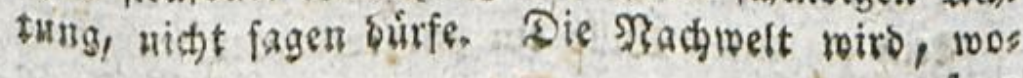
fera 
Diepe S3etradjtungen find widjtig, und sies

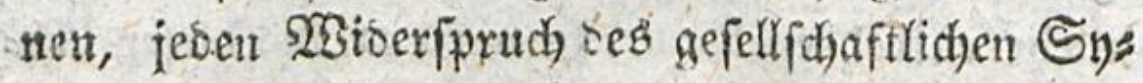
ftemb aufzulófer. Fes glebt zroeierlet 21rten 2l6hángigkeit; bie son sen Dingen bermittelff ber Natur; uno bie von ben Menfiden, vers

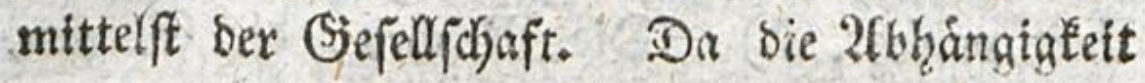
son ben Dingen feine Sittlidłfeit hat; fo f(c) a

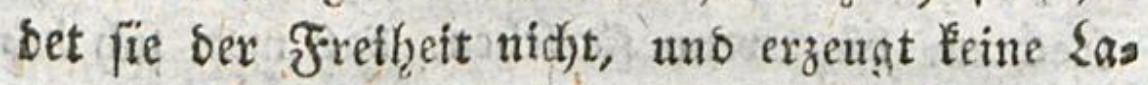
fiter. Die 2fohángigleit oon sen Thenfoden hingegen ift ungeoronet, uno $\dagger$ ) ergettgt fie alle; surdy fie berberben ber Seerr uno ber Rinecht einanber gegenfeitig. গTur bas fann ein Mit:

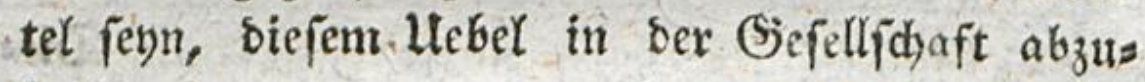
Kelfen, wenn man sas Sejefer bem Mtenchen - alb Sugabe giebt, und ben allgemeinen $\mathfrak{F i l l e n}$ mit einer die Şandlung jebes einzelnen $\mathfrak{2 B i l l e n s ~}$

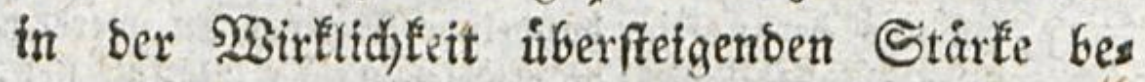
wafnet. Rinnten die Serefre der Sisfer, fo wie bie Geferge ber ЭRatur eine bon feiner menfdy.

Yichen

fern set 2 Inti= Fmil zu ifr fommen follte, fich fd) lverlich úberrében laffen, bak biefer \$hiloioph das (3) luid gebabt bat, unter Friedrid) Dem (Finzigen zul leberr.

Eampe.

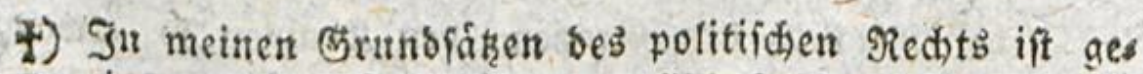
zeigt toproen, baß̉ in ber gefellichaftlichen Einrid,tung Eein sinzelner şille eir gutgeorbneter fenn fann.

D. Berf. 
Vidyen Strilke liberminobare Itnkeugfamtett bas ben: fo wirbe bie 2tobángigleit von ben Mens

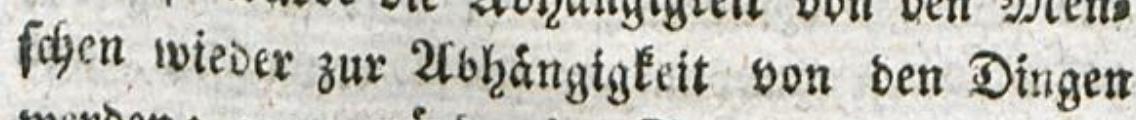
werben: man wirbe im Staate alle $\mathfrak{B}_{\text {ortheile }}$ Des natirlidyen Standes mit ben 2 ortheilen Seb burgerlidyen; und mit ber Jreiheit, ble ben Menficen bou Laftern rein exhålt, bie Sitts (icheteit, weldye itha zur Zugeno exhebt, wers binben. *)

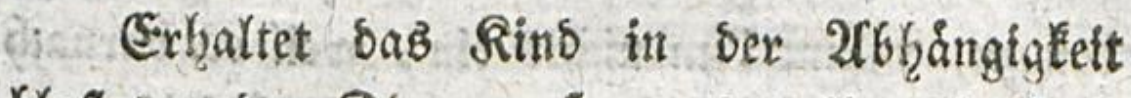
blofi bon ben Dingen, fo merbet ibe bie Sros nung ber Natur in ben Fortichritten feiner (5is ziefhung befolgt haben. **) Stellt feinen unvera nưnf:

9) Yortrefliche Gebanten, die man bei ber Befétges butg immer vor Stugen haben follte, und woran atth Sichter und Sadwalter inmer benten follten.

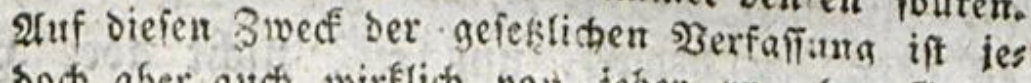

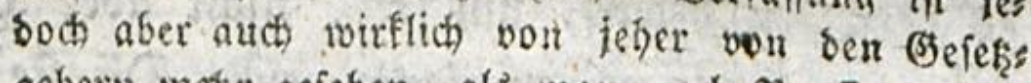
gebern metr gefében, als man nach Nouñeaur wers muthen follte.

(Ë) lers..

-) Man muß aber ein אind es auch zeitig wiffen lafs fen, Dẩ eine nach Nouffenus Joeen eingerichtete

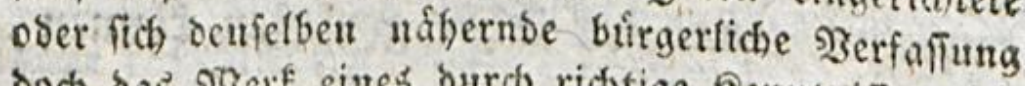

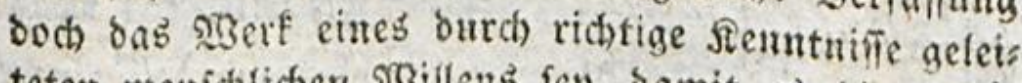

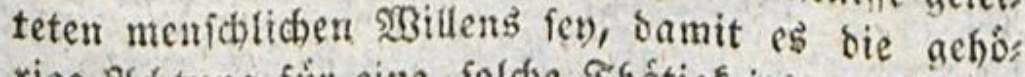
rige Ifobtung für eine foldie Státigfeits: uno \&ens fungsfraft in ber Natur Der Dinge beformme und

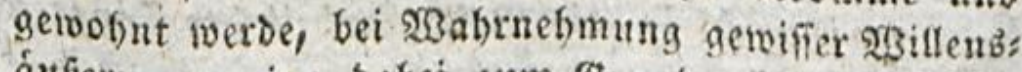
áuberungen eine babei zum (Srunbe liegenbe richtis Emil Ifter $\mathfrak{T}$. 


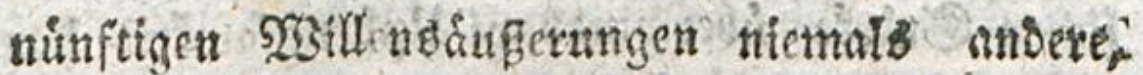
als phofifdue Sitioerniffe oder Strafen entgegen, bie aus den Somblumgen felteft erroadgfen, uns beren es fid), wenn die (S)legenbitt ba ift, crs

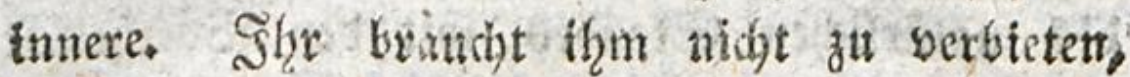
Ulebels zu thum; $\mathrm{eB}$ ift genug, baf ifgr $\mathrm{cB}$ Dare an berhinsert. Dis Exfahrung ober bas Utt: vermigen allein muffen ihm fatt bes Seferes bienten. Geftehet teine Sadje feinen Begiers sen 3แ, råumt ffim nichtô ein, weff eb barnads Derlangt, funbern weil es ein Şeburfnif bazu bat. (5.B miffe gar nidjt wiffen, wao Serhors ram ift, wetn es handelt; noth was Serrfajaft ift, wenn man etwas für baffelbe thut. (5.8 fühle gleich ftart in feinen und in euren Şanda lungen feine Freibeit. SMan exfege die Stars te, oie ihm gebridht, mur gerabe fo siels als es berfelben bebarf, min frei, nidjt abe: Serrs fcher zu fein; es emprange eate Dienifte mit einer 2rt bon Demuthigung, uno Yerne Doburds uad sem 2fugenblid ftreben, mo $P B$ threr wirs entbehzen, uno oer E.jre geniefien tonnen, fich felbif zu bebienen.

Dic

ge Einficht in bie Befdaffenbeit ser Dinge, als ets was uicht gan 11 moabribeintiches ficts zu benfen.

(E) lets. 


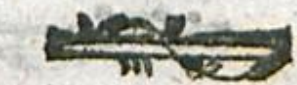

Die Slatur ḩat zur Stintung $u$ sut

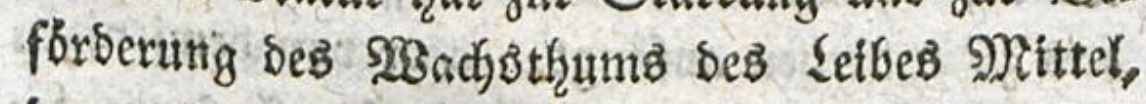
Senen man niemals entgegen arbeiten mu. STan foll eit Rino nidht zum Stillfisen zwingen, menn es̉ getzen will, nod) zum Giehen, wenn es bleiben will. SIStro ber NBille ber Rinber nidjt surd unfre Sdults berberbt: fo wollen fie nidjts umfonft. ") Sie miffen fpringen, laufen,

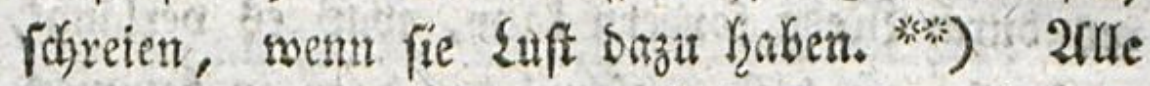

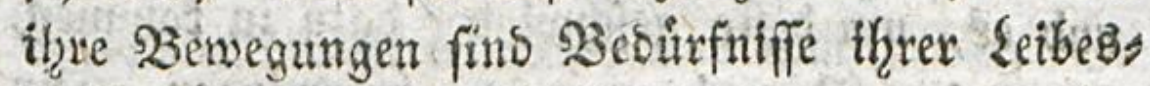
befodaffenlicit, bie Gtarke zu geminnen fucht: man mus aber mit mißtrauenber \$orforge nuf bas zreyt haben, was fie berlangen, wenn fie

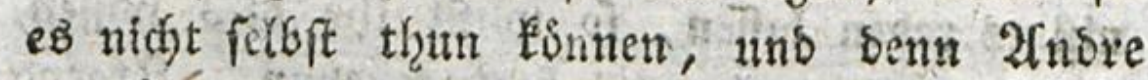

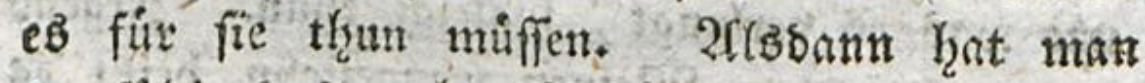

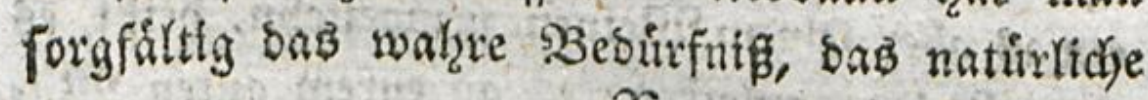

$$
\text { モ2, SBe }
$$

-) Das ift wabr ; aber auth foldhe Simber loollen boch nicht felten etwas, was ihuen oder uns foldalich ift, uno in bergleictien fodllen muf' benu boch ifr 25ille notbwendig butd) den unfrigen eingefordunt

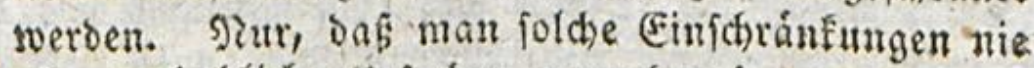
ohue erbeblidife Hrachen vornefme!

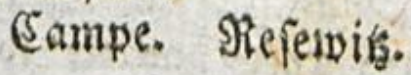

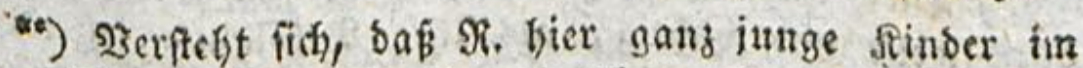

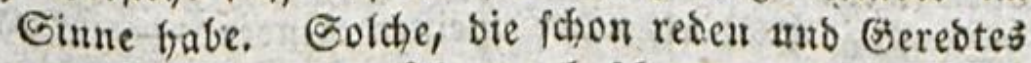
veriftehen fónen, múfien auth idson angehalten wevs Den, burch ibe Lermen imb Edfreien 2(nbern nidst

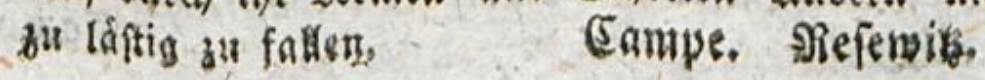




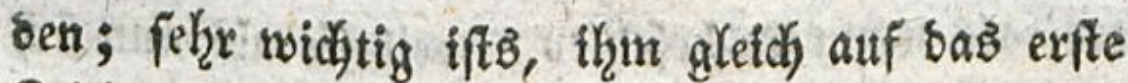
Zeidjen bas zuzuftehen, was man nidjt bers fagen will. Sens nidyt berfdymenterifó, mit abfaldigtgen 2fntworten, wiberruft fie aber aud niemaไs. *).

Scitet euch) vor $2 \mathbb{U l l e m}$, bem Sinbe citele.

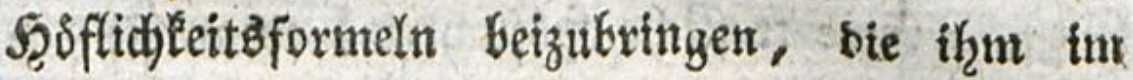
Slothfall ftatt Bauberworten bienen, 20he um (id) herum feinem 2 Stllen zu unterwerfêt; uno augenblictlich zu erhalten, was thum gefallt. Sth

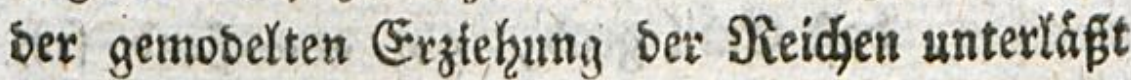
man nie, lie hoffich) befehlishabexifh zu madjen, inbem man ifynen bie 230 orte borfdjueibt, beren

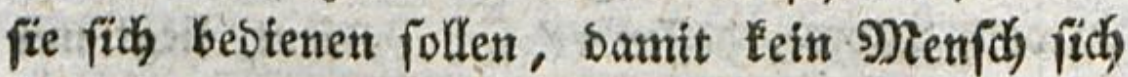
getraule, ifnen zu wiberftreben. Die Rinber Dex Reiden f̧aben nie einen Semulthigg bittens ben Ton nodh Benbungen: fie fins eben fo ffolz anmafieno, jo anmafenber, wenn fie bito

$$
\text { X } 3 \text { tert, }
$$

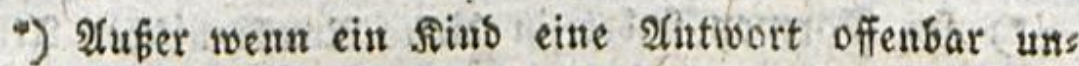
recht gefunben hat, unb unredit bat finden múfien.

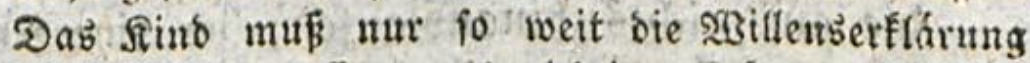
gerne gelten lafien, als richtige Erfenntnif oabei zum Sratube fiegt, ober als es wenigftent Eeine uns richtige Erfenntnif babei zum strunbe liegen fieht. Ein Erziefer, ber in einem folden fall feine 2 hut:

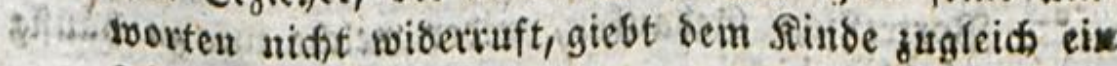
febr bojes $\mathfrak{B}$ eifpiel.

Eblerb. Seufinger. Fiejewit. 
ten, als menn fie befehlen; weil fie alosann fid nut nod) biel berficherter halten, baf thnen wexbe gehorcht merben. Man fief̨t gleid, baß̈ bas, welnt e' Slynen beliebt, in if̧rem Mans be ein: mit beliebr's! bebentet, uno san: itif bitte Cie, bei ifrnen: itf befeble sutch! Grift. Sine trefliche Sooflidgleit! wern fie bas ourch) weiter nichts als ben Sinn ber 28 orter berwedgfeln lernet, unb immer Soch -nur alB

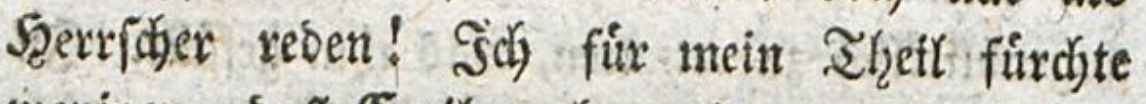
ronenigex, saf̧ Emil grob, als anmafieno fey, uno will Yieber, bafi ex bittens fage : Slut

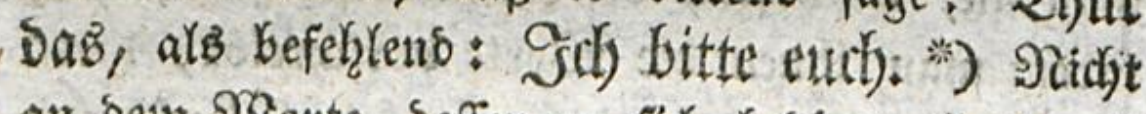
an bein gुorte, beffen er fid bebient, Yiegt mit (Etwab, aber tool an ben शserfande, in sem ero nimmt.

(5) gebt eit Utebermaaf bon Strenge uns ein Uebermaaf an Slachficht, mobon jebes gleids

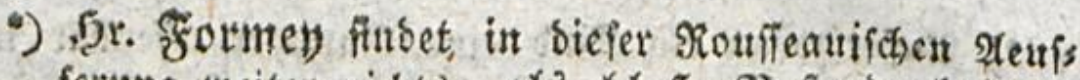
ferung weiter nichts, als blofe Sefonberkeiten,

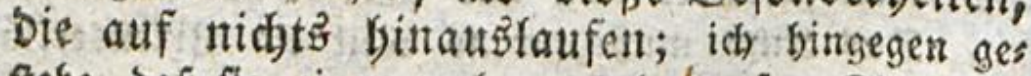
ftebe, dafi fie cirren wabren uno grofen Sinn fuir

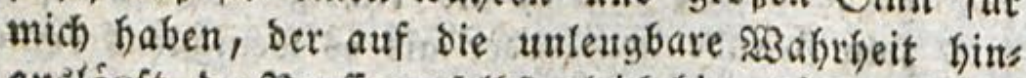
auslauft, bie Rouffenut felbft gleich Ginguftigt : "NRicht an ben $930 r t e n$ u. f. wo. Campe.

av) Sortreffiche Eebanfen, wiber weldhe mur zu báuig gefúnbigt wirs.

E)blevb. Eampe. Etube. Itapp. Referwib. 


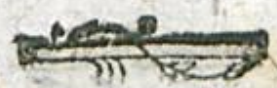

gletd) fef̧r zu vermetsen tft. Safft tfer bie Sine

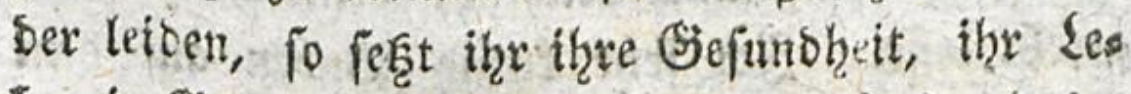
ben in Sefahr:; ihr madyt fie gegenwartig elent; iberthebt ibr fie unit gav ju vielex Sorafalt jes Ser Ulubehaglictseit, fo bereitet ihre ithnen grof (5ileno zu, berzartelt fie, madst fie empfindlid); uno bringt fie aus ihrem 3uftoube bes Menfd)e feyns heraus, in ben fie einft wiber euren SBits Yen wieberum zunididteren werden. Damit ifge fie nidyt einigen Llebeln ber Natur ausjegct, maritt ifs euch zu Lrheberu bevienigen, bie lie ridjt íber fie verhångt hat. *) Shlzr merbet mir fagen, idy ftellte midy ben fdjlectiten $\mathfrak{B a}$ tern aleidh, benen idh vowwarf, fie opferten bie (S) ickéleligfeit three Sinber ber Betradytung efo ner entfernten -aeit auf, bie bielleidjt niemalsె Eommen fann.

2(ber mit nid̆ten! **) Denn sie Fretheit, bie id meinem $3 D_{g}$ linge ertheile, sergutet ihm

$$
\text { X } 4 \text { bas }
$$

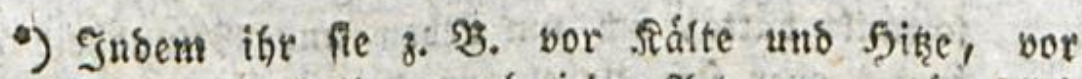

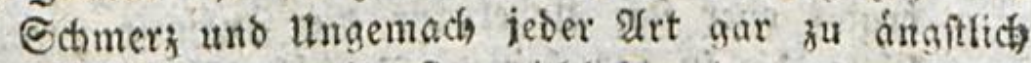
betwafret, madit ibs fie weichlid umb cmp find fich an 2eib uno Geele, uns werbet badirch bie Urbeher ats rer ber seiben, bie ithen, afb folchen, in ber Folge ganz unatsbleisfid beverftetin.

Camise.

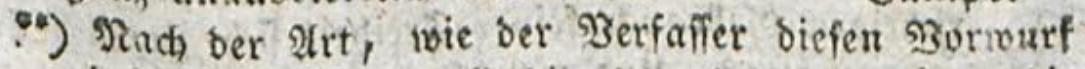
(intleibete, traf or allerbings aud foldhe \$áter, bie 


\section{8}

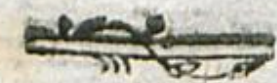

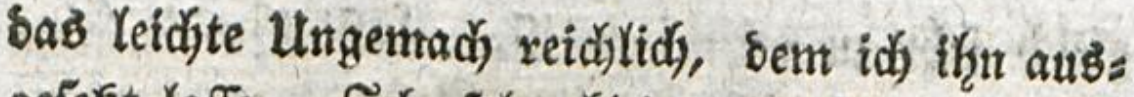

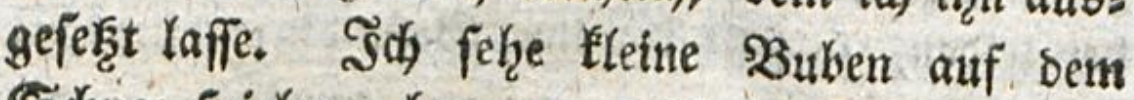
Sdjnee fpielen, bratn uns blau gefroren, uno exftart, Daf fie taum ste Finger regen fornnen. Sie burften ja nur an ben toarmen Dfen gehn; aber nefn! Bwainge man fie baju, fo wirben fie bie Strenge bes 3wanges zehnmal mefgr ema prinden, als bie Strenge ber Ralte. S2Gor=

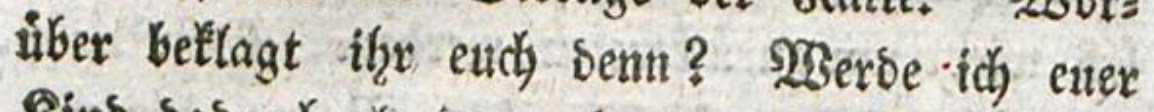
Rino basurdy elens madjen, wenn idi es̉ nur Dem Ungemadje aubjef̧e, bas ez gern Yeiben swill? Sch (h)affe in bem gegenwartigen 2fugens blide rein 230 brtrenn baburch, bafi id es fret laffe; ") ith beforbere fein 230 bुl anf sie 3 us funft

in bet Sadse, wovon hier bie Febe ift, mit eben ber soeisheit ibr Berbalten gegest ibre Rinber beftimms ten, als rouffeau in biefem, uno in bem nádhptfol: genben $\mathfrak{A b}$ fak es will beftimmt baben. Eblers.

-) פ্ber wem find, wenn ex গ̧ater ober Erzicher iff, nicht fallle geutg befount, worin cin Sinins, wenn man in biefem Puncte feine Sreibeit nicht einges fobránft badte, fich un Seben uns B̧efunbheit ge: bracht ober fíd Hebel fuir bie Bufunft zugezogen

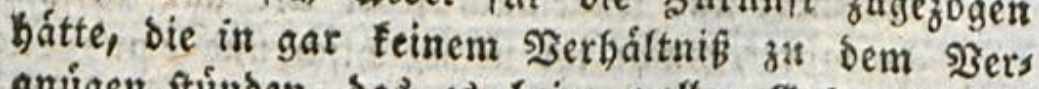
gnúgen ftúnden, bas ę beim vollen S̈ebrautch feis rer finbiichent freibeit fánbe, und bie pft dagegen zu bem ttrgemach genaut pafiten, bem es beim uns

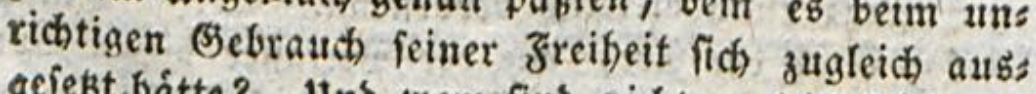

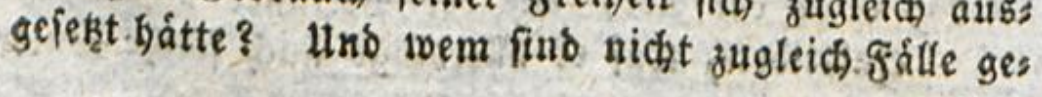


funft baburdi, bafi tid) es wiber bie lebel bee

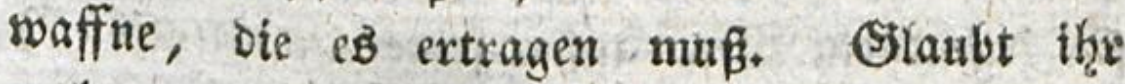
wot, wenn inm bie SGahl fret fiumbe, mein ober ener 3ógling zu fenn, baf́ eg fidy einen 2rugenblidé bebenten serbe? *)

\section{$\mathfrak{z} 5$}

RSnnt

nug befannt, ba fret nach ifrem Siun haubefnbe Sinber fich fur igre febensjeit wirf́fid) ungludflid macher. Afles fommt barauf an, baß man in bie fem Yunct Die Nittelfitrabe beobadite uno ber Silw Der Freiheit gehorig lenfe nno mit 23 eisheit ein fchränfe, welches freilid felten geichiebt.

Eblers. Nieferwis.

") "Dies beweifet nichts, fagt 5ar. Formey; ein Jins, weldhem man gleith anfánalich ben sfiget

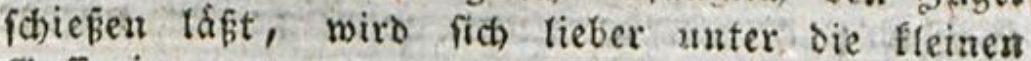
(3) fifenjungen mengen, welche auf Dem Echnce, ganz Graun uno blaugefroren uno erftart, baß̄ fie faum bie finger rúbren fonnen, fpielen, als einige Stune ben bintereinander mit feinem febrmeifter ober in ber Shute zubringen. Aflein man laffe einem Sinde, welches cin ober zwet Tafre lang wohl (?) ergogen worben, eben biefelbe $\mathfrak{S}_{\mathrm{S} a h) !}$ frei: fo wirb es fein Saffenláufer fegn mollen, uno bas nidht als lein aus cinem Triebe ber Ebre, fonbern aut B)es fdjmact und wegen bes Sergnigens, loelches ifm weislich) georonete (seícháfte verurfachen." - Nein; fonbern weil $\delta a b$ fogenaunte woblerzogene sinb an Seib uno Geele geidwiád uni verweidblichet iff, unb gaber lieber ftill fizt, als fich belvegt, lieber ber Stubentwarme geniefien, als braufen im Sdnee braun uns blau frieren mag. Eampe. 


\section{0}

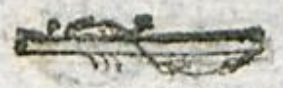

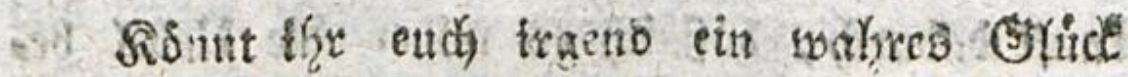
für irgeno ein $B$ Bejen auger feiner (onftitution *) als mogltas vorffeflen? uno heifft es nidyt, ben

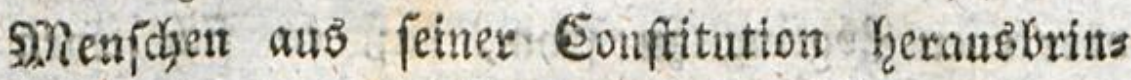
gen, wenn man itho boul allen llebeln feines Eattung ourdyaus befreten will? S Sa, ich) bes

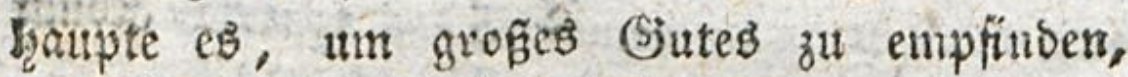
múp er bie Eleinen Llebel Éennen; bas forbert

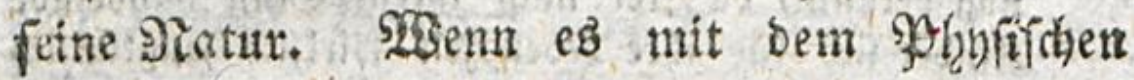
aflyut wobl geht, fo wiro das Sittiche sers Serbe. Dr Meníb, ber ben Sojmerz gar

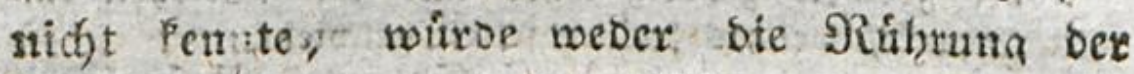

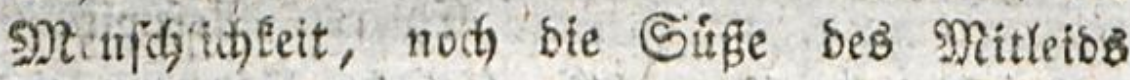

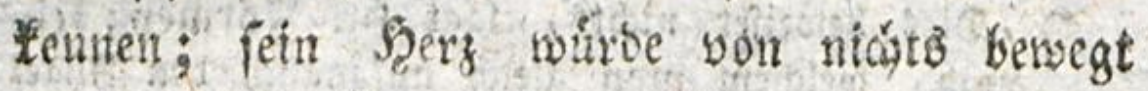
werben; er wuirde nidjt gefellig; er wirbe eirs Angefieuer unter feines (Streidyen fenn.

Soll id eudi Sas fidrmfe Nittel angebent, euter Sino elens zu madjen? Semsignt es wut baxs

- Tiofieau braubt bier Sas stort Conffitution in eis nem ism gans eigenthíntichen Einne. Nian vers ftebt bicfen aber gleids. Id wufte Eein bentides gleichbebeutendes utio befielt alio das franjoinioge. Er nennt námlich Eonfifintiout bier Nicht, was man

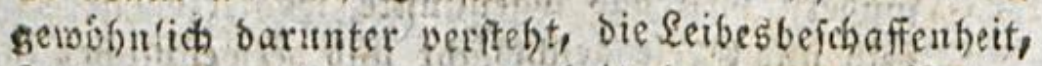
Pondorn bieientige Seichaffentheit ber ganzen Siatur und lage bes sienithen, bie ihn zu bemienigen, wab cr if: Nienfid! madit.

Snmert. Deg Heberf. 


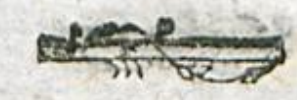

baran, 20utes zu exfrarten." Demn, ba burta sie Leichtigfeft fie zu befriesigen, feine Begier: ben unauftiorlidy wadjêt fo wirs itber furz ober latig bas Lluberniogen elidj miber euren

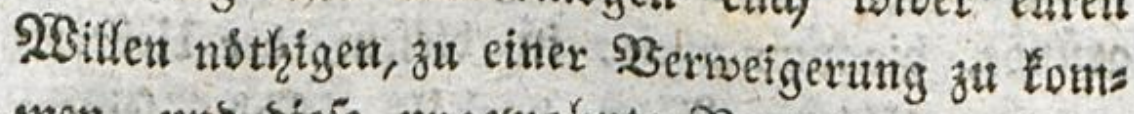
men, utb bteje ungewohnte serweigerung ifhm peintider ferm, ald felbft bie Entberzang beffen,

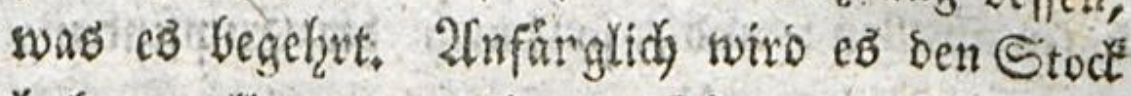
baten mollen, ben if̧r in Seanden tragt, balo ettre Lthr; hievauf ben 20 get in ber Luft; ents Yich Den Stern, ben es an Shtumel funfelt fieht; es wirs nach 2lllem begetzren, was es fefeer wirb; mofert the nicht Sott fego, wie bentet ifyr es zufrtesen zu fteflen?

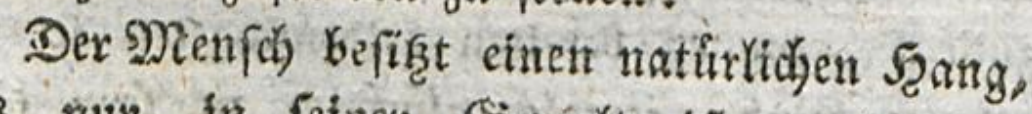
soas nux in feines Setwolt ift, alB bas Seine zu betricjten. Sin biefen $23 e x f a n d e$ bat bet Scobbefifche Sranbpars bis auf einert gemifien Funct 5 gabrbigeit: bersielfáltigt nur mit unjeri segieroen die Mrittel fie at Gefriebis gett, uno Seber wirb fich zum Seern von 2 (t) fem madjen. Dab Rins akp, bas nux wollen Darf, um zu erlangen, hålt fich fir ben (sigens

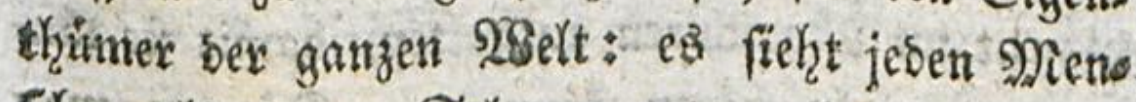
Jojen als feiten Sclaben an: uns wenn man enos

9) Do 2sittel if nosllig probat. compe. 
enslief genothiget iff, ihm etwas zu berjaget, fo nimint es, ba es Ulles für mỏglid hált, fobalo es gebent, diefe abjaldigige 2intwort fir cine 2lut ben Simporung an; alle 2 Bernunte grimbe, bie nan ifyn, in otejem dex lleberles gung unfäbigen 2orter borbált, fino, feinem Sinne nach, nux 2lubflidbte; es rebt aberall bofen $23 i l l e n: ~ 1 m$, fo surch ble Empfindung einer bermeinten lligeredjtigfeit exbittert, faft es gegen Seberntann einen Şaß́: uns wirb, ohne ingens fur bie Sefâlligteit Dant a sotjs Fen, úber jebe $23 i b e r j e f u n g$ unwiflig. *)

I28ie foll ith mix nun sorftellen tonnen, baf eit bout 3orn fo beherriátes, uno bon ftets zum Ergrimmen bereiten Leibenidgaften fo bers zebrtes Rino, jemals gludéltida zu febn fahtg wåre? Slúclitich? Dies Rins? Ein Defpot iftB̈; beibes ber niebertrád)tigfte Sclav uns bas

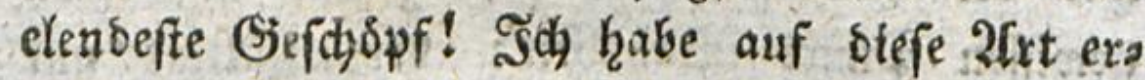
zoaene Rinber gefeffen, bie begehrten, man follte ธas Şaus mit ber Schulter unrennen, man follte thnen ben IZetterhahn von ber Spis be bes Rirdythurms langen, man follte cin Re? giment in Maridotren auff̧alten, samit fie läns ger trommeln bojen Eounten. Sfunte man

ifnen

2) Ifles wahr uno vortreflió, gefagt! Bambe. 


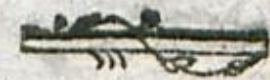

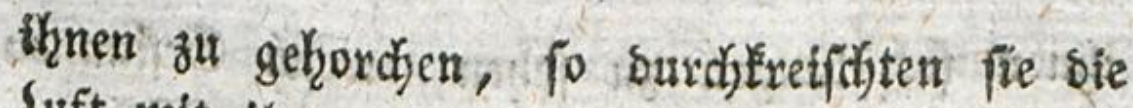
Suft init ihrem S̈efdjee, , olyre auf Semand zu horen; Dergebens beetferte fin 2llles gefalling gegen fie zu fenn; ba ihre Begterben burch ste Seichtigfeit, mit ber fie erilangt batten, fimmer mefir angereizt wurben, fo orangen fie balöftars rig auf anmonliche Sachen, unt fanden tiberall

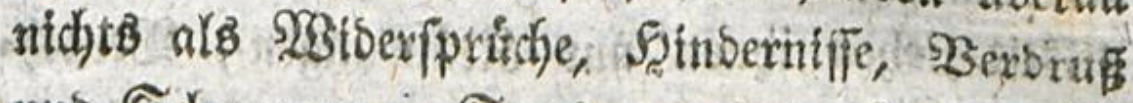

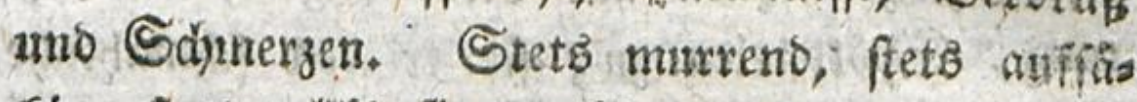

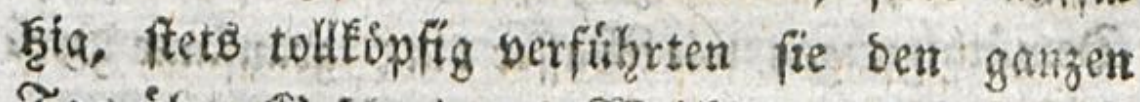

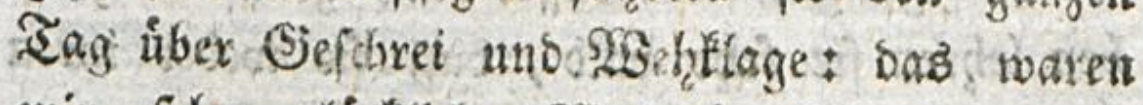

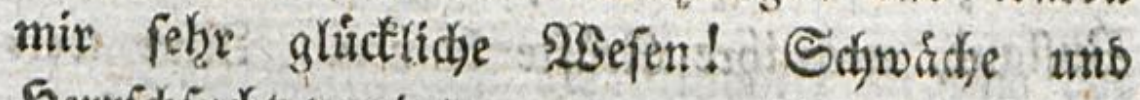
Serrfidfutcht vereint, erzeitgen nidjtB alB I gó heit und Elend. SBon zweien verberbten Riti bern fohlagt bas eine ben Itfch, mb bas ant bre låpt bas Meex geiffeln. "*) Sie wirben

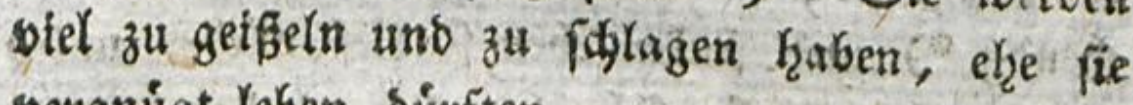
vergnught Yeben buirften.

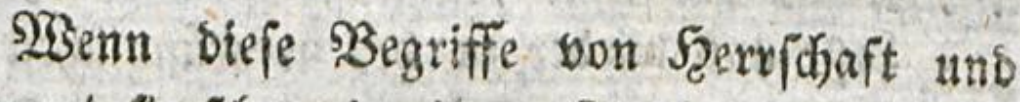
Itrannet fie folon in thrix Rinotheit eteno mas đen, twä wirb benn vollends baraus werben, wenn fie nun erwadjen; uno ihre Berhątriffe su anbern Menjiben anfangen fid) atsizubreiten unb zu berbielfältigen? Sienoḩnt, 2llles gor

ihnen

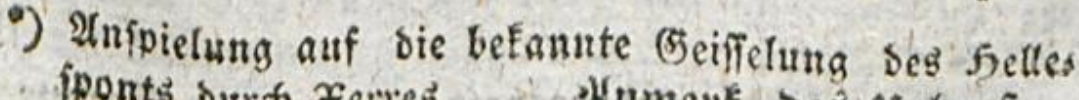

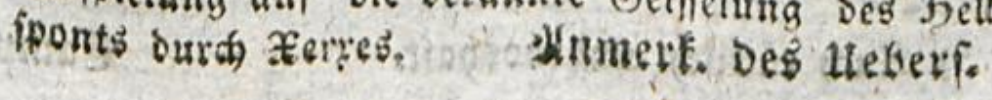




\section{4}

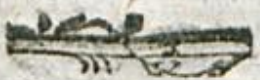

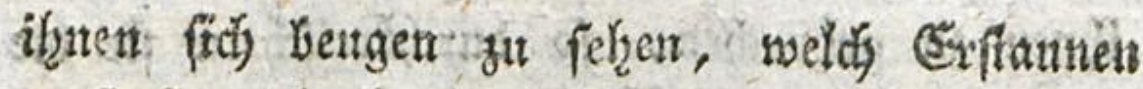
muß fie nicht bet ben Gintritte in bie Srelt ens greifen, wean fïe mon merten, baf 2 Klles thnen

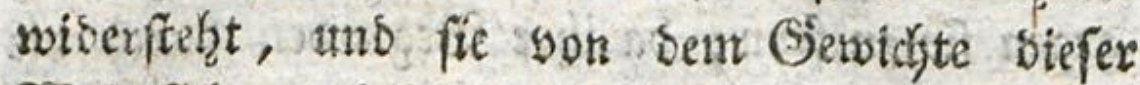

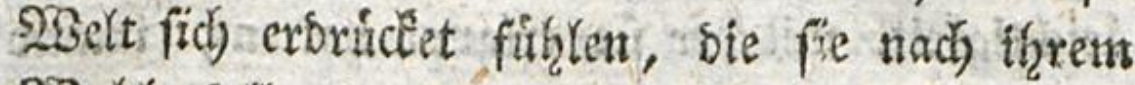

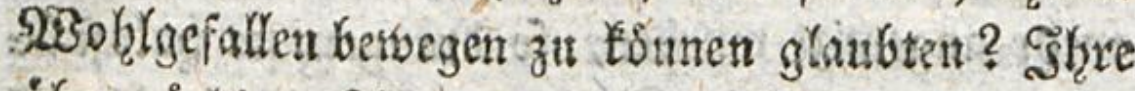

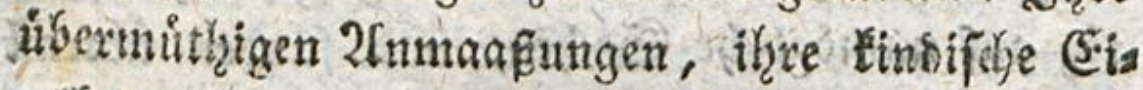

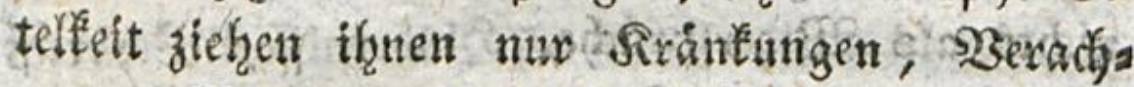
tung, Spsttereien zu; pie trinten fountablitye Demuthigungen wie $\$ 3$ affer eit : graufame \$ros fen lefyen fie fehr bals, baf fie neder thren Bufano, nod) ihre Rraffte Eennen. Stun wera Den fie glauben, ba fie nitht 2fles sermigen,

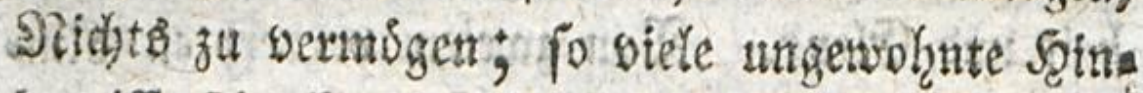
Serniffe fortedien fie zurict; fo viele Beradjtung erniebrigt fie; fie werben feig, furditfan, fries deno; ") uns finken cbet fo tief wieber unter fich herats, als fie fich iber fict) erthoben hattet. Lafit une wieber za ber merpringlidyen Res

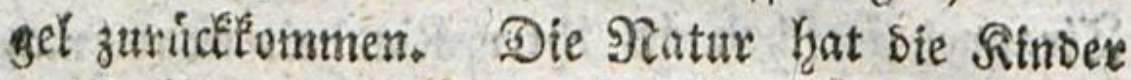
sefchafien, geliebt uns gepflegt zu werben: hat fie fie aber gefdoufers, bag thent gehordyt werbe,

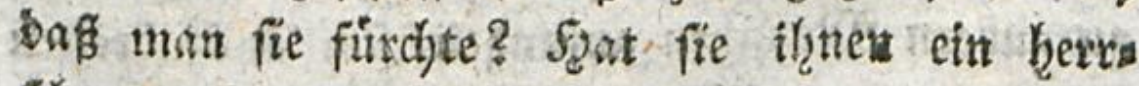

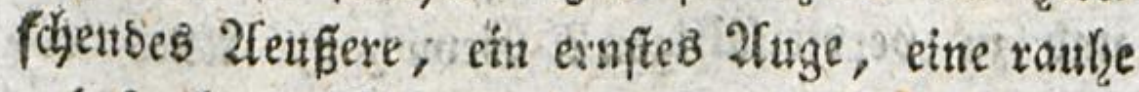
unb brokgende Stimme gegeben, burd die fie

fich

2) Ifuch trictich und bosbaft.

Cumpe. 


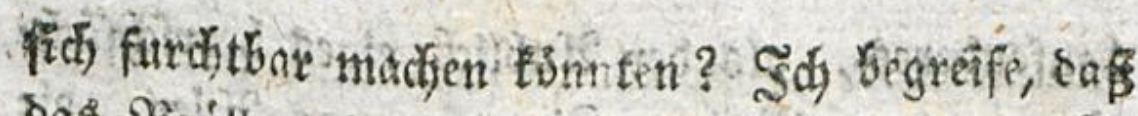

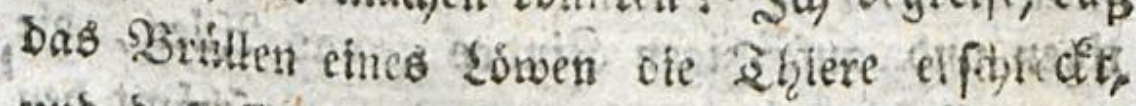

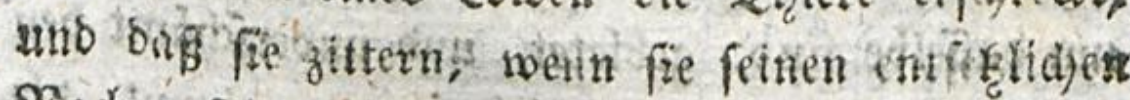

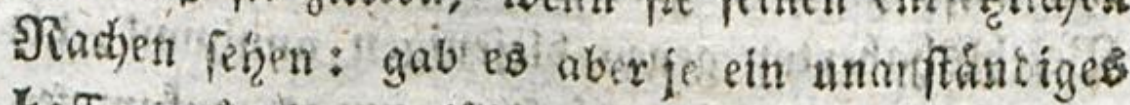
baffenswitothes, raberlides (Ed)aupiel: fo ifi

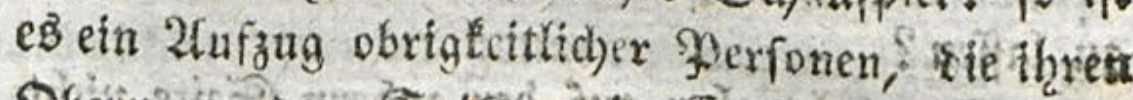
Sber̂n di der Spithe, in Eereironienfleidern,

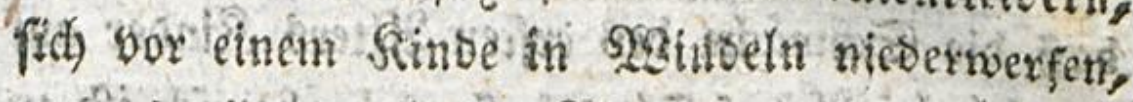
Ind es mit pouphaften 2 sorten anreben, woraif

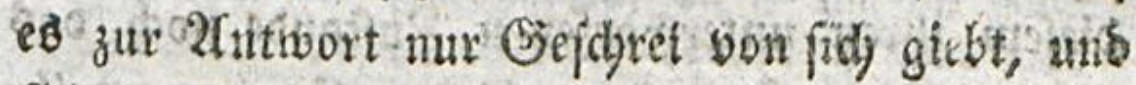
fid bejabsett. ")

Setraditen wir bie Sinsheit in und soe fich felbrt fo mag ja wol auf ser sieft tein

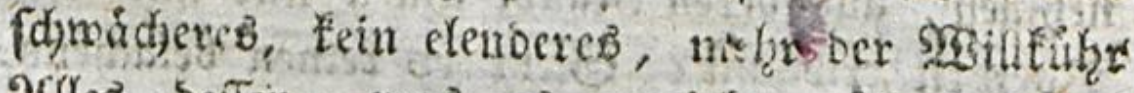
2lles befien, was es numgiefr, ubberlaffnes,

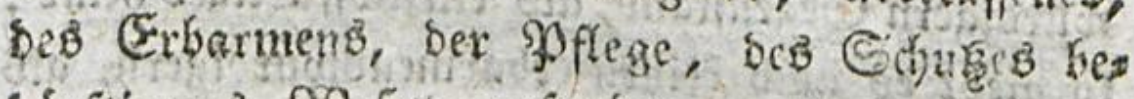

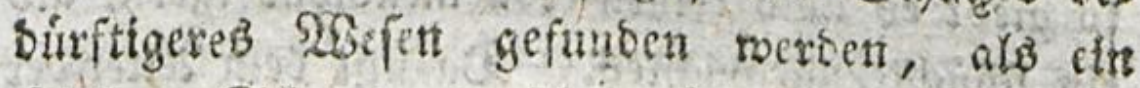
Sint, Sheint fo nidt, fhm fer nur bartim eine ro lieblidse Sieftalt, ein to herghewegenbes

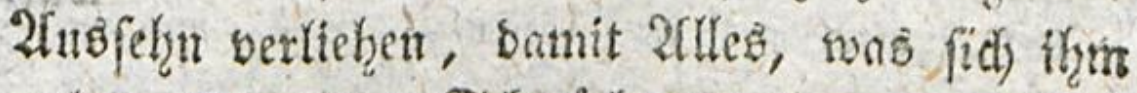

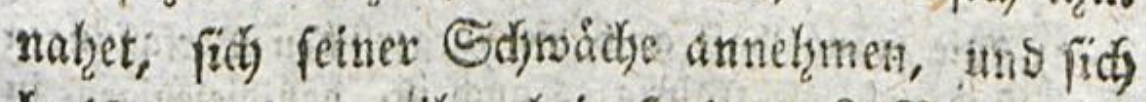
beeffern mogte, ikm beizupringen? SIBns gitbt es afo 2fnftopigeres, was ber serotung zumiser Lans

") Bittre Infrpieling auf sas, was itr franfreid bet Der Geburt eines Daupfins Ecremonicl ift.

Inmert. pestekers. 


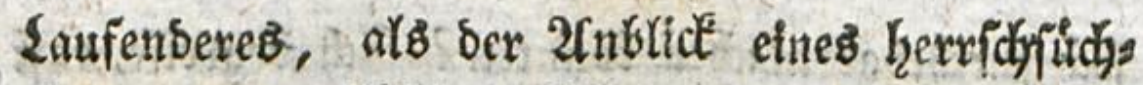
tigen und auffärigen Rindes, dab 2Ullen, die un baffelbe fint, gebietet, uno unverichaimt ben

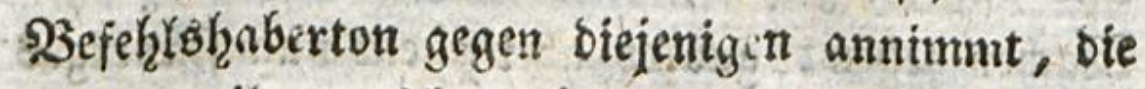
sur bon ifm weidgen burften, umes unfonmen zil laffen?

2Ber fief̧t aber auf ber andern Seite nidjt,

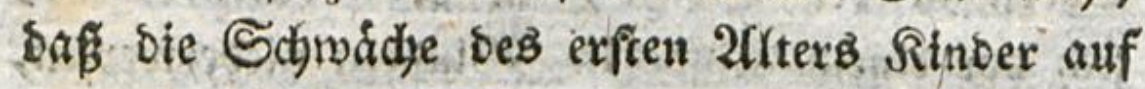

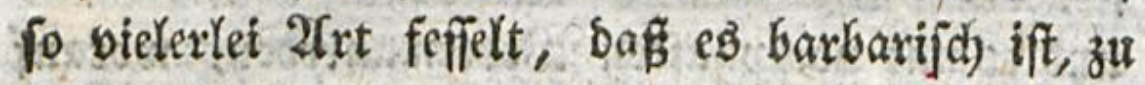
Diefem ifren unterworfemen auftande noch bas Soch unferes Eigenfïns binzurufigen, uno ih= nen eine fodon fo eingefdyrátifte, ihrerfeits to wenig eines Misbrauds forlige Freilgeit, zu nelguten, ans beren Raube ihnen uns uns Eeftn "Sortheil erwadift? Siebt es leinen Beladjens: witrbigern Siegenftanb, als ein hoffärtiges Sinb: fo giebt $\mathrm{eB}$ auch feinen erbarmenswourbigern, alsె ein fojuidjterngemadjtes. Da mit bem 2flter bev SBernunft bie birgerlidje Snedhtichaft *) beginnt;

wars

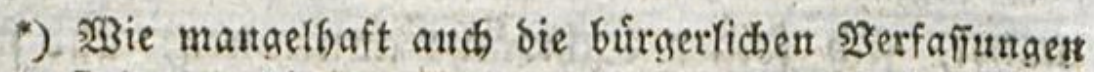
fund und wie traurig es auch ift, baf biejenigen, in beren Niacht es ftumbe fie zit verbefiern, geivihntich theils Schtendriansfokfe find, bie alles beim 2 !tten laffen, theils unveife seutungsficthtige, die alles umfebren, das bute mit bem Sbofen wealwerfen, unb an bie Stelle bes, feblerbaften Banzencin an:

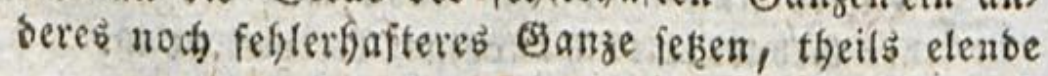
une 


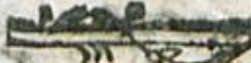

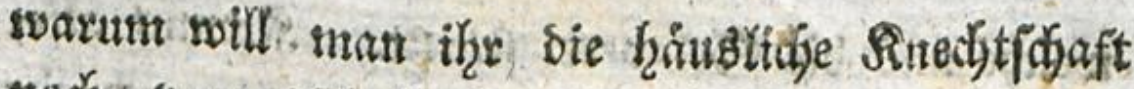

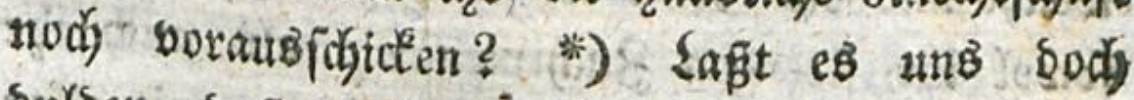

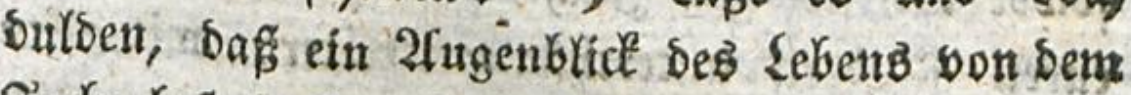
Sodhe befreit fen, bab uns bie Natur nicht aufe

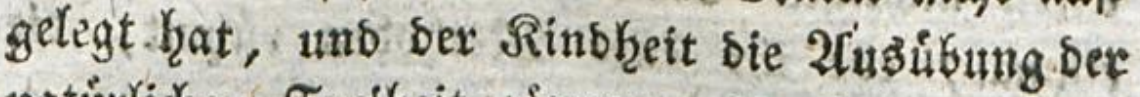
naturlichen Freiheit gonnen, bie fie, zum wea migfen eine Jeitlang, von ben Laftern entfernt, it

\section{wels}

ntob verworfue Eigennúbige, bie ibr ánferes Bn tide auf andrer biend uno s2oth, bauen: fo farn mar Soch manche Staatbverfofiung nidit eine burgetliche Sinechtiofaft nenten. Es giebt felbit inenige buirs gerliche Eintidutungen, worin ein Nienid niobt ges wobnlicher Şeife zu einer biel gróbern Eumme pou wabren Lebensuortbeilen gelangt, als wozu er im aubergefellichaftlicten 3 utande gelangen founte.

Ebfers. Trapp. Siefenis.,

* Coen beslvegen, fonnte man fagen, um bas Sins

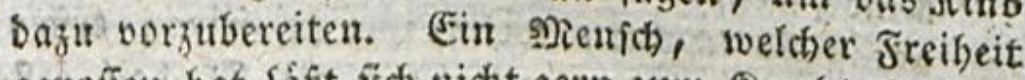
genofien bat, (áfit fich nidht gern zum Sined)t machent.

ミillaume.

Die Sinder unferer Surechte belveifen, in fofern von ben etfen Gabren bel Sintbeit bie Nede ift, bas Segentfeit. Diefe geniefien in biefer erften Epoche untăugbar merse naturfiche Sreiheit, als bie uts frigen; unb ob(h) geben fie fich nachber flweit willis

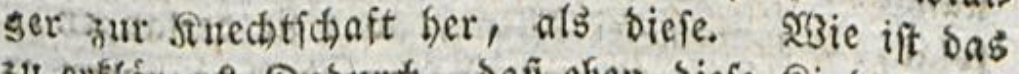
ot erefaren? Daburd, Dape eben biefe Rinder, bie man vor alfen natuirlichen, von ber menichlichen Siatur ungertiennlichent Hebelnt viel wentiger, als bie utrírigen, zu fotuken fucht, von frúber sints

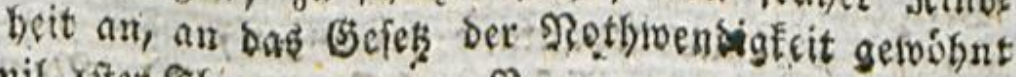
Emil. fiter \&s 


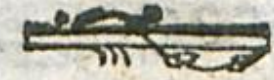

gefagt, es miffe nidats aus (Sekgorfam, *) pons Dern allein aus Nothwendigeteit thun. Die 2usbruide: gebordben uns befeblen, werben

$$
\text { (2) } 2 \text { als }
$$

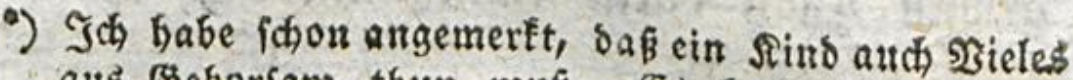
aus Eeforfam thun muß. Es faun úber গুeles, bab es zu thun ober zu lafien hat, noch nicht zur richtigen (Einficht in bie ßुeichaffenbeit ber Dinge gelangen uno es mú alío vielmefr nach ben Joen ber Eltern ober Erzieber, als nach feinen Ioeen

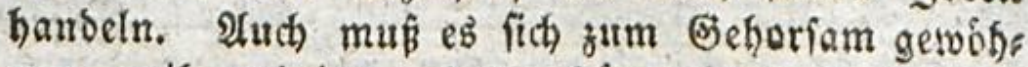
nen, weil autb in ber beften burgerlichen Berfaffung

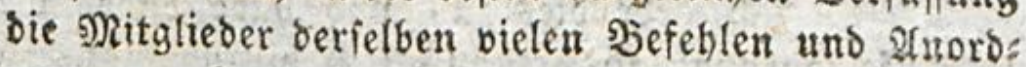
nungen geborchen múfilen, Deren S3erth fie nicht ers fennen fonmen, ober bie, wenn fie auth noch fo sveife und vortreflich eingerichtet find, boch als utte nothig ober wol gar als fldádich vou ifnen angefes ben werben.

(Eblets. Nefemis.

Ein verftánbiger Ergiefer twirb aber fo viel móglich alles fo eimzurichten fuchen, bấ bas Jint, indem es feinen 2 sillen erfúlit, glauben mús, es handle aus siothwendigfeit, $\delta$. i. es werbe von ber Nintur ber Dinge, nidht vou ber sosillführ feiner Erziefer, gezwungen fo uns nidit anders zu han beln. Ein folcher Erzieber wiro alfo von jungen Sindern nicht gerabe (5) forfan verlangen; aber er wirb bas Jind jebesmat in loldhe lagen und $4 \mathrm{~m}$ s

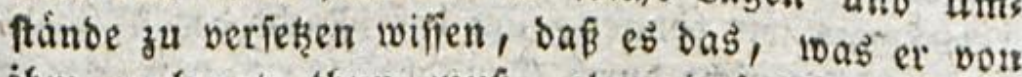
inm verlangt, thun muf́, obne baß́ befefle ober willfúbrliche 3wangsmittel es bajur zu zivingen braus (b)en.

Eampe.

In allen f̧allen ift $\delta a b^{3}$ auth beln verftánbigften Crziefjer nidit móglich, felbis toent man einen Rouf: 


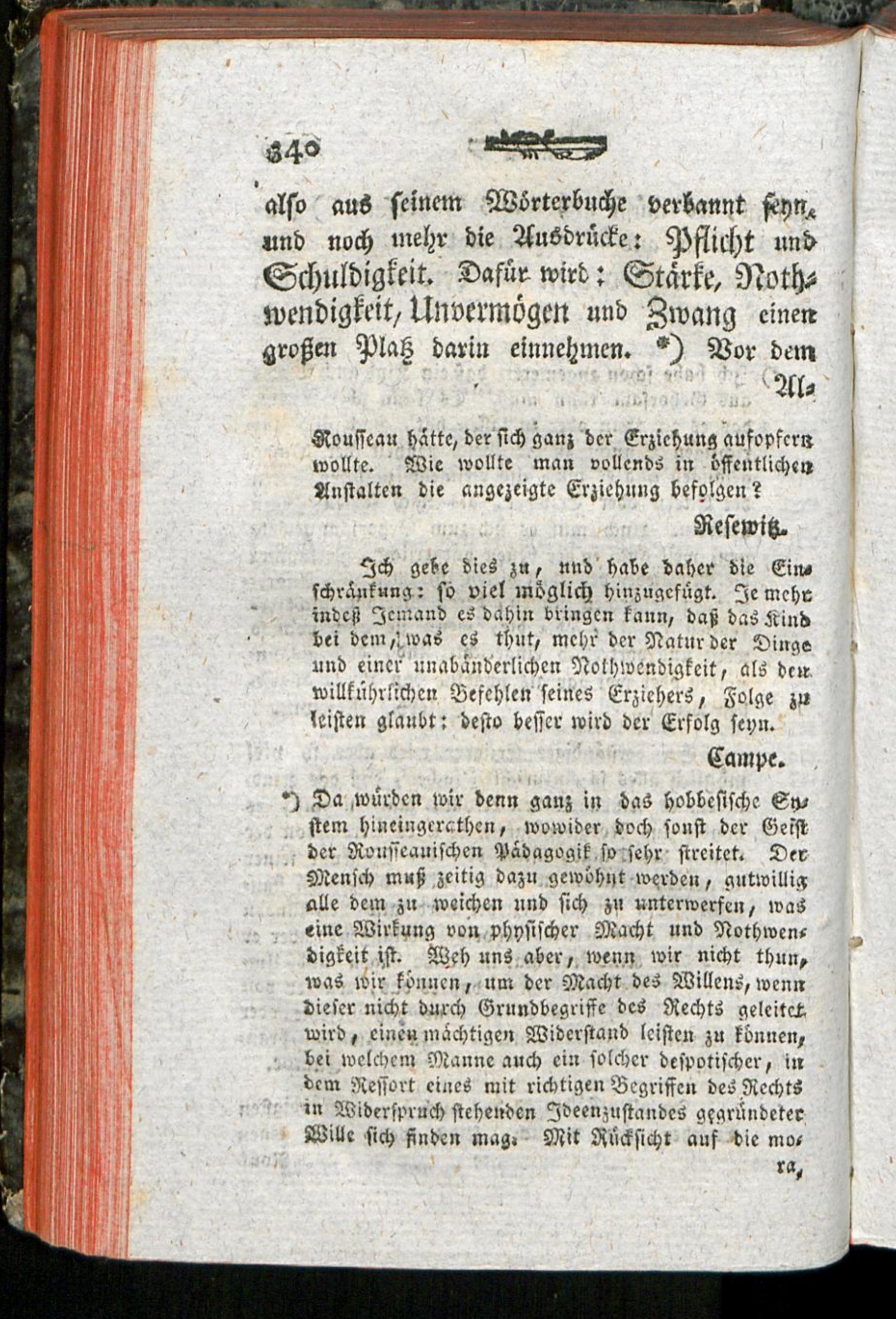




\section{1}

2rter ber Sermuft tant man feinet siegitff

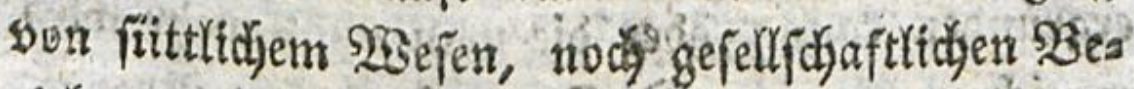
zichungen haben: num muf alpo, fo otel ats moglich ift, sermetsen, sissirter zu braubetr,

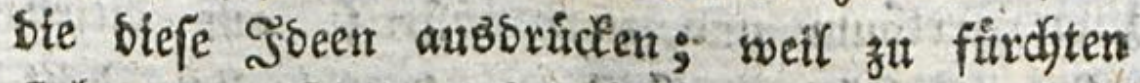

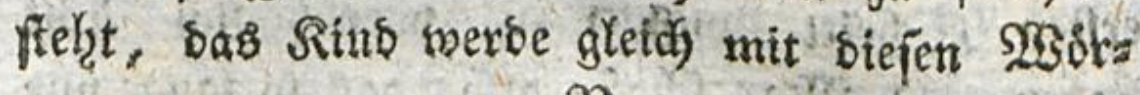

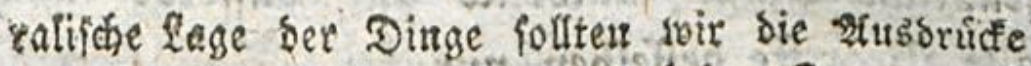
vout Szefeblen, Befordsen, Etárfe, Swang uns

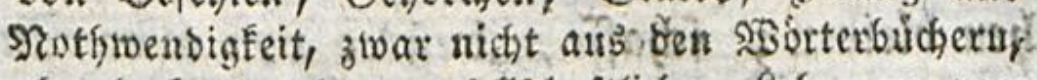
abee boh auts bem gefellichaftlichen feben zu ver baumen fuchen, went beim sebroutch jener 2 tus

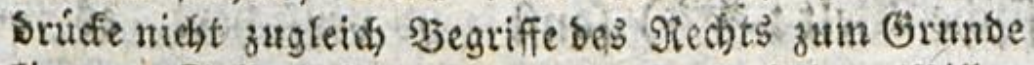
Jiegen. Solfte aber bem blopeut befpotifchen sisilfen bev Menfichen alle bespotif(he Madbt genommer

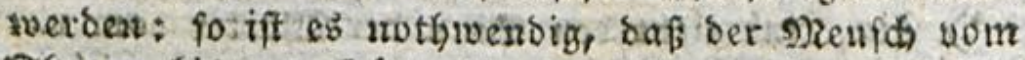

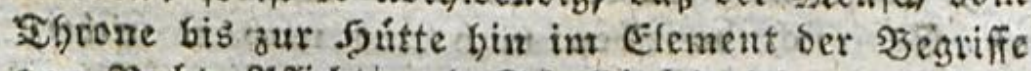
son Irecht, Pficht; uts Edyulbigleit rebe uno webe uno bafies eirtem, ber fich aus biciem Element berauts loagt, fchlver ober umın'glich lvúrbe, ficb aufier Demielbenzu erfalten. Es follte alio unter vernúnf: tigen 28 eien und unter uns Mierictien, toenn wir siefer ebrenwollen S3entenung wirbig fenn wollen, urt eine phpifiche Nzacht uns Notbwentsigfeit uns cine aus Sechtsbegriffen und ans weifen (s)efeţen entipringende morafifche, fich mit phyfitcher Madte und Niothwendigfeit verbinbende, Nacht und Netho wentigfeir getert.

Ebiers.

Mein twirbiger Frentus toûrbe, vermuthe id, bie Iheorie unfers şerfallerb von ber feinigen bier minder abweidjento gefunben baben, wenu er auf

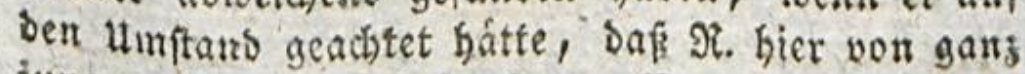
jumgen sindern rebet, beren saermunft fich noch nicht entividelt bat.

Eampe. 


\section{2}

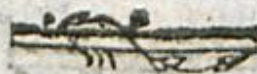

tern falidje Begriffe verbinben, bie man nicht ergrinben fann, obee bie man nidjt melgr nirs zernidften Esnnen. ") Dex exfte faliche Begriff, ber in feinen Sopf Eummt, it in thut ber Reim

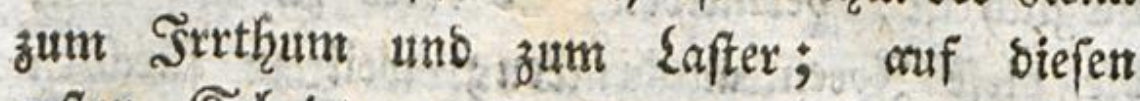

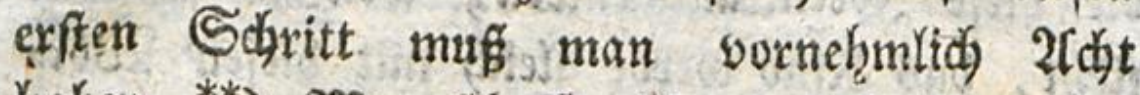
Kaben. **) Man ídaffe alfo, baf fo lange nux finnliche Dinge Einoruct auf baffelte madjen, alle Begriffe befferben nur bei Senfationen ftes ben bleiben; fdjaffe, bag̈ eb̉ von allen Seiten nidjts un fich herum wahrnehme, als bie phys

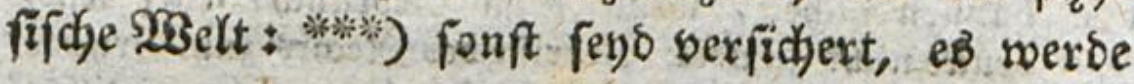

") Ein Sind gieft ben Ginn ber Nobrter vom xidjtigen Gebrautch berfelben nach und nach fo richtig und feir $a b$, als felbit eir gelebrter Pbilologétibn faum att ben beften Exflärungen und aub vielen geges betren Szeippielen beraubleitet. Man gefrautche alio nur immer bie 2Borter und গedensarten ridftig und

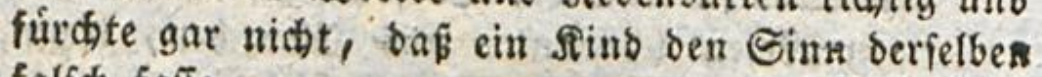
falich fafie.

EEblers.

-) Freilich mǘ man bab. Nan hat aber nichts aus

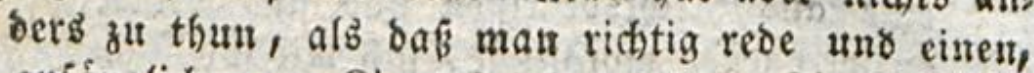
anfánglich vom Siube falich gefápten Sinn berich: tige, wenn etwain ein şort unb eine giebensart nidht oft borfomme. Sommt ein Short oft vor: fo formt ein Sind bon felbêt fehr bald sum richtigen Einn Defielben bin, wie falfich anth der Ginn befielbers zuerfit aufgefaft fer. Eblets. Refewis.

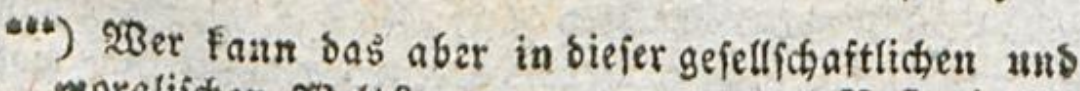
moralithen gselt? Refêtwik. 


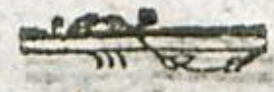

gar nidht auf etch hosren, ober fidf oon ber

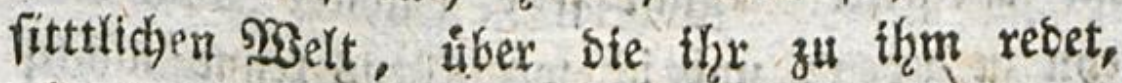
Whantaftifue Begriffe madjen, bie thr in jeinem Leben nicht wieber ausisfchen ksonnte, *)

Sockens Sgauptgrunofa was mar, man folle smit ben Sinbern raiforniten; und **s) blefer Srundrar ift auch heut zu Zage rehre gange und gebe。 ****) Das, was ex herworbringt, iheint

$$
\text { (1) } 4 \text { mir }
$$

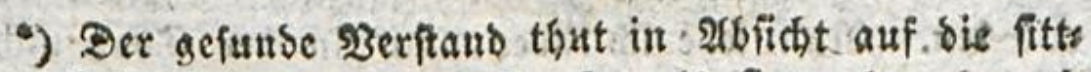
lide barauf wirft, fein $23 \mathrm{erf}$ eben fo gutt, als iù $26 \mathrm{~b} s$ ficht auf bie phyfitide $\mathfrak{x}_{3}$ elt. Hebrigens muß man évenfalls bie auf bie fittlide গ্র̧elt fich beziehenben Jocen bes Sinbeß anfánglich nicht forvol burch forms fichen Unterricht, als burch ricbtigen Gebrautch Der babin gehórigen 233 orter, uni burch ein auf vor: liegende ober veranla fte fälle fich beziehenbes ridh: tigeb æerbalten mit aus

Eblerb. Neferwis.

**) Darin hatte Rode $\Re e c h t$, mur mús man lode recht verfethen. Deun er wollte nicht, Daß man barin

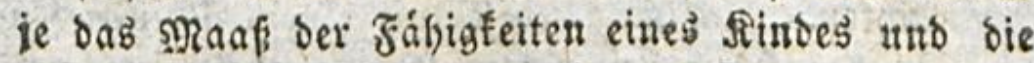
von demfelben fhon erivorbenen Senntnifie tifers fogreiten follte.

\section{(E) Ters. Trapp. Refenis.}

***) Diefer angeblidbe Brunbfakz gebótt ju benen, welche wahr ober falfich finb, ie natioem fie verftanden ant angewantst werben. STeifst raifonniren úbers baupt to viel, als Gritibe fur ober wiber etwas ans fuifren: fo will is Den Erziefger Dber bic Erzicherin fehent, 


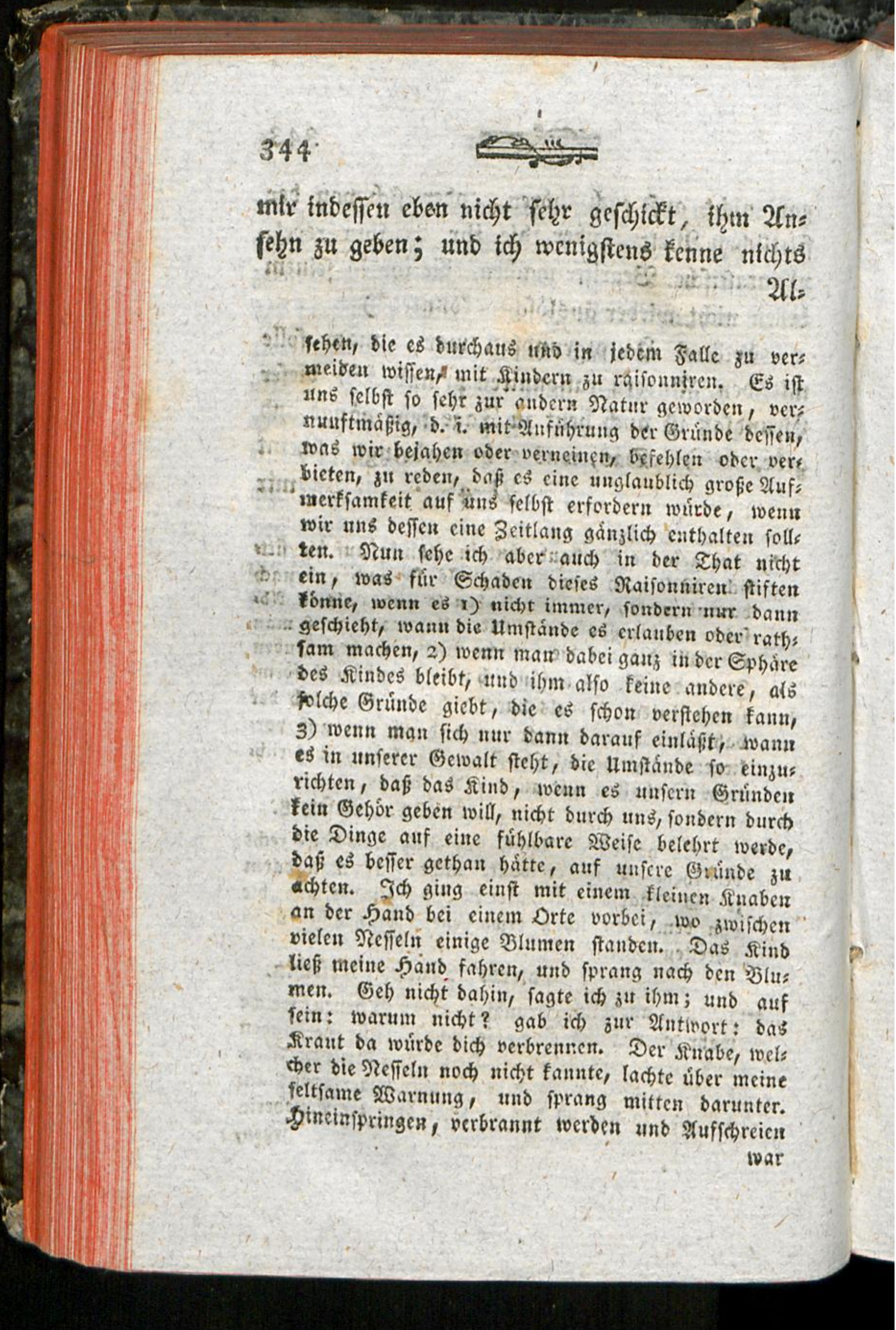


2uberners, ala bie Rinber, mit betrent tuant 5 fefzr viel ratfonnirt bat. Inter allen Seetent Eáften Ses Memidjen entwictelt fid bie Dera munft, bie fo zu fagen, aus allen atroen zufant? nengejest fft, am fojwerften uib ipateftent; uns beren will man fich bebienen, int bie exfert 3 h entwidteln? Das Meifferfticl einer guten Ers ziehuthg ift: einen bermittfigedt Mlenfchen zu bilben: uns man nimmt fids vor, ein Sind Surch bie ßernunft zu erziehen? *) Das beifft,

$$
\text { (2) } 5
$$

son

war eints. Simftatt ifh zu bedautern, fragte ich ifn iesh blok: ob er nicht befier gethan baben whirbes auf meinen-Siath zu adjen; uns nut zeigte idi ihm bie Etructur eines Nefiflblatts in ber Niáfer um es ifm begreifich zu mactsen, pofjer bie Gethmers 3on, die er empfant, cigentlić rúbrten. Das war, bunft mich, eine nicht blok unidjabliche, fonbern.

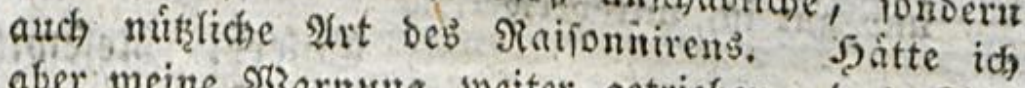
aber meine stsarnumg weiter getrieben, bas Sins zurudfgefolten, uno ifm eine wortieidie Sorlefung úber bie Natur ber Neffel gehalten, benor er ifre 23irtung ant fich felbft erfabrent fatte: 10 wurbe id ifm eine fefr beifome Erfabrung entzogen haben: unto in biefem falle tware ifm mein Saifonuiren fohablich geweien. 2allo bie 2rt und sigeife, wie man fich babei nimmt, und bie tumitinde, unter bea uen man fich barauf cinláft, geben dem Raijomis ren mit Sindern feinen şerth Doer Huverth.

*) Nict Eampe. Trapp. Stuve. Nieferris. (Evithts, als Sogumachie. 9ran muf freifich bei ber Ergieghng cines fimbes beffen sermuniffraft nicht soeis 


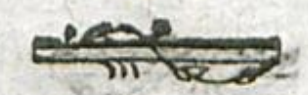

nen ourch verninftige Bervegungş grinde zu ex: halten glaubt, nie andero, als burd serwes gungs̈grinbe ber Begeţridideteit ober ber Furdht, ober ber Eiteléeit, bie man ftetỏ binz̧ưfúgent gensthigt ift.

Şier ein Formular, woruntex faft alle Sitt tenlehren, bie man Rinbern giebt ober geben Eann, gebradjt seroen Esmen.

\section{Der}

Sinbern von ifrem erfen झlter nu bie Spradie ber Sermunft fprecten foute uto muifle, aber freifich auf bie 2 rt, twie es in ben vprbergebenden Anmerfungels von meinen verehrungstourbigen Mitarbeitern bes fimmt ift. Dafi bie sinber biefe Spradbe anfänglich nicht veritely, if fein Eimowrf, forit múste mat aud viber finnliche Begenfánde nicht mit ifonen fprectent, weil fie bies anfanglich eben fo wenig vers ftebn. Daß $\Re$. wiber ben Misbratch bes Raifonnis rens fchrieb, war fehr gut, benu biefer Misbraud if grós uno mamigfaltig; er hátte aber anbeuten follen, dấ er mur biber biejen ichrieb.

\section{Trapp. Stuve.}

Rouffeau hat hier offenbar zu einfeitig geuts: theilt - bie fleinften Sinber vergleichen, untericheis

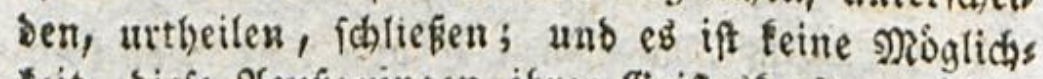
feit, biefe Aleuberingen ifrer Beifesfraft zurúffus halten und ungetibt zu lafien. Es formt afles aber freilid) auf bie sirt an, wie man bte Sache bctreibt. Statt auf verfebrte $\mathfrak{A r t}$ und uiber ibr $\mathfrak{A l e}$ ter mit ifnent za rarfomiren, ifts freilich loeit beffer es gar nicht zut thun, und fie blof ben meiften Eins Driden uno ifrer etgenen Entwidfelung zu riberfarien. Etupe. Pieferwis. Eampe. 
*3 Det Sebte:" Man thif Dab nicht thitm:

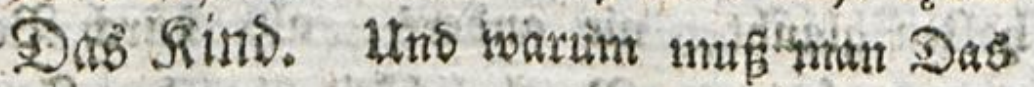
stod t) tfutt.

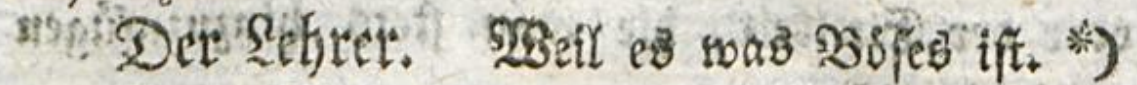

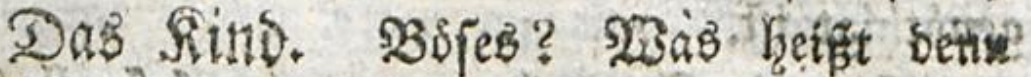

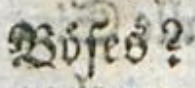

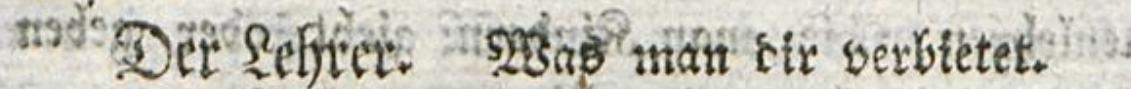

Das Rind. 928 arum ift bas setin bofe, sols man mir serbietet?

Der Seftet. Mlan ftraft sidy kernady. wenn bu ungehoriant gewefen bift.

Das Sint Sib will es fdjon madjen, sas mm nidyts babon exfábet.

Dip, Pifler. Man wirs auf sidy paffen. Dab Sind. Setn fo berftecte id midy. Der Rifreer. Nian wiro didy befragen. Dab Sitito. Dain lige id.

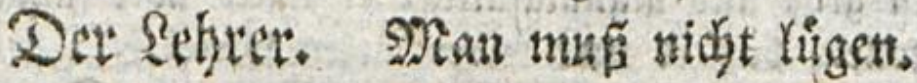

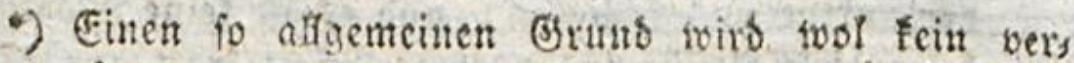
nunftiger Erjielfer einem filnde anfúbren; or toirb ifm viefmebs das beftimute sofe fagen, welches nus bei franblung folgen witroe; unt bann ift ber Eirfel, ben utifer 23 erfaffer umbermeiblich netnt, bev: micben.

(sampe. Siejerviş.

Freilich to einfáltig, wie bier $\Re$. bent \&ebrer raifomiren lábt, raifonnit wo feine $\mathfrak{A m m e}$ mit bum sinter.

Stube. 


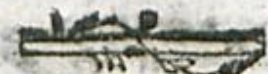

lingen?

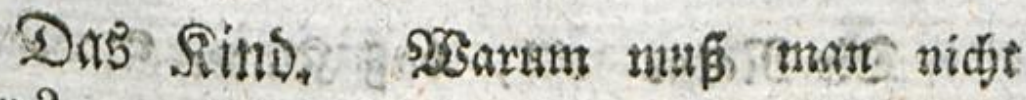

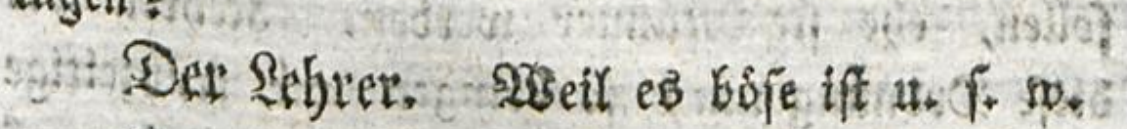

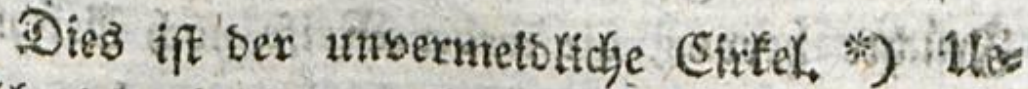
berfdyeitet iffr ben; fogleid serfekt tench bas Sinb nicht mehr. Sins das nidgt fergr exfprieg:

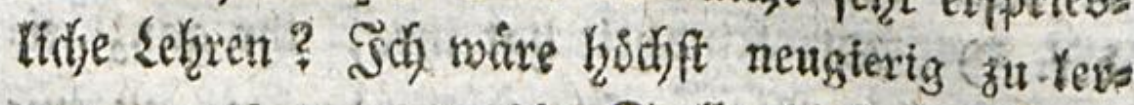
nen, was man an bie Stelle diefeb Dialogs resen Esonnte? Socte felbft wirbe fidjertich felze berlegen babet getwejen fenn. **) Dab Oute uno Dab 38fé exfenten, Den Grund zu best Sfliditen eimfehen, if nidjt bie Sidje eines Rindes, ***;)

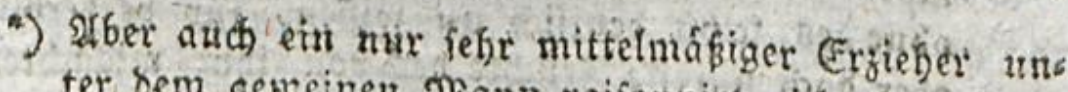
ter bem seveinen Niann raifonnirt nicht jo init eis nem finte. (et madtes logleit) auf bie nalutis

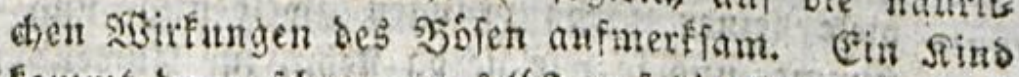

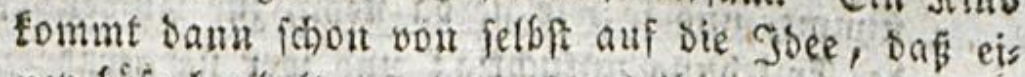
net bove bandelt, weme er etwas thit, bas mit nacts= theiligen sGlifungen nerbinten ift. CS befommt

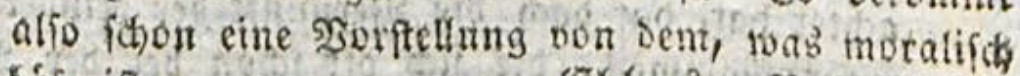

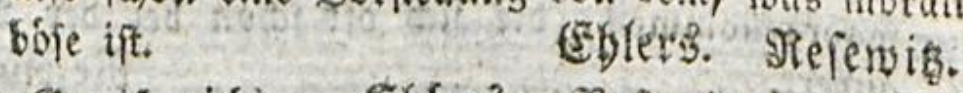

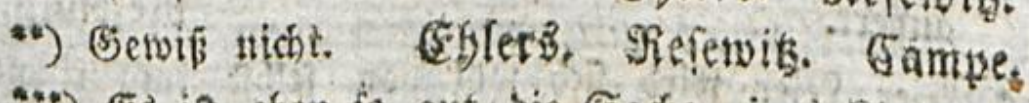

*.*) Es if eben to gut bie Eadie eirres Jintes, als Segriffe wout phyiliden Eigenidaften Ser Dinge zu befommer.

Eblers. Traps. Mejemith. R. Shat Giet in biefem ganzent shichnitt wiber Was Naifontiren mit ben Stinbern ofenbar Hniedt, bate 


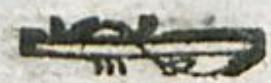

Die פlatur will, baf Rinber Rinber feyse pollen, eḩe fie Mlaner werben. Siehren wir biefe Sronung um, fo Gringen wir fribgettige Fridide herbor, bie meber Reife noch (Sefdumact kaben, uno fehre buld verberben werden; wir exhalten benn junge Docenten und alte Rins Ser. *) Die Sinoheit ḩat thre, thre ganz eis

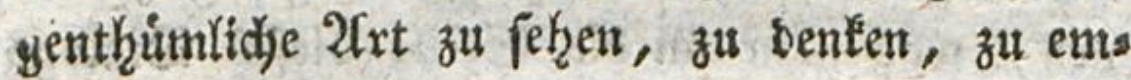

pfins

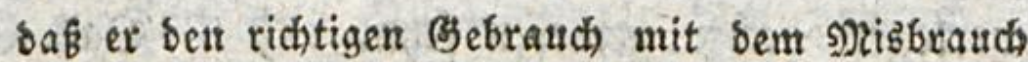
zugleidh verwirft. Er begeft auch hier ben Febler, ben er oft begeht, uno ber viele feiner Febauptun gen urbrauchbar macbt; bafi ex blof́ den siatur; menichen, ben er fich gebilbet bat, unto ben-er fuir ben beften aienfchen balt, erzieben will und sie moralijthe und verninftige 95iloung bes Nienfden, ohue es felbit beutlich zu wifien, fúr verderbliche ober bod) unreife fridite bes von ifm mišndhteten gefellfchaftlichen Lebens anieft. Daburdi werben viele feiner গ3ehauptungen zweidentig uno unber ftimmt, unb fo wie lie ba ftebn, zut 2Amvendung in Der Erziebung untúd,tig; uno wer fie gerabe zu ges braucht, gerath in bie Sire. $R$., ber fo viel beobs: ad)tet hat, hat boch bie Sernunft ber Sinder nidht wahrgenommen, bie fich oft fchon bei ber $\mathfrak{A m m e}$ autiert.

Niefervikg.

*) Der Sefer wiro ficty wol von felbfi immer mefé

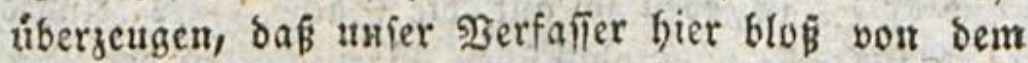
Misbrauthe bes Raifonnirens rebet, ba man bem Sinde theils ju oft und fat viel von Gritinten vors fitwakst, theils ifm foldhe Srúnde giebt, bie es nods nidst faffen fann. Diefer Misbrauch ift wirflids nicht jelten; an Gáufigften habe id ihn bei Dar

meni 
pfinben; nidyts if unberninftiger, alö mens wir bie unirige thr unterífieben wollen, uno idy mógte eben fo gern verlangen, Dä̧ cin Rino

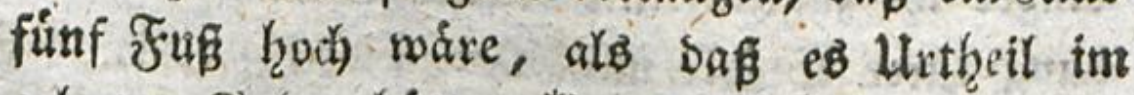

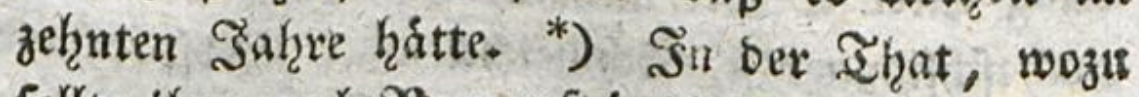

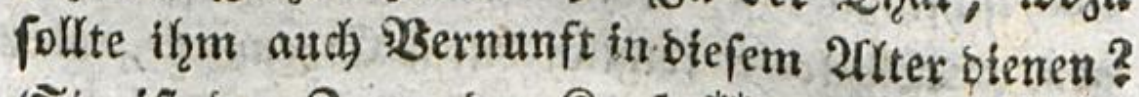
Ste ift ber 3aum ber Rraft **) und bas Rind bebarf biefes 3aume nidt. ***)

\section{รัก}

men, befonders bei folden wahrgenommen, roldge. viel Selefenbeit und litterarifhe Eultur hatten.

Eampe. Irapp. Stuve.

Diefer Nisbrauch if wafr und baufig; aber ber entgegentehende, bie शुernunft bei Findern nicht zus bemusen uno nicht zu úben, fo weit fie Bernunft

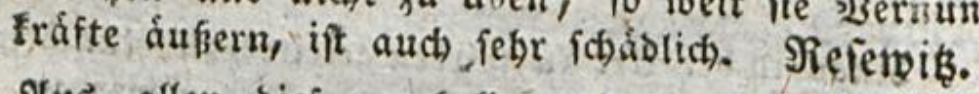

7 Fits aflen bieien erbellt weiter nichts, als bas man bei ber Entrivicfelung ber Rráfte eines ßindes mit oer naturlichen 3 unafme der Iirdfte Sctbritt hale ten uno fich bor allen Hebertreibungen húten tmiffe. 20ite cin Sins allmálig in Strfebung ber lánge jur Brófe des Sauns empor wáchit: fo gelangt es auth nllmátig jur vollen Etárke ber \$ernunft in $\mathfrak{B}_{\&}$ jiefung auf fittliche \$egriffe.

(Fb)ers. Trapp. Reperwib. Eampe.

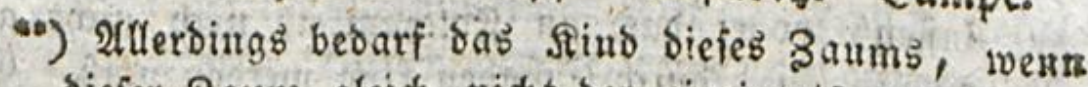
biejer saum gleich nicht ber eimzige ift, beffen es bebarf. Das Sint hat ia auch fthon firaft, wenn gleids nidht to viel als oer Erwadsiene.

Trapp. Stuve. Refemił.

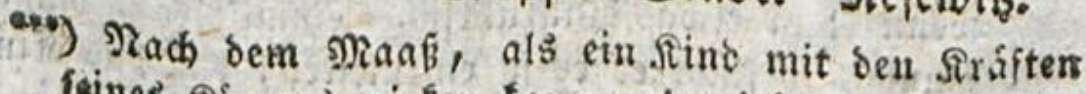
foines Rorpers wirfen famm und toirft, muß es allers Dings 


\section{2}

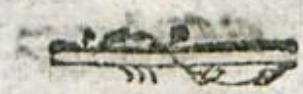

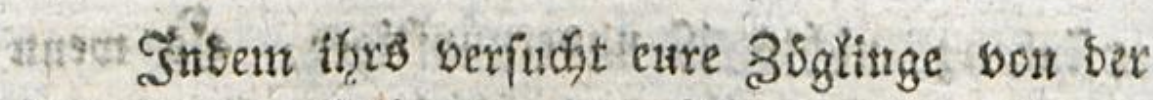
- Soflidit bes Sefgorfams su itberzengen; fo ber: Ginbet ifgr zugleid) mit biefen Senuihen 20nwens sing curer Stâke uno Drokungen; Dber, waz

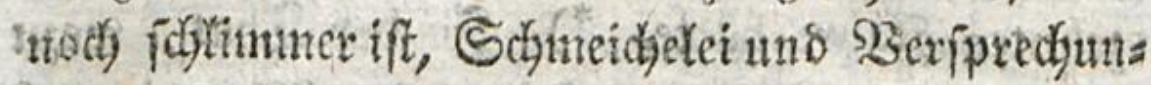

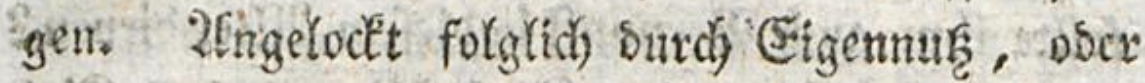
geznungen surdy Starte, ftellen fie fid), alb waren fie surch bie Sernunft uibergetght. Ste Yolgen felgre wohl, buf ser Gehorfam. vorthetls

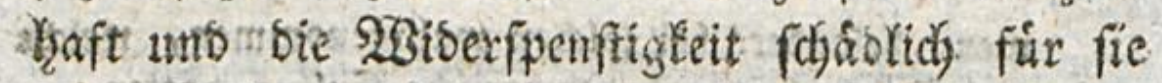
ift, fobals ifir biefés ober jenter gewahr wers Det, $\%$ 2fber ba ther wou ifnen nidyts forbert, 24: 1 daits

was

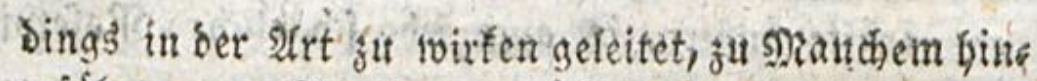
the gefífrt, won Dianchem zuriffigehalten werber. 29.

Hind 11

(Eglet:3. Refentit.

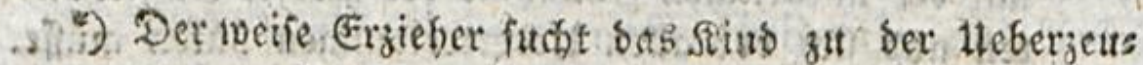
I/f gang sul bringen, onf Fohgiamfeit gegen veruinf:

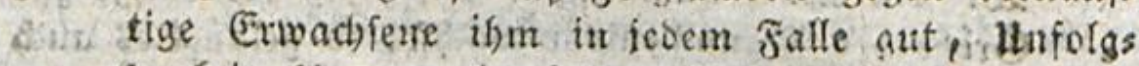

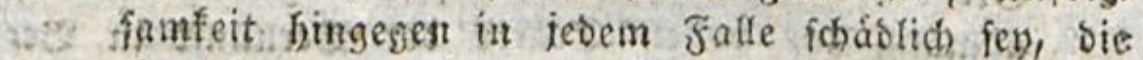
Szandung bes Sindes moge benterft werdea ober nicht. Cr weik bierza folche Siorfálle zu verans laften, wobei das ait Tolgfamfeit nod nidht ges (2) wobnte find burd Schaden flug verden mus. Ev sirf bermeiset aber auch, nitht blob in jeinen Sekblen unb syerboten, fonberm auch in ben. Folgen ber vebertectung berjelbes, alles sisiffulbrlictie, ober

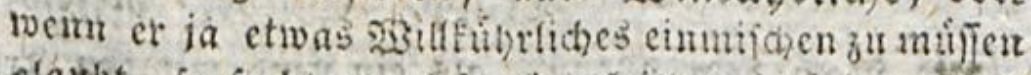
glattot, fo fitht cr es is cinzuletter, bab das sind 37. $\mathrm{eg}$ bod for eire hothivertbige folge feiner thands igniद Yung 


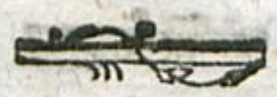

353

was ibnen nidjt umangenehm wåre, *) unర immer befdjwerlid) ift, ben 28 illen eines 2 nbern ou thun; fo serheimlichen fie, um thren eignen su bollbringen, fiberzengt, bafi fie robl baran thun, wenn man bon ibrem Utngeborfam nur ricfsts weißß; aber such) bereit, zu gefteben, baf fie Unrecht gethan baben, menn fie entbed't roctoen, aus furd)t bor cinem noch grófern Uebel. Da bie Betnunftmáftgfeit ber \$ुDftadt nicht fur ifgr 2fter ift: **) fo gieft es Einen

Miens

lung habeu muf : uno bann fallt ber ఇachtheil bes Befeblens und Behorfamforberns, weldhen $\Re$. bier befdreibet, weg. Eampe. Trapp. Stuve.

Sebr gut, two nur Das İillfibrliche ver mieden toerden farn: ob es immer vermieden unb alleb auf notbwenbige folgen rebucirt werden fonne; baran ziveifele ich.

Refenvis.

-) Nber ift bas bei etwas verninftigen Erjiehern ber sall?

Qjoer immer ber fall?

(E))lers.

Refenis.

-) Eine geiviffe গ̧ermunftmápigffeit - freilid feine buchgelebrte, feine entwoidelte, feine aus ङd)lubreiben beftefinde, - ift allerbings fur ibr Alter. Hno was veriftebt $\Re$. unter Sindern? Er, und viele nats ifm fprechen fo oft von Sindern, wh beptimmen nicht, was fur Sinber fie meitten, Sinber vom eriten bis zebnten Jabre fins exfauneno von cinans ber verfctieben, und múfien ganj verfdeieben bee comilifter if. 
92)enfdjen auf ber 9 Belt, ber int Stanie soire, fie thnen wahrbaftig begreiflidy zu mas d)en; ") aber bie Furcht vor Bird)tigung, Sofnung zur Dergebung, ungeftime Dringen in fie, ifre $\mathfrak{B}$ erlegenheit 2 ntworten zu finoen, entreiffen ihnen alle (Sieftánoniffe, die man fors bert; uns man glaubt, fie liberzengt zu baben, wenn man ifnen nur Zెeit uno 2 geile lang ges madjt, ober fie in Furdjt gejagt bुat. ***)

I. $23 a s$ entfteht darans? (Erftlich bas, saff, insem ifgr ibnen efne goflidgt auflegt, bie fie nicht

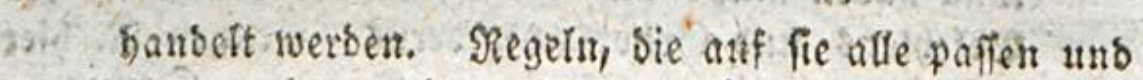

- Wargewant werben follen, miffen unbeptimnt un' feblerbaft fenu. Refenvib.

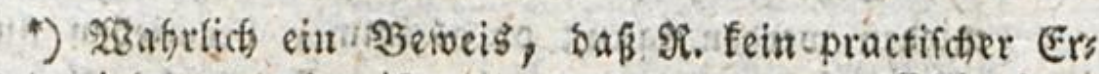
ziefer geveren ift.

Eblets.

Eo weit fie Sinbern begreiflidy ju fenn braucht, fattn fie ibter immer begreiflić gemacht werbert.

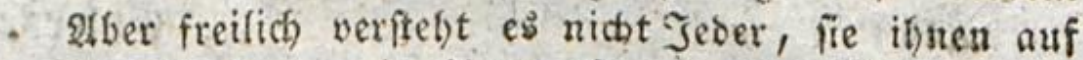
ifre. 2Beife uno in iffem Naake begreiffich zu mas chen. Daber fommen benn bie zrectlofen furgen unb langen moraliichen \$rebigten, bie nichts, oder roas fchlimmers als nidhts, die bab toirfen, waś

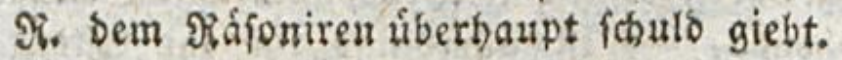

Srapk. Refenitb. Eampe.

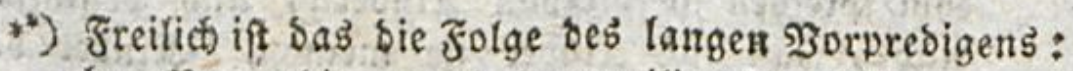
aber Sorprebigen und langtoeilig Mioralifiten, und

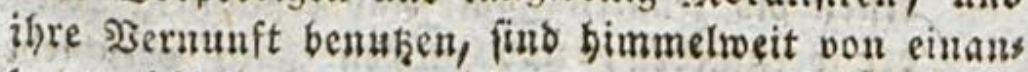
ber verichioben.

ঐejemibs. 


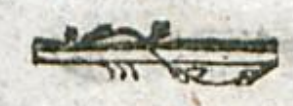

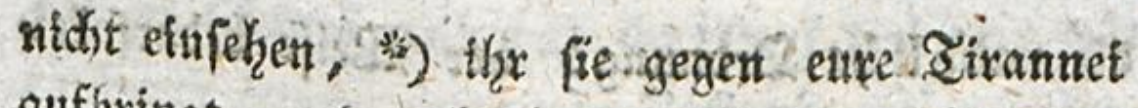
aufbringt, und eud ifgnen berhafit madjt; baß the fie lefgrt, berfellt, farfed, signer zu wers ben, um Betohnumgen auszupreffen, ober fich

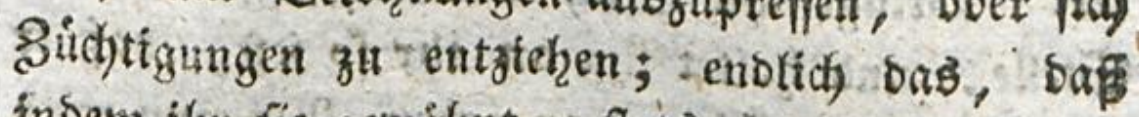
inbem ifye fie gewoftht, ftets init einem fojeins baren Bemegungzigrunbe einen geheimen zu bes

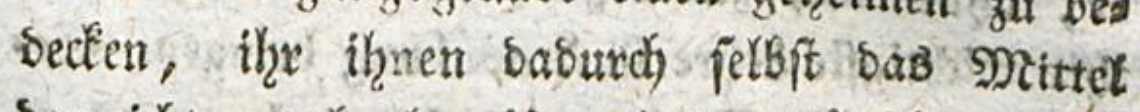

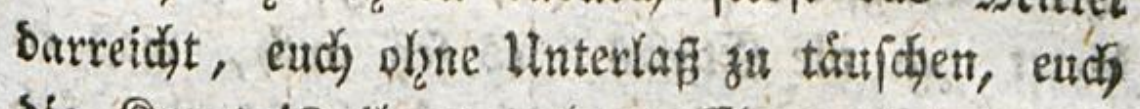
bie Renntnig ihres swahren Characteris za enta ziehen, unb endy und 2 nbere bet Siclegentzett

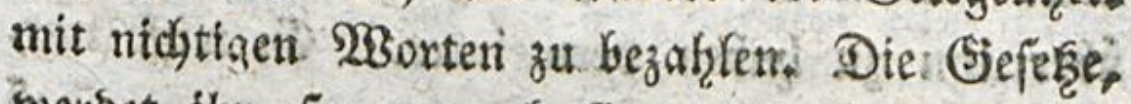
merbet thr fagen, of fie gleidf fir. Das Ejes wiffen berbinolich find, bebienen fich ebenfalls bes awanges bet ben erwadjfenen Menfiden. Sh) gebe es zu; aber was find biefe Menídjen anderb, alz burch ble Erzlełung verborbene Sinder? Serabe Dem, follte man sorbaum. Mgendet die Starte bet ben Sinsern uno bie 3ernunft bei ben (Erwactifinen an; 32 bie

-) Das muk nie gefhelin. Ulber bas ift auth ganz was andewb, als bas (Sefíbl ber 9 flicht in Rinbern erveden, und biefes (sefúfl nach und nach zur Ero

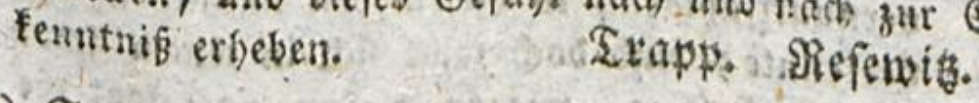

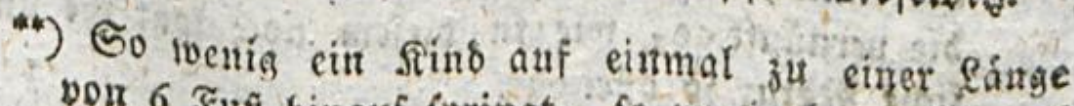
von 6 Jü binauf ppringt, to wenig fann fich auf eins 
bie natirltife Sronung; Ser SIGeife bebarf leb seer (Seferge. ") troc

Bekanbelt euren $3 \delta$ glting nach fetnem 21ts (ert Bringt ifge gleich son 2 njang an fine Stelle, und haltet the an thr fo frit, baf ex

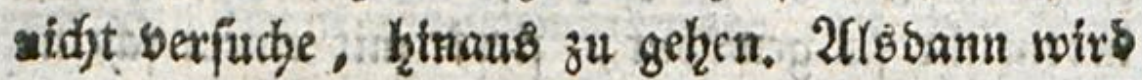
ex, ofrne nod, za wiffen, was 28 eisheit ift, thre wtdotigfte lelgre in 2fusitbung bringen. Ges

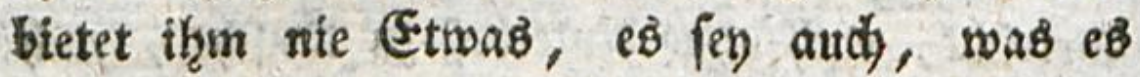
roolle; fojlechteroings nidjtè! Laffet ihn fich aidit cinmal einbilben, baf́ if̨r einige Gemalt ster thn zu haben vermeintet. Er siffe nux, baß

eirmal bei Erroadfenen Bernunft finben, soens viefe nicht allmátig ausgebiloet uno nach bem $\mathfrak{\text { Raa }}$ 2toge wirffam geivefen ift, als fie fich entroidelte.

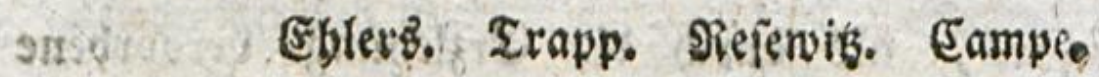

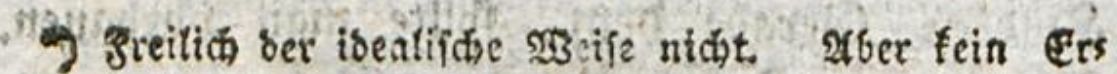
beniobn ift biefer 23 eife; und fo bebarf auch ber

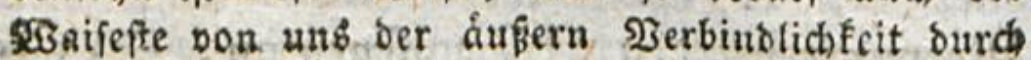
Gefeb̧e, venn gleich weniger alb der llmweife. 2fuf ber andern Seite bebaxf bie Erzichnng bes stinbeb nidht blok bes Bsebrauths ber Etátfe, fonbern auds

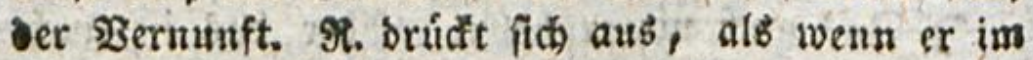
Sinde, wie im şeiren Den Renfchen, in jenem bert vernunftfábigen, in biefent ben finntichen shenfchen Derfente; und ood zeigt fich in jenem fochon fríb sie vernúnftige, wie in biefem nod fpát bie finw Sidge Ratur fo offenbar.

\section{Srapp. Referwis. Campe.}




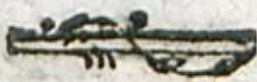

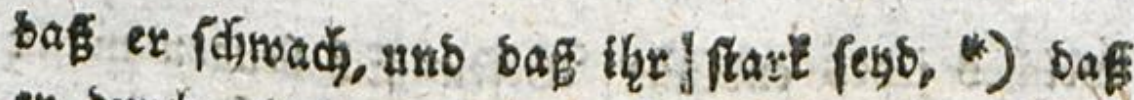
ex burch jetnen unb euren 3uftano nothwenbiger 2 elje in eurer frand fteht; bies wiffe, bies lerne, bi s fúhle ex; fühlle bei 3eiten uber reinem hod)getragenen Sraupte bas harte Sod, Sas bie Matux ben Mienjodyen auflegt, bas

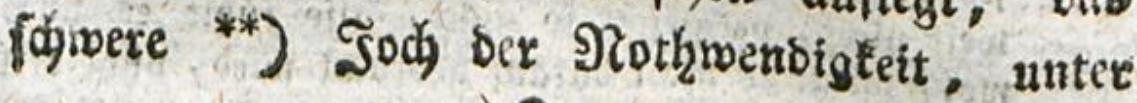

wels

eहै

ist

alt

$u r_{\text {, }}$

aßs

$n$

$\operatorname{ta}$

Ens

bex

rch

tuf

seb

uा

im

ient

ens

tib

ins

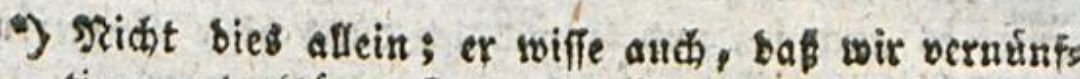
tiger und flúger find, als fitider; es wiffe aud - unt biefes sornehmlich - daf́ er von ung goc liest toerbe, utho dáf́ twir, vermóge biefer unferee Siebe unb unferer Rlugbeit, nidbts von ihm vers langen, als wos itsm wirflids nüblich if. Davon áberjenge man inn burdh einige ihm gan begreifide unb anfichauliche Jálle, und ex roirb in ber Folge leiner netten Heberzeagung mehr bebírfer. Da sino wirb pon felfoft ats einigent folden frappanten Jállen auf alle anbre fdlliefen, befonbers toenz wir ifh fonft feine bielegenheit gegeten haben, uns

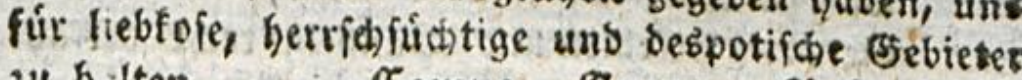
ou bulten. Campe. Trapp. Siefenib.

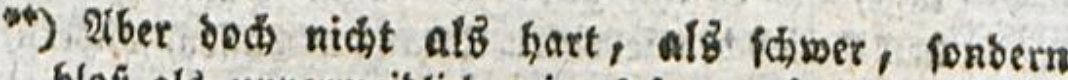
blop̉ als unvermeiolich, in fofern sómlich ber Ẽ gieher durch 230 ort uns That baju beitragen fann, wie cin אind bie Nothrwentigfeit fúblt. Ind von felbrt, follte id meinen, wirb eb nidst viel 5artes unb Edmeres barin finden. Das $\Re$. bie Nothwentigs teit als ein hartes und folweres Jod fuiblte, fam Dafier, bafif er fie fich to Dadite. Hub bies fam mieber baher, baś er fie mit bem entgegengejetten mógliden, freilid blö in ber Joec mógliden, Sur

กaxs 


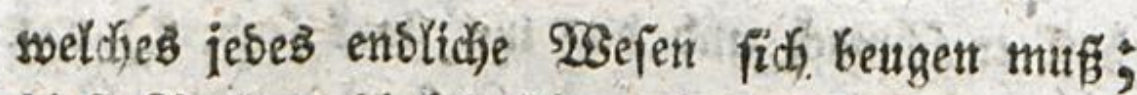

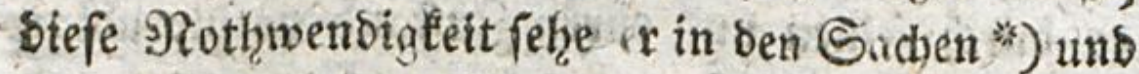
niemals in bem (Gigenfinn $\dagger$ ) Der Mienfdjen; $: 3$, 2 ser

ftande ber Freiheit verglidg. Ein find denft fo toeit nicht, vergleicht fo nid)t, alfo fúblt es auch wot, westi es nicht darauf gebracht wird, nicht viel Invehagliches bei ber Niothwendigfeit, fich der Noths woendigfeit zu unterwerfen. $\Re$, gtaube ich, meint

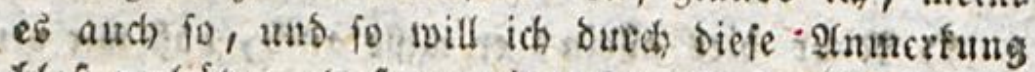

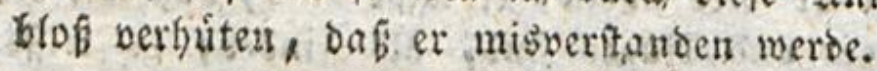

\section{Trapp. Nefewiz. Eampe.}

2) SIS wenn ein Stirt, gegen das man mit peiner obermadht fandelt, es uicht fábe, bápi ser (sébrauch berfelben im sisillen feinen (Srfino bat, itho als soenu es darin, nicht eben to gut Eigenfint fande,

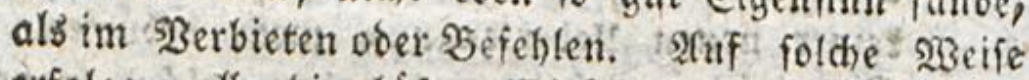
erfolgen alle bie bofen ŞGirfungen, wiber weibe

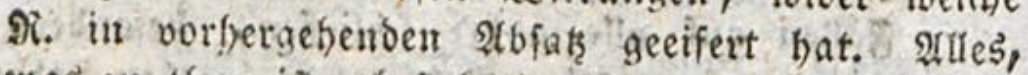
was at thun ift, befteht barin, oaf man im $3 e r s$ bieten, Befehlen unto janbeln recht verfabre unb

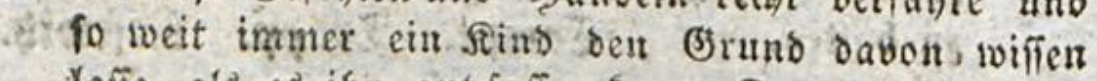
Yaffe, als es ifn gut fafien faur. Dann wirb es nie atrah bell Eryieljer, wie eitren Diratnen haffen, fondern, loie

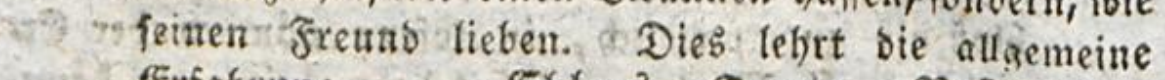
Erfabrung. Eglety. Srapp. Nefeniks.

7) gran fann berfidert feyn, baf finb wetbe tebell, bem jeinigeit juviderlaufenden $29 i f l e n$, jeben, wovon es ben छrunto nidht ciufehen wirb, fúr Eigenfin balten. Sebt aber fúfit ein Jins bei alle sem, was fcinen Einfällen wiocrîtrebt, nicht den Brund.

D. Betfaffer. 


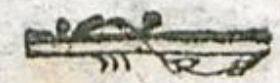

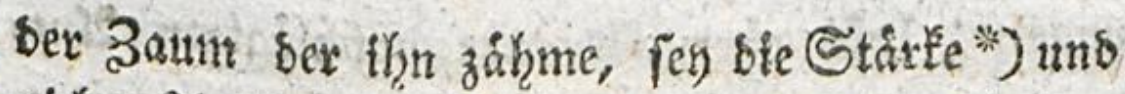
nidyt 2 nfehn. **) 2 geffen ex fich enthalten

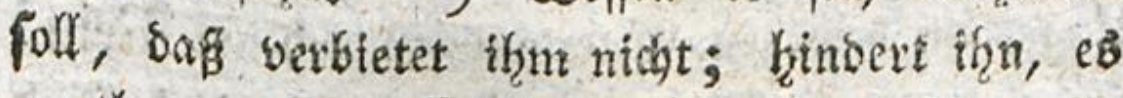
ơt thun, ohne Extharungen, ofgne BBenumf: fdhliffe! S2Gas ifyx ifym bewilligt, bas bewilliat ifhin auf fein exftes Sigont, obne saf́ ex brum anhalte, ofne Bitten, wornehmlich vhne Ses bitigung. ****) Bewitligt mit SBergnugen, veringt

$$
34 \text { ma }
$$

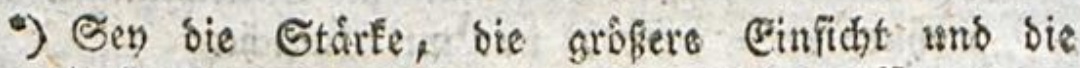
Hebergengung von unferer wabren Riebe. Campe.

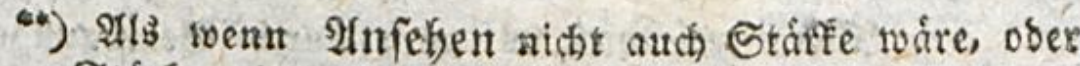

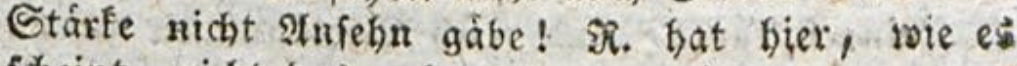
fideint, nicht bas rechte. 233 ort gewáblt.

Trapp. Refervis.

Foufieauts ganzes Raifontement úber ben Ges horfam ber Ninber, ift offenbar viel zu cinfeitig, unb uibertrieben, unb ich unterffreibe sie bagegen gemachteu 2tumeifungen meiter Seern Mitarbeiter, of ich gleich auf ber andern. Seite iefre uberzengt bin, baf bie unverminftige 2 frt, wie fo viele Eittem (5ehorfam von ifren Sindern forbern, and foldse zu

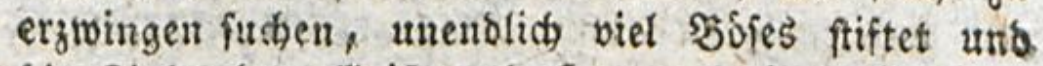
sie siner dem (seifte und Syerzen nach verbirót.

\section{Stuve. Siefervib.}

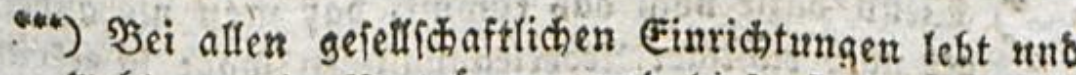
rebt man in \$ertrakgen, und diefe find wefentlich mit જ̧ebingurgen verbunden. Selbft taab ein cins zetner झenifh in blofer Seziebung auf leblofe und snverminftige Gejdopfe thut, beftimmt er nad lims 
ungern; lafft aber alle eure abfdiblagigen 2unts sorten unvioerruflid, fern uns euch ourch) Eeinen Ungeftum bewegen. Fuer aubgefprudnenes Sein! fen eine eherne Mauter, wiber welche bas Rins nidht finf ober fechisual feine Sixafte exfojopfit babe, ofne oon sen Berjucjen fie umzufto get. abuftebn. *)

2uf

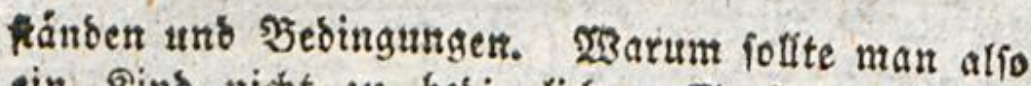
ein Sins nicht zu bebinglidoen Finrichtungen ges wófnen? Es gefobebe nur mit Einfidjt.

Еb)

2therbings mut es auth burch গुebingungen cingefdränt, uno nach ஒebingungen zH banicln gewófnt werben, fo bald es mur einigermafien eins fehen oder fühlen fann, bas es in ieinem Sirfer vou gegenfeitigen Эoebinguttgen abbánge.

repentis.

3. Gatte biex vermuthlidi iene unverftándigen eltern tund Erziebser im Sinst, die bab, wab fie Trtigfeit nenuen, ben sinbern abjubandeln pfles sen, inbem fie ifnen dies und ienes verfprecten, soenn bas find bagegen geruben will, búbich ftill

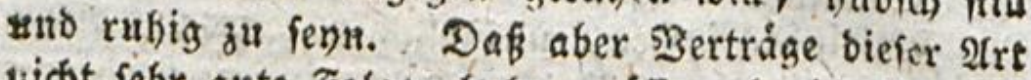

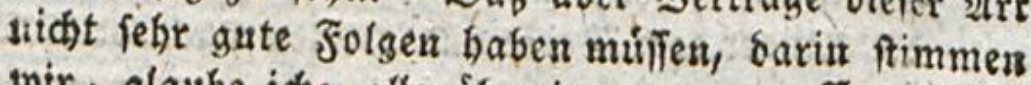
soir, glaube ids, alle tiberein.

Eampe.

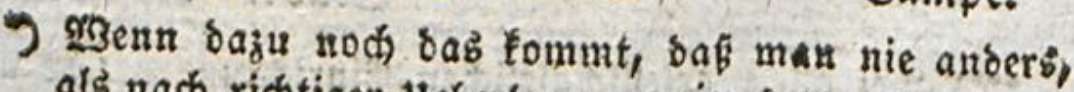
ols nach ridtiger Heberlegung nein fagt: fo erfennt bas fins felbft balb, bab es fowol butch ein Nein, als burds ein Ia auf sen ş3eg ber Olúfieligfeit ges fifrt wirb. Daut mubes felbit fur ein Nein feinem Ergieber banfert.

Glers. Rejerwis: 


\section{एकाषे 301}

2tuf foldye 21nt merbet ifye es gebulsig, gleidymúthig, getaffen, uno fetbft wenn es bas nidjt-erlangt ḩat, was еб gern geḩabt hâtte, rubig madjen; benn es liegt in ber গatur bes Meufden, vie Nothrwensigleit ber Dinge ges

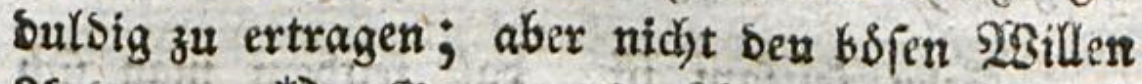
2nberer. *) Segen bie 2ntwort: ba if nidjts mefle! hat jich noch niemals ein Rins geregt, es mífite fie senn für eine Singe geo halten haben. Hebrigens giebts hier teiners Mittelweg; man mup entweber ganz und gae nichts son ihm forbern, **) ober es gleid ars fangs zu bem volleommenften Sehorfam betrgen. Die fdlechtefte Erzithung if, wenn ihr es

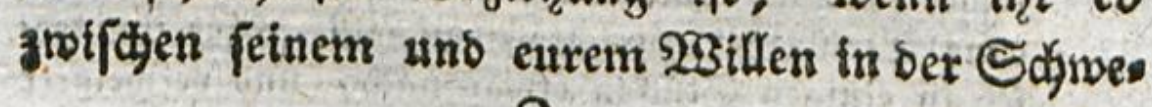

$$
\text { 3. } 5
$$

be

9) Itm es babin, zu bringen, baß bas Sind in 2flem was wir von ibm perlangen ober ibm abishlagen, mefr bon ber Ratur ber Dinge afs bon uns uno

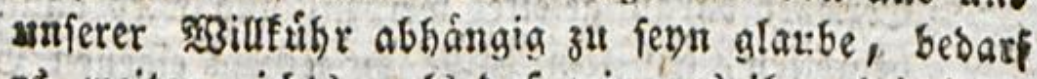
es weiter nichts, als daf wir uns ifm bei jebee Belegenteit wabr, feft, liebevoll und nach Hee berlegung bandelnd zeigen. Daun finbet fich der roillige Beforfam sanz von feltbp, utus brautd, ibne

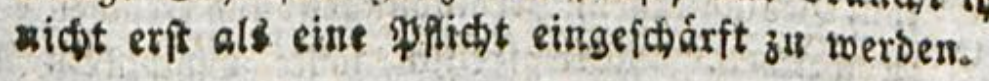

\section{Campe.}

") Eraurig ift of, baß cin Swriftffeller, bem fo piele forgen uno ben fo wenige gebórig zu muķen twiffer, fo oft ben mittelweg verlábt und ioft, roie bier,

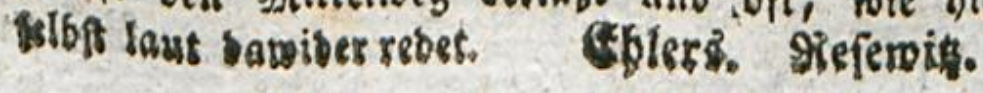




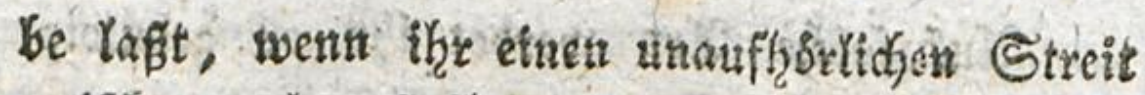
zwifiden enc) und thut, mer son beiben Meifter fenn foll, herborbringt; ich wollte zehumal lies ther, baf́ es felbft allemar den Sieg bason trige. ${ }^{*}$ )

- Sebre feltam ife, saff jeitoem man fich

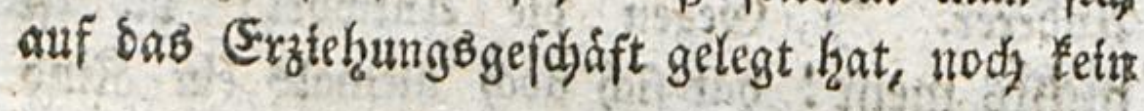

atts

7.) Eant bie Eprache eitres in feinen steuferunget von Geibenichaften ober cinfeitiger Lebraftigfeit bet Einbifoungsfraft geleiteten Nanues. (E)levi.

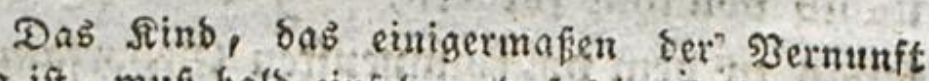

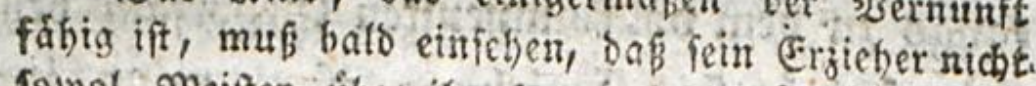
folvol Neifter tiber inn forn, als'es liber foine eis gene SIJohlfabrt jurechtweifen will. fifft jhm dies fer in einigen Stuffen etivas nach, uno verweigert swieder in andern: fo ternt es bals cinfehen, went es-anders fonft mit Siebe bebandelt wirb, bafi fat

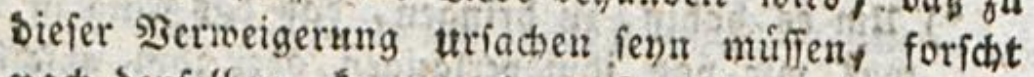
nad denfelben, fann uno mui alsoanin burch ben Ergieher barauf geleitet werben, und wird bann bald begreifen, baf fein $\mathfrak{S}_{\text {Sille }}$ z乡 feinem eigenen כefter eines anbern $23 i l l e n$ untergecronet toorben, Nidat 3u gedenten, bap bas vermunftfátrige Jinto auch ges wobhnt werben muti, wenn es 23 eltbirger, werben foll, গ̧ebingungen, গ̉erbinoungen un fremben șillen

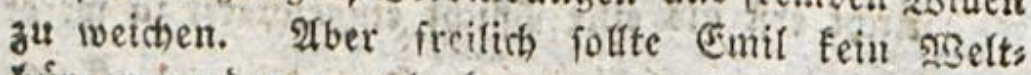
burget iverden, auth fonnte er es nidht leerden; Tonberu mufte ju einem z!veiten Rouficau erwadbien, ber fidh nidbt nach ber sielt uno ber menfóliches Befelfichaft, fondern biefe nach fids bequemen wollte.

Piefentis. 


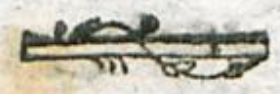

anderes Mittel ausfinsfó gentadjt morben, bie Sinber zu teiten, als ber S2Betteifer, bie Ei fexfucht, ber Rets, sie Eitelleit, bie Sierbe,

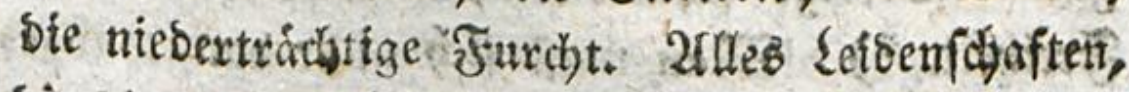

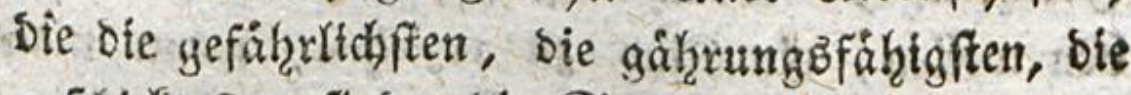
gerdjictieften find, bie Seele zu verderben, felbfit noch ehe ber (eib gefitset if. *) Sei jeber au frubzeitigen Unterwetpung, fo man in sen Ropf Ser Rinder fineinbringen mill, pflanzt man eits Safter im Srunde ifyres Scerzens ; unverftandige Sefiver glauben Sunber gu thun, wenn fie fie bofe maden, um fie zu lehren, was gut fen; **) uns bann fagen fie tuns ebrenfeft: fo ift ber Menich! $j a$, fo iff ser STeníd, , ben ifgr gemadist habt!

9)

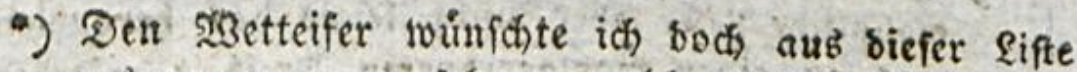
nubgenommen zit fehen, welcher cine nothwendige Frucht bes geielligen Lebent iff, und obme welchem in ber (Sefelfichaft nicht viel bewirft loerben wirb. Die Pplicht bes Eittenlebrers aber if es, biejen

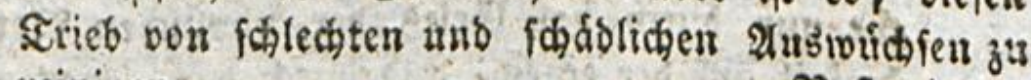
reinigen.

Refenvib.

94) भ. will fagen : man feţt foldhe Triebfebern in ber Sinterfeele in S3ewegint, weldhe bie Seele verbers bet - .3. 3. Speid, EitelEcit, Sierbe ut, f. to. um fie zu betwegen, aufmerffam auf benienigen line terricht as fenn, woburch fie gut gemacht rerben follen. Daß bies båufig genug geideke, ift leiber: lut allzubabr,

campe. 


\section{4}

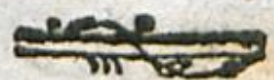

is Mran hat alle Mittel serjudit, Eins auss genomimen, bas cinzige gerabe, weldjeb vou gutein Exfolge fegn taut, Sie noblgeoronete Freibeit. ") Dtan mug fich nidit bamit abges ben wollen, ein Rinb gu exziehen, wenn man es ttidjt burch bie bloģen Gerége bes Moghlidjen

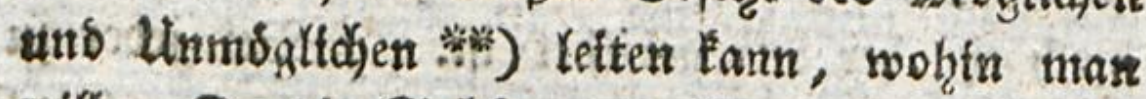
will. Da bte Sphatre bes cinen uno bes 2 ns bern ifhm solffommen unbetannt ift, fo berens gert ober erweitert man fie um baffelbe herum, wie man will. Stau feffelt es, man treibt es, man hât es zuriacte mit bem bloken $\mathfrak{B}$ ans be Der Nothrwendigteit, ohne baf es bariber murre; man madjt eb ourdy bie bloge Starte

9) Xus Nouffeaus bisherigen Forfwriften wirb ber ges wófuliche Lefer aber nitht leicht bas berausfeiteti,

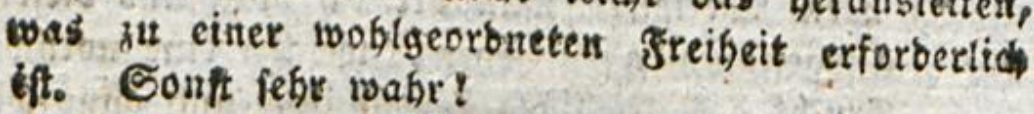

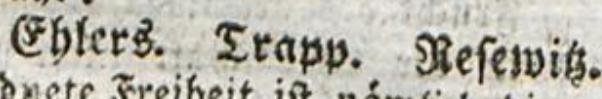

Die wohlgeorbnete sreeibeit ift námtich oie, weets de nur burch dad Befets ber Dhmifeden Nothwens bigfeit auf bex einen, and butch bas, toas zut peir

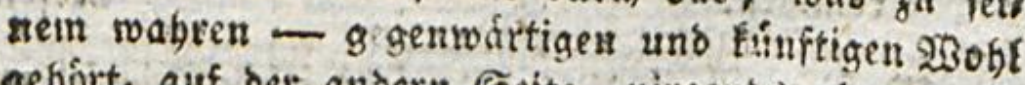
gehort, auf ber andern Seite, nirgende aber burch

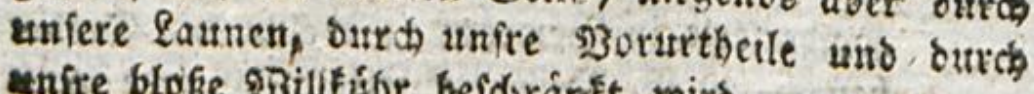
unfre blofe sobilltúbe bejdyránft roizb.

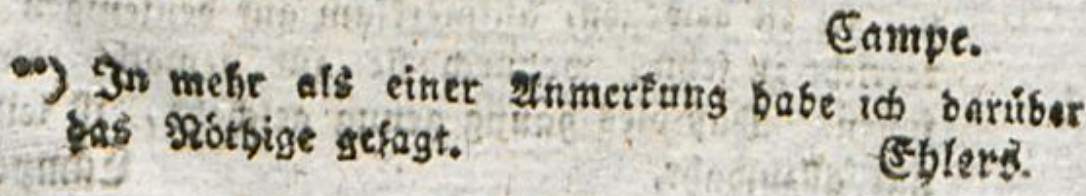




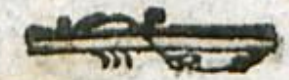

Ser Dinge geffjurtotg uno folgfam; unb Pein Eafter findet oabei Selegentzeit, in thm gu tei men: Denn niemals entflammen fidy bie Leiben

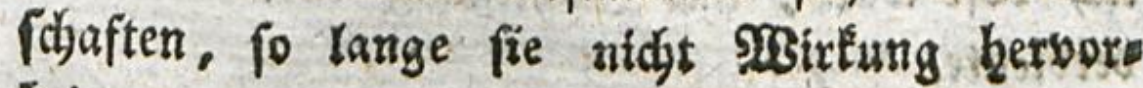
bringen.

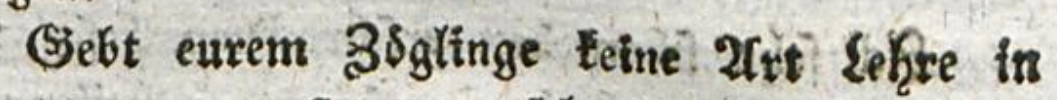

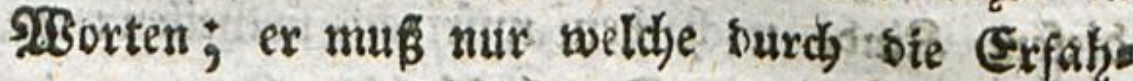

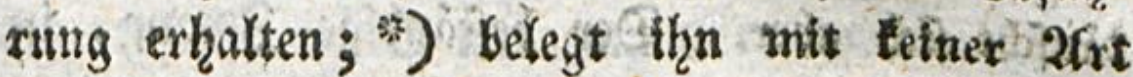
Don 3údjtigung ***), benn er weif nicht, was

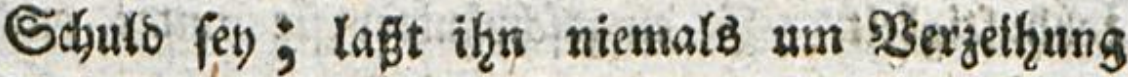
Sttten, Denn ef tann eud nidht beleibigen. ***)

Da

7) Sidtiger: gebt eurem Soglinge feime Lebre, Ste ifhe nicht auf feine eigenen Empfinbungen uns Erfabs sungen gruindea fount. Rommt aber beibes unfre wortliche S3elehrung unb bas cigene (5) fúbr Des findes - zufammen: Dann entfebt eine Ers Eenntuifi, welche beutlich uns anf(hauens zugleich ift. (Eine folde Erfenntuib aber ichafft unausbleibs lichen und bauergaften Nuķes.

Campe. Traps. Siefenvit.

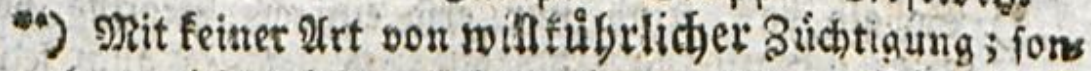
bern ridatet iebe nothwendig gewordene stiditiguns

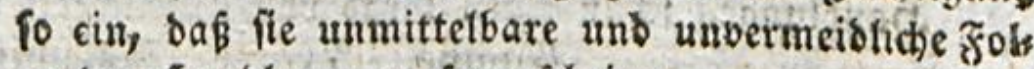
ge der Jpanolung zu fenn ideine.

(5ampe. Srapp.

So weit es nut immer moglich ift. Refentib.

o) Sjierin fimme id 2 vollig bei.

Srapp. Sampe.

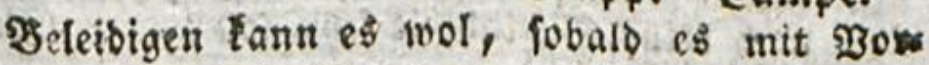
fats baudeit, und das thut es jiemlich frúb.

Riefewit.

arber 


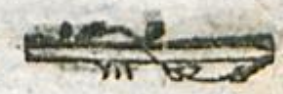

Da itr allen feinen Sganslingen noch Feire Sitts Itdjleit if, *) fo tann ex ntdjts thut, was fitts

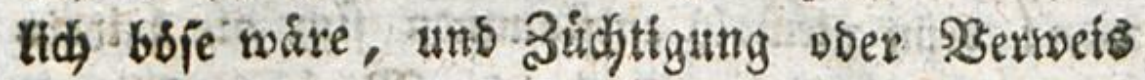
verbiente. * *

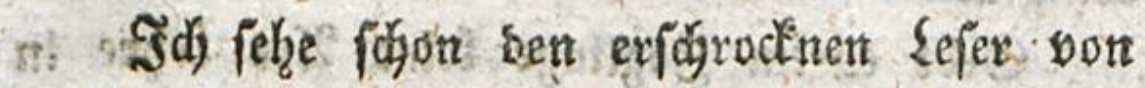
stefem Sinbe nady ben unjighen unthetlen: ex tangdyt fid aber. Dex beftäntige 3wang, in Sem the eure Untergebenen haltet, reizt thre

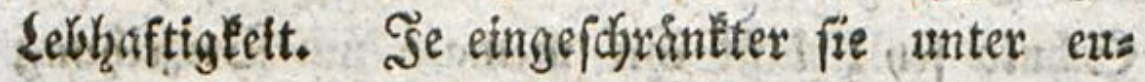
ren 2 ungen fitto, Deffo aubgelaffener werben fie in bem 2fugenblicte, wo fie lostommen; ${ }^{* * *}$ ) fie mífien fich wol, forls fie tosnnen, fưr ben kars

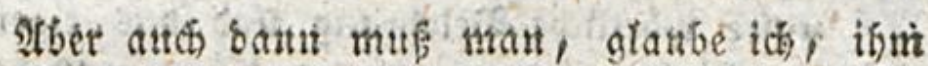
niemals zu etkennen geber, bab man fich für beleis bigct balte; tunb bas 3 itten um Berscibing foheirt aud in biefem folle mehr 900 es, als (5)tes jut wirfert.

Eamipe.

*) Sobals bas fino intr stit einiger Segriffe you Rectit und lurecht fásig lvirb, fo rebmen and Yeine Scandungen fobn cinen (s) vod won Sittlicheit aut.

Sampe. Trapp. Siejenta.

*) Det ganje Sibiats if voll von theils falicten, theils nicht genug. beptimimten: Bjebanfent.

(E) flet?.

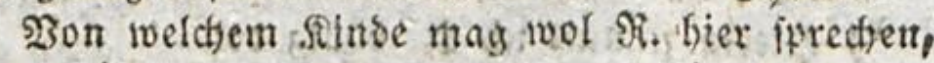
oom einjábrigen, ober acht bis zebniabrigen, two

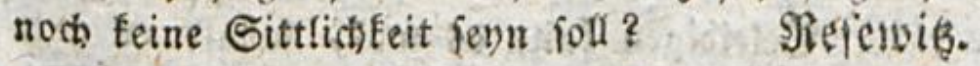

wav) Dies wirs von sflgemeiner Erfabrung beftatiget. Sampe. 


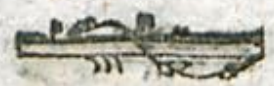

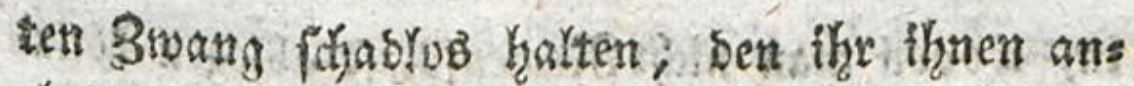
that. Bwei Sinaben aus ber Staotfoulue wers ben auf bem kande mehr zu nidje maçen, als bie Sthgend eimer ganzen Dorffhaft. Eperret einen tlemen gnábígen $55 \mathrm{errn}$ und einen Etteinen Bauerjungen in eit Btmmer: Dex erfe with alles um unb um getefert, 2Clles zerbrodjen has ben, etge ber anbere num einmar pon feinem झुOta Ge gemicgen ift. 230 oler bas? menn nidjt baa ber, Drof ber, Eine Eile hat, eines 2rugenblictes Der Utrgesumbentheit zu mişbraudgen, indeß ber 2fnore, immer feiner క̌reifeit gemis, niemals (iic) ib bereilt, fie sus nuken? Itho sennod) find Die Dopftinter, benen gletcyoul noch oft ges fidmeidyelt uno wiberfprodjen wirb, fehre weit son bem 3uftanbe entfernt, morin, meiner Deta numg nady, Sinder gethalten werben fullen.

Saf́t uns als unwiberfprectlichen Srrunsfas feftftellen, baf die erften Benegungen ber গas tur immer fofledjt unb redjt fino; eB giebt feine

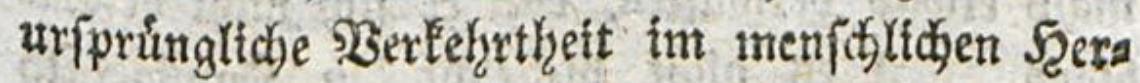
zen. *) (E) finbet (id) Éein einzigea Lafter bar in

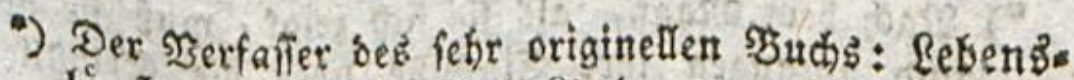
láufe in auffeigender Binie, fagt febr treffend: ber erite follecte Erzicher, Den es gegeben habe, feD Der Erfinder ber Sehre von bor Erbfunbe gewefen. 
in, rowon man nidit Rechenfdaft ablegen Estno te, wie uno woourdh es hineingreformmen. Die cingige sem Menfibu angebohrne Leibenfidaft Ift die Siloftlibe, Doer ste in einem aubigetehn ten Sine fogenannte Sigznliebe. Diefe Selbft liebe an fich, ober in 9 Bezielfung nur auf uns felbft, ift gut uno nußzlic); uno ba fie fein notha

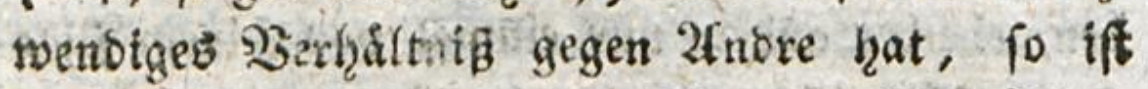
fie in Diefem Betracht son Natur gleid)gultig; fie wito nur burth bie 2urwenouttg, die man bagon macht, uno burib bie Serhäâltniffe, bic man ther giebt, gut ober boje. So lange affo,

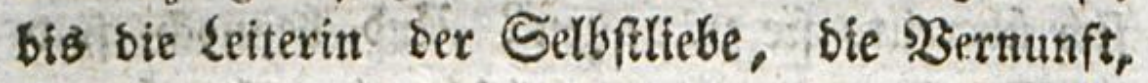
fich zeigt, *') liegt viel Daran, bag ein Rins

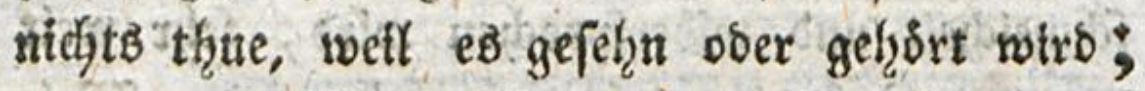

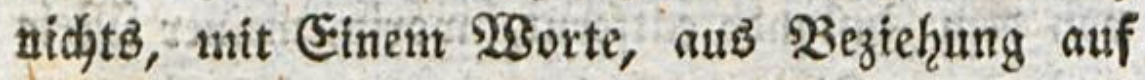
2rnore; $\left.{ }^{* *}\right)$ fonbern nux bis, was die Nas tur bon thm verlangt, uno alobann wirb es nidjt als Ġutes thun.

Sंd berftehe barunter nidat, baß̧ es nies

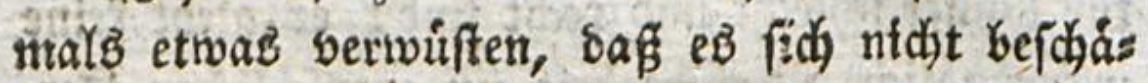
bigen, baß́ es nidjt vielleicht ein Şausgeratth

son

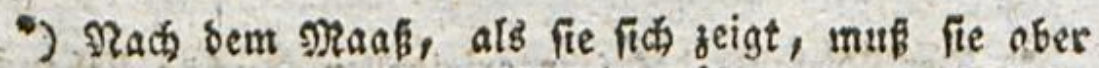
auth anfangen ibre Einfluffe úber bie Eelbftliebe ou befommen.

Eblers.

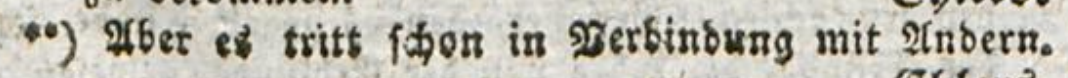
(ङ) 


\section{- 369}

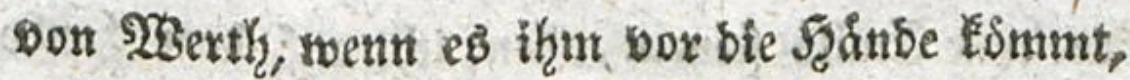
zerbrect)en soird. Es tisnnte viel Sajlimmes than, ofne forltmm zu bandeln, weil nur bie

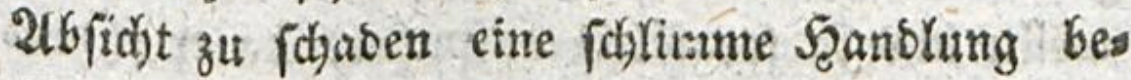
fimmt; *) und biefe 2(bicht swiro es nie has ben. Sochtte es fie ein einziges̉mal; fo wáre

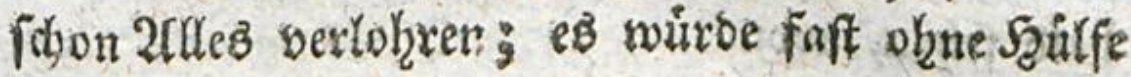
bife pern.

Mandice ift in ben 2lugen bes Seizes 6sie, was in ben 2tugen ber \$ermunft nidyt bofe ift. SRBir braudjen aljo nur, inbem wir ben fínbert bsulfige Freifgeit geftatten, fo unbefonnen sul jegn als fie wollen, 2ffles von ifnen zu entfernet, woburi' uns sieje thre Utnbejonnentheit theuer zH fithen tommen tosnnte, uns nidjts zerbredjliches oder toftrares ffrnen im spsege zu Kaffen. Şbe - Zimmer fey mit grobeen uno ţanbfeftem Sexdo the verfekzen; Keine Spieger, tein shorzellain,

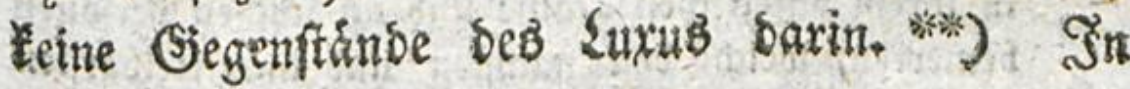
meis.

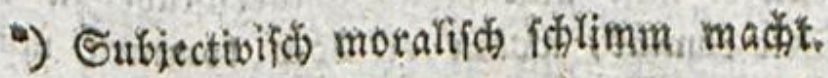

Eblers.

".) Ulit bas nicht blof beswegen, bamit fie nidft vots raetth gerberechen ober befwádigen fosmren, fonbern nuth vornefumlich bestwegen, weeil es ibnen an Reib unb Geele gut thut, won allen Begentianien und Benúfien bes \&ukn fo entfernt als mogglid gebals - ter zu werben.

Emil riter $\mathbb{E}$.

Is a

Eampe.

sit 
meines Ěmilb feinetn, Den id, attf bem Lanbe

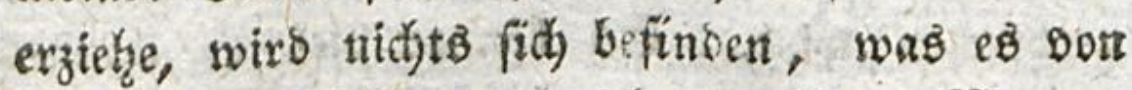
einex Baterfube auszzeid)nete. *) ${ }^{*}$ Barum wollte tad fo forgfoltig aufpulgen, ba or fo wes nig sarith bletben foll? 2lber nein! id irre midb, en wiro es felbft aufpurien, und six werben bals fetren, womit.

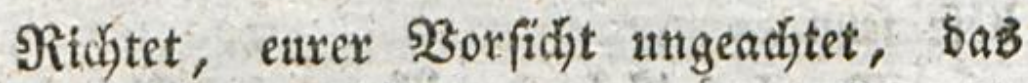
Rino sennody efnige llnoronung an; zerfchmeifst es etn mistities Stuct: fo ftraft es nicht firt

ente

Jî bieje entfernung itt ber jeţigen feineren 2trelt wol móglich? Sollten wir ifnen auch biefé Giegenfrande bet uns verfergen fonnetr, fo jeben fie

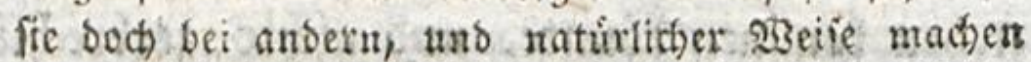
fie angenebme finuliche Einbricfe \$efeidis.

Seiber utur zu roabr! Jubes ichabet, glaube ich, sos, was Sinber in frember Shátfert und sut frems ben Menídfell fefen, weit wentger, als bas, was fie in ifrem vdterfichen f̧aule uns an folchen Perionen bemerfen, welche ben nádhften uno umittelbarftent Einfú suf fte haben.

Eampe.

-) Uno wenir er mur aus diefer Sbautruftube in bie grope grgelt formint, wohin el bod foumen mufs, twirb bant baa oblanzendere nid)t befto fárfere uns fiefere Eindrtide auf ihn maden? Sefehis?

Sian founte viefleicht antworten: baß man ifm vorker erft, aufier bem vátertichen Syaufe, bie şelt zeigen múfie, wie fie nut einual ift, und

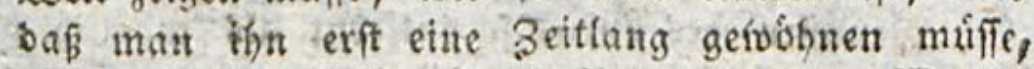
die Dinge in ber 2 SBelt nach ibrem wabren

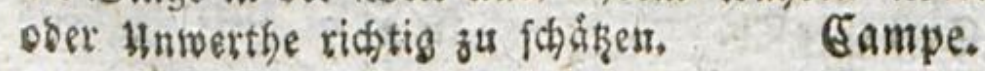




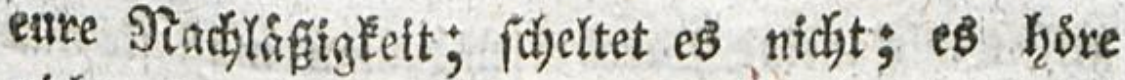
nicht ein einziges 23 ort von 2 ermeis; laffet

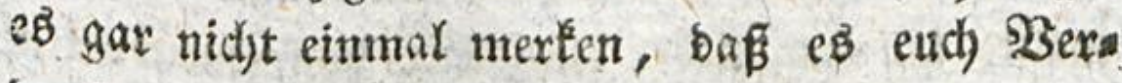
Druß grmadyt ḩabe; ḩandelt genau, als went bas Studé bon felfif gebrodjen ware; *) Eur: glaubt, bafi if̧x viel gethan habt, wenn the euts babt iberwinoen tomen, nichts zu fagen.

Dirfte id hier nol bie groffte, bie midy. tigfte, ofe nislichfte Riegel aller Erziehung oor tragen? Sie ift nidht, Beit zu gewimnen, fons

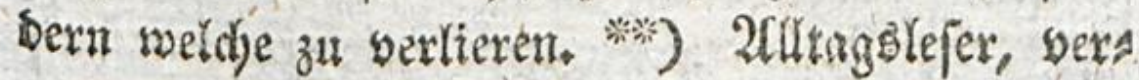

$$
\text { if } a 2
$$

zets

*) Nan mún ein Sins nicht ben (sebanfen befommen lafien, oaß man einfáttig genutg fen, um fo etwas nid)t gemerft zu haben. Es wírbe baburch auf bie goee geleitet werben, uns in ber Folge abfict)tlith binters Sicht zu fúbrear. 2luch if $\mathrm{eb}^{\mathrm{b}}$ nicht alleits zatúrlich, Dáp marr uiber etwas, bas Nisfallen erres

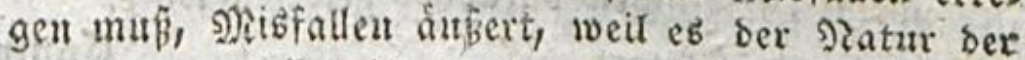
Sacte angemefien ift, fonbern es if aud fur bas

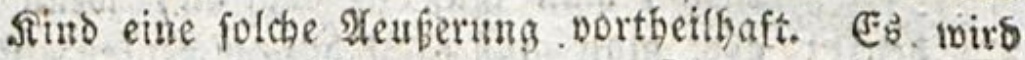
Dabutch in Der beurtheitung oer. Dinge uno in 2 Gs ficht auf eit bazu ftimmendes \$erbalten richtig ges Ieitet. Es mü fruh lermen an lebes tlebel, das

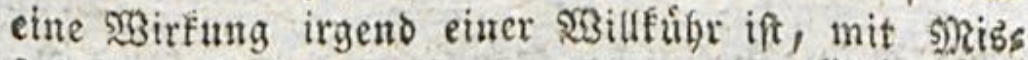
fallen zu benfert.

(5)blet⿱⺈.

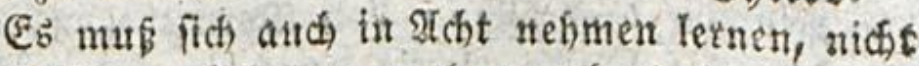
unvorfeklichen Schaber zat thun, of es fithon nicht sur(t) Şetweife oder Suchtigungen bazu gebracts werben mus. Rejentis. Bampe.

*) Diefer (3runsfan ift in cimem getwififen Gimte feís.

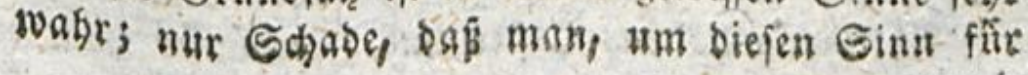
gemets 


\section{2

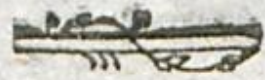

zeifget mir meine Sुaraboxien; man nuff fie ma d)en, wenn man benft; ") und fagt, was thro sollt, ich wag Yieber ein Miam von Sparaboxien, als ein Mann bon Sorturtheilen jeyn. ***; Der

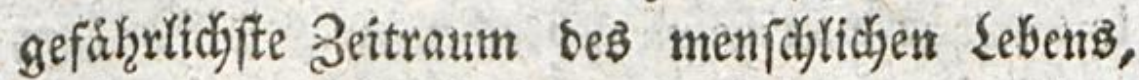
ift ber son feitner Gjebutt an bis zum zhoulften Sabqre. Dies ift bie 3eit, worin bie Sirththa mex itno Safter feimen, ohne baf man noch trs

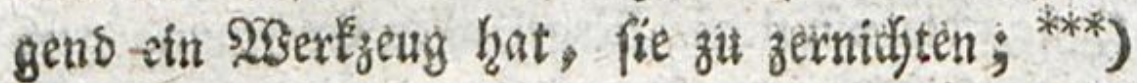
thethe

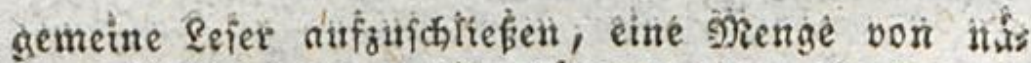
hern Şeftimmunacu hiuzufúgen muste, bie ber ges

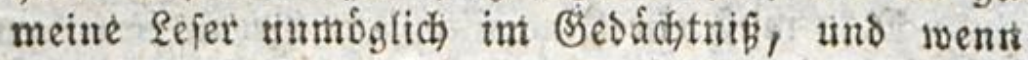
es zut Antwerioung fommt, unmoglich slle im Stuge bebaltent fäm.

Sante. Niefewiţ.

-) Sefr wafje! Sach bat eइ nod nie cinten benfelu ben Ropf gégeben, ber tidit fúr viele - fúr bie ineiften Nenfden barabog geloeisn twáre.

Eampe.

Freitich, man maẗ fie machen, foenn matt Senft; aber man muß suidt barauf benfen, fie zu madhen. - Dies fúr Sie, twelche Rouffeaus zu fern glauben, went fie \$araborien yortragent.

\section{Trapp.}

4*) Battz gut, lieber Sioutifeat, twenth beine Marabds rient unt bem Nann von Soruttkeilen, unto nicht Dem bie Eache richtig burchifhautenden Mann im

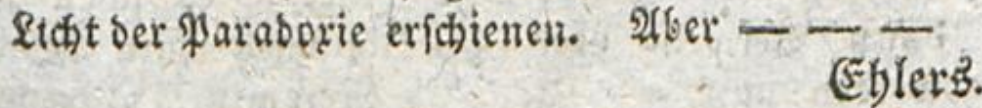

4**) Nor bem zwólften Gabre follte man nod teis

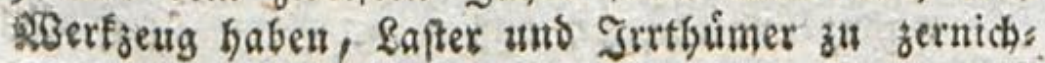




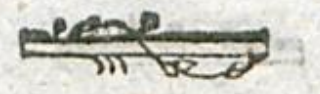

4no menn bas flyon fo tief 23 urzel gef hlagen, bas es nidjt mehre 3eit ift, fie wieber berauszureiffen. ") Sprangen die Rimber gleidy auf einmal son Dex Mutterbutut in bas berninftige 2flter liber, To fonnte die Erziefung, die man then giebt,

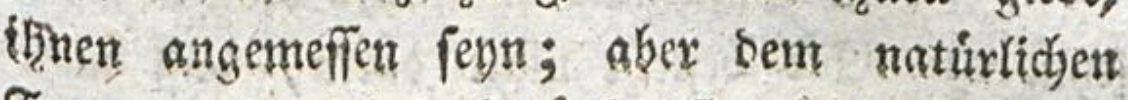
Fortgange zufolge, bebirfen fie ciner ganz ans bern. Sie misten etgentfich nichto mit therer Seele thun, bis bieje za allen ihren Siraften

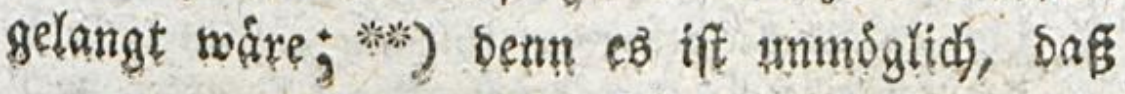
से 3

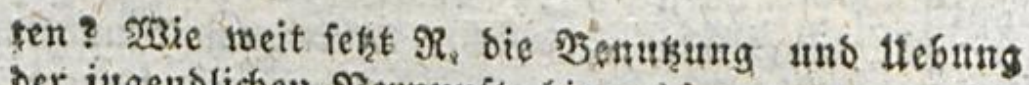
ber iugendlichen शernunft biuaus!

Refenitg. Eampe.

7) Iftch dies ift úbertrieben und der Erfabrung entges gen. Gerabe vom zwolften bis ad)tzefonten Safore ift ber sRenich noch am erften umjubiloen.

Siefemits.

*) Nian fieht lwol, bab bie gibficts, cinen fobonflingens ben segenfak zwif́chen nichts und allen zu mas ()en, uniern $\mathfrak{s e r f}$. fier abermals irre gefífrt babe.

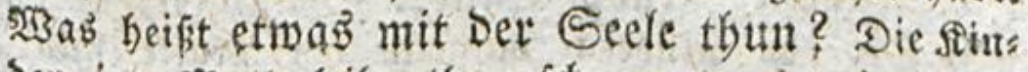
Der im Nutterleibe thun fhon ctwas mit ibrer Seele; benu fie baben bunfle Sorftelfungen, Ino was thut nicht pollents die Geele cines fichon jut 2̧elt gebogrmen Sinbes? - Fermer, inann fant man fagen, baj bie Geele su allen ibren seraften gelangt fell? Nian fieft wol, baj bies. nie mit eis ner-menshlichen Geele bienieben ber Jall fenn foune.

Eelbit 


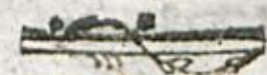

fie bte Factel, welche ihr bexfelben vorkgaltet, fehen Esonne, fo lange fie noch blino ift, uno baf fie auf ber unermef́lichen (Evne ber Soeen

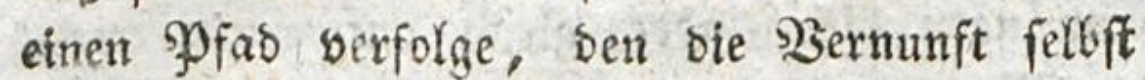
fir bie beften altugen nux fo Yeidothin bezeidsnet.

Die erfte (Erziebung nun alio blof negatio fernn. *) Sie befteht nidht barin, Daß̃ man

bie

Selfit Nethufalems Geele fonnte im 969 Sabre feines Alters noch eine oder bie anbere von ifren ins Hnendide gehenden stulagen entroideln uno Daburch eine Straft erlangen, bie fie vorher noch nicht in fich gefúflt hat. Es.ift alfo flar, bas ber Saţ von qullen Seiten unbeitimmt unb fchwanfend ift. Das 28 abre, welthes dabei zum Brunde liegt, fdeint in folgendem zut heftehen: man forbere vou feiner Seelenfraft bes Simbes cine Anftrengung, jut Ser fie fich noch nicht verbáltnißßmáfig entwicfelt hat; man toolle alfo z. গ. Die Geele cines ledbus achts Dber zefniályrigen Sindes noch nicht mit metaphyfis fchen, logifchen oder grammatifchen 2 fofractionetr quálen, weil bie fábigfeit bagn fich in bieiem ter ordentlicher uno maturiticher 23 eife noch nidht entfaltet hat.

Bampe. Srapp. Stuve. Seufintget. Refervig.

-) Die Sen Rinbern mitgetheilten Rráfte fino aber nicht blopi uegatio. Sie fúbren eimen Trieb zu irs geno einer Nobification ber gbátigfeit weientilón mit fich. Ebler?. Trapp.

Id) habe fanon im zweiten 9 ande ber Revifion ङ. 236 un Th. 5, 5. 37 unb folg. gezeigt, Daß auch biefer Errutbiak̨ úbertrieben ift; baß man in taufens fállen sicht umbin Eann, etwas \$ofitives 


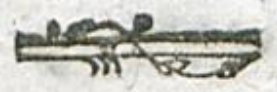

sie Iugens uns 928 ahrheit Yehre, fottorn baf man bas Seerz bor bem Lafter, und bet Geift

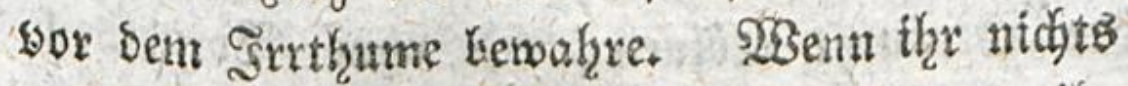

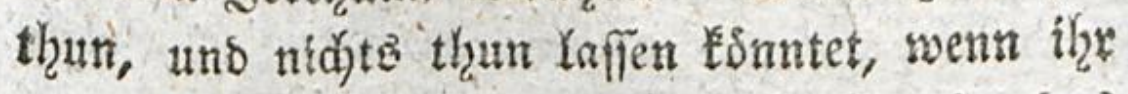
euren 38gling gefund uno farte Gis in bas

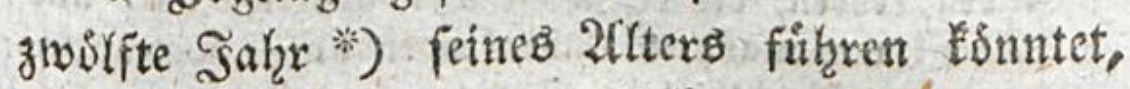

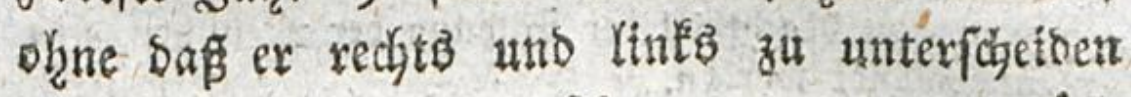

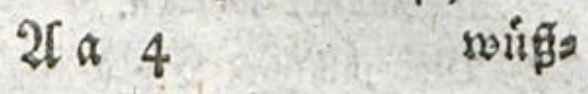

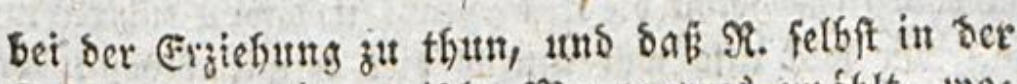

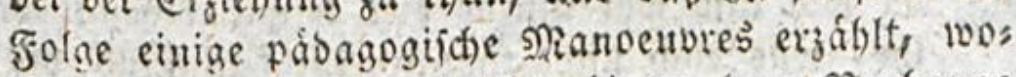
bei el fur bas Sind freilich binter bem Sorhange blieb, aber nichts befto weniger auf bas, was mit sem fiutbe vorizing, einen fefr pofitiven Einfuti hatte. Der Gabi follte olfo heifien: man muE bet Der Erziebung in vielen fällen mebr nega tiv als pofitio verfabren, uno feloft Dann, want man auf eine peñtive 2lit einjugreifen nidht umbin fann, Doch oft Das Infebn antunebmen miffen, als thue man nichts. Daßs $R$. hier aubs brufflich vou ber etfiten Exgiehung reset, fheint feis ser Şebauptung nidat mehr (sewicht ju geben; benu 1) láft er unbeftimmt, wie weit biefe erịte Ergiehung gehe unt loo bie jueite eigentlich anfange; 2) foheint wnifere pofitive Nitwirfung zur Erhaltung ano Ents widelumg ber iungen slenichentfiange in ber erften Periobe ber Rinbheit noch unentbebritcer, als in Den folgenben $z^{\mathrm{H}}$ fenn.

Eanpe. Trapp. Stuve. Seufinger. Sieferwiş.

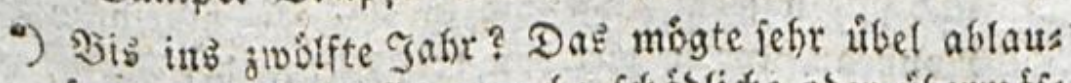
feit; ba wútben fich manche fababliche ober stbermás fige ariebe fdyon feftgeiest baben. Dics ift eine son ben untigtigen uno im (Sebrauch febr verberbs lichers 


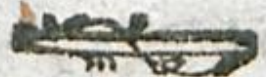

wiffte *): fo wirben gleich bon euren exften Eelyren an, bie 2 ugen feines ßexftanontifes fich ber $\mathfrak{B e r n u n f t}$ exofnen; ***) olgne Sorurtheil, ofrie

Iidhen Sefren, Sie $\Re$. in bie 2 Selt geftrentet bat, uno leiber! yon marthen Undentenden unb Hubedathtfa: men zum 2rachtheil ber \$biloung ber sRenishen fint angewandt toorben.

Sieferwiks.

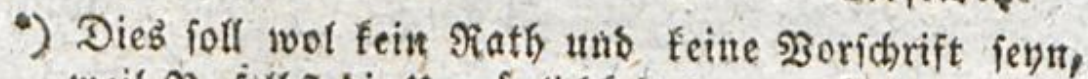
soeif $\Re$. felbft bie Ilnuéglichfeit bnoon fribfen mufite. Ex wifl alfo wol nur fo viel bamit fagen: fonntet ibr, was bod nicht thunlich ift, das fins bis, ins zwoolfte Şahr vor jeber Art von Renutnif bewabren, und es babei nur gefunb an feib und Seele erfals ten, fo wirbe fich aub eimem folchen Subiecte nad) ber ein befferer Newfich machen lafien, als aus eus ren Nobefindern, die ibs ourch úberfruben Hnters ridht ieder 21tt an Seib und Geele ju verberben pflegt.

*) 23enu Serftand unb \$3ermunt zu ciner gefunden Stárfe ausgebiloet weiben follten: fo múpte ben: Hod) auch bann bie Entivicfelung ber weiter unb weiter gehenden gisirffamfeit alfmálig fortichreiten. Diefe sirffamfeit luirbe aber eben fo feicht und

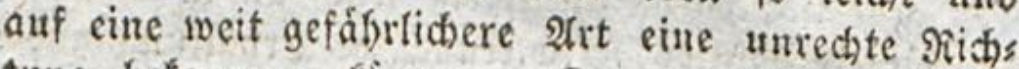
tung befommen fonmen. Der gewaltige shátigs feitstrieb einer ftarf getwordenen bisher zurucfigebals tenen Siraft wúbde Ieicht Nittelfufen, bie boch ges fannt und betretent werden múften, liveripringen uno mit bilbem Ingeftum in 2 bovege- bineinfturzen. Rouffeau, ber fo viel pon ben $\mathfrak{s}_{\text {egen }}$ ber Natur res Det, follte bier ermogen habelt, daf ber mit ber alls máfigen Bumahme ber Siráfte allmáiige fortítheis tenbe Entiviffelungşgang ber Ihátigfeit felbft ju ben

soeis 


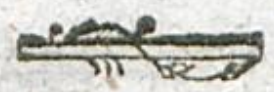

ohne Esewokgnkeit, wirbe ex in fich nidfts kas ben, was sie \$Bintumg etrret Sorgfalt hemmen Honnte. Bald murbe ex unter euren Seanden ber seifefte Mann werben, unb ifgr hätter, ba

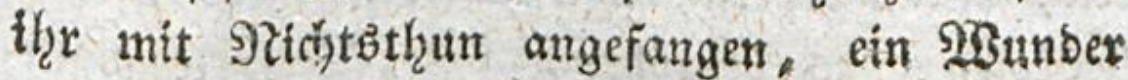
Der (5rziełung verridjtet. *)

Thut bas Giegentheil befien, was geworhris (id) geichicht ***), und ihre werbet faft allezeit bas (Sute gethan haben. ***) 28 Beil man abex 2(a 5 aแอ

meifeften Eintidtungen ber Matur z" rechnen ift.

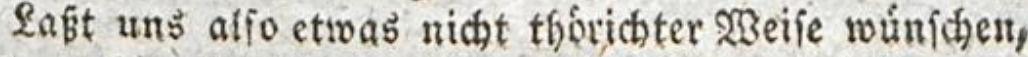

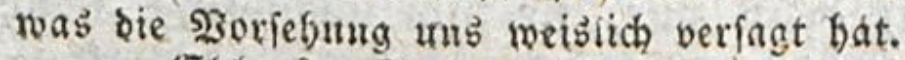

Eblers. Trapp. Refenib. Eampe.

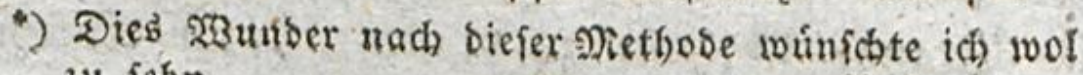
zu โehr.

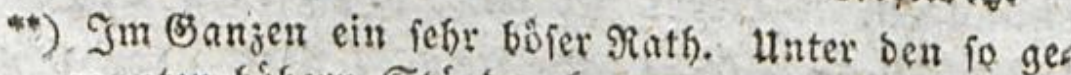
uanuten Gobern Stánden faurn-es wol zuveilen aus biefem ober ienem Ort bei einem fraufen son Diens fchen to weit mit ifrer afbleidsung von ben sisegen Der Satur Eommen, Dak mant ienen Rath befolgen fann. Suth fónen iefuitiche ichlaute uno máchtis ge Nenisten trof große Niángel bes Denfens uno Des Santlents anf eine lange 3eit weit nmber liber ibre Nebenmenifen verbreiten. 2ttein bas betrift

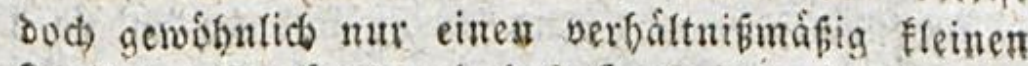

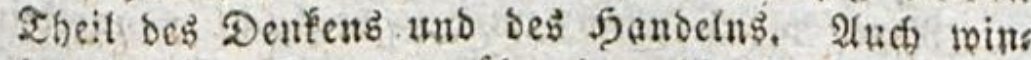
Det fich liber Furz ober luber lang bie. Siraft bes ges

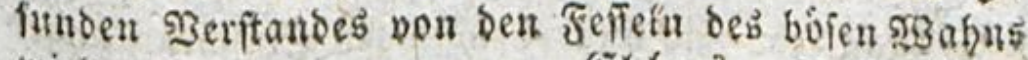
wieber 103.

Ëblet:s. Rejemits.

***) Sreilid it biefer Path viel zu allgemein ausgee brukft tun bas allejeit bebarf allerbings mancher

Eins 
aub einem Sinbe nicht ein fints, fonbern cinen Docenten madsen will: fo fonmen bie Batex uno Sebret tie zettig genug ein fitro ausfolyels ten, baran beffern, ifgm 3 erweife geben, thm Yicbiofen, es beorohen, thm SBerpprechumgen thum, eB unterridhten, if̧m 2 Sernumft vorpresis gen. Sanbelt beffer, ferb verninftig uno rais

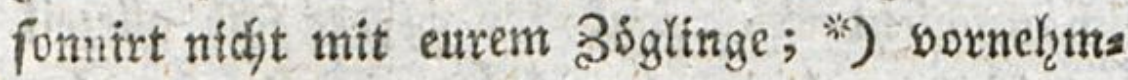
(idi) nidjt, um ibm basjentige birligen zu-madjen,

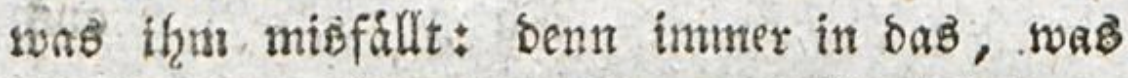
thim unargenef̧m ift, Bermunft bineinbringen mollen, beifit nur, fie ifm langroeilig madyen, uns fribzeilig bor einem Öeifte, ber noch nidjt im Stande ift, fie zu verftehen, ihr 20nefgrt fdjmålern. Hebet feinen Eeib, feine Srgane, feite Sinne, feine Rraffte; Kaltet aber feine

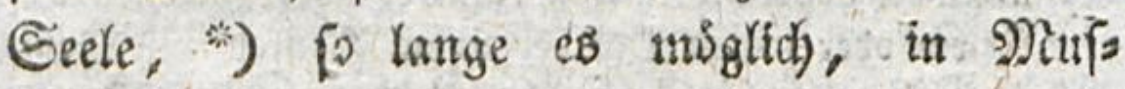
fe.

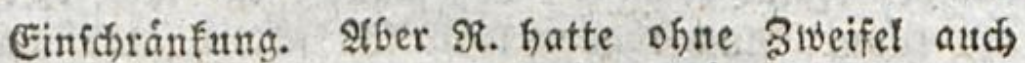
bier, wie tiberay, bie vergarteinte, ángittidhe, weichs liche, und alles inbertreibente Erziefungsforgfalt, welche an ben Sinbern vieler Pieichen uno Broben verichivendet wiro, im 2uge; uno ba mogte feine Siegel unter zloanzigmalen vielleidit neunjefnmal vollfommen anvenbbar (e)n.

Eantpe.

") Nan febe bie hicrbei notbigen Einfhránfungen in verichiebenen obigen 2tumerfungen. Bampe.

a*) Abermals ein Satz, ben man, feiner Hnbeptimmts bait regen, umekren fant ohne baf er bebivegen wenis 


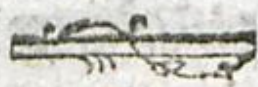

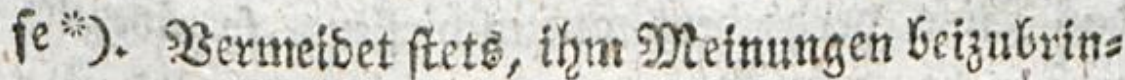
gen, ehe feine Utrthetlsfraft ermadyt, Durch ofe er fie witedigen foll. ***) Sealtet bie fremben Ein

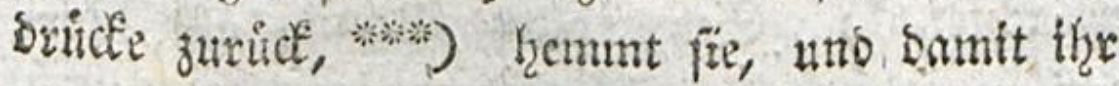

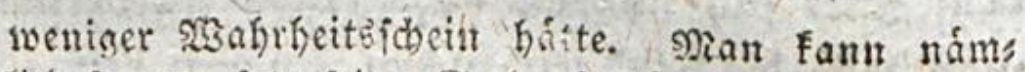
Yich fagen: iefzt feine Geele, fo:viel moglich in ฐbás tigfeit' Das 2isie? ift ber \$utuct, Der bier alles entideribet. Befd)aftiget man bie finberfecte mit

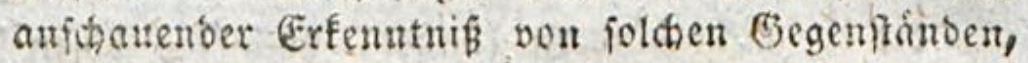
bie umerbalb ibrer Spháre liegen: fo faun man fie onbei nicht leicht ju fefor in Shátigfeit fizen. Serifeft man aber, wie fier Sionjeau vermathlich thut, unter Dem 230 orte Seele bie bohere 33 crmunfts:

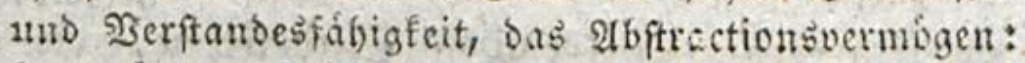
fo mus man freifich rathen, biefe nicht zu frith, uno nicht zut fehr zu liber.

Eampe.

*) भI: went Die Siatur fich im Punct bet menfchlis chen Geele cincs foumptoergehens in thren Eintichs tungen folloig gemacht batte!. Sebe Siraft ift ju fiben nach bem Maaf iffrer Fabigfeiten uns ifrer

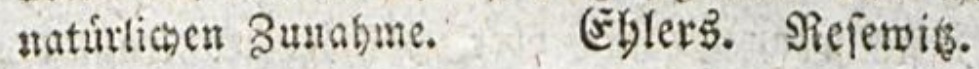

*) Dicie Sieael ift beftimmter, als die vorhergebende, unb allerbings non grofer 2 sidatigfeit. 2tlles, was bas Sino in feinem jeoesmaligen flter noch nicht felbift erfenuen, fafien unb begreifen faun, toas ifm

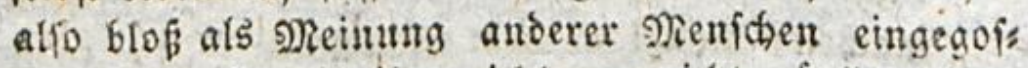
fen wiro, bas ifit ifom nicht mur nid)t mik̨lich, fons bern auth fódidich, weil es baburch vom eigenen S3abruebmen entwobut und jum gebanfentofen sad)s beten angefúfrt wirb.

Sampe.

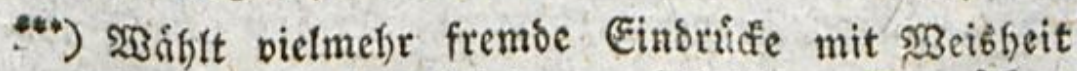
aus, uns Gindert bei beu nachtheiligen Eindrúcten, bie 


\section{0}

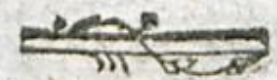

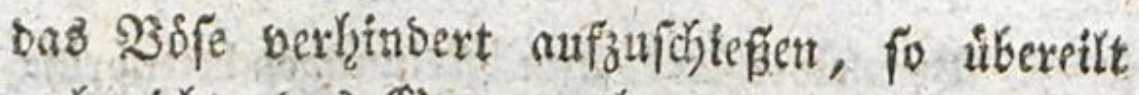

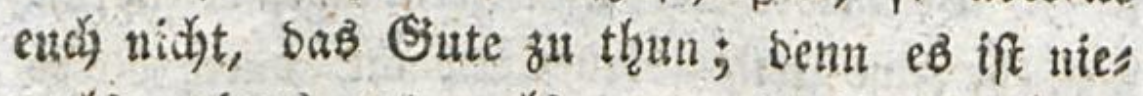
malb anders gut, alz wenn bie Bernunft eह ertcud)tet. *) Seket allen ${ }^{*}$ Berzug als $\mathfrak{B o r}$ theil an; bem 3icke fich naffert, ofgne ctwas zu berlferen; man laffe bie Rinskeit in ben Sindern reifen, ***)

Rutz

bie ift nicht finbern fönnet, boch bie bífen schirs fungen berfelben, fo weit ibr fount.

(57) lev3. Refenvis.

Sumal ba feine Ergiefrung frembe Eintrúde ătricf́alten fant.

Refenis.

unter ben frembent Einbruicten, bie man

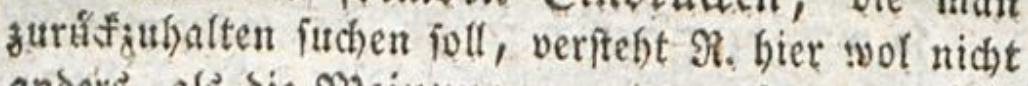

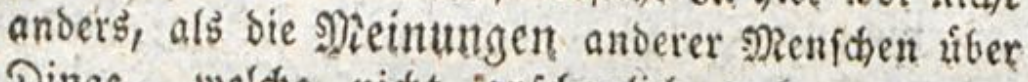
Dinge, weldie nicht aurfhaulich wabrgenommen werben fónuen; und rach biefer Erflárung, bie ber

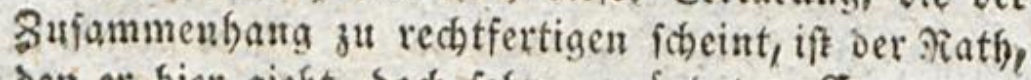
Deft et bier giebt, boch fech gegrúndet, Campe.

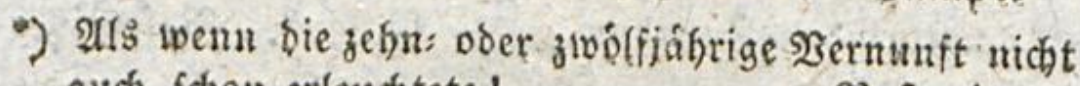
audb f(bou crleuthtete !

Siefenis.

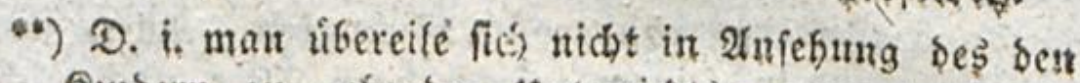
Sinsern ju gebenden Interrichts; man wolle fie nid)t vor ber zeit zut Gelefrten und Wieflwiffern madben; man laffe bem ஒ̧áumden seit, bu wads: fent, und Ifefte und Sweige anzulekzen, bevor mart eb butrd treibenbe Mittel ziwingt, fruidhte ju tras

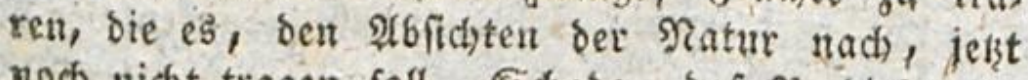
noch nicht tragen foll. Cedabe, bẩ ग2. Diefen fo

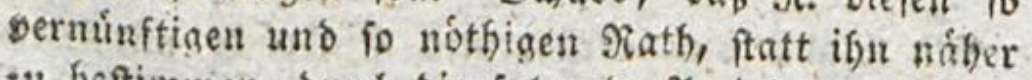
in beftimmen, burch bie folgende Periobe, ant Neis 


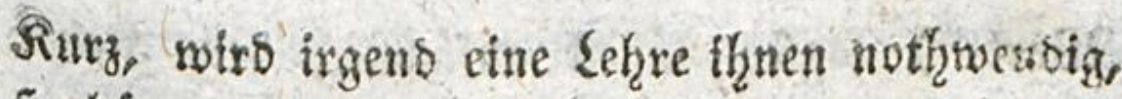
fo hitet euch, fie heute zu geben, ") wenn thr fie Dhne Sefahre biz morgen berfihieben thont.

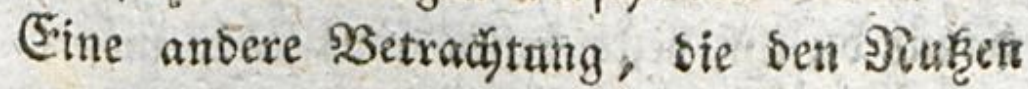
Siefer Miethabe nodh mef̧r beftátigt, if bfe

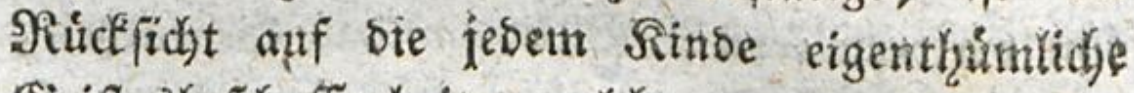

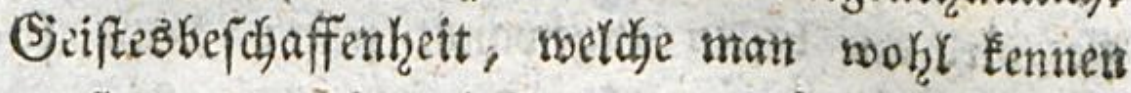
muf, um fu beurtheilen, was filit eine fittlidje Sebenzorbiung fich für bafferbe foicte." Jebe Seele fzat ihre eigne, trad) wetcher fie regtert werben muf́; uno ber glitclitcte Exfolg bet

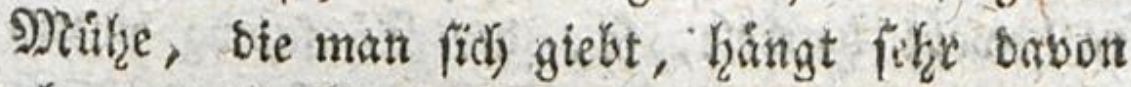
ab, oafi die Seele nach diefer und feitter andent Fornt regiert werbe. Bift but alfo weife; fo fwibeft bu lange bie STatur aus, beobachteft sohl beinen 3oggling, besor bu thnt bas erfte

288 ort

gung etwas Sinnreiches fu fagen; fur bie meiftet Lefer mefs verbunfelt, als erfellt uno faflich ges inndit hat!

Eampe.

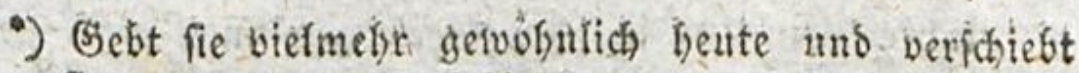
fie nur auf ben fall bis morgan, ba fie heute nidht

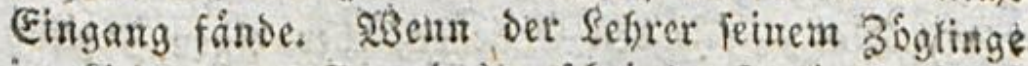
im Richte cines freunbes erfotheint: io tommit oes Sall felten.

(E) lets. Mefendis.

92. ganzes Raifonnement fít einfeitig unto this Der ble Natur, uns fo wie es ba gegeben ift, in bef Ergiefung bes Mienichen nidht nut unbrauthbar, forth sern fitábltọ.

Siejemita: 


\section{8}

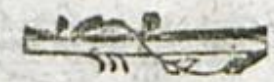

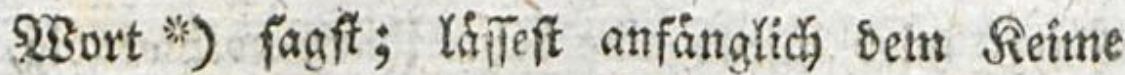

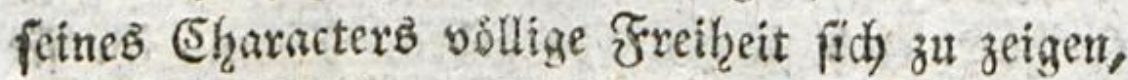

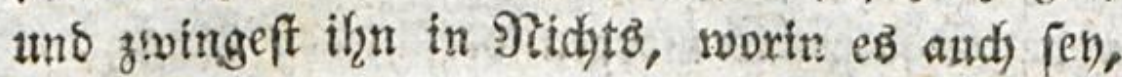
Damit ou thn befto befier ganz fehen mogeft. **) Dentet ihr, biefe 3eit ber Freifgeit werbe fir ifhn vertoren fent? Sielmehr bas Siegentbeil; fie wirb am beften angeroandt fern: Denn fo werbet ihr Yernen, nidjt einen einzigen 2rugens blice in einer Foftbaren Beit zu werlieven: an ftatt, sag wofern ihr anfongt zu handern, ehe ihre wif̈t, was man thun miffe, ihg aufs (Sies rathewohl hanbelt, fo, ber Zäufdiung unters worfen, bielleidyt euren sigeg zurudetthun minfet, uno weiter spm 3tele entfernt fenn werbet, als wenn ifgr nicht fo fehre geeilet b̧attet, és zu exs reichen. Mtadjt es arfo nicht, wie ber Geizige,

ser

") Dab uttn trot nicht. stber freilith mus icis bas

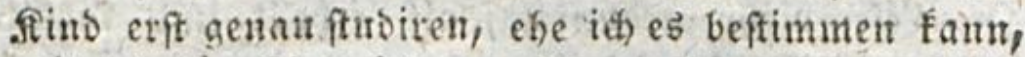
wie ich fúr Eimbride Der giernunt un ber Sitt: fidbfeit eingang in feine Seele gewinnen mill.

Refervis.

5*) Dieb ift fuir bet Erjeffer, ser einen Bögling bes foummt, den bis babin 2 mbere unter Shánben Gatten,

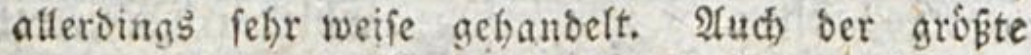

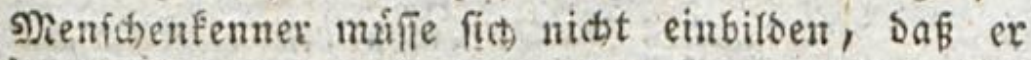
jebes Sind gleich in ben erften Eagen feiner $\mathfrak{b e}$ famtiof aft mit igm villig ourchiehen fonne.

Eampe. Nefenis. 


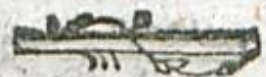

Der um nidjto za sarlieren, fefar siel berlfert. Spfert in bem erfen 2rter eine Beit auf, bie

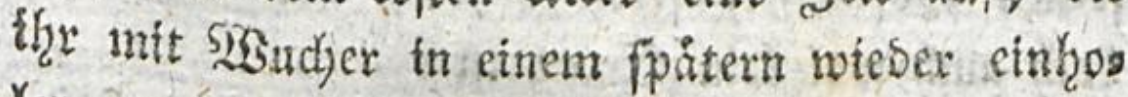
Yen werbet. Der weife 2frzt verurbnet nicht unbefonnener SIBeife gleid) auf bie erfte Befiths tigung 2frzeneien; fondern er fusint exft bas Zemperament bes Siranken aus, ehe ex bers

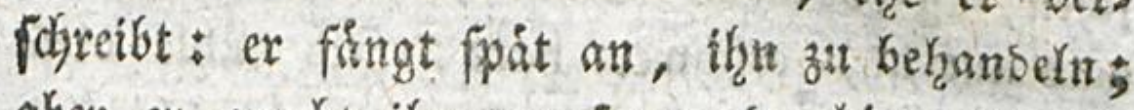
aber ex madit inn genejen; ba hingegen ber allzueiffertige 2 rzt ihn tsstet. *)

2200 wollen wir abet biefeB Rino bitnbringetr, un es alB. ein unempfinthitues sgefen, arb cin

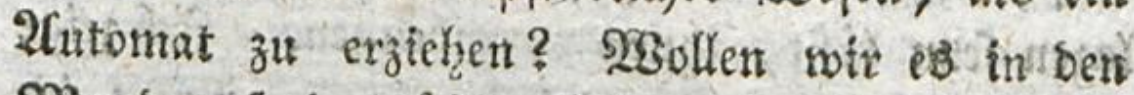

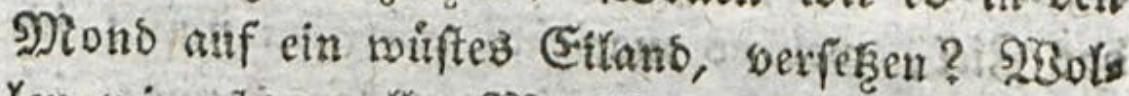

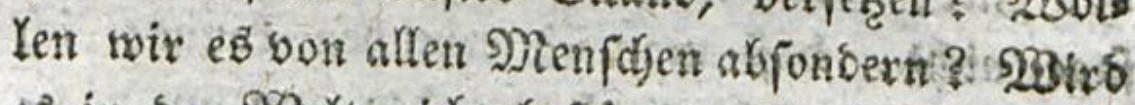

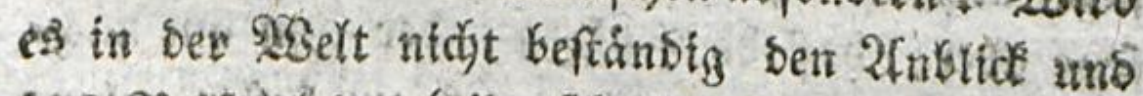

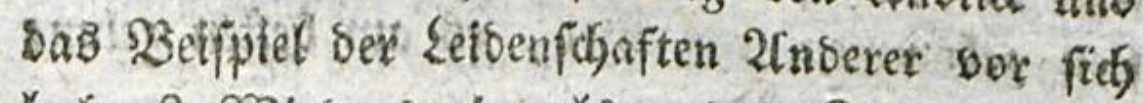
baben? 28 iro es niemals andere Sitnoer feines

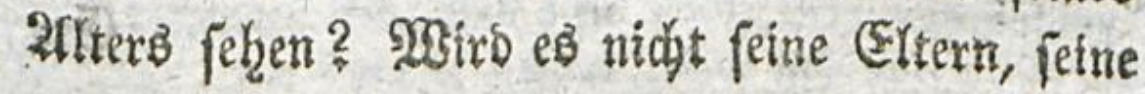
Nacks:

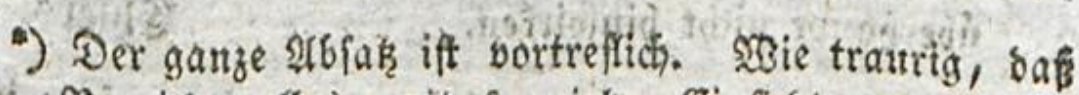
(b) 20. nidat alles mit fo vieler Einficht uno - ich 3to. darf wol fagen - mit fo gefundem şerftande alles seiagt uno beftimmt bat? Nant barf fich indelfer nicht wurbetu, baf en \$2ant, ber in ber 2norbs numg feines eignen lebetts fo oft und fo weit bous Der $3 a b n$ bes gentuden SBerfandes abgemidmen if bicfe 3ahn auch als Sdbriftiteller of verlafient bat.

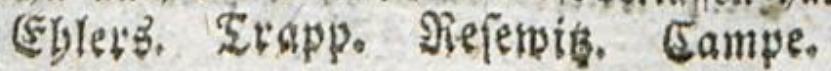




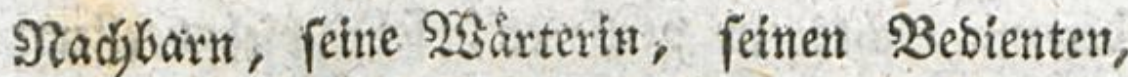
feitren Scofmeifter jelbit fethen, ber am Enbe bock aud wol kein (Engel if ?

Diefer Einburf ift faut und bunbig. 2rber

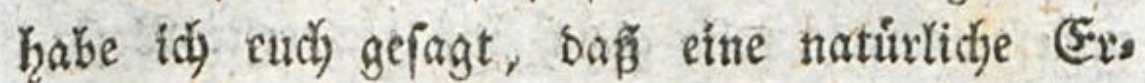

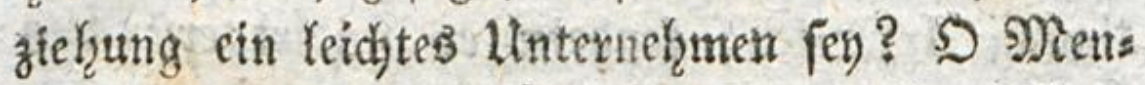

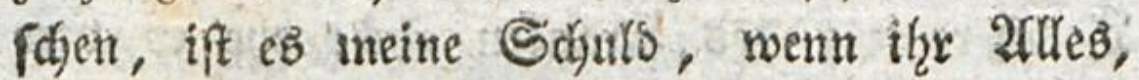

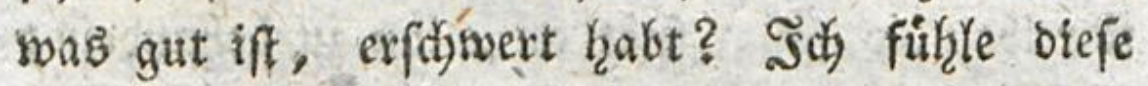
Sdjwterigteiten, id gebe fie zu: vielletdit fins fie unuberfteiglidy. 2liein immer ift fo biel

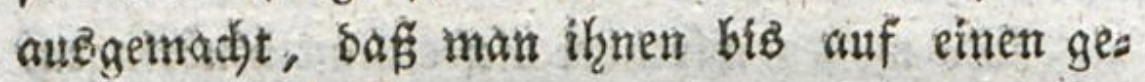
wiffen Shunct vorbeugt, went man fichs anges

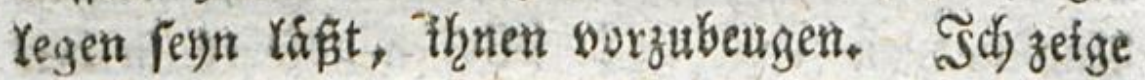
baß Biel, weldhes man fich sorjeren mur : id fage nitift, bas man $e^{b}$ erreidjen tonne; id

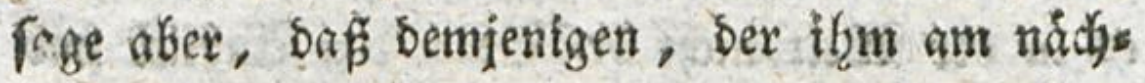
ften getommen fegn wiro, eb an beften getume gen fern wird. *)

Ere

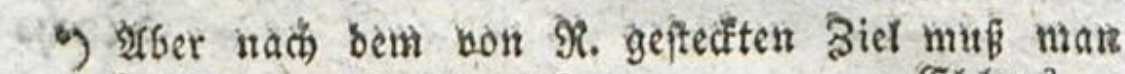
kiberbaupt nicht binivirfen.

(E) blers.

6: … Diefes, etriab harticheinenbe Itrtheil mogte id

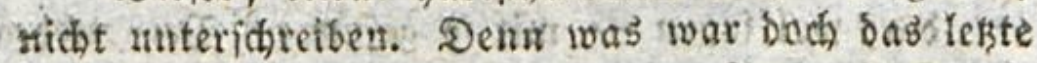
Siel, foorailf St. In biefem ganzen Fird)e hingrbeis tete? Dinfreitig diofes! ewien gefunter, an Leib unb Scele ftarfen; bebirfniejfreten, vorittheillojen

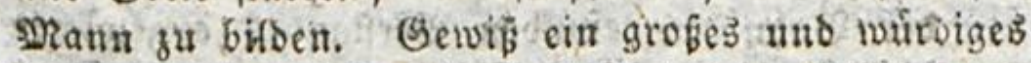

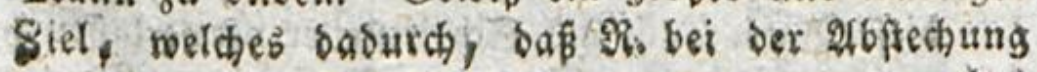
bes 


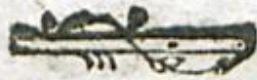

\section{5}

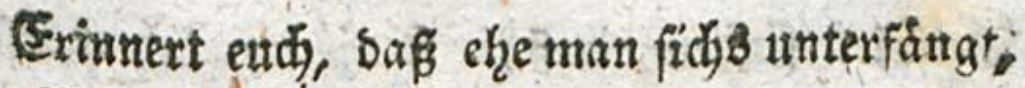
einen Menjojen zu btloen, man fich erft pelbit

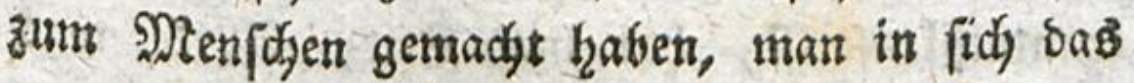

Des 23 cges sabin oft geniemdîige 26 fpringe maditep

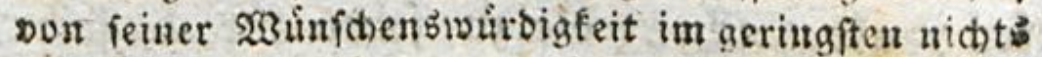
verlobren bat. Lafit unb bieies erhabene Biel nie aus bem aluge verlieten, und uns von $\Re$. unr bas ourch untericheiben, bá ivir babei nicht blop auf bas ifolirte Jubivioum, toelthes woir bilben vollen,

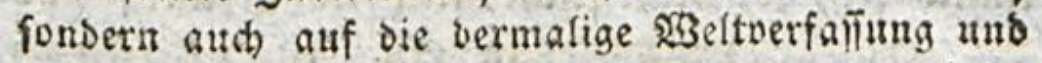

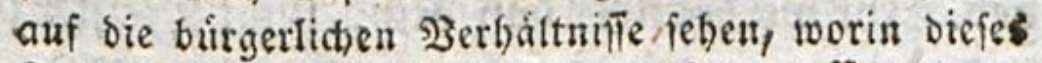
Jnbividum cinft gejekt werben toird. Eampe.

Deet bem allen fann $\Re$. dicien 'wahren Blwed socber ribtig gefapt baben, noch buth feise ges roablte sittel erreichen. Alles in ber menichlicber Beiellichaft ift ifm boje und verwerflich; er will nicht fúr bie (Befellichaft erziebeny pondern blope शratmmenfhen bifoct: Senes if allgemein gemoms

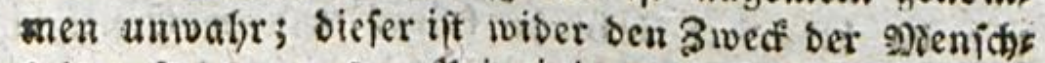
Jeit, In ben erften Prinjipien ber Erjiefoung ift et alio fchon irrig; wno unter ben Mritteln, bie ex anwenden wiâ, find viele jlvedivibrig uno untawgs Iid): wie fant or fitherer Sefrer und SBeglveifer gut

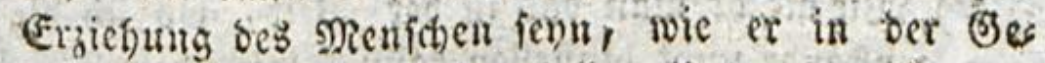
fellichait ienn umb toerben foll. Hnter ben siegenp Die er einjoldagt, find zwat biele oortreflides; andere ber \$hantaile febr gefallende, bie aber nidht ans roenbbar fub; viele unichtige, uneftimmte uns im Sebrauta ben Menfuben berftimmende, SBer ba nidat cum grano falis $\mathrm{R} \mathfrak{a b}$ Sichtige, Şeftimmte unb

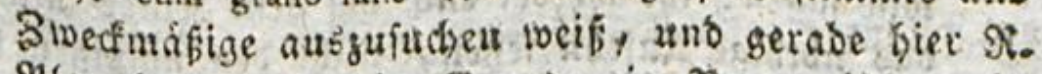
Plan befolgt, Der im Srunde ein Roman if, worin er leiue grámliche Bebauptungen geger pie menidh Emil 1 iter ईb.

2.3 5

tik 
Beifpiel finden mus, po jener fich borfect foll. *) So lange bas find nodh ofye (5rs fenntniß̨traft ift, hat man 3eit, 2tres, was fitf them nábert, geb̧orig zuzuriften, banit auf feine erften Blicle Feine anore Eiegenftande trefs fen, als foldye, bie zu fetzen fur baffelbe ans gemeffen find. **) Madyt euth bci jebermann elcrs soiroig; madit elld zuerft beliebt, bamit altes mano fet), ber nidgt fudbe, fid) eud gefallig zu bezeis

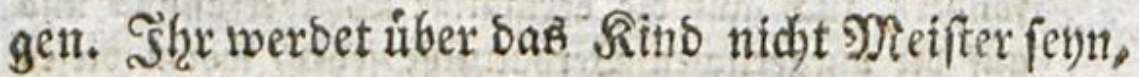

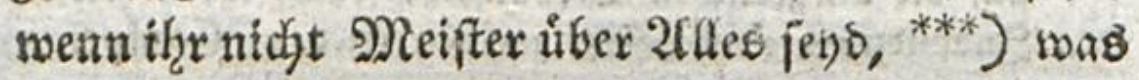

utm

liche Seyelfichaft buthjek̨en wollte, ber wirb feimen

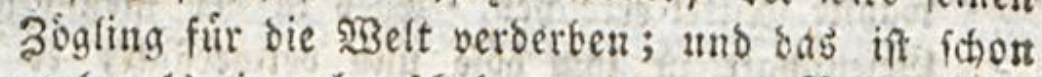
mefir als einmal geicheben. Rejenis.

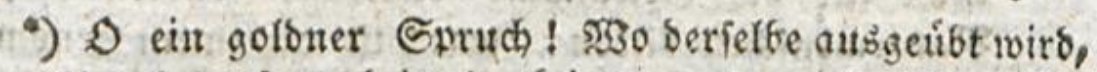
ba bebarf eb beinabe feiner andern Erziehunabres getn; two er nidit ausgexibt wirs, ba werben alle andere (Ergiebungšregeln beinake vergeblich angewandt. Eampe. Stapp.

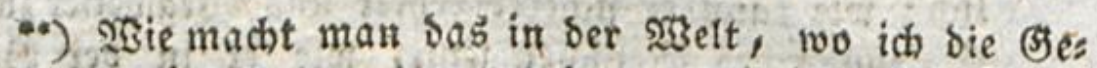
genfánbe nicht binftellen Eann, wie ich wifl? Ober (oll id) mit bem 3ogfing in bie 23 fifte zellen? Rejervitg.

*au) 2tbermals eine Fouffeaulifoe, butch bie જegierbe frappant zu fojreiben, veranlapte Hebertreibung. Er will fagen: ihr werbet ench bei bem stinbe nidht in bas nóthige Infehn feţen, nidht ben nothigen (Fins flú altf feine fittliche 2fusbiloung erlangen fonnen, womn ibs nicht wirflich bodjactungstwuirbige Mens fiben 
un Das Rino ift; *) uns biefes शnjehn wiro nie zureidjen, weun es fich nidjt auf bie Şodjachtung grünot, weldye Zugeno ges gebiert. **) 2foer es ift nidht hinlanglid, bafs man, diebz zu bewirten, feinen $\mathfrak{B}$ entel anfthue, uno. Selo mit vollen Şanben veripende: tis Tabe nie gejeben, baf oas Sielo wen beliept mache. Freilich muß man nidjt geifig uno bart fenn, nody bas Eleno betlagen, welchem man abbelfen tann; allein ihr mogt eure Raftet sffuen, wie ibre wollt, wenn thr nitht aud) enter Serz offnet, fo mirs bas Sherz 2(noever euch

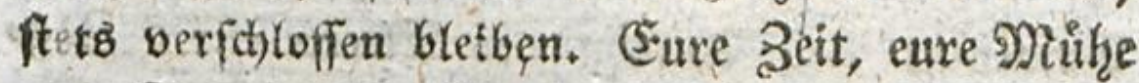
uno Sorge, eure 3uneigungen, euch felbft might the geben; benn was ihe aud thum tonntet, fo fieht man boch tmmer ein, Dafí (Sield uns ifye 2362

felbif

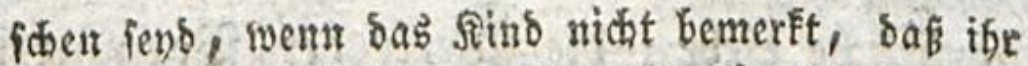
felbft von verftandigen und guten Menfchen euree Duaend und Fechtichaffentheit wegen geícháb̨t uno geliebt werbet. Hnd wie fefhr bat er darin Fecbt?

campe.

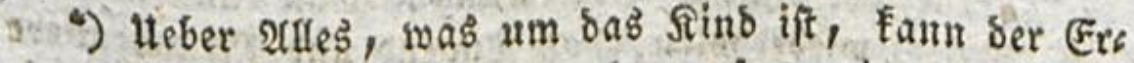
zielser nicht meifter werben; fo roenig er bei allem gefälltgen uno bod)adtungswourbigen 5 (Beien fich bie Siebe थller wirb erwerben fonnen. Siefenvib.

6*) Sortreflic)! Eampe: Trapp. 


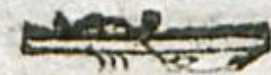

[elleft ztocierlet fino. ") Es giebt Ertweife

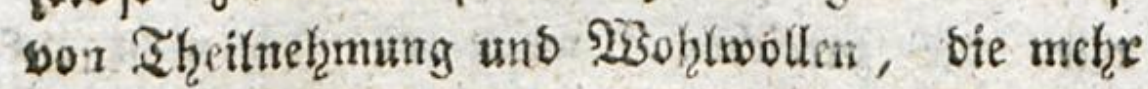
T3irtung thut, utro in ber Shat aud nifglidger fino, als alle Gieichente. MBte biete Ungtuicls Xicje, wie wille fronfe braudn nta)t mithe Troft als 2flmofen! IBgie mandje Unteroridite giekt es nidft, Senen Sdyus melze oient, als Gelo! 23ereinint otejentgen wieser, Die (id) entymeit hyaben; fommt Sुroceffin zubor; bes segt bie Sinder zur Erfúflung ibrer Fflidst,

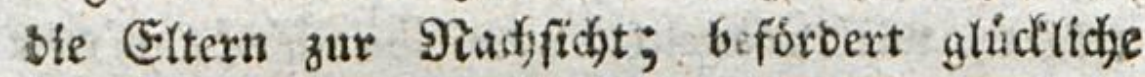
Spetratlen ; serkimbert Expreffungen; gebraudyt,

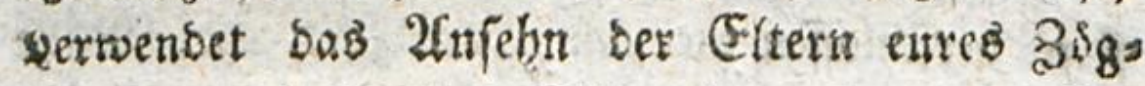
Itrgs zum Gefren bes S Stywadjen, bem man Cies redjitgleit serjagt, uno ben ber Mád)tige zess

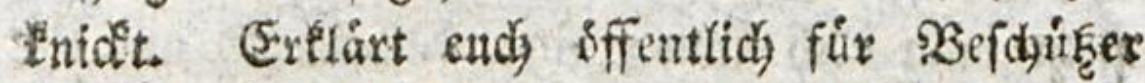

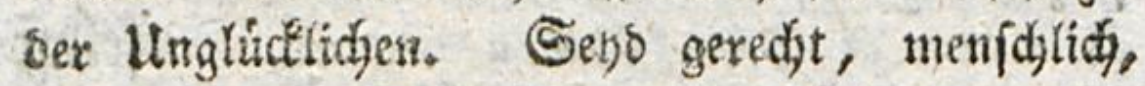

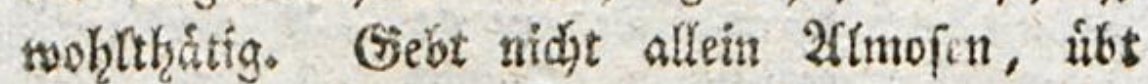

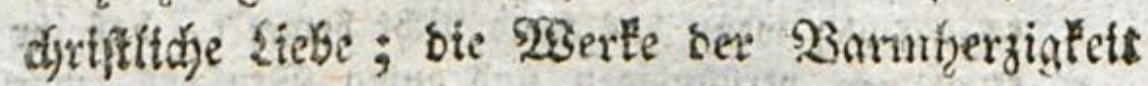

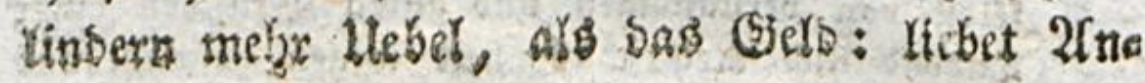

Dea

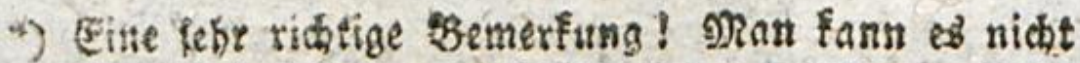

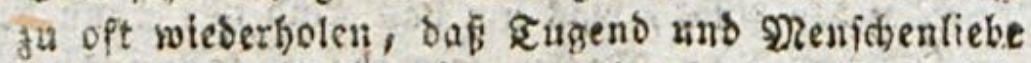
richt blos im Geltogetien beftehn, and ons es viele Anseve erroeifungen derfelben giebt, weldbe oft now side ntothiger, viel rooblthátiger und viel verbienptis (her fino. Mian febe, was $\Re$. bierniber in bem fols

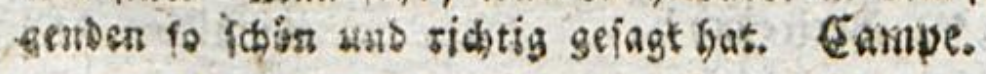




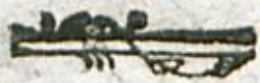

\section{0}

bere, unb fie merben eudy aud lieben; sient ifgner, und fie werben eutch bienen; fend threa 93 hater ento fie werben end Rinder fern. *)

Sierin Ifegt noch einer son sen S̈rünben; soarum tid, Emilen auf bem Lanbe exziefzen will, fert bou bem Bebtentengefinber, siefern $2 \mathrm{Cb}_{2}$ (d)aume ber Menichen nadj thren Sgerten; ferm bon ben fámarzen Sitten der Stádte, meldje ber Firniff, momit man fie iberziebt, fitr bie Sinder berführerifíly unb anfectens madit; are Itatt baf bie Itntugenden bet Bauern, ohne Uebertundung uno in aller three Srobheit, fá ghiger fino, abzufichrecten, als zu verfúf̧ren, 23 is 3

swents

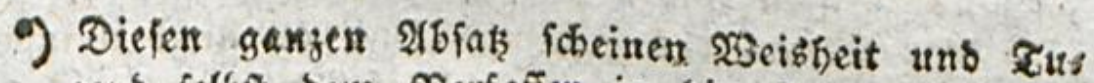
geno felbet bem פerfafier in die zeber bictirt zu baben. Eampe. Srapp.

Das ift nol waht; aber stieleb, was bier mit Fecht als liebewirfend angepriefen roirt, wiff ber rechts idhaffene wol gerne thun, aber er fann es nidt im: sner; weil es ifm entweber an $\mathfrak{A n}$ fefen mangelt, - ober er nicht getiort wird, ober viele פenfásen bie Sanb lieber zum Eelbe, alb bab 5̧erz zum Қrofi aufthun, lieber ibre Seibenfchaften unterftínt feben, als nach fremben fugen, fo riditig fie aud fefjen, gludition fern wollen. Si. bat bier sen sycroruE vergefien, ben er úber die æenichen, dabfie feinen woblwollens gemeinten shweinungen nicht folgen bollten, gefaft batte.

Refenith. 


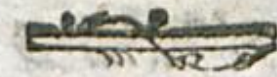

went man feimen Sortheil babei hat, ifnen rachjuabmen。" *)

2uf bem Dorfe tann ein Soofmetifer weit mebre Seerr uber bie Eiegenfiande renn, bie ex bem Rinde wiro zeigen nollen; **) fein guter જuf, feine Reben, fein Beifpiel werben you einem 2rnefnn fenn, meldyes fie in. bex Strot nidat haben fónnen. Da ex aller Sgelt nüblich ift, fo wirs (ich ein Seber beeifern, fid) ith zu verbinden, von if̧m gendjet zu feisn, fich bem Sdyulex fo zuzeigen, als bex Sehrex wúních) te, Dafí man in ber That fegn ntogte; ${ }^{*}{ }^{*}$ ) uno wenn man fich nicht bon bex Untugend beffert,

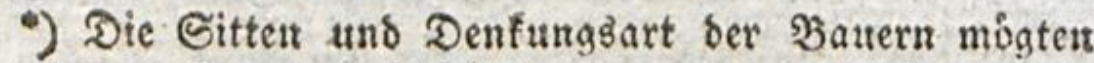
bem 5erzen bes Sugtings aud an nicht wenigent Drten Befahe bringen; uno ifolirt man if a ganz bon Nenichen, fo mus er bod lool zu den Nens fohen fommen; und dant ift bie Befahr fur ibn, svenn iich Die Einoridfe Der Neubeit uno Gimnlid̄s feit mit bem Eindrut ihres Untgangs und ihrer Eits ten vereinbaren, boppelt fo grop. Sefenib.

**) Dies iff einet von ben ausgemachteften Bortheis len, ben sie Erziebung auf bem fonbe, caeteris paribus, vor ber Stabterziefung voraus hat.

Sampe.

4**) Jjergu geborf geiviß auch búrgerfiches 2infehen uno Einflití anf bie Dorfbemolgner, font bleibt ber ganze

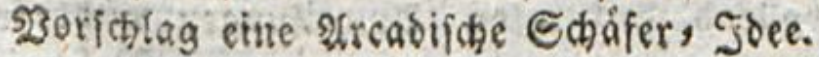

Siefermiks. 


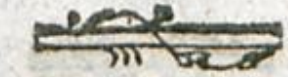

To wirb man fids body bes 2Tergernififes enthals

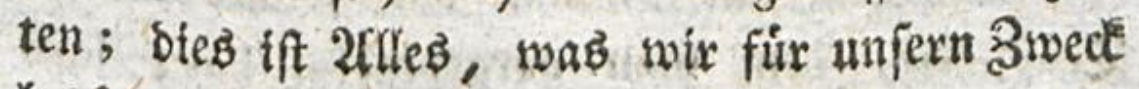
beriirfen.

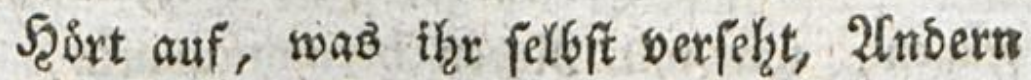
beizumeffen. Das 38śe, Das Rinber erblicken, verberbt fie mentger, alb bas, was thy fie lefgret. Fiur einen Begriff, Den ifr emige Sorebiger, ewrige Sittenlehrer, ewige Mesanten, ifhnen in ber Steinung, bá̃ er gut fey, beta bringt, geft ihre ihnen zugleith zwanzig andere, Die nichts taugen; woll bon bem, wab in eurem

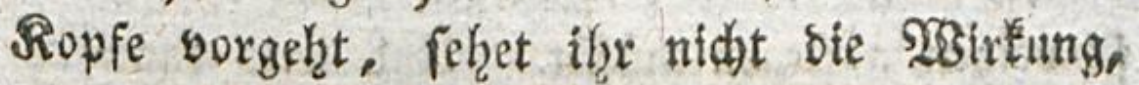
bie thr in bem ihrigen herborbringt. Glaubt

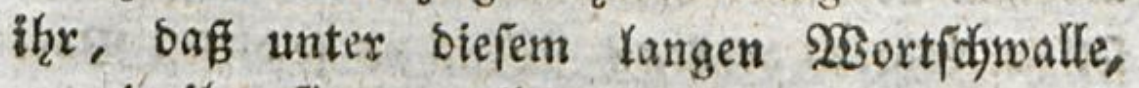
wounit ibre fie unaufforlich ungebuldig madyt, nidft auch eine Rebe ferni werbe, bie fie jodjef faffen birften? *) Denft thr, baßj fie eure Derwajd)nen Ext(arungen nidjt nad) three 2frt mit 2Cmmertungen begleiten, uno baf, fie nidjt etwas barin finden werben, woraus fie fid bann

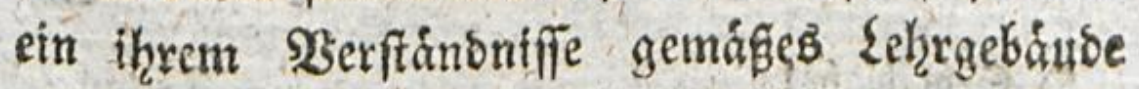
alffithren, bas fie bet Gelegenheit ench werben entgegen fiellen formen?

$$
364
$$

Bes

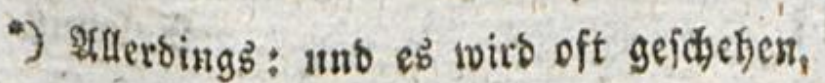

Meferwis.

Ton gewin̄

Enmpe, 
Beḩordat nut einmal eit foldjes teleines Zrospfden, bem man vorgeprebigt hat; laft

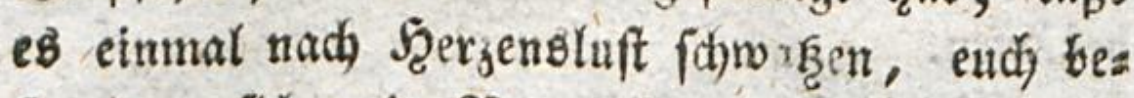
fragen, fidh mit Resen herumtumineln, uns

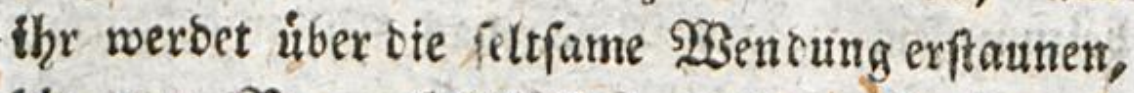
bie eure Bernumftidlufife in feinem Sieifte ges nommen ḩaben. Es verwedhelt alles, fehrt 2llles um, madit. euch ungeoulsig, bringt etid's guweilen mit ben unverpef̧enften Sinuxirfen bas

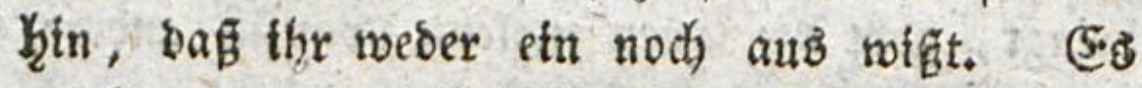
madjt, bas ibr felbft fdymeigen, ober thm Sttll,

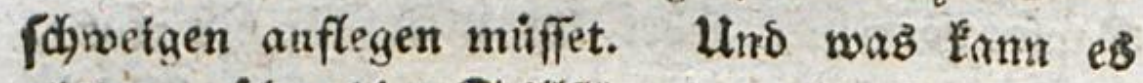

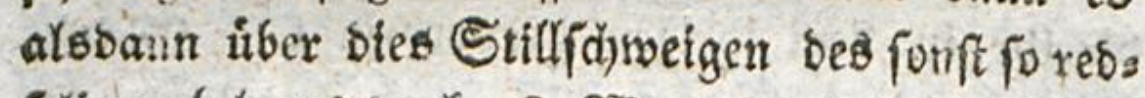

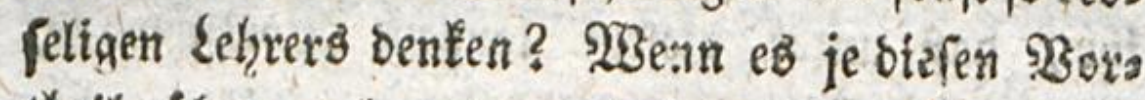
theil úber end babon tragt, uns feir inme soirb; bann lebe wohl Erziefgung; 20les ift son biejem 2ugenblicte an vorbet; ez fudst nidat mebr, fich zu unterrichten, es pudjt eud all miborlegen. *)

Oegrix trafr!

Selys Trapp.

Ther foü etive barang folgen, Dá̉ ich besz 33ógling gar nidht belefren, gar nidit unterridsten,

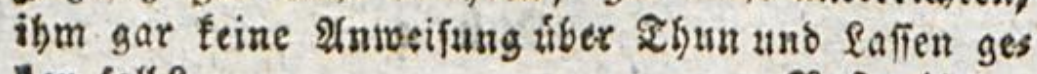
tent foll?

Refenvis.

203enn $\Re$. bies meinte, fo batte er obne sivess

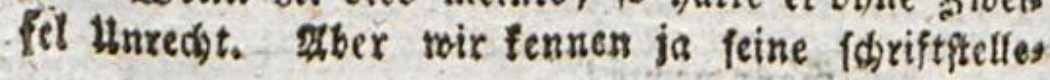




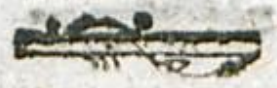

Eehree, bie Eifer befeelt, fergo cinfadj, bes fotben, uberlegt; eift nie zu banbeln, atb um zu verhindern, baf 2indre hanoeln; inmer soerbe th es wieberf̧olen, verfbiebt, wo mogs Yid), einen guten Unterrid)t, ans Futucht einers fodolichen zu geben. *) Şitet euch, auf siefert 30oen, wormis die Slatur Das erfe Parabies Des Nenjwin gemadjt hatte, bas (5)efdyaft bes

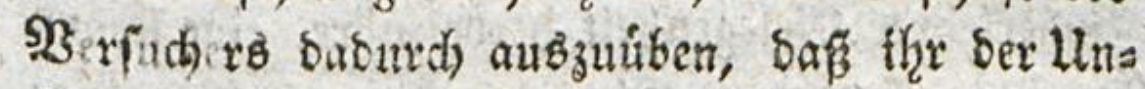
for uro bie Ertenntnif Gutes uto soffes geben sollet. **) Dathr nidjt werhitibern Esonnt, baßs

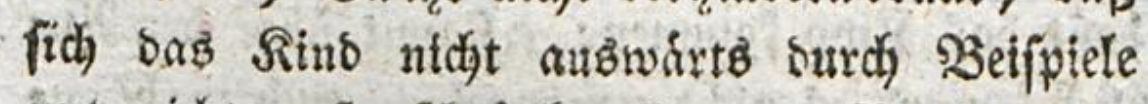
unterrichte, fo fojránft alle eure $\mathfrak{B}$ adjamteit barauf ein, biefe Beifpiele feiner Seele unter

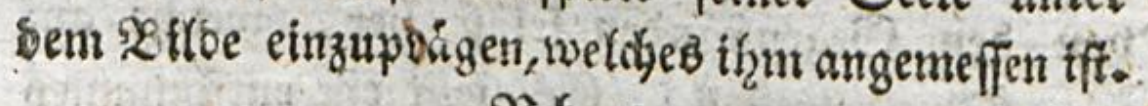

$$
365 \text { Utw }
$$

rifdie Sanier, tmo wiffent, twie biel twir sarauf abs rechnen muifien, fo oft er obne nábere รeftimmuns gen ins allgemeine bineinrebet. Sisir wollen alfo bermutien, onß er auch bier nur vor bem Mig̈s: brauche Deş Moralifirenz, por bem enblofen \$ors, prebigen resfeliger uno lebrluftiger Sáter, skitte unb Erzieber warnen wollte. Campe.

-) Freilid wenn ihr curer Sahe nidbt gervip fens. (E) 1 et?.

2uber ganz ftill surft ifre aud nidbt fiscen. Seferwiks.

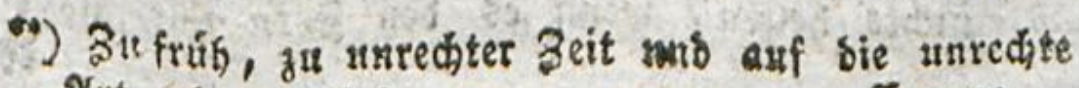
art geben wooll! 
Utugeftime Seibenfthaften wirten fart auf bas Rint, inas ifre 2dengerungen fieht, weil fie jebre auffallenbe Mertmale haben, uno bie Das Sins zwingen, Darauf 2 djt zu gebent. Sor: nelgmitid ift ber 3orn in feiner Entriftung 10 Yárment, bafi man unmoglid, then nicht wahys nehmen tann, wenn man ein Seuge bavon ifi. STan frage nicht, ob ein foldher fall fir einen Rinbertehrer Sjelegentheit herbeiführe, eine fdjone Riebe anjufangen. (5i, gar feine fodsnen Res

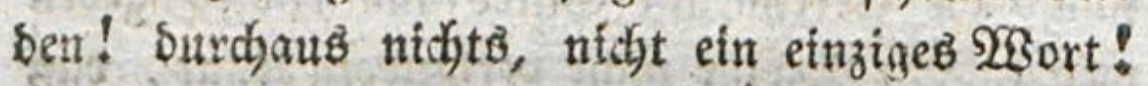
Eafit bas Rind fommen: erftaunt iber ben 2 na Glide, notro es nidjt ermangeln, eud) zu befras gen. Die 2fntwort ift einfach; man nimmt fie von ben Giegentánben felbit her, weldhe auf feine Sinne treffen. (5B fiefrt ein entflammtes Gieficht, funkelnbe 2rugen, eine brokenbe Sies

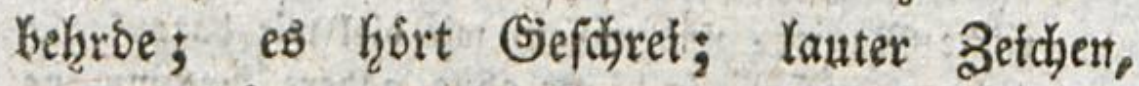

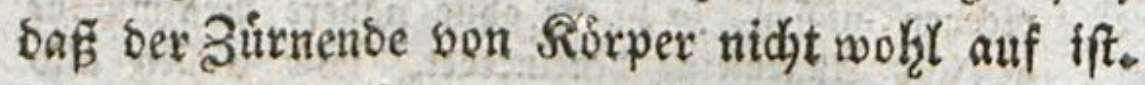
Saght enrem Rleinen, gefergt, ohne Siezier,

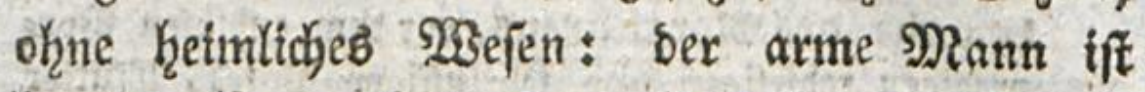
frant; *) er hat einen 2 frfall von Fieber. Ş̧⿻上丨

*) Ifber fúgt hingu: an ber Geele; benn fonft wuirs bet ibr, bem gewóbntichen Eprachgebraudie nad, eine tunvahrheit fager. Stuch wurbe es bem Sinbe sichts belfen, bem es ben Sorn sur als eine

forts 


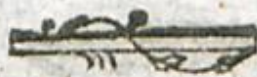

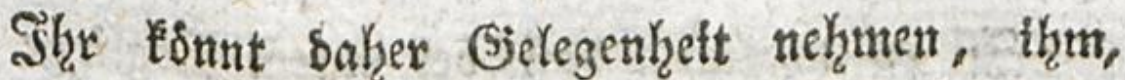
aber in wenig Borten, einen Begriff ban Sirmelfyeiten und thren 5 sirkfungen zu macken: benn auch) fie gefloren zur Natur, unt fino eins Yon ben Bamben Der Niothrwendigfeit, Denen ex fich unterworfen fithlen muf. *)

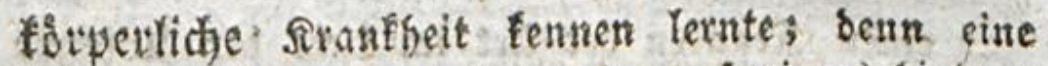

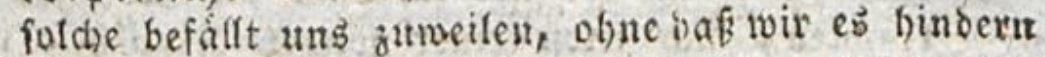
foumen. sisenn loir ifm aber fagen: es fen eine

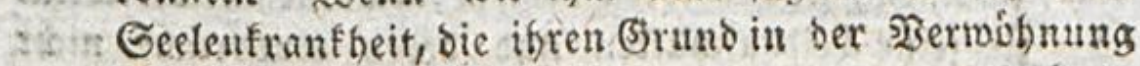
bes Matienten habe, und wenn wir es babei tur: belebren, worin biefe serivohnung beftehe: fo mird

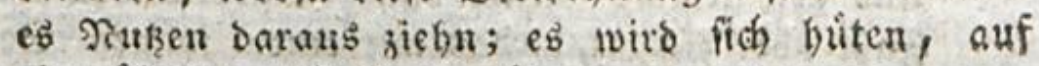

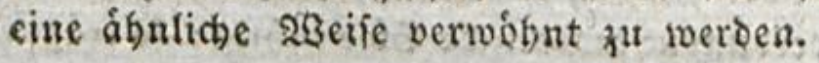

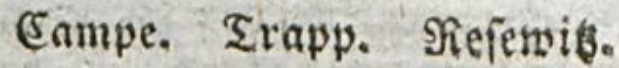

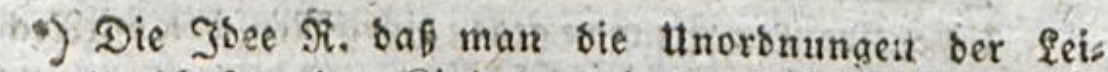
Denichaften ben Sindern, wie Siranfheiten, vovitellen folle, ift pon fo Sielen gepriefen. Hno bod fommt

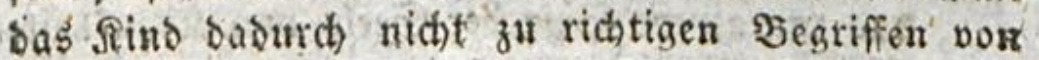
ber wefentlichen Befdiaffenkeit foldher Seelemunorbs nutgen unt forpertichen firantheiten. Şei forpers Yichen Sirunfheiten findet fein Buftand ber Schuls Statt, als in fofern man fie burch irgend ein 3 ers fehn veranlapt bat. $\mathfrak{A}$ uch fann main cine Srants beit bes Rorpers nicht burch bie beftimmte Senfung bes şillens beben, wenn bie srantheit námlich nicht burds beftimmte Soeen ins Niervenfuitem bine

6.. eingebracht ift, und fo auch durch entgegenwirfende Toeen gehoben werben fann. MSenn ein Rino bas erfennt unb bann bas Toben ber feibenfithaften blof als eine Nranfbeit betradtet: 10 wirb es auds 


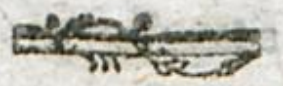

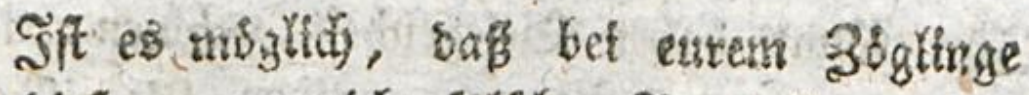

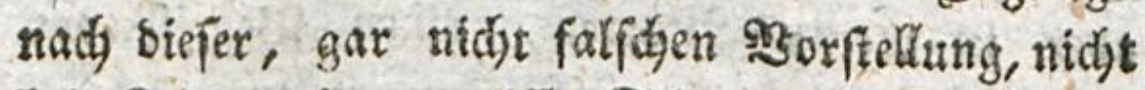
bei Beiten eine gerviffe Edjeu entftehen follte,

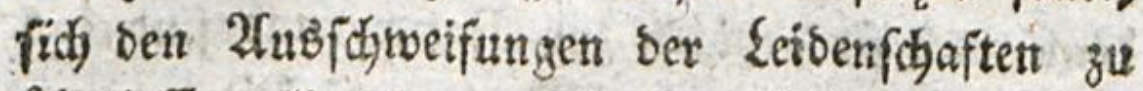

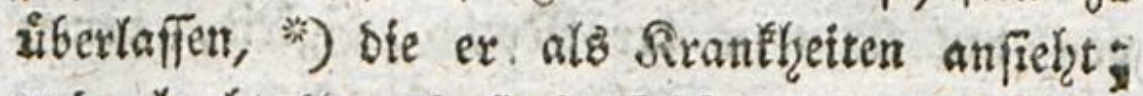
uno glaubt the, bas ein foldger if̧u zat redjtes

3eit

cinert Siranfen ber strt im sidbt ber Innfentlo bes trachter, fich felbit einer folchen Sitantheit sticht. fhámen, uno 2 noern es febtr úbel nehmen, wense fie feine Reidenfhaften und beren Ausbrúche nidat gebulbig ertragen ober westn fie lool gar Etrafe utto gewaitfame Nittel bagesen gebrautien rooller. Frafit aber ein Sind, bas mit eimem folthen Seelens sibel verbuttone moralifde 2 bóie rid)tig: fo trágt es gar leidit Den Begriff per Sibuld mit liber auf bie Niranffeit bes forpers unb handelt gegen einen forpers

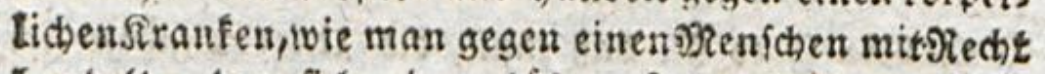
bandelt, ber fid einer boien Letoenichaft ergiebt. Der gefunde Serftand aller Nationen hat immer Das moralifthe જófe der Seele vou Stranfheiten bes Silorpers ridtig unterichieben. Das grofite OSenie follte immer Mistrauen in feine Bhilofophie feBzen, soent fie ifn it ber Sjinficht anf etme neure Sebre Eeitet.

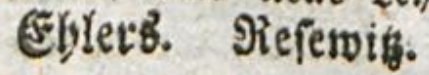

2) Diefe Sdaeu twiro nidgt ontfehen, weun bie leibens \{chaftlidjen beroegungen unmittelbat wit angenehs men ober felbit wolluftigen Empfindungen verbusts ben fino. SBie mancher 2yollífting, ver bod feine Seibenfhaft nidht, twie cine blofe Siranfleit, ans fiebt uno ber fich onbei in sicht ber Straffichleit

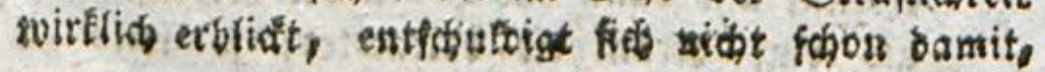

yats 


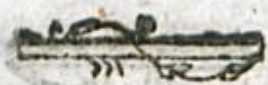

3ెeit betgebracter Begriff nidj: cime eben fo

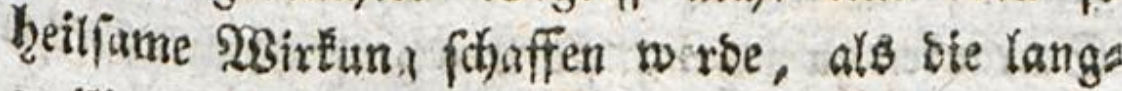
soillgfte (Sittenpreotgt *) gethan histte? 2lber Feht, was fur bie Z3uétunft aus biefen Begriffetr fitr Folgen erwadjfen werben! Eogleich, falls ithe jemals bazu gezmungen merbet, feyo flfk nun berechtigt, bas anffáfigige sind als eftr Eranté Rino zu betzanbeln; es auf fein 3ims

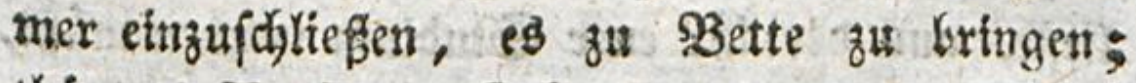

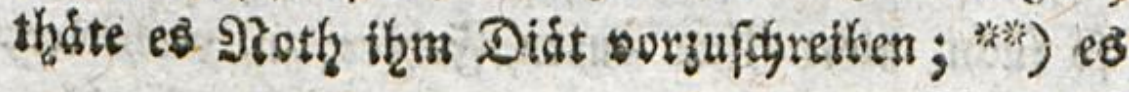
ourds

2

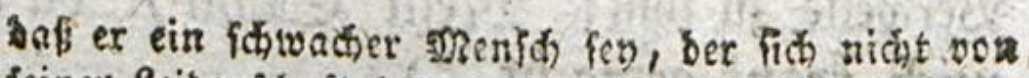
feiner Qeibenichaft tos madben fonste! W3ie viel ges zahiger wirb ein fordher Nentich fid feiner Qeibent idhaft ergeben, wenn er pids babei fúr eben fo uns fchulbig bált, als er einen am sórper frant lies genten Nenfoden fubet! Eblevi. Neferwic.

9) \%. verichafft feinen goeen bei gewobntidjen Scfern leicht baburd Eingang, baf et bem, was er ems Dfiefirt, etwas weit úber bie Mittellinie des Fechts und ber SBafrheit finauzliegendes jeflerfaftes jur

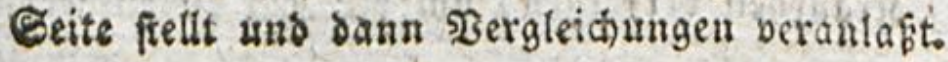

\section{Eblets. Trapp. Fiefenwio.}

ety ocrabe atz pent cin Sino bon gutem Sopf nidbt

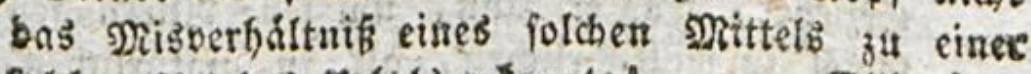
folchen 2 rt bes Hibels erfenntes Eblerş.

Inb, wenn ic bem Sinde, ber $23 a$ hrkeit ges måb, bie Eaf̣er als Eeelentrantheiten geidhitbert babe, bin id banu in porlommenden fallen nidt auts, 


\section{8}

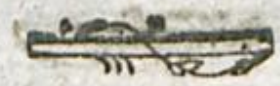

burd) feire entftehenben Untugenbeir felber in Sd)ranten zu fergen; fie ifgm werhagt un's furdyts far zu madjen, ohne baf ed bfe Strenge, beren thre etch bielletdit, bamit es genefe, fit bebienen gezmungen fúblen werbet, als eine

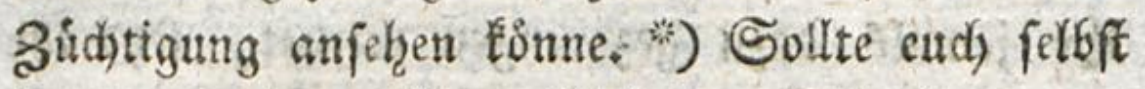
in trgeno einem 2lugentidte ber Şifge begegnen,

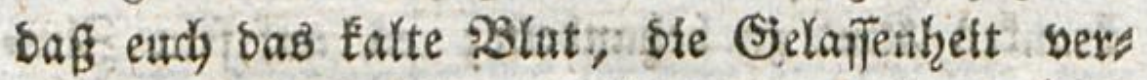
Yieffe, aus ber the euter Stubium madgen mingt,

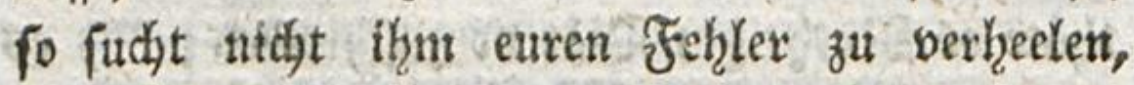
fonbern fagt offenherzig, mit einem zartlidjen Serweife zu ihm: Plein Sobn, Du batt midi) franf gemadit. *)

Lies

aud, und fwar nad, ben eigenen Seariffen bes Thtoes berécbtiget, es ju einer unangenefmen Sit zu verutheilen?

Eampe.

(E) wird aber in manchen Fafllen bas s)isvers háituif ber Jiur jur angeblicten firanfheif wabl nebmen, jene als ctes willfubrlide Sbehandung aniebent und baffen, und befto berfiarfer feine Sirunfbeit verbergen, um der Sur zu entgebent.

গTeTewis.

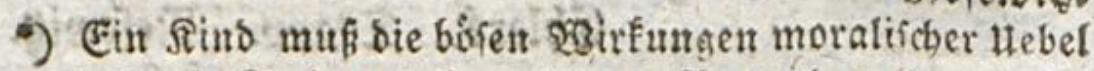
juit wie Buthtmittel anfebn. Nut thue ber upeife Ericher, was er fann, um iene SBirfingen nidbt fowol it willeúbrlichen, als in naturtichen, aus ber Satur ber Sade entipringenden," Siritingent beftebut ju lafient.

So viel es nur móglict) ift. Elyetr. Siefemis.

-) Sieine weife Ergiebungstegel. Ein Simo inuk es

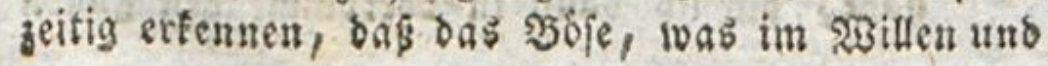
ben 
Utbrigènz Yiegt biel baran, baffalle Nai= bitaten, welche bie Sinfalt ber Begriffe, in

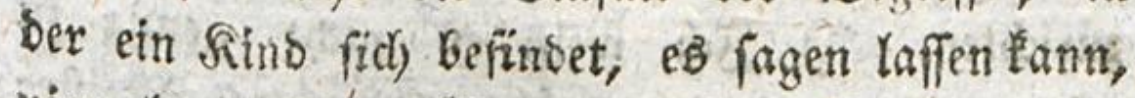
niemalo in feitier Gegentwart bemertebar gemadjt, noch aud) to wheber exzáţlt werben, bafi es z̆ feinen Dhren fomme. *) (Sin einziges un= surfichtiges Getadjter ift in Stande die 2robeit

Don

Dem Joeenzuftande liegt, ganz natuirticher 23 eife Inwillen uno 293 iberitand in einem guten und burch einen ridhtigen Gocenjaptand Belenten șillen erres

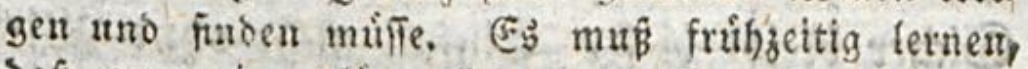
Daß̧ man einen forpertichen Sranfen liebreich ver: pflegen, auf cinen bifen $2 B i t l e n$ aber weife jurnen múfie. Şat mau mit Invernunft gęźrut unb aud fich vergangen: fo fage man abermals nicht: bu baft midh frant gemacht, fonbern beim Hnwillen úber bein 'Jbofes babe auch idb mich niøt gemásigt, babe auch ich mich vergangen. So ift bie Sadje beichaffen und to mun fie auth vorgeftellt werber.

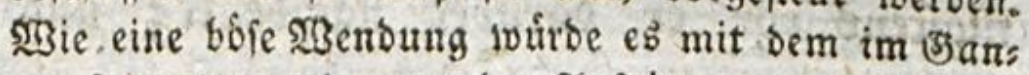
zen fo guten unb unter ben Anipinnen des gefunden Serjtandeb gebilbeten Sprachgebrauch nehmen, wenn ein burch feimen Sortrag Ginreifiender Reoner ober Edhriftiteller ienen (sebraud) nicht andern fonnte!

\section{Eblets. Referwits.}

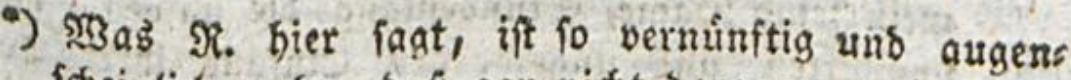
fcheinlids mafir, bafi gar nicht Daran zu zweifeln ift. शुber es ift eridhedfich und bejammernzlourbig, baß oft gerabe bie gelehrteften, flúgften, feinften Serren und Damen ein fo ftumpfes ober verwabritofetes geiftiges und moralifकes @efúbl ober einen fo fकánb: 


\section{0}

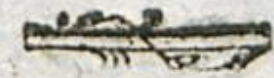

gon cinetn balben Sabre zu verberber, unb einen unerfef̧lidjen Sdjaben für bas ganze Leben ans

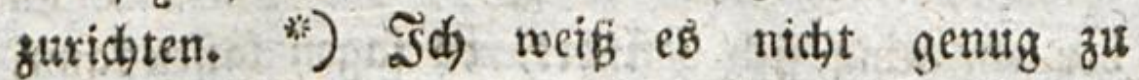
soieberholen: man muß Fegn, wenn man über bas Rino Meifter fenn will. Bum Beifpiele, ftlle id mir meinen Ileiuen Sunil bor, wie or mitten bei cinem bejo tigen Reifen unter zwei Nadjbarinnen auf bie exbogtefte zu liefe, uno in einem Ione bes 92tits leibs zu ihe fagte: sgocine liebe Fraul, fite ift rectot franf, es thut mir fibr leid. Sidjer bletbr btefer (5infall nid)t of ne IBtrtung auf ben 3ujdauer, villeidjt nidjt einmal auf sie Sdaunpielerinnen. Shye zu ladjen, obze auf înt zu fdymålen, obne ilnt zu loben, fithre id) thn gutwillig, ober mit (semalt fort, ehe ex biefe $2 B$ irtung wabrnebruen tann, ooer wes rigftens ebe ex bariber naboent; uno eile, itst

Lisen Reiditinn bafen, baf fie in ifrem betragen gegen finber aat nicht darauf acten.

- Эell babe nod) oor furzem eite vornebme unges mein feine Dame, Etumbentang bie naiven, abges \{chmacfteit uno ungejogenent Einfálle ibrer ßod) ter, in beren Segenwart, ergáblen und beladjen boren múfien.

Stuve.

5) Sefre wabr unb fehr widtig!

Bfblers. Eampe. Trapp. Seufinger. Miefenith 


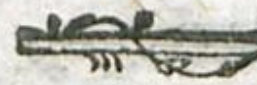

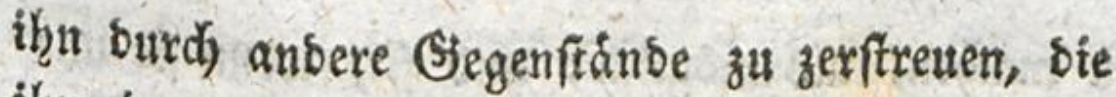
ihm jenes fefgr bald aus bem Siebddtniffe britte gen werben, ")

Meine 206idyt if nidjt, bet 2Ollem bier fo ins Einzelne zul geţen, fonbern nur sie alls gemeinen Grunbfăke gorzutragen, uno bei fónes ren (Selegentzeiten Beifpiele **) zu geben. Să balte es fír unmoglich), baß̧ man mitten in bex

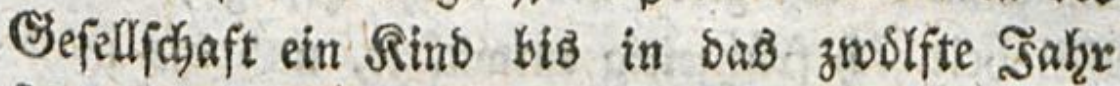
feines 2aters fübre, ohne thm einen Begriff son bem

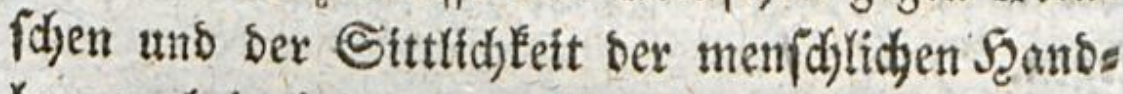
Yungen beizubringen. Es ift genug, faf́ man (iid) befleifige, ihm biefe Begriffe fo fpat nothig

-) (3ants gut, went bas Sins surch fich, felbft ouf goeen ber firt gerathen todre, unb barauf fich to allogebructit bátte. Eoll ber Erziefer felbpt aber eine Sitt zu benfen und zu handeln veranlaffen, nach Deren 2 triventung man folche Naafregeln ergreifen muß ? Sisem ein Rinb aber outh felbjt aulf folche Soeen gefommen wáre: fo müpte ber Er zriefer es Darauf bod miglichit bals von beren unrichtigfét unb von ber llnpaplidfétit folder, leidyt Lachen ers

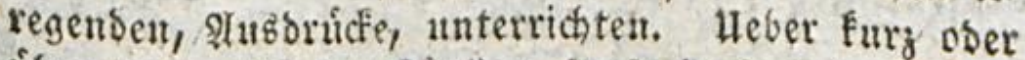
liber lang wirb ber 3ogling fonft boch aus ber ltw richtigfeit foldjer goeen und Nebensarten heraub geladbt.

(Eb)ers. Repenits.

*) Die bann aber beffer, wie bas \$orkergethente ges wábit toeroen mifien.

Emil Ifter ₹b.

(5blers. 
sut madjen, als miglict); uns fie, went fie uns

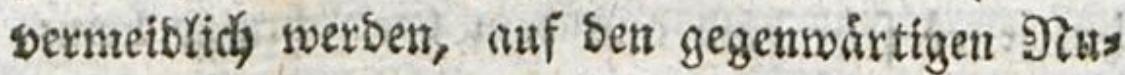
Gen cinfdyranfe, max bamit es fich nid)t für ben Sgerrn bon 2fllem balte, uns OHbern nicht ohne

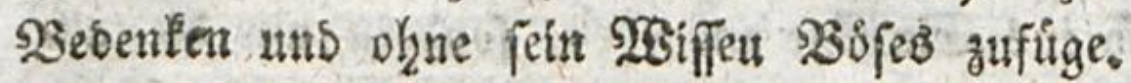
SEB giebt faufte unb ruhige Sharactere, ote man ohne Sefaber in threx erfiten linfduls weit fitha ren tant: es giebt aber autd feftige, berent 203itsheit fich frithzeitig entwidelt, uns sie mant

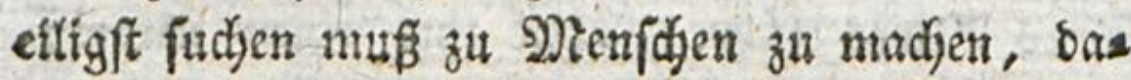

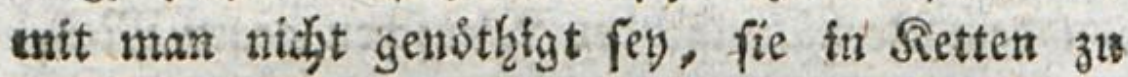
regen. *)

LInfere exffen syflidyten baben wir geget มีย felsft; unjere exften urfpringlidgen Empfins sungen concentriten fid) in uns felbft; alle un fere natirlichen Semegungen beziefren fich ans

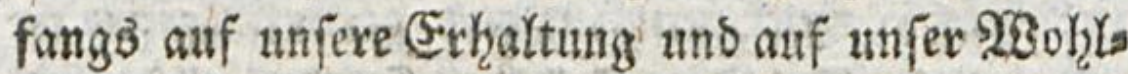
fentr. Demtrids gelangen suit zut Dent exften

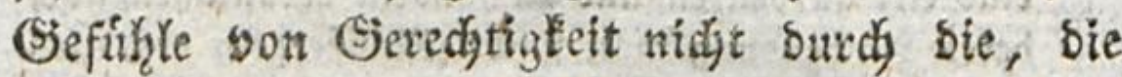

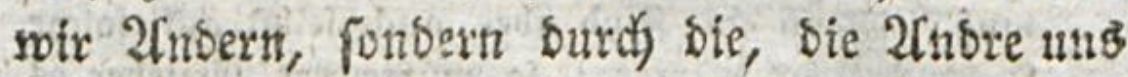

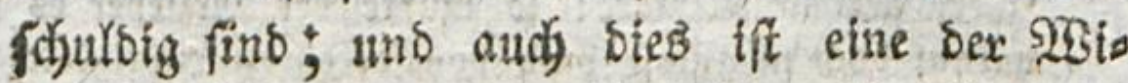
berfinnigheiten ber gewoignlidjen Erzief̧ungen, \$of.

e) Nan mus fich alio in ber Shinficht won ber erfen

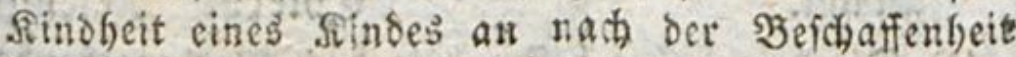

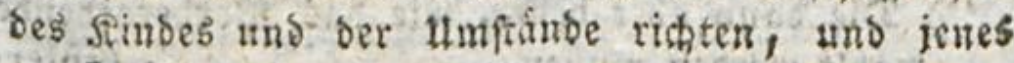
swedmáfig leiten unb bilben.

Eglers. Trapp Rejewißs. Eampe. 


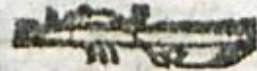

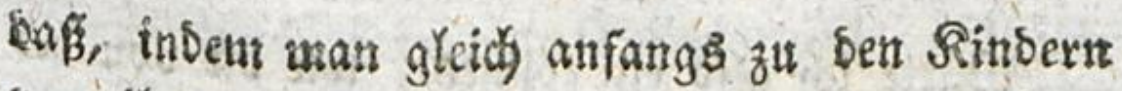
bon ihren Syflidten, niemals aber yon ifren (Sieredtfamen rebet, man iffnen folglich bas Segentheil Desjienigen zu fagen anfängt, was man jagen follte; mithin Dinge, bie fie nidyt Derfitefyen fisnnen, und bie fein Intereffe fir fis haben. *)

\section{(S) 2 *}

Shatte

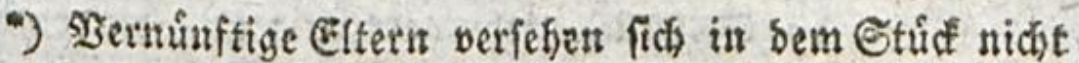
fo fefre, als man naक $\Re$. glauben follte. Dura's alles bas, was fie einem Sinbe in feinem sterfals

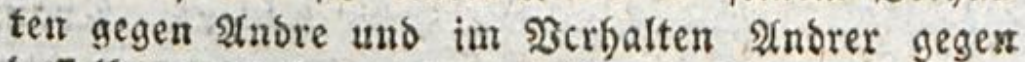
bafielbe jugeftehen unb was fie von Geiten bes Sims Des 2 ntbern zugeftehen, werben bie 3 jegriffe von befs

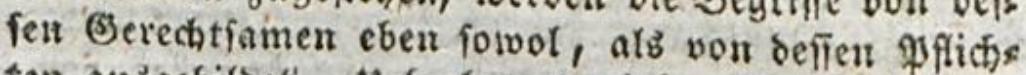
ten atzagebildet. Heberbatpt wirfen bie \$orftellane.

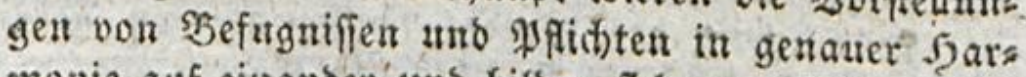
monic auf einander und bilben fidh gegenfeitig leidht. bis zur 93olffommenheit aus. Der weife Errjiefer bat ieboch dafuir zu forgen, baf bies in einem ges wiijen Ebenmaấ geichelye und es int, bamit bas geichehe, bei eirem Sinde eben aus bem Srunbe,

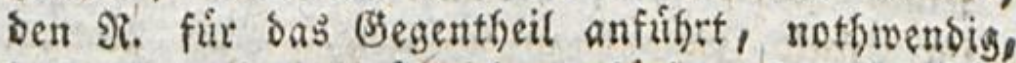
Daß̉ man ihm frúbzeitig geforige \$̧egriffe vout

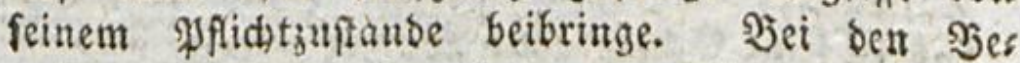
grifren, bie befien (5eredifame betreffen, wirkt bie

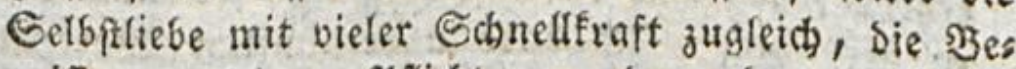
griffe von feinen Pfithten soerben aber vorjúglich nur burch Burúctioirfung jener Geelenthátigfeit auf eine merffid) fdrwádere 2 int mit gebilbet. Diejer fobwád)ern Gegentwirfung múffen alfo gute Erryiblet

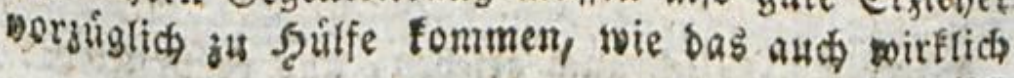

felbft 
Shatte idy aljo ein foldyes, wie bie von bes nen id rebe, zul fîhren; fo wirbe idh zu mir fagen: ein Rins vergreift fïd) niemalz an ફpers fonen, + ) fondern an Dingen; und bald lernt

felbft bei redht gutbenfenben gemeinen Setten, wie bei Perionen von Einficht, geíhiebt. Dabei ift nod fu betradten, Daf, wenn ber Erjieber mit-F̧eiß an Pflidtbegriffen und Pflichtgefublen bes. Nindes are beitet, bie Eelbittiebe fefrer gefchaftig ift, bie bamit zufammenpafienden গjegriffe eigner গ̧efugnifie uแb Serechtiame zugletch mit ausjubitben.

(E) lers. Trapp.

Einer biejer beziehenden গ̧egriffe regt auth bie anbern in ber Seele an; ba aber ber Jegriff ber Sefugniß ourd) die Eelbftlicbe gelehrt uno unter,

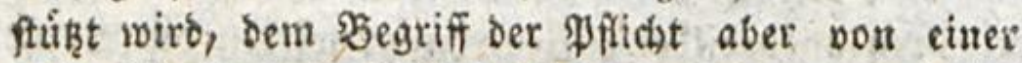
Seibenichaft bes Sinbes leicht entgegen gearbeitet soiro, fo mui ber Errziełer den şegriff ober bas (s)e fúbl ber Pfidit unterftifzett.

Referwis.

*) Nan muß́ nie zugeben, baß cin Nind fith mit (Ev bachferen, twie mit Sintoen, bie unter feinem, ober feines afters find, herumgerre. Grfúbnte eins fidg im Ernfte Semano zu folagen, wárs auth feizen 2lufivairter, wárs ben Syenfer, fo místet ibr forgen,

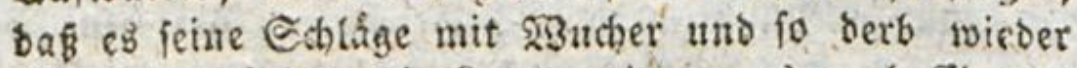
erbielte, bẩ ihm bie luft verginge, ebे nodb Einmat zu veriutben. (马) babe unverninftige SBgarterinnen

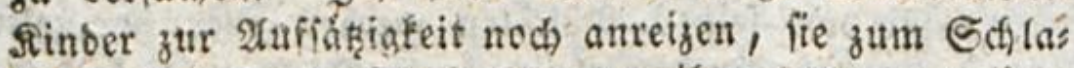
gen aufunutern, iidh felbft wou ibm ich!agen lafien,

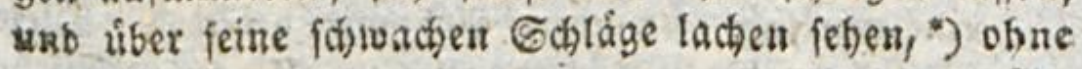

2.r. $\mathrm{r}$

5) Das habe ith auth seferen, uns es ift leiber! nor bुăufis zu febu.

Trapp. 


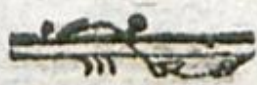

C\$ aus Der Frfaffurung, EFrerbietung vor bem,

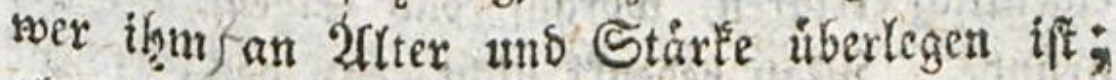
aber bie Dinge bertheibigen. fid nidat felkft.

Der erfte Begriff, Den man ihm geben muf, if alfo nid)t funot ber Begriff ber Frets heit, als ber Begriff bes Eigentfiums; unb

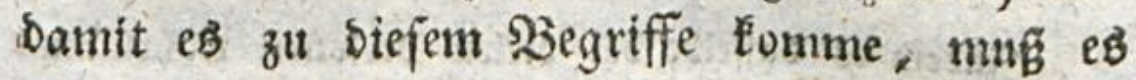
etwas Figenes haben. Şhum feine Rteioer, fein Serath, rein Spielzeng anführen, heipt nidfts geragt; weil, ob eB gleidh mit biefen Sachen nad) Belieben fdualtet, es body nidht weiff, wars um, nod) wie es biefe Dinge befigt. Shl一m jas gen, bafi es fie befifet, weil man fie ifin geges ben, bebeutet aud) nidjt viel mehrx; Denn um ร̆u geben, muf́ man baben. Soier will man ifm num eit Eigenthum, bas vor bem feinen Da ift, ertelaren; *) uno man follte if̧m bod' (E) 3 eis

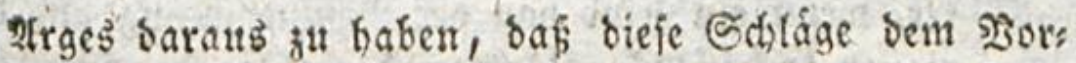
fake bes fleinen 23 uttbrids nah), eben fo viele \$oos

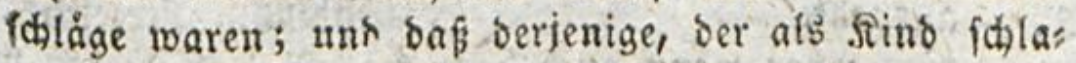
sen will, als Erwadjener wirb tobten wolfen.

D. Berf.

2) Das ift nicht notbig. Ein Sino nimmt ofne शris: trauen an, baßs bie Dinge, bie ciner befikt unb mit benea er nach Ђelieben fáaltet uno maltet, biefem gefóren und es jeigt feinen হrieb an zu erforidhen, wie ber Befişer urfprínglid bazu gefommen fev. গm 


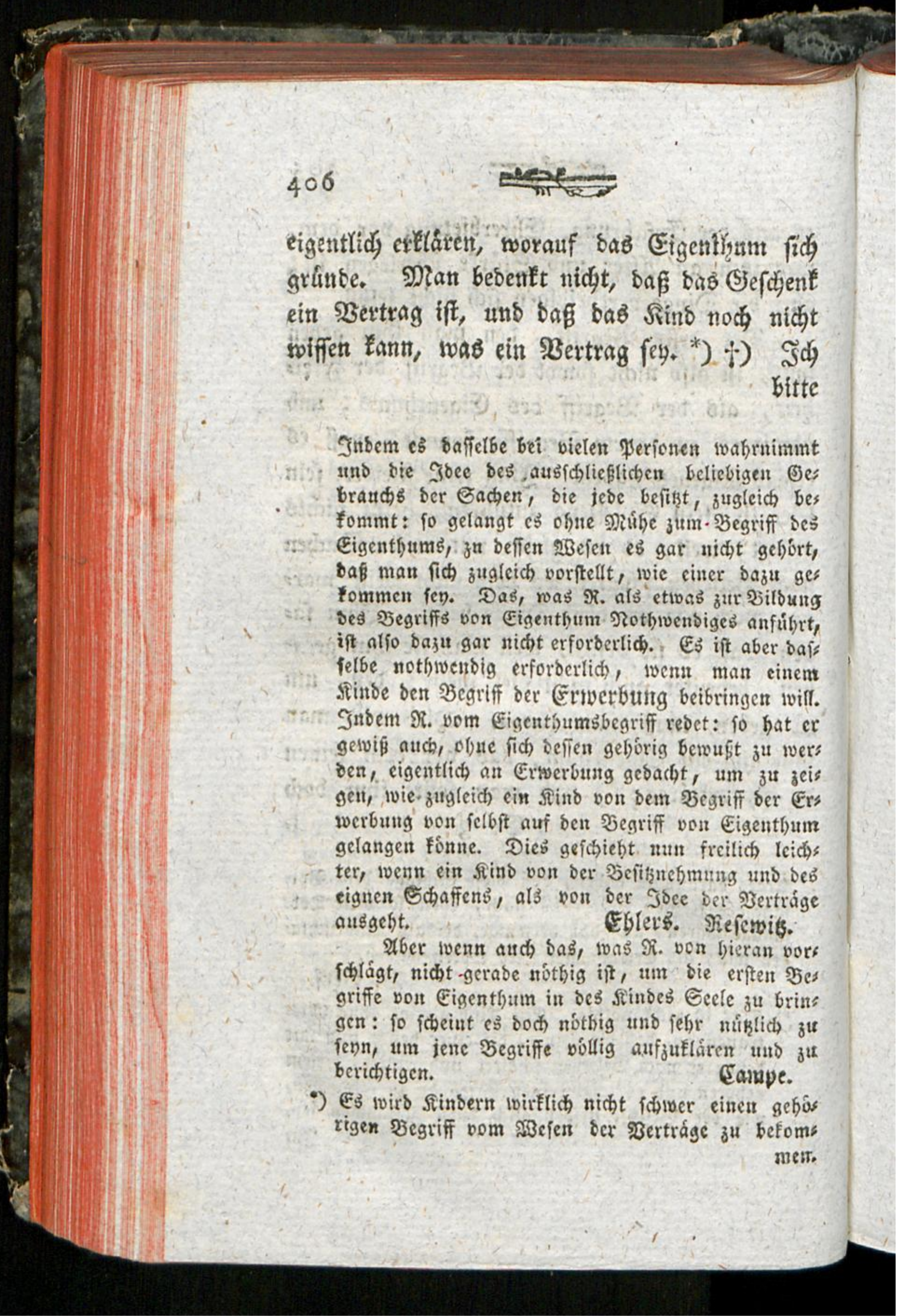




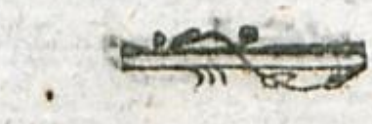

Gitte etcdi, Ecjer, bemertt aus siejent und f̧urs berttaufend andern seifpielen, wie, inbein man ben Finbern 28 sorter in ben Ropf pfroyfet, be"s sen Serftans if̧ve Jaffungstraft itberfteigt, man fie gleidjow gut untervidgtet zu ḩaken wålgnt.

\section{- Stgir follen alfo num bis zum ltriputuge} bes Eigenthumb Kinatuffetgen; Denn sabon

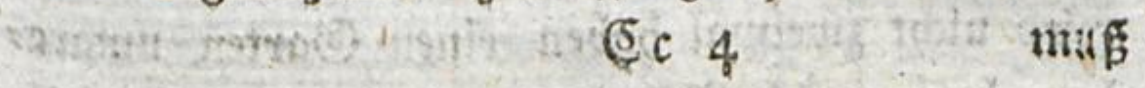

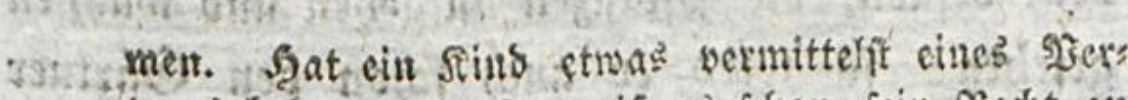

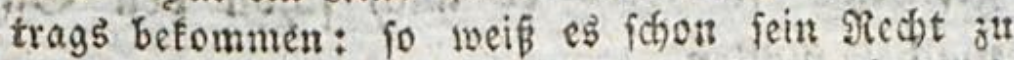

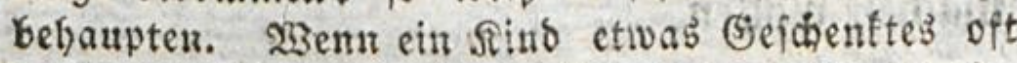

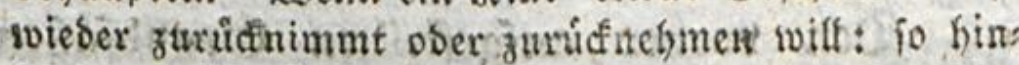
Dert nur bie Rebhaftigfeit ber goee, welche das 34 :

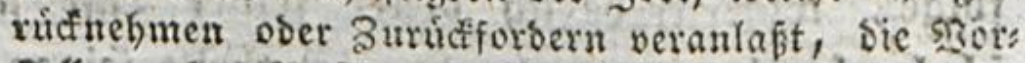
Fetling Des Nechts, weldhes fich auf sefien Geite finset, bem es geidenft war. siscil bas Gelbitge: fíbl in Suftande bes cignen siectits mitwirft: to ift es eben nothmendig, baf man in biefem salle

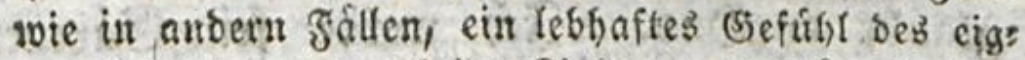

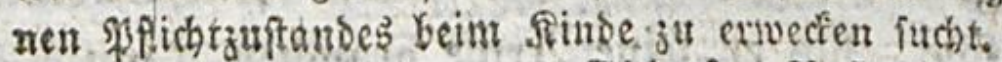

(E) leţ. Referwis.

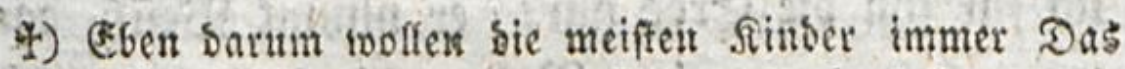

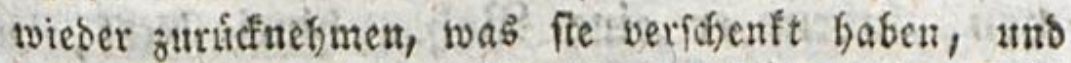
weinen, weut man es ihner nicht twiebergeben- wifl. Dies gejdieft nicht meft, wenn fie reht begriffen haben, Juas ein (Berchent ift; ") fie werben alsbank

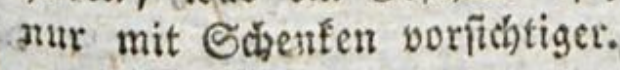

-) Oder viefmefir, wenu fie zu mefeerer feertigfeit ber शुefinnlichfeit in alle bem fommen, wă eitr "Ges fderff ber Natur nach ift uno toas bie Folge bavon

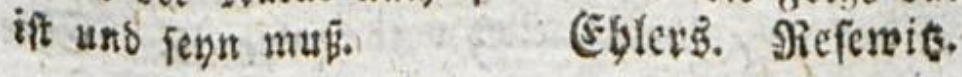


mus Ser erffe Begriff *) Deffeltben Kergeleitet werben. Das Rins, bas auf bem Lanbe Yebt, siro eintgermaf̧en Felbarbeiten baben fennen Yernen; es braucht bazu nur 24ugen, nur פTuge; uno an beiben wiro es ifut nidjt gefeblt baben. (Fin jebes 2llter, vornef̧mlid) bas feinige, will erjobaffen, nacbahmen, herborbringen, Errwetfe

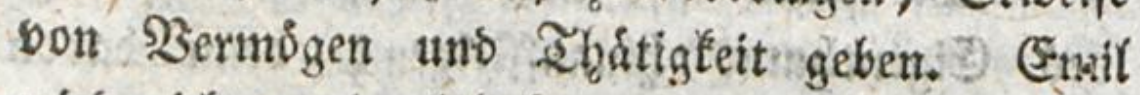
wiro nidyt zweimal foben einen (Sarten untgras ben, befaen, bie Pflanzen aufgeken unb wadysen gefefzen: fo wiro ex autd fdjon ben Esartner madyen wollen.

Den vork̨er aufgeftellten Sirundfigen zu= folge, wiherftrebe id biejer feiner suft nidjt; id, beginftige fie bielmebre, idb theile feimen Sips fdimad, ich arbeite mit ifhm, nidjt ofu feinem, ponbern zu meinem Sergnigen; wenigitens

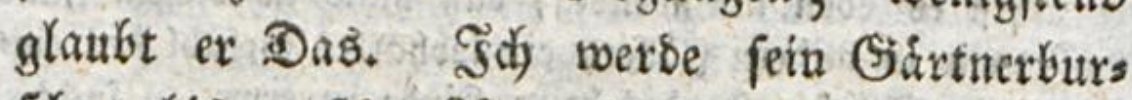
fiche; bis ex feine 2frme braudgen fann, grabe ich fit ifhn bie serbe um; ex nimmt Befig bas son, insem ex cine Bobne hineinftect, uno sotrtlich ift oiefe Befifgnehimung beiliger uno

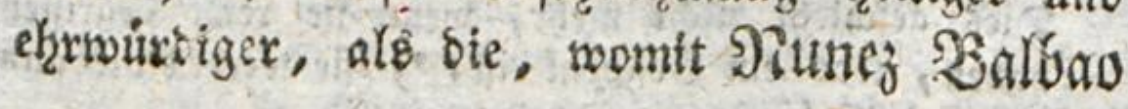

Das

-) Der פegriff von ber erften Entftehung eines Eigens thums vichmefr, weicher nidht toefentlich jum $\mathfrak{\text { Jegriff }}$ bes Eigentbums feibft nothuendig ift. Ë) (erš. 


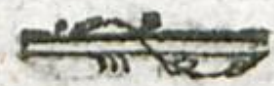

409

bå̉ füblidye 2lmerica bem Ronige bon Epanten sueignete, als ex feine Fabnne auf ben Riffen des Sísmeers aufpflanzte.

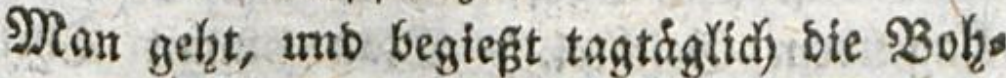
nen; man fiebrt mit frohen Entzudiungen fie auffeimen. Sdb vermehre siefe freuto baburdj,

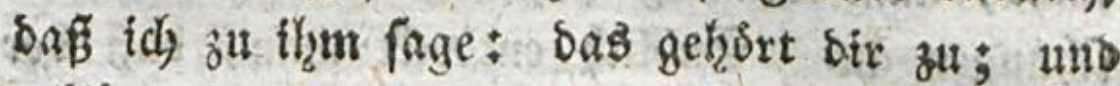
erflare thm mun fiterbei bas 280 ort zugeboren, inbem id ifn beruerten lafie, baf ex feine aeit, feite 2ribeit, feine Mrube, turz fid) felbft dars an gewendet, baf ex in biefer Erbe etwag yon

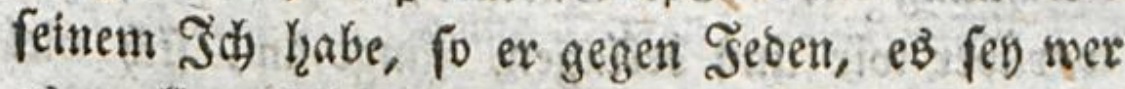
es wolle, Gehaupten barf, gleidjute er feinen Zrm aแs ber Şand eines 20 ndern, ber thn wis ber feinen 28 illen zuridthalten wollte, feranbs zieḩen fonnte.

Sinft, fiehe ba! tsmmt er, fekgr eiltg, bie

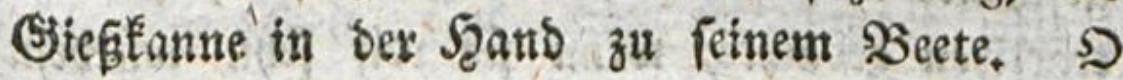
2trblta! o Sdymerz! 2ule Bobnen fins kers aügeriffen, bie ganje Eroe umgemiblt, ber şolag felbit nidjt Eennbar mebr. 2(d)! wo tf meine 2rbeit, mein S2bert, bie liebe Frudjt meinex S) ithe, I meines Sdyweiffes! $928 \mathrm{er}$ hat mix mein Sint geraubt? wer bat mir with Bohnen genommen? Sein junges Sexz wallt auf; Die exfte Empfinoung ber Ungeredytigleit

$$
\text { S } \subset 5
$$

ers 


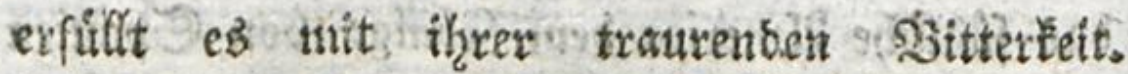
Shburnen fliegen ifgu frombetfe; or ourdjian: mert troftlos bie \&uft mit Senfät, mit wehs

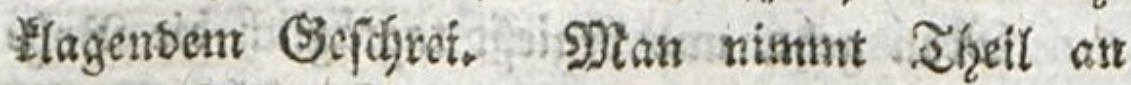
feinem Sdymerse, an feitem lliwsillen: ntan fitdit, ntaiv erfunbigt fich, man frellt פiachfors pdungen an. Enslid entbedt man, baf́ ber Girtmep Den Streich gemacht: man laft tfut somnon?

esn 2tber fiebe! ba finb wir weit oon itriferer

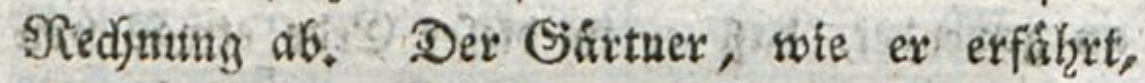
tooriber tofr uns bellaget, fängt àr, fich biel

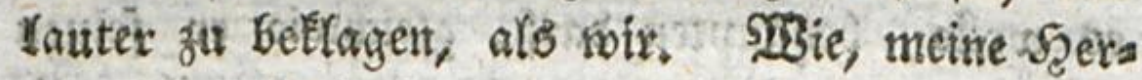
ven, fie alpo baben mit smeithe 21rbeit benbenbt?

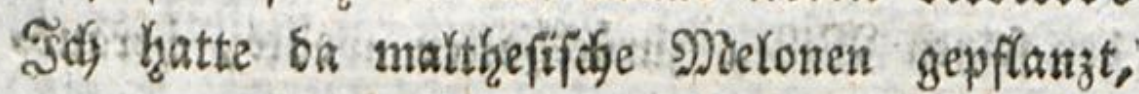
wobon mir ber Caanten alb eine Roftbarteit gefdente toosberi war, und womit th Ste zu tractiren gebadjte, wemt fie reif fenn woirsen. Da fonmen Sie mix tutn Ger, Fteden ihre elens

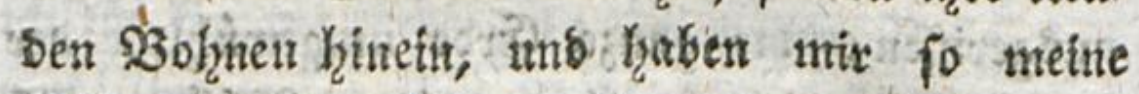
Melonen, sie-fdyont aufgegangent waren, Ders

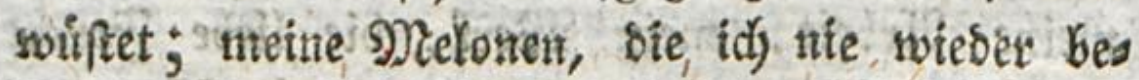
contmentann! Sie faben mix eitret tnevfergli, dien Sigaben zugefingt, uno fidis peltoft bes

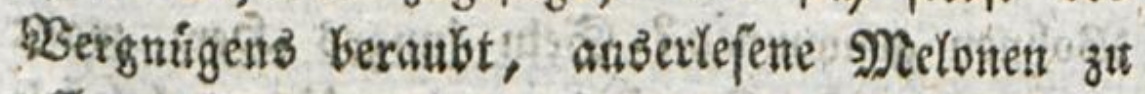
effen. 
Sobant Sacob.

Entidurbige er uns, metn lieber Srobert. Ex Katte ba feine 2trbett, feine Maihe bran ges

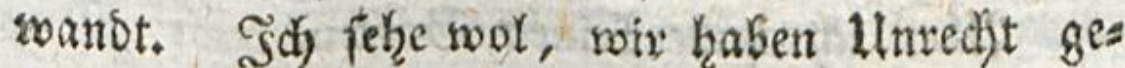
than, feine 2frbeit 3a verwerben; aber wir wots len tham andern Saamen aus Sialtha tomment laffen, uno ein andermal teine Erbe mef̧r bes arbeiten, ehe twir twiffer, $\mathrm{ob}$ nidyt fdjon Semans vor uns ble Sgano baran gef̧abt baat.

\section{Robert.}

Redjt fo, meine Secrren! Wber benn fons nen Sie nut fiul frigen; Denn eliegt teine Erbe meķr unangebaut. Sh bearbeite baz

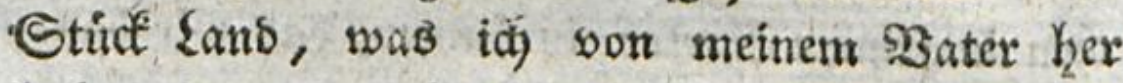
habe, ber ę urbar gemadyt hat; ein Seber thut peiner Seito beggleidyen; uns alle Fetber, bie Sie fehen, finb fdyon feit langer 3eit in Sefis genomment.

\section{Enil.}

Seerr Robert, es̉ geht ałjo nol oft Metos nenfaamen wertohren?

Ribert.

Bitte um నुergebung, junget Şerr; es

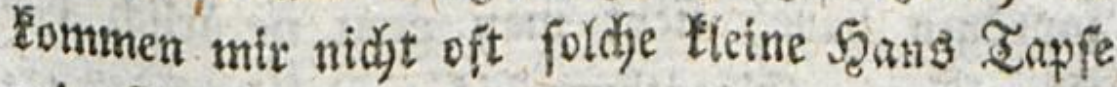
wie Sie her. গRiemant taffet feines Niadjs bars 
412

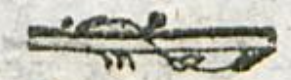

bars Sarten an; Seber hált bes 2lnoern 2r: beit in Egren, bamit feine in Sidjerbeit fen.

Emil.

2fber idi) habe Éetnen Garten.

Robert.

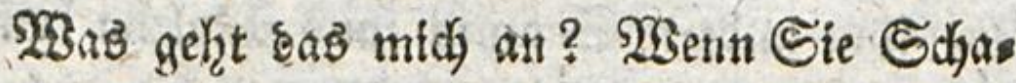
ben antidten, fo werbe thy Sie nidjt mehr bare tun pargeteren getrn lañen; Dent, fehen Sie, (id) will meine Silihe nidjt verlohren haben.

\section{Jobant Sacob.}

RSnnte man aber nidjt bem guten Robert einen Bergleid) boridjlagen? Misgte ex nidjt urefnem fleiten Freunbe uno mir eft $2 B i n t e l=$ d)en in feinem Soarten einxäumen, bas wir bauen Is sunten, mit ber Bebingung, baf ex bte Sedrfte son Dem haben foll, was es trigen wiro?

\section{Robert.}

Ia) will Shzten einen ohne ßesingung eitt

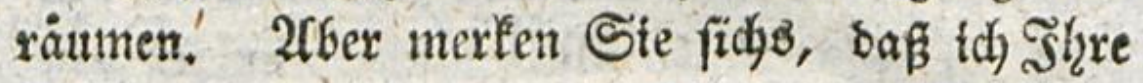
Bohnten umboiffle, menn fie meinen Mitonen zu nabe tomuten.

Sit Eiejen Berfudje, auf weldye 2 rt man Rinsern bie erften uripringliajen Begriffe eins zuprágen habe, fìţt man ganz natürlich ben Begriff von Eigenthum bis aufo Recht bes ex 


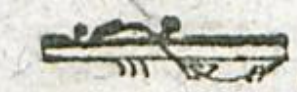

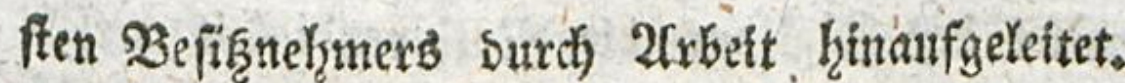
Soldjes ift flar, beatltib), einfach), uns immer Dex Faffungžtraft bez Rinbes angemeffen. Bort ba bis zum Redjte bes Eigenthums uno zum Zaufde ift nux nod) Ein Sdyritt. Sgat man ben gethan, fo mü man ftehen bleiben.

M(an fiebzt auci) noci), bafi eine Exilarung, Ste ich) bier in zoet Seiten zufammenoränge,

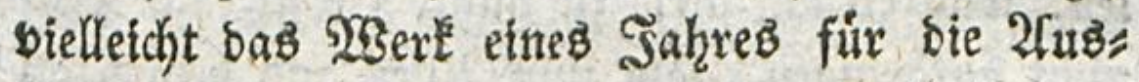
itbung fenn werbe: benn auf ber Laufbafgn ber fittlichen Begriffe fann man nidjt zu langfam fortricléen, nod) fid jorgfăltig gentg jeben Sdyritt borker fichern. Sunge Lehrer, bentet, bitte ich ench, an biefeb reifpiel, uns sergegt nie, baßß allenthalben eure Seḩren meḩr in Şands lungen, als in Reben befteb̧en miffen; *) benn bie Rinber bergeffen leidit, was fie gefaght has ben, uno twab man ifhnen fagt, nicht aber, mas fie gethan baben, uno was man thnen setḩan ḩat.

Dergleicyen Unterweifungen miffen, mée fhou gefagt, frúber ober fpater gegeben werben, je nadbem ber rubige ober braufendere Ehas racter

") D baf soch alle junge Erjieffer biffe fautptreger fafien uns behalten mogten! Campe. 


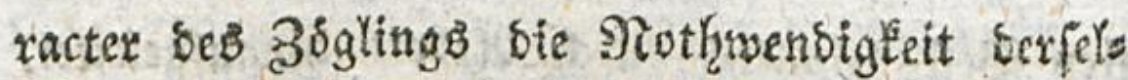
ben berejlennigt ober vergigert; Der Sinsen ip sabon fo offenbar, baf́ ex liberzengent in die 2lugen follt: aber um in fofweren Sadjem nidjts

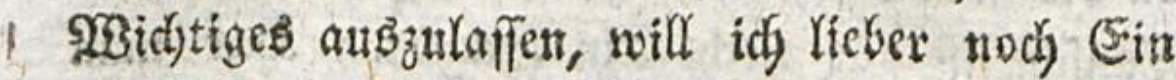
Secipiel geben.

Cuex fower zu erziehendes Sind madjt 2 fls Kes, toas eв anxifhrt, zu nichte; lafit ench Das

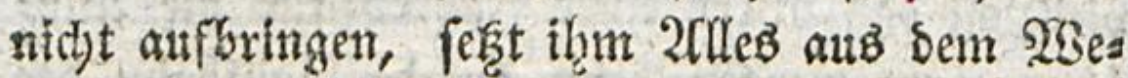

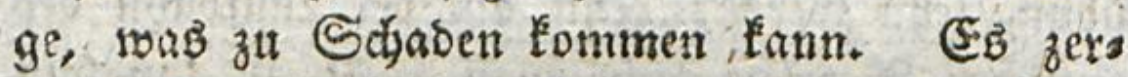
Sridjt bas Gerath, seffen es fich bestent; ubers eilt ench nicht, thm anderes wieber zu geben; laffet $C B$ bas Utmangenchme ber Entbehrung ems

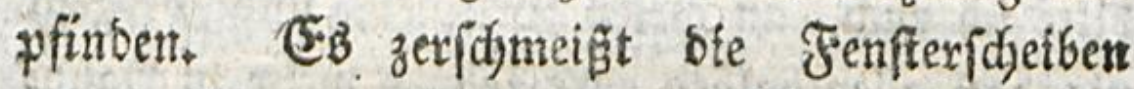
feines Simmers; lät ben 533 ino Jag tno Siadht burchftreidjen, uns betummert eud nidat srum, of es einen Frǘ babon trägt; beffer es Habe einen $\widetilde{f}$ tuff, als etuen Zollfinn! Beflagt

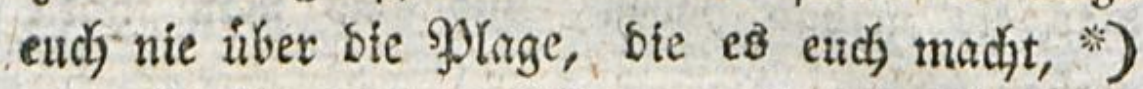

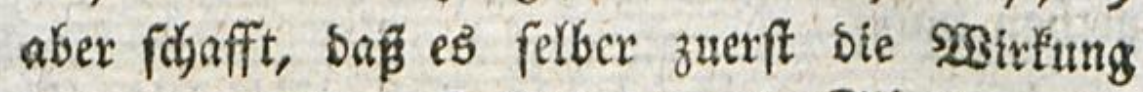
babon genieffe. Enolidy lafst die Sdjeiben wies

Ser

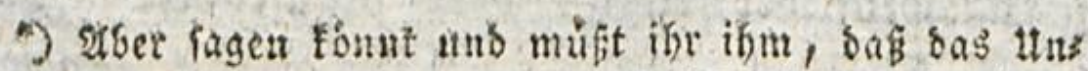
angenefhe, weldes er mu felfft leibet, fein eigen

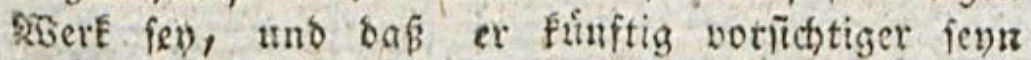

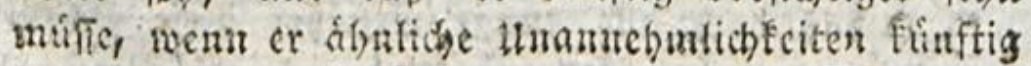
3̆ vermeiten wúnthe.

Eampe. 
Sit einfesen, immer ofye neiteres 28 ort. zerforsmeifft fie weteser. Sache an einem andern Ende an; fagt ifm tros

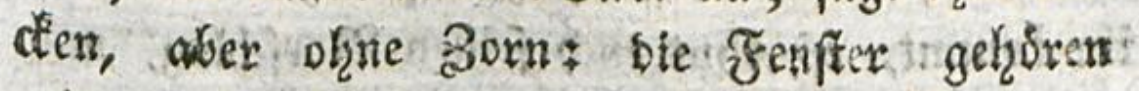
mir; F) id hatse fie bahin bejurgt; ich mut fie in Sitdertheit ftelfen; Dunfeln an einen Snt ohne Zzenfer ein. Sei

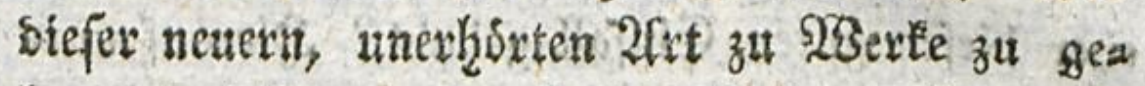
Ken, erheht eह̉ ein 3ిetergerdsrei; tobt; nies

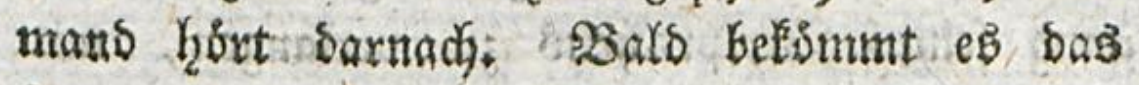
fatt, uno żêtht anbere Saiten auf, Es fenfzt, es jontrert, ein Sebientex ling̈t fich febent; see

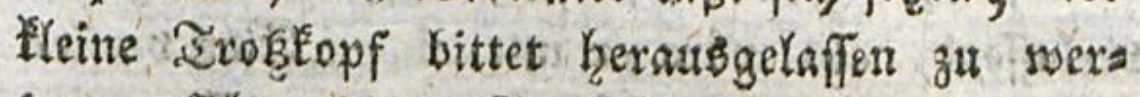

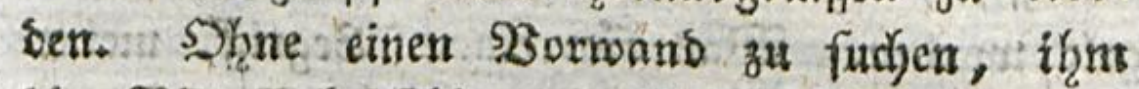
bie sitte absurflagen, ift Die 2fntwort: ich batbe audj meine Giasfdyelben zu berwahren; uno weg ifter. Enolith, nadjbetn bas Rins: eintge Etunddyen baxin miro geblieben fenn, frintánglictje Langeneile zu empfinben, uns jich ilyer zit eximnern, giebt thm irgeno wer unter

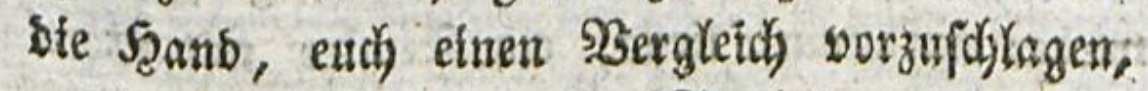

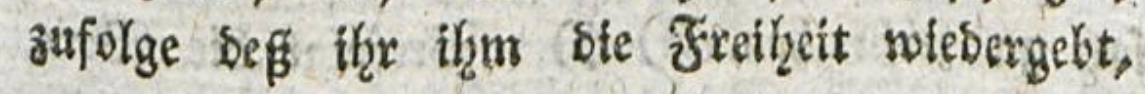

ธัตื

-) Dieje Jelebrung Gatte eben fo gut fogleich Statk funden fonnen. Die fomftige 2rt zu verfahren wáre unn in swieberfommenden fóllen bę Einwerfento anders sinzuriden.

(E)blers. 


\section{6}

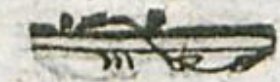

bas Sind aber teine Srjeiben mekge zerbrechen will: bas ift 2llles, wab eb ttux wuimjdjt. Es

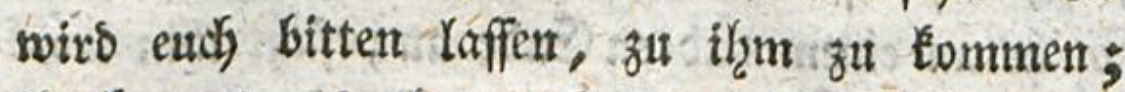

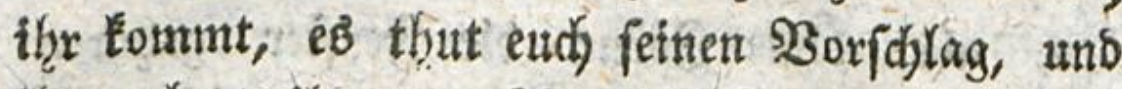
the nefimt tha ben 2lugentidic an, mit bem Beifügen: feftr wohl exfüben! 933 ir werben beibe babef gewinnets; warum haft bu nidjt efzer Siefen guten Einfall geḩabt? Şierauf ums armt the eB, ofzne Betheurung ober Beftatis

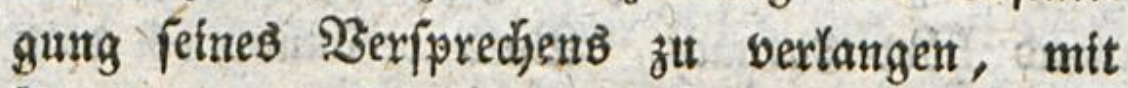
Frettben, unb füfrrt es fogleidy in feine Stube, eben to heilfig uns feft euch auf ben SBergletch verlafient, als ware ex mit einem Gibe berfies gelt morben. $228 a b$ fúr einen Begriff, meint fhe wol, wirs nicht zufolge ofejes నerfahyrens Das Rind von ber Ireue in \$eriprechungen uns

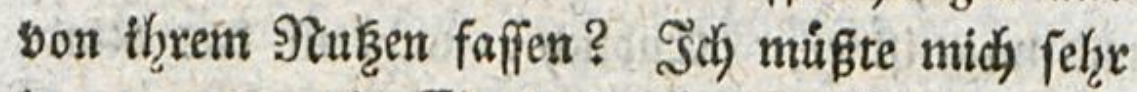
irren, wenn ein Einziges wåre, falls es nicht fhon verberbt ift, bas auf ein foldyes \$erfalis ren fid, nidst gábe, uns bas inštinftige ficjs je

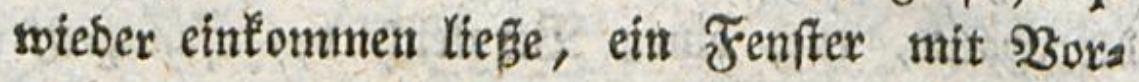

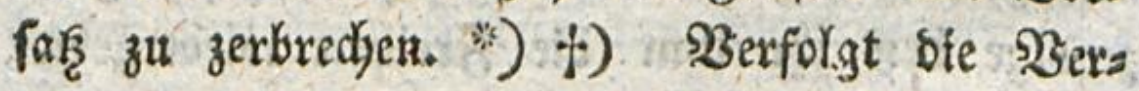

Éts

-) Ia twenn die Sinber nicht fo reichtinnig und vers gefilich wáren, uno von ber luft nicht fo getvaltiam Dingeriffen wurben! $\Re_{0}$ miffet bisweilen feinen ฐoeen 


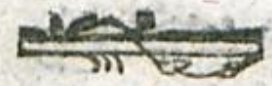

Eeftung vott alle Diefent. Der Heinte Mutha will bachte nidjt, ba er ein Soch madjte, feine Boly

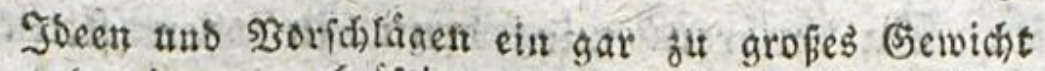
atno eine fu fraftige uns unfeklbare Sirffams Feit bei.

Jjer tibertreibt er auf ber einten unb ein paar Slâtter weiter gerabe auf oer entgegengeiekzten Eeite. Doch ich bin alferdings felbjt úberjeugt, buß bet mand)en bon ber SRatuc etwas eruftbaften uns verminftig uno gleidfitimmig erzogenen finbern eine. einzige folche Jjandlung einen folchen Ertolg auf ibe ganzes Leben baben fann, 2ludi billige uno ems pfeble id bie fier voracichlagene Niethode im Ees gentakze des btoken leibigen Moratiürens, welches bei iuncen findern zumal fo fruthtios ift, von gans zem şerset.

গ. fagt Stuve. Riefents.

Dins right eigentlich mir, dap ein fo belebrtes

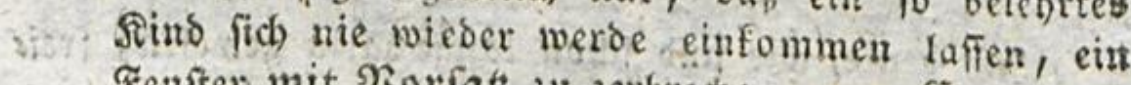
21: Genfer mit Sorfats zu zerbrecten: Eampe.

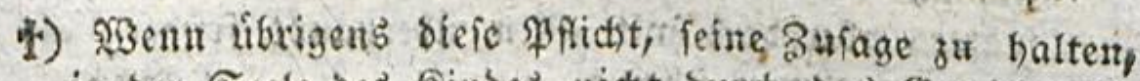
in ber Seele des Sinbes uicht Surch bas Bewicht ihs res Nukens befeftigt feyn follte; fo warbe die innere Empfinbung, bie mun bervorzubrecheit anfängt, fie ifim

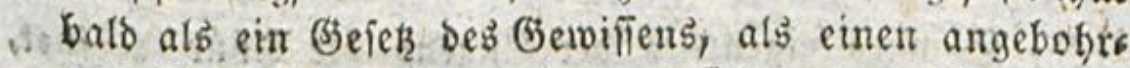

7. nen Strundjak auflegen, ber un fich zu entivicfeln, nur Die Renntnifie erwartet, anf bie or fich Ptukt. Diefer erife 3 ung ftammt nicht aus ber Sand Des Mienfchen ber, fonbern ber thrbeber aller B̈erechtigfeit hat ifut unfern, serzen eingeprágt. Nan nefue das utr

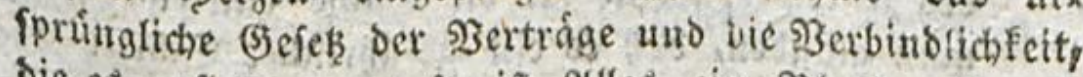
bie es autfegt, weg; fo ift 2tles cin ßiendwert uno

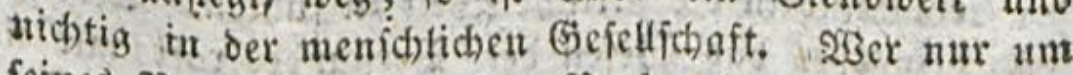
feines Sortbeils willen fein geripredgen bâtt, ift we Buif Ifter $\$$,

Do nits 


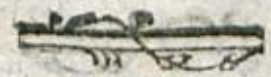

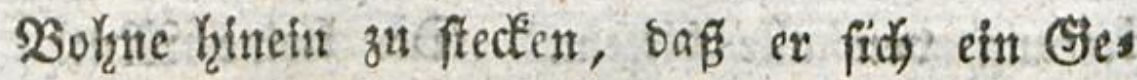

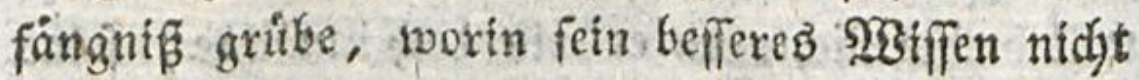
fämen wirbe, ithn zu fperren.

Da waren wir benn in ber fittlicher FSelt; *) nun iff bem Lafter bie Thúre ges

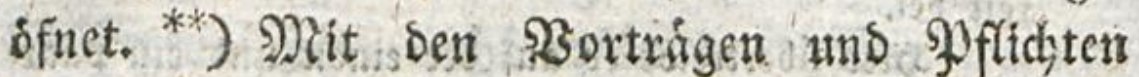

ents

mig mebr gebutiden, als went er tichts beriprochen batte: oier bochftens wirb es intt ber glacht es zu brechen, wie in salfipiele mit ber sjisatue ber Epies fer fern, die nur jugern, fich berielben ju bevienen, un best afingenblid at erfeben, ba fie es mit mebs rerm Bortheile thun fornen. Diefer Brumbian if

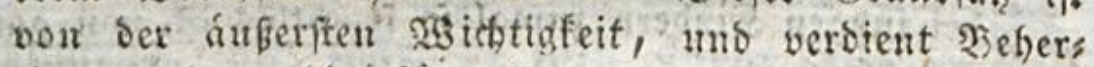
zigung; Denn biet fängt ber Nenfich an, fich mit fíb felbit in sibiberfpruch ju feken.

D. Berf.

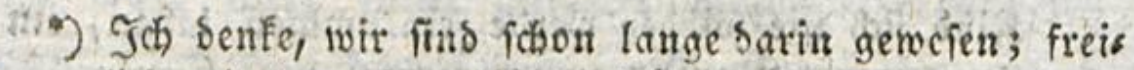
(ich mit bem einen Sinto frúber, mit bem andern fpáter, aber boch mit alfen úberbaupt frúber, als 尺. anzunebmen icheint. Srapp, 2fllerbings. Rệnikis.

a*) Ës tvird eigentlid) ber Tutgens die Thuir geifnet, romit aber naturlicher $23 e$ fife jich bie Moglidifeit

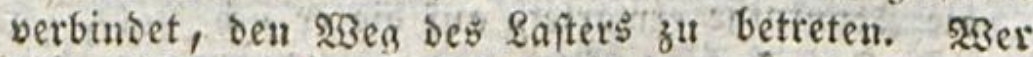
einen Segriff bom Recht befoinint, gelangt auch bermittelfi sés entgegertgeiekzten Salls zum গুegriff Des Itntechts. SBBie $\Re$. Die Sache einfleidet, follte man glauben, baß es ein gefábrticher Sd)ritt toáre, ein Rino in bie fittliche şelt zu fúf)ren. Hebrigens bringt es bas 2Bejen ber Berftandestraft mit fich,

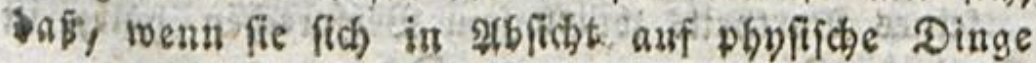




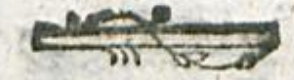

entfelfen die Betrigereien uno bie Liget. So balo man bas thun fann, was man nidst thun foll, fo will man basienige serbexgen, was man nicht hat thun follen. So bals ein Sn= tereffe etwas beriprechen läp̈t, tann cin 2 fnores gróperes uns bas \$serfprechen ibertreten laffen;

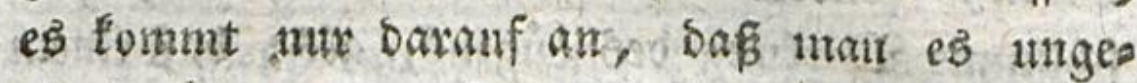
ftraft ibrertrete. Die 2Cusffurd) ift natirlich.

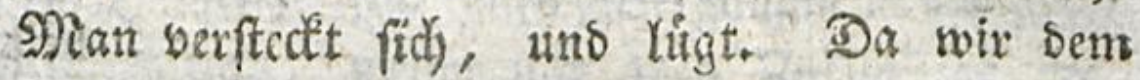
Safter nicht baben vorbengen Esnnen: fo fints wiv an foron fin bem Fint, es beftrafen za miffen; und jest beginnt bus (5Tens bes nemichs lidfen Sebens mit feinen \$erirrungen.

इ⿻) habe gemig gefagt, un zu erfennem zu geben, Dap̧ utan Den Simbern nie *) Búcty= B) 2

tis

entiviffelt, fie fids auth, loent ein Sind unter ans bern 2ienidien lebt, fogleidi in 2abficht auf fittliche Dinge mit $j u$ entwifeln anfängt. Das bringt bie Siatur jeber fich aut alnocte bejieljenbent ober vou

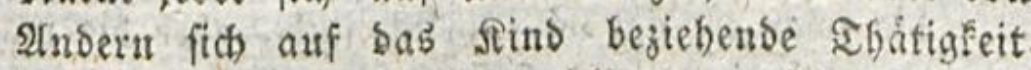
mit fich. Diefer stativeinrichtung muß ber Nenf(h) auch feinesweges fjimberniffe in ben $53 e g$, legen, fondern feine Erziehungbeintichtung mit iener Nas tureintidhtung vielmefr in Hebereinftumung bringen.

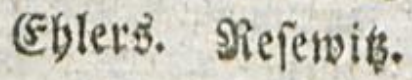

-) गtie? Sas Cinfperren in bie sunfle Soummer war boch eine folche Subtigung. Dap Sind muß nur in

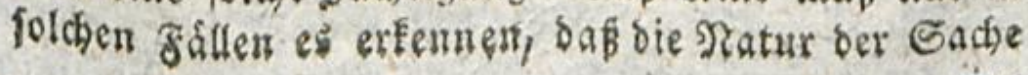

sint 
tigung alB 3 Bubtigung auflegen, fonbern fie thas nen frets als natirliche Folge three fadtinmen Sganslung wiberfähren laffen folle. So mift ihr bentr alfo auds thidgt gegen toab singen prebigett; fie nidjt gerabe seshalb frrafen, safs fie gelogen f̧aben, fondern es arfo einxidften, baf̈ jebe

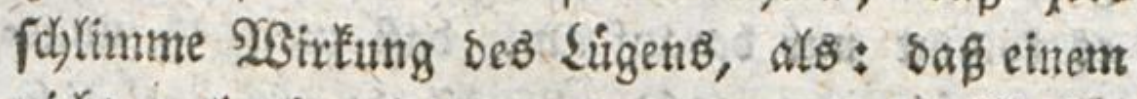
nidjt geglaubt wirs, wenn man audi sie 28 ahere beit

eine fold)e villffifrliche Suchtigung ebent fo noths wenbig madit, als eine naturliche Jolge nothwenbig

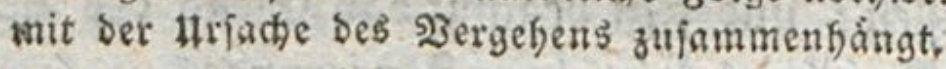

\section{(E)}

Das Einfpersen in sie finfere Sammer follte, itt Fioufieans Seift, bem Seitro niost als, eine will: fubrtiche aúchtigung, fonbern als eime nothwendige folge feiner foundung anfgelegt werden. In bem Simmer mit jenter founte man és lánger nidht Iafien, weil es oa fenfteridseiben entjweibrach; man mute ifsm alio cinen Slufenthalt anweifen, mo es nichts zu zerichlagen gab. Solde Etrafent, bie zivar an fich ivillfífrlich, find, aber bie man fo einzuleiten weiff, dafi fie in ben 2tugen des Jindes bas 2rnefhn naturficher uno nothwendiger folgen feiner frandlung erlangen, babe ich in meiner 2 fb handfung úber ß̧elofmungen und Strafen ( Reviffon. X. Ef.) vermifhte genannt. Die nas

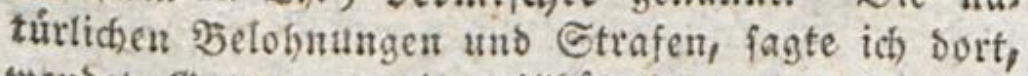
wentet, Bott au, bie willfubrtichen ber fiblechte, sie vermiichtent ber gute Erzieger. 23on biefen vers mij(bten Strafen rebet ben auch) $\Re$. Gier, ofngea(ds tet er fie natúrliche uent. Eampe. SReferwib. 


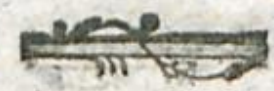

Keit fagt: baf man etwas linrechts gethan zu fraben befduldigt wirb, waB man nidjt gethan What, ofune bafi Bertheibigung bagegen helfe: auf ithren Ropf fid, härfen, wenn fie gelogett

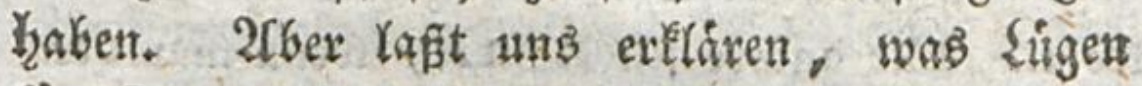
fir Rinder ift.

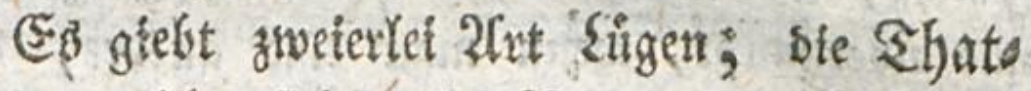
Yige, meldge fich aufo 23 ergangne, und bie Rect)tslitge, meldje fidi aufo Buténftige bes ริfeht. *) Die exfte finbet ftatt, wenn man ges

$$
\text { Do } 3
$$

than

\% Eine Einthelfung, bie nidf gemtg in bet Notue ber Gane gegrandet if, went man ben Ginn ans simmt, ben $\Re$. Damit verbinbet. $23 \mathrm{em}$ man fagt, baf man etioas thun trolle, was man nicht thur wits, ober with: fo ift bas auth cine fich auf Thun und Nichtthun befiehende Qúge. SBollte man biefe: Súge aber vor Serfentgen, bie das bergangene Ehur ober Nichtthut betrift, burd cine befonbere Szes nenung unterideiben: fo batte man fie eine গJors Patzlige zu nennen. Eime Techtshlige wáre aber,

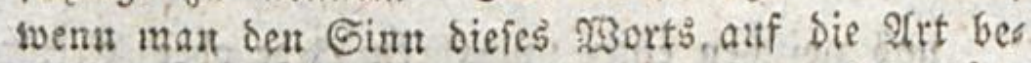
ftimmen wolte, wie er bei bem 230 ort Shathige beftimmt wirb, eine Piebe, in welcher man bas fúr Recht elflárte, toas man bod fiir unrecht hielte, uno

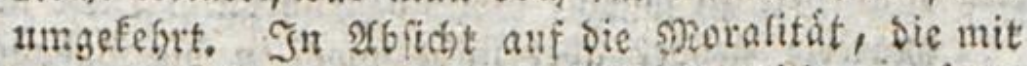
ciner, berGache, bnoon bie Siebe ift, nid)t gemápent

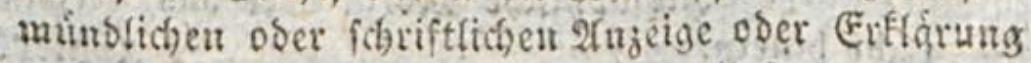
perbution ift, gatte man viefmegr tirjache bent tins

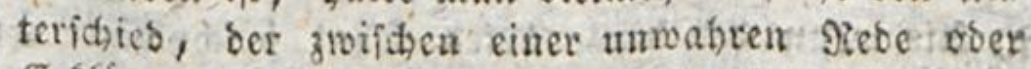
Exffarung, baburd) man f(habet uns wobei man

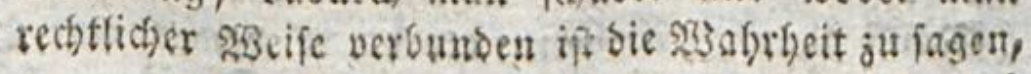

แนกิ 
than za Kaben Yengnet, was mutt getb̧an f̧at; ober wenn man bef̧auptet, gethan zu habeh, was man nidfit gethan b̧at; uno úberf̧aupt, went man wiffentlidy twiber bie $2 B$ ahrheit ber Sarjent rebet. Die anoere finoel fatt, wenn man bexs fpridjt, was man nidyt 23 illens ift zu halten; Ind Hberliaupt, wenn man eine anbere, bers jenigen 20ficjt, oie man hat, entgegengerécte 20bidgt aufgert. Diefe beiben 2rten bon Lis get fomnet zumeilen in Sinter zufammen foms. nten: $\nsucc$ ) aber idj. Betradjte fie hier son Seiten sebjenigen, tras fie Unterfchiebenes Kaben.

Dexjenige, welcher Eein $B$ eburfnif zu bem soeiftande 2nderer empfindet, nie etwas als Betweife iffres 980 hylwollens exfafhrt, hat fein sntereffe fie zit bintergeken; vielmefir bat ex ein auffallentos, fie sie Sachen po jehien zu laffen,

wie

and zivifhen einer untwabren Rebe ober ErElárung Statt findet, wosurch mant nidit fchabet, uno wos bei man nicht rechtlicher siseife verpflichtet ift bie $523 a b r$ heit zu fagen, hier anjuffihren. Diefe ganze Raterie gebort aber nicht fowor in bie Yabagogif, als in bie philofophifoche storal ober bas Gervifiens" recht hinein.

Eblers.

7) 213 wemt ber einer bifent Shat befchulbigte Strafs bare fich sawiber vertheibiget, who fieh eimen efrlichen sionn uetrnt. 2itsbaun begelit ex beibes eine Shats o.und cine Rechtstige.

D. : Berfaffer. 


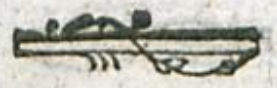

wie fie find; bamit fie fich nidgt zu feinem

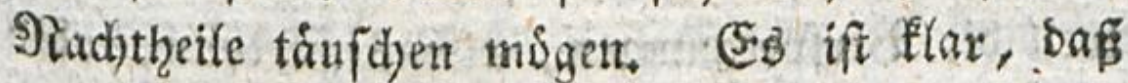
bie Thatluge ben Rinoern nid)t natirlich ift; fonbern nur bas Siefes bes Sehorfants bie

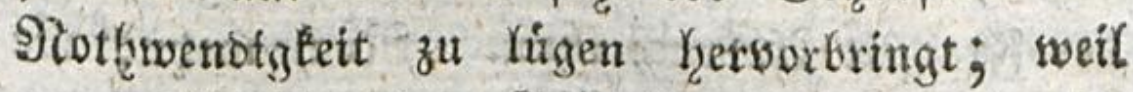
man fid, foa sber Gehorfan befawerlich ift, gern inşgeḩeim fo feftr babon frei madis, als man łann, uno bas̉ gegenwairtige Sntereffe, bie 3uichtigung ober ben Berweis zu bermietben, uber bub entfernte, bie Makhrheit zu Belennen, bie Sberhano bef̧alt. SEarum follte benn, in ber

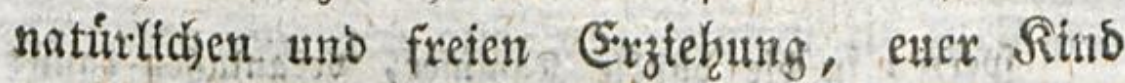

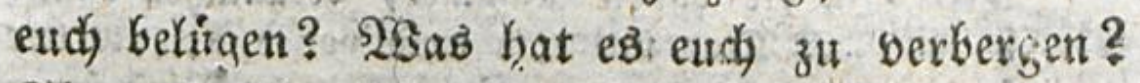
Shtr gebt ifgm feine Berweife; ihr firaft es wes gen nichts, ihe forbert nidgts bon them. S2Bars

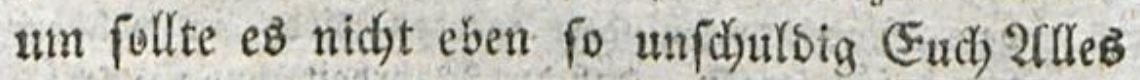
fagen, was, 83 gethan hat, als feinem fleinen Girpielen? Es Eann bet einem foldyen Geftäns. niffe nidyt mehr Gefalgr auf ber einen Seite fehen, alb auf iet anbern.**)

$$
\text { Do } 4
$$

Die

2) Ich Blaube bod)! Denu man mag ben vermifchten Etrafen noch io jefr bas enjefm ber naturlichen zu geben futchen, fo wirb boch sas find uniern sistlen Sabei hervoridfinmern feben, weil, wesn wir nidft toáren, biefe Gtrafen aud nicht fevn wurben. 5 Beir

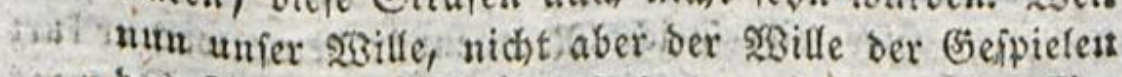

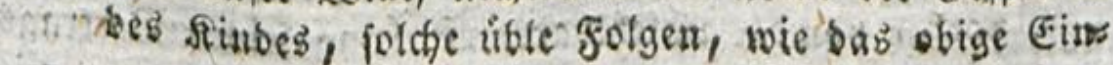
\{per: 


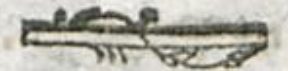

Die Redotblüge ifft nod wettiget ntaturltdj; sweil bie Serfpreffungen, etwab: zu thun, ober

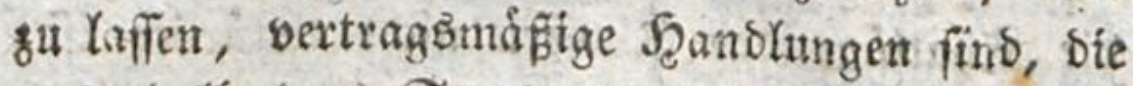
auferhalg bem Stande der Natur liegen, uns

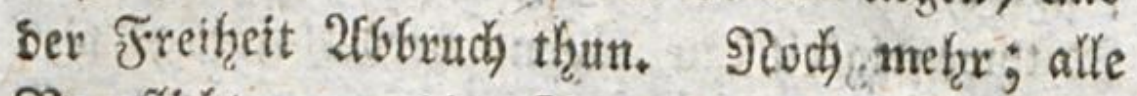
SBerpflithtungen, bie Rinter auf fid nefgmen Iormten, fino an fich nidftig; fintemal, is a thre

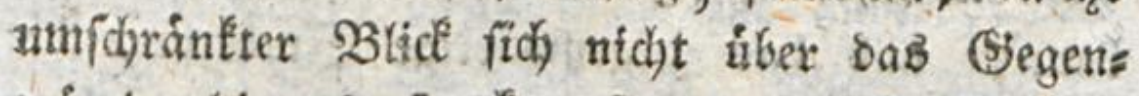
sodrtige binauberftreclt, fie, wemt fie fich bers Pflidhten, nidst wiffen, *) was fie tḩun. Riaun tann

fperren in bie binfle sammer, verantafien fantus fo wirb bas Sint fici soch urche vor umb, als vor

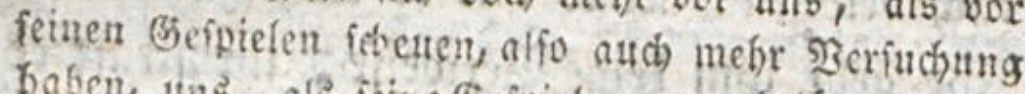
baben, uns, als letue Geipiclen, zu belugent. Ins

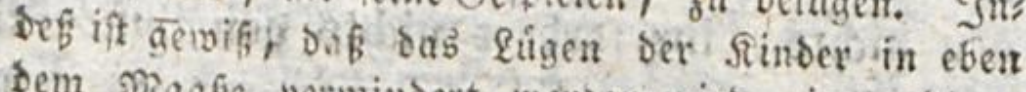
bem Naafic vexmindert werten mirb, in welebem wir bafur forgen, bas die $\$ 3$ abrbeit thm nie ichibs Yid), die Saise nie vorthetthaft werbe. Dab enftere gefchieft, went ntan cin Sint, bas feinen Feflet freimuthia geiteht, ne jur Etrafe jiebt; oob andere, Jve:n ma das. finb immer im 2luge bebált, um es auf icter Linge, bie eb wagt, fogleich su entapwer,

TH. und es dann, nab bem obigen Rathe, als eintu

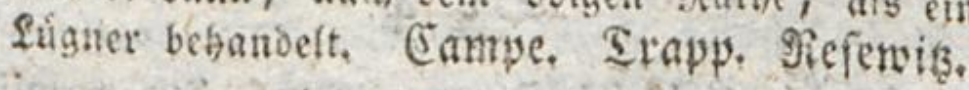

y Sic fonten bas jooh willer, ivenn bas, bavon bie Rebe it, in ibre Erfenntnifipgore und in ibre युirfungsiptore fineingefbrt.

Ebler's. Tlapp. Siefemit.

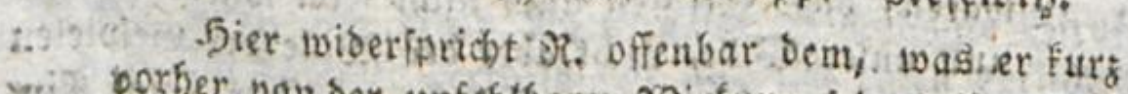

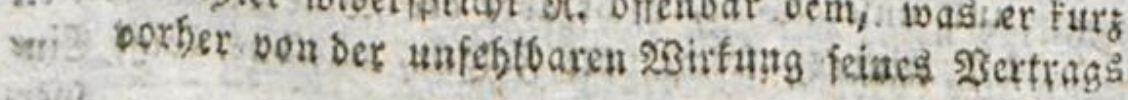




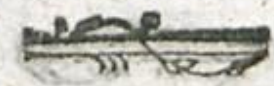

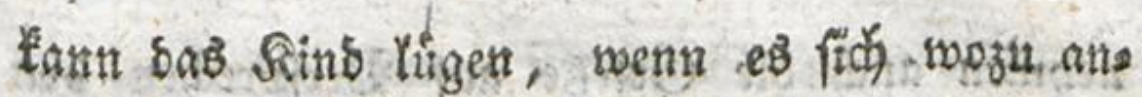
beifditg madjt; eb fucht fich mur in bem ges

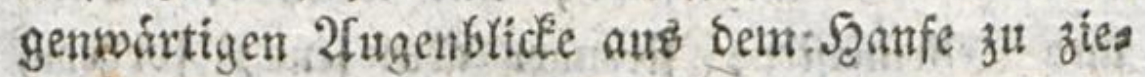
Yzen, und jeses Mtittel, bas nidyt eine unmite telbar gegenwartige tible s3irfung hat, gilt thm folglidg gleich: verfpricht es etmas fúr eine túnfs tige 3eit, fo verfpridyt es nidats; uns feine

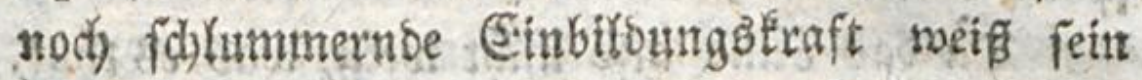

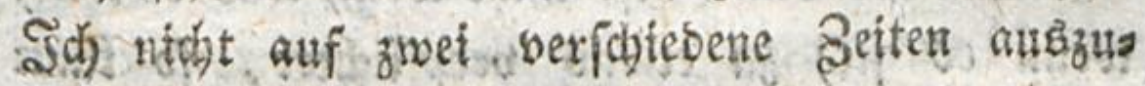
Dehnen, ") Sismute es ber Ruthe entgehen, ober

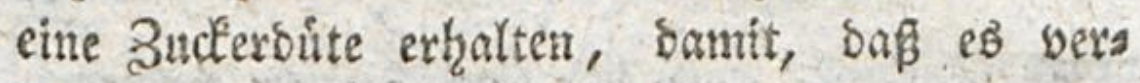
fpractje, morgen cuts bem Ġenfter zu fpringen, fo wurbe es ben 2 rugenblide mit feinem şers

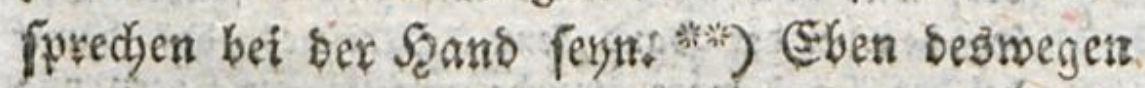

$$
\text { (D) } 5 \text { netro }
$$

mit bem Sinbe, wetches sie Jenfter einwarf, bes hauplete. Stuve. Repervifg.

-) Der Erfenntuifsuftand cires findes ift weito volfs fommute, als ifin $\Re$, bier vorfetht. Seber, ber is fidi biel mit sinbern beidsdftigt, ober fellot viele Sirtber ergogen bat, weip es genttg, dafi fie fehre frib bie varfhtedenen 3etten fu untericheiben uno

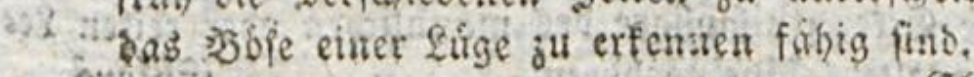

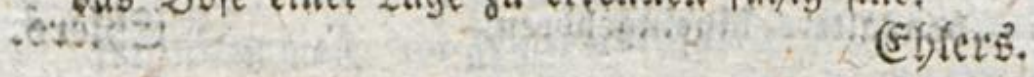

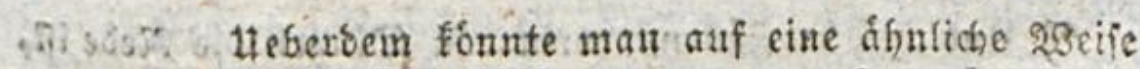

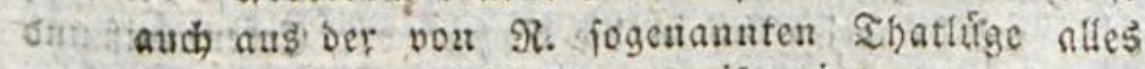

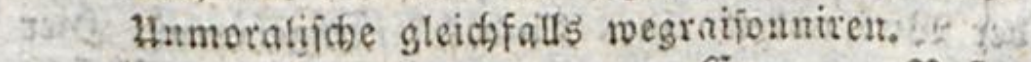

Campe. Drefersik.

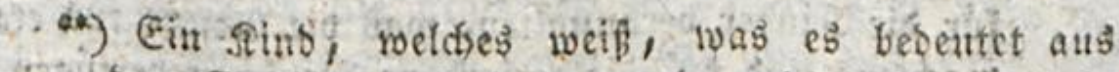

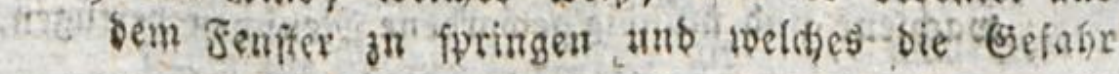

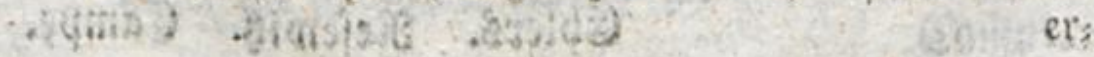




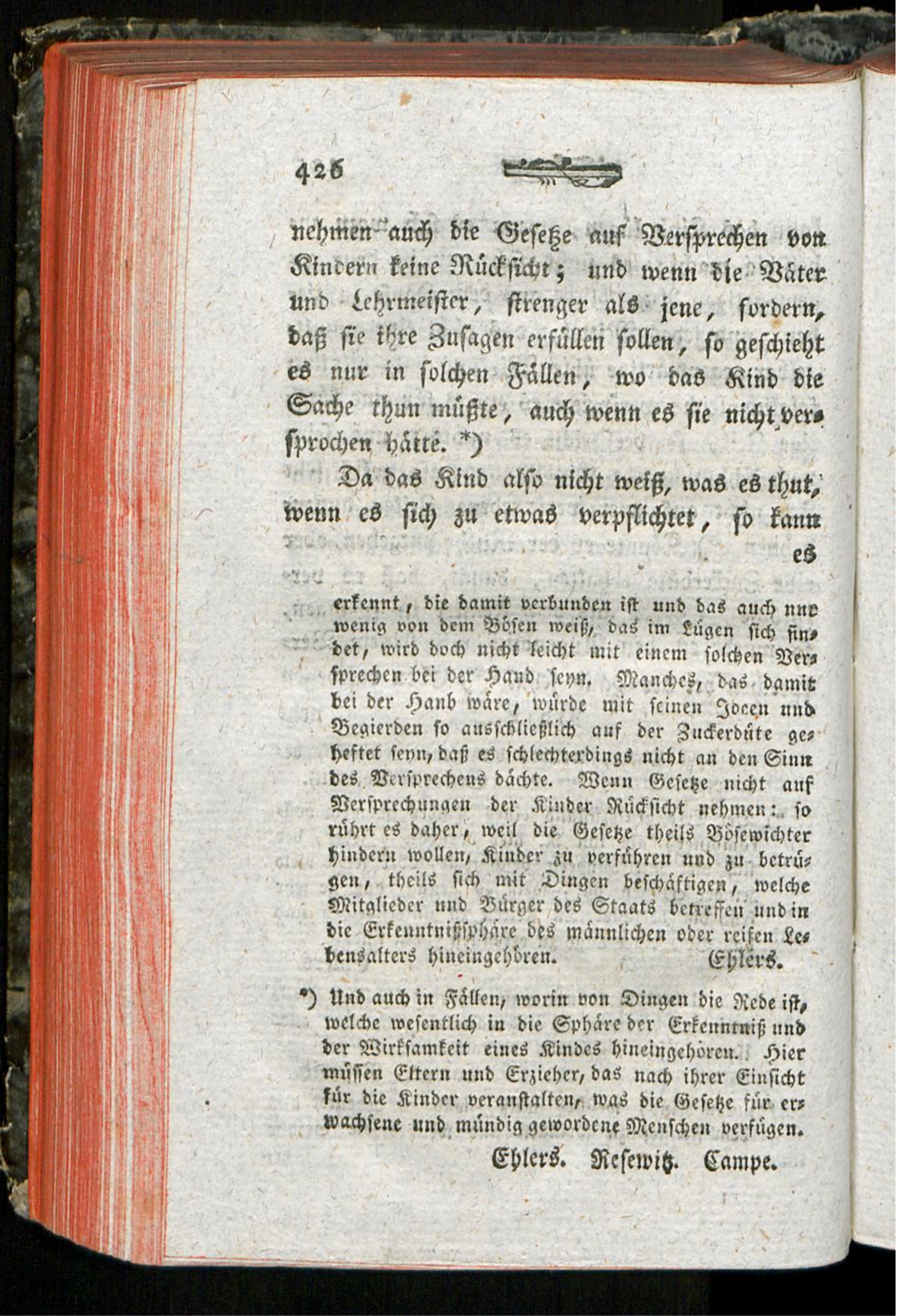




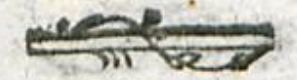

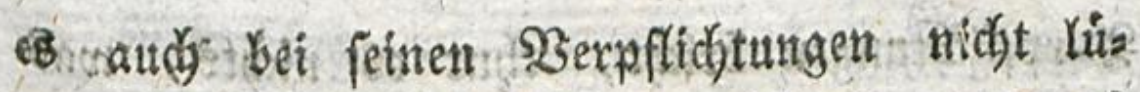
gen. *) Sidyn etwas 24riber ift. es, wenn eb feite :3erfprechen nicht hailt, weldjes nody eine $\mathfrak{t r}_{\nu}$ 2trt bon zuxicelwirfender Lige ift; benn es ers ite

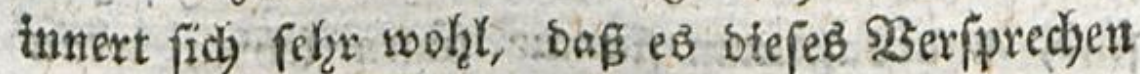

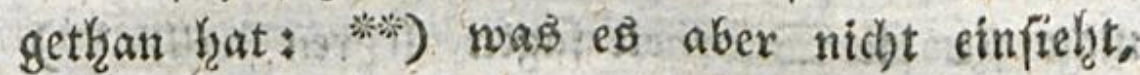

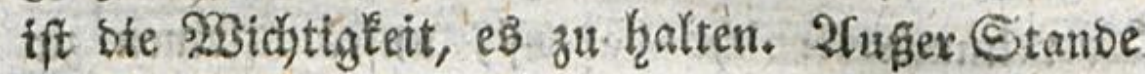
in bas Sinnftige zu bliden; Fann es bie Folgen ber Dinge nicht sorkerfehen; uno roenn es feine

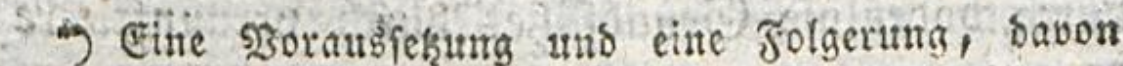

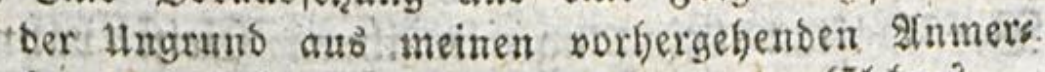
Eurigen ergellt.

(Eb)ler's.

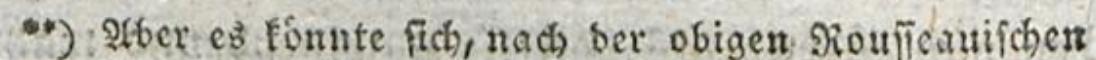
Entichutbignng Damit rechtfertigen, Daß es in sem Ifugenblicte, ba es verfprach, nicht twufte, was eb that, weil es nicht vermogens fen, in bie sufunft

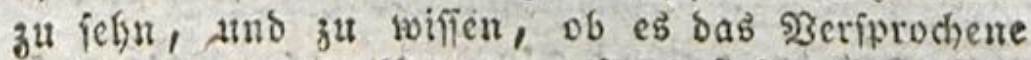
audh lwerbe leiften fortnen. Mian fieft nber leidht ein, baf diefe ganze Eheorie von ben Kuigen ber Sinter feineti (5)turo bat. Simber fonnen in ber That fo gut ligen, als erwadiene Nienichen: fie

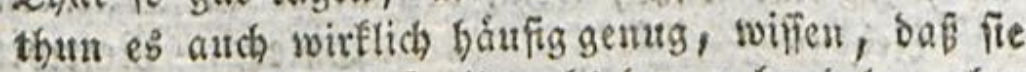
es thum, und saf fie lluredit Daran hanbeln: aber freilich if siefer ihr zebler allemal bie folge einer fehs lerbaften Erzichung. F̧enn Der Ergieber uno alle, bie mit bem Sinte unseb)n, aufmerffam uns vers ftánbig gesutg fints, um $c$ b sabin zu bringen, bafi es you bem frigen nie Bortheil, von ber şabrheit binnegen nie Sachtheil habe: fo fált alle פ̧ers fuchung jut biefem fafter weg, und bas Jimb wits tisber bie sisabrheit reben, atb thigen wollen.

Eampe. 


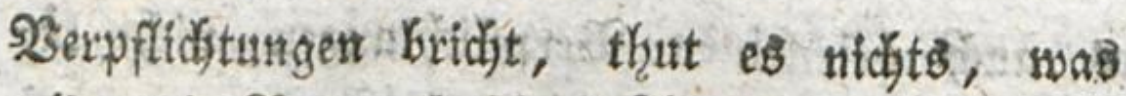
wiber die Bertunft fitnes 2lters nóre. *)

(E) folgt Saraus, saf oie Sigen ber Rits

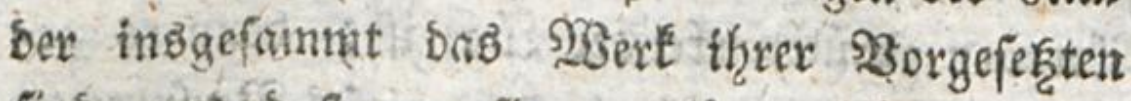
fitto, uno bof utan fie nux Keigen Yefyrt, went stan fie bie 233 ibrfecit fagen lef̧ren will. *\%*) 2lber inmè érpidgt batauf, unfre Siteinen zu Yenten, zit regieren, fie zu unterridjten, wiffen wir nie goittel genug git finben, un mit unferm 23erte zu Stanbe zu tommen. Man will fich burd) bobenlore (Sirunofäge, surdy bermunftleere Sorfdriften Sinzang in thren Eeift bahnen, und fieht lieber, baf fie thre Cectionen inne bras ben uno liggen, als baf fie unwiffend uno swabzt bleiben, 3\%*\%)

23it

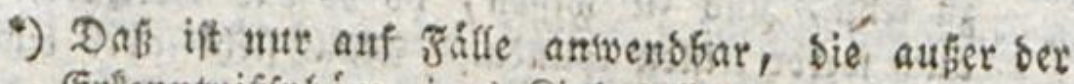
Erfenntuiffpháre cines Nitibes liegen.

(5-blerv. Nieferuiţ.

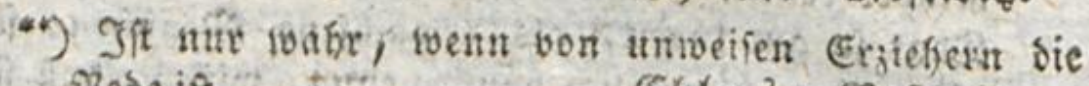
Webeift. treflers. SReferwik.

*) Eine écen ro harte, als intrichtige beutthcilung befs fen, wab unter etwas verninftigen ferten im \$unct bet Erjiebung gefdiebt, Foulleaul geht es bet feis neir Itrtheiten tiber die Ergieburg eben 10, wie es Mauchen Noraliften und Re!gioustebrern gebt, bie

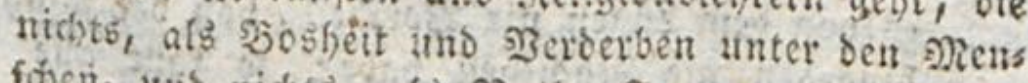
fáen, uib nichts, als Noth), Jammer uno Eleno auf biefer Eroc fitton.

(E) let?. 


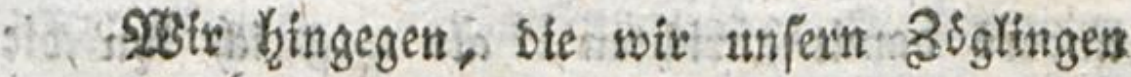

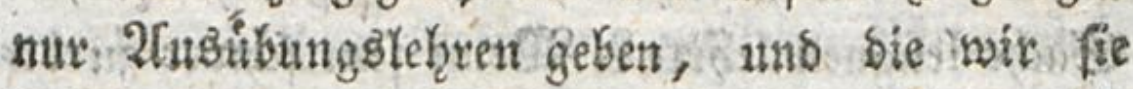
lieber gut, alo bieltwifiens baben mollen, wir forbern bon ihnen bie SBaknrkett \%) nidjt; Desin wir firrchten ans, fie mógten fie berthets

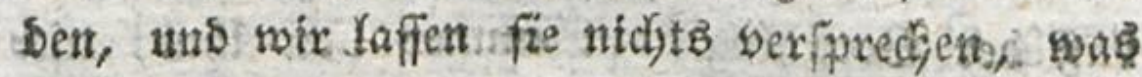

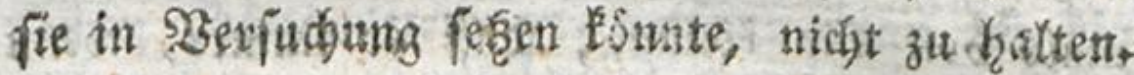

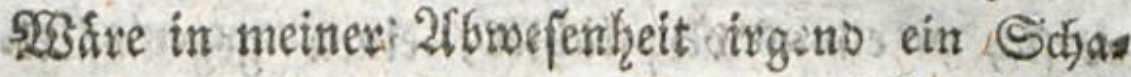
be borgefallen, wobon ich ben Ifbiter nidjs soiffe, fo werbe idy mich wol byiten, Emilent

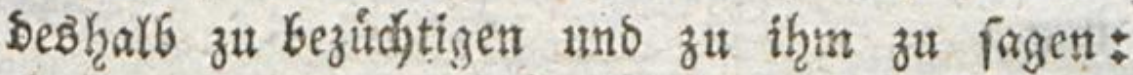
Scaft dit es gethan? 4) Dern was wirte ich

an?

Sube巨 muß man boch wol cingeftehn, bas sas,

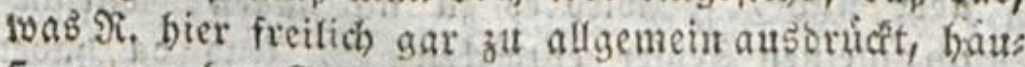
fig genug ber fall fer), um berectifiget zu (ev) , ftatt fidledte (Erzieber das affomeinere man zu jebert.

Eampe. Srapp.

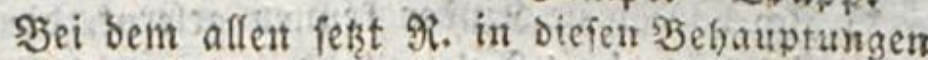
won ber sichtigfeit ber \$serprechungen eines Sims Des wentiger Moralitat uno Bermunitfraft voraus, als wirffich bet ifm zu firten ift. Der Sirthum,

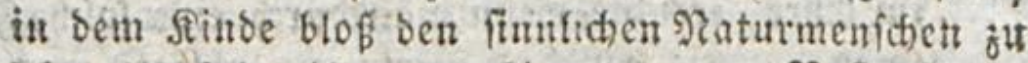
feben verfolgt ihn autch fier. Neferwt3.

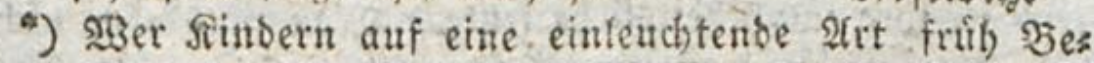
griffe von der $\$ 3$ abrbeit ant ifrem 23 erth beiftingt, weranlapt fie frib die $93 a b$ theit lieb za getwintuen unb fid vor litgen zu butten. Eblet:?

Dab beftátigen meine Erfaḩrungetr. SReferviş.

(2) Nicits fann unbejonnener jeyn, als po cine Frage:

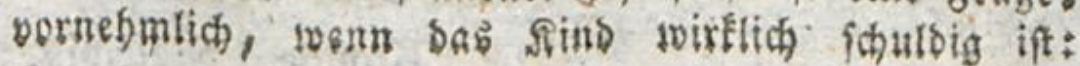

bens 
anbers bamit antibten, als bag if ifn sie Gadje Yenguent leb̧rte? $23 e n n$ fein folnwer zu bes fanbeltioer Eharacter midj, nithight, irgens einen 23ertrag nit ifh binzugehen, fo werbe id

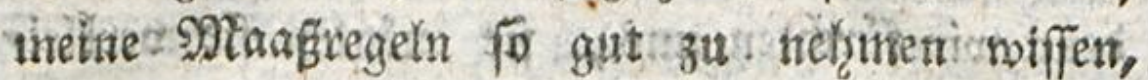

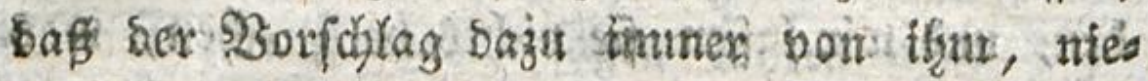
mals bou sir tontuc; oaff or iminet, wem

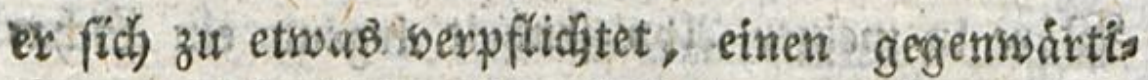
geri und finultaten Boutheir babe, feine SBev

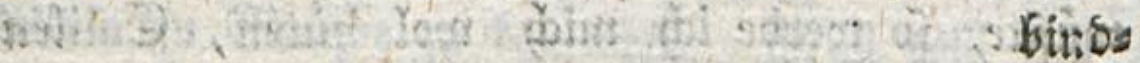

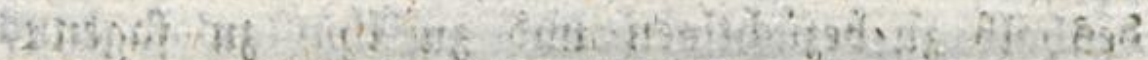

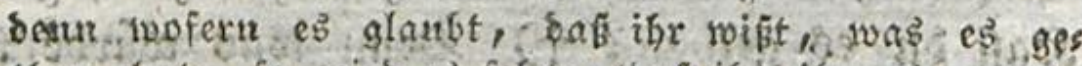
than hat, to wirs es pelen, dak ifh ifin ene falle

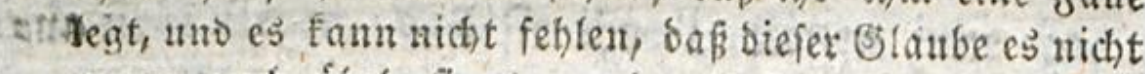
gegen euch díclgefinnt, machent follte. fregt es inn - aber nicht, fo wirt es gu pith lagen: loarum follte ich meinen febter entbecten? *) Into ba foten wir Deun bie erfte şerfuching zur Quge, bie sistifung etter unvernunftigen frage ift.

3). Berf.

-) Sch babe viele Sintor Fenten geternt, bie fibon feft genug in iffer 2tuthänglicheit an 28 abrheit waren, bak fie anf eine folche frage nie unwaby antwortes terr, uno bie es aud begriffen, wie fehr es ifnen zur (5hre gereichte, weitn man burch eine folche Frage einen Jెeweis von dem Sertraten ablegte, bas man in ifre $23 a f r b e i t s l i c b e$ ferte. Nan muß aber nicht of ne Sorficht mit einer folchen Frage fich an ein Sims riditen.

(E)blers.. Refents.

Das Rind mus nut wiffen, dẩ es für ein wahs rés Geftantonis nie geftraft werbe: fo twirb es lieber sie stabrbeit, alถ eine \&ige fagen wollen.

Sampe. Яiefenis. 


\section{1}

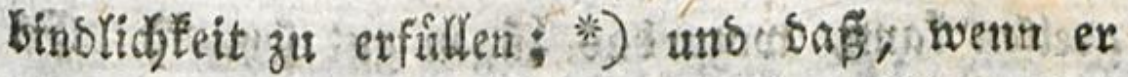

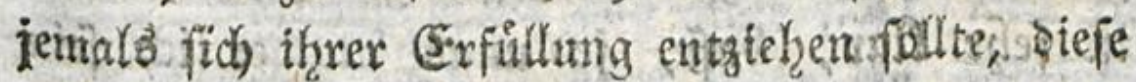

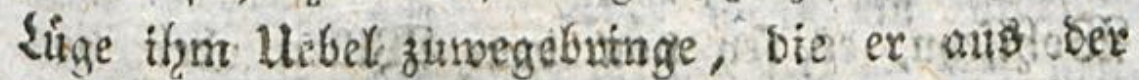
Dronung Dex Denge felbfir und nitht ans ber

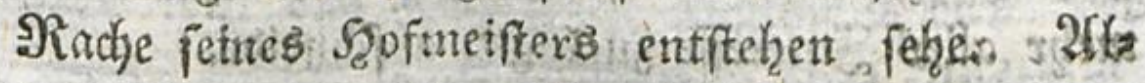
Yein idy merbe nidjt nothig haben, zu fo grauls famen Shilfs̈mittelit zu greifen; Denn id bin beinatge genoif verfichert, bas. Emil peht lpat, was ligen heist, lernen, imb, wenn et es einjt

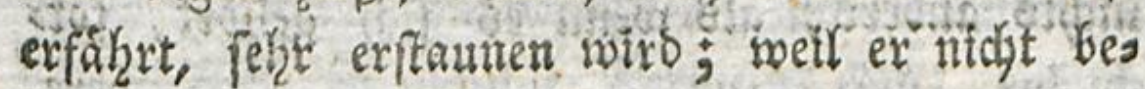
grei=

") Dieje Erziefungseinriktung mur ia nicht datrge bauern. Dzan siebt foñft ats einem folchen Sinbe

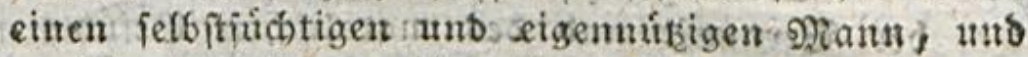
was nod folimmer ift, einen Mann, ber in bell fâlfen, woriu bie গুofolgung Der Rechtb̉grunbighţe

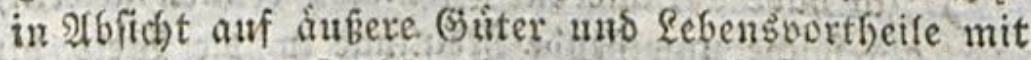
Siachtheil uns Selfitwerleagnutug verfmipft ift, uno soorin man bei ber stbweichung von ienen os mubiás ben lict) ánfern Hebeln uno Gtrafen auf rigend eine

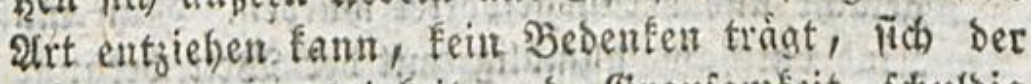
gropiten Ingerechtigfeit uns Grauianfeit idulbig

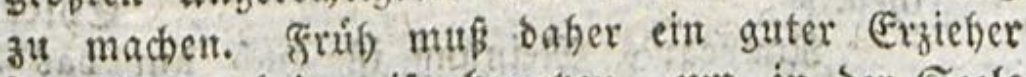
jede Selegentheit weife benuken, un in ber Seele

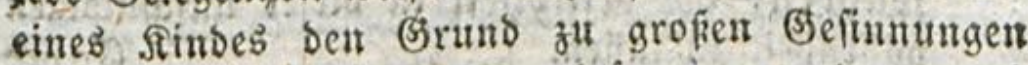
unb zu ciner edelu Gelbpperletignung ơ legen und

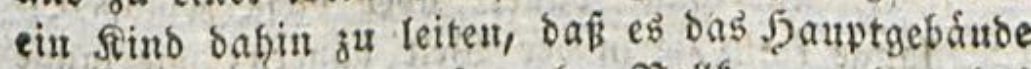
feiner strucfeligleit auf wahre Sollfommenteit bes Beiftes uno bes Characters und auf bas Sbelvufts fenn ciner weifen Dronung in feiner ganzen wirfs famen शatur in 2 (bfich)t auf vortreplicbe \$lótigfeit, Ber 


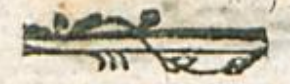

Dere. 2Ulsoann bilbet bas Rind fich; weil es ridyt berberbt wirs. 2(G6er menn eill unbefons nener Eehrer, ber nitht weiff, wie er fich nefy= men foll, bas Rind jeben 2lugenblide sies ober jenes, ohne Unterforibung, ofne Yuswafsl,

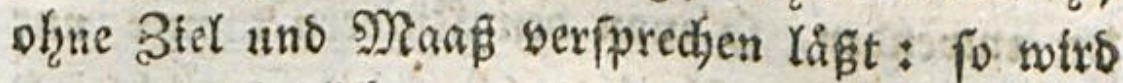
es, berorieflidy gemadt und tnit allen biejen Dexprect)ungen ib berlaben, *) fie bernach)(affigen, threr vergeffen, fie beradten; uno ba fie thm sum nidyts als nidhtige Formetn fins, enoltés es als ein Spiel anfeken, Sextgeifungen zu

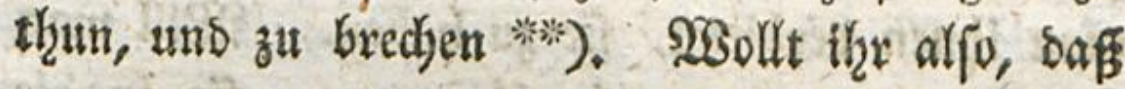

\section{es}

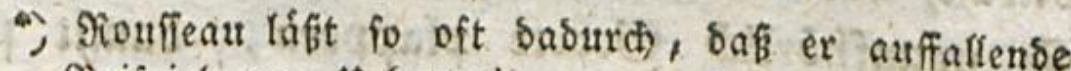
Эeifpicle von Hebertreibungen unb von einer boblt

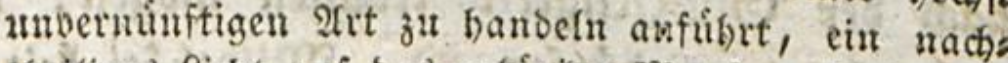
theiliges lid)t auf $\delta$ as geforige Maan, auf die Nits telftraße und auf wirflich gute und weife Einridtutuns gen fallen. Das gefdieft auth bier. Eblers.

Diejer Misbrauth Gebt ben Eebrauch nidht auf.

Fieferwis.

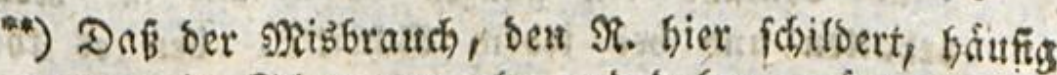
gentg im Schwange gebe, und Dafer gerúgt zu wers

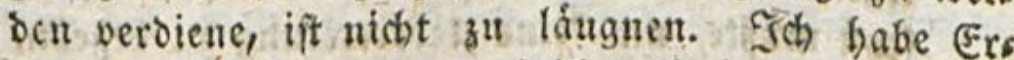
zieber gefaunt, und hivar folche, bie in mancher an

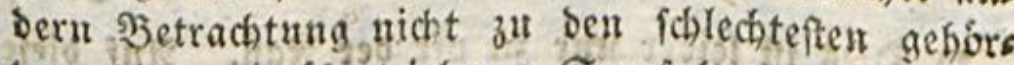
ten, bie aus ubertriebener Sorgfalt into aus Jुes gierde fo frúb als mónlich etivas recht Tollfommes nes aus ibrem zoglinge zu machen, jebe feiner J̧andingen, aud bie unbebeutenbfen und gleids. Emil Ipter $\cong$ b.

(F) gifls 


\section{4}

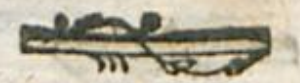

es feinem 5 Borte trea fey, fo pers sorfiditig in Forbern.

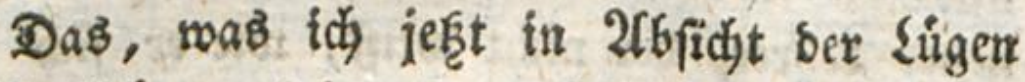

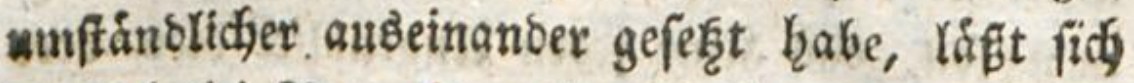
in vielertei Betracht audy auf alle andere \$oflidys ten anwenben, fo man ben Rinbern immer nur auf eine 2frt borfdjeibt, bie fie ihnen nidjt ato lein verthafit, fonbern aud, unerfúllbar madjt. Damit man bas 2 ñethen habe, ifhnen siẹ Zus geno zu presigen, läft man fie alle Eafter liebs geninnen: man bringt fie thenen bei, inbem man ihnen berbietet, fie zu habeu. SISill man fie fromm machen: fo füfyrt man fie in bie Rirche, bort Langerveile ou fómedten; man läpt fie unaufberbrlich Sebete plappern, bamit fie

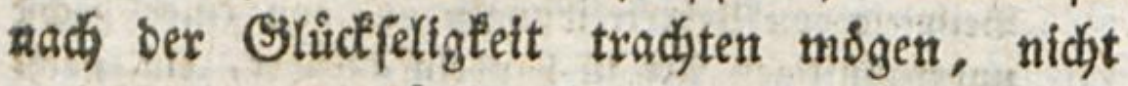
meḩr beten zu búrfen. ") Matlothåtigteit tha.

nett

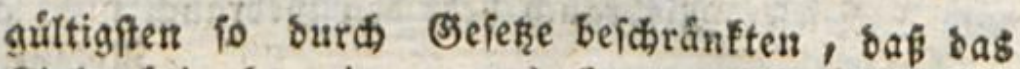
Sind beinabe ein gamzes Corpus iuris in Sopfe behalten unb bei jebem Schritte, ben es that, irgenb eines barin enthaltenen (Befeţes fid) betwulst fenk muste, um feine llebertretung zu begehn.

Eampe.

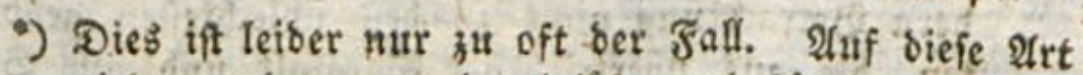
miro mancher ganz irreligibjer und bófer Nentich in ber Stirche ind in ber פbetfammer vorbereitet. Eirz

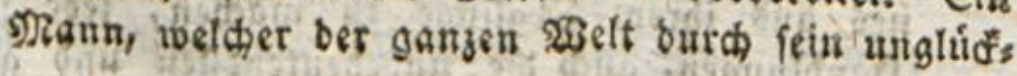

lichet 


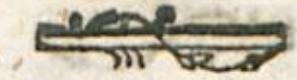

nen einzufloffen, láf̧t man fie 2ltmofen geben, als bielte man ess unter feiner 23 itrbe, bies felbft zut thum. Ei! nidjt bas Rino mus 21: mufen geben, fonbern ber \{efrer! So lieb ex fets nen 3̊gling hat, mus er bodi biefe E.hre thm freitig madjen; muf ikn urtheilen laffen, saf man in feinem 2fter ihrer noch nidjt wurbig Fey. *) Das 2(Tmojengeben ift bie Şandlung eines Nannes, ber ben 2ßerth beffen, was ex giebt, uno bas sebuirfnif, bas fein 9iebens menidh bazu hat, Fennt. Das Rins, weldyes

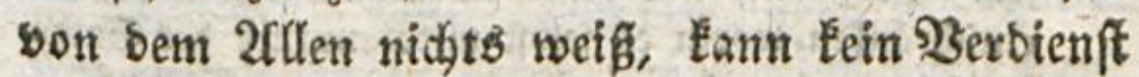
Gei bem Sjeben haben; $e^{3}$ giebt ohne Mtilbe,

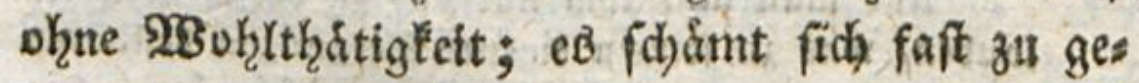
ben, wenn es auf fein uno euer seifptel fḯ)

$$
\text { (5. 2. Ptis }
$$

liches Ende befannt getoprbent ift, befannte es mir einmal, baß̉ er burch immerwábrendes Beten und Sirchengeben, troju or in feiner findheit uns Iue gent angebalten war, nach uno nad einen unúbers roindlichen 26fitheu vor ber Religion befommen báte. Eblev's. Rejenis. Eampe.

-) Unb baf man eber feine 2limoien acben fonnes bi man exf ein wohlerworbenes Eigenthum babe: Daßs bis dabin bas Sind felbft mur oon 2lmofen lebe.

Eampe.

2ufer wenn es vom $23 a t e r$ ein (Figenthum ers balten hat, dariber eb bifponiren fann.

nefernis. 


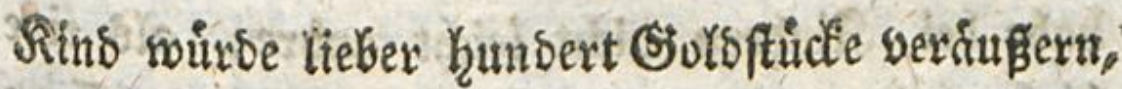
als Cinen Sucken. 2lber haltet einmal piefen Heinen bexfdywenderijajen 2fustheifer an, Sa dyen wegzugeben, die thm Yieb fins, Spielzeng, STafdyert, fein SBepperbros, uno wir werben bald folyen, ob ifge then wahrehaftig freigebig gea madjt halbt.

2tuch nod auf eine anbere 2 trt glaubs man. biefen Enozmed zu erreichen; námlidy, indem man dein Rinde fefrt gefd wins wiebergiebt, was eả weggegeben hat. Daburch indeff gensifnt es

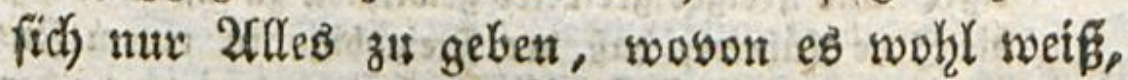

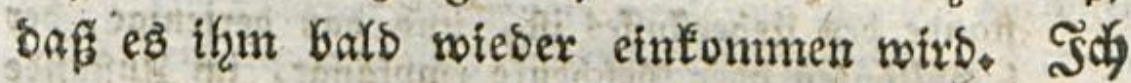
(E. 3 habe

ant ber Erfahtung, bẩ ifnen siefe Dinge and baun im Heberflus gereicht werben, wann fie ifor eis genes Dafchengelb reggegeben baben. Heberbem bat $\Re$. Gier vermuthlich ganz junge Sinder in Einn.

Campe.

Ittho eb giebt auch wirflich fojon grógere Sitts Ser, bie nun gerabe Diefe Flinte, ober Diefen Stod, wenigftens zur zeit ifres Enthufiasmus fưr diefe Sachen nicht weggeben wurben, uno went fie es offenbar cimföben, dapi lie fúr cine Summe die Sas (b)en breifach Faufen founten. , Seufinger.

Heberhaupt befteft aud. Sie Freigebigfeit nidht im siseggeben befien, was man leidst entbehren Eam, fondern im s)ittbeilen befien, bas ber andere

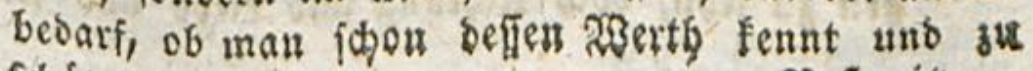
ईळáţ̧en weif.

Mejentig. 


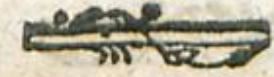

nach frèigebig, und getşig ber That nadi madjen. Ex fiugt binzu, bie Rinber witrben fo eine Fers tigkeit in ber Freigebigteit exlangen: $j a$ ! in einer

\section{(5) 4}

เols

ber liebe, 2(h)tung unb ber গुerehrung Inorer bou felbît eine Quelle mannigfaltiger áufierer (5) Liter un গ̧ortheile findet. Es erfenue alfo ein Sius am Ende, Daßj ein freigebiger ebler Maun ofne die Ers werbung auferer शुortbeile zu feituer \&bficht zu mas कen, bet Natur ber Sad)e nad) bennod ein (ebr guter Soubhalter im \$unt ber \&ebensvortbeile fer. In allem biefem finbet man bie richtigften

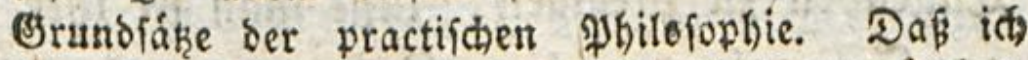
jene (\$) runbiakze aber Locien uidut blof gutmitbiger SBeife beitege, wirs Seber erfennen, ber ben 53 unb Io 6. feiner Pábagogif nid)t uur obenbin ourdhlieft, fonbern forgfáltig burchftubirt, welches leḩtere bei diefen beibent of nothwensig geichehen mur. Deun wenn man nid)t alles barin entbaltene forgfáltig mit einanber vergleidst: fo fann man leidht biec Socte mit Rouffeau farfo berfteben. Jefonders giebt bie Stelle \&utab́ baju, wo es beist, man foll jo oft bas Rind etwas weggebe, diefes mit sinfen erieben. (im englifden Driginal fitebt bier nid)t be. lobnent) San bat geglaubt, Rocte toolle, baf man jebe 5randlung ber freigebigfeit fo kelobnen foll. Pocfe will aber nuts bon Bclohnung wiffer, fons bern er will nut, bấ man unbemerfter şeije bem simbe einen reichlichen Erfats für bas, was es regs gebe, wieber zufliếen laffen folle, bamt es feime úble wirfungen des Nzangels barauf exfabre, ebt es in jener sugeno befeftigt ift, uno bamit es bet

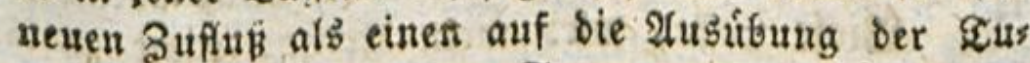
gend natúrtich folgenden Segen anfeben móge.

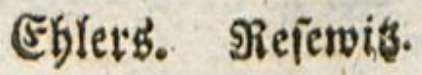




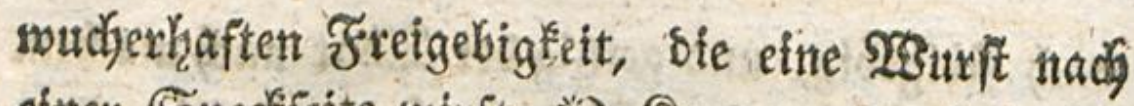
einer Spedfeite wirft. *) Siommt eB aber eins mal baranf an, im Ermfte zu geben, alsoant

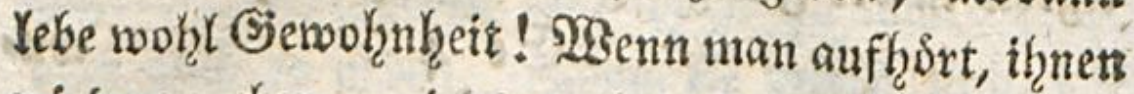
soieberzugeben, wiros auch bald mit bem Èeben

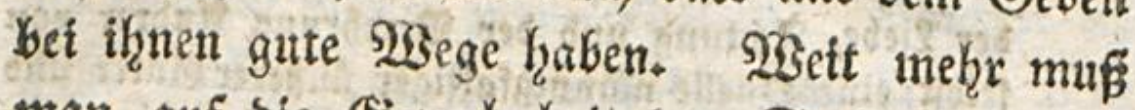
man auf bie Semohnheit ber Seele, als auf

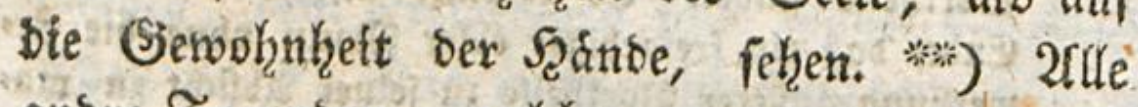
anore Ingenoen, welche man oie finver lebrt, gleidjen oiefer; und um ifonen biefe ftattlidjen Iugenden zu prebigen, lást man fie ibre juns gen Sabzre in traurigem Summer berzehren. S茯

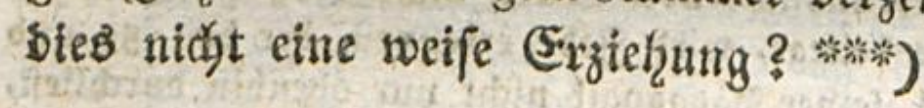

") Diefe Deutung ftimmt gar nicht zum Bseift ber for

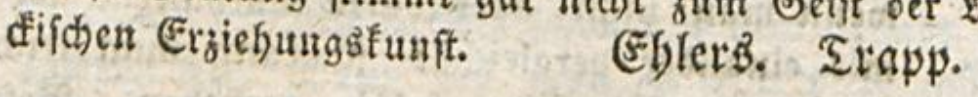

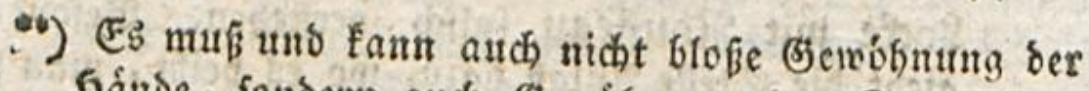
Şânde, foubern auch). (Setwobunng ber Seele fern, Sie Durch Şeifpiel, Denfungs: und Şandlungsant ber Ëttern uns Ergieber unvermerfft ber jungen Geele eingeflofit wirb.

Referwiţ.

9*0) Eine in 2 (bficht auf viele vernúnftige Eltern unó Ergieber eben fọ ungeredjter, als bittrer Tabel!

(E) lets.

206er unter bem 250 orte man brauchen wir ia nicht gerabe 2llfe zu veritefn. Daß aber ber Tabel Biele treffe, wirs mein freuns nicht zut láugnen tegebren.

crimpe.

Man 
Eeliver, meibet alle ben وprante! fens tus genohaft uno gut; eure SBeippiele múffen fich bem Sieochitnif eurer Bỏglinge eingraben, bis fie in ihre Serzen bringen tionnen. 2inftutt aljo mich zu übereilen, pon Dem meinigen Şanblungen ber Milbthátigfeit zu forbern, thue ich lieber weldye in feiner Siegentwart, unb benehime thim fo gar sas . ग) Nittel, mir barin nadjuahmen, als eine (F) fre, ste nidat fir fein 2atter gehoirt. Dent eB ift siel baran gelegen, baf́ ex fich nidjt ana

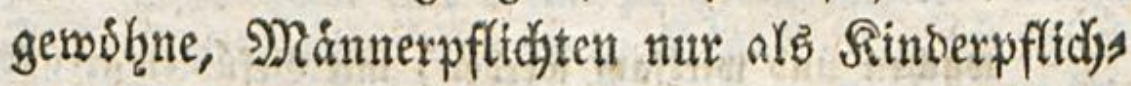
ten zu betradyten. *) ISEenn er midy 2(rmen beis (s. e 5 fies

Nan muk aber, toenn man nicht nutgerecht \{el\}n twill, 2lffen nicht 2lusf bie nut mandje ober aud \$iele treffen.

Diefervitß:

-) Ş̧ohlthun gehort wahrlich nicht blof̣ zu ben Mâus nerpflichten ober zul ben ङstúcfieligfeiten ber männlis (h) Sable.

Ëblers.

Heberbem muf man ia auch ben feim zu

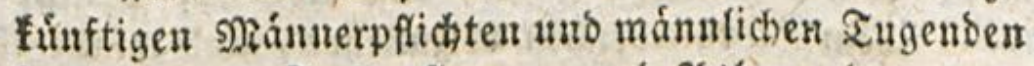
in bie junge Eeele pflanzen, unt 2Allagen $\delta a_{j} u$ rege machen, bie fich in ber Folge entwiffeln follen. $\Re$. fdeint mir liberfaupt bei Sinbern zu wenig Noras Yitát vorauzzuficknen, ober fie zu wenig bearbeiten 3u wollen; und bas mogte in ber siactabumung fowwerlich yebeihlich uno fur bie Sittlichfelt ber heranwachienden Gabre vortbeilfaft fern. Das Sino mui gegen bie seit, of feidenfhaften in ibm ers 
Itehen fiefht, nitch bariber befragt, uns es a ait ift, thim zu antworten, $\dagger$ ) fo werbe id fu thm pagen: "Niein Sofyn, ałs bie 2trmen zut geftanden b̧aben, סaß̃ es Reidje geben mógte; fo haben bie Reidyen weriprodyen alle biejenigen zu exnåbren, bie weber oon iḩrem Bermogen

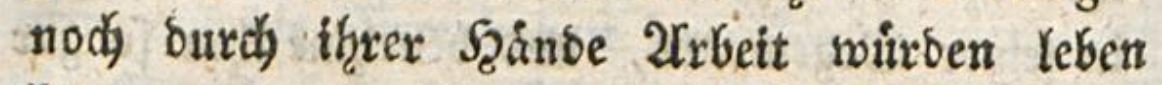
tonnen. *) - Seaft bu bent bas aud ver: fprodjen? wirb ex midy wieber fragen - : Das

wachen und wirfiam werben, mit (3) efúblen gerúftet

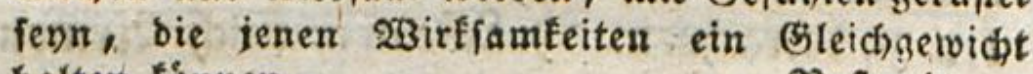
balten fónuer.

Siefenvis.

*) Man muf fid merfen, bafs id ifm auf feine Sragen ridat Şeicheib thue, wenn es ifm, fondern wenn es mir gefâllt; fonft wúrbe mich biefes feinem sBillen :uns terwerfen, uno mich in bie gefábrlichfte Abbángigfeit feß̧en, worin ein Syofmeifter gegen feinen Hnterges benen nur fteben fanu.

D. Berfaffer.

*) So wúrbe id) bod nidat antworten. Dies leitet ia bas Sind auf irrige Yorftellingen vom Entftehen

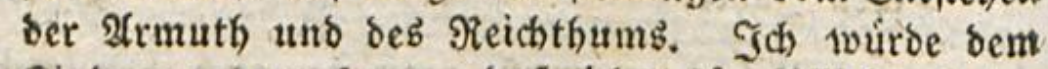

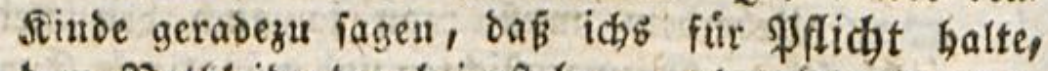
bem Niothleibenbett beizuftehen, unb wirbe ifm bex

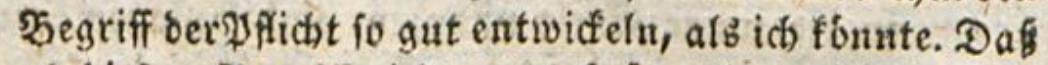
es biejen şegriff nicht gaur faft, thut nichts. SAlle

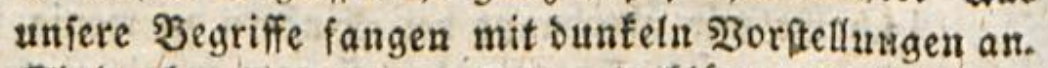
Sind aber biefe nut etit ba, fo fláren fie fich nads unb nad) auf, theits init; theils obne 3utbun bes Erjichers.

Erapp.

Diefe dimerfung ift febr gegrinbet.

Stude. Refeníg. Sampe. 


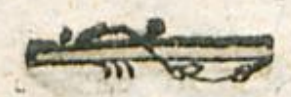

443

bexfteft fid)! Sad bin bon bem Bermogen, was burdi meine Şande gèbt, nux auf bie Sebins gung Seerr, bie mit bem (5igenthum babon vers bunien tf. " *)

(5in 2rnberer ald Emil, wirbe, went ex

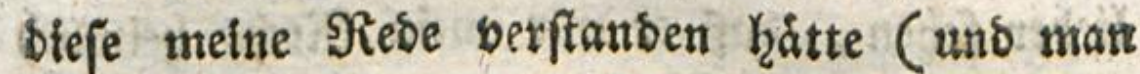
bat

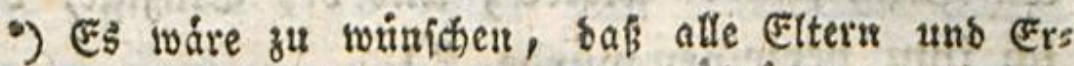
zieher ben Rinbern biefe Tbee beibråchten, und bers felben Seben uns Siraft zu geben fucken. Afleir es giebt leiber angefebene Nánuer, bie mit fleif Joeen ber Alt von ber Eeele ifrer Sinder allf ims mer entfernt zu halten fuchen. Ein Niam von biefem Salage, ber feinen Sobn bie Fechte ftur biren tiek, hatte cinmal fich nicht geichent zu fagen, er ließ̉e feinen Gohn fein Gollegium úber bas Mas turrecht und bie philofophifche Moral horen, weil er baruber leicht fu einem tuichtigen Suriften vers borben wúrbe, ber von feinen andern Rechten unb Ijflichten etwas wififen múpte, als bie in ben Lans besgefef̨en ifren (B)unb baben, unb befien Betwiffen bon allen Scrupeln frei bleiben múpte, bie aus ans bern Goeen entipringen. Sreilid) faun burch io ges bilbete Guriften leidht ein viel gróberes Maaß bes aus Ungered)tigfeit entipringenden Elends úber einen Staat gebracht werben, als wenn man bie Suftiz fhlechtweg ourd) etwas rechtíchafne Эanern

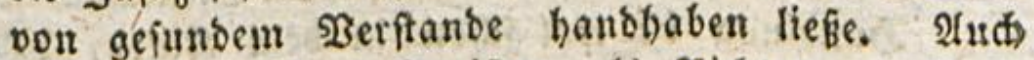
fommen fo gebilbete Suriften, ald Fidhter und Sacho walter weit beffer fid bereichern, als wenn man fid auker ben Rechten bes Lanbes bie Red)te ber Natur beilig fenn láft, unb fị verpflichtet bált tinfould

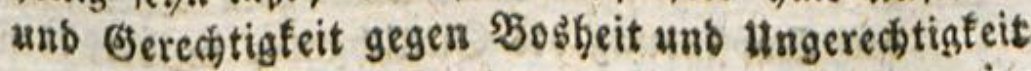




\section{4}

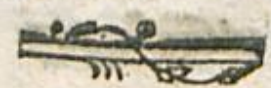

brat gefeken, soie man ein Sind anfühten tóntme, fie zil verftehen) fick gereizt fuhklen, mir nacty zuabmen, uns fich alb reidyen Nann zu zeigen. Sn foldyem Falle wirrbe idj minbeftens vera

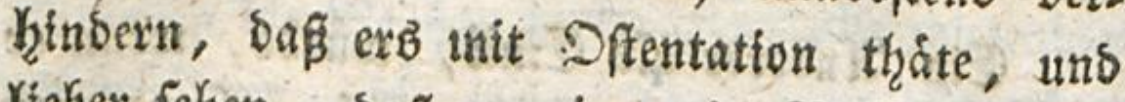

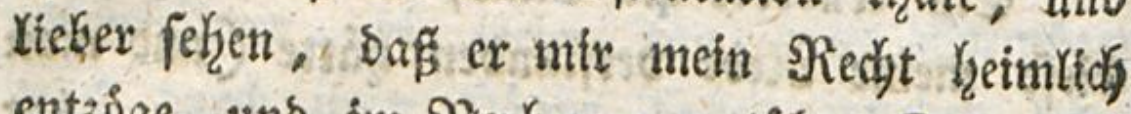
entzo̊ge, uno im \$ierborgenen giábe. Dieß wât ein Irug feines 2U1ters ; unઠ ber Einzige, betw id) thm berzetfen wirroe *)

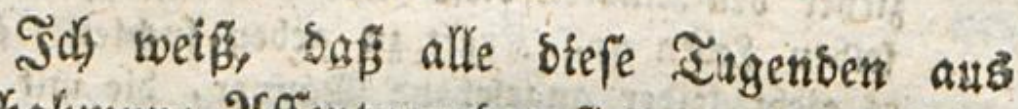
Sachahtmung 2fffentugetioen find, und baf feime gute Sganolung ander: fittllich gut ifi, nlb twenn man fie als eine foldhe thut; ${ }^{* * *}$ ) uns nidjt bess wegen, weil 2lnore fie thun. In einent 201ter cher, wo bas Seerz nod) nichts fúf̧lt, muse man

wol

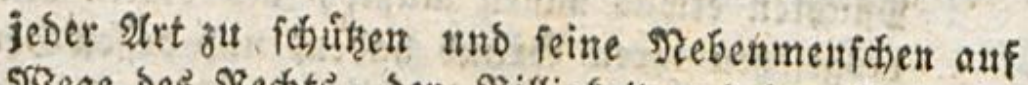

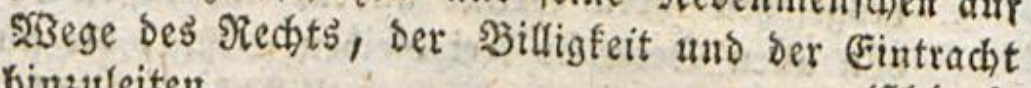
binzuleiten.

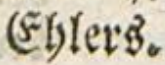

4) Sut bem man aber bow nicht geffiffentlich 2ultaß geber mutb.

Ebler:

**) Eine bunfle פorftellung von bem Gittlichgutefl einer Syandung ift wol foron in bem Sinde, bas ente folche fyandlung uoch, wie es fcheint, bloṕ aus Nachafmung verrichtet. Die श्रnchafmung zeigt ia, Daß es bies 200 ) lgefallen nicht auth zum Iheil mit aus ber Empfinoung bes Sittlichguten in berielben ents ftebn?

Trapp. Refewits. 


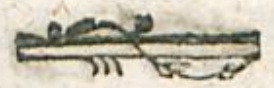

wol bie Sinser Şandlingen nachathenen Yaffen, sourin man ifnew eine Fertigleit zumegefringen

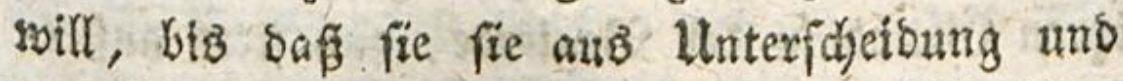

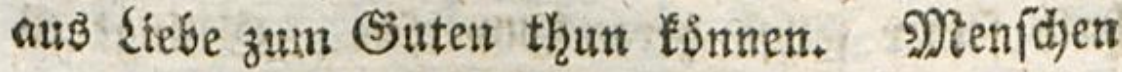
und Thiere afcmen nad); Dex Trieb zux Natad) ahmung ift ein 3rieb ber mohtgeorbueten গias tur: in ber SEefellychaft aber artet ex in Eafter aแย. *) Der 2(ffe ahmt Dem Mtenfdcen nach, Den er firdjtet, und af̧mt nidjt ben Thieren nach, bie ex berachtet. Er kgalt bas für gut,

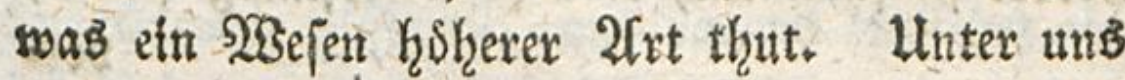
hingegen ahmen unjere Scartetine aller 2 frten

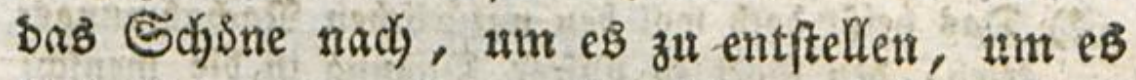
Xachertidy za madjen; fie fuchen bei ser (5ms pfindung threer SRtebrigkeit Denjenigen gleich zu swerben, bie beffer alö fie find; ober wenn fie fid) anfitrengen nact)zuafimen, was fie betwundern,

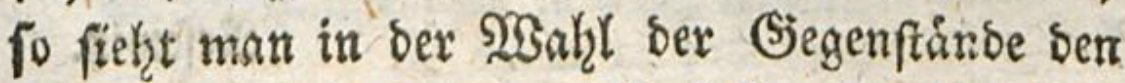

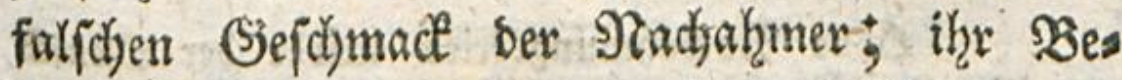

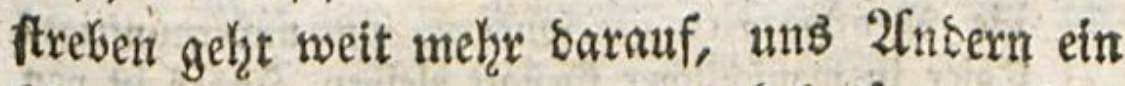
Slenowert porzumadjen, ober Lob fir ifge Zaa

Yent

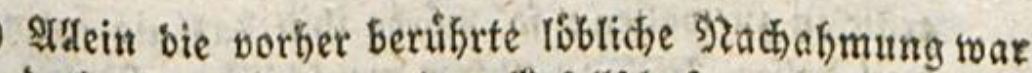

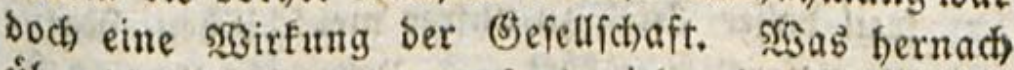
uiber bie szachafmung gefagt woird, ift theils nicht genau gentg beftimmt und freft theils nicht genug im

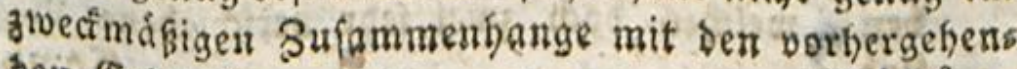
ben Bebanfert.

Eblersิ. 


\section{6}

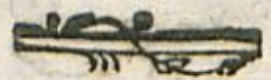

Yent einzuernbten, alz ferbft beffer ober setfex fu werber. Die Nadhab̧mung b̧at untex uns

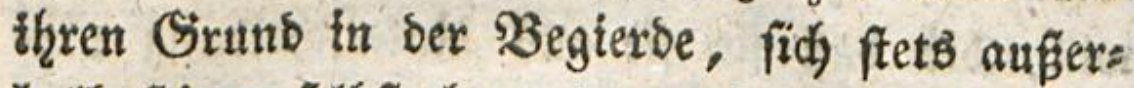
balb feiner felbft heraugzumberfen. Sielingt es mir mit meinem 30 ornehmen, fo wiro Emil fichers lich bieje Begierbe nicht haben. 238 ir miffen alpo bes Skjeinguten entbehren, bas fie hers vorbringen Lann. *)

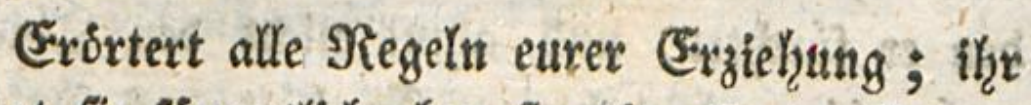
werbet fie farmmtlidy eben fo wiberfinnig finben,

bors

* Das beift boch wol ben uatútichen Nachabmungss trieb, ben sott zu unfrer sjiloung in bie menfids: liche Seele gelegt bat, burth Dorftellung eimzelner

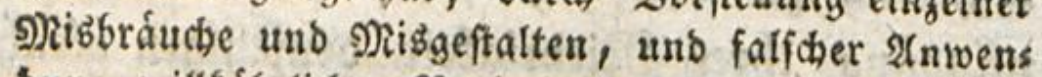
Sung willfíbrlicher Plachabmungen herabwurbigen. 2. wirb es auch burch fein Nittel verbinbern fónnen, Dap fein ふ̧ogling biefe Şegierbe nicht habe.

\section{গieferwik.}

Ohne Nachafmungstrieb wirbe ber Nenfa nie Menich werben, fontern ein unvernúnftiges æhier in menfshlicher steftalt bleiben. Tnoes ift vou

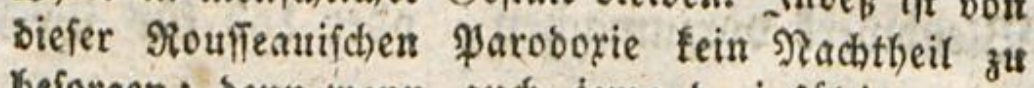
beforgen; benn wenn aud jemant einfáttig genug soáre, ben Nachabmungstrieb in feinem Soglinge erfticfen zu wollen: fo wirbe $i f \mathrm{~m}$ bas nie gelingen, weil biefer פrieb zu unfrer menfchlichen Natur gar zu vefentlich gefort. - Ulebrigens fheint $\Re$. bier 9?adjabmung mit Nacháffung verwechfelt zu ha: ben weldes bech zivei febr verichiebene \$egriffe finb.

Gampe. 
sornehrmliţ in bem, was Iugens uns Sitten betrifft. Der einzige fittlidide Unterricht, ber

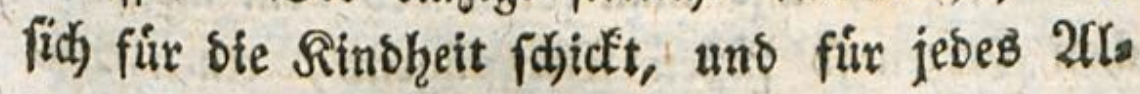
ter ber widytigfte ift, ift bie Sebre, bafi man niemals Semano Uebels zufúgen múffe. Selbft bas sebot Gutes zu thun, monn es biefem nidht untergevronet ift, hat feine Gefafyren, ift falfd, wiber(predyend. *) SIBer thut nidat $\mathbb{S}_{4}$

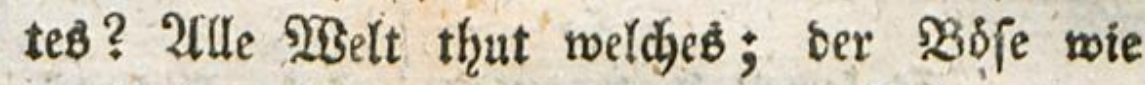
Die Ulebrigen; ex madht Sinen auf Soften huns bent (Elender glúdelids), uno baraus entftehet als les Ueber, was uns orickt. Die erb̧abenften ßugenden fino negatio; **; ) fie fins aud bie

fifwers

9) Dies ift unwiberiprechlich wahr unb mus aller fittc lichen Erziel)ung jum Grunbe liegen. Die Dentart

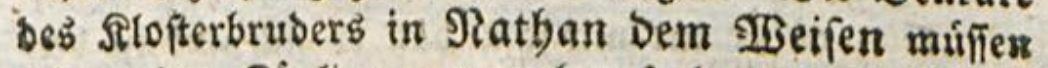
roir unfern Bóglingen zu geben fuchen:

- 2Benn an Das C5ute,

Das iक zu thun vermeine, gar zu thah

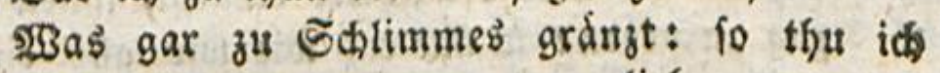
lieber

Das ङ̈ute nicht; weil wir bas Schlimme zwat So ziemlid) zuverláfig Eennen, aber

গ̧ei weitem nidit Das G5 tute. -

Trapp.

-) Negative Sugenben fino ber Regel nach meder eve baben nod fowwer. Sie find es nur unter felten Etatt findenden IImftánden. Iक Joffe bas nidt beweifen zu sürfer.

(E)ไerî, 


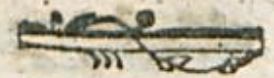

fofmerfer, wetl fein fut Sdjatragen babef Statt findet, und man fogar bes bem menf(d)lis

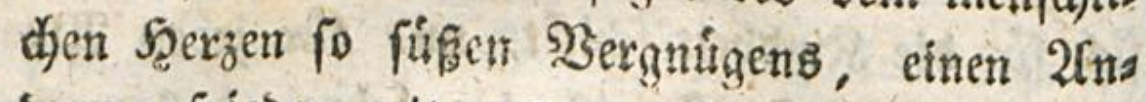
bern zufrieben mit uns von fich zu Yafen, oas bet entbehren muf. \$, wie biel Sutes erzeigt nitjt nothwentiger $23 e i j e$ feinem Nebenmenjhen Ders jenige unter ifhnem, wenn es anders einen fols chent

Es. fommt liberbem theils auf ben 2fusbrnd, theits auf bie Art an, wie wir basjenige, was bet einer tergendbaften Saantolung in bem Menifhen vors gefht, uns vorffellen, un eine unb eben biefelbe ?us gend bald fúl eine pofitive, bald für eine negative zut balten. 'Qfusfpruiche biefer 2 frt fagen alfo im Grunbe nichts, weil man fie eben fo gut bejahens als verneineno einfleiden famn. Campe.

(Sd) bin aud biefer Meinung. Ssema aber

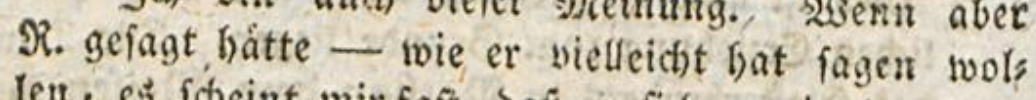

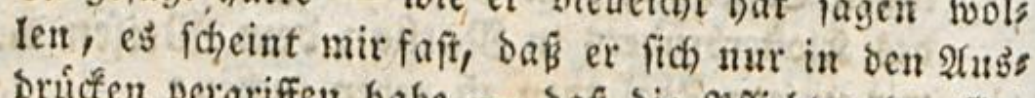
sruicén vergriffen habe - Daß sie Pfichten ber (5es

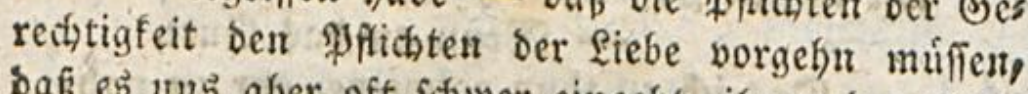
baf es uns aber oft fitwer eingeht, ifuen ben $30 \%$ zutg fut geben: fo hat er, wie wir alle eingeffehent, vollfommen Niecht. SBeil sie Beredstigfeit fo oft

5. im Nichtthut beftegt: fo hat গ. wie es mir icheint,

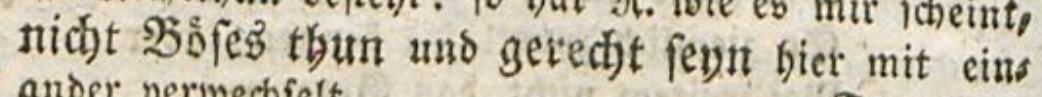
ander verwechfelt.

So if auch feine গुchauptung nutr wabr. Jus befien geforen boch zut 2 tušbibung fulcher negativen Rengenden pofitive fittliche Gefúble, bie uns bazu reijeth múfelt, unt biefe muifien Dent boch in ber

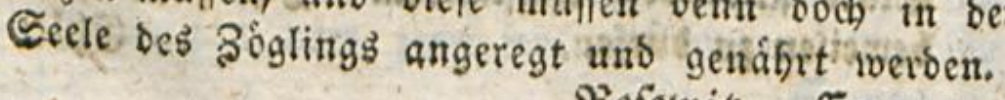
Meferwiş. Eampe. 


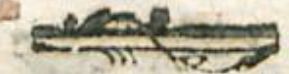

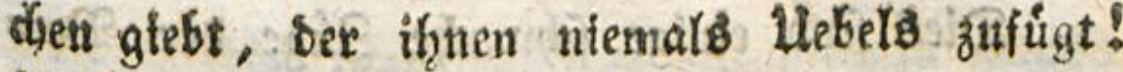
2lseldyer Unerfdyrodtenbeit ber Seele, weldjer Riaft bes હharacters bebarf er nidat bazu!

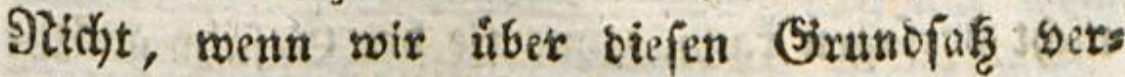
nưfteln, fondern wenn wir uns bemithen, ithn atżuxben, empfinoen wir, wie grof uno bes (d)werlid) es ift, bुierin zur 230 olltommenheit zus getangen. †)

Dies

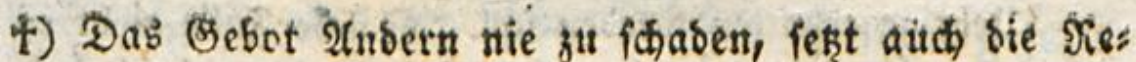
gel voraus, an ber menfichlichen Befellichaft fo wenig als imoglich zu bängen; benn in bem gefellichaftlichen Stunde fhaft bas SSlidfe bes Eimen notfivendig th: glúd fur ben $\mathfrak{A n d e r n . ~ D i e s ~ s ̧ e r h a ́ l t n i ß ~ l i e g t ~ i n ~ D e m ~}$ 2refen ber Sache und nichts faun es ánbern. ") Nan Fefe und biefem (5runbiakze, wer ber beffere Mienfd iff, ber menich ber (Eefellfictaft, ober ber, ber fur fict lebt? Ein berúbunter Sdriftiteller fagt, nur ber 3ुófe fer allein: idh fage, wur ber (stute fen allein. Weenn bies fer Salz nicht fo felfr Eentenz ift, als ber anore: fo

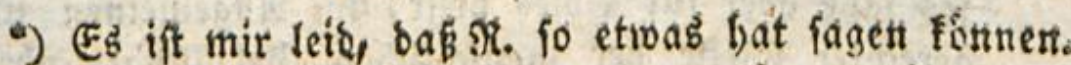
In einem gut organifirten Etaatsforper fuifyrt bas

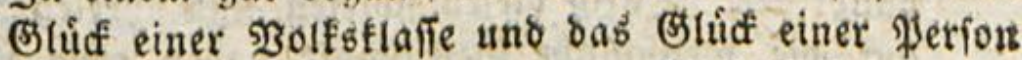
- ffenbar bas sslúd einer andern net anbern Perion mit fich. WBie it einem gefune ben menfolichen Sorper alle gbeile befielben sots theillhaft in einander wirfen, fiet an einander bitne

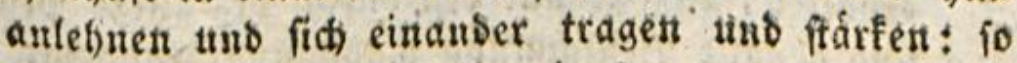
thut $\delta a s$ aud alle Theile eines guten gefellictaftlis d)en forpers. Nur wesin Inorontuget in beiren Arten bes Sospers entfteben, fo mus oft ein sheil Emir sfter 26. If

teis 


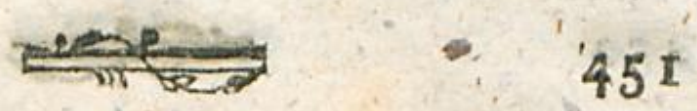

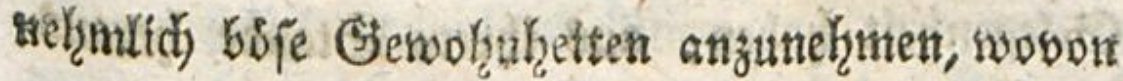
man hertad) Miuke haben wirbe, fie zu beffern.

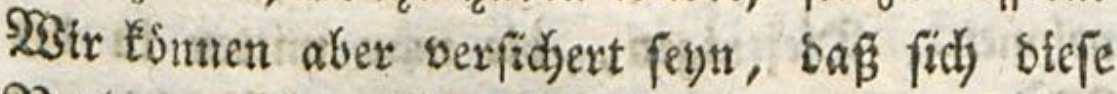
9iothrmendigheit fetten bei Rinbern' zeigen wirs, bie fo erzogen fint, wie fie es fenn miffen; weit es unmóglich ift, baf fie unforg fam, boss raft, lignerifd), habfichtig werben follten, wetn man nidjt bie Lafter, Die fie bazu machen, it

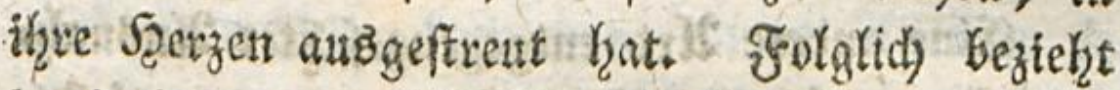
sasfenige, nas id liber biefen spunct gefagt habe, fid mehre auf bie Trünathmen, alB auf bie SRegeln: aber bieje 2luşnahnten finden fich in bem Mange thaufiger, in bem bie Sinber Ff 2

(Sies

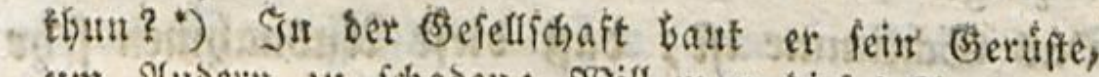

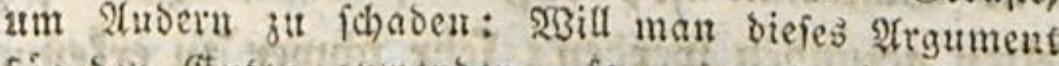
fir belt (s) itfen amvenoen, fo antworte ich barauf Dutch ben 2frtifel, fint ben biefe Mnmerfung gefchries ben ift. D. Berf.

gierbe nit ibm vetoindet. 23enn ber berufinte. Schriftfteller nuch ein Edirifftelfer bon gejundem Serftande ift, welches Yeiber oft genutg nicht ber Fall ift: fo burfte er bas allein fegn wol in jenem Sime genommen baben.

Eblers. Refemis. Eantpe.

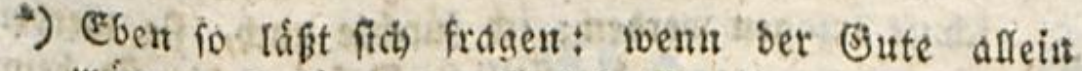
wáre, toas fointe er sutes thun? - Das moras

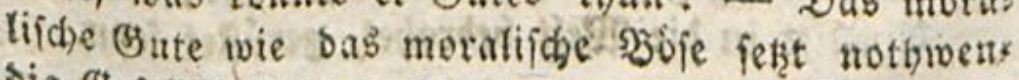
sig Becellichaft voraub. Eampe. 
Gelegenheit ḩaben, aus threm Stanbe bृeraus. zugehen, unb bie Eafter ber (srwadyfenen anzus netzmen. Dicjenigen, bie man mitten in ber Welt erzieht, bebirfen ofynftreitig fribzeitigeres Unterrichtb, ald Die, bie man in ber Einjame Feit erztefyt. Diefe einjame (Erziehung *) wuirs be alfu ben 3 borzug berbienen, wenn fie ber Sinoleit aud) nur bie 3eit zu reifen gábe.

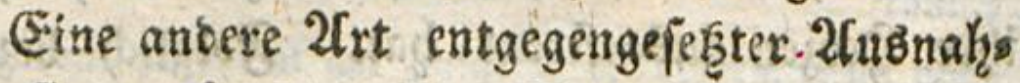
men findet fír biejenigen Satt, bie eine glicilits the Seelenbeid)affenheit ilber ibre 2ftex erhebt. So wie es Menichen giebt, bie niemals bie Sinoheit vertaffen, fo giebt es andere, bie fo zut fagen, fie nidjt cinmal burd)leben uno beis nabe gletch von ber Sjeburt an Erwady fene fins.

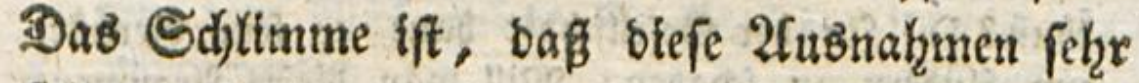
felten gefunhen merben; fehr fóswer zu erf́entuen find; und bafí jebe Mutter, bfe fich einbiloet, the Rinb tonne ein 2 Sunber fenn, nicht zweto

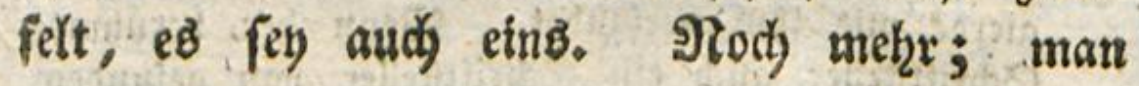

\section{nimmt}

*) Die einjame Erzichung if aber sur frir toenige moglids; es if Befabr babei, baß fie alsbann niकt fattfam fúr bie \$3elt ober bie menfकhlide Befelf: fchaft erzogen werben; in fúrchte auxch, fie werbess nicit gemug gegen die fittliche (Sefabr, bie lie betm Eintritt in bie 3 selt bebrobet, geruffet fern.

Repervits. 


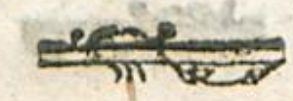

ntimmt felbft ofejenigen 2frzeigen, bie nux in Dex ganz getoofhnlidjen Sroming find, firr auf ferorbentliche an; 3. (5. bie rebhaftigteit, bie Einfalle, bie unbejonnenheit, etne gefallenbe

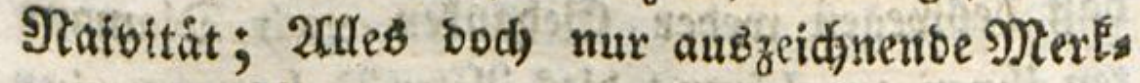
male bes 2 fterb, aus benen weiter nidjts ers hellt, als baf ein Rind nur cin Rinb ift. Mag man fidy bariber berwumbern, wenn ber, ben man biel reben láft, bem man erlaubt 2flles zu fas

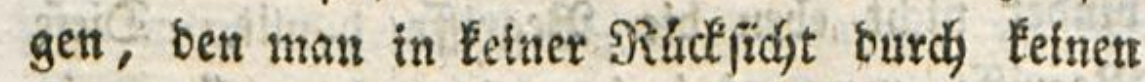
SBoblitano in 3̧wange ḩdit, von ungefdigr ein

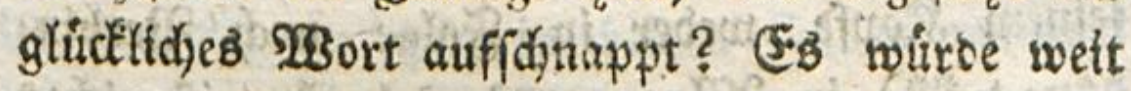
meţr zu vertwunbern fenn, wenn bies niemals

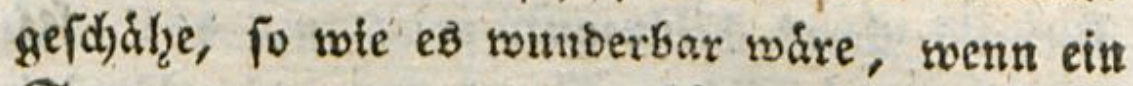
Sternbenter unter taufend Sígen nidjt Einmal etwas Sintreffenbes borher fagte. Sie werben

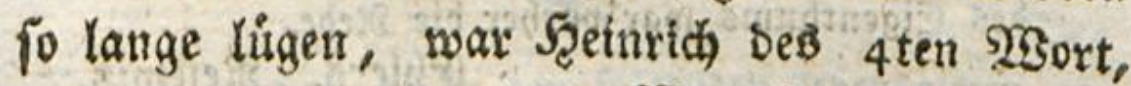
bas fie enolid einmal bie $23 a b r b e i t$ ragen wer. ben. $\mathfrak{M}_{e x}$ bann uno wann einen Einfall has ben will, barf nur viele Niarrheiten vorbrim. gen. *) Zreflitic Leute, bie nach ber Mlobe, bie teine anbern Berbienfte befiffen, atb ber Ses genftanb bex gefellidaftliden Bemumberung zu fern!

$$
\text { Ff } 3 \text { Die }
$$

*) Gebr riditig bemerft!

ธambe. 


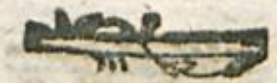

Die glånzenoften Siedanten founen ben Sin= bern in iffe Sehinn, ober bielmehr bie finne reidyften Einfalle in ben Mund fallen, wie bie foftbarften Diamanten unter ifre Soande, ohne baf besmegen meder Gedanfen noch Diamam ten ihnen zugehiren; Dies 2Clter *) bat nun ein mal in Eeiner Sattung Dinge ein wahreb (5is genthum. Dab, was ein Rind fagt, ift fir

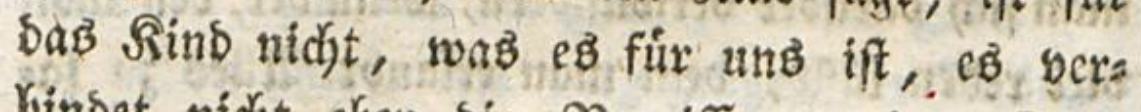
binoet nidyt eben bie Begriffe bamit Diefe Begriffe, wenn ${ }^{\circ} \mathrm{j}$ ia bergleidjen hat, liegen in feinem Ropfe weber in Folge nod, Berbins

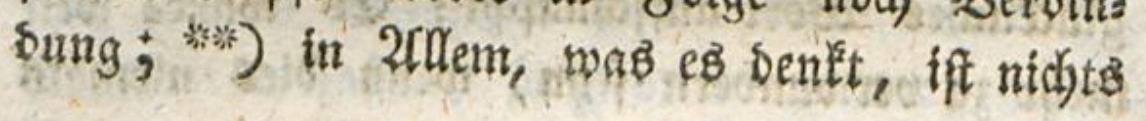

- Das finblithe after bat allerbings green unb bes

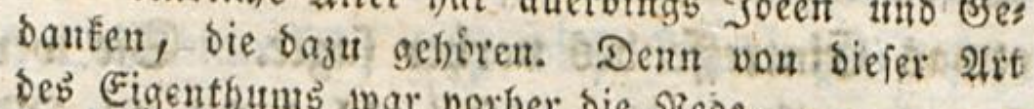
Des Eigentbums yor porther bie Jieoe.

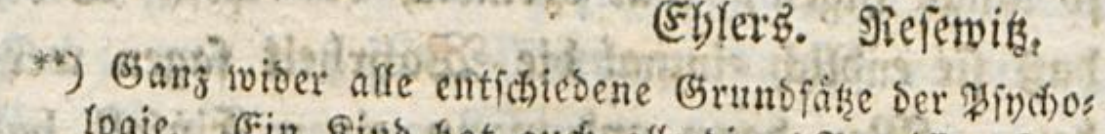
logie, sin fint that aud allerbings ?egriffe. Das fielt man, wemn man es auth fonft nicht wubte, auta Den Sandfungen unto siedent eines. Simpes, 100burch , 2 do beftimmte Begtiffe an Den Ta gelegt werben. Ein

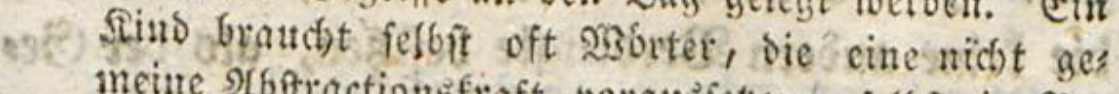

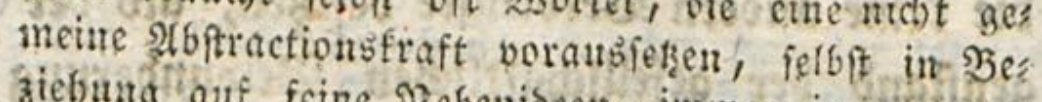
fiebutr anf feine Nebentbeen, immer in genaner Itebereinftimmung-mit dem, was fie bebenten. TEs veihen fich auth bei einem Sinbe bie nuf einnuber

folgenten und bie fid, mit eiranter verbindenden \$orjteflungen nach eben ben Befecten zulammen, nach 
feftes, nicjts beftimmtes. Interfucist elter bev meintes 23 sundertino. Sin gewiffen 2ugenbli den werbet the bet ifhm eine Sdynelltraft oon 3iberaus grofer Jigatigfeit, eine Silarheit bes

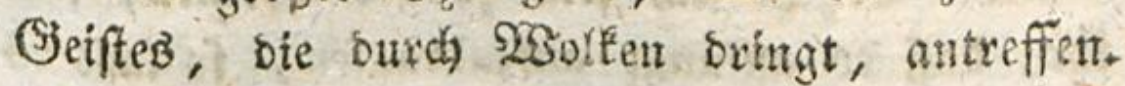
$2 \mathrm{~m}$ sfterften aber etfiseint auch eben berfelbe (Seifít fablafi, milduwetch, uno wie mit einem bicken Nebel umfdreient. Barb eflt er end zăbor, uno balb bleibt er mbemeglid) Dahinten. Den einen 2 tugenblice mogtet iber fogen: $e B$ ift

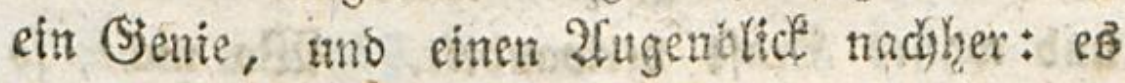
if ein Dummitopf; in Setben Fatlen surbet ihy trren, es ift ein Rino. Es ifte ein 20 ters d)en, sas ben einen 2ugenblice durdy ste Euft einherfowebt, uno bea 2fugenblicé barnacly wies per in fein গeeft kgerabflattert. *)

$$
\widetilde{F} 4
$$

Bes

nać) weldien bas in ben folgenden febensaltern ges

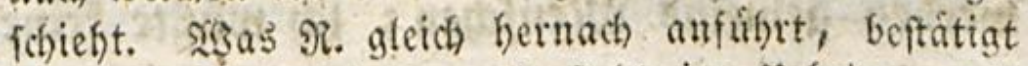
bieb felbft zum Theif, uno fieht im Hebrigen mit bieier 2lit von sigirffamfect, welche bie Einbildungbs: fraft und Der Eeift ber Sitrser mit ber Einbildungs" fraft und bem (s)eift ber Erwachienen gemein bat, gar niblt in sisiberiverth.

(E) ler:3.

Das Rint fpricht zwar Manches nut nad, was es aufigej(t) nappt hat; aber es áuß̉ert alfe die Geelenfráfte

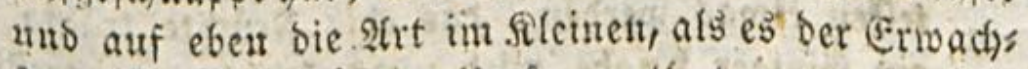
fene in cinem groffern llmfange thut.

Siejenith. Sampe.

*) Simber, weldie viel rebrafte uno wikige Einfâlle vor" fringen, find, in Anjehung ifret Seplenfóbigtẹten $g^{\prime}$ 


\section{6}

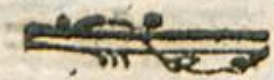

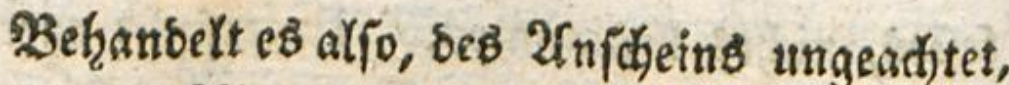
nad) Feinem 2(tter, unb ḩutet end), feine Sirdfte

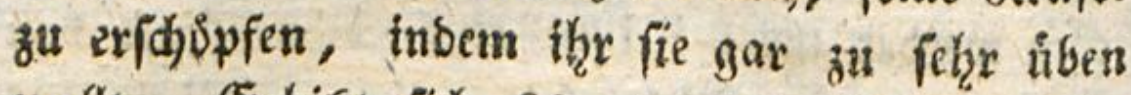
soollt. (Erhight fid) fein junges (Siphirn, feht flbx, bafi es anfíngt aufzubraufen, fo tagt es anfínglich in Freitheit góf̨ren; erregt es abcr niemals, aus Furdht, es mógte 2tlles auds buinften; uno wenn bie erften Ssetfter verflogen fenn werben, fo kaltet, bringt bie anbern zus

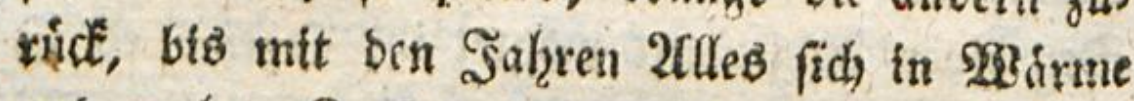
unb wahre Riaft verwandelt, 280 nicht, fo swerbet ifge eure 3eit unb eure Eorgfalt verlieren; euer eigenes SIBert zerftoren; und nadjoem ibr eut) unberonnen in allen biefen entzinbbaren

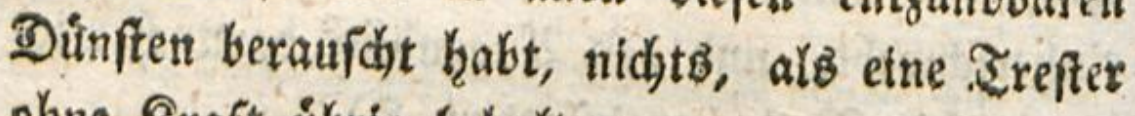
Dhne Rraft übrig behalten.

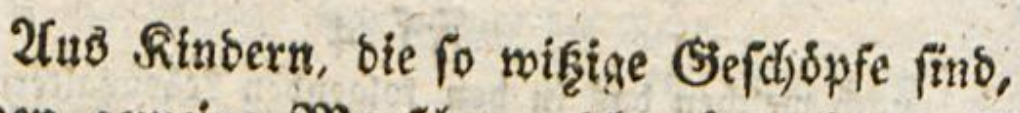
werben gemeine Menichen; id) wúgte feine alls gemein wahrere und gewiffere SBeobid)tung, wile biefe. *) Slidjts ift fobwerer, als bei einem

Sins

gerabe nidht bie hoffnungbuollten. $23 a$ a fonell aufs fbiefit und ficúh zu feiner Sollenduna gelangt, wirb feflen etwas werben, has eble frúchte trágt; uno ein wikiger Snabe wirb nicht leid)t Jum tref̂ichen Raun reifen.

Eampe.

9) Diefe ஒ̧cobactung fimmt mit ber meinigen vóftig riberein. Eampe. 


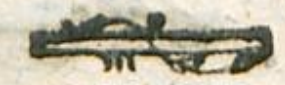

Sinte bie wirtlidje Dummbeit von bet fdjetnt baren uno táurchenoen zil unterfítjeiben, bie farte. Seelen anthinsigt. Eib formmt einen anfangs

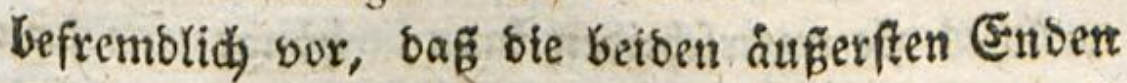

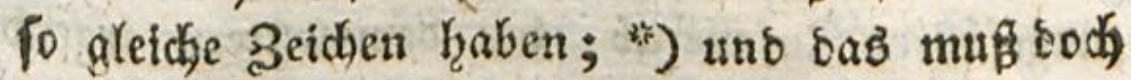
gleidyrol feyn; benn in einem 2flter, swo ber Menfdh nod teine wafhre Begriffe hat, ift allee Unterichles, ber fidd zlvifdjen bemjenigen, mels der Sente uns bemjentgen, weldjer Heines hat, ber, baf ber leşte nux falfdje Begriffe ans nimmt, und baj ber erfe, ba er Eetne andre ald falidje *) finbet, aar Eeine zuldaft. Ë fons Ff 5

bert

-) Ein guter Meníbenfenner toirb biefe, manchem icheinbar gleiche 3eichen nicht gleidh finben. Эुei mantien Sinbe wirb auch bie Entwifétung bes ficts fpát erfít zeigenden Senies eine geraume 3eit burd Staturbindernifife zuridigebalten, bie in ber Folge - geboben reerden. Fblerz. Refemis.

-) So if es ficher nidit mit ber Sahe befdaffen. Die grópere $2(n z a b)$ von Norftellungen unb \$cgriffen, weldse, wenn ich mich fo utboríden barf, von bem ein Sind umgebenden Nenichen ausgehen, uns einen Eintritt in bes Sinbes Seele fuchen, befteht

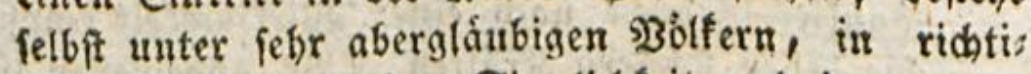
gen Sorftellungen ber Einntidbeit nno in wahress allgemeinen Begriffen. SBie fonnte alfo ofn fint ven vielem Benie feine anbre, als falfene veregriffe bei benen, bie es umgeben, finden! Selbft ein eben fo vorficitig als grindlich benfenber spanis

fins. 


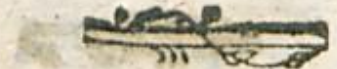

bert ifhn alfo son bem Dummen nichts, als Siefes: Dafi oiefer zu nichts fóhig ift, uno bem anbern nidjts anifeht. Das einjige Sెeidjen, weldjes fie unterfibeioen Ean, Kaangt von betn ungefăbren 3 ufalle $a b$, ber Dem Yerstern irgeno cinen Begriff madj feiner Fabbigteit Darbieten tamn, anftatt baś ber erfte allenthalben immer

bete

findet bei einem guten ivifienibaftlichen Syftem nicht alles fo voll bon gitrtbumern uno Rángelit, als ein raich utb umorisctig jufahrenter Sopf, Der alles, was er yorfunbet, umwirft ober refors

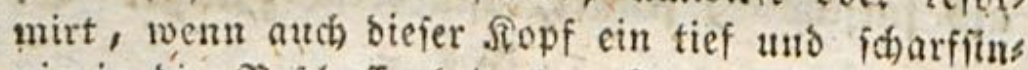
sig in bie Sejchaffentheit ber Dinge eindringenter

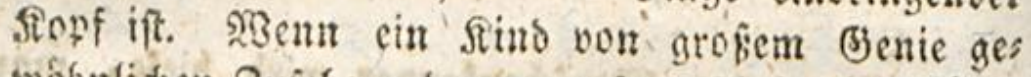
wobuliden Bujehern oumm ju fen. ideint: fo rúbrt es entweder baher, weil es nichts um fich berum wafrnimunt, was it bas gad, beb Denfents mo

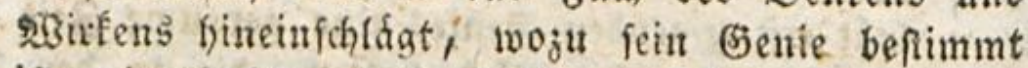
iit, ober bafer, weif es bie worgelegte Sarte bet Erfenntnip geicivino fid) balb befannt madt, weif es nichts melr barin findet, was intereffirt, peil eb bavon sicht reben uno fprechen mag, weil eb Dennoch oft bavon rebent foll mid weil es entlich baher gebanfenloier siscife leicht etwas febr :ुers fehrtes und Dummes bariber fagt, indem es cin puntes Gehneu nach ciner şirffamfeit empindet,

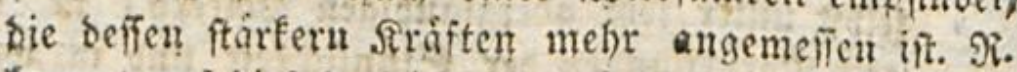
fommt auf biejes sleich bernach, wie auf eirte Res benfache, sa es bock bie frautiache iff, und da bas, was er zur Jauptjache macht, nur in cinjeluel? Fáflet, als siebentacie saza fommt.

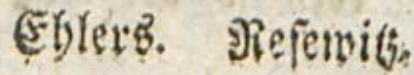




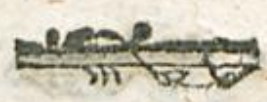

Dexpeltie Breibt, Dex junge Eato fdjien, fo lange ex Ritno war, in feirem Şanfe fumpfes Sieiftes

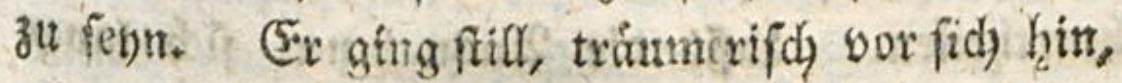
zeigte fich fteifinnig; bas war bas ganze thr theif, was man fifser ifgr fâtlte. Niur in bem Borgemady Sylla's lernte ifyn fein Sheim Eemmen. 2Bár ex nicht in biejes 230 orgemach getomment; fo batte man ihn bielleidit bib in fein verninfo

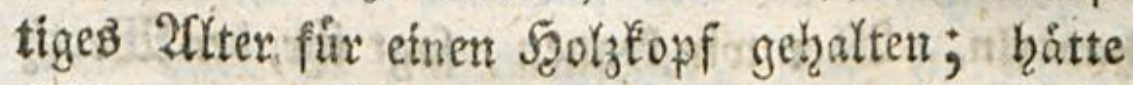
Eajar nidgt gelebt, fo sitrfte villleidst eben diefen Eato, der bes Erobevers gęrberblictjen Seift Surdjorang, uns alle feine 2 fnjajlige bon weitem boraแ fah, fur einen Bifionair gegolten haben. S), wie leidht tamn body wer fo boretlig von Sinbern urtheilt, iich irven! Dieie Utrtheilev finb oft weit mebre Rinder, als bie Rinder felbft. Fdy habe, in einem ziemlidy berangewady fenen 20Iter, einen Mann, ber midy mit peiner Freunsfdsaft. beebrte, in feinem Scaufe uno bei feinen 2 ngges biorigen fir einen eingefäraneten (S)eift gebalten gefehn; Dex sortreflictje Ropf reifte in Stillen.

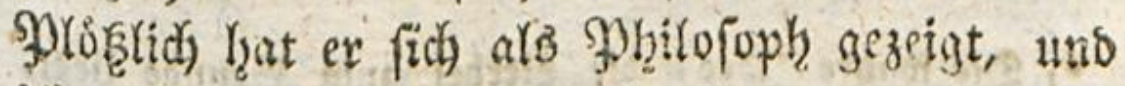
id) zmeifle nidyt, bie গachyelt werbe if̧m cine rifhmliche uno angefeliene Stelle unter ben exfent Dentern uno tiefïmighten Methaphyfitern feines Salzrķunberts anmeifent?

5ुato 


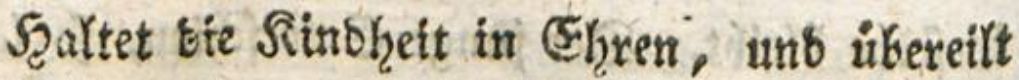
eudi) nidjt, fie weber im Sinten noch $B \delta$ fen zu

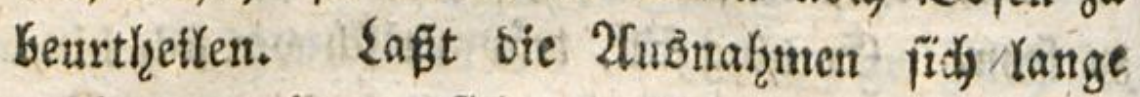
sorkger angeigett, fïch) erweifen, fich beftatigen,

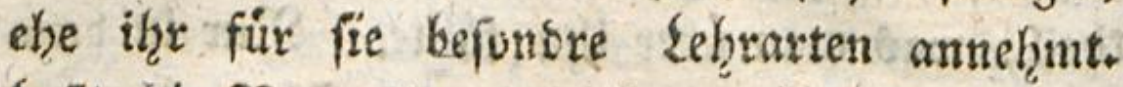
Safit bie Natur lauge wirten, ebe ifgr eud oas ntit abgebt, an threr Stelle wirten zu wollen; the mbyter ifhren Berridgtungen tur zumiber banbeln. 2fber wir tennen, fagt thr, ben 23 eeth ber 3eit, uno mollen feine vertieren! Seht ffre bena nidjt, bafi the vielntefgr bavon berliert, soenn ihe fie foled)t anwentet, ałs wenn the gar nid)ts thut; uno bafis ein ibbelunterricis, tetes Sino weft entfernter bon ber 28 eiobeit tift,

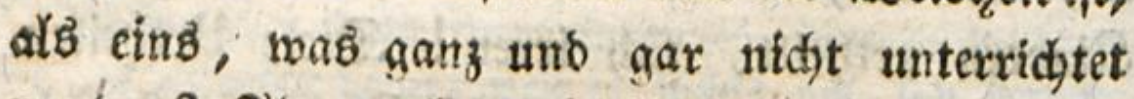
soorben? Shr madjt eud 3eforgniffe, wenn e\$ feine exften Sabre mit গltd)töthun zubringt.

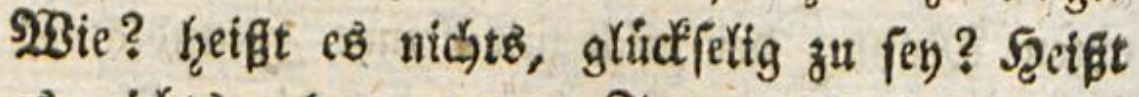
es nid̄ts, ben ganzen Iag $3^{u}$ fpringen, zu fpielen, herunizulaufen? *) Sein Eebelang wirs

-) Die wabre Joee, bie Gierbei zum Grunbe liegt, wirbe pielen feiern weniger anftofig flingen unb leidter Eingang fuben, wenn $\Re$. fo gefragt hatte: feiśt es uidts, feinen Rorper ausjuarbeiten, su fárfen, abzubártẹ? Niichts, feine iungen Geelens

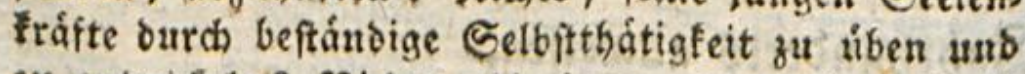
ju entwoideln? Nidgts, bie iunge Sorftellungstraft 


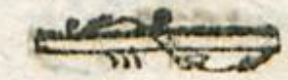
461

(6) nifit fo beedifitigt feyn. Sylato, ben man fur jo ftrenge hadit, lafgt in fetner Repubtie die Rinber unter lauter \{uftbartéten, Spielen, Sins gen, Beitbertreiben erzithn; man polte meinen, er hielte afles fúr gethan, wenn er jie redjt fich luffig maithen gelef̧rt; und inbern Seneca son ber alten rómifdsen Şugeno fpridt, fagt ex uns, fie fen ftets auf ben Beinen gemefen, man habe fie nidjts getetzrt, was fie fikeno fiatte lernen muffen. * S Fatte fie barum mes

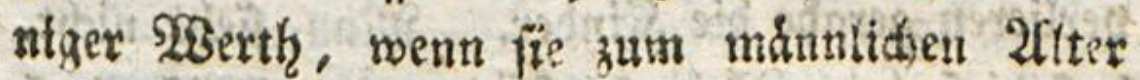
getommen war? Erfdjredít atfo nidjt vor siefem

\section{bre}

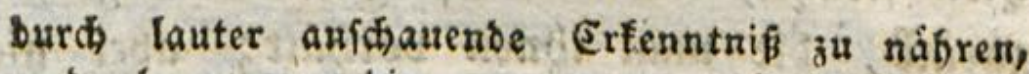
and, bevor man bie vergangenen, bie fermen, bie abfracten Dinge fenuen lernt, erft mit ben gegens mártigen uns finnlichen Begemî́nben um uns ber Durch eigene Sinne und eigenes Empfindungsvers mógen Befanntichaft zu maden? Jyeif̧t es nichts, burd eine friblich verlebte Sindbeit ben unjerftors baren Gruno zu einer gludilichen Bufriebenbeit in jebem barauf folgenden 2llter ju legen?

\section{Eampe. Stapp.}

Itn' beifft es nichts, fie burd Inregung uni llebung fittlicher Éefúble fut guten und edlen Neus fdeell vorzubereiten?

Rejerwib.

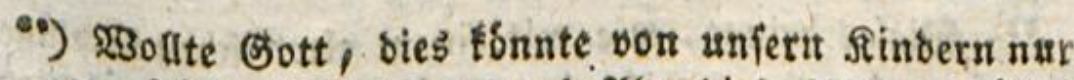

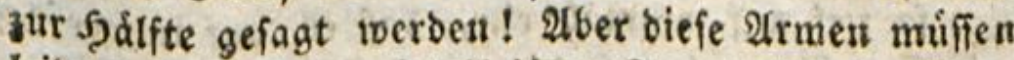

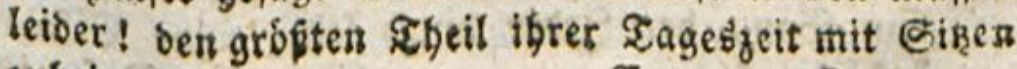
क्षubringen.

Eampe. Trapp. 


\section{2}

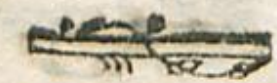

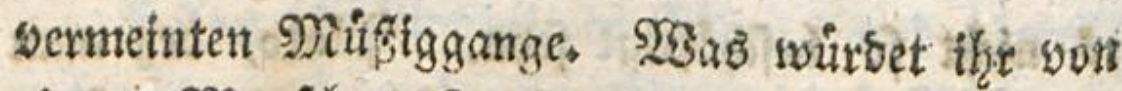
einem Mienfdyen fagen, Der, un fein ganzes Seken zu nuken, ntemals foblafen wollte? g్sly

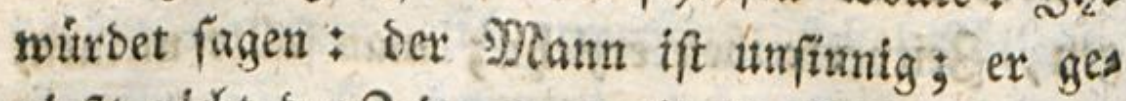
ntept nidut ber Beit, er raubt fie fíd; um betk Sidlaf zu entgeben, fucht ox ben Ioo. Saebentt alfo, bafi jener fall mit siejen gleich ift, und. sie Rindbeit ber Sdylaf*) bex SBermunft iff.

Jumd ibre foreinbare seid)tigheit im Sertien serlieren gerabe bie Sinber. פNan fieft nidgt,

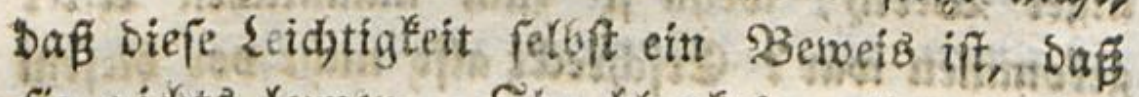
fie nicjte Yernen. Sub blantes, glattes (Sies fyirn ftrahlt, wie ein S̈piegel, die Siegenftänse zuride, die man thrien vorbart, aber nidgts Sleitet, nidgtz Dringt ein, **) Das Sind bebalt

-) Sithit ber Ëalaf, fonbern bie 3eit ber allmálig fich entwicfelnden Sernumf. Der weife Ergieger mú nuy bem Sinbe nicht andre Nlebungagegenstube worbaltén, als polshe, welche bem lebesmaligen sróoe

Der Entwictelung angemefien find.

(5) lerz:

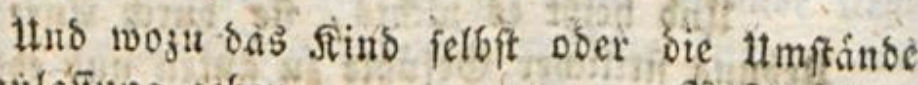
ģeraulâfitug gebet.

Sieferwiz.

*h) sièles bringt, wie mit einent electeifoben Gstalage, fo tief auf eimmal eiu, bak es auf immer bleibt. Ein Gath, ben Seder Durd jeine eigne Erfafrung beftitigt findet.

(5)leris. Niejento. 


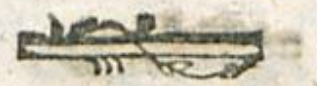

Die Sgorte, sie Segriffe praflen ar. ") Diejenigen, weldye es hyoren, verftethen fie; bas Sind allein verfeftrt (îe niclyt.

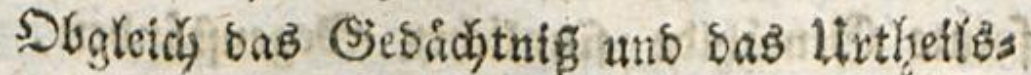
vermogen zroei wejentlid) von eiranber berjojies bene Seelentráfte find; foentwidfelt fid) bods bie eine nut mit ber andern bahtrthafig. Borbem.

$2 \mathrm{Il}_{\mathrm{s}}$

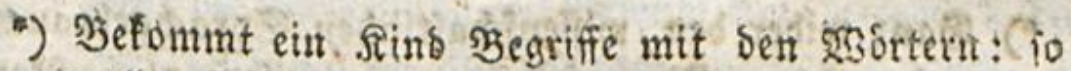
prallen iene fo wenig, wie biefe ab. Nicht feidst formen fid bie Epuren ber şegriffe in ber Folge cher. Derlieren, als bie Epuren ber sxobrter, bie bem Eeift bes begriffs jum Nớrper gegeben fins.

Eglers. Necenvit.

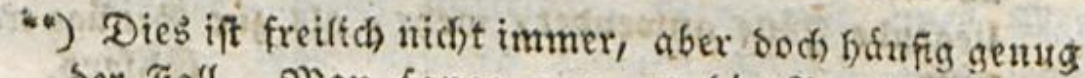
ber Fall. Dian fange thur an bie Begriffe zut ;ers

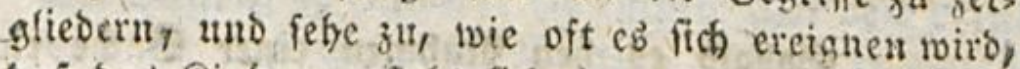

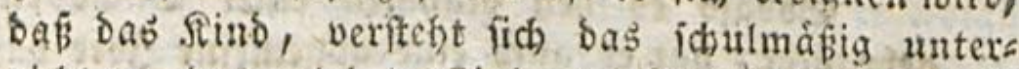
richtete, bas getefrte Stind, wiréfich bifine, toas es gejagt bat.

Eampe.

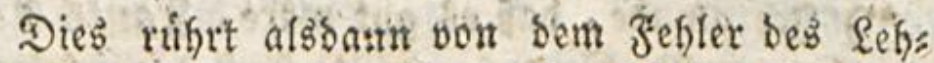
rers, aber nicht von ber Natur bes Jimbes hee, Das etwa, als Sint, bie Segriffe noch nicht faffert fontute. Der Misbrauth bebt aber Den (setraudi) sicht auf. Mefemits.

allerbings! ber Fefler ses \&ehrer's liest theils

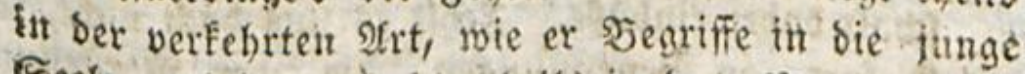
Secle zu bringent hutht, theils in bem Mantgel eitnet richtigen duswahl berienigen Socen, welche fut cint geviffes alter gehoren, von benen, twelthe ntitht bas firi geforen:

Bampe. 


\section{1ttx ber Bernuft empfängt bas Sins teine} Soeen, *) fonbern Bilber; uns zwifden beiben fif biefer Unterfajieb, dafi bie sitloer nur abs

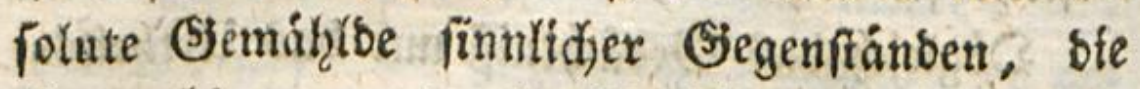
Soeen bingegen ourch Berbुaltniffe beftimmte Begriffe bon ben Gegenfánden find. ***) (Fin Silo tann in einem Sieifte, ber fid) es vors

fitellt,

-) Bang wiber ber wiffenithaftlichen Spradigefrauds

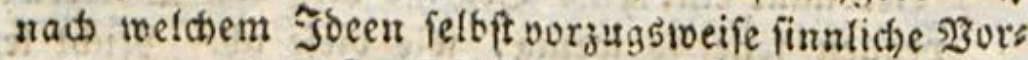

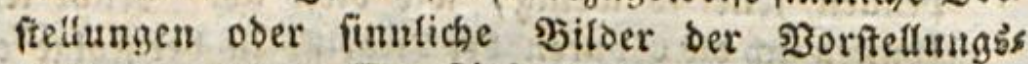
fraft beocuten. Ein Sint befommt aber auth von ben Goeen, bavon $\Re$. redet, fehr bald eine grope Menge, welches aus ber richtigen 2rt, wie ein Sint gBorter unb Rebenzarten gebraucht, und auf vors liegende fâlle anvendet, mebr, als zur Benuige ers bellt.

Eblet?.

Sobalb es dent Nabmen einer Sache richtig gebraucht, bat es auch eime alfgemeine Toee bavon,

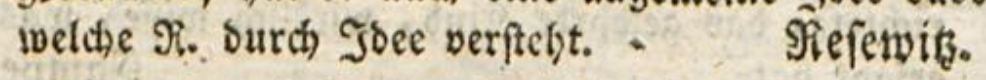

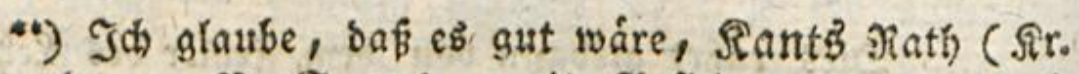
ber x. $\mathfrak{~}$. S. 376 , zroeite $\mathfrak{2}$ uf.) ) zu folgen, unb

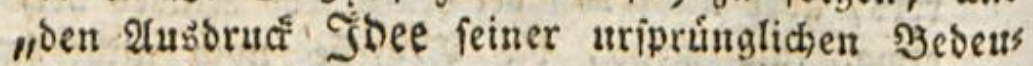
tung uac) in Schus zu nebmen, Damit or nidht fernerbin untẹr bie úbrigen 2ussriffe, womit ges wóbulich allerlei $\mathfrak{B}$ orftellungsarten in forglofer $\mathfrak{U n}$ orbunng bezeichnet werben, gerathe, unb bie şifiens ichaft babei cinbúfe. F̧eblt es unt boch nicht, fábrt

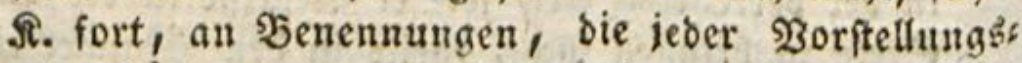
art geforig angemefíent fino, ohne bas ivir nothig. baben in bas Gigenthum einer andern eingugreifen. 


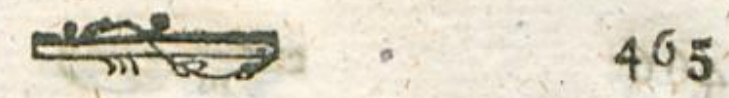

fellt, allein ba fenn; aber jebe Foee fert ans bere soraus. S3enn man fich einbitoet, if fief̨t man tur; wenn man begreift, fo sere gleidst man. Utnjere Senjationen finb blof Yeidend, *) auftatt baß alle unfere Derceptios

nento

Sier ift eine Etufenteiter Serfelben. Die Battung ift Sorftellung überhaupt (repraefentatio) Hnter ifr fteht bie 20 orfeflung mit \$erwitiftienn (perceptio). Eine Nerception, bie fich lebiglich auf bas Gubject, als bie Nobification feines Suptandes, beziebt, ift (F)t pfinoung (fenfatio); cime objectibe Berception, if Erf́enntnif́ (cognitio). Diée iff entweder $\mathfrak{Z} \mathfrak{n}=$ fif)aung ober Segriff (intuitus vel conceptus), Jente bejieht fich unmittelbar anf ben (Segenftand und if einzeln; biefer mittelbar, vermittelit emes DierÉ mals, was mefrern Dingen semein fern fant. Der Segriff ift entweder ein empirifher ober reinet 5egriff; uno ber reine Jegriff, fofenn er lebiglich im Berftande feinen Hifpring bat (nid)t im reinen Silbe der Sinnlichfeit) beip̄t notio. Ein כegriff aut Notionen, ber bie Nioglicheit ber Erfabrung ubers fteigt, if sie Soee ober ber Bernunftbegriff. Dem, ber fich einmal an biefe Untericheisung ges soofint bat, muß es unertráglich fallen, bie शुors ftellung ber rothen farbe Soee nennen zu boren. Sie ift nicht cinmul Motion ( $\$ 2$ erftandesbegriff) ju mennen."

Trapp.

2) Sicht blo pi Teibeno; bie Drgante muifien, toenn Dinge auf fie wirten, bis auf einen gewifien (5rab bages gen wirfen, elge fie bie Nobification ibres 3utpanbed aunebmen, barin bie Empfindung gegrandet ift.

Emilifter If. (Eblers. Refenis. 


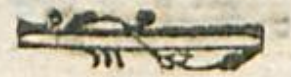

tonen, *) ober Soeen, burch ein wiretidy thas tiges Sorincipium entfetheit, weldyes untheilet. Dies wiro hernach berwiefen werben.

Jah fage aljo, bafs bie Rinber, ba fie nidjt fâhig find, ou urtheilen, **) fein eigentliches

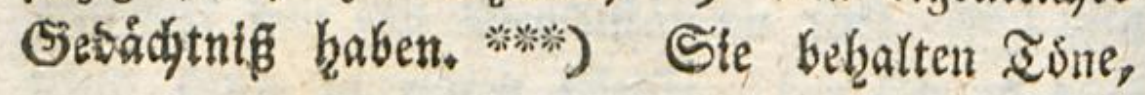

Fis

2fuberom bleibt eire Eenfation nie ofue fols gen, nie ofne irgend cine pofitive Siraftánberung ber Seele.

Eampe.

-) Perception if̂ iebe Thátigfeit ber Geele, wobutch

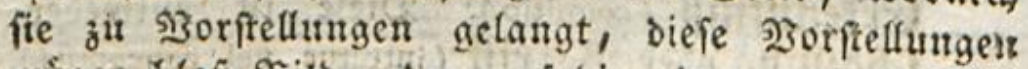
mógen blof́ গ̧itber ber auf bie Drgane wirfenden Dinge, oder Segriffe des Seritanbes fentr. Nors zuglich bebeutet Perception felbft bie 2tmmefmung finticher soeer.

(E)blet?.

\#) Dies behauptet $\Re$. mit Untecht. Ninder vergleis den 3 orftellungen mit einander, unb trenuen ober verbinden fie, b. h. Fie urtheilen; unb weun fie fpres ben fonnen, ober felbit burch andere Beichen cúfern fie auch ifr thtbeil. Dies ift autch von ber Ibátigs feit ieber menfeblichen \$orftellungsfraft umzertrenn lid). Hrtheilen fie mu, fo mus aud ibr Urtheil auf eine angemeffene sgeife getibt uno berichtiget, ano Darf nicht, wie $\Re$. meint, vernachláfiget werben. Rejewiz. Campe.

-**) Einen allgemeinen, it allen mir befannten Spras (hen Statt findenben Sprachgebrauth nad wirb bie willfúfrtiche şiebererwectung ver Tone, Siguren

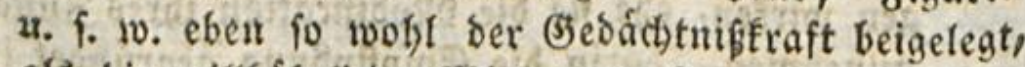
als bie willfúfrliche $23 i e$ erertvedfung ber Berftans Desbegriffe, ber Hrtheile uns Schkinje.

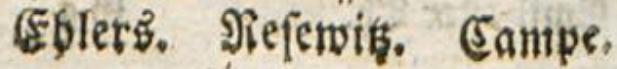




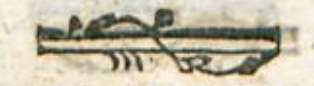

$40 z$

晾

Figitren, Senfationen; felten Socen; nodi felta ner ifre Serbinoungen. शan wiro mir eine wenden, fie Yenten body einige Grunofäre ber Mathematí, und Dann gegen mich bewiejen zu. baben glauben; allein man ḩat gerabe fíc mid: bewiejen, uno gezeigt, bafie fie nicht cinmat bie

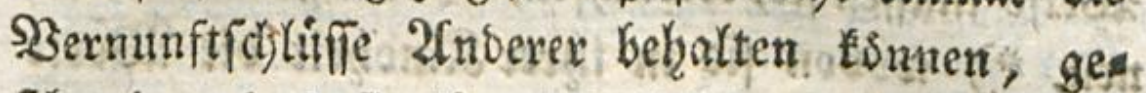
foswige, bafis fie fur fich felbft zut raifonniten fábig ferti follten. Denn man verfolge biefe Heinen Nintlematifex mur in îzrex Nethode, und pogleity soiro man inne werben, sas fie blof̈ genau den Eindruck der Ftgur und bie 22Borte bes Serweifes behalten ḩaben. Bet bem geringften neuen (Sinwurfe fino fie weg; *)

$$
\text { (S) } \mathrm{g} 2 \text { man }
$$

9) Dies fonnte wahr fenn, ohne bafi etivas fur dic vorhergebende S3ebauptung baraub folgte. Ein Jind fan einen Saķ uadh bem baburch altsgebríffen Itrtbeil richtig gefafit baben, unib boch noch nicht fábig lenn, cinen Eimwurf zu loiberlegen. Ein ges

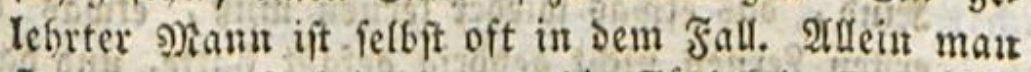
Finbet auch oft bei Sinbern oie Jåabigfeit Einwúrfep wovon es, noch nie etwas gehort bat, bermittelft ber borbin erworbenen Begriffe, gut zu heben. Daf nber ein ふind, wenn esi feine \$segriffe aus Erfaha. rungen und 3 cobaditungen abftrabirt, ober von eis .ro nem guten fectrer empfougt, nicht etwan oft, fonberu uts fof immer nicht blofi ben finulichen siorper eines

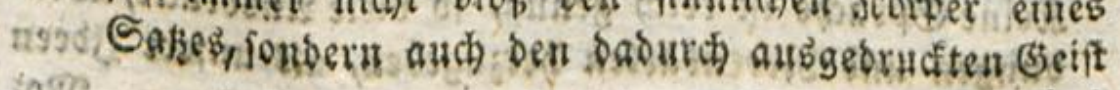
iage bet 
408

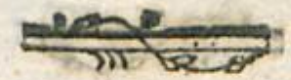

man Eebre bie Figur um, fie find sweg. 2Ulle ifhr IStifien liegt in der Senfation; nichtỏ ift bis in ben Berftand gebrungen. Shy Sebádjts

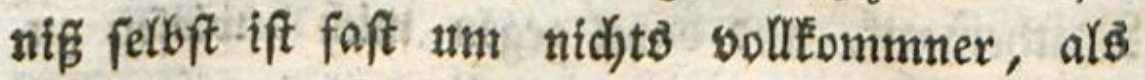
ithre anbern Seelentrafte; benn gewoshnulicher şsetfe muffen fie, erwadyfen, bie Dinge wieber lers nen, $\left.{ }^{*}\right)$ novon fie in ihrer Rindheit bie 230 orte geternt ḩaben.

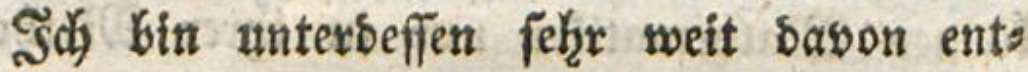
fernt, ben Rinbern alle und jebe 2trt bon Rais ponnement abzu(prect)en. + ) Eegentheits fehe id),

Des Ittheils falfe, follte feinem Sejer von einigen Senntniffen erwiefen- werben búrfen.

(E)lers. Refenik.

-) Jm Fall bes sobiebrlernenmúfiens in felbft oft ein Miann, Der beim Lernen etivas febr gut gefaft uno werffanden bat. 2 Benn bas bei einem תinbe geíces ben muß $:$ fo folgt baraus alfo gar nicht, baß ein Stind, Das etwas wieber lernen muś, etwas beim erften \&ernen nidht gehórig gefaft hatte, und dafi nicht in ben \$erftand eingebrungen fen.

Eblers. Rejerwits.

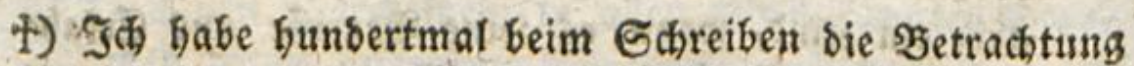
gemadit, twie unmoglich es in einem tangen 5 serfe

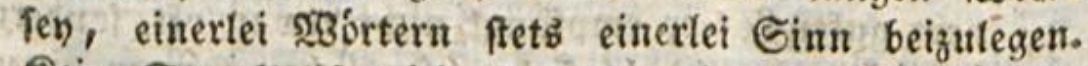
Deine Epracte itt reich genug, to viele Anstridfe, EBens:

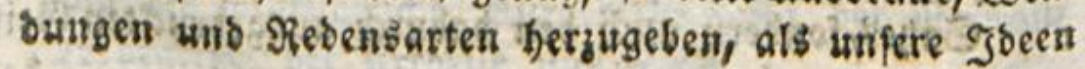




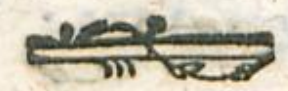

td, baf fie feht wohl in 2flletn, wab fie tennen; und was fidg auf the gegenwártiges uno finna lidjes Sntereffe beziehst, raifonniren. 2Ullein

$$
\text { Gु } 3 \text {. } 3 \text { in }
$$

Nobificationen (eiben. *) Die Siethobe, baß man alle 230 orter befinire, uno ftets die Definition an die Stelle bes Definitum ferze, ware trefich; aber nicht anuenos bar. Deun wie toill man bie Sirfel vermeiden? **y Defintionen fonnten gut fenn, wenn man nicht-2Borte Erauthte, fie zu machen. Demofngeadtet bin id \{iberjengt, man foume felbpt bei der atrmuth unerer Eprache, beutlich fenn, uidht eben daburch, oak mat

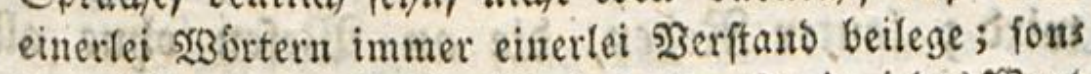
Deru indem man fo fabreibt, bafi, fo oft ein jebes gebraucht wito, sie bebeutung, die man ifm giebt, ourds bie fich auf baffelbe bejieflenden gocen hinlangs lich beftimmt werben, unb bá ieber Periobe, worin fid) biefes 'SGort firber, ibm, fo zu fagen, zut Defis

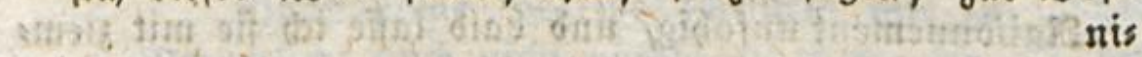

-) Das ift freifich wabre. Fffein wenn ein Serfafier Sie şorter unb Tebensatten nicht iminer in einers 11. Tei Einn gebraucbt: io if es vielleicht zehnmal feine Echulb gegen cinent Sall, oa es in ber 2 rmuth ber Spradje feinen Srund bat. Und weun $\mathfrak{x}$. in bets f(hiebenen. Stellen mit fich felbot in Siberipruch fommt: io ift bavon oft gar nichtb auf bie Fechs nung ber Evrache, foutern anf bie Nech)mung einer lebfaften Einfeitigfeit feines 3łticfs und einer uns besingten ober uneingeichránften Şebauptung ober

Sảugnung zu feķen, wo etivas nur bebingter ober eirgeichránter 23 eife bebauptet ober gelánguet wers be: follte.

(5)

Gefr wahr!

Siefervis.

4*) सts wenn bieje nicht vermiedea werben fonnten. (Eblers. গiefewis. 


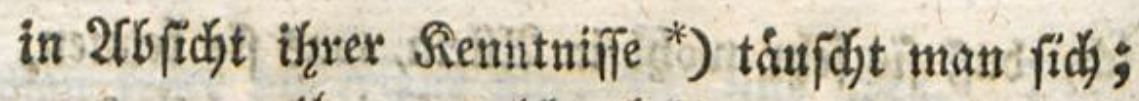
wenn unan thrien welche beilegt, bie fie nidjt Haben, und fie liber Sadben xaifonniren lägt, bie fie zu begreifen nidjt tm Stande find. 2ưd nod) Sarin taufd man fid), wenn man fie anf Betvarbtungen aufmerfiam machen will, bie

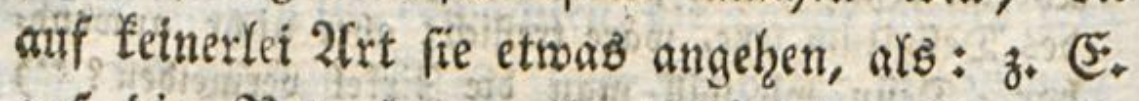

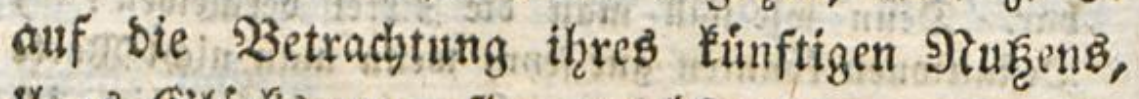
theres Glidid's wenn fie crtwadbfen fern werben, ber Shodjadiung, bie man bereinft fúr fie labent wird; Inuter Reben, bie an Sgefen ohne alle

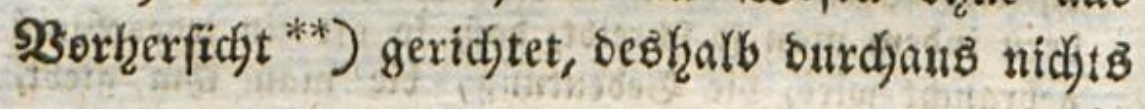

fúv

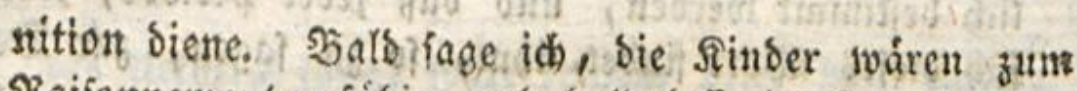
in saifonnement unfábig, uno balo laffe id fie mit fiems Yidser Seinbeit raifonniren; ich glaube mir bierourch nicht in meinen Sुegciffen ju Jviberiprechen: ich fann aber nicht in 2rbrebe jenn, bas ich mir nicht oft in $\begin{array}{ll}\text { meinen 2rusoricfen wiseriprácbe. } & \text { D. 3erf. }\end{array}$

*) $\mathfrak{A l}$ ibent ridfiges Siaifonniren nid)t eine richtige Erfenntniß̄ wefentlich jur Folge hátte. (E) flers.

গ. will fagen: man táuicht fich) in ÂAfehung ber burch eigentlichen Unterricht erfoltenen Senuts sifîe der Sinder, bie man ifnen zufdidreibt, weil fie unfere soorte wiedergeben foumen; und barin hat er obuftreitig aiecht.

Eampe.

*) Snbem ein Sind richtige Segriffe bon bein 3 uftande erivachfenter Perionen befommt, uno es erfent, baß es felbft einft in cinen ábulichen eber gleichen 3us ftand fommen werbe, welches beibes gar nidjt úber 


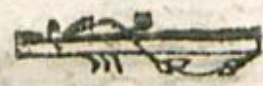

fir fie bebenten. 2Ules erzmungene Sernen bies fer armen Utnglicteltchen wiro baber nur alf ihs rem Sbeiffe ganz frembe Giegenftunde bexfdwen?

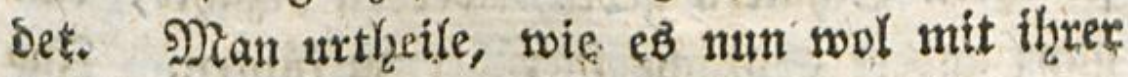
2ufmertfamét barauf befdjaffen feyn tann.

$$
\text { (5) } 8
$$

die Jáfigfeit eines Jintes geht: 10 befommt es bas burdh eine geforige Sorftellung von fúnftigem Nus

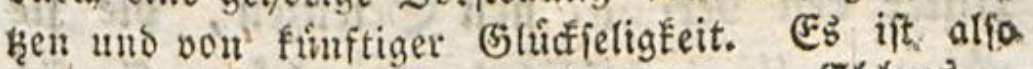
gar nitht obne atle sjorberfidit.

(E)blers.

Qhber cin Simb fann wou bem suftande eineb Erwachfenen noch feine richtige, viefweniger an

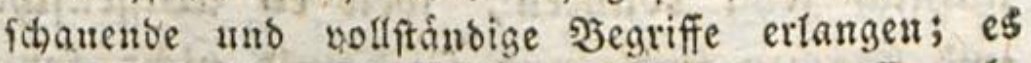
fann fid bafer and in ben Buftand eines Errvads fenen unmoglich lebhaft hineindenten. Bampe.

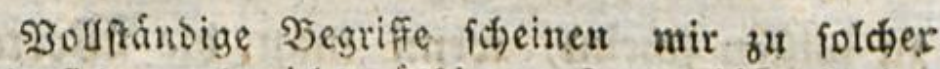
gorberficht aud nicht nothig zu fenn, bie oft ber (5rwadjene nid)t eimmal hat, fonbern nach פermus

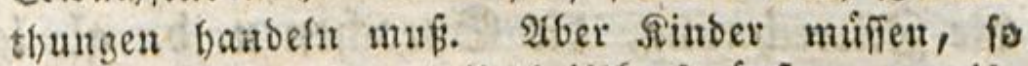

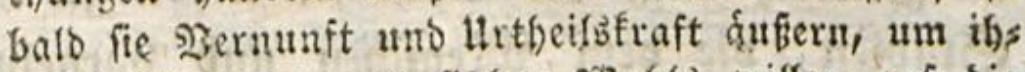
res fittlichen und whyilichen 230 hls willen auf bie

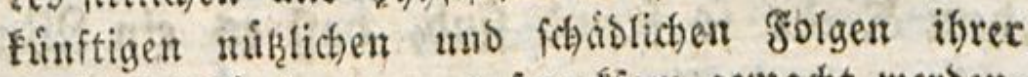

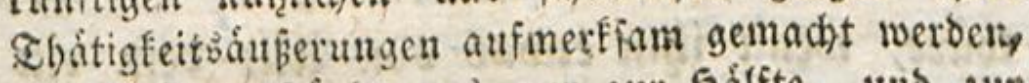
gejekst, fie veritunden es nur zur Şálfte, unb zur

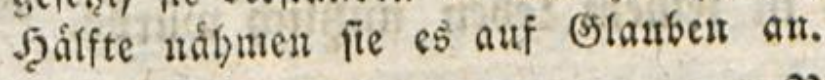

\section{Rejemis.}

g(t) bin cben biefer Neinung; nue glaube ich, จ. wolle fagen, man maffie niकht barauf rechnen,

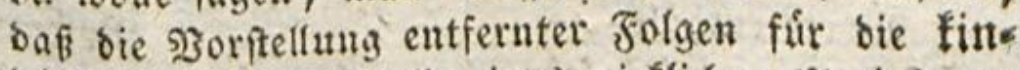
Difde. Seele bie Stelle eines wirfliden Mrotivs vern treten fonde, uno parin foreint er Fecht zit haben.

Eampe. 


\section{2}

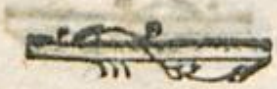

Die Eehrumeifter, Die uns mit grof̈em Ses prange bie Unterneifungen austramen, weldje fie igren Schuterm geben, werben bezahlt, eine ganz anbere Spradje biteriber zu fübren. Sns Deffen fielgr man bod ans ser 2 rtt, wie fie fich feloft babei nelymen, bafi fie billig fo wie id benten. Denn mas lehren fie fie am Ende?

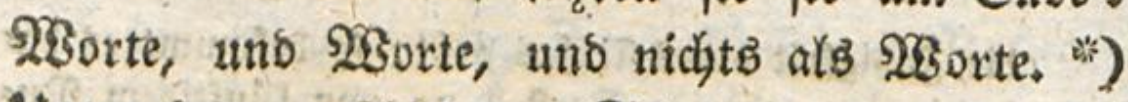
Unter ben verfibiebenen Sctenzen, bie-fie fich) riffmen, ifgnen beigubringen, biten fie fich nol stejenigen zu waiḩlen, bie thenen wahrhaftig

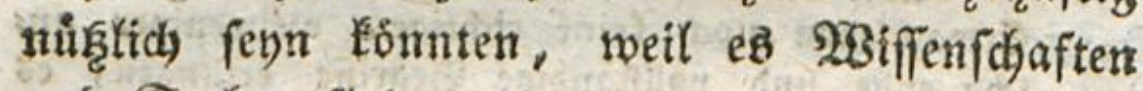
und Sachen find, und fie bamit nidyt fortéoms men witsen; fie netzmen alfo foldhe, bie mat 3u solffen fojeint, wenn man bie skorte babou

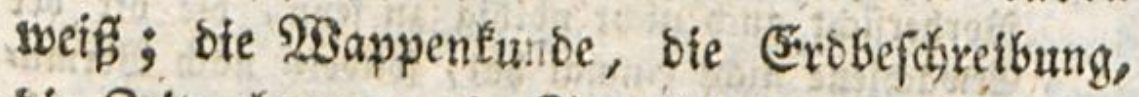
bie Beitredjnung, bie Spradjen 11. D. gl. lauter Stubten, bie bem Menridyen uno surnefimlita bem Rinbe fo fremo finto, bafi es ein 23 unber wake, wenn ihm etwas von aflé bem ein eins

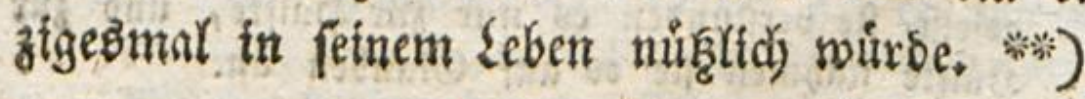

*) Solcher Itnterriché iff freilich foblecht, 2 toer es giebt auch einen Hnterridht firir Sinder, ber mefor alb

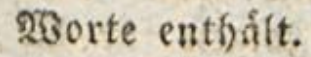

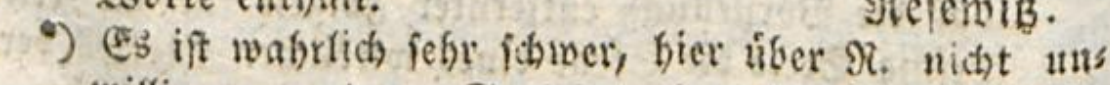
swillig su werbers. Bo jebr geht er bier in gans un segrindete Darabajien bincin.

(5)blers. 


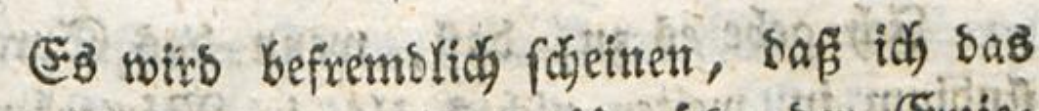
Spradjfubtum unter bas Lunibe ber Ergiez hung recinne: aber man erimnere fidi), bap id her nur bou bent Eernen bez erfen 2flters rebe; and was than audy intmer fagen mag, fo glauts $\mathrm{Be}_{e}$ idf nidyt, es hgabe jemals ein Rino, bie 228 undertinder ausgenvinmen, biB fns znolfte boer funfzelgnte Sabzr wainrhaftig zwei Spradben gelernt. *)

\section{(S) $g>5$}

ฐ)

ह3 ift bies allerbings eine unbeftimmte গुes bouptung, fo lange mant nicht angiebt, twas fur Sinder man meine, jweis ober zefniabrige. Hno Diefer Niangel genauter sjeftimmung ift eben (chuld

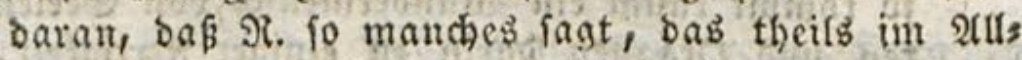
gemeinen unrictig ift, theils in ber atnwenoung feblíclágt.

Sieferwiţ.

-) $23 \mathrm{em}$ ein Rint in biefem 2 Alter brei bis vier Spras

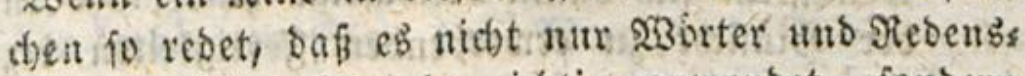
arten in jeber Epracie richtig anvenbet, fonberr felbft in bie ieber Gprache exynen Speenfellungen ant 2 Bendungen bineingeft: fo hat $e^{3}$ oud wol bicfe Epradjen gefernet. lint viele Lefer burften bavon mit mir nicht wenige Seifpiele-wiffen uns zuar Sieipicle, bie Jinter betreffen, bie nod) gar nicht sisuberfintor finb. In Sopenfagen reben feffr viele Sinter angefchence foánfer mit nidst ges ringer fertigfeit uno felbf mit cinem, ieber Epras de eignen 2fceent bánifich, bentich uno framzofich. Ein weife cingerichtetes Enrachitubium iff voráglid ein ben frihern Jabren des menichtichen febens an 


\section{4}

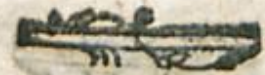

Sal) gebe es zu, bafi, went sas Spradly ftudium in weiter nidjts als in 28srtertennts nif́, das Keight, in Fienntnif ser Figuren ober ZSne, bie fie suebricten, beftúnbe, alsbanis biefes Sernen für bie Finser zwedtmápig fentm fonnte. 2ullein bie Sprachen mobificiren bet şeranderung ber 3eichen aud bie Sheen, bie fie vorftellen, Die Roppfe bitben fich nach bent Spratien, bie Sebanten nehmen ben $\mathcal{V}_{n}$ ftrich Der Soiomen an. Die Bernunft allein ift $2 \mathfrak{H}_{2}$ ren gemein; ber Geift hat in jeber Spradje

feine

gemefienes Stubitm. Fanht mau bamit fpat an: fo fommt faum ein 298 undermenión von Geelentråfs ten und Dignen Darin ju eintger Sertigfeit, wie es auch midht leidst ciren sirtuofen in bet practis fden Nufif giebt, ber nicht vom achten Jabr an wenigftens fich bamit beidiffigt isat. Die in beis ber fjiuricht ju etwerbenten Fertigfeiter begiehent fich auf ein zu gropes Detail, und erfordern zu zarte uno bieglame Digane uno Stlieber, als bą́ fie balb ober fpat erworben rerben fonntẹn.

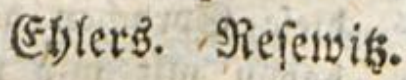

Э(4) interiftetbe bas Stubium einer Eprache

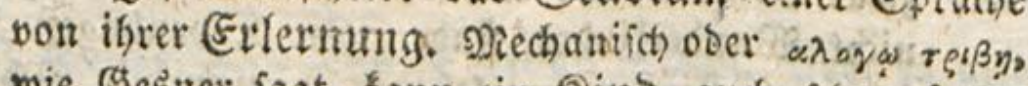
wie Besner fagt, tann ein Sind auth fojon frems be Epracten fernen, gerabe fo wie es bie Dintters fwrache lernt. 2fber cine Epractie alB Spradje frubiren, b. i. Fich von bem Eprachforper beuttiche

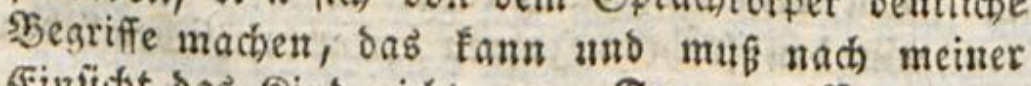
Eiritidt das sind nicht. Trapp. Campe. 
feine bejonore Form; ein Anterfjteb, bex not zum Theil bie Unfacte ober bie $\mathfrak{Z}_{3}$ irfung Der Sationaldjaraftere feun fonnte; ano was biefe Muthmaß̧ung su betraftigen fheint, ift, baf bei allen $\mathfrak{B}$ orfern in ber 2 Beft bie Spradje ben 2lbwedyfelungen sev Sitten folgt, uns fidy wie

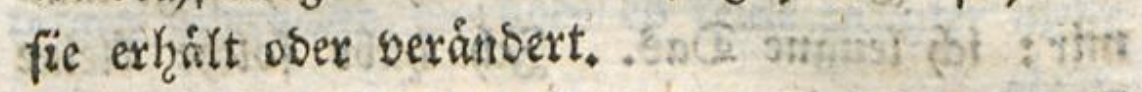

3on biefen verfoflebenen Formen gieft ber Eebraudy bem Rinbe Fine; uno bie if bie ein=

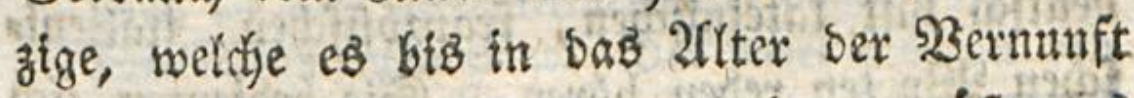
beḩalt. Lim threr zwet su haben, mügte es Soeen zu vergleichen wiffen, *) uns wie wollte

SYl") Das ift nut ber Fall, went man frembe Sprad)en aus श̧úchern uto zuar fír fich lernt. Eiu guter Spradhlebrer bat bas 23 ergleidungsgeithaft fhon vollbradt uno fuhrt jeine Boglinge alfo fogleid in

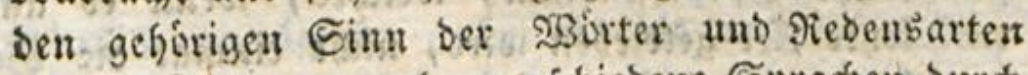
hinein. Lernt man aber peridbiebene Eprachen burch Ulmgang nit verifbiedenen \$erionen, bavon jede eine Eprache rictig rebet: fo ift jenes 3 ergleichungsges f(t)aft gar nicht einmal nothig, fo ferm es Die vers fdicoenen Eprachen betrifft. Es lernt ein Jint fo iebe Gprade, wie es fonft eine Nitteriprache (ernt. Es zieft ben Sim ber 230 orter unb Rebensarten bant von bem Esebranch Derielben ober von ber In wensung berfelben auf vorliegende finulide Dinge, Bewegungen, Samblungen und sirifungen ridtig ab und befommt alle bie Niodificationen des Beis (fes, bie mit bem rid)tigen (s)brauch einet jeber

Spras 
es fie bergletdjen, went es taunt in Stanise ift, fie zu begreifen? Sine jebe Sprache tant fir Daffelbe taufend berfdebene Beidjen, aber jeber Segriff nut eine einzige Form haben; bas Sind fann alfo audy mur cine Spradje reben

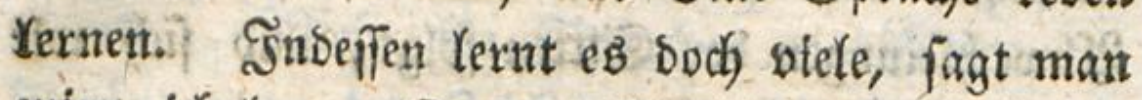
mir: id Yentune Das. Sch babe fordje fleine 228 under yerehen, die funf bis fechs Sprachen zul reben glaubten. Sh) habe fie weăfelèmeife seutrob mit lateinifhen, franzofifchen, ttalients fdgen 23 orten reben biơren. Sie beoienten fich

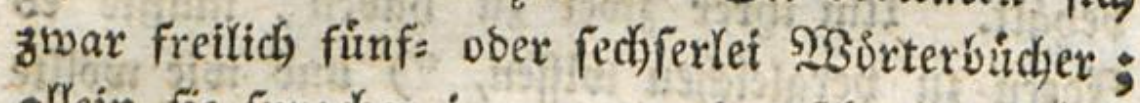
allein fie fprachen immer nur beutid\%. *) Sury, man gebe ben Ritroen fo biel Synonymen **) alछื 79214

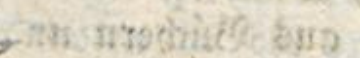

soth Epradie befentlicb fufammen hángen. Itto bas (2) frúbe Eprad)fubium, welches, weut es anf bie

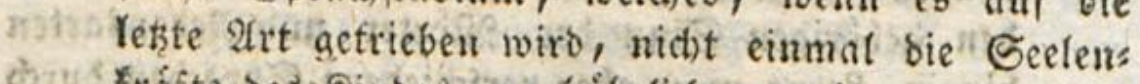
fráfte bes Sindes ingebuibrlich annreift, follte nicht nutizlicb letsu?

Eghlerb. Sicfervit:

-) Das it weder ber Erfafrung noch der Nintur ber Eeele gemáb, die in genauer trebereinftimmung mit ber Dienge uno Nannich faltigfeit ber Eindrúde, bie Hie auf ingend cine Art erfáfit, vicle uno mannid)? foltige formen in ifren goeen sunimmt, who bes ren Fáfigheit in ber foinficht weiter geht, als man es fidh vorftellen fann. Eglers. Siefenvits.

*0) Eigentlich giebt es faft feime Enuonmen. Sit von eister und derfelben Eprache bie Rebe: fo weidhen,

wie 


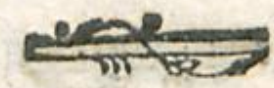

als man will, man wirb bie SSOrte berånbern, nidjt aber bie Spradje; fie merben nux Eine siffen. *)

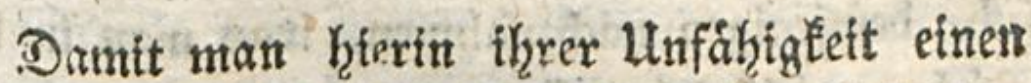
Mantel umb̧ânge, úbt man fie oorzúulidd in ben tobten Spractjen, woriber eo Eeine SRidyter meḩe

twie aus Girards und Stofhens X6handungen ers

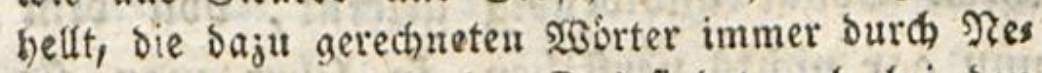
begriffe von einander ab. Das fintet auth bei ben zu verfbiedenen Eprachen gehorigen Wortern faft immer Etntt. Einne uno Seele Gaben aber eine 2tunebmungsfábigfeit, die allen Berichiebentheiten

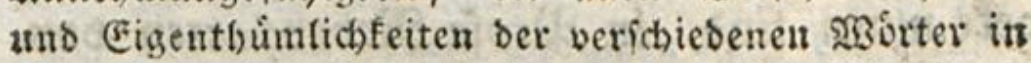
einer Sprache uno in mebrern Sprachen bis auf eis nen bewubernewarbig hohen Bras eine Bentige thu fant, wenn bie Einbriffe nur uach ihree (Fis

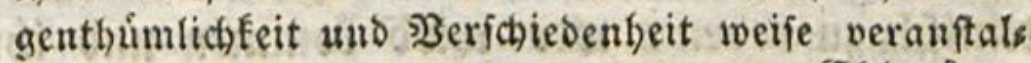
tet werben. (E) lers.

-) Námlich vorzåglich, methr als bie anbern wif̂̃en, woru fie fith weniger habent úben fonnen. Hns gewóndich wiro biefe Eine die Natteriprache fenn, weil bier gewobntich weit mehr Hebung moalidg ift. Trapp.

Eigentlich lernt maniebe frembe Sprache, neenn fie nicht burch Hebung erlernt wirb, burch Sergleis d)ung mit ber Nutteriprache. Hno in fo ferm bat alsbaun \%. Fecht, Daß̉ man eigentlich nur Eine Eprache in biefer 2 bjicht weif, auf weldhe man bas Berfteben anderer Eprachen reducirt. Dies ift aber sicht blok Siniern als Sintem, fondern allen \$rens fichen, die eine Eprache alfo lennen, gemein.

Rệenis. 
giebt, bie utan ntcht ousfdylagen Esnnte. Da Dex getmeine Sebraudy biefer Spradjen feit lans ger Beit verloren gegangen ift, fo begnitgt man fid), bemienizen nadjatuahmen, was man in sett Buidjern gefourieben finbet; und bas nennt man : jie reben. Sift nun oas Grriechifde uno Latein ber Eefirmcifter Der 21rt, fo urtheile man, wie ber Sinoer ifres feyn mag! Saum baben fie ifren Donat auswendig gelernt, bon bem fie num gar nidhts verfitef̧en, fo lehrt man fie fos

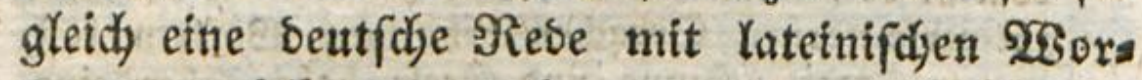
ten auborúcken, uno kernad), wenn fie weiter getominen find, in Profe Rebensarten bon (5) cero, und in Serfen Eentonen aus bem פrirgil zufammen zu nihben. 2Tbisann glauben fie las teinifd) zu reben: wer wiro fommen uno ifgnen wiberipredyen? *)

-) Poutfeau feflt hiet bas, twas man in unfern Beis ter vou bet alten Spracten weí, in ein vief $j u$ nadtheiliges Sicht. Die alten Riomer wurben ztwat auch in ben Edhriften, bie roir vom Ernefti haben, manthes zu tabeln finden; fie wúrben aber benunda gewik bie Gite feines Sateins beivundern. 28 en man eine Ev:ache in ben beften Эुichern, bie bar: in berausgefommen futs, mit Steif ftubirt: to lernt man fie aud sut. 2 tus ben unzáblich vielen Stels fen, worin 238 irter uno Rebensartent vorfommen, jiebt unan ben eigenthutmlichen Gimn und Sebrauch Ders 


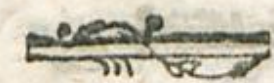

Sel eimen jesen Sernen, es fey weltheb es swolle, fins, ohue den Begriff ber borgeftellten Sachen, bie berffellenten 3etdjen nidytz. (Sileidy) sol jobrintt man inmer bas Rint anf biefe 3el

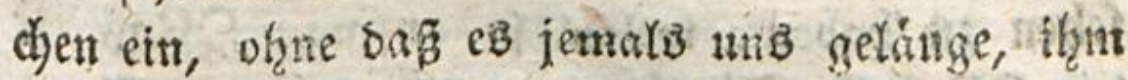
etne ber Sadje begreif(id) fu macken, *) bie fie

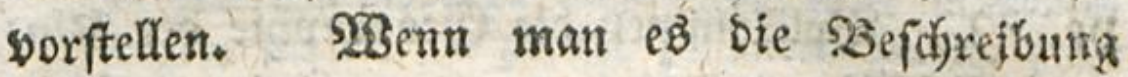
Der Errbe zu lebren glaubt, fo Yelint man es sur Lanofarten fennen: man Yefgrt es গTament

botl

Serfelben bei fortgeiekten unb anfmerfiament Sefen nach uno nad fefor gludelich ab. Das jeigt jicts auch), wenn man netere Eprachen nach oer Grame

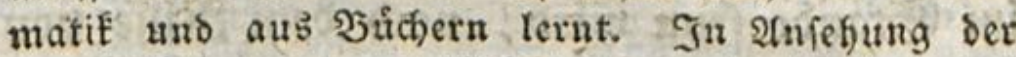
frangififden uno englifchen Eprache ift das faft ganz bei mir ber fall. $23 \mathrm{enn}$ ich aber mids verans lafit gefunben babe, etwas in biefen Eprdden ju febreiben: fo haben felbit ftrenge prifende Franzofen und Englander oft wenig in meinen গुriefen ober $\mathfrak{A}$ uf:

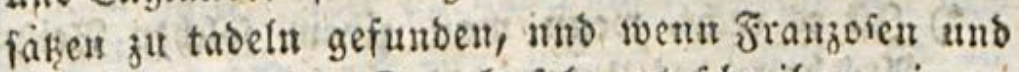
Eugtánber, bie iffe Sprache Pefo gut fotreiben, mir zut reifen etwab im Danufcript gezeigt haben: fo habe ich oft, blopi ben eigentbutumtidien Sinn uno (sebrauch bet 230 orter unb Siebensarten betreffenbe fleine mán get entbect uno serbefierungen angegeben, bie fie anerfannt uno angenommen baben.

\section{(Е))(et?.}

5) In biefem fall find bie Lebrmeiffer bóchit clende Sebrmeifter, weldies aud ber Fall fenu muf, wenn bas nádiffolgende wahr fenn foll.

Eblets. Meferdis. 
bon Stibten, Länern, Fluffen, wowon es nidht

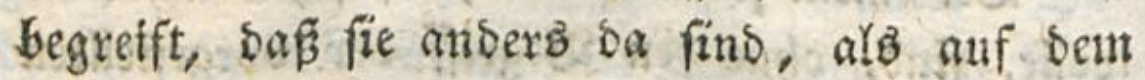
Şapiere, auf bem man fie thm zeigt. Sd) er: innere midh irgeniono eine Erbbeidireitumg ges feken zu baben, welche fo anfing: $203 a s$ ift Die 2Belt? Sie ift rine sugel won 11. *). Zollfammen sie Eleographice oer Sint ber! Sid bin, wie pon meinem Seben, ubers

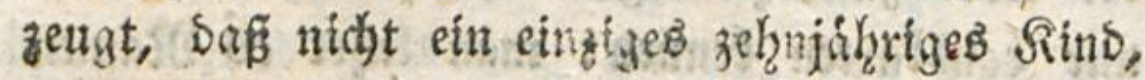

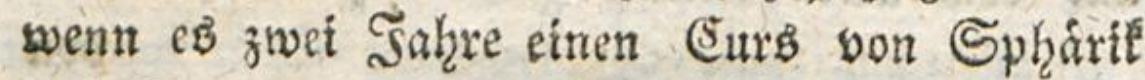
und (Sosimographite surchgemacht hat, nach allent tham gegebenen Regyeln fich von Paris nady St. Denis zu finden wiffen; Daßs nidjt ein etmaiges in Stanbe fenn wiro, nach bem Riffe bon feis nes Saters Sarten, Den Siangen Darin zu fols get, ofgne fich zu berlieren. **\%) Das find mitr

*) Sit es recht, toent man finem folchen Feifpiel in 2f: foung bes Unterridts Liberbaupt einiges Bewidht beilegt?

Eb)

Dies ift bier auds $\mathfrak{R}$. Abficht nicht. Er fúbrt siefe 2 necbote nur bazu an, um bem feier nod beutlicher ju macten, was bie Seographie Det Rin Der semeiniglich zu fenn Fflegt - Jefanutichaft mit einer Sugel von Pappe und mit ben Figuren und शahmen, bie fie auf ber Eharte fehn.

\section{Eampe.}

*) Nouffeaus Şchauptung founte fier (eid)t ourch sine Nenge von Meriuchen unb Erfabrungen wibers 


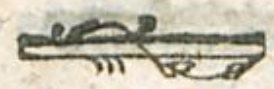

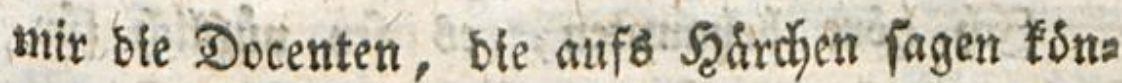

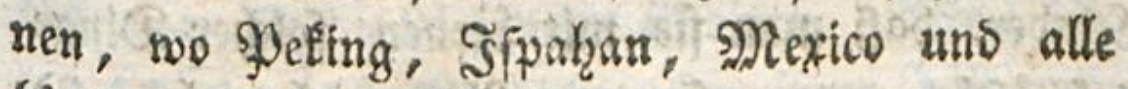
Sánber ber Erbe liegen.

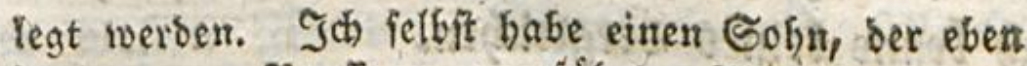
in bem von Fouffeaut augefuifrten 2liter in Sopen: hagell, fút fich gut zurecht zu finber wispte, nads bem ex nur auf eine furge Beit Den Grunbrißß vou Sopengagen angefeben batte. Nit bem Srumbrißs in ber şand wirbe er fonleich nach jeber beptimms ten Śtrabe in gan Sopentagen haben geben fon nen. In meitier frúbern Jugend bin id, ofne vors her cirren Lehrmeifter in ber Beographie gehabt zu baben, auf bie şseife wirlfich butch ganz J̧amburg gegangen. Das fint Dinge, wozu leber nur etwab̆ gute Jopf fábig ift.

Dẩ man bưch einige Hebungen zefniábrige, ia nod) jungere Sinber bafin bringen fonne, fich nach (Srunbrifien uno (5)arten zurecht zu finden, Saran ift fein zweifel; ich fellof habe es bei jebem Simbe erfabren, bem ich Die (Erobefchreibung beizus bringen fatte. 2 ber ith fing and jebesmal mit bies fer llebung au. Sb bieb úberall geichebe, ob és befonders in ben eingefoloffenen Simmern einer Etabtichule geichefien forme, bei weldhen mant oft

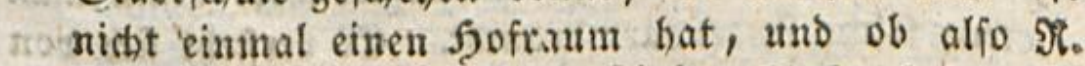
nicht in 2nfebung vieler Rinder Recht babe, if sine andere Frage. Eampe.

Banz ficher gat $\Re$. Fecht. Nur Sinber, bie auf eine ber getwobnlichen entgegengeieşte Nrt in. Der (5)egrapfie unterrichtet werben, erhalten gebós rige Эुegriffe don EGarten, Grunbriffen 4. 1. w. Der nen, bie nach befanter gewófnlidber Ant unterrids. tet werden, und, wohl zu merfon, micht burch ane Emil Ifter If. S马 Dere 


\section{2}

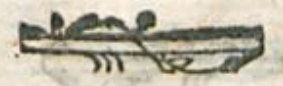

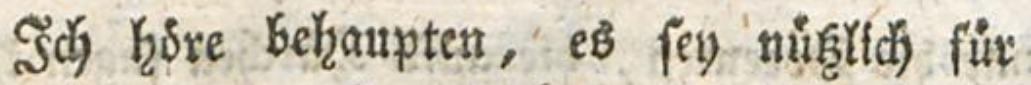
Sinber, Daf man fie mit Eernen foldyer Dinge befdiftige, wozu fie nux 2lugen braudien. *) 2Bathr wáre bieb, bafern eb irgend ein $23 i f f e n$ gábe, wozu man nux 2lugen braudite; allein id Eenne teineg Dergleicjeri.

\section{องเนต}

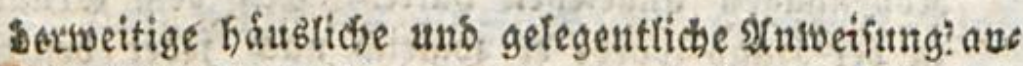
id)auliche 123orftellungen bavon erhalten, find sund bleiben bie Szegriffe ber mathematifchen und politis fchen Eeographic blob̂ inmbolifche, áuberft verworres se unb falfche \$orftellungen, wie ich nicht nur aus eigener Erfahrung vou meinet Jugendiafren, fom

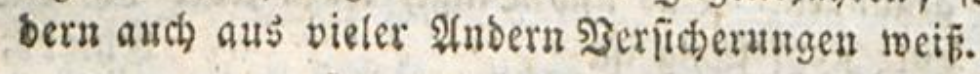

\section{Stuve.}

Situs fehlern ber Sehter im Ituterrichten mú

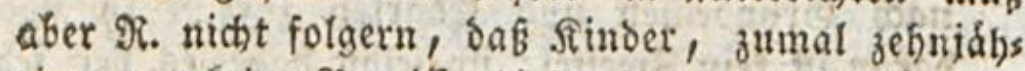
rige, gat feime ஒ̉egriffe blefer $\mathfrak{A r t}$ erbaften fonnen, Itno iffre Sinbernatur fie baran binbere. Denn bas

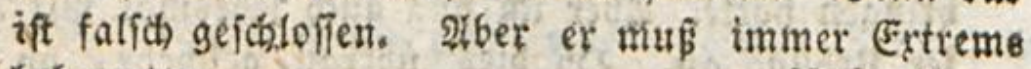
behalapten.

Refentí.

D) भ. mú soch getwufit baben; in lveldem Sinn mat eime folche Ferensart braucht. EB verfteft fid won felbet, bafi 2Betnunft und Derftand in foldhen Dins gen etroas mit thiur. Şabr ift es aber, baf fie bet Sreibung ber Seographie, wobei bie Erfenntnis in fo weientlicher Şeziehung anf ben Sinn bes Ges fidts ftebt, vergleidungsweife fehr lvenig fut thun

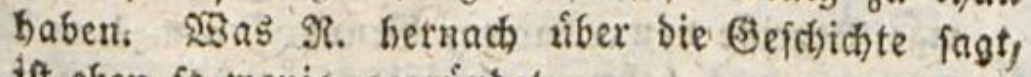
ift eben fo trenig gegrúnbet.

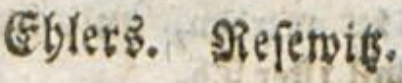




\section{3}

Dourch einen 'nod) racherlidjern Srrthum

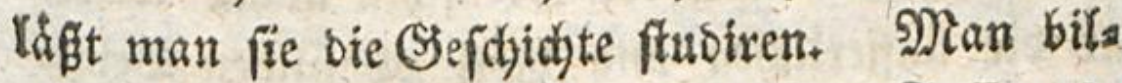

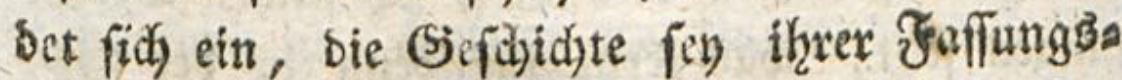
traft angemeffen, weil fie nutr cine Sammlung son Thatfacden ift; allein was berfeht man

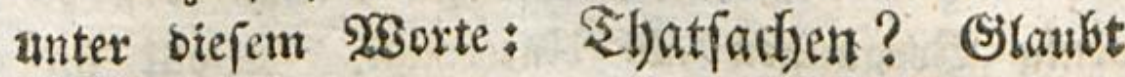
man, Daf́ Die 2 Beziełzungen, weldye die hifturia fdjen Facta beftimmen, fo Yetchi zu faffen finb, baf fich bie Segriffe babon ohne Muihe in sex Seele ber Rinter biloen? Staubi man, bie wahre Renntnif ber ßegebentzetten laffe fich von

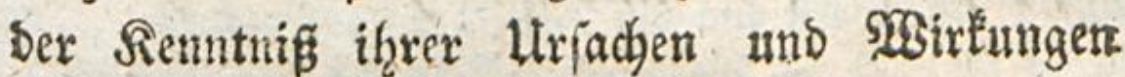
tremen unb Das Soiftorifde bzabe fo wentg tnit

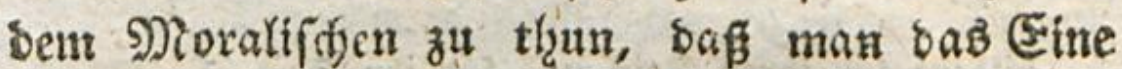
Dhne bas 2fnbere erfennen tonne? ") 23 enn SE 2 in

*) Seiser leiber glaubt man bas, ober hanbelt sods beim llnterridat, als twenu mans glaubte. Dañer reitb benn bie Befchichte ber Tugend zur Wlage, da fie, iecht getriebea, iffnen bas grópte গ̉ergnigen ger

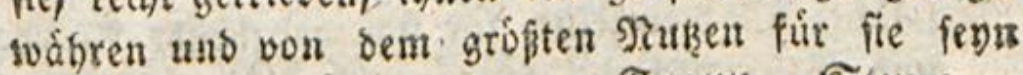
witibe.

Trapp. Stupe.

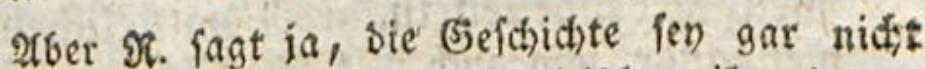

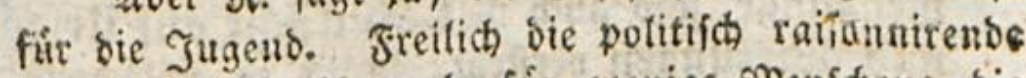

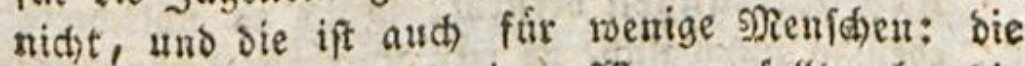
meiften fannegiefern barin. Ţasum follte aber bie

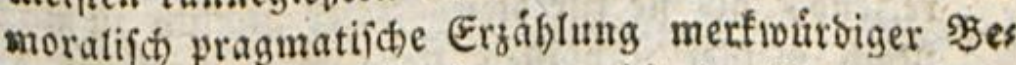
gẹbentheiten nicht fúr heranwadjende Sinber fernd Da fie ibrer Fafiung angemeffen und regrreich int 


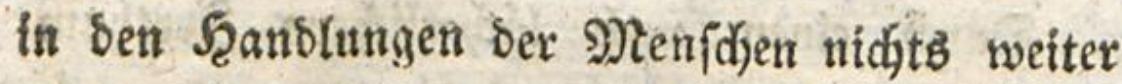

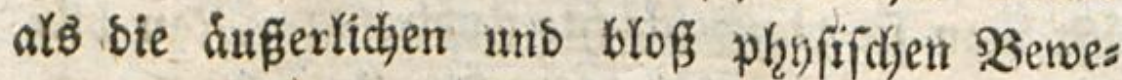
gungen felht, mas Yernt ifir benn in ber Sjes fdjidjte? Durchaus nichts; uno biefes bon als lem Sturen entblogite Sernent giebt end eben fo wenig Sergnigen als llnterridjt. $230 l l t$ ibst

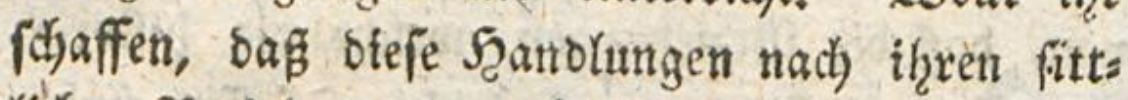
Yidjen Beziehungen gewirbiget werben, fo fucht

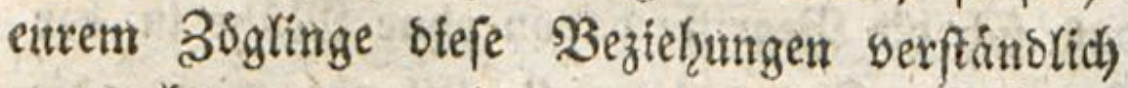
zit macken; bann aber werset the fehen, of bie

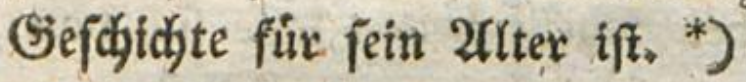

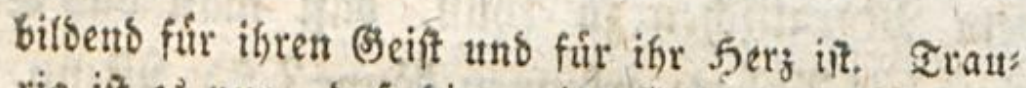
rig ift es nur, dấ bie meipte (Sefchichte, bie roir fennen, Jiriegeb: und Regentengeichichte, felten Niens fchengeichichte ift.

Refentis.

*) Sernunft unb Erfahrung - wenigitens bas, lvas von beiben mir zat Theil warb, unb oab meint ia am Enbe Yeder, ber fich barauf beruft - treten bier auf $\mathfrak{R}$. Seite. 28 enu man námlich unter (3)s f(d)ichte nicht einjelne, für fich beftehende 2rnecboten unb Beichichtchen, fondern eine Erbáblung Der Feltbegebenbeiten in ibrem naturlichen 3uiam= mentange, alfo auch mit Ficffictit auf Utrachen

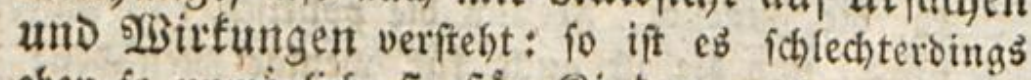
eben to unmoglich, fie fuit Sintoev anichautich uno reizent, als fie fúr biefes alter unkb̨lich ju madhen. Nac) meiner imigften Heberzeugumg follte bafer bieie eigentliche (seichichte nie frúber, als nach z" rúdgelegter Sindheit, angefangen voerbet. 2fupier 


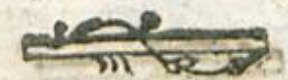

Sejer, erimnert euch ftetb, baf, ber bier ful end rebet, weber ein Sielehrter, nodh ein Sobitofoph ift, fondern ein Mann fdjled)t uno

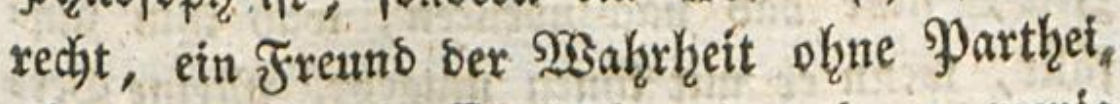
ohne Syftem, cin Einizebler, ser, oa ex wenig

$$
\text { इ? द } 3
$$

mit

ben von $\Re$. angefúbiten Srínben, berbient unter andern aud hoch biejer angemerft zu werben: baf es eben fo unvermunftig als fodsdich ift, bie junge Secle fhon in entfernte Seiten und Sánder zu fúths ren, beren Berfaffungen, Sitten, Sprache uno B̈es bráuche fie nodh nicht fennt, ช̆u einer Beit, ba fie von ben taufens Dingen un und neben ifr, bie alle eine weit nábere Э̧eziefung anf fie und ifre 230 bls fenn haben, faum ben taufendften Theil fennen zu lernen fdon (5)legenheit hatte. Sampe. Trapp.

Szou ber Univerfalgefdidhte, fo wie fie ba ift, if bies waht: aber wo foll bas Sinbesalter ans fangen, wo fie gelernt werben foll? SSenn man beftimmen will, was Sindern angemeffen fen ober nicht, muß man immer beftimmen, was nach Sers f(f)iebenheit ber Gahre mit ben Entwicfelungen ifrer Siraffe unto $\mathfrak{2}$ nlagen und Thátigfeiten úbereinftimme. Ind bas fheint $\Re$. gar nicht beobahtet zu habent. Er behauptet oft Dinge, vie von vieriábrigen sims beru vabr, vouzebniábrigen es nidht fino.

\section{Rejenis.}

Td finbe biefe 2fumerfung febr richtig; $\Re$. hat oft barin gefeflt, bafi er ganz junge uno áltere

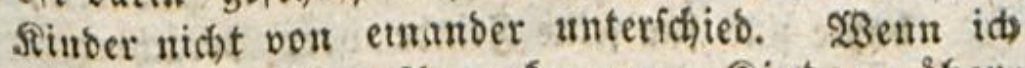
felbit, wie in obiger $\mathfrak{A}$ umerf ang, non Rinbern niberbaupt rebe, fo meine ids immer foldbe, bie noch sidat igr zrwoffteb gabr crreicht baben. Eampe. 


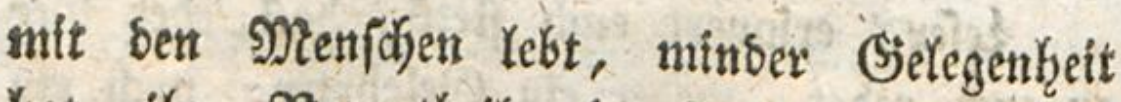
bat, thre SBouturtheile einzufaugen, uns melgr

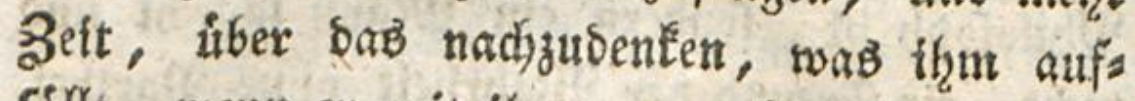
fallt, went ex mit ibzen ungefrt. Neine Sers

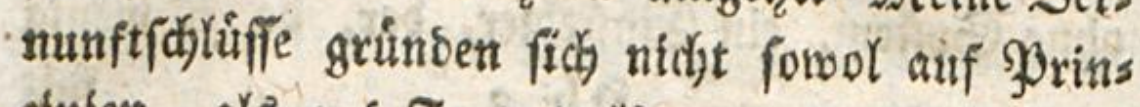
ctpten, albs auf facta; *) und ith glaube end sitcht beffer in ben Stano fergen zu Esnnen, úber fie zu urtheilet, als wenn tch) eud oftmals ein Beifpiel yon ben Beobadjtungen beibringe, bie - unir fie eingeben. ${ }^{*}$ )

Ӭib) batte einmal efnige כage auf bem

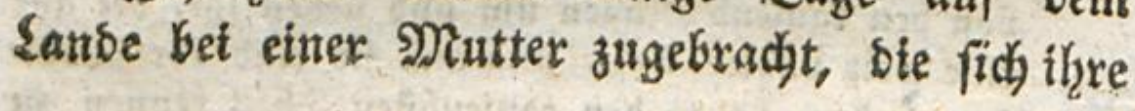

Ritis

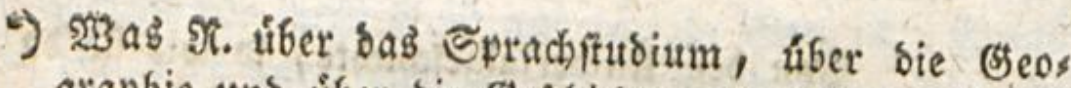
graphie und uiber bie Ëefchichte geiagt hat, gruinbet fich fo wenig auf facta, als auf Principien.

(E) ler:s.

Diefem Itrtbeile muḱ id trach meiner ttebers jethgung gerabezu wiberiprechen.

Stuve. Sampe.

Die facta find unt fefr einfeitig gewáblt uns sargeftellt. Der Eimfitedler hat bie wahren \$̧erbálts niffe unb Entwiffelungen ber Nenichen iu ber B̧e: fellfhaft nicht ruthig und unpartheiifich genug futs sirt, fich von vorgefapten s) eimungent biureifien Yaifen, uns bie Nienthen narh ben Parifern, bie er baß̧te uno fúr feine Jeinbe ober Seráchter bielt, bes urtbeitt.

शieferwigh.

**) R. Lat uns in ber ฐgat boburch einen grofien 2iente geleiftet.

Stapp. 
Rimber uns beren Erzitehung feffr angelegent fegre

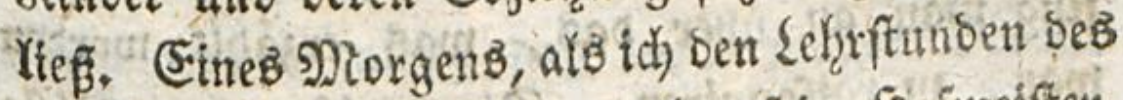
2lelteften mit betwohnte, nahm fein Scofimeifter, bex ifgnin ber alten Sefdichte fehre wohl unters

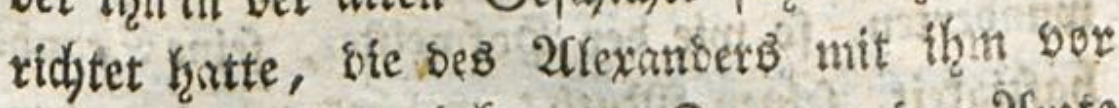
und fam auf ben betunnten 3ug oon bent 2 rate

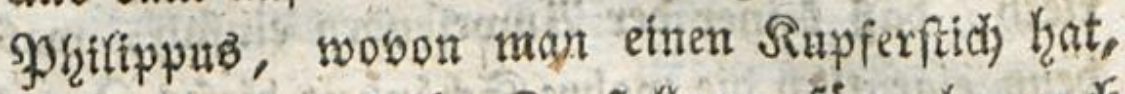
uno ber eine folche Darftellung firmafye aud wol verbieute. Dex Şofmeiffer, ein geffhid'ter Mtann ibrtgens, madjte bet Ëelegenhett ber Utrs

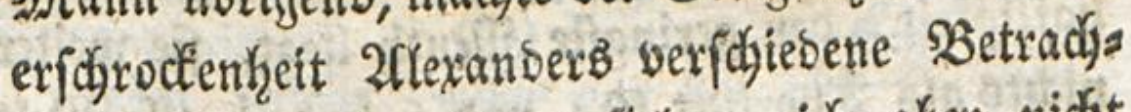
tungen, sie mir nidjt gefielen, id's aber nidjt beftreften mogre, bamit id) ifgn nidht in ber D)einung feines Hntergebenen herabjerte. Bef Bijche unterltefs man nidyt, nach franzofificher

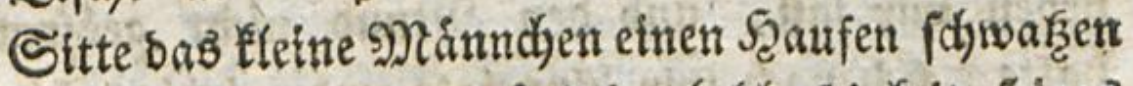
zut laffen. Die natirlidje Sebraftigfeit feineỏ 2liters und bie Erwartung eines thrm gewiffen Beifalls mathten, bape ex bie Nenge 3horkets ten sorbradyte, unter benen senn von 3 eit zu 3ett elt glictíliches 2980 ort nit unterlief, woriber man bas Llebrige vergeffen fonnte. Enolicy leant auch

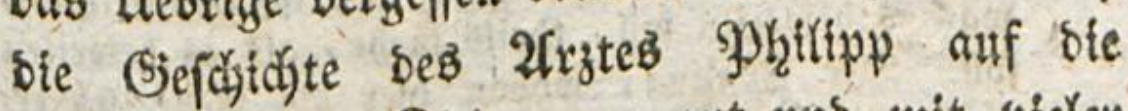
Bałzu, sie ser Sileine ganz gut uno mit bielex

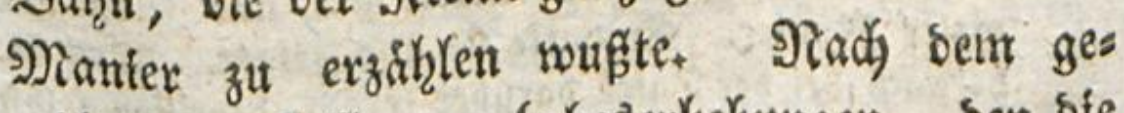
woskznliojen 3olle von Lobeserkebungen, ben bie

$$
\text { S马 } 4
$$

Nopts 


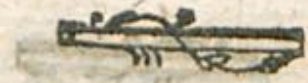

9) Dutter forserte, uns bas. Sofhudjen erwartete, fing man an îber oas, was erzâhlt worben swar, zu ratfonniren. Tie meiften ber Gáfte tabelten 2llexanbers Berwegenheit; einige bes wunberten, fo wie ber Şofmeifter, feine Stunds baftigleit, feinen Muth; weldhes mir benn bero rieth, bafi feiner ber 24 nwerenoen einfah, mas senn eigentlid) ote wahre Sdjonlzeit biefez 3uges aubimadite. Mír beudit, fagte id) sarauf, bafi, wenn in 2llexanders f̧andlung ote gexingfte Seerg. baftigteit, ber geringfte - Nuth liegt, fie meiter

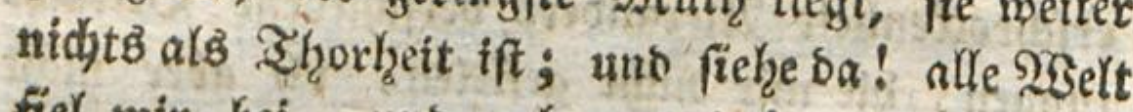
fiel mix bei, unb gab. zu: ja! es nitue nux eine Thorbeit getweren! Schon wollte id, ants soorten, uno aufloderu, als eine Frau, bie neben mir fä, uno ben Mand nidbt gesfnet batte, fich nady mir binneigte uns mir ins S brx flifterte: Stille, Saans Sacob; ie werben bid nidjt verftehen! Sid fah fie an; waro betroffen und fdnieg. *)

\section{S(ad)}

-) Das bier gegebene Beifpiet beweift theils nidt, was es belveifen foll, theils mebr, als es bewcifen foll. Der Sogting, wovon bier die Siebe ift, ers zåflte die (sefichichte des arytes gut und felbit mit vieler s)ianier. Ex batte fie alio gefagt, $23 a s \Re$. hernach bei ber Safel barúber (prach), begriffen felbit die (Sáfte nicht, und or und bie bei ifm fiß̨ende

weis 


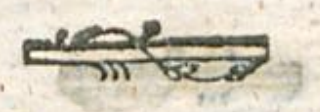

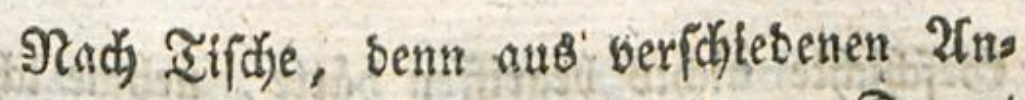
zeigen ainnoete mirB, 'baß̈ mein junger Docant yon der ganzen burd) ihn fo brab exzáftien

$$
\text { S马 h } 5
$$

Sies

meife zran glaubten felbit, baß $\Re$. fich vergeblids bemúhen wúrbe, ben, hoffentlich zu verninftigen Gabren gefommenen, (s)áften es begreiffich) zu machen.

(E)lets. Riefẹvig.

2tber bieie inecbote ketweift benn bod wot fo biet, baह̉, wenn oft cine ganje (sefeflichaft gebifs beter Nenichen nicht in ben (seift einer (seichichte einzubringen, ia nidht einmal bieien Beift aufarta fafien vermag, wenn man fich auch bie Mitifye nehmen wollte ifn fur fie beraugzujiehn, dicb nou einem Sinbe nod) viel meniger erwartet werben fonne. SRebr aber wollte $\Re$, Damit nicht anbeuten.

Sampe. Stuve.

Sian founte aber auch nod weiter baraus folgern, Dafiach gebilbete Nenfden feine Beichichte leien ober ftubiren musten, weit fie nidht immer in ben Eeift berfelben einzubringen vermógen. $\Re$. irrete aud, Daf et 2llecanbers Entichloffenheit láugnete, weit es cine Shorheit gewefen. Befę̧t shorbeit ober Eitelfeit fey bei ifm mit im Epiel geweien, fo boret es bebs wegen nicht auf Neuth zu fenn. S3enn aber bas Eittlidse ber Segebenfeiten fo fehr verichicben unb

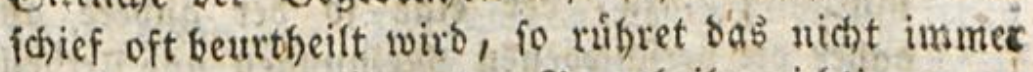
von bem llnvermigen ber \$curtbeiler ridtig zu urs theilen her, fonbern bánfia uns mehrentheils, bafi

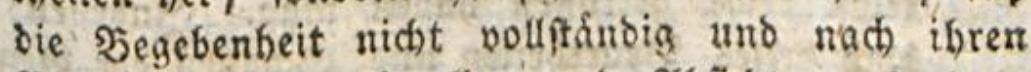
3eranlaffungen, Quellen und 2ibfichten, fonbern

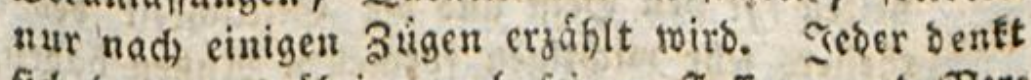
(id) Dann bas úbrige nach feiner Fafiung und כers muk 


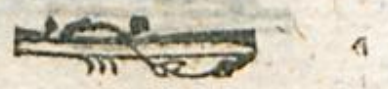

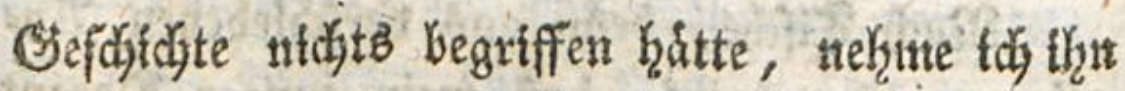
bei ber Şand, getge nit ifm tm Sarten auf uns $a b$, and finde senn, nadjoen idj tha in

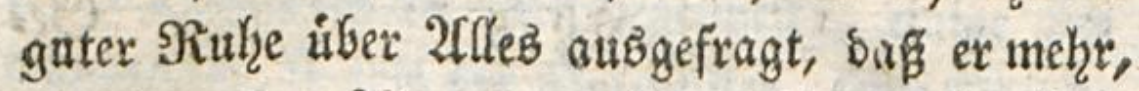
alв jemano, 2trexanders fo gexifhmte Sgexzhafs rigéeit bewunderte. Sollte mans aber mol glaus Gen, worin ex biefe Sgershaftigteit fudyte? Fins

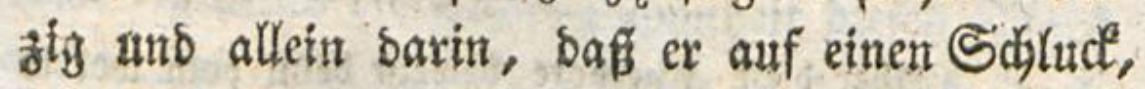
whne fids zu befinnen, ohne ben geringfen 238 is berwillen zult bezettgen, ein úbelfdjmedtenbes Zråntchen zu fich genomuren fatte. Das arme Rino, sem man vor nods nicht vierzelyn Iage 2 rzes

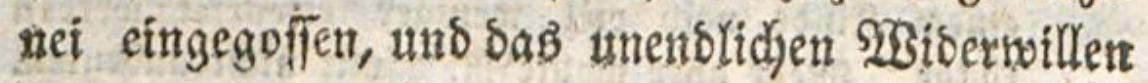
babei empfundent, Gatte nod, Den SRadjgerdjmad

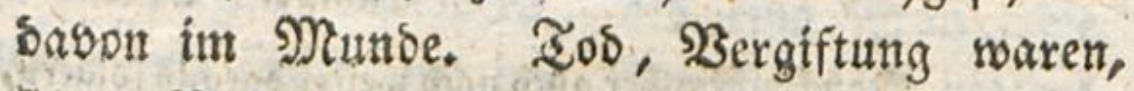
Peinet Meinung tach), weiter nidhtb' als unans genefime Ermpfintungen, uns es̉ fonnte fich) feit anderes Sift, als Senesblatter gebenten. Ș: bef mußs man geftehen, baf die Stanshaftiga Eeit

wuthung bints, bei eine fo ser anoere anders: baher bie verfohiebenten खeinungen und urtheile bar: fiber, wovon es Ecincs fur Den biftorifchen zall felbit recht getroffen baben mag. Inbelien fann

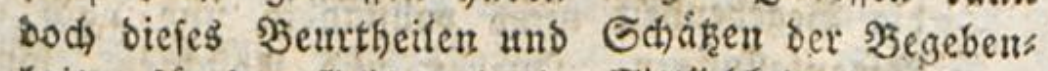

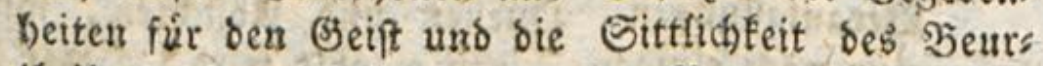
theilers jebr widhtigen formellen situsen baben, unb bat ifn oft, wenn bas lejen ber befchichte zu bies fer tebung angetwanbt wirb.

গefervik. 


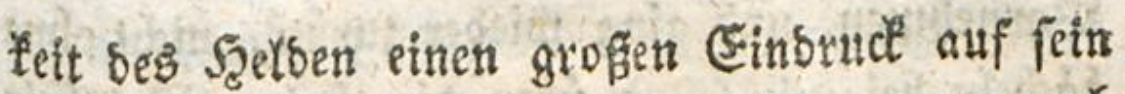
junges Serz gemadit hatte; und ex war aud nut Des ferten פ̧orfares, bei ser exften 2irzenei,

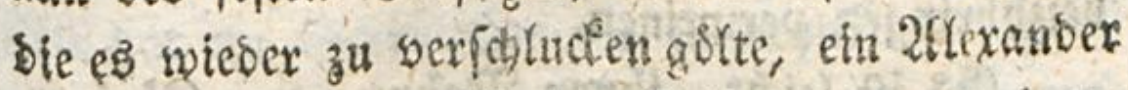

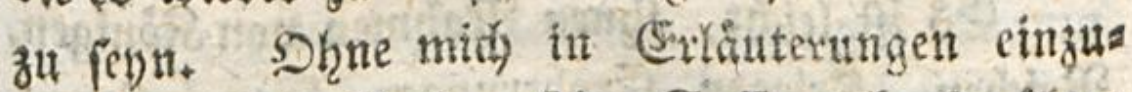

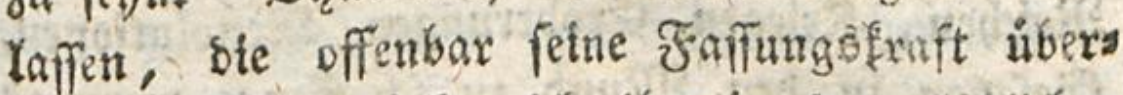

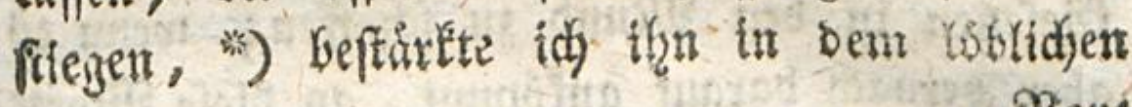

Box:

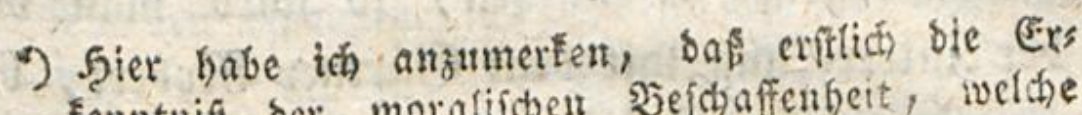
fenntnis ber moralifchen bejchaffenteit, welche Aleranbers franblunis batte, nitht eigentlich zwr

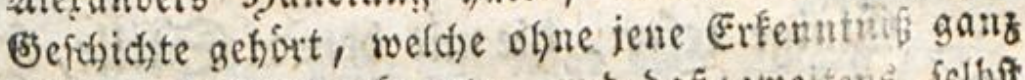
riditig gefapt ienn fonnte, unb baE: zweitens felbit

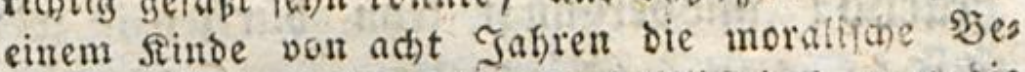
foraffenbeit iener Jyandung, unb felbit das, loas bie

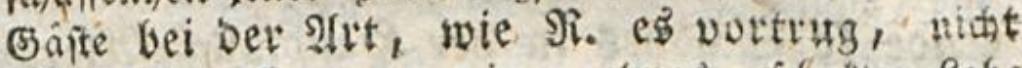
fogleid begriffen, vou cinem etwas geidstôten Sebs rer feffr gut begreiflida gemacht werben tant. Hes brigents erwedt bas, was bier $\Re$. von dem 3oglinge fagt, uicht febr vortieilhafte Sुegriffe bou belien

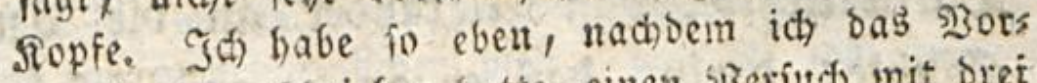
hergehende geithrieben batte, einen sjeriuth mit brei Tónten bon 6, 7 uno 9 gabren- hiber chen piefe 2aterie argeftell und gefunden, bá́ felbft bie jungite îch alles richtia vorftellte und on felbit bie áltfite erfanute, Alerander batte, oa et eizr feftes Butrauen zu feines 2frotes Sreute uno Restichfeit gebabt hatte, znm (Einnebmen bet 24 rzenei feinen S) (utt) gebraucht. Tuf bie Srage, ob auf ben Fall, sa flferander uber bes 24rztes Srene elinen Smeifel gehegt bátte, Allerander Sorghaftigfeit lewiefen bátte, antwortete iie fogleich: is, Ituf bie fernern

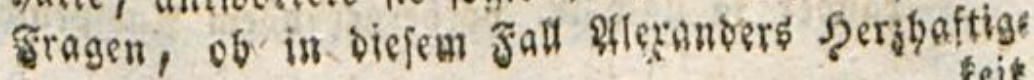
feit 


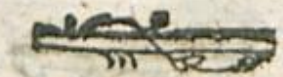

23ornefinen, uns ging mieber zuxict, nicht ofne sadjeln bei mix felbft utber bie hobe 2 Betshbet ber Sittern uno Lebrer, bie Rinbern Sefdjichte beizubringen. vermeinen.

SB̉ ift leidjt, ifnen Scahmen von Róntget, Reidjen, Rriegen, Eroberungen, Rebolutionen, Serergen in ben Manno ou fojaffen; wenn es aber hernad, sarauf anesmmt, an biefe 238 orte reine Begriffe zu Enupfen, fo wirs man von

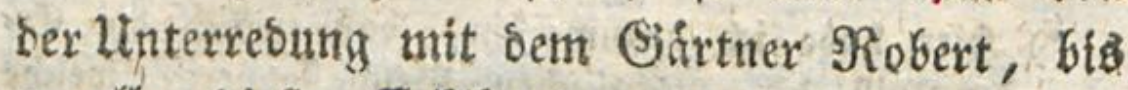
zu allen biejen Ertárumgen, noch weit bin hatben.

Einige sejer, bie mit bem: Stille, Şans Sacob! misbergnugt fenn burften, werben, id) febe es sorams, fragen: was idj benn am Ende fo Sidjones in bex Şandlung 24rexanders liegen finde? Sceillore Frarger! wenn man es euch fagen mus, wie werbet ifhrs beritehen? Darin Yiegts, bafi 2lexander an bie Zugeno glaubte; barin, bafí er an fie auf Siefahr peis nes Sauptes, auf (S̉efalar *) feines eigenen Ses

feit zu fobentoáre, antwortete fie: nein, benu in

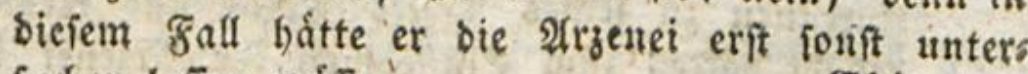
fuchen lafien inififer.

Sebri gut!

(5) lers.

Nieferviz.

") 2uf Befabr feines eignen Lebens? Da hátte alfes zander ia nach $\Re$. vorbergebendem अus\{pruch eine 


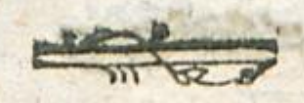

Sebens glaulte; Dartn, Dä́ feine ganze Seele gemadyt war, an fie zu glauben. $\$$ weld eir

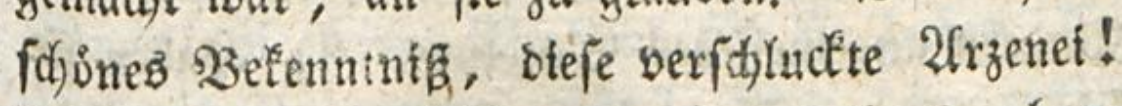
Site hat ein Sterblicter ein fo erhabnes abges legit: giebt es irgend einen heutigen 2flexants ber: fo zeige man thm mir an Dergleichen 3itgen! *)

\section{İBen}

Thorbeit begangen. Er wanfte aber gar nicht in

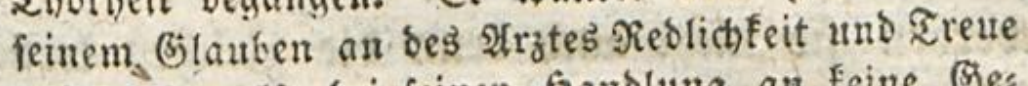
und bachte allo bei feiner fyanblung an feine (Ge: fabir.

(E)

Ifleranter batte allerbings nod einigen Btweis fel; benu er fahe, wie Eurtints erăbált, bent leẹns ben Whitipp mit unverwansten 2 fugen an. Hnd barin liegt ia eben bas Grofe ber faanblung, baß er, ba Brinbe fúr und viber bie Piechticthaffentheit Des $\mathfrak{A r}_{j}$ tes ba twaren, ber Seld fich fúr verpflidtet bielt, aud mit Befafr feines lebens, nur bent erftern, nicht aber ben lekztern Behor zu geben, weil er, wie $\Re$. fagt, an bie Tugend glaubte $\delta$. i. es fuir waffrifteinlicher bielt, daf bie ifm juges fommenen Nad)ridten falich \{evnn, als. baß̉ cin

- Siann, defien Rectitichaffenbeit er immer belvábrt gefunben hatte, mut auf einmal zum Echurfen twers ben finne. - Hcbrigens fpricht wol nichts ftárfer fúr bie গ্র̧ahrheit belfen, was $\Re$. mit biefer 2Anecbote

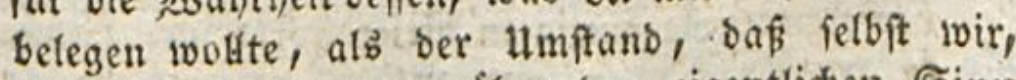
feine Commentatoren riber ben eigentliden Sinn berfelben, nachbem $\Re$. ifn uns f(t)on aufgefthlofien batte, noch bifipentiren fonnten. Sampe.

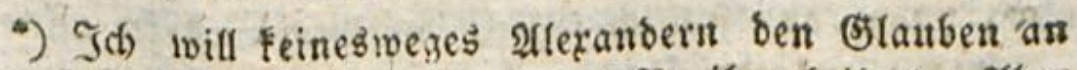
bie Eugend abiprechen, ben $\Re$. ifm beilegt. 2tber fein 


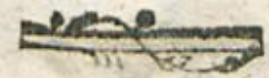

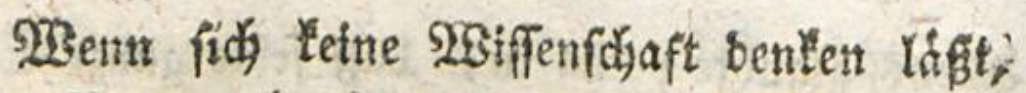
bie in 2 Şorten beftitnde, fo giebt es auch Fein Rinbert angemeffenes Stubium. *) Shaben fie Feine wakten Soeen, fo hatben fie and keit

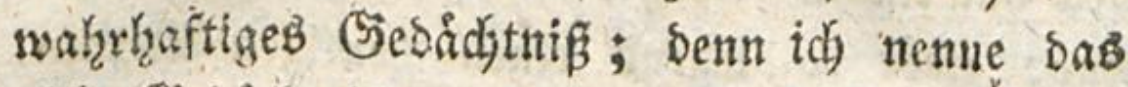

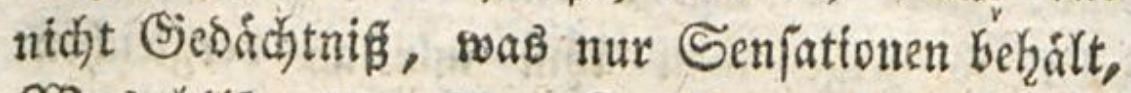

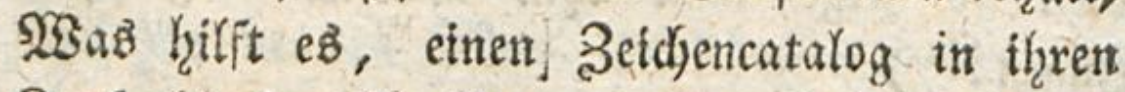
Riopf hineinzujdoreiben, Deffen Sinhalt fur fie

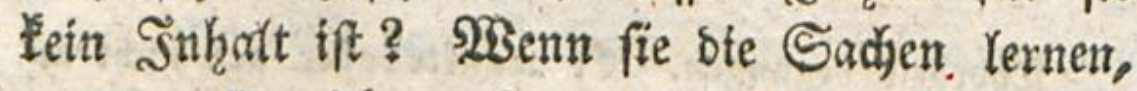
werben fie nicht and) benn bie Beidyen lemen?

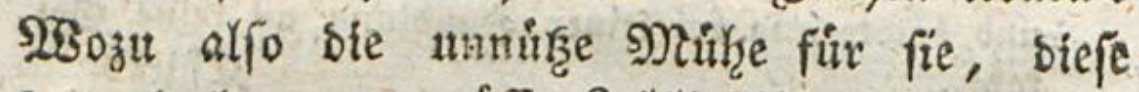
boppelt Yertien zu muffen? ${ }^{*}$ ) Und was fúr ges fákzrs

Feit Temperantent und feitre Sage ivirftett auth

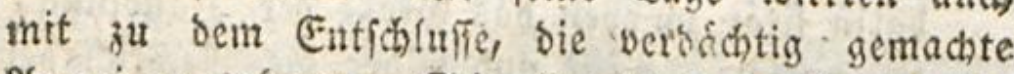
Ilignci zu nefmen. Shanell gefitno ober tost wolle et \{eyn, mufte er, etlerander, feynt wollen.

Trapp.

-) Cum grano falis berftanten, ift bies allerbings wafir. 2tber eben fo verfianden if auch bas Begentbeif

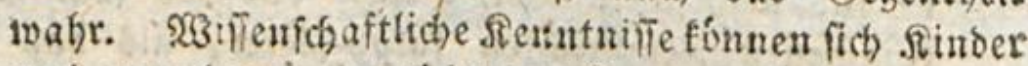
nof erwerben; nur nicht ber frorm nad, nur nicht in foffematifher Siomung. Beffort diefe form,

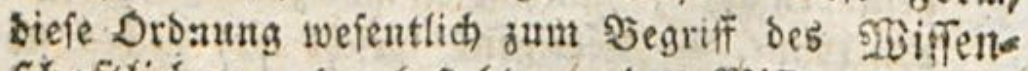
(d)aftlichen, ober bepeft gar bas $23 i$ fienchaftliche ber Senntuifie einsig in biefer form unb Dronung: fo freitich fonmen unt múich ben fintorn feire

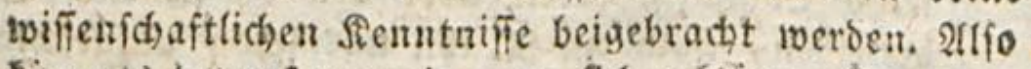
Fomunts batauf an, lvie man fich etflart. Stapp.

Oa) Dian fanu freilich, fagen, Dak bics alles zu allges

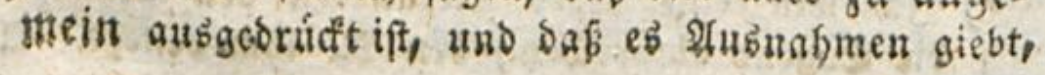




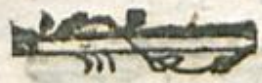

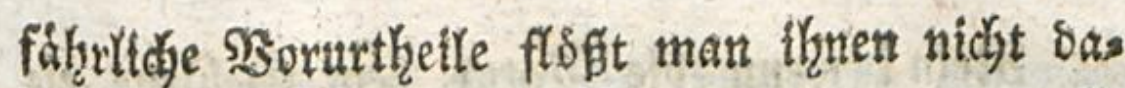
Durdi) gleidy som 2lnfange ein, wenn man fie S28orte, bie teinen Serftano für fie Faben, für

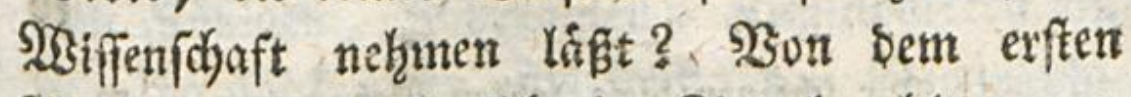
2Borte an, womit fich ein Sind bezahlt; bon ber exften Sadje an, bie es auf Treu und Grauben eines 2tndern Yernt, ohne felbft ben

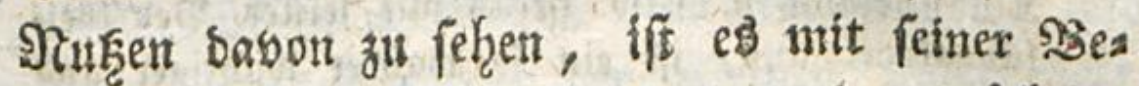

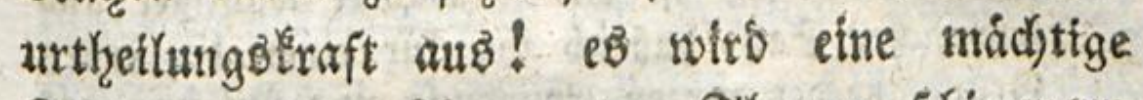

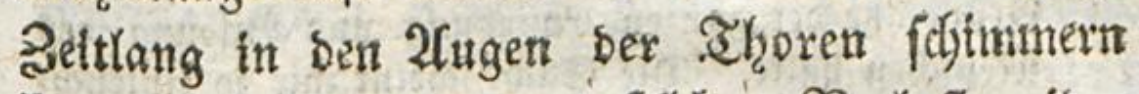
tounen, bebor es einen foldien গ3ertuft witbet expest. *) †)

Tein!

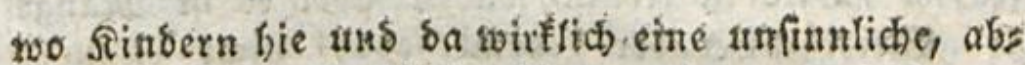
fracte, wiffenfchaftliche Ioee wabre und beftimmt beigebracht wirb: aber wollen wir, biejer feltneren Fálle pegen ben friben wifienf(b)aftlichen Hnterribet im (sanjen billigen, ba es fich boch grofgtentbeils svinflich fo mit ifm verfált, wie fo. bier befchrieber bat? 290 flen wir bestwegen, weil eहै wirffich ie zus soeifen Sinder gab, Sie bon zwanzig uno mebr fuinftid zubereiteten (5) erid) fen und (Jetránfen ges nießen und das Senoffene veroanen fonnteli, itm biefer fétenen 2tusnabmen roillen, es billigen, baj unfere Sinber úberbaupt wie unjere f́djuelgerifchen alter za leben angefuibrt werben? Eampe.

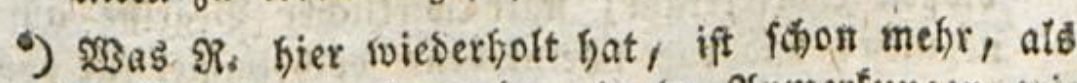
binlánglich bur borhergehende Samerfungen tois berlegt.

(5) Jlet:3.

2) in febe aber audi meine vorftebende 2nmerfung.

Gampe. श्यें 


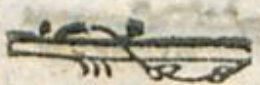

SRein! wenn bie Matur bem Şehine eis neß Rindes btejenige Sefdjmeioigfeit giebt, bie

5) burchaus richtig uno vollfommen wahr ju fevan bap fie fich auf feine 23 eife wibertegen laffen. Der Eak̨: von bem erfen Şsorte an, womit fich ein Jind bejafit ut. f. 10. ift es mit feiner Şeurtheis lungstraft aus, ift ein fo waljer widtiger uno

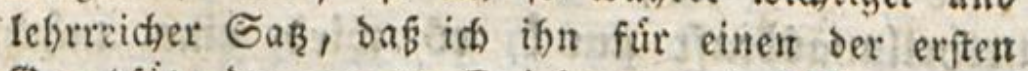
Grundiákze der ganzen Frziehung und જilsung des Mienchen halte. Die Sache icheint mir to einleuchs: teno, baß̈ ich ben Ilnwillen des Sejers zu nerbienent glaubte, wenn id etwas. SBeiteres zur Ertáuterung ober zum গ̧eweife berielben, fagte.

Stuve.

Dies ift freilich wabr, aber es ift Nangel ber NGeisheit in ber Lefirmethode, nicht Naangel bes Trafrungsermogens in ben Sinbern, woraus boch $\Re$. immer araumentirt: unb ba if es boch unerweiss lich, bafi Sinder, wohl zu merfen, bis ins zebnte, zwolfte $g a f r$ nichts 28 iffenichaftides zu falfen vel:s monten, joubern uur bie şorte bebielten.

Miefenviz.s.

93 en man Sinber vor bem ziwblften ober gar vor bem zehnten Эahre in wifienichaftlichen Dingen wiffenichaftlich unterrichtet: To fheint es ooch wirks Iich, auch bei ber beften Sefrart, unvermeiblich zu

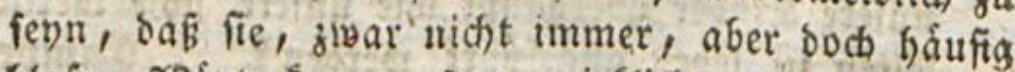
blofen 280 rterfram, ftatt wirflicher Sbegriffe aufs nefmen; und bas fheint benn boch immer fuir bas

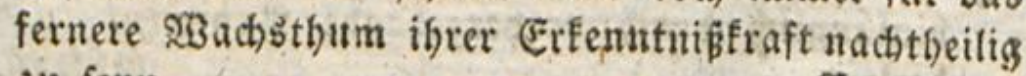
วu \{evu.

Sampe.

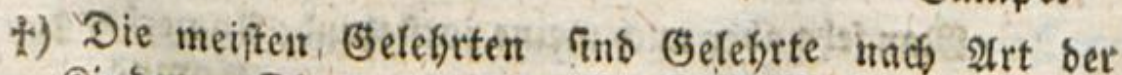
Riuber. Die weitidichtige selebrfamfeit entfpringt nicht 


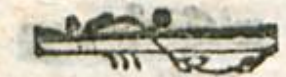

es fathig madit, allerb̨and Einbridle aufzunehg men, fo thut fie es nift bartm, baß son Rosnigen, Sałzrzablen, Runftwơrtern aus Der Steraloidf, ber Sphäride, Der Sieographife, phute ben geringften Sinn fir fein, uno ohne Den geringften গtuken fúr irgend ein 20tter, ober andre alfnlidje, womit man bie traurige unb unfrudftbarre Sindheit ber Sileinen untersridt, hinetingegraben werben follen; ponsern bazu, bing

nicht forvol aus einer Mienge gocen, als atts einet

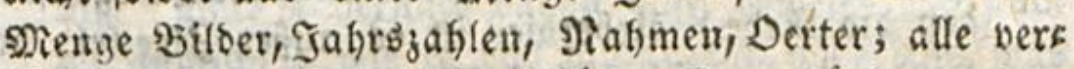
eimzelte ober won goeen entblópte Siegenftánbe werben

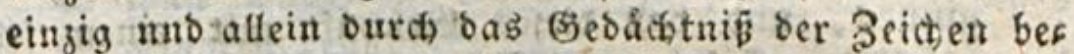
balten, unb. felten extinnert mast fich eines biefer Dinge, ofne fith zugleich bie erfte oder zweite Seite Des Blatteb, too man fie gelefen bat, ober bie stgur, anter ber man fie bas erffe mal fab, Dabei vorjus fiellent. Diefer girt wat beinatie alle sasifenfigaft, sie in bem vergangenen gafythunberte Nrode war; mit ber bes unirigen verhált ces fid wiber anbers. Mant ftus.

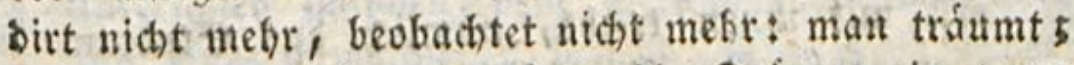

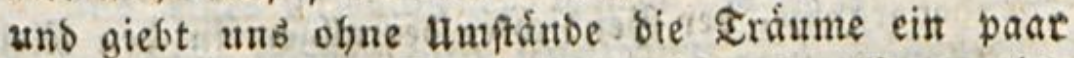

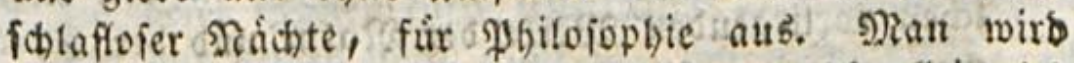
mir fagen, iff́ tráumte auch : zugeftunben! allein id werfaufe end, twas bie 2nsern fich wol zut thut

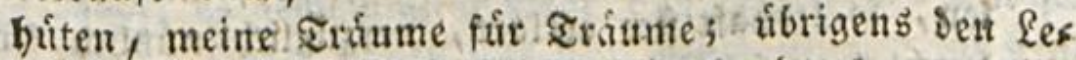

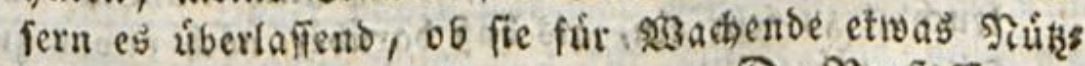
liches baben tónnen. ")

D, Berfaffer.

*) $\Re$. hat fier bie franzofitchen Gelehyten bor Aftagen; nur biejé Eannte er.

Niejerwik.

Emil af̂er §\%. 
Saf ntan alle bie Şben, *) bie fie begreifen fonnen uno bie thunen nüglidy fins; alle Diejents

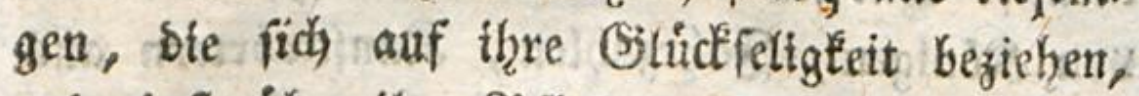
uno einft biber ihre Pflichren fie erleudjten for

-) Da wirb es benn abermal zugeftanden, baf́ Ninder nicht nur Beichen ber Soeen, fonbern auth Joeen falien fonnen. Jionnen tie aber goeen aunefomen * fo múffen fie vorzúalich leicht Goeen won. S36ortern annebmen, bie eriftirente finnliche Dbiecte bebenten. Bei ber Sftt von fienntniffen, wovon $\Re$. vorber ges fagt bat, סaß́ bie Ninber nichts bavon begreifen Fonnten, if aber immer von funticher (5egenftán ben bie Rebe. Heberbies ift es aufser 3weifel, Daß Sinter bas Steicháft des alfitrabirents fefr frúh bes ginnen, uno baf biefes Befháft mit einem jebr

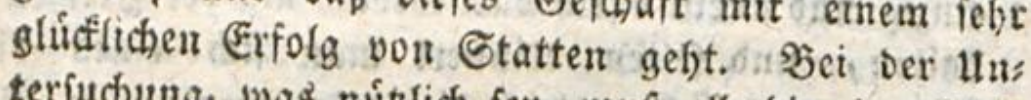
terích)ung, was núblich fer), muk allerbings auf bie Eage ber Sinter, auf bie fich áupernben Naturfas lente uns auf beren wabricheintiche Sbeftimmung ges fefent werben. Daṕ fúr alle bieientigen finber, bie fu einigem Brabe ber Eultur gelangen founen und follen, aber vorjuglich $\delta a b$, was man getwobulich zus erft mit ifuen treibt, námlich bas Etubium ber (5),ograpbie, ber (3eichichte, bev allgemein ben \$ew

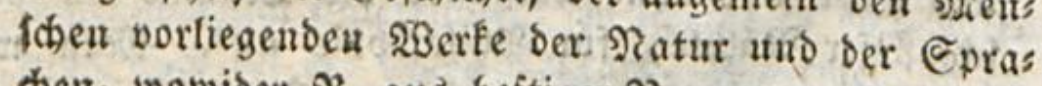
(h) wo wower $\Re$, auts beftiger Necugung, alles, was er im Punct ber \$ásagogif vorfindet, nieberzureifs fen, fo lebbaft nidh erflart, vorgulglich núb̨lich fery, Yeuchtet zu felgr ein, als dấ barúber noch etwas zu fagen ware.

(5) levg. Neferwig.

2i. eifert nur riber bie gerwobnliche und vers febrte 2 rrt bes Unterridhts in ber Seograplie, Sies f(bichte uno Niaturgef(birbte:

Stuve. Eampe. 


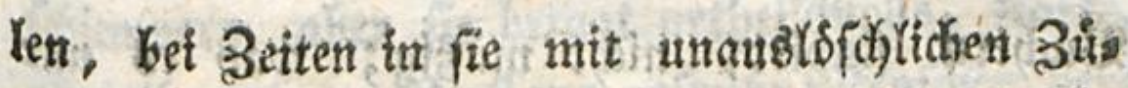

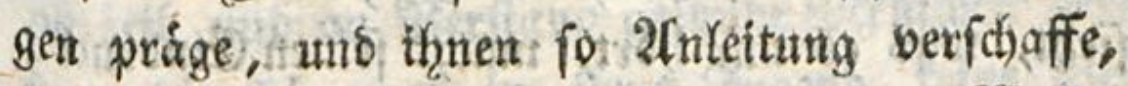

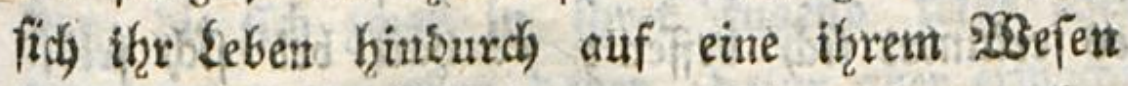
und itgren Seelentraften angemeffene 20rt su be tragett.

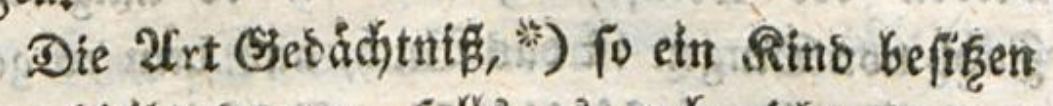

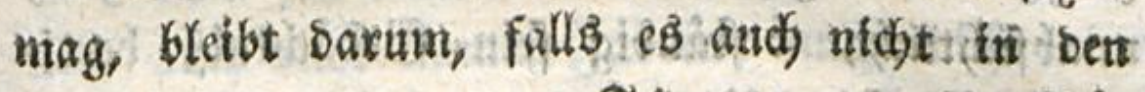
St

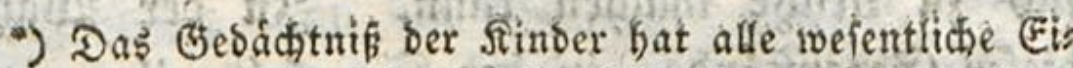

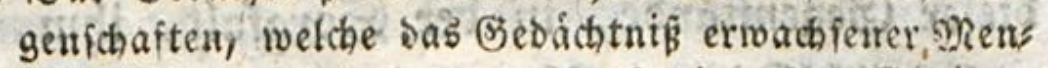

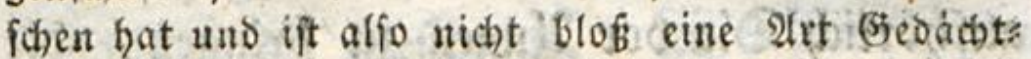

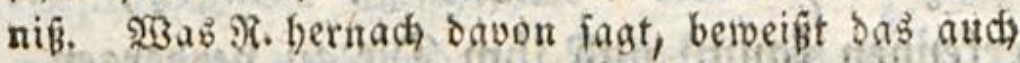

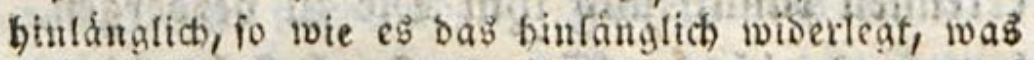

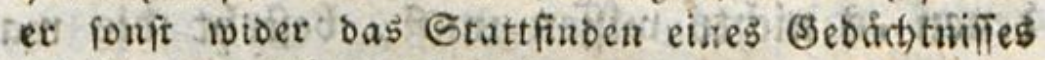
bei నindern belauptet bat.

EGlers. Mefenits.

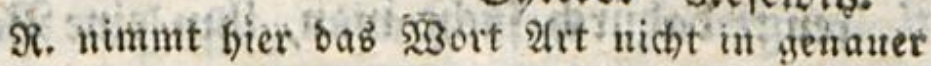
pbilofophifchen bebentumg, fondern in gemeistern $\mathfrak{E x}_{\mathfrak{x}}$

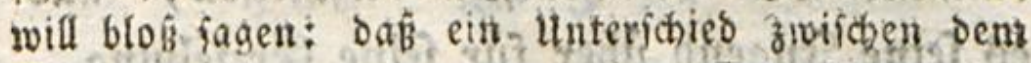

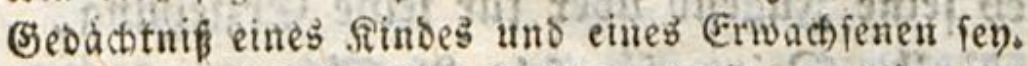

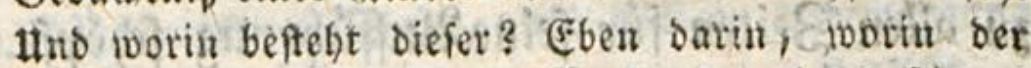

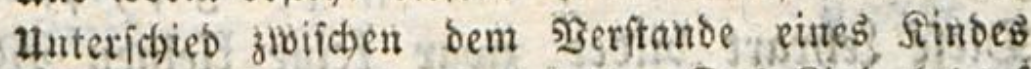
unt eines Errvachfenen befteht. Das $\mathcal{R}_{\text {inh }}$ bedarf

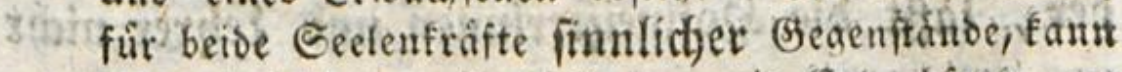

- fich mit beiben nod nicht fo, wie Errwachiente, fut abgezugenent Begriffent erhebent. In Ştidern aber findet es gemeiniglich mebr bon biefent afs, bont ies nen. Daber paffen mur febr wentig bricher für Sin Der; fur ganz junge Du fiur finter, bie nicht wes

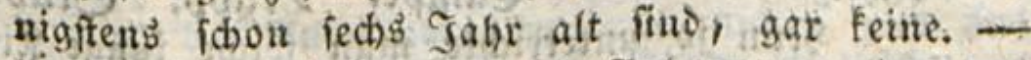

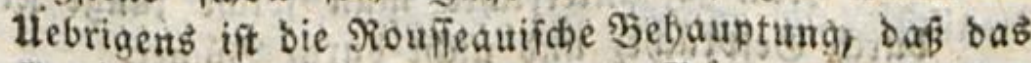

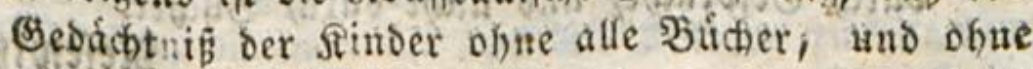
alles 2lustwendiglertent febr gut - id wage es. fos 
500

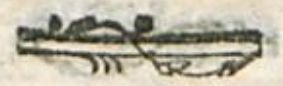

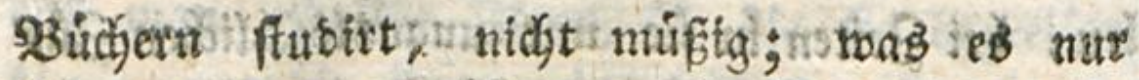
fiefgt, mas es nux bibrty madjt feinen (Einonuct; eB erinnert fich befen; es fialt bei pich felbft ein $\mathfrak{B}$ erzetdint if iber bie Scanolungen, iber sie Reben ber Menichen; und bie es umgetrente. 3ablyon Dingen if bas Bubh, aus betu es ganz

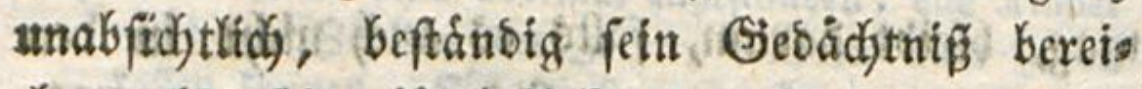
chert, bis fetue llitheifótraft biejen Reichthum

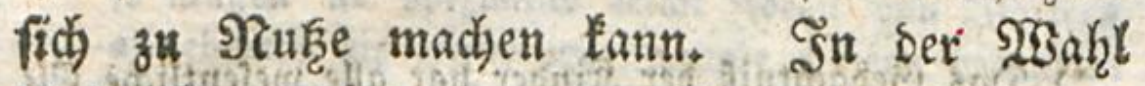
biefer Segenftante, in bex Sorgfalt, ithm ins auffgortid) Die wor 2fugen zit bringen, bie es erfennen tann, uno thm Die zu berbergen, bon beten 23 nid)ts miffen muf, befteht bie mahre Runft, biefes fein erfteb Seetenbermogen zit culs tiviren: Saburch fucke man, then eine 30 orraths fammer von Renntniffen anzulegen, ans ber es peine Sugens úber fúr feine Erzielutung, uns zu allen Beiten fir feime 20uffihlyrung fojopfe. *)

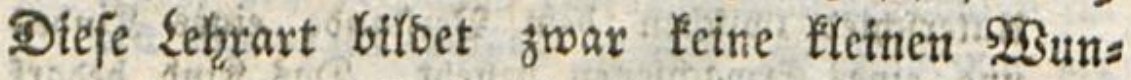
oer, raffit bie Sofmeifterinnen uno Sehreer nidjt

fojim:

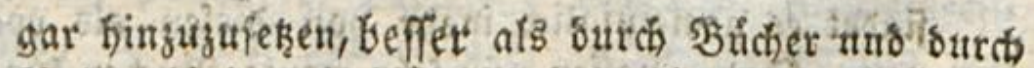
2fusivendiglernen getibt werben fonme, volfommen richtig.

Eampe. Trapp. Stuve.

श्रin fo unterrib)te man folche jutige finber ourd şefpräche, und nicht burch şüber.

Siejeroib.

) Eine goidene segel! th Trapp. 


\section{$50 \pi$}

fhimmern, aber fie bringt urtheftzbolle, ftarke, an Leib und an \$erftano geiunde Nenifgen hers Sor, bie fir swar in ifrer Sugeno feine $\mathfrak{B e s}$ sundertng exworben haben, bafur aber erwactse Fen, Ehre serbienen werben。*)

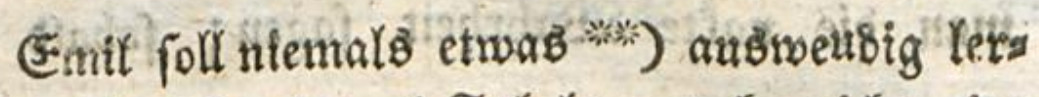
nen, aud nidjt einutal Fabeln, audy nidjt eins mal Eafontainifdce, fo naio, fo allerliebft fie audh find ; benn bie 528 orte ber Fabeln madjen fo wenig sie Jubeln felbft alis, als bie \$3orte

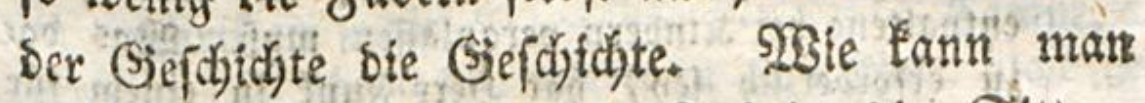
(iid) gemugfam verbleaben, Fabeln bie Sittens. Yefree ber Rinber zu mennen? uno nidgt bebens

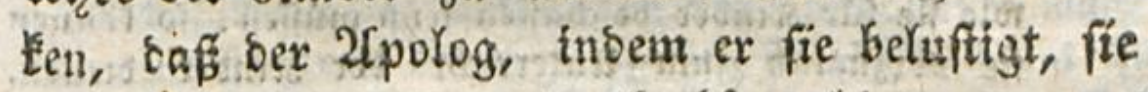
mislettet, Dấ fie, surch Sige hintergangen,

$$
\text { st } 3 \text { bie }
$$

*) Ganz meitier (Etfaffrung unt volligen tteberzengung gemáp. Campe.

*) Litro bic Sugeno fernt bod fo leicht und fo gern ets was aubivendig, und cs giebt Soch fo vicles, bas ir ber erfen cugend ausivendig gefernt ju werben vers Dient! Neine vier jüngften Sinter haben wirflid won fel6ft ofure alle 2fnfrengung einen fébr betráchts

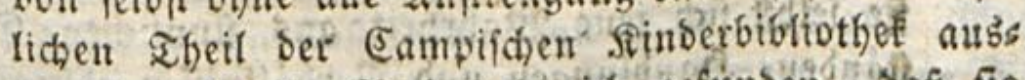
soenbig gelernt. 2fuch babe to gefunben, dap fie

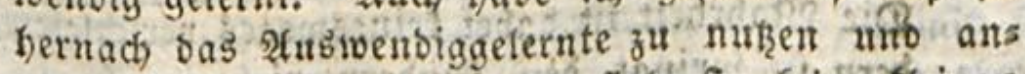
zuvenden viffen. Hns sod find fie fétie fleinen

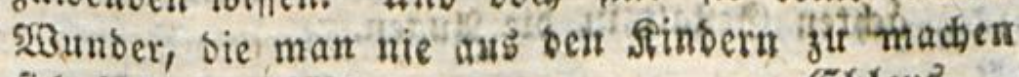
(iich beftreben mus.

Ebler6. 


\section{2}

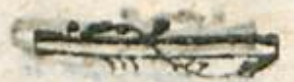

Die 2 Babrbeit fid entwichen laften, uns man bermittelft 2ffein, was man thut, finen ben 1 un terricht angenebm zu machen, fie binbert, গ? Gen Daralls zu foripfen. *) Fabeln fonnen Er. wadjenen Ulnterridjt fentr; Sinderi abex muff man bie nafte Sahahtheit fagen; fobals man

*) SGenn Fabeln und Erzáblungen finderu nưb̨lich fenn follen: fo muk man babei freilich forgáltig anf

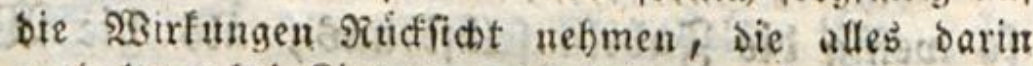

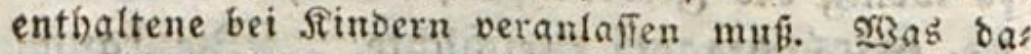
zu erforderlich fen, bat feer funf in eimem fúr Sinoer eingerichtetent \$ुर्(d)ein vortreflich gezeiat. Sind aber Fabeln uno Erzablungen fo beichaffen, wie fie fur Sinder bejchaffen fenn miffin: fo formen fie vorjuglich zum-Interricht der Rinder brenen, Ant unzáblig vielen Şeriucben uno Erfiffungen weif ich es, baß ein fino beim erfen şinf, ben man ifm giebt, es exfenne, ba自 cine fabel feime Seichidte, fonvern nur ein finulithes Siemaloe von Dingen, כerfáltuifien uno Jjandhungen feru foll, bas ihm angenehm fenn und Seleaenteit geben foll, fur fich Sehren und 3 arnungen baraus berizuleiten. Setzteres thun bie Sinder audh gewoibnlich mit grofs

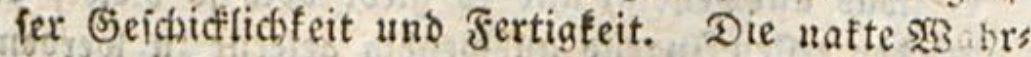
heit der Begrifie fommt auth wirflich nicht berier und reiner in bie Eeele ber Jinder hinein, als we:un fie felbeft iich iene $23 a b r h e i t$ aus fimnlichen Gie ns

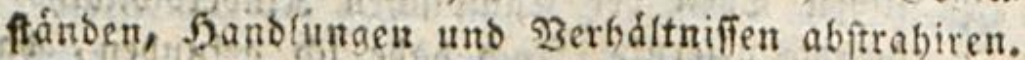
mo Die saabrheit if babei feinesiveges verichleiert, fons swais pern fie fpringt ben findern vielmebr fo in ibrer moprodichten Geftalt in Die Ingen.

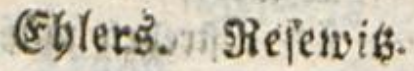




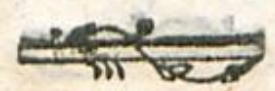

fie serid)leiert, geben fie fich nidjt mefyr bie Mithe, fie zu entichletern.*)

Man låft Eafontainifdye Fabeln alle Rint ber austwenotg Yernen, uno es finbet fich nidit

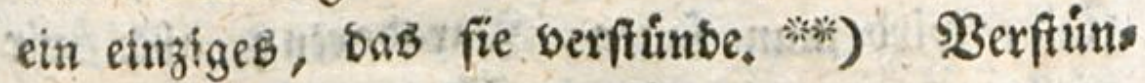
St 4 Fent

-) Tob habe sab, roas nach meiner Heberiengung, in diefem uththeil liber ben pábagogifonen (sebraud bee Fabel $2 B$ ahres unt Hnwaf)res enthalten ift, in eto ner befondern abbandung entwidelt, bie fich in

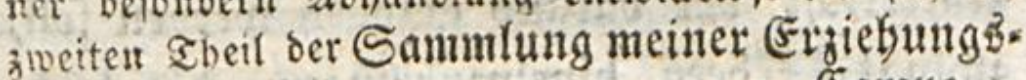
fothiften findet.

Eampe.

R. fdeint hier roieber in sem finbe nidht ges nutg ben Dienichen zu feben. Der Sd) eier (en mu biune genug, baf fie etwab hinter ifm erblicfen,

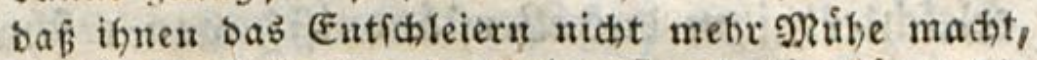
alb fie Rraft haben, to soerben fie, bafur buirgt bie menichliche Natur und bie Erfabrung, an bem Ents fdileiern જergmigen finben.

\section{Trapp. Nefervikg.}

**) Das . Yerftefen fat feine vielen (3rabe. Die unters fien berielben funn man in Sfinficht mancher Fabeln fefr vielen finbern, nidit abfprechen, uno two nur biefe unterften Srabe Statt finden, ba ift es fichou nidbt mredt, Simber fabeln ober bergleidfen leien

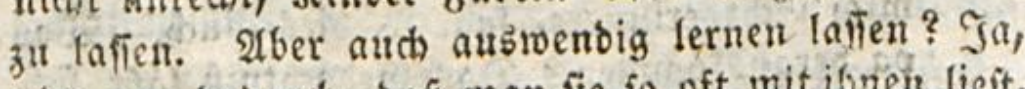
aber nur baburch, bak man fie fo oft mit ifnen lieft, bis fie fie auswentig wifien. Doch mûfien bie Sins ber Dies mit \&uft thum, fonft ift es nicht gut. Nres

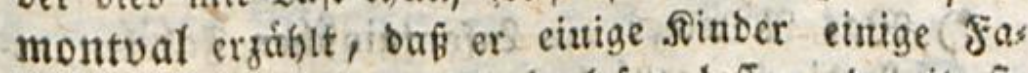

2ax betn eniae bundertmal habe tefen laffen, bainit fie

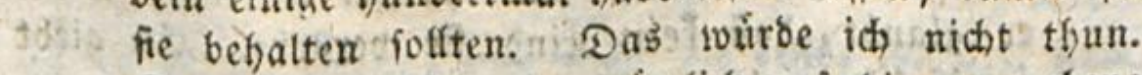

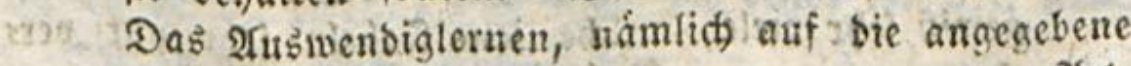
2irt, 
ben fie fie, fo wát bas Ulebel nod årger; benn bie Sittenlebre barin ift fo gemifdyt, ifrem $20 \mathrm{r}$ ter fo menig angemefien, Dafi fie efger Lafter als

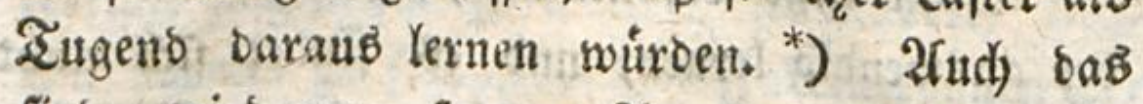
fino, wiro man fuigen, Paraboxen; abex wir swollen feben, ob es nid)t Wablerbeiten fint.

S.l. fage, ein Rino verfteht die Fabeln, die man es lernen lágt, nicht, weil fo wiel Miúbe wir uns audh geben, fie zu fimplificirẹn, ber Unterridgt, ber baraus gezogen merden foll, uns zningt, Şbeen hineinzubringen, die bas Rins nicht erreichen tann; uno bie poetifdye SIBens

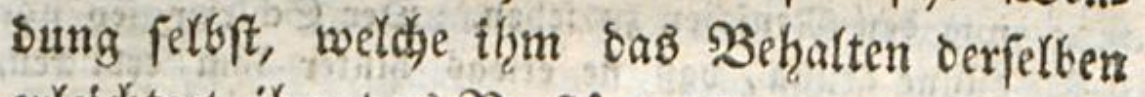

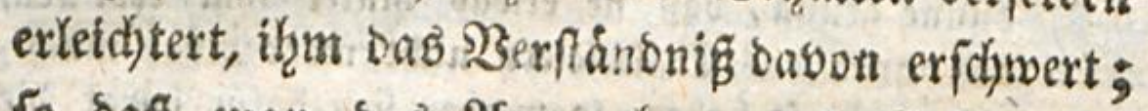

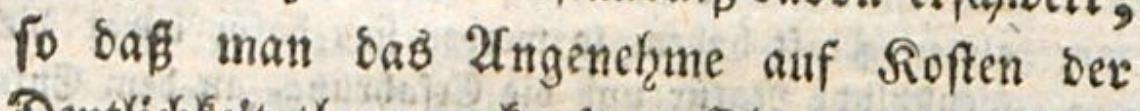

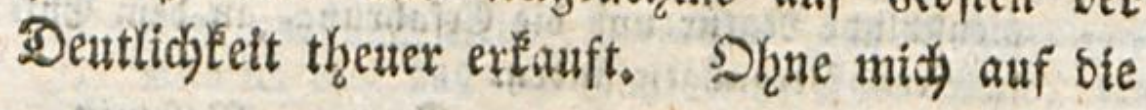

grens

2rit, ift viel werth, aber bei weitem nidht fo viel, bafi es fo theuer elfauft werden miste. Die Rims ber múfien die fabelu fo oft wieberfolt mit aufers ordentlichem şiderwilfen gelernt haben; wenn ids mich recht erimmere, fagt $\$$. Dies auch. $23 a^{3}$ fant Da herausfommen? Das Bebácbtniß̉ lágt fich nicht

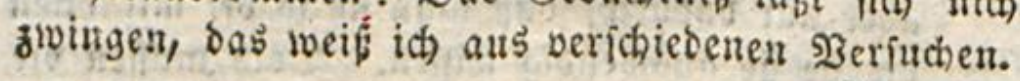

\section{Trapp.}

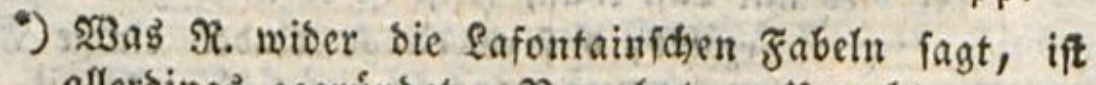
allerbings gegrútndet. Nur bat er Ulnrebt, wenn er glaubt, baf fein Sind fie verftehe. Es giebt getwif febriviele, weldhe ienel Fabeln fehr gut vers facbr.

(5) lers. Refewiş. Campe. 


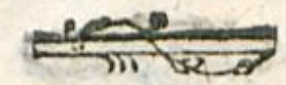

Menge bex Fabeln zu berufen, in benen nichts

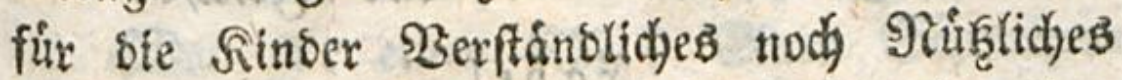
enthalten ift, uno bie man fie bod neben ben andern hodjft unbebaditfam lermen lápt, nur weil fie mit in ber Meif̧e oortommen, fabrante id) midy mur borerft anf bejejenigen ein, bie ber Serfaffer befonbers fưt bie Sinber gemacht zu kgaben jodeint.

Sáf Eente in bes Lafontaine gatrzer Fabels fantulung nur fünfe odex fectje, beren Ebaralter

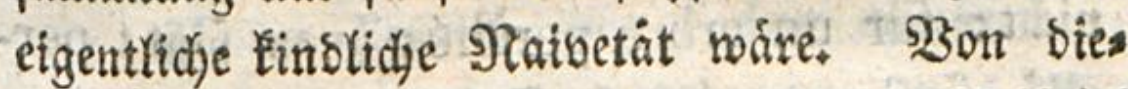
fen funfen oder fectjen neţme idy als Socifpiel bie erfte, *) weil es biejenige ift, beren Mtoral ant meiften fir jebes 2flter pant; siejentige, wels dye bie Rinber an beften fafien; biejenige, wets

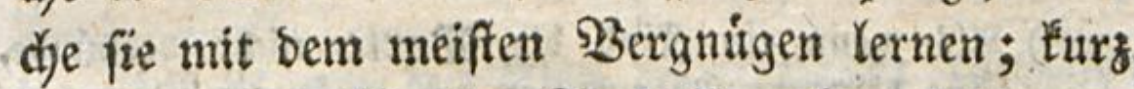
siejenige, weldhe ber 2 erfaffer eben beşwegen sorzugaweife bie erfte in frinem 3 udy hat fenn

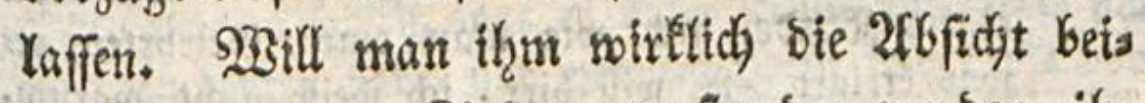
meffen, son ben Rinbern berftanben werben, ifs nen gefallen uns fie unterritytet haben zu roots Yen; fo ift siefe Fabel gewif fein Neifterftude: eB fey mir aljo exlaubt, fie surchaugehen, unb fie in wenigen 2 Borten zu unterfuchen.

$$
\text { Si } 5
$$

Dere

4) Es if bie zweite, und niaht die eqfe, twie Şr. fow mey es fehr wobl bemerft hat.

(2nmertung Der leşten (EDition.) 


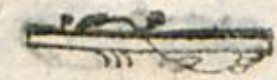

\section{Der Piabe und Der Guth be}

$$
\text { Faber. }
$$

Maitre Corbean - fur un arbre perché,

Maitre! $23 a \mathfrak{b}$ bebentet biefes 280 ort an (iic)? *) 3 as bebentet es oor einem Nomine proprio? $23 a s$ fúr cimen Berfand bai $\mathrm{CB}^{3}$ hier?

SBas iff bas für ein Ding, ein Rabe? **)

$28 n$ ift: un arbre perché? Nian fagt nidit: fur un arbre perché; man fagt: perché fur un arbre. Folglidy mufg bon ben poetiflien Snberfionen gerebet, e\& muf́ gefagt

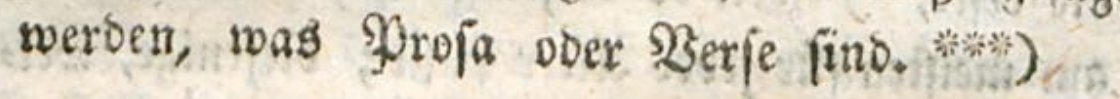

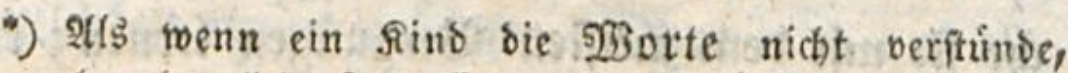
ohne beutliche Begrifferon Den gibirtern zu baben, aus benen fie bepefn! Sy und wieder nut man freifich ein einzelnes sgort erflaren, aber lo te nah cinem Rinde, nicht wie man einem ßelehrten ets

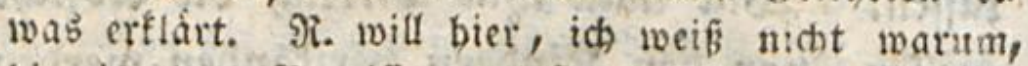

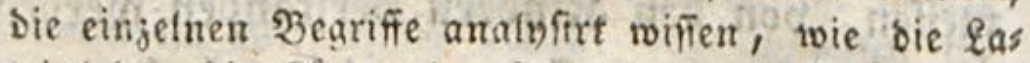
teinlefrer bie forper ber Begriffe analyitien.

Erapp. Siejemits.

*) Nun, biefe frage wirb bei uns wol nidht leicht ein

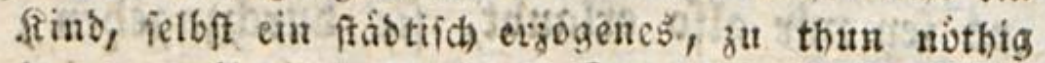
haben, weit dieier Bogel, in Deutihlano wenigftens,

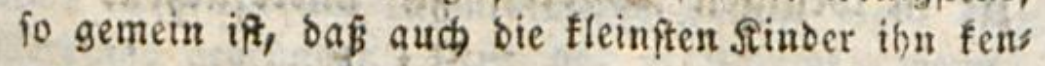
35. nent.

Eampe.

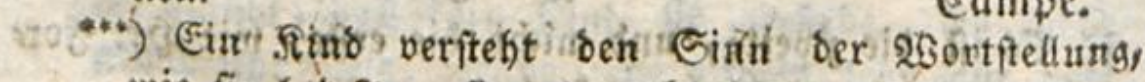
soie fie bet Gmoerfieneti vorfommt? recht gut; whe bák 


\section{7}

\section{Tenoit dans fon bec un fromage.}

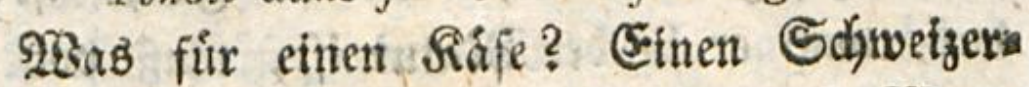

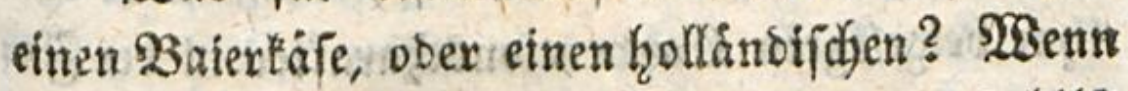
bas Sino feinen Raben gefeben hat, was bilft eవె, mit thm babon zu reben? Sgats weldye ges feben, wie wirb es begreifen, bas ein Rabe eis nen Rifie in feinem Schnabel halten isnnte? Man gebe bud immer Bilber, bie in ber Stas tur fino! *)

\section{Maitre Renard, par lodeur allechs.}

Sgieber efn Nietfter! 2(ber ben Zitel fübrt

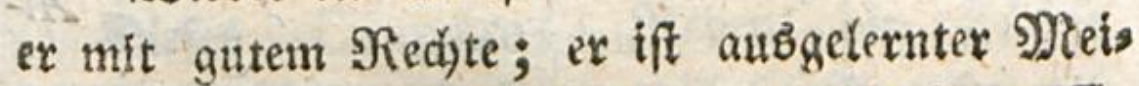
fter in allen Sinften feines Sanowertis. ए5 murf

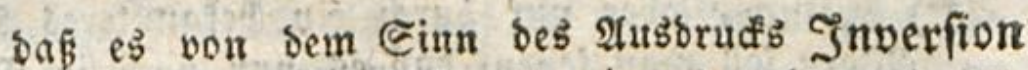
etwas gu wifilen braucht, fo wie es recht gut vers febt, was in Noefie ober Profa vorgetragen ift, obne zu wiffen, was es unter Moetie uno Mrofa fich ju benfen habe, und woburch Poefie und Mroja von einanber unterichieben fenn.

Eblet?. Trapp. ঐefervig. Eampe.

-) Ein Deutičser, der die Ziegentáa ober bie fleinen

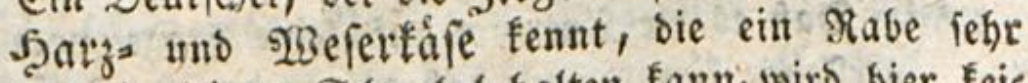
moht in feinem Edhabel halten fann, toir fier feis

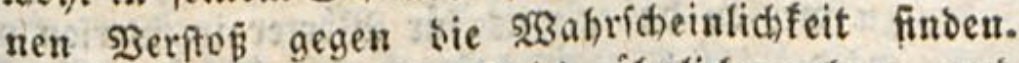
Sollte es nicht in Franfreich âfnlliche geben, uno ber Didter berszatur fo gefeblt haben. - Nit un ter dicauirt Rouffeau ben Rafontaine ein wenig. Inmert. des Hebetf. 


\section{8}

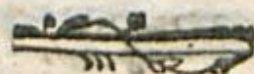

muf gefagt werben, was ein Fudjs ift; *) bas, was ex in bex Natur ift, mus bon bem thym betgelegten Eonbentionzdjarafter in ber Fos bel unterjdjeben werben.

\section{Alleché. Dies Bort ift nidjt gebráudys} (id). San muß es extlären; **) man mus fagen, baf es nut noch in Şerjen vortónmt. Das Sino wiro fragen, wartm man in \$ers

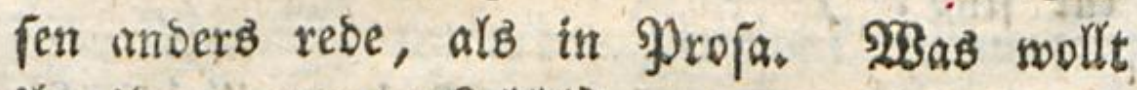
iby ifgm antworten? ****;)

\section{At}

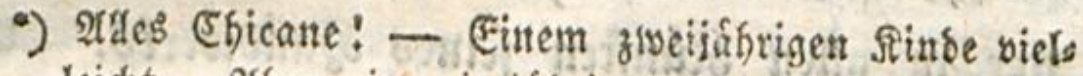
leict. 2 fber eint pierjáfriges bat vielleid)t fhon

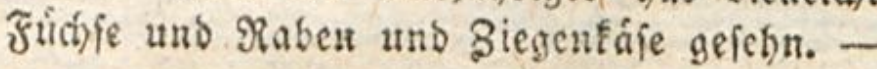

*.) Freifich, aber unt surch cin befannteres gsort.

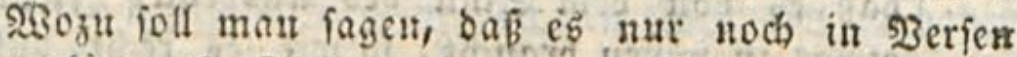
vorfommt? Dics berfangt bas నino nidit žt wif fen. Und fagt mails ifm, fo hort es nicht barauf

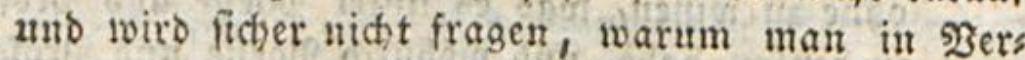
Fen anders reive als in Mroic. Fragt es aber, fo fage man ifm, dá̆ es bie Bermohnheit ber Dihter (ê). Damit if es geiviś jufrieben.

\section{Trapp.}

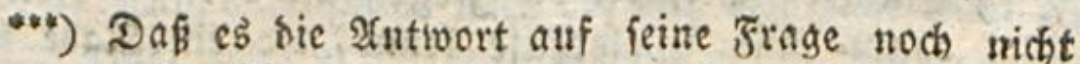
veriteben fonne, unb baf es vor ber Shand fich nur zut merfen babe, was fúr şórter in \$erien ober itr Profa úblich fera, indem es fich fo Materialien fammle, bie es einft bei ber ltnteriudung bes Bruns Deb, nach toeldfem eb iţt zut frifh gefragt habe, who Ben fónue; bas toáre zu antroorten. Eblerb. 


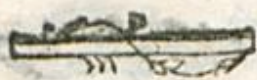

'Alleché par d'odeun d'un fromage?

Diefer Ráfe, is Den, ein Rabe auf einem Baume hielt, mubte einen fehr farfen Seruch haben, bafi ifn ber Fudjo in einem Dictigte Doer in feiner Sirnbe wittern funnte! *) Llebt ifyr fo eumen Sdjuler in bem Eseifte urtheifbols

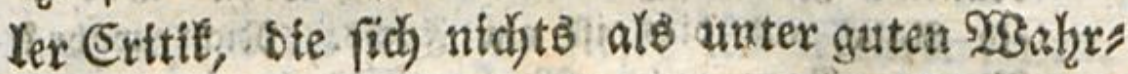

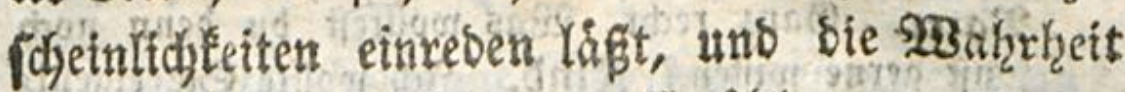
son ber singe in 24noerex (5rzáhlungett zu wn terfcheiben toeip?

\section{Lui tint à-per-près ce langàge.}

3iefes Langage! Reben die Füufe Denn? *) Reben fie senn bieferbe Epradje, mie

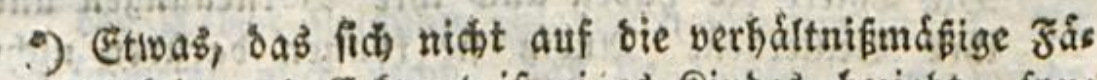
(1ish bigfeit und Erfenntniß eines Sindes bejieht, fons

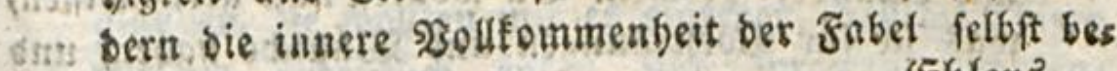
stivistrift.

(5) lers.

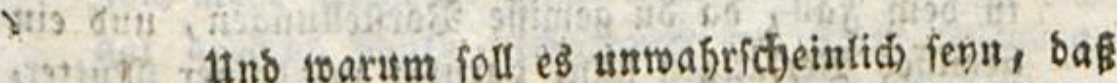

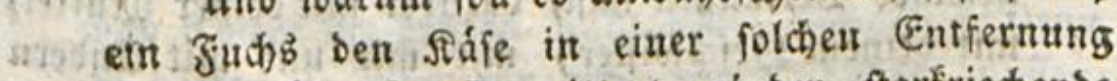
nn: soitteru foune? Er wittert minter farfíriechende 1) Dirge in nodh weiterer Entfernung. S)tan muE

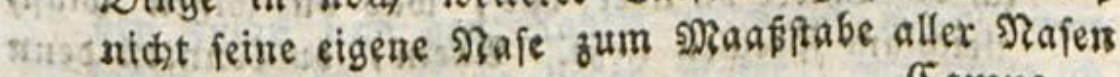
mactert.

Eampe.

2) Sind, auf Sen zur zabel gefóriget Supferitio zeic gent: $\mathbb{X}_{3} a_{5}$ bebentet, fieber \$ater, Das, was oa abgebildet ift. Bater. Collte mein tieber Emil den शुoget bort oben und bas Fier bier unten nitht fens 


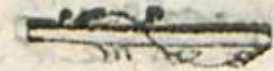

Dte Raben? Sehrer, wenn bu weife bift! fieh sid, wol vor; wage beine 2fntmort wobl, eh Du eine giebfi. Sie bुat melzr auf fich, ars. ou benten magft.

(3) त? Eh!

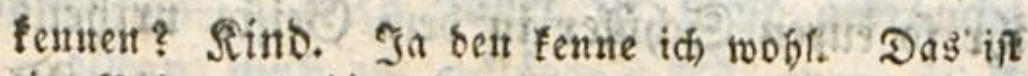

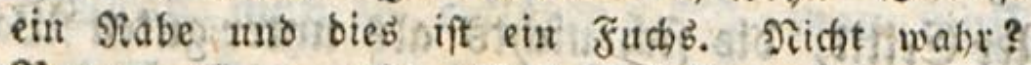

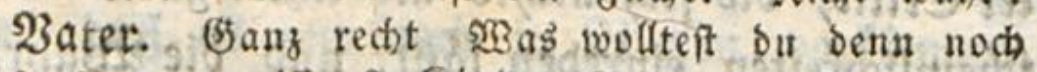
fonft gerne wifjen? Sind. Id wollte Gie eigent

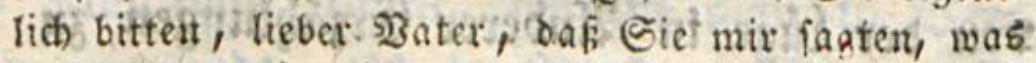

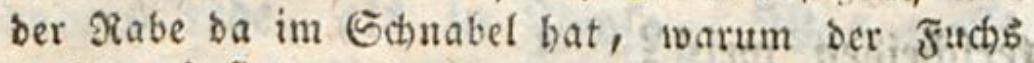
fo binauf fiebt und wartum Der Pabe jum fatths binabfiest. Bater. Ş3em joir jufammen find, mein lieber emil, fo iprecten wir úber bas, was weir gerne voin einanber baben, ind fit eimander fagen, dwollen. Go gebent mir unfere Neigungen, şiurche unb (sedanfen einaitoer ju erfennen, mit fo unterbalten toir uns auf ene angenehme 23 ei Die Thiere bie baben auth ibre sorftellungen und

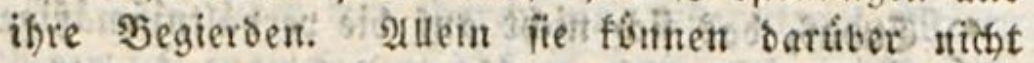

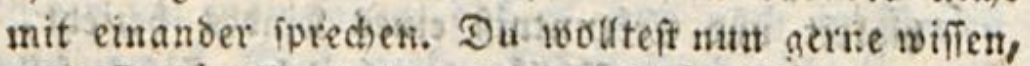

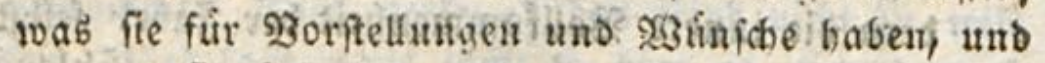
wortum fie fich to anfelsen. 23 eif bu num gerne in bem Fall, ba du geivifie Sortîlltungen, uno ein gevilfies syerfangen hafe, bariber mit beiner Nutter, mit beinein SEeftwifter, mit mit und mit \&roern

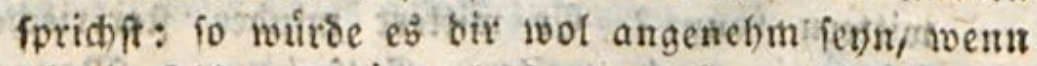

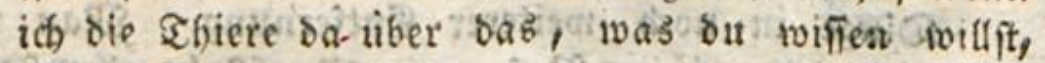

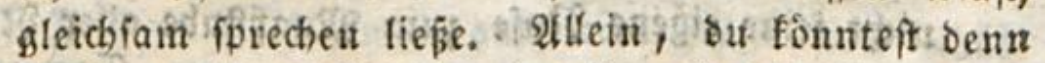
Denfen, ich wollte bir eine thrwabrfeit fasen und Dich auf ben Bebanfen teiten, dak biefe Shiere

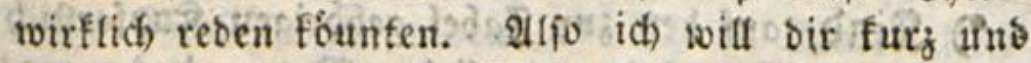
gut fagen, warum fie fich fo anfelfen und was ber Tatabe im Edrnabel hált. Diefés ît nun ein Ráfe.

Rind. D lieber গ̧ater erzáglen fie bas nidit blof̣.

(3)ar 
Eh: bon jour, Monfieur le corbean! Monfieur! gine Benenmunge welche $\delta a s$ Rino veripottet fieht, eh eह noch cinmal wet5. Dẩ fie eine Ebrenbenenmung ift Denenje? nigen, meldie Monfieur du Corbeau lefem, wiro es noch) etwas ganz 2ndero zu jhaffen madjen, wenn fie ihm oiefeo du ertikren follen. Que vous ètes charmant! que vous mefemblez beau? Flictroorte! unnifger Leberfluf ! Das Rino, Das einerlei Sache mit Deridiebenen 28 orten wieserbzolen fiebzt, lernt verwafd,en resen. *) Sagt thr, Siefex Uleborflue fey bifi Runft oon Seiten

(3) ar zu gerne febe if́) es, wenn fie benn fruct) unb Den Raben gleidfam zulammen ipredien lieken. Es

Iits f(hmerzt mich recht, bap ije bachten, id) wurbe glauben, fie wollten mir es einreden, daf die Thiere soirfich orbentlich enfen uno fprechen fonnten, nod mebr wuirbe es mich fómerzent benn fie wol gar gebacht baben, ich wuirbe im Ernft glaubent, Sab Thiere fo benfen und reden fonnten. Denn fo batten fie mich fưr febr oumm balten múīeu, Bater. Te nun, wenn bns it: io will ich benn ben fuch und ben Staben gleidham lelbft reden Iafien. Rind. $D$ ta lieber $\mathfrak{X a t e r , ~ w i e ~ f r e n e ~ i r b ~}$ mid) bazu 4. 1. 10. (Eblers. కrapp. Niefervik.

*) Sinder werbert ourch Seípiele gebilbet. Es mag immerbin auf bie bier angegebene 2art verwaidien reben lernen, upenn der Plann, als firitifer, iente 2irt on reben bier gut findet.

(s) 


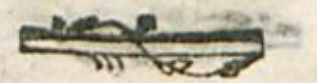

bes গ̧erfaffers, Der Futbs rebe abfidtlith fo; fisetne feine Sobjpridic nit bet 228 orten bers bielfaltigen zu wollen; fo wirs diefe Entfouls sigung fir midj gut febn, aber nidht fir meinen Untergebenen.

Sans mentir, fo votre ramage.

Sans mentir! श्रran liugt alfo zumets len? *) $23 a s$ tvirb bas Sind varaus. folgern, wenn thre es belefirt: ber Fuchş fage nur, fans mentir, toeil ex rigt? **)

Repondoit à votre plumage.

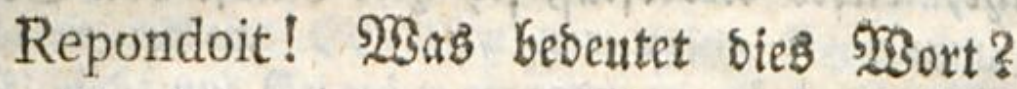
Sebrt einmal sas Rino po verichiedne sefdyaffens beiten, alö bie Stimme uns bie Febern mit

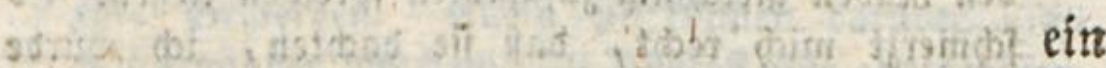

a) Ein Sino wiro uno muk eş ballo lernen, bẩ die NRenf(t)en oft lugen uno borjugfich bann oft liggen, wann fie oft verficherm, baf fie nicht ligen.

(E) levs. Refeivits.

Iक) habe in ber oben anaefibrten 2 bbandofutg uber Den (Gebrauch ber ápopifden Fabel bet ber Erjiehung angemertt, baf main fie voruehulich baju brauchen múpte, den fintern bie eafter als etwas Thierifoch barguftellen, indem man fie biefelbent an Thieren bemerfen liefe, bevor fie Sclegentheit batten, fie an Nenichen wahrzuebmen. Eampe.

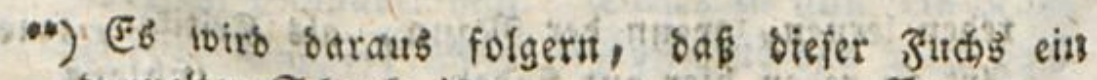
boppelter Gdurfe ift. 
eltanser bergletchen, iffer werbet fetgen, wie es eud Derficţen wirb! * )

Vous Jeriez le Phénix des hôtes de ces bois.

Le Phénix! $\mathfrak{T a} a$ if efn Whonix? Da fino wix alf eimmal in bas ligenhafte 2flters thum, faft in bie Ninthologie, hineingewor: fen. **)

Les

-) Ein etivas fátiges Sint suirbe in eitter besfalls anzuftellenben Prifung geiviß fehr gut beftehen. Id bin verîthert, baß́ in Franfreich Sinber von etwa fed) Эafren, bas şort repondre nicht nur úberhaupt in bem bier Statt finbenben Ginn, fonbern auth in sállen biefer 2 trt ribtig gebrauden.

(E) Jers.

Gdiverlich anbers, als in fállen, too fie etwas 2Hitsentiggeterntes berfagen, fo wenig unfere beuts

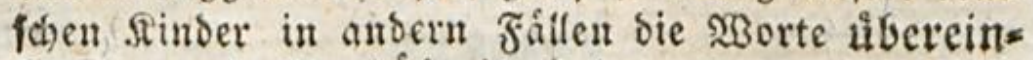

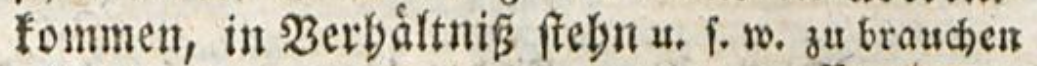
pflegeti.

Eampe.

-.) Nan fann auth mit ben Sinbern eben fo ums

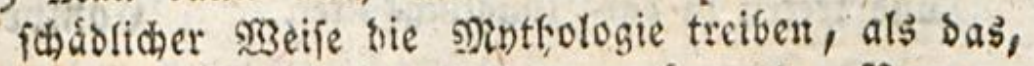
toas gevobinlich in Gabein vorfommt. Nar ets forbert beides einen verninftigen \&ebrer, wenn bavon

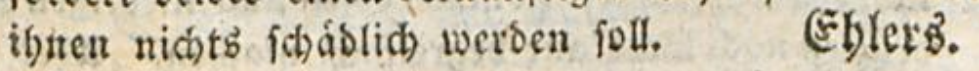

2tber auch bann fornte mair unterbeß etwas befieres mit ifnen treiben. Campe.

Iflerbings mit jutngen Situbern. 2 ber mit einer fúr gevifife şiffenf Sinber, bann, wann gerabe bie 3eit if, bafifie mit siefem nothivenbigen Hebel befannt gemacht twerben is follen, nicht. Evil Ifter ₹r. Soufinger.

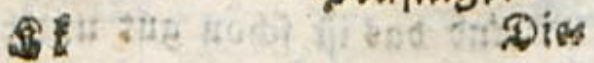




\section{$5^{\mathrm{r}} 4$}

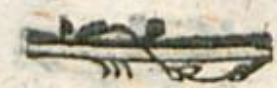

\section{Les hôtes de ces bois!}

SBeldie figurtliche Benennung? Der Sdjmetdjo ler berebelt feine Spradje, uns giebt ihzr mehr SBurive, um fie befto berfúfrererifder zu madjen.

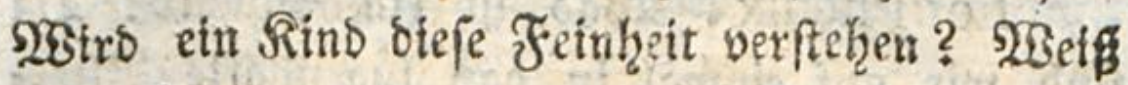
eb, fann es wol einmal wiffett, was cin ebler uno ntebriger Stil if? *)

A ces mots, le Corbecu ne se Jent pas de joie;

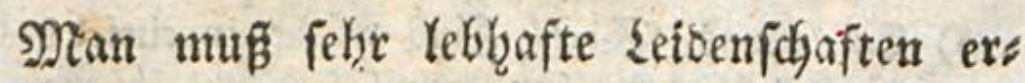
fakgren ḩaben, wemn man siefen fprichwortliden

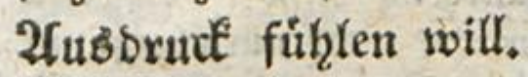

It pour montrer fa belle voix.

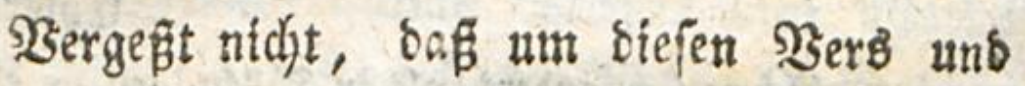
bie ganze Fabel zu verftehen, bas Sino wiffen เmแf,

Dicfe âttern Sinber Yóren zu eben ber zeit, ba bies wirffid notthig wirb, auf Sinber zut fenn uno treten in bas Singlingsalter. Campe.

-) Durd Erflárungent wirbe man einem Sinte free

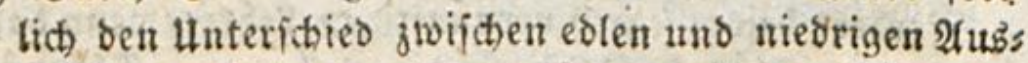
brúden nod) nidht gut begreiffich mad)en. 2(ber aus Beifpiclen und aus 2teuferungen Der Stnvefenden

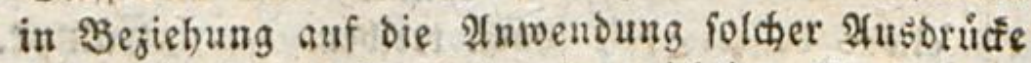
jieft ein Sind febr bald eine richtige গুorftellung bon bem $a b$, wab edel und niebrig in ber Nebe if.

Ëblers.

2Benigitenz fant eร Gefúbl bavont cthalten, fo wie vom Ebeln und Niebrigen in den fandungen:

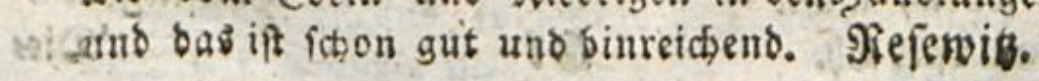




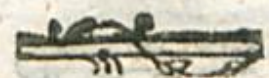

muß;, was die fojine Stimme bes Raben (ey)? *)

Il ouvre un large bec, laiffe tomber fa proie.

Diefer Bers ift vortreflidy; fdyon ber Tons aussruct bavon madit ein Bilo. Säh fehe sinen grofen garfigen aufgeiperrten Sdinabel; id hiore ben Râje ourch die 3weige niederraffetn. 2lbex biez find vertuhrure Sdjonheiten für Rins Der. **)

\section{Le Renard f'en faifit; et dit, mon bon Monfieur.}

Da bुaben wir benn fajon bie Giute in Dummbeit verwandelt; furrwahr ! man verliert Heine 3eit bie Rinber zu unterridten! 券范)

$$
\text { Iit } 2 \quad A p-
$$

-) Der iesod, wie fdon gefagt, ein fo gemeiner $\mathfrak{3 0 s}$ gel bei uns ift, baß lool f(h)ertich ein fechsiábriges Sind fier zu Lanbe gefunden werben oúrite, weldhes ifn and feine Stimme noch nicht feunte.

*o) Sie find es seniép nicht.

Eampe.

Sobald man fie nut aufmerf́am barauf madit.

Eampe.

**v) Sinber werben in einer seit, ba fie felfit nichts

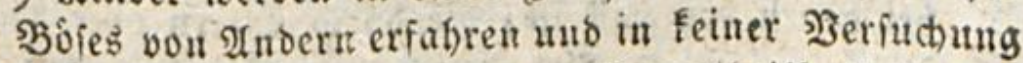
find etivas biofes zu thun, aufs vortheilfaftefte vou moralifchen llebeln unterrichtet itno baaegen-vers twabrt. Ein shenich wioerfteht vonf der Sindbeit ant bis ins hobere alter binein am gludflidffen bofen 


\section{6}

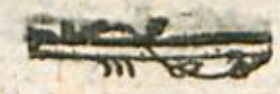

Apprenés, que tout flatteur.

(Ein allgemeiner Sars: weg ift bie 2luff mert f́amét ! *)

Vit aux depens de celui qui Pecoute.

Nite verfitand ein Rino won zef̧n Saf̧ren Siejen $\mathfrak{B e r} z_{+}$

Cette leçon vaut bien un fromage fans doute.

Dies läpt fich serftehen; uno ber Ġes banke if fefgr gut. Sndeffen wirb es nods wol wenige Sinder geben, bie eine Selgre mit

eis

Qeisenfibaften tho Htroronutugen, went er in bev Seit, ba bie Seele bavon frei ift, iene Hebel gea borig femen fornt and jum poraus dienlide Maafis regeln bagegen nimmt. (Ein unid)uldiger und alles (5) berzlid) liebender Şungling, ber yon ber unis nerpitátşeit niớt von ben geloóhnlichen Hnorbume gen und glángeln bes acabemifiçen Rebents unters richtet wird und es nidht vorber lebhaft erfenter lernt, wie viele ltnorbnungen an fith veráçtlich unb fochánblich find, burch wie vieles man fich wuiften Sandwerfsburiden gleid) macht und in wie vielen Dingen man findifch uno foulfnabenmáfig bandelt, woiro, weun er auf ber llniverfitát, als ein une wiffender sceuling ericheint, gewobnlich febr bals Durchs গ5eifpiel, - ourch Burebungen und Spottereien in jede llnoronung bineingezogen, weldbes felten bei benen ber fall ift, bie Durch EItern ober Lebrex auf eine weife 2lrt von allen thorbnungen bes Univerïtátbleben' belebrt unb bagegen eingenommen find.

Eg)

-) Ein allgeneiner Sak, zu befien 26ftrabirung ein sino fकon vorber surch bie fabel fingeleitet und 
einem Råk zu bergleichen woipten, uno ben Riaje nicht ber Eef̧re sorzogen, Man muf thren alpo exofnen, biefer Safg pein num in

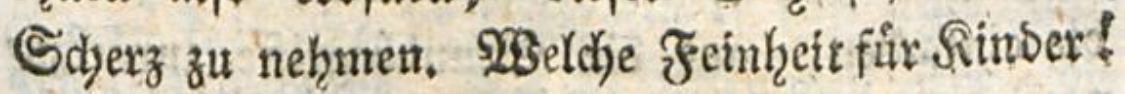
Le carbean, honteux et confus.

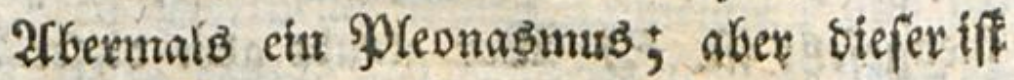

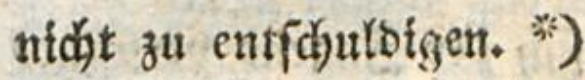

Iura, mais un peu tard, qu'on ne Ry prendroit pius.

Iura! 280 giebts einen Eefzrmeifter, ber şoinfel genta barzu wáre, einem Rinbe extlds ven zu mollen, was ein Sdimur ift?

Rt 3 Das

worbereitet ift, und Der fo futr abgefafit wiro, ftellt auf cinmalben Abfractionsbegriff in ein befles \&idnt and wiro baher nicht nur 1pohl bemertet, fondern macht auch einen bleibenben Einonuc anf bie Geele ser Sinder, wovou geber fich auth burch Berfucte xiberjeugen fann. 24lles, was bei bet fogenauntert Sioral emer fabel zu fuchen if, beftebt barin, Daf fie fur uno treffeno fery, uno bab fic ben Lejer, ber ben Sim der fabel nicht richtig and ficher gans fafite, fogleid auf ben rechten Sinn hinfúbre. S(d) babe baher wabrgenommen, baf nicht nur Sinder, fonbern auch geanner in einem foldsen fall bei ben frabeln ungern bie fonftige Schtrifmoral bermiffen. (F)lers. Mefenib.

*) Honteux uns confus untericheiocnt fich Suroh , Nebens ibeen, bie in naturlicher פejiefing auf die szatur ber Sache fteben und bie ben lefer biulángltob) ins tereflicen.

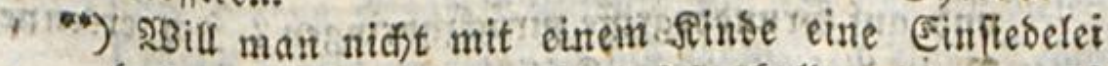
beziehn: io mus ein sins febr bald siffen was ein Sơnur. icn.

(E) let:3. Sebx 


\section{8}

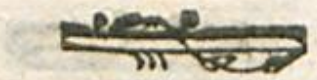

Das Keifft fehre ins Einzelne gegangen;

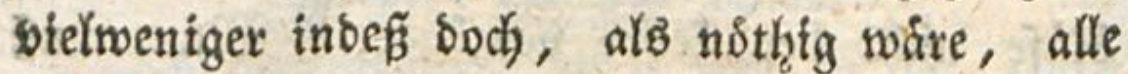
Begriffe biefer Fabel zu analtifiren, uno fie auf bie einfadjen, auf bie Srunobegriffe zurididu bringen, aus benen ein jeber berfelben zufam

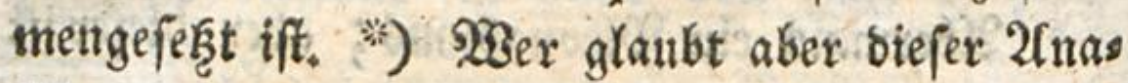

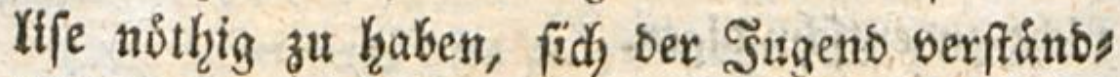
(id) zu madjen? Reiner bon uns ift sohilofopk geturg, bafi er fid an bie Stelle eines Sinbes

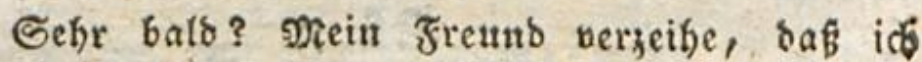
auch bier feiner Meinung nid)t feyn faun. Nut bann erif, báchte ich, weun mau bas Sind nicht mefr vor bem llmgange mit Seuten verwabrea fann,

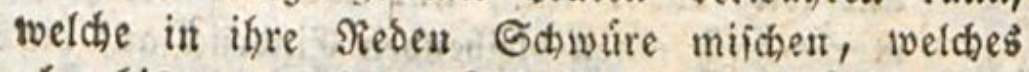
aber bis zum fechsten Jabre gar wobt moafich ift.

Eampe.

Shiverlich mógte bas bis zum fechsten Iafke móglich fern.

গiefenis.

9) $23 i e$ fann ein $\Re$. glatben, baf́ bie nothig fen? $\Im$ gm gemeinen \&eben verftehn wir uns - freilich in einem untern Brade bes 2eritebens, ber aber in ben meiften sáflen binreicheno ift - obne auf bie Brunbbegriffe zuriefzugebn. Dab Sind lernt bie Sprache des Ilmgangs bald; bie Fabeln fint, bis auf einige \$tusbrúfe uno $2 B e n d u n g e n$, in biefer Sprache abgefaßst: twas ift nun ba viel zu creláren unb auf ङrundbegriffe zuruchubringen? Ich erfenue $\Re$. in biejer ganzen firitif nicht.

Erapp. Nepéruis. 


\section{I9}

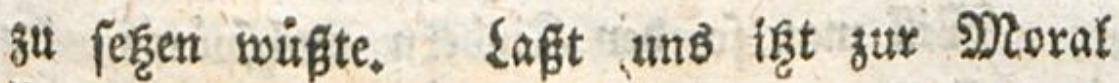
tommen. "*)

S4) frage, ob man sinier son fed) Salhs ren Yehren múffe, baß̈ es Mtenthen gebe, bie

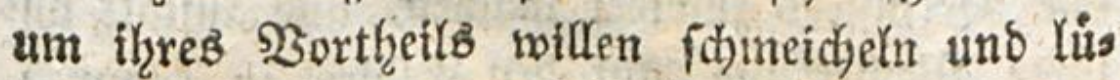
gen? Mian Esonnte fie ḩסdyftens Yehren, bajes Spottobgel giebt, bie bie fleinen Miänndinen aubs lachen, uno fid inşgeheim iber thre thorigte (5iteléeit luftig madjen: aber ber Raje verbirbt 2tlles; man lef̧ert fie nidjt fowol, than nidyt aus ibrem Sdjnabel fallen zu lafien, alö viels

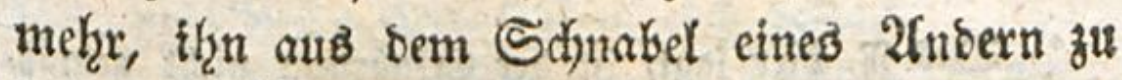
bringen. **) Dies ift mein zweites \$ुaraboxon, und mit nichten bas unwidjtigere.

\section{Sit 4}

WBEIl

*) Sier hat $\Re$. mehr Recht, aber ntte in Shinficht biejer, mur in Jjimitift einiger Fabeln, nicht ber gabeln úberbaupt.

Erapp.

-) Freilich, wenn berienige, ber mit einem Sinde bie

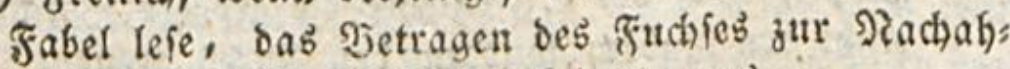
mung anpriefe, fonft aber feinesiveges.

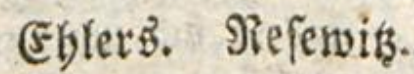

Im ivenigiten, went bet Lefrer bie Belegen: beit ergreift, bem Sinte sit fagent, bafs lift, lug uno Şetrug etivas fo Unnurbiges fen, baf ein bicien

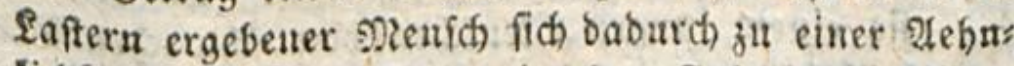
lichfeit mit bem fuchs in oer Fabel erniebrigen wourte.

Eampe. 
NBill man fo ben Rindern nadjpipuren, ins bem fie thre Fabeln lernen, fo wiro man felgen, bafi, wenn fie im Stande find, bie 2 2 nwendung babon zu madjen, fie fie faft immer ber 20 bficht Des $\mathfrak{B e r f a f f e r s ~ z u m i b e r ~ m a c h e n , ~ u n s ~ a n f t a t t ~ m i t ~}$ threer Bemertung auf ben Feb̧ler zu tommen, ben man an ibnen befiern, ober wovor man fie wars nen swill, beinah immer geneigt fins, baß Las fer zu lieben, burch melches ber \$enjich aus Dea Febglern 2(nberer $\mathfrak{B}_{\text {ortheil zieht. *) }}^{*}$ ) ber

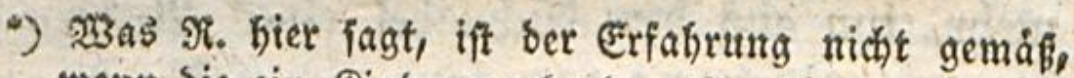

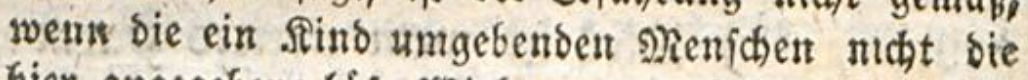
bier angegebene bófe rsinfung veranlafien.

(E)

93ena wir aber aufrictstig fenn wollen, to múfs

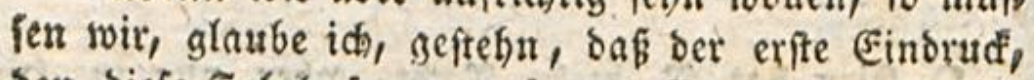
Den biefe Fabel fogar allf uns Errvachlene macht; allemal babit ausfchlage, baßs wir es mef̧r mit bem Juchie als mit bem Staben Galten, weil jener flug und liberlegt, biefer bumm verfábrt. Hno boç múf̈te, Hach ber Sittenlebre bie grófere siserad)tung nicht ben Raben, foubern ben Juchs treffen, Dies ift wirflich ber f̧auptpunct, worin viele áfopifhe Fabeln fich nicht zu einem pádagogichen Bicbrauche

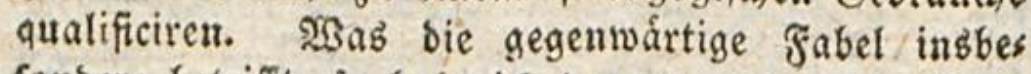
fonbere betrifft, to habe id bavon noch ganz fúrzs lich folgenbe 2frecbote erlebt, bie bas, was ich fo eben fagte, vollfommen beftatiget. Ein \&efrer hatte fie einem jungen \$ienfien von fhwaden Merftans besffáften vorgelefen, und batte nachber gefragt;

num 
Ser borftekgenben Fabel Kalten bie Sinber fid faft alle ubber ben ßaken auf, sem Fuchfe aber find fie fämmtlià) griu. In ber forgenben glaube man ihnen bie Scenfadrecte zum Beifpiel zu geben, unb nidjts meniger als Das! Sie wers

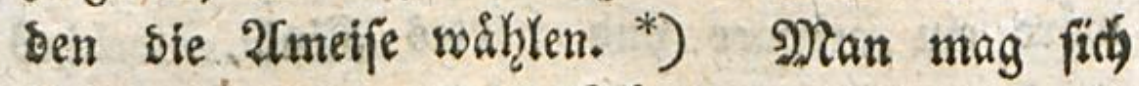
Sit 5 nidjt

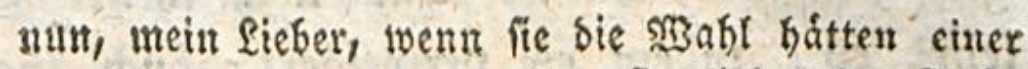
won beiben zu werben, wollten fie licber ber fuchs ober ber Rabe fenn? "Der Rabe!" antwortete ber sutmitbige Singting: uno feime funtwort waro in einer Ssefellichaft, als ein Эjerveiz feinet Stupibitát, zid)t blof erzáblt, fondern autch befacht.

(Sampe. Trapp.

Der Rabe, buinft midh, folf and burch feine Dumme Eitelfeif veráchtlich fern, uno an Den f̧ưd, fen unb liftigen Nienf(hen liebt man naturfićs ben berviefenen 2 serftand, aber bestregen nicht bie $\mathfrak{A b s}$ fidht, wozu fie ifu brauchen, ober bas lafter, befles şegefung fie fich baburch zu erleidtern fucher.

Niefernits.

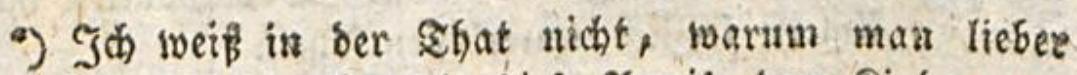

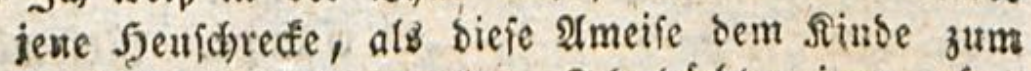
Şorbilbe auffellen wollte. Id) bádbte, iene wáre 100 uidht weniger, bock eben fo wenig geichifft baju cin Nufter zur Nachabmung abjugeben. Eime Pers fon, welche bie Bcit, ba fie (5) legenbeie, uno firafte za erwerbender Strbeit hat, mit Nicht 3 thun Ginbringt, aub beswegen barbt, perbient boch wol in Affgemeia sen und ofne auf Eefondere, ben Fall nd her beftima mende umftánde zu fehrn, eben fo viel, we nicht mére Sabel, als ber fleifige, ber mit bem, was er burch fauern Sdweiß erivarb und leas es Telbft hebarf? peenses 


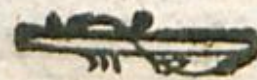

sitd)t gern bemithigen; wer will nidjt immer gern bie fidsnen Siollen nethmen; Sas ift bie S2Babl ber Eigenliebe, etne fehr naturliche 2 Babl!!

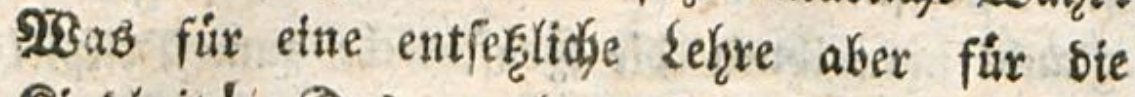
Rinsheit! Das verḩaftefte allex Ungebruter wáre ein geiziges uno hartes Rino, weldjes soúgte, warum man es bate, und es abfoblis ge. *) Die 2fmeife thut nod mehr. Sie refjrt es, inbem es serweigert, auds. zugleid, fpotten, **)

In allen Fabeln, two ber Eswe eine भुers fon tit, exmangelt, ba ex gewooknnlid, bie glans zenofte Rolle fpielt, bas Sind nidyt, fid zum ¿swen fu madjen, unb wenn eв ben Borfic

(benn two fteht in ber zaber, bap die efmetie llebers flü gebabt habe?) ben Fauten in feiner Faulbeit nicht zu beftárfen gefonnen ifi. Das Epotten hátte bie $\mathfrak{A m c i j e}$ freilib) unterlaffen follen.

Eampe. Refenits.

") Itud ber şzeife weif oft recht gut, warum man ihn bittet, tho folágt es bods ab. Nit Necht; bent wo ift bas sefetr, weldhes uns verbindet, Jeei nem etwas abzulchlagen? Dit ift eine ablalágige Afutwort gútiger ols eine getvábrenoe; uno bei ans ficheinender Şárte liegt oft mebr Sugeno zum (5) an: be, als bei úbertriebenter șute.

Bampe. Sieferpis. (ang) Daran thut fie nun freilich febr unrecht.

Eampe. 
bef einer Iheilung fuffrt, wohlunterridutet surdh fein N)tufter, fehre forafáltig fid) bes (5anzen zu bemádytigen. 2 genn aber bie Miucte ben Somen ibermetifert; ałsbann ift eB umgefefhrt; baz Sind feflt nid)t mefzx ben Sowen vor, fome Sern ste Mücte. $\mathfrak{F}_{\mathfrak{B}}$ lernt sereinft mit Sta deetn tosten, wo.es feftes Fufes anzugreifen fidh nidft unterfiethen wirbe. *)

2Uื ber Fabel vom magera SBolfe und bem fetten Şunbe nimmt es fich nidjt sie Sehre ber Mäßigung, bie man ifm zu geben gebentet,

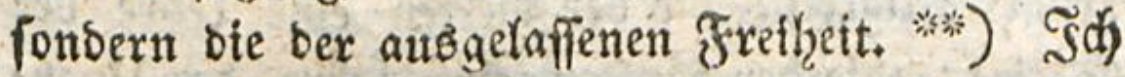
werbe niemals vergeffen, baf́̈ th̆ einmal etn fleis nes Miadjen weinen gefefzen babe, bas man ourch

-) Son biefer Seite betractet, fins sie meiften ga beln, bie wir haben, in ber That umpábagogich. 2lber biefer Fehler fann vermieben werben, unb wir baben wirflich einige Sabeln, worin er vermieben

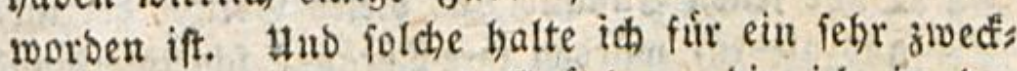
mápiges $28 e r f z e t g$, auts (srúnben, bie ich in ber angefúbrten 2 bbandlung tiber Den (Bebrauch) Der åfopif́chen grabel entwidéelt habe. Eampe.

**) $\Re$, traut im Banı en genommen, ben \{ecbisiábrigen Sinbern zu wenig moralifchen Sinn, ich meine, Hns

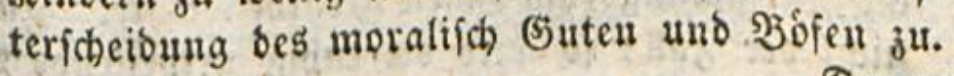

Trapp.

9raeil or jiberhaupt nicht viel moralijhes (Bes fúfl in Sinbern fieft und fucht, noch weniger zu entwideln nothig finbet.

Siejervita. 


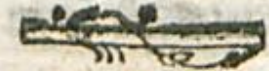

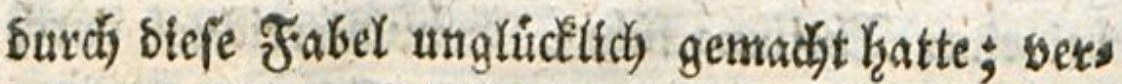

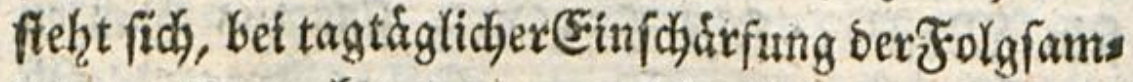
Feit. Man tonnte gar nidgt hinter bie Utraas dje ber Bhrainen tommen; endidy entbectite es fich. Das arme Rino war ber Feffel úberorifs

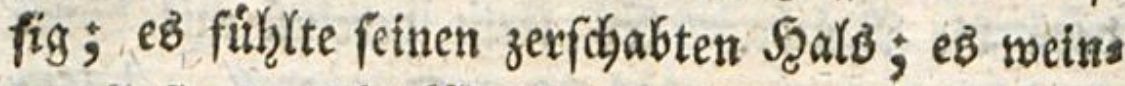
te, baf es nidjt 2 olf war. *)

2llio ift benn bie moral dex exften Fabel für bas Rino eine \{efqre be: niebrigften Sdameis d)elet, bie ber zweiten eine (efgre ${ }^{* *}$ ) ber IIn menffalichleit; Die ber britten eine Sehre ber Inngereç,tigkett; bie ber sierten eine \{eḩre ber Satire; bie ber finften eine Sefore ber Unabs

-) Ein ebfes Rint, wertf cine gebofrme giómerin ober Spartanerin zu fern! Sie wutrbe ofne 3weifel fclas

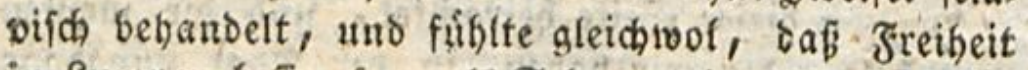
in Eumpen befier febt, als Ectaberet in fotimmernbent alleibern und bei tleberfifu. Desibegen weinte fie. Dhe ienen suftand und diefes Gefábl bei ihr vors

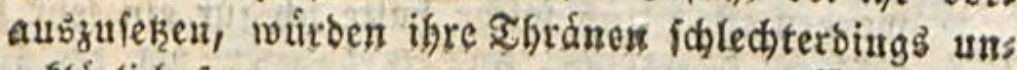
erÉfárlicț feins,

Eampe.

a) Ein \$eifpiel, bas nur in to fern bie ox̧irfung eis ner Gebre haben fónte, als bie Seele bes Sinbes Burch gegenvártige Umetánbe zugleich in eine dobntis de Serfuthung zum ģofer geratben wáre. Sit bies nicht ber fall : fo wirb bie ruffig artheifende Ceele

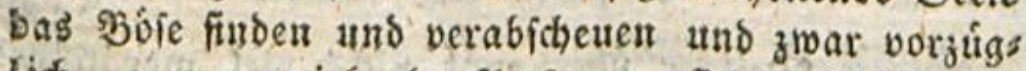
Yid, wenn ergiefende \$erforen fich mit für bie Gode Des Buten gebörig intereffitien.

Eblers. Siepenit. 


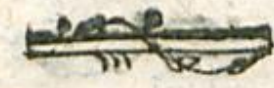

bुangigtett. Diefe regetere ift iflerfliffig, fix metnen 3 goling, aber fur bie enrigen barum nidyt angemeffen. 2 Benn ifyr ifynen Borichrtfs? ten gebt, sie fid) wiberiprechen, wab fit Frudt erwartet if̧x oon euren Semihungen? 2(bex bielleid)t mag wor, bis auf Das nakge, Diefé ganze Moral, bie mix als Einwensung wiber bie Fabeln bient, eben fo siele Erunde an bie Şand geben, fie beizubehalten. S2Sir brautyent in ber Sejellichaft eine 230 ontmoral uno eine Shatmoral; unb biefe beiten Noralen gleict)ent (iic) nitd). Die erfte fteht in bem Eated)ismus, so man fie Yağt; bie anore in oen Jabeln bes Eafontaine für bie Rinber und in feinen Contes für bie Mintter. Derfelbe Sdjriftifelo ler iff fur 2lller Soburfniffe gemadjt. ${ }^{*}$ )

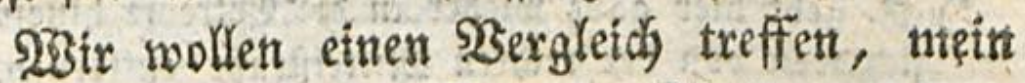

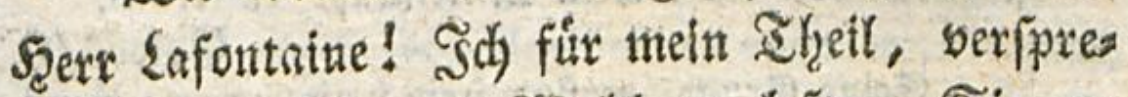
de Şhnen, Sie mit $928 a h l$ zul lepen, Sie zu Yieben, midj in ihren Frabeln zu unterrichten;

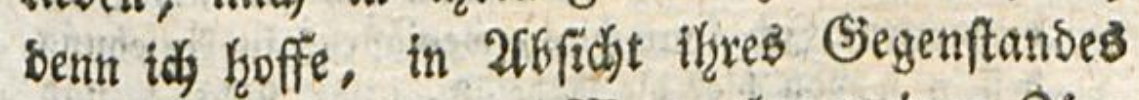
nidat feht zut greifen. $23 a s$ aber meinen 3 S'ga ling betrifft, fo werben Sie mir erlauben, Daf id) if̧n nidjt eine einztge ftusiren Yâfe, bis Sie mix bersiejen bूaben, es jey gat für ihn, Dins

7) Sittere Gatire !

giepêtwiş. 
ge zu Yernen, wobon ex nidjt bas vierte Thetl verfteken wivo; bewiefen haben, ex werbe bies jenigen, oie ex verftehen tann, niemals serḱetgrt faffen; bemiefen baben enolid, ex werbe nicht, ftatt fid, nad) bem Setrogenen zu beffern, fid nad) bem Setriger bilden.

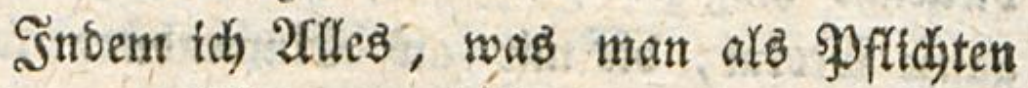
Rinbern aufbirbet, abidyneibe, fo ráume idj

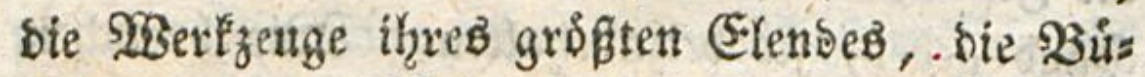

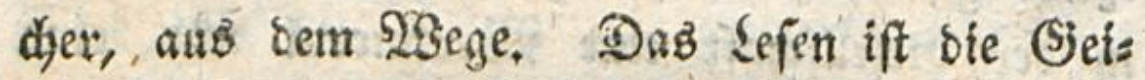
Fet ber Rinokgeit, uno faft bas Einzige, womit man fie zu befdaditigen berfteht. Mein Emil soiro thum im zwolften Sahre wifien, was ein gud (e\%. *) Er muf dody aber wol wenigz ftenz,

*) গ. geht hier ganz loieber in bie Extreme binein, bie fitch weit won ber rechten Mrittelitrafe entfernen.

(E) Ier.

Seine Srunbiákze find freilich oft Extreme, wenn man fie mit dem gewobnlichen 3 erfabren vergleicht; aber aud banu nod), wenu man fie fúr fich felbft betrachtet? Ict faun bies, wenigftens in 2Infehung befien, wovon hier bie Rebe ift, nicht finden; und ich f(heue mich nicht, bas offentlich, zu geftehn, obus geachtet ich feht roht weiß́, was für Эegriffe man baburch von fich veranlapit. Tich beziche mich ber Sirrje wegen auf meine $\mathfrak{A b G a n b l u n g ~ l i b e r ~ D i e ~ g r o f i e ~}$ Scbadichfeit einer alfufrúben drusbiloung Der Sinder im 5 ten Dheile ber allgem. Revifion.

Eampe. 
fens, wirs man fagen, lefen tonnen. Buges ftanden! Iefen mus ex fónnen, wenn ihm bas Sejen nitģtid) feyn wiro; bis bahin taugt es nur, thm Langewitle zu madhen. ")

Soll man von Sindern nidjts and Giehor fam berlangen, fo folgt, baff fie nidjto lernen Esnnen, wobun fie nidjt ben wirllidjen uns ges

Whe lange follen benn Sinder folde Sinber fenn, bie gar nicht aus \$ुthern unterridtet werben follen? Denn bis itt zlvolfte Jabre ift boch wirftich zu lang.

siefervis.

Id) Fann bas nicht finton: vorausgefę̧t, ba

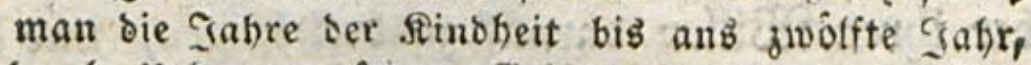
burch Ueburaen feiner Beiftes: unb Rorperfráfte, bie feinem jebcsmalizen 2ltẹr angemeffen tint, ges borig auszuffillen verfteht, um bas నind nicht vers wilbern ju lafien. Ich bejieke mich bieviber auf bie oben angefúbrte 2tbhanblung.

Eampe.

2) Sreilich unter ben llmptánben, unter weldien fich 2. jeinen Emil benft. 2aber in minber gúnftigen fagen, in folchen, worin wir getwibntich, mit findern

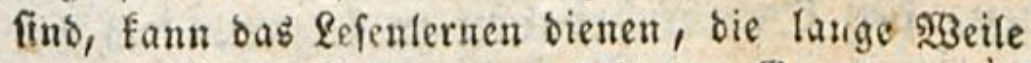
zu vertreiben. Hnd nur aus biefem Grunbe, nur un einen Seitvertreib mefr fur Sinder, bie unter fechs Jafren fino, zu baben, Eanu id es billigen uno aurathen, fie mit leienlernen uno Lejen zu bes fcháftigen. Ifls Epiel, nicht als Stubium fann es in biefem alter unichádich, ober weun man will, mík̨lich (ev)n.

Trapp.

Und biefes Epiel wirb boch auth nod reellen Nuken baben, weun fie lefen, was fie veritefn, ober burch Intidaum falfen fonnen.

গiejenik. 
gentwartigen Sortheil empoinbent; btefer beftehe nun in SBergnigen ober exnfterem 9uisen; benn weldyer Bemegunggignun mirbe fie fonft

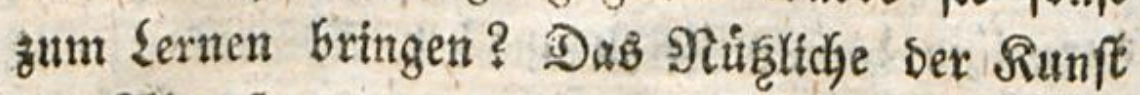
mit 2lbwejenoen zu reben uno fie zu f̧oren, ber Runft, thunen in Ser Ferne, ofhne Mittelöpers fon, unfre Sjebanten, unfern Millen, unire 23inidje zot exsfnen, tann cinem jeben 20iter begreiflidy gemadnt merben. Durch was für ein SWuncer benn ift steje fo nügridje uno fo anges nehme Runft fux bie Sinskgeit eine Narter gea worben? Sur indem man fie zwingt, fid wis bex thren SBillen barauf zu befleifigen, uno lles bungen an bieje Runft Enipft, wobon sies 201s ter nidyts begreift Sin Sins fiblt nol eben

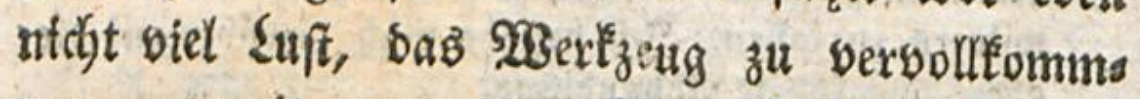
nett, womit man es̉ qualt; btefes 2 sertzeug aber biene nur zu feinem $\$$ sergnigen, und

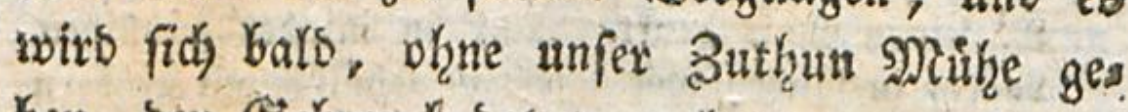
beu, Den (sebrauth bason zu Yermen.

Mian if fehr sariber aus, beffere g) Tethos: Dett, Lejen zulexnen, zu exfinden; nan exs bentit Sejetifftjen, Rarten; man madjt aus bem Simmer eines Sinbes eine 2 udisoructertwert.

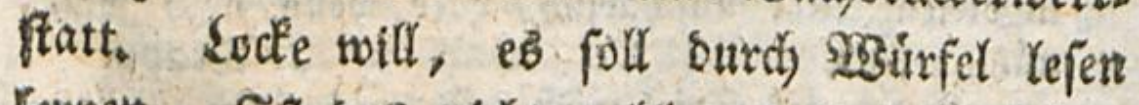
beznetts Sif sas nidjt wobl ausigebaht? şams,

. mery 


\section{9}

mexlid5. - Ein ficherer STittel, als alle bie, sub beffen man tmmer vergifft, ift cinflofung ber Begierse zu lexnen. Man bringe bem Rinbe biefe Begterbe bei, ${ }^{*}$ ) bann braudjt mant

?) Das if rahr; unb bann wirb nuter genifien গ̧es Dingungen bas Lefen balo von ftatten gefen. Eine Semerfung mut man aber nicht ans beu stugen lafien, bie id burch melitere Erfabrungen beftatigt gefunden habe. Brevade bie fimsor, bie am richtigs ften benfelt, und bicienigen, welche eine ichnelle Fafs fungstraft haben, lermen nur mit vieler gitife les

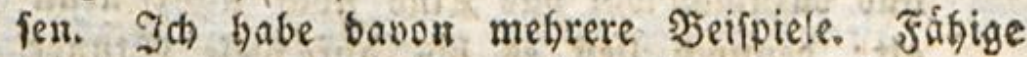
Siopfe, welthe einen Vెegrifi fonell fallen, fins ims mer mit thren sebanfen voraus; fie fefen ridhtige Sák̨e, nicht aber bie, bie im ऊ̧uche furb. Das ift leicht zu begreifen. abber wie geht es zu, oak recht

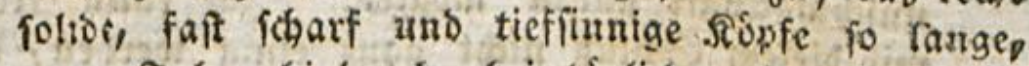
gange Sabre fintourch, bei tigglicten Hebungen, fo

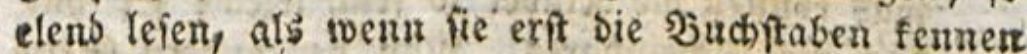

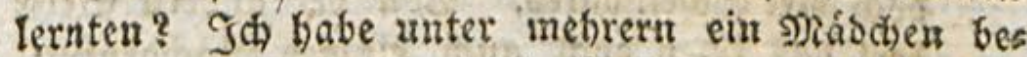
sumbert, welches fefor richtig bachte, bortieflich rects nete; und zivar bemonftrativiid, nach meiner Nes \$5obe, die Fiechtichrcibung ziemlich beobachtete, aber faft budftabiren mufite, wem ite las. Id habe nod eitren Sinaben von jein Jahren, Der ieķt noch nidit lefen faun, of er gleich gern fiefet, und alles beobrichtet, vber alles nachoenlt, im Nechnen gute

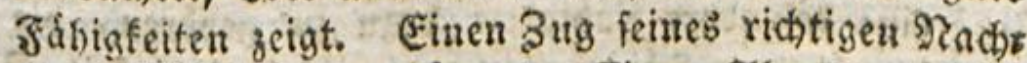
Denfens mun ich anfúbren. Einen Q mit einem Eumeraben bei 2rondenichein pajteren. Eiefe, fagte iener, Der siono geft mit uns, Nein, antwortete unier Sinabe, bas ift nidst moglid, 3 benn toen vir uns umfefren uns sortbin gefen, fo roirs Enil 1 fter $\$$ \%

2!

es 

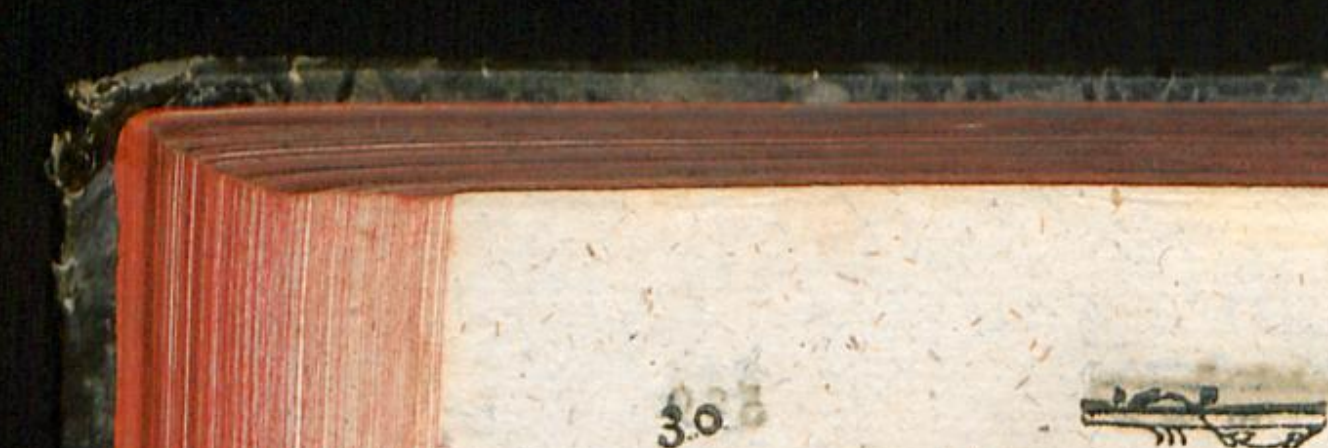

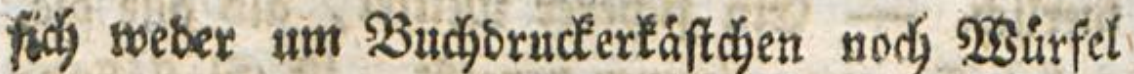

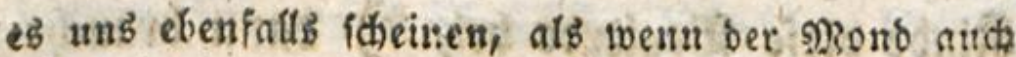
mit uns ginge. Fiu andermal, ba wir nom Eles phanten fpracben, uno wir feine Teftigfeit gegen bie flintenfugel bemertten, fragte er: Stber bie Ranos nenfugel? $\mathfrak{D}$ fagte idh, biefe witroe wol burahgeben. 2(ber, iprad) bas Sind, fie nimmt Dod mebr Siaum! Das ift aufs genauefte pein 'Ausbruć; nobei bie Soee einer grófern Diefiftenz. nach bem Raume folvol, als ber genaue philofopfifhe 2 tus's oruit zu bemerfen ift. Es war nicbts Bselerntes, nno bazumal war bas Sind noch nicht neun Iabr alt; Dennoch lieft es bis auf bieie Stunbe nodh falecht. Daraus zog iemand ben Echlu bi, bấ man bie sinder fruth, ind ebe lie benfen, le reu lefreu Follte: weil fie nachber úber bas Denfen bas Eeien smichmacthaft funden inigten. Sob fam freilich mit biefem Schlup nicht ganz einig werten, benu rob tommen bie finder fo friil) lefen? Er bat aber boch viel Gcheinbares: $B$ on Der anbern Geite for: bert bas leien Doch aud einiges Tracboenfer. Eg wåre z̆ whinfden, baß biejenigen, welche bicrin webr Erfabrung baben, als ich, uns ibre Fiemers fung mittbeitten.

Sillaume.

भRach meinen Erfabrungen fann ich toeder bie fábigen stopfe fúr unfábiger fum Leienternen, wodh

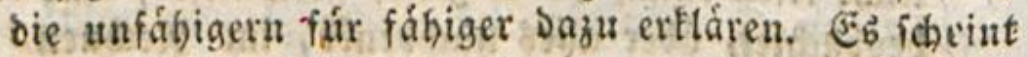
zot serine befondere fábigfeit bazu ju geboren, bie Lei 3s ber ubrigen Jibigfeit jolvol als llnfábigfeit Statt

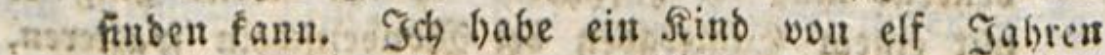
stis bei mir, bas moch inmer mit ber áuferften ontibe zingo ano finlecht lieft. Fin anders uno jwar fábiger's

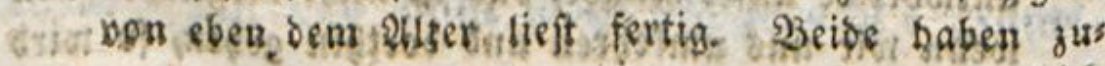




\section{1}

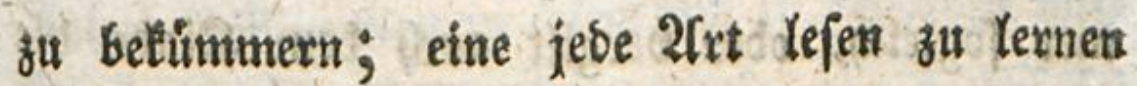
wiro tbm gut feyn.*)

Das gegenwätige Sntereffe, bas if Das grofie Mittel; סas einzige, ১az fidjer unb weit fübrt. **) (Emil empfángt bisweilen von fet: nem $\mathfrak{B a t e r , ~ f e i n e r ~ M u t t e r , ~ f e i n e n ~ S e r w a n d t e n , ~}$ jeinen Befiunten, Einlabungabriefchen zu et. nem Saftmable, zu einem Spariergange, zis einer Fabzrt auf bem sibaffer, eine offentlidje Suftbarkeit mit anzufehen. Dieje Briefdyen fins Eurz, beutlid, fauber, fajon gefdjrieben. Es mus wer ausfintig gentadyt werben, ber fie ifm leje; biejer 23 er finbet fid) entweber nidjt tma I 2

mex

gleidh angefangent. Beibe fint feit fuinf Iabrent nad) derfelben Methode unterwieien. Das (d)ledter tejende red)net im Siopf fehr gut, faft befler als bas andere, butchftabirt aud) vorgefagte f(f)lvere sBorter febr oft leichter als bas andere, urtheilt langiam, aber immer ridhtig, lernt franjoltich uno Fied) uen auf ber Safel fehr f(hwer, auch Ealligrapbifich fatreis ben viel langfamer als bas andere. Srapp.

-) XBem ein Rebrer bie Gache getórig anjufangear roeiß: fo lernt ein Simb leisht mit ßergnigen les fen, went man aud feine von den eben angefuibs: ten sitteln gebraucht. Darum find indeflen boch bergleichen sittel nicht z" verwerfen.

(E) lets. Referwib.

co) Dak fann nie laut unb oft genua gefagt merben! Srapp. Eampe. 


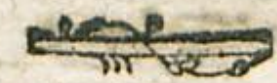

mer pogletey), ober bergilt aud bem Sinbe ofe Ilngefálligkeit, bie es̉ geftern gegen ifhn bemies. 2 lyo frethit bie Sielegenheit, ber 2 tugenthlid vorbei. Enblich lieft man ihn bas 3riefohen: aber ez̉ tif nicht meţr 3eit. 2Cdy! wenn man jelbfit haătte Yejen tónnen! Man betósmunt an sere; fie find fo furz! Der Snkhalt Dabon fo interefiant! es wäre bes 2 seriudjo werth, fie zu entziffern; bald wird Sgille gefunden, balo Heine. Man ftrengt fid an; man entziffert enolich bie Sod्alfte eimes soriefdyens; es foll morgen zur frifden Mild! - — - man soiß nidjt wohin? nod) mit mem?

Wote biel Muthe wiro ba tidjt angewnanot, bas Ulebrige herauşzubringen! Sđ zweifle, Emil werbe eines Budjorudertäftchenz besurfen. Soll idh jef̧t bon Sdjreibenlernen reben? Neein!

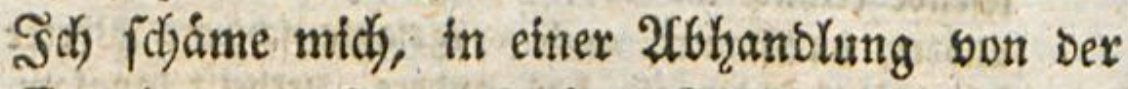
Erzief̨ung midj mit foldyen Sileinigteiten aufaus bुalten.

Nur nod, Dab einzige N2

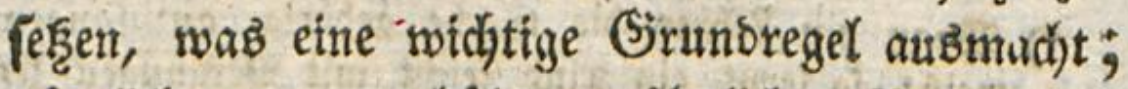

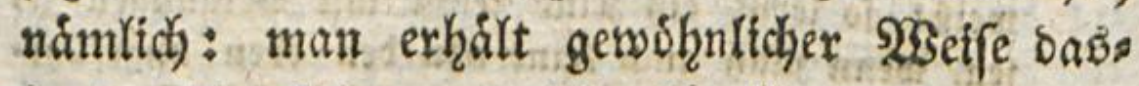

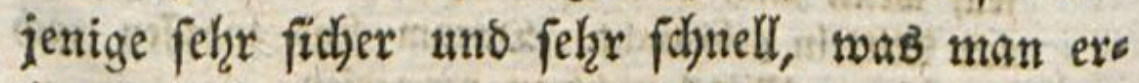

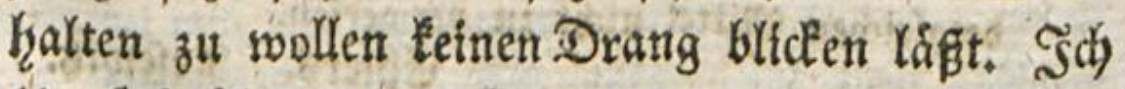
bin faft iberzengt, Emil mirb yor bem zelntent Sathe 


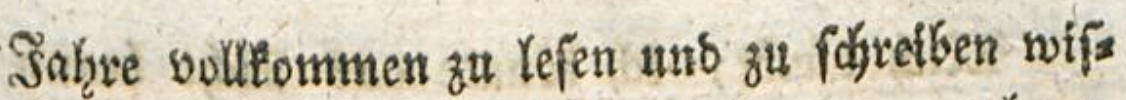
fen, gerabe weil mir fehr wenig baran gelegen

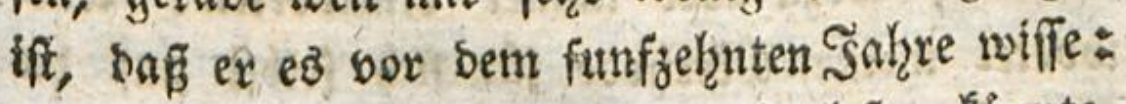
lieber aber wollte idy, bás ex nie lefen Esimte,

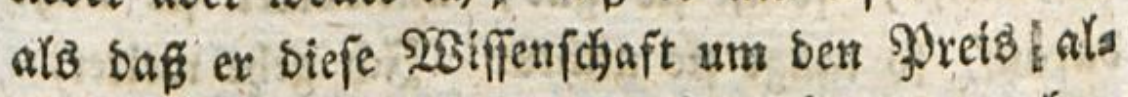
Yes beffen extaufte, was fie ifm nif lid madjent fann: benn wozu mirb tf̧m bas sejen bienen,

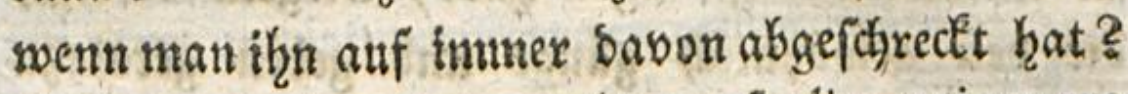
Id inprimis cavere oportebit, ne ftudia, qui amare rondum poterit, oderit; et amaritudinem fomek perceptam etiam ultra rudes annos reformidet. $t$ )

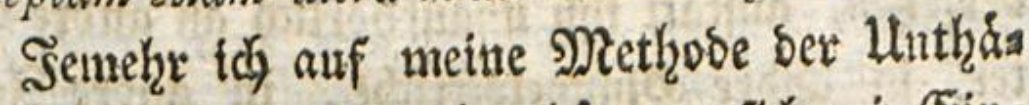
tigleit bringe, befto mehre thúrmen fid, mir Fina

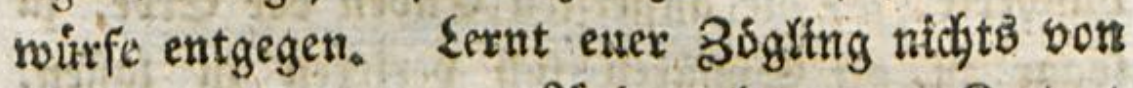
(Eid), fo twirb ex bon 2Inbern ternen. Rommt

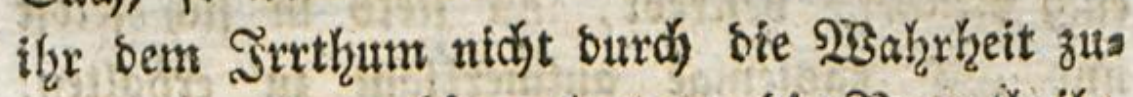
wor, fo wiro ex Singen Kernen; sie Borurtheile, bie thr if̧m betzubringen fúrditet, wirs ex bou Ullem, was um ifnn ift, einfaugen; fie werben burch alle petne Sinne einbringen; werben ents

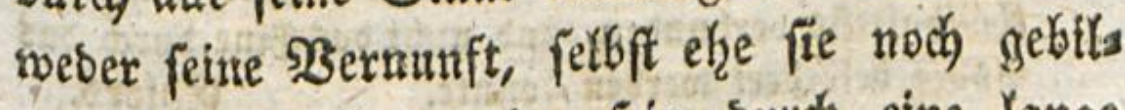
bet ift, verberben; ober fein surch eine lange Untḩåtigkeit eingejaldaferter Geift wirb in bem num auf tha zubringenden Stoffe expticten. Die Ungewohnheit zu Denten in ber Rinskgeit benimmt వas Bermogen bazu auf bie úbrige Eebenszeit.

$$
\text { II } 3 \text {. }
$$

SPlity.

t) Quintil, Inftit, L., I, G. I. 


\section{4}

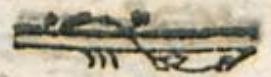

Midi buift, ich fonnte bas reidjt beants worten; wozu aber immer 2(ntworten? 2Cnts wortet meine Methose fir fid felbft auf bie Einwurfe, fo ift fie gut; antwortet fie nidjt barauf, fo taugt fie nichts. Sal gekge weiter. 253enn ibre nach bem Srumbriffe, ben icl)

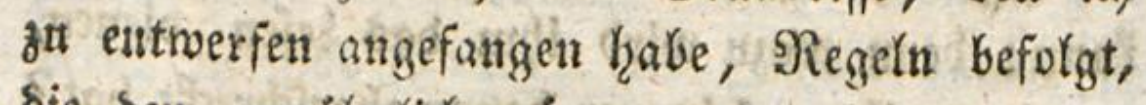
bie ben gewoblinlidy gănge uns geben gerabeza entgegengefert fits; went ifre, antatt ben Seffe eures 38aling tumer in sie Ferne zu

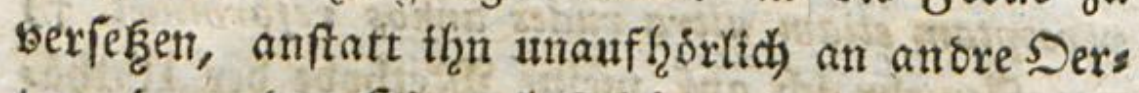
ter, in anbre Soinmelöftriche, tn anbre Jahze bunberte, an bie aufferften Enben ber Eroe, ia fogar in bte Sphairen fich berirren zu laffen,

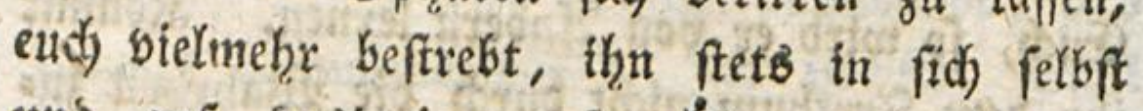
uno auf sasjenige aufmertfam zu erhalten, soas ifin utmittelbar angeht: *) fo werbet thr alds:

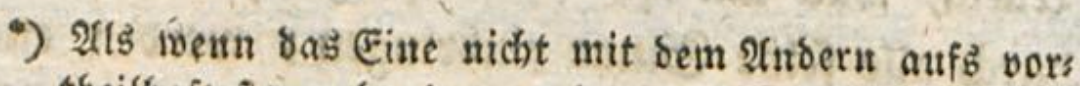
theilhaftepte verbunden, und nicht bas (sine burch bas stubre beforbert toerben founte.

(E) lers.

भber biejes- geichiaht nidst bei unfern bisheris gent Metboden: ba jielt, wo nicht alles, boch bas Mieite darauf $a b$, das Jino von fich, von dem Orte feines Afufenthalts, pon ben ihm nahe liegenden Eegențínben, von ber gegenwártigen Seit zu ents feruen; und Sas ift bod anweife gehaubelt?

Eampe.

Eben 
alsbant ihn fâhig zum Einfolien, zum Bef̧ats ten, unb felbft zum Lrtheilen finden. Dies ift Sie Sobuing ber Natur. *) ९rad bem Maafé, If 4

nite

Eben fo unveife binft mich, swenu riber bem Бegenwártigen bas fermere uno Sunftige ganj vers nachlápiget wiro; bem es foll bods nach uno sach unm vernuffigen Nenifsen gebilbet werben. Int

Niejewis.

Gchr wabr; aber 1) fanm, bunft inid), bie

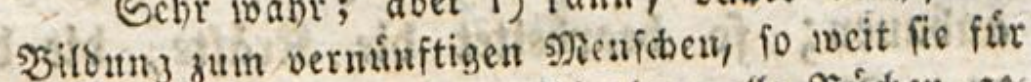
bies allter gefort, gav wohl ofne alle ßutcher ges fhebn, menn nur biejenigen, bie mit bem Sinde nugeben, vernúnftige uno gebilbete Nenfchen fint; 2) ift, glaube ich, bas die befte Borbereitung fúr jebes fúnftige 2utter, wenn bas fino in jebem ges genmartigen Alter gerabe bas thut, was feinen aed

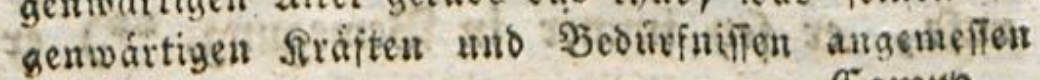
ift.

Eampe.

*) Eben fo gut gebort es jur. Dronumg ber Natur, baß Erwadfene mit ihrem Erfentmifoorrath auth auf Sinber toirfen; Jemntuifie, ote in cintr fangen fes bertseit nicht ervorben werben fomten, fanit man

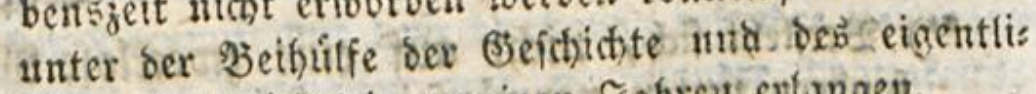
lichen Unterich)ts in soenigen Fabrest entunaen.

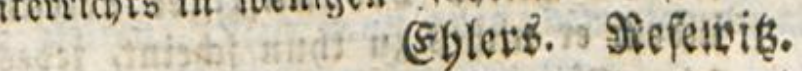

Siut affes zu feiner seit. Die uabe liegenden Begenftande bieten ber Scele bešstindes zur the: bung aller ifgrer Siráfte mehi Stoff bar, als fie in Dẹn erften guvolf Safren veratbciten fann; soarum wollten wir fie benn idson von bicien Gtoffe entiers nen, befonders da fie fur jeben andern Stoff nod

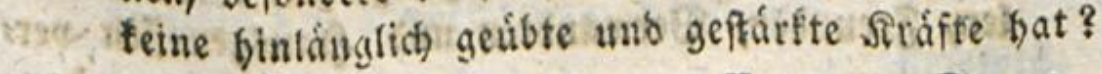

Eampe. Stuve. 


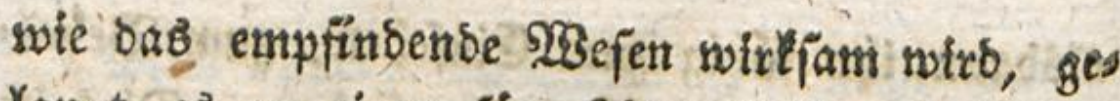
langt $C^{B}$ zu einer fúr feine Sidafte fdjid'lidjen

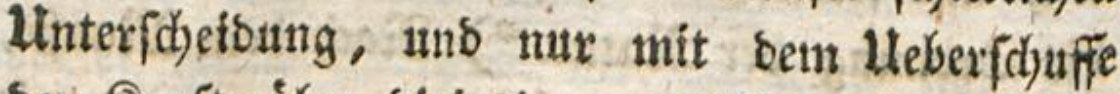
Ser Riraft itber siejentge, weldje es zu feiner Erf̧altung braudit, *) entwidfelt fict) in ifm sie fipeculatibe $\mathfrak{F a b j g t e i t , ~ s i e ~ i m ~ S t a n d e ~ i f f , ~}$ Son biefem Ulebermaafe bon Rraft Siefrand auf nody andre Dinge zu madjen. 230 llt ithe

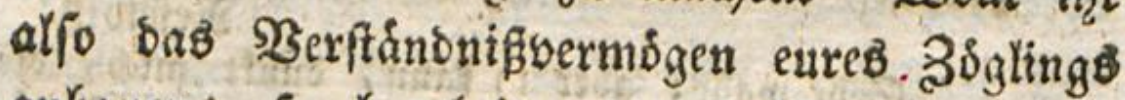
anbauten; fo bearbeitet bie Rirdfte, bie Durdy biez Sermogen regieret weroen follen. Ulebt beftansig fetren Setb; madyt biefen fart uns gefunt, um Şlon felbft seife und bernunftig zu madjen; (rt arbette, ex rege fich, er laufe, ex sufe, ex fer) immer in Betwegung, *\%) ex fer)

-) Dies ift ebent fo richtig gebacht, als gludellich auts gebrucit und veroient, nidat obenbin angefern zu werben.

a*) Berfeht fich, nicht auf eine swedolofe ISeife, fonberm unter vermuinftiger Reitung, bamit er, inbein er nichts au thun foceint, iebesmal nicht nute peine Roupers fonberit auth feine Bseiftesfráfte wibe. Eb: ift eitre ausgemacte Sache, daî uniere Eduls znaben ben groften פheil ifrer Entwidfelung und 2(ubbildung, nicht bem Unterrid)te in ber Sd,ule, fonderit ber freien 2eufierung ifrer Frafte in ben Bivijchenzeiten und bem Umgange mit ifren Befpies

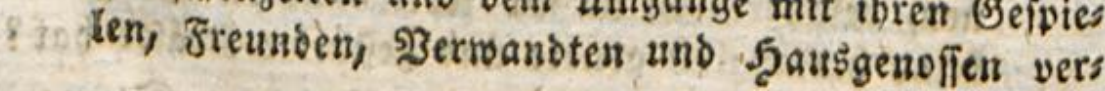
bank 
Feiner Yebensigen Siraft nad Mann, und wito es aud bald ber Berminft nady (eyn. *)

(EB ift wahe, ihr witset if̨n ourdy bicfe Methode balo zum Thhiere madjen, wenu ihe ihn ftets Yenten, ftets zit thm fagen wolltet:

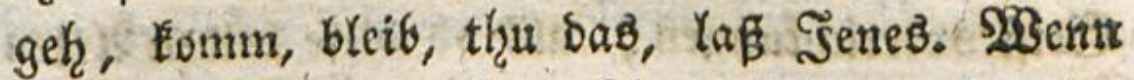
etter Sopf immer feine 2frme reitet, fo wirs fein eignex ibm unníg. 2(Ger bentt an bas, \{l 5

stos

bauffer. Sşie viel gróber aber múfte bie şsiffung won dem allen fenn, wenn es immer unter ber Leis tung cines verffanbigen Fúbrers geíháhe, ber bie letenbe Siraft, mit ber er alles lenfte, zu verbergets wífte, und bie Sandlungen des Sinbes beftimmte,

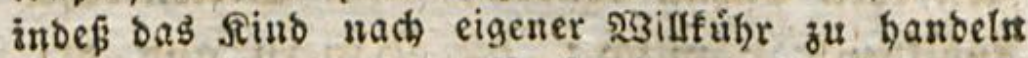

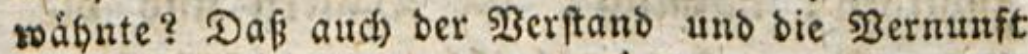
Dabei nidht ungeribt bleiben roúrben, leuchtet gang won felbet eirs.

હampe.

-) So wie alle zíbrige Irráfte beß నindes Reitung, Plege und Hebung brauthen, wenn fie fich reche

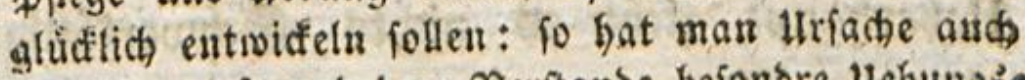
Der Şernuft und bem serfinate bejondre Hebung: mittel zu verfchaffent uno wi befonbre Ifhátigfeitss gánge binzuleiten. Nür muf allés bem iebesmatis gen Zuftande ber Srráfte augemefien fern.

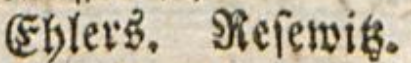

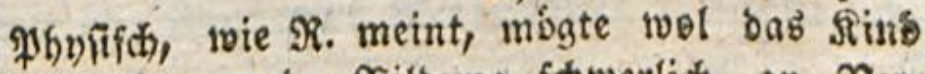

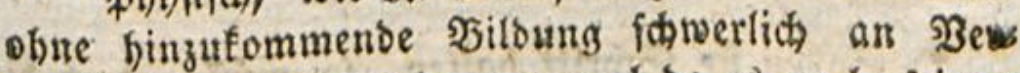

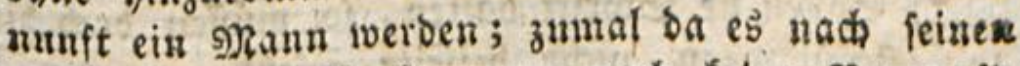
vorhergehenben. Aeuferungen noch feine פernunfts. fraft in ben simberiafren baben foll.

siefemis. 


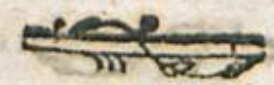

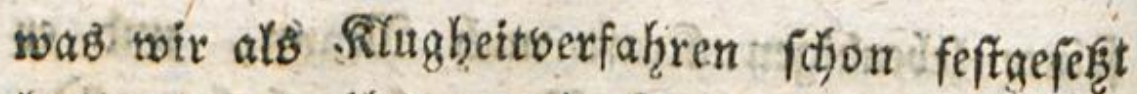
baben; fend the sur ein Jeoant, fo bertolynt fidjs nidat ber Niube, midy zu lefen.

7j) Ces ift ein fehrr tlaglidjer Srrthum, went ntail fith einbilbet, Leiberibungen fil)abeten oen Seiff soerricftungen; als ob biefe beiben 2frten 25etrid)tungen nidgt mit einanber Sdyritt bielten, and bie etne nidjt ftetso bie andere lentét inifgte. *)

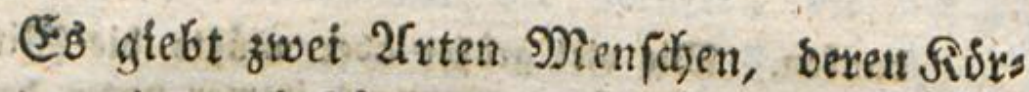
per in einer beftandigen Bewegung ift, unb won benen gemíf bie Einen fo wenig, als bie 2noeren baran benten, ihre Seclentrafte auts

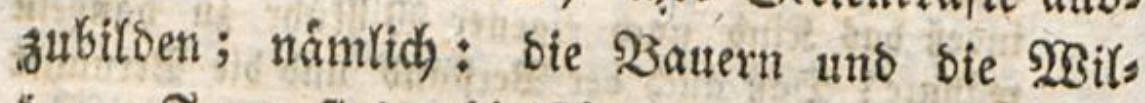

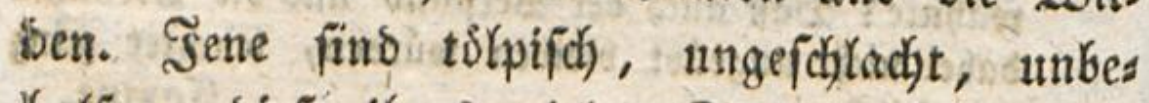
tholfen; siefe thres bielen Sirnes, uno nod mefir ber Feinkeit ihres Geiffes wegen befannt. Uleberhaupt giebt ez nidjts Sdjwerfalligeres, alB einen SBaner, uno nid)ts Gewanteres, ałz einen $23 i t b e n$. Igohcr biefer Llnteriófied? Das ker, bafi ber exfte, ber immer thut, was man

ifin

-) Eoffen fie Edritt halten, fo múfen bod bie (seis fitesubbungen nidht beifeite geferkt werben. Durw blofe Eeibesúbungent wirs fein Beift gentbt; unt wenn er fich ofne leitung und $\$$ frege entwicfelt, wite er fehr rol werben.

Siejerwis. 


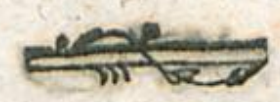

tiju befiehlt, ober ex felbft bon feiner Sugend an gethan hat, blof nach betm alten Sextoms

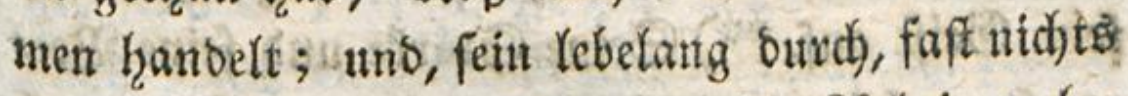
ดไร ein 2utontat, mit eimerlei 20rbeiten bes fbjåftigt, fich bịe Siewohntheit uno bet (Sielzors fam fratt ber Sermunf bieneu baft. *)

Sei bem SBilben if ber Fall ganz anberE. Er, an Exinen Drte gefeffelt, ofine irgeno ein thm vorgefdyrebnes, obliegendes zagewert, ohne Serbinslidjeteit jemano ju gehordgen, ohne wets teres Sépers aló feinen SBillen, füft fich noths georumgen, bei jeber Şandlung fetmes cébens Heberlegungen anzuftellen; ex rúbrt keine Şanb, thut Écinen Sidritt, falls er nidyt die Jolgen Das

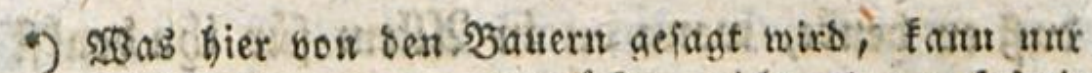
auf leibeigue uno unterbruffte, nidht aber auf freie uno mit máfigen $\mathscr{2}$ usgaben belaftete ஒautern anges roand loerben.

Daber wirb man aber aucb bemerien, baj bet Shawer in ebell bem Srabe gewander, fluger unt berftandiger ift, in welthem er weniger Getav uno

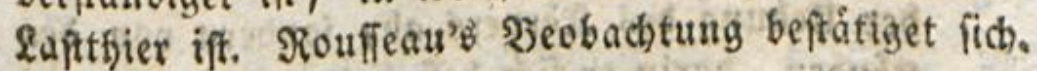

Eampe.

Freibeit madit allerbings ben (Seift acturnoter, thátiger und entichloffener; aber bic 2Bitbheit alb 2Ssitobeit trágt nicht baju bei; verftumpft vielmebr oft ben seift.

Refernits. 
babon im voraus exwopgen hat. ${ }^{\text {*t) }}$ ) Je mehe

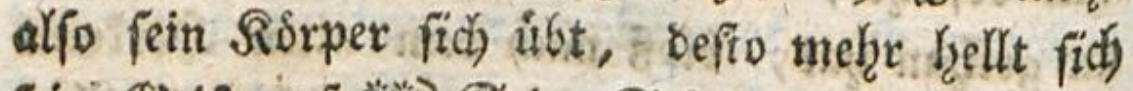

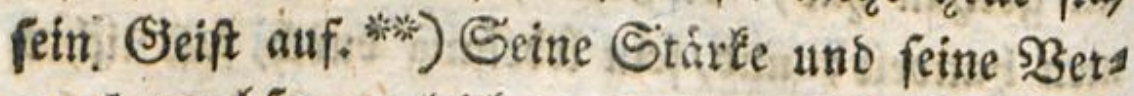
nunft wachjen ougteid, erweitern fid (Fine ourd bie 2rovore.

Sielef̧rter Eefrrex! wir wollen fefgen, weldyet Don unfern beiben 3ỏglingen bem 23 itben uns wels der sem Bauern gleidje. Der beinige, in 2rlem cinem flets unterridjtenden 2 nfehn unterworfen, thut nidjtB, alB auf bein $2 B_{0}$ ort; ex oarf nidjt effen, went ihn hangert, nod ladjen, went ex frofhlid, nod, weinen, went er traurig iff, noch eine Şans vor ber 2rnbern reidjen, nods

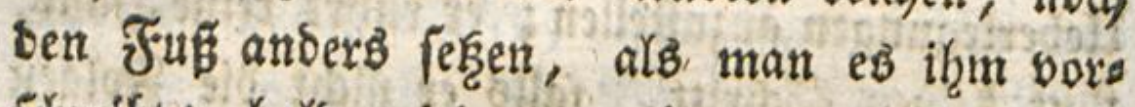
icjueibt; bald wird ex aud) mut nach beinen Regeln Soem holen birrfen. SYie willit bu, bafier bente, wenn bu in 2llem fir thn bentift?

$2 \mathfrak{B}$

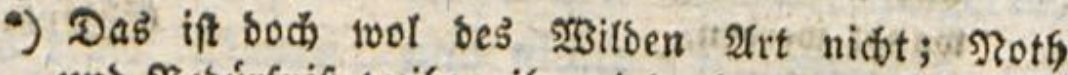

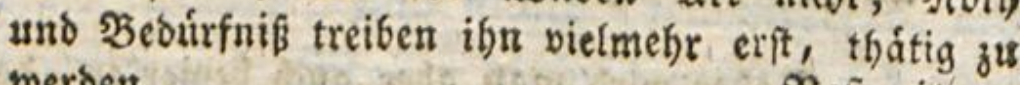
werben. शejentib.

0) Die 2ufbellung bes Ģeiftes hángt mit nichten von ber tlebung bes Rérpers ab, fondera von ben $11 \mathrm{~ms}$ ftánben, barin er fich bep̄ndet, und bie ifn in গ3ers tinigung mit feimen Srieben zum Nachbenfen nothis gen. Eobald die Ilmftánde ifn nicjt mebr nothigen, hort feine Beiftestbátigfeit uno bie Entivicfelung beffelben auf, und er verfinft loieber in Schlummer.

গejervik. 


\section{$54 \pi$}

be

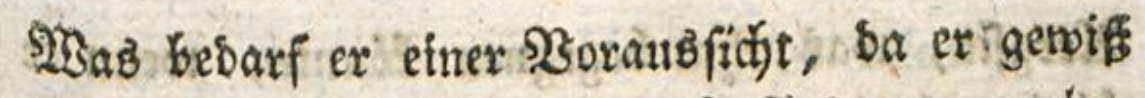

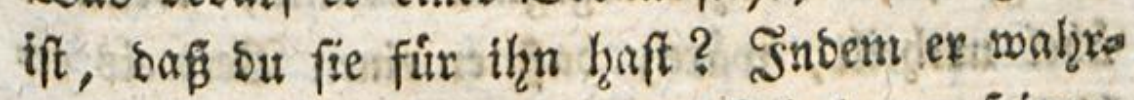
ninut, bafi su bich mit feiner Errbaltung, feinem

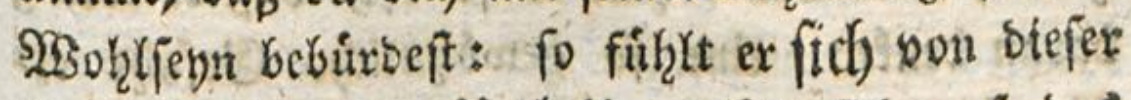
Sorge frei; fein lirtheil berligit fich auf bas beinige; 2ules, was bu ihm nicht-berbieteft, thut er ohne Nadjsenten, weil er wohl weifs,

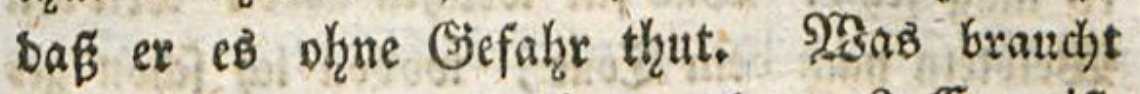

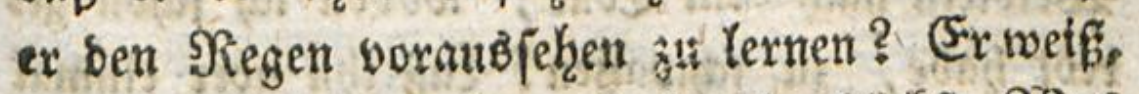

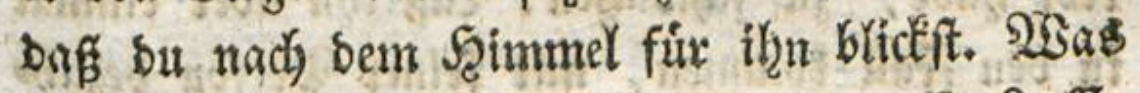
braudit ex fetne Epariergánge nfzumeffen? Et furdstet nidyt, bu tonnteft sie 3eit bes Mits tagsmahlz firr ihn serfitreichen laffen. So lange suthim nid)t zu effen serbieteft, fo iffer; fo bals su es iffm berbieteff, fo ifft er niddt mehre; ex hort nidjt weiter auf baB Eutadden feines Magens, foubern auf befnes. Du magft, we sul willft, Feinen Leib in Llnthätigleit weid)lich soerben laffen: ou wirft baburch fein Berftänos ní̈ nidjt bieglamex mathen. Sm Siegentbeil sirft bu bollenos die SBernunft sor feinem Geiffe um ihy $2 \mathfrak{n}$ fehn bringen, ba bu if̧m bie wenige, bie er hat, an Dinge weridjwenten Kaffeft, Die

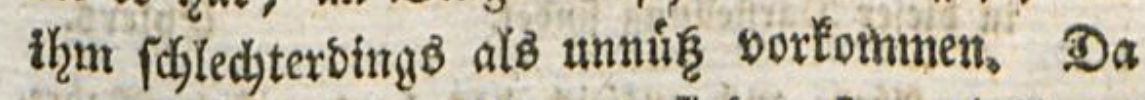
er nie fieht, wozu fie gut fins; fo urtheilt ex enslid, Daf fie zu nidjts gut fins. Das 2 ferg, 


\section{2}

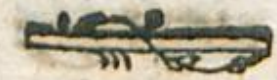

2lergfte, was thin begegtren tounte, wenn et

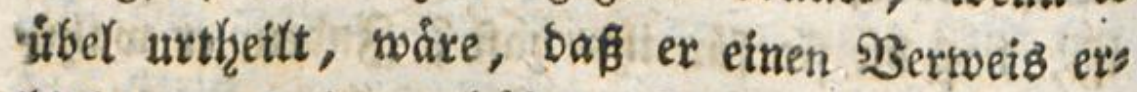
figitte, uno ben exhalt er fo oft, baf er menig baran bent: eine fo gewoshnlthe Siejahrs ex (d)recte than nidjt metrr. *)

Du finbeft inbeffen boch, ex kqabe ङ゙eift; uno es mag fenn! SBabs fur welchen abex? Mitt seat 23 eiblein nath dem Iotre, wovon id fojon ges reot habe, za fojwaken! Lafi inn aber einmal in ben Fall Eommen, mit feiner glerfon bezafis

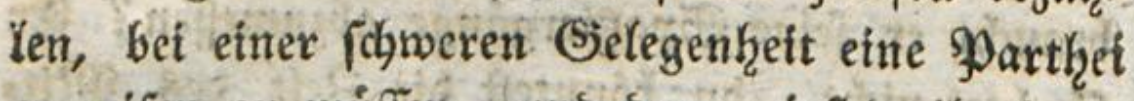
ergreifen zu miffen, utto bann wirft ou if̧n hums bertmal bámifcher und bummesspfiger finden, als Sen ungefdoladyteften Bauertôlpel.

$23 a b$ meinen, ober vielmelgr ber SRatur 3ogling betrift: io gemobnt fich Det, frithzeis thig geubt fich felbft genug zu fern, nidjt une

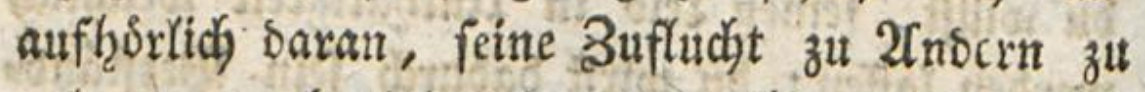
neţmen, noch sielweniger, vor ifgnen fein grofes IIBiffen auszutramen. Dafur aber aud urtheflt

ex,

(9:3 ) Gebem muf bas Hebertriebene einteuchten, bas fich in biefer Darfellutng findet. EEbler'.

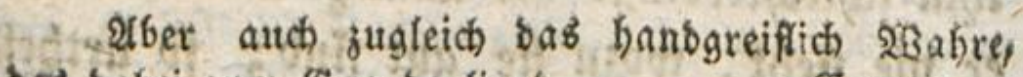
bas babei zum Grunbe liegt. Campe.

Die thebertreibung fiseint mir boch bas bants greiflich 2̧3abre zu úbertreffen.

Fefentio. 


\section{3}

et, fief̨t soraus, uno uberlegt in 2cllem, ras fich unmittelbar auf ifn begieht. (5i plaubert nidat, ex hamoelt, Ex weip nidyt ein slsort Davon, twas in ber SBelt gerthiebrt: ex verfteht fict) abex febre nohl auf ote 2usirichtung befien, was fur ifg zutriglich ift. Smmerfort in Seroes gung, oringt tign bie Noth viel Dinge zu bes merten; viele 28 irtungen zu extennen; Fr er wirbt fich bet Betten cine groffe Erfahrung: empfängt feinen Unterridgt oon ber Natur, nidgt bon ben Nenfiden; *) und lernt um fo viel

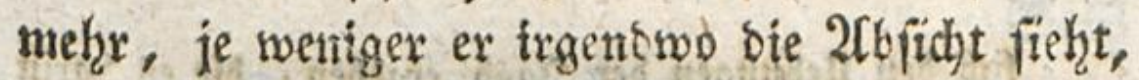

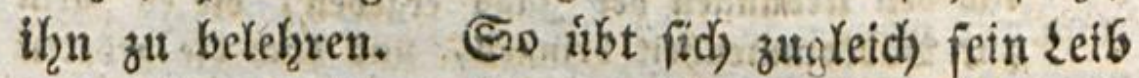
uno fein Sietft. Da er immex nady feinem Denten handelt und nid)t nad, bem Denten cines

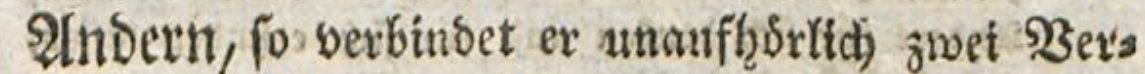
ridbtungen. Te fister uno hanofefter ex fich madjt, befto berftániger und urtheilobollex wirs ex. ***) Dies if bas Mitttel, sereinft zum Bes

firge

-) Wenur er gar feimen vou gieurchen erhált, fo mogte ich wiffen, wie weit fein Serftand und feine. S马ermurft reidsen wuitbe.

Refewis.

-) Ssohlverfanben liser Dinge, die innerbalb feiner Spháre liegen. Sidher if unter biefer Einfthrans Fung ber farfe uno gewandte Nienich, catteris paribus, au(b) allemal ber geicheitefte. Feert Forme

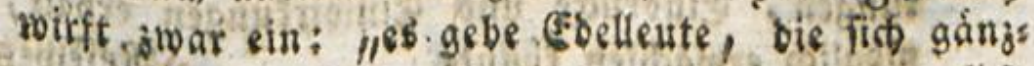




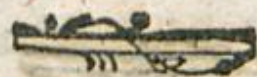

fif̧e you bemienigen zu getangen, woson mats glaubt, baś eş nidjt neben einatioer beftehen fonne, uno ras faft alle groffe Menjidjen wers einigt ḩaben: Stâtée bes Leibes uno Stárfe ber Seele; Die \$eruunft cines 2 Beifen, uno bie Sirdfte eines $2 \mathrm{Ith}_{\text {feten. }}$ )

Singer \{elyrer, idy prebige bir eine fadyere Rumft; bie fiunt, ohne $\mathfrak{B}$ orjáriften zu res gieren, und burd) গitchtstḩun 2rles zu thum. Dhefe Rumft, idh geftehe es, if nidgt fúr bein

Fiab bett Itebutgen bet Jagb etgeben, bie es baritt

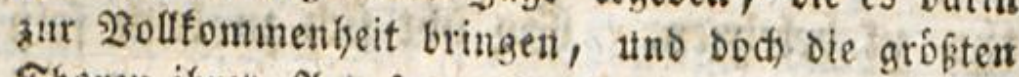
Ehoren ifret 2 (rt fet) sicht, bafi foldse Nimross auch auf ber Jagd ben fleiren Sultan machen, fich autb ba bebienen laffen, 2ndere fúr fich benfen uno fü fich erfinben lafien, und baff fie bas fchon alb guábige Funfer io zu

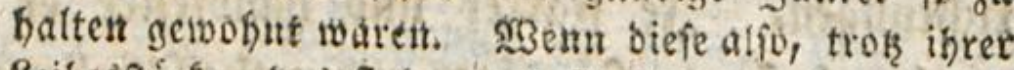
Leibebfárfe, sas futb, was fie find, darf mant fíds Sarúber toundern? Into bod wiffen fidter aud diefes in ibrer eingeidhiónften Spháre, ihre Ecelenfrafte befler attzutwenden, alb Itnbere, bie bet gleicher Ers

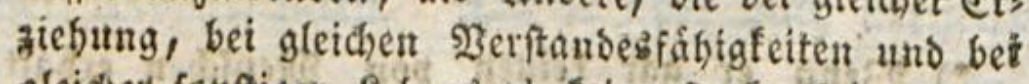
gleid)er fouftiger Sebensart feine ftarte Jager von geribten Leibestráften finto.

Eampe.

-) Lauter Extreme auf beibett Geiten! uno Tauter romathifte Buge elués Sjelden, Ser weing, ex aud móglich Iváre, boch in ber şelt, und unter Nens foeri, bou benen er ibre Joeen, Neinungen, few tungen, Einbrúcéc uno Cimivirkungen etrolt, uns greglich strocijen fónite.

Rẹpibis. 
20rter; Seine Zalente merben surdy fie nidjt gletch anfang $\mathfrak{B}$ fichtmmern ober bu bid bet bem Eftern viel gelteno baburch madjen; abee es ift sie einzige, surch bie man zum Bitele tommt. Du wirft nie bazu gelangen, Meile zu bil en, wenn ou nid)t exft 1 Bifofánge bilbeft; *) bas war sie Errzief̧ung Der Epartaner; man heftete fie nicht an oie Siucher, fonbern lefrinte fie zus erft ifre Mittagsbroot ranben. WBaren bie Spartaner Darum erwadfen, ungefaldachte Nen iden? **) MSer Fennt nidjt bie Stírte uno bas

Salls

") Serr Formey ruft bier uns: "1 as heift eire auss erlefene fdyoue frucht auf einen fefor foflechten wiben Stamm pfropfen!" Das פ̧eimort Febr fiflect)ten ausgenommen, bat er refbt. Man pfropft is wirtlich auch bie ebelften Fruchtbánme auf witbe Stamme, unb, wenn man mich recht belefit bat, fo iit eine andere Dietfode gar nidst thunfich. Sollte es mit ber mablen siseibleit hidbt etwan aud fo fenn? Sollten wir nicht fchon Erfabrungen genug baben, um uberzeugt ju fenn, Daf auch biefe nur folchen Geelen einverleibt werben finne, beneit noch Eeine falidhe Weisheit eingepfropft ward? Eampe?

Der Ausfpruch $\Re$. verdient both cum grano falis verfanden zu werben, uno ba wáre es boch, um Misbrauch zat berbiten, beffer, bás or beftimmter, uno minder vizig wáre. Referwits.

**) Epartaner fonmen uno follen nidit mebi gejogen werben, ob man foon in 2aficht der Eeibestibungent von innen mandes lernen und anvenien fonnte. Fmilifer to Niefenis. 
Salz fhrer turzen 20ntworten? Stets gemadjt zum Lleberwinten, folughen fie ihre Feinde in allen 2frten Ded Rrieges nieber; und bie fchwazo haften 20thentenfer furchtete eben fo fef̧r ibre S280rte, alb ibzre Soiebe.

Sn ben aud mit ber grofgten Sorgfalt bes trifebenen Erzielzungen, befieḩlt Der Lehreer ano glaubt zu regieren; wirtlid) aber regiert bab Sind. Es bestent fidj oeffen, was ihn bon ithm forbert, um von euci basjenige zu erhalten, was thim gefâlt, unt cs weiß ftets fich fúr eine Stunde Freis burch adjt Iage (Sefalligheit bes zab̧len zu laffen. Seben 2Tugenblict muf man

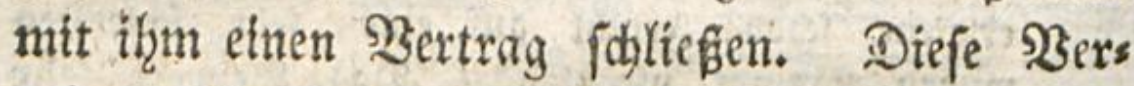
trage, bie ifrr nad) curer 2(nt borfd)lagt, und bie es nady feiner $2 \mathfrak{B} e i f e$ exfúllt, fallen ftetỏ feinen Srilllen zum \$ortheile aus; , borneḩmlid, wenn man fo ungefdjidt ift, Dabjenige, als feinen Sortheil zur Bebingung zu fergen, was es fehzr ficher ift, es mag bie sBebingung ers fưllen ober nidjt, bie man ihn zum Taufde auflegt, bennoch zu erlangen. Das Sino lieft

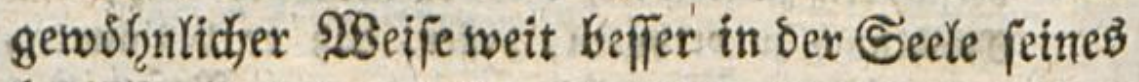
Eehreers, als ber Lehree in bem Şerzen bes Sin Des; ") und bas mus fo fern; denn alle Sd)arfs

ficidy)

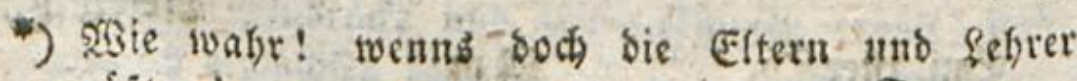
toif îten!

Trapp. 


\section{4 \%}

dijt

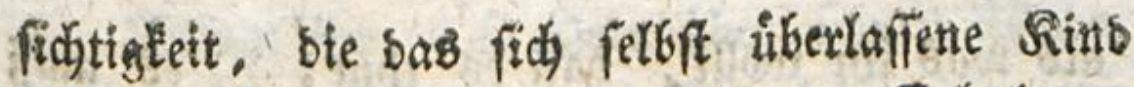
suirbe angetwands haben, furr bie Erthaltung

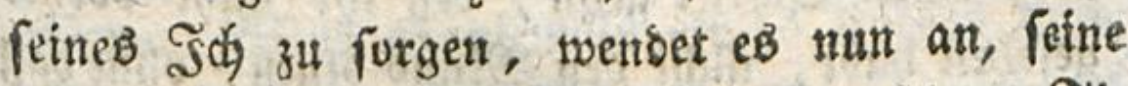
natírliche Frreiheit auts ben Feffeln feines rannen zu retten; anftatt, baf biejer, ber Eein fo oringendes Sintereffe hat, bas Rinto zu ets forfóben, biżweilen beffer feime Rechnung babef findet, wenn ex bempelten feine sirahgheit obex fetne Citeltét Isfat.

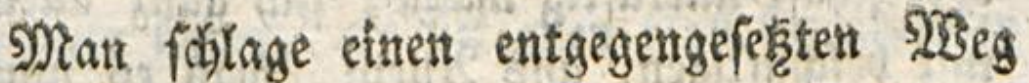
mit feinem $3 \delta$ glinge ein. Er glaube fteto ser Meiffer zu feyn, uno matt jey) es ftets felbft. Es giebt feine 10 , sollfemmne Untermirfighteit, als biejentge, weldje ben 2 nnichein ber Freiheit betbehált; fie nimmt betr şillen jelbfit gefangen.

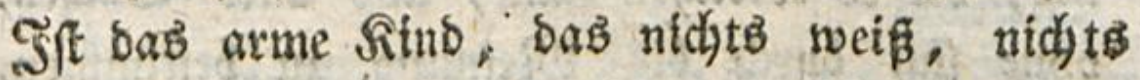
vermag, nidjts Eennt, iff $e^{\beta}$ nidjt in eurent Scanden? Sdjaltet thr nidjt, in 2Unjełung feiner,

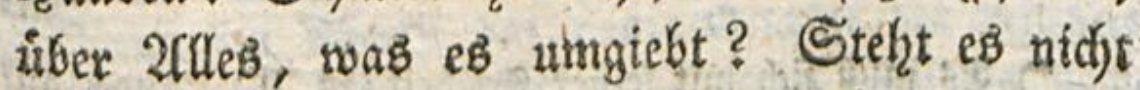
in eurer Siensalt, fo barauf zu wirtéen, wie es eudy gefallt? Seine 2trbeiten, feine Spiele, retne SBergnủgungen, fein Ltngemadh, fiefft nidjt 20lle

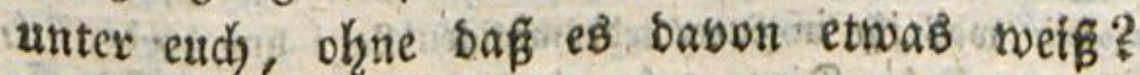
Freilid) muf es nidgts thum, als was es thun swifl; aber es mü son 2fllem nichto nollen, 


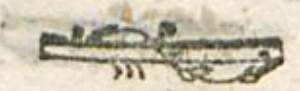

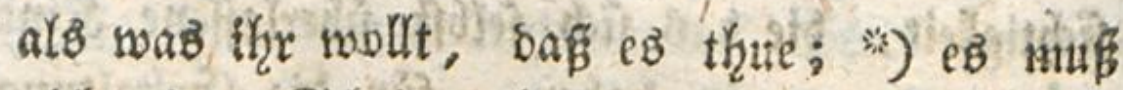
ntdyt einen Sdyritt geḩn, ben ifgr ntdjt borher gejehen habt, nidyt ben Mand \&fnen, ohne saf̧

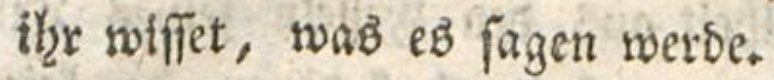

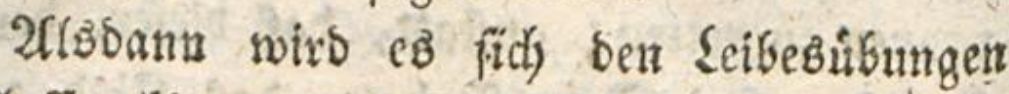
siberlafien fonnen, bie fein 2llter bon ihm fors Dert, ofne fenten Geeift abzuftumpfen; bไsbann wirb es, fatt nin barauf zu finnen, wie "es burdy geidjarfte Sdjlanigheit eine befdywerlidge Seerrid)aft untraftig mactse; fich ganz allehn bas

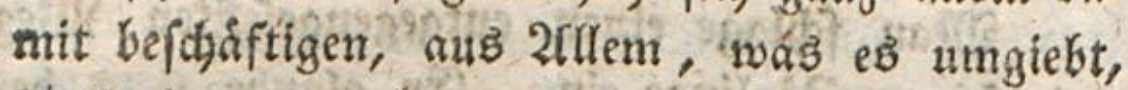
basjenige zu nefmen, nas fúr petn. jeşiges $230 h$ reyn bas 2 ortheillaftefte ift; alsoann werbet iffr ifber bie Jeinheit feiner Empfinouns getn, womit es fich alle bie ज゙egenftánbe zueigs thet, bie es erretcjen taun, uns allex Sircjen, okne fich burch bie Mteinung zu beftimmen, walfrkgattig ou gentefien fudt, erfaunet.

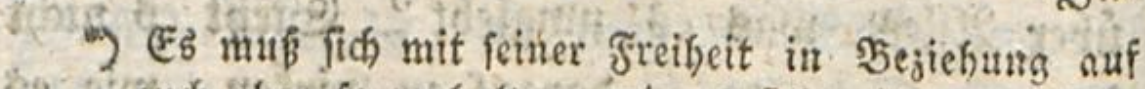

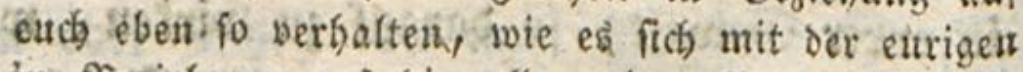
in פefiehung auf bie allgemeine. \$erfettung ber Dinge verbailt. Shbe thut nichts, als was iffer woilt, abet ifge fomnt nicht wollent, was ife wollt, fonbern

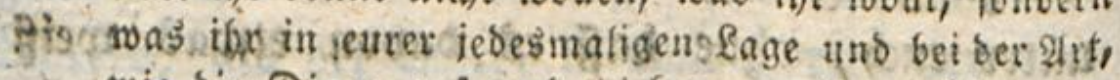

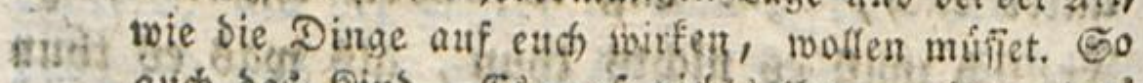
auch bas Sinto. C:s muk nichts thun, als was es

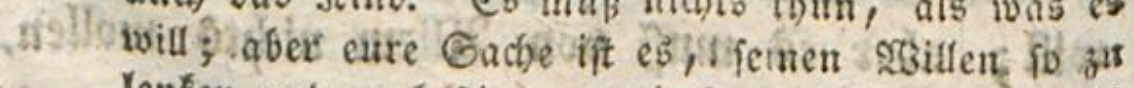

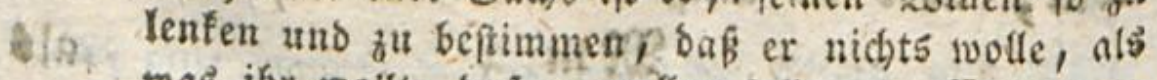
toas igr boutt, bẩ er wollen foul.

Eampe. 


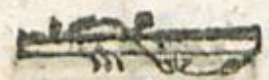

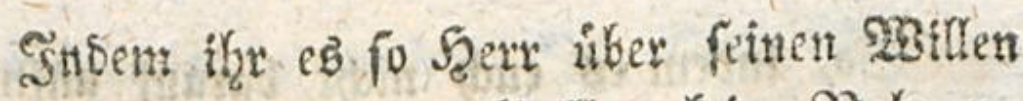

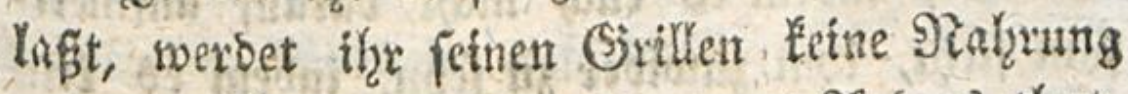
geben. S2Eenn $e$ b niemals etwas 2 (nders thut, nls was thm exipriefflich ift, *) fo wird es bald nur bas thun, sas cs tḩun muf; uns

\section{Mtm 3}

So, obgletd) fein seib in einex beftandigen Bewes gung fich befindet, fo langुe es ben gegenwartis gen uno finnlicjen 9:uken betriffi, wirs man Soch alle Dernunft, beren es fábig ift, fid stel beffer uns auf eine ifgu eigenthimlichere 2 rt entwideln fełsen, als bei allen blop̈ fpeculatínen Stubien. **)

-) Afber lvie fam eร, bent ofne antueifung unt \&eis tung wifien, was ifhm criprieflich ober fradstich ift? Refentik.

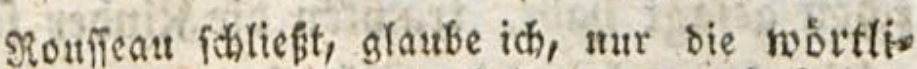
d) SInweifung, nidt bie Peitung Durd fagen und Almftande aus, worin vielmebr, nach feiser eigenen Theorie bas ganje (Seidaft bes Ergiehers beftefen foll. Diefer foll, feiner meimung nact), bem sitube nid't befeblen, biefes ober ienes zt thun, aber er foll eb in eine foldhe Sage zu bringen wiffen, bafí bas Sind bas, was er bon ifm gethan wuinfht,

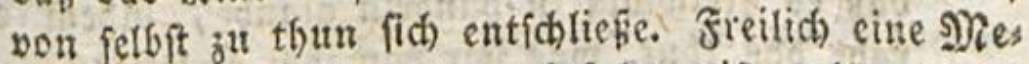
thobe, bie viet ichwerer zu befolgen ift, als bie ges wobkulidie!

Eminpe:

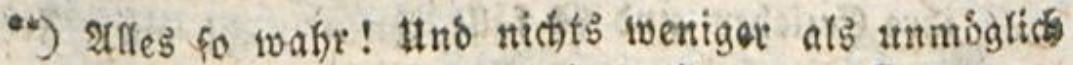
aubjufithren, fobalb wie wir wollen. Swapp. 
So, tnbem es eudy nidjt barauf anfinets fam fieht, ihm zuwiber zu fenn, inbem es fein

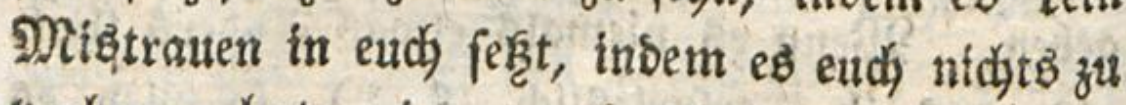
barbergen hat: wiro eb end nicht hintergehen, enth nidft beligen, es wiro fich ohne Futrdit fo zets gen, wie es ift; thr foinnt es bann nad) eurer Bequemlid, feit aubforidjen, uno runb utm bapa felbe ber bie Lehren oronen, bie ihr ifgun geben wollt, ohne baf̈ es̉ ihm jemals einfallen wirb, es exkelte (5ine. *)

Iudch wirb es eben fo wenig mit einer neus giterigen (Fiferfudit Sitten aubjpahen, ober fich ein gebeimes Bergnigen macken, eudj auf eis nem fahlen গRofie zu finden. Ein fehr grofies Uebel, bem wir zubortommen! **) SWie id folon gefagt kabe, tradjten die Rinser fehre fribs: gettig barnady, Die Sdywadje threr \$argeferg,

ten

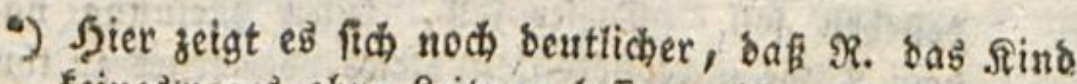
feineslveges obue leitung laffen will; er will nurp baß sie leitende firaft ifm verborgen bleibe, und baß $e^{3}$ freimillig zu banbeln glaube, indem es ges rabe bas thut, twas wi; von ibm perlangen.

**) In ber Ihat jo! Naturtich erzogene Sinder lieben

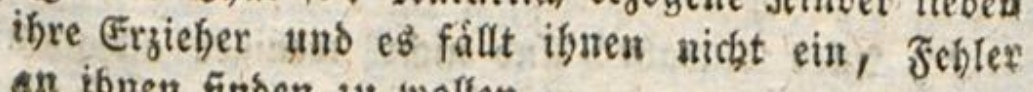
an ifuen finden z) wollen.

Trapp. Eampe. 
ten aubifindig วu machen. ${ }^{*}$ ) Diefe SRetaung madyt jux Sobloct aufgelegt; aber 200 bुeit ift nidyt thre Duelle, fonoera btelmebr was

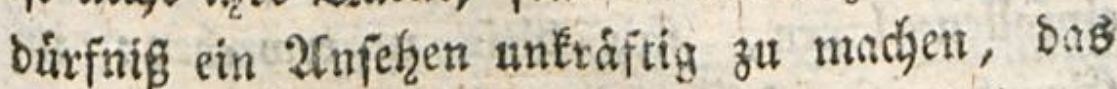

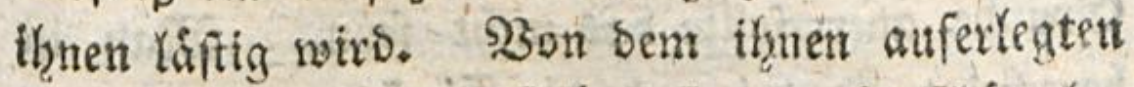
Sodje niebergebeugt, fudgen fie es abzufdutteln, uno bie siangel, bie fie an ben Eebrern finten, geben thnen gute glittel bazu an bie Soand.

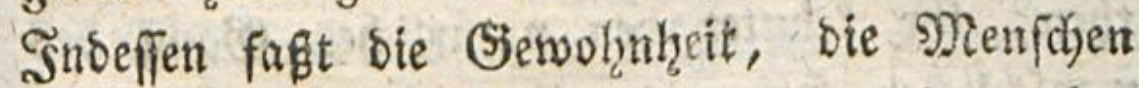
nad. ibren Fefilent zu beobad)ten, und an Der

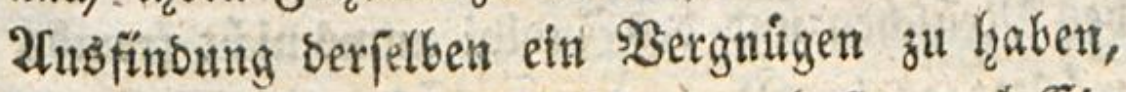
S2Burzel. Sffenbar ift alfo hier Dem Lafter noth Sin ב̧ugang zu Ėmils Şerzen verftopft. Da Kein Intereffe thrn treibt, Jiångel bei mix/ zu fittoen; fo wiro ex and nidjt barnady fudben, uns wenig geneigt jeyn, fie an anbern zu fuchen.

$$
\text { פ m } 4 \text { 2fllers }
$$

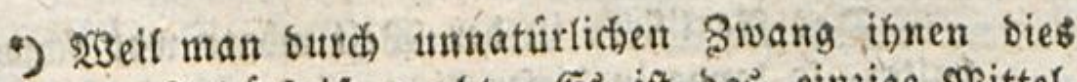
zum Şebrirfnifi macht, Еड ift bas einzige snitter, unfere જirannet úber fie zu fowwáden. (Sampe.

**) Yuch von biejer Seite betrachtet, ift bas Rouñeauts fibe Suftem auf eben fo tiefe als richtige pincholos gifche $23 a$ bruebmungen gegrundet, uno verdient bas ber auch um bestoillen, baj man es immer forgfáls tiger unteriuct)e uno mit bem fúr uns nuabánberlis chen şaltjuftande zufammentha!te, un enolich auss furbig-zu machen, wie viel wir bavon realifiren tonnctt uแ⿰ จu์tfett.

Sante. Tlapp. Stube. 


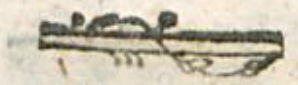

ZCllerbing erforbert biefe ganze 2 rrt zu bars fabren gewiffe (S)efdidilidyleiten, fo bafi fie fdymer fijeinen wiro, weil man fidjs noch nicit hat efnfallen lafien, fich steje zu erwerben: im Srunbe $a b x$ follte bas nidit fern. Nan ifí

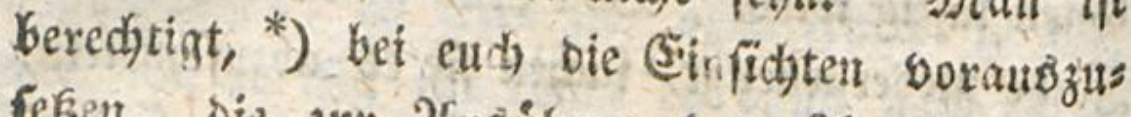

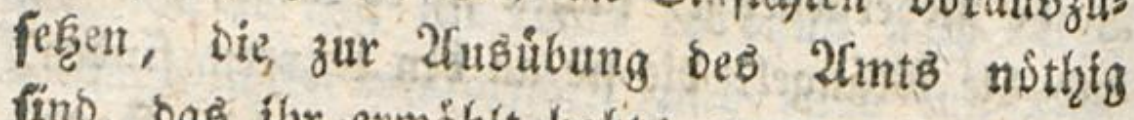
fino, bas ibre erwähit habt; man mü vermus then, ifgr tenntet ben naturlichen Gang bes menichlichen Scerzens, ibr wort im Stubium

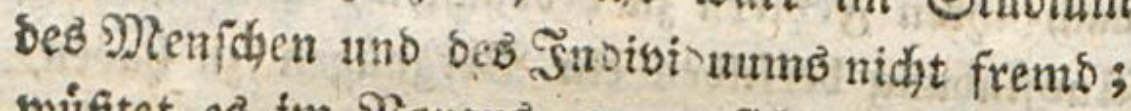

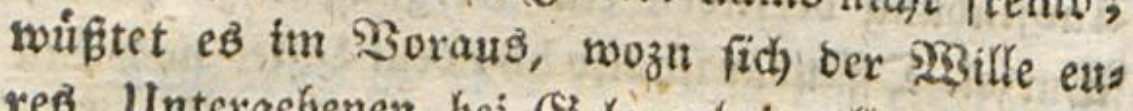
reb Untergebenen bei Selegentheit aller ber fein 2llter intereffirenden Segenftánde, bie ihr thm oor feinen Ztigen buríbergeben laffen werbet, binneigen mup. Sgeifit es aber nidit Seerr itber

Das Realifiren in ber s3elt moghte wol pthivet balten, fo lange in biefer nicbt alles umgeformt ift; aber Anícfiveife das Beprúfte unto richtig Befurbene (- benn 2 flles ift bei weitem nicht richtig -) ons zuvenden, und in ben unabánberlichen şeltzuitans einzufugen fuchen, das ift die Pflidht jebes weifen Ergiebers, fo socit nur immer feine Siráfte reiches.

Refewis.

o) Sieber Bott! wie weit find wir now won biefen betedftigt feyn. Ta, wenn woir Anffalten bátten, $E_{r_{j} i c h e r}$ ju bilden, dann fönnten wir forbern, dấ es \&eute gebe, bie bie Ergiebung verftúnden. 2aber fo:

Srapp. Eampe. Stuve. 


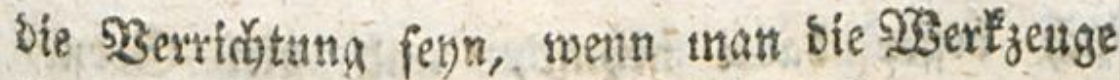
hat und ihren (S) brauch recht fennt?

Şfre nenbet mir ein: Sinber waren eigets: fimig; und ifgr babt Lured)t. Der Eigenfin an Rinbern ift niemals *) Das $2 S_{\text {ent }}$ ber פ?

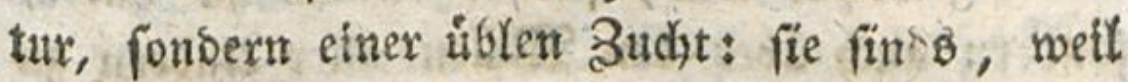
fie entweber getzordit ober befohlen baben; uns hunbertmal ift bon mir befagt worben, meber bas (5ine noch bas 2trove miffe fitt finden. *\%) Euer Intergebener mirs alfo von Keinem ans Sern Eigenfinm etwas wiflen, ałв bon bem, Detr ihr ihm nerbet beigebradyt baben; es fit billig, Daf ifge bie Strafe elwer Febler traget. 20? Yein, merbet ihre fagen, wie ift sem Hebel abzus 'Kelfen? 2fuch bas Eann nodh gefdyelgn, wenn ibe

\section{9) $m 5$}

eแd्य

-) Niemals? Das if viel beliauptet. Th bin gerreigt biç Niemalb bier sur im íbertriebcien rebneris ficen Cinn zu sefimen, in weldhem man bei $\Re$. manche 2fusbruide nehmen muईp. Trapp.

Sgeetrt man, wie mant follte, Eigenfintt von

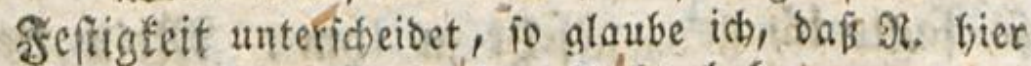
witlig unb obne 2ubuabme récht babe.

Campe.

") OEthorden und Befeften fann mit ber beften Erzies Jung nicht wur beftefen, fonbern getort trefentlict 3u einer guten Erziehung, wie auts vorhergemads ten Ifumertungen genug crbellt. Nar muf aud in Der frinfirdit alles weife eingerimtet werben.

(5) 1 et?. 
"uck beffex babet neh̨mt, und biel Bsebuto habt。

Sid) Gatte eintge 290 ochen lang bie 2ufficht L̇ber ein Rind úbernommen, baв nid)t allein baran getwobhnt war, feinen $28 i l l e n$ zu fiaben, fonbern auds uber ben 28 iflen aller 2 inbern zu herriden, uno folglid ouf eine Menge bex felts famften Einfálle gerieth (Steich) ben exften

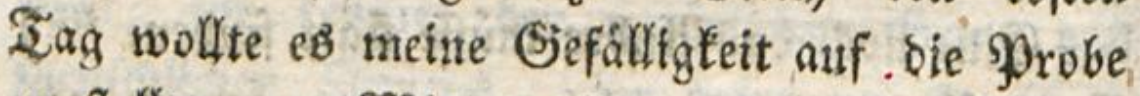
zu ftellen, um SPitternadyt auffteȟen. S2Bte id fn meinem beften Schlafe liege, fpringt eß auత feinem Sette, nimmt fein Nacjtrodchen uno suft mich. It) ftehe auf, zunbe bas sicut, an;

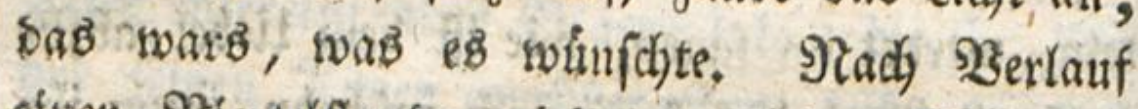
efier \$itrtelftunde miro es wieber fobläfrig; uno legt fich bergnight mit feimer 9 robe nieber. 3wei Zage barauf wieberholte es fie mit eben betn guten Erfolge, unb idj meinerféț Yies vicht bas gerfngfte äeichen von Ungebuld blicten. Da es mich nan beim SWiebernieberlegen fitjte, fo fagte tá) ganz gefert za ihm: Mein liebes Sánncben, bas iff red)t gut; aber fornt mir fo nidjt wieber. Dies 2 Bort erwedte feine Deugtex, unb gletdy ben anbern ₹ag, um zu

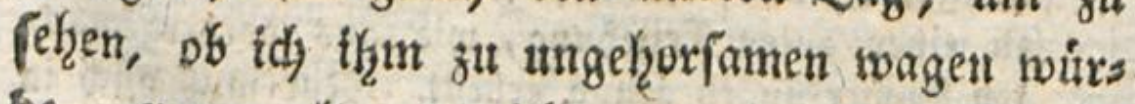
be, ermangelte es nidyt, zu eben ber Stunbe wies 


\section{5}

tib

d)t

in

wieber aufzufteben uno mich zu rufen. Sha

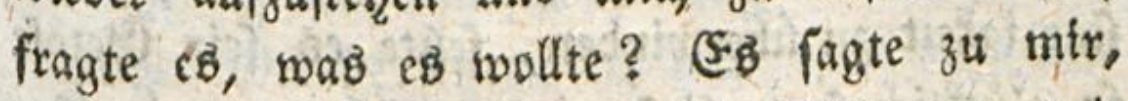
es fỏnte nid)t fdlafen. Defro fojlinmer, ants wortete ich, uno hielt midy ftill. (Fs bat mid, id) mógte \{idht anzunven: İarum - _- wieber ftill! Diefer laconifjue Zor fing an, es berlegen zu madjet. (Es tappte herum, sas feutergeng zn fudjen und that, als wenn $e s$ anfobligen wollte; ich Eonnte nich bas bef bes Lachens faum erwehren, wie ich horte, bafis es fidy immer auf bie finger flopfte. (snds lid) wohl mestens, es fáme samit nidjt fort, Gradjte es nir Staḩl uno Stein an mein Bets te; id) aber fagte, ids hatte was 20nders zu thum, und felzrte midh auf bie Seite um. Niun fing es an, queertspfig in ber Rammer hexum zu laufen; rief, fang, madite biel Sarmen, uno gab fich an Zifdy uno Stíhlen Stope, bie es fehr forgfaltig zu máfigen fuichte, wiewol es nidot untertief laut auf Dariber zu fdreien, in

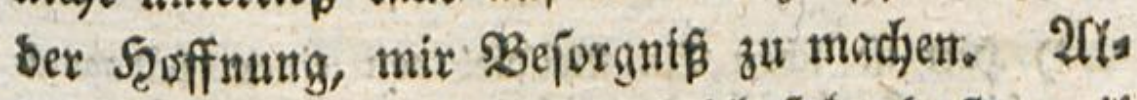
Yes bas verfing nichts; wno id) fah, baf, wetl

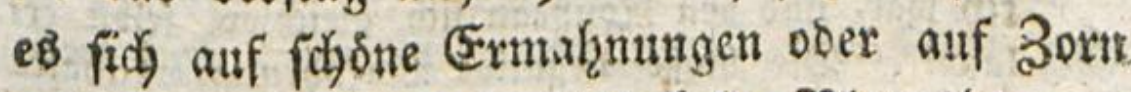
gefät gemadjt batte, bies Kalte Blut tham gav nidjt fdimedten wollte.

Ento 
Entrohloffen indef meine Seoulo surd Sautg: farrigleit zu úberwinben, ferste es fein Getópe fo glüctich fort, baff mirs enslidy warm im ios pfe mutroe. Sil alfo, im 3 oraus ahnoeno, if svinbe burch) eine unzeitige Entriftung 2flles vers berben, ergriff meine Sarthei auf eine andere

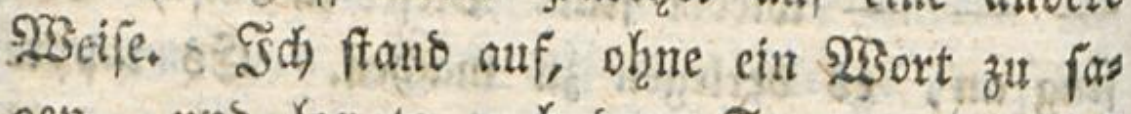
gen, und langte nad sem Fenerzenge, $D a s$

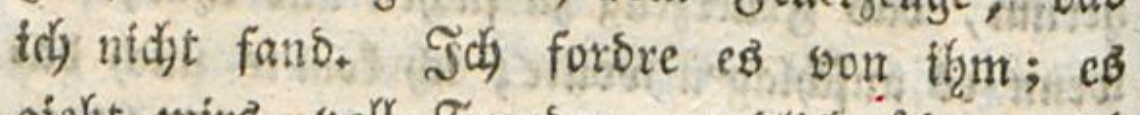
giebt mirs boll Frenten, endlid siber mids

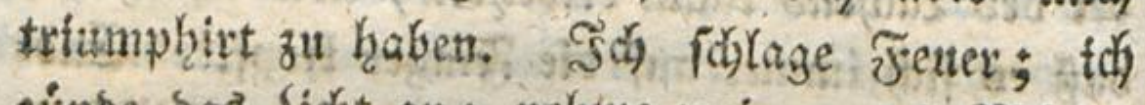
zunbe bas ficht an; nefhe mein gutes Manns dien bei ber Seand; füfere es gerulfig in sin bes stadjbartes Cabinet, mobon bie Fenfterlaben feft sugemadit waren, uno in bem es nidhts zu zeve bredjen gab; idy laffe es barinnen ofme Sidjt; id) getze zuride, fornappe bie Zhüre hintex mir ab, ") ıno lege mid̆ wieber ă ßett, ohne cin einziges 230 att zuthm gejagt ou knten. (5)

bers

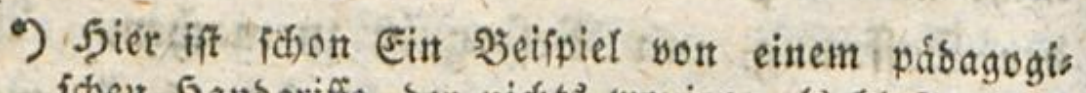
fheur J5anbariffe, ber nid)ts weniger nls blok negas tiv war, und ben Nouffeau fich gleichivol felbft ers laubte. - Die blofie negative Berfabrungsart batte ifm unr erlaubt, in feinem \$ette ftill liegen fut bleiben, unb den fleimen গ̧uben machen zu laffen, was er wollte. Sielleidht ware bies Nerfabren im gegentwartigen falle anch wol in ber इhat bas befte gesucper.

Eampe. Trapp. 


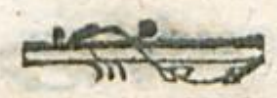

บระ

tof

Ros

idf

exs

ere

fos

as

$c B$

(id)

(idi)

berfeht fich nol oon felluft, baf́ es mun cin ges waltiges (Setobe ferste; id, batte midd oaja vere

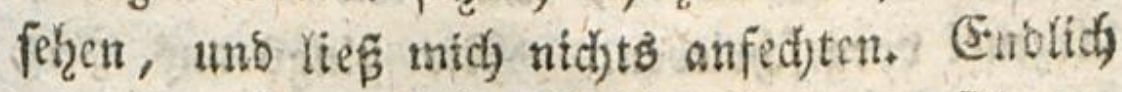

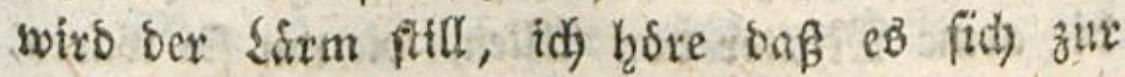
গluhe giebt, id̄ beruhigge midy audy. Den ans. bern Miorgen gefe id, mit Zagesanbrud in baß Eabinet uno finde meinen Sleinen Startopf auf einem Snubefef̃el in tiefen Cojlafe Yiegen, beffert ex nady fo vielem 2frbeiten twol nistsig haben mufte.

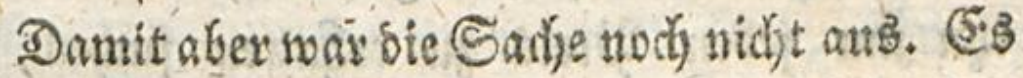
Eam ber Matter zu Shren, ifr Sgerzbiattchen Ķåtte zwei Drittel ber Sadjt auffer feinem Sette zugebradyt. Nun war bex jüngfte Iing bor

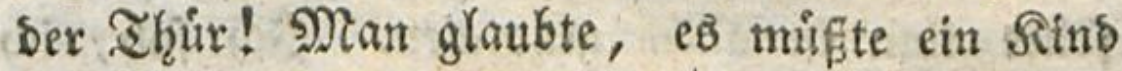
Des Iudes fenn! Da der Silcine gute Gieles genbeit mertte, fich ju ráchen, fo fpialte er ben Sranten, fah aber nidjt babei vorher, bafi ex Samit nicht beffer fafgren wurbe. Dex 2 rat surbe gerufen. Bum Unglide fir bie Niutter war biefer 2ryt ein Sdyalf, ber, mit ifrer Furcht feinen Shinerz zu treiben, fidjo angelegen fenn lies, fie zu vermebren. (Ex fagte mix ins Shr: Eaffen Sie midj nur madjen, iff berppredje if̧nen, saş Rino folf anf einige Beit lang oon feiner luft, trant su fern, gebeilt

wets 


\section{8}

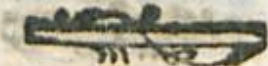

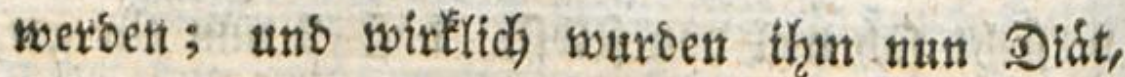
Şiten bes 3immers, uno etwas unlfeblidje 2rzenet vorgefdyrieben. Mir gingु anż Seerz, bie arme Mitter bon 2Cllen, bie um fie waren, fo lyerumgefithrt fat fehen; mid) nux aubges nommen, auf ben fie einen 3ahţ betam, ebent besiwegen, weil ich gerabe gegen fie hanbelte.

Nach ztemlid harten Sormirfen, that fie mir futto, thr Sulgn ware zórtticher Satur, Der einzige Erbe peiner Franilie, man miffte

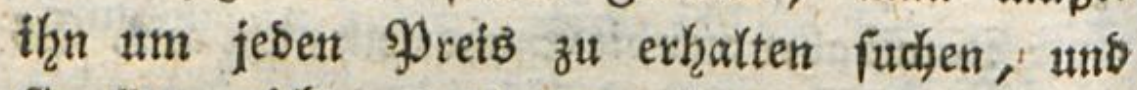
fie litte ntdjt, baßj man thm zuwiber ware. Daruber war toj ganz mit ifre eins; nur bers

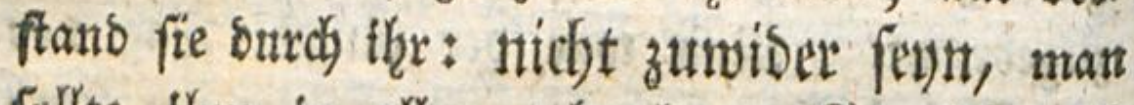
follte then in allen gefgorchen. Sd) $\mathrm{Fah}_{\text {, }}$ ich thif ttelymen, wie nit bem Rinbe: Mabam, fagte td) alfo zlemlich falt zu ihr : id weif nicyt, wie man einen Erbent exzieht, uns nod) mefre! id will es aud' niç) lernen. Sie mógen barúber nut (thre Daafregeln exgreifen. Dan fiatte meiner nod) auf etnige Beit nothig : Der Bater fellte wiber Frtede her; sie Matter fobrteb an Den Srofmeifter, ex mogte feine Ricténft bes fa)leunigen; uno ba sab Sins fah, baf es nichts babei gewann, weber, wenn es meinen

Sdylaf 


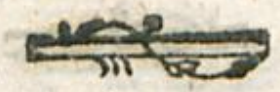

iat,

idife

xrs

en,

ges

bett

fie

ur,

ite

ñ

Be.

is

att

(i)

If

te

ie

4)

$x$

te

it

Sdjlaf fitorte, noch wenn es fid trant ftellte, ergriff es endith bie \$arthei, felbft zul fblafen und fich wohl zu befinden.

Mian fann fich gar nidjt porftellen, wie Dielen áfzulicijen Launen biefer Eleine Tirann péinen geplagten Sgofmeifter unterwirfig gemad)t hatte;

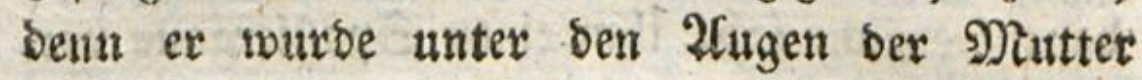
erzogen, bie nidjt zugab, Daß Dem Erben in bem geringiten nidit geţerjamet wirbe. 3at weldyer Stunde er wollte, mogte er aufzuftehen belieben, fo mufte man bereit fern, tha zis fúhren, ober vietmeţr thm zu folgen, uns fehr

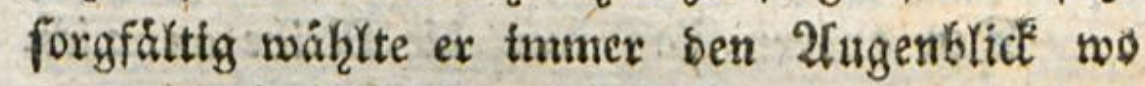

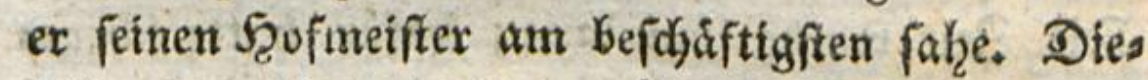
felbe Sgerrichaft badjte ex itber midh fich Kerauts.

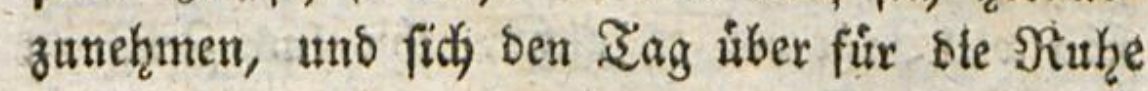

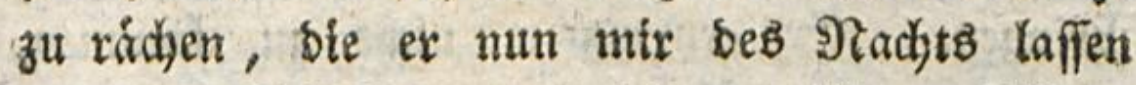

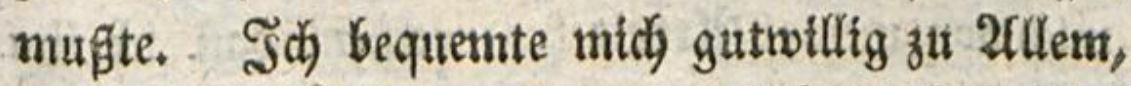

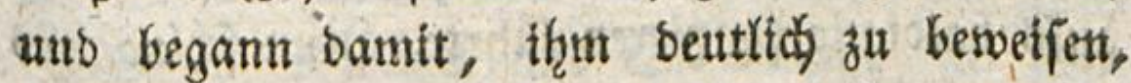

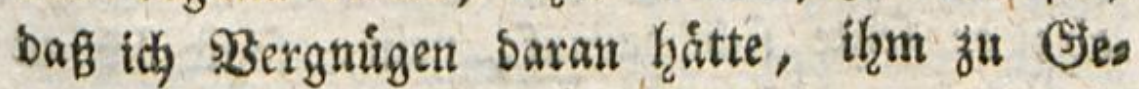
fallen zu feym. Nacidher aber, als es galt fets. nen (Eigenjïn zu beffern, nakgm idj) midy anders Dabei.

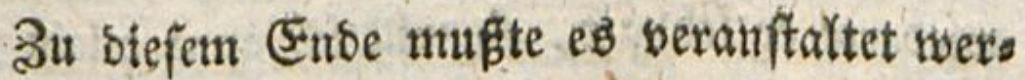
ben, tḩn fein Ulnred)t füblen zul laffen, eine

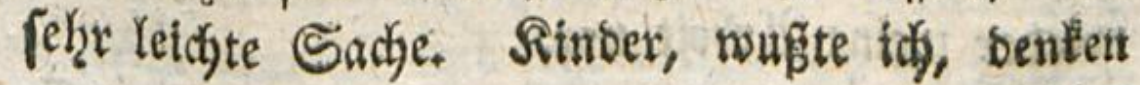
blop 


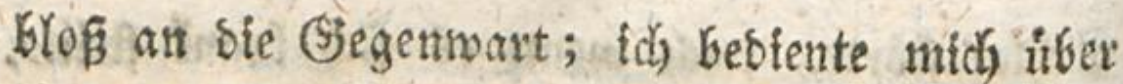
ifgn bes leidsten Bortbeils ber Borausfirbt; forgte bafir, ifm zu Sourfe einen Beitoertreib zu verfijaffen, bon bem idj) wuß̧te, bafi ex

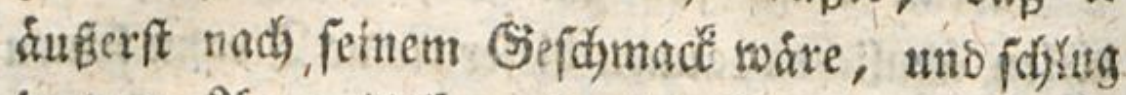
in bem 2lugenblicte, oa idy thn am eifrigfter barauf erpid)t fah, thm einen Spafiergang vor. 23 er mid) fondoe abfertigte, war (5r; ich orang barauf; or hisite nid)t, ich) mufte inich barein geben, uns er mertte fidy bies mein Nadygebent forgfältig, als ein aeichen bes Itntermerfung.

Den anbern Iag Eam bie Reibe an micf. Die Beit nurbe ifin lang; bafir bitte th ges forgt; aber ich that befd)aftigt bis an bie Slgren! So viel braudjte es nidist, ihn ins 3eng zu bringen. Ex ermangelte nidjt zu fommen,

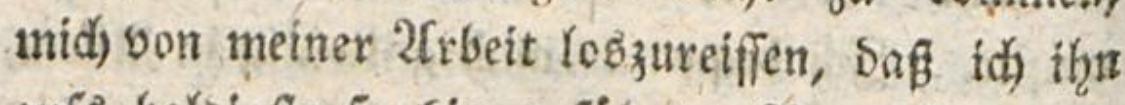
aufs balotafte fwaçicren fiibrte. Niun foblung idjo $a \mathfrak{b}$; er ferste fich barauf; nein, fagte idh fat thm, ba ou aeftern beinen MBillen hatteft, fo tehreft ou mich beute aud) meinen zu haben; idi) will nun nicht qubgehen. Şm! qut! ex wieberte er Kebhaft, fo mill id ganz alletn aubs gehen. TBies beltebt; uno bamit neb̧e it wieber meine 2rbeit vor. 


\section{$56 \mathrm{x}$}

bet

it;

eib

er

ug

teit

or.

ug

int

lett

if.

Er Eletset fich an, ein wentg beuntuhtgt,

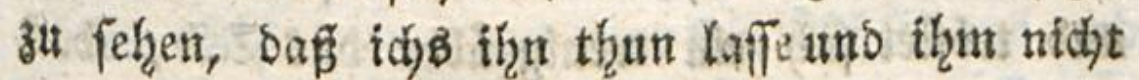

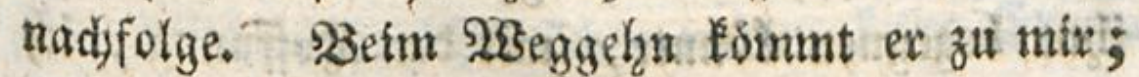

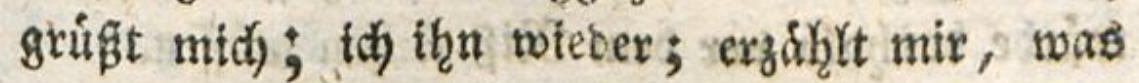
ex alles fúr SRitterzigge thun wollte, fuctit midy basurdy tit Unruh zu fergen; man hatte fagen follen, ex gebádyte an ber $23 e l t$ Enbe hitr. Shne nidy vom Flecte zu rifgren, minfiche ids

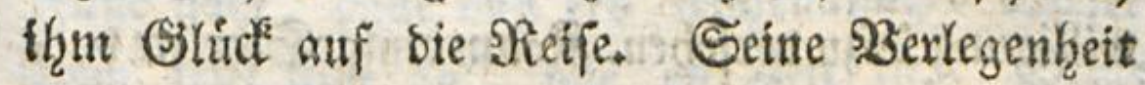
verooppelt fich; unterdefi bialt ex fich gut; und sa ex mun wirltidy fortwill, fo fagt er zum Dies ner : ex folle ibum folgen. Dex wufte aber fojon

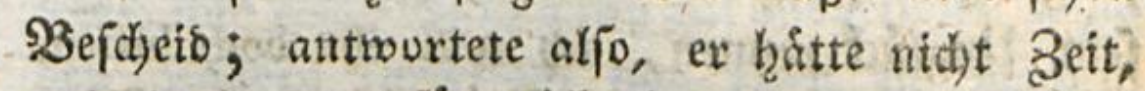
und ba er tras fư mid, thun tnufite, fo twårs feine gुoflicht, mix eher zu gehordhen, als iftm. Šest mufte mein Sunferdjen nidjt aus, nodj

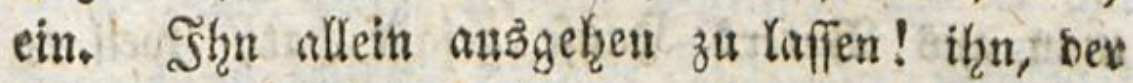

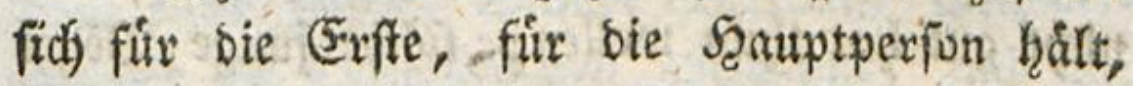
ber meint, Sotmmel uno Cros miffe fur feine Erthaltung in Fummer fenn! Das war fodwet zu berbauen! Mitlerweile fätngt ex an, feine Sdywåd)e zu fitblen; er begreift, ex werde fidj allein unter Eeute berirren, bie thn nicht tens nen; er fieftrt bie Sefabcr boraus, bie er laufent wiro; nux nod) sie Salşforriglett exbalt ibu; er fteigt langfam and fefrr bellommen bie Ireppe Emil Ifter $\$$. ?ำ

bitts 
562

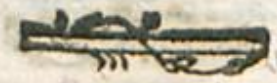

hinunter. Enblidy tsmmt ex anf bie Straffe, unb troffet fich ein wenig ůber bas Łeib, baß them begegnen fonnte, mit ber Seoffnumg, id

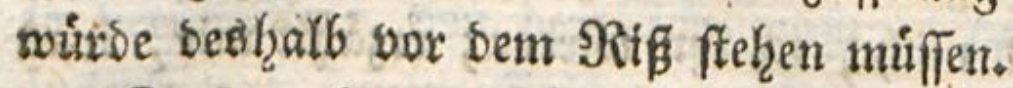

Da nun batte ich ihn eben erwartet. 24les war fhon in boraub ourch mich beranftaltet; uns), lvefl es hier eine 2frt bon bffentlichem 2fufa tritte fergen follte, hatte idy mich mit beß 2 aters (Ein silligung bazu berfehen. Raum einige Sctyritte vor:

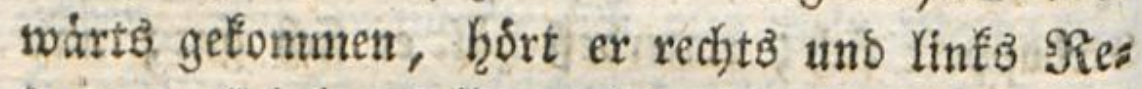
ben um fich ker fallen. Sadjbar! wo geht ber junge Seerr fo allein bor fich hin! (5) wite in

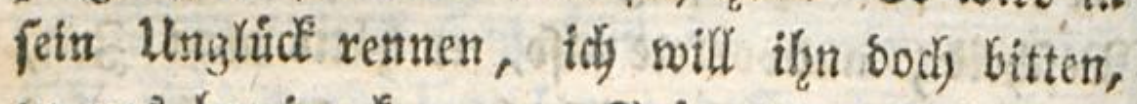
fu uns hereinzutomnen. Sse! nidjt bodh, fraut

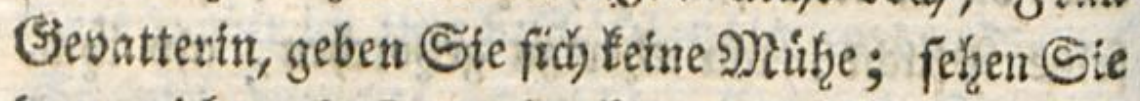
benn nidjt, baf́ eß̉ ein flelner Babe ift, ben mat aus: SBaters Şauje gejagt hat, weil cr sidjt gut hat thun wollen; forbe jutige 38 gat mufi man nicht aufnetzmen, laffen Sie ihn laus fen, wo ex hin will. Siun gut benn! gejegne thin Goott; es follte mix aber body leis feyn,

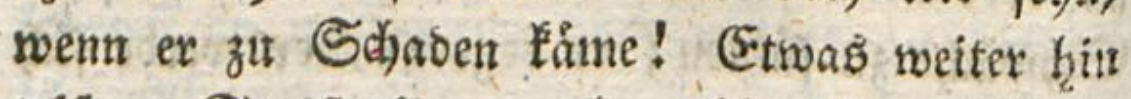
trift ex Strafienjungen vhngefálye feines 2fters an, bie thn nedten uns auszifdyen; er twift

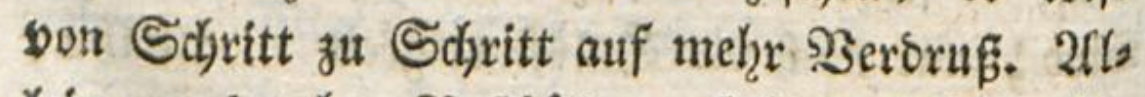

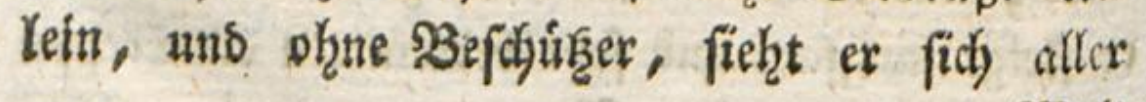

ISBelt 


\section{सौहित $56_{3}$}

fie,

)as

idi)

les

it:

IIf

ins

urs

tes

er

in

in,

uit

ite

ent

$\mathfrak{c r}$

c)

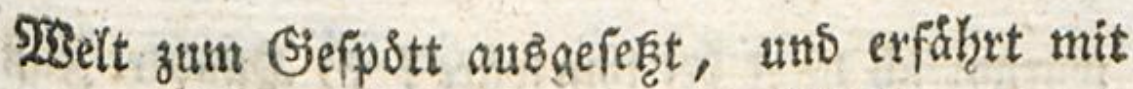
Dielem Exftaumen, baf itzm fein 2rdyflbano uns fein golobeblechtea Sisckidjen weiter Heine (5.hrers bietung verfitjaft.

Snoeffen folate ifm einer meiner Freunbe, ben ex nidht fannte, unb bem idis aufgetragent hatte, 2Adtung auf then zu geben, auf bem

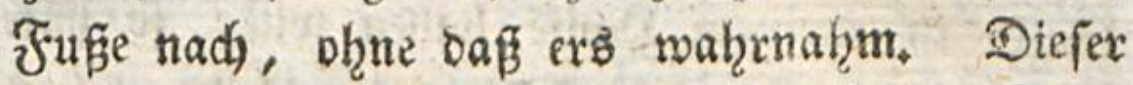
Demn tritt thm an, wie es 3eit ift. Seine Rolle, bie ziemlid) ber beß Sbrigain in Şoutro ceaugnal glich, exforberte cinen Nann von $\mathfrak{B}$ ers ftano, uns roaro vollétommen gut aus geführt. Shye Den Rnaben furdstian uno fhen zu machen, swent ex ihn gax zu fehr in Sdjredien feģte, nahut er fid) fo, baf biefer sie Unvorfidytigleit feines

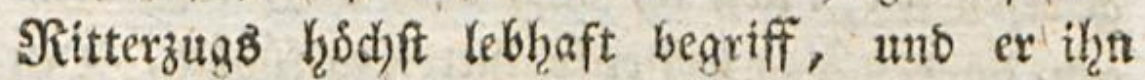
nach einer halben Stunde Berlauf, gefdmei= big wie ein Shrwitmdyen, bejdánt, wno mit tief niebergeldlagenen 2fugen, wieber zurúcts bradjte.

Das Şerzelets feines 2(1usfluges nut red)t soll zu madjen, fam fein 3 ater in bem 214 genblick, ba ex wieber ins Shaub trat, bie Ireppe herunter, um auşz̆ fagt werben, wo ber fleine Ntann bertame, tho

$\mathfrak{n} \approx$

wats 


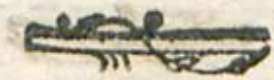

soarum idy nidjt bet ifgm wodue? †) Şundert fouf tief b̧ätte find bas arme Rind lieber unter bie

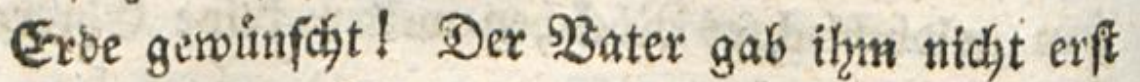
ainen langen Serweiz, fonbern fagte nux zu ifgm, trodiner als ich oon ihm erwartet hatte: wenn bu ein andermal allein ausgeffen willft, fo ftehts bei bir; weil ich aber feinen Straf̧ens Yaufer in meinem Shaufe bzaken will, fo buite bici) benu, falls es trods einmal geideken follte, mir wieber ins Şans zu Lommen.

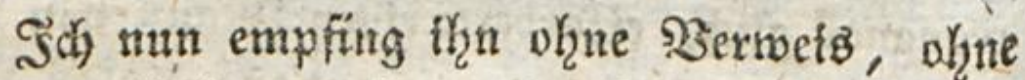
ihn auszulachen, aber mit ein wenig Ernft; und weil id furchtete ex moghte argwohnen, baß̈ 2tlles, was vorgegangen, nux ein Spiel

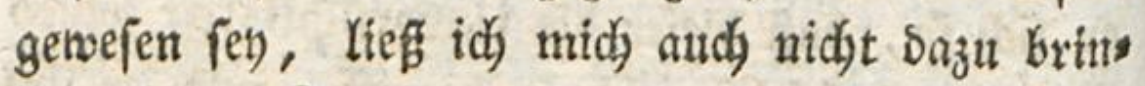

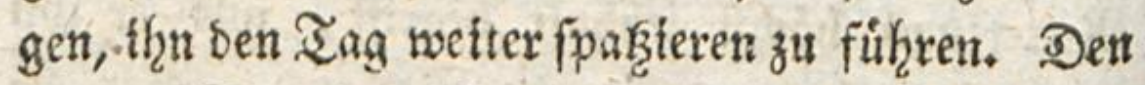

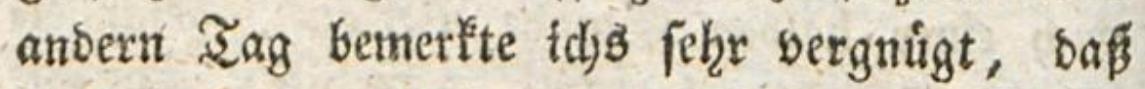

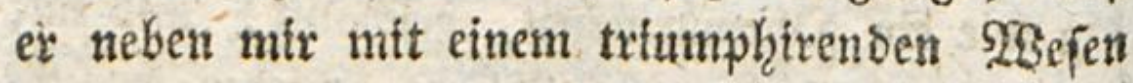
oor ebent ben Letten worbeiging, bie fidi) ben zag zusor ifber then aufgehalten hatten, ihm allein zu begegnen. Mian begreift Yeidjt, ex babe midy.

nidyt

4) In bergleichen falle fann man, ofne was'zu gefăhts ben, von einem Sinde bie Wabrheit fu wiffen vers

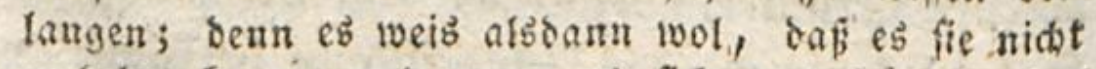
verbeleat faun, uno wenn es fich unterfinde, eine Qúge ju fagen, es ben 2 angenbitif fonute liberfúbrt werben.

D. Berfaffer. 


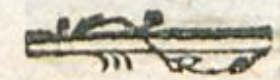

;

bie

enft

zथ

te:

litt,

ents

inte

te,

ine

it;

in,

iel

ins

ent

$x$

en

ig

in

(4)

nidje weiter bebrob̧t, of̧ne mith ausgeţn zu wollen. *)

Durdy biefe und affrnlidje Mittel bractite

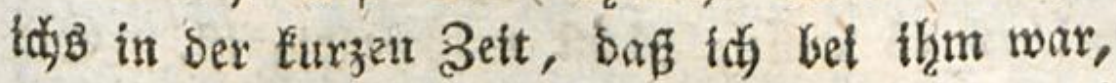

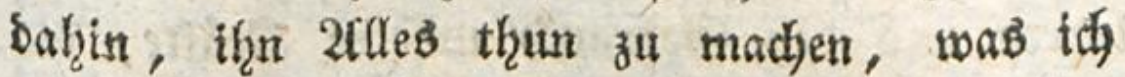

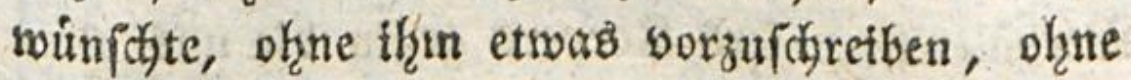

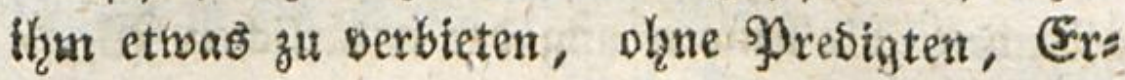
mahnungen, ober Setåubung Durd, unnuige Selquen bei iţm nothig za haben, 2fud war ex vergnigt, fo lange idy nur rebete, aber meit Stillfdymeigen bielt ihn in Furcht; ex mertre

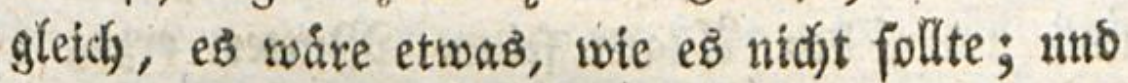
tumer exhielt ex bie Belehrung surd bie Sadje:

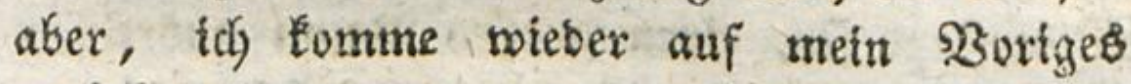
zurict.

STidjt allein ftumpfen biefé beftánoigen, ber

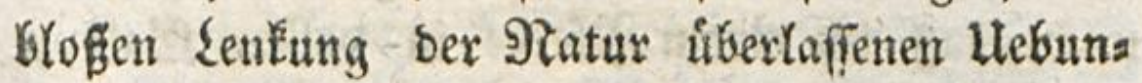
gen, ***) indem fie ben Leib ftárten, Den Setít 9זก 3 nicht

2) Ghade, bapi bieie an fich gut erbachte und erzáblte Eefchidate in 2 nfébung cinzelner Unjtande gar zu unwabricheinlich flingt! Sie wirbe leftreid)er fenth, went fie wafher wáre. - thebrigens bird wol feiner bas pábagogifche Nafchinenterf, ineldse Rounfeau sabei pielen ließ, fúr etwas blof SRegatine bals ten wollen.

Eampe. Trapp.

*) SBgie tant mait fagen, baṕ bie eben erjáflten lles bungen der blofien Lenfung ber Niatut מ́berlafien 


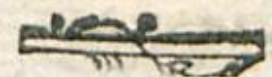

sticht $a b$; fondern fie bilden vielmefle in uns bie einzige 2 rt wan 2 sermunft, beren Dos exfte $2 \mathfrak{l}$ ter fåbig, und bie einem jeden alter, es fer) welches es wolle, bुodtit nothwendia ift. Sie Yehzren uns den (Sebraud) unferer Sirdfte, bie গBerb̧åltniffe unjers Riorpers gegen bie uns unts gebenden, bie 2 nnenoung ber naturlicken NBerts zeuge, fo in unferm (5rreidungstreife fino, uno fich) für unire Ģltebmaagen fohicten, fennen. Giebt es mol irgend eine Dummbeit, bie bit eines Rindes gliche, bas ftets in bem 3immer und untex ben $2 C_{\text {ugen }}$ feiner Mutter erzogen worben, bas, nidjt wiffens, was Serwicht und 928 iberftand fer, einen grofien Baum ausreiffer und ein Felfenftict aufbeben will? 20(s id) zum

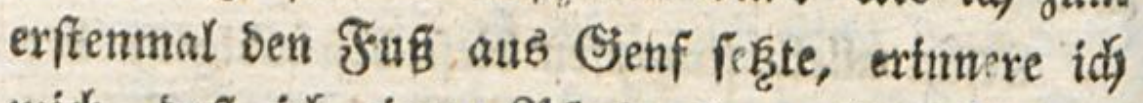
midh, baş id einem Mferbe in vollem Salopy folgen wollte, bafi ich) Steine mioer ben Berg son Salebe warf, ber eine Meile weit oor mir lag; tih war alfen Dorffinbern ein Sicfpstt, uno unter thenen ein wahrer Tropf. Sm adsts zefhuten Sabre lernt man in ber angewansten Nathefis, was ein Scebel ift: aber es giebt

tei=

1baren? Sie waren ia vielmefr fefr bedáchtig won

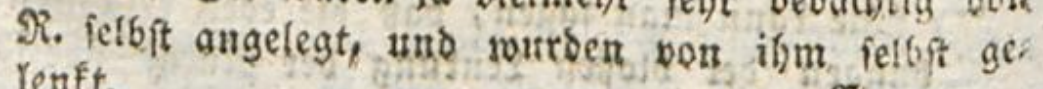
lenft.

Bampe. 


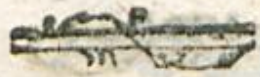

Eetnen Eletnen 2 auterjungen sort zwolfen, Dex $2 \mathfrak{d s}$ niod) einen Sgebel beffer zu bुandhaben wiffte, als ber exfie Medjanifer ber 2fabemie. Dex Unterridht, weldjen sie Schúler von einanber felbft im Scofe ber Sdaule exhalten, ift thrnen

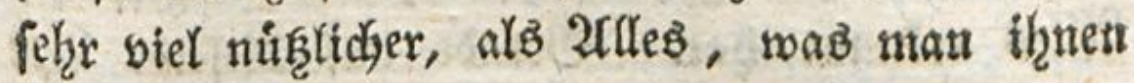
jemals in ser Sdjulle fagen wirb. *)

\section{$\mathfrak{n} 4$}

\section{Nian}

") So wafir biefer Gak ift, fo wirb er bod fobluerlids iemals allgemein bafur erfannt uno angenommen weroen, weil man ju fefje getwohnt ift, uur bas fút Untertidyt zu halten, was bas Sind in ber Ed)ule ano mit bem গ̧uche in ber frant lernt. Into boch ift bies gerabe bas গ̧enigfte unt unfroftigfte vou bem, woas ju feiner 2 (usbiloung beitrágt. Die alltáglis ben Soeen und Empfindungen, weldhe bem Rinde in sem Sireife feiner Sefpiefen, bei feiner felbftgervábls

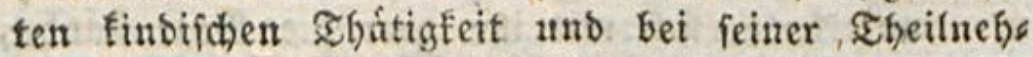

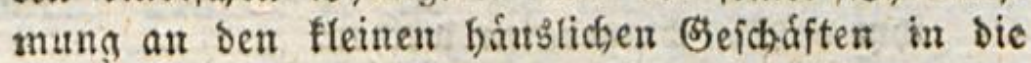
Secle fommen, wirken ju feiner Atusbilbung am Siftande, Eharacter uno Sorper bei weitem bas meifte.

Eampe.

Dhue stucifel. Und fo lange wir bas nicht ans extentren, ift an fein grunoliches פeffern ber Ergies bung uno bes Hinterrichts zu benfen. - Tsen ubris gens Souffeaus ftarfes febr viel uno jemals beicis sigt, der riberief̧e es in bas freilid wabrete aber zus gleich mattere oft uno mandzmal, bas er vermuths (ic) nur fagen woffte.

Stapp.

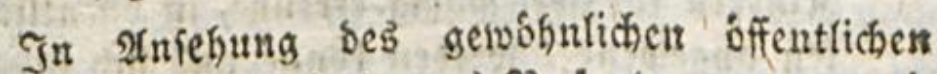
S(b)ulunterridots ift bas, was $\%$. fagt, ganz unzlocis felbaft wabr. Whas binbert unb aber, biefem erfen 


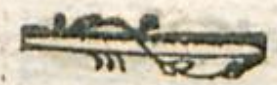

Man beobadite eine Rakge, wenn fie zim exftenmale in ein 3immer fojleidyt; fie unters fudjt; fie fieht um fidd ber; fie befdynatbt 2 Its Yes; fie hat nicht einen 2lugenblice Raft; fie traut feinem Dinge, bis fie jebes ausgefpabzt,

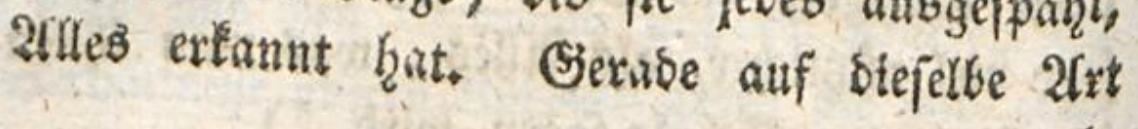

madys

Ilnterricht ber Sinber in Sơuten eime gang andere

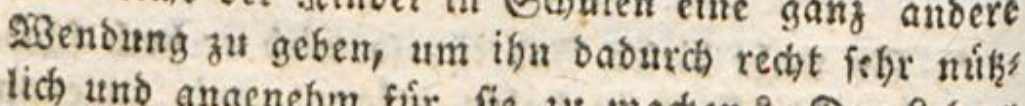
lich und angenefm fur fie zu madhen? Der lebrer beid)aftige bie 2ufmerfiamfeit ber Gugend mit finm Tichen Segenfánben, ube an bestelben ifre Sinness frait uns ifr ß̧egefrungsvermogen, ibre Einbildungs:

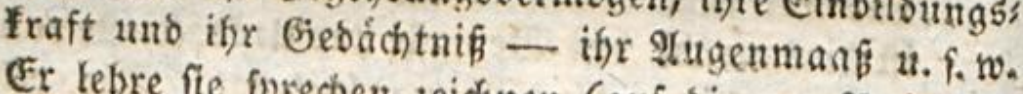
Er kebre fie fprechen, zeidhen (auf bie von 2 . in ber Folge angegebene $\mathfrak{A}$ it) záblen, rechnen, mefieu. Er fuibre fie oft ins freie felo, ober in Şarten, anb unterfalte fids mit ifre riber sie Segenftánde, die ifim saiefbit bargeboten werben.

Er erzáble und laffe fich von ibnen erzakglen. S3uchftabenfeuntnif̈ and Sefenlernen twerben nur als Nebenfachen und anfánglich felbft als eine Atrt bon
Spief betrieben.

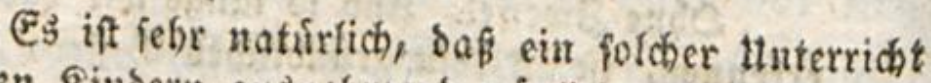

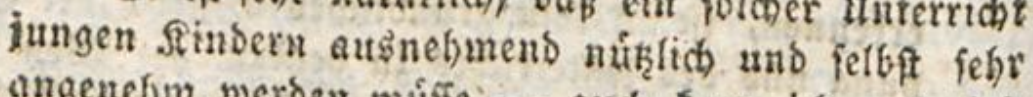
angenefm werben miffe - auch fann ich aus viels

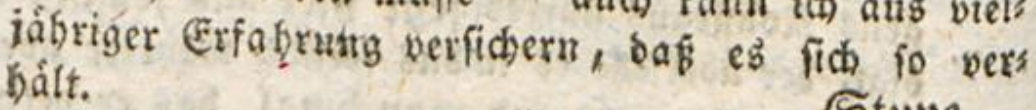

Stuve.

Db bieie Nethode, bie ich zlwar bei jungen Sindern fúr zmedfmáfig erfenne, in offentlichen Ed)u fen angetvendet werben fonne, und fich tangliche unb

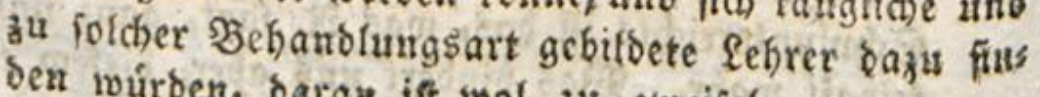
ben wúrben, baran ift rool zu zreifeln.

Mefenis. 


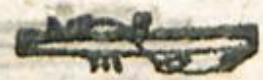

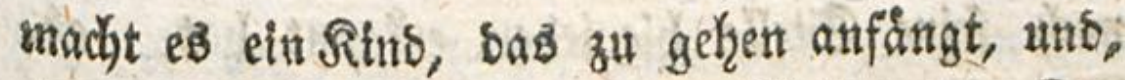
fo zu fagen, in Den Raum ber SBelt tritt. Des ganze llnterfdites ift, baf siefes, mit sem Ëes

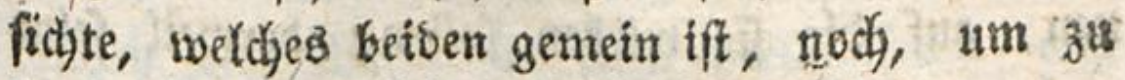

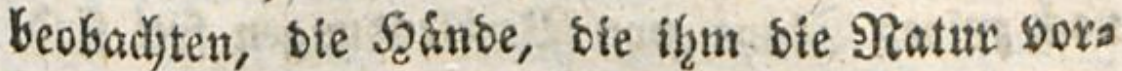
aแs่gab, jene aber ben feinen (Sierudi, ser wies ber ifre Eigenthum warb, gefrautht. Diefe, wohl ober ibel gerillote Difporition if es, wels de die Sinber gelentig obex plump, fónerfäls lig ober gewandt, fafelid ober sorfichtig madjt. Da alfo bie erften, bem Menfichen naturlis

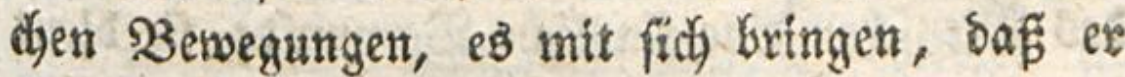
(iic) mit 2fllem, was ihn umgiebt, miffet, uno in jebem Siegenftande, ben ex wahrnimmt, alle sie finnlidgen sigenfinaften, sie fick auf ihn bezieben, pruft: fo ift fein exftes Stubiren eine 2urt bon sxperimentalphofifi, in fo fern fie feine eigne Erthaltung betreffen Eann; bon biefer Yente man ifyn burch ppeculative Situbien, ${ }^{*}$ ) efge ex

$$
\text { an } 5 \text { nod }
$$

-) Speculativel Stubien aber find fúr iunge Sinder,

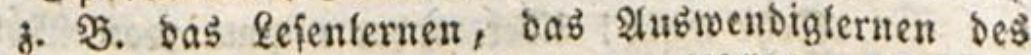
- Eatechismus uno unveriftantoner bibfijcher Stellen. bas lefen folcher Sachen, bie bas Sind fich nod nicht verfinnlichen, vergegentaártigen ober veranfic)assa fichen faun, jeber grammaticalifche Unterricht, er bes treffe meldie Sprache er wolle u, f. to. Stle biciez noch immer io gewibntiden Ifnterridtsarten, fere 
nody jeine Stelle hifenieber extant hat, ab. Derweil nody feine zarten und biegramen Siliebs: maafen fich nach ben Riorpern mobifitiven form nen, auf die fie wirten follen; bermeil feine snod) reinen Sinne bon SBerblenoungen frei find, ift bie 3eit, jene uno biefe zu ben ilgnen eigens thimlichen \$erridytungen zu iben, uno fie bie finnlidyen Seztelzungen, weldhe bie Sachen auf uns haben, Eennen zu Yehren. Da 2Ules, was

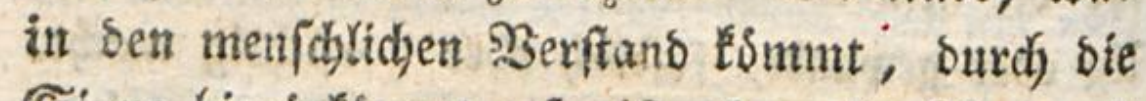
Sintre hineintormmt, fo ift bie erfte 3 ernunft

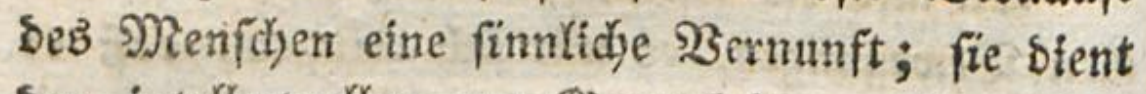
sev intellectullen zur Grumbfefte: unfre erften

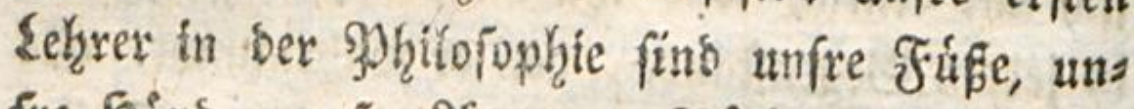
fre Şănse, unfre 2lugen. Buicher alfo an bie Stelle son alle biefem feren, keiğt nidyt uns

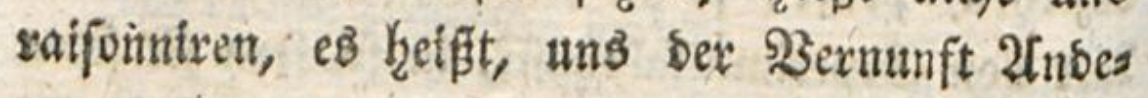

beru nicht allein bie 2 tutsbilbung bes Sinbes nicht, fonbera Ginbern fie auth.

\section{Campe. Trapp. Stuve.}

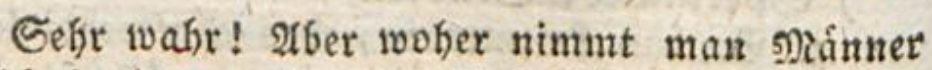
stt Gdulmeiftern, bie mit philofophifchem Breipte juns ger Sinder Geelen fennen unb zu behanbefn wifien, und practifche Jienntnifie genug baben, jie anichaus Yich ju unterrichten, uno patriotif(c) genutg fins, bei biciem múbepollen und fortgefeţtes Nacjuenfen ers

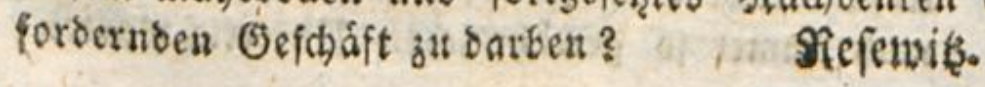




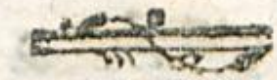

ab.

lebs:

Sins

ine

no,

ents

bie

auf

las

bie

uft

int

en

ns

ie

1 16

es

ef

it,

er

Is

t)

ts

ii

is

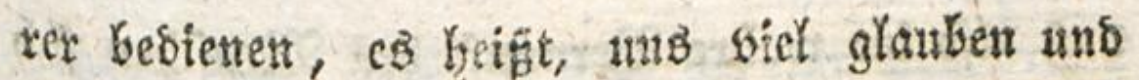
niemalo etwas wiffen (etgren. *)

(Eine Simft auszutiben, miffen wir mis exftlich bie slbertigenge bazu verifgaffen; und

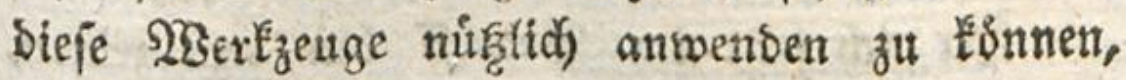
miffen wir fie frort gemug Dazu madjen, beint Sebraudbe zu wiberftef̧en. Folglid, um Dens ten zul lernen, miffen wir unire Gjlieber, uns fre Sinne, unfre Srgane, welche bie SBertzens

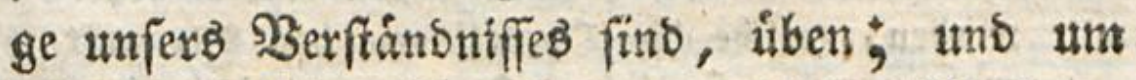

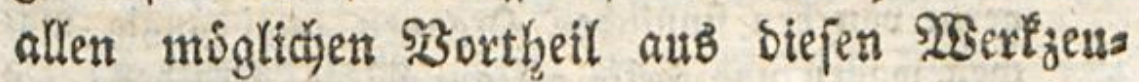
gen zu ziehen, muß ber Sisrper, welcher fie barreidt, gefund uno ftark feyn. **) 2(nftatt,

ba任

2) Scibes faun ia fo leidht auf eine weife 2rt mit cins ander verbunden und burch einander befordert wer: ben.

Ëblex?.

Afferbings; aber wohlverftanden! uur bei ber reifern, nid)t bei ber zarten Sugend von fünf bis

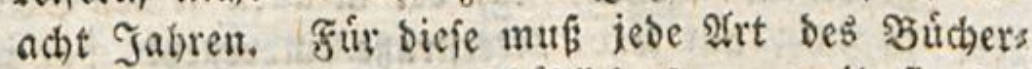
unterrichts nothwendig fod adfich fepn, weil fie bas

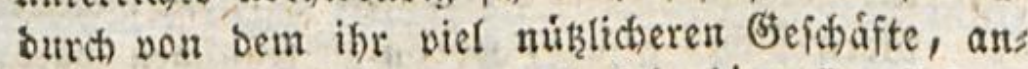

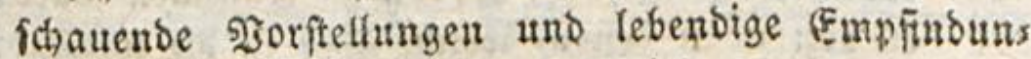
gen eingufammeln, abgebaiten wirb.

Eampe. Fejenits.

**) Thatigfeitstrieb uno sirfirfamfeit fino mit ieber - Traft verbunicn, haben folon Statt bei ben gerings ften Straben ber fraft wh nehmen mit jebem hos hern Grabe ber Siraft ju. 2alles fommt bei ber thes bung ber Siráfte alfo baraut an, bafi jener zu siefer

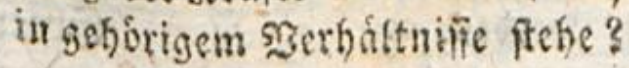

Eblers. 


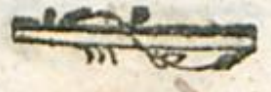

Dafi alfo bie wakgre Szernunft bes SRenichen fich unabhangig vom Siorper bilben follte, macht

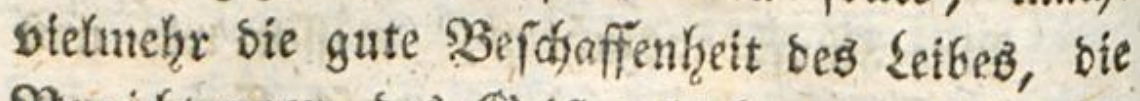
Berridytungen des (Sicifec leidjt uno fidjer. ") Da idy jesct im Begriff bin, zu zeigen,

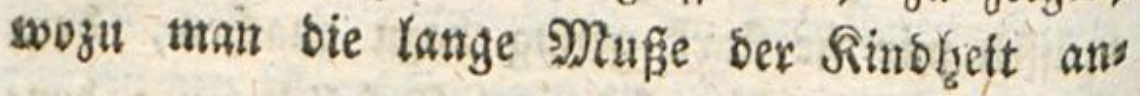

wets

-) Eine fefr wafre Shebauptung. Mógte biefe boch vou vielen unferer iekzigen beften Rópfe beherzigt werben, welche bie Sperationen der Bernunft fo gerne von ben finnlichen Organen unabbángig mas den wollen itms theirs oft auf 233 ege gerathen, bic

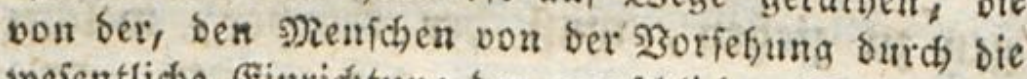

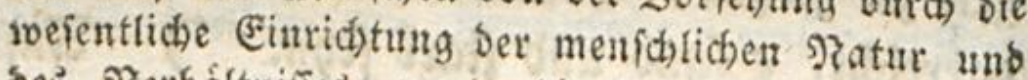
bes \$erbáltuifies, worin bie merrichliche Natur ju andern Dingen und andere Dinge ju ber menfibst chen Natur; unb worin die Seele zum Jírper unb ber Sibrper aut Geele burá) gegenfeitige EHvirfung geferst find, vorgezeidinetent Syeerftrafe bes gefun ben Serftandes nidse wenig abweidhen, theils immer in Befabr fint, in bergleichen Grinege binein $z^{\text {th }}$ gerathen. Spalbing, ber it alfen feinen Edsiften fo fither auf fener Jyecritrafe einbergebt, hat in feis ner Bugabe zu ben vertrauten şriefen hievíber vief 25ortreffiches gefagt, joovon zu wuinichen wáre, bẩ es von aflen benten, welche eher in bie pwinfindigfent Epeculationen fith hineinivagen, als fie bie Netas phyfif ber gefunden Bermunft fić) forgfáltig befannt gemacht haben, reiffich erwogen werben mogte. \$ूुent bas geicháfje: 00 warben fie nidht leicht von gróbern und feineru Eaglioftros, bie boskafter ober betrogs

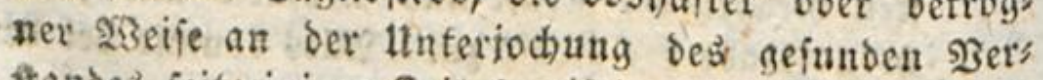
frandes feit einiger Beit fo eifrig arbeiten, angeftedt wins irre geleitet werden.

(5) lerb. 
(iic)

acht

bie

*)

ent

ans

ene

1006

jigt

fo

nas

bie

bie

ins

के 18

Jis

116

utg

ins

ier

$z^{\text {th }}$

ent

eis

ef

if

in

as

it

$\pi$

II

je

"s

t

wenden folle, muf id mich in eine Crorterung dez (sinzełnen einlaffen, bie redjerlich fcheinen bixfte. Enfige Itnterweifungen, wiro man mix fagen, bie, inbem fie wieber unter beine Eritil zuridefallen, fich nur barauf einfodránten, et:

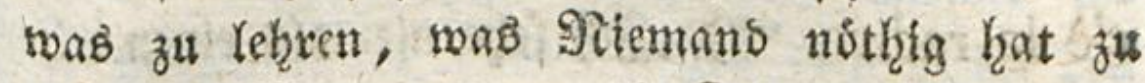
ternen. Sรgarum benn bie 3eit mit Linterridyt vertrobeln, der fteto vou fich felbft formmt, und

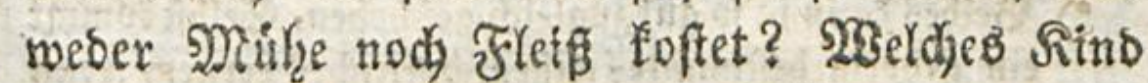
Don zwolf Sahren weif nidj. 2Clles Das, was bu $e$ S Yehren willft, und iberotes auch noch tas, wab feine Lefreer es gelefrixt haben?

Metne Serren, Sie irren fidy. Sid) Yehre meinen 3ioling eine feht lange, fethr berdjwers liche, uno son ben Şhrigen gerwín nidjt begrtffne Sunft; bie Sunft, unwiffend ju fern; *) bentr bie İBifienddaft besjenigen, ber mur bas za

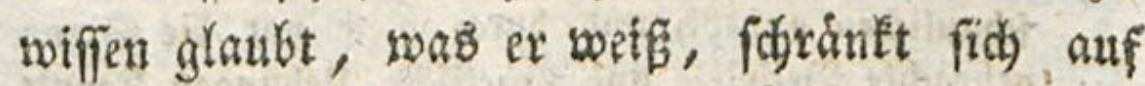

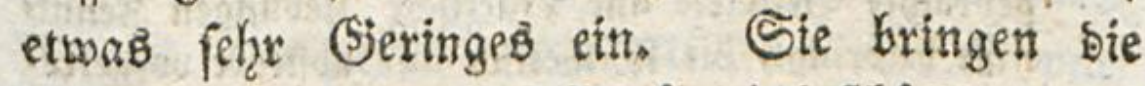
2Biffenfthaft bet; (S)hick zu! idy befdaftige mids nit bem 2 gertizenge, Das zu threr Ermers bung

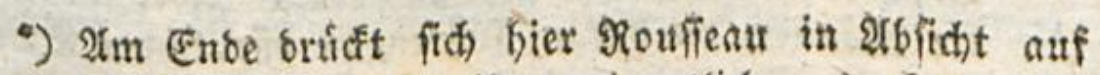
baร, was er fagen will, uneigentlich aus. In einem \&ebrouth follte bas nicht in bem \$iank gefdehen, als es hier fo oft gefdieht. ए5 giebt mat zu \$iele, bie besivegen গzieles misuerfetenen.

Eblers. Trapp. Nefewik. 


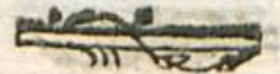

bung *) geḩrt. Man fagt, alB sie Nenetianer eimf mit grofiem Sèpránge thren St. Marcuş fijach einem fpaniföen 2logefanoten gezeigt, fo byabe biefer, ftatt alles Sompliments, nadbom ex unter bie Iifde gefehen, gefagt + Qui non

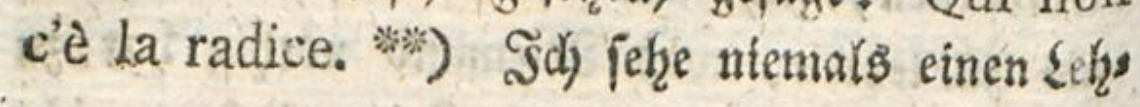

rtrer

2) Seibes faum ia io gut jugleión geicheben. Eelbpt fommt ein geborig beptimmtes wif̄en chaftliches lernen, went matt anders bas, was Sinder uns Sinaben treibent fo nenmen fann, ber Searbeitung uno Hebung ber Drgane fefr ju Statten.

Dann mús aber bas, was man fie lebrt, ges woiß etwas ganz anders fenn, als was fie gewónus fich Iernen; uno bann burfte bieier Itnterricht mit bein, welchen $\Re$. für Sinder voridhlagt, wahricheins Vidb einerlei (enn.

Sampe. Stuve.

Die ganze Sache ficheint mir Darauf anzufoms men, dá̧ mant mit dem, was man Sinder lebren svill, aualntich verfábit, vom Siunlichen wnb 2ins fchaulichen anhebt, und burch viele vor bie Ginne gebrachte Şeifpiele und practifde Ulebungen Rennts niffe beibringt, bie (n) thetiich uno abftract uorgetras gen, von Rinbern nicht begriffen nod) angewanst, bochitens nur buchefablic') und inmbolifich, folglich ofne Nuk̨en gefaft werben founen. Dies ift bet ${ }_{3 e g}$ gefunde 2 Beruunft ju bilben und vorzubereis ten, wie fhon Andere gejeigt haben. 2 ber wo fint bie Nánuer, bie barauf fúbren, in offentlicben $S$ d us

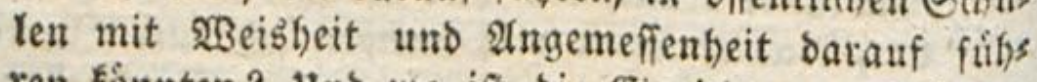
ren fonten? Ino wo ift bie Einriḑtung, Nianner

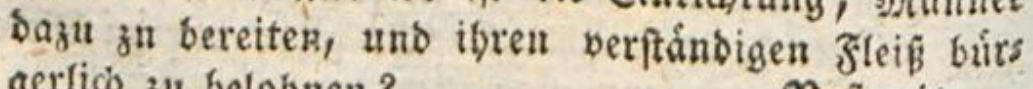
gerlicis zu belobnen?

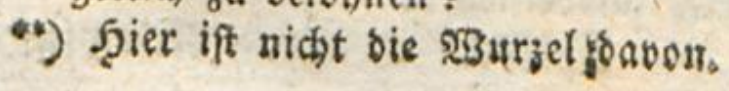

Rejemik. 


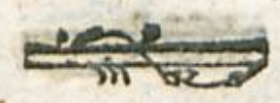

tuter

:I13s

nant enti beIt; ber

ver sab SBiffen feines Sdjuters zut Sdjan tras

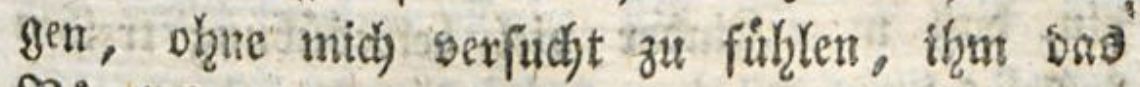
Stälithe zu fagen.

2lle biajentgen, weldye ilber bie 2rit zu lea ben ber acten nadgadodjt haben, pejretben ifg ren gymnaftifơsen Letbebitlungen biefe Rraft bes Rorpers unb ber Seele zu, burch bie fie ficts

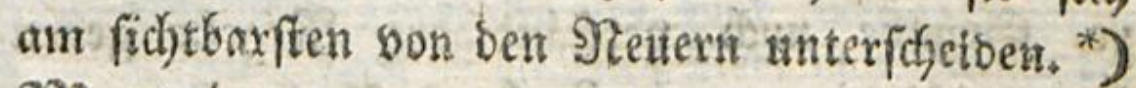
Montnigne tritt diejer Neinung bet, und feit Eifer fie zu exweijen, zeigt, baß ex bon ifir exnft: lich Durch)rutigen war; Intublaffig, atif bums berterlet 93 etje fehrt ex fmmex mieber barautf za

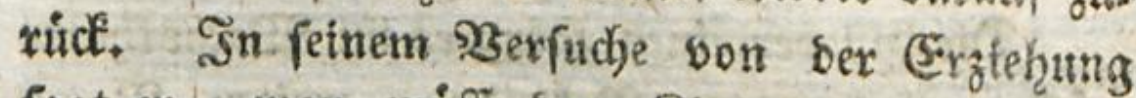
fogt er, man muffe bem Rinbe, um iffnt bie Seele zu ftarten, bie Minsketu ftraf madjen;

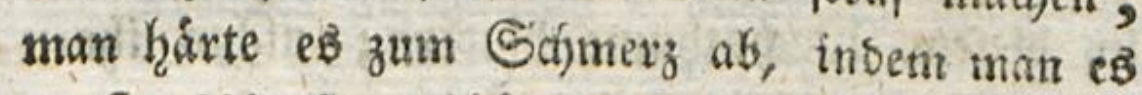

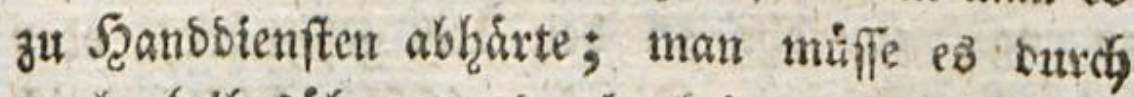
raukge ¿eísebuffungen surcharbeiten, Samit man

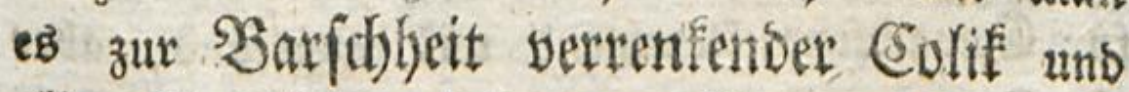
allex forpertichen Leiben gewoikne. Der seife Socke, ber gute Rollitt, ber getef̧rte Fleuri, ber \$ebant Crouffar, alle unter fich in bem Ulebrigen fo veridjiebener Meinung, fommen

Dody

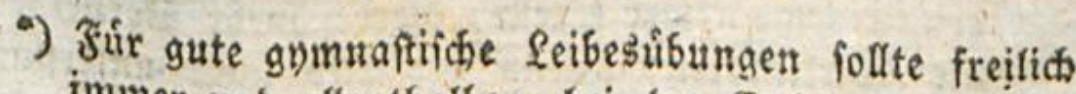
immer unb allenthalben bei ber Eroiegung geforgt werben.

Eด) 


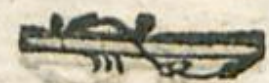

boch farmmtlidy in biefem einzigen Whate ưbers ein, baf̈ man Sinber biel Seibebifbung tretben laffen folie. Diefe unter ihren Borjchriften if auth bie iberlegtefte, fo wie fie auch bie fteto am meiften bernachläirig te if uno bletben wirb.

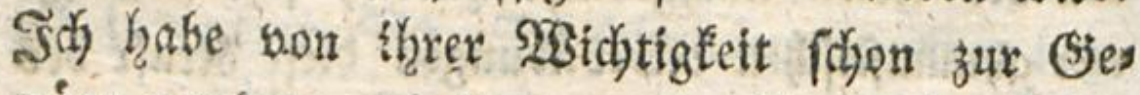
nige gerebet, und ba man baxiber feine beffes

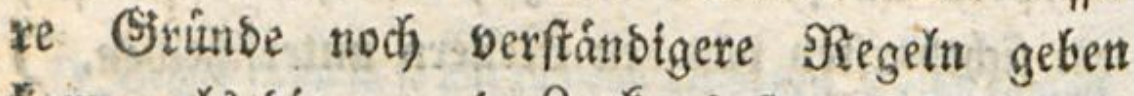
tant, alz bie man in Soctens Butbe- Fïndet, fo mage bitretdjens jeyn, auf felbiges zu berwets fen, wenn man mir nur nod) einige Beobadjtuns

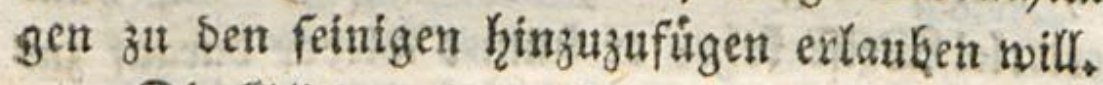

Die (S)lieber eines fiorpets im 23 adjothume smiffent alle in ihrer Befleibung weiten Raum baben; nidjts foll fie in ifrer Soewegung, nod in oizjem 2 Sachstthume hinoern; nichts thnen

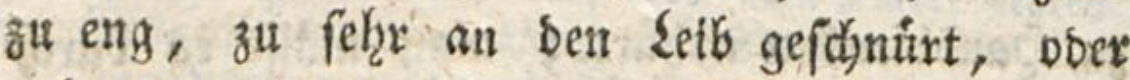
getunben fifen. Die franzofifise Rretoung ift fur Erwadjfene Elemmens uno ungefuns, aber fir Sitnber vollendo nernerblich. *) Die ftoctens

Den,

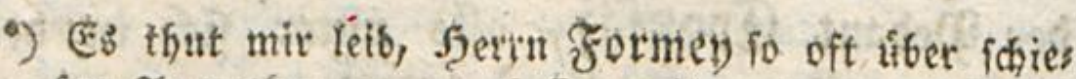
fen Atwerfungen jut treffen, bie wir, weil tie jut

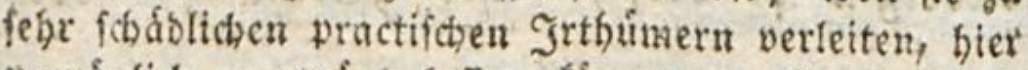
unmbglich ungerúgt lafien Ebunen. "Es iff, fagt er gut gegentuártiger Stelle, bierbei mely 3orurtbeil,

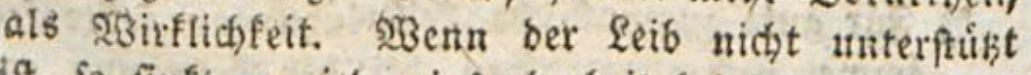
ift fo finft er nieber, infonberbeit bei ben Sinbern."

atber 


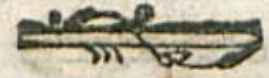

Den, in ihrem Ulmhufe aufgehaltenen Safte ftes ben babei in etmer Ruke ftifl, weldje das uns thatige und fikende Seben nod) vermethrt, fiteckert

atber tweldher Sel6? ber eines Sindeb, twelches it natúrlither Freibeit aufivád)ft? (Berviß̂ nicht; wes nigitens nidit mefyr, fobals es aufred)t ftefn uns Iaufen faun. Fei einem, an ben B̂wang ber Sthnirs bruft fiton gelwobuten und burch) anbere Untaturs. lid)Eeiten fichon gefichwad)ten Sinbe ift es freifich ber

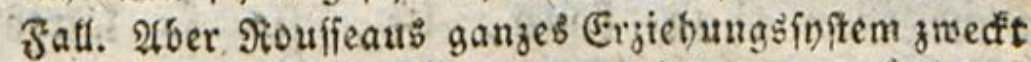
in barauf $a b$, bie Sinder yor biefer unnaturlithen Echroachung zu verwahren. Sherr formey fahrt fort. "Das Schuírleib fommt eirer Nienge ubler Biegunger vor, weldhe bie Selvobnteit, unmáfige Epiele, uno anbere 3 ufalle in biefem Ifter verurs fachen fonmen." Wenn bem fo ift - obngeachtet bie Erfabrung bas Esegentheil fton Yange auper Baweifel gefebt hat - und wenn bie Furcht vor moglichen Sufallen chre fo gewaltfame maafregel, als bie Sifmurbruth ift, rectifertigen fant: fo has ben wir llnrędt, es blop bei biefem einen 3wangse mittel belvenden ju lafien; fo follten wir audi bie Sánbe, bie J̌ifie und bent Sopf ber finder in feffeln legen, baunit fie gang unb gar feiner wills turlichen Эelvegung fábig blieben, weil iebe beriels ben moglicher greife ifnen fhádich werben faun.

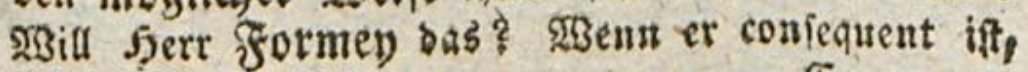
to mus ex es wollen.

Eampe.

Die Schádichleteit ber Shnútbruifte ift lool ik̨t burch bie Ednepfenthalifhe Prelbichrift fo aufier

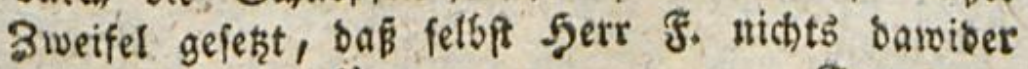
soiro emwenben fónnen.

Trapp.

Mieine eigenen Sinber, bie nie Ëchnútbripte ges tragen baben, uno febr gerabe gemodifen find, fóntuen Cmil xpter

So. Das 
fich an, unb ocrurfachen ben Sibarbodt; efire

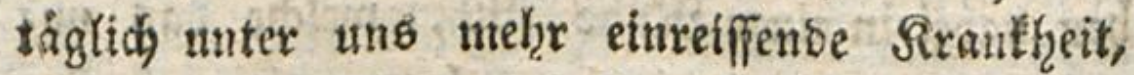
Sie ben 2frten faft unbefannt war: Denn ifre 2frt fid zu betlition uno zu leben verwabrte fie Davor. Der Soufarenanzug ift uta nichta beffer, conberu macht viełmehre sas llevel áger; uno

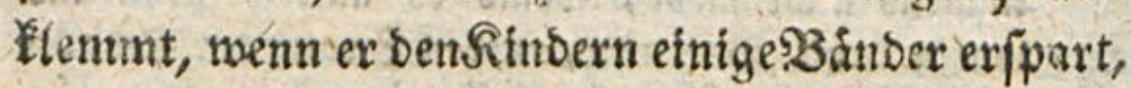
thenen bafiir itberall den Letb ein. Das befie, was man thu fann, ift, fie fo. lange in Sáctidsen laufen zu laffen, als misglich, uno bernach thnen eine felgr weite Bef́letbung zal geben: beun es wirbe ifgre Taille ohneb̨in nux Derumfalten, wenn wir uns einfallen liegen, sieje in ihrem Bortheile zeigen zu wollen. Săhre Isrpertichen, fo wie die Jehter ifgres Selftes, entipringen fait alle ans (5iner und berfeltben Suelle; man will fie vor ber Beit zu Ev: wadb (enen mad)en. ")

(E. giebt fusblicke und traurige Farbent. Die erften find methr nad dem Gejétmucle' ber

Sins

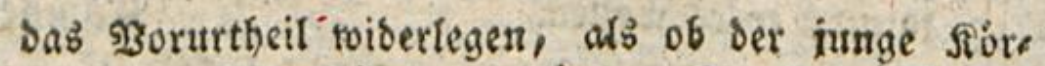
per einer Unterftúk̨ung bebúrfe. Die Hnterfțtįung

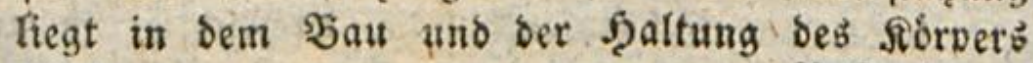
felbit.

গejerwis.

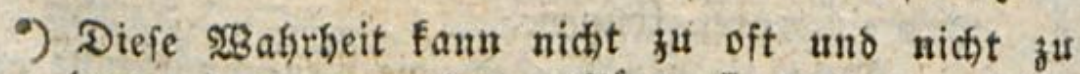
laut geprediget werben. Niogte ile boch von vielen gehort und behergiget werben!

Eampe. Srapp. 
Ninder; fie ftehen ifhen aud beffer; uno id

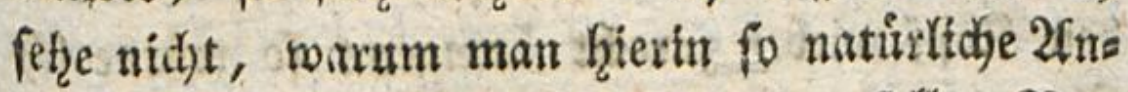
gemeffenḩeiten nidyt za Rathe ziehen follte: Bon bem 2Cugrnbltcte aber an, ba eure Rleinen eiren 3eulg vorzitehen, weil er reich ift, fino ihre

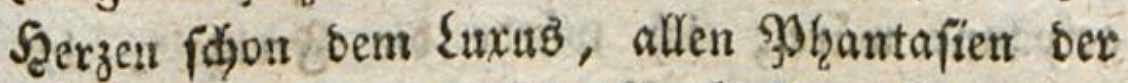

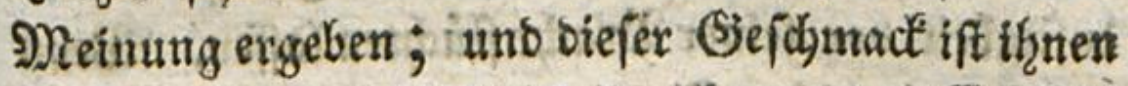

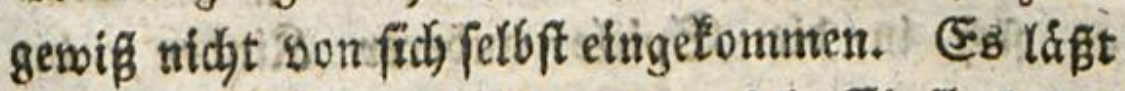
(iid) nidjt hgenug fagen, wie siel Einfluß̧ bie

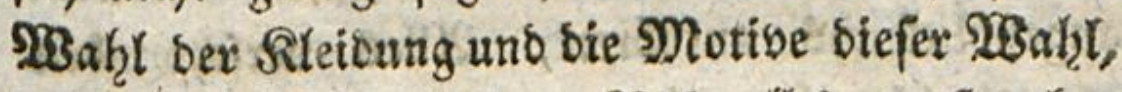
in bie Erzziehumg haben. গRidjt allein beripredjen

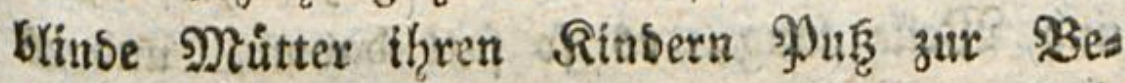
lof̧nung, man fieht fogar ambernúnftige Şof's meifter tbre Untergebenen mit einer gróbern uno

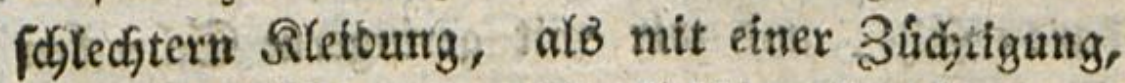
bebrohen. $\Re_{\text {Benn }}$ ou nidft fleifigiger lernft, wenn ou beine Suchen ntajt beffer in 2 dat nimmit, wirb man bidh, wie einen Eleinen $B$ auteriungen anziehzen. Fft bas nidjt, alö ob man zu ihnen fagte: bu muft wiffen, bafi ber Menfó nidjts als burch feine Rleidung ift; baf bein ganzer 28 erth in ber beinigen fectit. Darf man fid nundern, wenn fo weife Eef̧ren bet ber Sugens

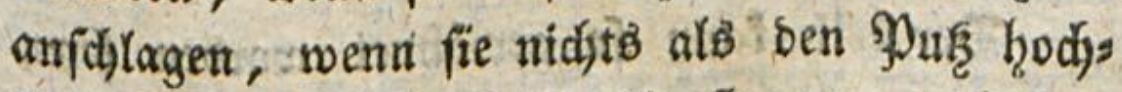

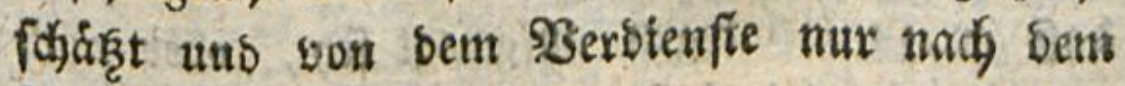
2(eufertidgen urtheilt?

Do \&

Solls 
580 .

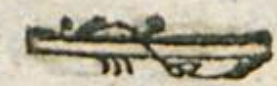

Sollte idy alpo einem fo verberbtent Sinse ben Ropf wieber zuredt brisgen: fo wirbe th Sorge bafur tragen, baf̈ feine reidjfen Rletbet bic unbequemften watren, baß́ es ftetB barin eingeztwángt, getlentmt unb auf taujenberlei 2frt

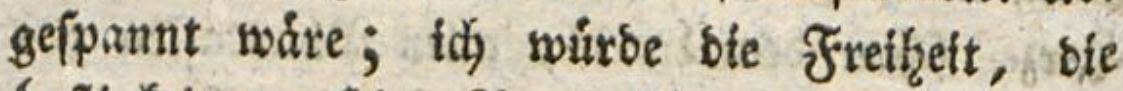

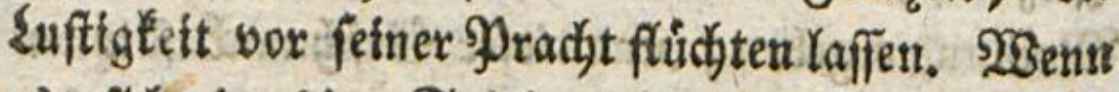
es fid. in bie Spiele anberer Rinber, bie fijledyter gingen, mifchen rollte, fo follte 2rlles

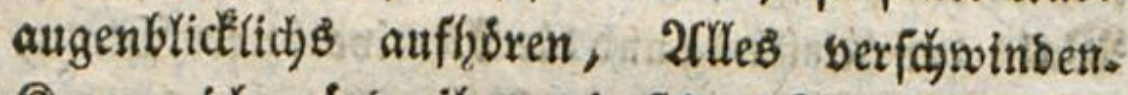
Riurz, id wuirbe ifhm mit feiner \$rad)t fo 3eit uno Weile lang, es fo fatt bavon, uno es pelbft zunt Sclaben fetnes mit Siolbe bejeşten

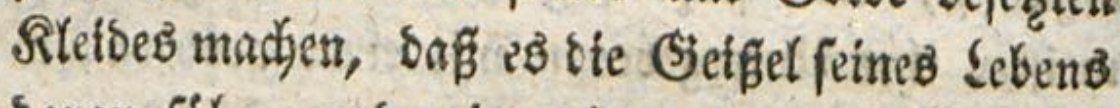
baran fóke, und mix mit geringerm Styrecten Sinjperrung in ben bunfelften Rerfer, uls $2 \mathrm{In}$ ftalten zu feinem Suf̧e betradyten follte. So range man bas Rinb noch ničnt unjern :orur theilen unterworfen hat, geht immer feine exfte Begierbe barauf aแs, eह̉ bequem zu haben, uno fret zu fern; bie eimfachfte, bie gemaddylidafte, ofe eb am wenigften einzwångenbe Sileibung ift ifw ftets bie toftbarfte:

Der Leib fann fo gewoihnet worben feyn, baß ex zu Lebungen aufgelegt fen, Dber aud

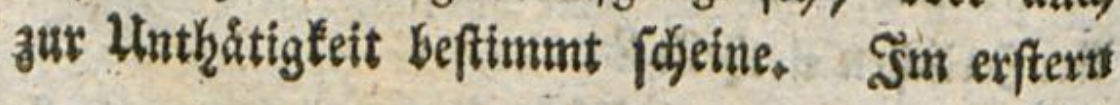


Falle wiro ben Siften beffelben ein gletder uns einformiger Sauf gelnffen, uno ser (eib saburcí) vor ben Beranderunget ber Laft gefdukt: int anbern fralle, wo man ifn unumfhorlids sou

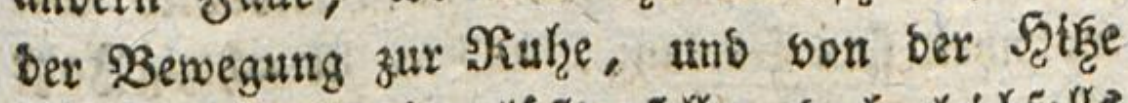

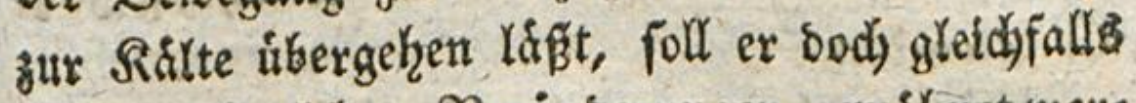
zu ben námliçen ßeräberurgen geroshnet wers ben. Daraus folgt oent, baf wer in Shatreru unb Stuben hoct, fich ou allen Beiten warm Heiben muiffe, bamit ex fich ben seib in etres

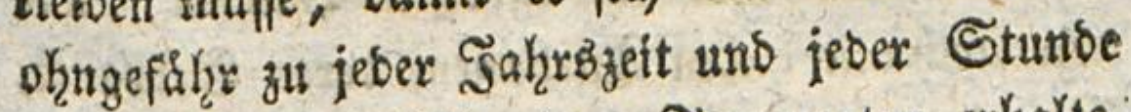

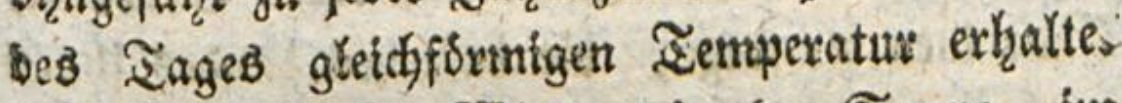
2Bor fitugegen in SBinbe, in ber Somm, im Regen fich berumtreibt, feȟr rege ift, uns

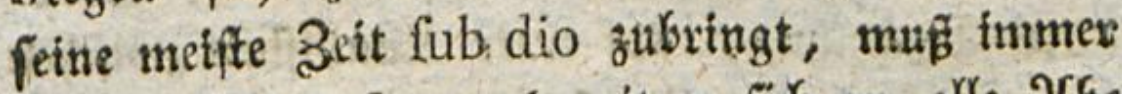
leidjt gefleitet feyn, bainit er fich an alle $2 \mathrm{Cbs}_{3}$ wedjfelumgen ber 2 Bitterung und an jesen Sirab oon Zemperatux genofbne, ohne baßk es ihm

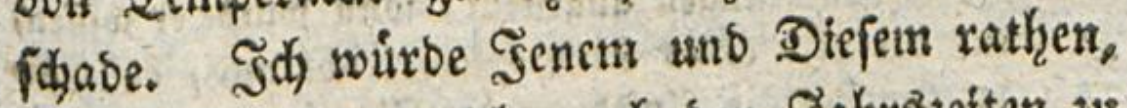
mit ben Sileibert nidyt nady ben Şabrrizzeiten zu sodj] notzhbeit meines (5nits fenn. *) Damit bers

$$
\text { SD } 3
$$

Yans

7) Dicier rath, faat Sgerr Formebs feķt fichon gan: gebilbete Emile voraus, anftatt bafi es noch barauf allfommt, fie erit zut bilben." satan fieft wol, foerr Formen bat fiber bie forperliche Natur ber Nimber 
Kange tć) nidot, ex folle im Sommer féine 233 ins tert́letber tragen, wie bie Stubenfiser, fonbern im $23 i n t e r$ feine Sommerlleiber, wie bie $21 \%$

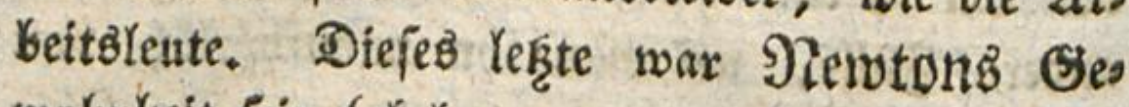

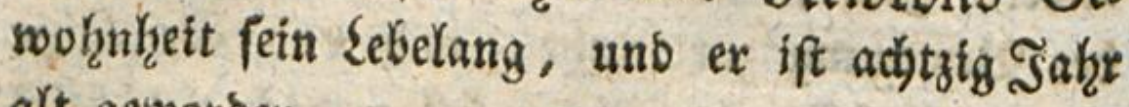
alt geworben.

2 Benig ober gar feine Bebectung bes Rion

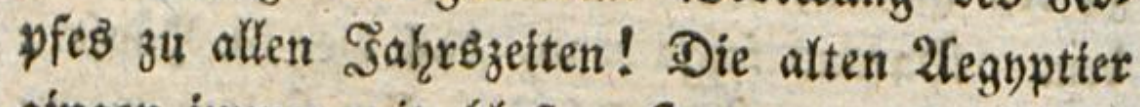
gingen inmer mit blogen Şaupte; bie Perjer bebecten bas ihre mit grofien Sunden, uns jef̧o noch mit bicten Iurbanen, seren Şebraud̆, 厄harbinen zu folge, bie Luft bes Landes ifhnen nothwenbig madyt. Sal) babe anberwairts $\dagger$ ) (chon eines Linterfdjęeb erwáh̨nt, ber, nach Sero:

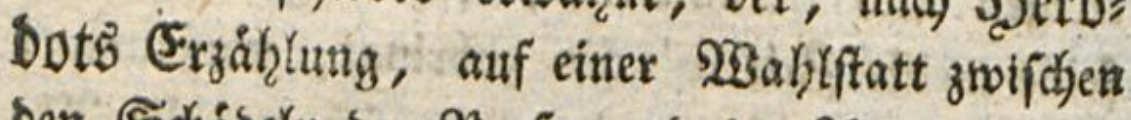
ben Schábeln ber Эoeŕer uno ber 2Tegyptier ans

nie Seobaditungen angeftellt; fouft wirbe er wiffen, baß ber leib cines rinbes fehr leidht uno, bei einis ger Sorfid)t in Anjefung ber Affufung, obne alfe Sefahr iebe Bewohnheit annimmt, die man ifm fu geben nothig finot. Nichts ift leidhter, als alle Sinder, felfit bje febon verjártelten nicht ausgenoms men, bahin zu bringen, baß Sommer einerlei Sleibung, no jwar eine febr reidyte geniget. Id) wenigftens babe oies bei, allen Sinbern erfabren bie id le unter f̧anben batte.

Campe. Niefeswis.

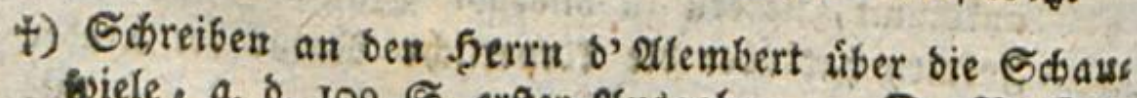
wiele, a. ১. 109. ङ. erfter 2tusgabe. $\begin{array}{ll}\text { D. Berf. }\end{array}$ 


\section{4}

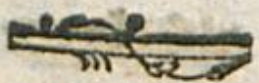

- Şautgetwebe nod gar zu zart utio zul folaf tif,

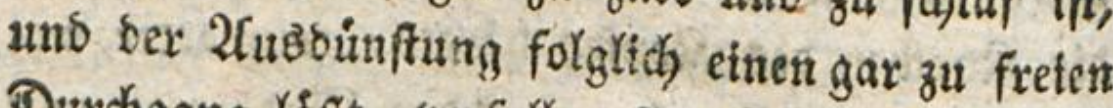
Durchgang lafgt, verfallen fie, ibertrieben warut

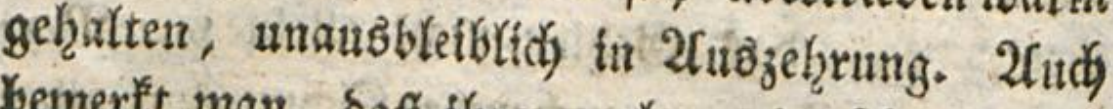
bemertt man, bafif three tnefreere in 2fuguft, alo in trgend einent anbern Monate fterben. Lebers bem fojeint es aud eine burdy bie \$ergleidfung

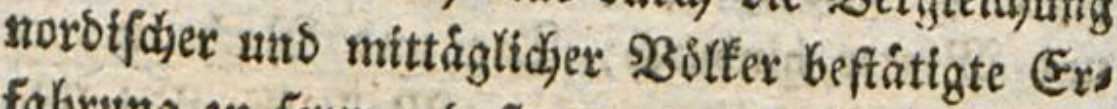

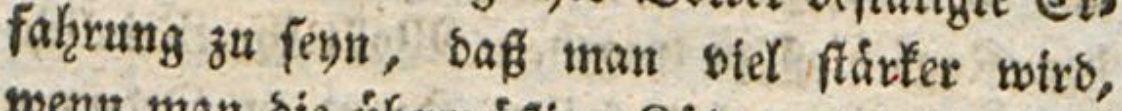
wenn man bie úbermafige Sílte, als bie übers

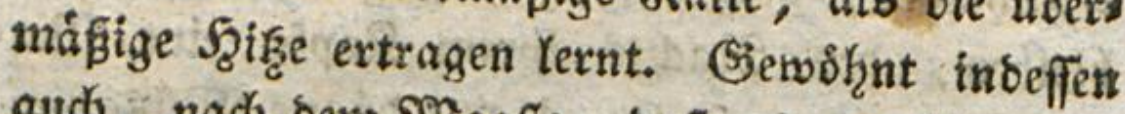

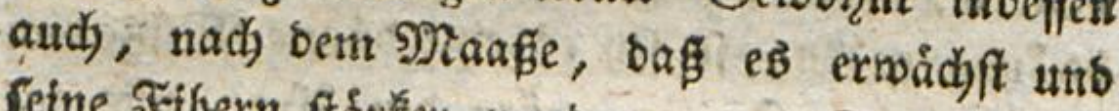
feine Fibern ftarter werben, ener Ritno buran, allmälig ben Somnenftrablen zu trofgen; ifhe soirbet, wenn ifgr nux ftufenweife zu 938 erte gingt, es ofhne Gefahre bie Şluten beß brens nenben Erogúrtels zu extragen, abf̧ẩten.

Socke verfollt mitten unter ben mátnlichen uno verninftigen Borfïbriften, bie er uns giebt, in 23 iberipriche, bie man bon einem fo bes

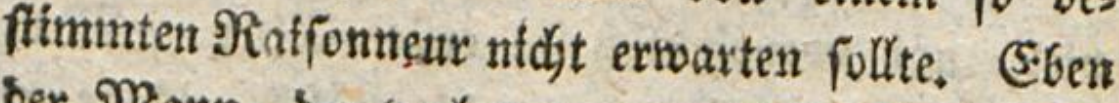
ber Mann, ber berlangt, man folle ble Rinber

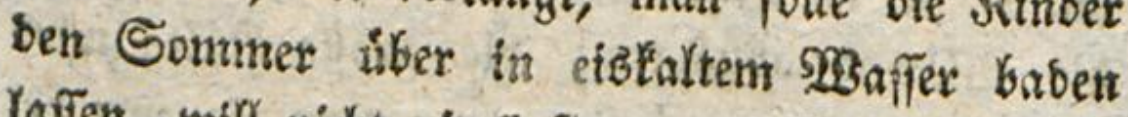
lafien, will nidyt, baß̈ fie, wenn fie erhicht find, falt trinfen obez fich an feuchten Dorten auf bie 


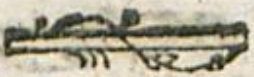

Erbe regen follen. *) †) 2fber er will ja, on bie Stjuhe sea Rinbes zu nllen Zeiten So 5 burdys

4) GuGen besu bie fínber ber Banetn redt trodentet

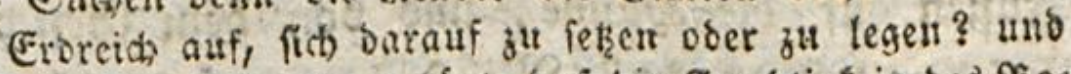

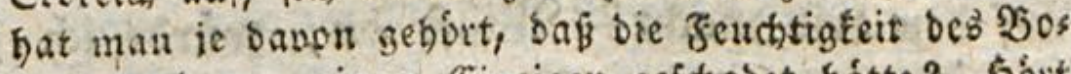
bens aud un einem Eimzigeth geftsabet hátte? Şout man bie Siergte barüber, fo follte mar glauben, bie whilben umiften alle bon frtuffen gelábmt fern.

Itnm. Deత3 2setf.

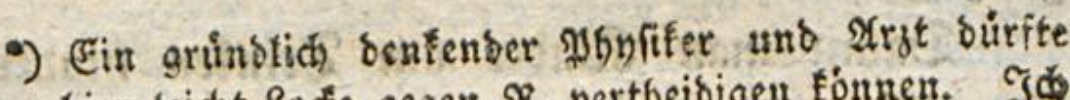

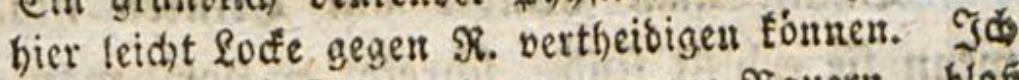

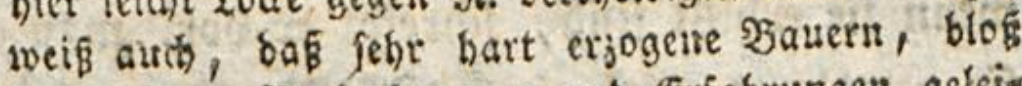
Durch cigene Beobachtungex unb Erfabrungen getei tet, fich fo verhalten, als locie mill, bafis ber mentón fich verbalten fotle. Streilich faun ber झRenid burcá anthaltende llebung fich auch zu Dingen gewóbuetr, Die fhablid) find. Der Menifh fann ia felbit nads uno nach zientid vief erträen lernen. Sltein es

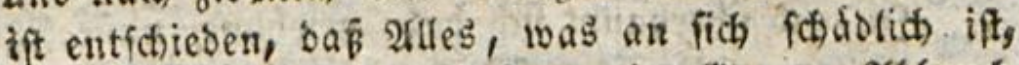
Der Befunsheit und dem felen in Banzen 2fbbruch

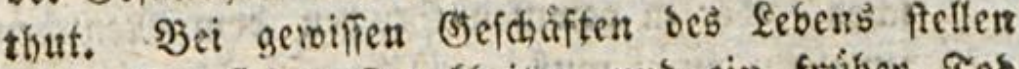

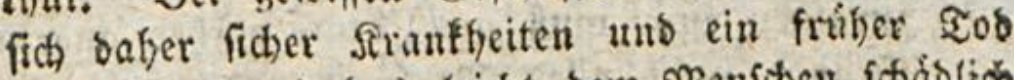
ein. If etroas, bas leidit bem Menichen fichablich soird, fo befchaffen, baf ber gRenif bei feiner les bensat, ober liberbaupt es gar nicht ober nicht leicht vermeiben faun: fo thut ber miench freilich wobl, went er fich baju geivibut. Randhes smenichen lee bensart if fo beficaffen, bas er fehr oft bon frarter Şiz̨e zu fturfer Rálte, vom Troćnen zur Siáfie uno umgefefyrt plozzlich úbergehen muf. Tn biefem g̈ats muf er in ber fríbiften Itgend fchon allmálig bazs gewobnt werben, wie bas o. B. bei ben Salloren bee Fall ift. Fint alle Nenichen befommen leidt nafie ริipa, 
Surchlaffen follen; werben fie benn weniger welk wes burchlafien, wenn bas Rino beiß̈ ift, uns fann man nidyt bon ben Fiffen auf ben Lefb eben bie Sinbuctionen madyen, bie ex von ben

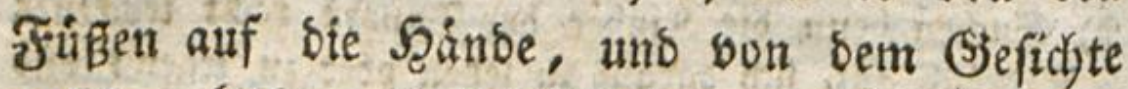
auf ben \{eib madjt? SBillft bu, mirbe id zu

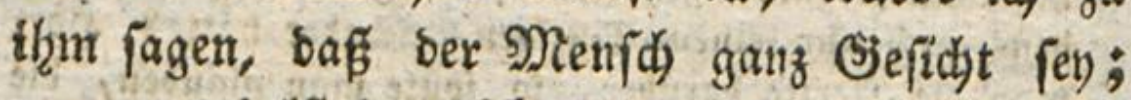
sarum tabelif bu mid, wenn ide will, bage er ganz Fuß Fey?

Damit man Sinder an Trinfen b̧inbere, wenn fie exhifgt fins, forretbt er bor, man folle fie gewofhnen, erft ein Stuck 3 rod zu efpen, eḩe fie Nafies zu fidi) neţmen. *) Sehri feltiam,

Fúfie, uno lode ráth baher weislid att, baḱ bie Gugeno tiberbaupt fich bazu geróbne, nafie fáfie ers

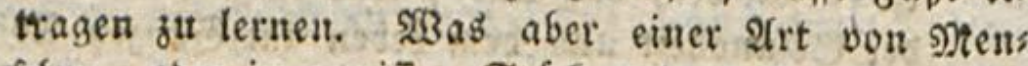
fisen, ober in gewiffen Stuffen bem Nenfichen ans zuratben ift, muf aus bem vorber angefíbrten Grumbe nicht allen Neníchen und, uneingeidbánft angerathen werben.

Eblers. Trapp. Enmpe. Rejewits.

*) Man muń es den 2ferzten tibertajicu, zu entícheiden, ob biefe teichtfinnige sheorie des Serfafiers oum Erinfen bei ber Erbihung nidht eine fefr ju weit getriebne, perverblide joppotbeie lev? Die unmits

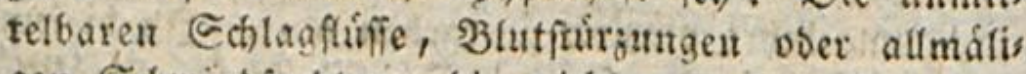
gen Gdwinturuten, bie nicht mur bei Menichen, foncern auch fogar bei Ifieren, i. E. \$ferbeu, went man fie erbişt trinfen láft, fo oft die folgen fint,

mas 


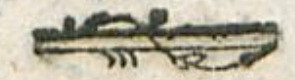

daf man einem Sinde zu efien geben foll, wenn ihn burftet: id) mogte ifhm lieber, went $e^{8}$ bzungert, zu trinten geben. *) Man wirb mid, nie iberreben, unfre exften Segierben wáren fo ungeoronet, baßj man fie nicht befriebigen burrs

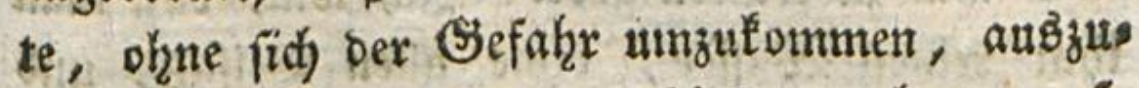
fefen. * Fosnte man bies annebmen: fo wáre

machen ben Rath: auth bierin ben Trieben ber S?as sur fie blinto folgen a lafien, bodhit bebenflich. Locfe geht ficher den vernunftigern $23 e g$; ben $2 \mathbb{B}$ g ber Entbaltfamfeit; ben jeber vermuftige Erziefer mit ifm betreten wirb.

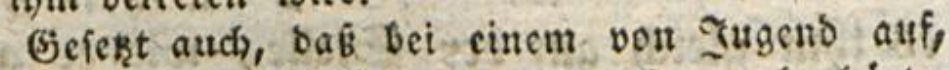
uad) ber ganzen siethode von sionfieau abgetártes ten Siorper, bas Frinfen in folthem Falle nicht fdadolich wáre; fo wirrbe bod berienige, ber jeß̧t, ba niemand, auch ber Eohn bes Lanbimants nicht, fo abgefartet wirb, ben Erbizten trinfen lafien nolls te, ein inconiequenter $\mathfrak{z}$ bor feys. Labit uns bamit soarten, bis wir şitbe alts Eanaba find, und aud anf cine Neile weit bas sibild witterm fonnen.

Inm. Deg Heberf. Eampe. Erapp. Rejewibs.

-) $2 B i \hbar$ ! 2 (ntitfefe! aber nid)t 2rigument.

Itum. Des Heberi.

-) Der vollfonumen natúrlide ober voilbe Nieních barf fid feinen Fegierben, wie bas vollfommen wilbe Thier, obne alle Befahr ubertafien, batf alfo auth trinfen, wenn er erbiz̨t ift, wie ber . Sirich uno ans bere wilbe Ehiere eb ofue allen Niacitheil thum. 2uber to wie bab zabme Sthanf ullo bas zahme Yfiro fich niaht nach bem જ̧eifpiele bes Şiritges richten sarif, 
ware bas menfalidje (Siefajlecht hunbertmal foros ausgeftorben, ehe es geternt bृatte, mas es tḩun miffe, fict) zu erfralten.

So oft Emilen burften toirs, will ida, baf unan thut zu trinfen gebe. Sds will, baf man

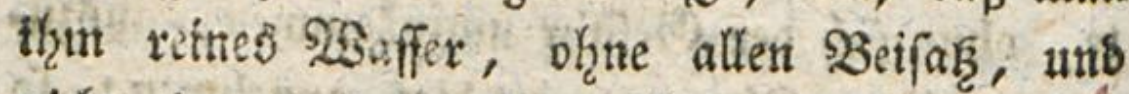
nidjt eimual ein benig berichlagen gebe, fdymoins me or audy in Styweifi, uno bies mitten in bet bitterften 2 Eintentalte. Die cinzige Sorgfalt, *)

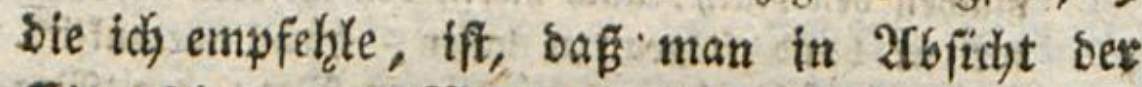
Eigenjd)aft bes SIBaffers bie geḩorigen ltnter. fohtebe madhe. Sit es Fluṕtwafier, fo gebe mat es ifgm gleidh auf ber Ctelle, wie ez̉ aus bem Jtufe gejdjpft witro. Sift es Quellwafer, fo raffe

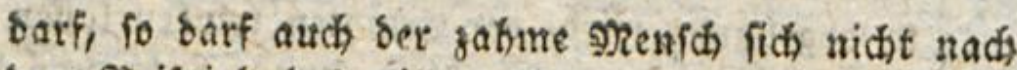
bem SBeifpiele bes wilden Renichen richten.

Eampe. Trapp.

$23 e n n$ auf bas falte ฐrinfen gleich wieder ans gemeffene Solvegung folgt, ift es ber Evfahrung zu Folge minber itháblid).

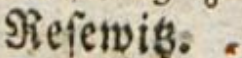

*) Illo sod) eine Corgfalt, unb eine, mit ber es am Ende auf Locfens Stưf গ̧rob hinaustáuft. Dent wenn Emil warten foll, bib bas Queflwatier bie Semperatue der Suft hat, fo sarf er ja boch nicht immer gleich trinfen, benn ibn buirtet. SBarum foll er mun niaht unterdeffen ein Stud જrob efien, beionder da bies, went es gefáuert ift, wirflids eis nen Durft, ber aus Etbiţung entitanden ift, Iofobs soie ich aus eigner Erfagrung toeif. S Srapp. 
Yafje man es einige 3eit in ber Suft fethen, efe

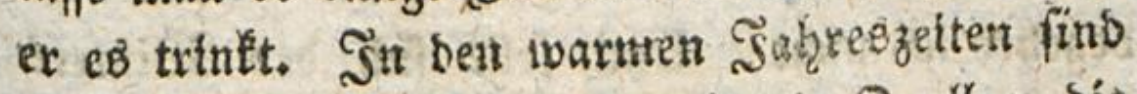
sie Flüfie warm; fo aber nidht bie Duellen, bie teine Suft beribgrt hat. Mian mus warten, biö fie mit ber 2 ttmofplyare in einer gleidhet

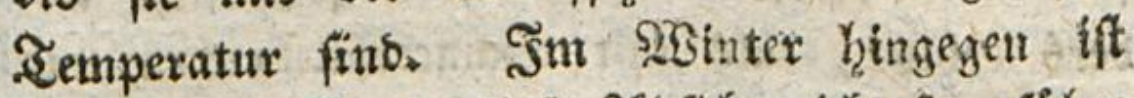
sas Duellmaffer in sicfer 2lbfid)t nidit fo gefabrs?

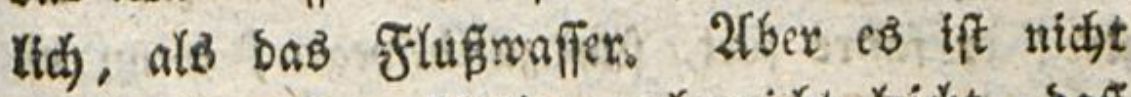

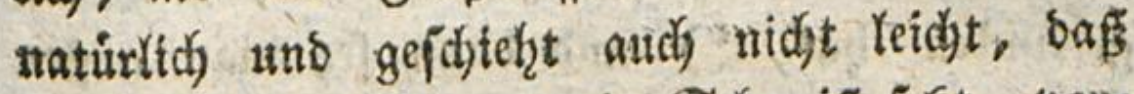
man fids bes 23 inters in Sidweiff fert, bors rehmlid nidjt im Freien. * ${ }^{*}$. Denn bie immer auf bie Sgaut treffende falte Suft, treibt ben

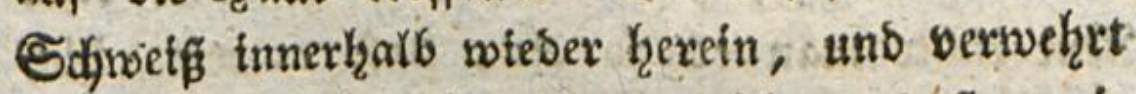
ben Poren fich weit genug zu-sfnen, baffer eis

nen

D) Eefir oft. Durch Behen, buth Eangen, burh Schrittínublaufen, burch jugentolide fiampfipiele

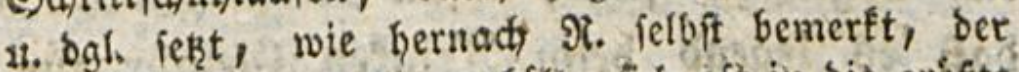
shenifh in ftarfer 2 Binterfátte (iid) oft in bie grobite

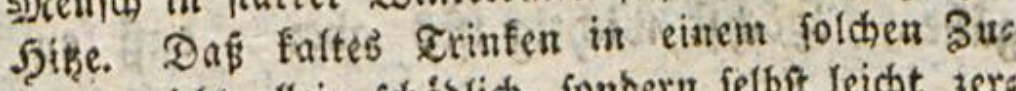
fande nicht allein fdáblich, fonbern felbft leicht zers fioren' unb tostend feb), if feimem sweifel unterwore fen. Es if bamit eben fo beichaffen, wie eb mit sem suftande beichaffen ift, ba ein Menid, nachs sem er fíh ftark erfikzt bat, auf einmal in ber ßálte ftill fteht, oder in eine ftarfe Sibltung bineingebt. Ser in bem Fall fid)abet beibes nicht leicht, da man foglecich fich wieber eine farfe angreifenbe Beloegung macht. Itno boch erforbert ein foldes গ̧erbalten sod) nod sinen re(b) guten Sibrper.

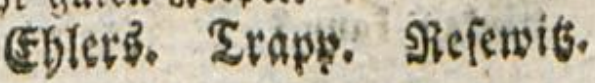


nen ungehinderten Durd)gang b̧abe. Nun aber begehre id nidjt, Euril folle fid bes 2 Binter an einem guten Feuer Bewegung macjen, fors bern aufer Shaule in freieu Felbe, mitten in ftarrenbem Froft. So lange er fich niddt att:

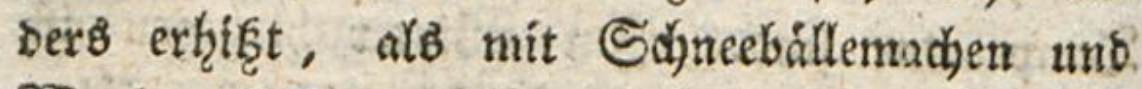

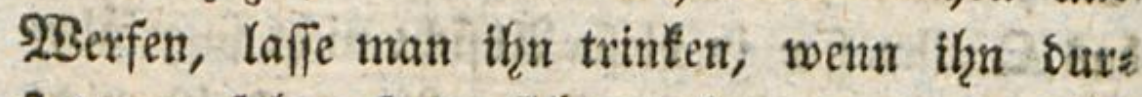
ftet; ex fahre fort, fidd zu bewegen, wenn eiv getrunfen bat, ") nno Dann fet man auger Sorge, ex tonne Sdjaben babon haben. (5r: hifict ex fich burd ingenb ein anberes Spiel uno hat Duteft, fo trinte er aud bann Ealt. গiur vidyte man ed fo ein, bag ex meit biti, unb etwas langjaut gehent, fein $23 a f f e r$ fudjen miffe. ***) Durdh bie in ber Suft, wie man vorausiegrt, befinoliche Rålte, wirb ex hinlang. lich) abgetifhlt fern, wenn ex antounnt, of̧ne

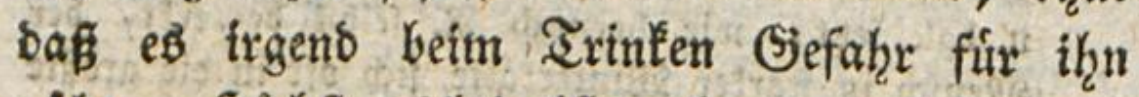
gabe. Sobchif widjtig ifts aber, baß ex von

- Diejer 3ufatz mad)t bie Sache weniger gefabrlíd. unter ber Bebingung ber fortbauternben Belvegung trinfen unfere fandeute, wie ifre $\$$ ferbe, wenn fie mit 'Schweis auch ganz bededt fint, obme alfe bse: fabr fo viel und fo oft fie wollen.

campe.

*a) $\mathfrak{B}_{03 u}$ bas, wemu man ofme Schaben fogleido Falt trinfen Eam? Elers. Trapp. 


\section{$50 x$}

allen foldjen Sorfichten niduts merte. Sa mógte Yteber, ex wäre zu Betten trant, alo ftets aufmertfam auf peine (E) junsheit. *)

Die Sinder bedurfen eines laagen Sdj) weil fie fid) fehrix viel bewegen. **) Eines bient Dem 2fnoern als Eorrectio; aud fieht. man, baß̧ fie bes Sd)lafs un ber Benvegung willen nsthigh ķaben. Die 3eit, wo man ruken foll,

-) Der grenifo muf fo oft auf fís merfen, alb cs bie Eache erforbert, uno in bem angefúfrten Fall ers forbert es bie 'Sache. Nart mub́ ber Nentín mit geruthiger Saffung bes Beiftes auf fich merfen, fo

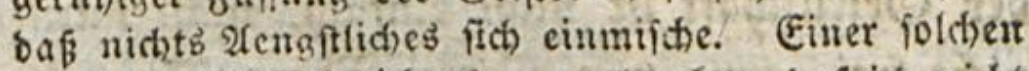
203achamfeit babe ic es zu verbanfen, bafich uid)t fhou vor mefr als zwangig Safren aub ber ISgelt gegangen bin, und bafi if́) aus einem Gefunbbeitbs zuttande, norin mein freund und bamaliger $\mathfrak{A r}_{3} t$ Senbler mir faum ein paar Sabre bes lebens glaubte juttauten ju fontell, allmálig unter iditwes

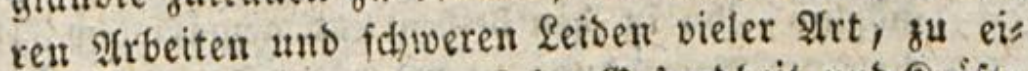
nem uicht geringen 2 aaf ber (ङejun১heit uno Sirafte wieber hingelangt bin.

(E)bletr.

*) Dešlvegent wol nid)t; bent id) habe (graumidiw. Sournal vom: Sabr 1788. (Gites Etutct) aus Erfah; rungen unb Bernunftgrinben gezeigt, baß̄ ein Nienich, ber fich ben Tag uiber ftarfe Rourperbelves gungen madt, weniger Schlaf brautht, als cin 2 (ns berer, ber bei forperlidher Sube nur mit ber Seele gefdáftig ift; fonbern beșmegen, weil ber Schlaf Das unentbefrlid)e Entroidelungsmittel fuir ben now

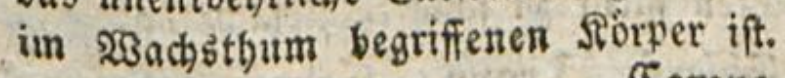

Campe. Srapp. 


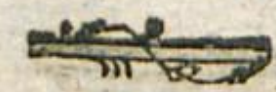

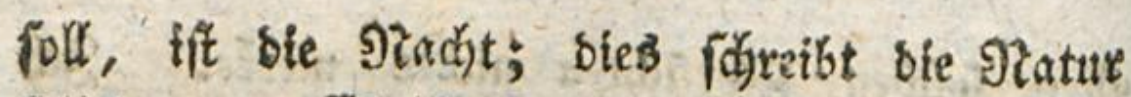
felloft oor. Ez ift eine bon jeher gemadjte 23 es mertung, baf ber Sdjlaf wit rubgger uno fḯs fer fen, fo lange bie Sonne fíf) nodi unter bem Forizonte befindet; uno ba ß̈ bie von thren Strahs len erchişte luft mifre. Sinme ntdyt in eimer fo grofen Stille exbalte. Die hetlfamere Siemohn heit if alfo gemifi, mit ber Sonne aufartehen unb fid, nieberzulegen. *) Daraus folgt benn, baf in unferm Eitma ber Meníd uns ibberhaupt

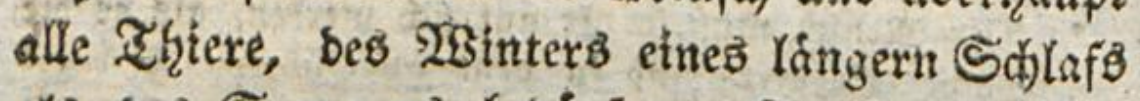
Als bes Sommers bedirrfen. 2lber bas Leben

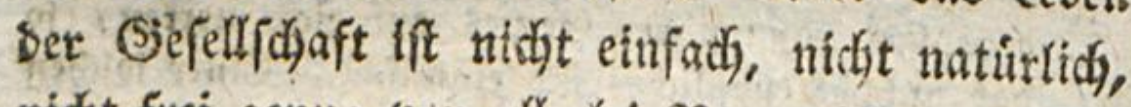
nidjt frei genug oon allerlet Begegnifiran uno 3us

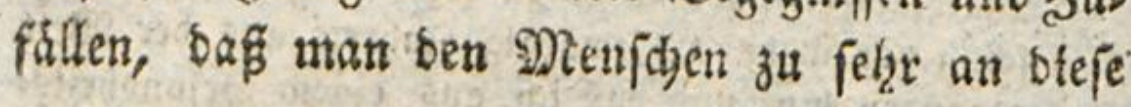

sins

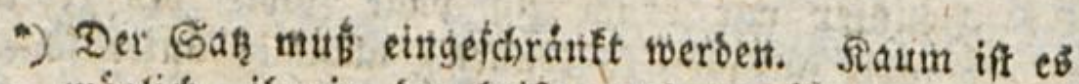
móglich, ifn in ben beipen uno gemáfigten Eroftris den zur Anwenturg hu bringent. In ben norblichent Begenden faun et fchlechterbings nicht angewanbt werben. Der Neni() mifite fonft zuveifen Nonas

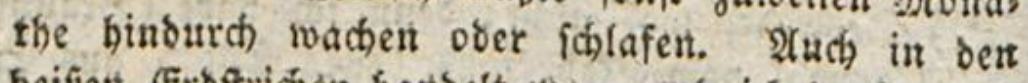
beikent Eroftriánen bandelt wan, und id, benfe, mit Grunb, bagegen, wo man in ber beifeften Tagess zeit forvol, als in ber mitte ber s?adt fdblaft, in . ber úbrigen Seit abet lvacht unb arbeitet. Nian fann wol nut fagets, bấ ber MRenín in langen Zagen verbáltnifweife mefr zt wadhen unb in lans gen gáditen mebr zu fallafen Itriadje babe.

Sylet:. Trapp. Eampe. Mejenis. 


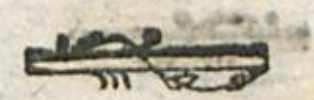

") Die Stotfivendigfeit, iunge leute zu gewófnen, als les ertragen zu fonnen, was im menichlichen Seber oft utwermeiblid ift, if feinem Bweifel unterwors fen: aber mit biefer (5)ewofmuta in 2frfef)ung bes Schlafs idton mit ganz iungen Sindern, o. i. mit

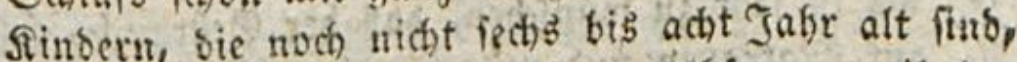
auzufancen, finde ich gar nicht rathfan, weil ber ungeftorte éthlaf für bieie gar zu wohtthátig, ber geftorte uno berfate bingegen gar zu ftablich ift. In ben erften fechs Gabren faun cin Sind nidht leicht zit viel follafert. Emil rfter Eb).

Campe. Trapp. Stuve. Referdib. 


\section{4}

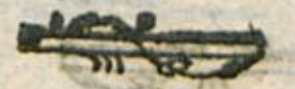

Extragnng eben ber Dinge, Sie fie zerfitsett; went man fie Denfelben, nadjoem fie fijon gans quछggebildet morben, unterwerfen will.

EF if soid)tig Daf man fich gleid, anfangs gewo̊hzne, aud úbel zu liegen; baburd lemt man, nirgenos ein folechtes Bett finden. Ues berfaupt berbielfâltigt ein hartes Leben, wenn es. eimmal in Serwohnheit ibergegangen tift, bie angenelgenen Senjationen; woidylidjes aber, bes reitet uns unzithlige misfälige vor. Die gar

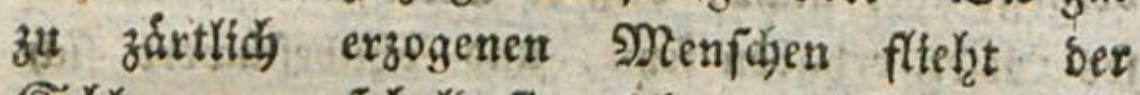
Sdylummer, fobalb fie nidjt auf $\mathfrak{P}$ flaumfeberm Itegen; wer fïh getwofhnt hat auf Btettern zu (c)lafen, ben fudjt er iberall; eb giebt fein bartes Bette für bert, Der einfchldft, wetn ex (iid) nfeberlegt.

(Fin weidjlidjes Bett, in Dem man fich uth ter Febern ober in Eiberounen begräbt, zer: fómelzt unb loff, fo za fagen, Den keib auf. *)

Die

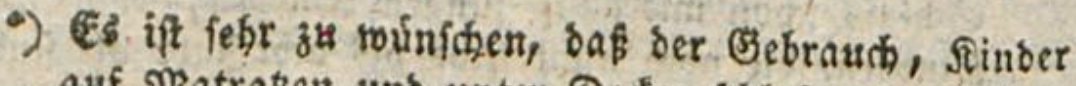
nuf Matraķen uno unter Deffen f(blafen zu la lien,

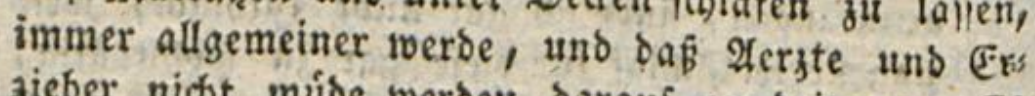
zieher nicht mide werbent barauf ju bringen. Eל ift unglaublich, wie viel bie Sisperfiaft Det Sinber surch bidfe und erbikzenbe federbetten verliert, uno

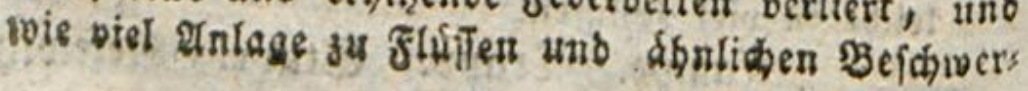




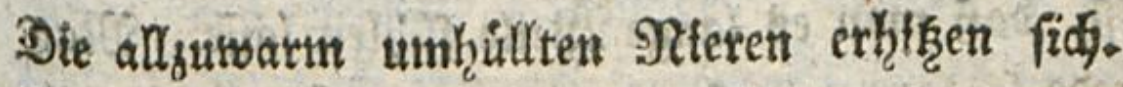
Daraus entffefte oftmats ber Stein ober anbre Hebel; uno unfehlbar eine zurtliche Letbesbea (üjaffenheit, sie jetem Nrahrung giebt. Das unt befte Bette ift sas, was ben beften Sthlaf ber. min fihafft. Ein foldhes madjen wix uns, (Emil bie. bes

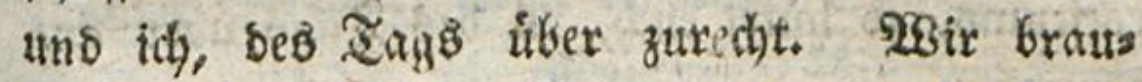
den Eetner perfifden Sclaben, uns unferez zts anberetten; inbem wir bie Erbe umgraben, idits teln wix uns unfere Mtatrasęt um. *)

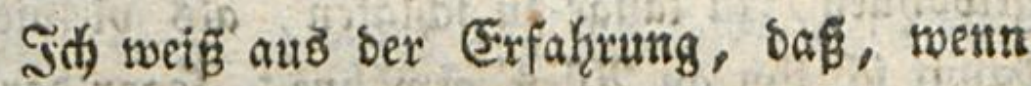
ein Sino gefuns ift, man es faft, wie es einem beliebt, zum Sidlafen bringen, ober wadi ex balten tann. Sit eB zu Bette gelegt worben, uno fâlt fein Seplapper ber Rinbermuhme zur Saft, fo fagt fie zu ithm: fajlaf! Das ift faft nithts anbers, als wenn fie zu fibm, wenn es fid) Franil befindet fagte: Befinbe sid) wohl! Das wabre Mitttel, es in Sojlaf zat bringen,

$$
\text { IP } 2
$$

if

ben baraub entiteht - ein anberes forrectiches phus

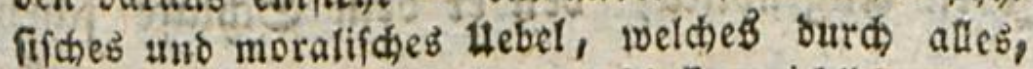
wab den férper ber Sinder erichlafft, weidslidh madis unb erfişt, fo leidht beforbert werben fant, gar nicht cinmal zu erivábuen.

Stuve. Siepervis.

7) Sobie oft werben biefe $23 a$ hrbeiten unjern Minttern nod vergeblic geprebiget werben? Eampe. 


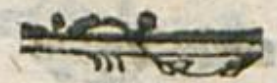

ift, baß̈ man es lange Weile fifhlen laffe. Nian rede fo lange, baf es gezmungen fey zu jobroie gen; anb es wiro balo einfdhlafen: Mresigtert find immer boch zu etwas nurs, eben fo gut, man prebige thm vor, albె, man wiege es. Bebient thre euch aber bes 26etros siefes glar: corfcumb, fo hittet euch, es Des ₹agb uber ans zumerben.

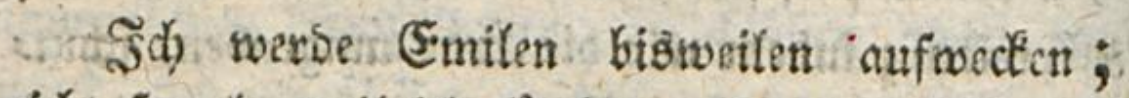
nidjt forol, weil id, furdote, er migte fidy ans gerwóhnen, zu lange zu fohlăen, als bielurchr,

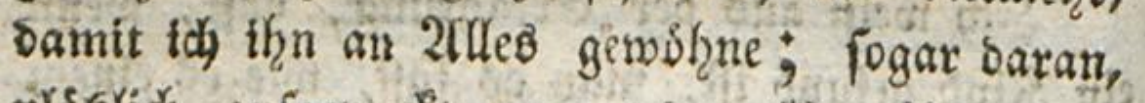
ploglich aufgendect zu werben. *) Lebrigens

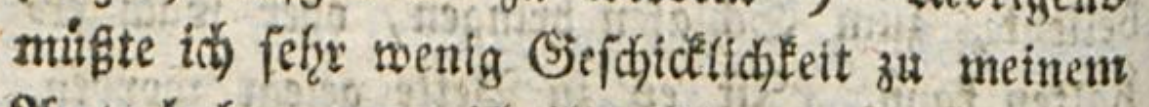

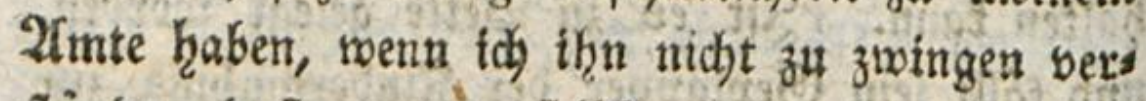

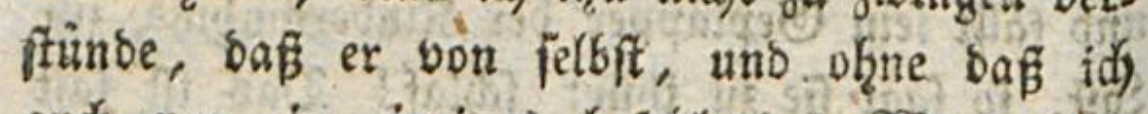
such) nut ein einziges befehlentes. 28 ort fage, aufwadie, uno nać meinem $\$$

Sd)laft ex nidgt genug, fo fpiegle ich) ifrm auf ben anbern $\mathfrak{I a g}_{\mathrm{g}}$ einen Norgen boll wers srieglicher Langenoile oor, uno ex felbif wiro jeben 2ugenbltad, ben er bem Sdjlafe fduenten

tann,

-) Şei Júuglingen if biefe Hebung allerbings nothig und miklich; bei iungen Sindern bingegen halte ith fie, wie gefagt, fúr fodidolich.

Gampr. Trapp. Siefenits. 
?ant

oeis

tert

Iut,

еตె.

art:

anต

in:

ans

bre,

in,

nB

ent

ers

id.

ie,

Ih:

im

ers

to

in

$\mathfrak{n}$,

ig

ing

Eum, aไs Setwinn bettadjetr. Sdjiałt er zu biel, fo zeige fidy then bei feiners errwachen einen

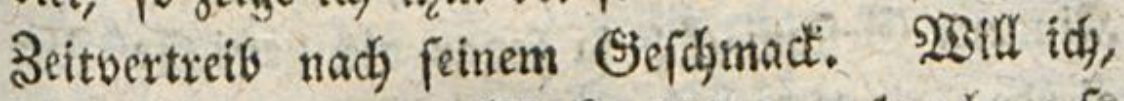
buf er auf einen Gloctenfichlag aufwadye, fo fage idy zu fizm: ntorgen um fed) Whe gehts

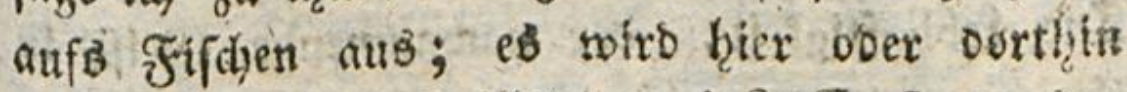
fpafirit werben; willft on intt? Er fagt: ja; er bittet mids, id) moggte thrs auffiveden; id) Darfpredse es; *) ober serfpredse es and nidyt, nie's tosmmt. S3adjt ex gar zul fpát auf: fort

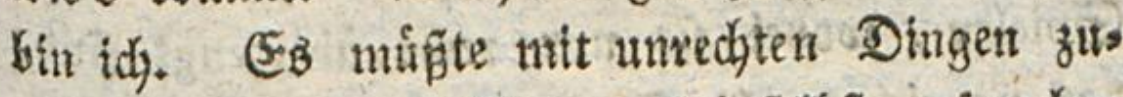

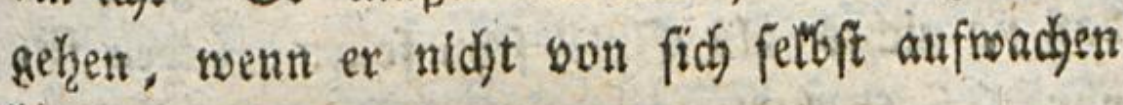
leinte.

Tráfe es fiád inbeffer eirmat, wab boch felten ift, baf irgend cin tráges Sind geneigt

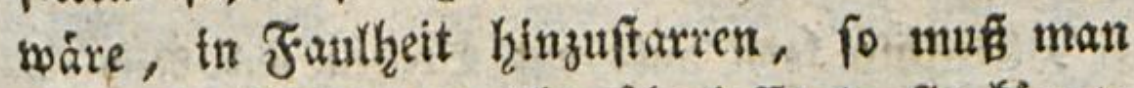

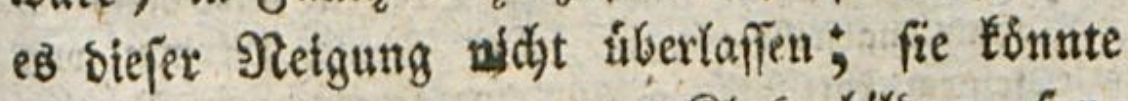
es zuleęt gaulz und gar zum ßloģe bitsen, forts

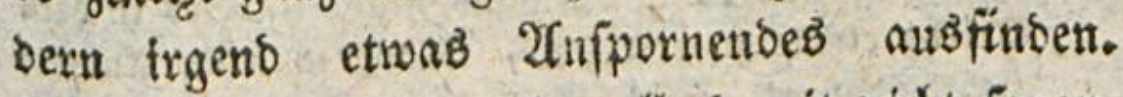
刃tan beareift (eid)t, id wolle banit nidft fagen, baf́ man es mit Serwalt in bewegung fergen, fondern es nur surch trgend eine Suft reizen

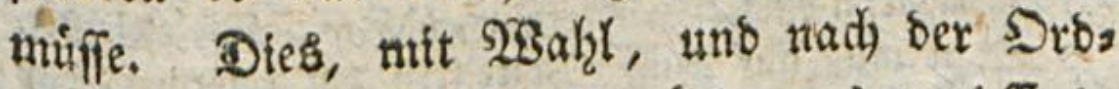
nuth ber গTatnx gethan, wúrbe uns zwet Endo zweete auf einnal etreiden laffert.

$$
\text { IP } 3
$$

*) In weldem fall bas şerfpreden aud gehaltent verben mus.

(E)blerzี. 


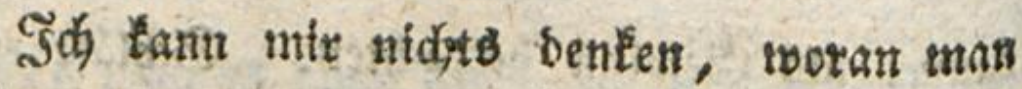
nicht, mit nur etmas Sefdoicflidjêteit, Denn Sinbern (Sefdimadt; ja fogar oie heftigfte Bes gleroe, einfiofen fónnte, ohne frgeno Eitelfeit,

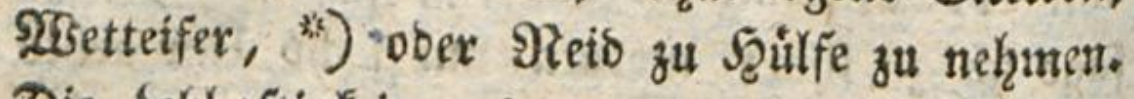
Die Kebhaftigzeit, ber nadbahmenoe Seift it then, reicht bazu bin; vorneḩmlid, aber if̧re

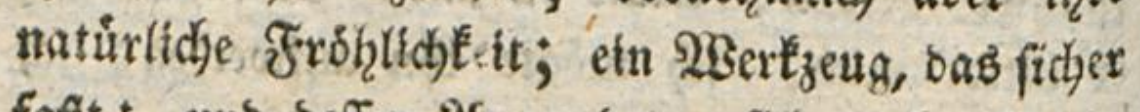
fafft; uno beffen 2 nnwenoung fid nod) nie ein

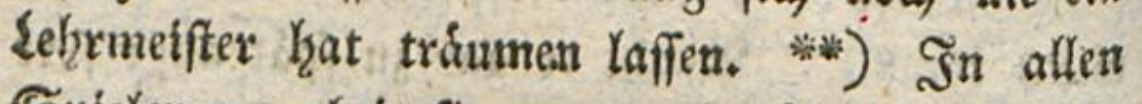
Spielen, wobei fie nur redi)t úberzengt find, saff fie nichts als Spiel fenn follen, Yetben fie, ofzue fith zu betlagen, uno fo gar mit Eachen, was fie fonft nie leiben witroen, olgne İhrátiens

ftros

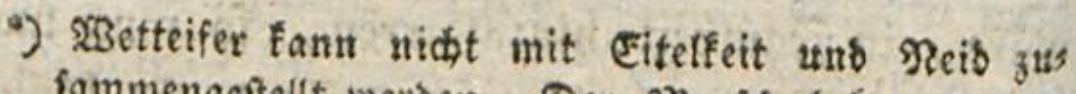
fammengeffellt werbest. Der Neerich befommt von feinem Fortifireiten mur eine goee burd 3 ergleis chungen, unt es if burdsaus nithts thredies in dem Sriebe etwas zu errerchen, wovoit mant an 21noent fieft, bá es crreichbar iff, ober etwas weiter zut fonmen, als ein 3 norer oser als man felbrt, bis

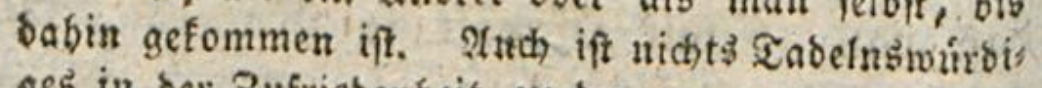
ses in ber 3ufriebertbeit, zu ber mun gelangt, wens

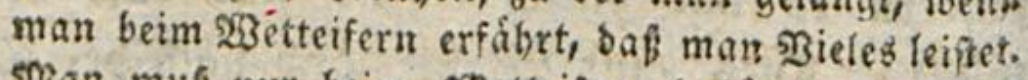
shan muß urt beim. 23 etteifern bafúr forgets, saf fich feine neidtiche Neigung bazut geielle.

Eblers. Niefenib.

*) Td habe felbft nidt twenige Rebrer gefaunt, weldhe

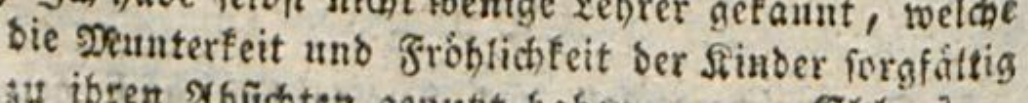

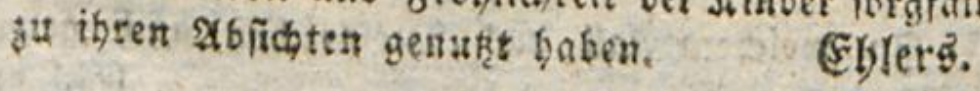




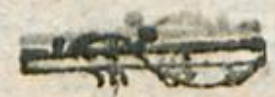

- Iuक bicier to kanbgreificion 2 afribeit glaubt berr ftrome zut vergiefsen. Earges Faftet, Stebe, S2erbrennen, 2fbriattungen jeber 2lit find bie Bettvertreibe ber jungen S2Bilven; cit SBetvels,

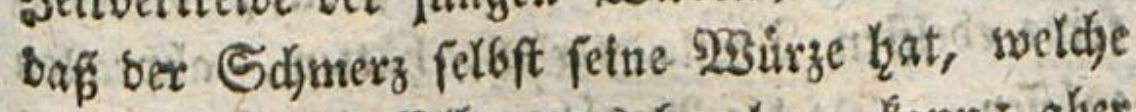
bie sitterteit beffelfentins Benehinen tann; abet

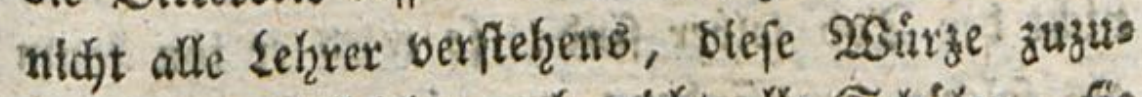
bereiten, bielleidit aud sitcht alle Sdjullex, fie obne faure Eefiajter gio gentefien. Da hätte (d) mid, oenu wieber, boent tdj midj nidjt oors fehe, tn bie, 2fusinalguten berirrt.

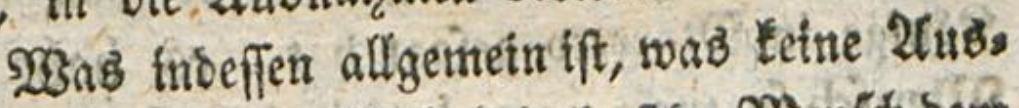

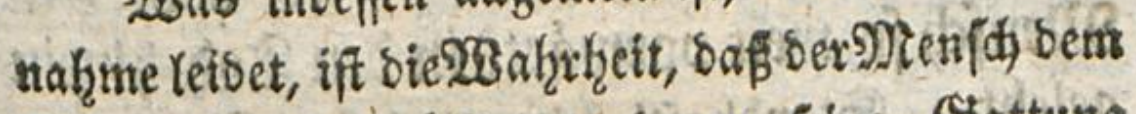
Schurerze, ben Setbent, benen feine Sattung

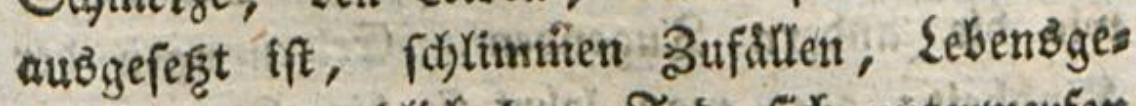
falgreti, und enolidi) bent Tobe fid, untertwerfen ternen muf. Se meţr man ihn mit allen biefen 90 orftellumgen befannt madjen wirb, befto mehre wirs man tha oon ber than beunrubigenden Empfinslichteit heilen, bie nods zu ben Eeiben bie Ungeoulo es zu ertragen, hingufugt. Te melix man than fürs Seiben zahn mart, bas tha treffen fant, befto mebre ftumpft man, wie ) Tontaigne wưroe gefagt f̧aben, für thgn bié Spithigfeit ber Frembleit $a b ; *)$ befto utw

$$
\text { भु } 1
$$

bers

Formen toiberfireden múffen. Er fagt; \#th eine obrigs 


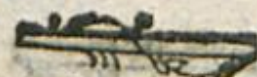

berwunbbarer utto abgehárteter madjt man audi feine Seele; Deftomefyr wirs endlidy fein Leib ber \$anzer jenn, an ben alle Mfeile, bie fonft feine ebelffen Theile berkert b̧atten, abprallen muiffen. Da bie 2tnnáherungen bes Iobes nod nidjt ber Zoo felber fint : fo wiro ex thn taum alö foldten empfinden; ex wirb, fo zu fagen, stidit ferben, fondern entweder lebens ober toot rewn; Hein britteb! \$3on ifm fiatte berfelbe Montaigne fagen Honnen, wie ex bon einem Rontge in Marocco geiagt brat, $\mathfrak{c} B$ babe fein Menid fo weit vorwairts in ben Sod bineitt gelebt. Stanohaftigleit uno fefter Sinn, fino, sole ofe andern Zugenden, Erlernungen ber Rinbkgeit: aber man lefert fie bie Rinber nidjt

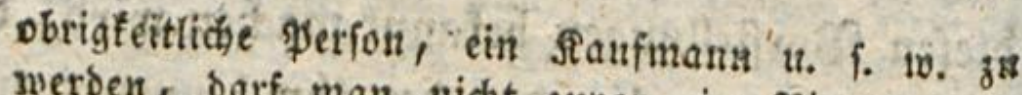
merben, barf man nicht zubor ein Finger, ein Epartaner, ein sgilber geivefen fenn." Dab freitich nicht; aber faut ein \$ieních in irgeno einem Stanbe fu ieber Seit thátig und jufrieben leben, ber nicht abgebártet ift? foerr formen fúgt hinzu: "Die, welde fich ben $23 a f f e n$ twibmen, fonnen im

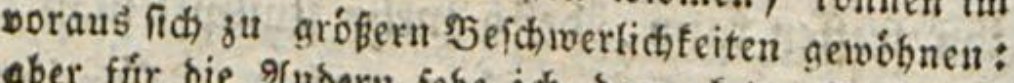

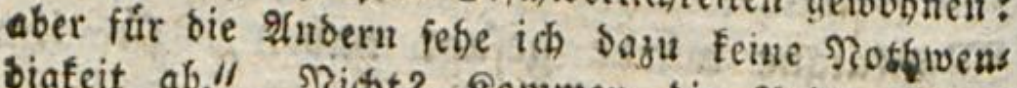
bigfeit ab." Nicht? Rommen bie 2nbern etra

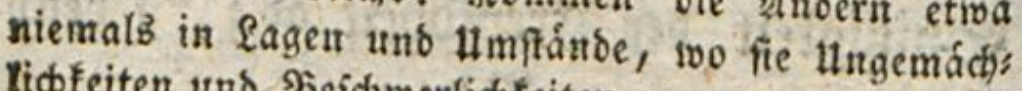
lidweiten und Şeidwerlichfeciten zu ertragen haben? Ind geję̧t bies twáre nie ibr gall, fann man volls lommen gefund fenn, ofne, im gevififem Orabe renigftens, abgebártet zu fern? Eampe. 


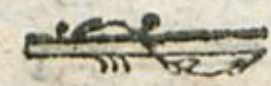

(it)

reib

$m i t$

Uletr

Saburdi, baf man thanen ifgre Mamen betbrimgt,

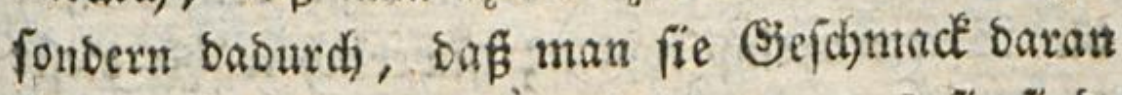
finden lafit, ofine fie zu belelgren, wab fie find. अber! - - weil bom Sterben bie Rebe fällt, wie wollen wir es bet nnjerm 35 glingen in $2 \mathbb{6}=$ umt

en,

obt

loe

$\mathrm{em}$

int

itt

(o)

ficht ber 3 latterngefahr balten? 230 llen mir fie ifh in bem zarten 201ter cimimpfen, ober sarten, bis or fie bon 9iatur betommt? Der exfte $\mathfrak{Z S}_{\mathrm{Sg}}$, ber gewshnlid)er eingerd)lagen zu werben pllegt, fidjert bas 2(lter, in wetchem bas Leben, ben grofiten 23 erth hat, auf (G) fahr besjentgen, moxin es ronigeren hat; falls man nur einmal eine geḩorig bebgandelte Etus impfung nods Sefabzr nennen tainn.

Das zneite aber, entipridat meל̧e umírm allgemeinen Grunofaze: bet Zllem, was bie Natur thut, fie allein hanoelt zu laffen, ${ }^{*}$ ) uń in nidgts bon ben fie gu ftoren; wo fie fich

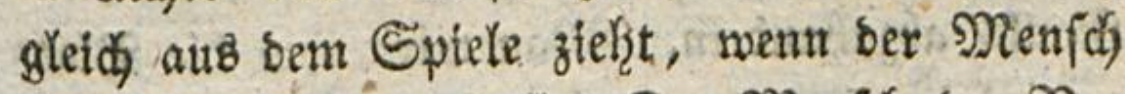
fich barein tnengen will. Der Menich ber ఇa:

$$
\text { भP } 5 \text { thits os tur }
$$

-) Nber roie? wenn bie Natur mit ben Pocen úbers baupt nidts zu thun hátte? SBenn bieie Jitanfbeit eime von benen toáre, die bas mienichengefchlecht fich erft burds eine von ben Gefekenen ber Siatul abs weichente febensatt jugezngen hat? SBollten wir aud in biefem Falle ihr tiberlaffen, was nidht von ihe herribrte? Hnd biefer fall ift boch zum wenigs ften refre wahricheintich). (Sampe. Stuve. 
602

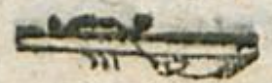

tur if ftets borbereitet. Man taffe ben Meifter bie slattern cinpfropfen; fidjerltd) wählt biejer ben beffern 2ugenbrict alz wit.

Daraus foll indef nidjt bex Sthhtü gezogen sverben, als ext́láte id) mich gegen bie Eins tumpfung: Dem bie Srunbrif̧e, zufolge benet idf meinen asgling uneingeimpft laffen wolls te, wirben auf ble eurigen nidst anmenbbat

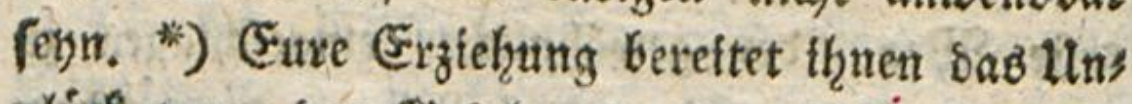
glicel sor, ber Sefaliz, ber ber Blattern, fos balo fie fie ethalten, zu interlfegen; iberlafit

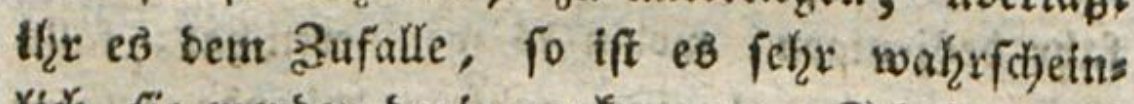
Yich, fie werben barin umfommen. इd bemerle, man wiberfegt fidj in berfojiebenen Sinbern ber Snoculation um fo meḩr, je notbwensiger fie barin mitro, uno ber Çrumb babon läpt fid

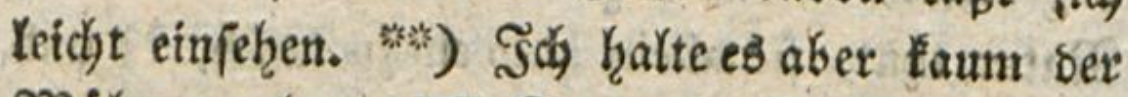
Maike werth, Diefe Frage in 2fbfidft meines Emilo abzuhandeln. Nan wirb ifgm bie Blats

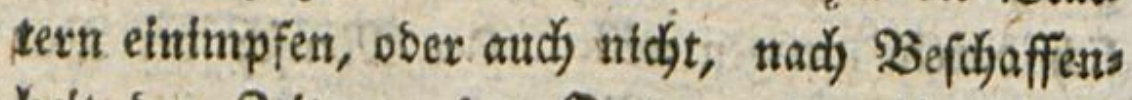
heit ber Zaiten, Ser Derter, ber Umftínbe.

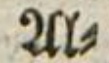

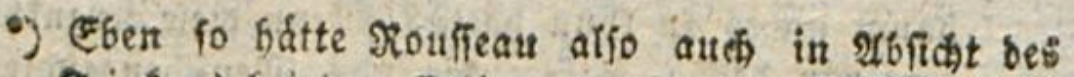
Erintens bei ber Erghiß̨ung raifonntiren follen.

Stmmetf. D. Heberf.

") IIm richt viełe Sinber ju ernáfren ju haben -

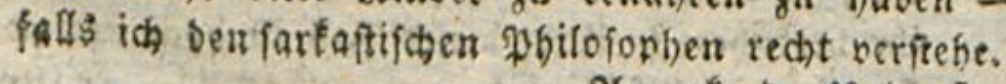

IImert. D. Hebel. 


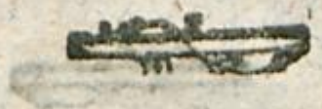

Zllles gilt beinalge fur ifn gleidy. Soringt mas then bie Slattern bet: fo toirs man bes 230 rs

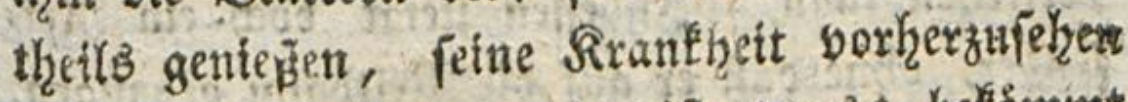
unb vorkerzuertennen; sas ift etwas; betomm ex fie aber bon giotur: fo merben wir thn bor bets 2rizte bewahrt baken; bas iff noch mebr. *)

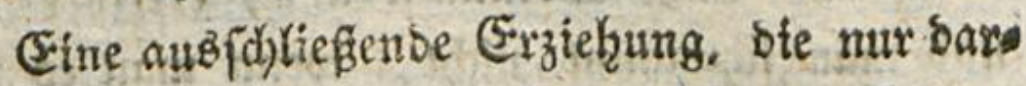
auf abzielt, biejenigen, soldge fie empfongen baben, sou bem gobel auszuzeitinen, zieht inmer ben Eoftbaren Unterridyt bem gemeiner und eben bestwegen nuiflidjerem vor. So z. (5. lemen bie mit Sorgfalt exzogenen jungen Leute insgefant reiten, weil bas thener iff; aber

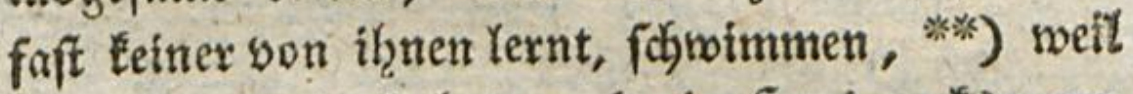

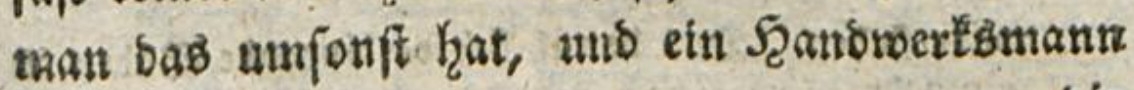
bie

2) Xuch fehr hart erzogne geiunbe Nenisen, ferben leicht an ben naturfichen Slattern. Treldbe 2 ser: muiftungen baben pieie nicht oft unter sisilben anges ridtet! (Ebletz. Trapp. Eampe. Rejewiśs.

*x) (Es ware freilid, biefer Itrfachen wegen gut, wente bas Sdyimmenternen befonders in Eandern, bie init Neeren ungeben find, bet ber (Erzichung etwas Qant 2fllgemeines wäre. Man entgeht baburch oft bene Zobe. ES giebt viele fälle, toorin man burdb Gdwimmen widhtige affichten erreidhen fann. Die תráfte bes Niorpers crbaiten baburdh eine vortrefiche Hebung. Der Rorper wirb badurd geivobnt bete Einoride ber Suft und bes 2 affers unntittelbar jie 


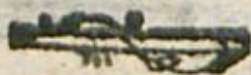

bie Renft gut fojwimmen to gut als trgento neet

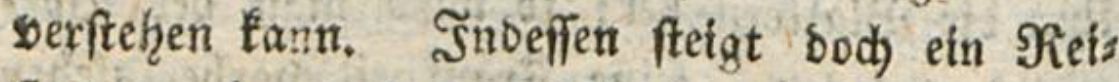
fenter, ohne baf́ ex auf bie Reitbabn gegangen, zu Mferbe, exhallt fid barauf, und weis auf Sen Nothfall genug babon. S̈m Waffer aber, svenn man nidjt fdowimmen fann, extrinft man; unb man fojwimmt nidft, wenn man eb nicht gelernit hat. Enblidy tie man nicht bei ses benzgefafir verbunben, zu reiten, sabingegen Siemanb fidjer fenn fann, ex werbe eine Sefahr soermeiben, ber man fo oft ausgereşt ift. Emilen swits es gletdjoiet fern, of im 928 affer ober at

wiberftebert. Das bamit ñd verbinbenbé Shaten if ein febr jutrágliches Reinigungsmittel. V̧eim forgs fáltigen Nachdenfen liber dieje Gathe loútbe man leicht noch mehrere Sortbeile ausfunbig madien. Subefien muts man bie Gugend beim Gdwwimmen burdbaus nidht leiditfinnig ju şerfe geben laffen. Sie múfte burdhaus burch einen sDieifter ber Sache barik unterriditet uno geibt werben. Sie fállt fonft leicht auf eine unregcháfige જ̧eivegung ber Jánbe

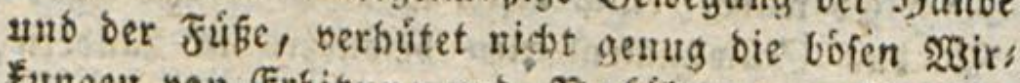
fungeu von Erbikung uno Rerfártung, gebt leidit bis zut nachtheiligen Erichópfung ber firafte fort, haubelt leicht, um fich feben ju Iaffen, toufúfin, if utides genug auf ber fyut gegen tief und am Srunde gehende Gtrome, geráth leidst in Shefabr bon eirem Raubfich veridslungen ober verftúmmelt zu sverden, verbált fich leicht richt gebórig bei erfols gender Strompfen u. f. to. Eglers. Sieferwiśs. 


\section{5}

Broctenem? STsurum tann ex bods nidjt in allen: Elementen leben! Siege fid) lernen, in bex Suft 3ut fliegen, thy wurbe einen 2loler ans thu madjen; einen Salamander, wenn idj ifgn zum Feuex abbárten fónte.

Dian furchtet, ein Rind migte ertrinlen, soenn man es fonwimmen lehrte; abex es ertrinfe. inben eह̉ bas Sdjwimtnen fernt, Doer meil es bas nid)t gelernt hat, betbes wiro inmer enre

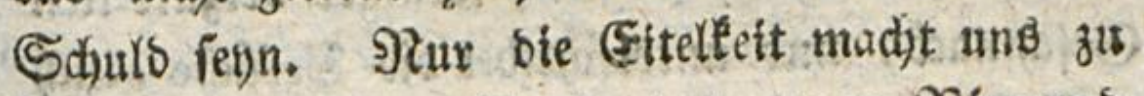
SGagehalfen; man ift es nidht, wenn Nitemano.

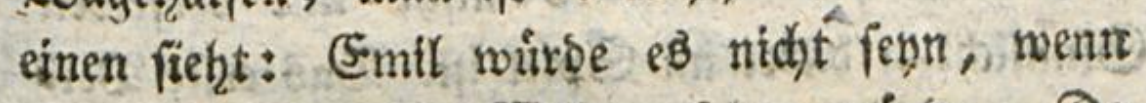
er bon ber ganzen $23 e l t$ gefetren wirbe. Da

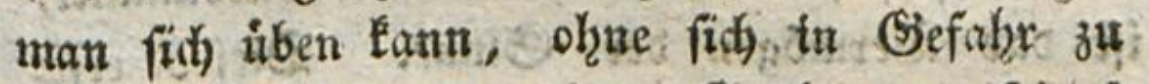
féken: fo follte er in einem Siraben bon feines. \$3aters Spart iber ben Sellefpont ") fitmimment lernen: man mus fich aber an Sefalbr feltaft gemoshnen; bamit man rerne; nidjt in $\mathfrak{B e r s}$

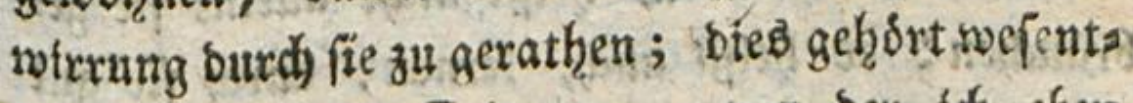
(id) mit zu ber Ertermung, pon ber th ebetr. rebete. Da idh iffrigend aufmertífam fésn werbe, Die (Sefab̨r nach feinen Rraften abzumefien, und fie ftets mit ihm zu theifen gebente, fo tann

- Intpiefung auf bie Gefdidte ber Şero unb Sean Ders.

Inmert. จ. Ueber\%. 


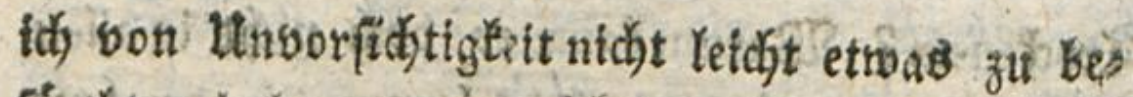
fiwchten baben, wenn idy bie Sorge fúr feite Erfhaltung nads berjenigen einridyte, bie idis ber meinigen foutloig bin.

(Etri Rino ift nict) fo grof als ein Matti,

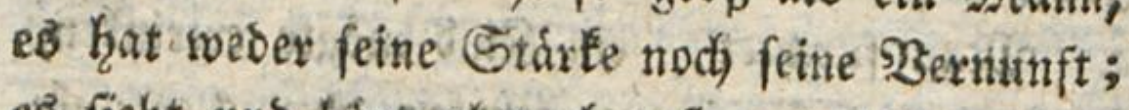
eb fieht unb fobrt aber eben fo gut als er, ober Soch wentgftend binabe fo gut; e\& ḩat einen eben fo zărtlichen, obglich wentiger berzårtelten (B)efimad', uno interidjefoet bie Gexidje gleich vollfommen; sterwot eB nidjt mit berfelben: Sinattutect babei in Splel ift. Das exfe $\mathfrak{B}_{\text {ers }}$ insgen, fo fich it ins bitset uns berbolleominnet,

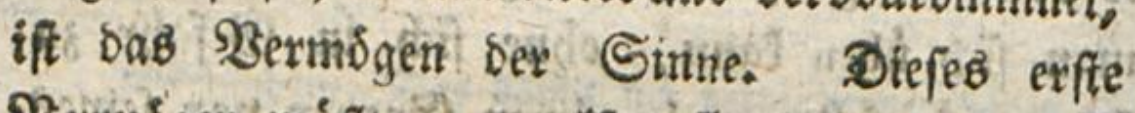
Sermógen múpte mait alfo pflegen; und gleidjs wot bergift ober vernachlafiget man diefés am nteiften.

Die Sinne iben, heift nidjt alletn, fie gee braucfen; es beifit audh, rernen, burd, fie gut urtheilen; es feift, fo zu fagen, lermen, zn empfinten; bent wir wiffen weder anders zu

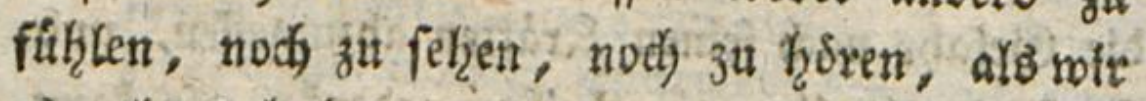
es gelernt baben.

Es giebt eine blof natủrlictje uno medjania

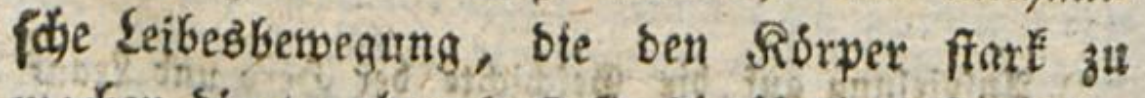

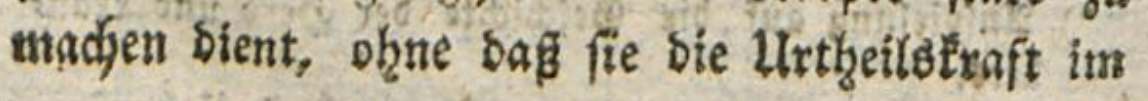




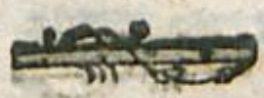

607

gexingften beforberte, Sdjwintmen, Loufen, Springen, einen Rráufel peitfden, Steine twers fen; 2fles bas ift fehr gut: aber haben wir

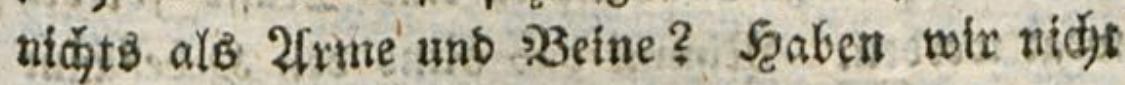
auch 2ugen, Shren; nno find Diefe Srgane

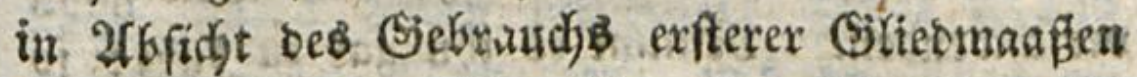
ufberflibig? Shan ube alfo nid)t allein bie Ririta te, man ube aud alle bie Sinne, die fie tens: fon; man ziehe aus einem jebem unter ilhnen ben moglichften $\Re_{3}$ ortheil, uno bemábre barauf ben (sinbrudé oes (5inen burd ben 2(nbern. *ै) Meft, záblt, wagt, bergleidht! SMendot bie Siraft

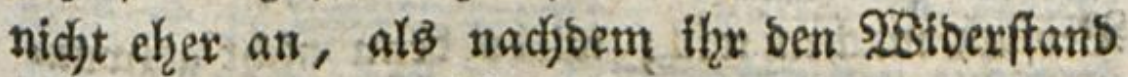
geidjąrt habt: tid́tet eb fo eit, baf bie Gchák̨ung ber 2 sirtung allemal bor bem. Giea brauche ber Mittel bergebze Lapt bas Sins: felbft ein Intereffe baran finten, nie fïh) umzus

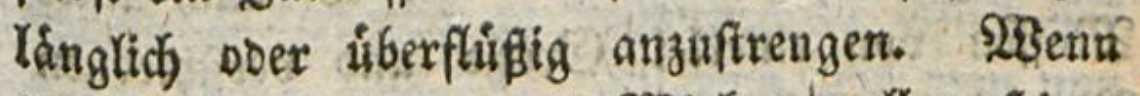
the es fo gemolgnt, sie 28 intung allex feitrex Bewegungen vorberzufeben uno feine Srthimet surch bié Exfafzrung zu berbeffern, ift es niffit

of:

-) Esenn man bas fríbe Qejenternen, unb úberbaupt ben frúben faulmábigen Ilnterridit aus Brichern wiberráth: fo phegt gemeiniglids bie Srage aufges worfen zu werben: 10ab man ben fonft mit ben sinbern nornefmen fonne? Sier ift sine von bsn auf biefe srage geborigen gintworten.

Eampe. Trapp. 
608

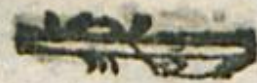

offenbar, eB reibe je mekzr eB kantolt, sent aud) befto wehrie litheil erlangen?

2x Cè foll sum Beifpiel eine Mafie fortbe: wegt werben. Mimmt bad Rino ben Selbebaunt gar zul lang: fo wirb es zu biel Bewegung verfdyenton. SPimunt es flgn gar zu furz: fo nitro es nidjt Stårfe genug haben; bie Erfaks, zung fam es lehren, bie gentu redjte Stange

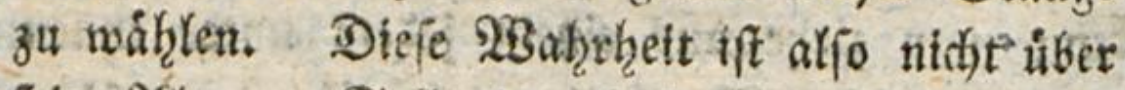
fein 2flter. Soll eine Laft getragen werben?

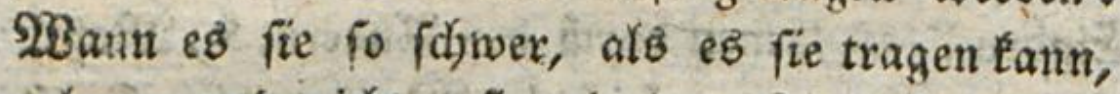
ziefrmen unb nicht erft mit bem 2lufbeben einen Serfucl machen will; wiros benn nicht gejwins gen fernt, bie Sdyweve berfetten nach bem 2tus genmaafe zu pdăken? Sobalo es aber Niaffen oon einerlet Miaterie uno verfditeonen Srofiget

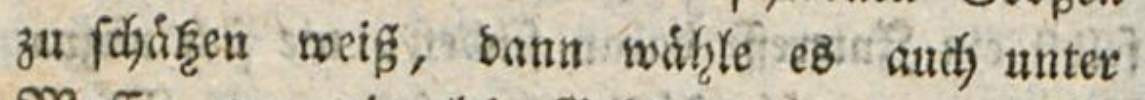

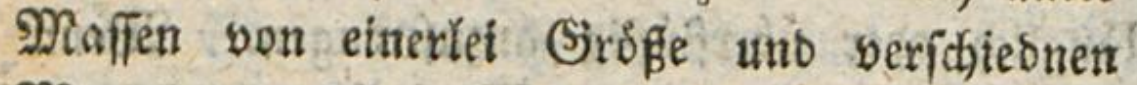
Materien: Saburd) wiro es wol genothiget werben, thx fpecififez. Sewidgt gegen einanber 3ubergleidnen. Sid habe eimmal einen jungen Minn gerefzen, ber einer fehre guten Erziehung genoffen batte, und nidjt eber, als nad ges madhter Srobe, alauben wollte, baff ein Cimer

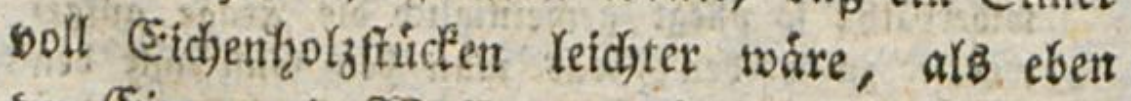
ber Eimer mit 2 Eaffer angefúllt.

Wir 
N3ir find nidit alif gleidje 2(rt liber bent Gebraud) allex unferex Sinne Seert. Sinen giebt es unter thrnen, bas Sefuhl, ber, fo lange wit wadjen, únausgeferct in Jhatigkeft ift; bie Natur hat ihn iber bie gange sobers flábe unjers Leibes verbreitet, samit er uns

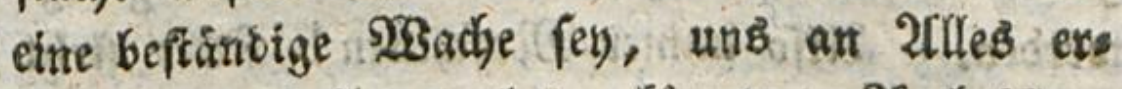

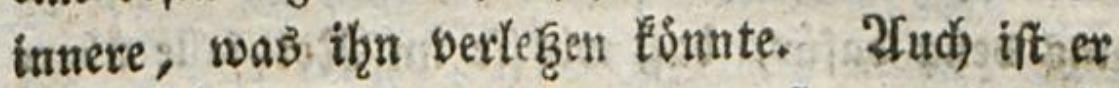
unter ifgnen serjenige, ber am erften, wir mbs gen wollen ober nidjt, bermittelft biefer beftans Digen llebuitg zat Erfahrung reift; und ber folglid) atn wenigiten von uns bejonsers ansె gebilbet zu werben bebarf. Interbeffen bemer, Een wir buch, bafie bie Blinben cin viel ficherers und viel feinerers Sefühl haben, als mir: wetl, oa bas Selidyt fie nicht leitet, fre ges groungen find, efnziy nno allein aus jenem Sinne bie lintheile zu nefgmen, d zu benen wit butrij) biefen gelauget. 2 Sarum ủbt man uns benn nicht auth, wie fie, im Dunketeln zu gehen, Sie Rorper, bie wir zu érreidjen vermógen, zu erḱennen, bie uns umgebenden (Segenftánbe zu beurtheilen; mit einem 250 orte, bet Nladjt uno ohne Sidjt, 2tlles zu thun, was fie bei Zage anb obze 2 uggen thun? So lange bie Sonne

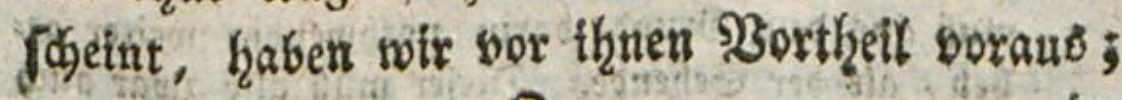
Emil Ifer \$6. Q. Q 
In Dunfelit fint fie bafư wieber unfere Seiter. 201r find ste Şalfte unferes Lebens uber blino: mit sem Ituterfatede, bafi bie wahren Slindett fid ftets zuredit zu finben wiffen, *) uns wir

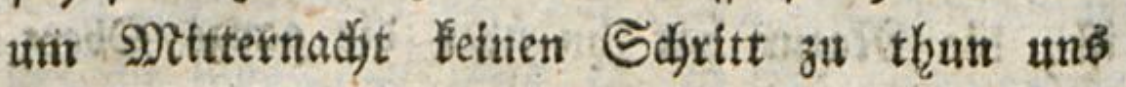
getrauten. Dafur hat min Sidht, wiro gefagt

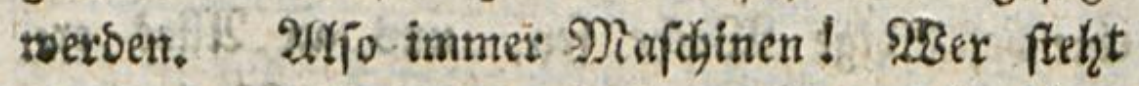
uns sent Safur, Saß wir fie im 9Rothfalle úbers all bei ser Scand haben merben? Sch, für meir Zheil, will lieber, baf Ernil 2fugen an feimen

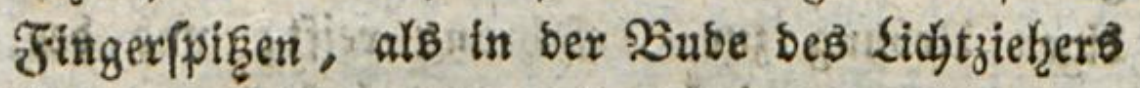
finse.

Seys iffr, mitten in sex Itadyt, in einem Gebalibe eingefdlofien? Sd)lagt in bie Sginde; iffer nerbet dus Dem IrBiberidjalfe twahrnebmen, of ber Raum grof poer ttein iff, of ifre

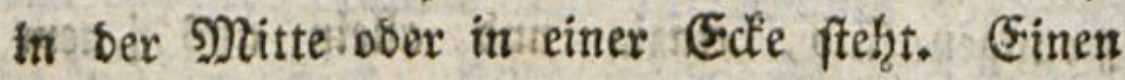
ballen Fuf ab von einer Mauer bringt euch etrt?

$$
\text { सritos whisin th ote }
$$

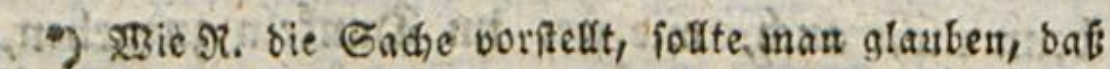
bie $230 x$ elgung mit dem herrtichen Gimu Des Ber fichts uns etwas febr lleberflúbiges ober wol gar Schadblidges gegebent hátte. Nach beu fier geaunertent

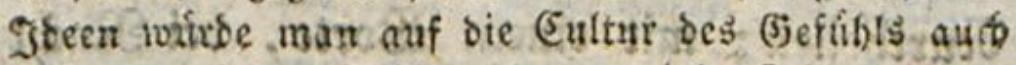
leidt 3 u vielen z!ciß und zu viele 3 eit wenbent. Dicie Euftur muß; wie ic dé snore, in achorifgem

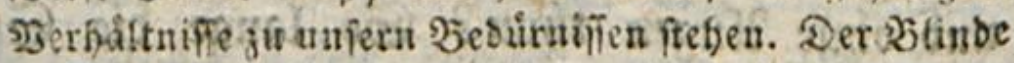
mus anj pem forunde barin notbiwentig weiter ges ben, als ber Sebende. Diefer mus alfo juar aud

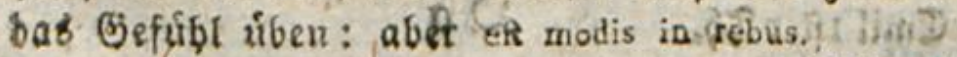

Ex!erz. 


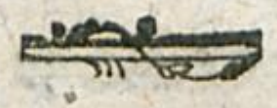

T. Sie nidjt is umftrdthenbe uns mefhr zuridges prallte Euft eine anore Empfinoung ins Eeficht. Bleibt auf ber Stelle, unb oreht end nllmáhlig vings nad) allen Seiten zu herum; menn eine I huir offen ifi, fo wiro ein Yeidgtex Suftitrom es endy anzetgen. Fahrt ihr auf einem Rahne, fo tosnut thr aus ber 2frt, wie bie suft enth ins Gefïht wehzt, extennen, nicht allein, nad meldjer Seite bin ifre eudi berwegt, fondern audid, ob ber \{auf bes Fłurfeछ etch Iangiam ober gez fonwino forttreibt. Diefe uno taujeno átzulidje Beobadjtungen Laffen fid mur STadjts anfellen; mie aufmertfan wir aud bei hellem בage brrauf fenn wollten, wirs uns bod) bas (S)efíd babet entweber unterftifizen, ober zerftrenen; fie wers Den uns entwifisen. 9Rody rabe idy nicht eins mal bas in 2 (nifhlag gebradt, wie man ourd, sie Soande ober einen Stab fich berfen émn; wie biet 2Uagentenutniffo Xaffen fid nicht ourch bas blofe Sefuthl erwerben, felbft ohne bafi man irgetto etwas betafte!

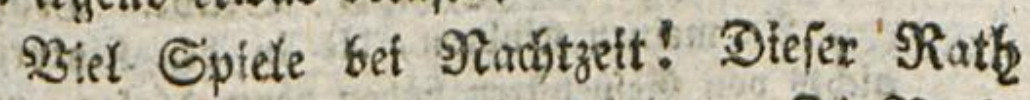

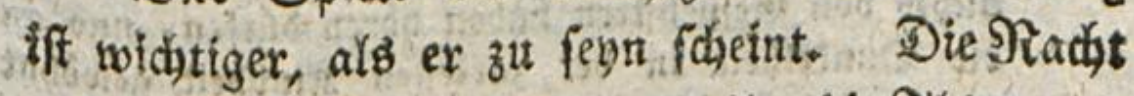

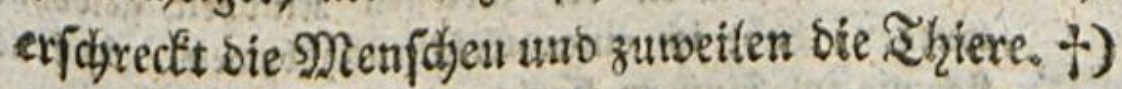

$$
292
$$

S2w:

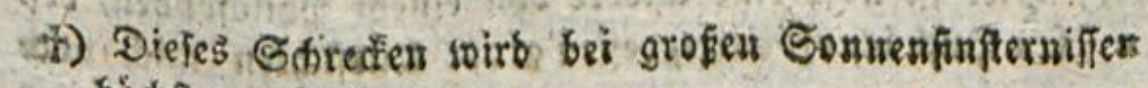
Thidift merflic. 
Dernutuft, Renntniffe, Seift, SMuth, befreten

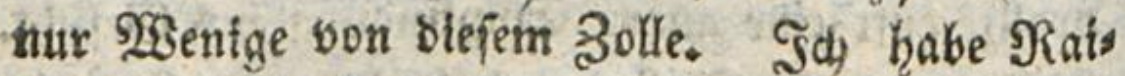
fonneuro, ftarte Escifter, Mhilofophen, Solsas ten, bie bei Zage fethr unerfachroden waren, beo Sladis bor einem raufdienten 3 latte wie 2 geis ber zittern fef̧n. Man leitet biefés Sdjredfent von. Dett Srzáblungen oer Rinbermukimen her;

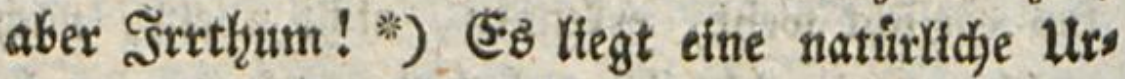
(ad)e zunt Strunbe. Und weldje?. Die nám lidae, woourd ber Zaube mistrauifach uns bet झsbel abergläubifd̆ wirb, bie Unwiffentbeit ser Dinge, bie uns ungeben, unb beffen, was um uns berum sorgeht. + ) Da id gewohnt bin,

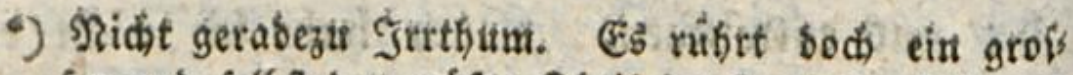
fer und fetbef der gróbte Theil ber-Furditfamfeit von folchen Ergáflutigen ber. Die bernad) angegebene maturridae Ulrfacbe trágt felbft nutr weniges zu jener Surchtjamfeit uno Scfutchternbeit bei. Sseipenfter

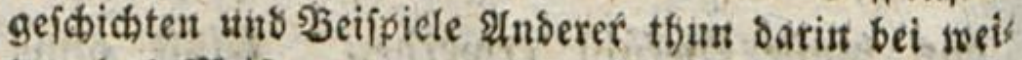
tem bas steifte.

Eblers. Eampe. Stube. Trapt. In meinen Sintern, bie in beth Sinberjabten aidits von ङefpenfern baben bóren búrfen, uno an sie Dunfelfeit in ber zarteften Jinsbeit getwoshnt

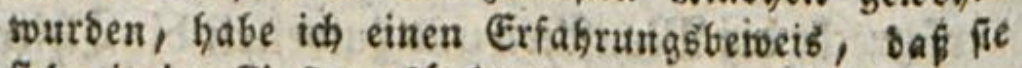
fich nie im finftern fúrchten.

গejentib.

5) Syier ift nod eine andere von einem \$hilofephen, ocís

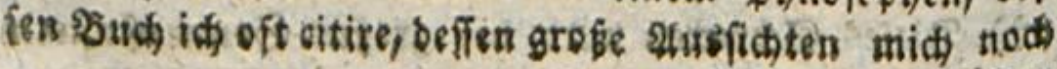




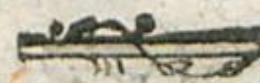

stens

iats

loas

ชeอ

Beis

ten

er;

Uts

ime

bet

ber

um

in,

sie

jrots

voll

bene

ener

fters

iveis

.

jerti

ant

brint

if iie

\%.

octs

10(

fter

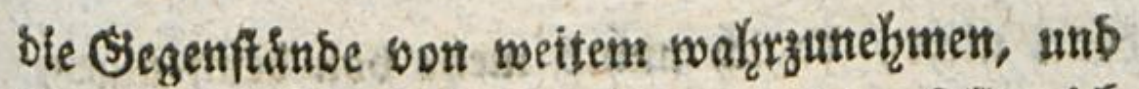
thre Einoridce soraubzufehen, wie follte id

$$
\text { 29 } 3 \text { bent }
$$

bfter unterriobten, angegeben und febr wogl auseinans ber geiefzt.

"I\$3enn ivegen befonberer umptánbe, wir feines genau ridhtigen begriff von ber Entfernung haben, unb von ben Begenftánder mur aus der Bróbe bes 2Bintels, oder vielmebr des \$ilbes, welches diefelben in unfern \&ugen malen, urtheilen fommen: io irren woir uns alsbanu nothivendigerweife úber die (5róbé bics fer Eegenftábe. Sedermann wei⿱ aus ber Erfahrung, bag, wenn man in ber Nacht reifet, man einen ganz mahen शुแf fúr einen entfernten grofen গুaum, ober einen grofen entfernten গুaum fúr einen naben Э̧uís Gált. EGent fo wiro man, weun man bie Begentánde nidit ifrer Beftalt nach erfennt, uno folglich burch bies fes Nittel feinen গ̧egriff von ber Eutfernung befoms men Eanu, fid aud notblendiger şeife táufichen, Eine Fliege, Die fehr fidnell einige Daumenbreit vor unierm 2 tuge vorbeifhivirt, wirb uns in foldsem falle als ein febi entfernter $230 g e l$ vorfommen. Ein Pferb, bas mitten auf bem zelbe obne গुelvegung uno in eis ner z. E. ber Stellung eincs Shafes ábulichen Stellung ftánbe, wirb nidit grófer als cin grofés Edaf zu fenn fócinen, fo lange wir nicht erfentuen, bap es ein Pfero ift: Gaben wir eb aber erfannt, fo fommt es $n$ ms aus senblidfich to grofi, a!s cin Yfero vor, ") unt wir bes richtigen fogleich unfer erftes Hrtheil.

-) Das bod eben nidht. Denn bie funnlicise Eríheis

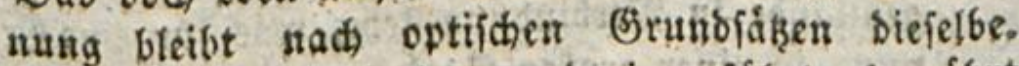
WBen man eine 2enberung barin erfáfgrt, to rúfrt

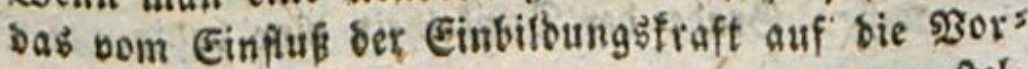

ptels 


\section{I 4}

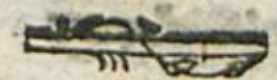

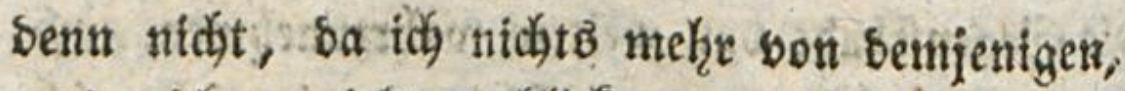
soas mid, ungiebt, erblicte, mix taujeno Dinge, talts

Jebesmal, baß man fich in ser slacht an unbes faunten Dertern befindet, too man bon ber Entfernung uidat

ftellungşfraft her. Fुei einem hoben obrabe von lebs hafter Ibatigfeit oer mechanifhen Phantafie fann bieje freilich auch auf bie áubern Drgane fo bin wirfen, dak fie eben cine folche Niobification bes Suptandes annehmen, als ite haben, wenn fie burdy

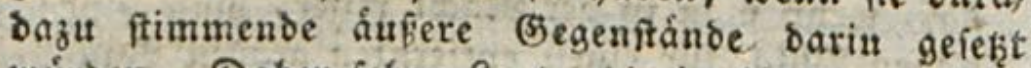
wuirben. Daber leben \&eute, bie in bikigem fieber liegen, ober die eine unbánbig wirfiame Einbildungs: fraft haben, nach iffem beften 53 ifien Dinge, bic gar nicht ba find, ober bie ganz anders futb, als fie fie fefent. SBie bei einem natuitliden Empfintungs: zuftande bie Natur von aufien nad innen wirt: fo wirft bei ienem wibernatúrfichen und ungefunben Empfindungs juftande die s?atur bon innen nach aufs fea. Ift diefer Buftand nicht mit einem orbentlichen Sieber verbunden, fondern blob cine sBirtung von einer feuria wirffamen Phantafie: io verbinbet fich

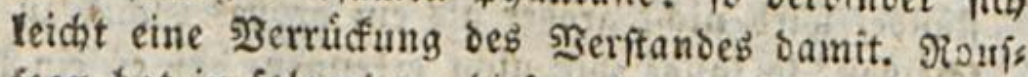
feau hat in folaenbem bieien lebten Suptand nidht ridhtig und beftimint genua erflárt. Mit Ruceficht auf bie bló, von Dunfelheit unb Entfernung ber: rúfrenben Erfocheintangen ift es úbrigens wichtig, Dafi bie Yugend uberbaupt wifie, nach weld)en optichen Sefeţen bie Erfacinung mit ber Realitát ber Bes genftánbe in \$erbindung ftehe, was fúr eiue Ericheis nung in einer grofen Entfermung und bei einem ges soiffen Brade der Dunfeibeit cine beftimute Sache 


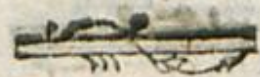

$6 \times 5$

taujetto Betwegungen erträunten, bie mit fó)as

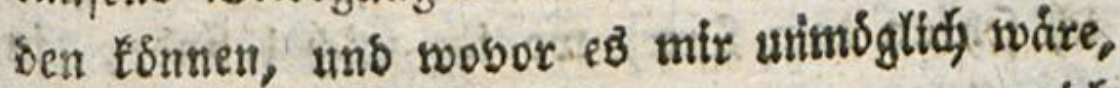

$$
\text { Q9 } 4 \text { mís }
$$

libes

niaht urtheilent und bie Beftalt ber Sachen wegen bet Dunfelbeit nidbt erfenten Eann, witb man in Bofabe fenn,

veranlafien, und, was fúr eine beftimmte Sache bei einer getviffen Erfheinung zum Br runde liegen múffe. Durch einen guten lluterricht ber Sint wiro eine

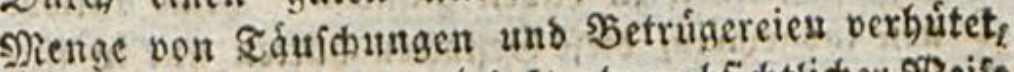

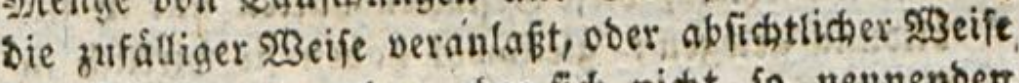
voul yich fo nennenben ober fich nicht fo nementer Taichenfpielern veranftaltet werden. Da Feide, Sornebme und fúrften vorzuglich von ber leţtern 2rt von Tafonenfielern in unfern Tagen fo báufig betrogen werben, und da biefe befonders ifre Shes trugsipiele in bie Naurerlogen Gineinzubringen unb biefe mit baburch unbefauten Dbern zu untermerfen fuchen: \{o wáre es vorguglich ju múnfhen, bấ bie Sugend ber hobern uno hóchten Stánbe burch richs tige practioche, metaphyfiiche, phyirishe, optifide unb d) nmishe Эegriffe gegen bie manutchfaltigen Eaglios ftros uno gegen bie felbft unter ber beibulfe von nicht wenig B̈clebrfamf́eit in mannidafaltige táus fitende (5)eftalten und formen fich hinein merfende Stalfen geforig verwabrt und onp̧ io bie \$olfer gegen bie von ben betrogenen Mádhtigen ber Erbe ausgehenden 2Birfungen gelichert und gefthúlst wurs ben. Ës fann fout nod babin fommen, bas unire

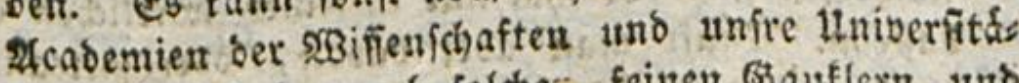
ten unb Sd)ufen noth foldsen feinen (5) auflern unb

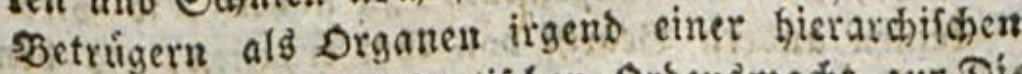
2Uleingewalt ober bejpotifhen Droenzmacht, zur Dis rection und zur Oberanfficht in bie Şánbe fallen.

Eglers. 


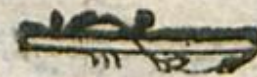

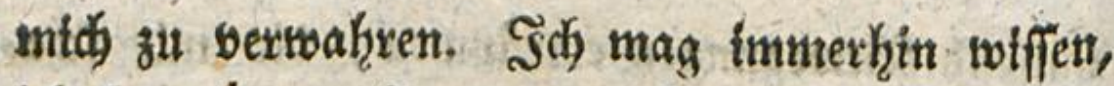

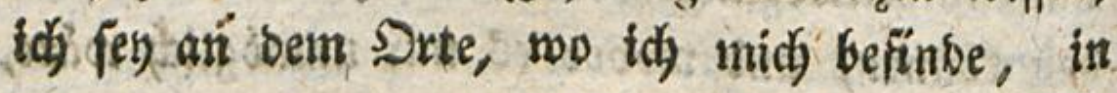

Pegn, bei sen llitheilen, bie man bon ben fich barbies

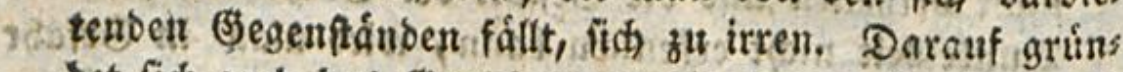
bet fich auch bas Graufen unb bie imnere furcht, wels

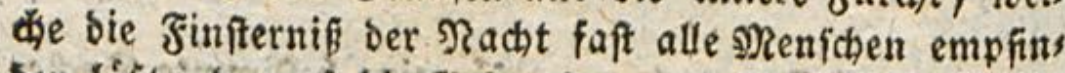

is ben lábt; סarauf bie Ssefpenfter: und anderer furchtbas ren Siefengefalten Erideinungen, bie fo Nand be mit Tugen gefeben zu baben glauben. Nan antwortet ibs nei ing̈gemein, biefe Beftalten båtten nur in ifrer Fins biloung gelegen; gleidblool baben fio witflich in ibren Ylugen fent, uns fie febr wahrfoleintich basienige wirfs Yich erblicfen tonuen, was fie gefeben zu baben vorges ben. Denn fo oft man bon einem Begenfande nur

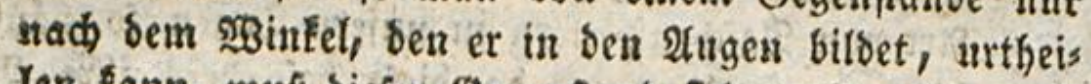
len fann, muí diefer (S̈egenftand fich nothwendig nach bem shafe vergrofiern uno erweitern, als man ibm naber ift. Sit er anfangs bem, der inn gefeben, und ber sas, hras er fiebt, nidjt erfennen uns beurtheilen lauti, auf cine Entferuung von zivanjig ober breißig Schritten, als einige fub foch vorgefommen, fo muB er ifm nun in ciner Entfermung bon blok einigen Schritten, mebrere Slafter bodh ericheinen. Dies fann aber nicht anders als ifn $2 B$ unber nebmen und eríhre: den, bis er enslich dazu fommt, ben (अegenfiand zu befúblen und inn zu crEennen; benu in bem Augen: Blide, wo er erfennen wird, was es fen, toird onsjes stige, was ifm vorher riefenmáfig vorfan, zufammens.

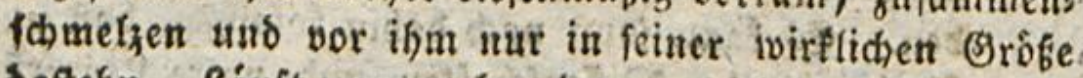
baftebn. Láuft man aber bavon, ober getraut fich nidht, fich bem Begenftande gu ydjert, fo mirb man Peinen andern \$̧eariff bon ibn erhalten, als ben griff bes Эilbes, $\delta .3$ er in ben 2 ugen malte, unb roirfs 


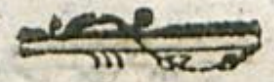

Sidjerkeit : Fo meip idy es ood niemals fo gut: als wenn ith es wirtlich jelge; id babe aljo inmer efne Ulrfache zur Furcht, bie idh bet lidja tem Iage nidjt hatte. Jreilid, meif in , oafs

rbies eit frember assper auf ben meinigen nitdit Yetdat wirten fann, ofne fid burch irgend ein (Sies

roels

pins

\section{Q.9 5}

råu[d

itbas

mit

$t$ ins

Fins

jren

oirfs

rgea

nur

heis

Iach

ibm

unb

ilear

isig

nuв

gen

inn

jres

fu

en:

Bjes

ens

of́e.

iich

an

lïi) eine riefenmápige, uno wegen iffer \&rofie uno Filbung fatrecflide Ëeftaft gefehen haben. Daß urtheil vom Daienn ber Beipenter ift bemnach in Des Neatur gegruinbet, uno bieje Erifheinungen hángen niche einzig unb allein, mie es bie Pfilofophen glauben, von bet Einbilloung ab. "12llgem. Şiff. Det S?atur atev Th. Ifter S. a. D. 204 S. nach Der Deutictien Heberi.

(⿹) habe mid) bemiht, im ฐerte meines গुuchs zu zeigen, wie fie bod immer zum :heil wenigftens von ihr abbángen; und was bie in gegentuáttiger Stelle exflárte luradie betrifft, to fieht man, baß̄ bie

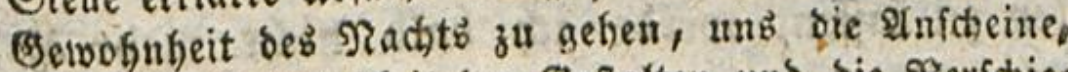

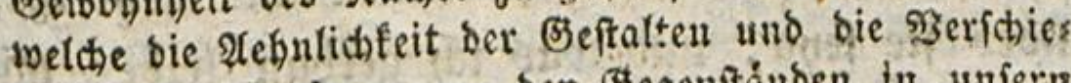
benheit der Entfernungen ben ङૈegenftảnben in unfern Sugen bei ber Dunfelbeit beilegen, unteríneiton leb: ren mup; benu wosm bie Suft ned, befl genug ifs, uns

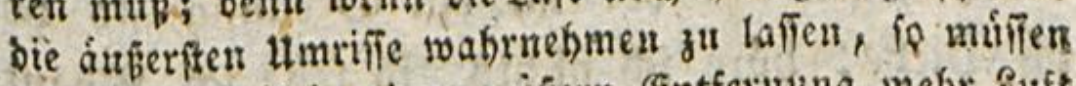
woir itets, weil in ciner grobern Entfermang mehr Quft bazwifden tiegt, bieie dlmrifie weniger beftimmt feben, wenn ber Begenftanb weiter vou uns entfernt it:; welo des benu, mit Shulfe bet Bewobnheit zureict,t, uns vor bem Grrtbum su verwabren, ben ber fierr ven S5iffon bier erflart. ŞBas fúy eine Eiftánurg man aber aud vorgiefe, fo ift bod meine sietbode pets wirfiam; unb bies bentatigt die Erfabrung voff

fommen. 2กm. Deื̉ खetf: 


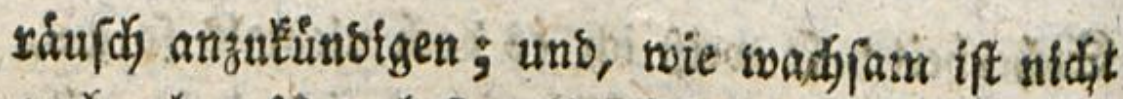
aud ohne Unterlafi mein Shr! 2 bei fem ges stngften Sakalle, won bemith bie litrache nidjt unterfótben tann, lágt bas Suttereffe meinter (5rbzaltung mich) fogleich borauş fescen, was mith am meiften, auf meiner Şut zu fegm, antreis ben tann, uno mid folglid) auch zu exfdjrectetr an fábigften ift.

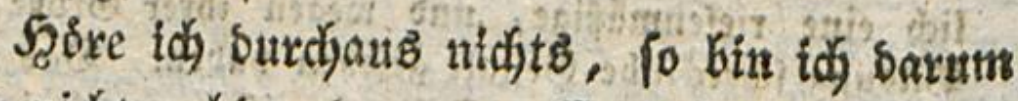
nody nidjt rubig, benn an Ense tonn idy bod) and oldte borker anfindigenoes Seråuich hbers

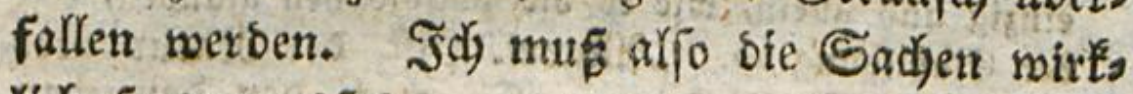
Itch) fo borausjefgen, wie ichs vorber that; fo, swie fie noch feyn miffen; uno bin folglidy gea

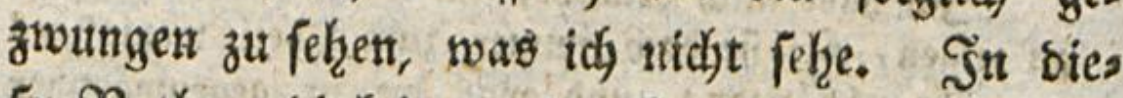
fer Nothwendigéeit, metne Sinbilbungštraft fpies Yent zu laffen, werbe idj balb nidjt mehre Şext ilber fie fenn, uno was id) gethan brabe, mich ficher zu ftellen, bient nux, midh noch meb̧r zu

- beunmuhigen. Sgorre id cin Sieraufd, fo hore id Diebe: hore id nichts, fo fehe tch. Whantos men; Sie mix burdy bie Sorge fur meine (5ts baltung eittgefloģte $\mathfrak{B}_{B}$ adgfamfeit giebt mix nux Uriachen zut Furd)t. 20lles, was mir - Muth

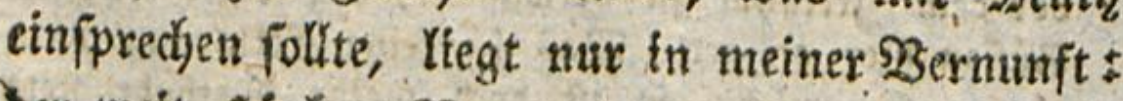
ber weit fisckere Niaturtrieb rebet ganz anders 


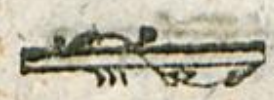

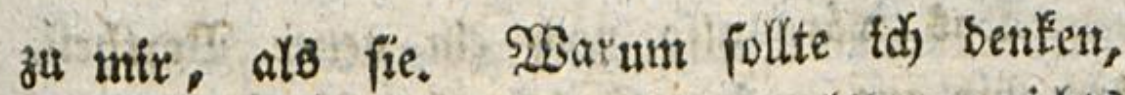

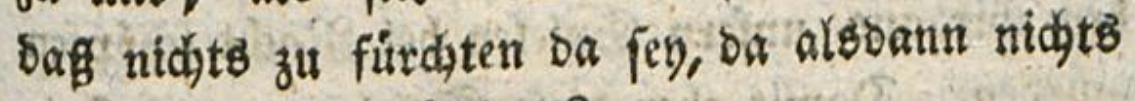
anbers midj befdjaftiget?

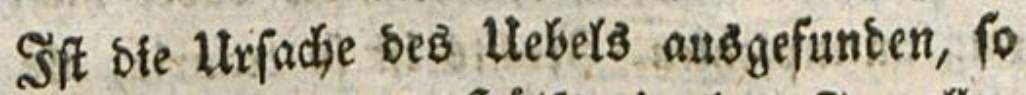
fennen wir audh bas Şilfömittel. Sin alletr

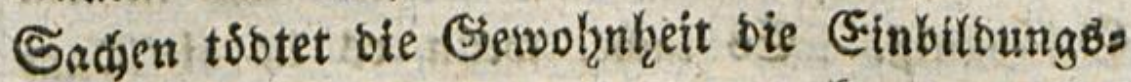
Eraft; nur neue Siegenftánbe erredten fie. Bet Denjenigen, fo man alle Zage fieht, wirtt nidjt meţr bie Einbilsungstraft, fonbern bas Ses badytnif; und barauf beruht ber Sirund far : ai affuetis non fit paffio; nur an vem Fener Der Einbilbungốtraft entzúnden fidy die Leibens

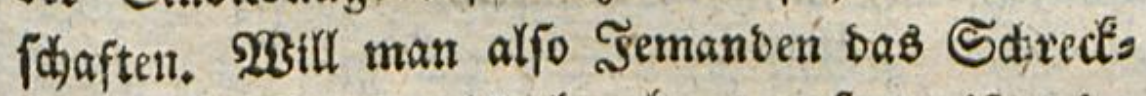
bafte ber Firrfeenif benefrmen, fo raifonnire man nidjt mit them, fonbern fúbre the oft ins Dunfle, uno feit) bann berfichert, bafi biefe Ses wohntheit weit mehre aubrid)ten wirb, als alle Srinbe ber 9 hrilufophie. *) Dem Schiefer: becter auf bem Dache fijwinbelt Der Ropf nidyt,

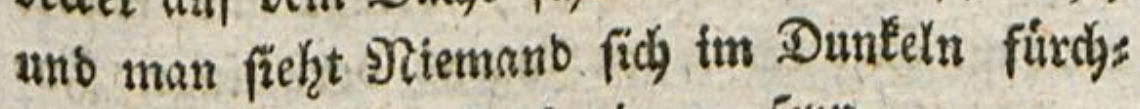
ten, ber gewohnt tft, barin zu fern.

\section{Das}

*) Nan verbinbe bas Eine mit bem 2anbern, nur lafie man 9hilofopfie nic fúr \$gilofophie gelten, joent fie ben

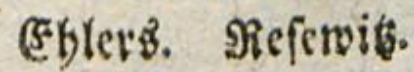




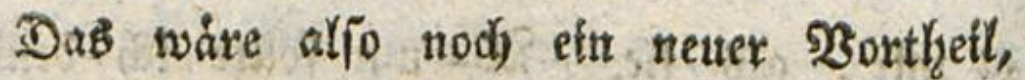
ben wir aus unfern Spielen bei Niadjt fdjopfen suirben. Damit aber biere Spiele gut von fat: ten gehen, tann idh Froblfltchlett babei nidjt ges nug anempfehlen, Nidits ift fo traurig, alo bas Duntle, Spernt alfo euer Rind nidjt in eit Sefángnif. Es tadie, wenn eB in bie Duns felheit eintritt; es ladje, menn es fie wieber

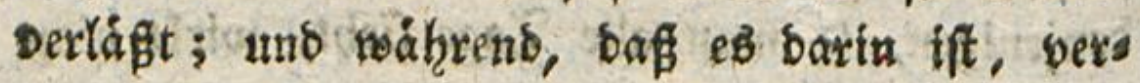
wabgre bie ßorftellung von Den Betuftigungen, sie es berláft, uno benen, bie es wieber fin ben wirb, es vor phantaftifchen Einbilbungen, bie Daxin eb anfallen tonnten.

Ein Biel Kat bas menf́allide Seben, jens

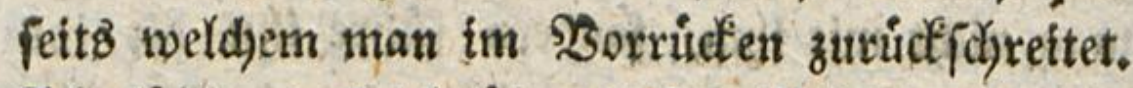

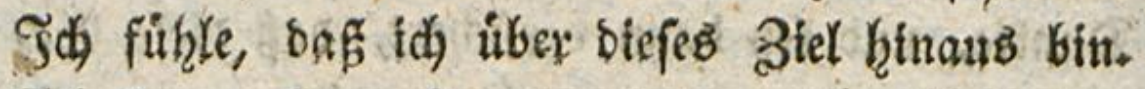
J山. fange, fo zu fagen, eine neue Laufbahn an.

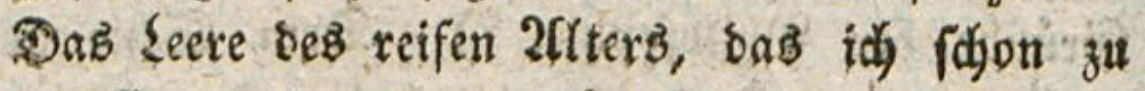
eimpfintoen begonnen habe, bringt mir wieber

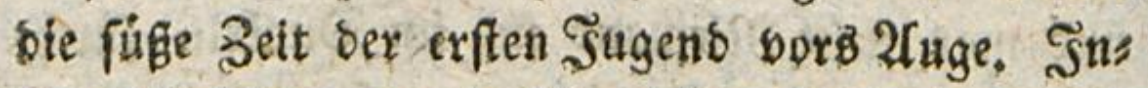
bem id) äitere, werbe ich wieber Rino; und id eximnere midi lieber beffen, was (d) in zehnnten, als was ids in breifigften salgre that. Sefer, sergebt mirs benn, baf id) bisweilen meine Bseifpicłe son mir felbft Kernehme; benn, um sies 


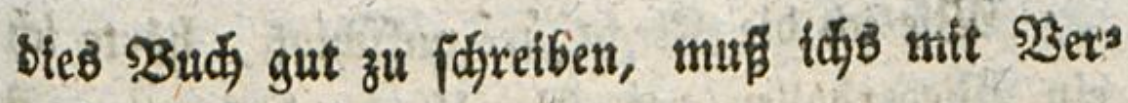
gnigen fojreitsen.

Sch war auf ben Sanbe in ber fioft bei eis nem Srebiger, ber Lambercier hief. Sid hatte einen Spielgefeflen, einen 2 Better bon mehr Bet: mogen, als idj, ben man als Erben behanbelte, indés mir, in ber Entfernung vot metnem $93 a$ ter alb ciner armen $\$ 3$ aife begegnet warb. Mleitt Natabor oon \$etter, SBernḩaro, twar eine

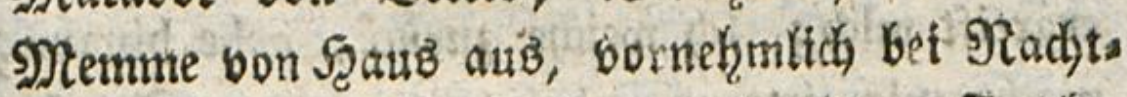
zeit. Sd) zog ifsn fo lange mit feiner Furtit:

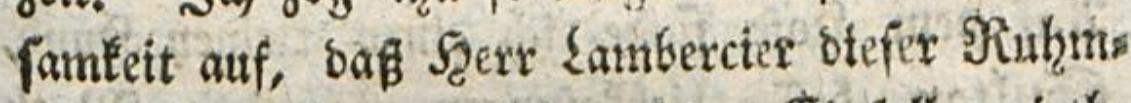
råthighteit múbe, enolid, auf ben (sinfall gerieth, mein Sterz auf Die Syrobe zu fellen. 21n ets nem fehre finfern Scerbftabende gitb ex mir ben

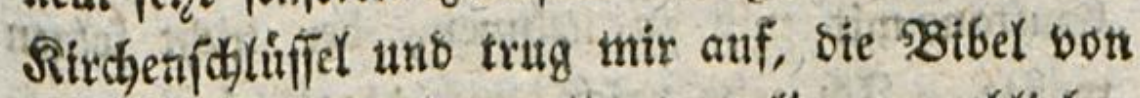
Dex Ranzel zut holett, bie sort liegen geblieben war. Er Feghte, mith ourch Estre fa piquirett,

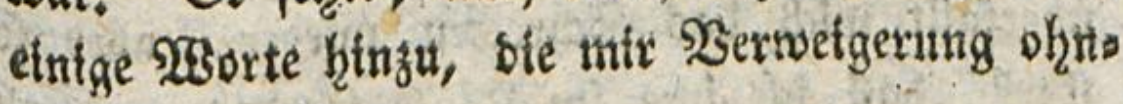
moglici madjtett.

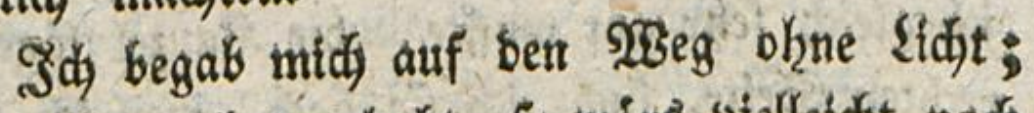
batte tich welches getzabt, fo wárs viefletdjt nod árger getwejen. (5s muste uber ben Rirchbof of gegangen (enn, thi surdjwanderte the luftiglid, benn fo lange the midy tin ber freien lift befano, swafte fid nie etwas von nadjttidjer Furdjt.

IISL 


\section{2}

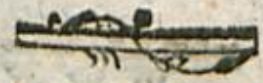

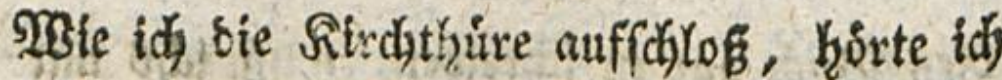

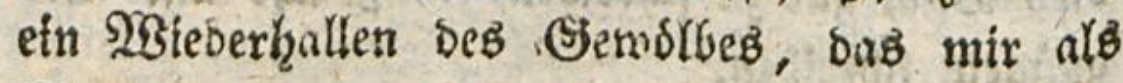
Stimmen vortam; uno bier begann fihon meine xomíidye Stanobaftigfeit eridjuttert zu seroen. Siad) gesfneter Thure mollte id) binein gehen. Saum aber batte id einige Sdyrtte gethan, fo blieb ich ftebn. Sish fehe bie tiefe Duntels beit, Die an biefem meiten Srte berrfdyt; ein

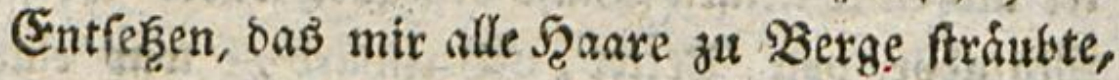
ergreift midh; id) meiche zuruict, gebe binaus; madje midh zitterno uno bebens aus bem Staube. Yui bem Sofe finde ich einen fleinen Şuns, Sultant, beffen Liebfofungen mir wieber \$ith erwecten. Befdant uber meine Furdìt tebre ich wieber un; benuife midh aber bod bent Sultan mit mir zu nefrmen, ber nidjt folgen mollte. Sah aehe raf(h) burch, die Bhitre, trete in bie Sirdje ein. Raun bin id brinn, fo uberfall midh bas Sdyrecten wieber, aber fo ftart, baf ids irre im Rupfe werbe; unb ob ich gleidh fetzr gut wuffte, Die Ranzel láge zur rechten Seite, fuche ida fie body, weil ith mich, ohne es zat merlen, linfs gebreht hatte, lange

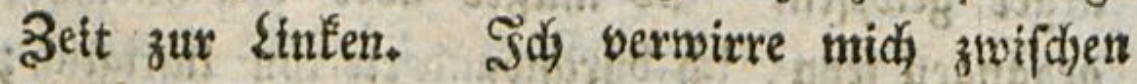

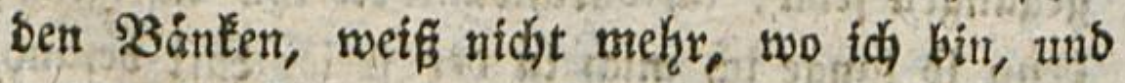
seber im Stande die Ranzel, nod, oie Igure 


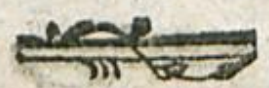

3u finben, berfalle ich in eine unattsipredjliche Serftortheit. Enolich merbe idy ber Izliure ges wahr; idy habe bas Glict aus ber Rirdje hers anszintommen, und entferne miď von iffr, wie bas exftemal, fehre feft entfoclofien, nie anders nieber als bei bellem Zage allein hinein zu getrn.

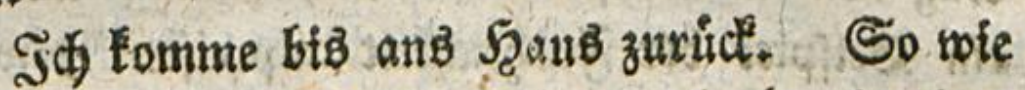
ich binein treten will, höre id. Eamberciers Stimme nut grofem Gelciçter exfduallen. Sch

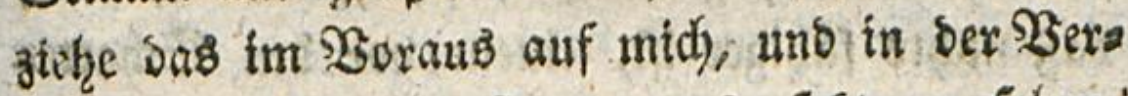
wirrung, mich Dem Sobhne ausgefergt zu feherr;

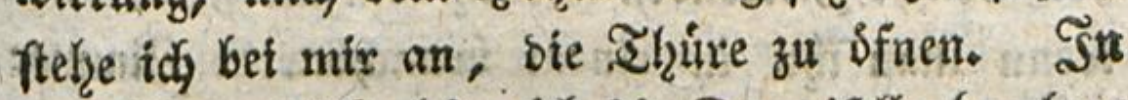

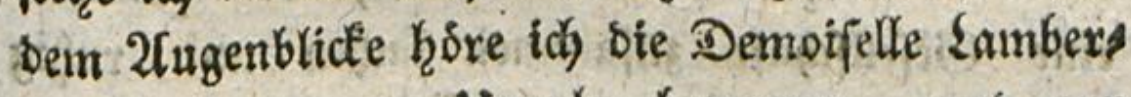
cier meinetwegen Unruke bezengen, uno zue SMago pagen, fie folle die Eaterne netzmen; hore Seerrn Lambercier felbeft 20nftalten madjen, mides zu holen, begleitet pon meinem unerfdjrodinen Setter, bem man nidt ermangelt haben wúroe, nachber alle Ethre ses Ritterzugs beizulegen.

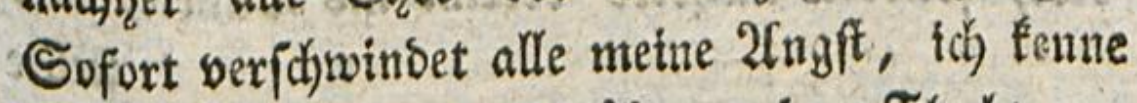
weiter feine Furcht, ałỏ ủber meiner Ftudot ers tappt zu werben, if raufe, fliege in ote Rircbe; Dhne midh fu verirren, ohne herum zu taften, getange id) zur Ranzel, fteige hinauf, neţme bie sitbel, fdiefe berittiter, bin mit orei Epringen 


\section{4}

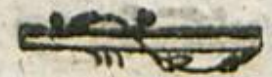

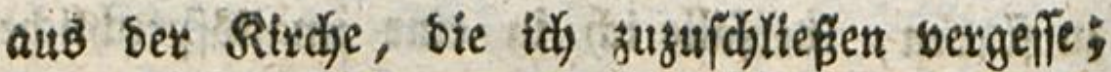
trete obemlos in bas Bimmer uno werfe sie sis bel auf ben Zific; etwas berftort zwar, aber bod) mit frobem Sergellopfen, bem mix beftimms ten Beiftunde suborgetommen zu feyn.

פ) Tan wirs mich fragen, ob idj diejen 2 fufs

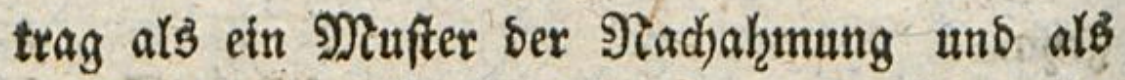
cin 2 Setipiel ber Frohlich)lett anpreifen *) nolle, bie bei bexgleidjen Ulebungen obrwalten follte. Nein; aber ich gebe sie Siefohichte als .Beneis, baj nidhts fákiger ift, etnem vor ben Scjatten

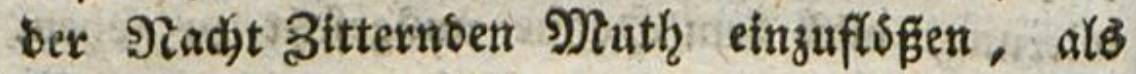
wenn man ifgn in einem benadj) barten Binmex etne Sejellidoaft zujammen lacken uns rubig

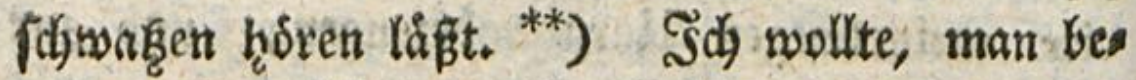
riefe, ftatt fich mit feinem Untergebenen ganz alletn zu unterb̧alten, bafü bes 20benos etne 2tizahl aufgewedter Sinber zufammen, man fübrte fie anfänglich nicost einzeln uns abgefous bert, fonbern mebrere beretnt fns Bunlle, und

fieltie

-) SR. Hat fich bier wahtitich nicht als einen furchtlofent Sinaben gejeigt. Iol weif viele Sjeifpiele, ba man in abufichen Syraben viel befier bejtanden ift:

(E) lerg.

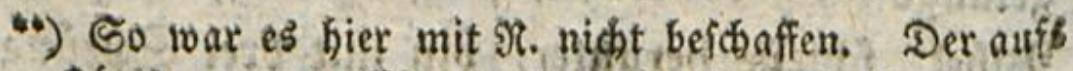

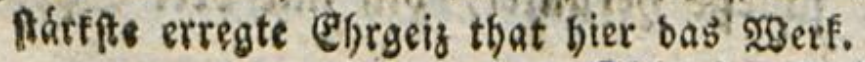

Eblerß. Rejenig. 


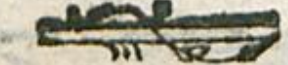

fillte Eeinen einzigen gamz allein blof, ohne im Bis

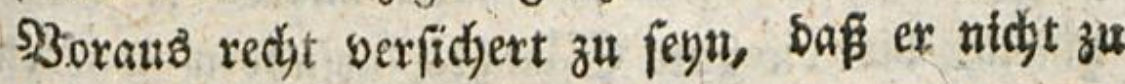

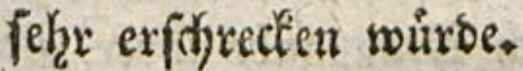

Ims

פeidyt3 ftelle idy mir luftiger und nükltidier luff oor, als bergleidien Spiele, falls fie nur mit

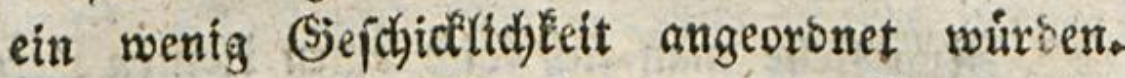
รish baute 3 . . in einem gropen Saale eine

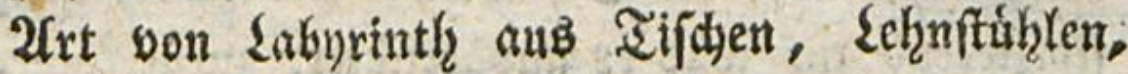
Seffetn, Sdjtrmen u. ogl. Sn ben unausiwirr

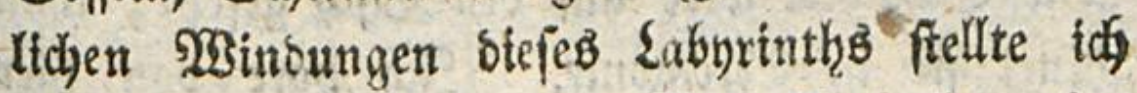
mitten unter adjt bis zebn Bexiridjadjteln, eine

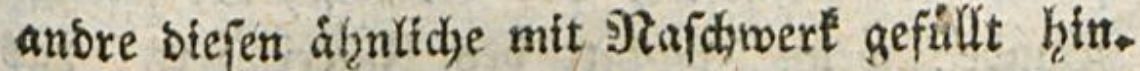
Dann zeigte id) in beutlichen aber furzen $2 B$ ors ten ben beftimmten Srt an, wo sie gute Sdjactja tel frimbe; furz, gálbe eine foldhe Beíd,reibung, bie für minber unaufmertifame uno fajeltige $23 \mathrm{ges}$ fen alв Sinber, $\dagger$ ) zureidjte; und fobictite nut bie Eleinen 2 Betteiferer, nadjoem id fie bas zies

เn็

Itte

4) Damit man fie in ber 2lufmerffamteit libe, fage mat ignen mur foldhe Sachen, bie, recht zu verfeben, fuir fie eis nen funfichen unb gegenwartigen शruben haben; hute

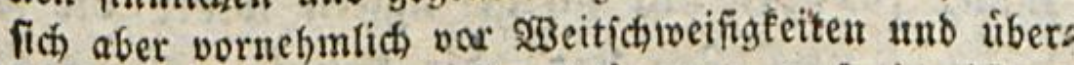
flubigen 2 Borten. Tnbeffen rafie man auth in feiners Reben weber Dubfelbeit nod stocibeutigfeit.

Guil Ifter §ด.

Inm. Deళ গুerf.

$x:$ 
ziehen laffen, einen nach bem anbern fo lange binein, bis die gute Sójachtel gefunben worben

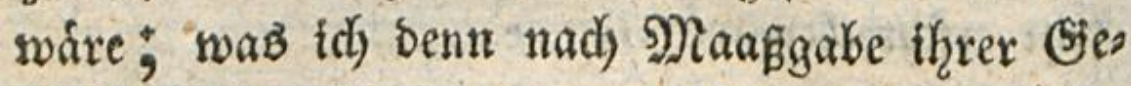
fordélidjeit fdywerer ober leidyter zu madyent Sorge getragen baatte.

Stun fille man fich folda einen Heinen Sers cules vor, ber, eime Sibachtel in ber Scano, gans

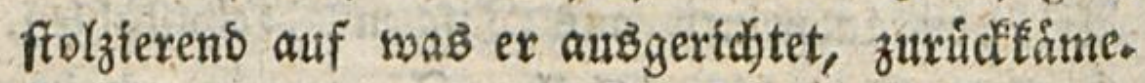
Die Sdachtel wiro auf ben ßijch geferst; man sfnet pie in Seremonte. Sch hiore bon hier. fdjon bas Sieladjter, bas Eefretid ber luftigen Bande, wetn, anfitatt bes Sudterwertio, das man exmartete, auf SNDos, anf $\Omega$ aummolle, ein Maitáfer, efne Sdynedte, eine Sioble, eine (ris d)el, eine Siube, ober etn anberer foldber Secters Giffen gar fauberlid) zuredytgelegt gefunden roirs. (Fin anbermal b̧ange id in einem frifch geweiften

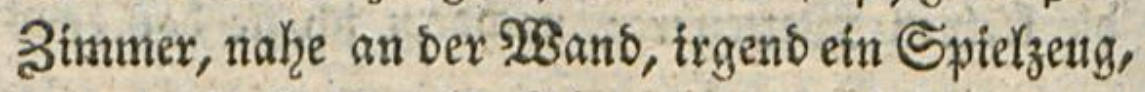

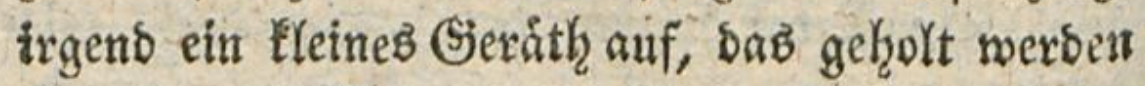
foll, ohne bie Slauer zu berif̧ren. Raum wirs bas Rino, bав eв fringt, wieber zuride fenn, alz man, falls es nux itn geringiften wiber bie $\mathfrak{B}$ es singung berftofien bat, sie Rrempe fetnes Sous tes, die Spife feiner Sdunhe, der Schoof feis nes Rletbeb, feinen 2lermel, feine Unjdjidélidys 


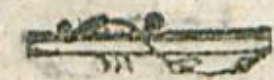

age

jen

ÿes

jett

ers

$m$

ae.

an

ter

ent

as

in

Eis

ers

is.

ent

g.

eII

$x 3$

13

ies

แ⿰㇒⿻二丨

ifs

Gs

it

teft Derrathen feflen wirc. *) Das if wol

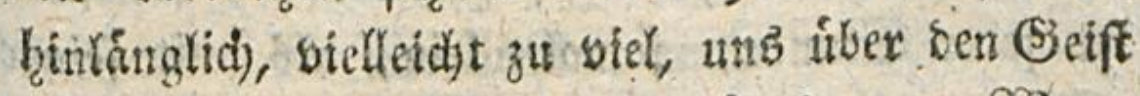
biejer 2Irtent Epiete zis berfitánbigen. SISenn

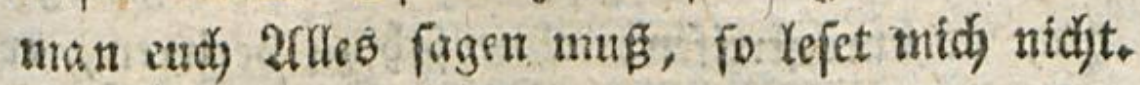

$23 a 8$ fir 3 orthetle wird ein to Erzogener nidjt bei Sacjt sor ansern boraus lgaben?

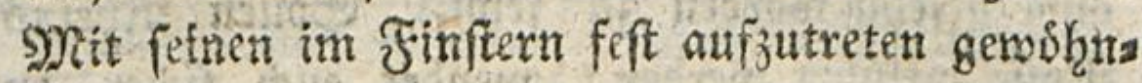
ten Seinen, mit feiten alle umgebinben אisrper

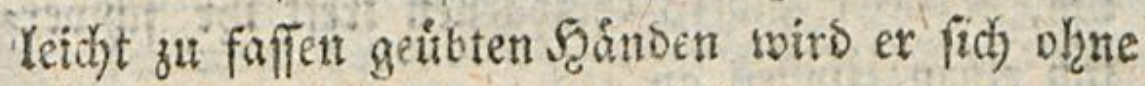

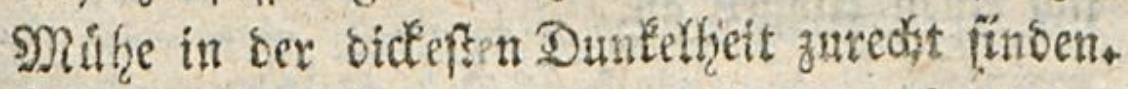
Seine Cinkilbungolraft, voll ber nidytlidgent Spiele aub ben 3eiten Der Sugend, wirb folyers

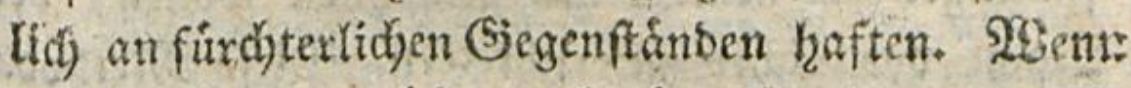
ex Getadejter zu horen grautbt, fo wirb eB nidat Gepládyter son Bootergeiftern, fonbern feiner ala tell Spiclgefelten ihreb; wenn ex fid eine Bers

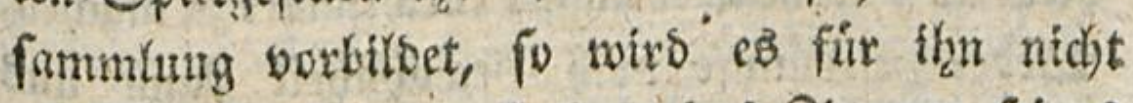
ein MBalpuraistanz, jonbern tab 3immer fénes Ergiehers fern. Die giadjt ruft thm nut frosha

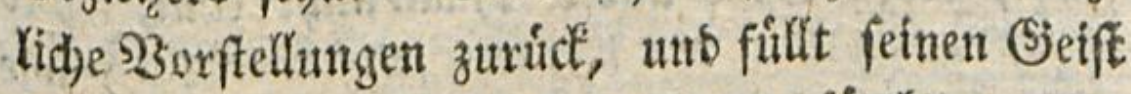
nie mit Graulet. 2frnftatt fie zul fưruten wirs er fie vietmef̧r lieben. Soll im Rirtege ein Rr 2 nadifts

-) Diefe Seifpiele fins fehr gut erbacht, und founten

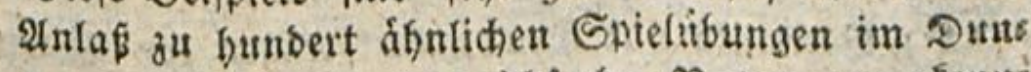

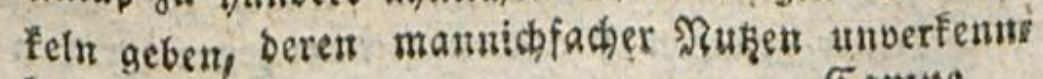
bar ift.

Eampe. 
nadjtlidifer Streich aubzefufhrt werben, fo if ex zu jeber Stunbe, forool allein, alo mit feiner Sdjaar, bereit. (5r wirb in Sauls sager ges hen, es burdhftreifin, of̧ne fids zu berirren, ex wirb bis an bes Ronigs 3ెelt gelangen, ohne jes mano aufzuwecten; uno toteder zuridfeftren, ofgne zejef̧n morben zu fenn. Sollen Siberas आoffe entfufgrt werben: wenbet eudi fidjer an ihn. Unter anders Erzogenen treft ifhr forwers ltid einen Llyfies an.

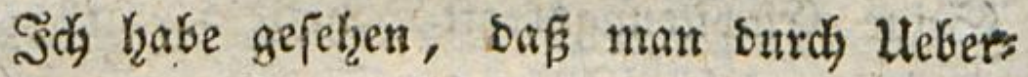
fallungen bie Rinoer hat gewshnen wollen, bei

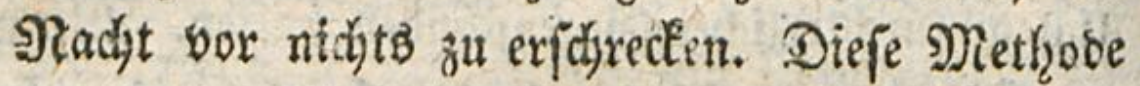
taugt gar nidht; ") fie fringt eine ber gewinidy, ten ganz entgegengefergte 23 irfung herbor; uno bient mur, bie Sinber immer furdyt famer zu madjent. 23 eber Seununft nod) Sewohnheit Fann unb über bie Sorftellung einer gegenwärtigen $\mathfrak{S}_{e}$ faftr, deren (Srad und 2(rt man nicht Eennt, **) fo wic

-) Gie ift vielmehr eine fehr verfebrte uno unfluge Sethobe, die gerabe bas Begentheil von bem bes roirft, was fie bewirfen foul.

Eampe. Rejerviks.

av) Siernunft und Setwohnheit tragen jur bewirfung eiucr gewiffen furdatlofigkeit beigegentwartigen felbit 


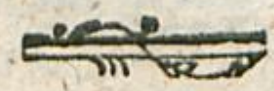

wie tiber bie frudjt vor ben lleberfallungen,

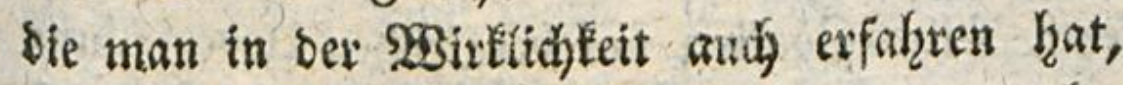
$\Re \times 3$

bes

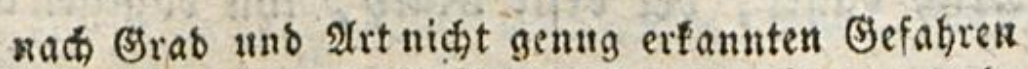

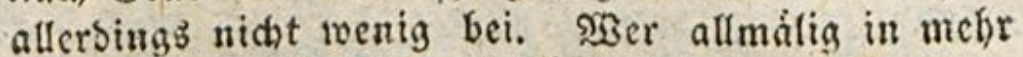
und mebr gefáprliche llmfánbe bincingefübrt roiro, unb oft mit Befabren umgeben ift, weif bals mit

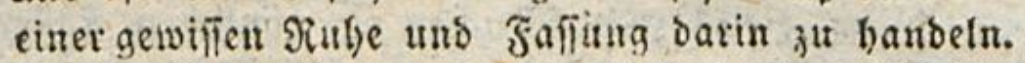
Befabr liferbaupt, und eine kefonbers modificirte

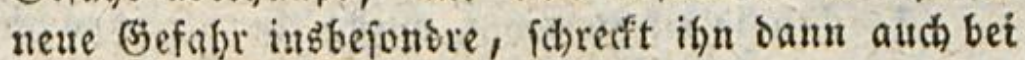
Der erften Dunfeln SBabrnefmung berfelben nidft

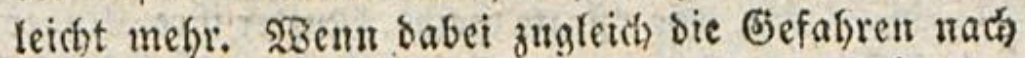

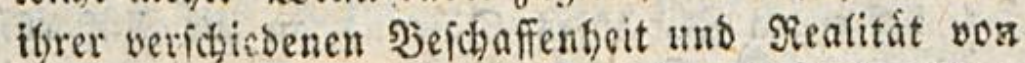
Der Sernunft berechnet werben: fo enthált bie 230 rs fellung ber Befabr oft faum bea hunbertiten. Theil von bem, was fie fonft in fich enthielt, ba man fich bie (Sefahr lveit úber ihr Naaf ucrgrofert vorffellte und fie Dingen beilegte, bie our(c) aus niđ)t ju fúrchten find. 2Beil id von ber allererften Sinbbeit an ges wohnt bin alleit im Finfern fu fern uno ju gehn

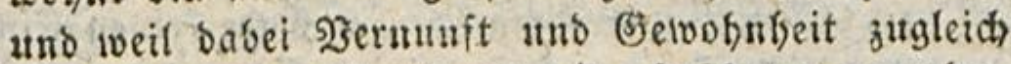
genukt wurben: fo ift es mir oft fdwer geworben einen jegriff von Dem 3uftanbe ber furd) ju has ben, Der mit bem Gein mo Gefu im Dumfeln fur

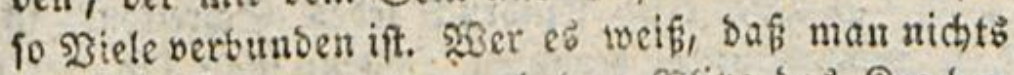
zu furchten bat, weun nach bem Sylike bas Rrathen bes Donner's erfolgt, ben wiro siefes sirachen nidht mebr angetiaent. Sger ez berechnet, ber wie vielpte Mienfich mu im Durchichnitt nom Slike getobtet oder bejóásigt wirb, fómmt befonbers in ber Ju

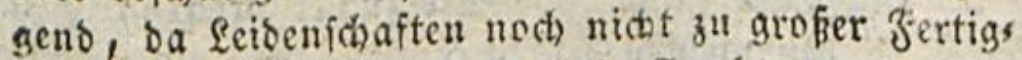
feit gefommen fint, bald von aller Furcht vor Dem Bes witter zurúd. Hebrigens hat $\%$. (ebr recht, wenn er fid) wiber alles lleberfallen erflárt. Ein foldhes Heberfallen neranlapt gewógnlich cine gewiffe Jibers 


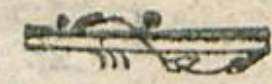

berubigen. S3ie will man tnbeffen verifidert fern, feinen 3sgling sur bergletden Llekeriallan, gen immer in Sidjerbeit frellen zu tomnen? Mich Dintt, ber befte औath, thn Dagegen ausas

erichlitterung uno Schwåchung im Nerveninftem, oas burch biejes zum şeidsen in áhntichen fällen ges ftimmt wirb. Srsenu man inbelien aflmálig jut forchtlofig eit getvobnt wirb: fo madht auch am

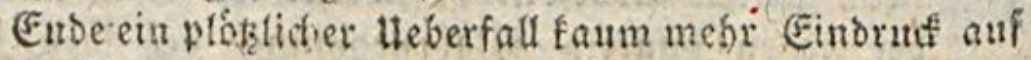
bie Natur. Go pllegte meine snatter ifre Sinder vou Det erfiren Seit ihres Daferns an zur Fimfternip ju gewohnen, fic, wenn fie gehen founten, bavin ju

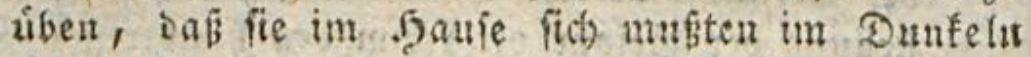
zurecht finden und jich vor einem gefábrlichen 2(nftope Giten Fonten, bem Einen ober bem Anbern zu fagen, bafi er im Dunfeln follte plobilich gefucht uno ers griffen werben, und juleţt Einen und ben \$noern,

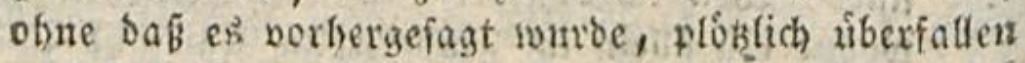
z" laffer. Qetzteres' madhte aut Enbe feinen Einorna bes Set)redtens mebr, wie es bei anbern fonft ges idiebt. (Eblers.

Det erfte Einduta iebes Sajrectens if nol richt ganj zu verfúten. SBenn man fich aber gleich vernúnftig voriagt; - es uvirb nidits Sebeutende

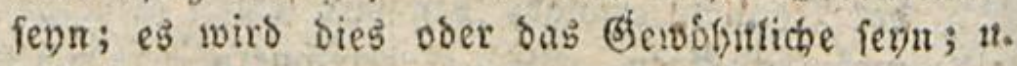
5. wo. - wenn man alfo zum voraus ichon auf uns

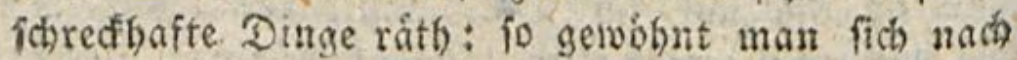
und nach immer weniger zu erichrecten, weit man

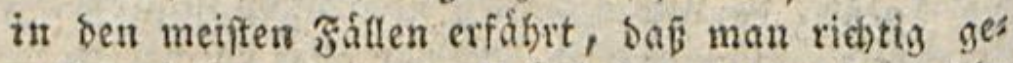
rather habe, uno bie lirfach bes (Erichrectens febt was Rutágligbes uns unbebentenbes fer); uno felbit fer erpte Eindond wirb anf bieje gुeife immer

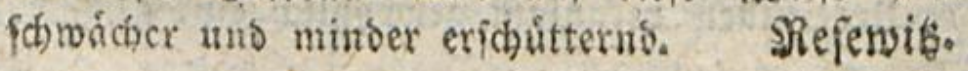




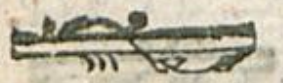

zuriffen, ift folgender: Dut bift alsbann, wurbe id) zu meinem (5mil fagen, in bem Falle einer gerechten תertheibigung; wex sich iberrajd laft bich nioust beurtheilen, ob ex bir Schasen zufügen ober nux sid) exfdyrecten will; und weil ex fich in ben sortheil gejest hat, fo wirbe felbft bas Entfliebren bir nidjts kelfen. Fafle alfo mur oreift an, was bich bei Nachtzeit íbers

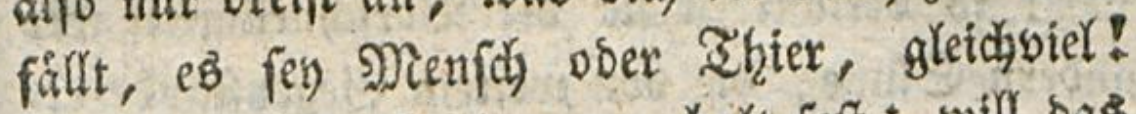
Sreif mit Leibestrifften zu; balt feft; will bas Ergriffene fid tosireinten, fo foldage zu; laf bie Schlige fallen, wohin fie wollen; uno was es aud) thut ober fagen mag: lap sor alletr Bingen nicht fahren, ehe ou wol entannt has

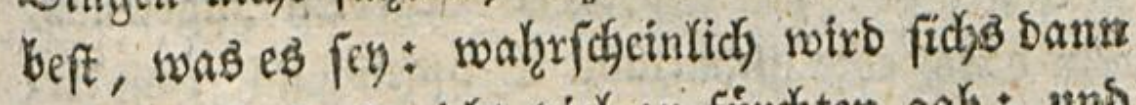
zeigen, baff es nidjt viel zul firct)ten gab; uns

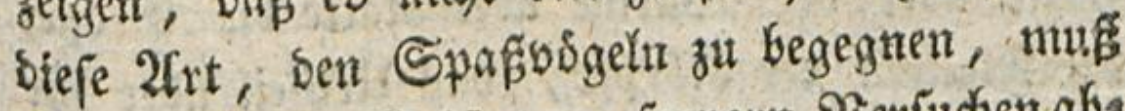
iie naturlicher $23 e i f e$ son fernern 2 sexjudjen abs fojredien.

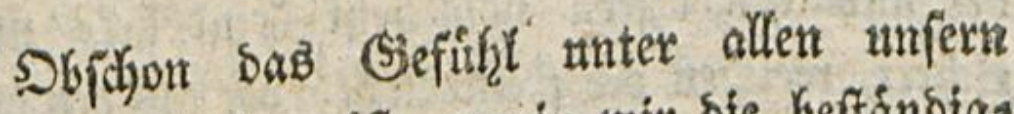
Simnen berjentgen ift, worin wir bie beftandigs fie llebung haben: fo Gleiben sic llutheike befiels ben gleichwol, wie idy fijon gefagt, unbollecoms nener uno grober alb bie Urtheile irgeno eines andern; fintemal wix beftanbig nebenkser auds a $\times 4$ sas 


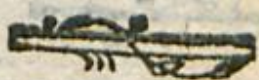

bas (Sefidjt gebrantiden; unb unfet Sefft nut, soeil bas 2fuge ben (Siegenttand eher erreid), als es bie Srant thut, faft allezeit ofgne bie Şand urtheilt. Dofúr find benn audy bie Urtheile beg Gefúhţ bie fitterften, gerabe weil fie bie eins gefdraufeften find. Denn, weil fie fich nur

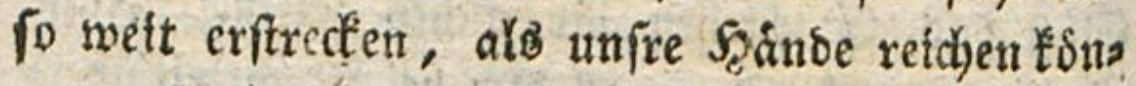

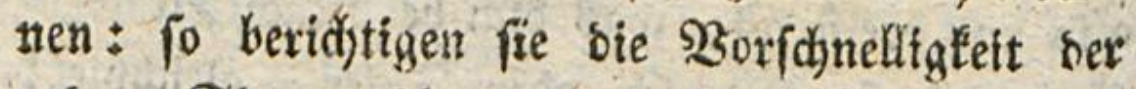
anbern Sinne, bie bon weitem Siegenftande ers faffen, beren fie faum gewalbr werben; ba hins gegen bas SSefúlhl 2rlles, was es waḩrnimmt, xtchtig wahenimmt. Şiezu fómmt nod, bafi, inbem wir ber 21ction ber शerben, wenn es uns gefállt, bie Rraft ber Mlufteln zugefellen, wir burdh eine fimultane Senfation mit bem 1 tr.

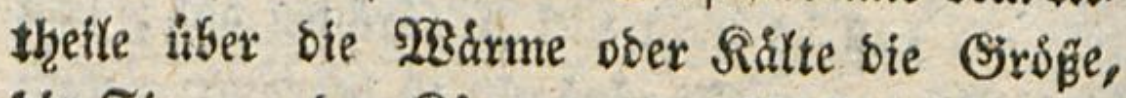
bie Figuren ber Rorper, bas littheil iber thr Semidyt uno ihre Didhttgkeft vereinigen. Da tum fo ธaื Siefúbll unter allen Sinnen berjenige ift, ber. uns am beften won bem Einorudze unters sidftet, welchen the fremben Riorper auf ben unjris genmachentosmen: fo ifter auch becjentge, bent soir am ḩăfigften anwenben, uns ber uns an unmittelbarften bie zu unferer Erhaltung notḩ soenbige Renntniffe mittheilt. 


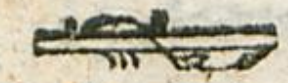

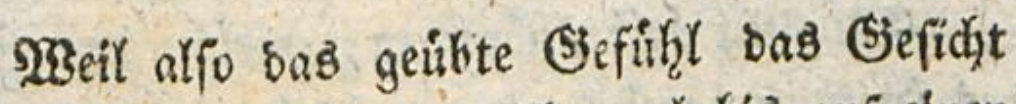

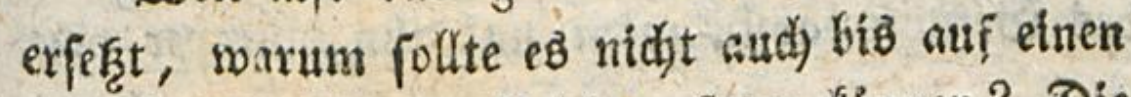

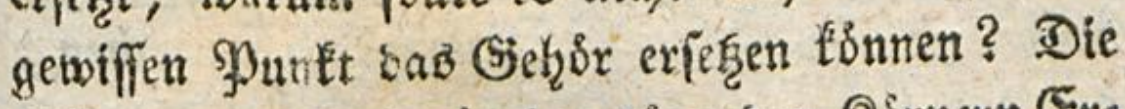
Rlänge erregen $j a$ in ben tónenben Rirpern Ers fdutterungen, bie sem (Siefühle bemertbar fins;

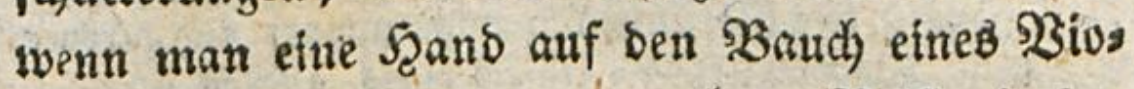
Yoncells legt, fann man, ohne Betfíano Der 2ugen und bex Shrren, aus ber blofien 2) Meife, wie bas Sgolz orofhnt und zittert, uns terfdyeiden, ob ser Slang, ben eB̉ giebt, tief

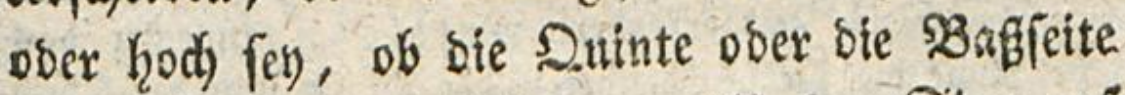
geftrichen merbe. Ulebt man aljo ben Sinn auf bieje lintexfdyetbungen, fo zrweifle id nidjt, bafi man nidjt mit Der 3eit fo empfinnolid barauf werben tonnte, pin ganzes Siufifficte surd Sie Finger zu horen. Diefes nun voraubigefergt, ift es Hlar, bufiman fut Zauben leidyt bermits telft bex Mufift reben tonnte; benn ba bie Tone uno bie 3eiten eben fo siel regelmáfiger bungen fâtritg fins, wie bie Silbenbiloungen uno Stimmen, fo fonnen fie aud eben fo gut alb Elemente zur গRebe genommen werben. *)

$$
\text { গ } 5
$$

-) Es wúrbe sie $\mathfrak{A}$ taffuftung ber Gade mit unúfers minbliden Echwierigfeiten verbunben \{cun, wenn טon ber Ertwerbung cigentlicher \$erftambe sbegriffe die 


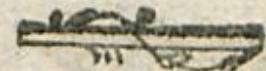

ËB giebt Eetbeb̉ibungen, welche Den Cinn beछ Gefúblz abfampfen uno ihn plumper ma

Febe twáre. Fi. Gat ichon vorber bemerft, baf bie Iltheile des Gefithls (Die Urtheile Der Seele ber: mittelip Des (Sefulgls) unvolfommner uno gróber fenn, als bie llithetle irgent eines andern Gimmes.

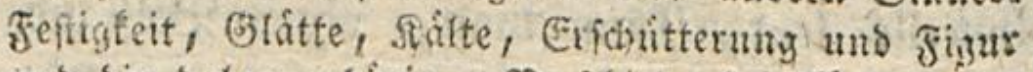
ino bie babun getorigen 2Jericticbenheit fonnen nur vermittelit des (Gefún!s wafigenommen werben. 2tlles zoirb babei, toen bex Sanbe basurd) Soeen erwers ben follte, ourch fecefivive sjervegungen bewirft, wels (hes biele Seit erforbern wuirbe, da Gingegen bas Inge bie Şerichiebenkeiten ber Dinge uno ber Efeis le eines Dinges zugleich wahrnimmt. Eine eins zelne 2 Bahrnebmung vermittefft bes Siefubls in כes ziebung auf bic Berictiebenbeit ber (brabe, Der Seftigs feit ut. f. w. erfordertl weit mehr Seit, als eine einzelne foldher 53 ahruebmungen vermittelft bes (j) ficht:̈: Die Sorftellung zufammengeick̨ter Elemente unb der cimzelnen elemente, welche permittelit bes Eefichts vermittelit cines ghlidfs erbalten uns zut -llarbeit gebrad)t wirb, wurbe fefor langfam durch fecefitioes গ̧efaiflet der Sheile erworben werben. Golls te eitem Nenichen burch Erichutterungen cines. Rör: pers, lvetche R. noch nicst Rufif nemen faum,

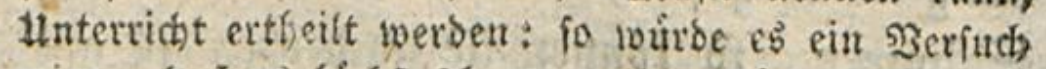

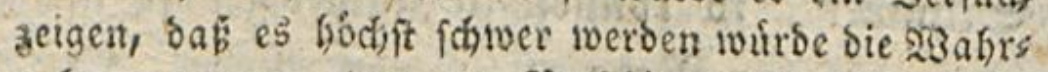
nefomung vou- etion 24 Perichiebenheiten ber Ers Schutterungen, als von Elementen ber Befúblyei(hen fo zur fertigfeit zu bringen, oafi der ฐaube fogleid iich cin beftimmtes Element jener Эorfchiebenteit bei ciner beftimmten Erichisterang vorftellte. Noch bicl forwerer winto es iverdest in einer Erfobutterung bie 2lobification ber Sujammenfek̨urg aus einzelnen 


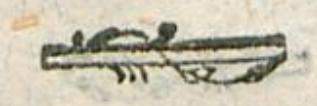

635

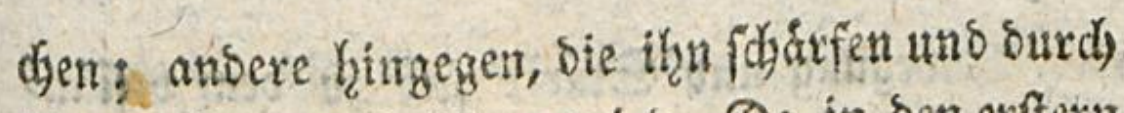
bie ex zirter uto feiner wirb. Da in ben exftern viel

Serichiebentfeiten ber Erfhlitterming ober bie গुes forffenhcit eincs gangen Erichutterungsiverf́s gehos rig uno finell zu ertennen. Nian hat entich such no(t) nie Saube gefunden, bie z̆ur Erwerbing iffer Goeen vietmebr zum (befúly!, als zum (scficht iffe 3ufutht genommen haben. Ifuch bebienen fich bies jenigen Ferionen, welche Saube unterridten, nicht

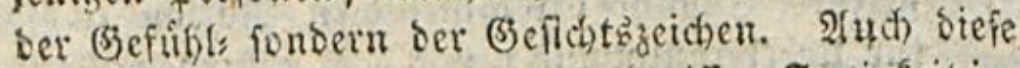
fino nur fur Errverbung ciner getvifien f̧ertigfeit im Denfen fofern gefochidt, als burch bie Befichtsjeichent bie Tonzeichen, woburch wir Goeen uno begriffe andeuten, nads diefer leţtern Elementen unb 3ufaus: menfeţung in ber Sarift uns im Druć bejeichnet werben. Soll man burch bie (5efichtsjeichen unabs bánaig von Tonzeichen denfen: io geft cs mit bem Fortichritt in fienntuifien felyr langiam uno man foumt nicht leicht au einer fo grofien Denffertigfeit, als wenr man fid beim Denfen blofí an Dune bált. Denn man ftelft if(h) weit eher vermittelf des Ees Gors eine grofie Nanniafaltigfeit Der Tone nub ber saburch bezeidneteir Joeen vor, als man fich eine grofe siannigfaltiafeit von Belidbtsformen in $\mathfrak{A b}$ fid)t auf Etemente unb Sufanmeniezung porftellt. Daber haben auth nur bie Efinefer noch eine von Toneu unabhangiae Befichts's Seichenfprache neba ber Toniprache. Daber mup ein Ebinefer fo lange lefen lernen, ebe er mit einiger fertigfeit lefen fom, baber wird ein guter Sopf unter ben Ebinejern fapt alt, ehe er ben gewobntichen 530 rrath erworbenes Senutniffe butch Selen cinftubirt und bafer bleibt bie dinelif he ration faft inmer in einerlci Enfents

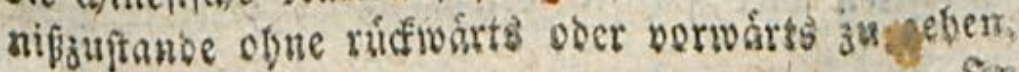
$9 n$ 


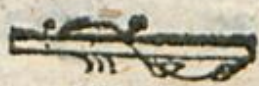

biel Betwegung uno Ståte fidy zu bem beftans bigen Einorudte gefellen, ben bie Şärte beş Siorpers felbit mad)t: fo wiro surd, fie bie scaut bart, fownielidyt und ifhr bie Empfindung bes

noms

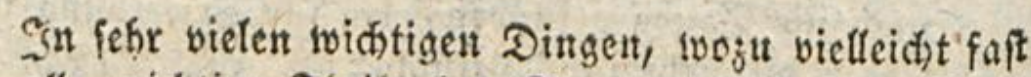
alle wichtige Dheile ber Staatswirthichaft getooren burften, fteft ber wiffenfdaftliche ober ber formelle gelebrte Buftant ber dinefichen siation in fo gus fur Hebereinftimmung mit bem geiunden Serftande, Dab man פ̧cocnfen tragen muf, iene siation wegen enes folchen Stillitefens uno wegen ber Einfors migfeit ifres Erfenntnib̧uftandes feht , zu bedauren, wie reizent audh bie Soeen bes Fortid)reitens in Bseiftesvollfommenbeiten ift. Denn Teiser bilden wir Europáer es oft uns citler şseife ein, baf lvir forts fchreiten, inbem wir bod) nur ubefounener $33 e$ ife alte foft gan vollfommen gebaute wifienfichaftliche Sniteme nieberreifien unb vermittefft bes Reizes ber Sieutheit ju einem fohlechter gebanten Eyftem viele Siebbaber finlocen, weun nut bie und ba Sirafttbeis

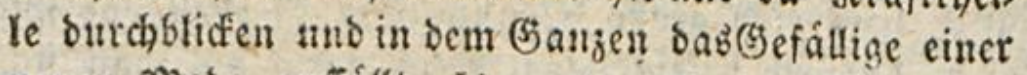
netuen Niobe aufffillt. $L$ ennui naquit de $P$ uniformité, weldes bas Mioto jum frauzifichen Mobenjournal ift, rebetfreifich bem Einerlei bes wiffenf(haftlichen Suttandes ber Ehinejer nicht fehr bas 230 t; allein Sofur tritt auch to viele Ilátigfeit thts fo vieler

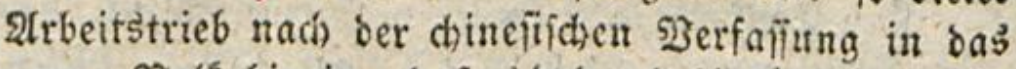
ganze Şole binein, bafies baburch) finlänglich wiber Sangetveile gefchúk̨t twirb. Denuroch wúniche ich nicht,

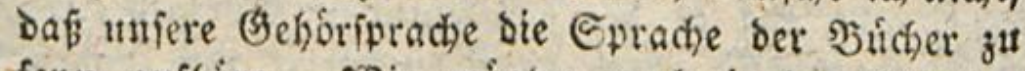
fenn aufbore. 28 ir mogten nod) in ben Elemens ten aller, unire striçieligfeit wejentlid betreffens 


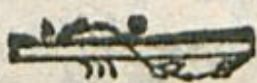

nommett, sie fie son Slatur frat, Bet ben

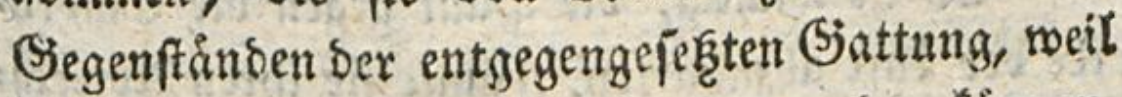
fie mit uref̧r Seidtigfeit tractirt werben tonnen,

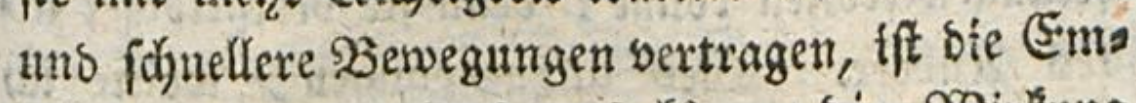

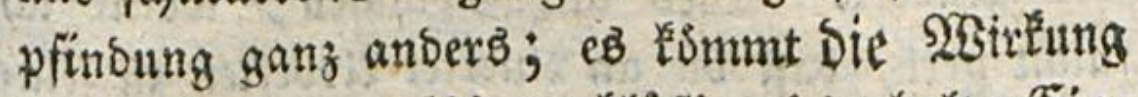
beraub, baf ber auf die unablägig mieberb̧olten (5ins britce adjtfane (Seift felbft zu einer(S)enandigett ges langt, bon allen thren Modificationen zu urs theilen. Diefen Ilnterfóbied bemertt man jogar

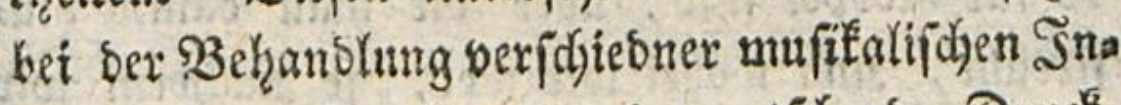
ftrumente. Der harte uno quetif̧endse Druce,

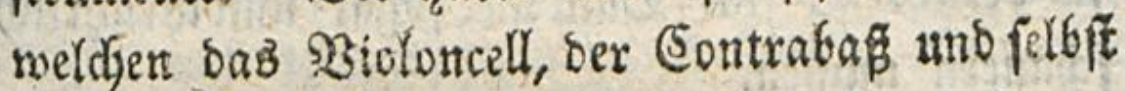
sie Bioline exforbext, berḩsenert, fo zu fagen, die Fingexpipizen, wenn aud) bie Finger fef̧r getentfan babei werbet. Die ebene uns glatte Zuudbe bes Fligets Kingezen madjt fie beibes gelentfam und empfinslick. Shierin berbient

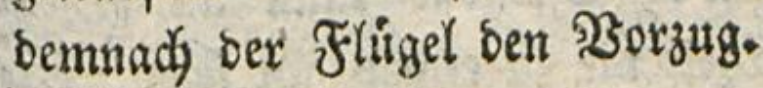

ben stzifienfdiaften enolich zu einer foldhen Feptigfeit Fommen, baß fein Sitúffall zu bejorgen twáre; twis mógten nod) bei bem হriebe fortzuichreiten uno neue Reize in Sienntnifien zu erobern, einmal fo weit

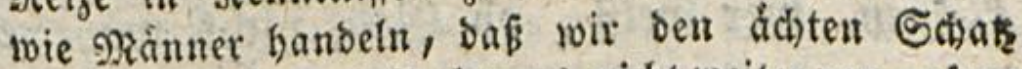

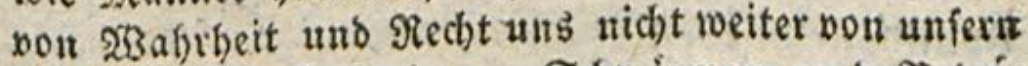
gelehrten Narftichreiern, Schwármern und Şetrú gern, nicht wieber uns aus ber Eniche fpielen, uno ibren and nidat weiter uns zupractifiren liefen.

Eblets. 


\section{5}

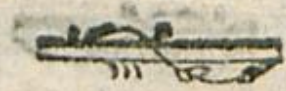

Es ift widytig, die Şant gegent sie Eimbris de ber Luft abzubárten, bamit fie thren 2leweds fetungen trofenen esune; Denn fie vertleetoiget als les 2 Inbere. Dies ausgenommen, wollet tid nicht gern, baf̧ bie an einerlei 2 trbeiten zu folas

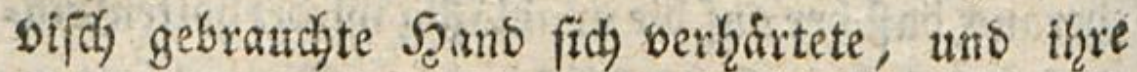
faft fnodyern geworbene Sgaut bas ausgefudte

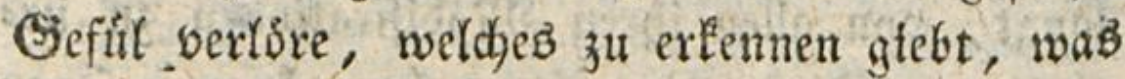
eह fúr Riorper fint, úber bie man bamit hins ftreidst, unt wobet wir wot, je nadjben wir fie berúb̧ren, im Dunkeln fogar unwilléthrtidy

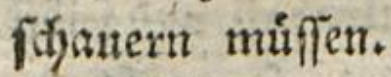

Sid) fehe bie Notḩwenbigkeit nidjt ein, wars

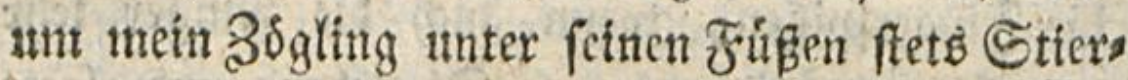
haut tragen foll? $23 a 3$ fü ein Ulnglide waire babei, wenn ifm reine etgne Seant in ?Rothfall zan Sohgle biente? Soffenbar tann an biefem Theile bie 3artheit nie zu etwas gut fern, of mils aber fehr jodjen. Matten in $2 B$ inter oon bem Feinbe in three Stabt anfgetwedt, fans sen bie Genfer eher ifgre Flinten als ibre Sduthe. Şatte feiner von thrnet barfus gehen Hormen, wer weiff, ob Gienf nicht watre einges noimment worben?

Laffet uns ftets ben Meníden wiber bie unberfethenen 3ufâlle bewaffnen. Sänft Emil 


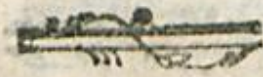

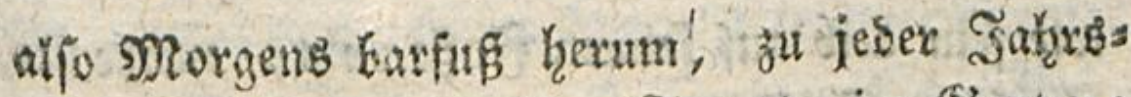
zett, in Bimmer, auf Der Zreppe, in Garten; id. werbe nidit oaviber fdielten, fonsern es thm bielmelgr nad)tfun; *) nux Sorge tragen, Daß̧

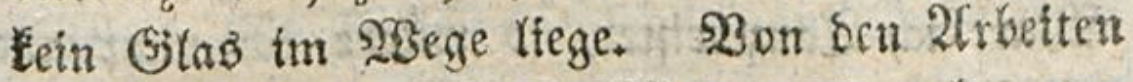
uno Spielen, nobei sie Sainbe gebraudat mer.

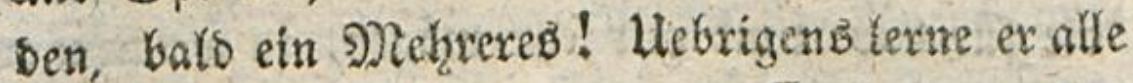
Sdyrtte und Irttte, welche die Evoluttomen Das Rorvers in allen Stellungen eituen Yeidjten und feften Stand zu nefimen beforbern; ex berftefie fidi) auf Den Sprung in sie 2 Seite, in sie Sobhe; soinfe, auf etnen Baum zu Elettent iber eine S) Tauter zu flimmen; finde frets fetn (s)leidiges widut; laffe alle feine SBewegungen, alle feive

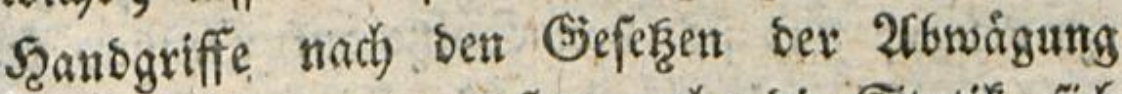
lange zuvor georonet fent, ebce ore Statit fid

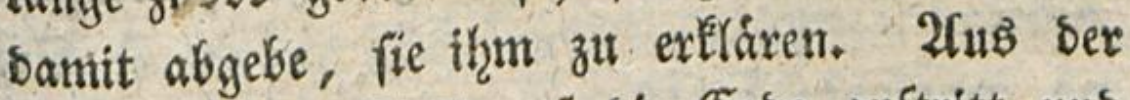
2rt, wie fein $\mho_{u b}$ auf bie Srbe auftritt unb wíe

-) Şr. Formes madt bierbei sie irontiche Snumers fung: $\mu^{\text {Dies }}$ toirs ein unvergleid)liches Siennzeichen fenn, um finfufyro die Emile und ibre Stifher zu exs fennen." Sleidfam als wenn bie 21bbattung ber frufe Durch Darfufigefn das Eimjige wáre, was eis sen Emil von andern Boglingen unteridjeidet! (F)

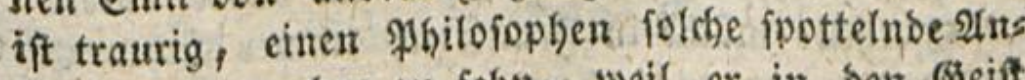
merfungen machen zu febn, weil or in bes seift bes IBerfs, woriber er forreibt, nicht eimzubringers vermag.

Sampe Trapy. 
640

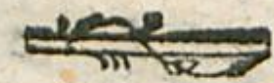

wie fein Seib auf feinem Fuge rubt, merke er, ob feine Stellung gut oder idgled)t fer). Ein fidjerer Stand hat allemal 2fnnehniliditeit, uno bie fefteften Stellumgen find andi bie zierlidiften. SBare idy Iamzmeifter, fo wirbe id nidyt alle bie Miannerchen bea Serrn Marcels †) machen, bie fứr baz Lanb gut fern mbgen, in welchem or fie lehart: fonsern, anftatt meinen 3 Sogling ewig mit Siambaben zu bejadaftigen, ihn lieber an Den Fuß eines Feljen fítzren. Dort Yehrte id ihn, wie ex ben Siopf und ben Letb halten, was fur eine Bewegung ex madjen, wie ex balb ben Fuß, bald die Şand vorwerfen muife, um leidjt ben fdjofen, hoocterichten unb rauhen Fuffifeigen zu folgen, uno fich von Spize auf Spize, fos wol im Şinaufs alz Şerabftetgen zu idwinget.

秥.

*) Ein beriffmter Eanzmeifer in Paris, Ser, feine Lente wohl fentent, aus Schlaubeit ben?arren madhte, uno

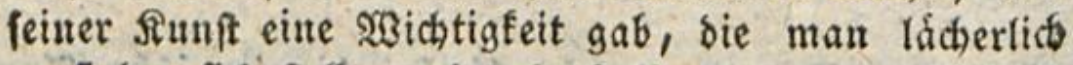
bit fiuben fich fellte, abet berhalben man im Srunbe bes f̧erzenb boch bie grofite Ëbrerbietung fur ifu begte.

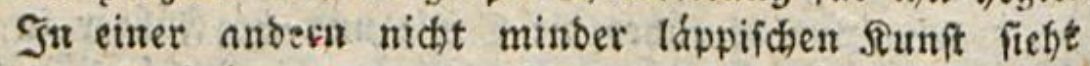
man no(h) jeşt z"s unfern Eagen cinen Sitrfter im (5os móbiantenfache, den wichtigen Mann uno ben शarren vorftellen, uno nidbt weniger gut babei fabren. Diefe

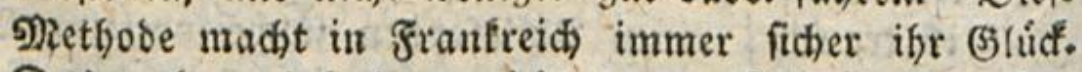
Das twabre, einfachere, nidht fo marftichreierif the $\mathfrak{T a s}$ lent gebeift bort nicht. ßुefcheibenbeit ift fúr bał

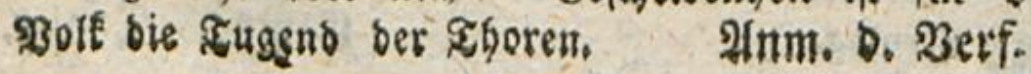




\section{हो $64 \mathrm{I}$}

er,

Fin

เimo

ten.

alle

en,

$i \mathrm{cr}$

vig

an

id

193

Dent

dift

jetr

fos

ett.

涢.

ute

into

icto

ioc

te.

the

Eos

ett

eic

idf.

is

$a^{2}$

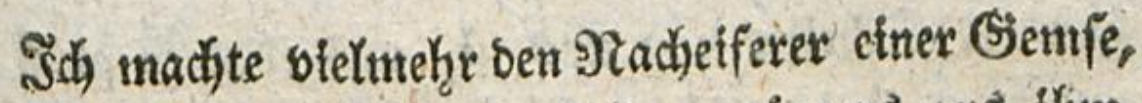

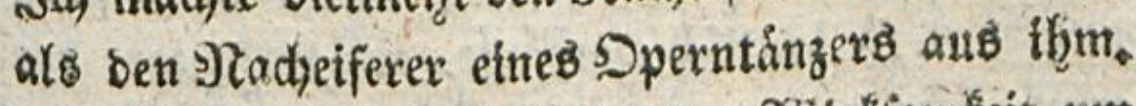

So fehr das Sefihbl feine 23 int famteit um Men erweitert Das Sefidht bie feinige auferthalb tḩm. Daher eben bie ßäu[d)ungen, benen eछ unters worfen tft: mit einem Blidée ber 2 uggen ums

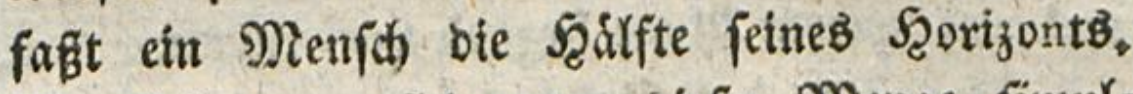
SBte follte man fich unter biefer Menge fimuls taneer Senjationen uno Urtheile, Die bas bies fidjt erregt, in feinem eimzigen hintergeben? Folglid mú es unter allen uniern Sinnen am meiften irre Yeiten, eben besెwegen, weil es oer fich am wetteften erftrediende Sinn ift, uno weil,

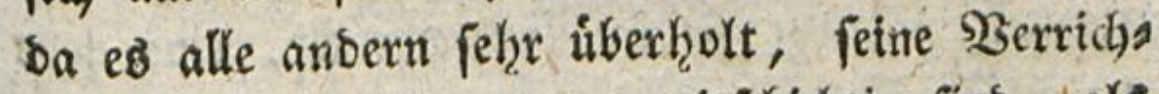
tungen zu fdanell uno zu wetrichiditia find, als

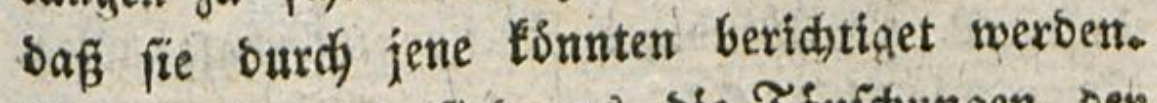

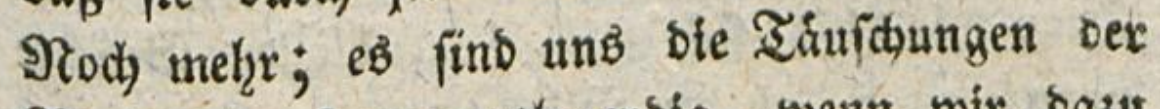
Soripective fogar notbmendig, wenn mir baza gelangen wollen, bie 2 seite zul extennen, uns ithre Thefle mit einanber zu bergleid)en. Shane ofe falíchen 2 fnifseinungen wirben wir nichts in ber Ferne felgen. Shrne bie 2lbftufungen von (Größge uno

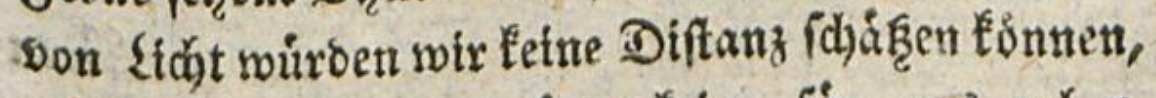
ober biełmehr, es wúrbe feine für uns geben.

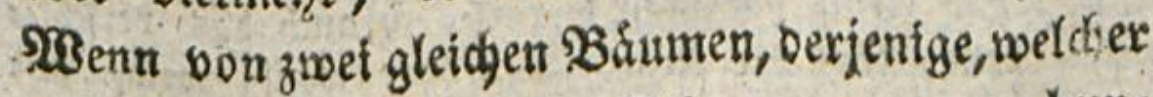
Emil rper 20 .

5 : bुum= 
bunbert Sdyrttte son uns ift, uns eben fo grof unb eben fo beutlid vortáme, als berjenige, ber zef̧n Sidjuitte von uns fid befinbet, fo wirben wix ben einen bem andern zur Seite fhbągen.

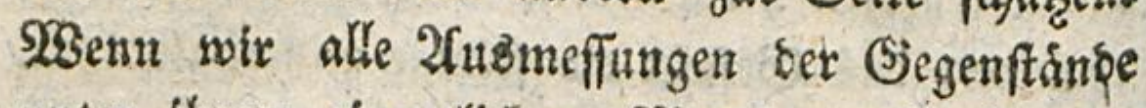

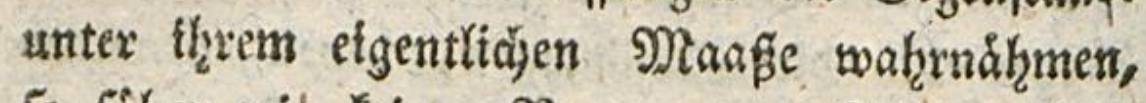

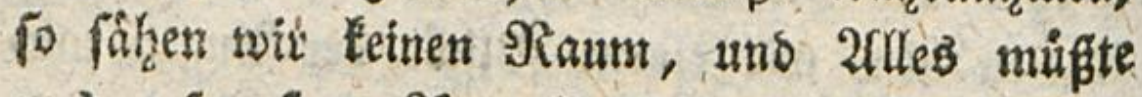
uns auf unjerm 2fuge liegend vortommen.

Der Sinn bes Fefidyts hat, von ber Erroffe Der Gegenftande uno ihres 2Coftandes zu urtheis, ten, mux cinexlei Naaf́; naiulid) bie Deffnung Des SBinitels, sen fie in unferm 2luge bilben; unb da biefe Deffitung cine einfacbe 2 Birtung

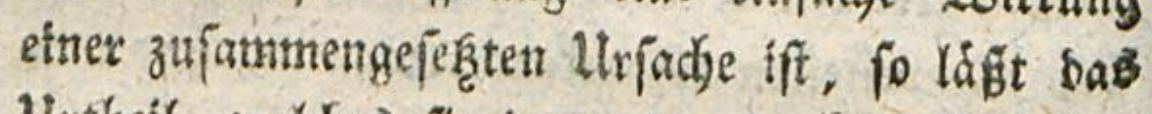
Litfieil, weldbes fie in uns erwed't, eine jebe befonsere Sadje unbefrimmt, oder wirft aud, bafi es nothwenstger assetje felglerkgaft wirb. Demn wie rafit fich nach dem blofien Gefidjte

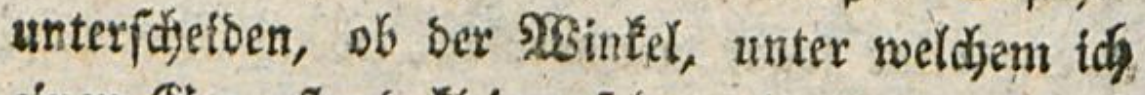
einen Segenftand Ileiner felge, als einen anbern, ein foldjer barum ift, weil biefer exfte Gegens ftans in ber Ifyat Hleiner, obes weil er entferns ter if ? *)

San

") Ein wenig bat man hierbei boch autch bas veribies bene Mianß́ ber Straft, weit ober wenig weit, gut 
Man mus alfo bier einer ber vorbergebem. Den entgegengeferten Sethobe folgeti. 2fnftatt bie Senfationen zu seretnfacjen, mus man fie seropplelt, muf man ftets bie eine burch bie

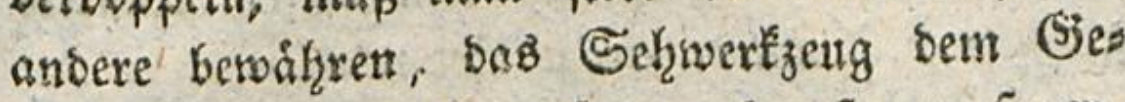
fiblobwertzenge unterwetfen, uno, fo zu fagen, bie Seftigleit Des exften Sinns burdy ben fitwers falligen uno georbneten (Sing bes andern zis

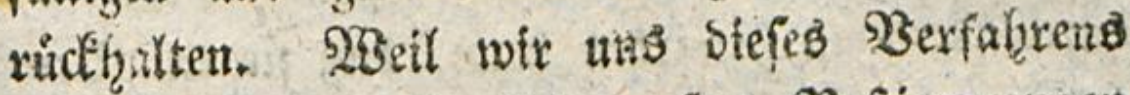
nicht bebienen, fo fint unjere $B$ eftimmungen

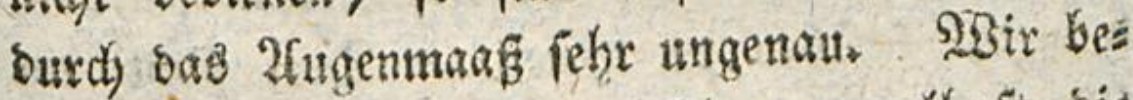
urthetlen eben beshalb nux fefgr mangelfhaft bie Sobten, bie Tiefen, die Langen, bie Szeiten; und ber Beweis, baß bie S̈dulb bavon nidjt fowol an ben Ginnen, als an threm (Siebrattje liegt, ift, bafi die Şngenieurs, Die Felbmeffer, Die Baumeifter, bie Minurer, Die Maler úbere

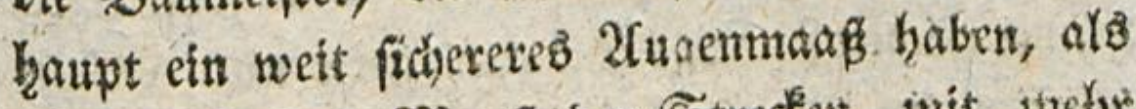
wir, uno bas MTaaf ber Strectent init itrefyr Nidftigleit fobsen; weil then, ba fie burds thre Runft biexin sie Eifahrung exhalten, wels SB 2 .

doe

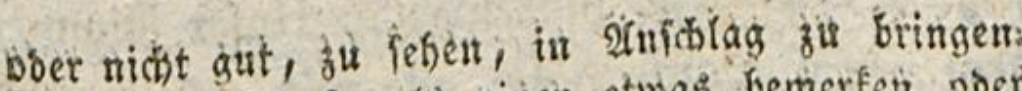
jach bem s)rás, als einer etwas bemerfen ober richt bemerfen fant, mufí ci es fúr mefir oder wenis ger entfertit haiten, wenn er bur(h) Berglcidunngen

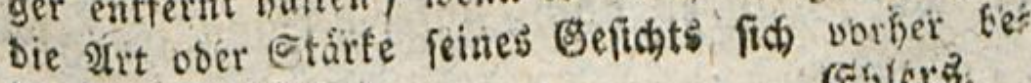
faunt gemadbs hat:

(s) blers. 
d)e wir zu erwerben vernadjláfifgen, bie 3wets

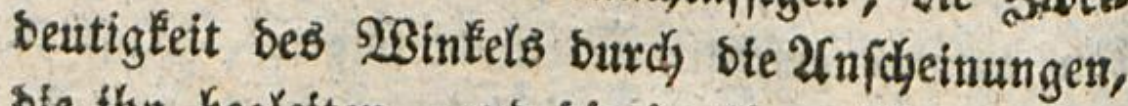
bie thrn begleiten, uno bie in ihren 2fugen bas

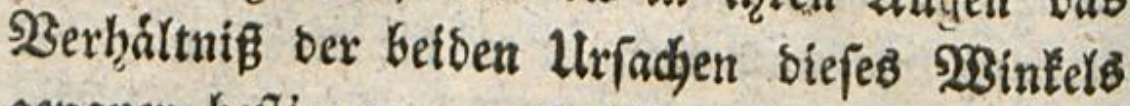
genauer beftimmen, aufgetllart wirb.

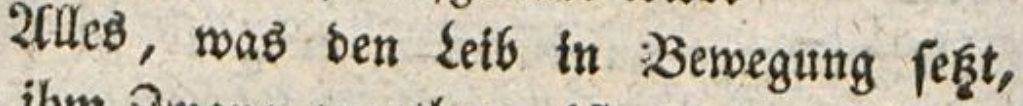
ohne ihm 3̂twang anjutthun, ift bon ben Rinbern Keid)t zu exhalten. Es giebt hunbert Nittel,

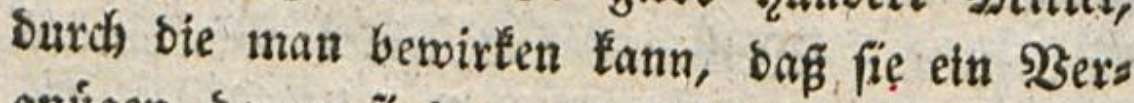
guígen baran finben, bie 2loftsnbe meffen, exs fentuen, fdydz̧en zu Yernen. Doxt fteht ein felgr hoher Rirfbhoum; wie werben wirs ans fangen, bie Ritridben bavon afzuptlicken? Sollte bie Sdyeumenleiter wol gut bazu feyn? Şter bुas ben wit einen febzr breiten Sach: wie wollen wir frinúber fommen? Sollte wol eines von ben 3 retern im Şofe bis an ben jenfeitigen Rand reidjen? SBir mogten gern aus unjern Fenftern in bem জdyloggraben fifdyen; wie viele Rlafter mús unjere 2Ingelichnur lang fenn? S.h) moghte gern eine Schautét zwifchen biejent beiben Báumen aufhången, burifte ein Seil von fečls (sllen bazu binneichen? Unjer 3immer in bem neuen Searje ḩalt, wie mir gejagt morben,

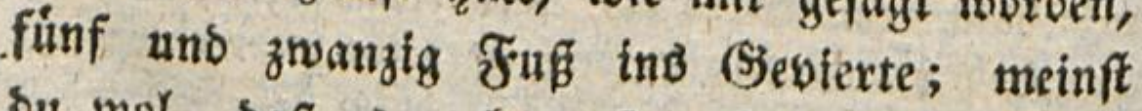
ou wol, baff es nad) unferm Sinn fenn mirb?

wito 


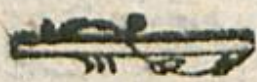

645

ets

'm,

$a s$

18

it,

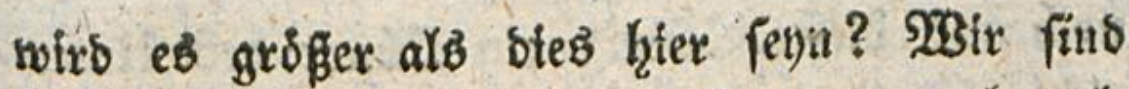
fefbr buungrig; ba ltegen zwei Dorfer; nach wets chem von beiben werben wir am eriten zum (5) fen Fonmen? It f. w.

(5in Rinb, bas tråger, unthátiger Natur war, follte im Eaufen geitbt werben. Bon felbit batte es teine Suft weber hiergu, nod) zu fonft irgeno einer seibebberwegung; ofnnexad)tet man es fux ben Solbatenftand ergiek̨en wollte. Şbm war, id weifs nicht wie, sie Ginbildung in ben Siopf getontmen, ein Rnabe frines Stanoes Sirfte nidbte thun und nidjts wiffen; fein 2loct misfte ifm ftatt sex 2trme, ber Beine, fo wie ftatt jeber anbern 2 trt bes 23 erotenftes gelten. 2us einem folchen soelmanne einen fónellfüls gen 2ldjill zu madjen, wirbe felbft Ehirons Şes

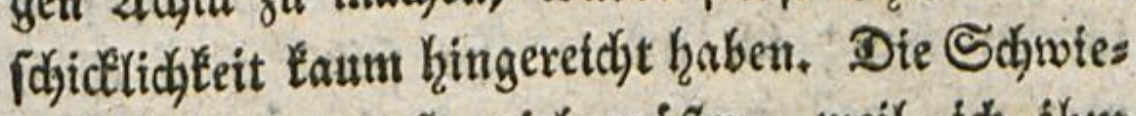
rigfeit war atm fo viel groffer, weil id ihm

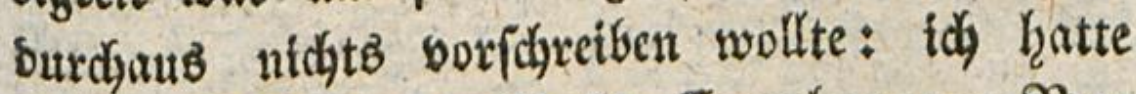

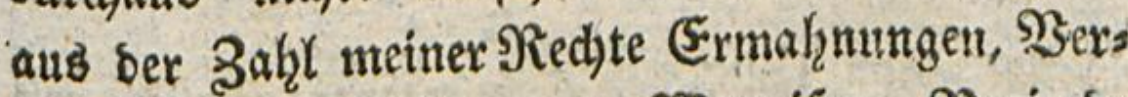
fpredjungen, Drokzungen, 23 etteifer, Begierbe za fdjimment verbannt: wie follte idj ihm bie Beglerke ju laufen beibringen, ohne ihgm etwas zul fagen? felbft zu loufen, wáre ein nidjt gar

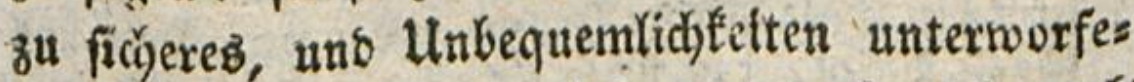
nes. Mittel gewejen. Lleberbies badte in andy 
646

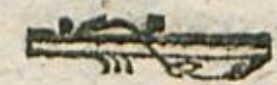

nod, ats biefer Llebung ein Sbject bes Unter

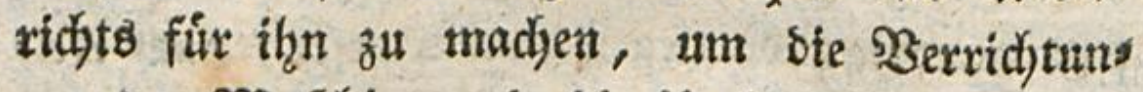
gen ber Mrafdidne und bie Hrtheildtraft inmer mit einmber gleid)ez Sdyrittes gehen zu Yaffen. Folgenbermafien fing id') $e^{\prime}$ an; idh, bas heifft berjenige, bex in biejem 3 eifpiele rebet.

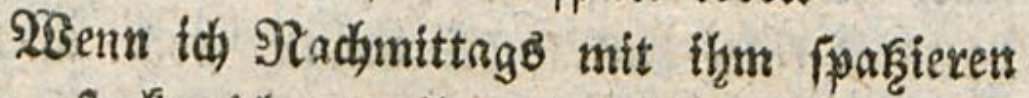
gieng, Ptecte id' zumeilen ein $\mathfrak{P a a r}$ Ruthen vort einer 2trt, bie ex fef̧r liebte, zu mir in bie zas fide; wir asken jeber ben feinigen beim Spas

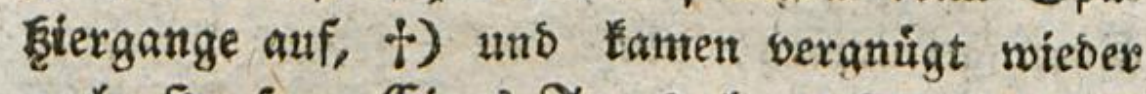
nach) Şaure. Eines Zages bemertte er, Daf id orei Ruchen bei mir führte; en ḩâtte beren

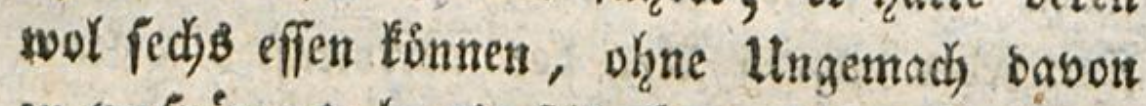
zu beripiren; hurtig folud ex feinen finunter, uno serlangt ben britten von mir, Nein, fage.

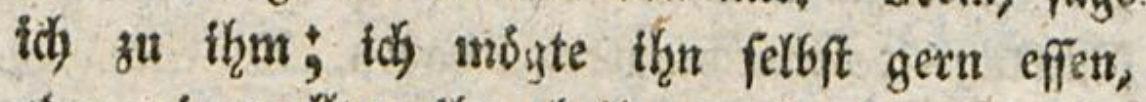
ober wis wollten ifgn theilen; aber idj mag ibn lies

7) İuf eintem lånblichen Spaķiergange, nåmlich, tvie man gleich feben miro. Die óffentlichen, in ben Etábs ten, find fúr oie Sinder beiberlei Befichlects verberb:

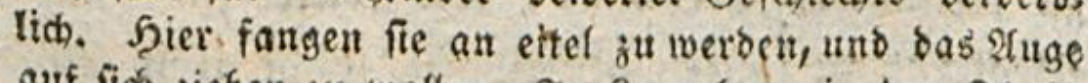
auf fich zieken zu wollen. Sn Luxenburg, in ben Ibuit: Yericn, vornebintió im Sarten bes Palnis Roval, exa fernt bie fosone \$arifer Gugend das unverichámte unp fdaale wefen, bas fie fo lácherlich madut; uno bess falb man fie in gan Eurdpa ausjicht, und unausfobs 


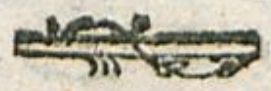

Vleber vout ben beiben łleinen Șungen sa, Surch 20ettlaufen exfreiten fehen. Shis rief fie, zeigte

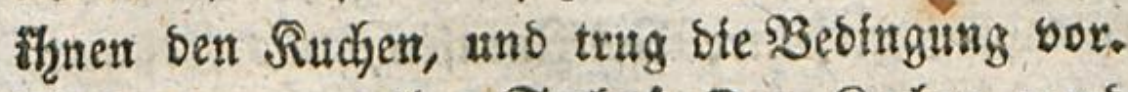
Das war ganz thre Sadje! Der Rudjen waro auf einen grof̧en Stein gelegt, oer ald ziel stente. Die Eaufbahn murbe abgeftect's; mir

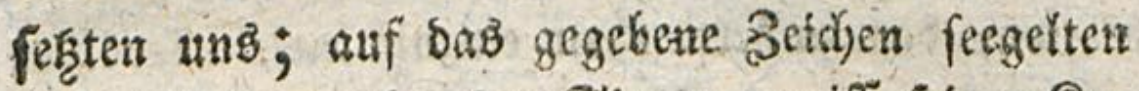
unire Rleinen $a b$; Der Sieger ergriff feinen Rits

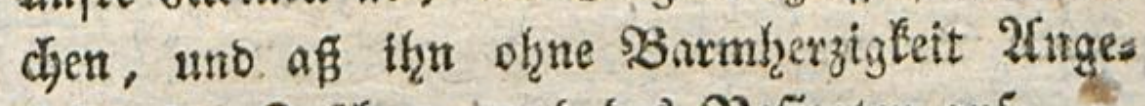

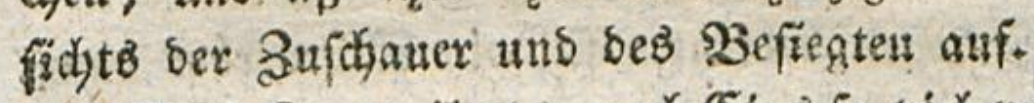

Dicfe Runzmetl war nody cins fo biel werth, als ber Ruchen: fie follug inbeffen nidjt gleids

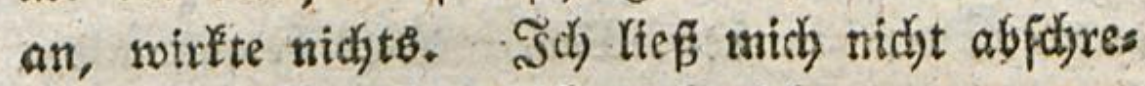
dèen, und íbereflte mich audy nicht; wenn man Sinber anfithren mill, muf man wiffen, 3eit zu

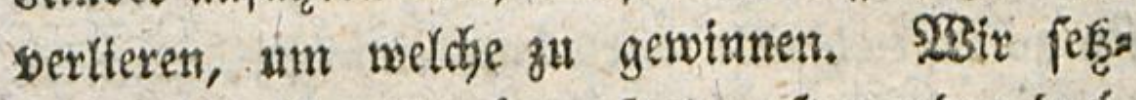
ten unfere Spariergánge fort; oft wurben ore;, zumeilen bier Rudjen mitgenommen, uno von 3eit zu ąeit feşte es einen, and wol zwei für

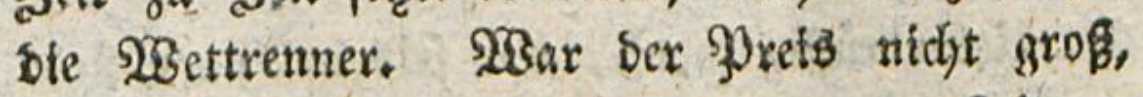
fo maren body biejenigen, bie barum frrtten, ehrgeizig; Derjenige, ber ihn babon trig, wurbe getobt, gepriejen; 2Cllez gejd)ah mit bielem Ses prang. Damit idj fu Llmifippungen des Streits

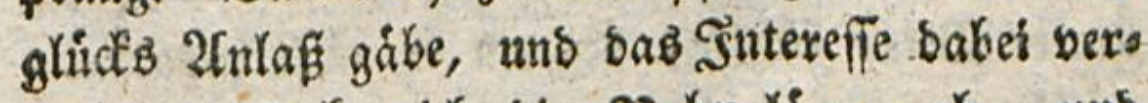

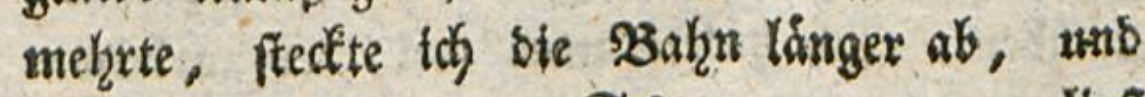
SB 4

Itefi 


\section{8}

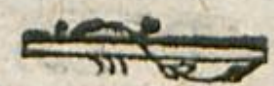

lieg mefgr Mitwerber za. Raum waren fie eins getreten, fo biteven alle Borbeigehenten ftehn, fï: laufen zu feḩn; bas Surufen, bas Siefdyrei, bas Şånbeflatidhen befeelte fe: ich fah bionsets len mein gutes Mánnchen vor Freube zittern, auffitehen, ausrufen, wenn ber Eine nabe bas bei war ben anbern eben einzuholen, ober ihrm zuborzulommen; es waren fir thrn bie olyms pirdipen Spiele.

Sinbeffen bebienten fid bie Mitwerber bann und wann fletner Siften, bielten einander auf, ober unadsten einanber Fallen, ober warfen eins ander Steine in ben $\mathfrak{Z B}_{\mathrm{e}}$. Dies bewog mid, fie abzufondern, uns fie von berichicbenen, aber bom 3itele gleith weit entfernten Stånben ablans fen zu laffen; man wiro balo einjelgen, was id́) zul eimer foldyen 30 rautsficht fir Srrinbe hatte:

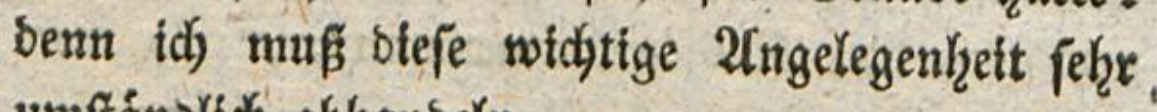
umitánolidy abhandeln.

Ueberbriffig inbef̈, vor feinen 2tugen ftets bte Rudjen, wozu er felbft grofse suft fpurie, aufeffen zu fehen, bie Gebanken: gut laufen tónne boch wol zu

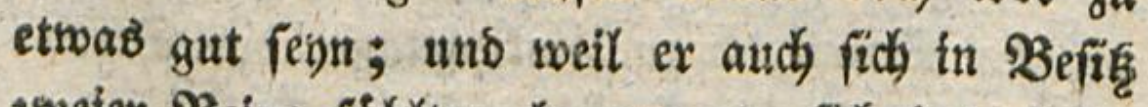
zoveier Beine fúflite, begann ex, fid inggeheim

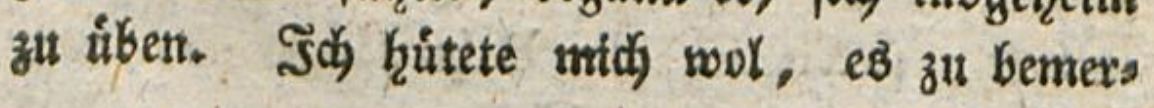

ten; 


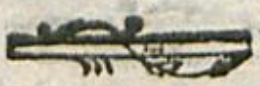

ten; fah aber, baff meine lift angejofllagen

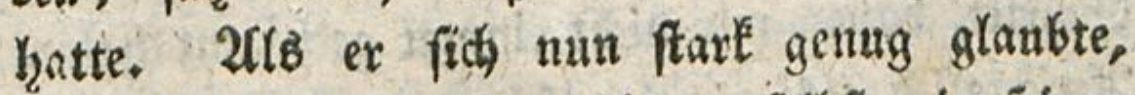
( anb bas las ich eher, als ex jelbit, in retnen Gebanten) fo affectirte et mit Lingeftum in mid) zu bringen, id) msgte ithm ben lef̧tern úbrigen Rutben geben. Das fd)lage ith thm $a b$; ex beharert mit Startnadéigteit; uns jagt

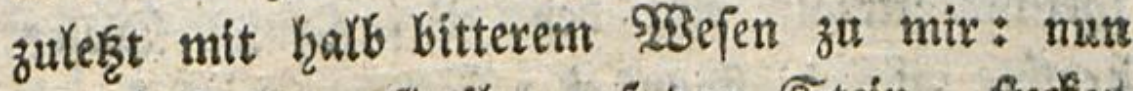
benn! fo legen fie ihn auf ben Stein, frectent fie sie $\mathfrak{B a b z}$ ab; und wir wollen Fehgen! Sut; fage id rachelno zu itgm; tann aber ein Sunter Yaufen? Der Muns mirb ifgnen nux nod' methr nad) bem Suçen róffiern, uno fie nidjt babei geminnen. Durch meinen Sdjerz piquirt ftrengte ex fid, an, und trug ben Sreis babon, um fo biel leidjter, weil tid bie Bathn fo turz, bes fftrmnt, uns Sorge getragen batte, ben beften Sáufer zu entfernet. Man begreift wol wie

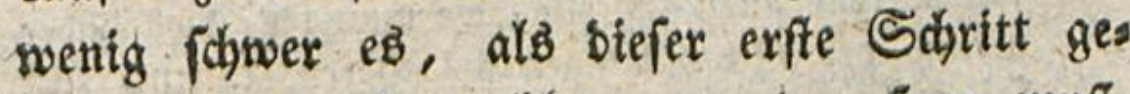
than wax, mir načsher gemorben renn mü, ihn in SDbem zu exhalten. Ex fanb bals einen foldyen Sefallen an biefer llebung, baf ex ohne Begúnftigung beinahe fidjer war, im Saufe mit meinen $\mathfrak{B a u t e r j u n g e n ~ a u d j ~ a u f ~ b e r ~ l a ̈ n g f t e n ~} \mathfrak{B}$ ahn Sieger zu feyn. 


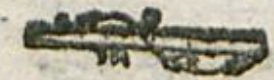

Mitt biejem Bortheil gewann tdy nocis cinten Edyritt, babon mir nidist einmal getriant hatte.

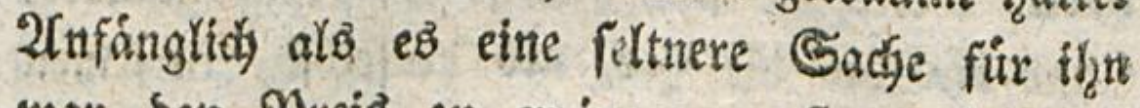
swar ben spreis zu erringet, afs ex thn faft intuner allein auf, nach) betn Seifpiele feiner Ditwerker. *) 2zie thnt aber bab Sieget gelaufiger toars, warb en groffurithig, uns theilte oftmals mit sen Befiegten. Diefes bradite mich felbfi auf eine fittlidse sbemething; id) Eam bahinter, was nol sas wahre Mrins cipium der Srosimuth fery.

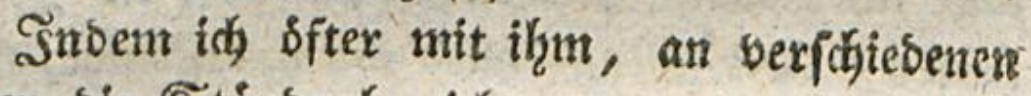
Srten bie. Stånbe bezeichnete, bon senen jeber mit bem andern zuglcich) ausloufen follte; richtete

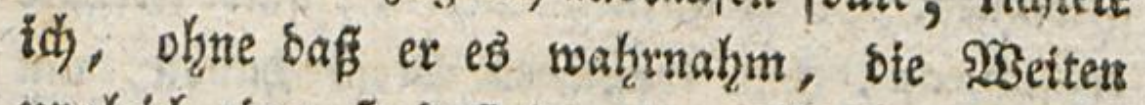
ungleich ein; fo bafí ber eine, fít ben ein láns

2) Serr Foumen ruft bierbei abermals, recbt findifa fchifanirend aus: "\$reife, bie man iñt, bies ift ber (5)und ber Schultibungen bes Serrn $\%$. und faft peines ganjen Bebáubes Der Er riebung! Mat fann bas 330 ort auf ibn jiehen: Venter artis magifter. Der Fauch ift ber Lefrmeifter ber Stunft." Jit es eines Philofoptien wurbig, aus einem enzigen જुeis fpiele einer eimzigen $\mathfrak{A r t}$ von Hebung, gleich cine allgemeine Nethode fui: alle llebungen zu machen?

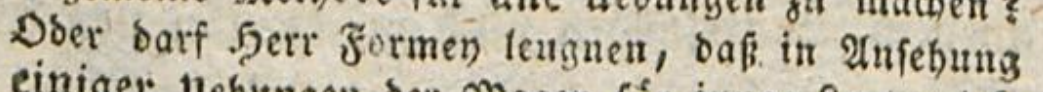
einiger Uebungen ber Magen, fúr iunge leute wirks lich ber befte lefrmeifter fer)? Sit es ifm unbefaunt, baf biefer \&ebrmeifter einft aus unfern 2̧orfabren

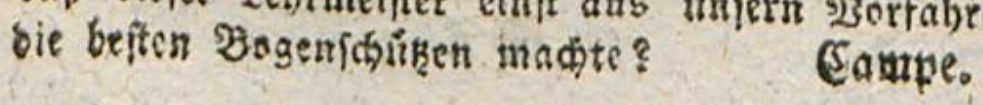


geter Noseg git surchlanfen mar, wenn ex git sempetben Bitele als ber Unore gelangen wollte, fichtlidben Nadbtheil sabei hatte; allein mein

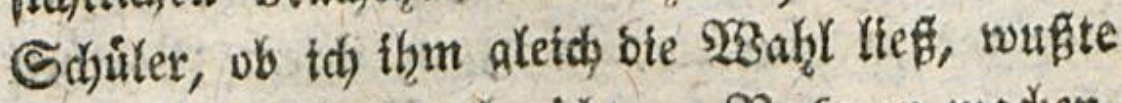

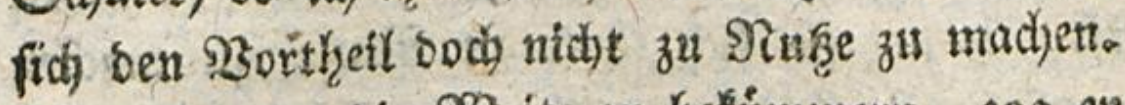
Shne fich um die SWeite zu bethmmern, jog et ptetỏ ben beften Sabeg vor; bergeftalt, bafi idy, sa ith reine 28 aht Yeidit ooraus fah, es beinafie

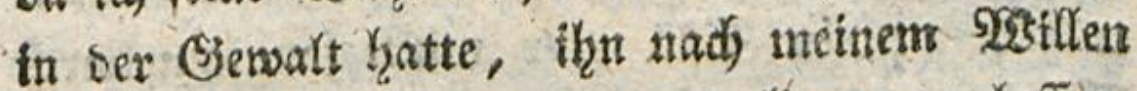
ben Sucjen gewtnnen doex Dexlieten zu lappen, und auci) biefe Sift mas zu mehc als einer Sadje gut. Da gleithoot meine 2lbfidjt sar, bafip ex sen Unterfichies wabrnefimen follte, fo bes

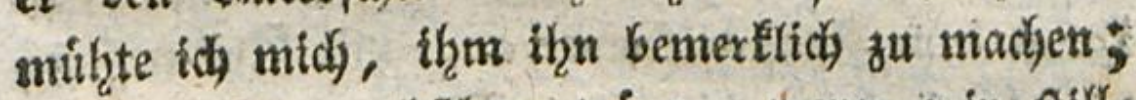
er soar aber, obfchon trige, wenn wir fitlls fafen, ood in feitten Sptelen fo rebtzaft, uns

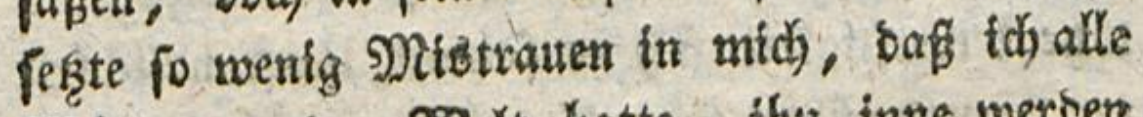
Mruthe bon bex 938 elt hatte, ing inne wersen on lafien, bafs th tha beruicte. Enolid gludite es mir bod), ungeaditet fetner Fafelet; et snadgte mir Sortwirfe bariber. Sh fagte zu ithm: Shoruber beftagen fie fird? SBin id bet

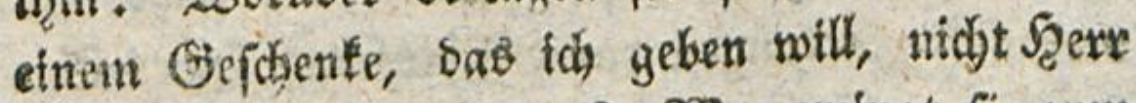
iber metne Bebingungen? SBex zwotngt fie zum Laufen? Sabbe idj thren berfprodjen, bie Bahnen

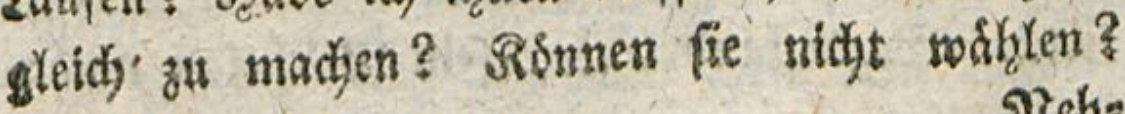
शtets: 


\section{2}

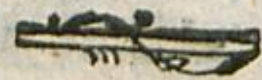

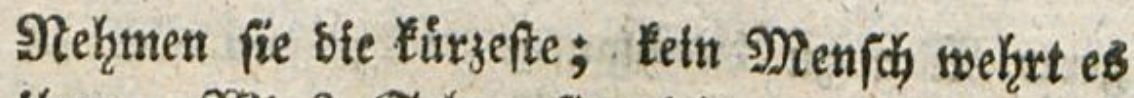
ifhnen. WBie? Sehra fie:nicht, bas ich eigents lich ifhnen wohl will, uns baff bie Ulngleidgheit, woriber fie murren, ganz zit threm Bortheil ift, wenn fie fich therex zu 9luke zu nacken serftehen? Dies wax thm bentlid); ex begriff eb; unb wenn ex wabhlen sollte, fo mufite ex nun fith borfehen. 2Unfangs wollte er sie Schrits te zafhlen; ein Rino aber mif̧t langfam burch Sdyritte und serzahlitt fich; íberbies verfiel id barnut, bielmal in einem Zage forches $23 e t t s$ rennen anzuffellen, uno ba nunmelgr ber Beit: sertreib eine 2trt son Seibenfobaft waro, io tams bem Ritaben fojwer an, mit 2rusmeffung ber Eaufbahnen bie zum $23 e t t l a u f e$ beftimmte 3eit zu verberben. Ungern bequemt bie jugenbs liche Eebhaftigteit fich su foldben Umptánolidjtete ten; man ibte fich alfo ridgtiger fehen, eine

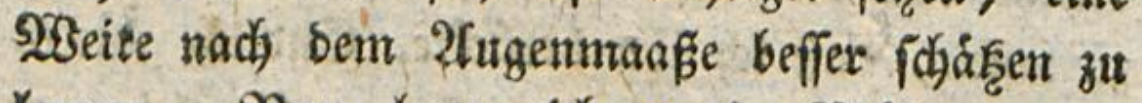
Yernen. গun hatte tids wenig, Maihe, biefe Mreinung ou ermeitern unb zu unterḩalten. Enbs Yid, bflbeten thm einige Monate Beriucbe und

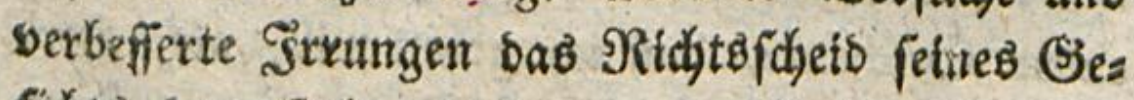
fichts bergefalt, baģ, wenn tid thm nur it Gebanfen einen Rutien auf irgens einen ents fernten Giegenftans legte, fein Blict faft immer 


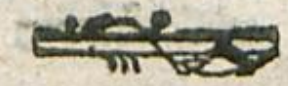

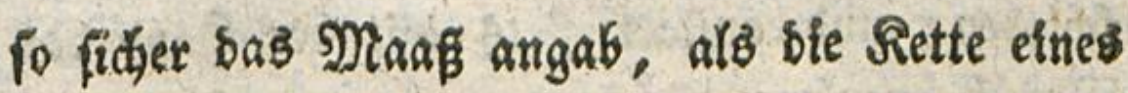
Felsmeffers.

Da bas Geficht untex allen Sinnen bers jenige ift, wovon man bie Itrtheile bes Ġeiftes am wenigften abjonbern fann; fo braudht man biele 3eit, feḩen zu Yernen; man muß lange bas Sefint mit bem Sefüḩle verglidjen haben, erfteres baran zu gemóhnen, uns ęinen treten Bertat bon ben Geftalten uns 2lbftánben zu geben: ohne bas Gefúḩl, ohne bie fortgehende

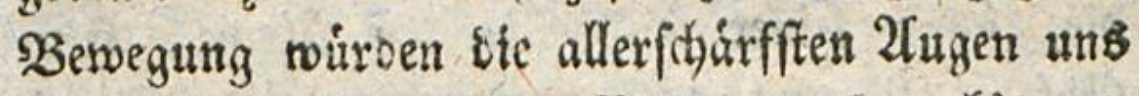
feinen $\mathfrak{B}$ egriff won ber $S_{3}$ cite machen tönnen.

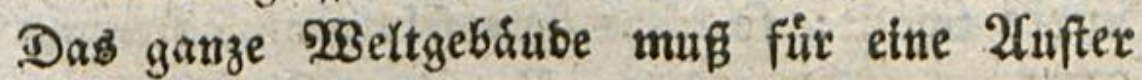
nur ein פ̧unt fern; vortommen, wenn felbit eine menich)lidue Seete fie belebte. গtur burd, oteleş জehęen, Zaften,

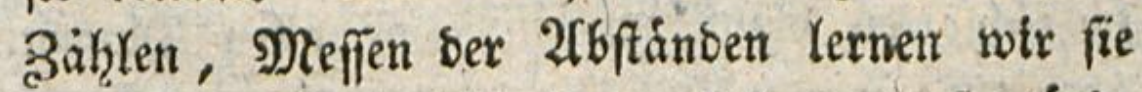
fagagen: máfen wir aber aud) immer, fo wirbe unfer Sinn, ber fich nun auf oas 2 Bert'zeug

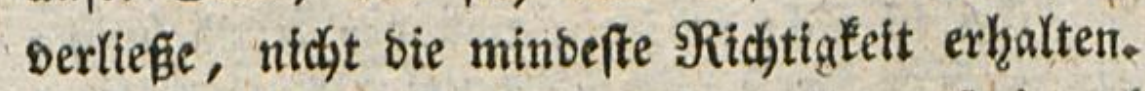
2fud) mus bas Rinb eben fo wenig auf einmal

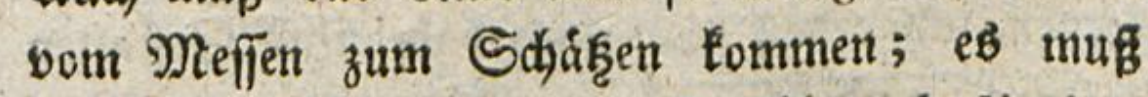
nux anfänglich, wenn man fortfăḩrt, basjentige, was es nidjt auf einmal bergletdyen $\mathfrak{t} a n n$, ftúcts wéife mit genauen 2liquwoten zu vergleichen, bas

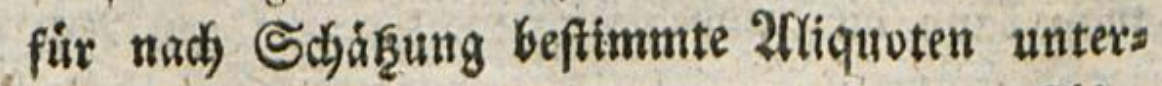
fidies 
fdiferen; uns anfitatt fiets mit set Şans bas

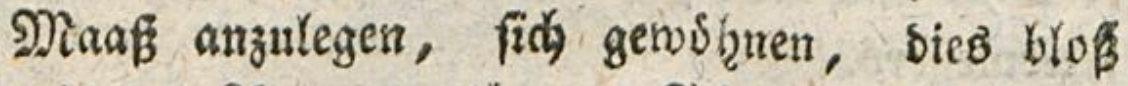
snit ben 2fugen zu thun. Şd boollte mit alles bem man bewahrheitete feine exften Sperationen

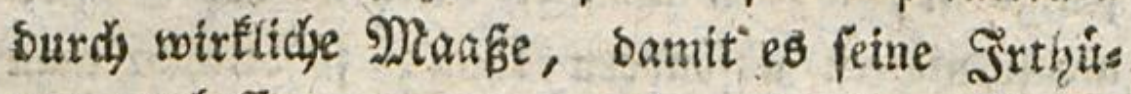
mer berbeffern, und, wofern in bem Sinue stoch ingens faliche 2 nnidheinungen blieben, fels bige Surch ein befferes Lintheil beridytigen lernte. Man hat natirliche g)taaffe, bie faft allerwärts

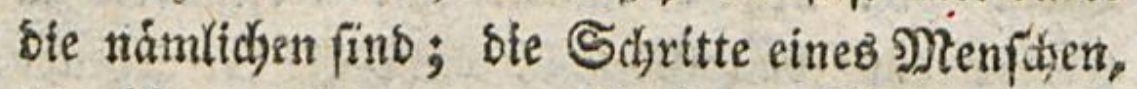
bie Lánge feiner ausgeftrecten 2 frme, feine

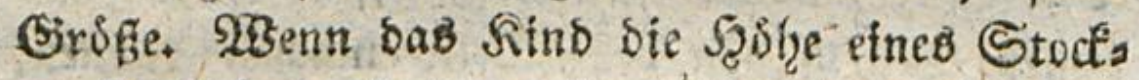
werts fodkrt; fo oiene thm fein Şofmeifter als Meffurbe; wenn bie Şohe eines Thurms, fo

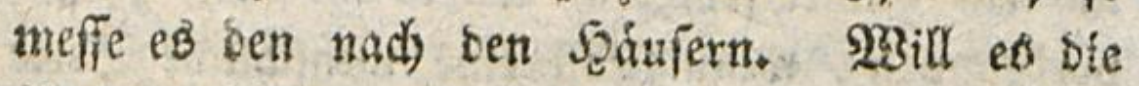
9) Ceilen $198 \mathrm{eges}$ wifĩen, bie es̉ zuriclégelegt, fo zå̉ble 1 es bie Stunben; vor allen Dingen aber thue man aidits sun Diefem fü bas Sitns, fonoern lafie es 2llles felbit tlyum.

(5. ift nidit mogltd, son ber 2 usbeknung und ber Grisfe ber RStper ridtig urtheilen zu lernen, obne baf man aud) babei thre Geftalten ertenne, und felbit fie nadjbtloen lerne. Delia

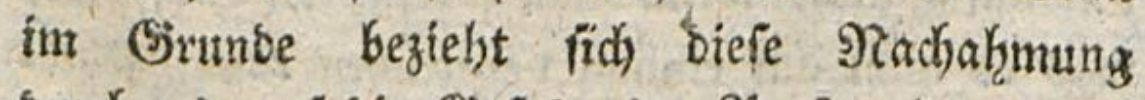
surdyaus auf bie Sefefge ber Đerpective, mis

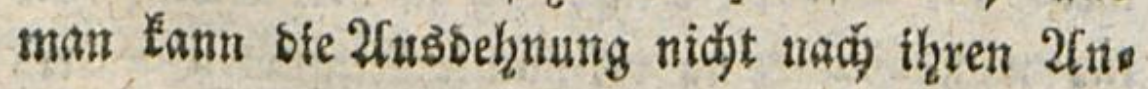

估e 


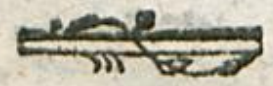

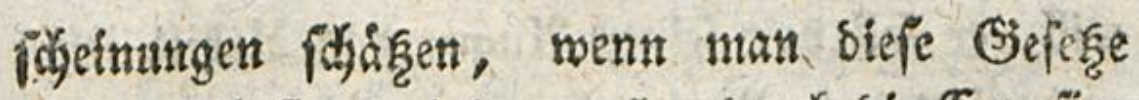
nidjt mentgftens einigermafien ourdy sie (Emp fin soung erkant bat. Die Rinber, fimtlich in

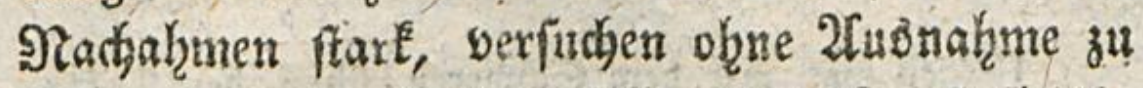
zeichuen; mein aigling follte bieje Rumf fleiffig treiben, ntd)t gerabe ats Sunft, fonbern bicts mekr, samit er ein ridytiges 2 fuge uno eine ges

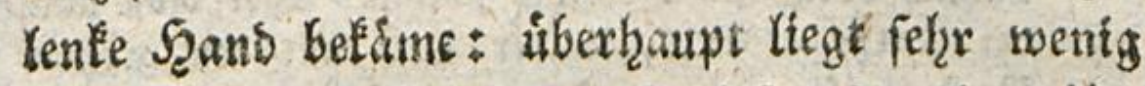
baran, er verftetze fidy auf sirfe ober jene lies bung, wemn er nur sie Scianfie des Sinnes

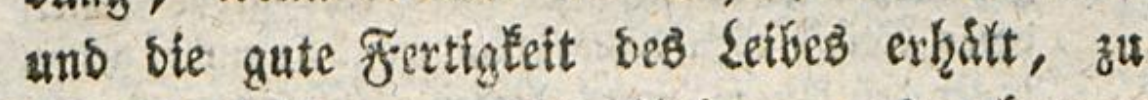
ber eine foldye ober foldje llebung ans getangen

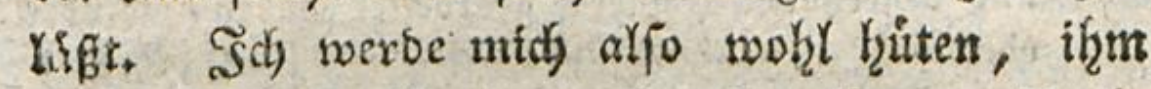
einen 3eidjenmeiffer zu geben, ber tîn nur פiady=

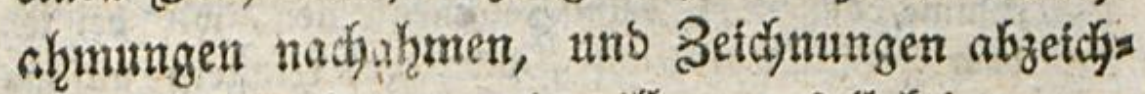
nen laffen whirbe; id will, er foll Ecisten ans bern Éţrer als bie Natur, unb Kein anberes

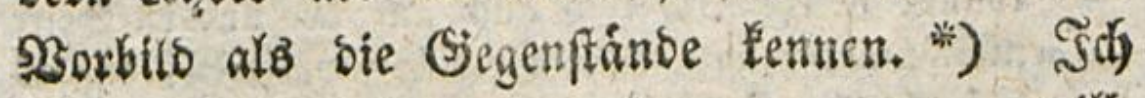
will,

a) Im Sanzen Gat man Itrache wie in allem, fo auth im 3eid)nen mit bem, vas leicht ift, bie Sugens

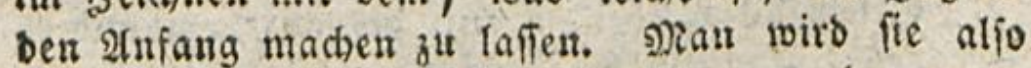
som Einfachen zum 3 ufaumengefeķten uno oon ber Nachbilbung ber Frikchen zur Nactbilbung ganzet Siorper fortgeben ju fiffen Uriache baben. So bat auch cin Sogling bett Tnfang beim Seidnen Damit

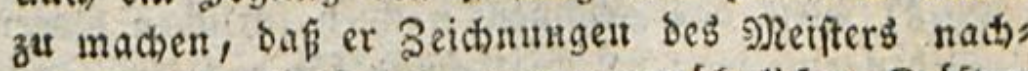
abme. 2ienficen pou ganz ungewóbulidien Siráftez fons 


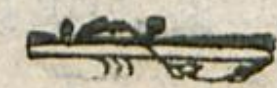

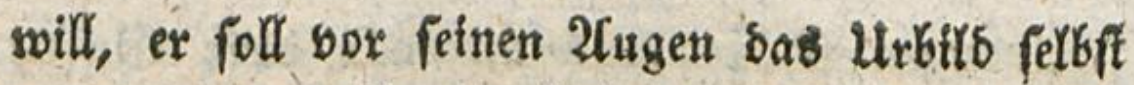 uno nicht bas Saplex haben, wetches es sors ftellt ;}

forthen wol mit bem Gchlweren fibon ben 2 nfang machen, und úber manche fonit zu betretende \$Rittels ftufen binwegfpringen. Hebrigens ift ber Sugend, wie in alfem, fo auch im Beidnen ein \&ebrer febr

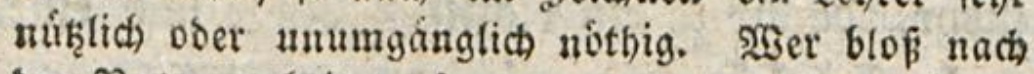
ber Natur arbeitet, fer er auci) mit ben grósten Beiftesłfáften ausgeruiftet, fehlt manuigfaltig, obne es zu merfen. Merft er es nicht, fo gelangt er ine Seblen jur Fertigfeit. Es giebt fehr große Naler, beren Studte eben debwegen, weil fie nidbt genug unter bell 2 ungen eines, ieben Feller bemerfendeu und befiernien sieifters gearbeitet baben, minber ober mebr verzeidnet fint.

(E) lers.

Dhugeadtet i(t) biefer 2 umerfung bariu beis ftimme, oaß̉ man beim Scichnenternen, mie bei jes bem andern Interrichte, mit bem Seichtern anfans gen miffe, und daß man bei Erlermung biefer funft ber f̧úlfe eines guten ఇeifters fthwerlich entbebren. fonme: fo fann ich boch aud auf ber anbern Geite nicht umbiu, uniern $\Re$. Daru beizupflichten, baß es befier iev, doen Sthiler ber Seichenfunit von Anfana an, an Begenftánden ber Natur, als an Nachafmungen Der Natur D. $i$, an Beichnungen fich úben zu Inffen. Die (srúnde biefer Meinung fund: 1) \$Beil man auf biefem $\mathfrak{X}_{3}$ eae eben fo gut, als auf bem andern, mit ben einfachiten Eregenfanden, bie febr leicht nachas" bilben find, ben Infang machen fann; 2) Feil bas

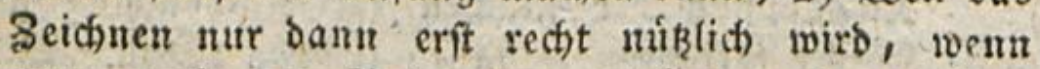
man nach ber Natur zu arbeiten gelernt bat; 3) SBeil bas Scichnen nach naturlicben Gegenftán: ben eine weit beffere llebung fúr bas भuge uno fúr bie Einbildungsfraft ift, als bas Beidhen nach Beich: nungen.

Eampe. 


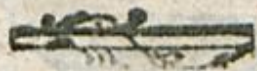

ftellt; ex foll ein Scaub nady einem Şaufe, eis nen Baum nady einem SBaume, einen Menidgen nach etnem Menfdyen abreifien, Danit er fich ges wothne, Die Rosrper und ithre $2 \mathfrak{C}$ (theinungen ridg" tig zu beobadjten, uno nicht falfdje und conben tionelle fir wahre NRachahmungen zu nelzmen. Fल werbe ifgn fogar babon abfalten, ingeno ets

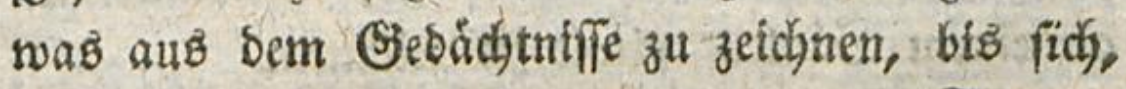
Durd sftere Beobachtungen, bie genauen Figuren feiter Sinbiloungteraft recht eingebriclet Kaben;

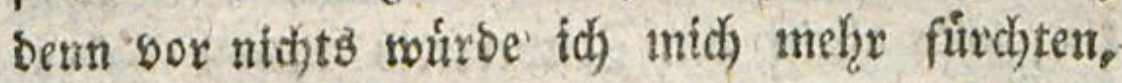

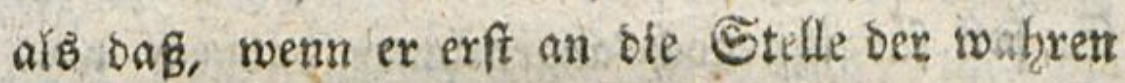
Formen ser Eiegenfiánde feltiame und phantaftis

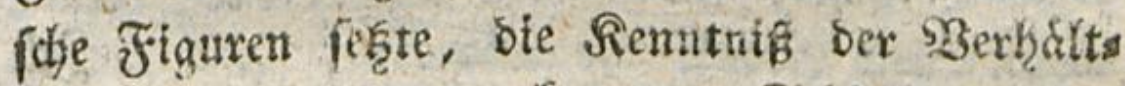
niffe uno ber Gejdjmadé an ben Sdjonhzeiten bex Siatur fur if nerloren gehen migte.

Id) meif̈ mohl, auf bieje 2 seife swirb ex Yange trifgetn, efge er etwas Renntbares berausz bringt; er wiro bie 3̈terlidjeteit ber Umriffe uns ben leidjten 3ug ber Beidjuer exfi fpat, fo wie bie Unterifheibungen ber malerifo, 2 sirfingen uno ben guten (Sejd)mact im Bridjnen, bielleicht niemals erreidjen: bafir aber wirb er zuberlajs fig eimen ridjtigen SBlict, eine fichere Spano,

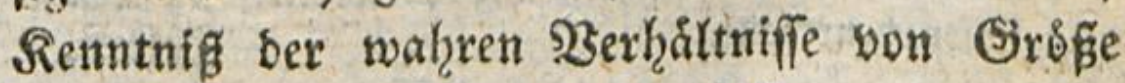
unb SEeftalt ber Zlbiere, ber Pflanzen, ber nas
Emil ster §\%.
it
tirte 


\section{8}

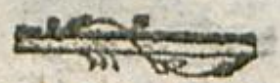

tirtiche Risper, uns eine fatrelleve Errfahrung fin Spiele Der Syerfpective fich ernerben: Dies

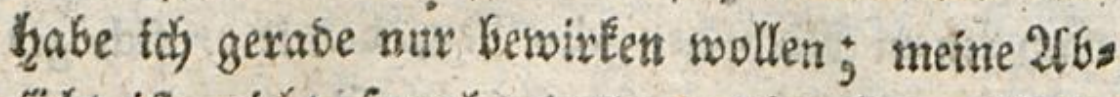
ficht if nicht fowol, oaf ex Die Giegenfisube nad)aubilden wiffen, als baf er fie extennen *) foll. Sid will lieber, ex fonne mir Batrentlate zeigen, unb berftehe minser gut bas Kaubwert an einen Sáulencapitale zu zeidjnen.

Utbrigens vertange th bei biefer Liebung, eben fo twenig wie bei allen anbern, mein $3 \delta$ gु ling folle allein ben 3eitvertreib babon haben. Ev foll für ifin nod) angenefimex saburch wexs

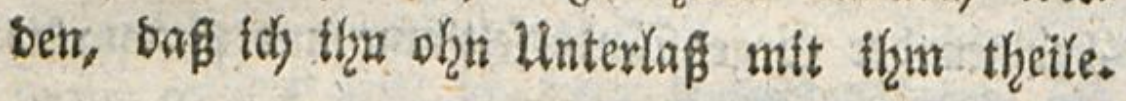

7) Sgerbent bie Itebungen nidjt gehorig angefellt unto gelangt ber Neen(d) nicht bei jebem Fehitritt, ben er thut, fur Eifenatuib bes Febiftritts: fo erfolgt endos lich eine mangelbafte und irrige Erfenntníp forvol, als eine mangelfafte utho feblerfyafte fertigfeit in ber Niachbildung ant feblerbaften llebungen ente fpringt. 23ser auch nod to febr fich ubt zu einem. guten গ্র gen fu getangen unto nidit butrd Niefien feine irris aen 20 orfeflungen beridtigt, twirb nie fo weit in ber Eichergeit bes \$litifs fornmen, als ein Menfith, ber

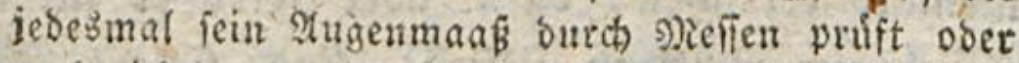
nach riftigen optifchen und peripectiviftben Sienuts nifisn beurtheilt.

(E) Ter's.

Aber Dergleident allersings nóthige ஒerichtigums

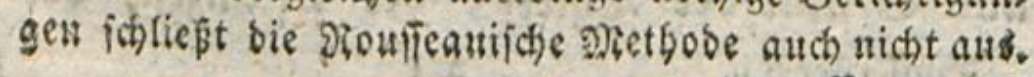

Eampe. 


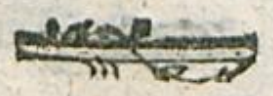

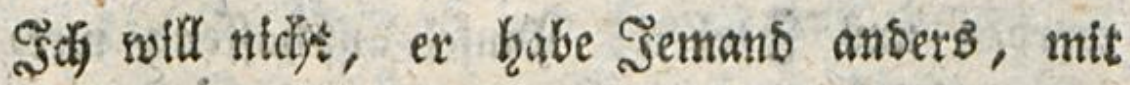
bern ev eifere, ") als mid); idy werbe aber

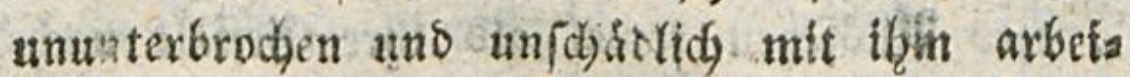
ten; Dies wito Sntereffe in feine Bepdaftigun

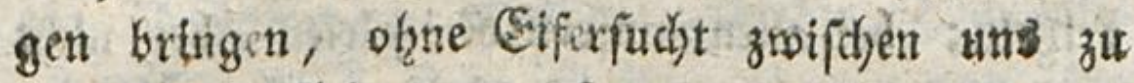
erweden. Silh werbe, fo wie er, beth Bleiftift

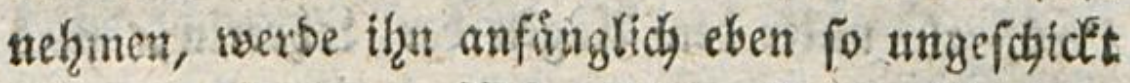

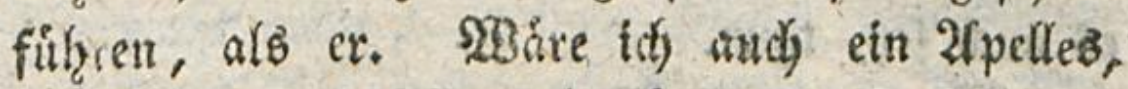
fo wirte id) hitex nut (S) getat)nete anfänglidy einen Menfdyen, wie bas

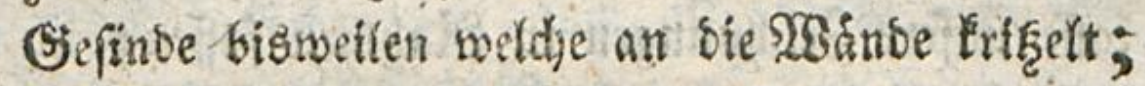
jeben 2 tru, jebez Soein ein Stridy, unb bie Finger groffer alo ber 2 rrm. Eange nadjher werben wir, Einer ober ber 2tnove, diefes Miz: berbaltniffes gewabre werben, mir werben bemers $\mathfrak{k} e n$, ba saff biefe Dicte nidjt won when bis unten bies

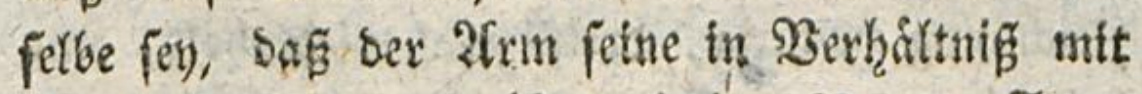
bem leibe beftimmte Eange habe. Bei ben Forte

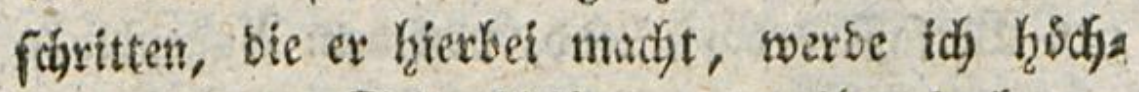
ftens ifm zur Seite blefben, ober ifgm sod) nux fo wenta juoorellen, baff ex midy fets leidjt wirs einholen uno of tmals ibertreffen Eonnen. SMBir

$$
\text { It } 2
$$

suers.

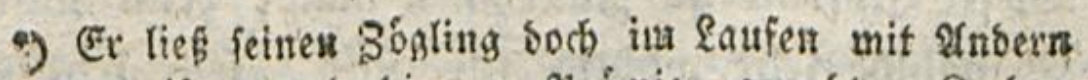
wetteiferł uno Die zur \$rámie gemaditen Suber

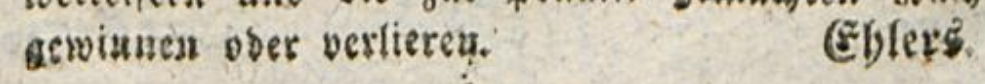


werben uns Farben, Spinfel anfduaffen; wets ben fuchen bas Eolorit bex S̈egenftande und thr ganzes 2fubjelgen fowol als ihre (Seftalt nach) zuahmen. STir werben ifluntniren, malen, Erişeln; bet allen unjern Rrifeleten aber nidjt

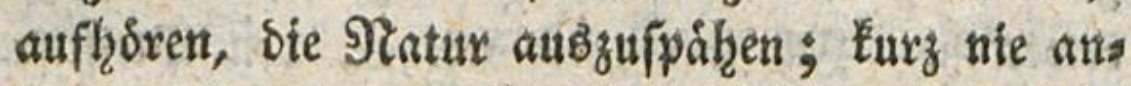
berb, ałB unter ben 2fuget ber Sefzrerit, was eB aud (et), thutu.

WBir waren in Serlegenheit tut 3ierrathen fitr unjer Zimmex; nun haben wir weldje. इdi laffe unfere Beid)nungen in SRahumen faffen; ich laffe fie jauber unter Ģlas féfert, Dafs niemano baran ritbren fonne and baf jeber bon uns, da wir fie in bem Stande bleiben jefren, worin wix fie gefert haben, ein Sntereffe sabei geninne,

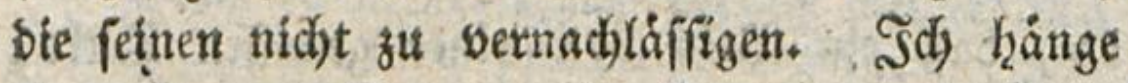
fie nady einer Sronung im 3immer auf; jebe 3eidhnung swanzig, oreifigmal wieberholt, uns bet jebem neten Exemplax die Fortidjutte feis nes 3 erfaffers barftellens, won bem 2ugenblicte an, wo z. (E. Das gezeid)nete Şaus nur ein faft unfórmlides $\mathfrak{B i e r e c t}$ war, bis zu bem, mo feine Facabe, fein Profil, feine Serhåltnifie, feine. Sdjatten nadj ber genaueften 2 gab̧rheit finb. Diejes ftufenweife 3uneţmen macht benn unfre

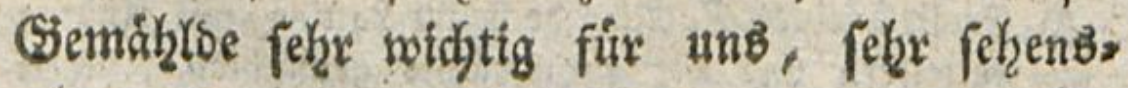
wits 


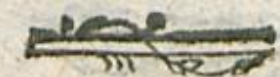

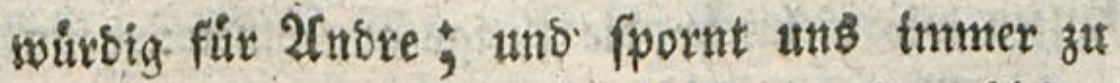
nenem 2 setteifer ant. Die exften, bie grobbften Defer 3etdynungen faffe id in glänzende, fajon vergoloete, fie erthebentie Sahgme; wiro aber bie Tiadjahmung genauer uno die 3eidhntng

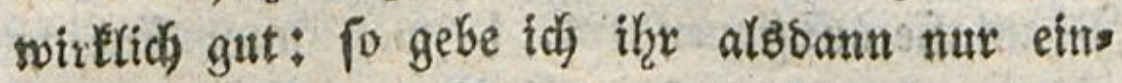
facthe fdymarze. Sie braud teines andern

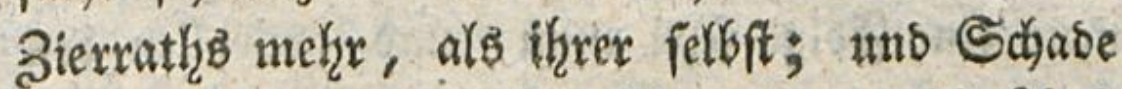
witroe eB fenn, wenn bie limrandung bie 2 nuf mertfamfeit theilte, weldye ber Segenftano vero sient. Gever son uns alio frebt nach ber

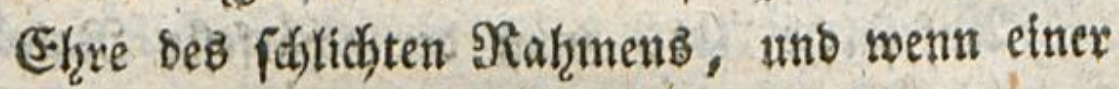
bes anbern Seidnung berachten will, fo vers bammt ex fie zum vergolbeten. Diefe bergol: beten Rahtmen werber bielleidjt ins Rinftige unter uns zum Sprichwort werben, und wir eß init నerwunberung bemerfen, wie Nandjer fich Seredytigleit exweift, inbem ex fich fo eins fafien lápt.

Sab) habe gefagt, bie Seometrie ifberftiege bie Frafinngerraft ber Rinber; eB ift aber uns

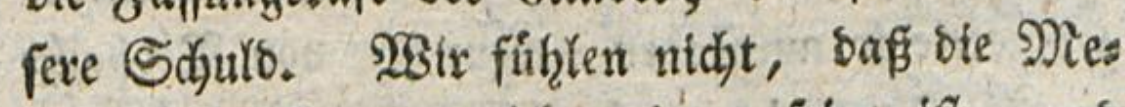
thobe ber Sugeno nidjt bie unfrige ift, uno baf, was fir uแs bie Siunft zu ratfonniren wiro, fur fie nux bie Rumft fu feben fenn muß. 2frftatt ifuen bie amfrige beizubringen,

$$
\text { \& } \mathrm{t} 3
$$


ollten wir bielmehr bie ibrige annehtuen: Demn mifere 2rt, bie Seometrie zu lexuen, ift mol eben fo fefar eine Sartje ber Einbiloungs = ats

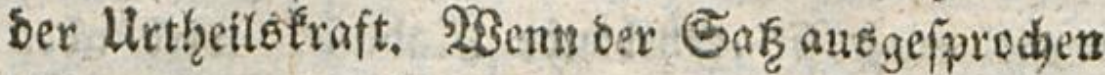
ift, mus man fich ben $\Omega$ seneis bavon in bex SPhantafie aแs่finnen, o. t. man mug finben, ans meldjem uns fohon belannten Saz̧e oiefer stue eine Folge fenn tunf, uno aus allen ben Fo'gen, bie man aus jenem Sarge herleiten łann, gerabe diejenige wábllen, woranf es it sem gegebenen falle antismmt.

2uf foldhe 2(rt, mas ber fdodrfefte Rais fonneur, wenn er nid̆t erfinofam tfí, zu Eurz

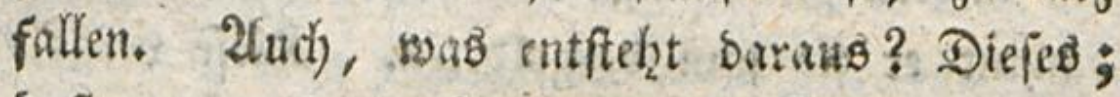
baf̧ man ans, auftutt uns bie Errvetfe finden gu laffen, fie nur borfagt; dafi ber Eehrer, ftatt uns raifonniren zu lel?ven, nux für uns xaifonnirt uno uner (S)edód,tnig úbt.

Reift genme Figuren $a b$; berbinset fie, regt fie eine liber bie andere, unterfucht ihre Serbáltniffe; ihr werbet bie ganje Elementar= geometrie fo ausfinten, wenn ibre bon Seobacks= tung zu Brobadtung fortichreitet; of hne baf oa, sweber defintion noch Sroblema, noch irgens eine an'ere bemonfratibe frorm, bie blofie Sils perpofition allein anghenommen, bortommen wiro.

șd 


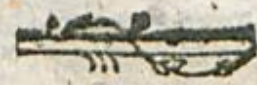

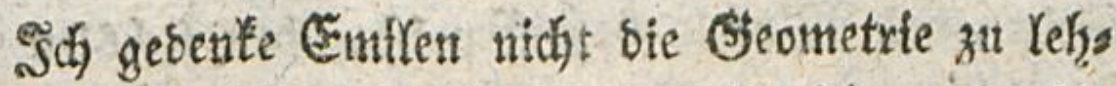
ren; er foll fie mich leţren; *) idh werbe bie Sertzálţiffe fucten, uno ex wirs fie finden; Denn id werbe fie fo fuchen, oag itif fie itha

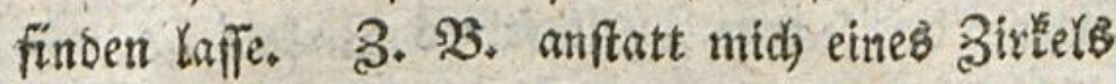
gu bebienen, um cinen Rreis abjuzeid)nen, werbe id) ifgn mit einer Spifge an bem Ente eines Fabens, Det fïh um einen feften Mittelpunct

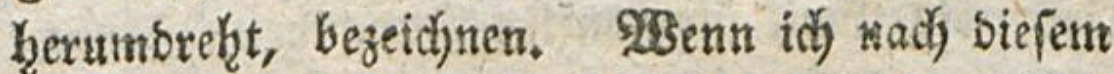
bie Rabios unter fich werbe sergleidjen wollen, sirs fid Eunil iber mich auflalten; uno mix begreiflid machen, bafi ber auf gleidje ${ }_{2 B e i f e}$ gefpannte Faben, Eeine unglethe Dinftanzen tann gezeidjnet habent.

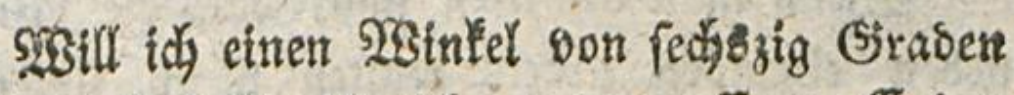
meffen, fo befdrreibe th an ben offenen Enbent siejes 2 Bintétż nidht einen Bogen, fonbern eitren ganzen Sireis; benn bet ben Finbern mus man niemals etwas fubintelltgiren. Ş⿻ finbe, bas Der Theil bes Sireifez, ber zwifdyen ben beiben It 4

Sito

\section{*) Ein blofes 2 gortipiet.}

(E)Glers.

SEorin aber boch ber gute Etun'fieat, baß $\Re$. nach focratifher 23 seife, mit feirem Süglinge nicht Dogunatifren, fonbern bei angenommener eigener this uvif̂enfeit butch einfáltig focinende Fragen babin bringen soill, ben Hnterricht, ben man ifm zu geben minisht, jelbft zu finbert.

Eampes 


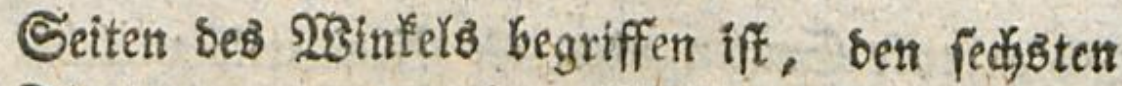
Theil babon ausmadit. Stach Siefem befdurefte id) liber biefem hinaus einen anbern grofern Rreib, und ich fittoe, bafi biefer zweite 20 gen wieber ber fechste 3heil feines Birkets ift; ich befchreibe einen britten concentrifchen; an sem id) bon nenem siefelbe Shrobe madje; unt ids forhre immer bet fernern Birfeln fo lange bamit fort, bis Emil iber meine Dummbeit erftaunt, mich) benadiridjtigt, ein jeber 30 gen, ex feb grofí ober flein, bex unter einerlei $\mathfrak{B i n t e l}$ bes griffen ift, múffe ftets bex fechste Iheil feines 3irfets fenn u. F. w. Da fins wir benn gleich) bet bem Gebrauche besె Iransporteurs.

$23 e n n$ man beweifen will, baf bie $23 i n t e l$ neben einanber zween redjen gleidh fins; io befdjreift main einen 3irtel. Sod hingegen madje es fo, baß Ermil biejes zuerit in bent Birtét bemerte; und barauf fage id zu ifgm: wenm man ben Sirtét roegnåkgme unb bie geraben Lis

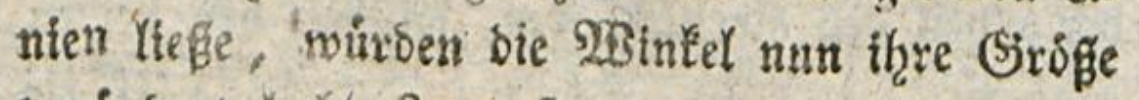
verdnbert hatern? 4. f. $m$.

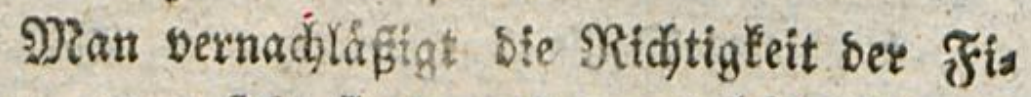
gurer, mau fergt fie voraus, und hâdt fich nut an ben Erweis. Unter uns bingeaen wirb niemals won bem Errweife bie Rebe fenn. Ulms fere 


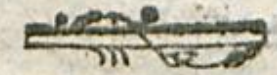

605

fere widjtigfte 2 fngelegentgeit wirb fenn, rectit gerabe, rech)t genause, recht gleidje Sinien zut ziehen; ein Sierect redjt solltemmen, einen 3ir: Eel recht runo zu madjen. Llm bie Ridhtigleit ber Frgux zu bewábren, werben mir fie nads allen thren finnlich bemertbaren Eigenidhoften unterfuchen; uno stes mito unB Gielegenheit geben, ti̊glid threer neue zu entoedten. 233 ir werben burch Den Durdimeffer bie beiben Scalbs zirtel, burch bie Diagonale die beiben Soflften bes $\mathfrak{B}$ icrecti zufammenlegen; wir werben uns fere keiben Figuren bergleidgen, um zu fehen, weldse bavon fid) mit threm Ranbe am ges naueften bedien, folglids am beften gemadyt febn wirb; wix merben uns baxiber freiten, of

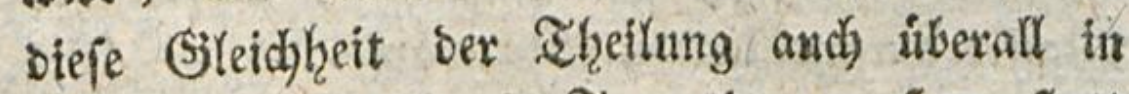
Parallelogrammen, in Irapetien, H. F. w. ftatt findet? Man wiro zumetlen verfuchen, ben Exo folg ber Erfahrung vorherzufehen, eḩe man fie anftellt; man wirb fith bemiizen, Srrinbe auss zufinden $\mathfrak{u}$. f. w.

Die Sieometrie ift für meinen $3{ }^{\circ}$ gling nidgte, als bie Runft, fity bes Sineats und bes 3irs felsz wol zu bebienen; ex mufip diefe beiben Sas dyen nid)t mit bem 3eidjnen verwed)feln, wozu or Keines oon jenen 9 Bertzengen anmenden wirb.

$$
\text { It } 5
$$
Lis 


\section{6}

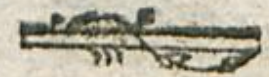

Sineal und Binkel werben unterut Sthlog uns

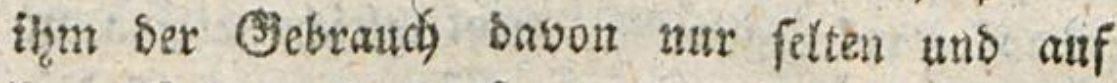
furze Seit verfrattet fenn; bamit ex find nidje ans Arifgeln genobhne; wir wereen aber zuweis Yen unpere Figuren mit anf ben Spariergang nefmen, tmb liber bas fdyargen, was wir sernadt haben ober nod madien wollen.

Shl) werbe es nie vergeffen, in Zurin einen jungen Nienfdjen gefehen zu haben, Den tran

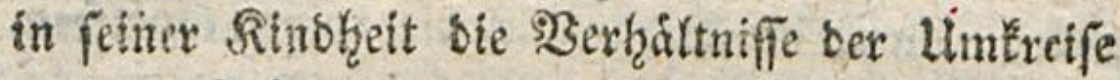

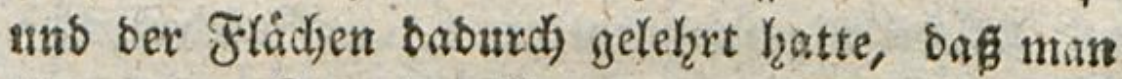
ifgm jeben $\mathfrak{Z} a g$ in allen geometrifdjen Figuren

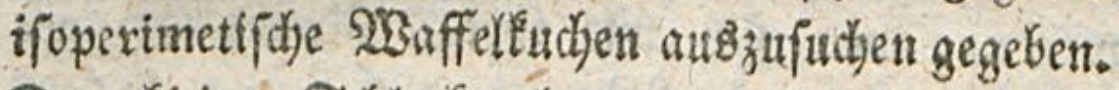
Der Eleine Sdyluder Wratte bie Runfi bes 2trs (b)inebeb erfdjopft, tum zu finben, an weldjer 13 affel am metften zu efien wáte.

,2Benn ein Sino ben Ball follagt: fo ibt

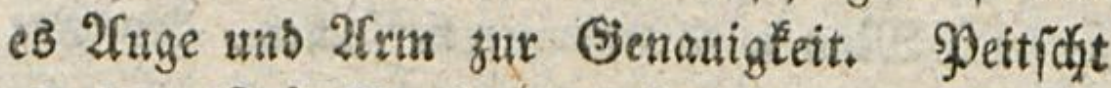

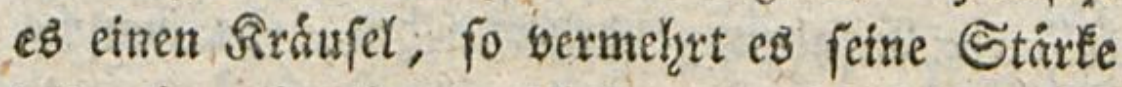
saburth, aber Yernt nidyts weiter Sabet. Sdy bुabe bismeilen gefragt, warum man bie Rinber

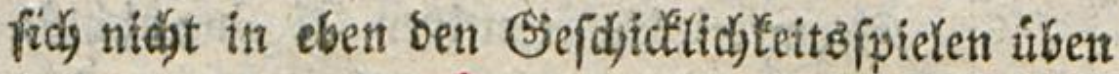
Yiefie, womit fich Ertwadyfene befdiftigen; in

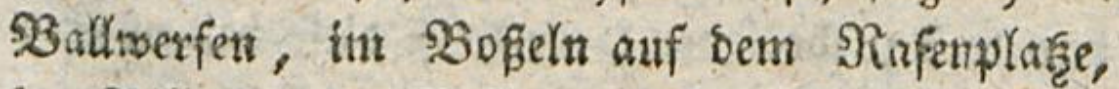
im SBillaxb, im Ballon, auf muifielifichen ș frumenten? Man bat mir geantwortet: einige ofes 
Stefer Spiele waren iber thre Srafte, nno thre Slteber und Srgane zu ben anbern nocy nicht glebiloet genug. Dieje Urjacken aber f̧alten nidjt Stid. Sin Sino hat richt bie Giroffe eines Nannes, unb tright bemohngendytet ein Rieto wie Ser Errwadfene. Meine Mieinung ift nityt, es folle mit unfern Mafen auf etrem bret $\mathfrak{F}$ uf bzoken Sillarb fpielen, nidjt, man folle in

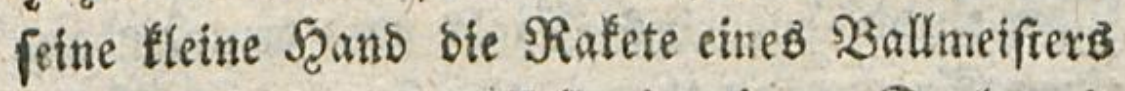
geben; fonbern es folle in einem Saake mit wohtberwahrten Fenftern atno mit feinen ancern als weidjen $\mathfrak{B a ́ l l e n ~ f p i ł e n ; ~ m a n ~ f o ̈ l e ~ f e i m e ~ e r f i t e n ~}$ Raketen bon Szolz, barauf von Pergament unb

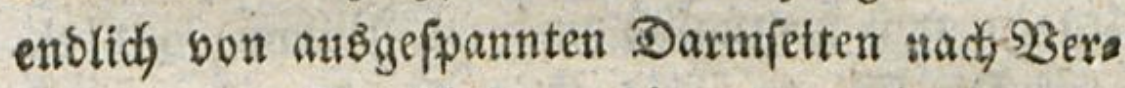
båttrifí ber Foutichritte, bie es machen nirb, fenn laffen. Şhr zieht ben Feberball oor, weth ex nidjt fo ermubet, Ino es Eeine Siefab̧r babei giebt. J̧b̨r habt aus zweterlet Urjache Unrecht. Der Feberball ift ein Spitl fir SIBetber; bor meinem Ball im Fluge híngegen nimmt gewif jebes Frautuzimmer bie Fludat. Shrre weife Şaut barf fid nidjt zu Dutf(d)ungen abhárten,

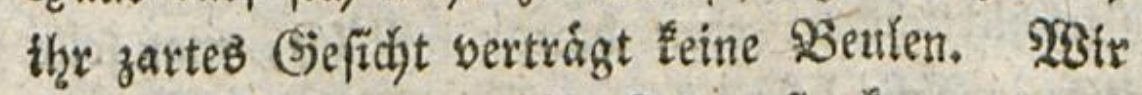
aber, bie wir gemadit find, ftart zu fern: hoffen wirs, ohne Erfahrung vom Sobmerz

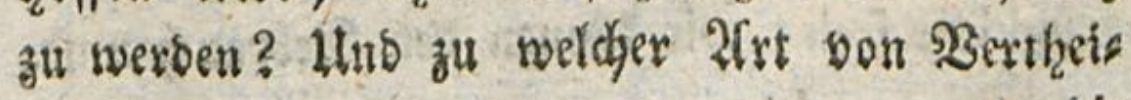
bis 


\section{8}

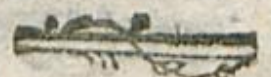

Digung birnftent wir fágig fenn, went wir nies malB angegtffen witroen? MTan fpielt ote Spiele Preto eleno, in senen man obne Šefabir unges flictit fenn famn; ein Feberball, bex niebers fallt, thut uiemano Sobaben, abex nidjto machs bie 2irme fo gelent, als wenn man feinem Ropf

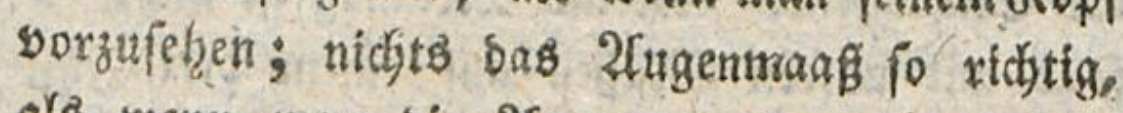
als wenn man bie 2rugen zu berwahren bat.

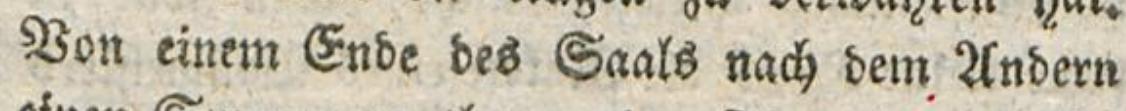
einen Sprung zu thum, ben Jług eines 20 alls in bex Luft zu beurtheilen, thn mit ftarter uns fichexer Saans zurid zufenden, Dergleidjen Spiele geziemen fich nidjt nut für Mánner, fonoert

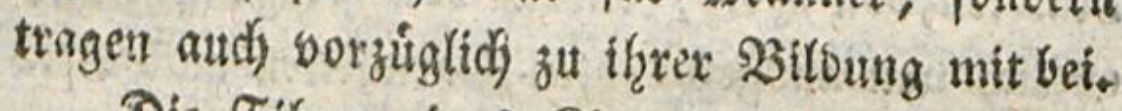

Die Fibern eines Rinbes, fagt man, fins zu weid), fie haben weniger Sdjnelleraft; abex eben besmegen fino fie befto biegiamer. Dex 2rm des Rinbes ift fobrody; aber am (5noe ift

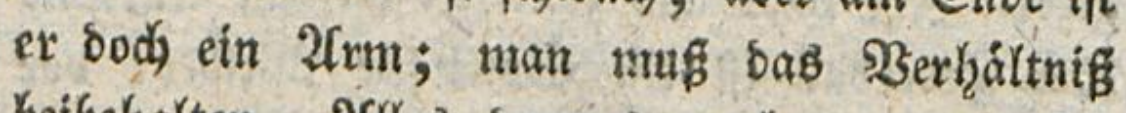
beibefalten, 21llez saraus mačen, was fich aแts einer andern åf̧nlidjen Mafdine madjen ráfit. Die Rinier haben in ifrren Şänden nod) Feine

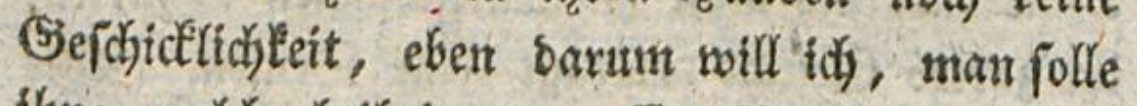
thrnen weldje beibringen. Sin Maun, ber eben fo wenig Uebung befäfe, alö fie, wuirbe nidat gejdideter jegn; wir tonnen ben Siebraudi unjes 


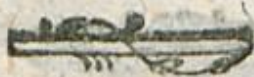

ref Sorgane nidjt eher extemen, als wenn wir fie erft angetwand haben. Niur eine lange Ers

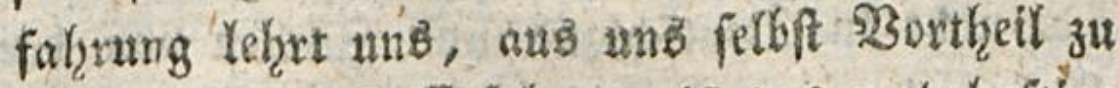
ziehen, uno otefe Exfahtung ift bas wathrhaftige Stubtum, worauf note uns nicht frúbzeettig genug Yegen Esunen. *)

2flles, was mast thut, ift thubar. Natu aber trift man nidts bånfiger, als gewanote uno gelenitge Rinber, Die eben bie sehenoig. feit in ben Glltebert baben, als nut ein Mann fie befifen tonn. Faft auf allen Sahrmårtent fieht man ifrer, bie Equitioniftentinfte berftes hen, mit ben Scanben geל̧en uno auf bem Seile hiupfen, tanzen. Sasie viele Sahre lang bza: ben

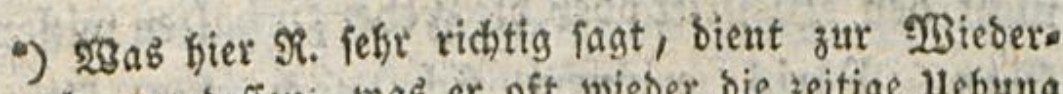
legring befien, was er oft wieber bie zeitige Hebung

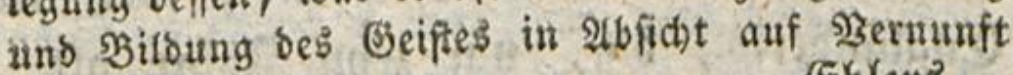
uno serftand fagt.

(E) $)$ lers.

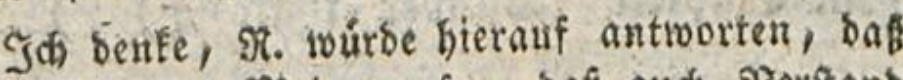
ex allerbings ber Necinung (ct), baß auch Nerftano unb Sernunft burch Hobung uno Erfabrungen aus? gebilbet werben múfien, aber baf bie litterarifonen Hlebungen biefer hófern Seetenfráfte, noch nicht fúr bie Rinobeit gelgorten; baßß bei biejen vor ber 5anto erit alles barauf antomme, bie Ginne uno

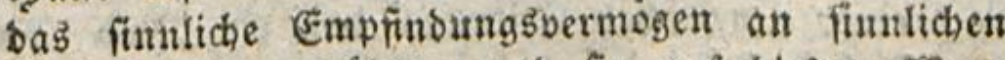
Gegenftánbeh zul uiben, und fie auf biefem şBege erfit einen Sthat von Erfabrungen einfammeln zh

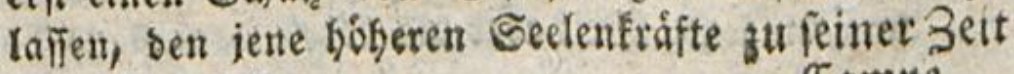
bearbeiten follen.

sampe. 
ben ganze Sintertruppen surch ifre 3 allette 3ns foraner in bie itultentiche (Somboie gezogen? $23 \mathrm{et}$ hat nift in Deutidilano uno Stalien won bes

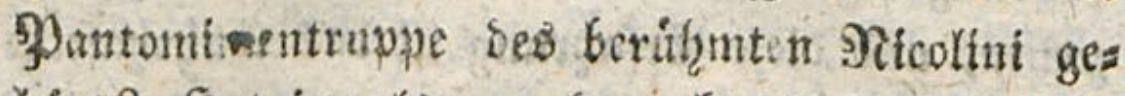
hơrt? Sgat jemalos wer benertt, Daff biefe Sitn Der nid)t clon jo entwickert in thren Bemegungen, nicht eben fo anmuthig in iffren Steilungen, nidjt eben fo ridbrig in threm Sieţis, nidjt ebent fo leidyt in ifhrem Zanze ģewefen wáren, alỏ die fojon ganz gebilbeten Tänzer? Şhre J̛inger fins anfänglidy bide, furr, nidst fehre beweglid), ihree

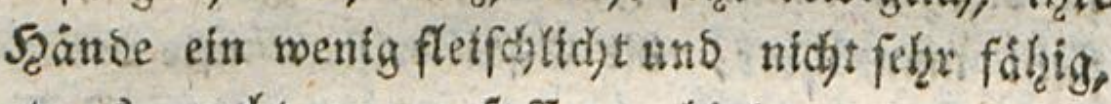
etwas recht zแ umfaffen; linbert bas aber, Dafi nidit ifree manche in einem 2fter foron fidreiben ober Beidynen tonnen, wo andre noch nifit ben 3 leiftift ober bie Feber zu halten wiffen? Sanz Saris exinnert fich nody ber fleinen Englanberin, bie, nut zefrn Sahre alt, aup bem (Elabiene 2 Bunder that. t) *) SEl habe bet

\$) Ein fleinter Sinabe bott fieben. Sabren, bat feitbem

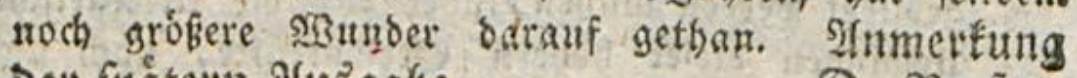
Det fpatern 2 uảgabe.

D. Berf.

-) CEgent izat (beir 25. Jumius 1788.) erfefe ids aus einer Englifcten Beitutrg, ১ấ ein Stino von brei Gabren burch ben hoben (5rao ber Gertigfeit, wo mib es bas Elavier fpielt, bie Sutfórer in fonden in Ete

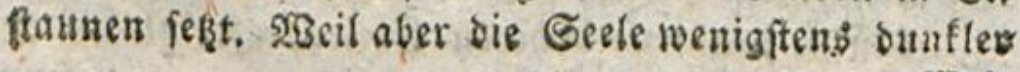




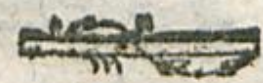

Get einew gewiffen Mianne, ber eit obrigteits Vidje 2fmt befletbete, feinen Solgn, einen Sinas

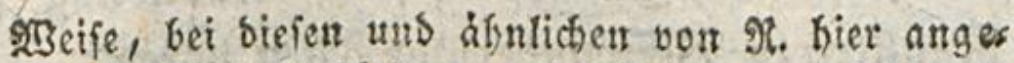

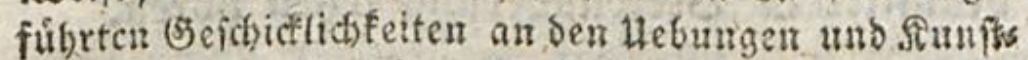
fertigfeiten des Norpers Fheil nebmen, uno bes feinbeftimmten uno fónelfen Betwegungen defie!ben folgen mutī: to wito Die menfchliche शtatur babei

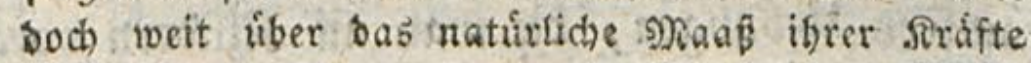
angegriffen. Tener Elavieripieler wirb getví nidjt alt, unto falls er alt wirb, feis Şändel merber.

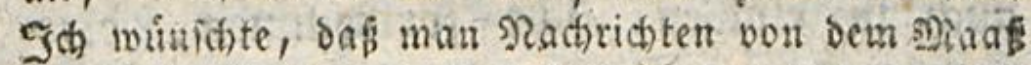
ber Sefmbbeit uno bes febens ber Sinder, Die sicolini gebilbet und gebraudit hat, und befonders auch) von bemestrabe ber Seclenfráfte, bie fie in ber folge mógen bemiefen haber, irgetrowo gefammelt bátteg mo fie ber S33ett mittheile. Niachoem, was ith vou ßerionen weib̈, welche bei ben Hebungen uns beim Ithterricht jener fituder zugegen getoefer, unb nach ben, was id it den Ricolinifton Pantomimen felb fit zu meinem uno aller anvefenten bochpten Erfauten von jenen findern aubgefiifrt geieben habe, zu urtheileu, mífien fie balb ju allen Schwád)en bes bofen elterb gefomment und fefor jung gefforber

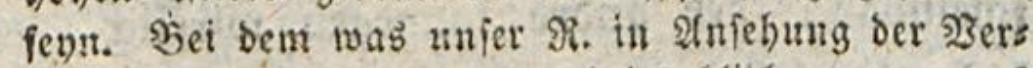
fanbezccultur fagte, uno vorichrieb, blieb er gaus auf ber einen Geite ber Mittellinie: unb bier ift es auf cinmal gam auf ber andern Geite bawon abgewidhen. Éler's.

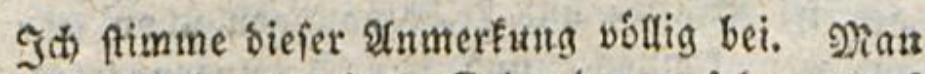
wirb aber enth auts bem folgenden eriehen, Daf

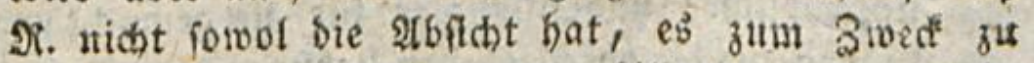
machen, iunge sjirtuofen zu bilbes, als vielmebr

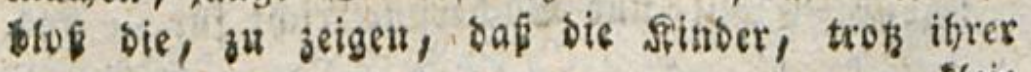
fleip 
ben bon adjt Sabren, ben man beim פachs tifche, als cine \$ुuppe jum 2uffar himftellte, eine foft eben fo groge Scige, wie ex felbft war, pielen, uno surch fine 2tububung fogar Rüftlex in Berwumberung feEzen hơren.

2llle btefe uno taufend andre Beifpiele bes

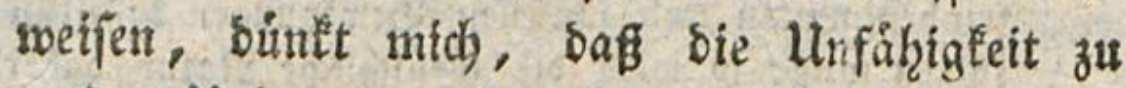
unjern Ulebungen, bie man an Rinbern borauss. fekt, nut eingebiloet fer, uno bag, wenn fie autb in eintgen nidjt fortfommen, stes nux saber vifhrt, baf man fie niemals barin gea ubt bat.

Dian wirs mir fagen, idh fibeitexte hier in 2rnjehung ser silbung Des Seibes an ber Silips pe, beb: zufrufl); vor ber id bet Rinbern it

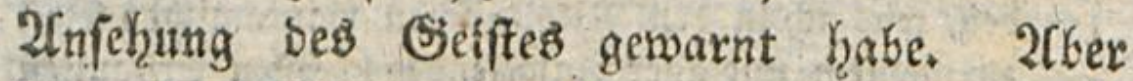
bier ift ein fefre grofier Ilnterfoties zu bemerten. Dentr ber eine son siefen Fortíchritten ift nux

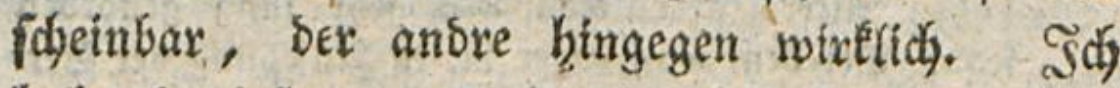

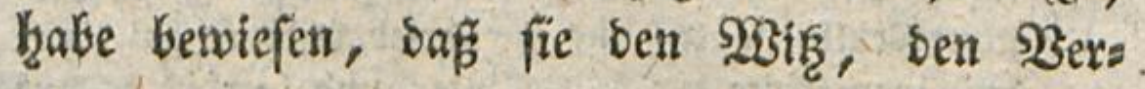

ftans,

Eleinen unauggebilbeten Bstiesmaapien, eร boch in allers lei Suruten uno Reibestubungen fd)on (eh) weit brins gen fonnen, uno bấ Hebungen folcher Aft viel unicháblicher und nüblicher fúr fie gemacht verben fonmen, als bie úbertriebenen Hebungen des \$eritanbes

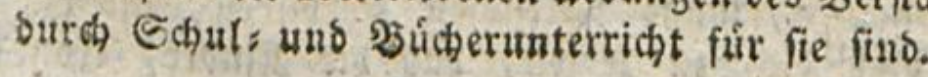

Eampe. 


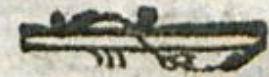

ftanb, ben fie zu haben fochetnen, nicht has ben ; *) ba fie fingegen 2(lles wirltich thum, was fie zu thun fodeinen: íberbies mǘ man

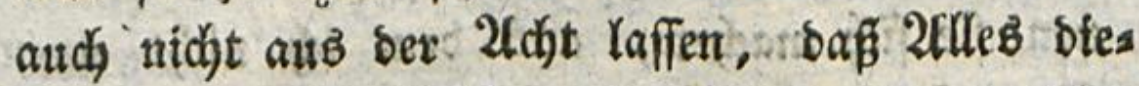
fes nur ein Spiel ift, ober ferno anuf́, baf es cine Yeichte und freimillige Sentung ber SBetwes gumgen ift, weldfe die Satur von ifnen for Dert; * * ) eine Runft, ihre Zeitbertreibe zu beråns bern,

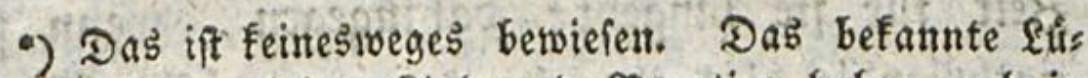
bedfoce gelebrte Sind und Saratier baben aud in 2tnfebung ber Seele eben baz geteiftet, toab in ben

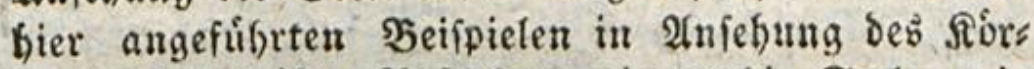
pers geleiftet ift. 2tuferbem nimmt bie Seele, wie id fhon bemerft babe, an ben, was burch ben Robrver ş̧underwolles geleiftet wirb, fegr ivefentlich Ebcil.

(E) โ)

Die Eeele wirft ja aud bei allen bieien Her bungen mit, und wiro in ibren Săbigteiten zuglei geúbt.

*) şsie ivenia benft hier $\Re$. an bie fállle, bavon bod

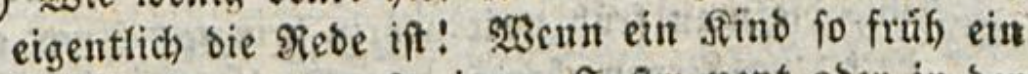
grofer Spieter auf einem Saltrtiment ober in Der Pantomime twirb: to it bas wahrlid nicht blok bie WSirfung von einer blok noch einer folden sunfts fertigfeit unaufbaltbar Ginfrebenben Raturffraft. Die nicolinischen Sinder haben, wenn fie zu ibren Her bungsfunden gerufen fino, gegittert itno gebebt. Das ift aud) ber Fall fehr oft bei ben Sinbern, bie man zum Seiftanzen unb zu Balancirfinten ges braudt, felbft in ber Beit ber óffentlichen Darfelliung.

Eblers.

Emil Ifter $\mathfrak{x h . ~} \quad$ औt 
Sern, um fre thenen angenefomer zu madjen, ohne bafi jemals ser geringfte 3 wang fie in 2 rbeit bertehret. Dent furz, weldfen Bెeitbertretb ton nen fie fid madjen, auti bem tơ nicht einest Segenftand deb Unterridyts fúx fie zu madjer soifite? Itno wenn id bies aud nidft verffitinde, fo liegt mircan ifgrem Fortforitte in jeber Sadje, infofern $e B$ bsis iţt betrift, fehr wenig, went fie fich nux unichadolich beluftigen, ") uns sie 3eit fur fie kitngeht; Dafingegen, went fie nothwendig dies ober jenes \ernen múffen, ***)

ftets,

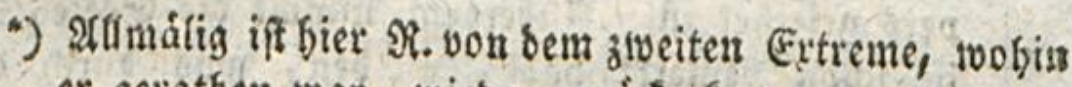
er gerathen war, wieber zuridgefommen.

(5blers.

"*) Dic Sindertimppe von Nicolini batte im eigents likchen \$erfande weit mehr zu lernen, als bie Sins ber zu lernen haben, 'bie man frubzeitig in ber S̈eographie, in ber (3efchichte u. f. w. unterridgtet uno bie man frúf weit worin bringt. Afuch erfors

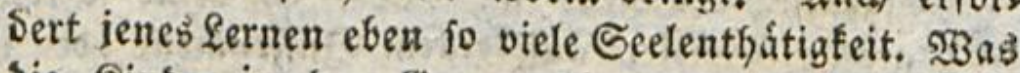
sie Sinber in ber Seographie u. F. w. lernen, if nutch eben fowol Realitát in Snjefung ber Ers fenntnifi, bie fie erwerben, als bie Nunffertigfeiten Realitáten fino, wozu fie gelangen. $\Re$. Dentet unb fdreibt in allen biefen Dingen nicht âs ein déter Nienichenfenner, nidat als ein Miann von grúnblis ben pinchologischen నentutnifien uns vorzuglich nicht aIs ein Mann, ber fif vor cinfeitigen Beipteşlicfen und vor leidenf(baftlichen uns launigten Syin = uns foer 


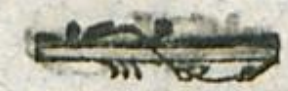

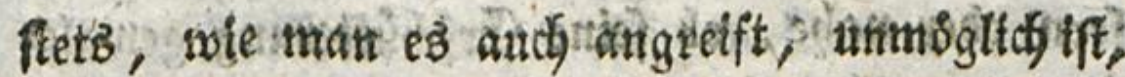
Bamit fortzutotumen, ofye tfgren 3wath atgos

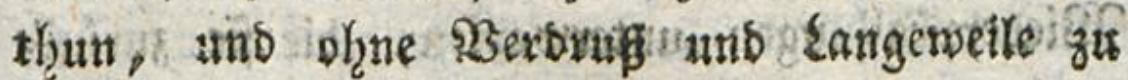

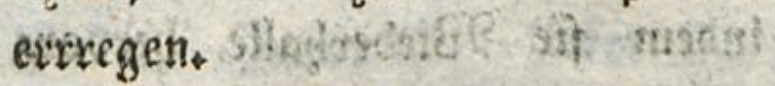

ifyilis:

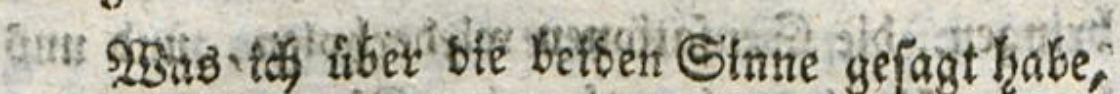
berent Sebraud ser fortgejesteffe uns widitigfte ift, tamt als Betfpiel iber bie zrt otenen. wie man ste ibrigen fiben folle. Das (Selidft uns bas Sefthl wetsen auf gleid)e 2frt bef

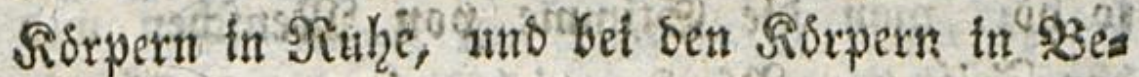
swegung angewantot; ba aber nur bie Erydjuts terutg ber fuff ben Sint bes (Siphoirs betwegen

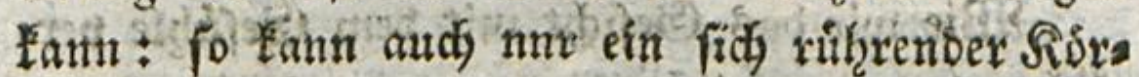
per Geránfíd oder Rilang berurfacjen, unib nits

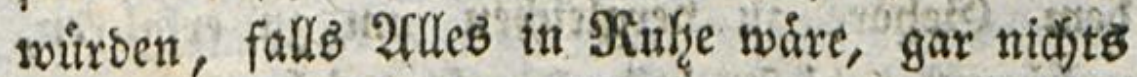
lioren. DeB STarits alfo, wo wir uns fetbit tum fo viel bewegen, ats eB uns gefalft, unb bafler nute ste Sisrper zu firthten baben, bie fids betwegen, lfegt und siel baran, ein wacfjes (Ses hobr zat haben, um burch die Senfation, ble auf uns trift, urthetlen zu somen, ob ber Sisrper, ber fie serurfacht, grof oder tletr, $\mathrm{Hit}_{2}$

fern

Serichwanfent gtwifben sent auf beiben Geiten ser 5ु3abrbeit uno bes Fechts liegenden Extremen mit manubafter Bseiftesfraft zu bútent weip.

Eblerz. Niefervito 


\section{6}

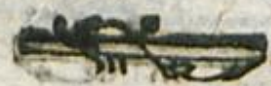

ferm ofer nake, ob feine Erfódtherung gewalts

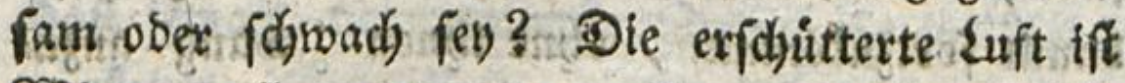
NBieserpraflungen :u unterworfen, bie fie zuricts treiben; sie, inbem fie $93 \mathrm{Gteberhalle} \mathrm{kervors}$ bringen, ofe Senfationen wieberhoten, uno uns Den raufhenben ober tonenden Rorper bon einem anbern Snt boren linfen, ald an bem ex fich. Gefindet. SWBenn man in cimer Ebene, ober in einem Thate, sas Shr an bie Sroe legt; (o hiort man bie Stimme pon Menityen unb ben Zxitt bon Pferben viel weiter son fich ab. als menn than anfredift ftetzen bleibt.

SBie wir baß Eeficht mit bem Giefüble bre glidjen baben: fo ift cs auch gut, es eben fo mit sem Gefiore zu sergleidjen um zu erfahren, weldjer von bieien beiberlet Einbricten, bie zus gleidh von bemjetben Rópper abgeben, am erfen

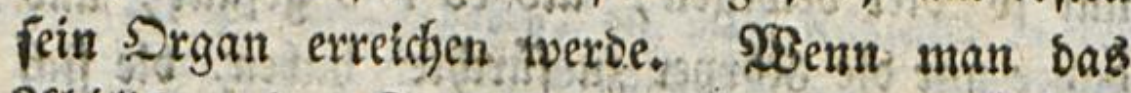
2 cbblizen einer Rampne fieht : fo fann man nod vor bem - Sduffe untegondien; fobals man abeg ben Ruall hort, if es nidht methr Beit, sie Rugel if ba. (Es lifit fich yon ber Entfers nung, in ber ein Donnerfdilag gefdjeht, aus ber Beit, bie zwifchen sem Blif̧e uno bem Sdijage ift, urtfieifert, wie weit ein Donners

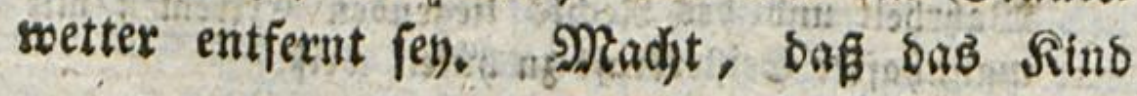
alle 


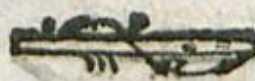

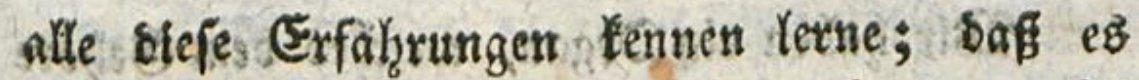
alle anftelle, bie feiner Fanfungštraft gemäß find, unb baf eb bie andern burd Snduction finbe. Sounbertmal lieber inbeß mige es fie gar nidjt wiffen, als von 2 tnoern fie fid) fagen laffen. *)

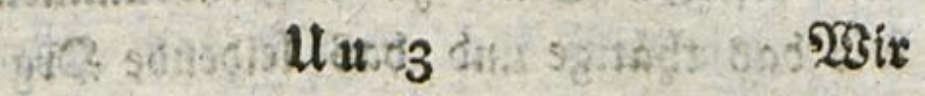

*) Sonberbar! Hebrigens, muk man freilich afles fo

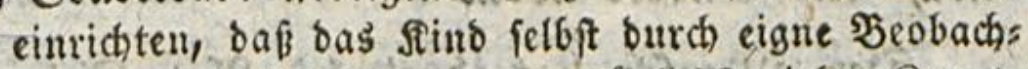
fungen und EFfahtungen ju mógficht viefen Rents niffen gelange. SSBer lange ein practifcher Erzieber

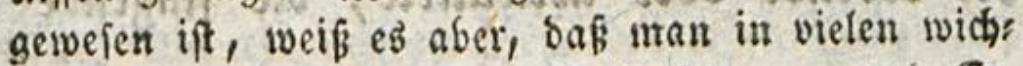
tigen Dingen bergleidhen গ̧eobachtungen unb Er: fabrungen nidht allentha!ben nad) 23 unich vorbereis ten fann uno baß inan, weun man nicht gerabeju Sienntuife mittheilen woute, fehr oft einen fehr

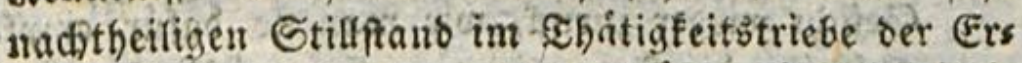

an fentnigftraft ober ciu gauz numiz̨es nicijt befriebis to gendeşánbelu berfelben Statt finden laliza mûfite. Eblers. Refewib.

Dies wutibe $\Re$. láuguen, unb vielleicht mit Siecht. Er wurbe fagen: wenn es nidht bei uns Pebt, gerabe jef̧t zut Erwerbung biefer ober jener Erfabrung cine bequeme Selegenbeit zu veranftalten: fo-merbent immer bunbert andere eben fo nithige uno núb̨liche (Etfabrungeu ibrig feyu, bie ber weife Ergiebler fo fange eimfammelu lápt, bis zu jener fí, greidffalls eine Belegenbeit finben wirb. - 23 as 8) indes meine eigene Neinung betrift, fo birt ich mit 5. meinetn freunbe cinberfanden, bẩ manches twirt: lich gelebrt werben mulffe, weil bie Belegenheit, eb

wort felbit zu finden, fúr ben sógling entweber niemals ts ober zu fpát eintretcr wurbe. (5ampe.

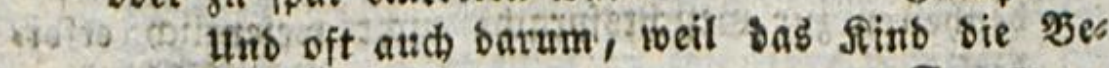
rêtiung burch 2tnocre verlangt. Srapp. 


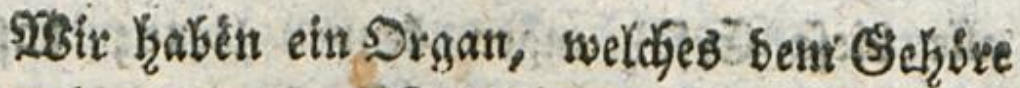
entipridjt, bab ber Epradje ; wir baben abee Yeinez, welches bem (Sefichte entfpratije, uno. wir geben bie fravben nicht po miebev zurict, wie

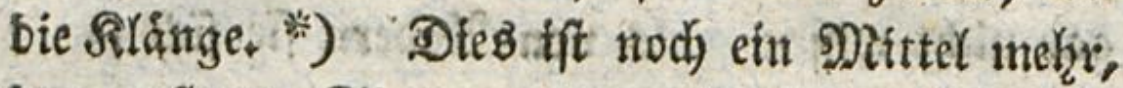
ben exfteren Sinn ă verbollétommnen, inbent wit bas thåtige und soas Keibende Srgan Eines burdi Das 2 noere áben.

Der Nenfo hat Dreienlet 2 rt Stimme bie rebende poer artculirte, bie firgende ober

mes

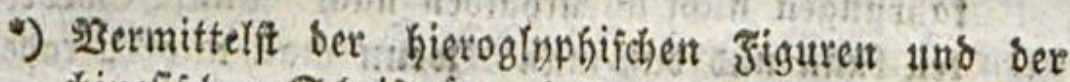

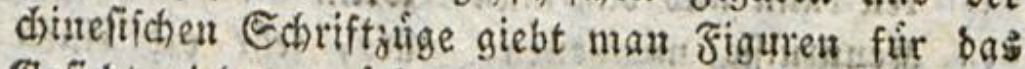
Befidit wieber zurúd, wie man fie bafú cimpfängt,

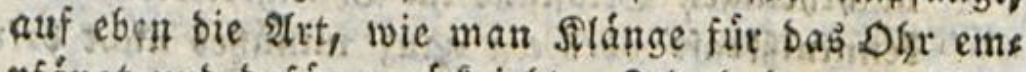
Hfánat uno bafút jurúçgiebt, Ith babe bas ithon vother bemerkt, 2Uluein bie Ertangung uno Mittheis Yung ber gocen permittelif Der formen, bic fid aufs Ofeficht beziehen, if weit grofiert Echwiprigfeiten sunterworfen, und if mit beit mehgerm Seitberlufit serfnupft, soir baben, weil wir burd, Hlebunget

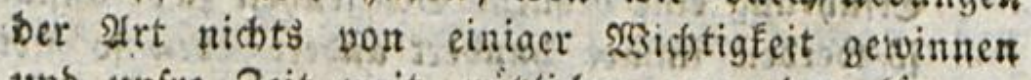

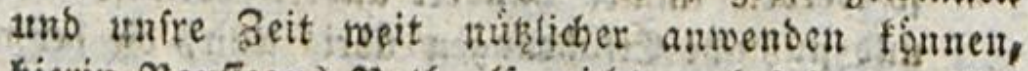

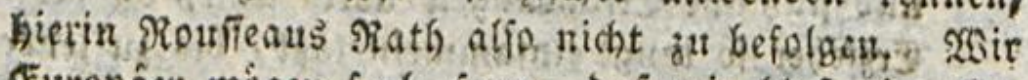
Europaer mogen froh senn, dab loir blos eine छses Górifrache haben, Geué Mittel ber Dittheilung

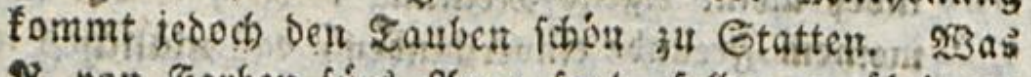
20, von Garben fúrs Yuge fagt, follte er úbrigens

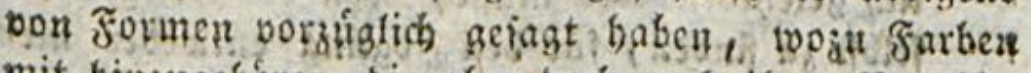

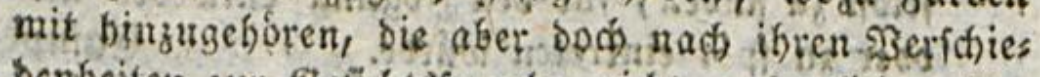

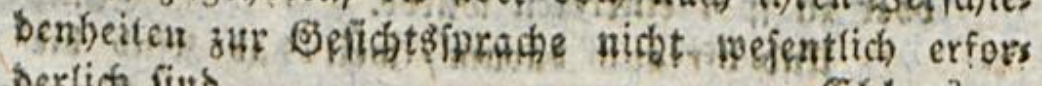
Derlich fints,

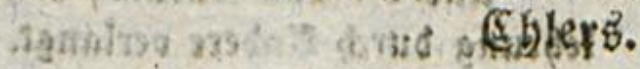


stelizmatifige, uns bie pathetifije ober accens Iutrte, sie ben Seibenfdjaften zur Spradje bient, uiti bas Singen uno Reden bejeelt. Dons sitns hat biefe oreierlei Stimmen, wie ber Ers sordjfene, mur bafí es fie nidjt, wie ex, zu bers Ginben weif. (5.s bat, wie wix, bas Eadjen, sas Sdyreien, Das Rlagen, Das 24uzrufen, bas

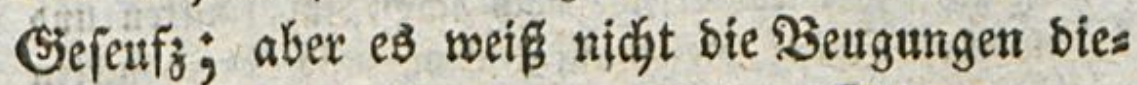
fer Zone tnit ben anbern beiben Stimmen zu

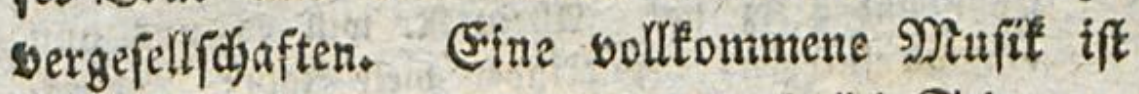
siejenige, bie am beften diefe oreierlei Stimment soreintght. Die Sinder find zu biejer গ্র)

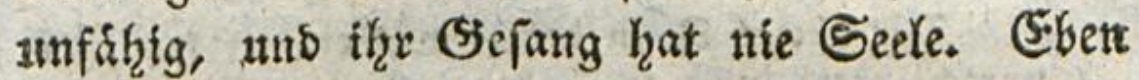
fo hat in der redenden Stmme ifre Spractje niemals 2lccent; fie fojreien, aber fie accentuis ren nidjt; uno weil tit three Siebe wenig 2 Ics cent ift, befig̨t aud) if̧re Stimme wenig SRadys sruct. Unfer Untergebener wirs in feiner Rebe sod) ebener, nodj einfacher fenn, weil feine nodh nidjt ermediten Seibenidjaften ifrre Sjaradje sidjt unter biefe feine Rebe mengen werben. Saft ifn Saf̧er Eeine Trauerfpiel = ober Romos stenrollen *) herfagen, nod) ilgn, wie matt

$$
\text { It } 4 \text { Fridat, }
$$

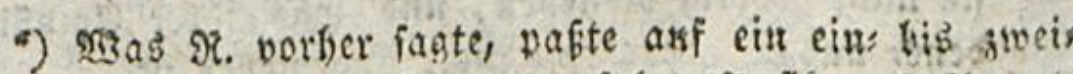

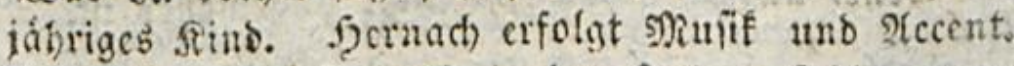
Ind Gier follen fie noch in ben Jabren feblen, wor 


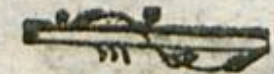

Ipridjt, beclamiren Yernen. Er wirb zu siel Sinn haben, um einen Zon auf Dinge, bie ex nicht verftehen tann, zu legen, um Regungen,

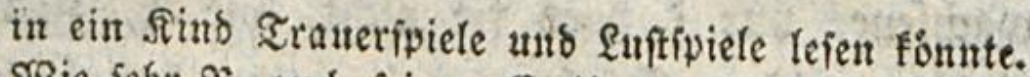

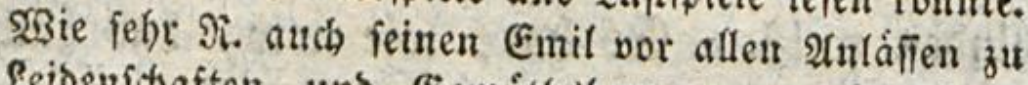
Seibenfitaften uno Bemútbabewegungen berabren

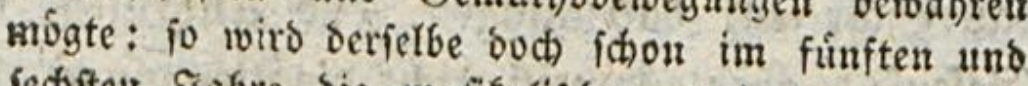
fechiten Jabre bie imuliffalichen uno accentuirten Sóne im Reben anbringen; went feir Emil anbers

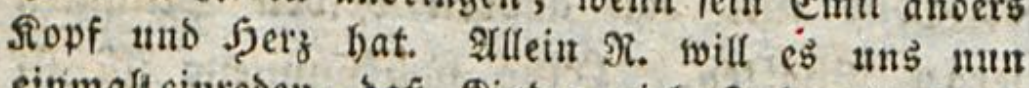
einmali einreden, bafi stintor viele Gahre bindurth nur eine Papageifpracte reben unb nidits vers ftehen.

(E) letş.

Mit ficeint $\Re$. in bem, was er fier fagt, fo unredt eben ridth zu haben. Sinder founen fich gevioí in bie Empfindungen uns Qeibenschaften ber

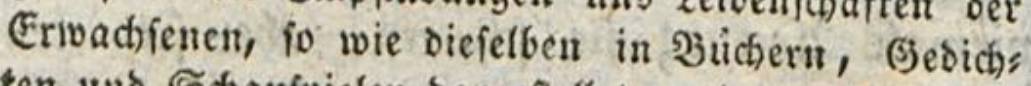
ten unb Schaufíielen bargeffellet werben, nicht ver: Ferzen, und formen alio auth bicfelben burch Eon

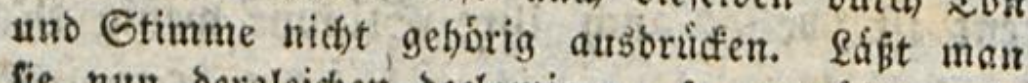
fie nun dergleichent dectamiren, fo verwoblnen fie fith entweber ju einem blof mechanifónen (Empfins bungss uno ausoruffoien Zon beim Reien - ober fie fangen au zu ichreien, zu affectiven, Nachbrudf auf $280 r t e$ zu legen, auf bie gar teiuter gelfort ut f.10. weburch ile benn forvol in 2 friefyung iffrer ganzen

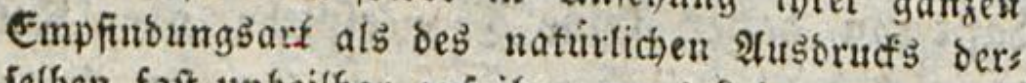
felben faft unheilbar auf ibr ganjes Reben verptimmt

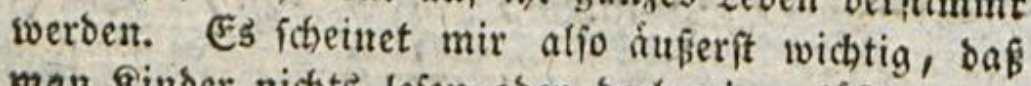
man Sinder nichts lêen ober beclamiren láft, was fie nicht gehórig verftehen, und was ibrer Emp fin Dens: und Denfensffraft nidst angemeffen ift.

Stuve. Sampe. 


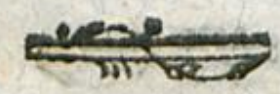

$68 \mathrm{I}$

sie ex niemats exfahren bुat, einen 24usbrude ôl geben.

Sehrt iffn alfo, eben, beuttedy moḩlarticultirt reben; genau uno ohne (Sizier subjprechen, ben grammatifjuen und profosticjen 2(ccent fennen, und ihm folgen, ftets genugfame Stimme geben, berftanben zu werben, aber nie mehre, alo bazu nothįg ift; ein Felfler, Den gewihnnlich Die itt ben Sdyulen exjogenen Sinber annehmen: in feiner Sacje nichts Lleberflipiges!

(5) ben fo madie man im Singen feine Stims me ridjtig, fich gleid), biegfam, tỏnend, feint Shr empfindlid fíc Tact und Şarmonie; abev nidjts weiter. Die nachahmenoe, bie theatrali=

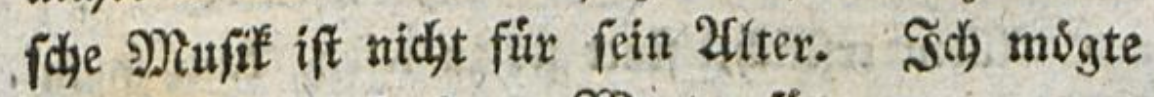

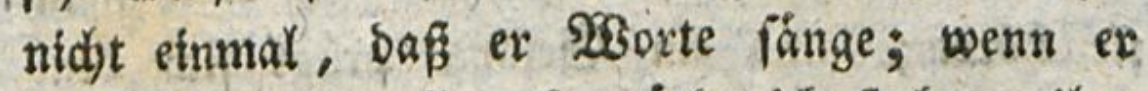
welche fingen wollte, fo mirbe ids fitchen, thm aubsriclétid) oazu Sieberdjen zu machen, bie fir

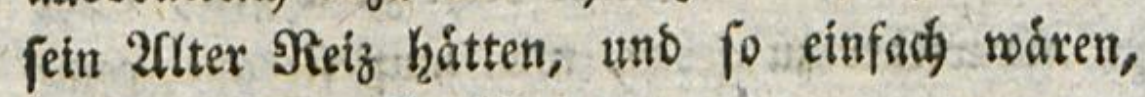
als jeine Begriffe. *)

\section{U 5}

Nhan

-) In Deutfăblano brauchen ivir bergleidaen \&ieberchen, Die fur Rinber, Der Nelobie uno Dem Intbalte nacts

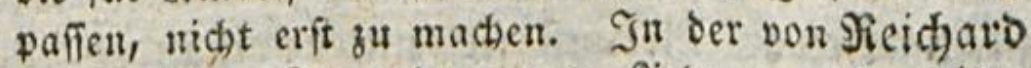
componitrten Sammlung von fiedern aus meiner Sinberbibliotbet finten fich viele, melthe zu bieiem ঔehufe ganj jueḉmásig fino. (Eam»e. 
Mant fant Yeidjt benten, baf́, ba tój fo

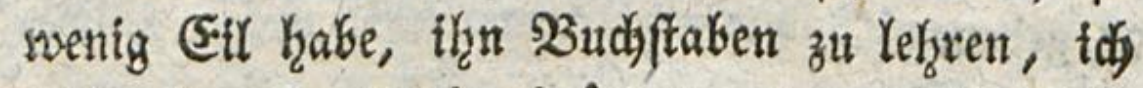
mid eben fo wenig brangen werbe, ihm bie

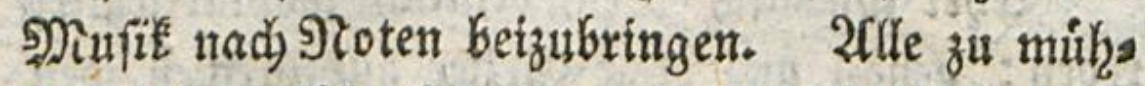
fome 2fufmertfamteit ftóre nie fein Seb̧irn; man eile nidyt, jeinen Eseift auf conbentionelle Beidyent 3̆ heften. Dies fojeint, thy geftehe $c B$, feine (Sd)wierfgeit zu baben; Denn wenn gleid, Die Renntnif́ bex Noten zum Singen nidut noths swenbiger zu feun fcheint, als bie Renntnif́ bees Suddjftaben zum Reben: fo ift bods gleidjwon blefer Unterfójies babet, bafs wir tm Reben uns vere eigenen Soeen aubbride'en, tin Singen hins gegen genosknlich nux 2inberer thre. Itm fie aber auszutritcken, muß man fie Yefen tónnen.

2lllein exfitidy, ftatt fie zu Yejer, Lani main fie hiven; und efin Sefang pright fich bem Shye nod) getreuer als bem 20 uge ein. Hebexs

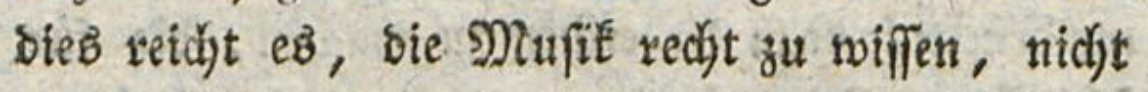
git, fie soleber fu geben, man muf fie aud coms poniten tónten, uno cineB leant fid nux mit bem anbern; fonft beyftelzt man fie niemals rec)t. Llebt euren Eleinen Mufiterer, anfingltd' felor regelmífige, wohll cabenzirte Siefangphrafen zul madjen; hiterauf fie unter einanter burd cine fefre einfache Mrosulation zu berbinoen;

ento 


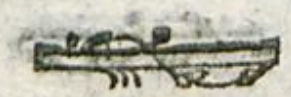

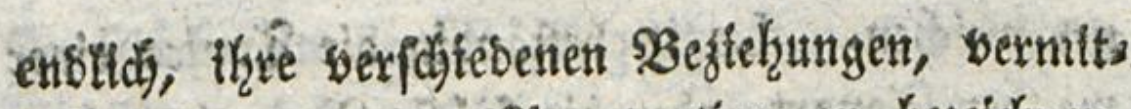
telfit einer correcten Syounctuation fu bezeidgnen, wellyes burch bie gute $223 a h t$ ber Eabenzen uns Set Sulfepuncte bewertfellige wirb. Sor 2Ts lèn, niemals serzerrte Giefámge, niemals Spas

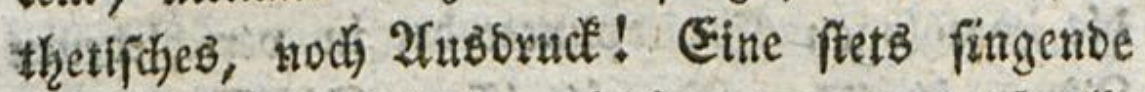
uno einfactye Melobfe, die immer aus werentlis chen ZSnen ber Sonart entipringt, uno immer

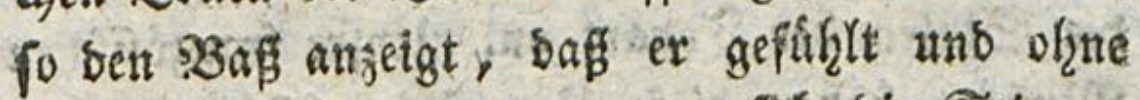
Mithe begleitet werbe; betm, fin bie Stimme

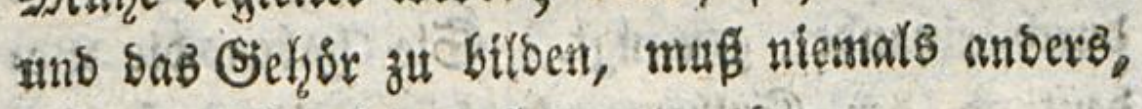
alo gitin Clabiere gefungen merben.

to banit man ble Silange beffee bezetdjue, fo articulirt man fie, insem man fie auspepridjt;

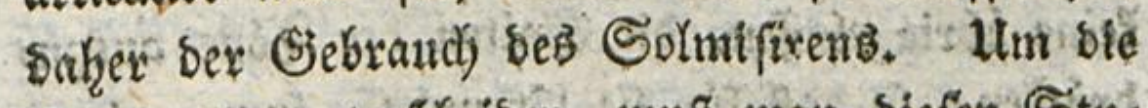
Stifen git anterfoeiden, muf man biefen Stus

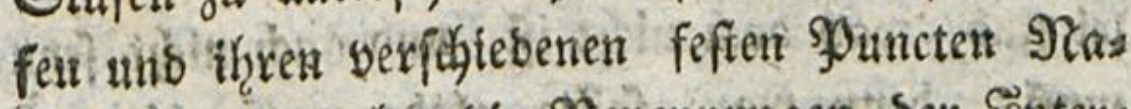
men getben; Saker bie senennungen ber Şnters valle unt audy bie alphabetifersen Buchftaben, fomit man bie Iaften beg Elasiers und bié Stoten ser Tonlelter bezeidjnet. (c) uno 2 . beaten feftbeftinnte, unveranberlidje, immer ath Denferten Zaften atgegebene Tone, at, spit nniern Senenungen Ut uno La hingegen, sers

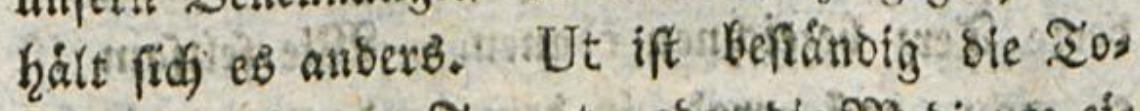

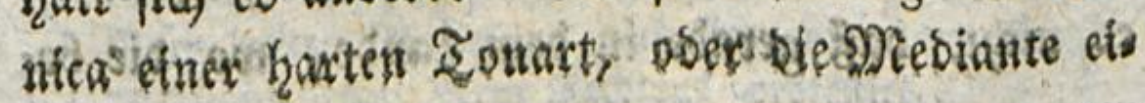
(เ9)

nex 


\section{4}

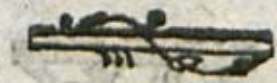

ner weidjett. La ift beftänbig bie Zonica einer weidlen Ionart, ober bie fechfife Frote eimer ham

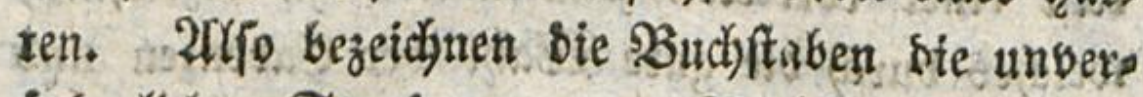
anberlichen Stanopuncte ber $\mathfrak{B e r b a ́ l t n i f f e ~ i n ~ w h ~}$ ferm mufifaliftien Syitem: bie Sylben aber, bie fromologen Stanopuncte ber in werfdjiebenen

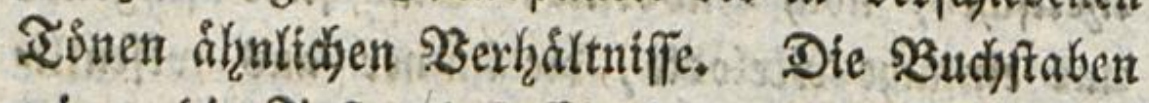
zeigen bie Zaften bes Elapiers, uno bie Sylben bie Stufen ber Zonart an. Itnje franzsfifchen Mufiker haben biefe Itnterichiebe fehr feltiaum burdy einanber getnengt. Ste haben bie Bes beutung ber Silken mit ber 3 edeutung Der

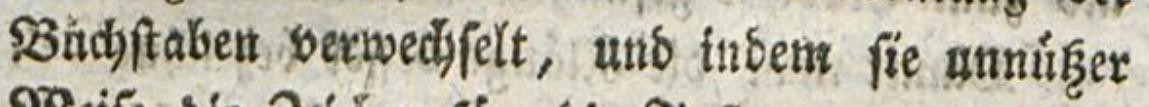
28 eife sie Zetojen fir bie Zaften beropppelten, *eine útriggefafien, die Saiten ber Ione, auszus bxictien; fo basi fir fie Ut unb (5. immer einer. let fint, was boch nidjt ift, nno ruth nicht fenn muf; denn mozu follte alobann हs. bienen? Shre 2rot zu folmifiren if baker aud auferove bentlith fidwer, ohne ben geringiten Nursen au Fiffen, voer in bie Seele bie geringfte beutlidye Sbee zu bringen; weil zufolge biefer Diethobe bie betben Sylben, ut ano mi *. $\mathfrak{B}$. gleidgers soije eine grofé, tleine, itbermágige ober vermin?

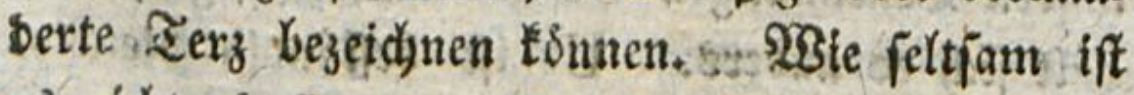
es nidht, bafisgende in bem Lanbe, wo bie bes 4985 ften 


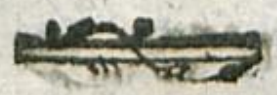

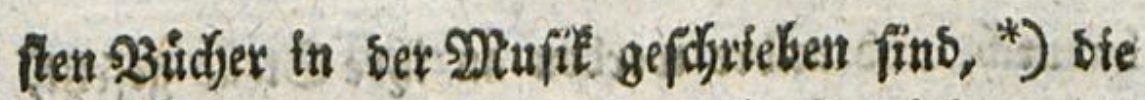
Soluriti gerabe am fojwerften exlernit wirb.

ISir wollen mit unferm 3̧glinge einer eine

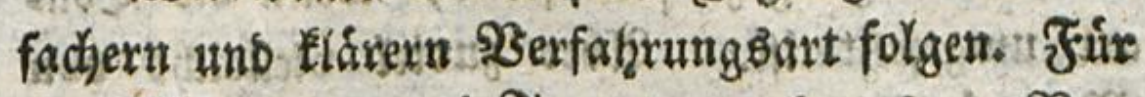
ibn foll es nur swei Zonarten geben, beren Bers hấtniffe immer siefelben bletben, uno fets burds einerlei Silben angebentet find. Ex finge ober fptele ein Sintrument, fo wiffe ex feine Tonart ouf einem jeben oon ben zwilf ISmen oufzurtchs ten, bie thr zum Grumbe stenen tonnen; uns es werbe in $D$, in $\mathcal{E}_{\text {, in }} \mathcal{G}$, H. F. w. modus Itrt, fo fer) der Sdj)úp fteta Ut ober La, we sie Zonart es mit fid bringt. 2uff biefe $\mathcal{U}_{\mathfrak{r} t}$ witro er endis ftets begreifen; Die wejentlicten Şerkâltniffe ber Zonart werben, bamit ex ridys tig finge uno fpiele, feiner Seele jeberzeit gegens

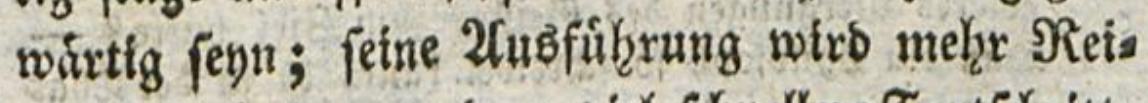
nigleit erhalten, uno ex biel fodnellere Jrortichritte macjen. Es giebt nidhts Seltfanteres, als bas, was bie Franzofen nach ber STatur folmifiren, nemnen. Die Begriffe ber Sadje berfjuminden

Das

-) Stogegen ber Deutiche, Der feinen Rirnberger bat, welchem, ob er wol, won einem Sdulls aufs netse bearbeitet, noch viel vollfommner fenn fonnte, boh feit tiber bie aheorie ber Eompofition geichriebenes Эuch unter Stalienern uno Srauzoien das $2 \mathbb{3} a$ ịer reicht, in befter Form Rechtens proteftirt.

Inm. Heberf. 


\section{6}

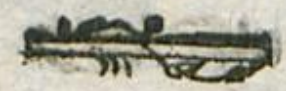

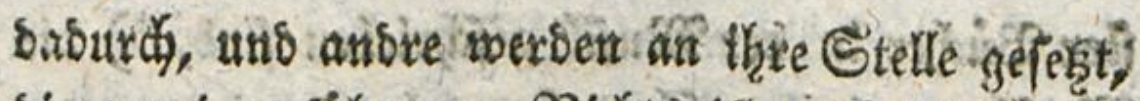

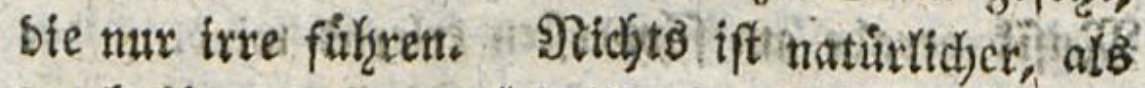

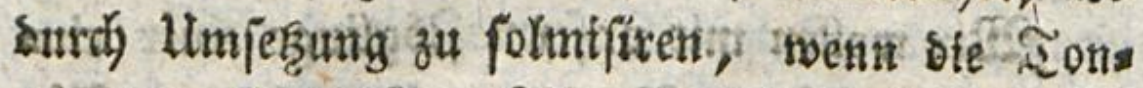

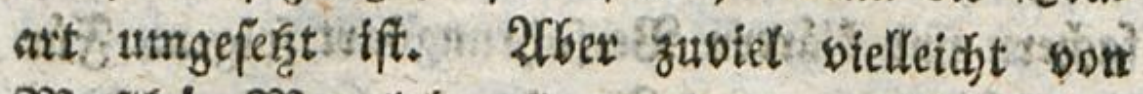

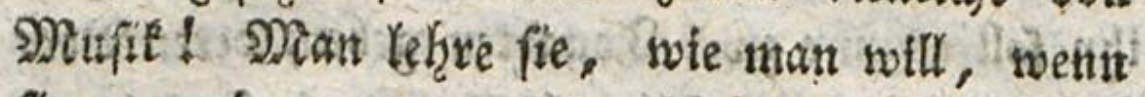

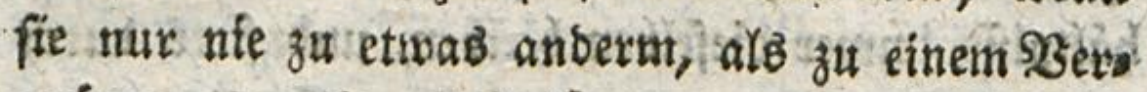
gnígen gemadjt wirb, *)

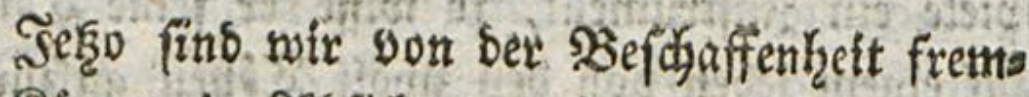
Ser Sisrper in 2 lbfídt auf ben unjrigen, yon three Scywere, vott threr Eeffalt, von threer Farbe, bot threr Feftigete, son ihrer Girsfie,

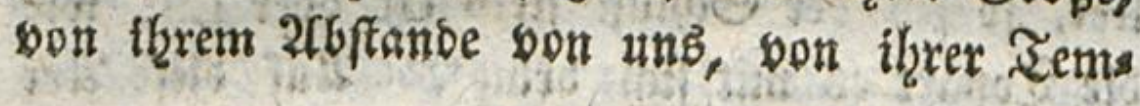

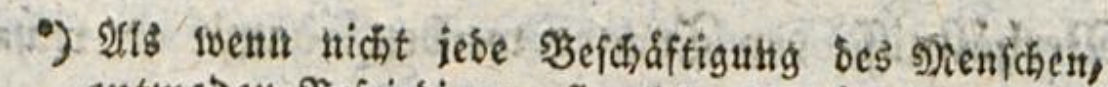
entweber befriesigung funnticher besurffniffe, obet

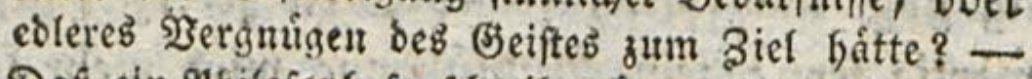

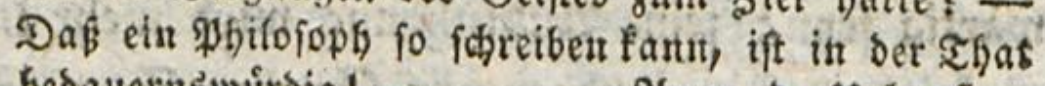
bebauernswirbig! - 2lnm, D. Heberf.

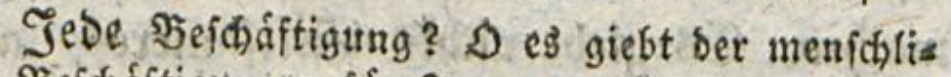

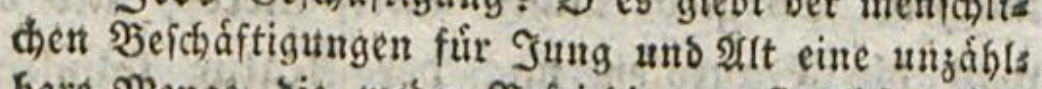

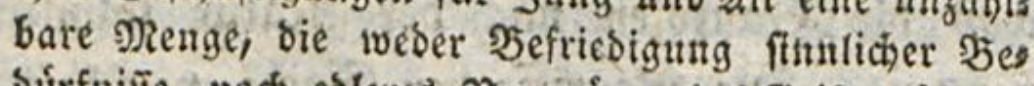
súrfniine, noch eoleres \$erginigen bes ङeiftes betwirs Een! 2tue Eclavenarbeiten gehórent babin; alles ans befoblne unto erzivungene Elusivendiglernen unvers ftanbener Sactiett gebort babin; alles getvaltame

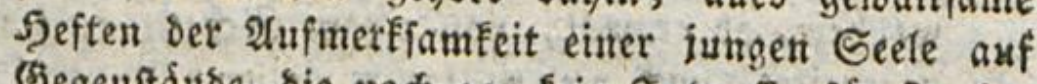
Gegenffatube, bie nod gar feit Jutereffe fúr fie bas

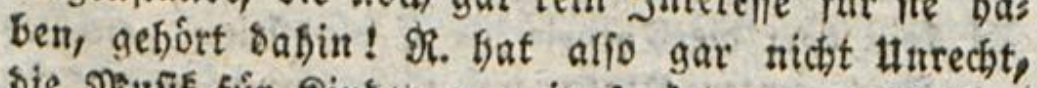

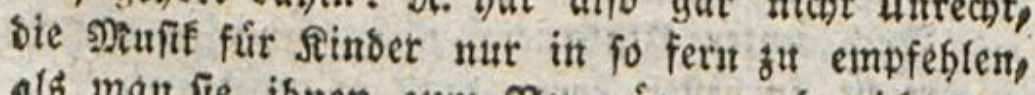
alf mant fie ifnen zum \$ergnugen utto nidit zut Qual zu machen weiß. Eampe. Srapp. Stuve. 


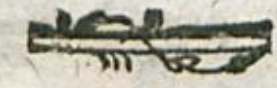

peratur, son ffree SRuthe, von three SBenegnng unterridjtet. S28ir Eennen biejenigen, bie wix uns náher britugen, Doer bie wir yon uns ents fernen miffen' wir wiffen, wie swirs anzugreis fen baben, thren S3Biberftand zu liberwinoen, ober ihuen einem entgegen zu feren, ber uns bor sem Sthabet, weld,en fie uns zufugen tonnten, bes

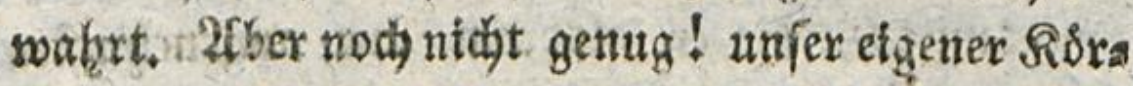

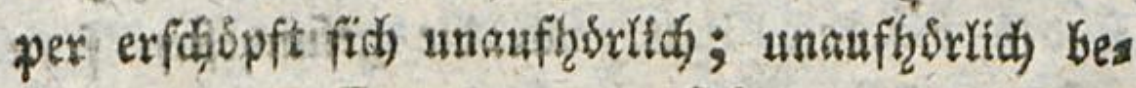
Darf er einer Erneuerung. $S \mathbb{b}$ wir gleid bas Şermógen baben, andere Sisuper in unire eigene Subftanz zu bermandeln; fo ift die SIGahl bod

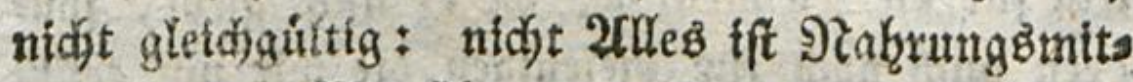
tel fur ben Menfchen; uns son ben Dingetr? bie es fegn tionnen, fint einige metzr ober wents ger gefdjidt bazu, je nach ber Berchaffenkeit jetner 2Crt, bes Elima's, bas ex berwofhnt, peis nes befondern Zemperamentes, uno ber Lebensa. art, an bie thn fein Stand beftet.

2Bir wirten vor Sounger ober son Stift fterben, wenn wir bie Niahrungşmittel zu wåh̆ len, bie fich firr uns fajicten, fo lange wartest mifğten, bis uns bie Erfahrung fie tennet uno

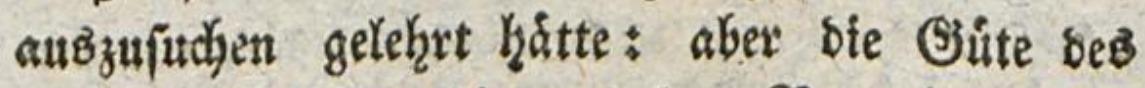
ķסdjiten 2 Befens, bie aus bem \$ergnigen ems

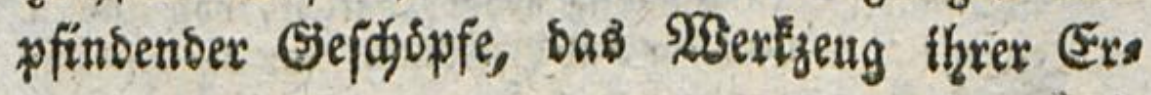
bुats. 
kaltung gemaidjt Kat, weift unż, bermittelet beffen, was unfern Ẽaumen gefallt, auf bas,, wab fich für unjern Magen fajtelte (Es giebt Don NEatur firr ben Menfchen feinen ficherern 2 rzat , als feinen eigenen 2Tppetit; uno went man ben in feinem exften mfpringlichen $3 \mathrm{at}$ ftanbe nimmt, fo zweifle ich nidt, bafs bie গakge vungsimittel, bie ex alsbann am nngenehmftent finben mirbe, ihm aud bie gefundeften fenu miften. *)

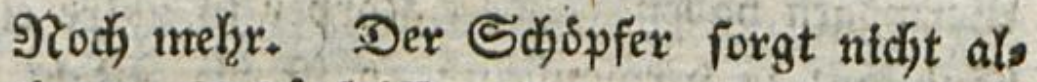
lein für bie Bebuirfniffe, bie er uns giebt, fon= bern auds nod fúr biejenigen, bie wir unb ferbit geben; unb, eben bamit immer bas \$̧erlangen Dem Bebirrfniffe zur Seite gefge, richtet erỏ fo

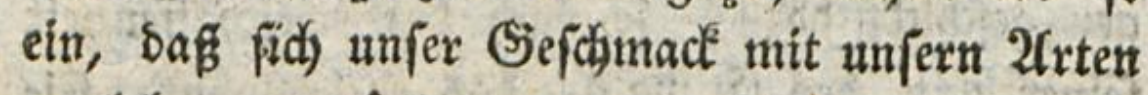

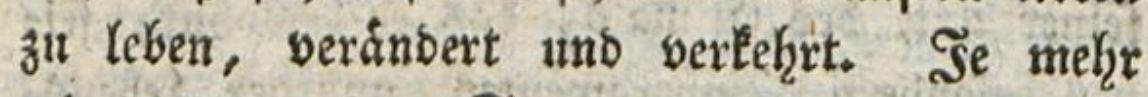
wir uns son bem Stande der গTatur entfernen, befto meḩr werlieren wir unfern natirlidjen (Se. fdjmad"; Doer es bildet uns vielmehr bie Sies wohnheit eine zweite Natur, bie wir bermafen

ant

-) Dieb fcheint burch bie ஒeobachtung beftátiget zu wer: ben, bá̉ bieienigen șilben, welde mit Europáern noch gar feinen llmgang geljabt hatten, von unfern europaifchen Speifen und (setránfen nur bie einfachs: ften, aljo auch bie gefunbeften zu geniepen bewogen ineroen fonnter.

Eampe. 


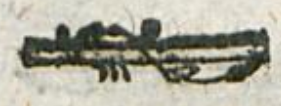

689

an Sie Stelle sex exftern Fę̧en, Saff Eeiner son unb eine anbre als bteje tennt.

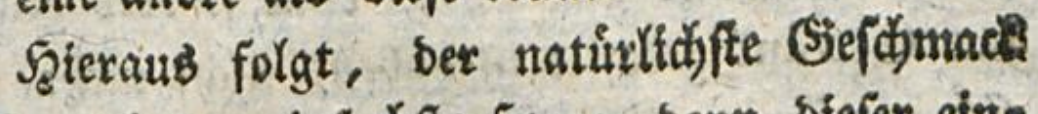
miffe audy ber eimfadjfte fevn; benn biefer ein: fache berwanbelt fich am allerletdyteften. Sgina gegen nimmt-er, inberm er burch unire şbantas fien geidjarft, gereizt soirb, eine Gieftalt an, oth ex niddt mehre änoert. Der Menif', ber nod ber Mienif teines Landes ift, wirb fich leicht an bie Ëebräudje, weldjes Lanbes es auch feyr gewóhnen, ber eines gewiffen Lanbes aber, nidet mehrs ber Menfd cines andera ruerben.

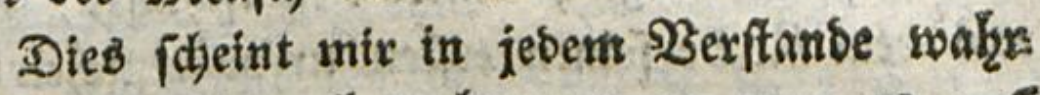
zil fern; imb nody wabrer, wenn mant es aur ben eigentilich fogenannten Sefdymadi anwenbet.

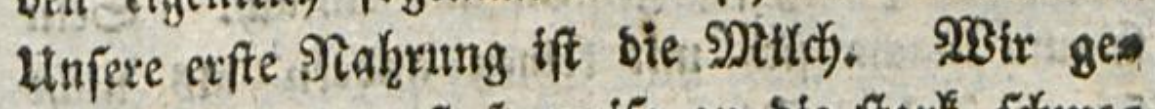

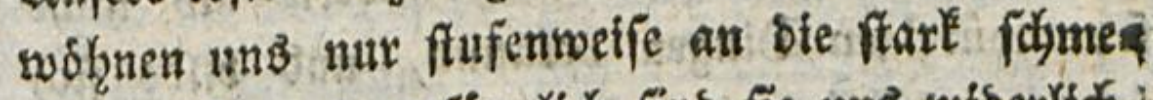
dienden Dinge; anfänglidy find fie แnB notberlidos a Gartenfrídjte, Siemiije, allenfalls bies uno jen nes gebratene F'elíd), ohne Szsirze und ohne Salz, madiste bie Mtahlzeiten bet exften Metri

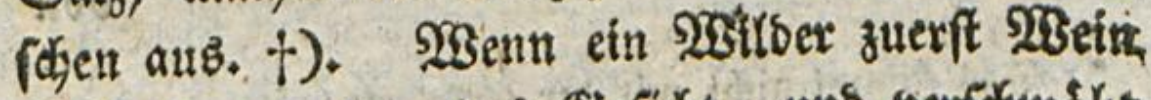
trinlt, verzertt ex bas Geficht, uns verifomathe tha:

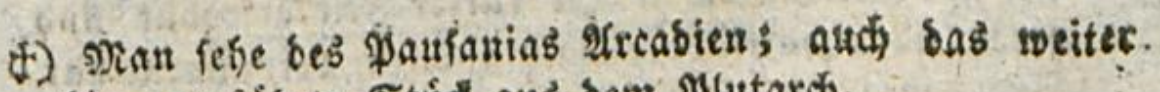
hin angefứrte Stúd allర bem \$(uttarch).

Intwet. o. \$erf:

Gril Ifer as $\mathfrak{x}$ 
thn; 1tn' felbfit water uns tann, wax bis in sas zwanzigfte Sahr gelebt hat, ohne ftartes gegobres nes: Sitrant getoftet zu baben, nidat mebr bazu

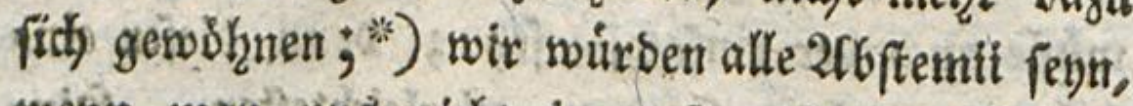
went man uns nicht in unfern jungen Sahrett

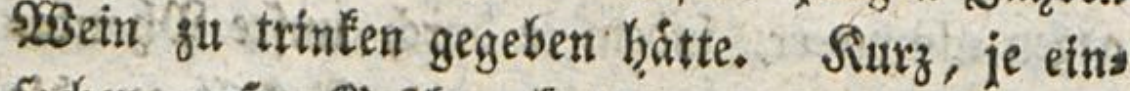
fridjer unjer Seffimade ift, befto allgemeiner ift er; bie gewshnultdyften 20bneigungen fallen trmmer auf zufammengefeģte Şerichte. Seat

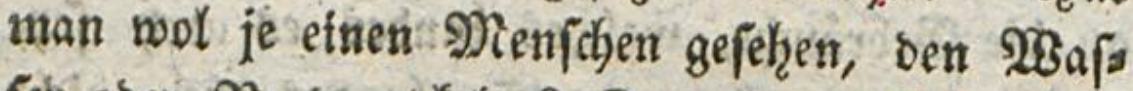

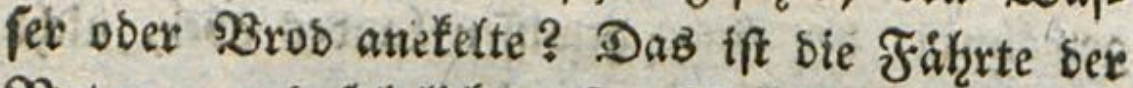

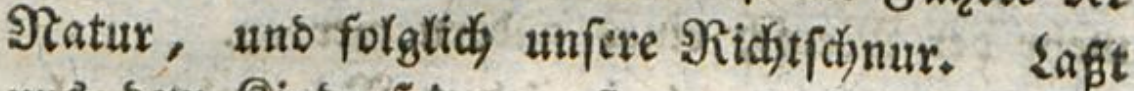
uns bem Rinbe feitnen exften urfpruinglituen Sies fd)made, fo biel als nur moglió) ift, exbzalten. Seine Nab̧rung feb gemein uno einfach. Šein Gaum madje fich mit feinen anvern als nidbt febzr wuirgigen (Dingen betannt, und bilbe fid) Eetnen ausfobliegéenden Siefdymadé.

29? Sch unterfucbe fiter nicht, ob siefe sebens? art gefunber ift, ofer nicht; the fehe fie nidat

Sott

7) Das ftimmt ficht mit ber Evfabrung úberein. Sक felbpt weís viel gálle, ba man fogar in ben fpátern mámulichen Sabren fich noch zu allerlei farfen Epeis fen und Getránfen in fefr furzer Beit gewobnt und

7. eine leibenichaftliche Neigung sazu befommen bat. 2us ben Reifébefdreibungen weißs man auch, wie leicht wilbe \$Solfer ben গ̧rantivein heftig zu lieben anfangen.

Ebler\%. Srapp. Rejemis. 


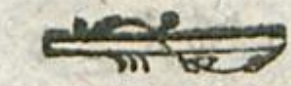

bon biefer Seite an. Cso ift mir genug, um

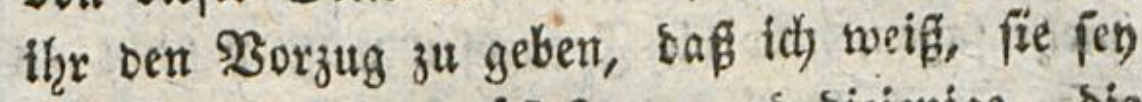
ser গlatur am gemáfeften, uno biejenige, bie (ich) am allerleidoteften zu allen ancern bequemen fann. Wer fagt, man milfe die Rinber an sie Speifen gemofhinen, sie fie gentefien werben, wenn fie grofi fino, urtheflt, beucht midy, nidbt gut. SBarum foll thre Sahrung siefelbe feyn, ba thre Sebensart fo berfatiesen tit? Ein Mant son 2rbeit, bon Sorge, von Mithjeligkett exs (d)spft, bebarf faftigex Epetien, bie ifgm neue

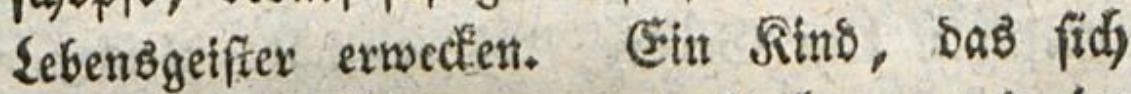
in Bettbertreib berumgetummelt frat, uno im

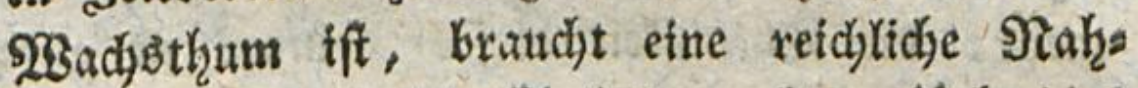
rung, sie thm viel Ęy)luz madjt. 1teberbies bzat ber exmadjiene Nenf(d) fhon feinen Stans, feine Besienung, fetne $2 B o b n u n g$ : wie Fantt man aber wiffen, was bas Echictial bem Sint be aufbewahrt? Laf̧t uns in jebem Dinge thent

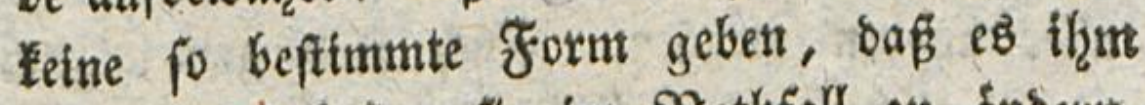
gat zu biel Eofte, fie in STothfall zu andert.

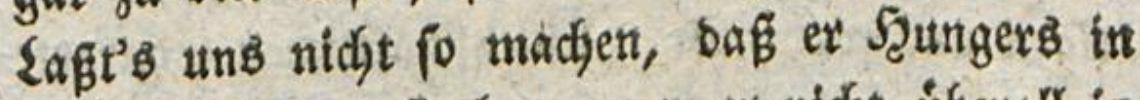
anbern Sanbern fterbe, went ex nidft liberall in feinem Šefolge einen franzspirftien Roch mits (d)leppt, noch baf er sereinft fage, man wiffe mur in Frantreid zu effen. STm Borbeigeben:

$$
x \times 2
$$

etris 
ein gat feltjaturer Eobiprudy! Salj mogte siela mef̧r fagen, nux tie. Fronzofen wifften nidjt zu effen, meil $e b$ firr fie einer fo befondern Runft bebarf, thonen die Geridjte efbar zu madjer.

3on unjern berfojiebenen Senfationen giebt uns ber Sefdamad biejenigen, bie aberķaupt ges noumen, am meiffen fúr unB Reiz baben. 2ud Yiegt uts wirtétid meler baran, recht bost ben Subftanjen zu atheilen, bie wir ber unirte gen einberliben follen, ałż von benen, sie auj" ferhalb ifhe bleiben. Taufens Dinge fins bent Eefühle, ben Siehrbre, bem Gefidhte gleidhgúls tig, faft ridsts aber sem (Siefdjmadie. Siods

= nuefgr: bie Thatigleit biejes Sinnes ift ganz phyfif as uno matertell; er ift ber cinzige, bet ber Einbitsungbifraft nidotib fagt, wenigftens berjenige, in beffen Senfation fie am wenigften

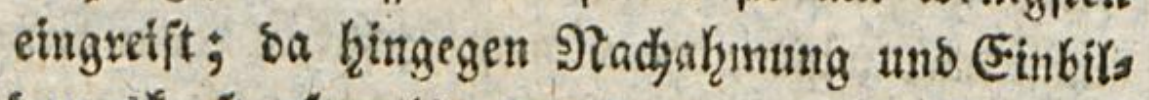
sungetraft oftmals etwas unter ben Einbruce aller andern mengen. $\mathcal{Y}$ uch) find gemeiniglidis bie zårtliden uno wolltiftigeren Şergen, bie hefs tigen uno wahrlhaftig leibenfohaftlicien Eharactes re, bie fidy reidjt burdy bie anbern Sinne in $2 e s$ wegung fergen laffen, in Ziffitht bes Sinno bes

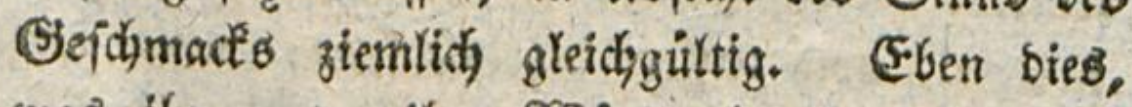

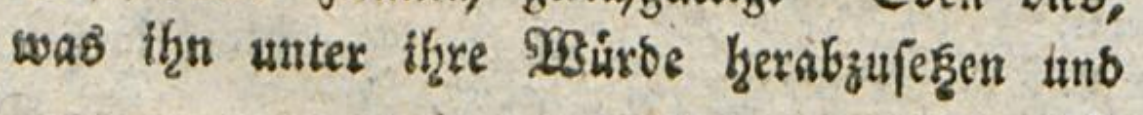
Sie 


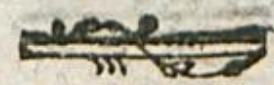

Sie Steigung, fo uns thm unterjodgt, betridgtlfici

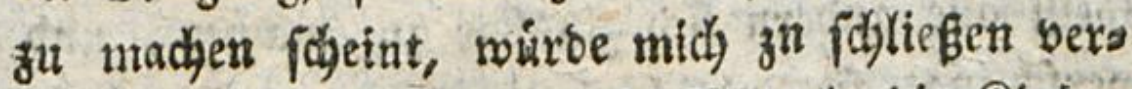
anlaffen, bas allirbequemfte Nittel, bie Rinbet ou regiexen, fen, fie sernittelft bes Şanmes zu Yenten. Das Mobile ber Najuluft if wors

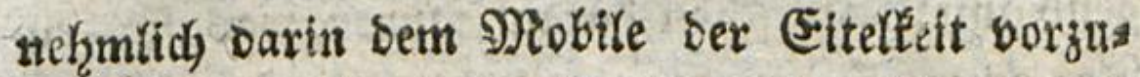
zielgen, baf jene eine SBgterbe ber SRatur iff, sie unmittelbar bon bem Sinne abhangt; tno

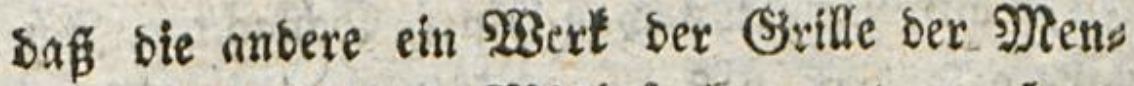

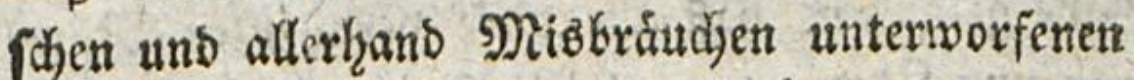
(Eitelfeit ift. Stâfaluft ifit sie Eeibenfdaft ber Rinber; Diefe hâlt vor Heiner anbern Stand; bet ber geringfien Eoncurrenz bexfdywinbet fie. (5)laubt, glaubt mirs, bas Sinb wito nur gat zu zeitig aufb̧oren, an Das̆ zu benten, rwas ę̧ geniefit; und went fein Seerz gar zn febr bes fodaftigt ift, bann wiro fein (S)aum es nidjt fehre meḩr befódaftigen. *) Mannigfaltige, unges ftume Emprinoungen veroraingen febr balo bet

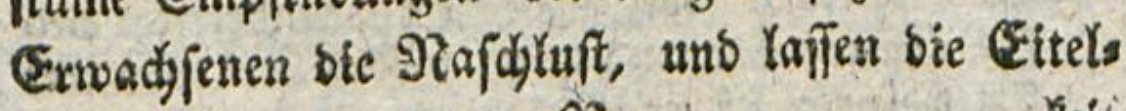

$$
\text { * } x 3
$$

reit

2) Dies mógte boch trot viele 2tusnabmen teisen. 2530 s ber fámen aud fonft die frrefier, bie fruges confumere nati, won benen \%. nadber felbft rebet?

Sropp.

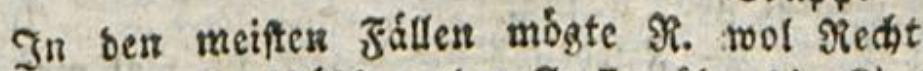

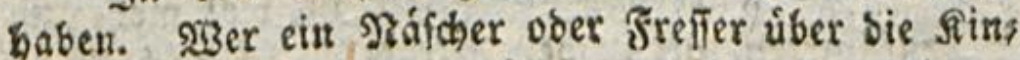
seriabre Ginausbleibt, migte nol teines geiftigern griebes fábig fẹu.

Iefervis. 
Heit bafur auftommen: benn bieje Setbenfowaft wefí alle andewn fid, zinsbar zu madyen, uns

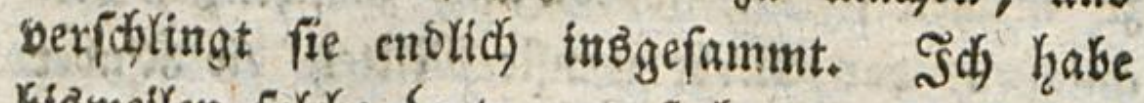
bismeilen foldse Eente unterfudit, bie fid fo biel aus einem guten Biffen madjten, bie frúf̨mors gens im Bette fohon barauf fannen, was fie ben Sag uber effen wollten, unb bie bon einer \$) ahts zeit eine genauere Bejchreibung zu geben wup: ten, als Polnbius von ciner Sd)ladjt. Sch babe gefunden, baßí alle biefe bermetinten Mans nex nur Rinder von bierzig ฐahren, okne Riraft uno Eonfiftenz waren, *) fruges confumere nati. Siefrafighteit zeugt immex von Şerzen, bie teinen Stoff haben. Die Seele eines Frefís fers if ganz in feinem Saum, ex tit nur gez macht zu effen; in feiner Dumpffinnigen thnfás bigleit findet ex fich nux bei Iifdge an peiner

Stels

- Sente von einer vorziglidien Erthabentheit des (5) ftes unt bes Eharacters fint freilich 2iollifitige ber 2frt wool nie. 2lber it babe manden grofen uns felbft grúnblićs benfenden Wolitifer gefanut, ber eis

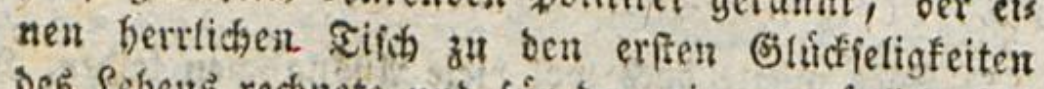
Deb febents rectnete uno fir den cin voriguglid fich ausjeichnender Roch ein ichr wichtiger Miann loar. Der grofe zriebrich war in biefem Punct auch nod nid)t grố geutug.

(E) blers. - Friebrids Befhmad ift rot mehr zu bet taffiriten, als zu ben gefrábigen zu reçnen.

Rejemik. 


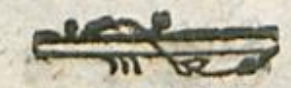

Stelle; ex weî́ nux son Shyuำeln zu urtheis Yen; uns bies fey immerhin fein Beruf! befier, ex kุabe ben, als efwen anbern, fowol fúr uลs, wote fuir ihnt *)

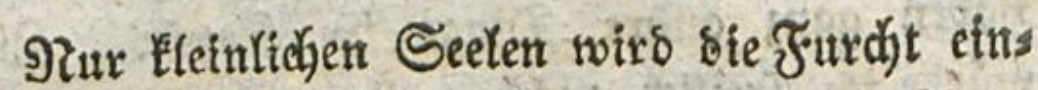
fommen, *) Nafdiluft tosnnte bet einem Rinbe

$$
\mathfrak{X} \times 4 \text { 甲on }
$$

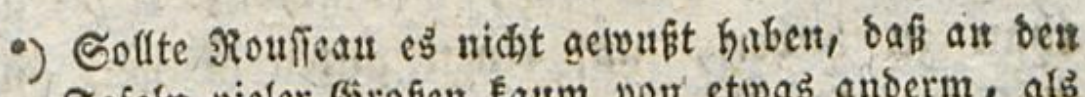
इafeln vieler-Sropien faum von etwas anderm, alb nou ber Rofftidffeit herrticher (seridste, von ben bes fen ben, uno wie man zu biejen gelangen fonne, unt non ben beften Eafeln, bie e's giebt, gerebet wirb? To erinnere mich einmal an einer ) genomment zaben, wobei ich viefe fehr angefebene Serionen von ber $2530 l l u f$ bes Eliens und bes ₹rims Een', ofue bas einer cigentlich betrunfen war, faft auper fich fah. Die heftige 3egierde zum ऊемu tmo bie 230 lluft des Befhmads blidte oft auf eine art aub Nienen uno 2tugen hervor, Dap̃ id) mich mauther nieberichlagenten Soritellung uto eines Daju fimmenden Gefubls ber Ghaam uno bes Mits leibens nidst enthalten fonnte.

(E)

Dicie Şcifpiele bezengen fool nicht fomol (5es

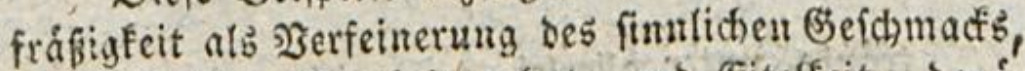
ber auth feitue. Seinheiten hat, unb Eiteffeit, barui ber utheilen ju fonnen: uicht zu gebenfen, baß́ bie Zafel oft bie Etholungşeit grofer mo benfender Sopfe ift.

Fejerwis.

**) รक mú buruber leiber anbers benfen, weil idh

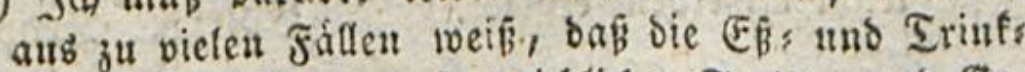
Iut in Şejiefung auf weidlide Gpeifen uno (5) trónfe, 


\section{0}

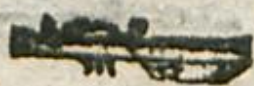

Sout irgets einigen Fåbighteiten 23 urzel fafien. Jin bex Rinblyeit bentit man auf nidjts als Effetr; in Singlingbalter weifs man nidyts enelge babon; 2llles ift uns gut genug, uno swir baben ganz anore Dinge in Ropfe. Z3war surbe idh freilich nidyt wollen, baf man fich einer fo gexingfddakcigen Sriebfeber unberninftig bebtente, nody bie (Ehre, eine fodjone That ges than zu baben, auf einen guten șiffen aufs

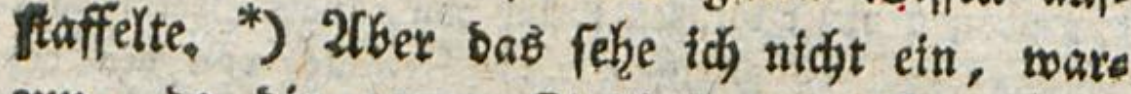
um, ba bie ganze Sinbheit nux Epiel uno frohlicher aeitwertreib ift ober peyn foll, blof Isrpertichen llebungen nicht aud ein materieller and finnlicher Şreis beftimmt fern burfte. 23 Benn ein fleiner Majorcaner einen Rorb vom - Bipfel eines Baums mit ber Saleuber herabs soirft; ift es nidft billig, bafs er Portheil bas son babe, unb baf́ ein gutes Jrififticé bie Rraft exfése, bie ex angemenbet, es zut gewitts

nen?

trånfe, unter allerlei uns nidit zum befferu forts

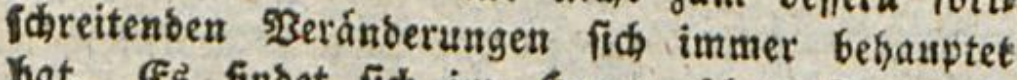
bat. EE finbet fich im Sergen fohou Raum zu mebrern 24rten ber 930 lluft unb ber Leibenichaften benen fich ber Jingling, ber NRann uno ber Nite leidht auferdem ergiebt. Eblers. Trapp.

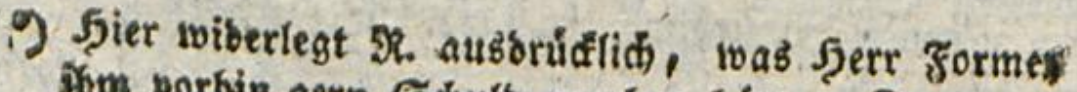

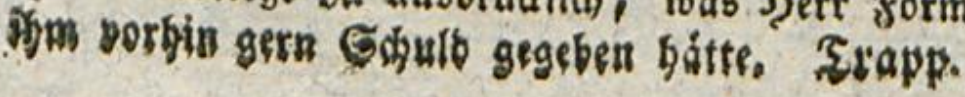




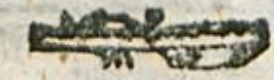

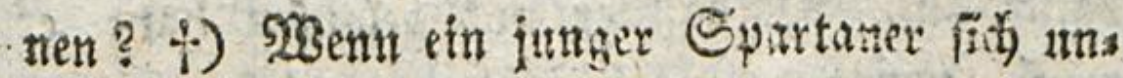
ter ber Gefabre von fzunbert Seifelfirrigen ges

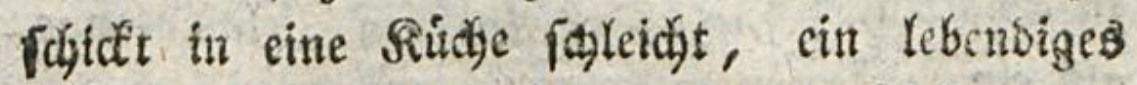

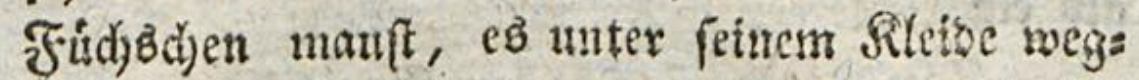

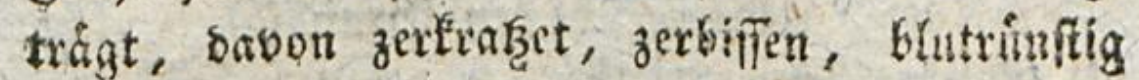

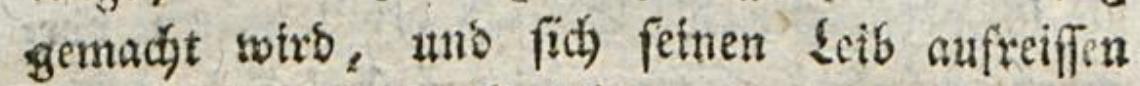
lifğt, ohne bas Sefizd)t zu verzitehem, ohne einen eingigen Schret za thum, nur bamit ex nidjt bie Sajanbe habe, ertappt zu werben:

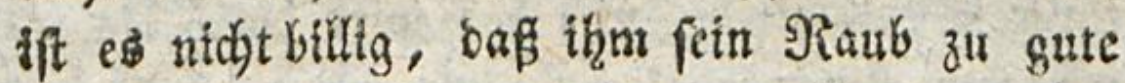
fomme, baf ex bavon zefree, nacjoem an fhm gezeţrt worben ift? *) SRiemals mus eine gute Mahblzeit eine Belohnumg fern: warum follte fie aber nidjt bie Frucht ber Bemifgungen feyn, sie man angerwanot hat, fich fie zu verfisafs fen? **) Emil fiefht ben Sinden, Den ith auf sen Stein gelegt habe, nidjt als ben Spreis

$$
\text { Xx } 5
$$

bis

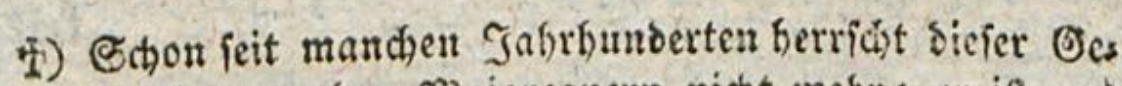
brauch unter ben \$iajorcanern nicht mebr; or ift aut

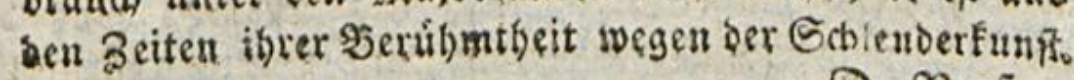

D. Setf.

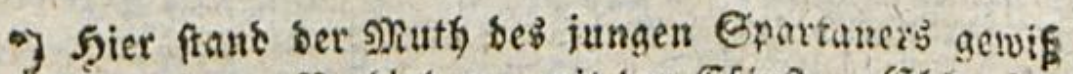

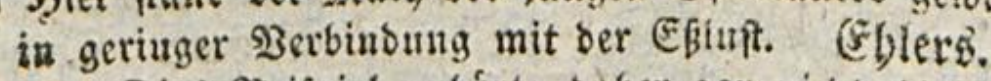

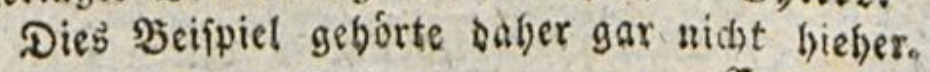

Eampe.

45) Unter biefer Einfduránfung ift in Dem, was $\Re$, ábe⿻ ben Bebranth ber Ejbluft, alb einer Zriebleber, ge:

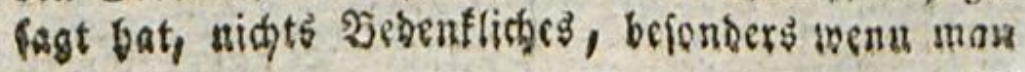


Safitr att, *) baf́ ex gut gelaufen f̧at; ex weiß̄, nur: bas cinzige Dlittel, biejen Rutjen zul erbalten, fey, baf er ether am Siele anlange, aไళ ein 2 noerex.

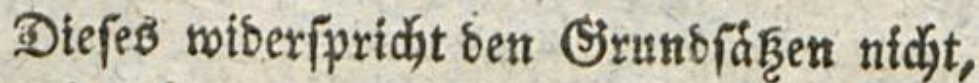
bie ich oben ifber bie Einfalt ber Speifen vors gebracjt habe. Denn um der Es gluft ber Rins ber zu fdjmeidjeln, bedarf es eben nidjt einer Erwedtung, fontern nux einer Befriebigung finere Sinnlidyteit, und bas wirs burd, ofe ges meinften Dinge erķalten, wenn man nidyt barauf aus ift, ihnen ben Sefdymact zu Dexfeinert. Shre beftandige som Bebirfnifie bes $23 a d j 83$ thums erregte E్f̧luft ift eine fidjere 2 Burrze, sie ihnen ftatt bieler andern bient. Durbh SWGit,

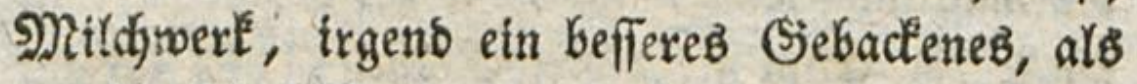

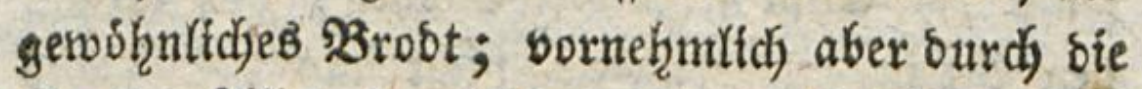
Runft, 2tlles bergleidjen mit weifer Sparjams Eeit

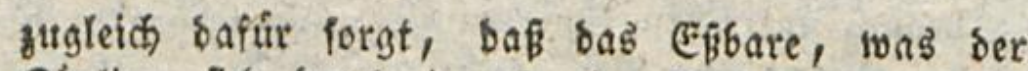
Sobgling fich burch irgend eine 2fnftrengung felbft erwerben mufi, nidft etwas fuinflid, Subereitetes, fondern ein einfaches, natirlich angenebmes গahs rungsimittel fer).

Eampe. Srapp.

Doch mú bies nur in ben Sinderjahren fratt finden, und das is viel vermieben werben.

Referwikg. Eampe.

") Das búrfte boch wol ber fall fern.

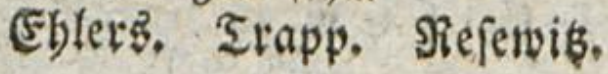




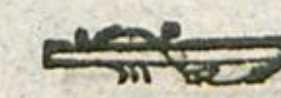

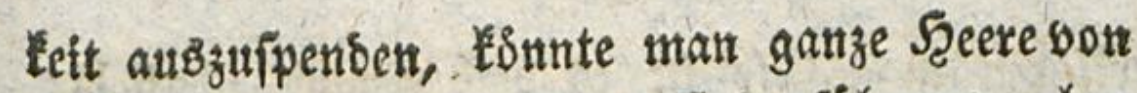
Sinbern bis an bex भigelt Enbe führen; ohne thrnen einen Sefdjmadé an gefdjmad'retzenben

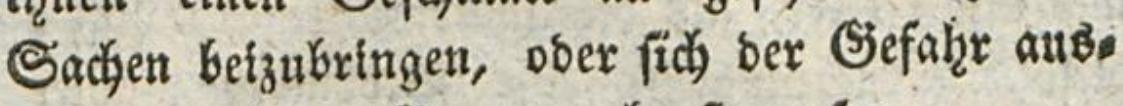

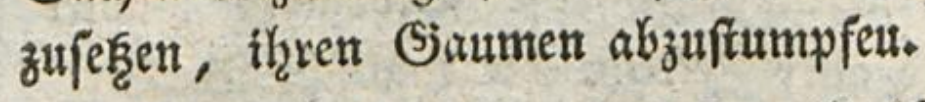

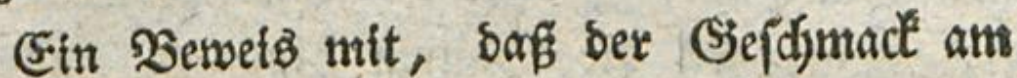

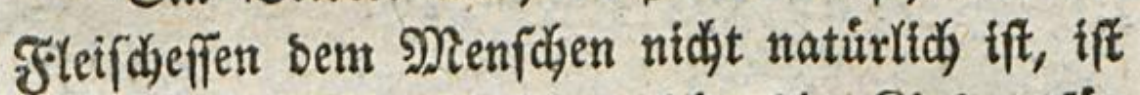
bie Siletdygilltigleit, *) weldye bie Rinder fur Fleifd)geridute haben, und ber Sorzug, ben fie alle ben begetabilifichen Speifen, bem Matilds: werte, bem Sebadénen, ben Fruidten $\pi$. Sglo geben. (5) liegt vornehmlich biel baran, baf́

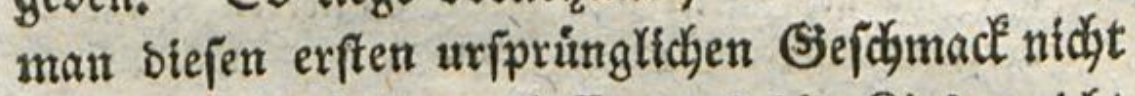
aus ber 2 rt fablagen laffe, uns bie Rinber nidut fleijd)liebeno madje; und bies,, wo nidjt unt threr Serunoheit, Sod) um thres (5haracters willen. *\%) Denn wie man aud bie Exfahrung

exs

*) Diefe Sleiđagúltigfeit babe iáb bei wenigen Sindern gefunden. Hebrigens meine ich, das unire einfidstss wollen uno gelebrten Phy)iologen itat jiemlich eins viber ben Gakz find, es gebore ber sRenfid eigentlich zu ben fleifh freffenden פthieren.

(E)) lev's. Srapp.

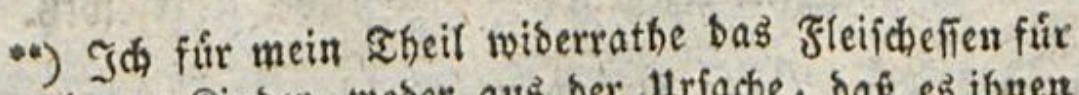
junge Sinber, weder aub ber Utrache, baß́ es̉ ínnen nicht gefuno fen, nod) aus গ̧eforgnif́, baß fie einer J̨ang zur Branjamfeit baburd gewinnen burften, fort 


\section{0}

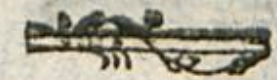

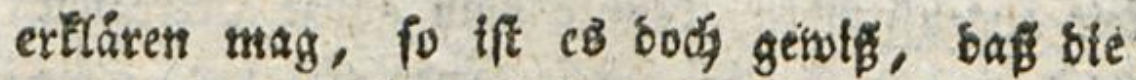
grofien Fleifdeffer biberhaupt genommen graufas sner unb wilber, als bie andern Mgenjutjen find; btefe Beobachtung ift eine Beobaditung allex Serter uno aller Beiten: oie englifiche Barbarei ifit betannt; ${ }^{2}$ ) bie (Gauren hingegen fins bie fanfs

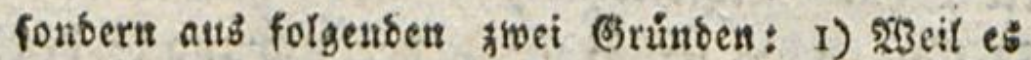
ben Sinbern in mebr als Einer গुetrachtung gut ift, bafi ifre stabrungsmittel nicht vervielfáltiget vers Den, 2) toeil ber Genuf ciner fo fráftigen Sveife, als bas freifch ift, ibrem florper eine zu fruble, alfo fitsáblide Feife und ifren Şegierben eine vers Derbliche Fichtung geben faun.

Eampe.

sheber att? biefen nod aus ben vou $\Re$ ans

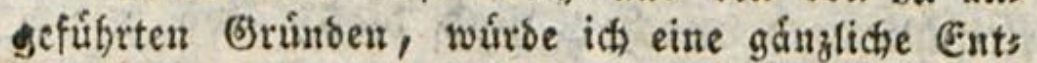
Laltung vom Sleifde für Sinder als notbig ober núbzlids aujeben. $\Im$ ch wirbe nur allmáblige (b):

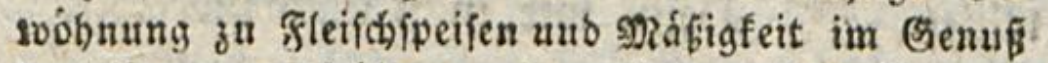
verjelben anempfeblen, and jugleich rathen, bie jars ten fleifharten in Infange vorzujieben. Sjier foron tommt eb bei biefer, fo wic bei faft allen biátetifden Negeln, noch auf bie Rórperbeichaffens beit nno febenbart ber Rinber an. Ein ftartes ges funbes Sino toeldeb natúrlid erzogen wirb, uns

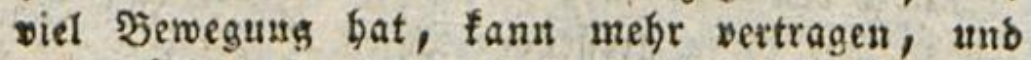

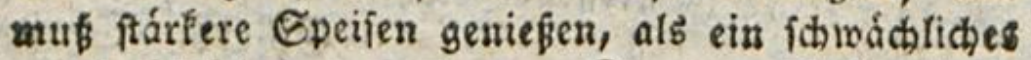
uno weidfich cragenes. Stuve. Referwib̆.

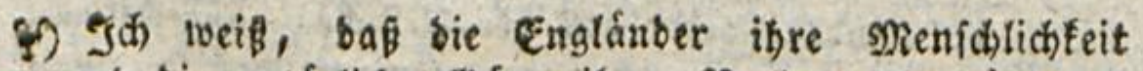
unb bie natúrliche of úte ifher station febr rúbmen; ôpe fie fidy the good natured prople sennew; fie mógen aber 


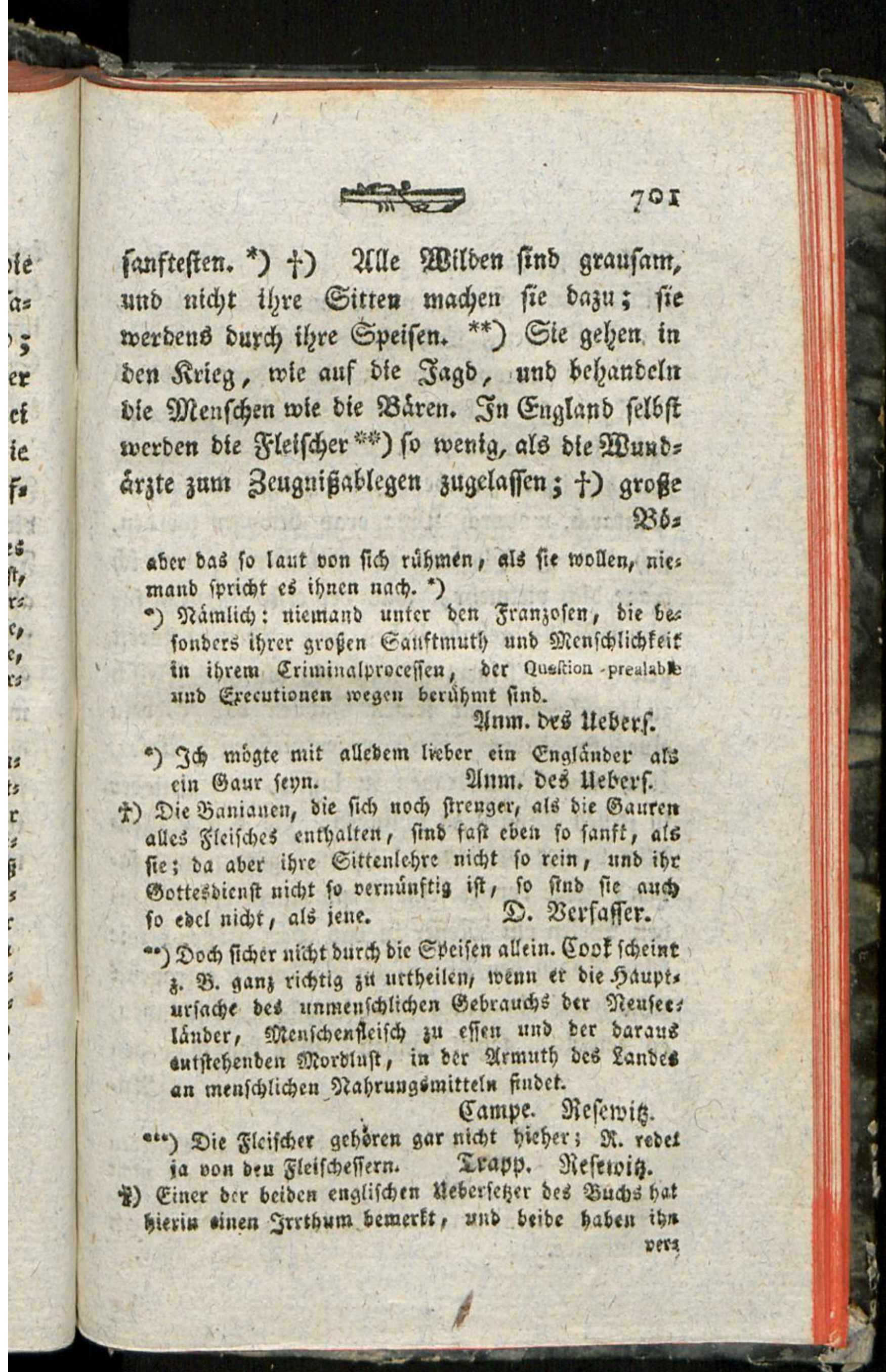




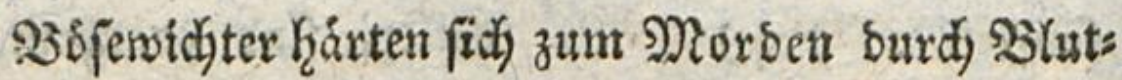
trinten $a b$. Şomer macht aus ben Enflopen,

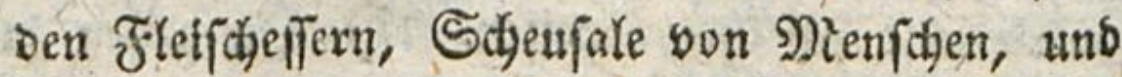
allo ben Sotophagen ein fo Yebenswirbiges Solte, baf́, fo ballo man thres llmganges ges foftet hatte, man fogar jein \$aterland vergafi, Im bei ihnen zu Yeben. "D̂u fragft midb, fagte Solutarci, woburdi) Şoytagoras berwogen worden, fich bes Fleticheffens zu enthalten; aber th

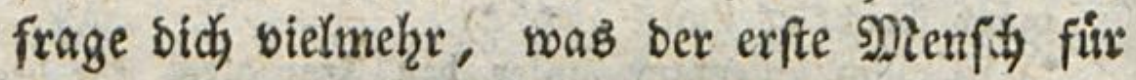
einen Nath geḩabt b̧aben mag, bex es̉ zuexft gewagt, mit feinem פinnoe ein blutiges Fleirád zu beribgren, mit feinen Bäbrnen bas Şebein

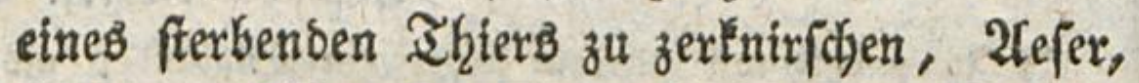
Seidname fid) auftragen zu \affen, uno Şlieber in feinen Sagen zu foblingen, bie ben ?ugens blid' vorker brillten, blockten, gingen und jas ben? SBie tonnte feine Sand einem empfindens ben Wejen ein Meferer it bas Şerz ftofien? wie jeine 2ugen ben 2Unblicl eines̉ Morbes extragen?

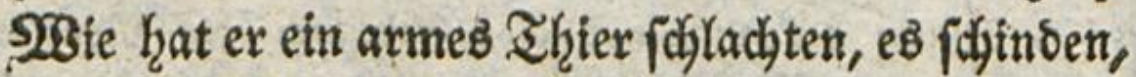
es zerftiden-febien isnnen? 2 Sie fonnte or ben $\mathfrak{U} \mathfrak{n}$

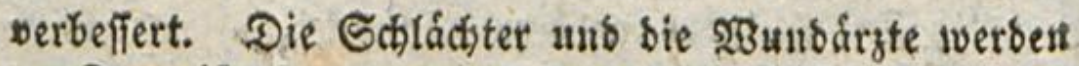
zu Seugnifigeben zugelafien; aber erftere werben nid)t als Elieder einer lury ober als Peers zugelaffen; lek̨, tere bingegen werbens. Inmerfung ber legtent slügabe.

D. Serfaffer. 


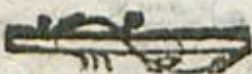

itut:

pen,

uns

tges

ges

zุaf́,

agte ben,

idi)

fir

lexft

eifक्ष

bein

efer,

eder

geths

, fas

bent

wite

jent?

ben,

Den

2)

erbent

nid)t

lek̨,

(Btent

it.

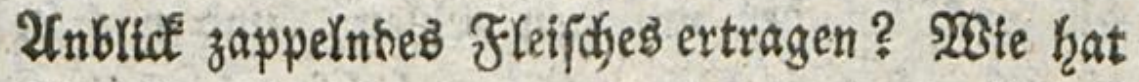
fein (E)eruch nidit bason empirt merben muifen? Sale hat nidit (5)el ifgn angenanbelt, than zus rictęgeftof́en, Srrítel iha ergriffen, ba er in

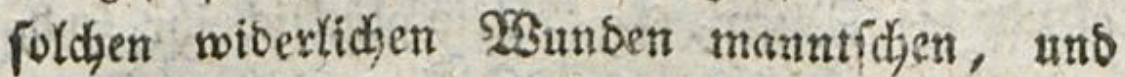
bas \{fjwarze geronnene Shut abtrodinen mufte, bas an thrnen flebte."

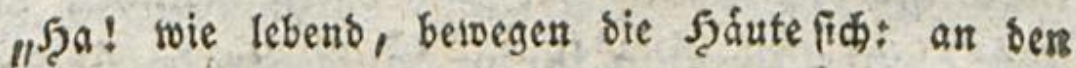
Spiepen,

Réptent, blullet now auf bes frich gefdilachteten Rinbes S3lutendes fleif ! Nit Schauber genieft ber $23 i l b e$ bes Nables;

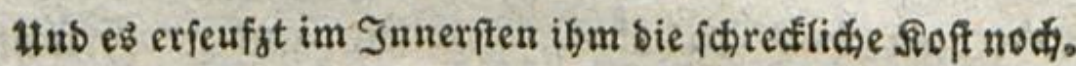

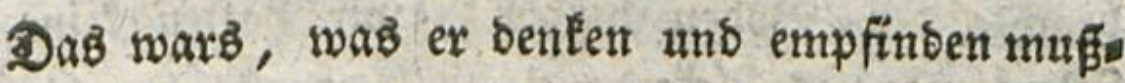
te, alo ex zum erftenmale bie Natur úbers

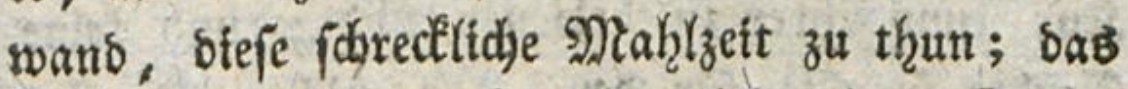
erftemal als thn nad, eitrem lebenstgen Thiere bungerte; al( ex fich mit einem গRinbe auf ber SOBeibe náhruen wollte, und fidjo felsfit jagte, wie erb anzufangen hadtte, ein Sajaaf, bas iȟm bie Şande lectite, zu ermirgen, zu zeríd, neiben, uno zuzubereiten. Lleber biejenigen follte man (id) wanbern, die biefe graujamen Fifte begans nen, nidjt úber biejenigen, bie fie zuerft bers liefien; unb gleidurol f́smten" jene Erftern (Ents fóulbigungen für thre Graujaméteit anführen, bie 
Sie mus Eet bet unfirigen fehletr, uns uns is cinent nod) weit blutburftigern Sidjte zeigen." "Selige, won ben Gottern geltebte Mien fden, wirben jene crifteren zu uno fagen, bers

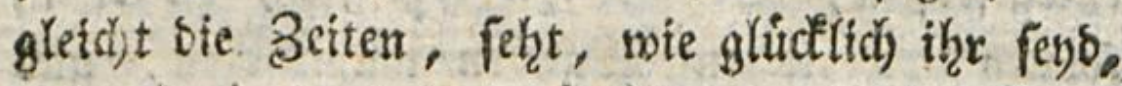
und twie clend wit twaren! Die neugebild bete Eroep bie nock mit Dimften gefd)wängerte Suft, ges borchte oer Sronung ber Sabsrozetten ridgt; ofe Friffie unbeftimmt in threm Enufe, traten biberall aus ifben lifern; Ietche, Seen, tiefe Sums Pfe iberfichwemmten brei 3 Berthel oon bet Eros b berfliche; Wäber uno unfrudjtbare Forften bebecten bas Ulebrige. Reine guten Friudjte bractste ber Boben berbor; wir batten Eeine

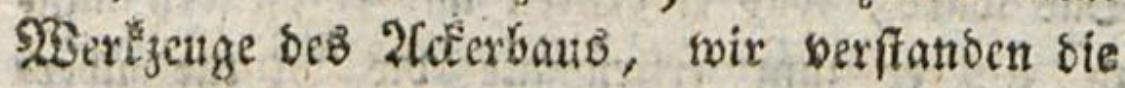
Runft uns threx zu beotenen ntcht; uns łeine Ernote fprofite für ben, ber nid)t ausgefaet Gatte. Sile waren wix aljo olgne Şungersinoth.

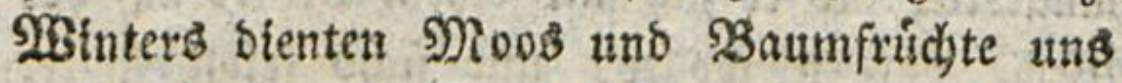

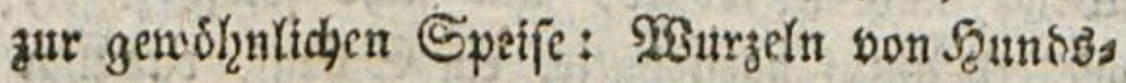
zabn ano Şeibe waren unfre Secterbiffen, uns

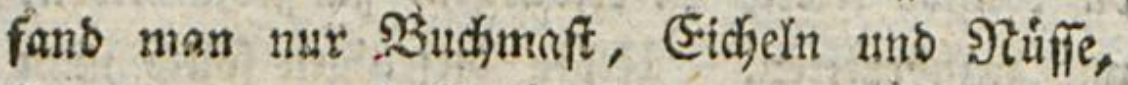
fo tamzte man frolyloctens um eine (siche ober 2Bube, ungefd)ladyte (jefinge anfitimmeno, berum. Die Erbe nannten diefe Elenben ihre Saugama ane and ifgre Datter; jeneo war iht einziges

گreft, 


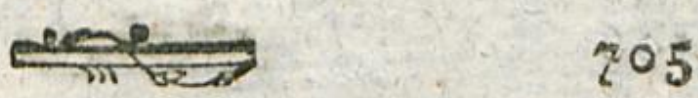

SFef, auferbem imigab nur Sdmenz, Noth uno ciens sab menfdalidje seben."

"Enolid, als oas entblspte uno nacte Lans uns niabts weitex mefgr sarbot, fahts soir uns gensthitat, um unjer Leben zu friften, Die Natur zu beletoigen, uno die SEeföhrten unfers Crenos rieber zi berzehren, als mit ib, nen unizufommen. Şłr aber, Erraufame, soer zrvingt euds Shlut zu vergiegen? Sebt, weldse Fulle bon (Eiten end ungiebt! SBie viele Fridjte bie crobe eud herburbringt! Stgie reithe Ernoten eure Felber uno 930 einberge end bats bieten! Irte viel Sgeexben eitch zu exnabrett, ibre Nilld, uno enth zu feiben, thre şolle

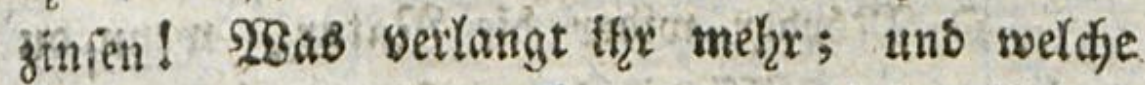
SEuth treibt euch, gefittigt non biefem Lebera flunfe an Sittern unb sebensmitteln, fo viel Morbe zu bigeben? S2Barum ligt thy gegen eure Nutter, ba thr fie antlagt, fie fonne euts nicht ernáfren? Warum serfintnotgt ihr ench an Eeres, ber Erfindertn Der hetligen Sielerge unb

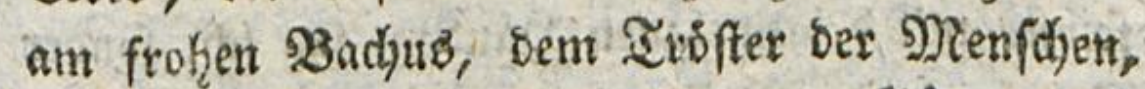

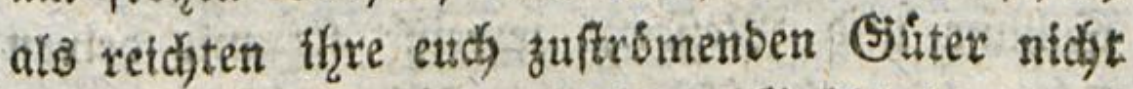

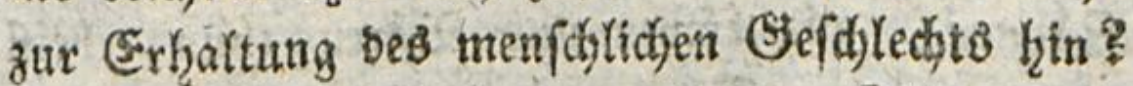
Sie babt the sas Serz, auf euten Sifhen uts ter thre fanften Saben Eebetne zu bxingen, uns Emir xifer

(2) 4

nes 


$$
206
$$

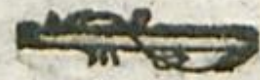

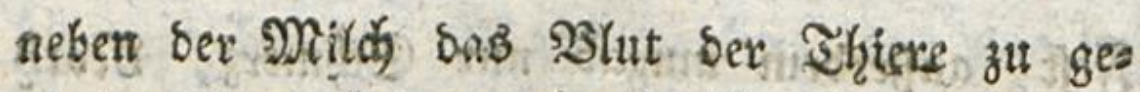
niefien, bie ent') jene getsen? Sarbel uno Sowen, steje swilben Intere, wie thr fie nennt, folgen nothgeorungen threm Sinfinct, uns tosten anore

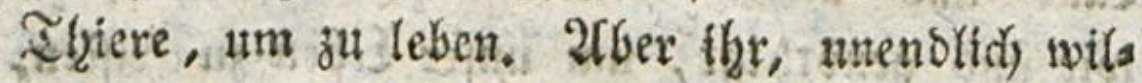
fer alB fie, beftreitet ohne 9ooth ben Suftinct, end) curen graujamen $2 B_{0}$ llifien zu diberlaffen;

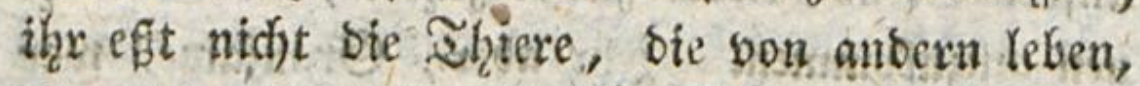

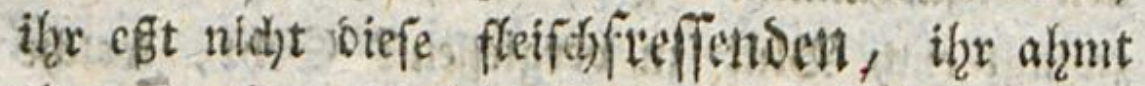

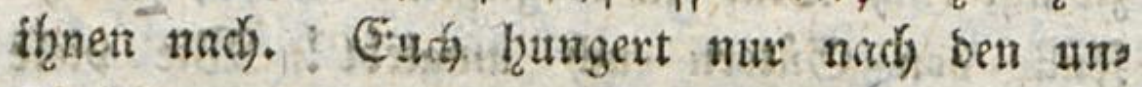
fiduloigen thun, bie fich an end bangen, bie end, bienen, uno bie the Jum Dant fir the Dienfte vers follingt."

"S) Msrber wiber sie Natur, wenn ou' noch immer fteiffinnig beharrf, su behaupten, fie babe oidh gemad)t beines gleidjen zu verzehs sen, 28 efen son Fiteifh uno Blut, Yebeus uns empfinslid), wie su felbf: anf benn! exfitite bas Granten, bas fie sir vor biefen fothrectlidjen Mahlzeiten einflsfit, toote biefe Zhiere, aber folbft, mit beinen eignen Seanden, fag idy, fortioer Sclunur uno Meffer zenreiffe fie mit beinen

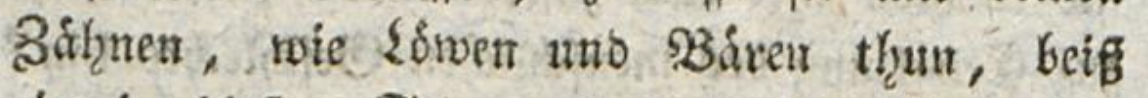
ein in biefen Stter uno zerfleifhe ibn, brau ein mit beinen Rlouen in feine Szmt; frißß Yes 


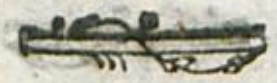

fensig biefes samm, zefrr nuf fein nody bams

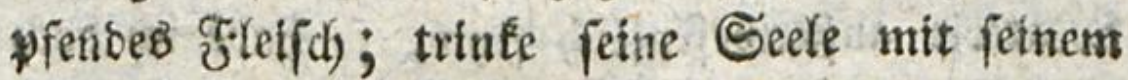
Blute! Du fdjauberft? Ou wagfỉ nidjt, unter

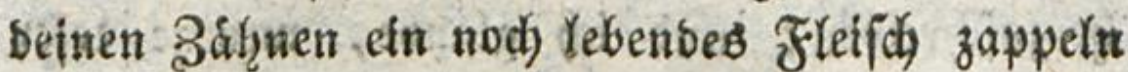

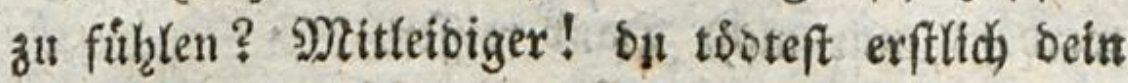
Shitex, uns bann iff it bu's, als mollteft but es zweimal fterben lafpen? Un' nidit genug! auta) Das tobte Fleifd wtoexfrebt bir nod), bein Fingetwetbe fann's: nidit vertragen, on mutifts

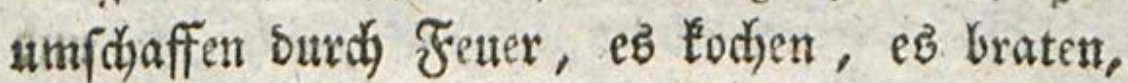
surch verindernde 23 irrze es bereiten; du bea Sarfit Sisdie, uno anbrex Selfer, un bir baв

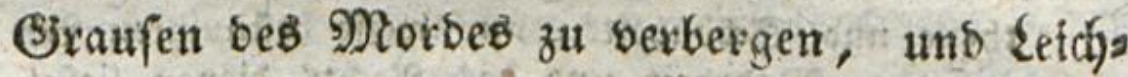
name efturuteiben, Damit ber Sinn des Ses

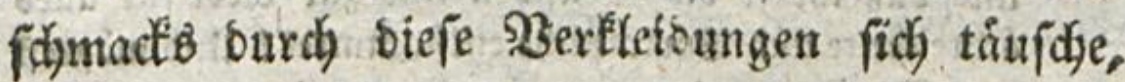
etr, efrs ins lite jeit ber nidjt abmeife, was ifnt fremo ift, uns mit 23expnigen an tooten Siórpern zefre, Deren 2Inblid felbft bas 2fuge taum batte extragen fismen!" **)

\section{I) 2}

M):

ber

tett

eif

au

Yeas

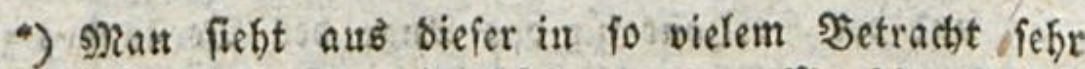
fobonen Stelle, wie leidst es bem Nemicten wirb, felbft Dinge, bie Den Einrichtnugen uno Gefercen ber Ratut uno einer zivedfmábigen Entwicfelung

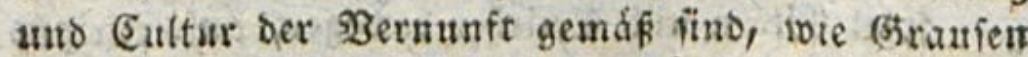
erregende oránel vorzutelfer. Niogte bies, Gtbrifts fteller, bie ift alle \$ortbeile ber গुerebjamfeit unb alle binreifienden Shonbeiten bes Stils in eurer olacht 


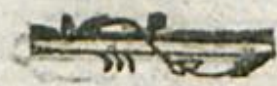

Mtsge stepes Strick aud eigetutlidi meitret Draterie aufermejentlidy pend, fo babe idy Doda Dex Berjufung nidjt wiberfteken fónnen, es herzuldyreifen; und ish glaube, wenige Lefer merbens mir nicht Sount wifien.

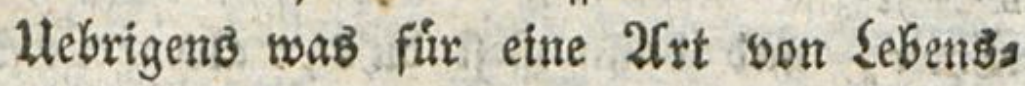
orbnuting man feinen. Rinbern auth boridgreibe; gewolgne man fie tut an gemeine und einfadie Speifen. 3tsbann laffe man fie effen, taufen uno

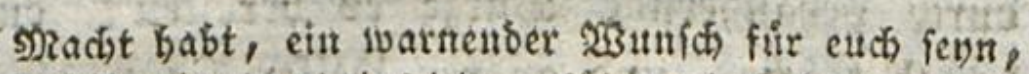

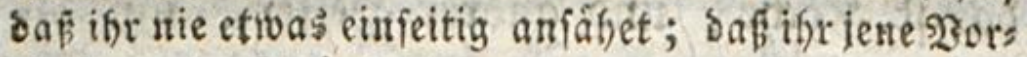
theile uno Schonheiten nur weife beftimmten \$es

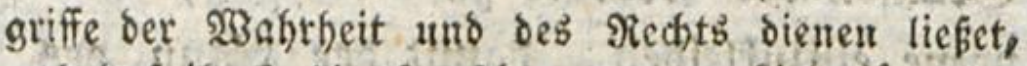

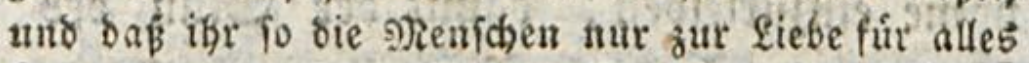

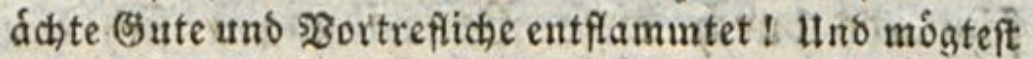
Du, Rouffeau, ber bu ein fo grofier Meifter it Der Sumf ber Darftellung warft, und ben Sters ftand bei bent irrigiten গुebauptungen fo teidht zun গुeifall mit sir for treifeft, diefe beine grofie Sinift blofi zum 2 ortheil ber auts allen Srthúmern reiz

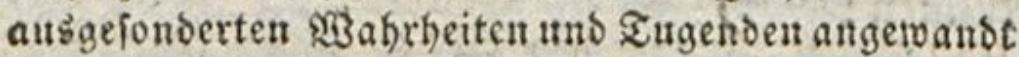
baben! Iflein beitle Geele wurbe auf bem Mieer ftúrs mifcher Seibenichaften zu farê bin uno hergelvorfeat

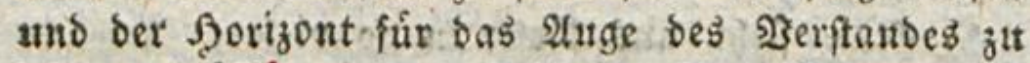

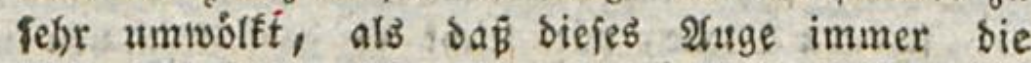
reine $23 a b r b e i t$ uno ₹ugend batte im Bificht bes balten fonnen. Noggte alfo mur bein eignes গुeis fpiel EItern un Erzieber beroegen, aufs eifrigfte uno weifefte bahin zu forgen, baf bie ibnen anbertraute Sugend fich nidht auf ein Mieer begebe, worauf felbit fo mandes grope Gente umfommt ober Sdiffs bruch) leibet!

Eblers. Sieferwik. 


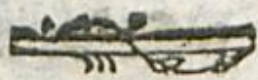

ưn fpielen, fo stel es ithnen gefallt, unb fey serfidjert, fie merben nie zu viel effen, uno teine Befdjwerben ser Ilnwerbaulidjett fraben *) Lafit the fie aber bie Solffte ber Beit ifber hungern, fo merben fie bann, wenn fie s) rittel finden, eurer $\mathfrak{Z}$ adbfamteit git entrinnen, fich), fo biel fie nux fonnen, fdjablos halten; fie werben einfiblingen bis zum 3erplaken. Stur barum uberfofreitet unfre Egbegfer: thr Inaaf, meil wir ifn andore Regeln geben wollen, a'z sie Regeltr ber STatur. Simmer mátetno, sors fdjefbend, binzutbuens, abnebrment, bandeln wiv nicht anbers als mit ber $23 a a g$ didale in ber

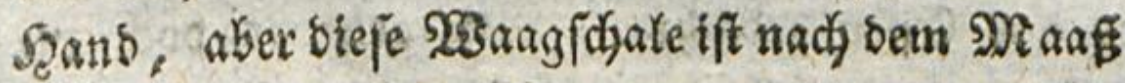

(2) y 3

utta

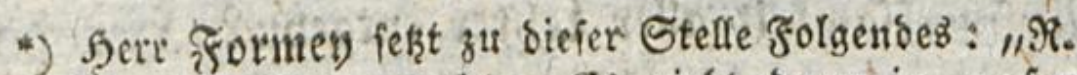
fent bie Rinter mucht, Es giebt deren in grofer 2frzahl, welche surd) Sefrảbigfeit fich ben god zu= jiehent wurben, wenn man nidat ein Stuge allf fie. batte." Seert Formey erlaube, dấ ió meine eigne Erfabrumg, auch mit (3efabr gleichfalls fur cinenNichts feuter bar finber gehalten zu werben, ber feinigen bieruber entgegenfeke. Gie ift biele: fein an eins fache Roft gelwobntes unb uicht burch unjeitige शुors ficht beim (semut einer folchen fioft zat fefir belvads= tes uno cingefdránf tes unb auf ber aubern Seite nicht in fruber Jugend muthwillig verwófhntes find if vou

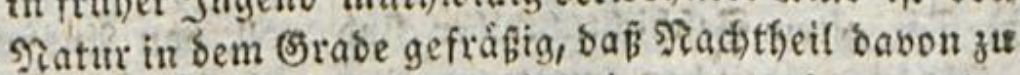
beforgen wáre; westigitens ift mirj unter obgenanter bebingurgen unter allen Ritrbern, bie ich, gefaitut habe, fein cintiges dergleichen vorgefommen.

Eampe. 


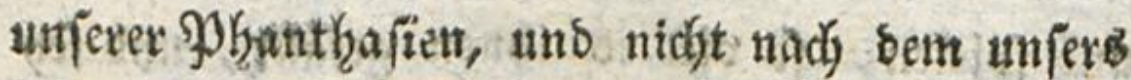
Nagens eingeridjtet. Sch tomme ftets wieber auf meine Belipiele zuridc. Bet ben Bauern

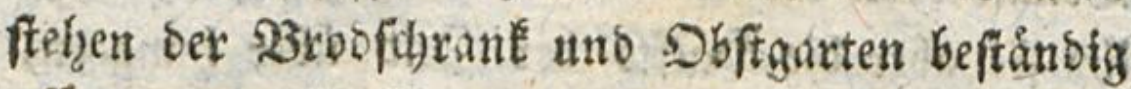
offen, und ble Rinber wiffen auf bem Lande fo weuig, als bie Erwadjenen, roas Ilnveroaulidys teiten fins.

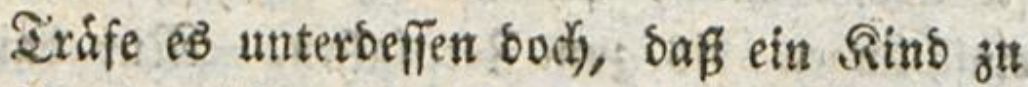
biel åfe, weldes iđh, wofern meine. Methuoe befolgt wirb; nitht fuir moglid, halte: fo ift $\mathrm{eB}$

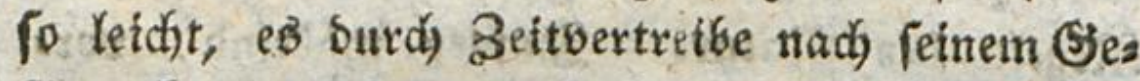
fidmadie zu zerftrenen, baf́ man $e B$ wirbe bahin

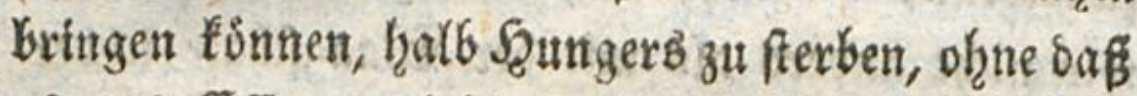

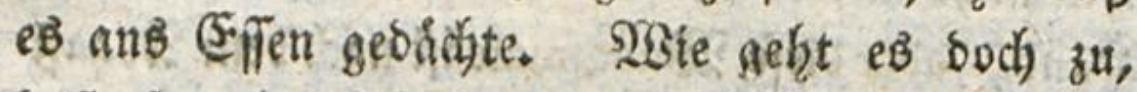
baf fo ofnnfehrleare und fo leidjte Mittel ser 2ufmertifamteit aller Sebrer entgehn? Serodot exzáhlt, bie Enoier haatten, cinft oon einer grofs fen Soungeršnoth geoxángt, fichs eufallen lajs fen, Spiele uns anbere Suftbarteiten zu exfins nen, womit fie ibren Seunger getánfobt, und ganze Iage zugebracht, obne an Eifen zu bens Fen. †) Eure gelehrten Suftititoren baben viela letdyt

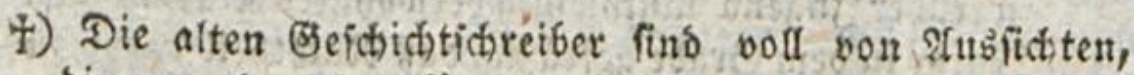
bie man brauthen fonnte, wenu aud oie Begebenheis ten, bie uns ile zeigen, falfes fenn follten; aber wir riffen aus ber Eeichidgte feinen Wabren 2sortbeil ju 
teidat biefe Stêlle fqunoertmal gerefen, ofzne bie Xnwenoung zu felzen, bie fid bavon auf bie

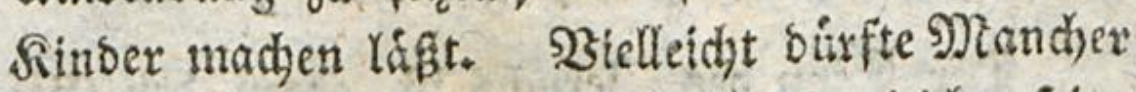
mir fagen, ein Sind verlieffe nidjt leidjt feine Mahlzeit, unt hinzugethn uro feine dection zu (3) ?) 4

Yers

zichen; sie selohrte Eritif berfotingt aftes. git senn

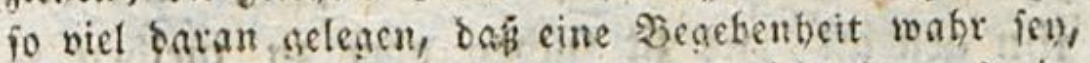
wenn man un einen mik̨lidsen Interridht baraus gic: ben fann? S) serftábige múpen chnedieg bie (3)e f(bichte als ein (5ewebe son fabeln betrachten, "*) Deren

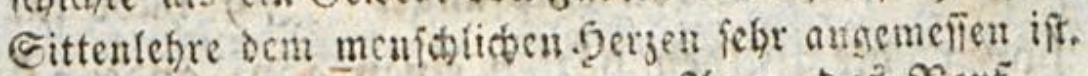
Sกm. Des ミerF.

-) seir focinet boca - ia - es tft viel baran geles gen - voriliglich itm den darats zin ziehenden thm terridht nuikelich ju mashen. sisenu idi) von ber

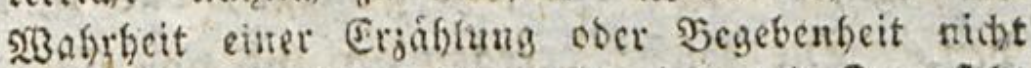
gewis biu, fo faun ich auth nicht mit Buverficht lefren uno Fiegeln baraus folgern, welche mir nicht auts anbern Grúnben f(t)on cinlendtento uno gewié fitro; noch weniger fant ich fite Artoen als 5eipiele

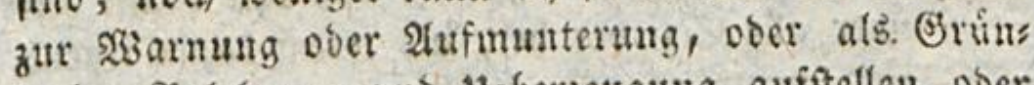
de ber গjelehrung unt Hebergengung auffellen ober anfuifrent.

Stuve.

**) Nouffeau geft fier zu weit. Siebt es gleid) feine burchaus in jebem Punct wafre (s) cidhichte: fo fommt boch manche Der 23 abrheit nahe uno fo muf ber (5)eichicitichreiber es fich bod) jur erfen Pflicht mas (hen, ber SBabrheit moglidhit nabe ju fommen. Ifuth)

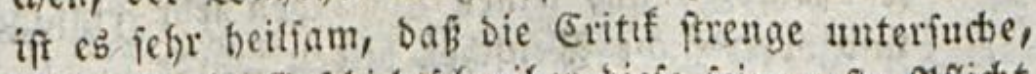
wie weit ein (sejdichtichreiber bieje jeine erfte - Pficht erfíllet babe.

(E) lers. Rejemis. 
Yernet. Meifter, ibr b̧abt Recht, an biefen 3eitbertreib lgabe idj nidjt gebadjt. *)

Der Sinn bes Șerudjo ift gegen ben (Sies

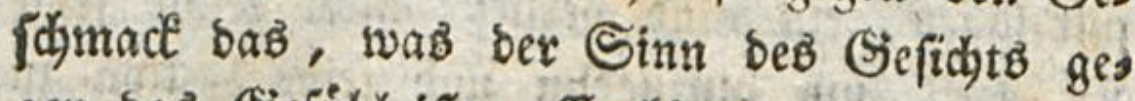

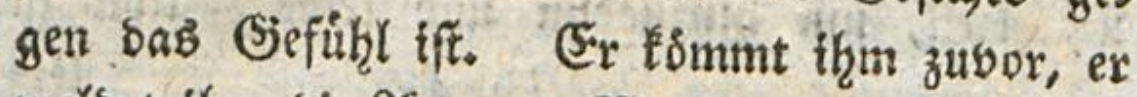
melbet iffm sie 2Art uno 2 Beife, wie bieje ober jene Subftanj barauf wirten foll, uno madjt ithn genetgt, fie zit fuchen ober zu tretben, je

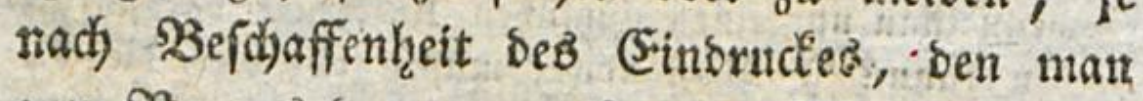
zum Soraus bavon empfángt. Sch frabe fagent bơren, bie ruch) als wix, und urtheilten ganz verfóieben son bem, was angenehtm ober unangeneţm bars auf tråfe. Şđ) bin fehr geneigh, bas zu glaus bet. Die Dufte erregen an uno vor fich ferbit

fojmas

-) Rouffeaut fállt nur zu oft anf cine hóght bittre 29rt liber alle Ergieber ber, alb ivenn faum irgenb einer won gefundem Berfande in feizen Erziefungseins riditungen geleitet wurbe, und fich liber eime geiviffe Nittelmáfigf́cit erbbbe. Daourch finto nur ju viele ftolje $2 a$ ter veranlaß̧t, auf bie Eebrer uno 5 ofmeis fter ibrer sinoce veráthtlich berabjuiefon. Lino un: ter biejen giebt es boch fo Nzanchen, ber, toenn thm nicht von allen Geiten Sindermiffe in den SBeg ges $^{2}$ legt wirben, aus feinen 3óglingen fehr einfichtroolle und vortrefictse \$ienfichen bitben wurbe.

(5) Iet:3.

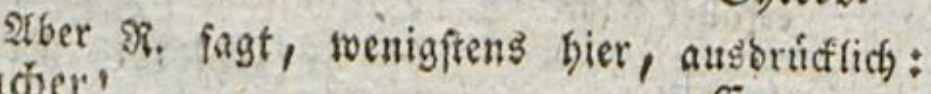
mancín!

Eampe. 


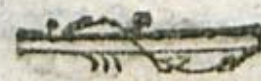

fdroadje Senfatiotien; fie reizen melge ste Eins biloungs fraft ato sen Sinn, uns rúbren nidyt 50. felzr burdj sasjenige, twas fie geben, ats mas fie erwarten Kaffen. Diefeb sorausgefert, mus

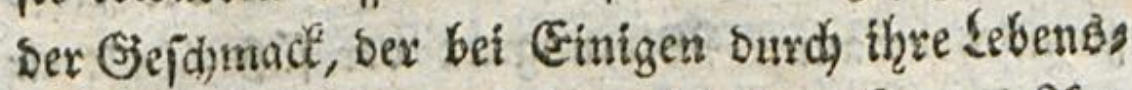

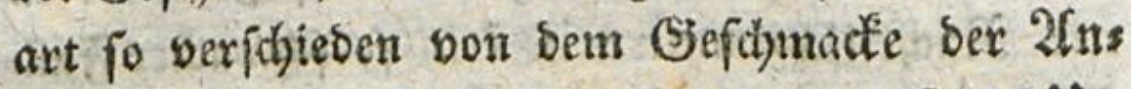
Dern geworben ift, auf ganz entgegengefeste lit: theike uber bas, was Ejefdmack hat, uno folga (id) auch uiber ben (s)erucb, ber jenen entundigt, fállen laffen. Sin Zartar mußs mit eben fo biet 528 ohlagefallen eit ftintendes Bierthetl eitues

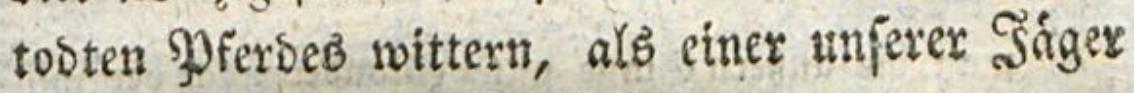
ein halb verfaultes ßebhuhn.

Lufere migigen Senfationen, als z. $\mathfrak{E}$. Sie, wenn man ben Balfambuft won ben 2 lus men eines̉ Beetes einathmet, múffen son Ment

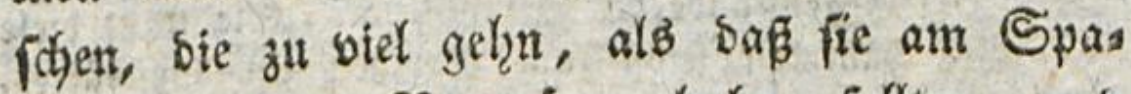

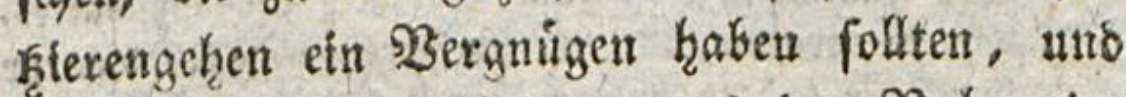
bie nidjt getung arbeiten, aแs ber アuhe eine S280lluft zieben zu Esonen; gax nidjt empfunbent werben. $2 B_{3}$ ftets lyungrig ift, wiro nidjt grop̧e Suft an Diften finden, Die if̧m nichtỏ zu effen antunoigen.

Dex Sierudd ift ber Sinn ber Einbilloung's Eraft. *) Da ex ben פierben cinen ftáteru

*) SRicht mehr als icber anbre Sinn. Xuch wirft jes ber Cinn gerabeju auf bas Nierbeninftem. 2Benu

man 


\section{4}

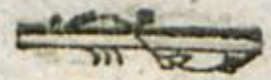

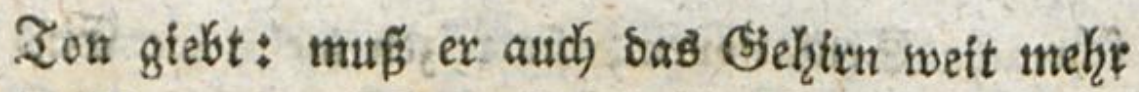
in Benegung fef̧en; burum belebt ex bas Tens pexatment wieber auf einen 2fugenblict, unb ers fajopft es auf bie Lange. Ev hat in ber liebe

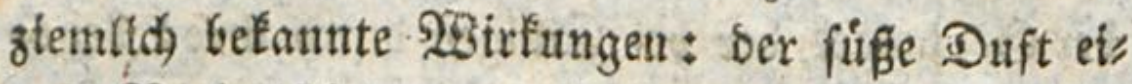

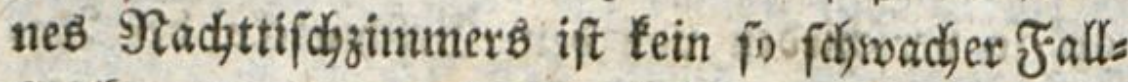

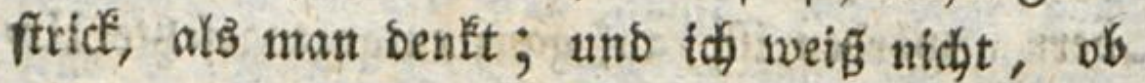
man bem weijen und unfíhl̨aren Manne Ģtid swinfthen, ober ifgu beflagen foll, bem batm

Dufs

man bie äffern Einne unter eitanber nac) ber min: bern ober mefferin şerbindung uno fefnlicbfeit, bie julifden ibnen uno bem innern Sim ber Einbils oungsfraft Statt findet, beuttheilt und vergleidht:

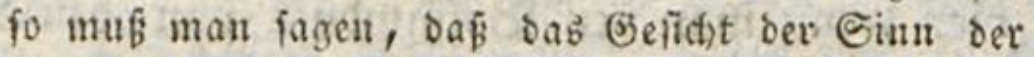
Einbildungstraft fev. Diefe fiellt fich vorjúglid)

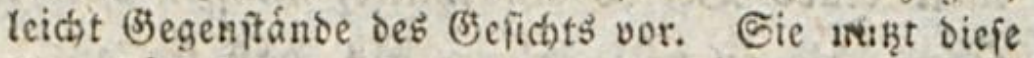
ifre fábigfeit felbft jun झुoutheil bes (3ejcháfteb, das fie vornimmt, wenn fie goeen erwedt, bie ifr ourch bie ambern ăubern Simue zugefúbrt füb. Das her entipringen bie Şortheile, bie twit vom Eocalges dáchtníb ziehen. Soll bus angegeben werben, wos burch fidh ber (5eruch von andern Ginnen untericheis Det: fo faun man bas nidht bariu fę̧en, bafi er mit ber Einbildungátraft náber verbunden oder wol gar eine bejonbre 9) Robification von Der 233 irffamfeit Der Imagination fen. Sartheit uno Schwádhe uno ein Damit ifich verbinbender iegr involffonmer Joeen juftano daracterifiren vielunefr vorgiglich ben Sinn Deb (5)

(E) 


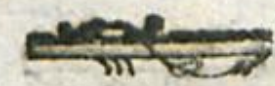

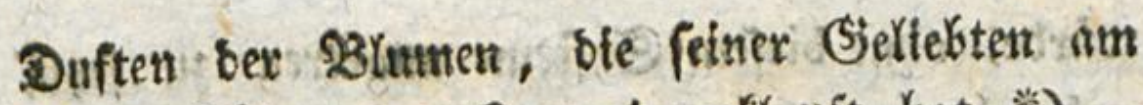
Bufen khtühn, bas Serz nie geflopft hat. *)

Der Serudy barf int erften 2fiter nid)t fef̧e

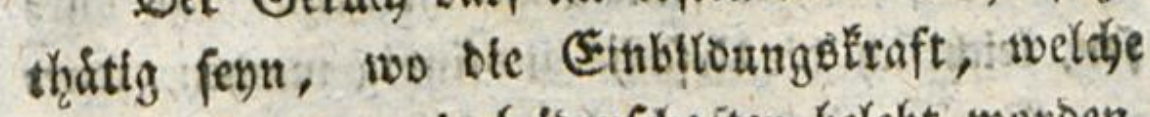
nux nod) bont wenig retbenfajaften belebt morben,

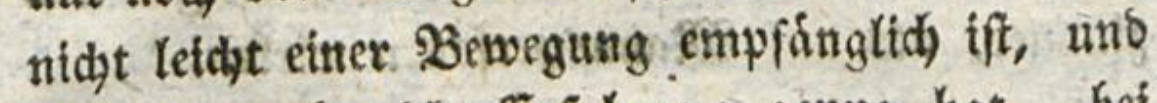
wo man nod nidut Erfakrung genug hat, bei vinem Sint bas sornis fu fehen, roas uns ein atberer verfprtat. 2tudy wirb biefe folges rung burd, bie Beobadtung bolltemmen beftás

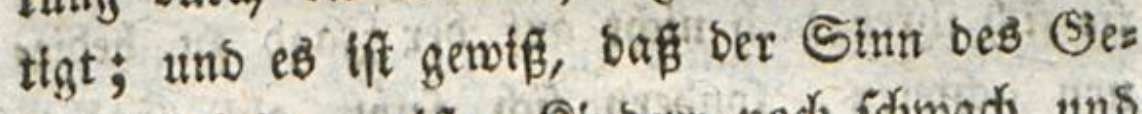
rudjs bei ben meiften Sinbern nodj fdrwady uns betinake ganz ftumpf ift. Sitdyt alo waire sie Empfinburg bet fhrnen nidst eben fo fein, uno btelletdyt jogar feiner als bet ben Erwadjenen, ponbern weil fie, ba fie Keinen anbern seghiff bamit bertenipfen, nicht letdstlidh eftie Empfirts

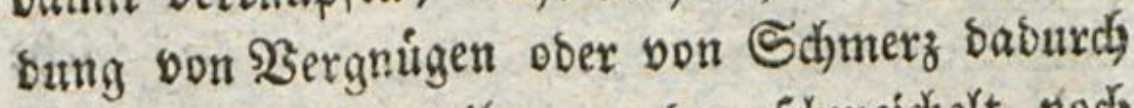
betommen, uno ex thnen weber (it)meidjelt noch fie beletbigt, wie und. **) Sdj glaube, man witrs

-) $9 \mathrm{~m}$ Yintet ber liebe fpielt in ber That jeber Giur eine febr bedeutenbe rolle. Dem Beruch ift bier gervif nicht die erfte jugefallent, weun vom Siange ser-berichiedenen Sinne in ber frimitht die গiede ferm foll.

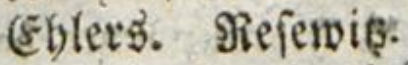

**) Es befommen finder wol gewiế eben fowol, als bie

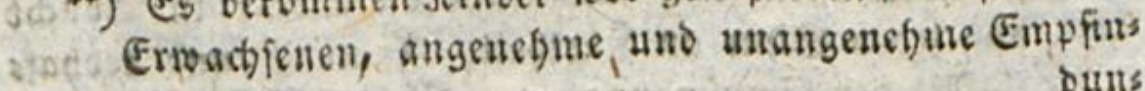
Dแแก 


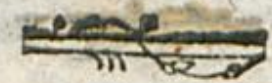

wurbe, of̧ne biefem Shfteme migetren zu pentr, und ofgne zat bev bergleichendan 2rnatomie ber

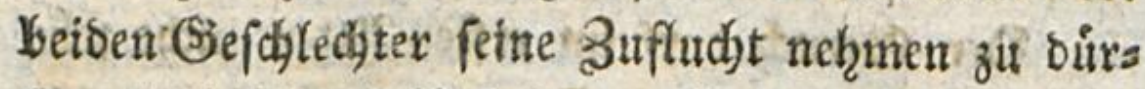
fen, Yeidgtlich bie thrfatje aubfinsig madjen, wars

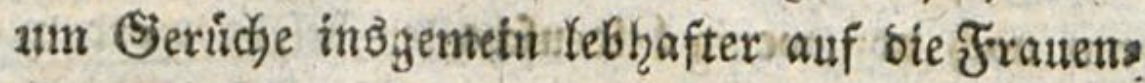

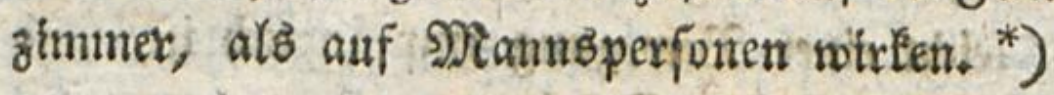

Man pagt, bie Szitton in Canaba erwirs ben fith von threx exften Sugens an cinen fo zarten Gerudy, baf́, ob fie gleich Sounde habert, fie fid ihreer boch nicht auf ber gago sut bebies nen achteten, fonbern fíd felbit als Stóber sienten. 2utch begreife ids in ber Ihat, mats swirbe, falls man bie Rinber bazu erzoge, ihe Mittaģbrod aufzumittern, wie ber Şmo bas SIBilo, es sielleicht bahia bringen, if̧nen sen Gerudy eben fo fefgr zu verbolltommnen; nux rebe

Sungen butch den (bertch. Iflein fre fins nicht fos big, fich úber biefen Empfintungşâtano gebirig zut átisern, weil theils bie Empfinbungen zart fino und theils fich jut viele $\mathfrak{A}$ rmuth in iffen ben (serud) bes treffenden Soeen findet. WBie wenig ift felbft ber gruindichite Denter im Stande, fich uber oie vers fchiebenen Mobificationen bes Ëerudbs zu erflären!

Eb)

*) Tranengimmer haben úberhaupt feinere Drgnie und

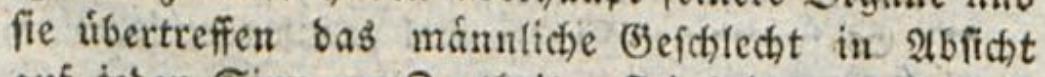
auf jeben Simn an Sartbeit, Feinheit und lebbafs rigécit ber Empfinsung. Eblers. \$eferpißs. 


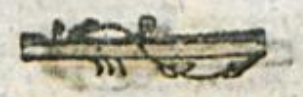

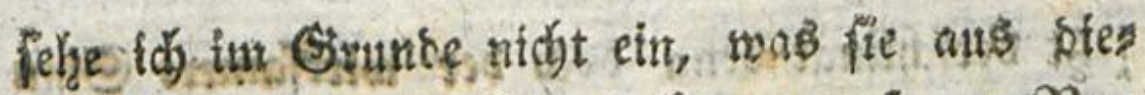

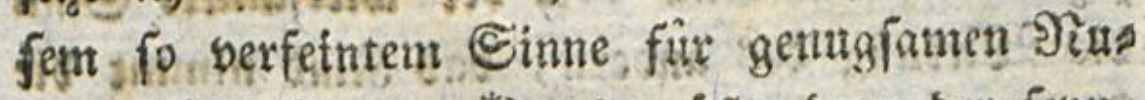
Gen ziehen finnten, *) eb mighte benu ber, ferm,

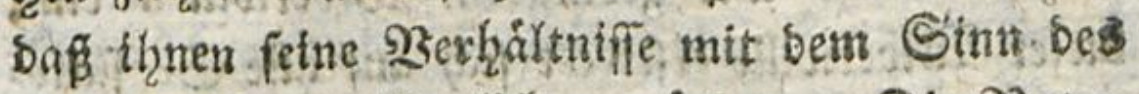
Eerdymad's anjhaulicher mirben. Die Niatux hat Sorge getragen, uns mit Genualt auf biefe Sermanotfdhaft adjten zu madem. Sle hat bie

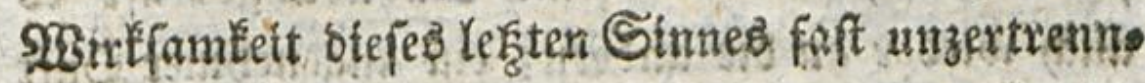
(iic) mit bex bes andern berbunsen, ba fie bif Srgane son beiben in eine Nadjbaridjafi fegte, uno in ben Miunde eine unmittelbare Gemein fidaft unter ibuen betben exridjtete, fo baf wite

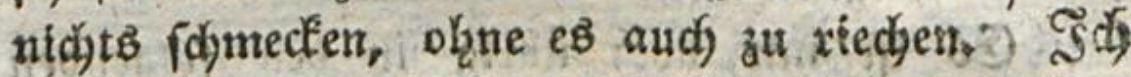
soimidjte nux, biefe natirliche Berwandfogaft wirbe nidjt beeintraidjtigt, ein Rino zu hinterges ben, indem mat zum (Sxempel surch ein ange

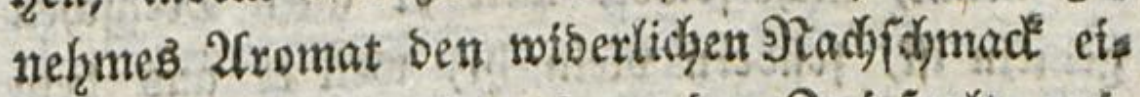
thet 2rzenet Dámpfte; Denn ber Brotefpalt zwts fdjen biefen beiben Sinnen ware in bem andern Falle zu grofi, als bafí fie fid trxen tounter;

jest

-) Diefe Keflection bàtte $3 t$. atrì bei bem machen folo fen, was er úber bie nach ifm fo weit zu treibenden Hebungen bes Befúflis fagte.

(E) lers.

Eine fánffere Hebung bes Sefuifls fotheinet mir

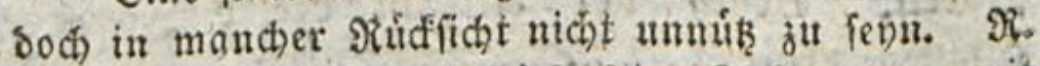
hat im \$orkergehenden diefé feine \$ebauptung mit scifpielen belegt.

Stuve. 


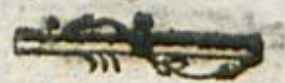

jest berfolingt benn bod ber whthameve Sinn bie $23 i r f^{\prime} n$ ges anbern; das Rind nimmt bie 2Tzenet nicht mit geringerm 28 iberwillen ein; Diefer 23 tberwille erfredt fid auf alle Senfatios nen, bie es zu gleidyer 3̧eit treffen; bei ber gles ringfen abermaligen 2 Inwejenbeit auth ter

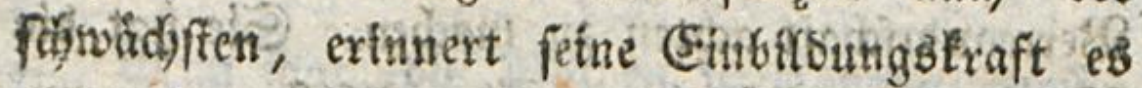
atich twieber an bie unsern; ein angenehgmer Duft botro thin mir ein efelkafter Seruá); und fo vermehren unfere unborfidjtigen Sorfichten ble Summe der unangenehmen Senfationen anf Sos fen ber angewehtnen.

(5.8 ift mix nod librig in ben folgenten Shichern Don ber (sultur einer 21ut von fechftem Sinn za reben, ben man ben fenfus communis nerint, nitht fowol, weil er allen פrenfiden gemein ift, fonbern biefmehr, weil er aus Dem wohlgeoroneten Sebrauche bex anbern Sinne ents fpringt, uno unb von ber Beffiffentreit ber

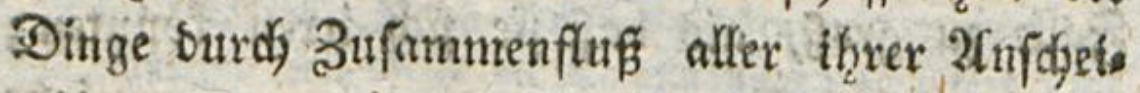
nuingen unterrichtet. Der fechffe Simn hat folgs Iich) fein thm bejonoeres eiaenthimlidyes Srgan; fein Siç ift nur in bem Siefrim; : uno peine blog innertichen Senfationen heiffen \$erceptionen oder

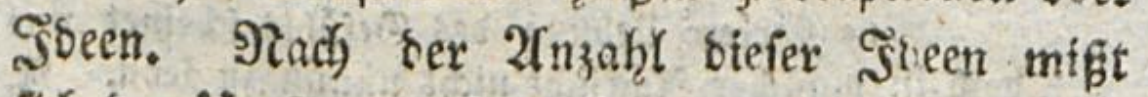
(iib) ber Umfang unferer Renutniffe; Deren Rein, beit, 


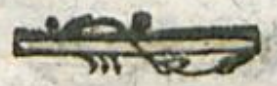

beit, beren Rlarkgeit madht bie Ridytigleit bes Seiffes aus ; fo wie bie finnfi, fie untev eimans ber zu pergleichen, bie menjalliche 2 ernunft.

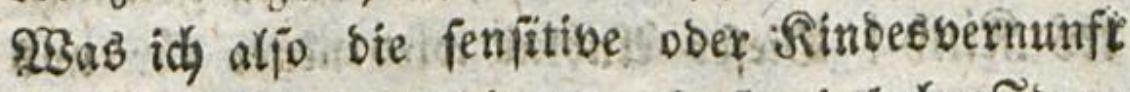
nannte, befteḩt barinnen, Daf́ einfache Soeen burch ben 3ujammenfuf mefzerer Genjationen gebildet werben

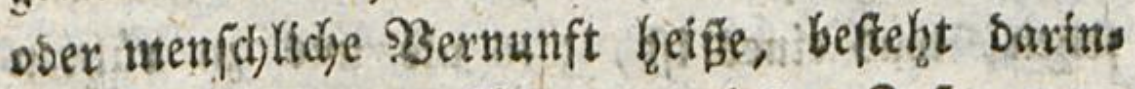
uen, baf complexo Soeen ourch ben 3ujammets fluf melrerex cinfacijen gebitbet werben. *)

Sejebt affo, meine Miethobe ware bie ser

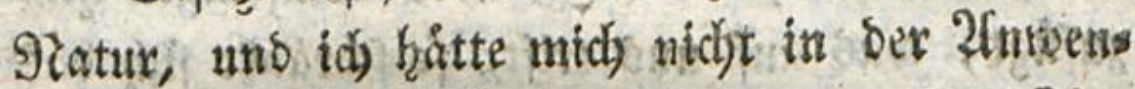

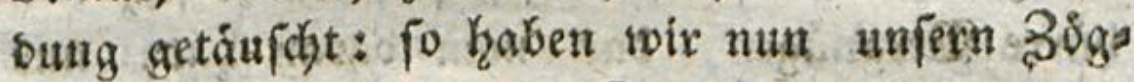
fing burd) oả Sand ber Senfationen bis an bie Srenzen ber Sinabengermunft gefúf̧rt. Der exfte Sdyritt, ben wir baruber hinansthut, muß

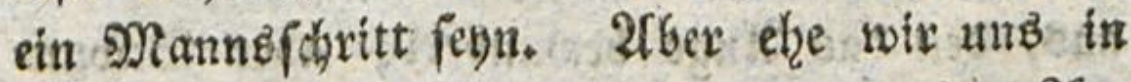
bieje neue Saufbahn begeben, laft uns etnen 2 Hu genblict nod auf biejenigen zuridifekgen, bie wir burchgerwandert find.

Şebes 2fiter, jeber 3uftano bes Sebens bat feine if̧m angemeffene $\mathfrak{B o l l f o m m e n t z e i t , ~ f e i n e ~}$ 2 trt

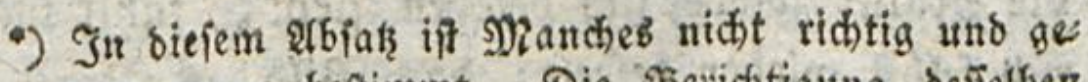
nau genrs beftimmt. Die 'berictifigung beffelben

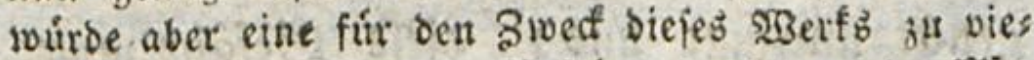

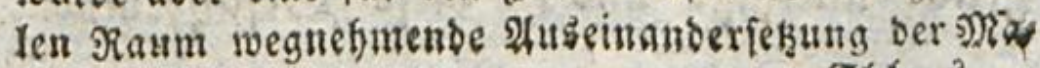
terie erforbern.

Ebler. 


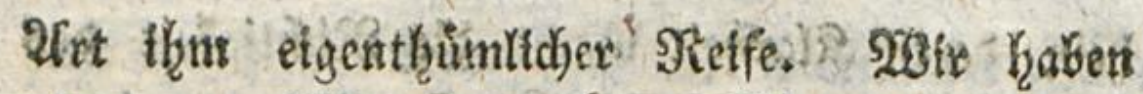
oft botn vollig gemachten Mante gef̧ónt; aber betraditen wir nun aud etu völlig gemartys tes Rind! Diefer 2fnblide wito neuer fir uns and bielleidjt ein nidyt minbet attgenebzer fortro Die Exiftenz der enolidjen 238 efen ift fo arm uns fo efrigefdedint, baf went soir mar bas

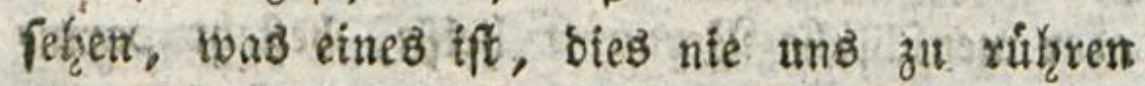

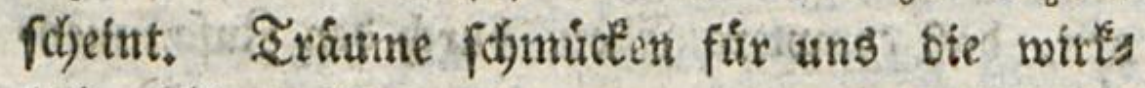

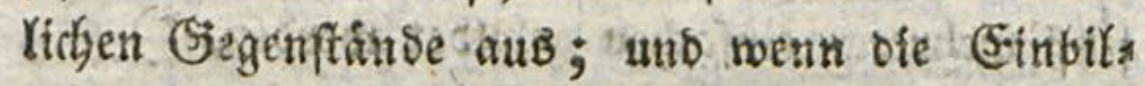
bungbltraft thidjt efnen 3auber bemfenigen hins zuffigt, was auf uns trift, fo fobcante fid bas surre Bergningen, bas inda baran hat, nut alf bas Srgat ein, uno läpt fmmer bas Seerz filt. Die Enoe, gerdumidit mit ben Sdjakęt

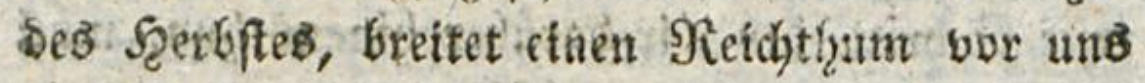

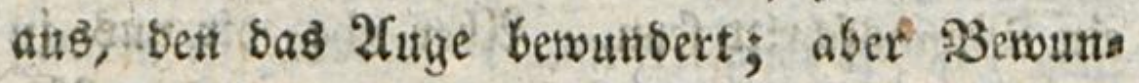
Derung rifhrt nidit; fie entfpringt mehe aus llebertegung, als aus 5mpfinoung. Smรxilgz jafir ift bas faif nod nacte Feto mit nidjts bes Dectit; bie $23 a$ aber geben feimen Săatten; bas Grủn fproǵt nur fierbor, uno boch wiro bas Serz bet feinem 2Unblide bewegt. Da matt fo Ste Natur wieber fid beleben fïehtt; fúhlt man

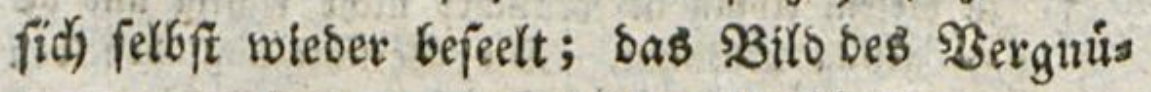
gens umringt uns: biefe Giefafyrtinnen ber

গุ马on: 


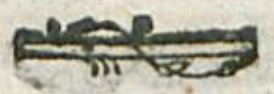

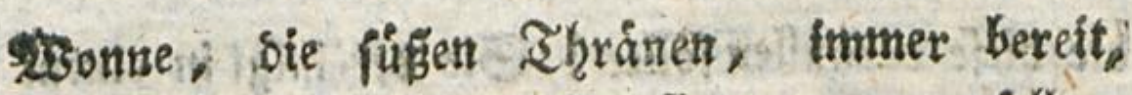
fiti) zu jeber liebliden (Empfinoung zu gefellen,

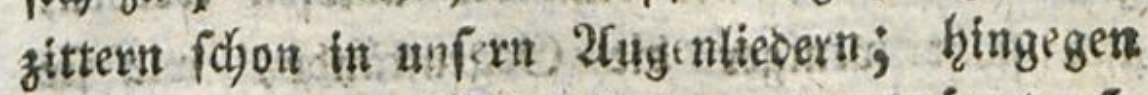
ber 2 2 nblick ber 29 einlefe mag fo gebrángt, ia befeelt, fo angenefim fentr, als ex will, man

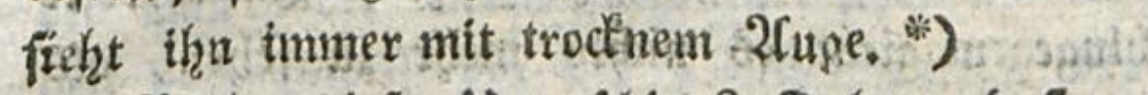
$280 h$ ir biefer Unteridjed? Daher, saf z\$

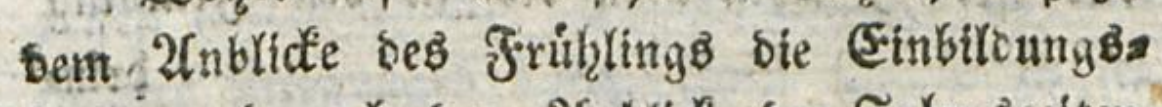
Eraft aud nod ben 2Unblict ber Jahreşzetters gefellt, bie barauf folgen follen; zu ben teia nenben Ginofpen, bie das 2 Tuge wahrnimmt, Sente fie fid bie Bluthen, Die Fruidhte, Die Shatten, bišmeilen wol bie Sgeimlidbeteiten, bie

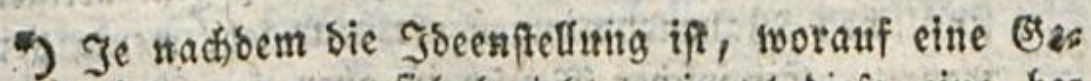
muthsbervegang fich bejiebt, nimmt biefe eine ber

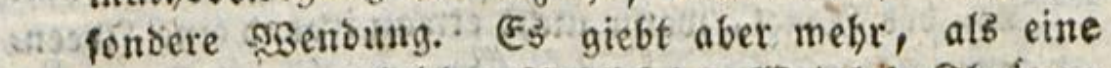

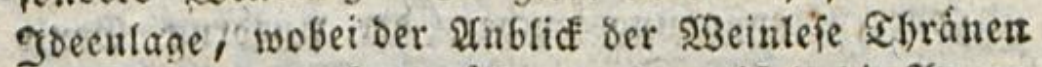

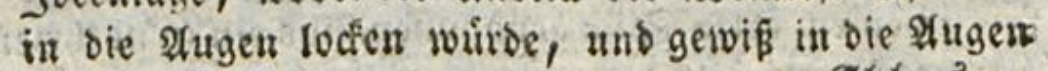
loft.

Eblets.

Der Einbrud und bie Rubruta felbit entiteht nidit blof auts bem fiunlichen Inblid, ober aub bem verp anlafiten Reiz finnlicher Drgane, fonbern auth aud affocititen Soeen, bie burd PGantafie, Erinnerun gen, Seelenftimunus jugleidh in uns bervorgebracht sverben, unb aus ben Reflerionen und Urtheilenp weldse fie verurfadsen. 2uf biefe vergefellichafte Ioeen unb Emprindungen hat $\Re$. in feinen philofos phisien Raifonnements theils úberbaupt nibt, theils uidit beftum gemug 2(d)t gebabt. Siefewio:

Gril Ifter \&l:

83 


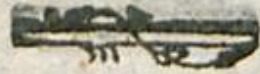

sie blefe berfintlen follen! Sle bereintgt in etrem Suncte Zeiten ; bio einanber nblopen weroen, uno fiefgt wentger bie Giegenftanbe, wie fie fern werben, als wie fie fid fie witurdyt, tweit eb auf fie antommt, fie zu wáķไen. Şm Şerbfte Kingegen giebt es nidgts melge zu jekgen, atz was ift. *) $233 i l l$ man bis in ben Frrihling

oring:

-) 2lber bas, wag ift, veranlafit gewiß eben fo viel uno nod mefrere rúhrende Bemuthsbelvegungen, als bie soee von bem, was fesn wirs ober fer)n Eann. Swar giebt es manchen Renidhen, ber fich inmer mit Soeen ber Whantafie beicháftigt uno auf

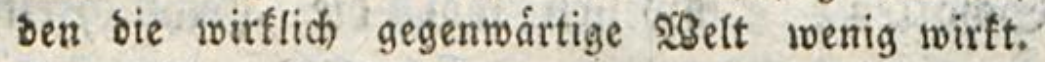
Ein foldher sRenich fommt aud ju Rutbrungen unઠ Sรemutt/şbetvegungen, wozu bie gegenwártigen finnlichen 283 abrnebmungen oft nur fefr wentg bei:

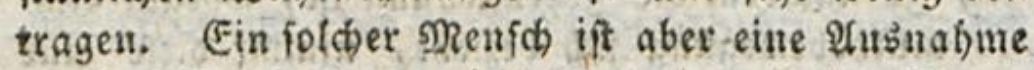
von ber Regel, wenn nicht etwan irgent eine goeen ober Empinoutgsfeuche (ber 2 ugbrud Benie ift, in einem edlen Giun genommen, uns ein zu nothwentis

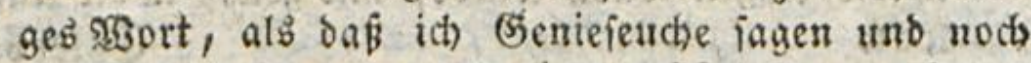
voieber bie Toee ber Sierichtlidfeit barauf fallen lafien founte, woju vor etwa zebu uno mefrern Jabren alle bie Stnmapungen fo vieler 2fftergenties Inlak gaben) in biefer ober jener (Begend bie \$iens fiben allgemein angefteft hat. Shei einer berrichens ben Geutche biefer Ifrt ober bei aimzelnen bupochons brifhen ober faunigten Nenichen fönnen bie Leiben und Frenden freilich auf eime noch viel fonderbarere 2rt, als bei Till Eulenipiegel im Bellert entiteben. WBenn inbeffen gegenwártige Dinge uns lebbaft in

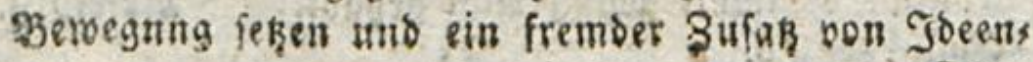

Daits 


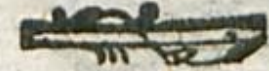

bringen, fo fteht uns ber 93 inter im $\mathfrak{L B g}_{\text {ge, }}$ und bie erftarrende, gefrierende Einbildungses traft exftirbt in Reife uno Schneegeftsber.

Dies ift gleidhfalls bie Duelle bes Zaubers, Den man in ber Betradhtung einer fojonen Rinos heit vorzugswetfe bor ber 2 ollfommenheit Des reifen 2fters finbet. 2Wann geniefen wir efn wahres నergnigen baran einen Mlann zu jes ben? 2llsbann, wenn bas 2Cnoenten feiner Şandlungen unz auf pein zuridigelegtes Seben timfebren láft, uno uns fo zu fagen, in ums

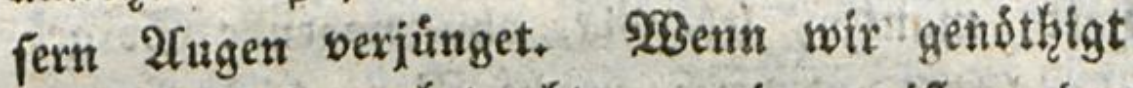
fino, ifgn fo zu betradgten, wie ex ift, ober ifn fo vorauszuferen, wie ex im 2orter fenn swirb; fo wertilgt bie Sorftellung von ber fid

$$
3 z 2
$$

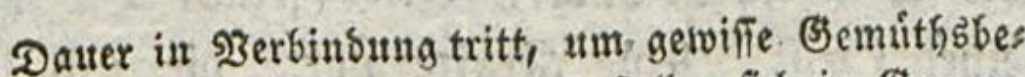
wegungen bervoryubringen: fo ftellen fich im Samjen reit mebr die bazu contraftirenden ober barmonife

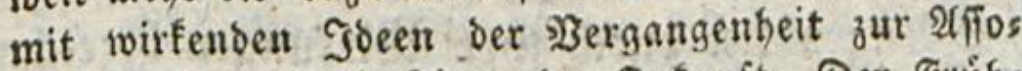
ciation ein, als bie Goeen ber Bufunft. Der Frúhs ling woirft vorgúglich fo angenefim auf unb, weil

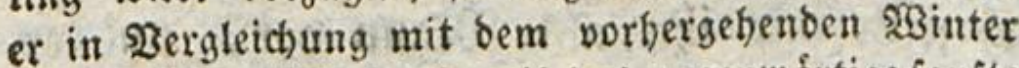
fo berrlich exicheint uno weil bas gegembårtige fanfte (5) efifhl fo fark mit bem unangenebmen (5efuhl bes SBinters abptidt. Der Menich fam aber in foldsen Fallen bie gocenaflociationen fefr willfibrlich orb: nen, und wenn er weife ift: fo oronet or fie fo, baß er Freuben uno Kroftungen bavon eiternotet.

Ebletr. Meferwit. 
abmatrts neigenden-STatur alles unfer Sergniss gen baran. Gistu tidit angenehm, Semans mit grofen Sdjritten petnetin Grobe fidg nábertz.

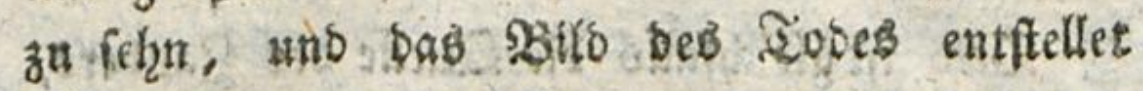
2tlieg.

Wenn ich mir aber eit Ging von zehri bit

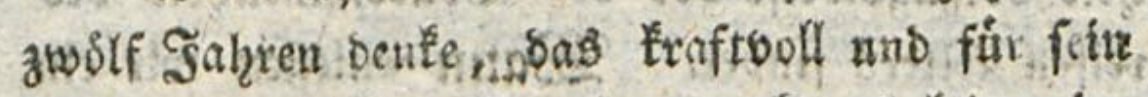
2ftter gut gebilbet iff, fo erwedt es teine eing zige Borfeellung bei nitr, bie nidst entweder fír. bie Siegenmart, bper für onв Riuftíge angenetzm wåre. Sal febe den Rnaben mutlywillig, Yebs, baft, munter, tebentig, obne nagende Sorge,

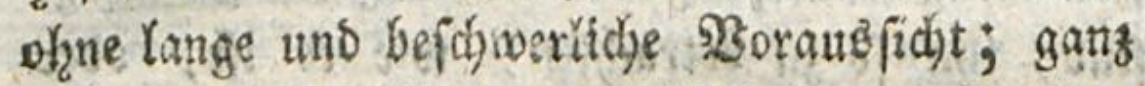

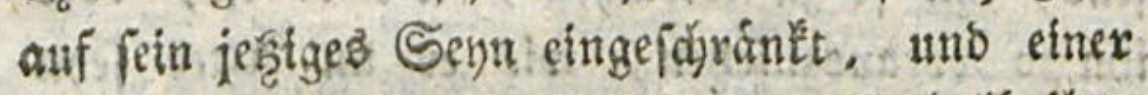

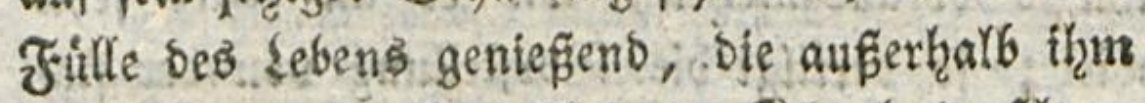
aubbreçen zu wollen fojeinet. Sidy ahnoe fichon, wie ex in einem anbern 2Citex feinen Berftanb, finen Selft, fetne Sirafte ifft, bfe fich) yon Zage zu Tage bei ifum mebre entwide'tn und jes

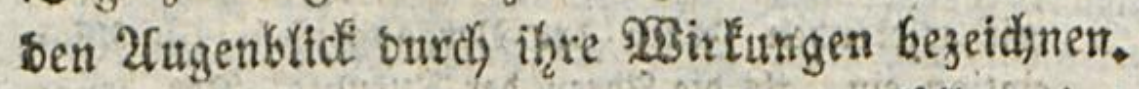

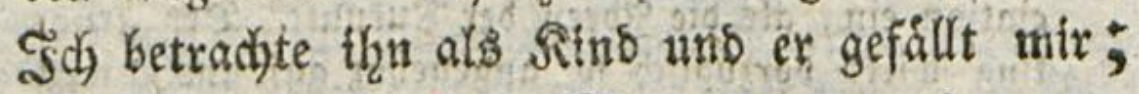
id) ftelle mix iḩn ols Mann sor, uno ex ges

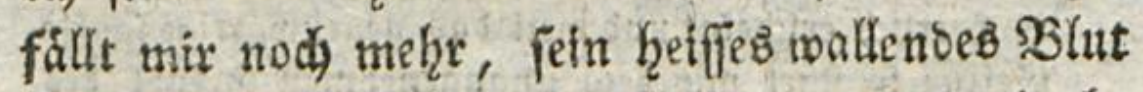
ficheint meines witeber zu erwármen; ich glaube in feinem reben za leben; und feine Lebendighteit vergnuigt midj.

Dié 


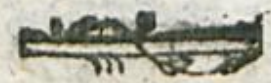

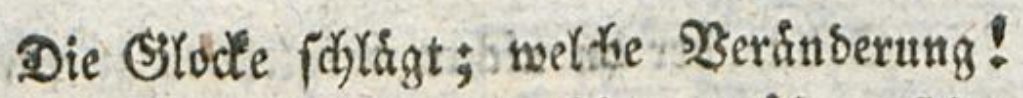
3fugenblictlidbs wiro fein 2luge tribe, feine

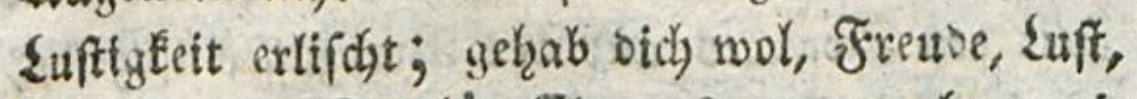
Sdyerz uno Spiel! Ein geftrenger, brummis fojex Mant nimmt if̧n bet ber Sond, Fagt ernfthaft: Rommen fie, Junter, uno weg führt

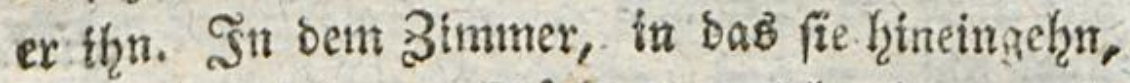
fibe id Sicher. Bither, weld ein trautig

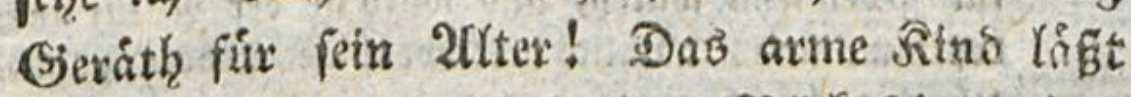
fich fortichleppen, wirft einen SBlide pdum trbafs tes Bebauerns auf 2Clles, was runb umber ift; forweigt ino folgt, mit thrinengefdyollenet Yugen uns bas Şerz von Seufzern fdywer, ohne

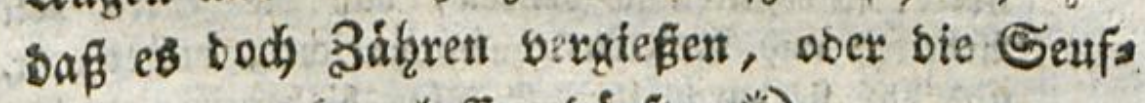
zer laut werben laffen burfte. ")

$$
\text { 3ิ } 3 \text {. }
$$

- Diefe Etelle hat fidher im \$unct ber Eryiehuttg melfr, wie futubertmal fo viel geídabet, als genutst. gür feinen Preis wollte id fie aber meine brei

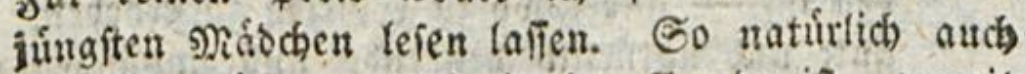

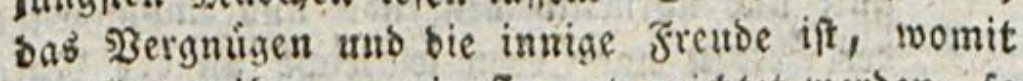
fie alles treiben, ioorin fie unterrribtet werben, fo fónten fie boch bei Seiung berielben, bejonders nachs oem fie fo, wie bier, vorbereitet ift, an fich und an ber siatur itre werben. Sung, wie fie fint,

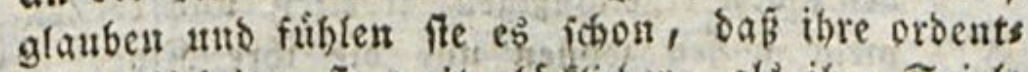
lichen $\mathscr{A}$ rbeiten fie weit glidefither, als ibre Spiele madben. 2arbeitsverguigungen fübren felbit nach ihs rem Befúbl foliten Benuß Ber Bstúffétigleit mit fis:. Epielvergnigungen find bei ifnest, wab fie fúe 


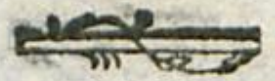

D sit, ber bu nidjts bergleidjen zu furdyten haft; bu, fir ben feine 3eit bes Lebens eine

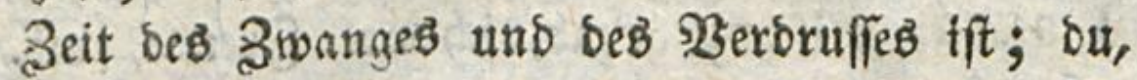
bex bu ben Iag ohne Unruhe, bie Nadigt ohne Utngebulb fommen fïelffi, uno bie Stunden nux

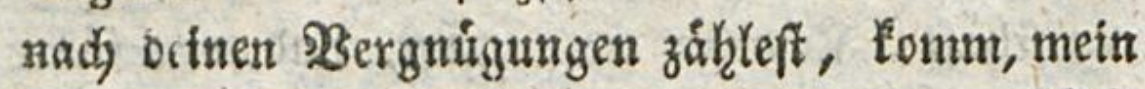
glicte

fur Jeben fenit follten, uno wogu fie ber Natur nad beftinmt firto, námlich nothivendige Errgolungsmit: tel, bie leidht ein fabes unb nidht genug gegen

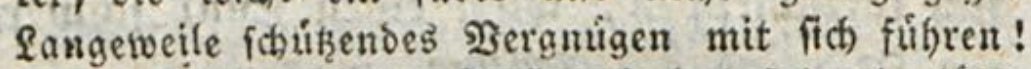
Egsenn fie bie gedachte Stelle und bas folgende láien uno borten, bañ cin grofer Nieifter in ber Erzies

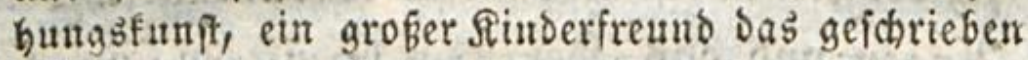
hátte: fo fonnten fie benfer, baß bie Toeen von 2rrbeiten und Spielen ihnen unridstig beigebracht, und $\delta a \xi$ fie burch ibre (b)efíle bisher irre geleitet roárben. Sie founten fich baun, wie es ia alle

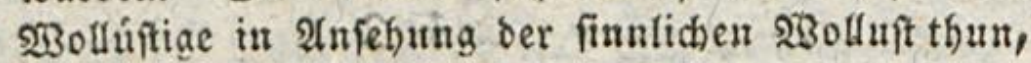
fith aufs Suthen legen um ben Schatz bes Spiels vergnuigens, ben fie nidht in bishberigen Spielen gefuns ben batten unb ber úberall nicht in Gpielen $z^{4}$ fins sen ift, - anderbłwo in Spiefen zu erheben. Denn gute und naturlich benfende und empindenbe Sius ber werben noch eben fo leidst an ber Natur ber Dinge irre, als im vernúnftigen 2 (tter, bie nad) fefung biefer unb áhiticher Stellen, obne bas \$ुors treflichite von $\Re$. Emil gefaft ober behalten zat has ben, von regelınábigen 2 rociten unb lernen nichts mehr wiffen wollen und bie ifhe Sinder bagegen

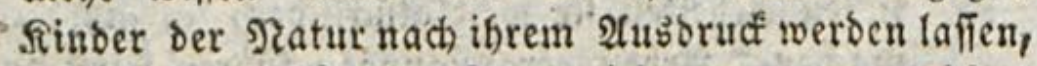
aus welchen funftige Taugenidhte empor wachien.

(E)blers.

Sebr wabt:

Siệnikg. Eampe. 


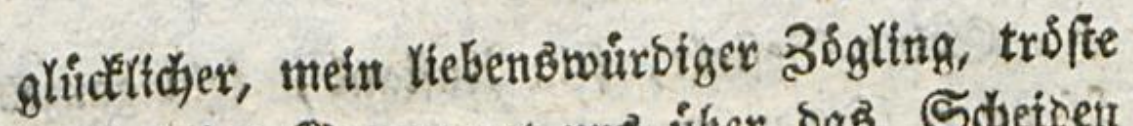
Durd) beine Esegentwart uns ůber bas Sdheireit jenes Unglưctictsen; tomm. - - Fr langt an; uno th empfinoe bet feinem গTahen eine frobe Seanng, bie idn ifgn theilen fehe. (5s ift fein Freuno, fein Spielgefell, ber Steffhryte

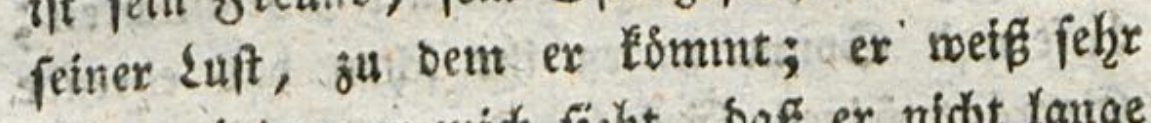
ficher, inbem ex midh fieht, baf er nidjt lange ohwe Beitbertretb bletben wirb; wir find nie ciner bon bein andern abbjángtg; aber immex sunter einander eins; uno ftrhen uns mit nies manben Frembes fo gut zu[ammen. *)

\section{4}

Sei:

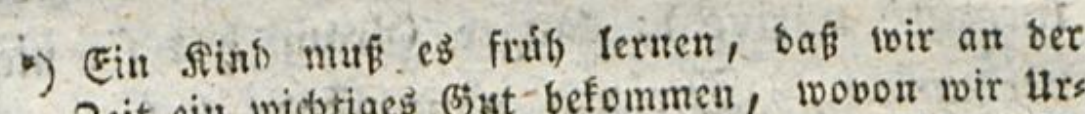
3eit ein widbriges (5) ut befommen, wovon wir thrs fache baben, ieben sheil burch ein vortrefliches $\mathcal{L e r}^{-}$

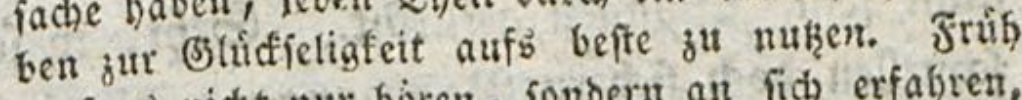

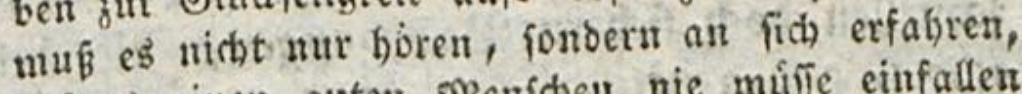

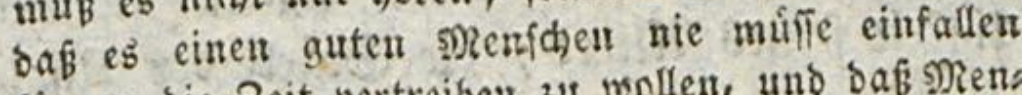
fonnen bie Seit vertreiben zu wollen, und baß Mens fhen, bie Beitvertreibe fuchen, armeetige uno anf bem şsege ber (slúdiefigfeit ganz verirrte Sefchopfe

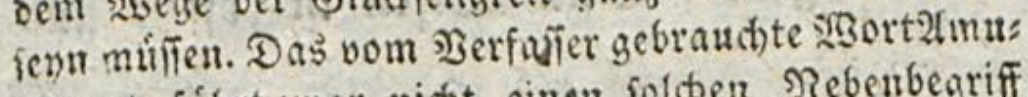
iement fúfhrt juar nitht einen folthen Nebenbegriff gerabegu mit fich; allein der Franjos findet fich

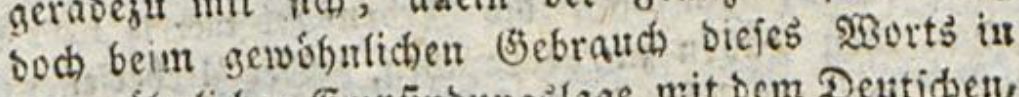
einer ábulicten Emprinbungslage mit Dem Dentiden, Der Scitvertreib fucht uno ber cine Gache, bie er fo neunt, loben und anpreifen will. 2(uch fóamt ein Franzos, der feinen Ginn fúr einen guten 3eitgebraud bat uno ben $23 e r t h$ ber 3 cit nicht fúblt, 


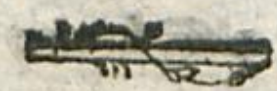

Settie Gieftalt, fin 2Tnftand, fett ganzes 2 cuf re fún bie Sejundheit glänjt auf feinem 20 ngefidjt;

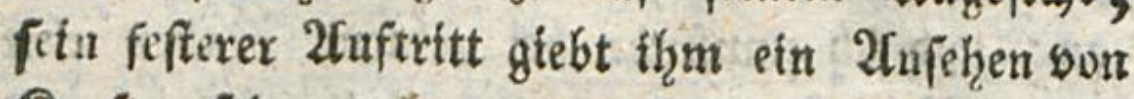
Rraft; fette nod) zarte, boch nicht mattherzige

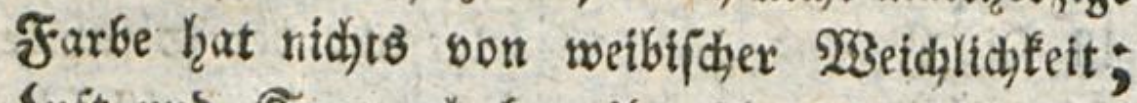
Suft und Sonne haben ifhr fchon bas efrrenbe Gepráge feines (Eefd) red)tỏ aufgebrictt; Feine srob gerunbeten Mtuítetn fangen an, eintge 3ảige einer merbenden Phypiognomie anzubeuten; feine 2rigen, nod) burd kein Fetter letoenfdyaftlidjer Eripfílobung befeelt, haben aber bod menigftens alfe itgre naturlich angebohrne Seciterkeit (leur ferenitè native); langer (Sram hat fie nicht serbunfét, . Shránen ofine Enbe haben noda

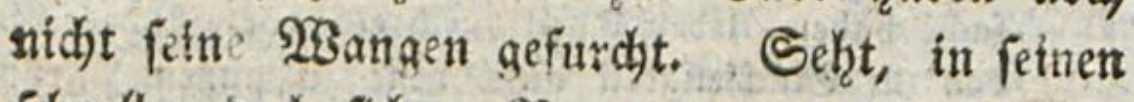
fidmellen bods fichern Berwegungen, bie Sebhafs tigkeit feines 2flters, bie Stárkée ber Unabháns gigfeit, bie Erfahrung ber verbielfältigten Leis Geobibungen. Sein 28 efen ift offen uno frei, aber

fúblt, fich nidyt die rebentart tuer le tems in fols den fällen zu gebrauchen. Der Heberietzer batbe, weil er fúr Deutiche uiberiekte, úbrigens Uriache bier Amuiement ourch Seitvertrcib auszubrífen: uno weil id meine $\mathfrak{A}$ umerfung fúr Deutiche fdreibe: fo batte auth id Uriache meine fnmerfung in eine Sejiebung anf fenen beutichen $\mathfrak{F}_{3}$ brud zu bringen.

E็ bletr. 


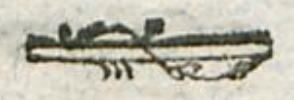

aber nidjt ibermithig, nod) eitel; fein (Sefidit,

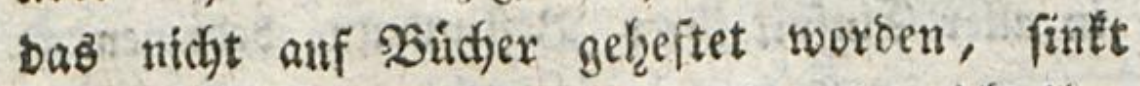
ihm nicht auf sie 3 ruft: man broucht nidjt ifbm

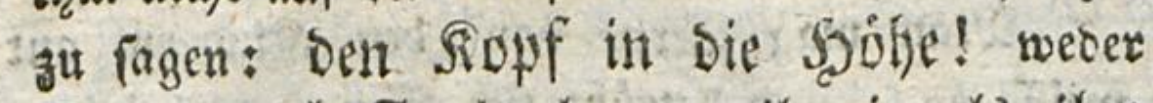
Scham nody Furdjt bengten tha jemalb thm nieber.

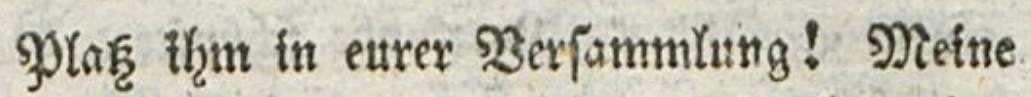
Sherren, prufen fie ithn; fragen fie ibn obne

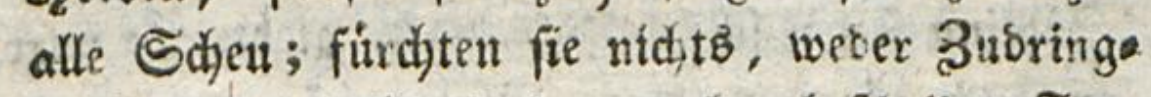
lidjeiten noch Gerplauber, roch unbeicheibne Fras gen bon ihm. Beforgen fie nidyt, Daf or lich three bemádjtigen, bas ex begehren werte, fie follen fidh mit ib̨m allein befd,dftigen, Dấ fie. feiner nidt wieber los werben tonnten.

Erwarten fie aber eben fo wenig oon ifhm angenehme Reben, noch baf ex ifnen rage, was idy ifgm werbe burgefagt haben; ermarten fie nidhts, als bie natirliche uno einfaltige SBabrheit ohne 3ierrath, ohne 2tufpurs, ofzne

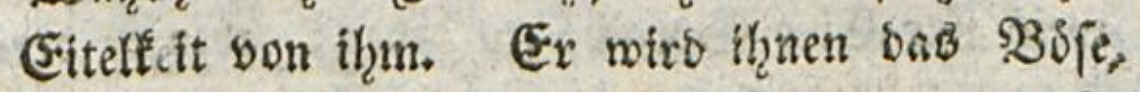
was ex gethan hat, Dter bas, was er bentet, eben fo fret fagen, als bas Ginte, obne fid, in geringften barum fu fiummern, was fir eine \$3itung bei ihnen bas baben werbe, was

$$
335
$$

ex 


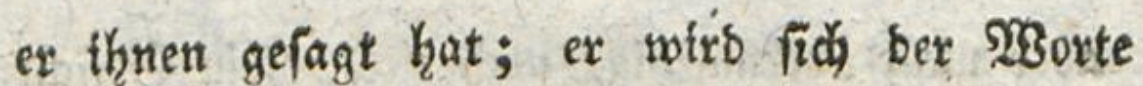
in aller Einfalt ibrer Beftimmung bebienen.

STan mag gern bon ben findern gut weiffagen; uno betribt fich bentn ftets bei bem Saufen oon Zhorhetten, Die faft immer bie Şofnung umftofien, welche man aus trgens etnem glidflidien 9 sortfunbe fidopfte, ber vort ungefabr auf the şunge fiel. $28 \mathrm{enn}$ mein Bogling felten folche Sofnungen gieht, fo miro er aud niemals bies Nisbergnuigen erregen; benn ex fagt nie ein unnitges 920 ort, und exs fdjopft fid nidat mit Siefdywar, worauf et

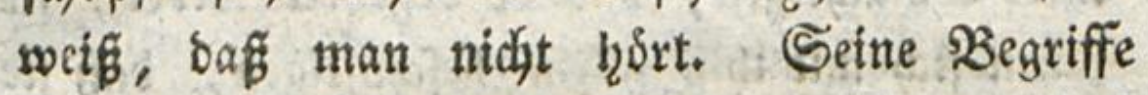
find eingefdurantt, aber rein; weif er nidyts aus bem Ropfe, fo weif ex biel aus ber Frs fahrung. Siift er minder gut, als ein ander Rind, in unfern Büdjern, fo liefít ex beffer in bem Budje ber Natur; fein Seift tft nidjt in feiner Bunge, fonoern in feinem Saupte; er

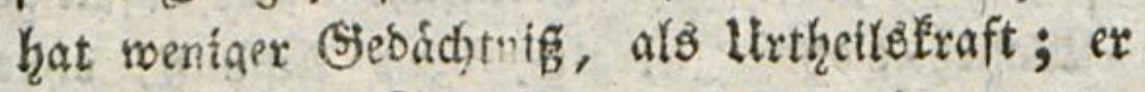
weis nux (5ine Spradje zut veben; aber er bers riteht, was er fagt; und wenn ers nidjt fo gut fagt, whe es 2furre fagen, fo thut ex bas, was fie thun bafiri befto beffer.

Er 
(E) weif nidyt, mas Shertommen, Siebraudid, Sewoknnheit ift. Şas ex geftern that, hat Eeinen Einflus auf bus, was er heute thut: $\dagger$ ) ex folgt nie einer Formel, weidjt weber bem 21ns fef̧n nody bem Betfpiele uno haandelt und rebet nux fo, wie es thm gut bortsmmt. Ertwartet aljo von thm feine vorgefagten SReben, nods ftubtrte Nanieren, fonbern immer ben getrenen 2uBsorude feiner Begriffe uno bie 2uffifhrung, bie aus feinen Iieigungen entipringt.

Shre werbet bei ifgm nux eine fleine 2(nzahgl fittlidjer siotionen finden und nur foldye, bie (iid) auf feinen gegenwårtigen Buftans beziehen;

7) Der Nieiz ber Belvohnheit frammt atts ber bem Nens

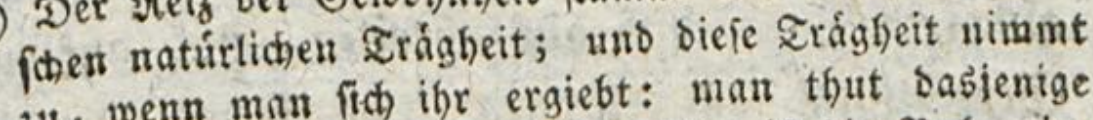
zu, wenn man fich ihr ergiebt: man thut basjenige leiøter, wab man fhour gethan bat; if bie \$̧ahn eins mal gebrochen, fo lápt fichs iffr leighter folgen. 2(unch

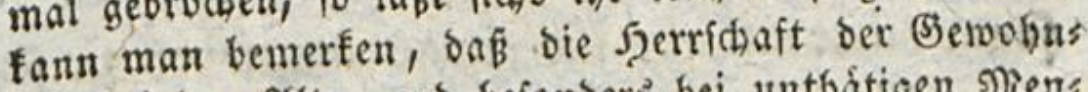
beit bei ben 2llten uno befonbers bei unthátigen siens

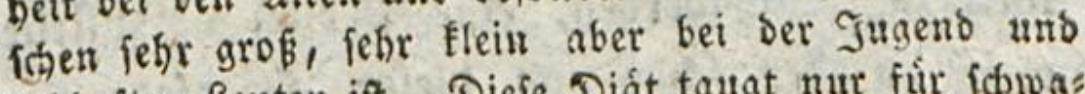
lebhaften Seuten ift. Dieje Diát taugt nut fúr folwas

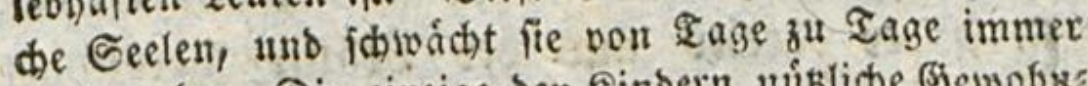
noch mefr. Die einzige ben Sinbern nuiblithe Gewobs: beit iff, fich ber Nothwendigfeit ber Dinge ofne Míne zu unteriverfen zu wiffen; unb bie einzige ben Erwacts fenen nutbliche ङewohnheit ift, fich ber \$ermunft ofne

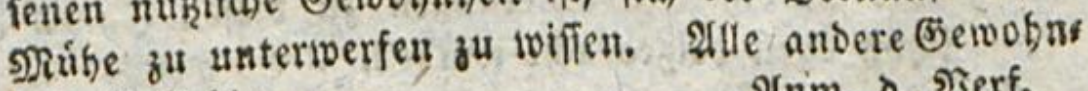
beit if zehler.

Hnm. ๖. গెerf. 
Eine aber, bie ben relatiben ber Menfthen bes treffen; und wozu follten fie thm bienen, ba ein Sino nod) nidit ein thatiges Mitglieb ber Siefellichaft ift? Reoet zu itm won Freiheit, von Eigenthum, ja fogar vom Bertrage: bis bahin reichen feine Renntniffe; er weit, warum Das fetn ift, was fein ift, und wartut was sein nidjt ift, nidjt fein ift. Dariber binaus

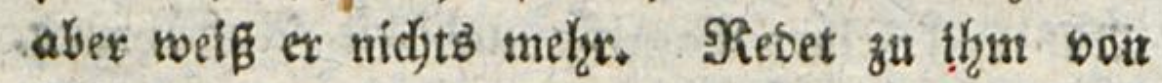
IJflicjt, won Giehorfam, ex werfteht nicht, was thre fagen wollt; befehtt itgur etwas, ex witro end, nidjt faffert; fagt aber zu thm: wenn but snir biez ober bab zu Giefallen thătefî, fo mutr. be idy bir bei Selegenheit wieber etwas zu Bes fallest thun; ;) augenblictlicho wirb ex fich beeifern,

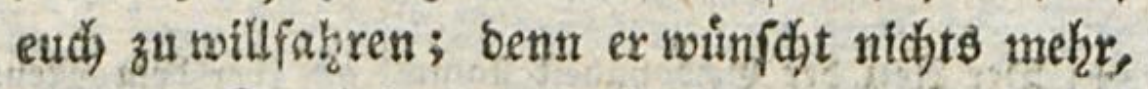
alछె fein Dominium auszubreiten, and auf end Seredtfame zul extangen, gon benen ex weif̈, baff fie unberlef̧lid) fint. Sielleidt ift fogar nicjt unleb, fúr etwas angefehen zu fenn,

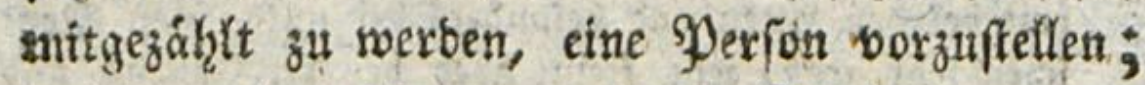

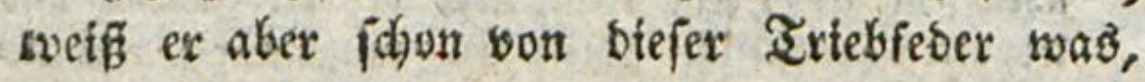
fo iff ex bereits aus bex গatur heraubgetres

ten,

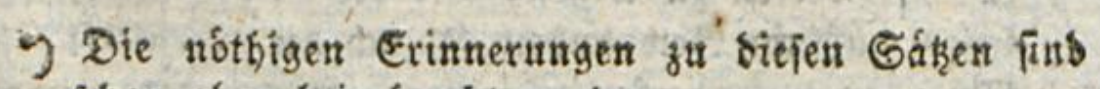
than oben beigestadt worber.

Eampe. 


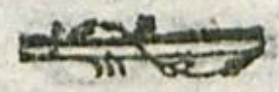

733

ten; uns thre kabt nidist forgfoltig gemug alle OFforten ber cittelfeit serftopft.

Bebarf ex feiner Seits irgeno cinez Beis ftandes, fo wirb er ifn ohne Unterifice son sem erfien beften begeb̧ren, ben ex antrift; er suirbe tha bon einem Rionige berlangen, wie von einem Bebienten; alle Mienfiden fins nody in

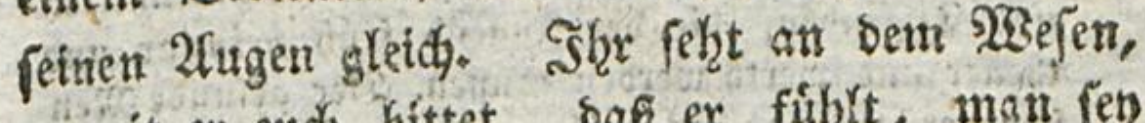
somit er eudh bittet, baf̧ ex fúbrt, man fen

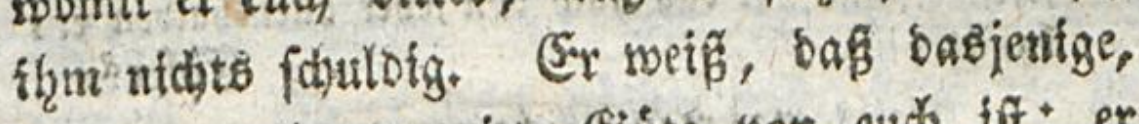
wab er vertangt, eitie (Siute von euth ift; ex

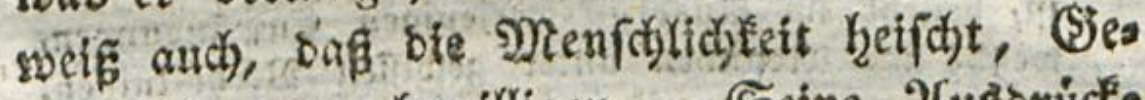

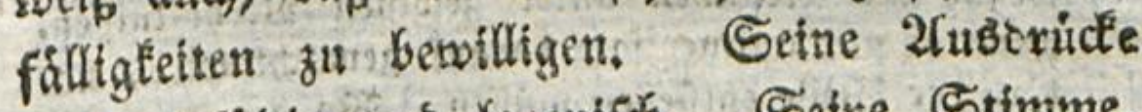
fino einfätig und laconifa). Setne Stimme,

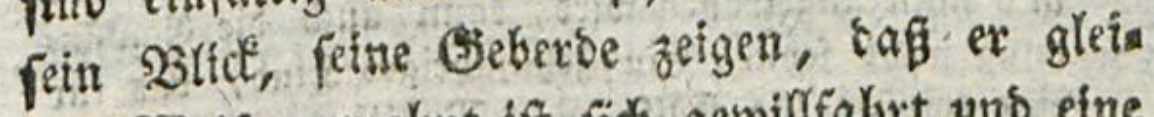
dyer 23 etife gewobnt ift, fid gewillfabyrt uno eine Sadje abgejalagen zu petzen. Es ift weber bie

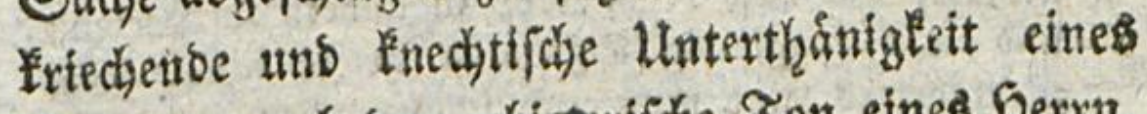
Sclaben, noth ber gebieteriface Zon eines Sgerrn, es ift ein fittjames 2 sertrauten in feines Sileis then, sie eble uno rifhrende Freundlichteit eines freien, aber empfindenden uns fiftwadien $\mathfrak{W B}_{e}$ fens, weldyes um den Beiftand eines freten, aber ftarten uno woḩlthátigen anjudyt. Geftehts efle ifgm bas, was er verlangt, zu: fo wirb er encis 


\section{4}

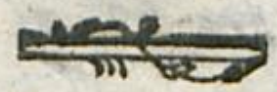

endi) nidit banken: *) wirb aber füfelen, baf et eine Sdyuld gemadyt hat. Berfagt thro then:

-) Dan ids bies, ivie mandbes andre, nidft an ben jungen sienfichen loben fonue, brauche ich bier nicht zu erintmern, weil ich mich in ben bibber gemahten Inmerk̂ugen binlánglich diber bas babin Sebórize erflàrt babe. Seboriam, Pficht, 230 hltbátigfeit und Danfbarkeit fut alferbingb : off fommenbeitent und Tugenten, bie ber Эugend frifh befannt und theuer und werth werben muffien. Der aefunde Men fhenverftand bat bas auch von ieber affentbalben er:s fanut.

(5) ler:

જieৎeร, wab man Pflicht nennt, und auch Pficht ift, beftebt im 24uborucf berienigen Empfindungen, welche im Netricben unter getvifien \$erkáltnifien, wenn er nur aufmerffam barauf gemadht wirb, nas

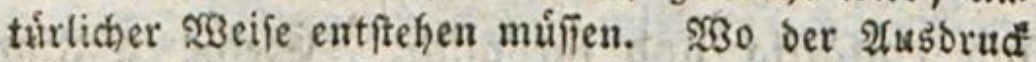
alfo nicht angetroffen wirb, fann auth bie Empfins bung nicht fenn. Fin zebniábriges Sind, bas fúr

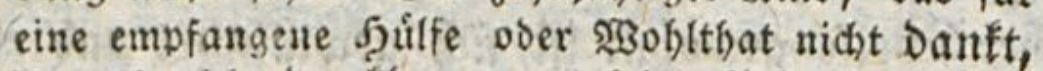
ift auds nicht Danflsar; was feine Siebe zu 2fndern

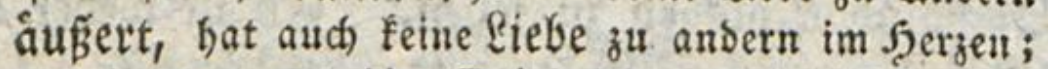
und Dant taugt bie Erriebung gemin nicht. Ein zebuiábriges Sinto mús auch ichon wiffen, was (5) ss.

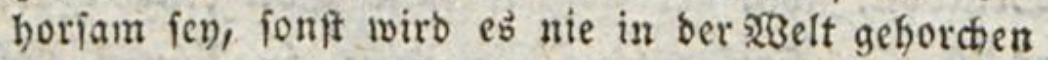

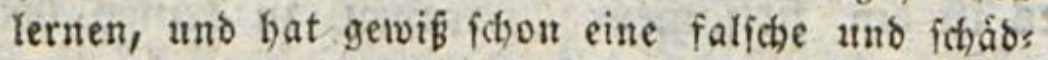
liche fralte erbalten. 2 us 5 ấ gegen alle convens tionelle áubere Iffichten, 10ozu freilich bie gangbare Erjichung Rinder obne Sin und \$erftand gewónt, und obne bie Empfindungen bei ifnen zu erwecfen,

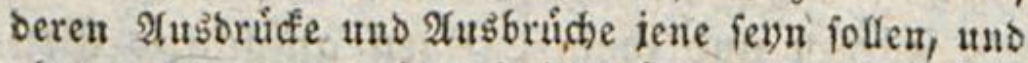
obne welche leţtere iene freilich Eeinen 23 erth babet, bat $\Re$. alles zufammen weggeworfen, und wiber die

भiat 


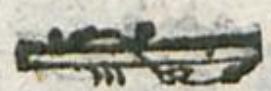

fo wiro et fich nidjt beflagen; ; wiro nidjt wets ter barauf bringen; ex weif, baß bas unniE fergn wirte; ex wirb nidjt bel fid benten: Nan hat es mir abgefallagen; fonbern ex wirb bens

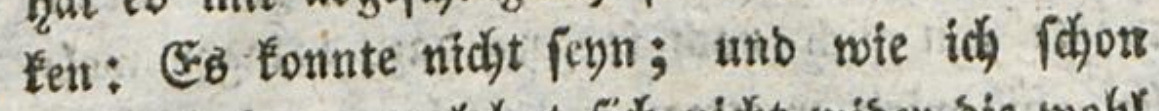
gefrigt habe, man Yehrnt fich nidjt wiser bie wohfl extannte Nothwendigeteit auf.

Man Kaffe ihn allein; fehe ihn kanbeln, okgne baf etwas zu iffm gefagt werbe; betrach: tet benn, mas ex thut und wie ex fich babef nimmt. Da ex nidjt nothig hat, fidso zu bes metfen, bafier fret ift, fo thut ex nie etwas aแb Llnberonnenbeit, und bloß bamit ex einen. 2tet bon (Sewalt iber fich folbft ausibe; Senn, sueip er nicht, baß ex immex fein eigner $S_{\text {ger }}$ ift? STatur gehanbelt, und bas Sinb mit bem รabe auts: er fo fchon gefchildert bat, wirbe auth ganz anders ausfehen, wenn or ifu wirtlid) nach feinen unbes

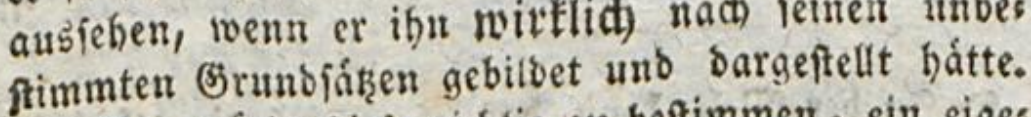
Gnbefien wurbe biefe ridtig ju beftimmen, ein eiges nes aubfúfrliches $23 e r k$ erforbern. Eeinen 3ógling bat er weber nach feiner innern beftimmten Natur, nod nach feiner lage in ber (sefellichaft ridtig ges

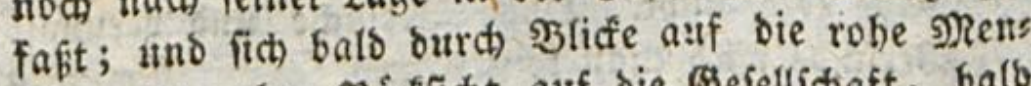
fichenatur ohne Ficfilitht auf bie Sefellichaft, balb burch ficheele Seitenbliffe auf bie freilich fehr obers fláchliche uno falid geftimmte franzófifche spobecrziss bung leiten laffen.

Referwis. Sampe. 


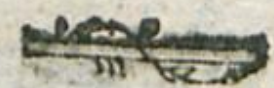

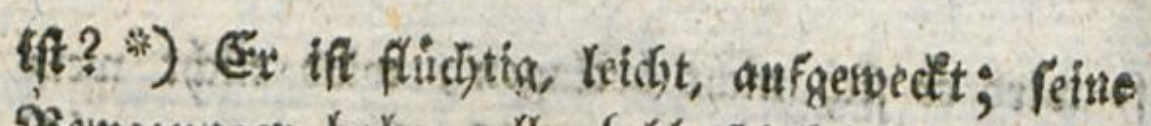
sèewsgungen baben alle Eebhaftigkeit fines ato tero; ibr bemertit aber teine einzige an ifm, wos

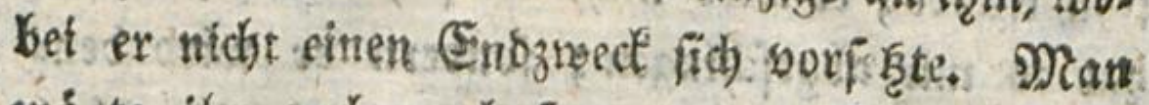
mọte then aud nod) fo gern bazu bringen wols len, nte wirs or etwas unternebmen, bas feine Sirafte iberfitiege; bent ex bat: fie mofir gevruft: uns fennt fie. **) Geine Mittel finto fets jets nen 20sfid)ten angeneff $n$; uns felten twirs ev

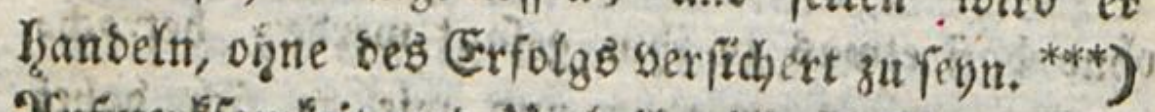

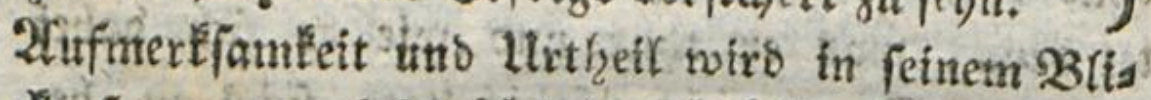
de fent or wirs nicht tropfmafig 2Tore liber 2tles befragen, was er fieb̨t; fonbern es felbit unterfucion uno fich anftrengen bas auszufins ben, was er Yernen wial, ehe ex Sarum fraght. Eieráth ex in tunsorbergefef̧ene 3 ertegenkeiten, fo wiro ex fich roeniger beunrubigen, als ein 2 (n) berex; if Giefolyr sabei, fo wirs ex fich aud wentger exförecten. Da feine Sinbiloungektraft "ทoch

- In ber sBelt fann bas aber aud eir zebniábriges sind nicht fenn, wie $\Re$. Sogting der sthantaric.

Siefervit. Eampe.

-0) 2alle boch nidat. Done sieriuche uno vermallifto Serfuche toirs man tein Nann. Refenis.

seo Dana if et in ein polffommener Nann!

Siejenvit: 


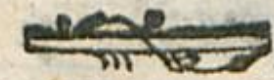

noch unthidtig ift, *) uno man nidjts gethan hat, fie zu erwecten, fo fielgt ex nur bas, was

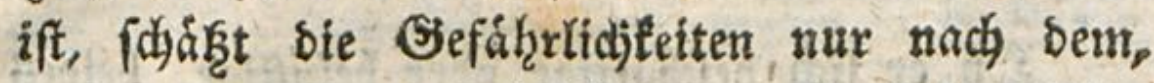
so bei. Die Nothnwendigleit legt zu oft ihre Eis jeahgand auf ihn, als Daf ex fich noch witer fie

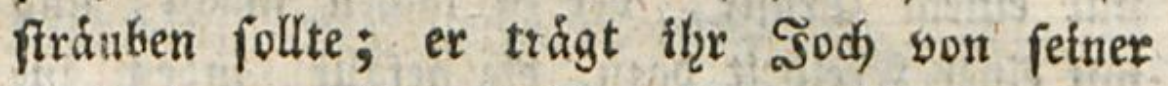
Geburt an; *\%) jefst ift ex fehr wohl baran ges wóh̨nt,

-) Sie if feinesiveges unthátig. Denn bie Eultur bies fer siraft fteht in einem wefentlichen Bufammenthange mit ben áufern Einnen. Sie ift nur, twenn alles

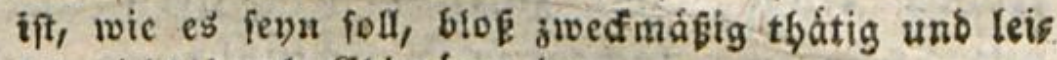
tet nidgt burd Ebimáren irre.

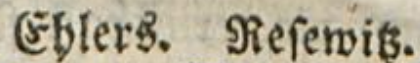

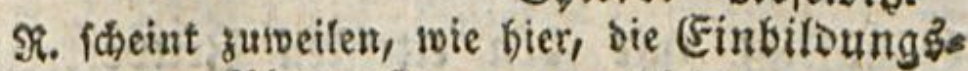
Itaft mit ber \$bantafie ju verwechfeln.

Eampe.

-) Eine Notfridenbigfeit, Die im \$Beien unb in ber

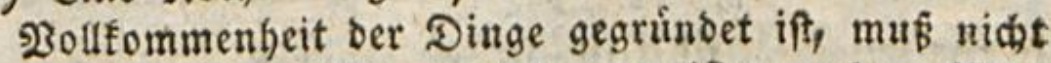
auf eine fo gehäffinge 2itt daracterifirt werben. $x_{3}$ as unts cine Eifenbano fúblen lápit uno unter befien Joch wir uns beugen múfien, Daran fonnen wir unmogs

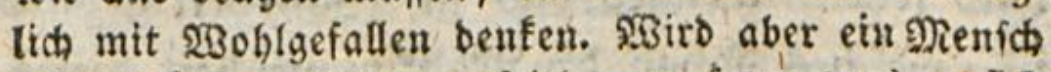
erfit getwófint mit bem jufrieben zu fenn, was er fï in \$erbindung mit einer Eifenband und mit einem god) benft: fo wire er aud fich bald mit bem goch ausfobnen, bas die eiferne fand bes menfwliden Despotismus inm auffegt.

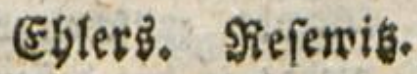

Eimil Ifter §6. a a a 
wshnt, ex ift fets bereit, fich jebes Dinges on verfertin.

Sob ex fich bejodaftige ober beluftige, betbes

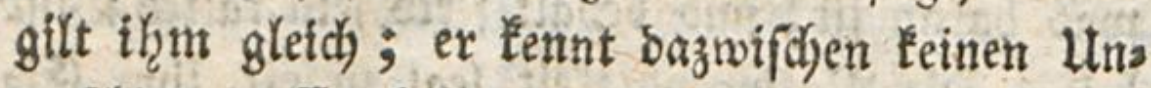
teridjed. Er behanbelt 2flles, was ex tḩut, mit einem Exnfte, ber zu ladigen mad)t, uns mit einer Freikeit bazu, bie gefällt, inbem zus

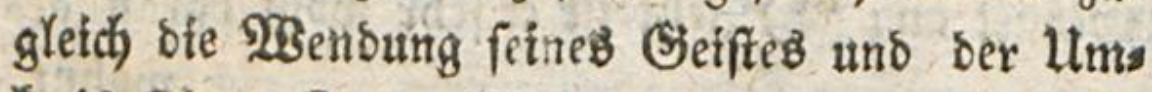
treis feiner Retntniffe fidjtbar wirb. Sit nicht

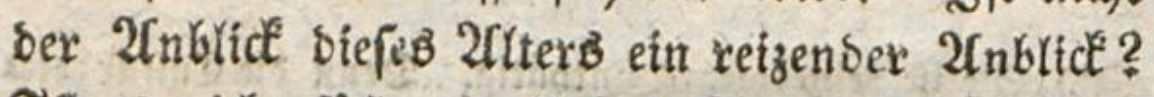
Sift es nicht fü̉, ein Yiebes Rino mit lebhaftem froken 2uge, mit zufriebrem hettern IBefen, mit ofner und lackender (Sefíchtebiloung, fpies Yeno bie ermfthafteften Sadjen thun, ober tief bejogsftigt mit ben eitelften aettoertreiben fethn?

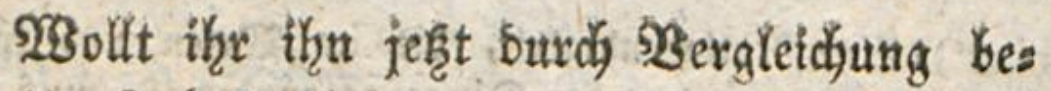
urtheilen? Eaßjt ifn unter andere Rinber geras then, uns ba fein 28 eren babent Şbr werbet bald fethen, welcjes bas in 28 affrbeit gebilbetere

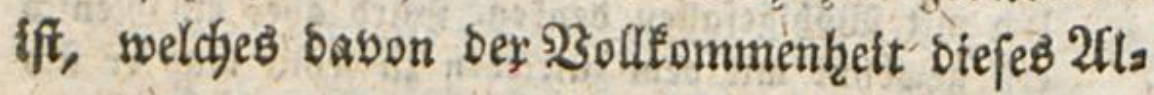

ters

-) פBenn bas Sino feinen begriff von bem großen $11 n$

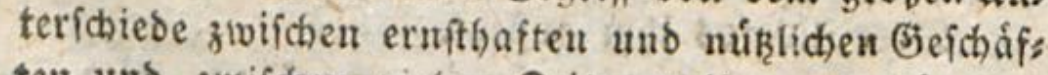
ten und zuifdsen vielen Beitvertreiben zu erfennen giebt: fo hat befien 2fublic darum wenigftens nichts

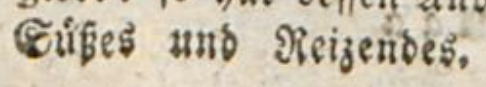

Ëbletr. 


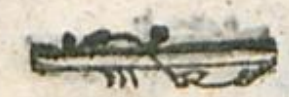

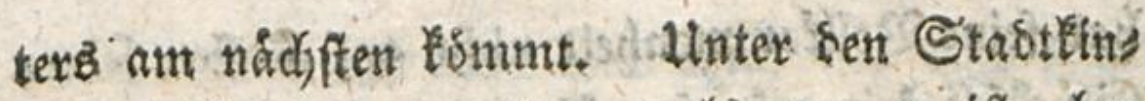
bern tif teines geroandter, als ex: ex ift abee siel ftárter, als irgend einb sabon. SBefindet ex fich unter Bauerjurgen, fo wirb ex fbnen an Stårke gletch, an Siemantotheit aber uiberlegen

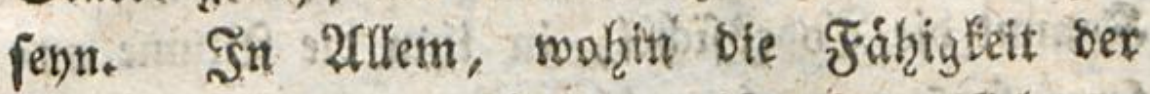
Rinohett reidyt, urtheift, ratfounit, fieht ex beffer etwas voraus, arb fie: 2flle. Silt es zit Kanbetn, zut Yaufen, zu fpringen, fefte Sisrper zu bewegen, Mtaffen fortzubritgen, গ̇zeiten zu fdakgen, Epiete zu exfinten, Sreife baown zu tragen: fo misgte man meinen, bie গatur ftehe

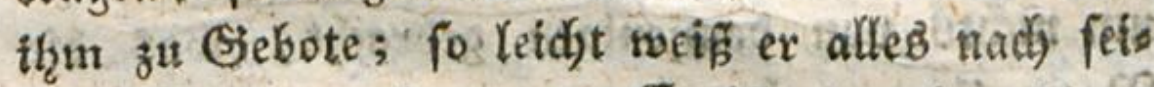

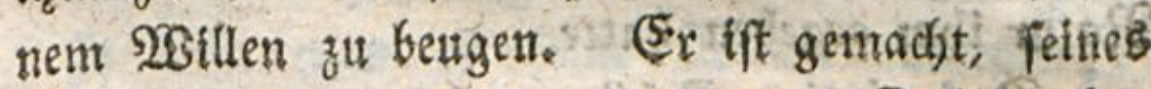
Glefthen zu fetten, zu regierett. Dulbfamfeit and Exfalfrang vertreten bet them die Stelle- bes

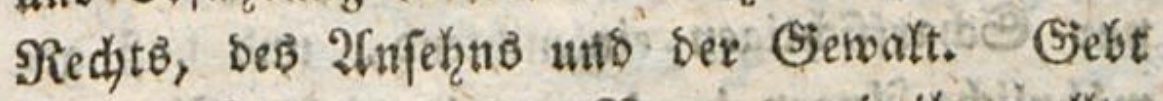

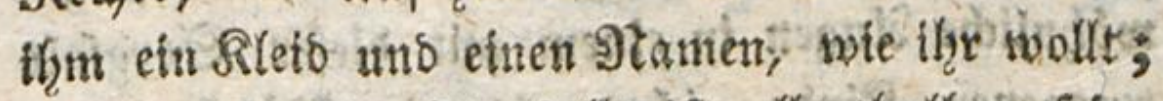
gleidy biel; Die Soberftelle ift allentharben pein, ex wiro hiberafl bab Sowut ber 2lnbern wetben fie werben biberall feine 1teberlegentzeit ůber fich empfinden. Shre befeblen zu wollen, wiro, er ber Serr fegn; ohne baf́ fie zu gehordhen glaus ben, werben fie gekordyen.

Er ift zur Reife Der Rintheit getommen; ex hat bas Leben eines Rinbes surchlebt; or I $a$ a 2 hat 


\section{0}

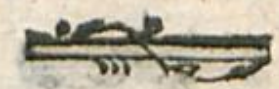

What feine $B_{0}$ ollentommenheit nidgt auf Roften feittex Gluidéfelighteit erfanft: *) beibe b̧aben vielmehe einanber unterftúgt. Snoem ex fid alle $\mathfrak{\text { Bers }}$ nunft feines 20Yters erwarb, war ex fo glicellid Into frei, als jein Rinsférn es nux sexftattete. Rommt bie Zobesfichel, in ihm bie $\mathfrak{B l u m e}$ :ns ferer Sofnung abzumáf̧n, fo werben wir nidjt zugleíd, fein Leber und feinen $\mathfrak{Z} 0 \delta$ zu beweinert Haben; uniern Sdjmexz miro Eeine Extnnerung an biejenigen nods verbittern, ste wir ifim vers

- urjadjt; wir werben zu uns fagen: wenigftens Kat ex feiner Rinobeit genoffen; wir baben ihn um nidats von bemjenigen gebracht, was bie Natur ifhm gegeben Ķatte.

Das einzige Shlimme bet einer fo einges ridjteten exften Erziefgung ift, bafi thre Síte nur Sdjarffidjtigen elulenditeno, uno baf ges sosfznlidbe $2 \mathfrak{A}_{\text {ugen }}$ in einem mit biefer Sorgfalt erzogenen Rinbe nidjto alb ein Búbdjen oon gemeinem Sdjage fehen werben. ***) Ein Lehrer benit

-) Woht igm! Trgie viel gebilbete Nenichen fonnen

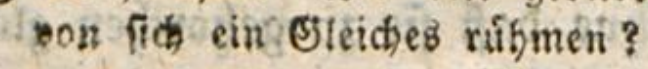

Campe.

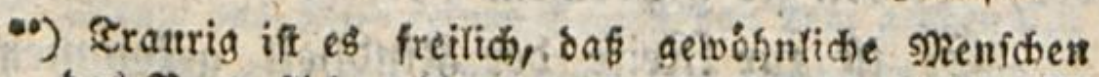
bas Sortrefliche eimer redit guten Erjiefung nicht

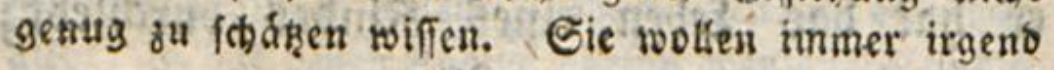

etivab 


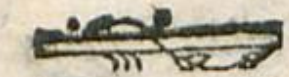

Sentt methr anf bas, wab thm, ałs was feinen Sdauller bortheilhaft ift; er lafift fid blof atts gelegen fenn, zu bemeifen, daf ex fetre seit

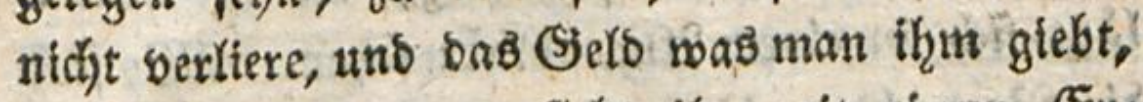
wohl berbiene; ex berfieht ifn mit einem Ere worbenen, bas fich leid)t austramen, (d'un acquis de facile étalage) und, wenn man will, zur Schau tragen lafpt; es ltegt thm ntd̆ts baran, lidj fey, wenn ez nux leidyt fict) zeigen läflt.

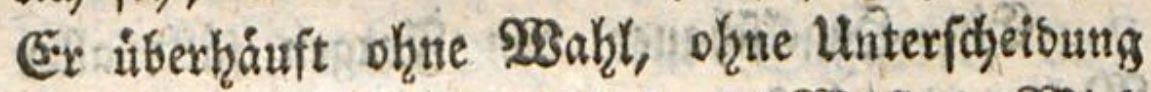

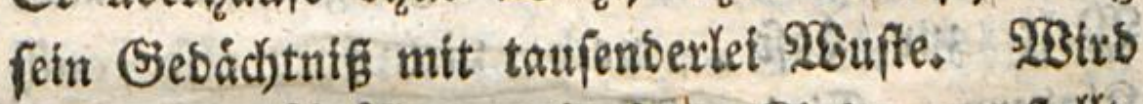
benn cine S3orifung mit bein Sitnbe augeftellt,

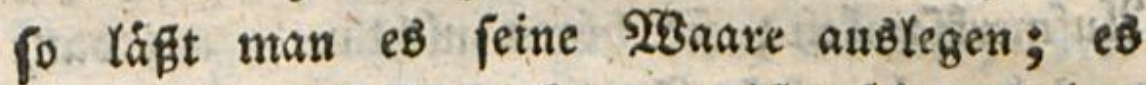
madht feinen Ballen auf; man ift zufrteben; legt thn wieber zufammen, uno fort ift man. *) Dleir

\section{2 a a 3}

ลื่gs

etwas unnaturitic Brofes, irgend efwas euffallens Inngewóbntidues finder. Siber fo geftet es faft úbers baupt mit allen ddten arten bes Şortreflichen in Shandlungen, in Edriftitellerarbeiten uno in Sunft? werfen. Son bem grofen Şaufen ber \$beurtheiler soirb ev nicht genug erfannt uno geichảkst. Hno rirb es eiumal geborig gefihák̨t: fo wirb es getwobns lid) burch bas 2 nfehn gewij̄er Nenichen bewirft, Die ben Ton angeben foumen und bem Indere nads ifrer sgeife nachempfinden und nachiprechen.

(E)

7) C'êt tout comme chús nouss'

Trapp. 


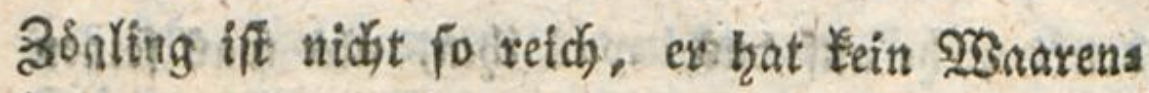
loger, ex hat nicht3, als fíth jelteft zu zeigen.

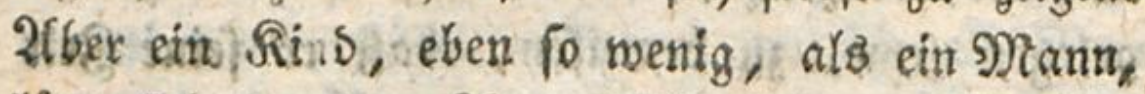
Lafi fid in einem 2 ugenblicle fehen. 230 finb Si 2Beobad)ter, bie auf ben exfen Blict pogleidy

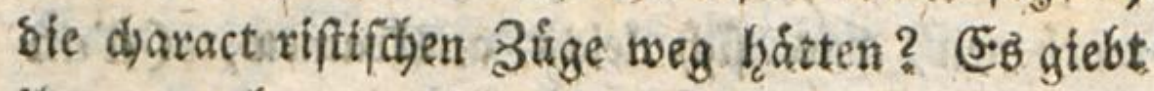
theer; aber menige; uno unter humberttaus

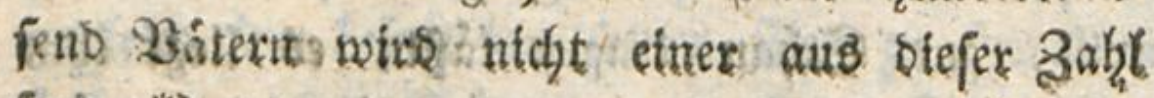
fenite * )

Ein fargelfogmè wen Fragen fallit allex

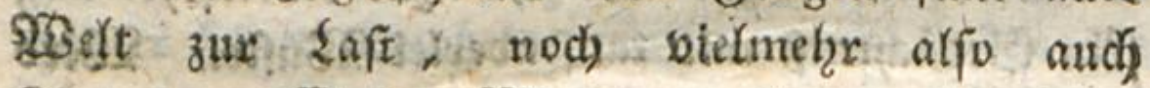
Rimbern. Cinige Stinuten, fo ermibet ibre 2tufmertfamteit; fie. ḩDren nidds meḩ auf bas, was bex efirenfefte Frager fie fragt, uno ant worten nux tns Sielag binein. (5in foldes

- Exaniniren if ettel \$pobanteref; oft malt ein S28ort, bas fállt, threen Simn uno Geift beffer,

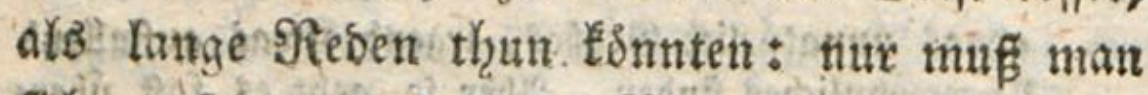
fici oorjebn, baf́ biejes 3 ort ihnen weber eina geflúftert worben, nod blofi ein Spiel des

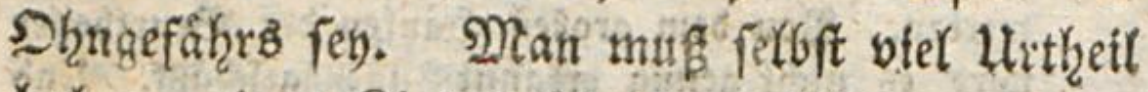
baben, eines Rimbes feines zu fdd

ฐक.

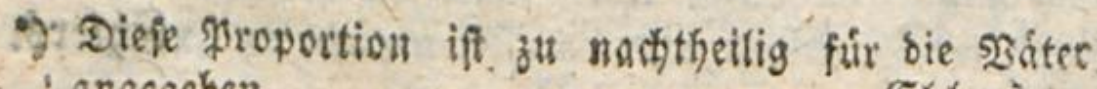
ingegeben.

Eblet?. 
Şa) habe ben berforknen Lors Schose ex. zăhlen hơren, baf́ efnmal ciner feiner frreunde; Der nach einer breifährigen 2lomejenbeit aus Stas lien zuridigefommen, bie Fortfdritte feines neut bis zehn Jahre alten Sohnes prifen mollen. Sie gehen eimes 206enbs fpaşiren mit bent Şof meifter uno ifm, auf einer (E)bne, wo fid) Sithi= ler einen Beitbertreib bamit madjten, SQ apiers bracken fliegen zu laffen. Der Dater fagt whḩreno bes Gehens zu jeinem Sohne: 2Bv ift Der Dracke won Dem Sibatten Da?

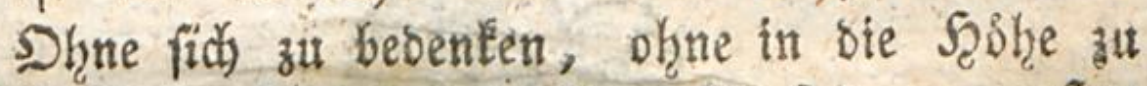
Feḩn, verfest ber Ruabe: Pluf Dem grofient

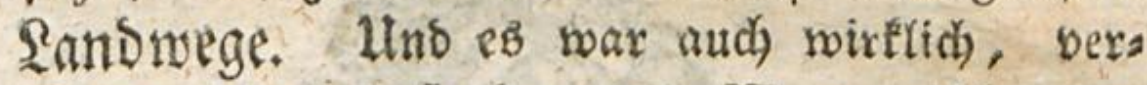

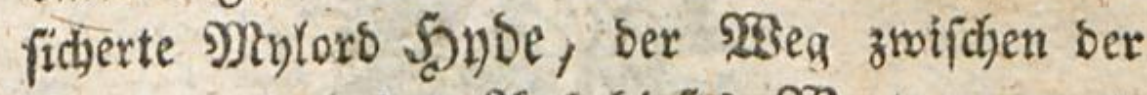
Sonne und unb. 24uf biefes 280 ort umarmte ber Bater feinent Soknn, endigte bamit feine Srifung uno ging fort, ofye eine Silbe meiter. Den anbern Norgen fidicte er bem Şofmeifter

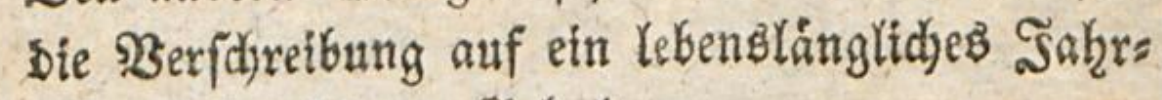
gelo aufer feinem Esehalte.

23elch) ein Mann, biefer $\mathfrak{B a t e x ! ~ u n d ~ w e l c h ~}$ ein (Soknn, ${ }^{*}$ ) war thim bertheifen! bas nenne id

-) Wie fjerr Wenbeborn erzaklt, war bas fo großi nid)t. S. Die 24llgemeine Sitteraturgeitung Eeptember 1788.

Srapp. 


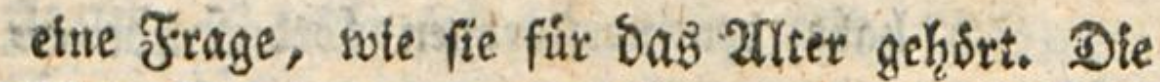
2fntwort war fefir einfadi); aber man fehe, sweldje Deutltdjeit Hinblidjes Urtbeils fie vors

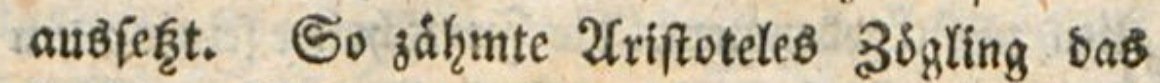

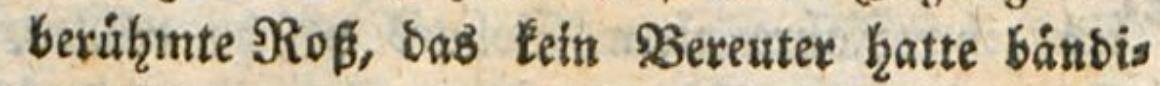
gen tontret. 


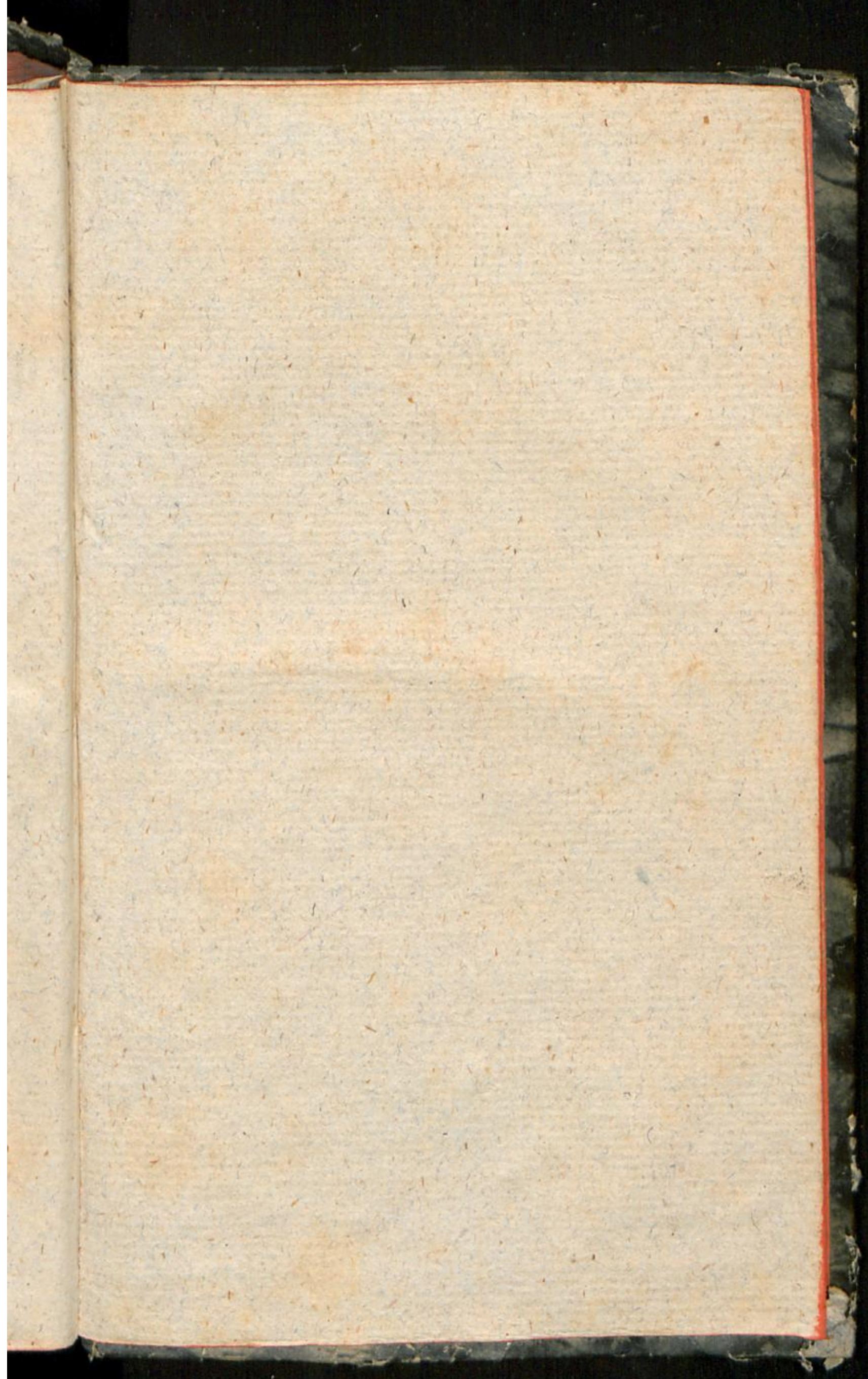




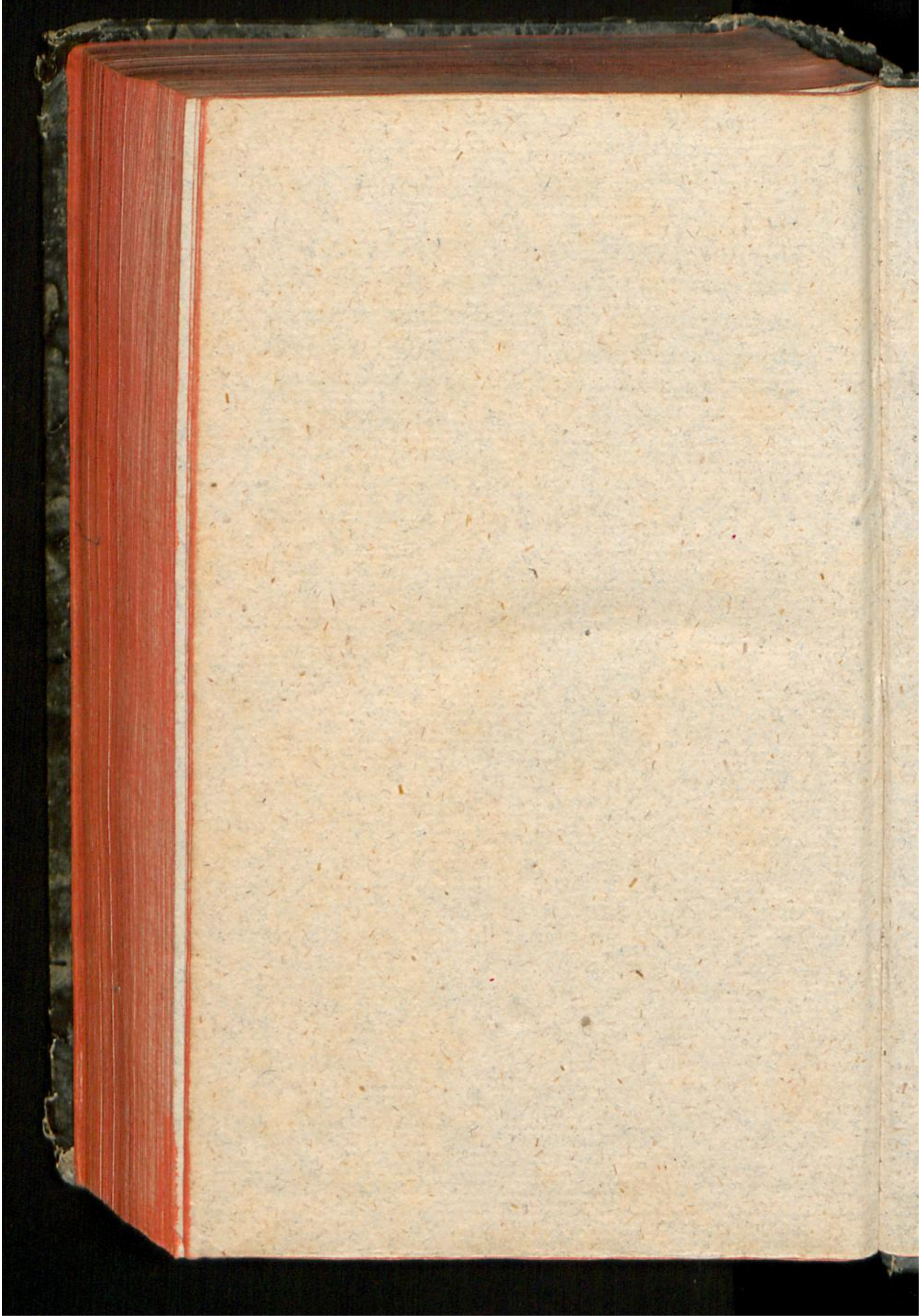




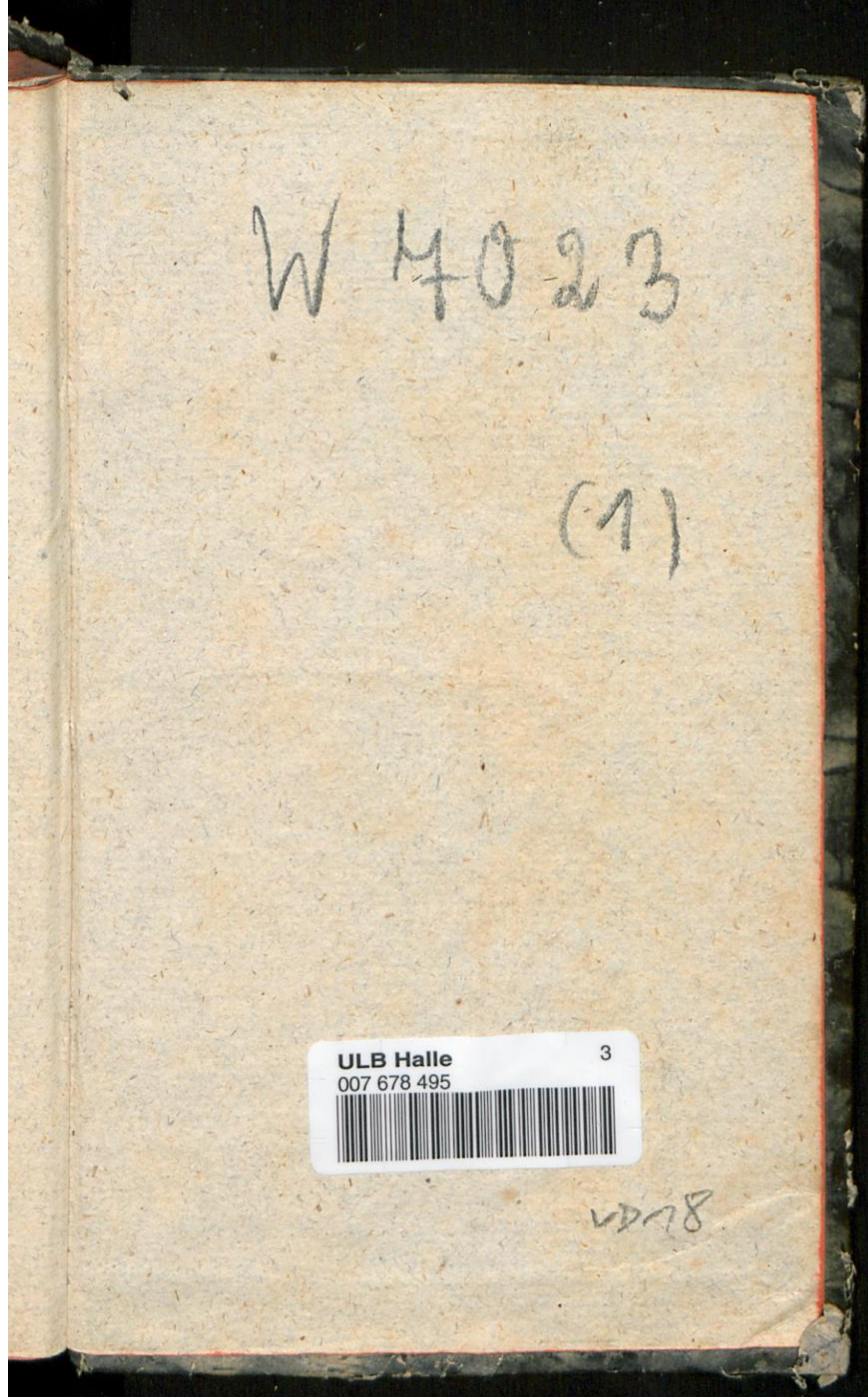




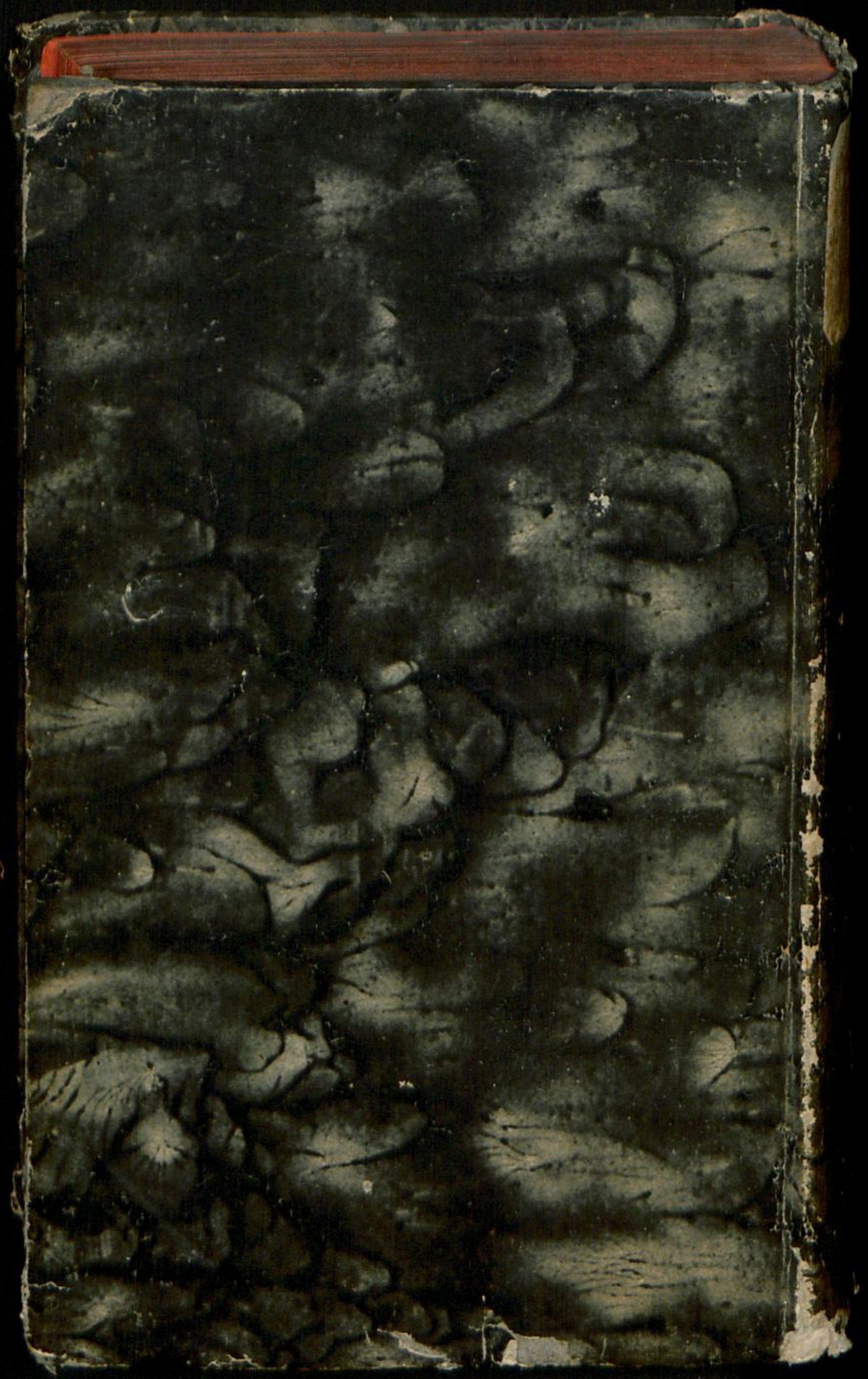

